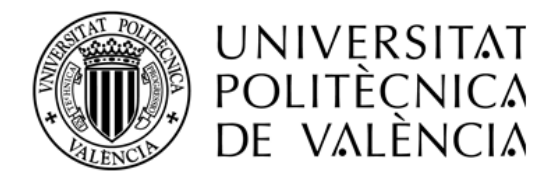

Departamento de Construcciones Arquitectónicas

TESIS DOCTORAL

\title{
INFLUENCIA DE LOS DISTINTOS TRATAMIENTOS SUPERFICIALES DE LAS BARRAS DE FIBRA DE CARBONO EN SU COMPORTAMIENTO ADHERENTE CON EL HORMIGÓN.
}

AUTOR:

VÍCTOR CALVET RODRÍGUEZ

DIRECTORES:

DR. JAVIER BENLLOCH MARCO

DR. MANUEL VALCUENDE PAYÁ 



\section{Resumen}

En los últimos años, debido al elevado coste de la reparación de las estructuras de hormigón armado con acero por el efecto de la corrosión, se ha tomado conciencia de la necesidad de utilizar nuevos materiales sustitutivos de las barras de acero corrugado. Estos materiales deben garantizar la seguridad y las condiciones de servicio, estéticas y funcionales de la estructura durante el periodo de vida útil para el cual fue diseñado.

En la búsqueda de nuevos materiales que sustituyan a las barras de acero corrugado, aparecen hace pocos años las barras de polímero reforzado con fibras carbono (CFRP). Este tipo de materiales es más ligero, posee una resistencia a tracción superior a las barras de acero y, además, solucionan el problema de la corrosión.

Antes de introducir este nuevo tipo de barras es necesaria la comprobación de la adherencia con el hormigón en las distintas condiciones térmicas a las que se encuentran expuestas las estructuras, debido a que éste es uno de los parámetros más importantes en el diseño de la estructura. Además, de ser una de las hipótesis en las que se basan las normativas actuales de diseño de estructuras de hormigón armado.

Este trabajo estudia el comportamiento adherente entre las barras de CFRP y el hormigón en diferentes condiciones térmicas. Para ello, se lleva a cabo una campaña de 175 ensayos experimentales de pullout. Estos ensayos se realizan en condiciones térmicas de Hielo/Deshielo, $5^{\circ} \mathrm{C}, 20^{\circ} \mathrm{C}, 40^{\circ} \mathrm{C}$ y $80^{\circ} \mathrm{C}$, tanto en barras de CFRP con tratamientos superficiales de arenado, texturizado y corrugado, como en barras de acero corrugado. Previamente a la realización de los ensayos experimentales de pullout, se realizan 21 ensayos de diámetro 
equivalente y 21 ensayos de tracción longitudinal en ambos tipos de barras. Además, en las barras de CFRP se realizan ensayos complementarios de análisis termogravimétrico (TGA), de calorimetría diferencial de barrido (DSC) y microdureza. Al mismo tiempo, se obtienen imágenes con microscopia óptica, microscopia electrónica de barrido (SEM) y microscopia de fuerza atómica (AFM) de las muestras ensayadas a pullout.

Los resultados obtenidos muestran que los diferentes tratamientos superficiales de las barras de CFRP, que a diferencia del acero no se encuentran estandarizados, movilizan distintos mecanismos adherentes y modifican el comportamiento adherente de las barras de CFRP, siendo el tratamiento de corrugado el único que produce una adherencia similar a las barras de acero corrugado. Además, se comprueba que las condiciones térmicas afectan de forma diferente a los distintos tipos de barras de CFRP. 


\section{RESUM}

En els últims anys, a causa del elevat cost de la reparació de les estructures de formigó amb acer per l'efecte de la corrosió, s'ha pres consciència de la necessitat d'utilitzar nous materials substitutius de les barres d'acer corrugat. Aquests materials han de garantir la seguretat i les condicions de servei, estètiques i funcionals de l'estructura durant el període de vida útil per al qual va ser dissenyat.

A la recerca de nous materials que substitueixen les barres d'acer corrugat, apareixen fa pocs anys les barres de polímer reforçat amb fibres de carboni (CFRP). Aquest tipus de materials és més lleuger, té una resistència a tracció superior a les barres d'acer i, a més a més, solucionen el problema de la corrosió.

Abans d'introduir aquest nou tipus de barres és necessària la comprovació de l'adherència amb el formigó en les diferents condicions tèrmiques a les que es troben exposades les estructures, pel fet que aquest és un dels paràmetres més importants en el disseny de l'estructura. A més a més, de ser una de les hipòtesis en què es basen les normatives actuals de disseny d'estructures de formigó armat.

Aquest treball estudia el comportament adherent entre les barres de CFRP i el formigó en diferents condicions tèrmiques. Per a això, es porta a terme una campanya de 175 assajos experimentals de pullout. Aquests assajos es realitzen en condicions tèrmiques de Gel/Desglaç, $5^{\circ} \mathrm{C}, 20^{\circ} \mathrm{C}, 40^{\circ} \mathrm{C}$ i $80^{\circ} \mathrm{C}$, tant en barres de CFRP amb tractaments superficials de arenat superficial, texturitzat i corrugat, com en barres d'acer corrugat. Prèviament a la realització dels assajos experimentals de pullout, es realitzen 21 assajos de diàmetre 
equivalent i 21 assajos de tracció longitudinal en els mateix tipus de barres. A més a més, en les barres de CFRP es realitzen assajos complementaris d'anàlisi termogravimètric (TGA), de calorimetria diferencial de barrit (DSC) i microduresa. Alhora, s'obtenen imatges amb microscòpia òptica, microscòpia electrònica de barrit (SEM) i microscòpia de força atòmica (AFM) de les mostres assajades a pullout.

Els resultats obtinguts mostren que els diferents tractaments superficials de les barres de CFRP, que a diferència de l'acer no es troben estandarditzats, mobilitzen diferents mecanismes adherents i modifiquen el comportament adherent de les barres de CFRP, sent el tractament de corrugat l'únic que produeix una adherència similar a les barres d'acer corrugat. A més a més, es comprova que les condicions tèrmiques afecten de forma diferent als diferents tipus de barres de CFRP. 


\section{Abstract}

Lately, due to the high cost of repairing concrete structures with steel on the effect of corrosion, designers have become aware of the need for new substitutes of corrugated steel bars. These materials must ensure the safety and the service, aesthetic and funnctional conditions of the structure during the lifetime it was designed for.

Searching for new materials to replace the corrugated steel bars, carbon fiber reinforced polymer bars (CFRP) appear a few years ago. This type of material is lighter than steel bars. Additionaly, it has a tensile strength greater than steel bars and also solves the problem of corrosion.

One of the most important parameters in the design of a structure is checking the bond to the concrete in any thermal conditions. As a result, before introducing this new type of bar it is compulsory to test it. In addition, it is one of the assumptions on which the current design standards of reinforced concrete structures are based.

This thesis analyses the bond behavior between CFRP bars and concrete in different thermal conditions. Consequently, a campaign of 175 pullout test is studied. These tests are performed under thermal conditions Freeze/Thawn, $5^{\circ}$ $\mathrm{C}, 20^{\circ} \mathrm{C}, 40^{\circ} \mathrm{C}$ and $80^{\circ} \mathrm{C}$, both CFRP bars with sandblasted surface treatment, textured and corrugated, like corrugated steel bars. Prior to carrying out the pullout experimental tests, 21 equivalent diameter tests and 21 longitudinal tensile tests are made in in both types of bars. Furthermore, thermogravimetric analysis (TGA), differential scanning calorimetry (DSC) and microhardness complemetary test are performed in CFRP bars. Simultaneously, 
images of pullout test with optic microscopy, scanning electron microscopy (SEM) and atomic force microscopy (AFM) are obtained.

Concluding, different surface treatments of CFRP bars are not standardized, unlike steel bars. They mobilize bond different adhesive mechanisms and modify the behavior of CFRP bars. Being among them the corrugated treatment in CFRP bars, only that produces a similar bond than corrugated steel bars. Moreover, it is found that the thermal conditions differentially affect the different types of CFRP bars. 


\section{Agradecimientos}

En primer lugar, a mis directores de tesis, Don Manuel Valcuende Payá y Don Javier Benlloch Marco, por hacer posible la realización de esta investigación, y especialmente, por su acogida y apoyo diario, por orientarme y guiarme en mi carrera universitaria y como no, por sus magistrales correcciones.

A los técnicos del laboratorio de materiales del Departamento de Construcciónes Arquitectónicas, Rafa Calabuig y Jesús Martínez, por su ayuda durante la primera parte de la ejecución del plan experimetal.

Al Catedrático Vicente Amigó y la profesora Montse Haro, de la Escuela de Ingenieria de Materiales, por su asistencia técnica durante los ensayos experimentales complementarios.

Al Dr. Rafel Díez por su atención inmediata y gratificante ayuda con los problemas estadísticos.

A mi familia, y en especial a mis padres, por inculcarme los valores del trabajo.

Y por último y no menos importante a mi mujer, Belén, por todo el tiempo que le he robado durante estos últimos años, así como por su incesante paciencia y comprensión. 
RESUM

ABSTRACT

AGRADECIMIENTOS

VII

ÍNDICE

IX

LISTA DE TABLAS

XV

LISTA DE FIGURAS

XXIII

NOTACIONES

XXXVI

CAPÍTULO 1 INTRODUCCIÓN

1.1. Antecedentes

1.2. Alcance y Objetivos 5

1.3. Metodología 6

1.4. Organización de la Tesis 7

CAPÍTULO 2 REVISIÓN BIBLIOGRÁFICA 9

2.1. Introducción 9

2.2. Composición de las Barras de CFRP 11

2.2.1.Matriz Polimérica 11

2.2.2. Refuerzo de Fibra de Carbono 27

2.2.3.Proceso de Fabricación 31

2.3. Tipos de Barras de CFRP 34

2.3.1.Grados de Resistencia y Módulo 34

2.3.2.Geometría Superficial $\quad 36$

2.3.3.Diámetro de las Barras $\quad 36$

2.3.4.Identificación de las Barras $\quad 38$

2.4. Propiedades Físicas, Mecánicas y Durabilidad de las 40

Barras de CFRP 
2.4.1.Propiedades Físicas $\quad 41$

2.4.1.1. Densidad 41

2.4.1.2. Coeficiente de Expansión Térmica 41

2.4.1.3. Conductividad Eléctrica 43

2.4.2.Propiedades Mecánicas 43

2.4.2.1. Tracción 43

2.4.2.2. Compresión 46

2.4.2.3. Cortante 48

2.4.3.Durabilidad de las Barras de CFRP 49

2.4.3.1. Efecto del Agua 51

2.4.3.2. Efecto de los Cloruros 52

2.4.3.3. Efecto de los Álcalis 53

2.4.3.4. Efecto de la Radiación Ultravioleta 55

2.4.3.5. Efecto de la Carbonatación del Hormigón 56

2.4.3.6. Efecto de la Temperatura 56

2.4.4.Comportamiento a Largo Plazo de las Barras de CFRP 61

2.4.4.1. Comportamiento a Fatiga 61

2.4.4.2. Comportamiento a Relajación 64

2.4.4.3. Comportamiento a Fluencia 65

2.4.5.Coeficientes de Seguridad 68

2.5. Adherencia Armadura-Hormigón 74

2.5.1.Definición de Adherencia 76

2.5.2. Adherencia entre el Hormigón y el Armado de Acero 79

2.5.2.1. Comportamiento Adherente Hormigón/Armado 79 de Acero

2.5.2.2. Factores que Influyen en el Comportamiento 84 Adherente Hormigón/Armado Acero

2.5.3.Adherencia entre el Hormigón y el Armado de CFRP 89 
2.5.3.1. Comportamiento Adherente entre Hormigón

y Barra Lisa de CFRP

2.5.3.2. Comportamiento Adherente entre Hormigón

y Barras de CFRP Corrugadas o con

Tratamiento Superficial

2.5.4.Parámetros que Influyen en la Comportamiento Adherente

2.5.4.1. Módulo elástico de la Barra

2.5.4.2. Resistencia a Cortante de la Barra

2.5.4.3. Resistencia a Compresión del Hormigón

2.5.4.4. Diámetro de la Barra

2.5.4.5. Geometría Superficial de la Barra

2.5.4.6. Confinamiento

2.5.4.7. Longitud de Anclaje

2.5.4.8. Espesor del Recubrimiento 124

2.5.4.9. Temperatura

2.5.4.10. Posición de la Barra

2.5.5. Métodos de Cálculo del Comportamiento Adherente entre el Hormigón y las Barras de CFRP

2.5.5.1. Métodos Analíticos

2.5.5.1.1. Método Malvar

2.5.5.1.2. Método B.E.P. Modificado

134

2.5.5.1.3. Método C.M.R.

2.5.5.2. Métodos Directos

2.5.5.2.1. Ensayo Pullout

\subsection{Ensayo Beam-End}

2.6. Normativa de Cálculo de Estructuras de Hormigón Armado con Barras de CFRP. Parámetros de Adherencia que Influyen en el Cálculo 
2.6.2.JSCE 1997(b)

2.6.3.CNR-DT 203/2006 154

CAPÍTULO 3 PROGRAMA EXPERIMENTAL Y RESULTADOS 157

3.1. Introducción 157

3.2. Materiales Empleados 159

3.2.1.Barras de CFRP 159

3.2.2.Barras de Acero 162

3.3. Ensayos Previos 163

3.3.1.Cálculo del Periodo de Exposición de las Probetas 164 de Pullout en cada Condición Térmica

3.3.2. Cálculo de la Longitud Mínima de los Anclajes de 169 las Barras de CFRP del Ensayo de Tracción y Pullout

3.3.3.Ensayo de Tracción para Definir el Material 178

Adherente en los Anclajes de las barras de CFRP

3.4. Ensayos Experimentales 190

3.4.1.Ensayos Preliminares 190

3.4.1.1. Ensayo de Diámetro Equivalente 190

3.4.1.2. Estudio de la Geometría Superficial 195

3.4.1.3. Ensayo de Tracción 208

3.4.2.Ensayo de Pullout 222

3.4.3. Ensayos Complementarios 253

3.4.3.1. Análisis Termogravimétrico "TGA" 253

3.4.3.2. Calorimetría Diferencial de Barrido "DSC" 258

3.4.3.3. Microscopia Óptica 263

3.4.3.4. Microdureza 270

3.4.3.5. Microscopia Electrónica de Barrido "SEM" 273

3.4.3.6. Microscopia de Fuerza Atómica "AFM" 278 
CAPÍTULO 4 ANÁLISIS DE LOS RESULTADOS Y DISCUSIÓN 283

4.1. Influencia de Diferentes Parámetros en el Comportamiento 283

Adherente

4.1.1.Geometría o Acabado Superficial 283

4.1.2.Temperatura 321

4.1.3.Resistencia del Hormigón 369

4.1.4.Diámetro de las Barras 377

4.1.5.Temperatura de Transición Vítrea " $\mathrm{T}_{\mathrm{g}}$ ” de la 385

Matriz Polimérica

CAPÍTULO 5 CONCLUSIONES Y FUTURAS LÍNEAS 393

DE INVESTIGACIÓN

5.1. Conclusiones 393

5.2. Futuras Líneas de Investigación 396

REFERENCIAS BIBLIOGRÁFICAS 399

ANEJO I: “Gráficas Experimentales de Tensión 419

Adherente-Deslizamiento" 


\section{Lista De Tablas}

Tabla 2.1. Ventajas y desventajas de las resinas termoestables y termoplásticas.

Tabla 2.2. Propiedades físicas y mecánicas de las resinas poliméricas.

Tabla 2.3. Comportamiento a fluencia (a temperatura ambiente) de diferentes tipos de resinas de epoxi.

Tabla 2.4. Composición de la fibra de carbono (precursor PAN) durante los diferentes estados del procesamiento.

Tabla 2.5. Efecto de la temperatura en el módulo elástico de las fibras de carbono.

Tabla 2.6 Propiedades de las fibras de refuerzo de barras de FRP.

Tabla 2.7. Valores mínimos de resistencia a tracción y módulo elástico de barras de CFRP.

Tabla 2.8. Diámetros de barras de CFRP contemplados por ACI 440.1R-06.

Tabla 2.9. Densidad de las barras de FRP y acero.

Tabla 2.10. CTE de diferentes FRP's.

Tabla 2.11. Propiedades mecánicas a tracción de diferentes barras de FRP y acero.

Tabla 2.12. Comportamiento a tracción de las barras de CFRP, frente ambientes alcalinos

Tabla 2.13. Comportamiento a cortante transversal de las barras de CFRP, frente ambientes alcalinos.

Tabla 2.14. Disminución de resistencia a tracción de las barras de CFRP en presencia de ambientes alcalinos.

Tabla 2.15. Resultados de ensayos de resistencia a tracción a diferentes rangos de temperaturas en barras de CFRP.

Tabla 2.16. Coeficiente de minoración de resistencia del armado $C_{E}$.

Tabla 2.17. Tensión límite del armado debida a fluencia.

Tabla 2.18. Coeficientes de minoración (por condiciones ambientales y por comportamiento a largo plazo de la resistencia del armado.

Tabla 2.19. Coeficientes de minoración (por condiciones ambientales y por comportamiento a largo plazo) de la resistencia del armado.

Tabla 2.20. Coeficiente ambiental $n_{m o}$. 
Tabla 2.21. Coeficiente ambiental $n_{T}$.

Tabla 2.22. Coeficiente ambiental $n_{S L}$.

Tabla 2.23. Coeficiente corrector $n_{d}$.

Tabla 2.24. Coeficiente corrector $n_{a}$.

Tabla 2.25. Coeficiente corrector $n_{l}$.

Tabla 2.26. Coeficientes de minoración (por condiciones ambientales y por comportamiento a largo plazo) de la resistencia del armado.

Tabla 2.27. Resultados de ensayos de adherencia por pullout en barras corrugadas de CFRP y acero.

Tabla 2.28. Resultados de ensayos de adherencia por pullout en barras

De CFRP arenadas y de acero corrugadas.

Tabla 2.29. Adherencia entre las barras de FRP y el hormigón a elevadas temperaturas.

Tabla 2.30. Valor de la tensión adherente en barras de FRP y acero a $20^{\circ} \mathrm{C}$ y $200^{\circ} \mathrm{C}$.

Tabla 2.31. Influencia de la temperatura en la tensión adherente de las barras de CFRP arenadas.

Tabla 2.41. Valores medios y coeficiente de variación de los parámetros de ajuste del Método B.E.P Modificado.

Tabla 2.42. Valores medios y coeficiente de variación de los parámetros de ajuste del Método C.M.R.

Tabla 3.1. Métodos de ensayo de barras de FRP.

Tabla. 3.2. Propiedades definidas por el fabricante de las barras de CFRP.

Tabla. 3.3. Propiedades definidas por el fabricante de las barras de Acero.

Tabla. 3.4. $\mathrm{L}_{\mathrm{a}}$ y $\mathrm{L}_{\mathrm{t}}$ mínimas en barras de CFRP arenadas y corrugadas.

Tabla. 3.5. Dimensiones, Codificación y Plan de ensayos previos para caracterización de La.

Tabla. 3.6. Planificación de ensayos previos para cálculo de $\mathrm{L}_{\mathrm{a}}$ en $\mathrm{CC} 12$, CA14 y CA8.

Tabla. 3.7. Planificación de ensayos previos para cálculo de $\mathrm{L}_{\mathrm{a}}$ en CT13.

Tabla. 3.8. Resultados ensayos previos de cálculo de $\mathrm{L}_{\mathrm{a}}$. según $\mathrm{L}_{\mathrm{e}}$. 
Tabla. 3.10. Test de contraste Múltiple de Rango de la variable Tensión

de la muestra CT13 según $\mathrm{L}_{\mathrm{e}}$.

Tabla 3.11. Dosificación Sikadur 42

180

Tabla 3.12. Propiedades mecánicas de los materiales adherentes

barra/tubo de anclaje

Tabla 3.13. Diseño de bloques aleatorizados del primer ensayo previo de material adherente

Tabla 3.14. Diseño de bloques aleatorizados del segundo ensayo previo de material adherente

Tabla. 3.15. Resultados de los ensayos previos de tracción para el diseño

del material adherente.

Tabla. 3.16. Tabla ANOVA de la variable Fuerza respecto de los factores Material Adherente y Tipo de Barra.

Tabla. 3.17. Test de contraste Múltiple de Rango de la variable Fuerza respecto del factor material adherente.

Tabla 3.18. Planificación del ensayo de diámetro equivalente.

Tabla 3.19. $d_{b}, A_{b}, C_{b} y \sigma$ de cada muestra ensayada.

Tabla 3.20. $d_{b}, A_{b}, C_{b}$ y $\sigma$ de cada tipo de barra.

Tabla 3.21. Planificación del estudio de la geometría superficial.

Tabla 3.22. Dimensiones de las barras de CFRP arenadas CA8.

Tabla 3.23. Dimensiones de las barras de CFRP arenadas CA14.

Tabla 3.24. Dimensiones de las barras de CFRP corrugadas CC12.

Tabla 3.25. Dimensiones de las barras de CFRP texturizadas CT13.

Tabla 3.26. Dimensiones de las barras de acero corrugadas A8.

Tabla 3.27. Dimensiones de las barras de acero corrugadas A12.

Tabla 3.28. Dimensiones de las barras de acero corrugadas A16.

Tabla 3.29. Parámetros de la geometría superficial de las barras de

Tabla 3.30. Diseño del plan de ensayos a tracción.

Tabla 3.31. Resultados ensayo de tracción en cada tipo de barra.

Tabla 3.32 Propiedades mecánicas $\mathrm{F}_{\mathrm{u}}, f_{\mathrm{u}}, f_{\mathrm{L} . \mathrm{E}}, \mathrm{E}_{\mathrm{L}}, \varepsilon_{\mathrm{u}}, \varepsilon_{\mathrm{r}}, \varepsilon_{\mathrm{E}}$ y $\sigma$ de 
Tabla 3.33 Propiedades mecánicas $f_{\mathrm{u}, \mathrm{ck}}, f_{\mathrm{LE}, \mathrm{ck}}, \mathrm{E}_{\mathrm{L}}, \varepsilon_{\mathrm{u}, \mathrm{ck}}$ de las barras

de CFRP y acero.

Tabla 3.34. Diseño Split-Plot del plan de ensayos a pullout.

Tabla 3.35. Diseño del plan de ensayos de control del hormigón a compresión.

Tabla 3.36. Resultados del ensayo de pullout en barras de CFRP arenadas

(CA8 y CA14), corrugadas (CC12), texturizadas (CT13), y acero corrugadas (A8, A12 y A16), sometidas a los tratamientos térmicos de $\mathrm{H} / \mathrm{D}, 5^{\circ} \mathrm{C}, 20^{\circ} \mathrm{C}$, $40{ }^{\circ} \mathrm{C}$ y $80^{\circ} \mathrm{C}$.

Tabla 3.37. Resultados del diámetro resultante de cada barra de CFRP y acero tras el ensayo de pullout.

Tabla 3.38. Diseño del plan de ensayos de TGA.

Tabla 3.39. Resultados del ensayo de TGA.

Tabla 3.40. Diseño del plan de ensayos de DSC.

Tabla 3.41. Resultados del ensayo de DSC en barras CA14, CC12 y CT13.

Tabla 3.42. Diseño del plan de ensayos de Microscopia Óptica.

Tabla 3.43. Resultados ensayo Microdureza.

Tabla. 4.1. Tabla de Contraste Múltiple de Rango de adhesión química en barras de CFRP y acero, a temperatura de $20^{\circ} \mathrm{C}$.

Tabla. 4.2. Estadísticos de cada tipo de barra, en la condición térmica de $20^{\circ} \mathrm{C}$, para el parámetro de tensión adherente máxima.

Tabla. 4.3. Estadísticos de cada tipo de barra, en la condición térmica de

$20{ }^{\circ} \mathrm{C}$, para el parámetro de deslizamiento en extremo tensionado.

Tabla. 4.4. Estadísticos de cada tipo de barra, en la condición térmica de $20^{\circ} \mathrm{C}$, para el parámetro de deslizamiento en extremo no tensionado.

Tabla. 4.5. Estudio estadístico de los resultados de tensión adherente máxima en la condición térmica de $20^{\circ} \mathrm{C}$ : ANOVA y test de Contraste Múltiple de Rango.

Tabla. 4.6. Estudio estadístico de los resultados de deslizamiento en extremo tensionado en la condición térmica de $20^{\circ} \mathrm{C}$ : ANOVA y test de Contraste Múltiple de Rango.

Tabla. 4.7. Estudio estadístico de los resultados de deslizamiento en extremo no tensionado en la condición térmica de $20^{\circ} \mathrm{C}$ : ANOVA y test de Contraste Múltiple de Rango.

Tabla. 4.8. Estudio estadístico del deslizamiento medio a tensión de $5 \mathrm{MPa}$ en la condición térmica de $20^{\circ} \mathrm{C}$, entre las barras CA8 y A8: ANOVA y test de Contraste Múltiple de Rango. 
Tabla. 4.9. Estudio estadístico del deslizamiento medio a tensión de

$5 \mathrm{MPa}$ en la condición térmica de $20^{\circ} \mathrm{C}$, entre las barras CA14 y A16:

ANOVA y test de Contraste Múltiple de Rango.

Tabla. 4.10. Estudio estadístico del deslizamiento medio a tensión de

$5 \mathrm{MPa}$ en la condición térmica de $20^{\circ} \mathrm{C}$, entre las barras CT13 y A12:

ANOVA y test de Contraste Múltiple de Rango.

Tabla. 4.11. Valores obtenidos del parámetro $f_{R}$ en cada tipo de barra.

Tabla. 4.12. Test de Contraste Múltiple de Rango del parámetro $f_{R}$ en condición térmica de $20^{\circ} \mathrm{C}$.

Tabla 4.13. Valores de la tensión adherente obtenidos mediante la regresión:

Tabla 4.14. Valores de los parámetros dimensionales que definen la geometría superficial de las barras CC12.

Tabla. 4.15. Valores mínimos, establecidos por EHE-08, del parámetro $f_{R}$.

Tabla. 4.16. Valores obtenidos del parámetro C.L.R en cada tipo de barra.

Tabla. 4.17. Valores obtenidos del parámetro $\mathrm{a}_{\mathrm{s}}$ en cada tipo de barra.

Tabla. 4.18. Análisis estadístico de la relación entre el parámetro $\mathrm{a}_{\mathrm{s}} \mathrm{y}$ la tensión adherente, en la condición térmica de $20^{\circ} \mathrm{C}$.

Tabla. 4.19. Valores medios del deslizamiento, en extremo tensionado y no tensionado, de las barras de CFRP arenadas CA8 en las diferentes condiciones térmicas.

Tabla. 4.20. Estudio estadístico del efecto de las condiciones térmicas en la tensión adherente de las barras de CFRP arenadas CA8: ANOVA y test de Contraste Múltiple de Rango.

Tabla. 4.21. Estudio estadístico del efecto de las condiciones térmicas en la tensión adherente residual de las barras de CFRP arenadas CA8: Test de Contraste Múltiple de Rango.

Tabla. 4.22. Valores medios del deslizamiento, en extremo tensionado y no tensionado, de las barras de CFRP arenadas CA14 en las diferentes condiciones térmicas.

Tabla. 4.23. Estudio estadístico del efecto de las condiciones térmicas en la tensión adherente residual de las barras de CFRP arenadas CA14: Test de Contraste Múltiple de Rango.

Tabla. 4.24. Estudio estadístico del efecto de las condiciones térmicas en la tensión adherente de las barras de CFRP corrugadas CC12: ANOVA y Test de Contraste Múltiple de Rango.

Tabla. 4.25. Estudio estadístico del efecto de las condiciones térmicas en los deslizamientos de las barras de CFRP corrugadas CC12: Test de Contraste Múltiple de Rango. 
Tabla. 4.26. Estudio estadístico del efecto de la temperatura en la tensión adherente residual de las barras de CFRP corrugadas CC12: Test de Contraste Múltiple de Rango.

Tabla. 4.27. Estudio estadístico del efecto de la temperatura en la tensión adherente máxima de las barras de CFRP texturizadas CT13: Test de Contraste Múltiple de Rango.

Tabla. 4.28. Valores medios del deslizamiento, en extremo tensionado y no 349 tensionado, de las barras de CFRP texturizadas CT13 en las diferentes condiciones térmicas.

Tabla. 4.29. Tensión adherente máxima.

Tabla. 4.30. Análisis de Varianza Multifactorial de la variable dependiente 355 tesnión adherente y las variables independientes tipo de barra (CA8 y A8) y temperatura $\left(-20,5,20,40\right.$ y $\left.80^{\circ} \mathrm{C}\right)$.

Tabla. 4.31. Rigidez adherente de las barras de CFRP arenadas CA8 y acero corrugadas A8.

Tabla. 4.32. Tensión adherente residual de las barras de CFRP arenadas CA8 $\mathrm{y}$ acero corrugadas A8.

Tabla. 4.33. Tensión adherente máxima (valores medios de los 5 ensayos de cada temperatura) de las barras de CFRP arenadas CA14 y acero corrugadas A16.

Tabla. 4.34. Análisis de Varianza Multifactorial de la variable dependiente tesnión adherente y las variables independientes tipo de barra (CA14 y A16) y temperatura $\left(-20,5,20,40\right.$ y $\left.80^{\circ} \mathrm{C}\right)$.

Tabla. 4.35. Rigidez adherente de las barras de CFRP arenadas CA14 y acero 360 corrugadas A16.

Tabla. 4.36. Tensión adherente máxima (valores medios de los 5 ensayos de cada temperatura) de las barras de CFRP corrugadas CC12 y acero corrugadas A12.

Tabla. 4.37. Deslizamiento a tensión adherente máxima en extremo tensionado y no tensionado.

Tabla. 4.38. Rigidez adherente de las barras de CFRP corrugadas CC12 y acero corrugadas A12.

Tabla. 4.39. Tensión adherente máxima (valores medios de los 5 ensayos de cada temperatura) de las barras de CFRP texturizadas CT13 y acero corrugadas A12.

Tabla. 4.40. Análisis de Varianza Multifactorial de la variable dependiente tensión adherente y las variables independientes tipo de barra (CT13 y A12) y temperatura $\left(-20,5,20,40\right.$ y $\left.80^{\circ} \mathrm{C}\right)$.

Tabla. 4.41. Rigidez adherente de las barras de CFRP corrugadas CC12 y acero corrugadas A12.

Tabla. 4.42. Resultados de ensayos de resistencia a compresión del hormigón. 
Tabla. 4.43. Análisis de Varianza Multifactorial en el tipo de barra CA8 de la variable dependiente tensión adherente y las variables independientes Temperatura $\left(-20,5,20,40\right.$ y $\left.80^{\circ} \mathrm{C}\right)$ y resistencia a compresión del hormigón (35-45 MPa).

Tabla. 4.44. Análisis de Varianza Multifactorial en el tipo de barra CA14 de la variable dependiente tensión adherente y las variables independientes Temperatura $\left(-20,5,20,40\right.$ y $\left.80^{\circ} \mathrm{C}\right)$ y resistencia a compresión del hormigón (35-45 MPa).

Tabla. 4.45. Análisis de Varianza Multifactorial en el tipo de barra CC12 de la variable dependiente tensión adherente y las variables independientes Temperatura $\left(-20,5,20,40\right.$ y $\left.80^{\circ} \mathrm{C}\right)$ y resistencia a compresión del hormigón (35-45 MPa).

Tabla. 4.46. Análisis del modo de rotura en función de la resistencia a compresión del hormigón en las barras de CFRP corrugadas CC12: ANOVA y test de Contraste Múltiple de Rango.

Tabla. 4.47. Análisis de Varianza Multifactorial en el tipo de barra CC12 de la variable dependiente tensión adherente y las variables independientes temperatura $\left(-20,5,20,40\right.$ y $\left.80^{\circ} \mathrm{C}\right)$ y modo de rotura (MA y MC).

Tabla. 4.48. Análisis de Varianza Multifactorial en el tipo de barra CT13 de la variable dependiente tensión adherente y las variables independientes temperatura $\left(-20,5,20,40\right.$ y $\left.80^{\circ} \mathrm{C}\right)$ y resistencia a compresión (35-45 MPa).

Tabla. 4.49. Diámetro equivalente de las barras de CFRP arenadas y acero corrugado.

Tabla. 4.50. Tensión adherente máxima (valores medios de los 5 ensayos de cada temperatura) de las barras de CFRP arenadas CA8 y CA14.

Tabla. 4.51. Análisis de la tensión adherente de las barras de CFRP arenadas en función del diámetro equivalente y la temperatura: ANOVA y test de Contraste Múltiple de Rango.

Tabla. 4.52. Tensión adherente máxima (valores medios de los 5 ensayos de cada temperatura) de las barras de CFRP arenadas CA8 y CA14.

Tabla. 4.53. Análisis de la tensión adherente de las barras de acero corrugado en función del diámetro equivalente y la temperatura: ANOVA y test de Contraste Múltiple de Rango.

Tabla 4.54. Temperatura de transición vítrea de las barras de CFRP.

Tabla. 4.55. Estudio estadístico del efecto del tipo matriz polimérica en la temperatura de transición vítrea de las barras de CFRP: ANOVA y test de Contraste Múltiple de Rango.

Tabla. 4.56. Pérdida de adhesión química a temperaturas elevadas de las barras de CFRP, en MPa.

Tabla. 4.57. Pérdida de rigidez adherente a temperaturas elevadas de las barras de CFRP, en MPa. 
Tabla. 4.58. Pérdida de tensión adherente máxima a temperaturas elevadas de las barras de CFRP, en MPa.

Tabla. 4.59. Pérdida de tensión adherente residual a temperaturas elevadas de las barras de CFRP, en MPa. 


\section{Lista de Figuras}

Figs. 1.1 Estructuras expuestas a ambientes de corrosión. España.

Fig. 1.2. Puente diseñado con armado de FRP, Canadá.

Fig. 1.3. Estructura del tren de levitación magnética, Japón.

Fig. 2.1. Barras de FRP.

Fig. 2.2. Barras de CFRP. 11

$\begin{array}{ll}\text { Fig. 2.3. Cadenas moleculares. } & 13\end{array}$

Fig. 2.4. Variación de la $T_{g}$ y rigidez del polímero en presencia de humedad. 14

Fig. 2.5. Unidad monomérica o constitucional del PEEK. 18

Fig. 2.6. Molécula inicial de la matriz de epoxi.

$\begin{array}{ll}\text { Fig. 2.7. Molécula de epoxi preparada para el curado. } & 20\end{array}$

Fig. 2.8. Estructura química de la resina de epoxi. $\quad 20$

Fig. 2.9. Gráfica de las curvas de Tensión/Deformación, de varias resinas de 21 epoxi de diferentes módulos.

Fig 2.10. Moléculas de poliéster insaturado, estireno, t-butil perbenzonato (tBPB). 23

Fig. 2.11. Gráfica de las curvas de Tensión/Deformación, frente a 24 esfuerzos de tracción y compresión, de la resina de poliéster.

Fig. 2.12. Estructura química de la resina de viniléster. 27

Fig. 2.13. Estructura química de la fibra de carbono. 29

Fig. 2.14. Grafica de tensión/deformación de diferentes tipos de fibras. 30

Fig. 2.15. Proceso de pultrusión.

Fig. 2.16. Tipos de geometrías superficiales de barras de CFRP. 36

Fig. 2.17. Tipos de geometrías superficiales de barras de CFRP. 37

Fig. 2.18. Identificación de barras de CFRP. 39

Fig. 2.19. Ejes de una barra de CFRP. 42

Fig. 2.20. Comportamiento tensión/deformación de la fibra de carbono, $\quad 43$ matriz polimérica y barra de CFRP. 
Fig. 2.21. Comportamiento tensión/deformación de diferentes barras de FRP y acero.

Fig. 2.22. Distribución de tensiones normales en la sección transversal de una barra de CFRP.

Fig. 2.23. Influencia de la dirección de la tensión aplicada en la rigidez de las barras de CFRP.

Fig. 2.24. Modo de rotura de las barras de CFRP en función de la dirección de la tensión aplicada.

Fig. 2.25. Influencia del porcentaje del volumen de fibra de carbono en la resistencia de las barras de CFRP.

Fig. 2.26. Tensión de corte transversal $\left(\tau_{3}\right)$ aplicada en una barra de CFRP.

Fig. 2.27. Ensayos de resistencia a tracción en barras de CFRP sometidas a diferentes temperaturas.

Fig. 2.28. Comportamiento mecánico frente a diferentes temperaturas en barras de CFRP, GFRP y acero.

Fig. 2.29. Comparación del comportamiento mecánico a) R. Tracción, b) Módulo elástico frente a diferentes temperaturas en barras de CFRP, GFRP y acero.

Fig. 2.30. Resistencia a fatiga de diferentes tipos de barras de FRP.

Fig. 2.31. Grafica tipo del comportamiento a fluencia de las barras de FRP.

Fig. 2.32. Comportamiento adherente entre el hormigón y las barras de acero. Gráfica de tensión de adherencia media/desplazamiento.

Fig. 2.33. Tensión en el extremo de la corruga de una barra de acero (fase elástica).

Fig. 2.34. Desplazamiento relativo de la barra de acero respecto al hormigón.

Fig. 2.35. a) Deslizamiento barra/hormigón y acción de acuñamiento b) Adherencia por adhesión química, fricción y acunamiento (los tres mecanismos no se producen al mismo tiempo).

Fig. 2.36. Fisuras transversales longitudinales por splitting.

Fig. 2.37. Modos de rotura por adherencia

Fig. 2.38. Relación entre la tensión adherente y la resistencia a compresión del hormigón. $\quad 85$

$\begin{array}{ll}\text { Fig. 2.39. Tensión adherente } & 87\end{array}$

Fig. 2.40. Efecto del confinamiento en la resistencia de adherencia. $\quad 88$

Fig. 2.41. Comportamiento de adherencia de los diferentes tipos de barras de FRP y acero. $\quad 89$

Fig. 2.42. Clasificación de tipos de barras de CFRP, según su geometría superficial. 
Fig. 2.43. Comportamiento adherente entre las barras de CFRP lisas y el hormigón.

Fig. 2.44. Gráfica de tensión adherente/deslizamiento de barras de CFRP lisas.

Fig. 2.45. Barra de CFRP tras el ensayo de adherencia por pullout.

Fig. 2.46. Gráfica que relaciona la tensión adherente y el cociente entre el deslizamiento y el radio de las barras lisas de CFRP.

Fig. 2.47. Gráfica de tensión de adherencia/deslizamiento de barras deformadas o con tratamiento superficial de CFRP.

Fig. 2.48. Fisuración del hormigón debido a que la tensión adherente de la barra es superior a la resistencia del hormigón a tracción.

Fig. 2.49. Comportamiento adherente entre el hormigón y las barras de CFRP corrugadas. $\quad 96$

Fig. 2.50. Representación esquemática del equilibrio entre la tensión adherente y la resistencia a tracción del hormigón.

Fig. 2.51. Formación de fisuras internas y externas alrededor de la barra de CFRP.

Fig. 2.52. Comportamiento adherente entre barras de CFRP deformadas y hormigón fisurado durante el ensayo de pullout descentrado.

Fig. 2.53. Comportamiento adherente entre barras de CFRP corrugadas y el hormigón.

Fig. 2.54. Parámetros que intervienen en la rotura por adherencia de las barras de CFRP corrugadas.

Fig. 2.55. Estado de la interfaz hormigón/barra de FRP corrugada tras el ensayo de pullout.

Fig. 2.56. Comportamiento adherente de barras de CFRP arenadas.

Fig. 2.57. Estado de la barra de FRP arenada tras el ensayo de pullout.

Fig. 2.58. Comportamiento adherente de barras de FRP con hélice adherida y arenadas. Las siglas CFRPsw se refieren a barras de CFRP con hélice adherida y arenadas.

Fig. 2.59. Comportamiento adherente entre el hormigón de alta resistencia (resistencia a compresión del orden de 57 a $63 \mathrm{MPa}$ ) y las barras de CFRP texturizadas.

Fig. 2.60. Restos de hormigón en la superficie de la barra de CFRP texturizada tras el ensayo de pullout.

Fig. 2.61. Comportamiento adherente entre las barras de CFRP corrugadas y el hormigón.

Fig. 2.62. Comportamiento adherente entre las barras de CFRP arenadas y el hormigón.

Fig. 2.63. Comportamiento adherente entre las barras de CFRP con hélice adherida helicoidalmente y arenadas y el hormigón.

Fig. 2.64. Comportamiento adherente de las barras de CFRP texturizadas. 
Fig. 2.65. Comportamiento adherente de las barras de CFRP texturizadas.

Fig. 2.66. Comportamiento adherente entre distintos tipos de barras de FRP con hélice adherida y arenadas y el hormigón.

Fig. 2.67. Influencia del módulo de elasticidad en el comportamiento adherente entre diferentes tipos de barras de FRP con hélice adherida y arenadas

Fig. 2.68. Influencia del módulo de elasticidad de las barras de FRP en el comportamiento adherente.

Fig. 2.69. Comportamiento adherente de barras de FRP lisas.

Fig. 2.70. Comportamiento adherente de barras de FRP corrugadas.

Fig. 2.71. Influencia de la resistencia a compresión del hormigón en la resistencia de adherencia de las barras de CFRP y CFRP corrugadas.

Fig. 2.72. Influencia de la resistencia a compresión del hormigón en tensión adherente de las barras de CFRP arenadas, texturizadas y acero corrugadas.

Fig. 2.73. Influencia de la resistencia a compresión del hormigón en la tensión adherente de las barras de CFRP texturizadas.

Fig. 2.74. Distribución de las tensiones normales en la sección transversal de una barra de CFRP sometida a una tensión axial.

Fig. 2.75. Influencia del diámetro en el comportamiento adherente inicial por el mecanismo de adhesión química en barras de CFRP.

Fig. 2.76. Comportamiento de adherencia de las barras de CFRP corrugadas en presencia de confinamiento, durante el ensayo de pullout.

Fig. 2.77. Comportamiento de adherencia de las barras de CFRP arenadas en presencia de confinamiento, durante el ensayo de pullout.

Fig. 2.78. Influencia de la longitud de anclaje en barras de CFRP (Ø 13,5mm).

Fig. 2.79. Influencia de la longitud de anclaje en barras de CFRP (Ø 7,9mm).

Fig. 2.80. Distribución de las tensiones de tracción en el hormigón circundante e influencia del recubrimiento en la capacidad de adherencia en barras de acero, CFRP corrugada y GFRP arenada.

Fig. 2.81. Barras de FRP y acero empleadas en el estudio.

Fig. 2.82. Disminución de la tensión adherente en función de la temperatura en diferentes tipos de barras de FRP y de acero corrugadas.

Fig. 2.83. Comportamiento adherente de las barras de CFRP texturizadas ante diferentes condiciones ambientales.

Fig. 2.84. Comportamiento adherente de las barras de CFRP arenadas a diferentes temperaturas. 
Fig. 2.85. Comportamiento de adherencia de las barras de FRP y acero en función de la temperatura.

Fig. 2.86. Gráfica constitutiva de tensión adherente/deslizamiento del modelo analítico B.E.P.

Fig. 2.87. Gráfica constitutiva de tensión adherente/deslizamiento del modelo analítico B.E.P Modificado.

Fig. 2.88. Comparativa entre el Método C.M.R y el B.E.P. Modificado.

Fig. 2.89. Comparativa entre el Método Malvar y el B.E.P. Modificado.

Fig. 2.90. Dimensiones y características de las probetas para el ensayo de adherencia por pullout centrado.

Fig. 2.91. Dimensiones y características de las probetas para el ensayo de adherencia por pullout centrado.

Fig. 2.92. Dimensiones y características de las probetas para el ensayo de adherencia por pullout centrado, con la influencia de la posición de la barra.

Fig. 2.93. Ensayos de pullout centrado.

Fig. 2.94. Dimensiones y características de las probetas para el ensayo de adherencia por pullout descentrado.

Fig. 2.95. Dimensiones y características de las probetas para el ensayo de adherencia por pullout con confinamiento.

Fig. 2.96. Dimensiones y características de las probetas para el ensayo de adherencia por beam-end.

Fig. 3.1. Barras de CFRP arenadas.

Fig. 3.2. Barra de CFRP Corrugada.

Fig. 3.3. Barra de CFRP Texturizada.

Fig. 3.4. Barra de Acero Corrugada.

Fig. 3.5. Imagen arcón, ciclo de hielo, probeta de hormigón con sonda.

Fig. 3.6. Ciclo térmico de Hielo/Deshielo en probetas de pullout.

Fig. 3.7. Imagen cámara, probeta de hormigón en caja térmica con sonda.

Fig.3.8. Gráfica de tiempo respecto al incremento de temperatura para el ciclo de $5{ }^{\circ} \mathrm{C}$.

Fig. 3.9. Gráfica de tiempo respecto al incremento de temperatura para el ciclo de $80^{\circ} \mathrm{C}$.

Fig. 3.10. Probetas de ensayos a tracción y pullout.

Fig. 3.11. Gráfico de Medias de la variable Tensión de la muestra CT13 según $\mathrm{L}_{\mathrm{e}}$. 
Fig. 3.12. Deslizamiento barra CA14.

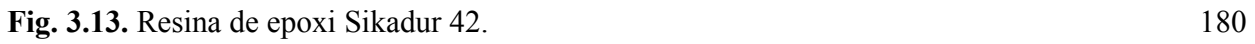

$\begin{array}{ll}\text { Fig. 3.14. Propiedades mecánicas cemento expansivo CBA S.L. } & 181\end{array}$

Fig. 3.15. Longitud de anclaje sin geometría superficial en barras de CFRP arenadas. $\quad 182$

Fig. 3.16. Deslizamiento en anclajes en ensayo de tracción de barras CA14. 185

Fig. 3.17. Anclajes máquinas de ensayo a tracción. 186

Fig. 3.18. Gráfico de Medias de la variable Fuerza respecto del factor Material Adherente. $\quad 188$

Fig. 3.19. Modo de rotura a tracción en CA 8 con diferentes materiales de anclaje. 188

Fig. 3.20. Gráficos de Tensión / Deformación en barras CA8 con diferentes 189 materiales adherentes.

Fig. 3.21. Agua destilada, Volunómetro, pajita y vasos graduados. 191

$\begin{array}{ll}\text { Fig. 3.22. Calibre digital. } & 191\end{array}$

Fig. 3.23. Muestras para ensayo de Diámetro Equivalente. 192

Fig. 3.24. Medición del volumen. 193

Fig. 3.25. Tipos de corrugas en barras de acero, CFRP corrugadas y CFRP texturizadas. 196

Fig. 3.26. Parámetros de la geometría superficial 197

Fig. 3.27. Máquina de sombras Starrett modelo HB-350 200

Fig. 3.28. Geometría superficial de las barras de CFRP arenadas CA8. 201

Fig. 3.29. Geometría superficial de las barras de CFRP arenadas CA14. 202

Fig. 3.30. Geometría superficial de las barras de CFRP corrugadas CC12. 203

Fig. 3.31. Geometría superficial de las barras de CFRP texturizadas CT13. 204

Fig. 3.32. Geometría superficial de las barras de acero corrugadas A8. 205

Fig. 3.33. Geometría superficial de las barras de acero corrugadas A12. 206

Fig. 3.34. Geometría superficial de las barras de acero corrugadas A16. 207

Fig. 3.35. Máquina de ensayo a tracción, Captador de deformaciones. 209

$\begin{array}{lr}\text { Fig. 3.36. Báscula de precisión. } & 210\end{array}$

Fig. 3.37. Tubos de acero y tapones de goma. $\quad 210$

$\begin{array}{ll}\text { Fig. 3.38. Barras a ensayar. } & 211\end{array}$ 
Fig. 3.39. Dimensiones de barras de CFRP para ensayo a tracción.

Fig. 3.40. Proceso de fabricación de los anclajes de las barras de CFRP.

Fig. 3.41. Modo de rotura.

Fig. 3.42. Deslizamiento sin rotura de las barras CA14.

Fig. 3.43. Comportamiento a tracción de las barras de CFRP CA8, CA14, CC12,

Fig. 3.44. Comportamiento a tracción de las barras de CFRP y acero corrugadas. Gráfica de tensión/Deformación.

Fig. 3.45 Metodología de ensayo a pullout.

Fig. 3.46 Barras de CFRP.

Fig. 3.47 Molde de fabricación de probetas de pullout.

Fig. 3.48 Émbolo de sujeción de LVDT's en el extremo tensionado.

Fig. 3.49. Placa de sujeción captador extremo no tensionado, Placa de sujeción de probetas de pullout.

Fig. 3.50. Cámara de curado, Cámara climática de condición 5,20 y $40{ }^{\circ} \mathrm{C}$,

Fig. 3.51. Arcón frigorífico para condición climática de Hielo/Deshielo a $-20^{\circ} \mathrm{C}$.

Fig. 3.52. Máquinas de ensayo.

Fig. 3.53. Preparación de moldes y barras para vertido de hormigón.

Fig. 3.54. Fabricación de hormigón, Ensayo de consistencia, Vertido y compactado de hormigón.

Fig. 3.55. Desmoldado y marcado de las probetas de pullout y control de hormigón.

Fig. 3.56. Fabricación de anclajes, Colocación de aislante térmico en probetas de pullout, Ensayo de compresión en probetas de control del hormigón.

Fig. 3.57. Caja térmica, Ensayo de pullout, Rotura de las probetas de pullout por la mitad.

Fig. 3.58. Comportamiento adherente de las barras de CFRP arenadas

"CA8 y CA14", corrugadas "CC12" y texturizadas "CT13" y acero corrugadas "A8, A12 y A16", sometidas a las condiciones ambientales de $\mathrm{HD}, 5{ }^{\circ} \mathrm{C}, 20^{\circ} \mathrm{C}$, $40{ }^{\circ} \mathrm{C}$ y $80^{\circ} \mathrm{C}$. Gráficas de tensión adherente / deslizamiento.

Fig. 3.59. Imágenes de la superficie de las barras CA8, CA14, CC12, CT13, A8, A12 y A16 en la zona de la segunda corruga.

Fig. 3.60. Modo de rotura de las barras CA 8 y CA14. 
Fig. 3.61. Modo de rotura de las barras $\mathrm{CC} 12$.

Fig. 3.62. Modo de rotura por pullout. 253

Fig. 3.63. Máquinas ensayo TGA. 254

$\begin{array}{ll}\text { Fig. 3.64. Proceso de ensayo de TGA. } & 255\end{array}$

Fig. 3.65. Pérdida de masa en función de la temperatura en barras CA14, CC12 y CT13. 258

Fig. 3.66. Sección transversal de la barra de CFRP tras el ensayo de TGA (x 200). 258

$\begin{array}{lr}\text { Fig. 3.67. Máquina de DSC. } & 259\end{array}$

$\begin{array}{ll}\text { Fig. 3.68. Ensayo de DSC. } & 260\end{array}$

Fig. 3.69. Gráfica de relación entre la tasa de calor y la temperatura en CA14. 261

Fig. 3.70. Equipos de ensayo. 263

Fig. 3.71. Microscopio Óptico, Muestras de ensayo 264

Fig. 3.72. Imágenes de las barras CA8 (x 200): a.1 y a.2) Intefaz núcleo-capa 267 de arenado y núcleo, MICRO/CA8/HD; b.1 y b2) Intefaz núcleo-capa de arenado y núcleo, MICRO/CA8/20; c.1 y c.2) Intefaz núcleo-capa de arenado y núcleo, MICRO/CA8/80;

Fig. 3.73. Imágenes de las barras CA14 (x 200): a.1 y a.2) Intefaz 268 núcleo-capa de arenado y núcleo, MICRO/CA14/HD; b.1 y b2) Intefaz núcleo-capa de arenado y núcleo, MICRO/CA14/20; c.1 y c.2) Intefaz núcleo-capa de arenado y núcleo, MICRO/CA14/80;

Fig. 3.74. Imágenes de las barras $\mathrm{CC} 12$ (x 200): a.1 y a.2) Intefaz núcleo-geometría superficial y núcleo, $\mathrm{MICRO} / \mathrm{CC} 12 / \mathrm{HD}$; b.1 y b2) Intefaz núcleo-geometría superficial y núcleo, $\mathrm{MICRO} / \mathrm{CC} 12 / 20 ;$ c.1 y c.2) Intefaz núcleo-geometría superficial y núcleo, $\mathrm{MICRO/CC12/80;}$

Fig. 3.75. Imágenes de las barras CT13 (x 200): a.1 y a.2) Intefaz núcleo-geometría superficial y núcleo, MICRO/CT13/HD; b.1 y b2) Intefaz núcleo-geometría superficial y núcleo, MICRO/CT13/20; c.1 y c.2) Intefaz núcleo-geometría superficial y núcleo, MICRO/CT13/80;

Fig. 3.76. Máquina de ensayo de microdureza.

Fig. 3.77. Materiales para ensayo SEM.

$\begin{array}{ll}\text { Fig. 3.78. Maquinas pulidoras de muestras. } & 274\end{array}$

Fig. 3.79. Recubridor de muestras, Microscopio electrónico de barrido. 274

Fig. 3.80. Muestras de CFRP para ensayo de SEM 276

Fig. 3.81. SEM/CC12/HD en núcleo de sección transversal, x 250 . 277 
Fig. 3.82. SEM/CC12/HD en núcleo de sección transversal, x 5000.

Fig. 3.83. SEM/CC12/80 en interfaz superficie/núcleo de sección transversal, x 5000.

Fig. 3.84. Máquina de ensayo de AFM

Fig. 3.85. Muestras de ensayo de AFM.

Fig. 3.86. Imagen de la sección transversal AFM/CT13/HD

Fig. 4.1. Tipo de mecanismo adherente de las barras de CFRP y acero corrugadas (condición térmica de $20^{\circ} \mathrm{C}$ ).

Fig. 4.2. Comportamiento adherente de las barras CA8. Gráfica tensión adherente / deslizamiento en extremo tensionado "ET" y no tensionado "ENT".

Fig. 4.3. Comportamiento adherente de las barras CA14. Gráfica tensión

Fig. 4.4. Barra EPU/L5/T20/P6/CA8 tras el ensayo de pullout.

Fig. 4.5. Superficie de la longitud adherente de hormigón

Fig. 4.6. Longitud adherente de hormigón, EPU/L1/T20/P2/CA8, tras el ensayo de pullout.

Fig. 4.7. Fibras y resina sin daños tras el ensayo de pullout.

Fig. 4.8. SEM/CA8/20 tras ensayo pullout.

Fig. 4.9. Gráfico comparativo de la tensión adherente residual ejercida por las barras una vez producida la rotura adherente.

Fig. 4.10. ANOVA Gráfico de adhesión química de las barras de CFRP y acero corrugadas.

Fig. 4.11. Comportamiento adherente de las barrasde CFRP y acero corrugadas.

Fig. 4.12. Rotura adherente por cortadura de las corrugas en la muestra

Fig. 4.13. Rotura adherente por modo combinado EPU-L1-T20-P1-CC12.

Fig. 4.14. Corruga, de muestra SEM/CC12/20, tras ensayo de pullout.

Fig. 4.15. Rotura del hormigón entre las corrugas y la cánula de PVC.

Fig. 4.16. Comportamiento adherente tras la rotura, debida a: corte de las corrugas de la barra "RA" y modo combinado "RC".

Fig. 4.17. Daños en las fibras y matriz polimérica tras el ensayo de pullout.

Fig. 4.18. Daños y fisuras en las barras de CFRP tras el ensayo de pullout. 
Fig. 4.19. ANOVA gráfico de tensión adherente residual en barras de CFRP y acero corrugadas.

Fig. 4.20. Detalle de superficie.

Fig. 4.21. Mecanismo adherente por acuñamiento mecánico de las corrugas de hormigón contra la barra de CFRP texturizada.

Fig. 4.22. Comportamiento adherente de las barras CT13. Gráfica tensión adherente / deslizamiento en extremo tensionado "ET" y no tensionado "ENT".

Fig. 4.23. Rotura adherente por modo pullout, debida a corte de las corrugas de hormigón EPU/L5/T20/P4/CT13.

Fig. 4.24. Imagen de zona próxima a la corruga. Daños en resina polimérica y restos de hormigón en la corruga.SEM/CT13/20. x 250.

Fig. 4.25. EPU/L1/T20/P3/CT13.

Fig. 4.26. Comportamiento adherente de las barras de CFRP y acero corrugadas, CC12 y A12. Gráfica tensión adherente-deslizamiento.

Fig. 4.27. Comportamiento adherente de las barras de CFRP arenadas CA8 y acero corrugadas A8. Gráfica de tensión adherente-deslizamiento.

Fig. 4.28. Comportamiento adherente de las barras de CFRP arenadas CA14 y acero corrugadas A16. Gráfica de tensión adherente-deslizamiento.

Fig. 4.29. Comportamiento adherente de las barras de CFRP texturizadas CT13 y acero corrugadas A12. Gráfica de tensión adherente-deslizamiento.

Fig. 4.30. Relación doblemente inversa entre la tensión adherente y el parámetro $f_{R}$. en los tipos de barras CC12, AT13, A8, A12 y A16:

a) Tratamiento térmico de $20^{\circ} \mathrm{C}$; b) Toda la población.

Fig. 4.31. Relación entre la tensión adherente y el parámetro $f_{R}$. en las barras de CFRP corrugadas CC12, en la condición térmica de $20^{\circ} \mathrm{C}$

Fig. 4.32. Comportamiento adherente en función del parámetro $f_{R}$. Gráfica de tensión adherente-deslizamiento.

Fig. 4.33. Relación entre la tensión adherente y el parámetro C.L.R.

Fig. 4.34. Relación entre la tensión adherente y el parámetro C.L.R, en la condición térmica de $20^{\circ} \mathrm{C}$.

Fig. 4.35. Relación entre la tensión adherente y el parámetro $\mathrm{a}_{\mathrm{s}}$, en la condición térmica de $20^{\circ} \mathrm{C}$.

Fig. 4.36. Comportamiento adherente de las barras de CFRP arenadas CA8 en condiciones térmicas de Hielo/Deshielo, $5^{\circ} \mathrm{C}, 20^{\circ} \mathrm{C}, 40{ }^{\circ} \mathrm{C}$ y $80^{\circ} \mathrm{C}$.

Gráfica de tensión adherente-deslizamiento.

Fig. 4.37. Tipo de mecanismo adherente en barras de CFRP arenadas CA8. 
Fig. 4.38. Relación entre la adhesión química y la temperatura en barras de CFRP arenadas CA8.

Fig. 4.39. Relación entre la tensión adherente y la temperatura en barras de CFRP arenadas CA8.

Fig. 4.40. Imágenes de la zona cercana a la interfaz entre la capa de arenado y el núcleo de la barra (x5000).

Fig. 4.41. Estado de las barras de CFRP arenadas CA8 tras el ensayo de pullout.

Fig. 4.42. Imágenes de superficie de la barra tras el ensayo de pullout

Fig. 4.43. Tipo de mecanismo adherente en barras de CFRP arenadas CA14.

Fig. 4.44. Comportamiento adherente de las barras de CFRP arenadas CA14 en condiciones térmicas de Hielo/Deshielo, $5^{\circ} \mathrm{C}, 20^{\circ} \mathrm{C}, 40^{\circ} \mathrm{C}$ y $80^{\circ} \mathrm{C}$.

Gráfica de tensión adherente-deslizamiento.

Fig. 4.45. Relación entre la tensión adherente y la temperatura en barras de CFRP arenadas CA14.

Fig. 4.46. Imágenes de la zona cercana a la interfaz entre la capa de arenado y el núcleo de la barra (x5000).

Fig. 4.47. Modo de rotura de las barras de CFRP arenadas CA14 en el ensayo de pullout.

Fig. 4.48. Rotura adherente de las barrras CA14 por modo combinado EPU/L9/T5/P2/CA14. 334

Fig. 4.49. Comportamiendo adherente, a diferentes temperaturas, de las barras de CFRP arenadas CA14 cuyo modo de rotura es combinado.

Fig. 4.50. Valores medios de la tensión adherente residual de las barras de CFRP arenadas CA14, a diferentes temperaturas y según el modo de rotura.

Fig. 4.51. Tipo de mecanismo adherente en barras de CFRP corrugadas CC12.

Fig. 4.52. Comportamiento adherente de las barras de CFRP corrugadas $\mathrm{CC} 12$ en condiciones térmicas de Hielo/Deshielo, $5{ }^{\circ} \mathrm{C}, 20^{\circ} \mathrm{C}, 40{ }^{\circ} \mathrm{C}$ y $80^{\circ} \mathrm{C}$.

Gráfica de tensión adherente-deslizamiento.

Fig. 4.53. Relación entre la tensión adherente máxima y la temperatura en barras de CFRP corrugadas CC12.

Fig. 4.54. Modos de rotura de las barras de CFRP corrugadas CC12: Imágenes y detalle de rotura por corte de las corrugas de la geometría superficial de la barra; Imágenes y detalle de rotura por modo combinado, donde se muestra la corruga intacta con restos de hormigón.

Fig. 4.55. Imágenes SEM/CC12/HD.

Fig. 4.56. Imágenes SEM/CC12/80. 
Fig. 4.57. Imágenes de Microscopia de Fuerza Atómica "AFM" en barras de

Fig. 4.58. Imágenes SEM/CC12/HD y SEM/CC12/20, x250: Detalle del estado del núcleo tras el ensayo de pullout en las barras $\mathrm{CC} 12$. Roturas más extendidas a $-20^{\circ} \mathrm{C}$.

Fig. 4.59. Imágenes núcleo de SEM/CC12/HD.

Fig. 4.60. Imágenes núcleo de SEM/CC12/80.

Fig. 4.61. Relación entre la tensión adherente residual y la temperatura en las barras de CFRP corrugadas CC12.

Fig. 4.62. Tipo de mecanismo adherente de las barras de CFRP texturizadas CT13.

Fig. 4.63. Comportamiento adherente de las barras de CFRP corrugadas $\mathrm{CC} 12$ en condiciones térmicas de Hielo/Deshielo, $5{ }^{\circ} \mathrm{C}, 20^{\circ} \mathrm{C}, 40^{\circ} \mathrm{C}$ y $80^{\circ} \mathrm{C}$.

Gráfica de tensión adherente-deslizamiento.

Fig. 4.64. Relación entre la tensión adherente y la temperatura en barras de CFRP texturizadas CT13.

Fig. 4.65. Estado de las barras de CFRP texturizadas CT13 tras el ensayo de pullout.

Fig. 4.66. Rotura por corte de las corrugas de hormigón, estado de las probetas de hormigón y barras de CFRP texturizadas CT13, tras el ensayo de pullout a diferentes temperaturas.

Fig. 4.67. Estado de la superficie de la barra de CFRP texturizada CT13 tras el ensayo de pullout a temperatura de $80{ }^{\circ} \mathrm{C}$.

Fig. 4.68. Estado de la superficie de la barra de CFRP texturizada CT13 tras el ensayo de pullout a temperatura de $-20^{\circ} \mathrm{C}$.

Fig. 4.69. Tensión adherente residual de las barras de CFRP texturizadas CT13.

Fig. 4.70. Comparativa del comportamiento adherente entre las barras de CFRP arenadas $\mathrm{CA} 8$ y acero corrugadas A8.

Fig. 4.71. Comparativa del comportamiento adherente entre las barras de CFRP arenadas CA14 y acero corrugadas A16.

Fig. 4.72. Comparativa de la tensión adherente, deslizamiento medio de ambos extremos y rigidez adherente, de las barras de CFRP arenadas CA14 y de acero corrugadas A16.

Fig. 4.73. Comparativa de la tensión adherente residual entre las barras de CFRP arenadas CA14 y las barras de acero corrugado A16.

Fig. 4.74. Comparativa del comportamiento adherente entre las barras de CFRP corrugadas $\mathrm{CC} 12$ y acero corrugadas A12. 
Fig. 4.75. Comparativa de la tensión adherente, deslizamiento medio de ambos extremos y rigidez adherente, de las barras de CFRP corrugadas CC12 y de acero corrugadas A12.

Fig. 4.76. Comparativa de la tensión adherente residual entre las barras de CFRP corrugadas CC12 y las barras de acero corrugado A12.

Fig. 4.77. Comparativa del comportamiento adherente entre las barras de CFRP corrugadas CT13y acero corrugadas A12.

Fig. 4.78. Tensión adherente residual a diferentes temperaturas de las barras de CFRP texturizadas CT13 y acero corrugadas A12.

Fig. 4.79. Relación entre la resistencia a compresión del hormigón y la tensión adherente máxima de las barras CA8.

Fig. 4.80. Relación entre la resistencia a compresión del hormigón y la tensión adherente máxima de las barras CA14.

Fig. 4.81. Relación entre la resistencia a compresión del hormigón y la tensión adherente máxima de las barras CC12.

Fig. 4.82. Gráfico de medias del ANOVA de la variable dependiente resistencia del hormigón respecto de la variable independiente modo de rotura, en las barras CC12.

Fig. 4.83. Gráfico de medias del ANOVA de la variable dependiente tensión adherente respecto de la variable independiente modo de rotura, en las barras CC12.

Fig. 4.84. Relación entre la resistencia a compresión del hormigón y la tensión adherente máxima de las barras CT13.

Fig.. 4.85. Comporamiento adherente de las barras de CFRP arenadas según su diámetro.

Fig. 4.86. Adhesión química de las barras de CFRP arenadas según su diámetro.

Fig. 4.87. Imágnes de microscopia digital de la interfaz capa de arenado y núcleo de barras de CFRP arenadas (x50).

Fig. 4.88. Gráfico de interacciónes entre la temperatura y el diámetro equivalente en la tensión adherente máxima de las barras de CFRP arenadas.

Fig. 4.89. Gráfico de la tensión adherente residual de las barras de CFRP arenadas según su diámetro.

Fig.. 4.90. Comporamiento adherente de las barras de CFRP arenadas según su diámetro.

Fig. 4.91. Adhesión química de las barras de acero corrugado según su diámetro.

Fig. 4.92. Gráfico de la tensión adherente residual de las barras de acero corrugado según su diámetro.

Fig. 4.93. Gráfico de comparación de la temperatura de transición vítrea media 
Fig. 4.94. Gráfico de comparación de pérdida de adherencia química, de las barras de CFRP con diferentes $T_{g}$, a elevadas temperaturas.

Fig. 4.95. Gráfico de comparación de pérdida de rigidez adherente, de las barras de CFRP con diferentes $\mathrm{T}_{\mathrm{g}}$, a elevadas temperaturas.

Fig. 4.96. Gráfico de comparación de pérdida de tensión adherente máxima de las barras de CFRP con diferentes $\mathrm{T}_{\mathrm{g}}$, a elevadas temperaturas.

Fig. 4.97. Comportamiento adhernete de las barras de CFRP arenadas "CA14", corrugadas "CC12" y texturizadas "CT13"..

Fig. 4.98. Gráfico de comparación de pérdida de tensión adherente residual de las 392 barras de CFRP con diferentes $\mathrm{T}_{\mathrm{g}}$, a elevadas temperaturas. 


\section{Notaciones}

$\mathrm{A}_{\mathrm{b}} \quad$ Area equivalente de la barra, $\mathrm{mm}^{2}$.

$\mathrm{a}_{\mathrm{m}} \quad$ Altura media de la corruga de la barra, $\mathrm{mm}$.

$\mathrm{a}_{\mathrm{s}} \quad$ Parámetro de adherencia, adimensional.

c Distancia entre dos corrugas de la barra consecutivas, $\mathrm{mm}$.

$\mathrm{C}_{\mathrm{b}} \quad$ Perímetro equivalente de la barra, $\mathrm{mm}$.

C.L.R Parámetro de adherencia, adimensional.

C.T.E. Coeficiente de transmission térmica,

$\mathrm{d}_{\mathrm{b}} \quad$ Diámetro equivalente de la barra, $\mathrm{mm}$.

$\mathrm{d}_{\mathrm{n}} \quad$ Diámetro nominal de la barra, $\mathrm{mm}$.

$\mathrm{E}_{\mathrm{L}} \quad$ Módulo de elasticidad de las barras de acero, MPa.

E $\mathrm{FRP}_{\mathrm{FP}} \quad$ Módulo de elasticidad de las barras de FRP, MPa.

F $\quad$ Fuerza aplicada, $\mathrm{kN}$.

fc Resistencia a compresion del hormigón, MPa.

$f_{c m} \quad$ Resistencia media a compression del hormigón a los 28 días, MPa.

$f_{c t} \quad$ Resistencia a tracción del hormigón, MPa.

$f_{c t m} \quad$ Resistencia a tracción media del hormigón, MPa.

fr Parámetro adherente, adimensional.

$f_{u} \quad$ Resistencia a tracción de la barra de FRP, MPa.

$f_{L . E} \quad$ Resistencia a tracción a límite elastico de la barra de FRP, MPa.

$\mathrm{L}_{\mathrm{a}} \quad$ Longitud de anclaje, $\mathrm{mm}$.

$\mathrm{L}_{\mathrm{a}, \mathrm{min}}$. Longitud de anclaje minima, $\mathrm{mm}$.

$\mathrm{L}_{\mathrm{t}} \quad$ Longitud total de la barra, $\mathrm{mm}$. 
$\mathrm{L}_{\mathrm{e}} \quad$ Longitud de ensayo, $\mathrm{mm}$.

$\mathrm{L}_{\mathrm{adh}} \quad$ BonLongitud adherente de las barras en el ensayo de pullout, $\mathrm{mm}$.

$\tau \quad$ Tensión adherente, MPa.

$\tau_{\max .} \quad$ Tensión adherente maxima, MPa.

$\mathrm{W}_{\mathrm{c}} \quad$ Longitud de la corruga de hormigón que produce el acuñamiento, $\mathrm{mm}$.

$\mathrm{w}_{\mathrm{f}} \quad$ Ancho de la corruga de la barra, $\mathrm{mm}$.

$\varepsilon_{\mathrm{u}} \quad$ Deformación bajo carga máxima de la barra, $\%$.

$\varepsilon_{\mathrm{r}} \quad$ Deformación de rotura de la barra, $\%$.

$\varepsilon_{\mathrm{E}} \quad$ Deformación a límite elástico de la barra, \%.

$\delta_{\mathrm{ET}} \quad$ Deslizamiento en extremo tensionado de la barra, $\mathrm{mm}$.

$\delta_{\mathrm{ET}} \quad$ Deslizamiento en extremo no tensionado de la barra, $\mathrm{mm}$. 


\section{CAPÍTULO 1}

\section{INTRODUCCIÓN}

En este capítulo se presentan los antecedentes del empleo de barras de CFRP como armado de hormigón. Y a continuación el alcance y objetivos, la metodología y la organización de la tesis.

\subsection{Antecedentes}

El hormigón armado con acero es el material más empleado en el diseño y ejecución de todo tipo de estructuras (Edificación y Obra Civil). El armado de acero puede estar expuesto a ambientes agresivos, tales como concentración de cloruros (estructuras marinas y sales para deshielo), bajas y altas temperaturas y humedad, que pueden producir la degradación y pérdida de servicio de la estructura y por consiguiente elevados costes de reparación (Figs. 1.1a, 1.1b). Por ejemplo, la expansión de la red de carreteras nacionales en los Estados Unidos en la década de 1950 aumentó la necesidad de proporcionar un mantenimiento de las mismas durante todo el año, lo que convirtió en común el uso de sales en los puentes de carretera. Como consecuencia, el armado de acero de estas estructuras expuestas a sales de deshielo, experimentó una corrosión excesiva. Se ha estimado el coste de la reparación de los puentes de carreteras de los Estados Unidos en más de 50 billones de dólares, y de 1,6 trillones de dólares para el resto de estructuras de hormigón con armado de acero. En Europa, se ha calculado el coste de reparación de las estructuras debido a la corrosión del acero sobre 3 billones por año (Faza, 1991). 

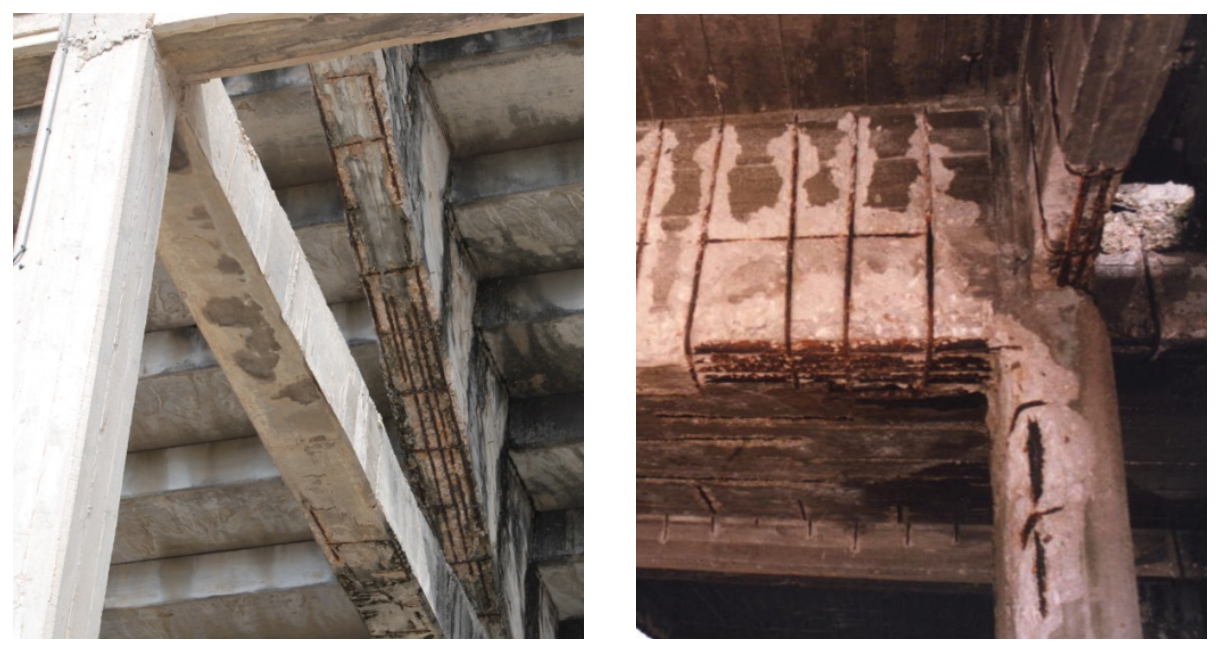

Figs. 1.1a y 1.1b. Estructuras expuestas a ambientes de corrosión. España.

Las diferentes normativas actuales definen los recubrimientos mínimos del hormigón armado con acero, junto con otras medidas de control, como el ancho de fisura máximo, la permeabilidad, la alcalinidad del hormigón. Con estas medidas solo se consigue ralentizar el inicio de la corrosión, puesto que tarde o temprano las propiedades de alcalinidad del recubrimiento de hormigón se reducirán (ACI-318-08; EHE; FIB; JSCE; CSA).

Las diferentes soluciones de reducción del riesgo de corrosión en ambientes altamente agresivos incluyen, láminas de protección superficial para detener la entrada de $\mathrm{CO}_{2}$, productos químicos solubles en agua, aditivos inhibidores de la corrosión, capas superficiales de epoxi y galvanizado de la armadura. También se utilizan técnicas de protección catódica, como es la colocación de un ánodo de sacrificio para proteger la armadura. En algunos casos el acero inoxidable ofrece la mejor solución. Sin embargo muchas de estas soluciones solamente consiguen ralentizar la corrosión, fallan o son muy caras.

Las armaduras de FRP aparecieron a finales de la década de los 70 como solución a los problemas de corrosión, estas, a su vez ofrecen una elevada resistencia a tracción, buen comportamiento a fatiga y son muy ligeras. Las 
armaduras FRP comenzaron a utilizarse en muchas aplicaciones, como en estructuras expuestas a ambientes marinos, en zonas de ciclos de hielo/deshielo, en cimentaciones y en industrias químicas (Fig. 1.2). A su vez, y debido a que las armaduras de acero interfieren en los campos magnéticos, se requerían estructuras con neutralidad magnética (bases de motores, escáneres magnéticos y trenes magnéticos con sistema de levitación). En este ámbito aparecen como solución, las estructuras de hormigón armado con FRP, debido a que no son magnéticas (Fig. 1.3).

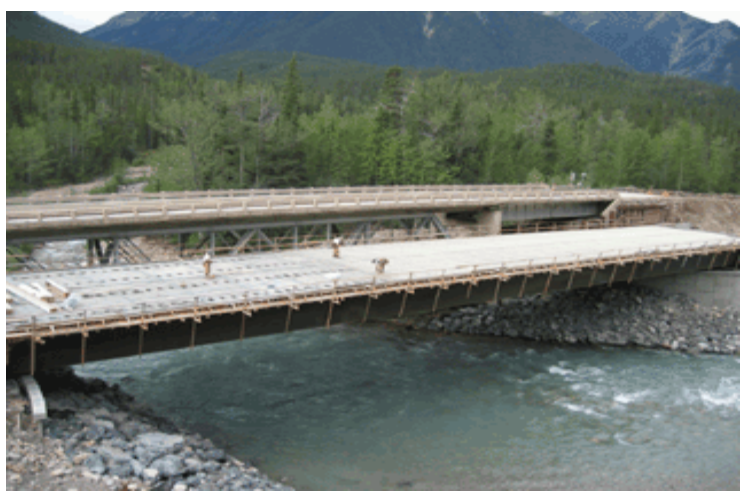

Fig. 1.2. Puente diseñado con armado de FRP, Canadá.

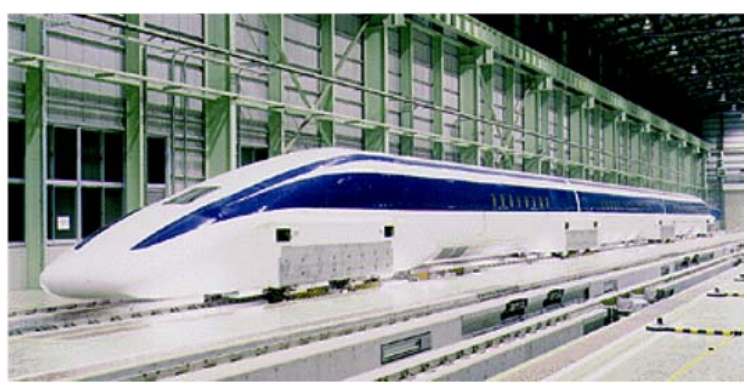

Fig. 1.3. Estructura del tren de levitación magnética, Japón.

Las estructuras de hormigón armado con barras de FRP se encuentran en servicio expuestas a ambientes agresivos en diversas partes del mundo durante más de 23 años sin problemas estructurales (ACI, 2006). En 1983, se realizó el primer proyecto financiado por el Departamento de Transporte de EE.UU. (USDOT) "Transfer of Composite Technology to Desing and Construction of 
Bridges "(Plecnik y Ahmad, 1988). Hasta mediados de la década de 1990, los japoneses realizaron la mayoría de aplicaciones de los armados de FRP, con más de 100 proyectos. En Asia, China se ha convertido recientemente en el mayor consumidor de armado de FRP para obras de nueva construcción, en aplicaciones que abarcan desde las cubiertas de puentes a las obras del metro (Ye et al., 2003). El uso del armado de FRP en Europa se inició en Alemania, con la construcción de un puente en 1986 con armado de FRP pretensado (Meier, 1992). En Canadá, el Headingley Bridge en Manitoba incluía armado tanto CFRP como de GFRP (Rizkalla, 1997). Además, en el puente de Kent County Road No 10 se han utilizado parrillas de CFRP como armado en zonas de momento negativo (Tadros et al., 1998). El Puente Joffre, ubicado sobre el río Saint-François en Sherbrooke, Quebec, se ha ejecutado con parrillas de CFRP en la losa y barras de armado de GFRP en la medianera de la carretera y la acera (Benmokrane et al., 2004).

A pesar de las diferentes ventajas del armado de FRP sobre el armado de acero, no se ha generalizado el diseño de las estructuras de hormigón armado con FRP.

Las diferentes normativas de diseño de estructuras de hormigón armado con FRP (ACI 440.1R-06, JSCE 1997(b), CAN/CSA-S806-02, FIB Task Group 9.3, 2007, CNR-DT 203/2006, IStructE, 1999) han adaptado los métodos de cálculo de las estructuras de hormigón armado con acero, introduciendo el diferente comportamiento de las barras de FRP. Una de las suposiciones de diseño de las secciones de los elementos de hormigón armado con FRP, es la perfecta adherencia entre el hormigón y el armado de FRP. La adherencia afecta al diseño frente a estados límites últimos y de servicio, ya que influye en la capacidad portante de la sección así como en el ancho y separación entre fisuras (ambas relacionadas con el efecto de la rigidez a tracción) (Nanni, 1995a). Además, la suposición de adherencia perfecta no sólo afecta al comportamiento 
a flexión, sino también afecta al comportamiento frente a cortante, torsión y punzonamiento. Por lo tanto, la adherencia es el mecanismo de mayor importancia y debe ser garantizada ante cualquier carga o condición ambiental (Cosenza et al., 1997; Pecce et al., 2001; Edwards et al., 1978).

Numerosos han sido los trabajos de investigación llevados a cabo sobre la adherencia entre el armado de GFRP y el hormigón (Katz et al., 1999; Nanni et al., 1993,1995; Benmokrane et al., 1996; Tighiouart et.al., 1998; Bakis et.al., 2007; Cosenza et. al., 1996,1997; Davalos et al., 2008; Larralde et al., 1993; Malvar et al., 1995,2003; Chaallal et al., 1996; Tepfers et al., 2003; Taerwe, 1995; Sield et al., 1997). Sin embargo, relativamente pocos son los trabajos de investigación sobre el comportamiento adherente entre el armado de CFRP y el hormigón (Davalos et al., 2008; Malvar et al., 2003; Aiello et al., 2007; Okelo et al., 2005; Achillides et al., 2004). Mientras que, los estudios sobre el comportamiento adherente entre armado de CFRP y el hormigón en condiciones ambientales, de altas o bajas temperaturas y ciclos hielo/deshielo han sido muy reducidos.

\subsection{Alcance y Objetivos}

El presente estudio experimental tiene como objetivo el análisis de la influencia de los distintos tratamientos superficiales de las barras de CFRP en su comportamiento adherente con el hormigón. Para ello, se han llevado a cabo diferentes ensayos de pullout sobre elementos de hormigón armado con CFRP.

Para poder abarcar las diferentes condiciones ambientales a las que se encuentran sometidas las estructuras de hormigón armado con CFRP a lo largo de todo un año, el presente estudio experimental analiza el comportamiento adherente entre el armado de CFRP y el hormigón tras una serie de ciclos de hielo/deshielo, y a los niveles de temperaturas de $5^{\circ} \mathrm{C}, 20^{\circ} \mathrm{C}, 40^{\circ} \mathrm{C}$ y $80^{\circ} \mathrm{C}$, obteniendo así el comportamiento en climas fríos y calurosos. Al mismo tiempo, 
se realizan ensayos de comparación de pullout en elementos armados con barras de acero, sometidos a las mismas condiciones ambientales anteriores, con el objetivo de cuantificar cualitativamente y cuantitativamente la adherencia entre el armado de CFRP y el hormigón.

Mediante los ensayos de pullout y con el apoyo de ensayos de microscopia electrónica de barrido "SEM", microscopia de fuerza atómica "AFM", análisis termogravimétrico "TGA", calorimetría diferencial de barrido "DSC" y microdureza se pretende alcanzar un conocimiento global del comportamiento de adherencia entre el armado de CFRP y el hormigón.

\subsection{Metodología}

Inicialmente se realizan ensayos previos para definir las longitudes mínimas y el material óptimo de los anclajes de las barras de CFRP empleados en el ensayo de tracción y pullout. También se realizan ensayos de cálculo del periodo de adquisición de temperatura de las probetas de pullout, estableciéndose la duración de los ciclos de hielo/deshielo y de temperaturas de ensayo, así como el tiempo de trabajo desde la extracción de las probetas de la cámara climática hasta su ensayo.

Para alcanzar los objetivos expuestos en el apartado anterior, se realizan los ensayos experimentales. Estos se han dividido en tres etapas: La primera etapa consta de los ensayos preliminares, mediante los cuales siguiendo las normativas ACI y ASTM, se han realizado ensayos de diámetro equivalente, estudio de la geometría superficial, y ensayos de tracción longitudinal, calculando así las características geométricas, resistencia a tracción, módulo elástico y alargamiento de las barras de CFRP.

La siguiente etapa y principal consta de los ensayos de pullout, mediante los que se calcula el comportamiento adherente entre los diferentes tratamientos superficiales de las barras de CFRP y el hormigón en distintas condiciones 
ambientales, a las que se encuentran sometidas las estructuras de hormigón armado a lo largo de todo un año, como son hielo/deshielo y temperaturas de $5^{\circ} \mathrm{C}, 20^{\circ} \mathrm{C}, 40^{\circ} \mathrm{C}$ y $80^{\circ} \mathrm{C}$.

En los ensayos experimentales, también se contemplan ensayos de pullout de comparación con armado de acero, con el fin de obtener una comparativa del comportamiento adherente entre los diferentes tratamientos superficiales de las barras de CFRP y acero.

En la tercera etapa, una vez concluidos los diferentes ensayos de pullout, se realizan ensayos complementarios de TGA, DSC, Microscopia óptica, Microdureza, SEM y AFM, obteniendo así los datos necesarios para el análisis a nivel microscópico del comportamiento adherente.

\subsection{Organización de la Tesis.}

El presente estudio se divide en cinco capítulos.

En el Capítulo 1 se introducen los antecedentes y aplicaciones del empleo de barras de CFRP como armado de hormigón. Así como, el alcance y objetivos, la metodología y la organización de la tesis.

En el Capítulo 2 se expone el estado de la cuestión objeto de la investigación. Para ello inicialmente se analiza la composición, tipos, propiedades físicas, mecánicas y durabilidad del armado de CFRP. Para concluir con el análisis del comportamiento adherente entre las barras de CFRP y el hormigón. Así como, con los parámetros de adherencia que influyen en las diferentes normativas de cálculo de estructuras de hormigón armado con CFRP.

En el Capítulo 3 se define el programa experimental y se muestran los principales resultados de la investigación. También se exponen los materiales y maquinaria empleados, así como los procedimientos de cada ensayo. 
En el Capítulo 4 se desarrolla el análisis de los resultados del programa experimental. Estudiando la influencia en el comportamiento adherente del tipo de geometría o acabado superficial, la temperatura, la resistencia del hormigón, el diámetro y la temperatura de transición vítrea de las barras de CFRP. Al mismo tiempo, se compara en las diferentes condiciones térmicas el comportamiento adherente desarrollado por las barras de CFRP con el de las barras de acero corrugado.

En el Capítulo 5 se enumeran las conclusiones y futuras líneas de investigación del presente estudio experimental. 


\section{CAPÍTULO 2}

\section{Revisión Bibliográfica}

\subsection{Introducción}

Las diferentes normativas de diseño de estructuras de hormigón armado con FRP (ACI 440.1R-06, JSCE 1997(b), CAN/CSA-S806-02, FIB Task Group 9.3, 2007, CNR-DT 203/2006, IStructE, 1999) contemplan los siguientes composites de FRP como armado del hormigón (Fig. 2.1); Polímero Reforzado con Fibra de Aramida (AFRP); Polímero Reforzado con Fibra de Vidrio (GFRP) y Polímero Reforzado con Fibra de Carbono (CFRP).

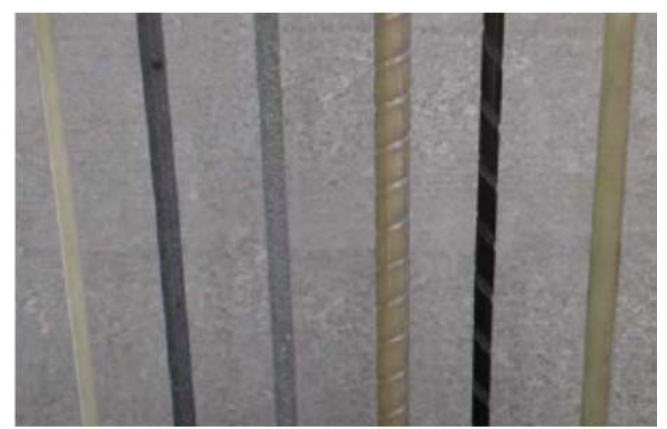

Fig. 2.1. Barras de FRP.

Los composites se definen como cualquier material sólido estructuralmente heterogéneo compuesto por dos o más componentes distintos con propiedades físicas o químicas muy diferentes, con el propósito de lograr un nuevo material con propiedades físicas, químicas y mecánicas que dichos componentes no pueden desarrollar individualmente. A su vez, los composites de Polímero Reforzado con Fibras (FRP) están formados por una matriz polimérica, termoplástica o termoestable, que se encuentra reforzada con fibras en una o ambas direcciones, encargadas de aportar resistencia y rigidez a la matriz en la dirección en la que se dispongan. El desarrollo funcional del 
composite de FRP depende de las propiedades mecánicas de la fibra, de la matriz y de la interfaz entre ambas.

Las funciones principales de la matriz polimérica (resina) son, unir las fibras entre sí, mantener las fibras en el lugar y la dirección deseada, proporcionar la resistencia adecuada a cortante transversal y resistir las diferentes condiciones ambientales (Hollaway, 1993). A su vez, la matriz polimérica protege a las fibras contra daños derivados de la manipulación, el transporte y la fabricación. A pesar de todas estas funciones, el papel principal de la matriz polimérica es la transferencia de tensiones a las fibras de refuerzo.

La interfaz entre el refuerzo de fibra y la matriz polimérica es una zona de transición importante, la cual debe proporcionar una adherencia adecuada a lo largo del tiempo, ya sea química o física (Hollaway, 1993). La transferencia de tensiones de la matriz polimérica al refuerzo de fibras tiene lugar por rasante en la interfaz fibra/matriz. La resistencia de la interfaz controla el proceso de transferencia de tensiones entre la fibra y la matriz, ya sea por rotura de la fibra o de la matriz. Las propiedades de la interfaz son muy difíciles de determinar; sin embargo, tanto las fibras como la matriz pueden ser caracterizadas mecánicamente mediante ensayos sencillos.

El presente estudio de investigación se centra en las barras de CFRP (Fig. 2.2). Este composite está formado por una matriz de resina polimérica (generalmente resina de epoxi) y por un refuerzo de fibra de carbono. Las barras de CFRP son anisótropas, puesto que presentan diferentes propiedades térmicas y mecánicas en las dos direcciones principales (Gay et al., 2003; Gibson, 1994). 

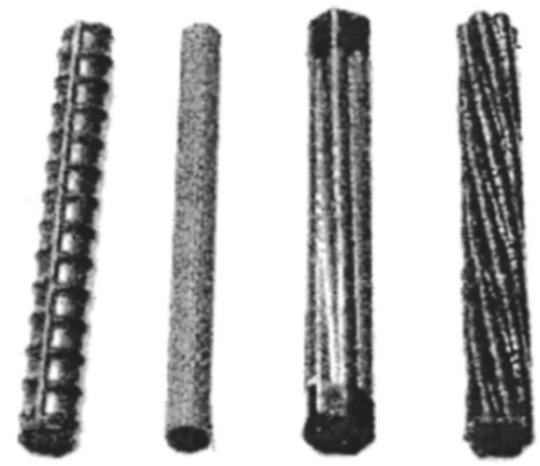

Fig. 2.2. Barras de CFRP.

La composición, tipos, propiedades físicas, mecánicas y la durabilidad de las barras de CFRP se presentan en los siguientes apartados. También, se analiza el comportamiento adherente entre las barras de CFRP y el hormigón.

\subsection{Composición de las Barras de CFRP}

En este apartado se procede a enumerar y definir los diferentes tipos de matrices poliméricas y refuerzos de fibra de carbono empleados como materiales constituyentes de las barras de CFRP. A su vez, también se desarrollan los diferentes métodos de fabricación de barras de CFRP.

\subsubsection{Matriz Polimérica}

Los polímeros son esencialmente compuestos orgánicos, formados por carbono e hidrógeno. Estos compuestos pueden obtenerse de la naturaleza o por síntesis de moléculas orgánicas en laboratorios. El polímero se define como una sustancia compuesta por moléculas (macromoléculas), caracterizada por la repetición múltiple de una o más especies de átomos o grupos de átomos (unidades monoméricas o constitucionales, "mer"), unidos entre sí en cantidad suficiente para proporcionar una serie de propiedades que no varían marcadamente con la adición o sustracción de una o varias unidades monoméricas. 
El término polimerización se refiere a la reacción química o curado, en la cual se añade un catalizador para iniciar el proceso de polimerización. El periodo transcurrido a partir del estado líquido (monómero) hacia un estado sólido (matriz), depende de la temperatura de curado, y se denomina tiempo de curado. Tras el curado, el producto resultante alcanza el estado sólido (GangaRao et al., 2007).

Los polímeros se pueden encontrar en estado sólido o líquido; el polímero curado se denomina matriz polimérica. Las matrices poliméricas se clasifican en dos categorías (basándose en la reacción ante calor y frio): termoestables y termoplásticas. Los polímeros termoplásticos los encontramos en forma sólida, mientras que los termoestables se encuentran en forma líquida (Mallick, 1993).

Aunque ambos tipos de resinas se componen de largas cadenas moleculares, se comportan diferentemente durante el curado debido al enlace de las cadenas moleculares. La Fig. 2.3 muestra esquemáticamente las cadenas moleculares de los polímeros termoestables y termoplásticos (Mallick, 1993). La mayor diferencia entre ambas cadenas moleculares es la ausencia o presencia de enlaces entre cadenas moleculares. En los polímeros termoplásticos, las moléculas individuales son lineales o ramificadas y están unidas mediante fuerzas de Van der Waals (Fig. 2.3a). En cambio, en los polímeros termoestables las moléculas se encuentran químicamente entrecruzadas o reticuladas por fuerzas covalentes (Fig. 2.3b), lo que proporciona una estructura rígida; es decir una red tridimensional. Como resultado, una vez que estas cadenas se forman durante el proceso de curado (polimerización), el polímero termoestable no puede ser calentado ni modelado (las cadenas no tienen posibilidad de movimiento). En los polímeros termoplásticos sucede lo contrario puesto que, al calentar la resina, esta permite movimientos entre cadenas moleculares (debido a que su estructura molecular es lineal o ramificada, y sus moléculas se encuentran 
unidas por fuerzas de Van der Waals); por lo tanto presentan un estado sólido/liquido reversible.

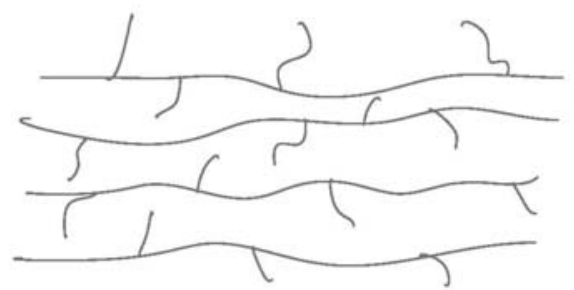

(a)

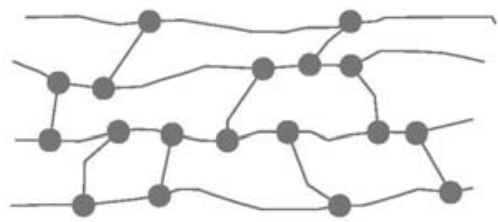

(b)

Fig. 2.3. Cadena molecular a) Termoplástico (Lineal o Ramificada) y b) Termoestable (Entrecruzada o Ramificada). Mallick, 1993.

La distinción más relevante entre los polímeros termoplásticos y termoestables, es el comportamiento bajo calor y tensión. Algunas matrices poliméricas termoestables son sensibles hirgrotérmicamente; éstas se pueden degradar a temperaturas moderadas ante la absorción de humedad. El incremento de la temperatura causa un reblandecimiento gradual de la matriz polimérica hasta un cierto punto, lo que indica una transición de un comportamiento vítreo a un comportamiento plástico ${ }^{1}$. La temperatura durante la cual se produce esta transición se denomina temperatura de transición vítrea, $T_{g}$, la cual disminuye en presencia de humedad (Fig. 2.4). Un incremento continuado de la temperatura más allá de la temperatura de transición vítrea causa en el polímero una transición de un comportamiento vítreo a un comportamiento plástico. Como resultado, la resistencia a corte y la rigidez de la matriz se reducen, y entonces el material deja de ser efectivo para uso estructural (Gibson, 1994). Los cambios higrotérmicos (expansión o retracción) pueden producir en el composite una alteración en el comportamiento de tensión/deformación. Estos cambios, se deben a dos causas diferentes: la expansión produce un aumento del volumen del composite debido a un incremento de la humedad; y la retracción produce una

\footnotetext{
${ }^{1}$ Este término ha sido traducido de la palabra inglesa "rubbery", entendiendo su significado como un comportamiento frente a un esfuerzo que genera una deformación remanente importante.
} 
disminución del volumen del composite debido a la reducción del contenido de humedad ${ }^{2}$.

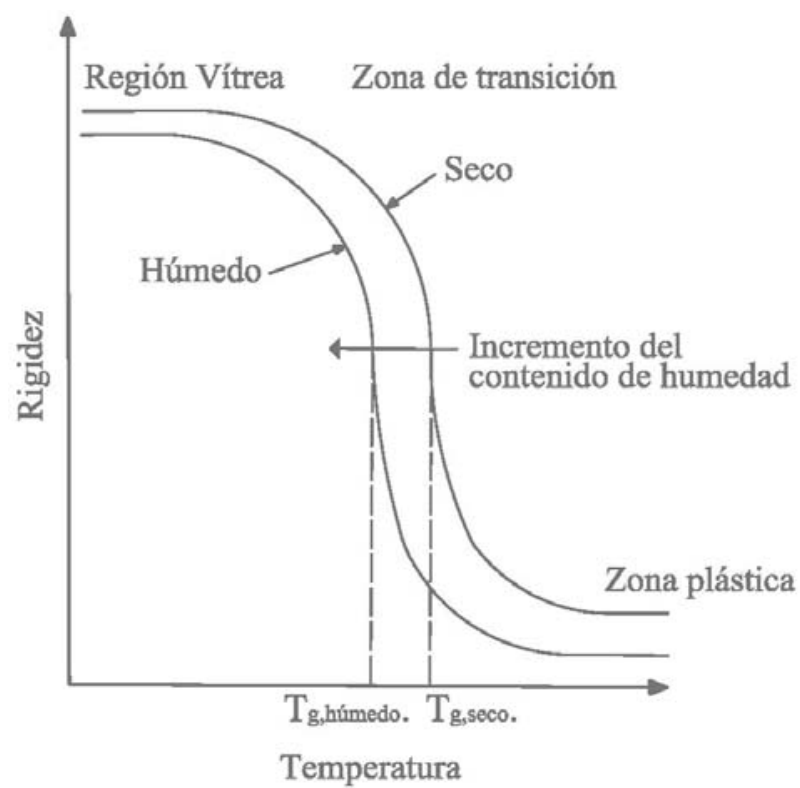

Fig. 2.4. Variación de la $T_{g}$ y rigidez del polímero en presencia de humedad (Gibson, 1994).

Las ventajas e inconvenientes del empleo de las resinas termoplásticas y termoestables se muestran en la Tabla 2.1.

\begin{tabular}{llll}
\hline \multicolumn{2}{c}{ Termoestables } & \multicolumn{2}{c}{ Termoplásticas } \\
\hline \multicolumn{1}{c}{ Ventajas } & \multicolumn{1}{c}{ Inconvenientes } & \multicolumn{1}{c}{ Ventajas } & \multicolumn{1}{c}{ Inconvenientes } \\
-Buena resistencia a & -Largo proceso de & -Corto proceso de & -Baja resistencia a \\
fluencia. & fabricación. & fabricación. & fluencia. \\
-Buena resistencia & -No permite el & -Posformado. & -Propiedades \\
química. & posformado. & -Reciclado. & mecánicas bajas. \\
-Temperatura & & -Gran tenacidad a & -Temperatura de uso \\
máxima de uso & & fractura. & máxima baja. \\
elevada. & & -Buena resistencia a & \\
-Propiedades & & deslaminación a & \\
mecánicas altas. & & fatiga. & \\
\hline
\end{tabular}

Tabla 2.1. Ventajas y desventajas de las resinas termoestables y termoplásticas.

${ }^{2}$ La mayor consecuencia se presenta debida a la retracción del polímero producida por las bajas temperaturas, puesto que el polímero cambia su comportamiento de dúctil a frágil. El término temperatura de transición vítrea se sustituye por temperatura de transición de comportamiento dúctil a frágil (Smith, 1986). 
Debido a las diferentes propiedades de las resinas poliméricas, generalmente, se emplean las resinas termoestables en el sector estructural (excepto el PEEK). El tipo de resina más empleado como matriz de las barras de CFRP, es la resina termoestable; Normalmente se emplean resinas de epoxi y, en menor grado, resinas de viniléster o poliéster. En la Tabla 2.2 se muestran la propiedades de las diferentes resinas poliméricas.

\begin{tabular}{|c|c|c|c|c|c|c|}
\hline Propiedades. & Epoxi & Poliéster & Viniléster & PEEK & $\mathrm{PC}$ & PE \\
\hline $\begin{array}{l}\text { Densidad } \\
\left(\mathrm{Kg} / \mathrm{m}^{3}\right)\end{array}$ & $1200 / 1400$ & $1200 / 1400$ & $1150 / 1350$ & 1320 & 1200 & $940 / 970$ \\
\hline $\begin{array}{l}\text { Resistencia a } \\
\text { Tracción } \\
(\mathrm{MPa}) .\end{array}$ & $55 / 130$ & $34,5 / 104$ & $73 / 81$ & 97 & $55 / 80$ & $21 / 38$ \\
\hline $\begin{array}{c}\text { Módulo } \\
\text { Elástico } \\
(\mathrm{GPa}) .\end{array}$ & $2,75 / 4,10$ & $2,1 / 3,45$ & $3,0 / 3,5$ & 3,5 & $2,0 / 3,0$ & $0,6 / 1,4$ \\
\hline $\begin{array}{l}\text { Resistencia a } \\
\text { Compresión } \\
\text { (MPa). }\end{array}$ & $103 / 172$ & $89 / 206$ & $121 / 201$ & $118 / 200$ & $69 / 86$ & $18 / 25$ \\
\hline $\begin{array}{l}\text { Resistencia a } \\
\text { Flexión } \\
(\mathrm{MPa})\end{array}$ & $90 / 145$ & $58 / 158$ & $113 / 153$ & 170 & $100 / 150$ & $20 / 45$ \\
\hline $\begin{array}{l}\text { Resistencia a } \\
\text { Impacto, } \\
\text { Izod }\end{array}$ & $0,1 / 1,0$ & $0,20 / 0,40$ & 3,2 & $1,0 / 1,6$ & $6,4 / 18,0$ & $0,5 / 20,0$ \\
\hline $\begin{array}{c}\text { Alargamiento } \\
\text { de Rotura } \\
(\%) .\end{array}$ & $3 / 6$ & $1 / 5$ & $3,5 / 5,5$ & $50 / 60$ & $80 / 200$ & $50 / 800$ \\
\hline $\begin{array}{c}\text { Dureza } \\
\text { (Rockwell). }\end{array}$ & M80/M110 & M70/M115 & M73/113 & M100 & M70/M78 & D60/D70 \\
\hline $\begin{array}{c}\text { C.T.E. } \\
\left(10^{-6} /{ }^{\circ} \mathrm{C}\right) .\end{array}$ & $45 / 65$ & $55 / 100$ & $50 / 75$ & $47 / 108$ & $50 / 100$ & 200 \\
\hline $\begin{array}{l}\text { Coeficiente } \\
\text { de Poisson's. }\end{array}$ & $0,38 / 0,40$ & $0,35 / 0,39$ & $0,36 / 0,39$ & 0,40 & $0,3 / 0,37$ & $0,42 / 0,46$ \\
\hline $\begin{array}{c}\text { Retracción } \\
\text { por Curado } \\
(\%) .\end{array}$ & $1 / 5$ & $5 / 12$ & $5,4 / 10,3$ & $0,01 / 0,02$ & $0,7 / 0,8$ & $4,0 / 4,5$ \\
\hline $\begin{array}{c}\mathrm{T}_{\mathrm{g}} \\
\left({ }^{\circ} \mathrm{C}\right)\end{array}$ & $45 / 120$ & $55 / 100$ & $21 / 73$ & 143 & 150 & $-78 /-110$ \\
\hline $\begin{array}{c}\text { Absorción de } \\
\text { Agua } \\
(\%) .\end{array}$ & $0,08 / 0,15$ & $0,15 / 0,60$ & $0,14 / 0,30$ & $0,1 / 0,15$ & $0,15 / 0,18$ & $0,01 / 0,2$ \\
\hline
\end{tabular}

Tabla 2.2. Propiedades físicas y mecánicas de las resinas poliméricas. Adaptado de GangaRao et al., 2007; FIB, 2007. 


\subsubsection{Polímeros Termoplásticos}

Los polímeros termoplásticos son amorfos o semicristalinos. Debido a que su estructura molecular (lineal o ramificada) no se encuentra interconectada mediante enlaces químicos, ya que está unida mediante débiles enlaces secundarios (fuerzas intermoleculares), llamados fuerzas de Van der Waals (Mallick, 1993); por lo tanto, las moléculas pueden moverse al aplicar calor y presión (el estado sólido líquido es reversible). Este proceso de calentamiento y enfriamiento (ciclo térmico), puede ser repetido varias veces; entonces el polímero se degradará lentamente y cada ciclo térmico lo transformará en un material más frágil (CISPI, 1992).

Tras la solidificación del polímero termoplástico (disminución de la temperatura), se observa un decrecimiento gradual en el volumen por unidad de masa (volumen específico). La $\mathrm{T}_{\mathrm{g}}$ de los polímeros termoplásticos depende del grado de cristalinidad, del peso molecular y de la tasa de enfriamiento. Se produce un decrecimiento repentino en el volumen específico cuando el polímero termoplástico cristalino solidifica y se enfría. El volumen específico disminuye si las cadenas moleculares del polímero (estructura semicristalina) se enlazan eficientemente. Un ejemplo de un polímero termoplástico formado por una estructura semicristalina es el polietileno, que posee una $T_{g}$ del orden de $-110^{\circ} \mathrm{C}$. El grado de cristalinidad del material termoplástico afecta a la resistencia a tracción, ésta se incrementa cuando el grado de cristalinidad aumenta (Beck et al., 1963). Las propiedades mecánicas del polímero termoplástico se degradan tras los ciclos térmicos. Sin embargo, estos proporcionan mayor dureza, incremento de la resistencia a impacto y aumento de la absorción de humedad.

El tiempo de procesado de las resinas termoplásticas es menor que el de las resinas termoestables, lo que conlleva numerosos métodos de fabricación, como puede ser el método por inyección. Otro método de fabricación continuo con resinas termoplásticas, es el de pultrusión. Este requiere la modificación de 
la maquinaria diseñada para la fabricación con resinas termoestables. En algunas aplicaciones estructurales se emplean materiales termoplásticos de altas prestaciones reforzados con fibras (normalmente solo se emplea el PEEK, debido a las propiedades y comportamiento de los polímeros termoplásticos), debido a que el proceso de producción es considerablemente más económico que con la utilización de resinas termoestables. Además, el procesado de las resinas termoplásticas no emite sustancias volátiles inorgánicas, y también se pueden incorporar materiales compuestos reciclados de bajo coste (Vijay et al., 2000).

\subsection{Principales Polímeros Termoplásticos}

En el mercado podemos encontrar un gran número de polímeros termoplásticos, siendo los más empleados: polímeros de acrilonitrilo butadieno estireno (ABS), acetal, acrílicos, policloruro de vinilo (PVC), policarbonato (PC), polietileno (PE), polipropileno (PP), polisulfona (PSU) y polieter eter cetona (PEEK).

De los polímeros enumerados anteriormente, el polieter eter cetona (PEEK), es el polímero termoplástico más empleado como matriz polimérica dentro de las resinas termoplásticas. El PEEK presenta una estructura semicristalina, y sus principales características son: alta resistencia a impacto (sobre un $50 \%$ a $100 \%$ más que los epoxis) y baja absorción de agua (menos de $0,5 \%$ a $\left.23^{\circ} \mathrm{C}\right)$.

La estructura molecular del PEEK es lineal, y su unidad constitucional o monomérica se muestra en la Fig. 2.5. La cristalinidad del PEEK alcanza unos valores de $30 \%$ a $35 \%$, si éste es enfriado a velocidad normal desde su fusión, y puede ser aún mayor, hasta el $48 \%$, si se enfría lentamente. Sin embargo, un enfriamiento rápido da como resultado una estructura amorfa. El PEEK, ante la presencia de fibras de refuerzo, aumenta su cristalinidad, debido a que las fibras actúan como zonas de nucleación para la formación de cristales, lo que puede 
desarrollar una resistencia química mayor que los grupos epoxídicos (Berglund, 1998).

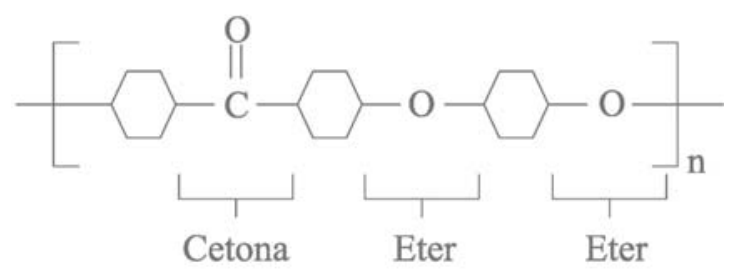

Fig. 2.5. Unidad monomérica o constitucional del PEEK. GangaRao et al., 2007.

El PEEK posee una $\mathrm{T}_{\mathrm{g}}$ de $143{ }^{\circ} \mathrm{C}$, su punto de fusión cristalina es de $335^{\circ} \mathrm{C}$ y su temperatura máxima de uso es de $250{ }^{\circ} \mathrm{C}$ (Mallick, 1993).

\subsubsection{Polímeros Termoestables}

Los polímeros termoestables son amorfos. Su estructura molecular es entrecruzada o ramificada, y sus cadenas moleculares se encuentran unidas mediante fuerzas covalentes, formando una estructura molecular tridimensional; ésta le proporciona propiedades mecánicas elevadas, estabilidad dimensional, buena resistencia a fluencia, bajo coeficiente de expansión térmica y excelente resistencia química. Sin embargo, poseen una vida limitada de almacenamiento, un largo periodo de fabricación y un reducido alargamiento de rotura que produce una pequeña resistencia al impacto (se realizan formulaciones especiales para mejorar la resistencia a la abrasión y al impacto). Los polímeros termoestables necesitan un agente catalizador para iniciar el proceso de curado o polimerización (endurecen por reacción química); una vez transcurrido este proceso de curado se formará la resina polimérica termoestable (unión de las cadenas moleculares). Las resinas termoestables, al contrario que las resinas termoplásticas, no permiten ciclos térmicos (fusión/solidificación), puesto que las unidades constitucionales o monoméricas y las cadenas moleculares se encuentran unidas mediante fuerzas covalentes, lo cual no permite el movimiento de las cadenas moleculares ante la aplicación de calor y presión. 
Las resinas poliméricas termoestables poseen baja viscosidad, permitiendo albergar un gran volumen de fibras de refuerzo. A su vez, su procesado es fácil y de bajo coste. El tiempo de curado es el periodo que transcurre una vez se ha realizado la mezcla de la resina polimérica con el catalizador hasta que ya no es posible el procesamiento de la resina. Éste puede llevarse a cabo a temperatura ambiente o bajo altas temperaturas, y dependiendo del catalizador y la reactividad de la resina, puede durar varios minutos o incluso horas. La reacción producida durante el periodo de curado es exotérmica y su gelificación normalmente es rápida. Una vez curada la mezcla, se espesa, libera calor, solidifica y se contrae. La retracción volumétrica una vez curada la resina termoestable varía entre 1-5\% en resinas epoxis hasta el 5-12\% del poliéster.

\subsection{Epoxi}

La resina de epoxi es un copolímero termoestable, compuesto por varios monómeros o polímeros de cadena corta, con un grupo epoxídico en cada extremo. Los grupos epoxídicos se conocen con el nombre de epoxi, epóxido, oxirane, grupo ethoxylino, alipático, cicloalipático o aromático (Dewprashad y Eisenbraun, 1994). Los materiales iniciales (precursores) de la matriz de epoxi son resinas líquidas orgánicas de elevado peso molecular que contienen un numeroso grupo de epoxídos, los cuales poseen un átomo de oxígeno $(\mathrm{O})$ y dos átomos de carbono (C) (Fig. 2.6) (Penn et al., 1998).

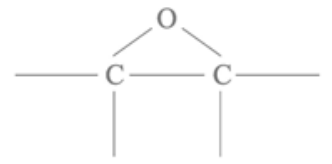

Fig. 2.6. Molécula inicial de la matriz de epoxi. GangaRao et al., 2007.

Es necesaria la combinación de varios precursores para alcanzar unas propiedades y características específicas. Los precursores epoxídicos más empleados son el diglicidil éter o bisfenol A, junto con las especies de epoxi de mayor peso molecular (Fig. 2.7). 
(a)<smiles>CCCOc1ccc(C(C)(C)c2ccc(OCC3CO3)cc2)cc1C(C)(C)c1ccc(OCC2CO2)cc1</smiles>

$$
\mathrm{H}_{2} \mathrm{~N}-\left(\mathrm{CH}_{2}\right)_{2}-\mathrm{NH}-\left(\mathrm{CH}_{2}\right)_{2}-\mathrm{NH}_{2}
$$

Fig. 2.7. Molécula de epoxi preparada para el curado a) diglicidil éter o bisfenol A (DGEBA) b) dietileno triamina (DETA). GangaRao et al., 2007.

Los precursores epoxídicos (DGEBA y DETA) son curados en presencia de catalizadores de anhídrido o aminas (alifáticas o aromáticas) (Fig. 2.8). Dependiendo del tipo de catalizador (precursor de la polimerización) empleado para el curado, aumentarán o disminuirán los enlaces entre grupos epoxídicos de cada cadena molecular, este proceso se denominará homopolimerización (CISPI, 1992). La densidad de los enlaces entre cadenas moleculares es el factor que determinará las propiedades finales de la resina de epoxi curada. Propiedades como el módulo elástico, la $\mathrm{T}_{\mathrm{g}}$, la estabilidad térmica y la resistencia química mejorarán, si aumenta la densidad de los enlaces entre cadenas moleculares. Sin embargo, disminuirá el alargamiento de rotura y la resistencia a impacto. Durante el curado de la resina de epoxi tendrá lugar la unión de las largas cadenas moleculares (DGEBA y DETA), y se formará la estructura molecular tridimensional característica del epoxi.

(a)

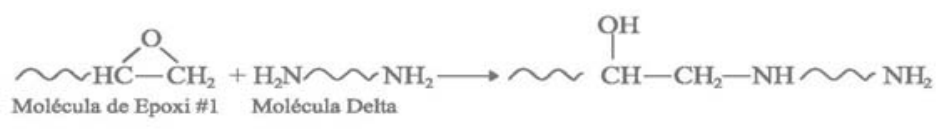

(b)

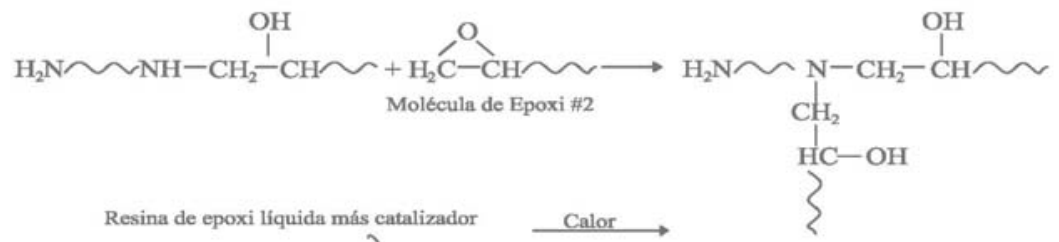

(c)

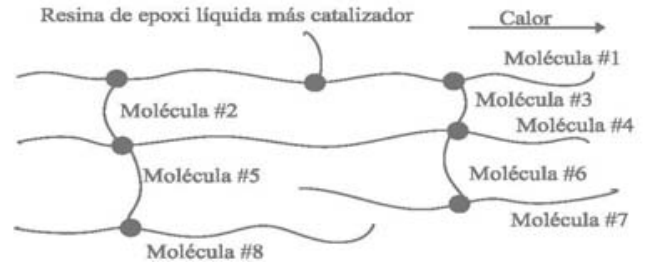

Fig. 2.8. Estructura química de la resina de epoxi: a) Reacción del grupo epoxídicos con la molécula DETA b) Enlaces c) Estructura tridimensional del epoxi curado. Mallick, 1993. 
Las resinas de epoxi se emplean en composites de altas prestaciones para lograr altas propiedades mecánicas y resistencia frente ambientes de corrosión. Sin embargo, su coste es mayor que el resto de resinas. Las principales ventajas de las resinas de epoxi frente al resto de tipos de resinas son: altas propiedades mecánicas, elevada resistencia a fluencia, facilidad de procesado, buenas propiedades eléctricas, baja retracción durante el curado, adhesión a una gran variedad de fibras y elevada resistencia química (Bakis, 2002). Al mismo tiempo, posee una excelente resistencia a la corrosión y es de todas las matrices poliméricas la menos afectada por el calor y la humedad. En la Fig. 2.9 se muestra la relación de tensión/deformación de diferentes resinas de epoxi.

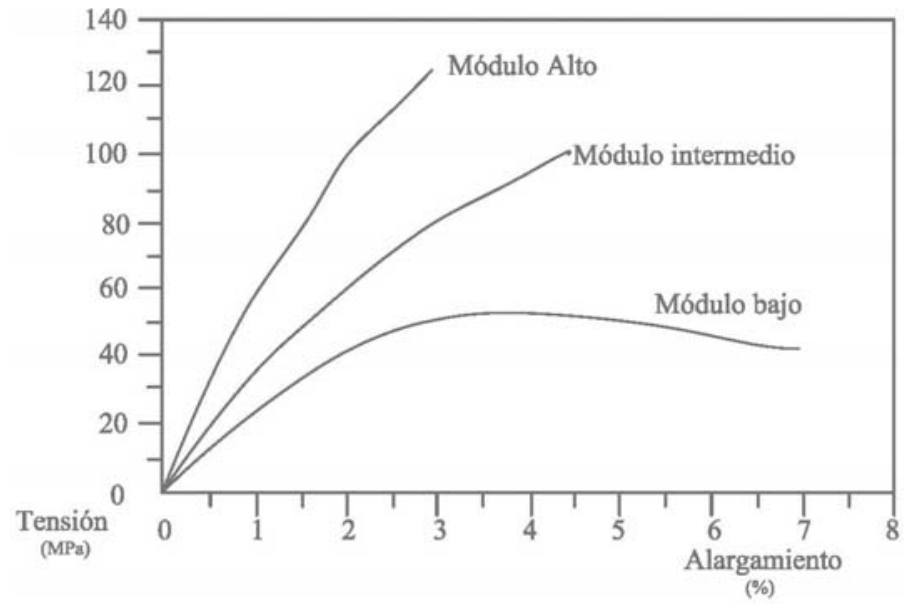

Fig. 2.9. Gráfica de las curvas de Tensión/Deformación, de varias resinas de epoxi de diferentes módulos. Schwartz, 1992.

La principal desventaja de la resina de epoxi es el elevado coste y el largo periodo de curado.

Las resinas de epoxi son las resinas más versátiles de los FRP, especialmente en las barras de CFRP. Estas resinas poseen una amplia gama de propiedades físicas y mecánicas, se fabrican bajo una amplia variedad de condiciones de procesado. Las propiedades tales como, la resistencia química, adhesión a fibras, dureza y resistencia a fluencia pueden ser alteradas mediante 
la modificación de los reactivos, la estructura química del catalizador y de la resina, y de las condiciones de curado.

La resistencia a fluencia de las resinas de epoxi depende del tipo de resina. Diversos estudios indican que los diferentes tipos de epoxis presentan distintos comportamientos bajo cargas permanentes a temperatura ambiente (Sturgeon, 1978; Miklofsky et al., 1965). La Tabla 2.3 muestra los alargamientos de tres tipos de resinas de epoxi bajo cargas permanentes a temperatura ambiente. La resina de epoxi MY 753 posee un alargamiento de 0,0022 bajo una carga de $13 \mathrm{MPa}$, mientras que, para la resina de epoxi ERLA 4617 el alargamiento fue de 0,0006 bajo carga de $17 \mathrm{MPa}$ después de 100 horas. Sin embargo, frente un aumento de tensión en la resina ERLA 4617, el alargamiento sigue siendo menor que para la resina MY 753. Por otra parte, para la resina de epoxi G, los valores de fluencia bajo carga permanente de 14,6 MPa durante 1.300 horas, fueron insignificantes. Sin embargo, una carga de 26,7 MPa provoca la rotura del elemento tras 15 minutos después de cargarlo (Sturgeon, 1978; Miklofsky et al., 1965).

\begin{tabular}{|c|c|c|c|c|}
\hline $\begin{array}{l}\text { Nombre } \\
\text { comercial. }\end{array}$ & $\begin{array}{l}\text { Tipo de } \\
\text { resina. }\end{array}$ & $\begin{array}{c}\text { Carga permanente } \\
\text { (MPa). }\end{array}$ & $\begin{array}{l}\text { Duración } \\
\text { (Horas). }\end{array}$ & Alargamiento. \\
\hline $\begin{array}{l}\text { Ciba-Geigy } \\
\text { MY } 753\end{array}$ & Termoestable & 13 & 82 & 0,0022 \\
\hline Union Carbide & Termoestahle & 17 & 100 & 0,0006 \\
\hline ERLA 4617 & & 60 & 30 & 0,0030 \\
\hline Formulación $\mathrm{G}$ & Termoestable & $\begin{array}{l}14.6 \\
26,7\end{array}$ & $\begin{array}{l}1300 \\
0,25\end{array}$ & $\begin{array}{l}18 \times 10^{-9} \\
12 \times 10^{-9}\end{array}$ \\
\hline
\end{tabular}

Tabla 2.3. Comportamiento a fluencia (a temperatura ambiente) de diferentes tipos de resinas de epoxi. Sturgeon, 1978; Miklofsky et al., 1965. 


\subsection{Poliéster}

La resina de poliéster insaturada ${ }^{3}$ con dobles enlaces de carbono $\mathrm{C}=\mathrm{C}$ (largas cadenas de moléculas poliméricas están unidas por enlace químico o molecular), es la sustancia precursora de la matriz de poliéster (Mallick, 1988). Por ejemplo, la reacción entre el anhídrido maleíco y el etileno o propileno glicol origina la resina de poliéster insaturada (polímero en estado líquido). Esta resina de poliéster insaturada se mezcla con el estireno (el estireno reduce la viscosidad y facilita el procesado), que contiene enlaces dobles de carbono $\mathrm{C}=\mathrm{C}$, y este actúa como precursor de la polimerización uniendo moléculas adyacentes de poliéster en los puntos de instauración. Las propiedades de la resina de poliéster dependen de la densidad de los enlaces entre cadenas moleculares. Si aumenta la cantidad de estireno se reducirá el modulo elástico de la resina polimérica de poliéster, ya que aumenta la distancia entre las moléculas poliméricas causando una reducción de los enlaces moleculares. En la Fig. 2.10 se muestra la estructura química de la resina de poliéster.<smiles>O=C(O)C=CC(=O)CCOCCO</smiles>

(a)

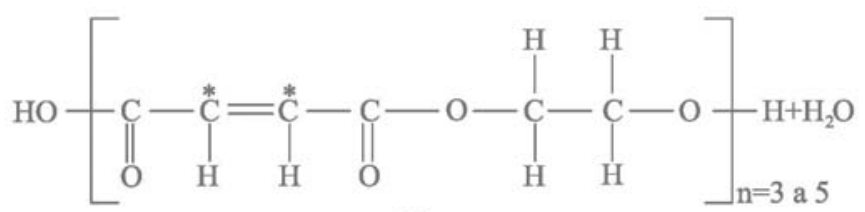

(c)

Fig 2.10. Moléculas de a) Poliéster insaturado, b) Estireno, c) t-butil perbenzonato (tBPB). El asterisco $(*)$ indica los puntos reactivos/insaturados. GangaRao et al., 2007).

\footnotetext{
${ }^{3} \mathrm{Si}$ uno o ambos de los principales constituyentes son insaturados (es decir, que contienen dobles enlaces $\mathrm{C}=\mathrm{C}$ ), el poliéster resultante se denomina insaturado. Sin embargo, los ácidos saturados, como el isoftálico o el ortoftálico (que no contienen dobles enlaces $\mathrm{C}=\mathrm{C}$ ) también son añadidos para modificar la estructura química entre los enlaces reticulados (Mallick, 1993).
} 
Las resinas de poliéster y viniléster son las más empleadas como matriz de barras de GFRP. Las propiedades del poliéster pueden variar en gran medida. Estas se pueden formular con el fin de conseguir una buena resistencia química y una gran variedad de propiedades como la dureza y fragilidad (Mallick, 1988). En la Fig. 2.11 se muestra la relación tensión/deformación de la resina de poliéster (a tracción y compresión). En la esta se puede observar que la relación tensión/deformación de la resina de poliéster no es lineal, debido a que la resina de poliéster es un material viscoelástico.

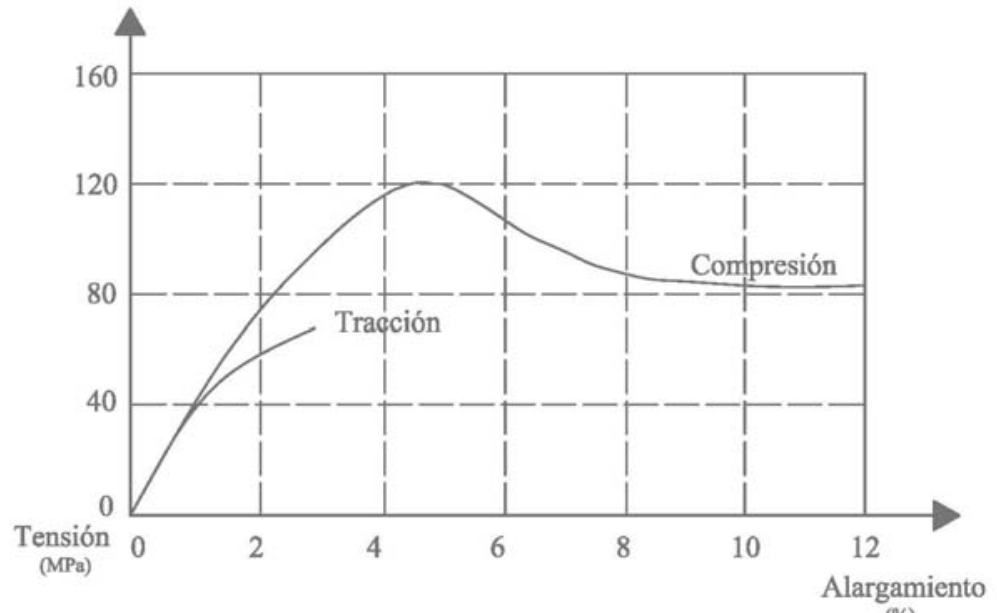

Fig. 2.11. Gráfica de las curvas de Tensión/Deformación, frente a esfuerzos de tracción y compresión, de la resina de poliéster. FIB Task Group 9.3, 2007.

En general, las ventajas principales de la resina de poliéster como matriz de las barras de FRP son: baja viscosidad, rápido tiempo de curado, bajo coste y resistencia química. Los principales inconvenientes son la elevada retracción volumétrica (5 a 12\%) y baja resistencia a fatiga. El inconveniente de la elevada retracción se puede reducir mezclando la resina de poliéster con un polímero termoplástico de baja retracción (Cossis et al., 1998).

Los tipos comerciales de resinas insaturadas de poliéster, pueden estar formados por varios ácidos, tales como: anhídrido aftálico, ácido isoftálico, ácido tereftálico, ácido adípico; glicoles como pueden ser el etileno, propileno y 
neopentilo. El poliéster ortoftálico (OP), está formado por anhídrido aftálico, anhídrido maleíco o ácidos fuméricos. Este tipo de resina no presenta unas propiedades mecánicas tan buenas como la resina isoftálica. La cual, también denominada isopoliester, está formada por ácido isoftálico, ácidoanhidrido o acido fumérico. Respecto a las propiedades mecánicas de esta resina como la absorción de humedad y la resistencia química, estas son mejores que en la resina ortoftálica. El bisfenol A fumérico (BPA) presenta mejores propiedades mecánicas en comparación con las resinas ortoftálicas e isoftálicas. En cuanto a las resinas clorendicas, estas se encuentran formadas por una mezcla de acido clorendico y fumérico, los cuales le proporcionan una mayor resistencia química y actúan como retardante frente al fuego.

Los efectos de la exposición de las resinas de poliéster y viniléster en ambientes acuosos, salinos y alcalinos fueron investigados por Chin et al., (1997), tras sumergir en agua (a temperatura ambiente) durante 1300 horas las resinas de poliéster y viniléster, no se observaron cambios significativos en la resistencia a tracción. Las resinas de poliéster y viniléster alcanzaron el equilibrio de absorción en cada solución, antes de 50 horas de inmersión $\left(a 60^{\circ} \mathrm{C}\right.$ de temperatura) en los tres ambientes (acuoso, salino y alcalino). Sin embargo, los datos indican que a $60^{\circ} \mathrm{C}$ de temperatura, las resinas de isopoliester pierden masa después de 100 horas de exposición a un ambiente alcalino, y tras 200 horas a un ambiente salino. Esto se debe a la posibilidad de la rotura del polímero seguida de la degradación de los productos solubles.

En el citado estudio, Chin et al., (1997), indican que durante la exposición de las resinas de isopoliester ${ }^{4} \mathrm{y}$ viniléster en un ambiente acuoso, salino y alcalino, bajo una temperatura de $60^{\circ} \mathrm{C} \mathrm{y} 90^{\circ} \mathrm{C}$, estas pierden toda la

\footnotetext{
${ }^{4}$ Las resinas de poliéster también pueden ser denominadas respecto a sus ingredientes (iso..., orto..., tere...). La resina de isopoliester está formada fundamentalmente por ácidos isoftálicos. Los ácidos ortoftálicos formarán la resina de poliéster ortoftálica, mientras que los ácidos tereftálicos constituiran la resina tereftálica de poliéster, los cuales proporcionarán mayor rigidez que los ácidos isoftálicos.
} 
resistencia a tracción. Las muestras que sufrieron mayor degradación son las expuestas a un ambiente alcalino bajo temperaturas de $60^{\circ} \mathrm{C}$ y $90^{\circ} \mathrm{C}$. Tras 10 semanas de exposición del isopoliester en un ambiente alcalino a $90{ }^{\circ} \mathrm{C}$, las muestras se degradaron gravemente y no pudieron ser ensayadas. Respecto a la resina de vinilester, se observa que presenta una mejor resistencia frente a ambientes acuosos, salinos y alcalinos, que la resina de poliéster.

También en el estudio anterior, el análisis mediante rayos $\mathrm{X}$, muestra que no se produce penetración iónica, ni daño superficial en las muestras de 25 $\mathrm{mm}$. de diámetro, tras la exposición durante 60 días en un ambiente salino y alcalino bajo una temperatura de $60^{\circ} \mathrm{C}$. Únicamente, se encontraron cantidades apreciables de sodio, potasio y calcio en el interior de la muestra de resina de isopoliester, ante la exposición en un ambiente alcalino a $60^{\circ} \mathrm{C}$. Sin embargo, esta muestra se apreció una degradación superficial y el paso de iones a través de la resina dañada.

\subsection{Viniléster}

La resina de viniléster es una resina insaturada. Se forma, a partir de la reacción entre la resina de epoxi y ácidos acrílicos o metacrilatos (grupo carboxílico insaturado), produciendo un estado insaturado y muy reactivo (Mallick, 1988). Su estructura química se muestra en la Fig. 2.12. Los enlaces dobles $\mathrm{C}=\mathrm{C}$, se producen en los extremos de cada molécula de viniléster, lo que dará lugar a una menor cantidad de enlaces, por lo tanto, la resina de viniléster curada poseerá mayor flexibilidad. El material resultante de la reacción anterior se mezcla con el estireno (precursor de la polimerización), este reduce la viscosidad y los enlaces en los puntos insaturados de las moléculas de viniléster. Las resinas de viniléster se curan con los mismos peróxidos orgánicos que se emplean en las resinas de poliéster. Estos mejoraran la resistencia química, la resistencia a fractura y facilitaran el procesado (CISPI, 1992). 


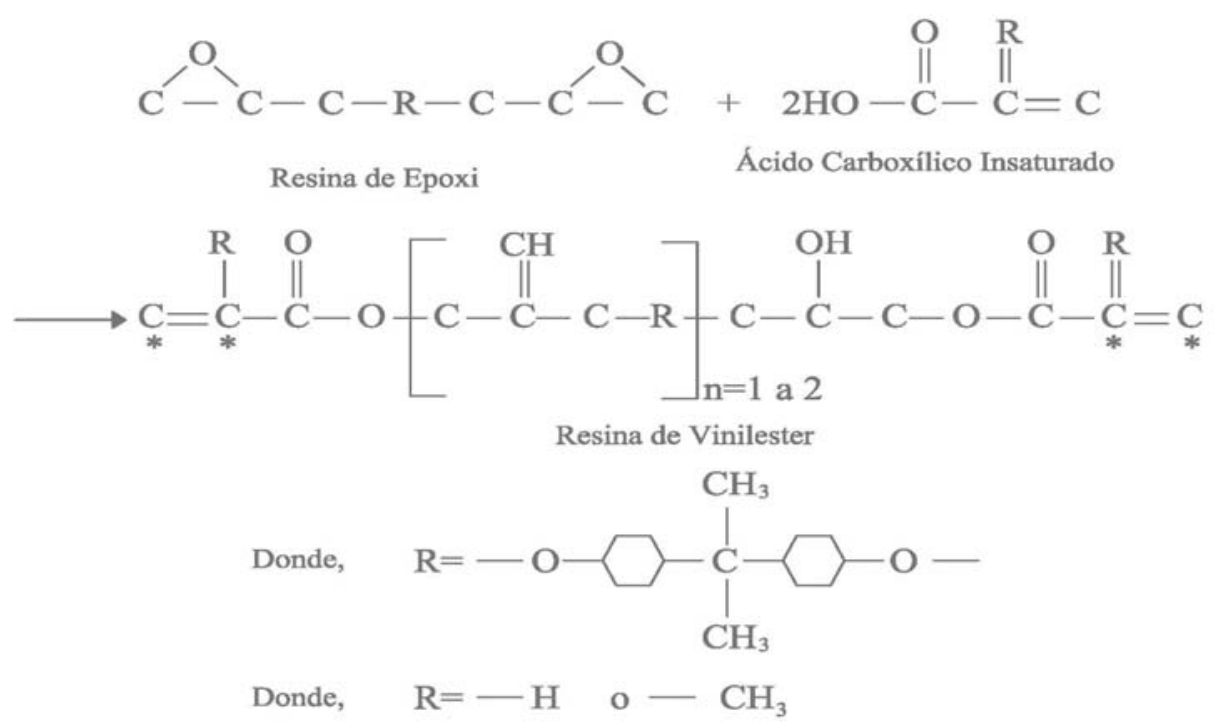

Fig. 2.12. Estructura química de la resina de viniléster. El asterisco $\left(^{*}\right)$ indica los puntos reactivos/insaturados. Adaptado de Mallick, 1993.

Las excelentes propiedades mecánicas, químicas, rigidez y resilencia de las resinas de viniléster, se deben a su alto peso molecular y a su composición de resina de epoxi (la resina de epoxi actúa como columna vertebral de la molécula de viniléster). El principal inconveniente del empleo de la resina de viniléster es su elevada retracción (de 5 a 10\%).

\subsubsection{Refuerzo de Fibra de Carbono}

El refuerzo de fibra de carbono le aporta a la matriz polimérica resistencia y rigidez. Además, es el encargado de resistir las tensiones aplicadas en el composite, formando así la columna vertebral de las barras de CFRP.

La fibra de carbono se define como, la fibra que contiene al menos un $90 \%$ de su masa de carbono. El término fibra de grafito se emplea para describir las fibras de carbono que contienen un $95 \%$ de su masa de carbono. Los principales precursores empleados en la fabricación de la fibra de carbono son: 
el poliacrilonitrilo (PAN) y el Pitch $^{5}$. Además, también se emplean como precursores fibras celulosas y fibras fenólicas (Mallick, 1998). El PAN es una fibra sintética prefabricada e hilada en bobinas, mientras que el Pitch es un subproducto del proceso de destilación del petróleo, o del carbón de coque, el cual es fundido, enrollado e hilado en fibras. Las fibras de Pitch poseen un alto módulo elástico y baja resistencia a tracción, mientras que las fibras PAN presentan un alargamiento de rotura alto, menor módulo elástico y mayor resistencia a tracción. Las fibras de PAN son mucho más económicas que las fibras Pitch.

Una vez obtenido el precursor en forma de fibra (hilo), se procede al tratamiento final que le conferirá las propiedades características (mecánicas, químicas, y físicas) finales de la fibra de carbono. El procesamiento de las fibras de carbono (precursores) se divide en tres fases, oxidación, carbonización y grafitación (Tablas 2.4 y 2.5) (Bakis, 1993). En la primera fase de oxidación, las fibras se calientan alrededor de una temperatura de $400^{\circ} \mathrm{C}$, durante esta fase tiene lugar el enlace de las cadenas moleculares de carbono, confiriendo así, mayor resistencia a fusión para posteriores tratamientos (estabilización del precursor). Durante la fase de carbonización, se procede a calentar las fibras, a una temperatura de $800^{\circ} \mathrm{C}$ en una atmósfera exenta de oxígeno. Así, se consigue eliminar las impurezas no carbónicas, obteniéndose fibras de carbono de alta resistencia a tracción y bajo módulo elástico. En la última fase de grafitación, las fibras son calentadas a temperaturas entre $1.100^{\circ} \mathrm{C}$ y $3.000^{\circ} \mathrm{C}$, y pueden ser estiradas entre un 50-100\% de su longitud. Con el alargamiento de las fibras se consigue la orientación cristalina y un módulo de elasticidad alto (300 a 600 $\mathrm{GPa}$ ). Finalmente se realiza un tratamiento superficial, que mejora la resistencia de adherencia entre la fibra de carbono y la matriz polimérica (Mallick, 1988).

5 La denominación inglesa Pitch, se puede traducir al castellano como Brea. Esta es un subproducto de la refinación del petróleo o del carbón de coque. 


\begin{tabular}{ccccc}
\hline Tratamiento & Oxígeno (\%) & Hidrógeno (\%) & Nitrógeno (\%) & Carbono (\%) \\
\cline { 1 - 4 } Sin tratamiento & - & 6 & 26 & 68 \\
\cline { 1 - 4 } Oxidación & 8 & 5 & 22 & 65 \\
\cline { 1 - 3 } Carbonización & $<1$ & $<0,3$ & $<7$ & $>92$ \\
\cline { 1 - 3 } Grafitación & - & - & - & 100 \\
\hline
\end{tabular}

Tabla 2.4. Composición de la fibra de carbono (precursor PAN) durante los diferentes estados del procesamiento. Adaptado de Guigon et al., 1984a.

\begin{tabular}{ccccc}
\hline $\begin{array}{c}\text { Grado de la Fibra } \\
\text { de Carbono }\end{array}$ & $\begin{array}{c}\text { Módulo } \\
\text { Bajo }\end{array}$ & $\begin{array}{c}\text { Módulo } \\
\text { Estándar }\end{array}$ & $\begin{array}{c}\text { Módulo } \\
\text { Intermedio }\end{array}$ & Módulo Alto \\
\hline $\begin{array}{c}\text { Temperatura de } \\
\text { carbonización }\left({ }^{\circ} \mathrm{C}\right)\end{array}$ & Hasta 1.000 & $1.000-1.500$ & $1.500-2.000$ & $\begin{array}{c}>2.000 \\
\text { (Grafitación) }\end{array}$ \\
\cline { 1 - 3 } $\begin{array}{c}\text { Módulo de } \\
\text { elasticidad }(\mathrm{GPa})\end{array}$ & Hasta 200 & $200-250$ & $250-325$ & $>325$ \\
\hline
\end{tabular}

Tabla 2.5. Efecto de la temperatura en el módulo elástico de las fibras de carbono. Adaptado de Guigon et al., 1984a.

La fibra de carbono posee una estructura molecular formada por átomos de carbono ordenados cristalográficamente en planos paralelos con forma de hexágonos, unidos unos a otros (cada átomo de carbono posee cuatro enlaces, dos enlaces sencillos y uno doble) mediante fuerzas moleculares, formando una red tridimensional azarosamente foliada (Fig. 2.13). Por ello, la fibra de carbono posee un alto módulo elástico, elevada resistencia a fatiga, bajo alargamiento de rotura, alta resistencia a tracción y rigidez, comportamiento elástico lineal hasta rotura (Fig. 2.14), buena resistencia química, y coeficiente de expansión térmica muy pequeño (Tabla 2.6) (Benmokrane et al., 1997).

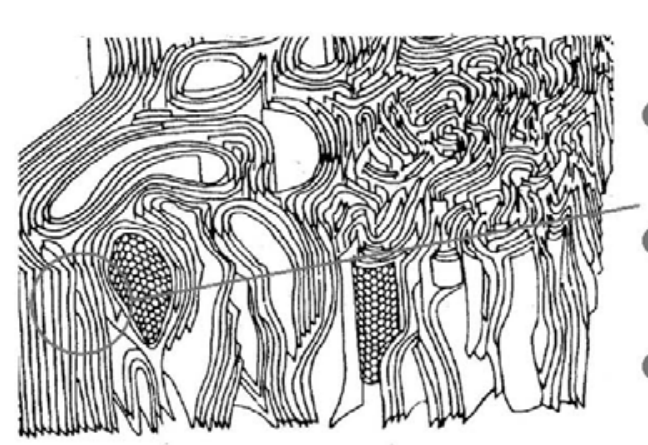

(a)

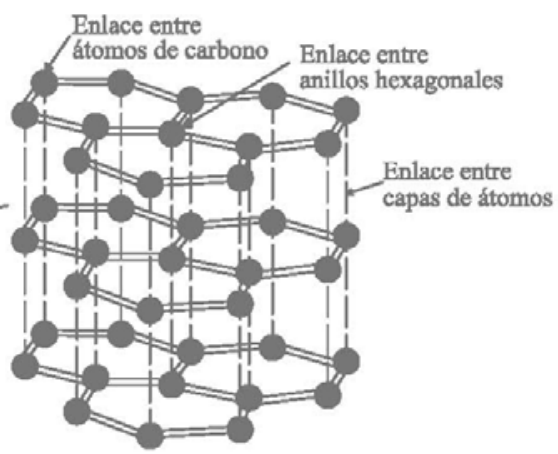

(b)

Fig. 2.13. Estructura química de la fibra de carbono. a) Enlaces entre capas de átomos; b) enlaces entre átomos. Adaptado de Guigon et al., 1984a. 


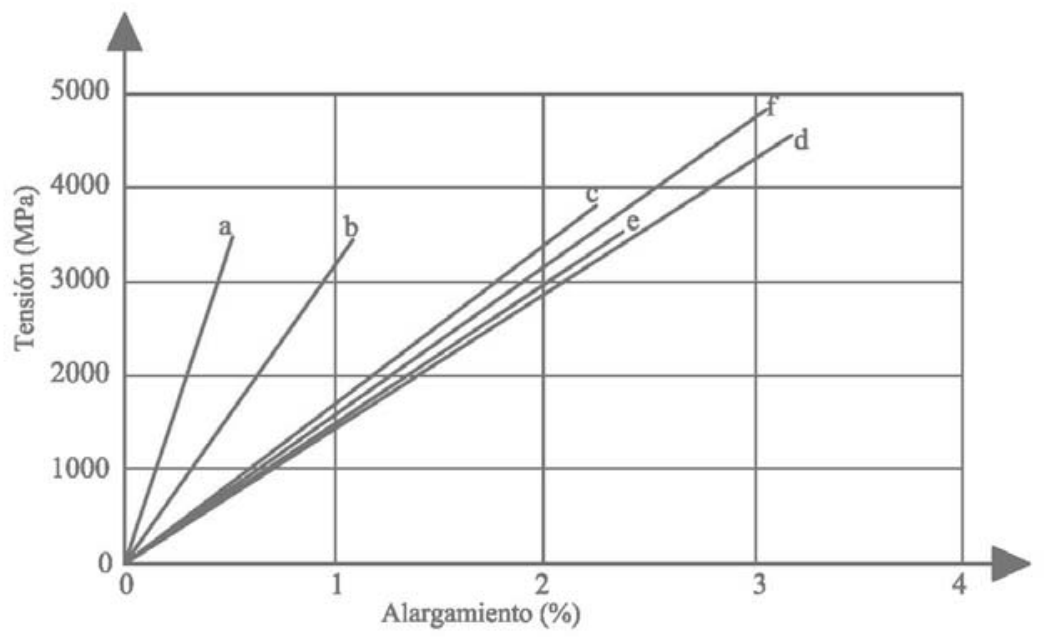

Fig. 2.14. Grafica de tensión/deformación de diferentes tipos de fibras: a) Carbono (alto módulo); b) Carbono (alta resistencia); c) Aramida; d) S-glass; e) E-Glass; f) Basalto. Adaptado de FIB., 2007.

\begin{tabular}{|c|c|c|c|c|c|c|}
\hline Tipo de Fibra & 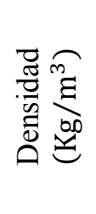 & 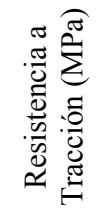 & 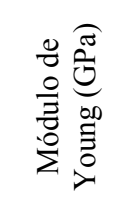 & 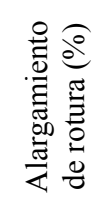 & بْ & 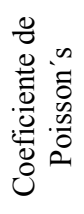 \\
\hline E-Glass & 2.500 & 3.450 & 72,4 & 2,4 & 5 & 0,22 \\
\hline S-Glass & 2.500 & 4.580 & 85,5 & 3,3 & 2,9 & 0,22 \\
\hline $\begin{array}{l}\text { Vidrio resistente a } \\
\text { los álcalis }\end{array}$ & 2.270 & $\begin{array}{l}1.800- \\
3.500\end{array}$ & $70-76$ & $2,0-3,0$ & - & - \\
\hline ECR & 2.620 & 3.500 & 80,5 & 4,6 & 6 & 0,22 \\
\hline $\begin{array}{l}\text { Carbono (Módulo } \\
\text { alto) }\end{array}$ & 1.950 & $\begin{array}{c}2.500- \\
4.000\end{array}$ & $350-650$ & 0,5 & $-1,2 \ldots-0,1$ & 0,20 \\
\hline $\begin{array}{l}\text { Carbono (Alta } \\
\text { resistencia) }\end{array}$ & 1.750 & 3.500 & 240 & 1,1 & $-0,6 \ldots-0,2$ & 0,20 \\
\hline $\begin{array}{l}\text { Aramida (Kevlar } \\
\text { 29) }\end{array}$ & 1.440 & 2.760 & 62 & 4,4 & $\begin{array}{l}-2,0 \text { Longitudinal } \\
59 \text { Radial }\end{array}$ & 0,35 \\
\hline $\begin{array}{l}\text { Aramida (Kevlar } \\
\text { 49) }\end{array}$ & 1.440 & 3.620 & 124 & 2,2 & $\begin{array}{l}-2,0 \text { Longitudinal } \\
59 \text { Radial }\end{array}$ & 0,35 \\
\hline $\begin{array}{l}\text { Aramida (Kevlar } \\
\text { 149) }\end{array}$ & 1.440 & 3.450 & 175 & 1,4 & $\begin{array}{l}\text {-2,0 Longitudinal } \\
59 \text { Radial }\end{array}$ & 0,35 \\
\hline $\begin{array}{l}\text { Aramida } \\
\text { (Technora H) }\end{array}$ & 1.390 & 3.000 & 70 & 4,4 & $\begin{array}{l}-6,0 \text { Longitudinal } \\
59 \text { Radial }\end{array}$ & 0,35 \\
\hline Aramida (SVM) & 1.430 & $\begin{array}{l}3.800- \\
4.200\end{array}$ & 130 & 3,5 & 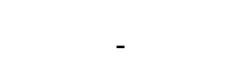 & - \\
\hline Basalto & 2.800 & 4.840 & 89 & 3,1 & 8 & - \\
\hline
\end{tabular}

Tabla 2.6 Propiedades de las fibras de refuerzo de barras de FRP. Adaptado de FIB Task Group 9.3, 2007. 
El principal inconveniente del empleo de las fibras de carbono es su elevado precio (sobre 10-30 veces más caro que el E-Glass) (Mallick, 1993).

La fibra de carbono dependiendo, del material precursor, las propiedades de las fibras y el tratamiento final, se clasifica en los siguientes tipos:

- Dependiendo del material precursor:

O PAN.

o Pitch.

o Rayón.

- Mesofase Pitch.

- Isótropas Pitch.

o Carbono extraído de la fase gaseosa.

- Dependiendo de las propiedades de las fibras:

o Módulo Ultra-alto (UHM): UHM > $450 \mathrm{GPa}$.

o Módulo Alto (HM): $325 \mathrm{GPa} \geq \mathrm{HM} \leq 450 \mathrm{GPa}$.

o Módulo Intermedio (IM): $200 \geq \mathrm{IM} \leq 325 \mathrm{GPa}$.

o Módulo Bajo y alta resistencia a tracción (HT): Módulo $<100$ $\mathrm{GPa}$, y Resistencia > 3,0 GPa.

o Máxima resistencia a tracción (SHT): Resistencia a tracción > 4,5 GPa.

- Dependiendo del tratamiento de temperatura final:

o Tipo I (Tratamiento a elevada temperatura, $>2.000^{\circ} \mathrm{C}$ ): asociado con las fibras de carbono de módulo alto.

o Tipo II (Tratamiento a temperatura intermedia, $>1.500^{\circ} \mathrm{C} y<$ $2.000^{\circ} \mathrm{C}$ ): asociado con las fibras de carbono de alta resistencia.

o Tipo III (Tratamiento a baja temperatura, $<1.000^{\circ} \mathrm{C}$ ): asociado con fibras de carbono de bajo módulo elástico y resistencia a tracción.

\subsubsection{Proceso de Fabricación}

Dependiendo del proceso de fabricación de las barras de CFRP, las fibras de refuerzo serán embebidas por la matriz polimérica, y curadas mediante diferentes técnicas. Durante la fabricación, las resinas son mezcladas con aditivos y modificadores (por ejemplo, aceleradores, pigmentos, inhibidores de rayos UV, retardantes contra el fuego, etc..) para alcanzar las propiedades de 
curado deseadas, viscosidad, durabilidad y apariencia. Los factores más importantes en el comportamiento a corto y largo plazo, durante el proceso de fabricación de las barras de CFRP son: las propiedades y configuración de las fibras de carbono, de la resina, de los aditivos y modificadores, porcentaje de resina y volumen de fibra, y parámetros inherentes del proceso de fabricación (temperatura, presión, tiempo de curado y las propiedades finales de la superficie).

Las barras de CFRP, generalmente se fabrican por el método de pultrusión. También, se emplean variantes del método de pultrusión como son, pull-forming y pull-winding (Peters, 1998).

El proceso de pultrusión se deriva de su propio nombre; la palabra inglesa "pull" (cuya traducción al castellano es, estirar) define la primera parte del proceso, en la cual se aplica tensión (mediante estirado) a las fibras de carbono; las cuales en la segunda parte del proceso van a ser embebidas por la extrusión de una resina polimérica, definida por la palabra inglesa "extrusion" (cuya traducción al castellano es, extruir).

El método de pultrusión consiste en el siguiente proceso (Fig. 2.15): las fibras de carbono inicialmente enrolladas en bobinas, son estiradas continuamente a través de unas guías, seguidamente se introducen en una máquina cuya función es precalentar las fibras para eliminar el contendido de humedad de las mismas (esta humedad dificulta la adherencia refuerzo/matriz), posteriormente se introducen en un baño de resina polimérica (este baño está compuesto por, resina polimérica, catalizador, fillers y aditivos para mejorar la trabajabilidad), se preforman (geometría superficial final) y atraviesan una máquina con resistencias térmicas que curan la resina (se curan en 2 o 3 máquinas contiguas, a temperaturas sobre $90-180^{\circ} \mathrm{C}$ ), seguidamente el composite es estirado y cortado. Esta última parte del proceso se puede realizar por dos métodos diferentes (dependiendo de la geometría superficial de la barra): El 
primero es el método anteriormente desarrollado. En el segundo método, la resina es parcialmente curada (tras el baño de resina), seguidamente se aplica una capa adicional de fibra y resina, la cual es comprimida obteniendo una geometría superficial corrugada (similar a las barras de acero corrugado), y finalmente se estira el composite y se corta a la longitud deseada (Paciomik et al., 2003; Suratmo et al., 1998).

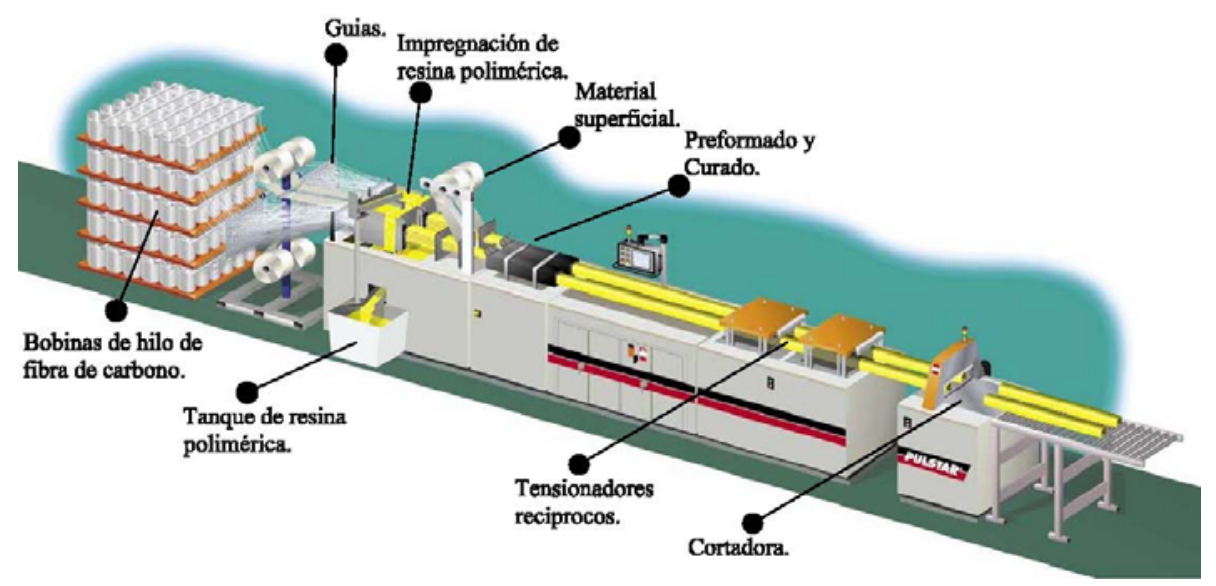

Fig. 2.15. Proceso de pultrusión. Adaptado de Strongwell.

Las diferentes geometrías superficiales de las barras de CFRP, se realizan para mejorar la adherencia barra/hormigón. Para ello, una vez terminado el proceso de pultrusión (generalmente la geometría superficial de las barras de CFRP al finalizar la pultrusión es lisa) se realizan diferentes tratamientos superficiales, como son: chorreado de arena (una granulometría cuidadosamente seleccionada de arena, se adhiere a la barra de CFRP mediante una fina capa de resina polimérica), banda de CFRP helicoidalmente adherida (una banda de CFRP es adherida helicoidalmente a la barra mediante resina polimérica), combinación de los dos tratamientos anteriores (Peters, 1998).

El método de fabricación de barras de CFRP denominado pull-forming es una variación muy sofisticada del método de pultrusión, mediante el cual, se 
pueden fabricar secciones curvas y rectas, con la capacidad de cambiar las dimensiones transversales del producto (Peters, 1998).

El proceso de fabricación pull-winding es análogo al método de pultrusión; sin embargo, este proceso introduce un zunchado (mediante fibras de refuerzo dispuestas transversal y helicoidalmente) sobre las fibras longitudinales, proporcionando una mayor resistencia transversal y de corte al composite (Peters, 1998).

\subsection{Tipos de Barras de CFRP}

A diferencia de los armados de acero, las barras de CFRP no disponen de grados de resistencia y módulo, geometría superficial y diámetros de barras estandarizados. La falta de estandarización es debida a la dependencia de las características físicas, mecánicas y comportamiento a corto y largo plazo, del proceso de fabricación y composición de las barras de CFRP. Esto supone que las diferentes normativas de diseño de estructuras de hormigón armado con barras de CFRP (ACI 440.1R-06; JSCE 1997(b); CAN/CSA-S806-02; FIB Task Group 9.3, 2007; CNR-DT 203/2006; IStructE, 1999), no dispongan de valores estandarizados de las características de las barras de CFRP. Por lo tanto, los valores de las características mecánicas de las barras de CFRP (Resistencia a tracción, módulo elástico y alargamiento de rotura) serán proporcionados por cada fabricante de barras, de acuerdo con la normativa aplicable en dicho país.

\subsubsection{Grados de Resistencia y Módulo}

Las barras de CFRP, disponibles comercialmente, presentan una gran variedad de grados de resistencia a tracción y módulo elástico.

Las normativas de diseño de estructuras de hormigón armado con barras de CFRP, ACI-440.1R-06; JSCE 1997(b); CNR-DT 203/2006, establecen un grado mínimo de resistencia a tracción y módulo elástico. 
La norma ACI-440.1R-06, establece una resistencia a tracción mínima de $414 \mathrm{MPa}$, y un módulo elástico mínimo de 110,3 GPa (denominado E 110,3). A su vez, en un intento de estandarizar los armados de CFRP, desarrollan una clasificación de grado de resistencia a tracción. Esta comienza con un grado mínimo F60 (presenta una resistencia a tracción mínima de $414 \mathrm{MPa}$ ), y finaliza con un grado F290. E1 paso de un grado inferior al contiguo superior se realiza mediante incrementos de $69 \mathrm{MPa}$ :

- Grado F60: $414 \mathrm{MPa} \leq \mathrm{f}^{*}{ }_{\mathrm{fu}}{ }^{6}<483 \mathrm{MPa}$.

- Grado F70: $483 \mathrm{MPa} \leq \mathrm{f}_{\mathrm{fu}}^{*}<552 \mathrm{MPa}$.

- Grado F.... (hasta).

- Grado F290: $1999 \mathrm{MPa} \leq \mathrm{f}_{\mathrm{fu}}^{*}<2069 \mathrm{MPa}$.

La norma JSCE 1997(b), establece unos valores mínimos de resistencia a tracción y módulo elástico, dependientes del tipo de geometría superficial (CR y CD, donde CR son barras de CFRP lisas con tratamiento superficial, y CD son barras de CFRP deformadas), volumen de fibra (entre 50-65\%) y diámetro (A y $\mathrm{B}$, donde $\mathrm{A}: \mathrm{D} \leq 20 \mathrm{~mm}, \mathrm{~B}: \mathrm{D} \geq 20 \mathrm{~mm}$ ) de las barras de CFRP (Tabla 2.7).

\begin{tabular}{cccc}
\hline Identificación & Volumen de Fibras (\%) & $\begin{array}{c}f_{f u}^{*} \\
(\mathrm{MPa})\end{array}$ & Módulo elástico (GPa) \\
\hline CR65, CD65 & $63-66$ & 1.240 & $99-170$ \\
\cline { 1 - 2 } CR50A, CD50A & 49 & 960 & 200 \\
\cline { 1 - 2 } CR50B, CD50B & $49-52$ & 780 & 190 \\
\hline
\end{tabular}

Tabla 2.7. Valores mínimos de resistencia a tracción y módulo elástico de barras de CFRP. Adaptado de JSCE 1997(b).

La norma CNR-DT 203/2006, establece que la mínima resistencia a tracción característica de las barras de CFRP no debe ser menor a $400 \mathrm{MPa}$, y el valor medio del módulo elástico no debe ser menor a 100 GPa.

\footnotetext{
${ }^{6} f^{*}{ }_{f u}$, es la resistencia a tracción garantizada de una barra de CFRP, definida como la resistencia media a tracción de una muestra frente al ensayo de tracción simple $\left(f_{u, a v e}\right)$, menos tres veces la desviación estándar $\left(f_{f u}^{*}=f_{u, a v e}-3 \sigma\right)$, en MPa.
} 


\subsubsection{Geometría Superficial}

En la actualidad no existe una estandarización de la geometría superficial de las barras de CFRP. Por ello, y debido a los diferentes procesos de fabricación, en el mercado encontramos una gran variedad de tipos de geometrías superficiales de barras de CFRP (Fig. 2.16 y 2.17).

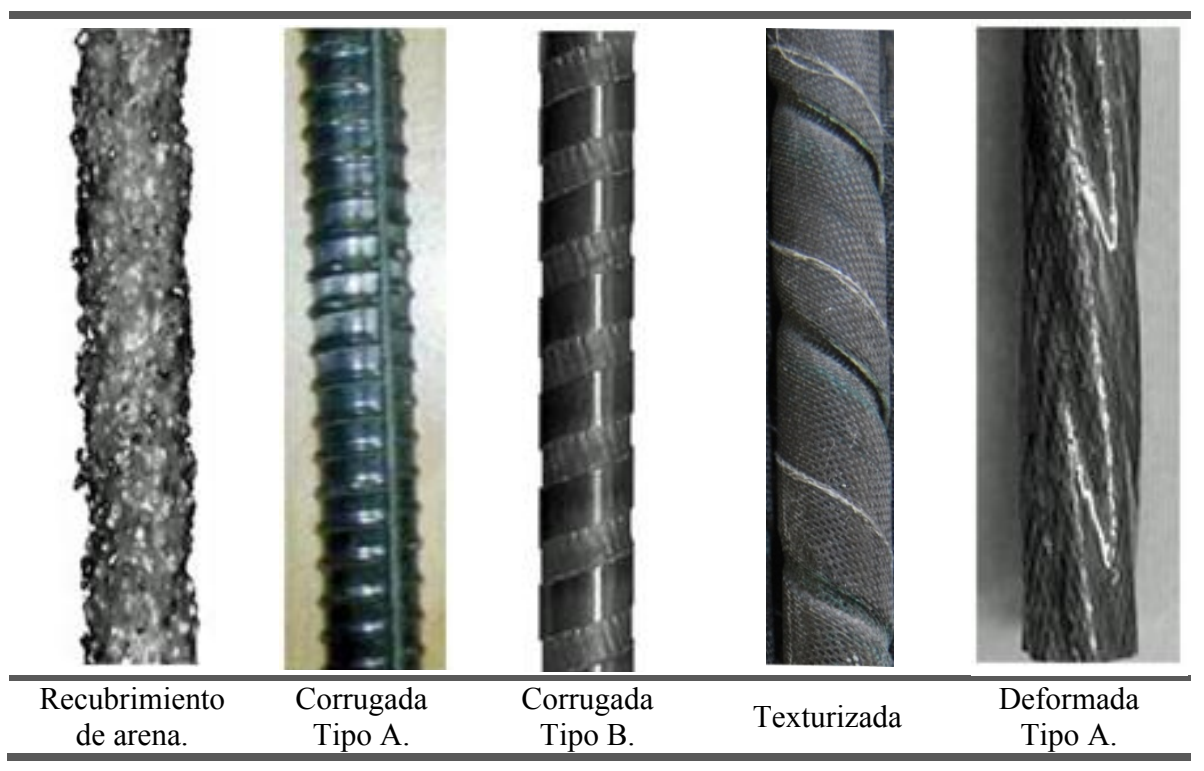

Fig. 2.16. Tipos de geometrías superficiales de barras de CFRP. Katz et al., 1999, 2000; Bank, 2006; Esfandeh et al., 2009; Wang et al., 2006.

\subsubsection{Diámetro de las Barras}

La norma ACI 440.1R-06 establece una clasificación del diámetro de las barras de CFRP (Tabla 2.8); ésta designa el diámetro de la barra de CFRP con un número correspondiente aproximadamente al diámetro nominal de la barra en milímetros. Esta clasificación es similar a la establecida por la norma ASTM para armado de barras de acero. 


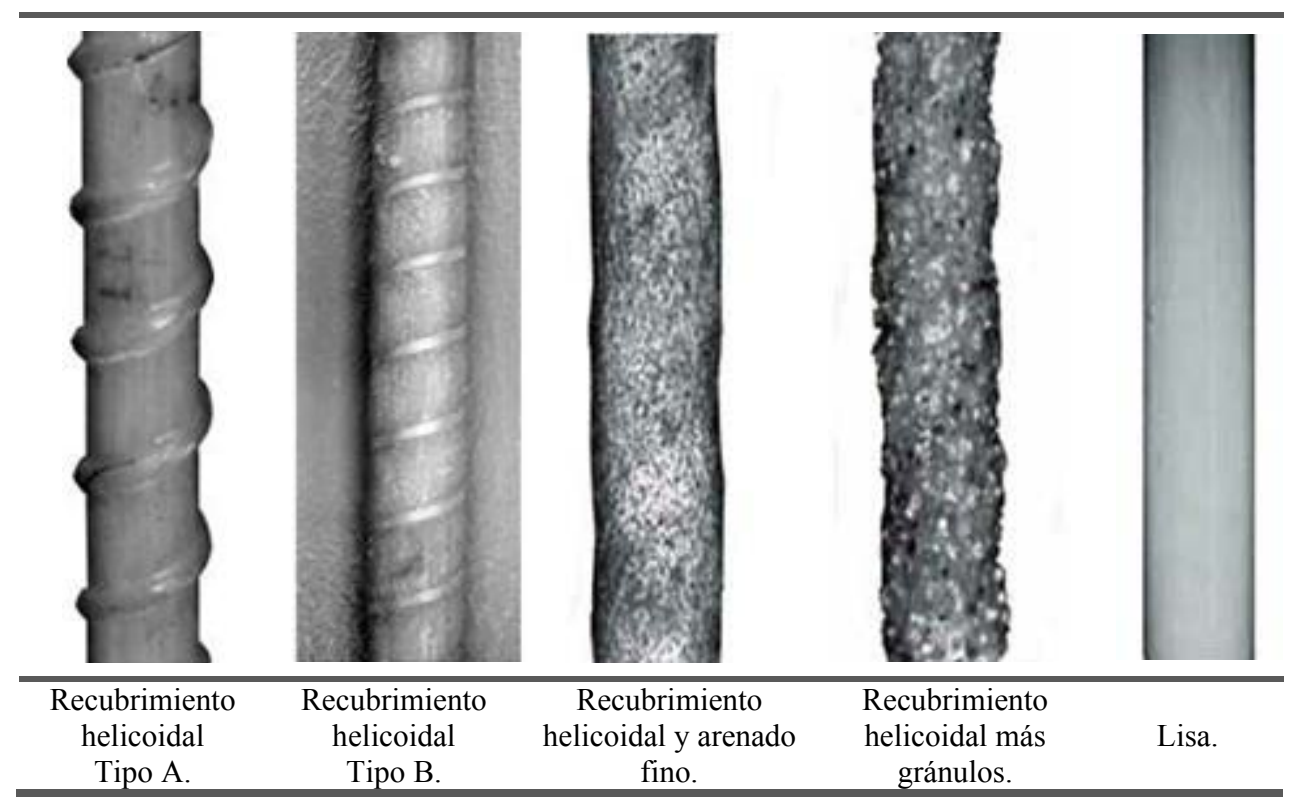

Fig. 2.17. Tipos de geometrías superficiales de barras de CFRP. Katz et al., 1999, 2000;. Bank, 2006; Esfandeh et al., 2009; Wang et al., 2006.

El diámetro nominal de una barra deformada de CFRP es equivalente al diámetro de una barra redonda y lisa, cuya área transversal posea la misma superficie.

\begin{tabular}{|c|c|c|c|}
\hline \multicolumn{2}{|c|}{ Designación del tamaño de barra } & \multirow{2}{*}{$\begin{array}{l}\text { Diámetro nominal } \\
(\mathrm{mm})\end{array}$} & \multirow{2}{*}{$\begin{array}{l}\text { Área } \\
\left(\mathrm{mm}^{2}\right)\end{array}$} \\
\hline Estándar & Conversión métrica & & \\
\hline $\mathrm{N}^{\circ} 2$ & $\mathrm{~N}^{\circ} 6$ & 6,4 & 31,6 \\
\hline $\mathrm{N}^{\circ} 3$ & $\mathrm{~N}^{\circ} 10$ & 9,5 & 71 \\
\hline $\mathrm{N}^{\circ} 4$ & $\mathrm{~N}^{\circ} 13$ & 12,7 & 129 \\
\hline $\mathrm{N}^{0} 5$ & $\mathrm{~N}^{\circ} 16$ & 15,9 & 199 \\
\hline $\mathrm{N}^{\circ} 6$ & $\mathrm{~N}^{\circ} 19$ & 19,1 & 284 \\
\hline $\mathrm{N}^{0} 7$ & $\mathrm{~N}^{\circ} 22$ & 22,2 & 387 \\
\hline $\mathrm{N}^{\circ} 8$ & $N^{\circ} 25$ & 25,4 & 510 \\
\hline $\mathrm{N}^{\circ} 9$ & $\mathrm{~N}^{\circ} 29$ & 28,7 & 645 \\
\hline $\mathrm{N}^{\mathrm{o}} 10$ & No32 & 32,3 & 819 \\
\hline $\mathrm{N}^{\circ} 11$ & $\mathrm{~N}^{\circ} 36$ & 35,8 & 1006 \\
\hline
\end{tabular}

Tabla 2.8. Diámetros de barras de CFRP contemplados por ACI 440.1R-06. Adaptado de ACI 440.1R-06.

El resto de normativas de diseño de estructuras de hormigón armado con barras de CFRP, (JSCE 1997(b), CAN/CSA-S806-02, FIB Task Group 9.3, 
2007, CNR-DT 203/2006, IStructE, 1999), no establecen ninguna clasificación de diámetros de barras de CFRP.

\subsubsection{Identificación de las Barras}

Las diferentes normativas de diseño de estructuras de hormigón armado con barras de CFRP contemplan la identificación de barras de CFRP.

La norma ACI 440.1R-06 establece el siguiente tipo de identificación de barras de CFRP:

\section{XXX-C\#5-F200-E200}

- Símbolo de identificación del fabricante de las barras de CFRP (XXX).

- Letra identificadora del tipo de fibra de refuerzo, en este caso "C", seguido del número correspondiente al diámetro nominal de la barra (según la tabla 2.8).

- Grado de resistencia de la barra (por ejemplo, F200), de acuerdo al punto 2.3.1.

- Grado de módulo de elasticidad de la barra (por ejemplo, E200), de acuerdo al punto 2.3.1.

- Se añadirá la clasificación del grado de adherencia, cuando esta, esté disponible.

La norma JSCE 1997(b) establece la siguiente identificación de barras de CFRP:

\section{CR50A}

- Letra identificadora del tipo de fibra de refuerzo, en este caso "C".

- Letra identificadora del tipo de geometría superficial de la barra de CFRP: "R" para barras lisas, o, lisas con recubrimiento superficial; "D" para barras deformadas.

- Número (50 o 65) que designa el porcentaje del contenido mínimo de fibra de refuerzo.

- Letra que identifica el diámetro de la barra: $A$ y $B$, donde $A$ : $\mathrm{D} \leq 20 \mathrm{~mm}$, B: $\mathrm{D} \geq 20 \mathrm{~mm}$.

La norma Italiana CNR-DT 203/2006 establece la siguiente identificación para cada tipo de barra de CFRP (Fig. 2.18): 


\section{FICHA TÉCNICA: barras de CFRP para estructuras de hormigón armado.}

El fabricante debe aportar los valores estadísticos necesarios para el cálculo de las resistencias características (p.e. la media, la desviación estándar, población, percentil).

\section{Descripción.}

Nombre comercial, tipo de fibra, tipo de resina, proceso de fabricación y cualquier información que resulte útil.

\section{Propiedades geométricas y físicas}

\begin{tabular}{|c|c|c|c|}
\hline \multicolumn{2}{|c|}{ Propiedades } & Unidades & Método de ensayo \\
\hline \multicolumn{2}{|c|}{ Geometría superficial. } & & Apéndice B \\
\hline \multicolumn{2}{|c|}{ Área equivalente. } & $\mathrm{mm}^{2}$ & Apéndice B \\
\hline \multicolumn{2}{|c|}{ Perímetro equivalente. } & $m m$ & Apéndice B \\
\hline \multicolumn{4}{|c|}{ Color. } \\
\hline \multirow{2}{*}{ Densidad. } & Fibra. & $\mathrm{g} / \mathrm{cm}^{3}$ & \multirow{2}{*}{ ISO 1183-1:2004(E) } \\
\hline & Matriz. & $\mathrm{g} / \mathrm{cm}^{3}$ & \\
\hline \multirow{2}{*}{$\begin{array}{l}\text { Contenido de } \\
\text { Fibra. }\end{array}$} & Peso. & $\%$ & \multirow{2}{*}{ ISO 11667:1997(E) } \\
\hline & Volumen. & $\%$ & \\
\hline \multicolumn{2}{|c|}{$T_{g}}$. & ${ }^{\circ} \mathrm{C}$ & $\begin{array}{c}\text { ISO 11357-2:1999(E)(DSC) } \\
\text { ISO 11359-2:1999(E)(TMA) } \\
\text { ASTM E1640(DMA) }\end{array}$ \\
\hline \multicolumn{2}{|c|}{ Temperatura máxima de uso. } & ${ }^{\circ} \mathrm{C}$ & \\
\hline \multicolumn{2}{|c|}{ Conductividad térmica. } & $S / m$ & \\
\hline
\end{tabular}

\section{Propiedades.}

\begin{tabular}{ccc}
\hline Propiedades & Unidades & Método de ensayo \\
\hline Módulo de elasticidad a tracción. & GPa. & Apéndice B/ISO527-4,5:1997(E) \\
\cline { 1 - 1 } $\begin{array}{c}\text { Resistencia a tracción (valor medio y } \\
\text { característico). }\end{array}$ & MPa. & Apéndice B/ISO527-4,5:1997(E) \\
\hline Alargamiento de rotura. & $\%$ & Apéndice B/ISO527-4,5:1997(E) \\
\hline Fluencia. & & ISO899-1:2003(E) \\
\hline Relajación. & & Pullout
\end{tabular}

\section{Condiciones de Almacenaje.}

\section{Seguridad y manipulación.}

Fig. 2.18. Identificación de barras de CFRP. Adaptado de CNR-DT 203/2006 (Apéndice C). 


\subsection{Propiedades Físicas, Mecánicas y Durabilidad de las Barras de CFRP}

En este apartado se desarrollan las propiedades físicas, mecánicas y el comportamiento de durabilidad de las barras de CFRP. Estas propiedades y comportamiento dependen del volumen de fibra, tipo de fibra de refuerzo y matriz polimérica, orientación de la fibra, proceso de fabricación y control de calidad durante el proceso de fabricación.

El elemento clave en la evaluación de las propiedades de las barras de CFRP es el volumen y masa relativos de los materiales constituyentes. Estos se calculan mediante las Ecs. 2.1 a 2.5 (los subíndices c, f y m, se refieren al composite, fibra y matriz respectivamente, $v$ representa el volumen, mientras que $V$ representa el volumen relativo. Se emplea la misma denominación para la masa del composite $m$, y la masa relativa $M$ ).

$$
\begin{aligned}
& v_{c}=v_{f}+v_{m} \\
& V_{f}=\frac{v_{f}}{v_{c}}, \mathrm{y}, V_{m}=\frac{v_{m}}{v_{c}} \\
& V_{f}+V_{m}=1 \\
& m_{c}=m_{f}+m_{m} \\
& M_{f}=\frac{m_{f}}{m_{c}}, \mathrm{y}, M_{m}=\frac{m_{m}}{m_{c}}
\end{aligned}
$$

Las barras de CFRP están formadas por una matriz polimérica reforzada mediante fibras de carbono longitudinalmente. Esta constitución proporciona la anisotropía característica de las barras de CFRP (la anisotropía de las barras de CFRP se debe al predominio de la matriz polimérica en el eje trasversal, mientras que en el eje longitudinal predomina el refuerzo de fibra de carbono), la cual influirá en las propiedades y comportamiento de las mismas, proporcionado 
diferentes propiedades físicas y mecánicas en los dos ejes principales de las barras de CFRP.

\subsubsection{Propiedades Físicas}

\subsubsection{Densidad}

La densidad de las barras de CFRP, basándose en una matriz termoestable y un volumen de fibra, $V_{f}$, de $50-75 \%$, es aproximadamente la quinta parte de las barras de acero (Tabla 2.9). Esta menor densidad proporciona un mínimo peso de la estructura, mayor facilidad de manipulación durante la construcción y un menor coste de transporte.

\begin{tabular}{ccccc}
\hline Matriz/Composite & $\begin{array}{c}\text { CFRP } \\
\left(\mathrm{Kg} / \mathrm{m}^{3}\right)\end{array}$ & $\begin{array}{c}\text { AFRP } \\
\left(\mathrm{Kg} / \mathrm{m}^{3}\right)\end{array}$ & $\begin{array}{c}\text { GFRP } \\
\left(\mathrm{Kg} / \mathrm{m}^{3}\right)\end{array}$ & $\begin{array}{c}\text { Acero } \\
\left(\mathrm{Kg} / \mathrm{m}^{3}\right)\end{array}$ \\
\hline Poliéster & $1.430-1.650$ & $1.310-1.430$ & $1.750-2.170$ & \\
\hline Epoxi & $1.440-1.670$ & $1.320-1.450$ & $1.760-2.180$ & 7.850 \\
\hline Viniléster & $1.440-1.630$ & $1.300-1.410$ & $1.730-2.150$ & \\
\hline
\end{tabular}

Tabla 2.9. Densidad de las barras de FRP y acero. Adaptado de FIB, 2007.

La densidad de las barras de CFRP " $\rho_{\mathrm{c}}$ " se calcula a partir de las densidades de los materiales que la constituyen (Ec. 2.6).

$$
\rho_{c}=\rho_{f} \cdot V_{f}+\rho_{m} \cdot V_{m}
$$

\subsubsection{Coeficiente de Expansión Térmica}

Debido a la anisotropía de las barras de CFRP, el coeficiente de expansión térmica (CTE) en el eje longitudinal $\left(\alpha_{L}\right)$, está dominado por las propiedades de las fibras, mientras que en el sentido transversal el CTE $\left(\alpha_{T}\right)$, está determinado por la matriz polimérica (Fig. 2.19). Ambos CTE's, $\alpha_{L}$ y $\alpha_{T}$, se calculan mediante las Ecs. 2.7 y 2.8 . 


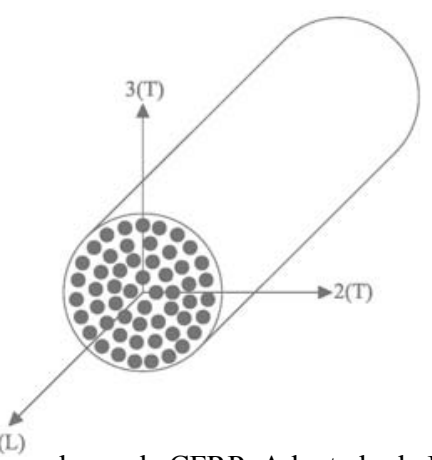

Fig. 2.19. Ejes de una barra de CFRP. Adaptado de FIB, 2007.

$$
\begin{aligned}
& \alpha_{L}=\frac{E_{f L} \cdot V_{f} \cdot \alpha_{f L}+E_{m} \cdot V_{m} \cdot \alpha_{m}}{E_{f L} \cdot V_{f}+E_{m} \cdot V_{m}} \\
& \alpha_{T}=V_{f} \cdot \alpha_{f T}+V_{m} \cdot \alpha_{m}+V_{f} \cdot v_{f L T}\left(\alpha_{f L}-\alpha_{L}\right)+V_{m} \cdot v_{m}\left(\alpha_{m}-\alpha_{L}\right)
\end{aligned}
$$

Donde: $\alpha_{\mathrm{fL}}$, es el CTE de las fibras en el eje longitudinal. $\alpha_{\mathrm{fT}}$, es el CTE de las fibras en la dirección transversal. $\mathrm{E}_{\mathrm{fL}}$, es el módulo de las fibras en el eje longitudinal. $E_{\mathrm{m}}$, es el módulo de la matriz polimérica. $v_{\mathrm{fLT}}$, es el coeficiente de Poisson's de las fibras en el eje LT.

En la Tabla 2.10 se muestra el CTE de las barras de CFRP y varios FRP's con un volumen de fibras de 50-75\%.

\begin{tabular}{lcccccc}
\hline \multirow{2}{*}{ Dirección } & \multicolumn{6}{c}{ Coeficiente de Expansión Térmica $\left(x 10^{-6} /{ }^{\circ} \mathrm{C}\right)$} \\
\cline { 2 - 7 } & Acero & Acero Inoxidable & GFRP & CFRP & AFRP & Hormigón \\
\hline Longitudinal, $\alpha_{L}$ & 11 & 10 a 16,5 & 6 a 10 & -9 a 0 & -6 a -2 & 7 a 13 \\
\hline Transversal, $\alpha_{T}$ & 11 & 10 a 16,5 & 21 a 23 & 74 a 104 & 60 a 80 & 7 a 13 \\
\hline
\end{tabular}

Tabla 2.10. CTE de diferentes FRP's. Adaptado de FIB, 2007.

Como se puede comprobar en la Tabla 2.10, las barras de CFRP poseen un CTE negativo en el eje longitudinal, lo que indica, que un aumento de la temperatura originará una retracción en dicha dirección, y al mismo tiempo en el sentido transversal se producirá una expansión de la barra de CFRP. Si la temperatura disminuye ocurrirá lo contrario, la barra de CFRP se expandirá en el sentido longitudinal y se contraerá en el eje transversal. 


\subsubsection{Conductividad Eléctrica}

Las fibras de carbono son conductoras eléctricamente, y su resistividad eléctrica es del orden de $1.500 \cdot 10^{-8} \Omega \mathrm{m}$. Las matrices poliméricas empleadas en los composites de CFRP poseen la propiedad de no ser conductoras eléctricas, siendo su resistividad eléctrica muy elevada, del orden de $10^{20} \Omega \mathrm{m}$. La matriz polimérica desarrolla una función de aislante eléctrico en el composite de CFRP, ya que envuelve a las fibras de carbono y le confiere esta propiedad no magnética que permite el uso de este tipo de armado en estructuras donde se requiere un material no conductor eléctricamente y no magnético.

\subsubsection{Propiedades Mecánicas}

\subsubsection{Tracción}

Las barras de CFRP, debido a su anisotropía, poseen diferente comportamiento frente a esfuerzos de tracción en los dos ejes principales de la barra. La dirección longitudinal de la barra está dominada por las fibras de carbono, por lo que presenta un buen comportamiento frente a esfuerzos de tracción, al contrario de lo que ocurre en el eje transversal, dominado por la matriz polimérica (ACI 440.XR-06). Por lo tanto, debido a que las barras de CFRP son elementos longitudinales, su comportamiento a tracción está dominado por las fibras de carbono (Fig. 2.20).

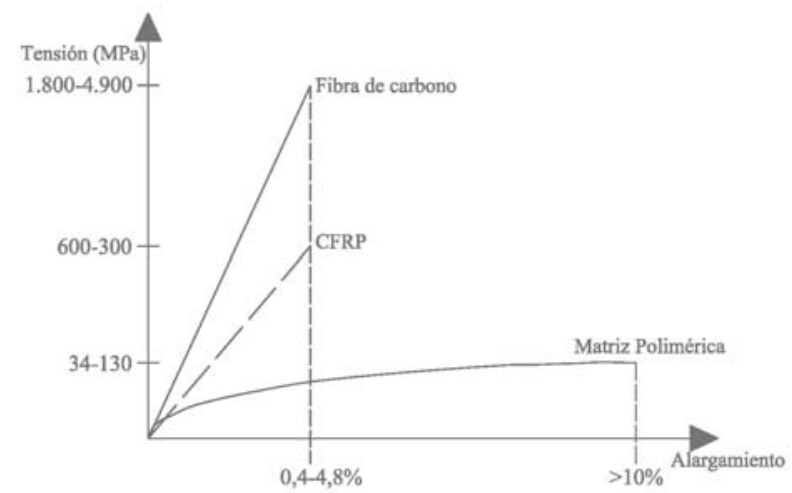

Fig. 2.20. Comportamiento tensión/deformación de la fibra de carbono, matriz polimérica y barra de CFRP. Adaptado de ISIS, 2000. 
El comportamiento de las barras de CFRP es elástico y lineal hasta la rotura. Al contrario que las armaduras de acero, no se plastifican y, por lo tanto, la rotura será frágil (ACI 440.1R-06; FIB Task Group 9.3, 2007) (Fig. 2.21).

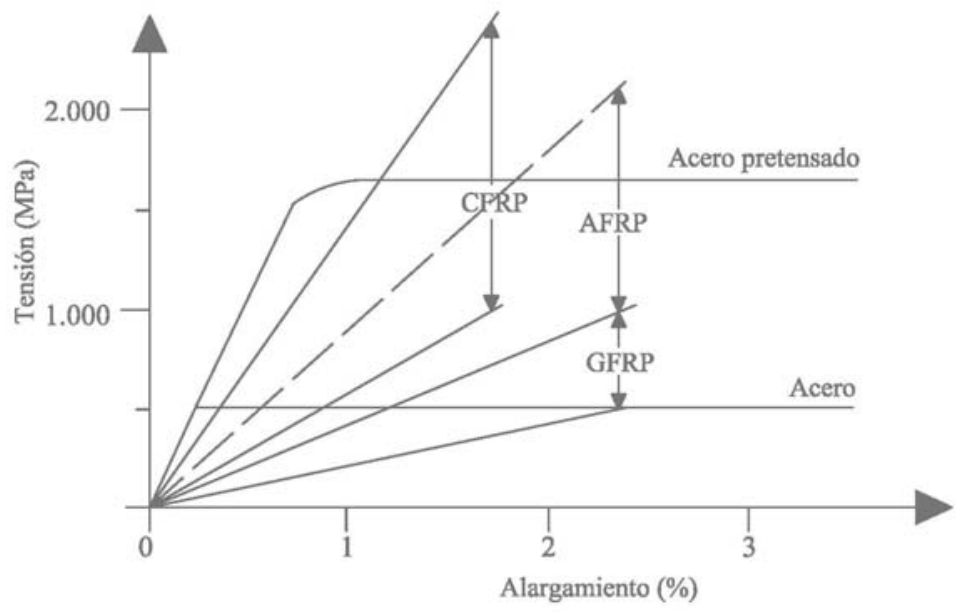

Fig. 2.21. Comportamiento tensión/deformación de diferentes barras de FRP y acero. Adaptado de Gdoutos et al., 2000.

La resistencia a tracción de las barras de CFRP varía entre 600-3.690 MPa (valores obtenidos para barras con un volumen de fibra de 50-70\%), es decir, hasta del orden de 5 veces la resistencia del armado de acero (Tabla 2.11). El módulo elástico depende del tipo de refuerzo de fibra de carbono (las fibras de carbono de alto módulo poseen un módulo elástico de 350-650 GPa, las fibras de alta resistencia presentan un módulo alrededor de $240 \mathrm{GPa}$ ), éste oscila entre 120-580 GPa. El alargamiento de rotura varía entre 0,5-1,7\% (ACI 440.1R-06; FIB Task Group 9.3, 2007).

\begin{tabular}{ccccc}
\hline Propiedades/Armado & Acero & GFRP & CFRP & AFRP \\
\cline { 1 - 1 } Limite elástico (MPa) & $276-517$ & - & - & - \\
\cline { 1 - 1 } Resistencia a tracción (MPa) & $483-690$ & $483-1.600$ & $600-3.690$ & $1.720-2.540$ \\
\cline { 1 - 3 } Módulo elástico (GPa) & 200 & $35,0-51,0$ & $120-580$ & $41,0-125$ \\
\cline { 1 - 3 } Alargamiento elástico (\%) & $0,14-0,25$ & - & - & - \\
\cline { 1 - 3 } Alargamiento de rotura (\%) & $6,0-12,0$ & $1,2-3,1$ & $0,5-1,7$ & $1,9-4,4$ \\
\hline
\end{tabular}

Tabla 2.11. Propiedades mecánicas a tracción de diferentes barras de FRP y acero. Adaptado de ACI 440.1R-06. 
El aumento de diámetro de las barras de CFRP produce una disminución de la resistencia a tracción de las mismas (ACI 440.1R-06; FIB Task Group 9.3, 2007; Achillides et al., 2004) (Fig. 2.22). Esta disminución se debe a la diferente respuesta entre las fibras de carbono situadas en el alma y en la superficie de la barra (la sección de la barra no plastifica debido a su comportamiento elástico y lineal), lo que produce una distribución no uniforme de tensiones a través de la sección transversal de la barra de CFRP (Z. Achillides et al., 2004).

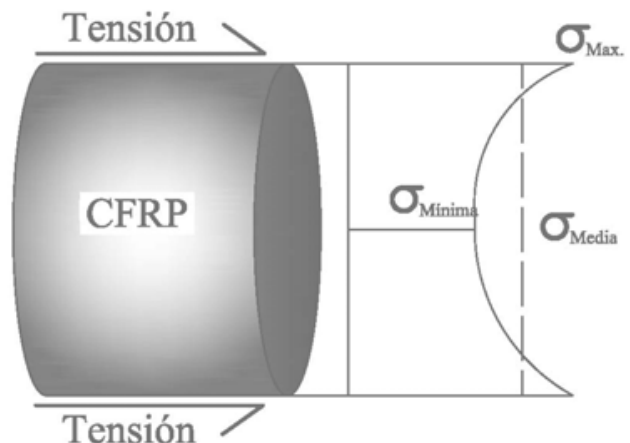

Fig. 2.22. Distribución de tensiones normales en la sección transversal de una barra de CFRP. Adaptado de Achillides et al., 2004.

Las barras de CFRP curvas poseen una resistencia a tracción inferior a la desarrollada en barras rectas (ACI 440.1R-06; FIB Task Group 9.3, 2007; JSCE 1997(b)). Esta reducción de resistencia de las barras curvas respecto de las rectas es alrededor del $40-50 \% \mathrm{y}$, se debe a la concentración de tensiones en la parte curva de la barra (ACI 440.1R-06; Nanni et al., 1998).

Debido a que las barras de CFRP son elementos unidireccionales y anisótropos, la resistencia a tracción y la rigidez variará dependiendo de la dirección de las tensiones aplicadas. Por ello, la resistencia a tracción y la rigidez en el eje longitudinal de la barra disminuye considerablemente cuando la tensión se aplica con un ángulo, $\theta$, superior a $15^{\circ}$ (Fig. 2.23) (FIB Task Group 9.3, 2007; Peters, 1998). 


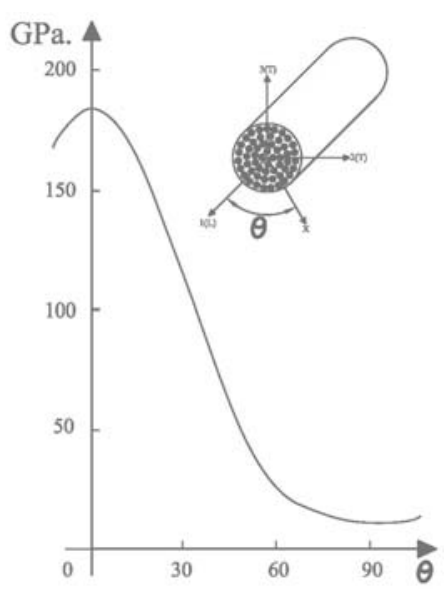

Fig. 2.23. Influencia de la dirección de la tensión aplicada en la rigidez de las barras de CFRP. Adaptado de Peters, 1998.

\subsubsection{Compresión}

Las diferentes normativas de diseño de estructuras de hormigón armado con barras CFRP no recomiendan el empleo de barras de CFRP en elementos sometidos a compresión axial (ACI 440.1R-06; JSCE 1997(b); CAN/CSA-S80602; FIB Task Group 9.3, 2007; CNR-DT 203/2006; IStructE, 1999).

La resistencia a compresión de las barras de CFRP es inferior a la resistencia a tracción, puesto que el modo de rotura de la barra cambia de rotura de las fibras de carbono por tracción, a rotura por microbuckling (micropandeo) de las fibras, rotura por compresión de la matriz polimérica, kinking ${ }^{7}$ o rotura por cortante de la barra (Fig. 2.24). Por lo tanto, la resistencia frente a esfuerzos de compresión de las barras de CFRP depende de las propiedades de la matriz polimérica, de las fibras de carbono y del porcentaje de volumen de fibras (Fig. 2.25) (FIB Task Group 9.3, 2007; Yuan et al., 2001).

7 Existe una dificultad notable para traducir vocablos sajones de modos de rotura sin uso en este país. Así, la denominación kinking no ha sido traducida al castellano en esta tesis doctoral. El modo de rotura de las barras de CFRP por kinking, es producido cuando se aplica un esfuerzo de compresión axial, y esta rompe por doblado de la misma. Yuan et al., 1999. 


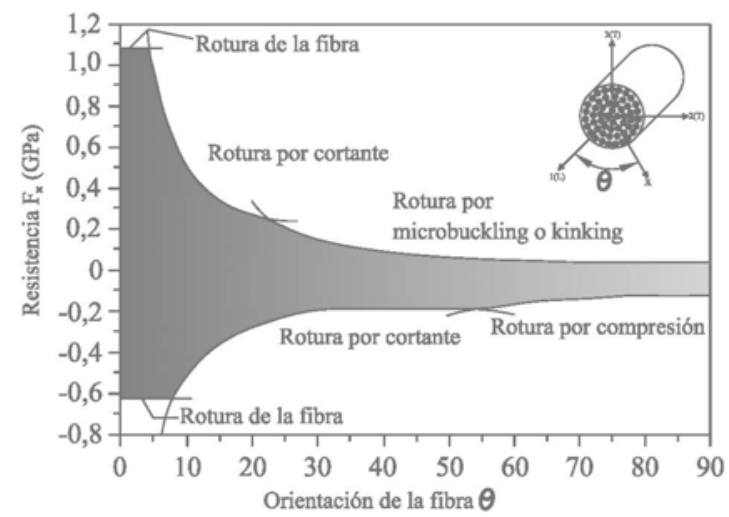

Fig. 2.24. Modo de rotura de las barras de CFRP en función de la dirección de la tensión aplicada. Adaptado de Peters., 1998.

El mecanismo de rotura de las barras de CFRP a compresión depende en gran medida del porcentaje de volumen de fibras. Si se incrementa el porcentaje de volumen de fibras del $10 \%$ a más del $40 \%$, el modo de rotura de la barra cambia de rotura por cortante $\left(10 \%<\mathrm{V}_{\mathrm{f}}<40 \%\right)$ a rotura por kinking $\left(40 \%<\mathrm{V}_{\mathrm{f}}\right)$. Al mismo tiempo, el ángulo de rotura de la barra depende del porcentaje de volumen de fibras de carbono. Un incremento del volumen de fibras aumentará el ángulo de rotura a cortante de la barra, con $\mathrm{V}_{\mathrm{f}}=10 \%$ el ángulo de rotura es de $\alpha=45^{\circ}$, hasta $\mathrm{V}_{\mathrm{f}}=30 \%$ con un ángulo de rotura de $\alpha=64^{\circ}$ (Yuan et al., 2001).

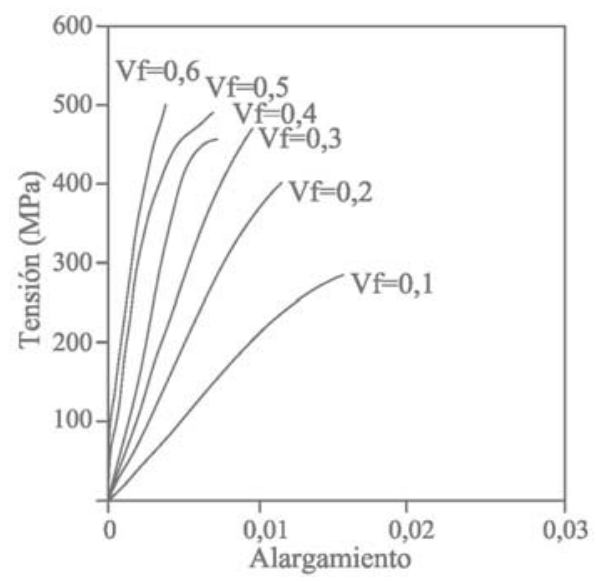

Fig. 2.25. Influencia del porcentaje del volumen de fibra de carbono en la resistencia de las barras de CFRP. Adaptado de Yuan et al, 2001. 
El comportamiento frente a esfuerzos de compresión axial de las barras de CFRP es aproximadamente elástico lineal hasta la rotura (Fig. 2.25) (Yuan et al., 2001), y poseen una resistencia a compresión alrededor del $78 \%$ de la resistencia a tracción. Generalmente, la resistencia a compresión es mayor en barras con mayor resistencia a tracción (Mallick 1998). En cuanto al módulo elástico a compresión, este es del orden del $85 \%$ del módulo elástico a tracción (Mallick, 1998).

\subsubsection{Cortante}

El comportamiento de las barras de CFRP frente a esfuerzos de corte está dominado por las propiedades mecánicas de la matriz polimérica y por la distribución de las tensiones a lo largo de la sección transversal de la barra (Fig. 2.26). Por lo tanto, la resistencia frente a esfuerzos de corte transversal varía ampliamente de un fabricante a otro. Aunque, los métodos de ensayo a cortante todavía no se han estandarizado (ACI 440.1R-06), éstos deben ser obtenidos de cada fabricante de barras de CFRP (cada fabricante debe describir el método de ensayo empleado). Normalmente la resistencia a corte de las barras de CFRP es superior a $120 \mathrm{MPa}$ (Fortecstabilization, 2010).

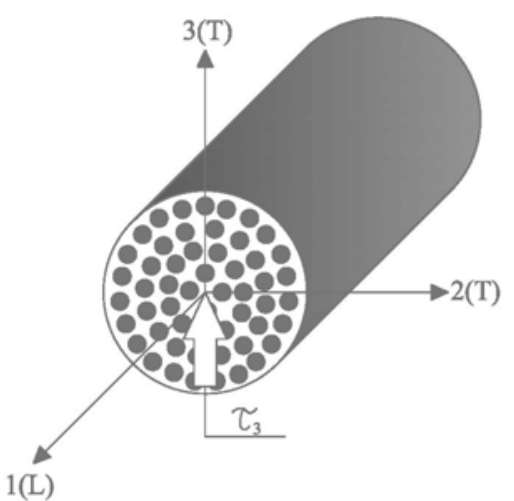

Fig. 2.26. Tensión de corte transversal $\left(\tau_{3}\right)$ aplicada en una barra de CFRP. Adaptado de FIB, 2007. 
El modo de rotura de las barras de CFRP por cortante puede ser debido a splitting de la matriz polimérica ( $\sin$ corte de las fibras de carbono), ya que, la tensión de corte actúa en un plano perpendicular a la dirección de las fibras. Por lo tanto, las fibras no resisten los esfuerzos de corte y, aún peor, las secciones transversales de las fibras pueden ser consideradas como inclusiones circulares en la matriz polimérica causando concentración de tensiones en la misma. Hasta la fecha, no se han desarrollado modelos teóricos de cálculo de la resistencia a corte. Como método de diseño preliminar se puede estimar la resistencia a corte de la barra de CFRP como la resistencia a corte de la matriz polimérica (Barbero, 1999).

Con el objetivo de mejorar la resistencia a cortante los diferentes fabricantes de barras de CFRP introducen un zunchado en las barras (el método de fabricación de este tipo de barras de CFRP se denomina pull-winding, desarrollado anteriormente en el apartado 2.2.3) o fabrican barras con fibras de carbono dispuestas longitudinal y transversalmente (ACI 440.1R-06).

\subsubsection{Durabilidad de las Barras de CFRP}

En este apartado se analiza el comportamiento de las barras de CFRP frente a diferentes condiciones de durabilidad (ambiente acuoso, cloruros, álcalis, radiación U.V, carbonatación, temperatura). El concepto de durabilidad de un material se define como:

“la capacidad para resistir la fisuración, oxidación, degradación química, deslaminación, reducción de las propiedades mecánicas y efectos de cualquier daño producido durante un periodo de tiempo considerado, bajo condiciones ambientales y de carga determinadas", (Karbhari et al., 2003).

El grado de reducción de las propiedades mecánicas (resistencia, rigidez y adherencia barra/hormigón) de las barras de CFRP bajo diferentes condiciones ambientales depende de varios factores, como son el tipo de fibra de carbono y 
de resina polimérica, la interfaz fibra-matriz, las condiciones de curado, el control de calidad durante la fabricación y el nivel de agresividad ambiental (GangaRao et al., 2007). En el composite, las fibras de carbono son el elemento encargado de resistir las cargas, mientras que, la matriz polimérica protege a las fibras de carbono y al composite de posibles daños, mantiene su alineamiento y facilita la distribución de la carga a las fibras individuales. También se añaden aditivos a la resina polimérica que mejoran el comportamiento del composite frente a condiciones de durabilidad (GangaRao et al., 1995; Kato et al., 1998).

Algunas de las diferentes condiciones ambientales que pueden afectar a la durabilidad de las barras de CFRP en términos de resistencia, rigidez, interacción fibra/matriz, y micro o macro fisuración son: agua (incluyendo agua del mar), soluciones químicas (salinas, alcalinas y ácidas), frío prolongado, ciclos térmicos (hielo/deshielo), temperaturas elevadas, gradiente térmico (altas y bajas temperaturas a lo largo de la sección de la barra), oxidación, radiación U.V, envejecimiento (físico y químico bajo condiciones aceleradas o naturales) y fuego (GangaRao et al., 1995).

Además de las condiciones ambientales anteriormente mencionadas, las propiedades mecánicas y de durabilidad de las barras de CFRP, también se encuentran influenciadas por: a) los enlaces químicos entre las cadenas poliméricas a través de la densidad de los enlaces y del porcentaje de curado; b) las fuerzas covalentes y de van der Waals; y c) el estado físico del composite, incluyendo su morfología, tamaño y orientación de la fibra. El envejecimiento y la degradación estructural del composite ocurre normalmente a través de interacciones moleculares entre la sustancia predominante en el ambiente (agua, ácido, etc..) y la estructura polimérica.

La acción higrotérmica puede originar: fisuración del composite, deslaminado fibra/matriz, pérdida de la distribución de las fibras y un 
incremento de las tensiones inducidas (residuales) en la barra (Parkyn, 1985; Rao et al., 1981).

El envejecimiento de las barras de CFRP es un fenómeno complejo debido a la interacción de numerosos factores diferentes que influyen en las propiedades mecánicas. Este puede ser significativo a partir de un periodo de vida de 75 años. El envejecimiento puede ser químico o físico. El envejecimiento químico implica un cambio en la estructura química o molecular del polímero debido a la rotura de las cadenas macromoleculares, la oxidación y pérdida de enlaces moleculares (GangaRao et al., 1995; Vijay y GangaRao, 1999a). El envejecimiento físico (temperatura), implica un intento de reagrupación de las macromoléculas a un nuevo estado por debajo de la temperatura de transición vítrea $\left(\mathrm{T}_{\mathrm{g}}\right)^{8}$.

\subsubsection{Efecto del Agua}

La penetración de agua en las barras de CFRP se produce por dos fenómenos diferentes: por difusión a través de la matriz polimérica o por grietas o poros en la superficie de la barra. Si se produce por difusión, el agua no penetra en forma de líquido, sino que las moléculas de agua penetran en el interior de la matriz uniéndose a los enlaces de hidrógeno del polímero. Estas moléculas de agua se disuelven en la superficie del polímero y migran hacia el interior de la matriz incrementando el gradiente de concentración de agua. La penetración a través de grietas o poros se produce por capilaridad (Parkyn 1985; Rao. et al., 1981).

La penetración de agua en la matriz polimérica produce un ablandamiento por hidrólisis, lo que conlleva una reducción de las propiedades del composite, tales como, la resistencia a cortante, temperatura de transición

\footnotetext{
${ }^{8}$ Dependiendo del tipo de matriz polimérica (termoestable o termoplástica), las propiedades mecánicas del polímero sufrirán en mayor o menor medida cambios en su comportamiento. Véase apartado 2.2.1 de la presente tesis doctoral.
} 
vítrea y resistencia y rigidez del composite. Esta reducción de las propiedades mecánicas puede aumentar en presencia de tensión y temperatura $\left(>60^{\circ} \mathrm{C}\right)$ (Chateauminiois et al., 1993).

De los estudios realizados hasta la fecha sobre la influencia del ambiente acuoso en las propiedades mecánicas de las barras de CFRP, se observa que la resistencia a tracción durante la exposición de barras de CFRP en presencia de agua y unas temperaturas medias de $25-60-70{ }^{\circ} \mathrm{C}$, no produce pérdida de resistencia considerable a edades de ensayo máximas de 1 año (Arockiasamy et al., 1996; Micelli, 2001; Myers, 2001; Nanni, 2001; Porter, 1997; Rahman, 1998; Tannous et al., 1998). Este comportamiento se debe al tipo de matriz polimérica que presentan las barras de ensayo, como son las matrices termoestables ${ }^{9}$, puesto que poseen un bajo coeficiente de absorción de humedad (Tabla 2.2) y sus cadenas moleculares se encuentran unidas mediante fuerzas covalentes, lo que se traduce en un buen comportamiento ante ambientes acuosos.

\subsubsection{Efecto de los Cloruros}

De las diferentes investigaciones llevadas a cabo (Saadatmanesh y Tannous, 1997; Sasaki et al., 1997; Sen et al., 1997; GangaRao y Vijay, 1997; Chin et al., 1997; Steckel et al., 1998; Rahman et al., 1998; Toutanji y ElKorchi, 1998) concernientes a la exposición de barras de CFRP ante ambientes en presencia de concentración de cloruros (de hasta un 4\%), variando la humedad relativa ambiental, con o sin tensión aplicada en la barra y un rango de temperaturas de 20 a $70^{\circ} \mathrm{C}$, se observa que la disminución de las propiedades mecánicas de las barras de CFRP es despreciable, mientras que las barras de

\footnotetext{
${ }^{9}$ Generalmente se emplean matrices poliméricas de resina de epoxi o de viniléster, debido a la compatibilidad de resistencias entre la matriz polimérica y la fibra de carbono, puesto que, no tienen sentido emplear otro tipo de matriz, ya que el desarrollo de propiedades mecánicas y resistencia a durabilidad y largo plazo no se desarrollará eficientemente. Si se emplean matrices de poliéster la disminución de la resistencia oscila entre 10-15\% (Peters., 1998).
} 
GFRP y AFRP presentan una reducción de resistencia y rigidez alrededor del $50 \%$.

\subsubsection{Efecto de los Álcalis}

En los ensayos de tracción y cortante en barras de CFRP (con matriz polimérica de epoxi) de $\varnothing 9,0 \mathrm{~mm}$, en un ambiente alcalino (compuesto por $\mathrm{NaOH}, \mathrm{KOH}$ y $\mathrm{Ca}(\mathrm{OH})_{2}$ ), con un $\mathrm{PH}$ de 13,6 (imitando el ambiente del hormigón) realizados por Davalos et al., (2005), se observa (basándose en el tipo de barra de CFRP, composición del ambiente alcalino y duración de la exposición ante el mismo) (Tabla 2.12 y 2.13):

"Las barras de CFRP mostraron una reducción de su resistencia a tracción tras la exposición al ambiente alcalino durante 70 días y a una temperatura de $60^{\circ} \mathrm{C}$, del $4 \%$ de su resistencia a tracción inicial. Al mismo tiempo, su resistencia a corte solo se vio reducida un $4 \%$ tras la exposición a dicho ambiente y 600 ciclos de hielo deshielo".

\begin{tabular}{cccccc}
\hline $\begin{array}{c}\text { Tipo de } \\
\text { barra }\end{array}$ & Ambiente & $\begin{array}{c}\mathrm{N}^{\mathrm{o}} \mathrm{de} \\
\text { probetas }\end{array}$ & $\begin{array}{c}f_{f m} \\
(\mathrm{MPa})\end{array}$ & $\begin{array}{c}\mathrm{COV}^{10} \\
(\%)\end{array}$ & $\begin{array}{c}\text { Resistencia } \\
\text { residual }\end{array}$ \\
\hline \multirow{2}{*}{ CFRP } & Sin exposición ambiental & 5 & 2.588 & 5 & 1,00 \\
\cline { 2 - 2 } & $\begin{array}{c}\text { Solución alcalina a } 60^{\circ} \mathrm{C}, \\
\text { durante } 70 \text { dias. }\end{array}$ & 4 & 2.476 & 9 & 0,96 \\
\hline
\end{tabular}

Tabla 2.12. Comportamiento a tracción de las barras de CFRP, frente ambientes alcalinos Adaptado de Davalos et al., 2005, Tabla 5.

Otros investigadores como Takewaka y Khin, (1996), obtuvieron como resultado de la exposición de barras de CFRP en un ambiente alcalino, pérdidas de resistencia y rigidez de 0 a $20 \%$ de su resistencia y rigidez inicial. En mi opinión, este estudio no es concluyente actualmente puesto que las propiedades mecánicas y de durabilidad de las barras fabricadas en la actualidad, distan mucho de las propiedades de las barras de CFRP empleadas en dicho estudio.

\footnotetext{
${ }^{10}$ Las siglas COV, se refieren al coeficiente de variación.
} 


\begin{tabular}{cccccc}
\hline \multirow{2}{*}{$\begin{array}{c}\text { Tipo de } \\
\text { barra }\end{array}$} & Ambiente & $\begin{array}{c}\mathrm{N}^{\mathrm{o}} \text { de } \\
\text { probetas }\end{array}$ & $\begin{array}{c}\text { Resistencia } \\
\text { a cortante } \\
\text { (MPa) }\end{array}$ & $\begin{array}{c}\text { COV } \\
(\%)\end{array}$ & $\begin{array}{c}\text { Resistencia } \\
\text { residual }\end{array}$ \\
\hline \multirow{2}{*}{ CFRP } & $\begin{array}{c}\text { Sin exposición } \\
\text { ambiental }\end{array}$ & 9 & 50 & 5 & 1,00 \\
\cline { 2 - 3 } & $\begin{array}{c}\text { Solución alcalina y 600 } \\
\text { ciclos de hielo/deshielo }\end{array}$ & 5 & 48 & 2 & 0,96 \\
\hline
\end{tabular}

Tabla 2.13. Comportamiento a cortante transversal de las barras de CFRP, frente ambientes alcalinos. Adaptado de Davalos et al., 2005, Tabla 6.

Por el contrario, Steckel et al., (1998), introdujeron barras de CFRP y GFRP en una disolución de $\mathrm{CaCO}_{3}(\mathrm{PH} 9,5)$ a una temperatura de $23^{\circ} \mathrm{C}$ durante 125 días, tras los cuales las barras de CFRP no mostraron disminución de su resistencia, mientras que las barras de GFRP presentan una disminución del 10\% en su módulo elástico y del $30 \%$ en su resistencia a corte transversal.

\begin{tabular}{|c|c|c|c|c|c|}
\hline Autor & $\mathrm{PH}$ & Ambiente & Temp. & Duración & $\begin{array}{l}\text { Pérdida de } \\
\text { resistencia }\end{array}$ \\
\hline \multirow{4}{*}{$\begin{array}{c}\text { Tannous et al., } \\
1998 .\end{array}$} & \multirow{4}{*}{12} & \multirow{4}{*}{ Sat. $\mathrm{Ca}(\mathrm{OH})_{2}$} & $60^{\circ} \mathrm{C}$ & 1 año & $0 \%$ \\
\hline & & & $25^{\circ} \mathrm{C}$ & 1 año & $0 \%$ \\
\hline & & & $60^{\circ} \mathrm{C}$ & 1 año & $0 \%$ \\
\hline & & & $25^{\circ} \mathrm{C}$ & 1 año & $0 \%$ \\
\hline Porter, 1997. & 13 & Sat. $\mathrm{Ca}(\mathrm{OH})_{2}$ & $60^{\circ} \mathrm{C}$ & 4 meses & $0 \%$ \\
\hline \multirow{4}{*}{$\begin{array}{l}\text { Micelli, Myers, } \\
\text { Nanni, } 2001 .\end{array}$} & \multirow{4}{*}{12,6} & \multirow{4}{*}{$\begin{array}{c}0,16 \% \mathrm{Ca}(\mathrm{OH})_{2}+1 \% \\
\mathrm{NaOH}+1,4 \% \mathrm{KOH}\end{array}$} & \multirow{4}{*}{$60^{\circ} \mathrm{C}$} & 21 días & $1 \%$ \\
\hline & & & & 42 días & $8 \%$ \\
\hline & & & & 21 días & $0 \%$ \\
\hline & & & & 42 días & $0 \%$ \\
\hline $\begin{array}{c}\text { Arockiasamy et } \\
\text { al., } 1998 .\end{array}$ & $13-14$ & $58 \mathrm{gr} / \mathrm{l} \mathrm{NaOH}$ & $70^{\circ} \mathrm{C}$ & 9 meses & $0 \%$ \\
\hline
\end{tabular}

Tabla 2.14. Disminución de resistencia a tracción de las barras de CFRP en presencia de ambientes alcalinos. Adaptado de FIB, 2007, tabla 3.1.

La normativa de diseño de estructuras de hormigón armado con FRP, FIB Task Group 9.3, 2007, recoge un amplio recopilatorio de investigaciones llevadas a cabo sobre el comportamiento mecánico y de durabilidad de las barras de CFRP en ambientes alcalinos (Tabla 2.14). En esta norma se afirma en su apartado 3.4.3: 
“Las barras de CFRP no muestran una disminución de resistencia significativa en presencia de ambientes alcalinos”.

\subsubsection{Efecto de la Radiación Ultravioleta}

La exposición de las barras de CFRP ante los rayos U.V. y humedad antes de su colocación en el hormigón, puede disminuir su resistencia a tracción debido a la pérdida de su peso molecular y enlaces moleculares de la matriz polimérica (Bank y Gentry, 1995; Kato et al., 1998; Peters, 1998). Sin embargo, las barras de CFRP en condiciones de servicio (embebidas en el hormigón), no expuestas a rayos U.V, no presentan ninguna disminución de resistencia (Tomosawa y Nakatsuji, 1997). Las diferentes recomendaciones de colocación y empleo de las barras de CFRP junto con adecuados aditivos en la composición de las resinas poliméricas pueden eliminar este problema. Las investigaciones llevadas a cabo por Sasaki et al., (1997), sobre la exposición de barras de CFRP frente a rayos U.V y humedad, han concluido con resultados de pérdida de resistencia a tracción de 0 a $20 \%$ de la resistencia inicial.

Kato et al., (1997), investigaron el comportamiento de las barras de CFRP, AFRP y GFRP, expuestas a un ambiente de rayos U.V $\left(0,2 \mathrm{MJ} / \mathrm{m}^{2 /} /\right.$ hora $)$ y ciclos de humectación/secado (250, 750 y 1250 ciclos de humectación/secado) y una temperatura de $26{ }^{\circ} \mathrm{C}$, obteniendo reducciones de la resistencia a tracción del orden de un 13\% en barras de AFRP tras una exposición de 2500 horas, 8\% en barras de GFRP de tras una exposición de 500 horas, y $0 \%$ en barras de CFRP. Al mismo tiempo, se expusieron fibras de carbono, vidrio y aramida, ante el mismo ambiente durante 1000 horas, no encontrándose degradación de las mismas. 


\subsubsection{Efecto de la Carbonatación del Hormigón}

El efecto de la carbonatación del hormigón en las barras de CFRP no ha sido estudiado ampliamente, únicamente el proyecto EUROCRETE ha realizado investigaciones en torno a este fenómeno. Sheard et al., (1997), con base en su investigación concluyó con la siguiente afirmación:

“la carbonatación del hormigón no mostró deterioros de las propiedades mecánicas de las barras de CFRP, al contrario, esta produce una reducción del $\mathrm{PH}$, lo cual incrementa la vida de servicio y mejora la durabilidad de las barras de CFRP”.

\subsubsection{Efecto de la Temperatura}

La temperatura modifica las propiedades mecánicas (tanto las propiedades a largo plazo; fluencia, fatiga y relajación; como las propiedades a corto plazo; resistencia a tracción, compresión, a cortante y el módulo elástico) y la absorción de humedad de las barras de CFRP (Allred, 1984 ; Devalapura et al., 1998; GangaRao et al., 2001; Katz et al., 1998, 1999; Pritchard y Speake, 1998).

La temperatura a partir de la cual la matriz polimérica comienza a perder su rigidez se denomina temperatura de transición vítrea " $\mathrm{T}_{\mathrm{g}}$ ”. A partir de la $\mathrm{T}_{\mathrm{g}}$ el módulo elástico de la matriz polimérica comienza a reducirse debido a cambios en su estructura molecular (véase Capitulo 2, apart. 2.2.1) (Fried, 1995). El valor de la $T_{g}$ de las barras de CFRP depende del tipo de resina polimérica (véase Tabla 2.2), puesto que las fibras de carbono presentan una resistencia muy elevada frente a altas temperaturas (véase Capitulo 2, apart. 2.2.2) (Bottle et al., 2001).

Las barras de CFRP son elementos unidireccionales, las cuales desarrollan su trabajo en la dirección longitudinal de las mismas. Dicha 
dirección está dominada por las fibras de carbono (las cuales presentan un buen comportamiento frente a altas temperaturas); sin embargo, al incrementar la temperatura, puesto que la transmisión de tensiones en el interior de la barra depende de la adherencia matriz/fibra, su resistencia mecánica en dicha dirección disminuye considerablemente.

Kumahara et al., (1993), investigaron la influencia de altas temperaturas en la resistencia a tracción de las barras de CFRP y GFRP, observando que:

“las barras de CFRP y GFRP presentan una reducción de su resistencia a tracción alrededor de 0 a $20 \%$ de su resistencia inicial, ante la exposición prolongada a una temperatura de $250^{\circ} \mathrm{C}$ ".

Otras propiedades en mayor medida directamente afectadas por la transferencia de tensiones a través de la resina polimérica, tales como el comportamiento a flexión y cortante, se reducen significativamente a una temperatura cercana a la $T_{g}$ (Wang y Evans, 1995).

Micelli y Nanni, (2004), realizaron una investigación sobre la influencia de diferentes gradientes de temperaturas (de -18 a $49{ }^{\circ} \mathrm{C}$ ), humedad relativa, radiación U.V y ciclos hielo/deshielo ${ }^{11}$, en el comportamiento mecánico de distintos tipos de barras de CFRP y GFRP, observando que:

"Las barras de CFRP no presentan disminución alguna de sus propiedades mecánicas, tanto de resistencia a tracción como resistencia a cortante transversal, frente a los ensayos de envejecimiento acelerado realizados en el presente estudio".

\footnotetext{
${ }^{11}$ Las barras de CFRP se sometieron a un ensayo de envejecimiento acelerado que consistía en los siguientes ciclos ambientales: inicialmente se realizaban 50 ciclos de hielo/deshielo con un rango de temperaturas de $4^{\circ} \mathrm{C}$ a $-18^{\circ} \mathrm{C}$, simulando la acción invernal, posteriormente se sometían a ciclos de altas temperaturas $\left(16 \mathrm{a} 49^{\circ} \mathrm{C}\right)$ simulando el verano, estos ciclos se alternaban con ciclos de alta humedad relativa (variando la H.R de 60 a $100 \%$ ) y durante los ciclos de H.R y alta temperatura se exponían las barra a radiación U.V. El total de ciclos de envejecimiento son: 200 de hielo/deshielo, 480 de H.R y 600 de alta temperatura.
} 
Kollár y Springer et al., (2003), afirman que debido a las condiciones de diseño de las estructuras de hormigón armado con barras de CFRP, estás deben de poseer una $\mathrm{T}_{\mathrm{g}}$ mayor a $30{ }^{\circ} \mathrm{C}$ de la temperatura máxima ante la cual va a ser expuesta dicha estructura.

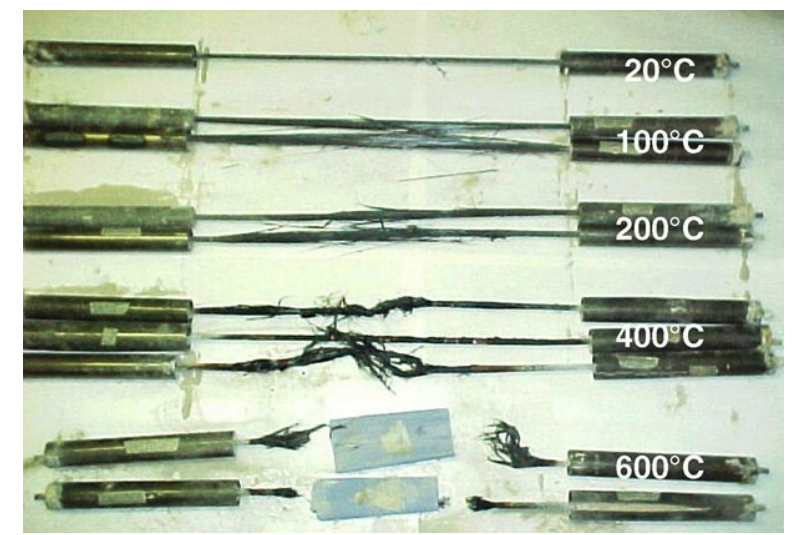

Fig. 2.27. Ensayos de resistencia a tracción sometidas a diferentes temperaturas en barras de CFRP. Wang et al., 2007.

Y. C. Wang et al., (2007), realizaron una investigación sobre el comportamiento mecánico de barras de CFRP sometidas a altas temperaturas. Se realizaron ensayos de tracción en barras de CFRP a 20, 100, 200, 400 y $600{ }^{\circ} \mathrm{C}$ (Fig 2.27), analizando la disminución de la resistencia a tracción y del módulo elástico (Tabla 2.15). El estudio concluye con la siguiente afirmación (Fig. 2.28);

\section{"las barras de FRP presentan una temperatura crítica de uso alrededor de $350^{\circ} \mathrm{C}$ ".}

En la Fig. 2.29 se muestra la comparativa de los resultados obtenidos por Saafi, (2002), en su investigación sobre el comportamiento mecánico de diferentes barras de FRP, y los obtenidos por Wang et al., (2007). En esta gráfica se puede comprobar que los resultados obtenidos por Saafi, (2002), para barras de CFRP presentan un mejor comportamiento a tracción hasta una temperatura de $330{ }^{\circ} \mathrm{C}$; sin embargo, a temperaturas mayores muestra una mayor reducción 
de su resistencia a tracción. En cuanto al comportamiento del módulo elástico, su respuesta es similar en las dos investigaciones.

\begin{tabular}{cccc}
\hline Diámetro $(\mathrm{mm})$ & Temp. $\left({ }^{\circ} \mathrm{C}\right)$ & Resist. $(\mathrm{MPa})$ & Módulo $(\mathrm{GPa})$ \\
\hline \multirow{6}{*}{90} & 1.260 & 121,41 \\
& 20 & 1.280 & 126,50 \\
& 100 & 993,21 & 105,10 \\
& 100 & $1.283,62$ & 132,73 \\
& 200 & 702,79 & 107,51 \\
& 200 & 763,05 & 107,27 \\
& 400 & 371,73 & - \\
& 400 & 387,70 & - \\
600 & 132,86 & 44,68 \\
\hline
\end{tabular}

Tabla 2.15. Resultados de ensayos de resistencia a tracción a diferentes rangos de temperaturas en barras de CFRP. Adaptado de Wang et al., 2007.
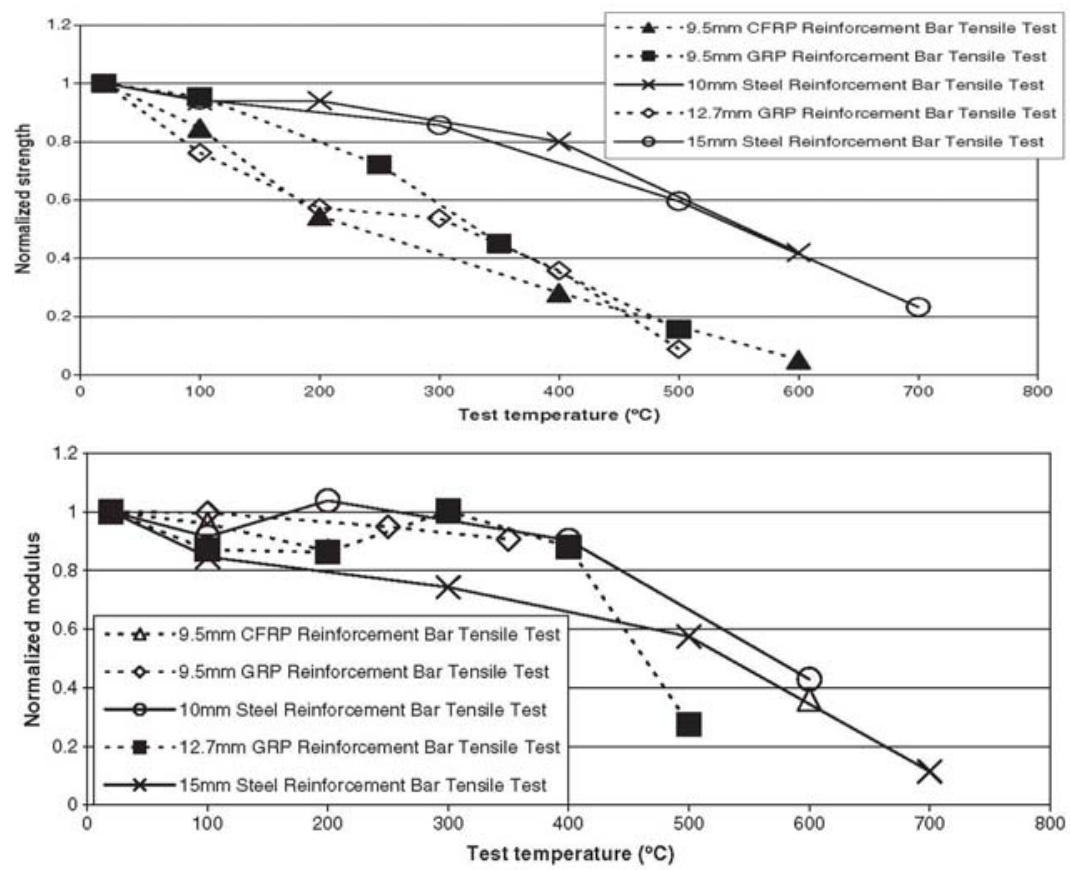

Fig. 2.28. Comportamiento mecánico frente a diferentes temperaturas en barras de CFRP, GFRP y acero. Wang et al., 2007.

La exposición prolongada de las barras de CFRP, en presencia de ambientes con temperaturas cercanas o inferiores a $0{ }^{\circ} \mathrm{C}$ produce los siguientes cambios mecánicos: aumento del módulo elástico y de las resistencias a tracción, 
flexión, fatiga y fluencia; Y a su vez, produce una disminución de la deformación, de la resistencia a impacto, a fractura y compresión, y del C.T.E de las barras de CFRP. Estos cambios mecánicos se deben a la estabilidad molecular proporcionada por las bajas temperaturas (véase Capitulo 2, apart. 2.2.1) (Allred, 1984; GangaRao et al., 1995; Kelen, 1983).
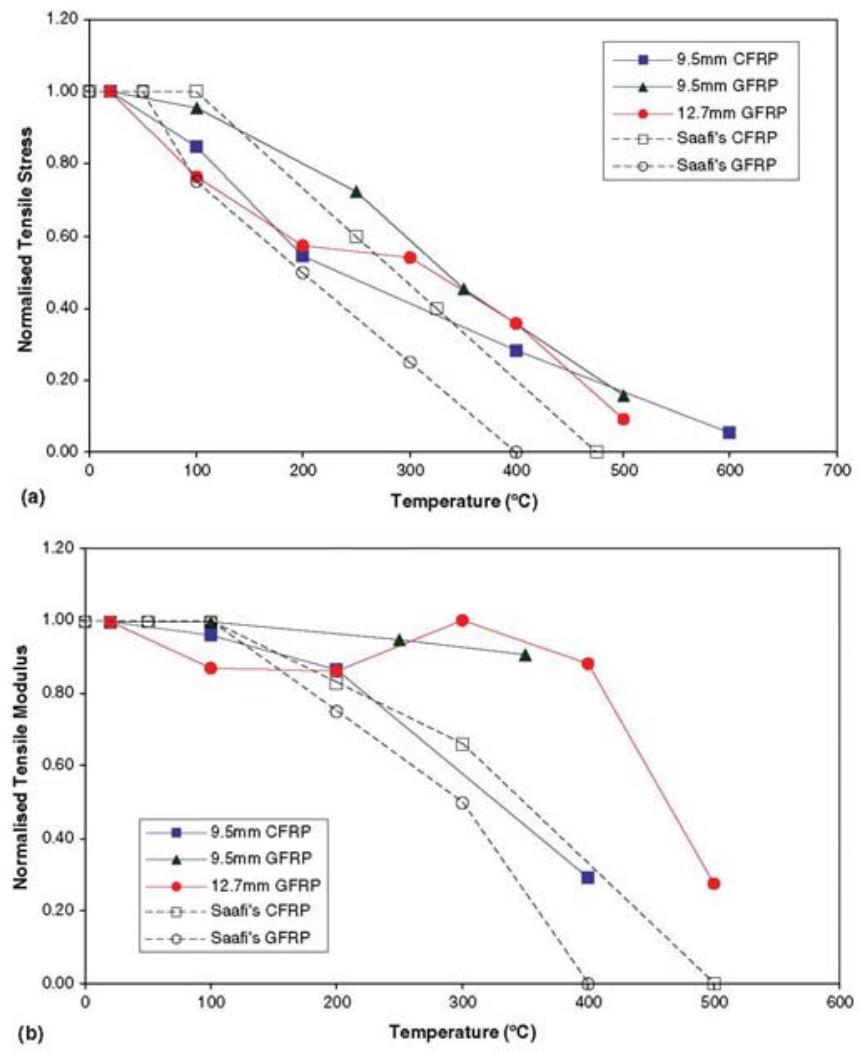

Fig. 2.29. Comparación del comportamiento mecánico a) R. Tracción, b) Módulo elástico frente a diferentes temperaturas en barras de CFRP, GFRP y acero. Y. C. Wang et al., 2007. 


\subsubsection{Comportamiento a Largo Plazo de las Barras de CFRP}

En este apartado se analiza el comportamiento a largo plazo de las barras de CFRP. Este viene definido por el comportamiento ante fatiga, relajación y fluencia. Del mismo modo que en el comportamiento frente a durabilidad, el grado de reducción de las propiedades mecánicas de las barras depende del tipo de fibra de carbono y matriz polimérica, interfaz fibra-matriz, condiciones de curado y control de calidad durante el proceso de fabricación.

\subsubsection{Comportamiento a Fatiga}

La resistencia a la fatiga de un material se define como:

“la fracción de la resistencia estática que un material puede soportar reiteradamente para un número de ciclos dado” (ACI 215R-74, revisada 1992), o también como:

“Ia degradación de la integridad de un material ${ }^{12}$ como resultado de la aplicación de un gran número de ciclos de carga” (FIB Task Group 9.3, 2007,

La resistencia a la fatiga de las barras de CFRP depende del comportamiento de los materiales constituyentes y de las propiedades de la interfaz fibra/matriz (FIB, 2007). A su vez, está influenciada principalmente por el régimen de carga, tipo de tensiones, carga histórica, propiedades del material ${ }^{13}$ y por las condiciones ambientales (ACI 215R-74, revisada 1992). La relación entre la

\footnotetext{
${ }^{12}$ La integridad de un material se mide normalmente en términos de propiedades mecánicas, como son la resistencia y rigidez.

${ }^{13}$ A parte de las propiedades físicas, mecánicas y químicas de los materiales constituyentes de la barra de CFRP, las diferentes geometrías superficiales (corrugado, hélice pegada, arenado, etc..) pueden introducir concentración de tensiones (la concentración de tensiones genera tensiones multiaxiales e incrementan los mecanismos de rotura de la matriz polimérica) que modifiquen el comportamiento global a fatiga de la barra de CFRP.
} 
resistencia a la fatiga y la resistencia estática " ${ }^{14} S$ ", y el logaritmo del número de ciclos de rotura " $N$ ", se denomina comúnmente curva $S-N$ (Fig. 2.30), esta muestra la comparación de la influencia de diversos regímenes de carga. Si la curva $S-N$ se muestra paralela al eje de abscisas, el nivel de tensión correspondiente se denomina límite de fatiga o de endurecimiento. Las tensiones aplicadas inferiores al límite de fatiga corresponden a una vida infinita del material bajo condiciones de cargas repetidas. La vida de fatiga, corresponde al número de ciclos hasta la rotura del material.

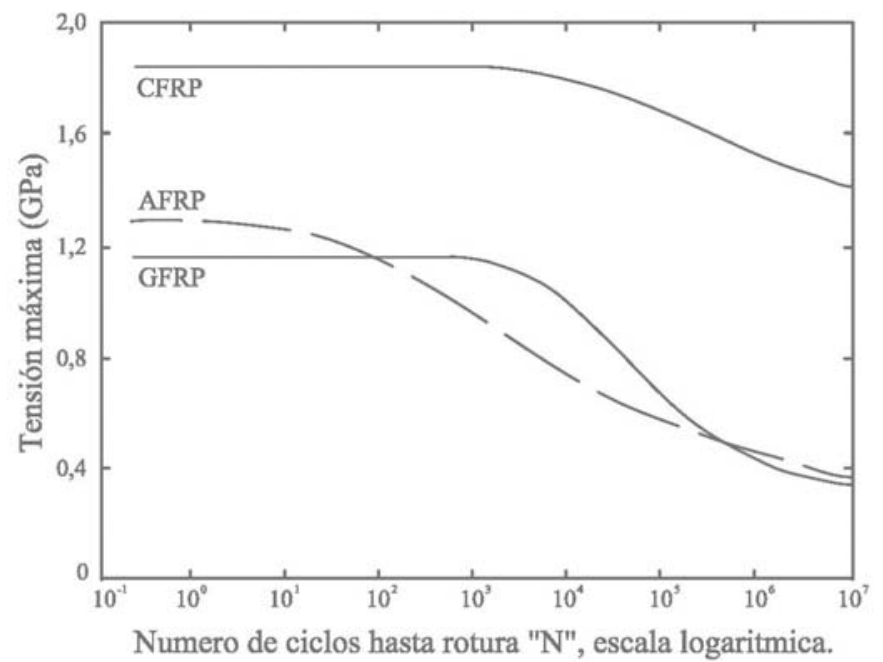

Fig. 2.30. Resistencia a fatiga de diferentes tipos de barras de FRP. Adaptado de Curtis, 1989.

El deterioro por fatiga del composite de CFRP es complejo, debido a los diferentes mecanismos que se producen en el mismo: fisuración de la matriz polimérica, rotura de las fibras de carbono, inicio y aumento de la deslaminación del composite (Schaff, 2001).

\footnotetext{
${ }^{14}$ La resistencia estática se define como la máxima resistencia de un material en condiciones de carga estática. A su vez, la carga estática se define como la carga que permanece constante con el tiempo o aplicada lentamente y monotónicamente con el tiempo.
} 
Las barras de CFRP poseen un comportamiento a la fatiga esencialmente lineal hasta rotura, y además, no presentan casi deterioro de la barra hasta la rotura $^{15}$ (Hollaway, 1993).

De todos los tipos de barras de FRP empleadas como armado del hormigón (CFRP, GFRP y AFRP), las barras de CFRP son las que presentan un mejor comportamiento a fatiga (ACI 440.1R-06). La reducción media de la resistencia a tracción por década logarítmica debido a fatiga en la curva $S-N$, es alrededor de 5 a $8 \%$ de la resistencia estática inicial. A 1 millón de ciclos la resistencia a fatiga es entre 50 a $70 \%$ de la resistencia estática inicial (Curtis, 1989; FIB, 2007).

La resistencia a fatiga de las barras de CFRP disminuye cuando la temperatura aumenta de $20^{\circ} \mathrm{C}$ a $40^{\circ} \mathrm{C}$. A su vez, el límite de endurecimiento es inversamente proporcional a la frecuencia de la carga. Para frecuencias de carga cíclica entre 0,5 a $8 \mathrm{~Hz}$ se corresponde una temperatura elevada de la barra de CFRP debido al efecto de la fricción. Por lo tanto, el límite de endurecimiento a una frecuencia de $1 \mathrm{~Hz}$ puede ser mayor a 10 veces que a una frecuencia de $5 \mathrm{~Hz}$ (Adimi et al., 1998).

Rahman y Kimgsley, (1996) y Saadatmanesh y Tannous, (1999a), afirman que la disminución del límite de endurecimiento depende de las tensiones principales (carga permanente) y de la relación entre tensiones " $S$ " (carga dinámica dividida por la carga estática; es decir, el valor mínimo entre el valor máximo). Grandes tensiones permanentes o una relación de tensiones " $S$ " pequeña pueden producir una reducción del límite de endurecimiento.

\footnotetext{
${ }^{15}$ Este comportamiento se debe a la localización de las tensiones en la matriz polimérica y en la interfase matriz/fibra. Las tensiones producen en la matriz polimérica, al cabo de " $n$ " ciclos de carga, splitting longitudinal a las fibras y daños en la interfaz, lo que conlleva una rotura frágil.
} 


\subsubsection{Comportamiento a Relajación}

El fenómeno de relajación se define como:

"la disminución de la tensión resistente de un material bajo una condición de alargamiento permanente", (Hollaway, 1993), y también se define en barras de FRP como:

"el porcentaje de disminución de la resistencia inicial en función del tiempo, bajo una temperatura, y alargamiento constantes, que experimenta la barra de FRP” (Machida A., 1993),

La relajación de las barras de CFRP, puede calcularse mediante el cociente entre, la carga final resistida a tracción en el ensayo de relajación, y la carga resistida por dicho material inicialmente. Este valor representa el porcentaje de disminución de la carga inicial a tracción, tras un periodo de tiempo determinado, y un nivel de tensión y alargamiento especifico.

Ando et al., (1997), investigaron el comportamiento a relajación de barras de CFRP (12,5 mm) y AFRP (15 mm), bajo diferentes temperaturas (20 ${ }^{\circ} \mathrm{C}, 40{ }^{\circ} \mathrm{C}$ y $60{ }^{\circ} \mathrm{C}$ ) y durante un periodo de tiempo de más de 3.000 horas. Las tasas de relajación calculadas para periodos de vida de la estructura de 50 años fueron del orden de 2,0 a 3,1\% en barras de CFRP, y 18,4 a 23,4\% en barras de AFRP.

Balazs y Borosnyoi, (2001), tras un periodo de ensayo de 1.000 horas, obtuvieron tasas de relajación inferiores a Ando et al., (1997) del orden de 1,8 a 2,0\% en barras de GFRP, 0,5 a 1,0\% en barras de CFRP y finalmente de 5 a $8 \%$ en barras de AFRP; en la misma investigación calcularon la tasa de relajación para un periodo de 50 años, obteniendo una reducción de la tensión inicial a tracción de 4 a 14\% en barras de GFRP, 2,0 a 10,0\% en barras de CFRP y de 11,0 a $25 \%$ en barras de AFRP. 
Por lo tanto, las barras de CFRP poseen un buen comportamiento frente a relajación. A su vez, puesto que este tipo de barras presenta una elevada resistencia a tracción, la disminución de la resistencia a tracción inicial no será tan acusada como en otro tipo de barras de FRP (GFRP y AFRP).

\subsubsection{Comportamiento a Fluencia}

La fluencia de un material se define como:

“Ia deformación progresiva de un material en función del tiempo, bajo carga permanente" (Ferry, 1980). La rotura por fluencia de una barra de CFRP, se define como:

“Ia tensión de tracción que produce la rotura de la barra de FRP, tras un periodo de tiempo determinado, después de aplicar la carga permanente” (F. Ceroni et al., 2006)

Es necesario distinguir entre los dos resultados principales originados por el fenómeno de fluencia: el primero, es el alargamiento máximo de fluencia bajo carga permanente, y el segundo, es la resistencia máxima a tracción a largo plazo bajo carga permanente. Ambos, pueden producirse repentinamente después de un tiempo determinado denominado "límite de endurecimiento" ${ }^{16 "}$ (Balazs y Borosnyoi, 2001).

La rotura por fluencia en las barras de CFRP depende del tipo de fibra de carbono y resina polimérica empleada, dirección de la tensión aplicada ${ }^{17}$, orientación y porcentaje de fibras. El límite de endurecimiento disminuye cuando aumenta la relación entre la carga permanente y la resistencia a corto plazo (ACI 440.1R-06; FIB, 2007).

\footnotetext{
${ }^{16}$ La denominación de límite de endurecimiento se refiere al periodo de tiempo máximo a partir del cual se produce la rotura de la barra de CFRP debido a carga permanente.

${ }^{17}$ Si la tensión se aplica transversalmente al eje principal de la barra, el volumen de fibra será menor y el comportamiento a fluencia dependerá en gran medida de la matriz polimérica.
} 
En la Fig. 2.31 se muestra una gráfica típica del comportamiento a fluencia de las barras de FRP (relación entre el alargamiento desarrollado por la barra de FRP y el tiempo transcurrido). Atendiendo a la gráfica antes citada, el comportamiento a fluencia de las barras de FRP se divide en diferentes etapas: inicialmente, se produce un alargamiento elástico motivado por la puesta en carga de la barra; seguidamente, en la primera etapa, se produce un aumento rápido del alargamiento en un corto periodo de tiempo debido a la fluencia; posteriormente, la etapa segunda, se caracteriza por el mantenimiento de la deformación de la etapa primera durante un largo periodo de tiempo (etapa de servicio); y por último, en la tercera etapa, aumentarán los alargamientos considerablemente en un corto periodo de tiempo, produciendo la rotura de la barra (esta etapa se produce debido a un alto nivel tensional).

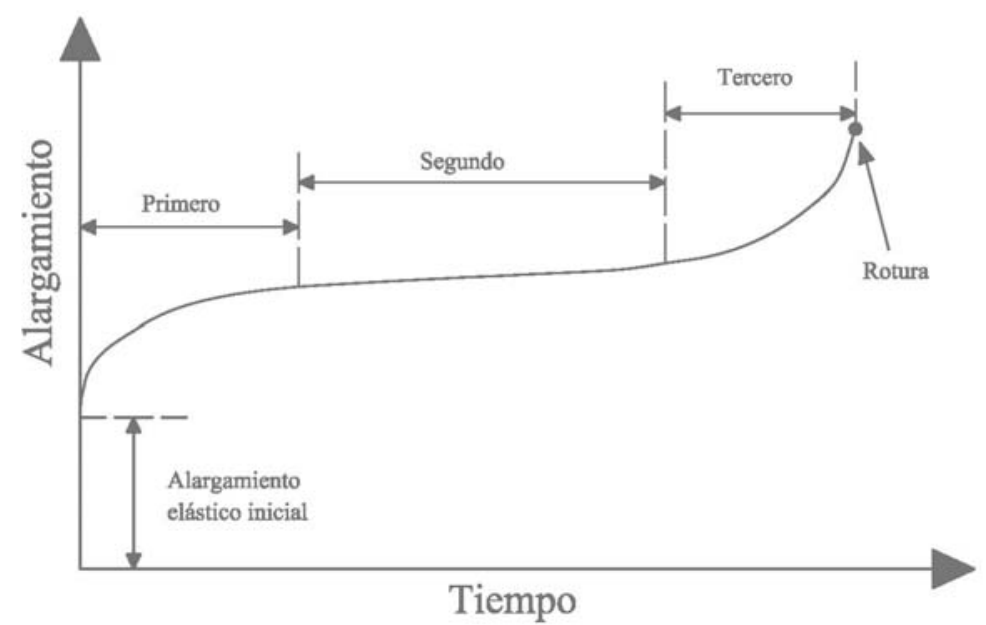

Fig. 2.31. Grafica tipo del comportamiento a fluencia de las barras de FRP. Adaptado de FIB, 2007.

Budelman y Rostasy, (1993), con base en la investigación realizada sobre el comportamiento a fluencia de las barras de FRP, observaron que:

"la rotura por fluencia de las barras de FRP no se produce si la tensión permanente es menor del 60\% de la resistencia a corto plazo". 
Por lo tanto, el fenómeno de fluencia en los elementos de hormigón armado con barras de CFRP en condiciones de servicio es muy poco probable que produzca la rotura del armado por fluencia.

Yamaguchi et al., (1997), en su investigación sobre el comportamiento a fluencia de las barras de GFRP, AFRP y CFRP (barras lisas de 6mm diámetro), obtuvieron una relación lineal entre la resistencia a rotura por fluencia y el logaritmo del tiempo, para intervalos de 100 horas. Mediante la extrapolación de los resultados anteriores a un periodo de 500.000 horas (57 años), los resultados sobre la relación entre la resistencia a rotura por fluencia y la resistencia a corto plazo de las barras de GFRP, AFRP y CFRP fueron, 0,29, 0,47, 0,93 respectivamente.

Ando et al., (1997), con base en la investigación realizada sobre el cálculo del límite de endurecimiento en barras de CFRP y AFRP (barras de diámetros 5 a $15 \mathrm{~mm}$, geometría superficial deformada, y matriz polimérica de resina de epoxi) observaron que el porcentaje de retención de la resistencia a corto plazo tras un periodo de 50 años fue de $79 \%$ en barras de CFRP y de $66 \%$ en barras de AFRP.

La empresa productora de barras de FRP, Tokyo Rope, (2000), realizó una investigación sobre la resistencia a fluencia de sus barras de CFRP (barras deformadas de diámetro $12,5 \mathrm{~mm}$ en un ambiente estándar), obteniendo un resultado de resistencia a fluencia para un periodo de tiempo de 100 años, de $85 \%$ de la resistencia inicial de la barra de CFRP.

Las barras de CFRP presentan un excelente comportamiento a deformación debido al fenómeno de fluencia. Se puede afirmar que el alargamiento de fluencia de las barras de CFRP (en condiciones estándar de temperatura y humedad) permanece por debajo de $0,01 \%$ tras un periodo de 3.000 horas, y un nivel tensional del $80 \%$ de la resistencia a tracción de la barra. 
Mientras que las barras de AFRP y GFRP presentan valores mucho mayores: 0,15 a 1,0\% en barras de AFRP y 0,3 a 1,0\% en barras de GFRP (Gerritse, 1993; Machida, 1993; Piggot, 1980; Saadatmanesh et al., 1999a,b).

\subsubsection{Coeficientes de Seguridad}

Las diferentes normativas de diseño de estructuras de hormigón armado con barras de CFRP (ACI 440.1R-06; JSCE 1997(b); CAN/CSA-S806-02; FIB Task Group 9.3, 2007; CNR-DT 203/2006; IStructE, 1999) abordan la durabilidad y el comportamiento a largo plazo de las barras mediante coeficientes de seguridad, minorando la resistencia de las armaduras de CFRP en las condiciones de diseño de la estructura. Los coeficientes de seguridad son estipulados por las normativas con base en los resultados de los experimentos llevados a cabo por diferentes investigadores. Puesto que este tipo de armado es novedoso en el sector de la construcción, los diferentes países que han desarrollado normativa de diseño de estructuras de hormigón armado con barras de CFRP todavía no han estandarizado los ensayos característicos de cada tipo de condición ambiental y comportamiento a largo plazo.

Los coeficientes de seguridad empleados en el diseño de las estructuras de hormigón armado con barras de CFRP por las diferentes normativas (ACI 440.1R-06; JSCE 1997(b); CAN/CSA-S806-02; FIB Task Group 9.3, 2007; CNR-DT 203/2006; IStructE, 1999) son los siguientes:

I.- La normativa ACI 440.1R-06 emplea diferentes coeficientes de minoración de resistencia del armado de CFRP, dependiendo del estado límite que se compruebe. En la comprobación del estado límite último emplea un coeficiente de minoración denominado $\mathrm{C}_{\mathrm{E}}$, que varía dependiendo del tipo de exposición ambiental de la estructura (Tabla 2.16). A su vez, también minora la resistencia de la sección mediante un coeficiente $\Phi$, que depende del 
comportamiento a fatiga del armado de CFRP. Cuando se diseña la sección por rotura del armado, $\Phi=0,55$, para rotura por compresión del hormigón, $\Phi=0,65$.

\begin{tabular}{ccc} 
Tipo de condición ambiental & Tipo de Fibra & $C_{E}$ \\
\hline \multirow{3}{*}{ Ambiente no agresivo } & Carbono & 1,0 \\
\cline { 2 - 2 } & Vidrio & 0,8 \\
\cline { 2 - 2 } & 0,9 \\
\cline { 2 - 2 } & Aramida & 0,9 \\
Hormigón en contacto con el & 0,7 \\
\cline { 2 - 2 } terreno y agua. & Carbono & 0,8 \\
\cline { 2 - 3 }
\end{tabular}

Tabla 2.16. Coeficiente de minoración de resistencia del armado $C_{E}$. Adaptado de ACI 440.1R-06.

Frente al estado límite de servicio plantea una minoración de la resistencia de la armadura, para tener en cuenta la fluencia (Tabla 2.17). A su vez, la deformación diferida bajo cargas permanentes, proporcionalmente, es un $40 \%$ menor que en secciones armadas con barras de acero (Brown, 1997), por lo tanto se introduce un coeficiente 0,6 , en el cálculo de la deformación a largo plazo $^{18}$ (Ec. 2.9).

$$
\Delta_{(c p+s h)}=0^{\prime} 6 \xi\left(\Delta_{i}\right)_{s u s} \quad \text { (mm) }
$$

\begin{tabular}{cccc}
\hline Tipo de Fibra & GFRP & AFRP & CFRP \\
\hline Límite de rotura por fluencia, $f_{f, s}$ & $0,20 f_{f u}$ & $0,30 f_{f u}$ & $0,55 f_{f u}$ \\
\hline
\end{tabular}

Tabla 2.17. Tensión límite del armado debida a fluencia. Adaptado de ACI 440.1R-06.

II.- La normativa JSCE 1997(b) emplea los siguientes coeficientes de minoración (Tabla 2.18).

\footnotetext{
${ }^{18}$ La fluencia del hormigón conduce a una reducción efectiva, tanto en secciones armadas con acero como armadas con CFRP, de la rigidez a flexión $E_{c} I$ de la sección del elemento de hormigón armado, lo que produce un incremento de la deformación a largo plazo. La fluencia del hormigón produce un incremento de la profundidad del eje neutro de la sección debido a la reducción del módulo elástico del hormigón. Esta reducción produce un incremento de la sección de hormigón (aumento del eje neutro). Al mismo tiempo y debido al método de diseño a flexión frente a estados límite último (rotura por aplastamiento del hormigón, lo que supone que la cuantía de armado necesaria para la sección sea mayor a la cuantía de armado en condiciones de equilibrio de fuerzas y momentos), la sección se encuentra sobrearmada, lo que supone una menor reducción de la rigidez del armado y por consiguiente del elemento de hormigón armado.
} 


\begin{tabular}{cc}
\hline Tipo de coeficiente & \multicolumn{1}{c}{ Valor coeficiente } \\
\hline $\begin{array}{c}\text { Minoración por condición ambiental (E.L.U) } \\
\text { Minoración de la resistencia por condición } \\
\text { ambiental (E.L.S) }\end{array}$ & $\begin{array}{c}\text { Reducción de la resistencia de la barra de } \\
\text { CFRP. } \frac{1}{\gamma_{f m}}=0,87\end{array}$ \\
$\begin{array}{c}\text { Tensión límite para cargas permanentes } \\
\text { (E.L.S) }\end{array}$ & 0,87 \\
\hline
\end{tabular}

Tabla 2.18. Coeficientes de minoración (por condiciones ambientales y por comportamiento a largo plazo) de la resistencia del armado. Adaptado de JSCE 1997(b).

III.- La normativa CAN/CSA-S806-02 emplea los coeficientes de minoración mostrados en la Tabla 2.19.

\begin{tabular}{cc}
\hline Tipo de coeficiente & Valor coeficiente \\
\hline $\begin{array}{cc}\text { Minoración por condición ambiental (E.L.U) } \\
\text { Minoración de la resistencia por condición } \\
\text { ambiental (E.L.S) }\end{array}$ & $\begin{array}{c}\text { Reducción de la resistencia de la barra de } \\
\text { CFRP: } 0,75\end{array}$ \\
$\begin{array}{cc}F_{E . L S}: \text { Tensión máxima bajo carga de } \\
\text { Tensión límite para cargas permanentes } \\
\text { (E.L.S) }\end{array}$ & $\begin{array}{c}\text { servicio: } 0,65 \\
0,65-0,70\end{array}$ \\
\hline
\end{tabular}

Tabla 2.19. Coeficientes de minoración (por condiciones ambientales y por comportamiento a largo plazo) de la resistencia del armado. Adaptado de CAN/CSA-S806-02.

IV.- La normativa FIB Task Group 9.3, 2007 introduce el comportamiento de durabilidad y a largo plazo de las barras de CFRP minorando la resistencia del armado a tracción, mediante una serie de coeficientes que tienen en cuenta el comportamiento a largo plazo (fatiga y fluencia) y durabilidad en diferentes condiciones ambientales. El cálculo de la resistencia de diseño de las barras de CFRP se realiza mediante la Ec. 2.10.

$f_{f d}=\frac{f_{f k 0}}{\mathrm{y}_{e n v, t} \cdot \gamma_{f}} \quad(M P a)$

$f_{f k 0}$. Es la resistencia a tracción garantizada por el fabricante a corto plazo, en $M P a$.

$\gamma_{f}$. Es un coeficiente de minoración que vale 1,25 para armados de CFRP. 
$\eta_{e n v, t}$. Es un coeficiente de minoración de resistencias que tiene en cuenta el grado de agresividad ambiental, el cual se calcula mediante la Ec. (2.11).

$$
\mathrm{\eta}_{e n v, t}=\frac{f_{f k 1000 h}}{\frac{f_{f k 0}}{\left(\frac{100-R_{10}}{100}\right)^{n}}}
$$

Donde, $f_{f k 1000 h}$, es la resistencia a tracción a 1000 horas. $R_{10}$, es la reducción estándar de la resistencia a tracción en tanto por ciento por década logarítmica debido a la influencia de las diferentes condiciones ambientales. Estos datos deben ser facilitados por cada fabricante de barras de CFRP. El coeficiente $n$, es la suma de cuatro coeficientes que dependen del comportamiento frente a la humedad, temperatura, vida de servicio y de las características de la barra. Se calcula mediante la Ec. (2.12).

$$
n=n_{m o}+n_{T}+n_{S L}+n_{d}
$$

Donde $n_{m o}$, es el coeficiente de minoración que depende del grado de humedad (Tabla 2.20). $n_{T}$, es el coeficiente que depende de la temperatura media anual (Tabla 2.21). $n_{S L}$, incorpora el comportamiento frente a vida de servicio del armado (Tabla 2.22). $n_{d}$, es un coeficiente corrector dependiente del diámetro de la barra (Tabla 2.23).

\begin{tabular}{ccc} 
Seco (H.R aprox. 50\%) & $\begin{array}{c}\text { Húmedo (el } \\
\text { hormigón no está } \\
\text { constantemente en } \\
\text { contacto con el agua, } \\
\text { H.R aprox. 80\%) }\end{array}$ & $\begin{array}{c}\text { Húmedo saturado (el } \\
\text { hormigón está } \\
\text { constantemente en } \\
\text { contacto con el agua, } \\
\text { H.R aprox. 100\%) }\end{array}$ \\
\hline-1 & 0 & 1
\end{tabular}

Tabla 2.20. Coeficiente ambiental $n_{m o}$. Adaptado de FIB Task Group 9.3, 2007. 


\begin{tabular}{cccc}
\hline$<5^{\circ} \mathrm{C}$ & $5^{\circ} \mathrm{C}<\mathrm{T}^{\mathrm{a}}<15^{\circ} \mathrm{C}$ & $15^{\circ} \mathrm{C}<\mathrm{T}^{\mathrm{a}}<25^{\circ} \mathrm{C}$ & $25^{\circ} \mathrm{C}<\mathrm{T}^{\mathrm{a}}<35^{\circ} \mathrm{C}$ \\
\hline$-0,5$ & 0 & 0,5 & 1 \\
\hline
\end{tabular}

Tabla 2.21. Coeficiente ambiental $n_{T}$. Adaptado de FIB Task Group 9.3, 2007 .

\begin{tabular}{cccc}
\hline $\begin{array}{c}\text { Vida de servicio } \\
\text { de 1año. }\end{array}$ & $\begin{array}{c}\text { Vida de servicio } \\
\text { de } 10 \text { años. }\end{array}$ & $\begin{array}{c}\text { Vida de servicio } \\
\text { de } 50 \text { años. }\end{array}$ & $\begin{array}{c}\text { Vida de servicio de } \\
100 \text { años. }\end{array}$ \\
\hline 1 & 2 & 2,7 & 3
\end{tabular}

Tabla 2.22. Coeficiente ambiental $n_{S L}$. Adaptado de FIB Task Group 9.3, 2007 .

\begin{tabular}{cccc}
\hline $\begin{array}{c}\varnothing \text { barra obra mayor } \\
\text { al Ø barra ensayado }\end{array}$ & $\varnothing$ barras iguales & $\begin{array}{c}\varnothing \text { barra obra } 75 \% \text { de la } \\
\text { barra ensayada. }\end{array}$ & $\begin{array}{c}\varnothing \text { barra } 50 \% \text { de la } \\
\text { barra ensayada }\end{array}$ \\
\hline 0 & 0 & $0,5(0,3)$ & $1(0,6)$ \\
\hline
\end{tabular}

Tabla 2.23. Coeficiente corrector $n_{d}$. Adaptado de FIB Task Group 9.3, 2007 .

V.- La normativa CNR-DT 203/2006 emplea coeficientes de minoración de la resistencia a tracción del armado de CFRP debido al comportamiento de las barras de CFRP frente a diferentes condiciones de durabilidad y comportamiento a largo plazo. El cálculo de la resistencia de diseño de las barra de CFRP lo realiza mediante la Ec. 2.13 .

$X_{d}=\mathrm{\eta} \frac{X_{k}}{\gamma_{m}}$

Donde $X_{k}$ es el valor de la resistencia característica de la barra de CFRP. $\gamma_{m}$, es un coeficiente parcial de seguridad del material cuyo valor frente a diseño de estado límite último y estados límite de servicio es 1,5 y 1,0 respectivamente. $\eta$, es un coeficiente de seguridad (mediante este coeficiente se introduce el comportamiento de las barras de CFRP a largo plazo y de durabilidad) calculado mediante la Ec. 2.14.

$\mathrm{y}=\mathrm{y}_{a} \cdot \mathrm{y}_{l}$


$\eta_{a}$ es coeficiente de minoración ambiental (Tabla 2.24), y $\eta_{l}$ es el coeficiente de minoración respecto el comportamiento a largo plazo (Tabla $2.25)$.

\begin{tabular}{ccc}
\hline Condiciones de exposición & Tipo de fibra/matriz & $\mathrm{\eta}_{a}$ \\
\hline \multirow{2}{*}{ Hormigón no expuesto a la } & Carbono/viniléster o epoxi & 1,0 \\
humedad & Vidrio/Viniléster o epoxi & 0,8 \\
& Aramida/Viniléster o epoxi & 0,9 \\
\hline \multirow{2}{*}{ Hormigón en contacto con la } & Carbono/viniléster o epoxi & 0,9 \\
humedad & Vidrio/Viniléster o epoxi & 0,7 \\
& Aramida/Viniléster o epoxi & 0,8
\end{tabular}

Tabla 2.24. Coeficiente corrector $n_{a}$. Adaptado de CNR-DT 203/2006 (Tabla 4-1).

\begin{tabular}{|c|c|c|c|}
\hline Tipo de carga & Tipo de fibra/matriz & $\begin{array}{c}\mathrm{y}_{l} \\
\text { (E.L.S) }\end{array}$ & $\begin{array}{c}\mathrm{\eta}_{l} \\
\text { (E.L.U) }\end{array}$ \\
\hline \multirow{3}{*}{$\begin{array}{l}\text { Cargas cuasi permanentes y } \\
\text { cargas cíclicas (fluencia, } \\
\text { relajación y fatiga) }\end{array}$} & Vidrio/Viniléster o epoxi & 0,3 & 1,0 \\
\hline & Aramida/Viniléster o epoxi & 0,5 & 1,0 \\
\hline & Carbono/viniléster o epoxi & 0,9 & 1,0 \\
\hline
\end{tabular}

Tabla 2.25. Coeficiente corrector $n_{l}$. Adaptado de CNR-DT 203/2006 (Tabla 4-2).

VI.- La normativa IStructE 1999, emplea los siguientes coeficientes de minoración de la resistencia de las barras de CFRP, mostrados en la Tabla 2.26.

\begin{tabular}{cc}
\hline Tipo de coeficiente & \multicolumn{1}{c}{ Valor coeficiente } \\
\hline $\begin{array}{c}\text { Minoración por deterioración ambiental } \\
\text { (E.L.U) }\end{array}$ & $\begin{array}{c}\text { Reducción de la resistencia de la barra de } \\
\text { CFRP. } \frac{1}{\gamma_{f m}}=0,87 \\
\begin{array}{c}\text { Minoración debido a tensión permanente } \\
\text { (E.L.U) }\end{array}\end{array}$ \\
$\begin{array}{c}\text { Coeficiente de minoración de resistencia } \\
\text { debido a acciones ambientales (E.L.S) }\end{array}$ & 0,60 \\
\hline
\end{tabular}

Tabla 2.26. Coeficientes de minoración (por condiciones ambientales y por comportamiento a largo plazo) de la resistencia del armado. Adaptado de IstructE, 1999.

Del análisis de los diferentes coeficientes de minoración de la resistencia de las barras de CFRP podemos extraer las siguientes conclusiones: de todos los tipos de armados de FRP, las barras de CFRP son las que presentan mejor comportamiento a durabilidad y a largo plazo; las normativas de diseño

${ }^{19}$ Sólo se permite el empleo de matrices de poliéster en estructuras de carácter temporal, $n_{a}=1$ 
revisadas con posterioridad establecen coeficientes ambientales de minoración de resistencia entorno a 0,9-1,0, menores que las normas editadas con anterioridad; en cuanto al comportamiento a largo plazo las diferentes normativas establecen coeficientes de minoración de la resistencia de las barras de CFRP alrededor de 0,50-0,70.

\subsection{Adherencia Armadura-Hormigón}

El comportamiento de los elementos de hormigón armado con barras de CFRP depende de las propiedades del hormigón, de las barras de CFRP y de la adherencia barra/hormigón. Es por ello, que el comportamiento de la estructura frente a estados límite último (flexión ${ }^{20}$, cortante, torsión, etc..) dependerá en gran medida de la capacidad de desarrollar una adecuada adherencia entre la barra y el hormigón. A su vez, el comportamiento en condiciones de servicio, tales como deformación y fisuración, dependerá de la rigidez a tracción ${ }^{21}$. En el caso de estructuras de hormigón pretensado, su comportamiento, ya sea en condiciones de estado límite último o servicio, también depende de la adherencia barra/hormigón. Por lo tanto, el comportamiento global de las estructuras de hormigón armado con barras de CFRP, está condicionado por el comportamiento adherente entre las barras de CFRP y el hormigón, y este comportamiento adherente a lo largo de la vida de servicio de la estructura, será un índice razonable de predicción del comportamiento a largo plazo de la estructura.

Los mecanismos de transferencia de tensiones por adherencia, entre las barras de CFRP y el hormigón han sido investigados por diferentes autores (ADulajian et al., 1996; A. Katz et al., 1999, 2000; Alunno et al., 1995; A. Weber,

\footnotetext{
${ }^{20}$ La resistencia a flexión de un elemento depende de la resistencia a compresión del hormigón y de la resistencia a tracción del armado (depende de la compatibilidad de alargamientos entre la barra y el hormigón que la rodea). A su vez, la tensión de tracción resistida por la barra (produce la tensión de adherencia) debe equilibrarse con la fuerza de compresión realizada por el hormigón.

${ }^{21}$ La rigidez a tracción depende de la adherencia entre la barra y el hormigón. Está será mayor cuanto más rápidamente se realice el anclaje del armado en el hormigón (Véase, Calavera, INTEMAC apart. 47.6.1 y 48.5).
} 
2005; Al-Zaharani, 1995,1996; Al-Zaharani et al., 1996, 1999; Bakis et al., 1983; Benmokrane et al., 1996, 2002; Boothby et al., 1995; B. Tighiouart et al., 1998; Challal y Benmokrane, 1993; Cox y Herrmann, 1992, 2000; Cosenza et al., 1995, 1996; Daniali, 1992; E. Cosenza et al., 1996, 1997; Ehsani et al., 1993; E. Bakis et al., 2007; Faoro, 1992; Foccachi et al., 2000; Freimanis et al,. 1998; Guo y Cox, 1999; Hattori et al., 1995; Honma y Maruyama, 1989; Ito et al., 1989; J. F. Davalos et al., 2008; J. V. Cox y K. Bergeron, 2003; Kanakubo et al., 1993; Laralde y Rodriguez 1993; Malvar, 1992, 1994, 1995, 2003; M. Baena et al., 2009; M. Antonieta et al., 2005, 2007; Makitani et al., 1993; Mashima y Iwamoto, 1993; Massoud E. et al., 2009; Nanni et al., 1995, 2001; Noghabai, 1995; R. Thamrin y T. Kaku, 2007; R. Okelo y R. L. Yuan, 2005; R. Masmoudi et al., 2005; Rossetti et al. ,1995; Soroushian et al., 1991; Tepfers et al., 1992, 1997, 2001, 2003; Tighiourt et al., 1998; Tomosawa y Nakasuji, 1997; Vijay y GangaRao, 1999, 2001; Z. Achillides y K. Pilakoustas, 2004; Z. Wang et al., 2010). Basándose en los resultados experimentales, se deducen los siguientes parámetros de influencia sobre el comportamiento adherente: resistencia a tracción y a cortante de la barra de CFRP, resistencia a compresión del hormigón, diámetro y geometría superficial de la barra, presión de confinamiento, longitud de anclaje, espesor del recubrimiento, temperatura y posición de la barra.

La mayor parte de las normas de diseño de estructuras de hormigón armado con FRP han sido desarrolladas a partir de las guías de diseño de estructuras de hormigón armado con acero. Sin embargo, algunos estudios experimentales han demostrado que las propiedades del comportamiento físico y mecánico de las barras de FRP son cualitativamente y cuantitativamente diferentes al desarrollado por el armado de acero (véase, apart. 2.4 del presente estudio). Estas diferencias surgen debido a variaciones en las propiedades de los materiales, y por cambios en los mecanismos de interacción entre el hormigón y las barras de FRP. Sin embargo, los diferentes órganos o comités normativos han 
optado por métodos de diseño de estructuras con armado de FRP's, basados (mediante una aproximación racional) en métodos de diseño de estructuras con armado de acero. Por lo tanto, los métodos de cálculo de la tensión adherente media desarrollada entre el hormigón y las barras de CFRP (Malvar, B.E.P Modificado y C.M.R), están desarrollados a partir de los métodos empleados en elementos con armado de acero (B.E.P).

\subsubsection{Definición de Adherencia}

El diseño de elementos de hormigón armado con barras de acero y barras de CFRP está basado en diversas suposiciones, una de ellas, es la suposición de adherencia perfecta entre el hormigón y el armado, mediante la cual se asume que no se producen deslizamientos entre los dos materiales (es decir, actúan conjuntamente). Implícitamente también se supone la compatibilidad de deformaciones entre la barra y el hormigón circundante debido a tensiones de compresión o tracción. Por lo tanto, se asume que el hormigón genera tensiones rasantes de corte en la superficie de la barra. Este mecanismo de interacción denominado adherencia, proporciona la transferencia de tensiones del hormigón al armado.

La adherencia es un fenómeno que se produce en la interfaz entre el hormigón y el armado, y este fenómeno, es un conjunto complejo de:

- La adhesión entre el hormigón y el armado, debida a las acciones moleculares en la superficie de contacto.

- El rozamiento producido entre la barra y el hormigón.

- La resistencia al acuñamiento mecánico movilizada por el anclaje del hormigón y la geometría superficial de la barra.

A diferencia de las barras de acero (material isótropo, homogéneo y de comportamiento elastoplástico) la adherencia entre el hormigón y las barras de CFRP (composite anisótropo, heterogéneo, con un comportamiento elástico hasta la rotura y cuyo modo de rotura es frágil) depende de nuevos parámetros 
motivados por la diferencia de propiedades y comportamiento entre las barras de acero y CFRP (véase aparts. 2.5.2.2, y 2.5.4).

La tensión adherente entre el hormigón y el armado se define como:

"La fuerza local de corte horizontal (contigua a la superficie exterior de la barra) por área unitaria del perímetro de la barra” (Park y Paulay, 1980).

La tensión adherente se transmite desde la barra hasta el hormigón circundante a través de la interfaz barra/hormigón, y es la encargada de movilizar la resistencia del armado, resistiendo las tensiones de tracción. Esta se origina debido a una variación de la tensión en la barra. Por ello, la tensión de adherencia no existe, a menos que los esfuerzos entre dos secciones de la barra varíen. Se calcula mediante la Ec. 2.15.

$$
\tau=\frac{q}{\Sigma o} \quad(M P a)
$$

Donde, $q$, es la variación de la tensión de la barra por longitud unitaria; $\Sigma o$, es el área nominal de la superficie de la barra por longitud unitaria.

La tensión adherente en un elemento de hormigón armado, se produce en dos situaciones diferentes: la primera situación, se origina por tensiones de tracción en la barra (anclaje de barras o tirantes), y la segunda, se produce por la variación de la tensión a lo largo de la longitud de la barra, debido al momento flexionante producido en el elemento.

Para el cálculo de la longitud de anclaje de una barra, tanto para barras de CFRP como de acero, la tensión adherente producida entre la barra y el hormigón es el factor fundamental del cual dependerá el desarrollo de la longitud básica de anclaje, y por consiguiente la longitud neta de anclaje. Aunque, no es objeto de este estudio experimental el análisis de la longitud de anclaje de las barras en el hormigón, considero que se ha de establecer los 
conceptos principales de cálculo de la longitud neta de anclaje, para obtener una mejor visión global de este fenómeno de adherencia.

La instrucción de hormigón estructural "EHE-08", en esta última edición, introduce un nuevo modo de cálculo de la longitud neta de anclaje, basado en el método que establece el Model Code 1990 "MC-1990" y el EuroCódigo 2 " $E C$-2". A su vez, continua con el anterior método de cálculo de la longitud neta de anclaje basado en el cumplimento de las características de adherencia de la barra certificadas en base a los resultados de ensayos de adherencia de barras en vigas (internacionalmente conocido con el nombre de "beam-test") en el territorio nacional, según el Anejo C de la normativa UNE EN 10080. La longitud básica de anclaje se calcula mediante la Ec. 2.16 (según MC-1990 y EC-2), o según las Ecs. 2.17 y 2.18 (según, Anejo C de UNE EN 10080).

$$
\begin{array}{ll}
l_{b}=\frac{\emptyset \cdot f_{y d}}{4 \cdot \tau_{b d}} & (\mathrm{~mm}) \\
l_{b I}=m \cdot \emptyset^{2} \nless \frac{f_{y k}}{20} \emptyset & (\mathrm{mm}) \\
l_{b I I}=1,4 \cdot m \cdot \emptyset^{2} \nless \frac{f_{y k}}{20} \emptyset & (\mathrm{mm})
\end{array}
$$

Donde: $\emptyset$, es el diámetro de la barra, en mm. $f_{y d}$, es el límite elástico del armado. $\tau_{b d}$, es la tensión adherente media. $m$, es un coeficiente en función del tipo de acero y hormigón empleado (Tabla 69.5.1.2.a, EHE-08). $f_{y k}$, es el límite elástico garantizado del acero, en MPa. Los subíndices I y II, corresponden a la posición de adherencia de la barra.

La longitud neta de anclaje se calcula a partir de la longitud básica de anclaje, con la aplicación de diversos coeficientes correctores de adherencia englobados en el coeficiente $\beta$ (Ec. 2.19). 
$l_{b, \text { neta }}=l_{b} \cdot \beta \frac{\sigma_{s d}}{f_{y d}} \cong l_{b} \cdot \beta \frac{A_{s}}{A_{s, \text { real }}} \quad(\mathrm{mm})$

Sustituyendo

$$
l_{b, n e t a}=\frac{\emptyset \cdot f_{y d}}{4 \cdot \tau_{b d}} \cdot \beta \frac{\sigma_{s d}}{f_{y d}} \quad(\mathrm{~mm})
$$

Donde: $\sigma_{s d}$, es la tensión de trabajo de la armadura, en hipótesis de carga más desfavorable, en la sección desde la que se determinará la longitud de anclaje. $A_{s}$, es la armadura necesaria por cálculo en la sección a partir de la cual se ancla la armadura. $A_{s, r e a l}$, es la armadura realmentene existente en la sección a partir de la cual se ancla la armadura. $\beta$, es el coeficiente de reducción definido en la tabla 69.5.1.2.b de la EHE-08.

Por lo tanto, a la hora del cálculo de la longitud de anclaje (longitud de anclaje neta) del armado en un elemento estructural, la tensión adherente media entre la barra y el hormigón es el factor fundamental, pues de esta dependerá una mayor o menor longitud de anclaje.

\subsubsection{Adherencia entre el Hormigón y el Armado de Acero}

En un intento de obtener una visión general, caracterizada y analítica del comportamiento adherente entre las barras de CFRP y el hormigón, y puesto que, como ya he comentado anteriormente (veasé apart. 2.5), los métodos de cálculo desarrollados por las diferentes normativas de diseño de estructuras de hormigón armado con barras de CFRP están basados en los métodos de diseño de estructuras de hormigón armado con acero. En este apartado se procede al análisis y desarrollo del fenómeno de adherencia entre las barras de acero y el hormigón.

\subsubsection{Comportamiento Adherente Hormigón/Armado Acero}

Con base en las investigaciones realizadas en los últimos 30 años por los diferentes investigadores, sobre la adherencia entre el hormigón y las barras de 
acero ante una fuerza de pullout ${ }^{22}$, se han caracterizado cuatro estadios o etapas de adherencia diferentes (Fig. 2.32):

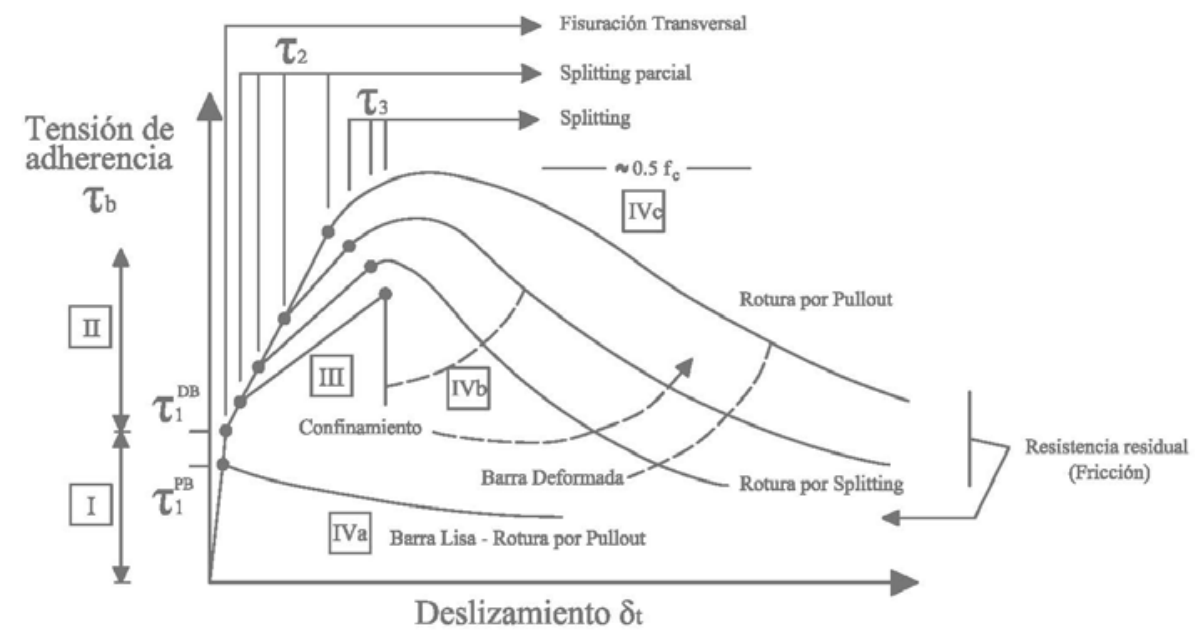

Fig. 2.32. Comportamiento adherente entre el hormigón y las barras de acero. Gráfica de tensión de adherencia media/desplazamiento. Adaptado de FIB, 2000.

Estadio 1 (hormigón sin fisurar): Este estadio es el correspondiente a pequeños valores de tensión adherente, $\tau \leq \tau_{1}=(0,2-0,8) f_{c t}$. La adherencia barra/hormigón se produce por adhesión química, por lo tanto no se producen desplazamientos, a la vez que se producen tensiones localizadas cerca de los extremos de las corrugas (Fig. 2.33, el comportamiento de dichas tensiones será elástico).

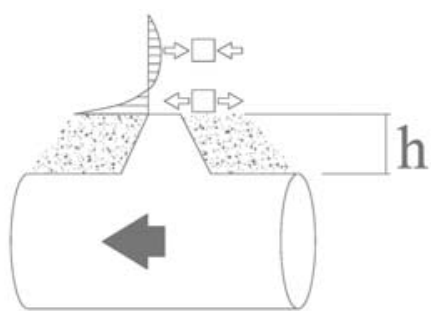

Fig. 2.33. Tensión en el extremo de la corruga de una barra de acero (fase elástica). Adaptado de FIB Task Group 2.5, 2000.

22 Existe una dificultad notable para traducir vocablos sajones de modos de rotura en este país. Así, la denominación pullout no ha sido traducida al castellano en esta tesis doctoral. La traducción al castellano vendría definida por la palabra estiramiento. 
La adhesión química barra/hormigón se produce junto a la interacción micromecánica (adhesión física) asociada a la rugosidad microscópica de la superficie del acero, pero en el cómputo global de la tensión desarrollada por el armado, la adhesión química y física no desarrollan un papel importante. Estos pequeños valores de tensión por adherencia química y física, se pueden observar en los armados de acero lisos, donde la adhesión química y micromecánica finaliza rápidamente seguida del desplazamiento de las barras (final del estado IVa, al cual le afecta en gran medida el confinamiento). Cabe destacar, que el deslizamiento relativo de la barra se mide respecto al hormigón, este consta de dos partes: el deslizamiento relativo producido en la interfaz, y las deformaciones por cortante en el hormigón (Fig. 2.34). Por lo tanto, incluso cuando no se produce deslizamiento de la barra, se origina un cierto deslizamiento debido a los alargamientos localizados cerca la interfaz. Todo ello explica el deslizamiento del estadio I.

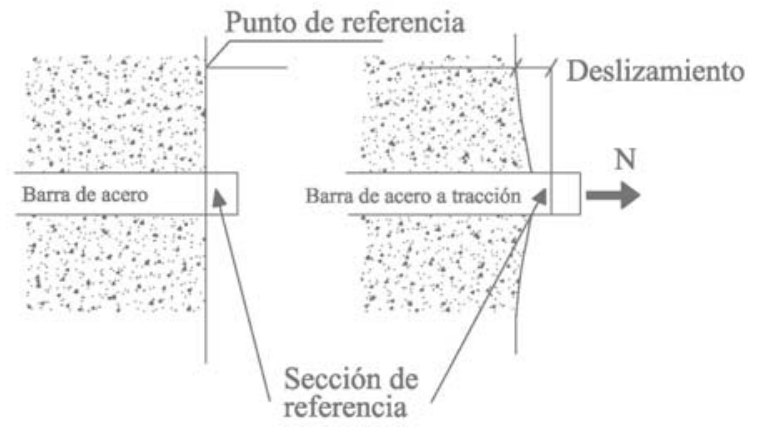

Fig. 2.34. Desplazamiento relativo de la barra de acero respecto al hormigón. Adaptado de FIB Task Group 2.5, 2000.

Estadio II (fisuración inicial): Este estadio se produce debido a valores elevados de la tensión adherente ( $\tau>\tau_{1}$ ); por lo tanto, la adhesión química es pequeña para mantener el nivel de tensión adherente necesario para que el elemento no fisure. En las barras corrugadas las corrugas originan tensiones de acuñamiento mecánico en el hormigón, cuya resultante es "p" "Fig. 2.35.a), que producen microfisuras transversales en los extremos de las corrugas y permiten 
el deslizamiento de la barra. En este estado el acuñamiento mecánico de las corrugas no es muy elevado, por lo tanto, no se produce splitting ${ }^{23}$ en el hormigón (Fig. 2.35b).

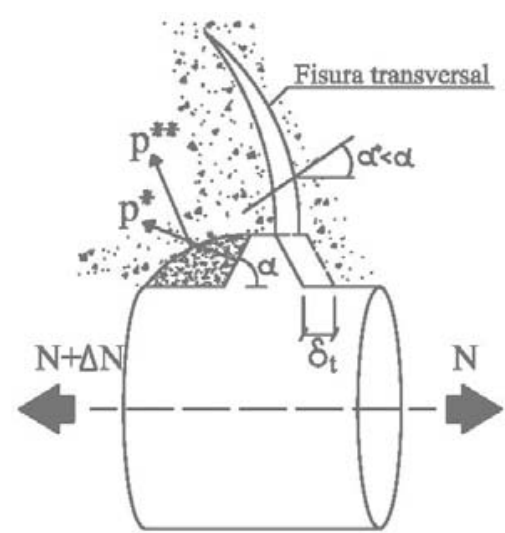

(a)

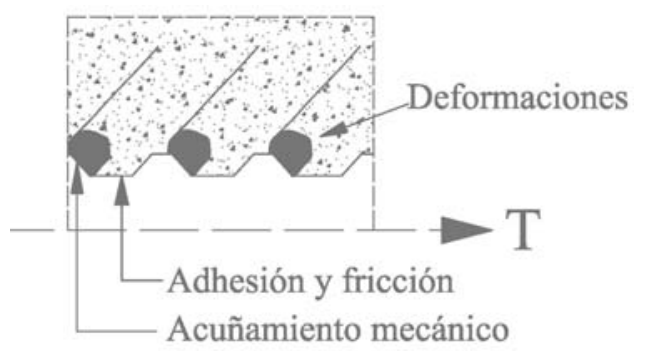

(b)

Fig. 2.35. a) Deslizamiento barra/hormigón y acción de acuñamiento b) Adherencia por adhesión química, fricción y acuñamiento (los tres mecanismos no se producen al mismo tiempo). Adaptado de FIB, 2000.

Estadio III: Este estadio se produce debido a elevados niveles de tensión adherente $\tau>\tau=(1-3) f_{c t}$. Las fisuras por splitting (Fig. 2.36) se propagan radialmente debido a la tensión producida por el acunamiento mecánico de las corrugas. En este caso, debido a que el hormigón en frente de la corruga se encuentra aplastado, la resultante de la tensión ejercida por la corruga "p" se desplaza hacia la zona inmediata de hormigón sin aplastar, obteniendo una nueva resultante $" \mathrm{p}^{* *}$ (Fig. 2.35a). En el caso de pequeñas cuantías de armado transversal, este estado finaliza tan pronto como el splitting del hormigón alcance la superficie exterior del mismo (Fig. 2.32, splitting “ $\tau_{3}$ ”). Del mismo modo, dependiendo de la cuantía de armado transversal se producirá una rotura menos repentina (Fig. 2.32, Estado IVb, rotura por splitting). Sin embargo, en anclajes relativamente largos con tensiones de confinamiento moderadas, la

\footnotetext{
${ }^{23}$ Debido a la dificultad notable para traducir vocablos sajones de modos de rotura en este país, la denominación splitting no ha sido traducida al castellano en esta tesis doctoral. La traducción literaria al castellano se define como la división o rotura del hormigón por fisuración longitudinal.
} 
rotura por pullout normalmente se produce por splitting del hormigón, manteniendo una presencia simultánea de diferentes estadios a lo largo de la longitud de anclaje. Por lo tanto, la rotura por adherencia puede ser definida como "rotura por pullout debida a splitting inducido". En el caso de una elevada cuantía de armado transversal o grandes espesores de recubrimiento, el splitting del hormigón es neutralizado por la acción de confinamiento que estos producen, y únicamente se producirán fisuras por splitting en el interior del elemento alrededor de la barra (Fig. 3.32, Estado IVc, rotura por pullout).

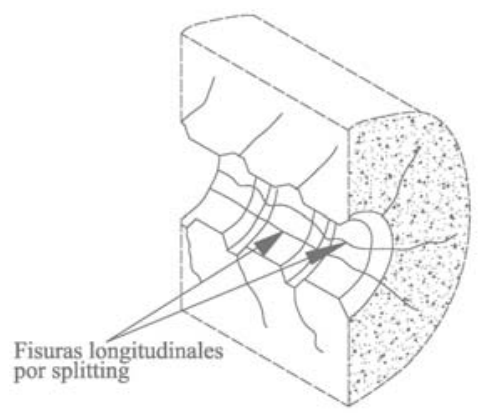

Fig. 2.36. Fisuras transversales longitudinales por splitting. Adaptado de FIB, 2000.

Estadio IVa: En barras lisas este estado es inmediatamente posterior a la pérdida de la adherencia por adhesión (Fig. 2.32). La transferencia de la tensión se debe al efecto del rozamiento (fricción) y en gran medida se encuentra condicionada por la presión transversal. La retracción del hormigón y la rugosidad de la barra favorecen la fricción.

Estadio IVb: En el caso de barras corrugadas confinadas mediante cuantías bajas o medias de armado transversal, las fisuras longitudinales (fisuras por splitting) se desplazan hacia fuera a través del recubrimiento o del espacio entre barras, produciendo una rotura por adherencia repentina. Al contrario, si se dispone de suficiente armado transversal (confina el armado) se puede asegurar una adherencia eficiente a pesar del splitting del hormigón. En este estado, se alcanzan valores elevados de tensión adherente, alrededor de $(1 / 3 a 1 / 2) f_{c}$, 
seguidos de grandes desplazamientos producidos por el aplastamiento del hormigón enfrente de las corrugas (Figs. 2.37a,b,c).

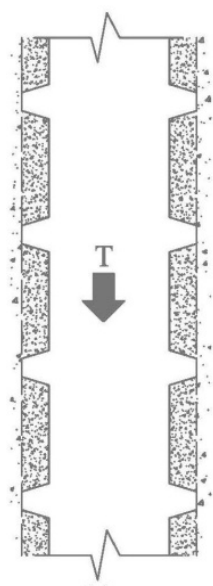

(a)

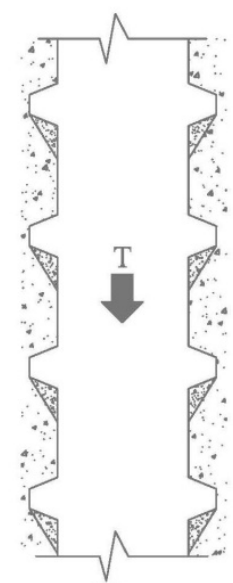

(b)

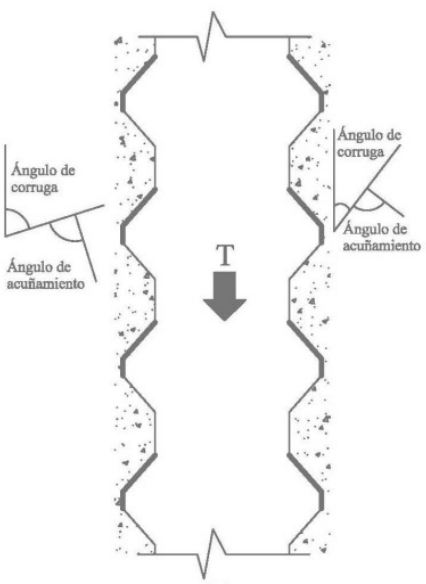

(c)

Fig. 2.37. Modos de rotura por adherencia a) Pullout, b) Pullout debido a splitting inducido acompañado de aplastamiento y cortadura del hormigón enfrente de las corrugas, c) Splitting acompañado de desplazamiento de las corrugas. Adaptado de FIB, 2000.

Estadio $I V c$ : En el caso de barras deformadas confinadas con elevadas cuantías de armado transversal, el modo de rotura se producirá por pullout, ya que el confinamiento evita la rotura por splitting. Dependiendo de la resistencia a corte del hormigón entre las corrugas, el mecanismo de adherencia cambiará de acuñamiento mecánico a fricción (Figs. 2.37a,b,c).

\subsubsection{Factores que Influyen en el Comportamiento Adherente Hormigón/Armado Acero}

En este apartado se analizan los diferentes factores que influyen en el comportamiento adherente entre el hormigón y las barras de acero. Es importante tener un conocimiento globalizado de estos factores, ya que así, posteriormente podrán ser comparados con los parámetros que influyen en la adherencia entre las barras de CFRP y el hormigón.

Los principales factores que influyen en el comportamiento adherente entre el hormigón y las barras de acero, son los que se analizan a continuación: 
I. La resistencia del hormigón es un factor que influye notablemente en el comportamiento adherente entre el armado y el hormigón, puesto que el fenómeno de adherencia depende en gran medida del acuñamiento mecánico producido entre las corrugas de la barra de acero y el hormigón situado enfrente de las mismas. Por lo tanto, la tensión ejercida por las corrugas contra el hormigón producirá esfuerzos de corte y axiales de compresión en el mismo, por lo que, el desarrollo de la adherencia entre ambos dependerá del comportamiento multiaxial del hormigón, tanto a esfuerzos de compresión como a esfuerzos de tracción.

Martin y Noakowski, (1981), con base al estudio realizado, obtuvieron la siguiente conclusión: el incremento de la resistencia a compresión del hormigón produce un aumento de la tensión adherente, siendo el comportamiento casi lineal (Fig. 2.38). Por lo tanto, la longitud de anclaje de las barras de acero es inversamente proporcional al cuadrado de la resistencia a compresión del hormigón.

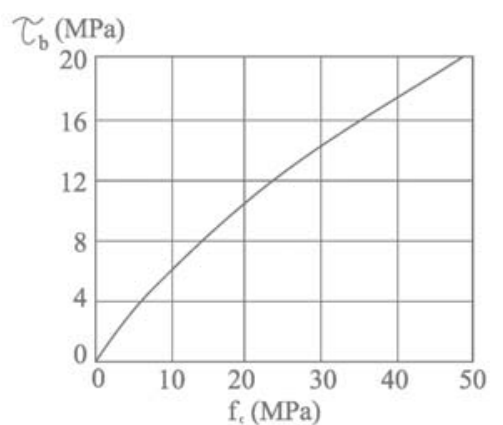

Fig. 2.38. Relación entre la tensión adherente y la resistencia a compresión del hormigón. Adaptado de Martin y Noakowski, (1981).

La resistencia a tracción del hormigón controla la fisuración del elemento, por lo tanto, el aumento de la resistencia a tracción del hormigón produce una menor fisuración, y por consiguiente, mayores valores de tensión adherente entre el hormigón y la barra de acero. 
II. El diámetro de la armadura. La fuerza que es capaz de desarrollar una barra es proporcional a su área, y por tanto, al cuadrado de su diámetro. Su superficie adherente es proporcional a su diámetro. La adherencia será, por tanto, más crítica cuanto mayor sea el diámetro de la barra.

III. El límite elástico del acero. A mayor límite elástico, mayores tensiones podrán ser desarrolladas por la barra.

IV. La geometría superficial. De todas las armaduras empleadas, las más lisas son los alambres trefilados lisos, cuyo empleo está prohibido en elementos de hormigón armado, salvo que no se anclen por adherencia. Es el caso, por ejemplo, de las mallas electrosoldadas lisas y de las armaduras básicas de celosías de viguetas para forjados, cuyo anclaje se realiza mecánicamente (presencia de armadura transversal).

Las barras de acero con geometría superficial corrugada desarrollan su adherencia fundamentalmente por acuñamiento mecánico. Por lo tanto, el diseño de la geometría superficial de la barra es un factor muy importante a la hora de desarrollar la acción de acuñamiento. Rehm, (1968), con base al estudio realizado, concluyó que la mayor tensión adherente, se obtiene mediante una relación entre altura y distancia entre corrugas (del armado) del orden de 0,065. Generalmente, con valores entre 0,05 a 0,10 , se obtienen buenos resultados de tensión adherente, ante rotura por splitting, y fisuración. Si la relación entre la altura y distancia entre corrugas es mayor a 0,15 (es decir, las corrugas son altas y se encuentran distanciadas estrechamente) el modo de rotura por adherencia se producirá por pullout, puesto que las tensiones generadas entre corrugas aplastarán el hormigón.

V. La posición de la barra influye en el desarrollo de la tensión adherente de dos modos diferentes. El primero, está relacionado con la dirección de vertido del hormigón. Martin y Noakowski, (1981), con base a la 
investigación realizada, afirman que la dirección de vertido del hormigón influye en la adherencia entre el hormigón y la barra de acero, puesto que, vertiendo el hormigón perpendicular a la barra se desarrollan valores inferiores de tensión adherente respecto al vertido paralelo al eje de la barra (Figs. 2.39.a,b). El segundo modo, está relacionado con el vertido del hormigón perpendicular a la posición de la barra, sin embargo, en este caso se desarrolla una menor adherencia en barras situadas en una posición más alejada respecto al canto inferior del elemento que en barras situadas cerca del mismo. Los dos modos anteriormente mencionados se deben a la formación de una mezcla débil de cemento, aire y agua que se deposita bajo las corrugas inferiores de la barra, afectando en mayor medida en barras situadas en la parte alta del elemento y con una dirección de vertido de hormigón perpendicular al eje de la misma.

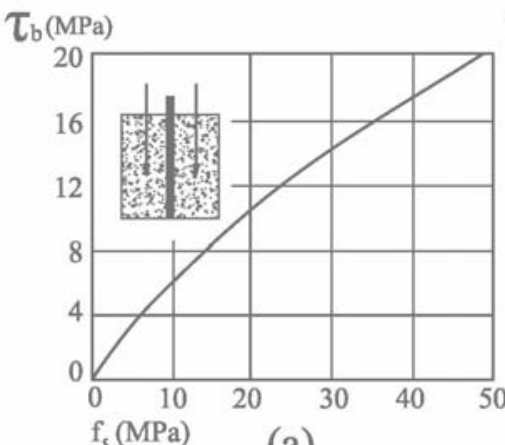

(a)

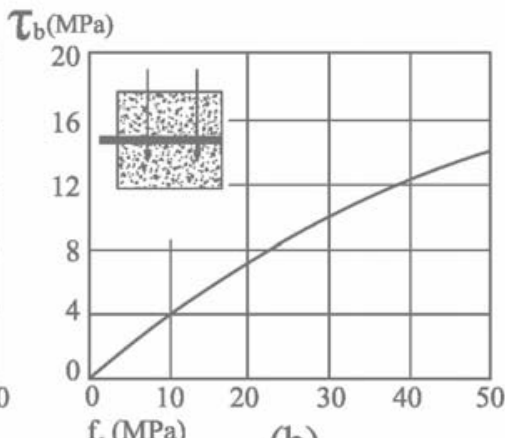

(b)

Fig. 2.39. Tensión adherente a) Vertido paralelo al eje del armado, b) Vertido perpendicular al eje del armado. Adaptado de Martin y Noakowski, (1981).

VI. El confinamiento del elemento mejora el comportamiento frente a rotura de adherencia por splitting, controla el ancho de las fisuras e incrementa la tensión adherente. El confinamiento del elemento se puede desarrollar por tres modos diferentes:

- Recubrimiento de hormigón. El incremento del recubrimiento de hormigón que rodea a la barra proporciona un mejor comportamiento frente a la rotura de adherencia por splitting, puesto que al aumentar la sección de 
hormigón, se incrementa el confinamiento de la barra, y aumenta la resistencia frente a fisuras inducidas por tracciones radiales (Fig. 2.40).

- El armado transversal, confiere un mejor comportamiento frente a rotura de adherencia por splitting, puesto que, el armado transversal soporta parte de las tensiones radiales inducidas por la barra de acero en el hormigón, controlando la fisuración por tracciones radiales del hormigón, y controlando el espesor de las fisuras y asegurando una rotura por adherencia más dúctil.

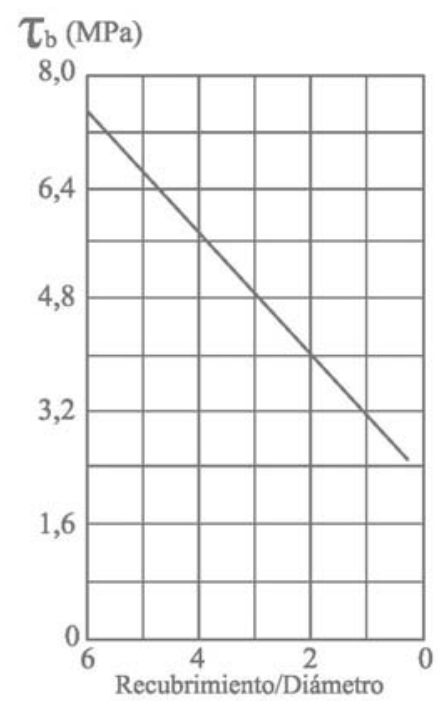

Fig. 2.40. Efecto del confinamiento en la resistencia de adherencia. Adaptado de Park y Paulay, (1978).

- Cargas exteriores. 


\subsubsection{Adherencia entre el Hormigón y el Armado de CFRP}

El comportamiento adherente entre las barras de CFRP y el hormigón ha sido investigado a lo largo de los últimos años. Es difícil establecer un comportamiento adherente común para todos los diferentes tipos de barras de CFRP, puesto que a día de hoy, todavía no se ha estandarizado por parte de las diferentes entidades normalizadoras (en cada país o región) una tipología de barra de CFRP, lo cual, conduce a diferentes comportamientos adherentes, y por consiguiente, a distintos mecanismos adherentes principales (Fig. 2.41).

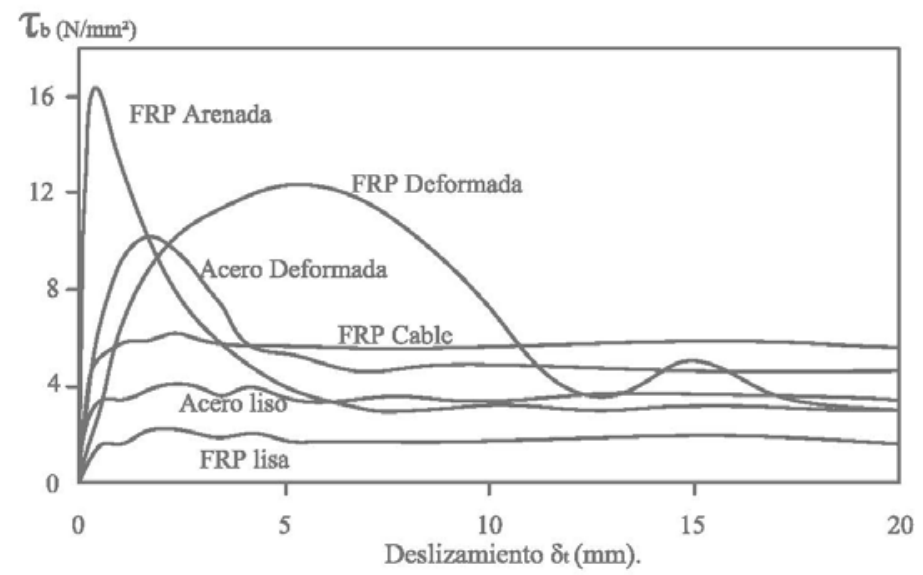

Fig. 2.41. Comportamiento de adherencia de los diferentes tipos de barras de FRP y acero. Balázs y Borosnyói, 2002.

Para establecer un comportamiento adherente representativo de cada tipología de barra de CFRP, se ha realizado el análisis del mismo, de acuerdo a la clasificación mostrada en la Fig. 2.42.

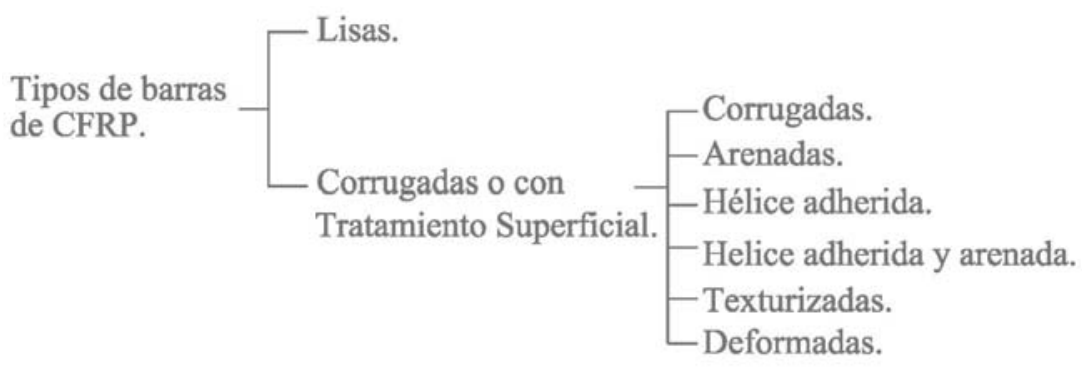

Fig. 2.42. Clasificación de tipos de barras de CFRP, según su geometría superficial. 
En este apartado, se desarrolla el comportamiento adherente entre los dos tipos principales de barras de CFRP, barras lisas y corrugadas o con tratamiento superficial, y el hormigón. Normativas como FIB Task Group 2.5, (2000), establecen una clasificación análoga a la realizada en la presente tesis doctoral (véase clasificación expuesta en Fig. 2.42).

2.5.3.1. Comportamiento Adherente entre Hormigón y Barra Lisa de CFRP

Con base en los estudios realizados en los últimos años por diferentes investigadores sobre el comportamiento adherente entre las barras de CFRP lisas y el hormigón, mediante el ensayo de pullout, se han caracterizado dos fases (Fig. 2.43):

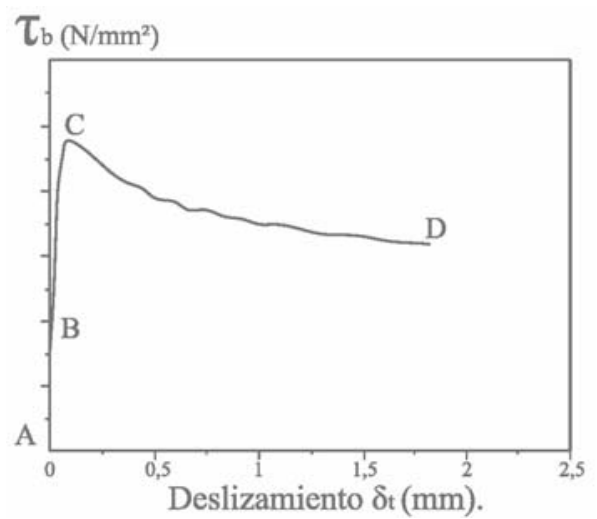

Fig. 2.43. Comportamiento adherente entre las barras de CFRP lisas y el hormigón.

Fase I (Tramo AB): Las barras de CFRP lisas presentan inicialmente un comportamiento adherente dominado por el mecanismo de adhesión química entre la superficie de la barra y el hormigón circundante, el cual, desaparece rápidamente. Durante esta fase no se produce deslizamiento de la barra.

Fase II (Tramo BC-CD): Posteriormente al mecanismo de adhesión, se produce el mecanismo de fricción, debido al microacuñamiento producido entre la rugosidad superficial de la barra y el hormigón (Katz, 1999). En este tramo 
BC la barra comienza a deslizar debido al incremento de la tensión de adherencia, alcanzándose la tensión adherente máxima entre la barra lisa de CFRP y el hormigón. Kanakubo et al., (1993), obtuvieron una tensión adherente máxima en barras de CFRP lisas de diámetro $8 \mathrm{~mm}$ y una longitud de anclaje de 15 diámetros de 0,84 MPa. Nanni et al., (1995), obtuvieron una tensión adherente máxima de 2,5 MPa, en barras de diámetros 6 y $12 \mathrm{~mm}$ y una longitud de anclaje de $63 \mathrm{~mm}$ (10D y 5D, respectivamente). Katz, (1999), obtuvo una tensión adherente máxima menor a $1 \mathrm{MPa}$, en barras de diámetro $12 \mathrm{~mm}$ y una longitud de anclaje de 5 diámetros. Por lo tanto, según las investigaciones realizadas las barras lisas de CFRP desarrollan una adherencia muy reducida (Fig. 2.44).

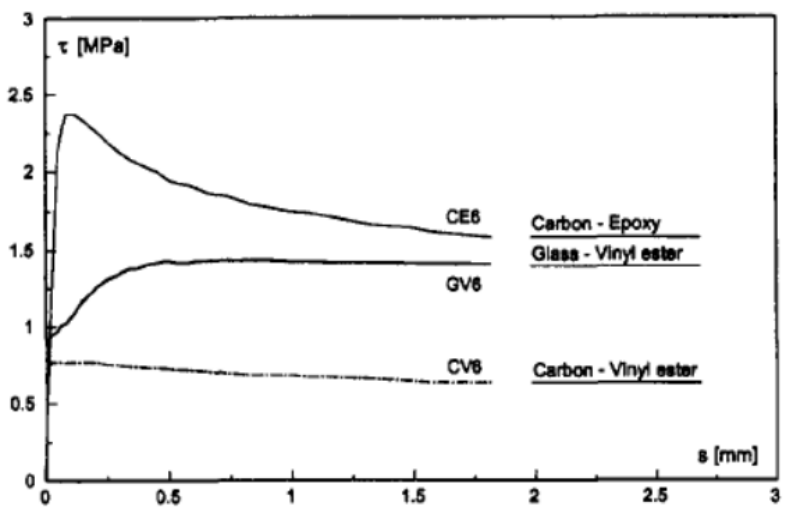

Fig. 2.44. Gráfica de tensión adherente/deslizamiento de barras de CFRP lisas. Cosenza et al., 1997.

El tramo $C D$, se produce tras la máxima tensión adherente, y en ésta sigue dominando el mecanismo de fricción barra/hormigón, hasta el agotamiento.

La rotura por adherencia se produce a lo largo de la interfaz entre la barra y el hormigón, como consecuencia de las tensiones de tracción generadas por la barra; a su vez, no se produce fisuración en el hormigón por esfuerzos de tracción, puesto que las tensiones radiales de tracción son muy débiles. 
Estas dos fases de adherencia se encuentran afectadas por la resistencia a cortante entre láminas de fibras sucesivas en la superficie de la barra (FIB, 2000). En la Fig. 2.45a,b, se muestra una barra de CFRP (matriz polimérica de poliéster) tras el ensayo de adherencia por pullout (Katz, 1999). En ella se puede observar como se ha producido el raspado (la denominación de este modo de rotura en inglés es "peeling") de la superficie de la barra debido al microacuñamiento entre la superficie de la barra y el hormigón.
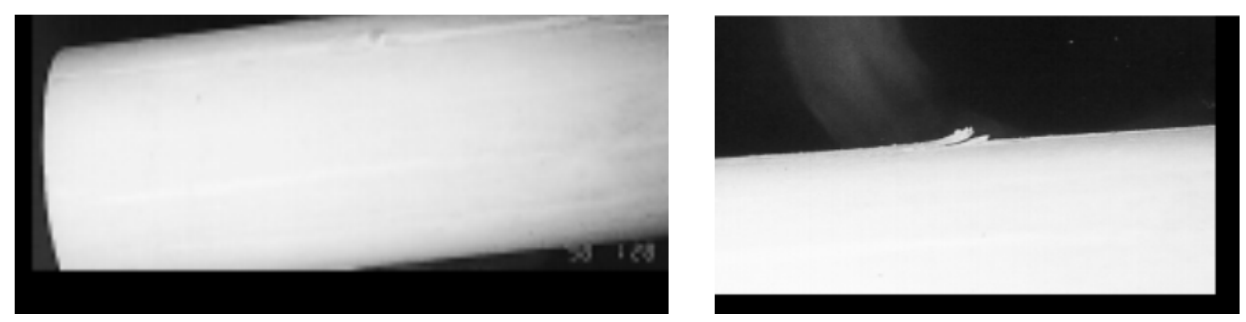

Fig. 2.45. Barra de CFRP tras el ensayo de adherencia por pullout. a) Daño en la superficie de la barra de CFRP, b) Raspado de la superficie de la barra. Katz, 1999.

El comportamiento adherente entre las barras lisas de CFRP y el hormigón depende fundamentalmente del tipo de matriz polimérica, tanto de sus propiedades mecánicas como de su rugosidad y, en menor medida del tipo de fibra de refuerzo empleados en la composición de la barra de CFRP (Fig. 2.46) (Nanni et al., 1995; Cosenza et al., 1997; Makitani et al., 1993). Por el contrario, la resistencia del hormigón no influye en el comportamiento adherente de este tipo de barras (Nanni et al., 1995).

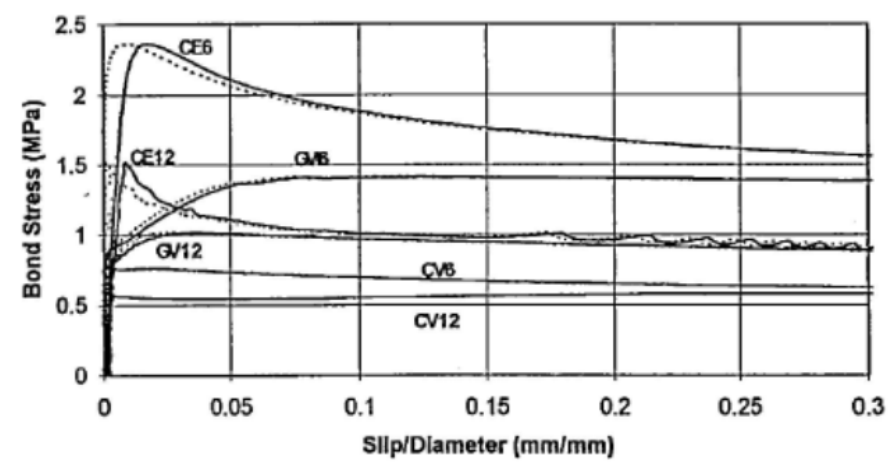

Fig. 2.46. Gráfica que relaciona la tensión adherente y el cociente entre el deslizamiento y el radio de las barras lisas de CFRP. La línea sólida está referida al extremo tensionado, y la línea discontinua al extremo no tensionado de la barra. Nanni et al., 1995. 
Otros factores, además de los desarrollados en el apart. 2.5.4 de la presente tesis doctoral, que influyen en la adherencia de las barras lisas de CFRP son: la presión radial del hormigón sobre la barra debida a la retracción del mismo, y la expansión transversal de la barra por absorción de agua, además del alargamiento longitudinal durante el proceso de adherencia (Al-Zaharani, 1995).

Las diferentes normativas de diseño de estructuras de hormigón armado con barras de FRP (ACI 440.1R-06; JSCE 1997(b); CAN/CSA-S806-02; FIB Task Group 9.3, 2007; CNR-DT 203/2006; IStructE, 1999), así como las distintas investigaciones realizadas, no recomiendan el empleo de este tipo de barras como armado del hormigón, ya que, su comportamiento adherente es muy deficitario (es decir, presentan rotura frágil y desarrollan una tensión adherente muy reducida).

\subsubsection{Comportamiento Adherente entre Hormigón y Barras de CFRP Corrugadas o con Tratamiento Superficial}

El comportamiento adherente entre las barras de FRP, corrugadas o con tratamiento superficial, y el hormigón se define mediante la gráfica que relaciona la tensión adherente y el deslizamiento, mostrada en la Fig. 2.47, obtenida mediante el ensayo de adherencia de pullout. Esta gráfica caracteriza el comportamiento de un modo general de todos los tipos de barras corrugadas o con tratamiento superficial descritos en la Fig. 2.42.

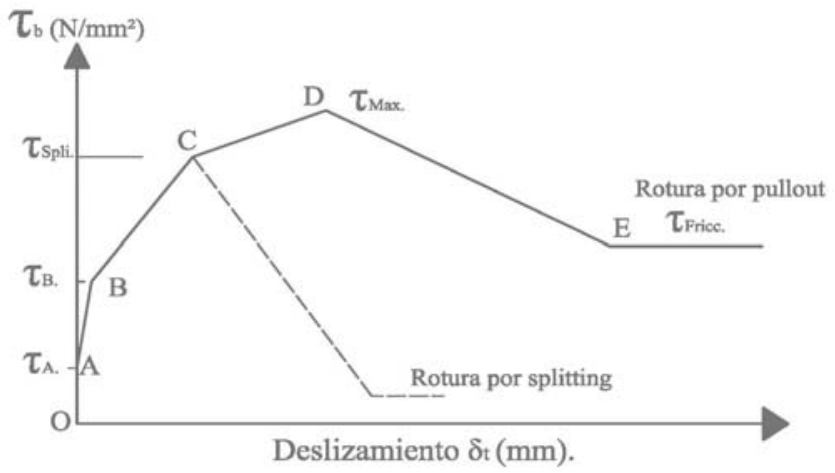

Fig. 2.47. Gráfica de tensión de adherencia/deslizamiento de barras deformadas o con tratamiento superficial de CFRP. Adaptado de FIB, 2000. 
Tramo OA: En este estadio (estadio en el que se comienza a introducir tensiones en el elemento), el mecanismo principal de adherencia se desarrolla por adhesión química entre la superficie de la barra deformada o con tratamiento superficial y el hormigón. No se produce deslizamiento relativo entre la barra y el hormigón. La tensión adherente desarrollada, en este estado, para cada tipo de barras de CFRP es: a) en barras corrugadas (corrugadas por mecanizado durante el proceso de pultrusión, similares a las barras de acero corrugadas) del orden de 2,5 a 5,0 MPa (Achillides et al.,2004; Okelo et al., 2005); b) en barras con recubrimiento de arena del orden de 3,5 a 12,0 MPa (Aiello et al., 2007; Baena et al., 2009; Okelo et al.,2005); c) en barras con hélice adherida del orden de 0,5 a 2,5 MPa (Aiello et al., 2007; Baena et al., 2009; Davalos et al., 2008); d) en barras con hélice adherida y arenadas del orden de $4 \mathrm{MPa}$ (Aiello et al.,2007; $\mathrm{Xu}, 2011)$; e) mientras que las barras de acero alcanzan valores entre 0,5 y 1,5 MPa (CEB Bulletin 151, 1982). Por lo tanto, las barras de CFRP arenadas desarrollan, mediante el mecanismo de adhesión química, una adherencia superior a los otros tipos de barras.

Tramo $A B$ : En este estadio, se produce un incremento de la tensión, lo que conlleva una rotura o pérdida del mecanismo de adhesión química y, el inicio del deslizamiento relativo entre la barra y el hormigón (en el extremo en el cual se aplica la tensión). Las barras de CFRP corrugadas, en este estadio, desarrollan su adherencia mediante el mecanismo de acuñamiento mecánico entre las corrugas y el hormigón. Las barras arenadas debido a su diferente geometría superficial desarrollan su adherencia por el mecanismo de fricción. El deslizamiento relativo, entre la barra y el hormigón, desarrollado en este tipo de barras es el más pequeño de todos los tipos de barras de CFRP (Aiello et al., 2007). En cambio, las barras de CFRP con hélice adherida desarrollan su adherencia, dependiendo de la adhesión entre la hélice y la barra, mediante el mecanismo de acuñamiento mecánico (mesoacuñamiento) o fricción. En este estadio el deslizamiento relativo de este tipo de barras es superior al desarrollado 
por las barras corrugadas y por las barras arenadas. Este hecho se puede deber a la menor rigidez de la geometría superficial de la barra (Okelo et al., 2005). Sin embargo, este deslizamiento relativo puede reducirse mediante la introducción de un recubrimiento de arena sobre la hélice adherida.

La tensión de tracción producida por los esfuerzos de adherencia alcanzará la tensión resistente máxima a tracción del hormigón, lo que produce el inicio de la microfisuración en el mismo, en los extremos de cada deformación o corruga de la barra (Fig. 2.48). Sin embargo, debido a que las deformaciones (hélice adherida o recubrimiento de arena) o corrugas de la superficie de la barra poseen menor resistencia a corte respecto de las barras de acero, en algunos casos el inicio de la microfisuración se retrasa relativamente. Tepfers, (1997), con base en la investigación realizada, sugiere que el comportamiento adherente de las barras deformadas o corrugadas de FRP, en este estadio, debido al retraso de la fisuración del hormigón es mejor que en las barras de acero.

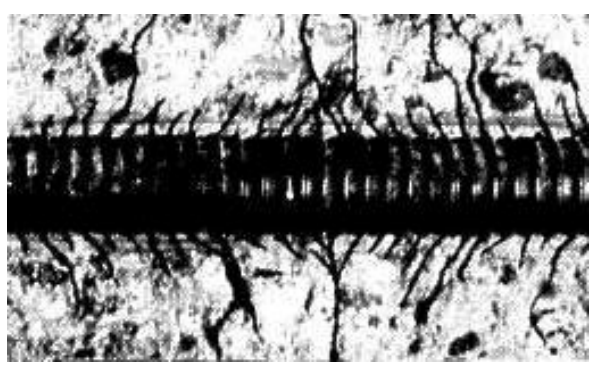

Fig. 2.48. Fisuración del hormigón debido a que la tensión adherente de la barra es superior a la resistencia del hormigón a tracción. Tepfers et al., 2003.

$\underline{\text { Tramo BC: }}$ : En este estadio, se produce un aumento considerable de las tensiones de acuñamiento (en el caso de barras corrugadas o con hélice adherida se produce acuñamiento, mientras que en barras arenadas y texturizadas el mecanismo adherente se desarrolla por fricción) así como del deslizamiento de la barra, lo que produce una disminución de la rigidez del comportamiento adherente en este tramo. En el caso de las barras de CFRP arenadas el 
incremento del deslizamiento relativo de la barra es el más pequeño de todos los tipos de barras (seguido de las barras corrugadas), por lo tanto, el comportamiento adherente no presentará casi reducción de su rigidez. Con base en los ensayos de pullout realizados se ha demostrado, para todos los tipos de barras de CFRP, que en el extremo no tensionado de la barra no comienza a producirse deslizamiento relativo hasta el final de este tramo BC (Fig. 2.49) (Achillides et al., 2004; Baena et al., 2009; Okelo et al., 2005).

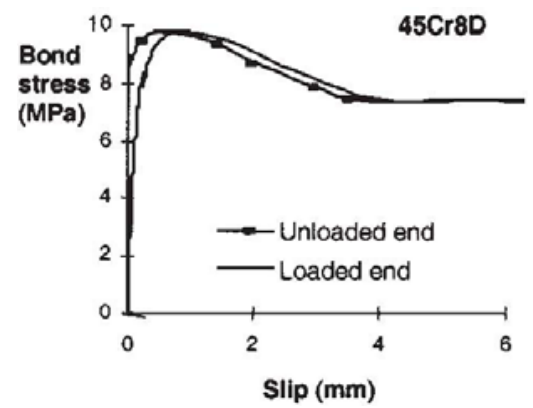

Fig. 2.49. Comportamiento adherente entre el hormigón y las barras de CFRP corrugadas. Achillides et al., 2004.

Las tensiones principales del acuñamiento mecánico son resistidas por el hormigón circundante a la barra en un ángulo " $\alpha$ ” o p " (biela de compresión, Fig. 2.50 y 2.35.a); éste puede variar si se aplasta el hormigón en frente de las corrugas, puesto que se desplaza a la zona inmediata de hormigón sin aplastar, resultando un nuevo ángulo o resultante $\alpha^{\prime}>\alpha$ ("p ${ }^{* *}$, Fig. 2.35.a). Esta resultante de tensiones $" \mathrm{p}^{* *}$ o ángulo " $\alpha$ " depende pricipalmente: del módulo elástico de la barra, de la resistencia a cortante del hormigón entre corrugas (Achillides, 1998) y del tipo de geometría superficial de la barra (Tepfers, 1997).

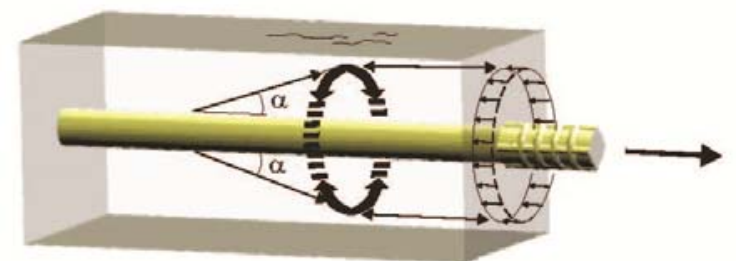

Fig. 2.50. Representación esquemática del equilibrio entre la tensión adherente y la resistencia a tracción del hormigón. Tepfers et al., 2003. 
En este tramo $\mathrm{BC}$, la resistencia del hormigón frente a splitting es decisiva; puesto que ésta determina la capacidad de anclaje de la barra. Ésta resistencia se encuentra influenciada debida al confinamiento producido por: la masa de hormigón circundante a la barra, por el armado transversal y por la presión exterior aplicada en la zona de anclaje. En este tramo si no se desarrolla la resistencia necesaria por el hormigón se producirá la rotura de adherencia por splitting.

Si la barra no se encuentra confinada adecuadamente y las tensiones de tracción producidas por la barra son mayores que la resistencia a tracción del hormigón, se producirán fisuras por splitting a lo largo de la longitud de anclaje de la barra (Fig. 2.51). Una vez que se han propagado las fisuras por splitting a lo largo de todo el recubrimiento del anclaje, el deslizamiento relativo entre la barra y el hormigón se incrementa considerablemente y se producen tensiones de adherencia uniformemente distribuidas a lo largo de la longitud de anclaje de la barra (Fig. 2.52). Estas tensiones ahora son resistidas por la resistencia a tracción del hormigón circundante a la barra antes de la rotura por fisuración del hormigón.

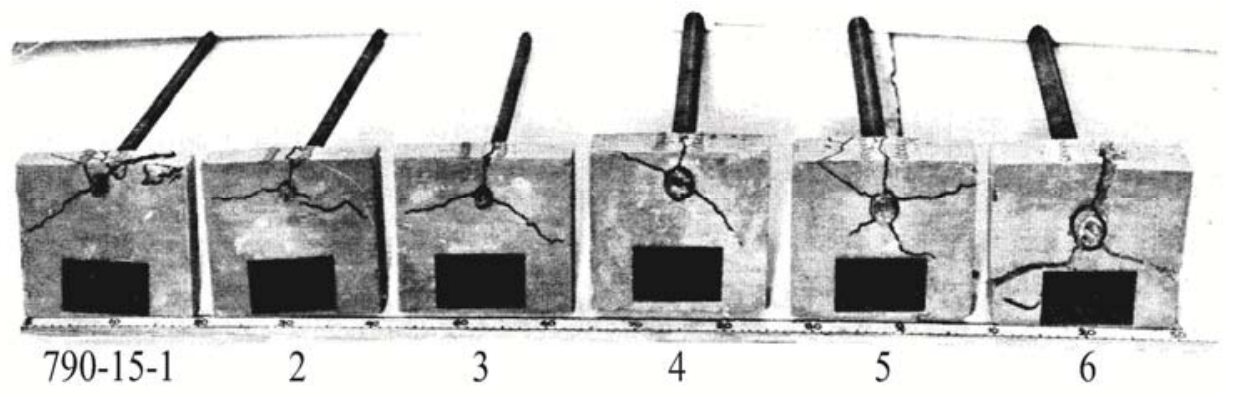

Fig. 2.51. Formación de fisuras internas y externas alrededor de la barra de CFRP. Tepfers et al., 2003. 


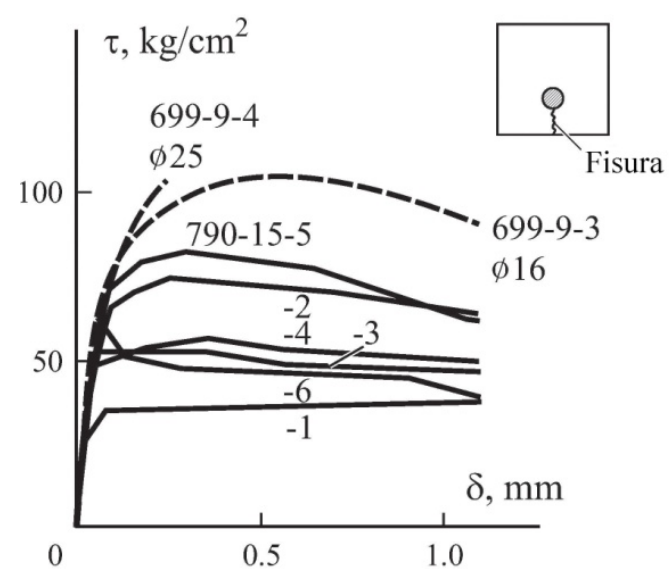

Fig. 2.52. Comportamiento adherente entre barras de CFRP deformadas y hormigón fisurado durante el ensayo de pullout descentrado. Tepfers et al., 2003.

$\underline{\text { Tramo } C D}$ : En este estadio, si el hormigón circundante a la barra proporciona el confinamiento necesario para evitar la rotura por splitting, se alcanza la tensión adherente máxima " $\tau_{\max }$.". Además, en ambos extremos de la barra se produce un deslizamiento relativo. Al mismo tiempo, dependiendo de cada geometría superficial el comportamiento adherente en este tramo varía.

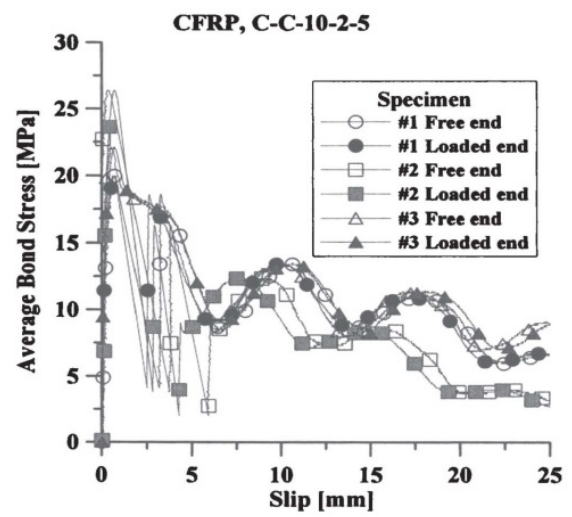

Fig. 2.53. Comportamiento adherente entre barras de CFRP corrugadas y el hormigón. Okelo et al., 2005.

Las barras de CFRP corrugadas desarrollan una tensión adherente máxima a un deslizamiento relativo (en ambos extremos de la barra) similar al desarrollado por las barras de acero corrugadas (Figs. 2.53). En la Tabla 2.27 se muestran los resultados de los ensayos de adherencia (método de ensayo por 
pullout) de diferentes investigaciones realizadas sobre barras corrugadas de CFRP y acero.

\begin{tabular}{lcccccc}
\hline \multirow{2}{*}{\begin{tabular}{l} 
Investigación \\
\cline { 3 - 7 }
\end{tabular}} & \multicolumn{3}{c}{ Barra de CFRP corrugada } & \multicolumn{3}{c}{ Barra de acero corrugada } \\
\cline { 4 - 7 } & $\begin{array}{c}\tau_{\mathrm{b}}, \\
\mathrm{MPa}) .\end{array}$ & $\begin{array}{c}\delta_{\mathrm{t}} \\
(\mathrm{mm})\end{array}$ & $\begin{array}{c}\delta_{\mathrm{nt}} \\
(\mathrm{mm})\end{array}$ & $\begin{array}{c}\tau_{\mathrm{b}}, \\
(\mathrm{MPa})\end{array}$ & $\begin{array}{c}\delta_{\mathrm{t}} \\
(\mathrm{mm})\end{array}$ & $\begin{array}{c}\delta_{\mathrm{nt}} \\
(\mathrm{mm})\end{array}$ \\
\hline Nanni et al., 1995. & 22,5 & 0,57 & 0,25 & 18,5 & 1,90 & 0,95 \\
\hline Benmokrane et al., 2002. & 23,4 & - & - & 24,6 & - & - \\
\hline Achillides et al., 2004. & 13,7 & 0,55 & 0,19 & 16,6 & 0,58 & 0,82 \\
\hline Okelo et al., 2005. & 26,4 & 0,66 & 0,30 & 23,8 & 8,15 & 0,36 \\
\hline
\end{tabular}

Donde: $\tau_{\mathrm{b}}$, es la tensión adherente máxima. $\delta_{\mathrm{t}}$, es el deslizamiento, en el punto de tensión adherente máxima, en el extremo de la barra tensionado. $\delta_{\mathrm{nt}}$, es el deslizamiento, en el punto de tensión adherente máxima, en el extremo de la barra no tensionado.

Tabla 2.27. Resultados de ensayos de adherencia por pullout en barras corrugadas de CFRP y acero.

Una vez alcanzada la tensión adherente máxima, dependiendo de la magnitud de la resistencia del hormigón respecto de la resistencia a cortante de las corrugas de la barra (En la Fig. 2.54 se muestran los diversos parámetros que intervienen en la rotura por adherencia de las barras corrugadas de CFRP) y a diferencia de las barras de acero corrugadas, se produce la rotura por adherencia de cuatro modos diferentes (FIB, 2007):

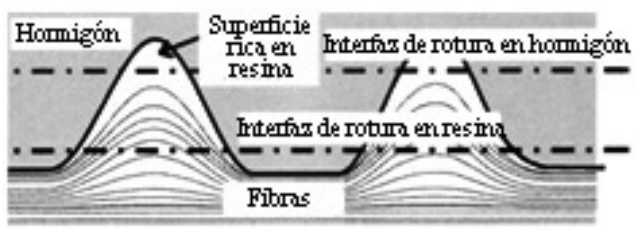

Fig. 2.54. Parámetros que intervienen en la rotura por adherencia de las barras de CFRP corrugadas. Achillides et al., 2004.

I. Corte de parte, o todas las corrugas de la barra: En este tipo de rotura, la adherencia de las barras corrugadas no está controlada por la resistencia del hormigón; en cambio, está dominada por la resistencia a cortante de las corrugas de la barra (Fig. 2.55). Por lo tanto, al contrario que las barras de acero, el incremento de la resistencia del hormigón podrá incrementar o no la tensión adherente (véase apart. 2.5.4 de la presente tesis doctoral). 


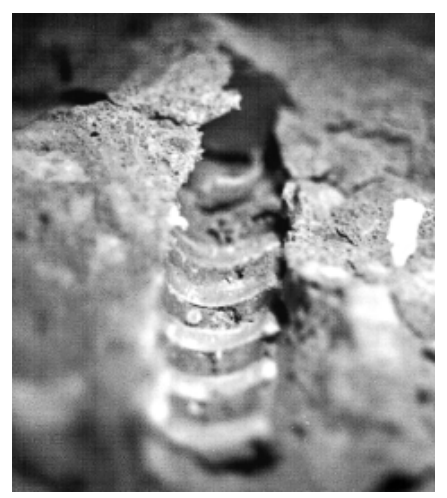

Fig. 2.55. Estado de la interfaz hormigón/barra de FRP corrugada tras el ensayo de pullout. Katz, 1999.

II. Rotura por corte del hormigón: Este tipo de rotura es similar al producido en las barras de acero corrugadas. La adherencia se encuentra controlada por la resistencia a cortante del hormigón.

III. Modo combinado: Este modo de rotura es una combinación de los modos de rotura anteriores (rotura por corte de parte o toda la superficie de las deformaciones o corrugas de la barra y rotura por corte del hormigón). Se produce en hormigones de resistencia a compresión superior a 30-40 $\mathrm{MPa}$ (véase apart. 2.5.4.3 de la presente tesis doctoral).

IV. Aplastamiento de la barra: Si la barra posee una rigidez transversal muy pequeña, puede ser aplastada por el hormigón circundante. Entonces, la adherencia se produce por fricción entre la barra y el hormigón circundante. En este modo de rotura la adherencia posee un comportamiento menos dúctil. Al mismo tiempo, la tensión adherente máxima puede ser bastante significativa dependiendo de: a) la geometría de las deformaciones de la barra; b) de la resistencia cortante de la barra y; c) del confinamiento proporcionado por el hormigón.

Las barras de CFRP arenadas desarrollan una tensión adherente y un deslizamiento relativo (en el punto de máxima tensión de adherencia) similar o menor que en las barras de acero corrugadas (debido a que el mecanismo adherente es por fricción). Esto supone un comportamiento adherente más rígido 
que el desarrollado por el resto de barras de CFRP y barras de acero corrugadas puesto que todos los tramos de la gráfica de tensión adherente/deslizamiento presentan una mayor rigidez (Fig. 2.56). En la Tabla 2.28 se muestran los resultados obtenidos, en diferentes investigaciones, mediante el ensayo de adherencia por pullout, en barras de CFRP arenadas.

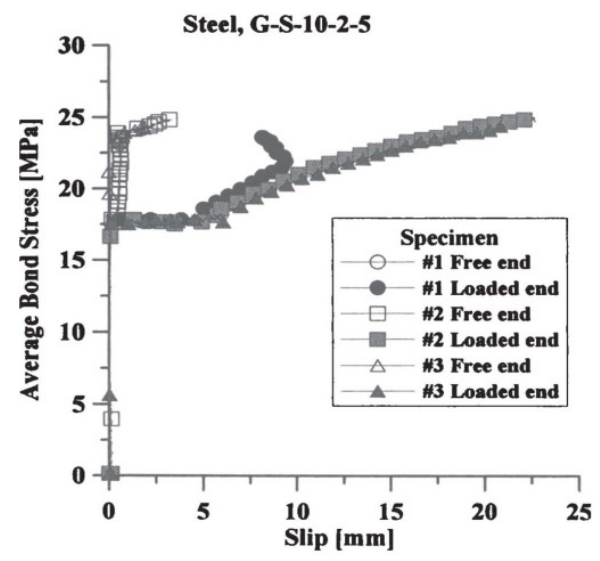

Fig. 2.56. Comportamiento adherente de barras de CFRP arenadas. Okelo et al., 2005.

\begin{tabular}{|c|c|c|c|c|c|c|}
\hline \multirow[b]{2}{*}{ Investigación } & \multicolumn{3}{|c|}{ Barra de CFRP arenada } & \multicolumn{3}{|c|}{ Barra de acero corrugada } \\
\hline & $\begin{array}{c}\tau_{\mathrm{b}} \\
(\mathrm{MPa})\end{array}$ & $\begin{array}{c}\delta_{\mathrm{t}} \\
(\mathrm{mm})\end{array}$ & $\begin{array}{c}\delta_{\mathrm{nt}} \\
(\mathrm{mm})\end{array}$ & $\begin{array}{c}\tau_{\mathrm{b}}, \\
(\mathrm{MPa})\end{array}$ & $\begin{array}{c}\delta_{\mathrm{t}} \\
(\mathrm{mm})\end{array}$ & $\begin{array}{c}\delta_{\mathrm{nt}} \\
(\mathrm{mm})\end{array}$ \\
\hline Benmokrane et al., 2002. & 20,0 & - & - & 24,6 & - & - \\
\hline Okelo y Yuan, 2005. & 21,3 & 0,15 & - & 24,9 & 22,66 & 2,87 \\
\hline Aiello, Leone y Pecce, 2007. & $\begin{array}{l}2,86 \\
3,64\end{array}$ & $\begin{array}{l}0,58 \\
0,36\end{array}$ & $\begin{array}{c}0,02 \\
0,034\end{array}$ & 8,82 & 2,13 & 1,4 \\
\hline Baena et al., 2009. & 26,11 & 1,45 & 0,179 & 29,09 & 7,64 & 0,534 \\
\hline
\end{tabular}

Donde: $\tau_{\mathrm{b}}$, es la tensión adherente máxima. $\delta_{\mathrm{t}}$, es el deslizamiento, en el punto de tensión adherente máxima, en el extremo de la barra tensionado. $\delta_{\text {nt }}$, es el deslizamiento, en el punto de tensión adherente máxima, en el extremo de la barra no tensionado.

Tabla 2.28. Resultados de ensayos de adherencia por pullout en barras de CFRP arenadas y de acero corrugadas.

En la Tabla 2.28 se observa que los valores obtenidos por Aiello et al., (2007), son mucho menores que el resto de investigaciones. Esta disparidad de valores se debe a la gran dependencia de la adherencia de este tipo de barras de CFRP en la resina polimérica empleada como unión entre los gránulos y la barra de CFRP. 
Las barras de CFRP arenadas poseen un modo de rotura frágil, a diferencia de las barras de acero corrugadas, puesto que una vez alcanzada la tensión adherente máxima, a un nivel de deslizamiento relativo bajo, se produce una rotura repentina, desprendiéndose parte o toda la geometría superficial a base de gránulos de la barra (Fig. 2.57). Si el hormigón posee una resistencia a compresión inferior a $30 \mathrm{MPa}$, los gránulos de arena se desprenderán poco a poco, produciéndose daños en la interfaz barra/hormigón. Sin embargo, con hormigón de resistencia a compresión entorno a $45 \mathrm{MPa}$, la rotura por pullout se producirá solo en la superficie de la barra por el total desprendimiento de los gránulos de arena. Este modo de rotura puede observarse en la Fig.2.56 a través de la elevada reducción de la tensión adherente. Del mismo modo que en las barras de CFRP corrugadas, y diferencia del armado de acero, si la barra posee una rigidez transversal muy pequeña, puede ser aplastada por el hormigón circundante

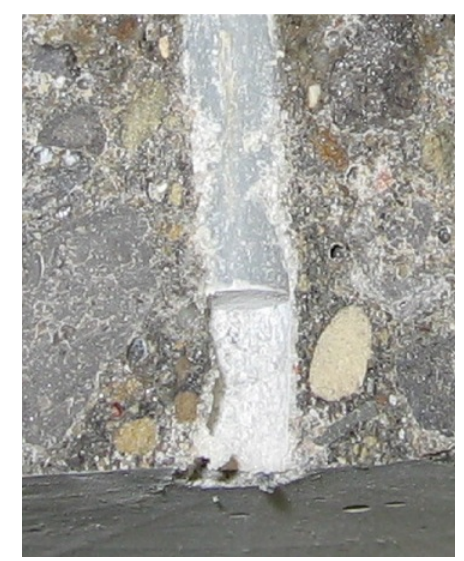

Fig. 2.57. Estado de la barra de FRP arenada tras el ensayo de pullout. Davalos et al., 2008.

El comportamiento adherente, en este tramo $\mathrm{CD}$, de las barras de CFRP con hélice adherida helicoidalmente, depende en gran medida de la resina polimérica que une la hélice de CFRP a la barra. Si la resina es capaz de resistir altas tensiones, el mecanismo adherente se produce por acuñamiento mecánico y, se alcanza una mayor tensión adherente. Kanakubo et al., (1993), obtuvieron 
valores máximos de la tensión adherente, en el ensayo de pullout descentrado, del orden de 8,38 MPa y mayores a 7,76 MPa en barras de CFRP con hélice adherida helicoidalmente y acero corrugadas, respectivamente. Si por el contrario la resina no resiste altas tensiones, el mecanismo adherente se desarrolla por fricción y, la tensión adherente es menor, del orden de 4,15 a 4,50 MPa (Cosenza et al., 1997). Este tipo de barras desarrolla una menor tensión adherente y un mayor alargamiento relativo (a tensión adherente máxima) que las barras de acero corrugadas y, que las barras de CFRP corrugadas y arenadas.

La adherencia de este tipo de barras de CFRP puede ser mejorada mediante el arenado superficial, reduciendo el alargamiento relativo e incrementando la tensión adherente máxima hasta alcanzar valores ligeramente inferiores a los obtenidos en barras de acero corrugadas (Xu, 2011). Aiello et al., (2007), con base en su investigación obtuvieron en barras de CFRP con hélice adherida y arenadas (de $8,0 \mathrm{~mm}$ de diámetro) una tensión adherente máxima de $15,08 \mathrm{MPa}$ a un deslizamiento relativo (deslizamiento medio entre los dos extremos de la barra) del orden de 8,0 mm (Fig. 2.58); mientras que la tensión adherente máxima alcanzada por las barras de acero corrugadas (de 13,3 $\mathrm{mm}$ de diámetro) fue de 9,21 $\mathrm{MPa}$, a un deslizamiento relativo (deslizamiento medio entre los dos extremos de la barra) de 1,52 mm. Sin embargo, Xu, (2011), obtuvo una tensión adherente máxima del orden de 14,54 MPa, similar a la obtenida por Aiello et al., y un deslizamiento relativo de $1,27 \mathrm{~mm}$, menor que el obtenido en la investigación anterior. La rotura se produce al alcanzar la tensión adherente máxima mediante el desprendimiento de la capa de arena y por la rotura de la hélice helicoidal. 


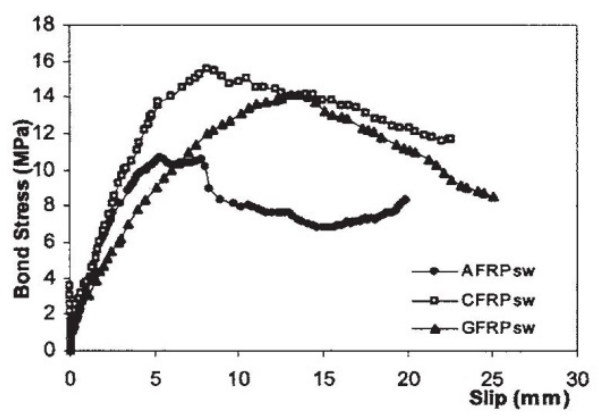

Fig. 2.58. Comportamiento adherente de barras de FRP con hélice adherida y arenadas. Las siglas CFRPsw se refieren a barras de CFRP con hélice adherida y arenadas. Aiello et al., 2007.

La adherencia de las barras de CFRP texturizadas, en este tramo CD, depende de las corrugas y la resistencia de la capa superficial de la barra, ya que su mecanismo adherente es por acuñamiento $y$ fricción. Según las investigaciones realizadas, el comportamiento adherente entre las barras de CFRP texturizadas y el hormigón es similar o inferior al desarrollado por las barras de acero corrugadas. Davalos et al., (2008), obtuvieron un valor máximo de la tensión adherente del orden de 22,26 MPa (resistencia a compresión del hormigón entre 57-63 $\mathrm{MPa}$ ) a un deslizamiento relativo (a tensión adherente máxima) de 0,15 mm (Fig. 2.59, gráfica “control”). Baena et al., (2009), obtuvieron, en el caso de hormigón de resistencia a compresión superior a 45 $\mathrm{MPa}$, una tensión adherente del orden de 11,85 MPa, a un deslizamiento de 0,33 $\mathrm{mm}$ (deslizamiento medio entre los dos extremos de la barra), estos valores son inferiores a los obtenidos en el mismo estudio sobre barras de acero corrugadas, las cuales desarrollan una tensión adherente máxima de 29,09 $\mathrm{MPa}$ a un deslizamiento de 4,11 $\mathrm{mm}$. Sin embargo, con hormigón de resistencia a compresión inferior a $30 \mathrm{MPa}$, la adherencia de este tipo de barras de CFRP se aproxima a la de las barras de acero corrugadas. Los valores de la tensión adherente obtenidos fueron de 13,13 y 14,06 MPa, a un deslizamiento relativo de 0,27 y 1,73 mm, en barras de CFRP texturizadas y de acero corrugadas, respectivamente. Okelo et al., (2005), dependiendo del tipo de barra texturizada empleada obtuvieron valores diferentes; en el caso de barras texturizadas 
similares a las empleadas por Davalos et al., y Baena et al., se puede afirmar que la adherencia es similar a las barras de acero corrugadas. En este caso, la tensión adherente (con una resistencia a compresión del hormigón superior a $40 \mathrm{MPa}$ ) obtenida fue de 25,4 MPa, frente a la desarrollada por las barras de acero del orden de 24,9 MPa. El deslizamiento relativo de este tipo de barras de CFRP fue de 1,80 mm, inferior al desarrollado por las barras de acero del orden de 12,86 $\mathrm{mm}$. Sin embargo, en otro tipo de barras texturizadas, sin endentaciones, el comportamiento adherente es inferior al de las barras de acero, puesto que la tensión adherente obtenida es de $18,3 \mathrm{MPa}$, a un deslizamiento relativo de 0,20 $\mathrm{mm}$.

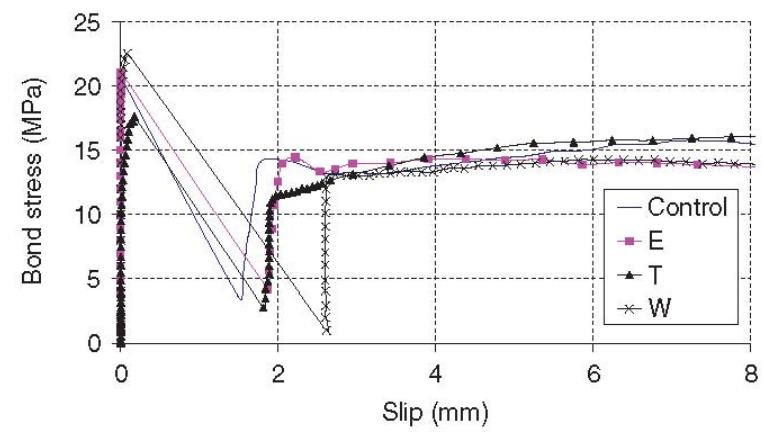

Fig. 2.59. Comportamiento adherente entre el hormigón de alta resistencia (resistencia a compresión del orden de 57 a $63 \mathrm{MPa}$ ) y las barras de CFRP texturizadas. Davalos et al., 2008.

Una vez alcanzada la tensión adherente máxima se produce la rotura por pullout. Esta depende de la resistencia a compresión del hormigón. Si la resistencia del hormigón es inferior a $30 \mathrm{MPa}$ la rotura se produce en la superficie de hormigón circundante a la barra y en menor medida en la capa superficial de la barra (Fig. 2.60). Sin embargo, si la resistencia del hormigón es superior a $45 \mathrm{MPa}$, la rotura se produce en la superficie de la barra, despegando la capa superficial que está adherida a la barra. Este modo de rotura puede apreciarse en la Fig. 2.59 mediante la perdida durante un corto momento el sistema no desarrollara resistencia de adherencia, hasta que nuevamente y por el 
mecanismo de fricción comience a producirse esta resistencia, hasta alcanzar valores alrededor del $75 \%$ de la tensión máxima de adherencia

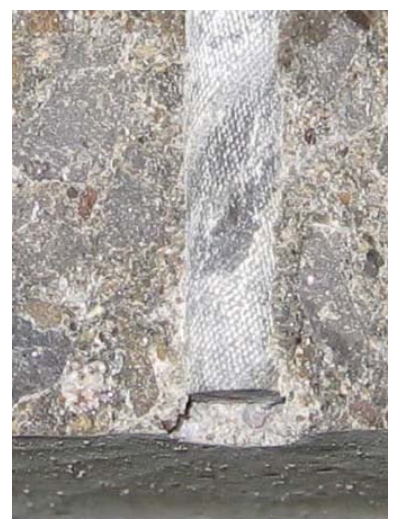

Fig. 2.60. Restos de hormigón en la superficie de la barra de CFRP texturizada tras el ensayo de pullout. Davalos et al., 2008.

Tramo DE: Este estado comienza una vez se alcanza la tensión adherente máxima. Las barras de CFRP corrugadas dependiendo del modo de rotura se comportan de un modo diferente: El comportamiento adherente en este tramo debido al modo de rotura por corte del hormigón es similar al desarrollado en barras de acero corrugadas. Si la rotura se produce por corte de parte o todas las corrugas de la barra, el mecanismo de acuñamiento mecánico por el que se ha alcanzado la tensión adherente máxima se sustituye por el mecanismo de fricción, el cual depende de la rugosidad de la interfaz entre la barra y el hormigón (Nanni et al., 1995). En cambio, si se produce la rotura por el modo combinado, la adherencia en este tramo se desarrolla por la suma de la fricción entre la barra y el hormigón y, por el acuñamiento mecánico debido a la introducción de una nueva corruga en la longitud de anclaje (Achillides et al., 2004; Okelo et al., 2005). Achillides et al., (2004), observaron que este fenómeno produce una tensión adherente residual " $\tau_{\mathrm{f}}$ " alrededor del $75 \%$ de la tensión adherente máxima (Fig. 2.61), valores muy superiores que los obtenidos en barras de acero corrugadas, del orden de 20 a $40 \%$. Sin embargo, con base en las investigaciones de Okelo et al., (2005) y Nanni et al., (1995), se observa un 
comportamiento oscilatorio descendiente (Fig. 2.53), diferente al obtenido por Achillides et al., el cual se caracteriza por ondas oscilatorias, cuyo ancho es aproximadamente la separación entre corrugas, que presentan una tensión adherente menor a medida que las corrugas se van deteriorando.

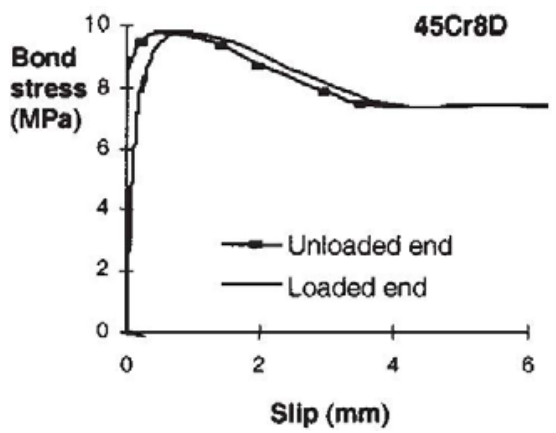

Fig. 2.61. Comportamiento adherente entre las barras de CFRP corrugadas y el hormigón. Achillides et al., 2004.

El comportamiento de las barras de CFRP con recubrimiento de arena en este tramo DE viene caracterizado por el modo de rotura frágil producido por el desprendimiento repentino de la capa de gránulos que recubre la barra, el cual depende de la adhesión entre la geometría superficial y el núcleo de la barra y la resistencia a compresión del hormigón (véase apart. 2.5.3.2, tramo $\mathrm{CD}$, de la presente tesis doctoral). Este comportamiento se muestra en la Fig. 2.62; en esta se aprecia que tras alcanzar la tensión adherente máxima, en el caso de hormigón con resistencia compresión inferior a $30 \mathrm{MPa}$ se produce una elevada disminución lineal de la tensión adherente y grandes desplazamientos. Sin embargo, si la resistencia del hormigón es superior a $45 \mathrm{MPa}$ la tensión adherente se reduce bruscamente hasta un valor del orden del $20 \%$ de la tensión adherente máxima mostrando unos cortos movimientos oscilatorios debidos al continuo desprendimiento de la capa superficial de arena. 

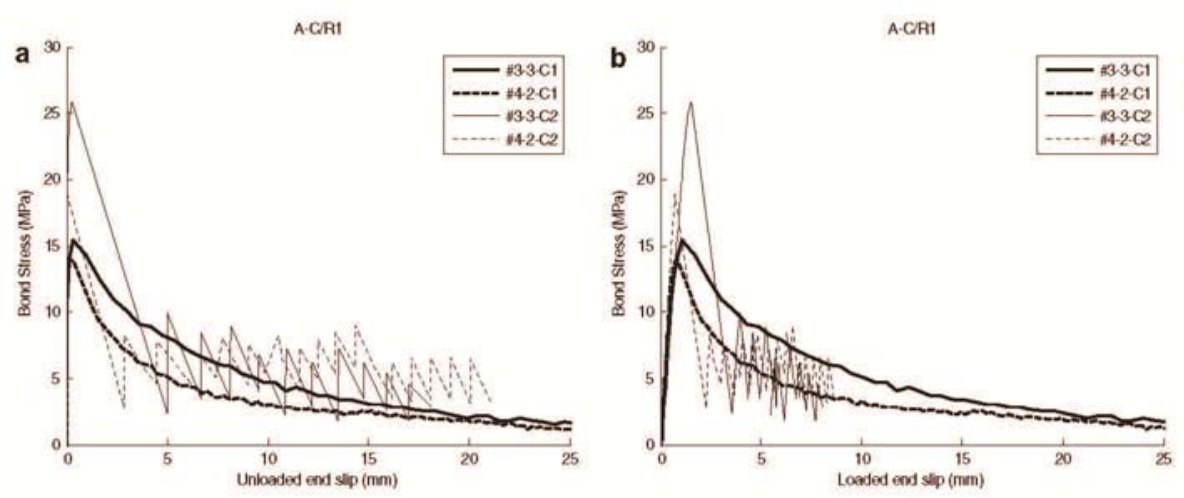

Fig. 2.62. Comportamiento adherente entre las barras de CFRP arenadas y el hormigón. Izda. extremo no tensionado y, Dcha. extremo tensionado. Las siglas: $\mathrm{C} 1$ y $\mathrm{C} 2$ corresponden a hormigones con $\mathrm{f}_{\mathrm{c}}>30 \mathrm{MPa} \mathrm{y} \mathrm{f}_{\mathrm{c}}>50 \mathrm{MPa}$, respectivamente; $\square 3 \mathrm{y} \square 4$ corresponden al diámetro de la barra en pulgadas. Baena et al., 2009.

En las barras con geometría superficial en forma de hélice adherida, tras alcanzar la tensión adherente máxima, la adherencia se lleva a cabo a través del mecanismo de fricción, mientras que la rotura de la barra se produce por desprendimiento de la hélice adherida de un modo más dúctil. La tensión adherente residual dependerá del mismo modo que en las barras corrugadas, de la resistencia friccional en la interfaz entre la barra y el hormigón. En el caso de que este tipo de barras posea un recubrimiento superficial de arena la tensión adherente máxima depende de la resina polimérica que une la capa superficial de arena y la hélice helicoidal a la barra, por lo tanto, el comportamiento en este tramo DE tras la rotura puede ser muy dispar: Xu, (2011), observó que este tipo de barras de CFRP posee un comportamiento menos dúctil que las barras con tratamiento superficial a base de hélice adherida (Fig. 2.63a). Sin embargo, Aiello et al., (2007), obtuvieron un comportamiento adherente, tras la rotura, mucho más dúctil que Xu (Fig 2.63b). 

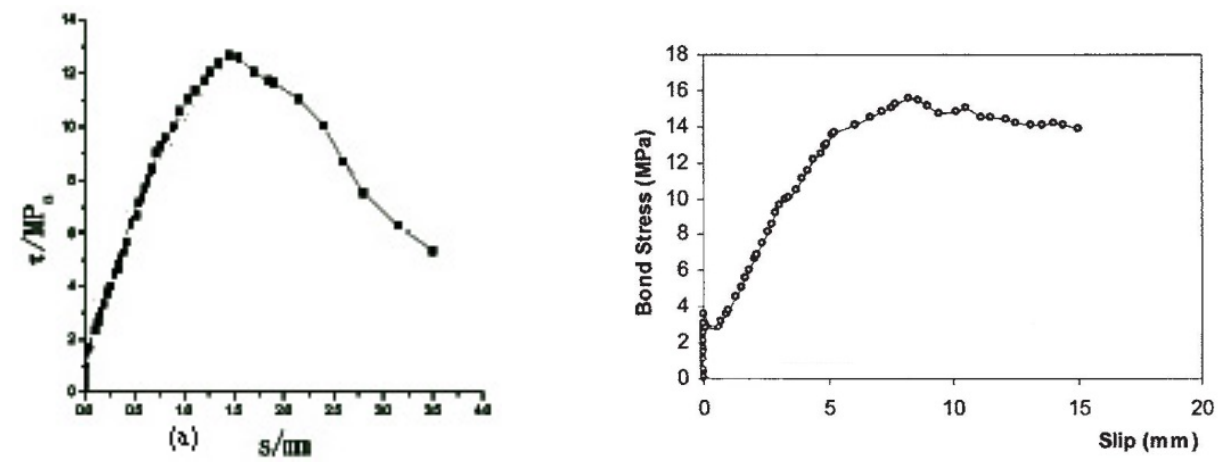

Fig. 2.63. Comportamiento adherente entre las barras de CFRP con hélice adherida helicoidalmente y arenadas y el hormigón. a) Xu, 2011; b) Aiello et al., 2007.

El comportamiento adherente de las barras texturizadas en este tramo DE depende del modo de rotura: si la rotura se produce en la superficie de hormigón circundante a la barra y en menor medida en la superficie de la barra el comportamiento adherente en este tramo se caracteriza por una disminución constante de la tensión adherente y grandes deslizamientos relativos (Fig. 2.64). El comportamiento adherente de este modo de rotura, en el tramo DE, también depende de la resistencia de la geometría superficial de la barra, pudiendo comportarse frágilmente si la geometría superficial de la barra no presenta la resistencia adecuada (Fig. 2.65). En cambio, si la rotura se produce en la superficie de la barra de CFRP el comportamiento en este tramo DE es más frágil, puesto que se reduce drásticamente la tensión adherente (Fig. 2.59). En ambos modos de rotura la adherencia se lleva a cabo mediante el mecanismo de fricción. 

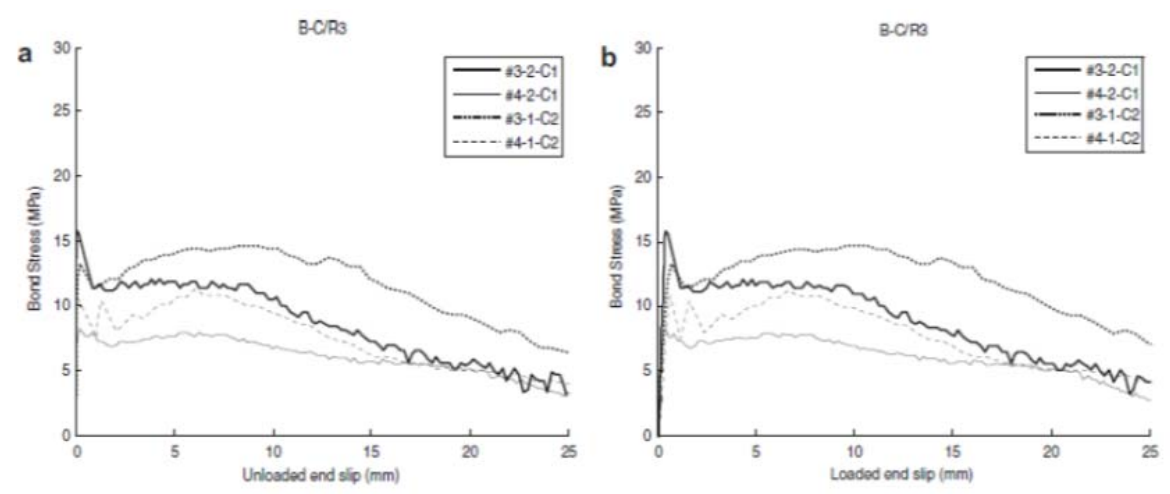

Fig. 2.64. Comportamiento adherente de las barras de CFRP texturizadas. Izda. extremo no tensionado, Dcha. extremo tensionado. Baena et al., 2009.

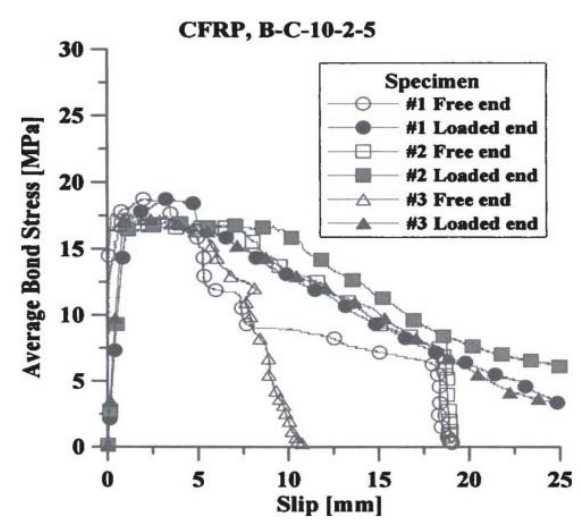

Fig. 2.65. Comportamiento adherente de las barras de CFRP texturizadas. Okelo et al., 2005.

\subsubsection{Parámetros que Influyen en el Comportamiento Adherente}

Del mismo modo que en el caso de las barras de acero en el hormigón armado, hay una gran cantidad de parámetros que influyen en el comportamiento adherente entre las barras de CFRP y el hormigón. En el siguiente apartado, con base en las investigaciones realizadas hasta la fecha, se definen y analizan estos parámetros influyentes en el comportamiento adherente de las barras de CFRP. Sin embargo, en muchos casos no es posible la comparación de resultados obtenidos en diferentes investigaciones, debido a los diferentes tipos de ensayos y barras empleados, puesto que no se dispone en todos los casos de ensayos y materiales normalizados. 


\subsubsection{Módulo Elástico de la Barra}

El módulo elástico de las barras de CFRP únicamente influye en el comportamiento adherente en el caso de barras cuyo mecanismo adherente se desarrolle por acuñamiento mecánico. Al mismo tiempo, este parámetro presenta resultados dispares puesto que en las investigaciones realizadas por Achillides, (1998, 2004), y Aiello et al., (2007), se observa que el módulo elástico desempeña un papel importante en el comportamiento adherente entre las barras de CFRP corrugadas o con hélice adherida y el hormigón; presentado así las barras con mayor módulo elástico, para una misma tipología de barra, menores deslizamientos relativos a una misma tensión adherente, que las barras con menor módulo elástico; lo que produce un comportamiento más rígido en la gráfica " $T-S$ ". Sin embargo, en contraposición, Kanakubo et al., (1993), en el estudio realizado sobre barras corrugadas de CFRP, GFRP y AFRP, cuyos módulos elásticos son $108 \mathrm{GPa}, 44,1 \mathrm{GPa}$ y $57,9 \mathrm{GPa}$, respectivamente, afirman que el módulo elástico no influye en la adherencia, puesto que los resultados de la tensión adherente máxima son de 7,80 $\mathrm{MPa}$, 7,37 MPa y 8,46 $\mathrm{MPa}$, para barras de CFRP, GFRP y AFRP, respectivamente. Sin embargo, esta investigación puede no ser concluyente, puesto que los datos se han obtenido mediante el ensayo de pullout descentrado, lo que puede producir que las barras de FRP no desarrollen la tensión adherente máxima, ya que el modo de rotura en estos tipos de barras es por splitting del hormigón.

En la investigación llevada a cabo por M. Aiello et al., (2007), se observa que para una misma tipología de geometría superficial de las barras de FRP (CFRP, GFRP y AFRP) con hélice adherida y arenadas "FRPsw", que las barras con mayor módulo elástico, como son las de CFRP (CFRPsw $\approx 169,37$ $\mathrm{GPa}$; AFRPsw $\approx 69,21 \mathrm{GPa}$; GFRP $\approx 48,83 \mathrm{GPa}$ ), desarrollan una mayor tensión adherente a un menor deslizamiento relativo (Fig. 2.66). 


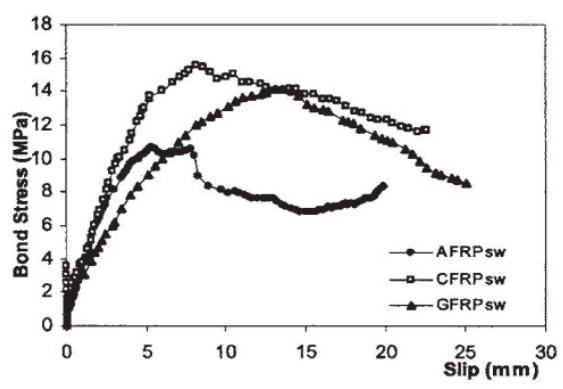

Fig. 2.66. Comportamiento adherente entre distintos tipos de barras de FRP con hélice adherida y arenadas y el hormigón. Aiello et al., 2007.

En la misma investigación también se observa que el módulo elástico de las barras de CFRP influye en la deformabiliad del elemento de hormigón armado. Presentando mayores deformaciones en los elementos armados con barras de menor módulo elástico, como son las barras de GFRP, que en elementos armados con barras de CFRP. En la Fig. 2.67 se muestra la influencia del módulo de elasticidad en el comportamiento adherente, mediante la gráfica que relaciona en el eje de ordenadas, la tensión adherente y la máxima tensión adherente, y en el de abcisas, la diferencia entre el deslizamiento de la barra en el extremo tensionado y el no tensionado.

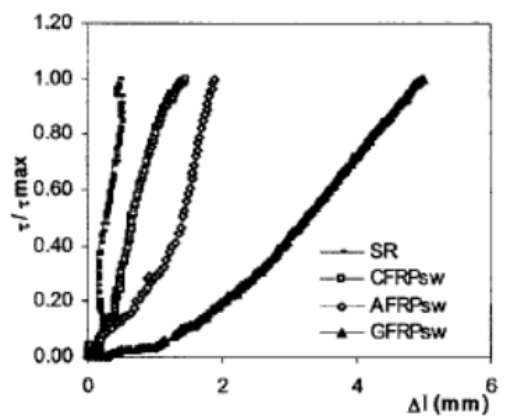

Fig. 2.67. Influencia del módulo de elasticidad en el comportamiento adherente entre diferentes tipos de barras de FRP con hélice adherida y arenadas (SR: barra de acero corrugada). Aiello et al., 2007.

En el mismo sentido Achillides, (1998), observó que el módulo elástico de las barras influye en la resistencia a rotura por splitting de la propia barra y por tanto en la adherencia, puesto que las barras de GFRP, con un menor módulo elástico del orden de $45 \mathrm{GPa}$, desarrollan mayores tensiones de splitting y, por 
consiguiente, menor tensión adherente que las barras con mayor módulo elástico, como son las barras de CFRP cuyo módulo es del orden de $115 \mathrm{GPa}$. En la investigación realizada por Achillides et al., (2004), también se observa del mismo modo que Aiello et al, un comportamiento adherente más rígido en barras corrugadas con mayor módulo elástico (CFRP con módulo elástico superior a $115 \mathrm{GPa}$ ) respecto a las barras con menor módulo elástico (GFRP con módulo elástico del orden de $45 \mathrm{GPa}$ ) (Fig. 2.68).
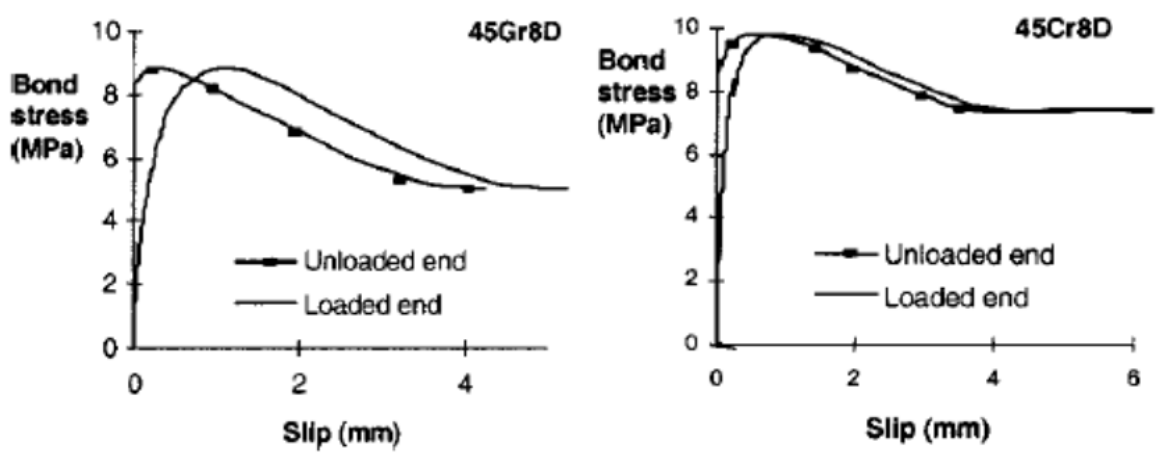

Fig. 2.68. Influencia del módulo de elasticidad de las barras de FRP en el comportamiento adherente. Izda. barras de GFRP y Dcha. barras de CFRP Achillides et al., 2004.

\subsubsection{Resistencia a Cortante de la Barra.}

La resistencia a cortante de las barras de CFRP lisas y corrugadas influye en la adherencia. De modo que las barras de CFRP lisas y corrugadas con mayor resistencia a cortante desarrollan una tensión adherente superior a las barras con menor resistencia a cortante. Este efecto se debe a una mayor resistencia a corte de la capa superficial de la barra de CFRP que proporciona un incremento de la resistencia de la interfaz de rotura entre la barra y el hormigón. Nanni et al., (1995), observaron que las barras de CFRP lisas o corrugadas fabricadas con resina de epoxi, de mayor resistencia a cortante, presentan una mayor tensión adherente, alrededor del doble, que las barras fabricadas con resina de viniléster, de menor resistencia a cortante (Figs. 2.69 y 2.70). 


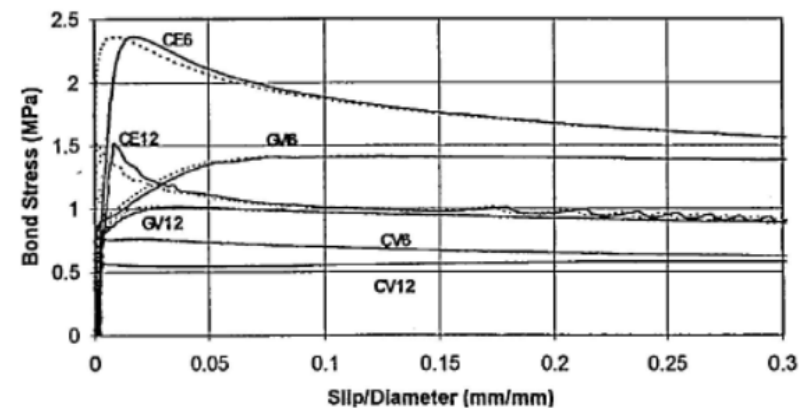

Fig. 2.69. Comportamiento adherente de barras de FRP lisas. CE: fibra de carbono y resina de epoxi; CV: fibra de carbono y resina de viniléster; GV: fibra de vidrio y resina de viniléster. El número índica el diámetro de la barra en mm Nanni et al., 1995.

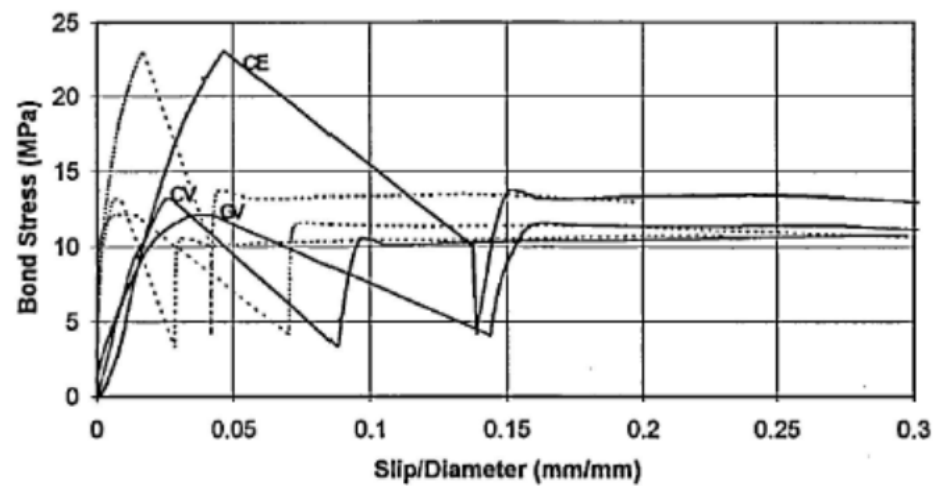

Fig. 2.70. Comportamiento adherente de barras de FRP corrugadas. CE: fibra de carbono y resina de epoxi; $C V$ : fibra de carbono y resina de viniléster; $G V$ : fibra de vidrio y resina de viniléster. Nanni et al., 1995.

En cuanto a las barras de CFRP corrugadas, Achillides et al., (2004), observaron que la resistencia a cortante influye notablemente en la tensión adherente máxima. En dicha investigación obtuvieron en barras de GFRP (módulo elástico del orden de $45 \mathrm{GPa}$ ) una tensión adherente máxima de 10,0 $\mathrm{MPa}$ menor a la desarrollada por las barras de CFRP, del orden de 14,0 MPa, cuyo módulo elástico es de $115 \mathrm{GPa}$, mayor que el de las barras de GFRP. En la misma investigación también se observa que la resistencia a cortante de las barras de CFRP influye en el modo de rotura, de modo que en las barras con mayor resistencia a cortante la rotura se producirá en mayor medida en el hormigón, mientras que en las barras con menor resistencia a corte la rotura se producirá en la capa superficial de la barra, sustituyendo el modo de rotura en el 
primer caso de rotura por aplastamiento del hormigón a rotura de parte o todas las corrugas de la barra o por el modo combinado. Al mismo tiempo, la resistencia a compresión del hormigón también será un parámetro muy influyente en el modo de rotura.

\subsubsection{Resistencia a Compresión del Hormigón}

Los resultados de las diferentes investigaciones realizadas hasta la fecha (Achillides et al., 2004; Dávalos et al., 2008; Baena et al., 2009; Tepfers, 2006) muestran que la resistencia del hormigón es uno de los parámetros, junto con la resistencia a cortante de la barra, que determinan el modo de rotura de adherencia de las barras de CFRP corrugadas, deformadas y con tratamiento superficial durante el ensayo de pullout. La Fig. 2.71 muestra el efecto de la resistencia a compresión del hormigón sobre la adherencia en barras de CFRP corrugadas. En hormigón con una resistencia a compresión mayor a 30-40 $\mathrm{MPa}$, el modo de rotura de adherencia se produce parcialmente en la superficie de la barra de CFRP (por corte de la geometría superficial de la barra) y en el hormigón. Por consiguiente, para el hormigón con resistencia a compresión mayor a 30-40 MPa, la tensión adherente en elementos armados con barras de CFRP corrugadas o deformadas no depende totalmente de la resistencia a compresión del hormigón, sino en mayor medida de la resistencia a cortante de la barra. Sin embargo, para resistencias del hormigón a compresión menores, alrededor de 15-20 MPa, el modo de rotura de adherencia cambia. En este caso, la rotura se produce de un modo similar al de las barras de acero, aplastándose el hormigón enfrente de las corrugas o geometría superficial de la barra. Por lo tanto, en el caso de resistencias del hormigón alrededor de 15-20 MPa, la adherencia se encuentra dominada por la resistencia del hormigón a compresión, y la tensión adherente desarrollada será significativamente menor que la desarrollada por este tipo de barras en hormigón de mayor resistencia. Entonces 
en este caso, se supone que "la tensión adherente es directamente proporcional a la raíz cuadrada de la resistencia a compresión del hormigón”.

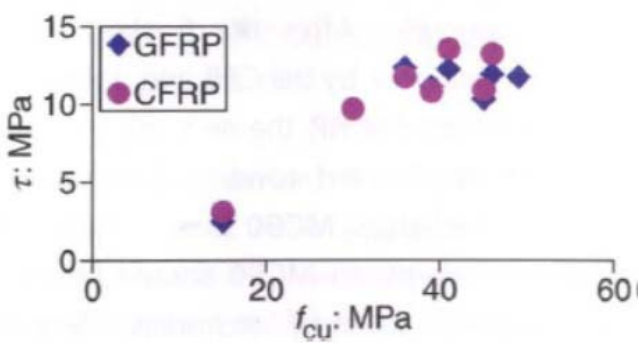

Fig. 2.71. Influencia de la resistencia a compresión del hormigón en la resistencia de adherencia de las barras de CFRP y CFRP corrugadas. Tepfers, 2006.

En la Fig. 2.72a se muestra la tensión adherente de barras de CFRP arenadas (R1), texturizadas (R3) y acero corrugadas (R7) obtenida en hormigones de diferentes resistencias $(\mathrm{C} 1$ y $\mathrm{C} 2$, con resistencia a compresión de 28,63 y 52,19 $\mathrm{MPa}$, respectivamente). Al mismo tiempo, en la Fig. 2.72b se muestra la relación entre la tensión adherente máxima obtenida en ambos hormigones $\left(\tau_{\text {bmax.C2 }} / \tau_{\text {bmax.C1 }}\right)$. Se observa que en las barras de CFRP arenadas el incremento de la tensión adherente en hormigón con resistencia superior es del orden de 1,5 veces respecto al hormigón con menor resistencia, en el caso de diámetros 10,65 y 13,43 mm (\#3 y \#4, respectivamente). Sin embargo, en las barras de CFRP texturizadas de diámetro 9,50 $\mathrm{mm}$ (\#3) no presenta casi influencia la resistencia del hormigón, al contrario de lo que ocurre en este mismo tipo de barras de diámetro $12,53 \mathrm{~mm}$ (\#4) que muestra el mismo incremento de la tensión adherente que las barras arenadas. Esto puede deberse a defectos en la superficie de la barra de CFRP texturizada, puesto que en la investigación de Davalos et al., (2008), se observa que este tipo de barras de CFRP texturizadas presenta una tensión adherente superior a 20,0 MPa en hormigón con resistencia a compresión mayor a $45 \mathrm{MPa}$. En la misma investigación también se observa que a partir de una resistencia a compresión del hormigón de $45 \mathrm{MPa}$ la tensión adherente para este tipo de barras se incrementa muy levemente (Fig. 2.73). En las barras de acero corrugadas se 
observa un mayor incremento de la tensión adherente debido a la resistencia del hormigón, del orden de 2,1 y 1,7 en barras de diámetros 12 y 16 mm, respectivamente.
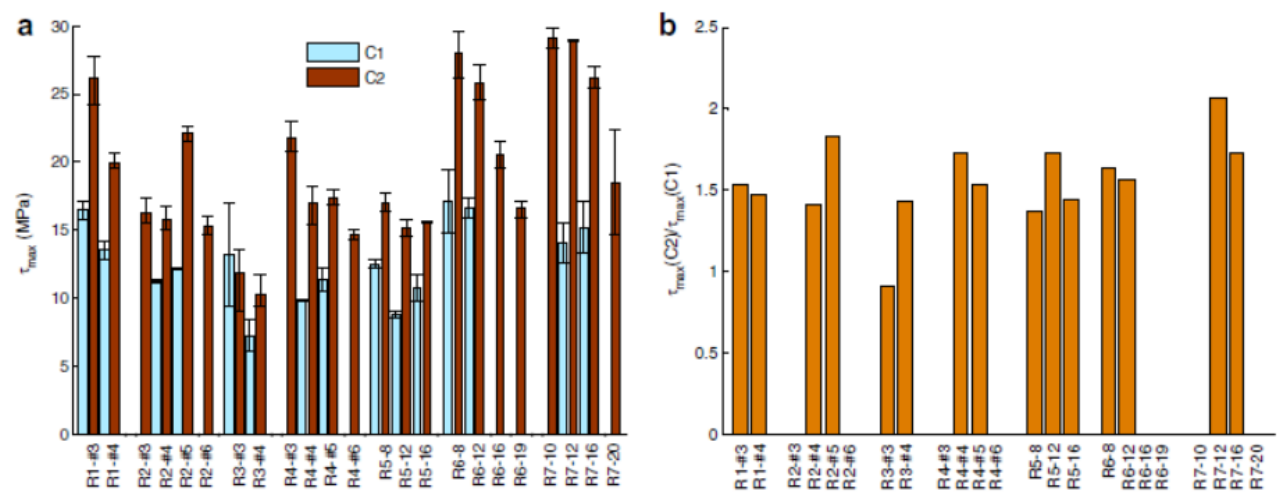

Fig. 2.72. Influencia de la resistencia a compresión del hormigón en tensión adherente de las barras de CFRP arenadas, texturizadas y acero corrugadas. Baena et al., 2009.

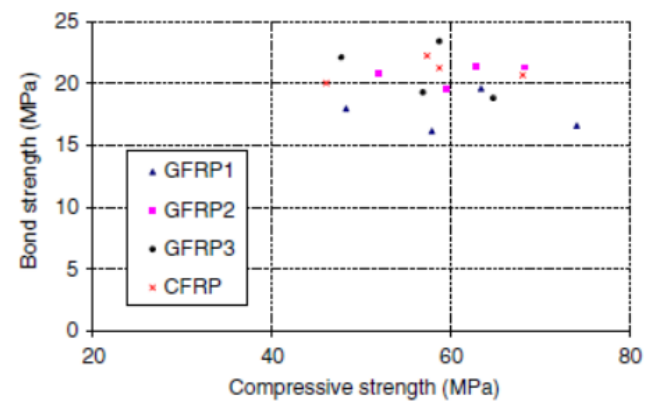

Fig. 2.73. Influencia de la resistencia a compresión del hormigón en la tensión adherente de las barras de CFRP texturizadas. Dávalos et al., 2008.

\subsubsection{Diámetro de la Barra}

El diámetro de la barra es un parámetro muy influyente en el comportamiento adherente entre la barra de CFRP y el hormigón. En las investigaciones realizadas hasta la fecha (Achillides et al., 1997, 2004; Nanni et al., 1995b; Baena et al., 2009; Tepfers, 2006) se observa que las barras de mayor diámetro desarrollan una tensión adherente inferior a las barras de menor diámetro. Este fenómeno produce una mayor disminución de la tensión adherente en hormigones con resistencia a compresión superior a $40 \mathrm{MPa}$ (Fig. 2.72a). La influencia del diámetro de la barra se debe a: 
a) El efecto Poisson, el cual, al tensionar la barra produce una mayor disminución del diámetro en barras con diámetro más grande, lo que origina una disminución de la tensión adherente.

b) El comportamiento elástico y la resistencia a cortante de la barra de CFRP. Debido a que cuando una barra de CFRP es sometida a una tensión a través de su superficie, se producen alargamientos diferentes entre las fibras más internas (menores alargamientos) y las situadas en la capa exterior de la barra (mayores alargamientos), lo cual, produce una distribución no uniforme de las tensiones normales en la sección transversal de la barra (Fig. 2.74). La tensión adherente desarrollada entre la barra de CFRP y el hormigón está directamente relacionada con el valor de la tensión normal ejercida en la superficie de la barra “ $\sigma_{\max }$ ” y, es proporcional a la tensión media desarrollada en la barra " $\sigma_{\text {media }}$ ". Por lo tanto, el aumento del diámetro de la barra incrementa la diferencia entre la $\sigma_{\max }$ y $\sigma_{\text {media, }}$ especialmente cuando la resistencia a cortante de la barra es muy pequeña, lo que produce la disminución de la tensión adherente de la barra. La resistencia a cortante de las barras de CFRP depende principalmente de la resistencia a cortante de la matriz polimérica y de la resistencia a corte de la interfaz entre la matriz polimérica y el refuerzo de fibra de carbono.

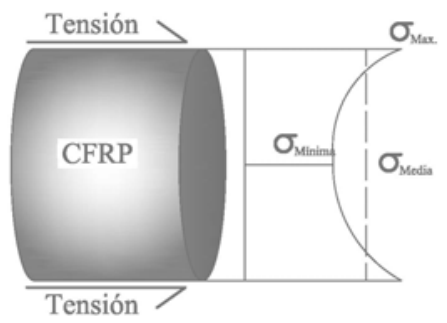

Fig. 2.74. Distribución de las tensiones normales en la sección transversal de una barra de CFRP sometida a una tensión axial. Achillides, 1998.

Este fenómeno no tiene mayor importancia en las barras de acero, puesto que estas poseen una mayor resistencia a corte, y su comportamiento es elastoplástico. En cuanto al comportamiento adherente Baena et al., (2009), observaron que el diámetro de las barras de CFRP no influye en la rigidez 
inicial. Además, Achillides et al., (2004), observaron que la etapa inicial de adherencia producida por el mecanismo de adhesión química finaliza más rápido en barras de mayor diámetro (Fig. 2.75).

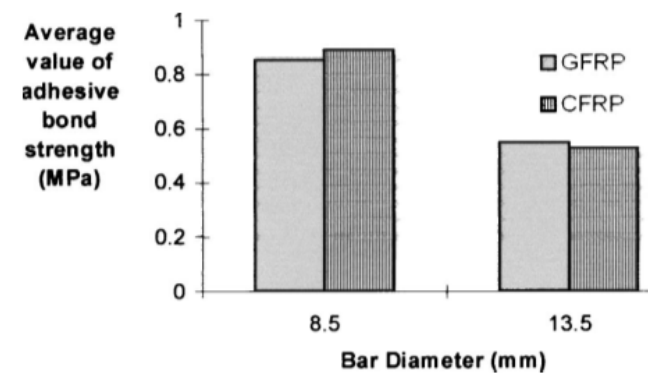

Fig. 2.75. Influencia del diámetro en el comportamiento adherente inicial por el mecanismo de adhesión química en barras de CFRP. Achillides et al., 2004.

\subsubsection{Geometría Superficial de la Barra}

La geometría superficial de las barras de CFRP es el parámetro más importante en el desarrollo de la adherencia (comportamiento pre y post tensión adherente máxima). A su vez, de este parámetro dependerá el tipo de mecanismo adherente principal mediante el cual se moviliza la adherencia entre la barra y el hormigón.

En este apartado, se analiza la influencia de las diferentes tipologías de geometría superficial de las barras de CFRP en el comportamiento adherente, basándose en la clasificación de los distintos tipos de barras de CFRP, expuesta en el apartado 2.5.3, Fig. 2.42.

Según las investigaciones realizadas hasta la fecha (Nanni et al., 1995b; Kanakubo et al., 1993; Katz, 1999), las barras de CFRP lisas desarrollan una tensión adherente máxima del orden de $\sigma_{\max } \approx 2,50 \mathrm{MPa}$ (alrededor del 10-20\% de las barras corrugadas) a un deslizamiento relativo muy reducido. Este tipo de barras desarrollan la adherencia por el mecanismo de adhesión química y fricción entre la barra de CFRP y el hormigón. El modo de rotura de adherencia se realiza por raspado de la superficie de la barra (la adherencia depende de la 
resistencia de la capa superficial de resina). Otros investigadores como Cosenza et al., (1997), obtuvieron valores medios de la tensión adherente máxima de $\sigma_{\max } \approx 1,19 \mathrm{MPa}$ (con un coeficiente de variación de 0,44 ) a un deslizamiento relativo del orden de $0,26 \mathrm{~mm}$ (con un coeficiente de variación de 1,29).

Las barras de CFRP corrugadas y deformadas presentan un comportamiento adherente similar a las barras de acero corrugadas puesto que desarrollan una tensión adherente a un nivel de deslizamiento similar al desarrollado por las barras de acero corrugadas (Tabla 2.27). Al mismo tiempo, su mecanismo principal de adherencia se produce por acuñamiento mecánico.

Respecto a las barras de CFRP con recubrimiento de arena, ya sea arena fina o gruesa, presentan un comportamiento adherente diferente a las barras corrugadas, debido a que alcanzan elevados valores de tensión adherente a un nivel de deslizamiento mucho menor (Tabla 2.28). Esto se debe al mecanismo principal de adherencia entre la barra de CFRP con recubrimiento de arena y el hormigón, puesto que tiene un carácter más friccional. Sin embargo, el modo de rotura de este tipo de barras a diferencia de las barras corrugadas, es frágil.

En cuanto a las barras de CFRP con hélice adherida superficialmente, su comportamiento depende en gran medida de la calidad de la barra, debido a que en las diferentes investigaciones realizadas sobre esta tipología de barras de CFRP se ha detectado una gran variabilidad de resultados. Generalmente el comportamiento de las barras de CFRP con hélice adherida difiere al desarrollado por barras corrugadas, deformadas, texturizadas y con recubrimiento de arena, puesto que desarrollan una menor tensión adherente que el resto de tipos de barras, del orden de $8,38 \mathrm{MPa}$, a un nivel de deslizamiento mayor. Este comportamiento está mejorado con la adición de un recubrimiento de arena en la superficie de la barra de CFRP con hélice adherida, ya que de este modo la barra alcanza una mayor tensión adherente alrededor de 15,0 MPa a un menor nivel de deslizamiento. La rotura por adherencia se produce por 
despegado de la hélice adherida de un modo más dúctil que en las barras con recubrimiento de arena.

Según las investigaciones realizadas, el comportamiento adherente entre las barras de CFRP texturizadas y el hormigón presenta valores en algunos casos similar al desarrollado por las barras de acero corrugadas (Davalos et al., 2008; Okelo et al., 2005) y en otros casos inferiores a estas (Baena et al., 2009). Sin embargo, se observa un comportamiento similar al de las barras de acero cuando la resistencia del hormigón es inferior a 30,0 MPa, aunque su adherencia se produce por el mecanismo de fricción.

\subsubsection{Confinamiento}

La presión de confinamiento sobre las barras de CFRP presenta una menor influencia que en las barras de acero, puesto que al poseer un módulo elástico menor (es decir, una resistencia a cortante menor) la presión de confinamiento se disipa en la superficie de la barra (Achillides, 1998). Otras conclusiones obtenidas por Malvar et al., (2004), respecto a la influencia de la presión de confinamiento en barras de CFRP corrugadas, y arenadas, mediante el ensayo de pullout con confinamiento (tensión de confinamiento de 3,45 a 24,1 $\mathrm{MPa}$, con incrementos de 6,9 $\mathrm{MPa}$; para eliminar la resistencia lateral entre la barra y el hormigón, antes de cada ensayo de pullout, se fisura la probeta de hormigón en ocho partes iguales), son las siguientes:

- Las barras de CFRP corrugadas en presencia de tensiones de confinamiento durante el ensayo de pullout, presentan un comportamiento de adherencia similar a las barras de acero corrugadas, puesto que su tensión de adherencia a un nivel de confinamiento máximo se incrementa 2,5 veces respecto de la tensión adherente inicial (Fig. 2.76). A medida que se incrementa la presión de confinamiento, las corrugas de la barra sufren mayores daños, llegando a reducir su altura ante una presión de 
confinamiento de 24,1 MPa alrededor del 63\% de la inicial (con tensiones de confinamiento de 10,3 y 17,2 la altura de la corruga se reduce un 18 y 55\% de la inicial, respectivamente).

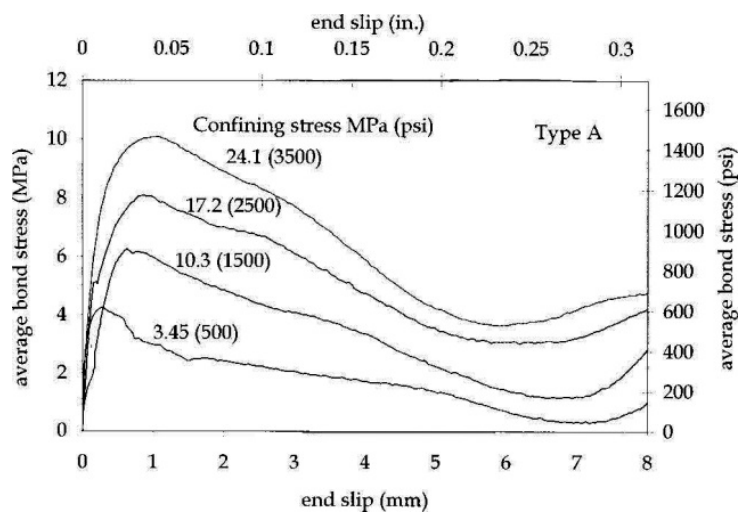

Fig. 2.76. Comportamiento de adherencia de las barras de CFRP corrugadas en presencia de confinamiento, durante el ensayo de pullout. Malvar et al., 2004.

- Las barras de CFRP arenadas no muestran un aumento significativo de la tensión adherente ante la presencia de tensiones de confinamiento (Fig. 2.77). Esto es debido a la pequeña altura de las deformaciones de la superficie de la barra; las cuales no producen el confinamiento necesario contra el hormigón para aumentar la tensión de adherencia.

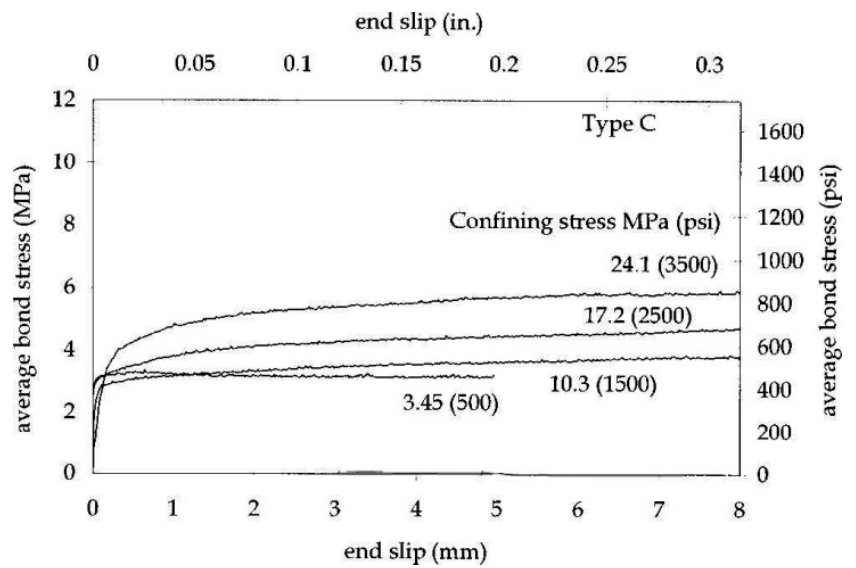

Fig. 2.77. Comportamiento de adherencia de las barras de CFRP arenadas en presencia de confinamiento, durante el ensayo de pullout. Malvar et al., 2004. 


\subsubsection{Longitud de Anclaje}

El incremento de la longitud de anclaje disminuye la tensión adherente máxima (Fig. 2.78) (Achillides et al., 2004; Nanni et al., 1995), produce un aumento considerable de la fuerza resistida y un incremento de la rigidez adherente inicial durante el ensayo de pullout (Fig. 2.79) (B. Benmokrane et al., 2000). Este fenómeno también se produce en barras de acero y es resultado de una distribución no uniforme de la tensión adherente a lo largo de la longitud de la barra. Sin embargo, el incremento de la tensión adherente al disminuir la longitud de anclaje es mayor en barras de menor diámetro que en barras de mayor diámetro.

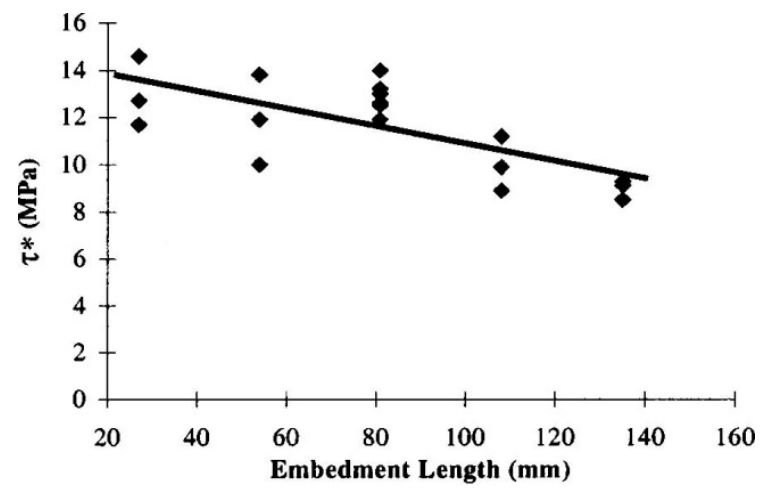

Fig. 2.78. Influencia de la longitud de anclaje en barras de CFRP (Ø 13,5mm). Achillides et al., 2004

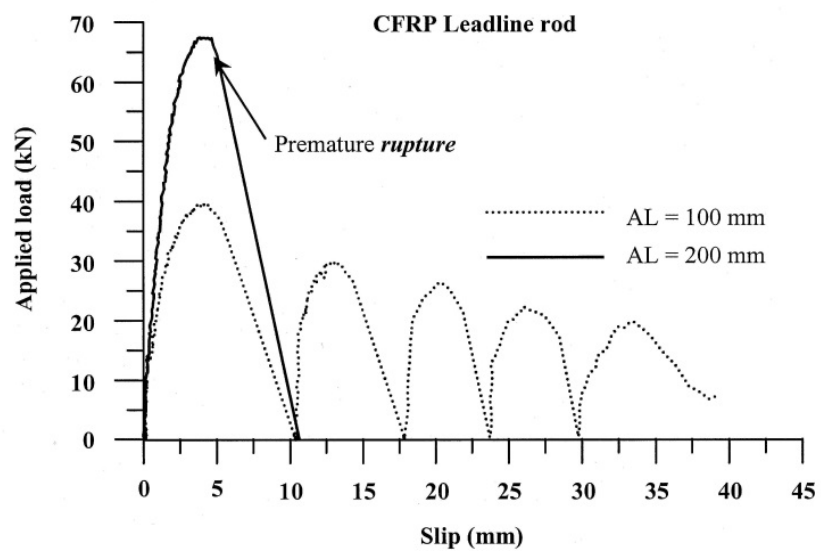

Fig. 2.79. Influencia de la longitud de anclaje en barras de CFRP (Ø 7,9mm). Benmokrane et al., 2000. 


\subsubsection{Espesor del Recubrimiento}

Las barras de acero corrugadas al someterse a tensión durante el ensayo pullout descentrado presentan un comportamiento en el recubrimiento de hormigón, situado entre el estado plástico y el estado parcialmente fisurado y elástico tendiendo más al último estado. Esto es originado por la mayor rigidez de las corrugas de acero debido a que fisura el hormigón circundante a la barra. Del mismo modo, debido a la menor rigidez de las corrugas, las barras de CFRP presentan un comportamiento similar con tendencia al estado plástico (ángulo del brazo mecánico de $45^{\circ}$ ) (Fig. 2.80). Por lo tanto, las barras de CFRP corrugadas presentan un comportamiento adherente similar a las barras de acero en cuanto al espesor del recubrimiento de hormigón. Sin embargo, desarrollan mayores tensiones de tracción en el recubrimiento que las barras de acero corrugadas. Por consiguiente, dependiendo de la rigidez de las barras de CFRP se pueden producir mayores tensiones de tracción y es necesario un recubrimiento de hormigón mayor.
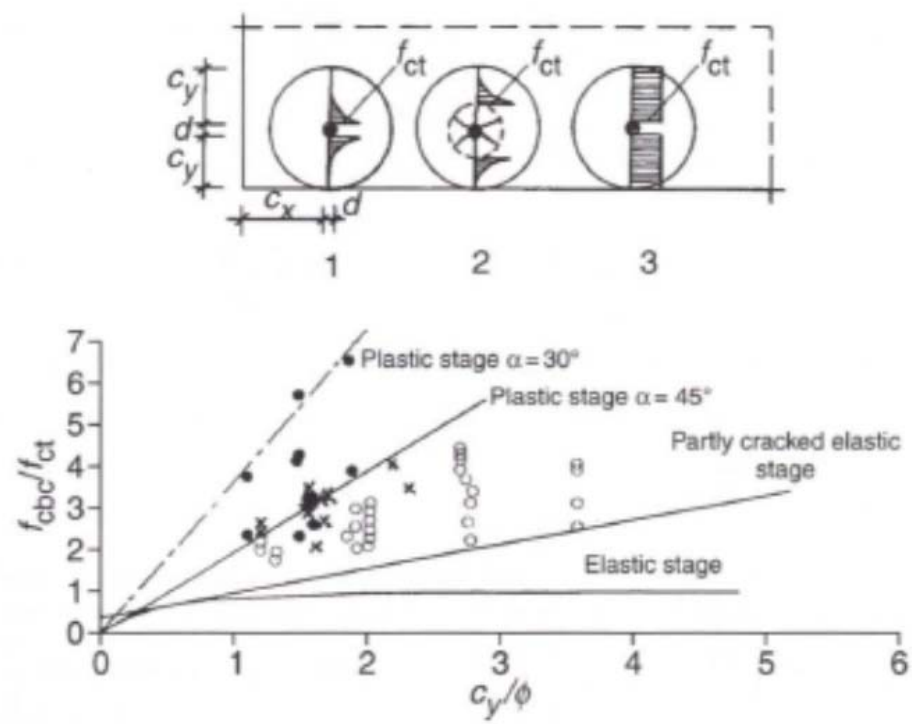

Fig. 2.80. Distribución de las tensiones de tracción en el hormigón circundante e influencia del recubrimiento en la capacidad de adherencia en barras de acero (círculos abiertos), CFRP corrugada (cruces) y GFRP arenada (circulo sombreado). $\mathrm{F}_{\mathrm{cbc}}$, es la tensión adherente de la barra, $\mathrm{f}_{\mathrm{ct}}$, es la resistencia a tracción del hormigón, $\varnothing$, es el diámetro de la barra, $\mathrm{C}_{\mathrm{y}}$, es el espesor del recubrimiento. Tepfers, 2006. 


\subsubsection{Temperatura}

El comportamiento adherente de las barras de CFRP frente a diferentes temperaturas depende principalmente de la matriz polimérica de la barra, tanto de su espesor como de su temperatura de transición vítrea. Las altas temperaturas, superiores a $100^{\circ} \mathrm{C}$, disminuyen considerablemente la tensión adherente de las barras de CFRP (Honma et al., 1989). Esta disminución se debe a la perdida de rigidez de la matriz polimérica de la barra. En la Tabla 2.29 se muestra la tensión adherente a temperatura final respecto a temperatura de $20{ }^{\circ} \mathrm{C}$, esta disminuye su tensión adherente inicial de 20 a $90 \%$ cuando se incrementa su temperatura de 100 a $250^{\circ} \mathrm{C}$ (Blontrock, (1999).

\begin{tabular}{cc}
\hline $\begin{array}{c}\text { Temperatura, } \\
\text { en }{ }^{\circ} \mathrm{C} .\end{array}$ & $\begin{array}{c}\text { Tensión adherente en función de la tensión } \\
\text { adherente a } 20^{\circ} \mathrm{C} .(\%)\end{array}$ \\
\hline 100 & $35-80$ \\
\hline 150 & $20-40$ \\
\hline 220 & $10-20$ \\
\hline
\end{tabular}

Tabla 2.29. Adherencia entre las barras de FRP y el hormigón a elevadas temperaturas. Los valores de la tabla dan los mayores y menores resultados de adherencia. Blontrock, 1999.

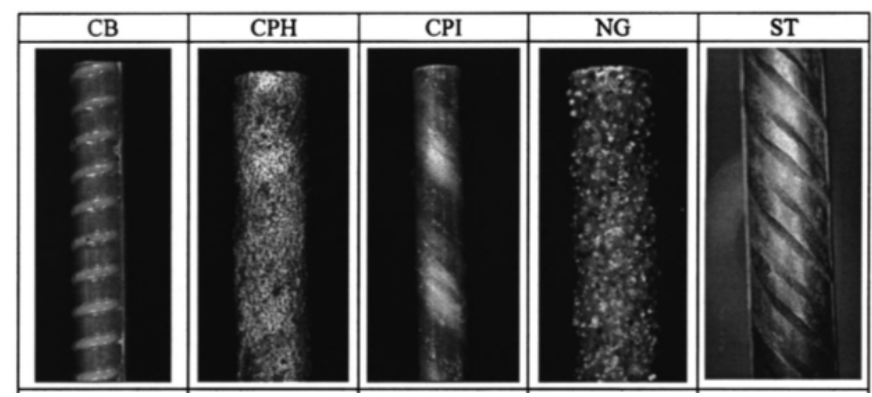

Fig. 2.81. Barras de FRP y acero empleadas en el estudio. Katz et al., 1999 .

En cuanto a la influencia de altas temperaturas, mayores a $100^{\circ} \mathrm{C}$, sobre la adherencia en diferentes tipologías de barras de FRP (Fig. 2.81): barras de FRP corrugadas "CB", barras de FRP con hélice adherida y arenadas "CPH", barras de FRP endentadas por hélice adherida "CPI", barras de FRP endentadas por hélice adherida y arenadas "NG", y barras de acero corrugadas "ST". La temperatura de transición vítrea de cada tipología de barra de FRP es de 124, 
122,95 y $60^{\circ} \mathrm{C}$, respectivamente. Se observa en el estudio de Katz et al., (1999) que la tensión adherente máxima obtenida en condiciones estándar de laboratorio, a $20^{\circ} \mathrm{C}$, es de 13,2 MPa en barras de FRP corrugadas, 12,2 MPa en barras de FRP con hélice adherida y arenadas, 10,9 MPa en barras de FRP endentadas mediante hélice adherida, 4,0 MPa en barras de FRP endentadas mediante hélice adherida y arenadas y 11,2 MPa en barras de acero corrugadas. Sin embargo, a una temperatura de $200{ }^{\circ} \mathrm{C}$ las barras de acero corrugadas presentan una disminución menor de la tensión adherente, del orden del $40 \%$, frente a las barras de FRP que disminuyen más del 80\% (Fig. 2.82 y Tabla 2.30).
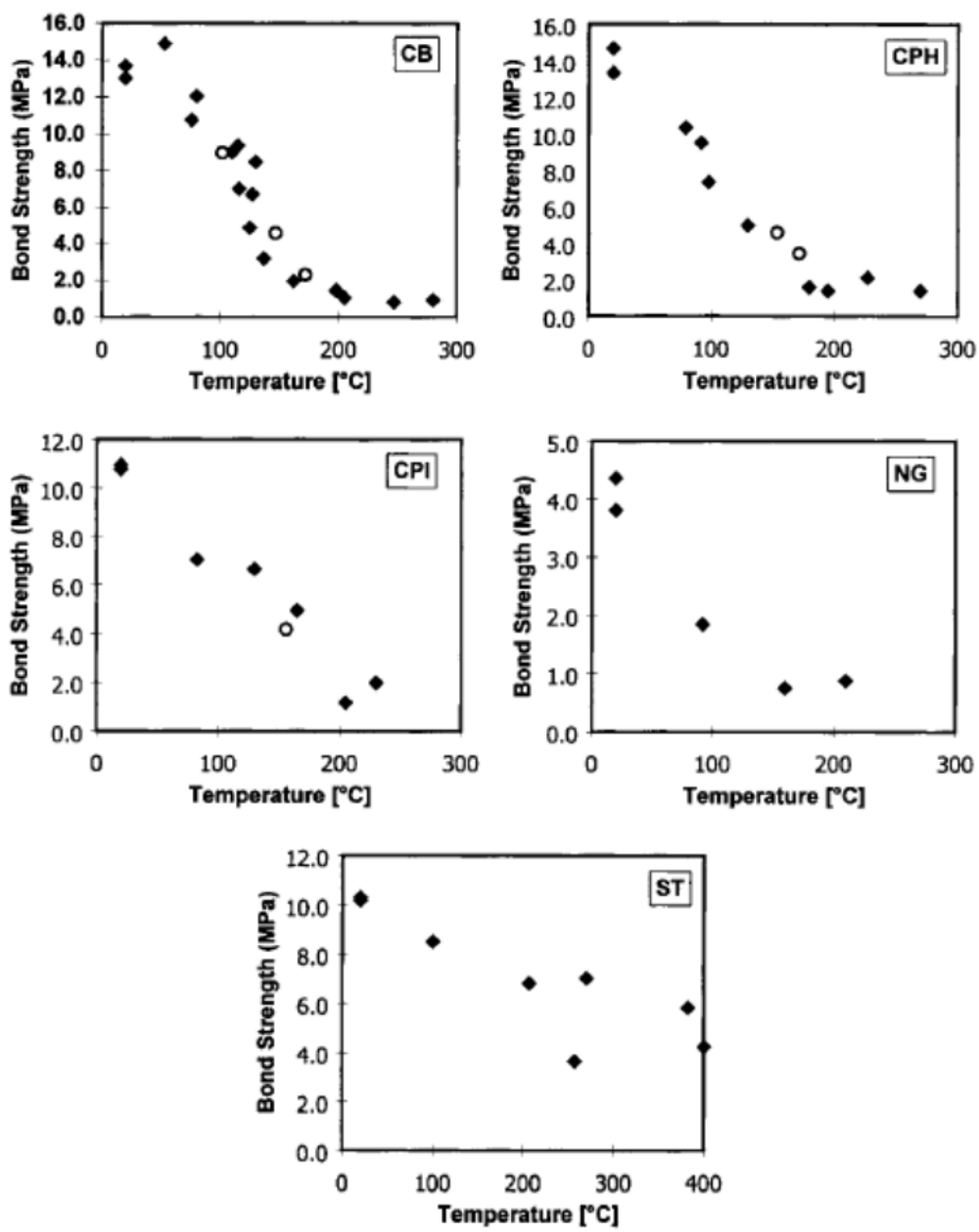

Fig. 2.82. Disminución de la tensión adherente en función de la temperatura en diferentes tipos de barras de FRP y de acero corrugadas. Katz et al., 1999. 


\begin{tabular}{|c|c|c|c|c|}
\hline \multirow{2}{*}{$\begin{array}{l}\text { Tipo de } \\
\text { barra }\end{array}$} & \multicolumn{3}{|c|}{ Tensión adherente, en MPa. } & \multirow{2}{*}{$\begin{array}{c}\text { Perdida de } \\
\text { adherencia a } \\
200^{\circ} \mathrm{C} \text {, en } \%\end{array}$} \\
\hline & $\begin{array}{l}\text { A temperatura de } \\
\text { laboratorio. }\end{array}$ & $\begin{array}{c}\text { Tensión adherente a } \\
130^{\circ} \mathrm{C}\end{array}$ & $\begin{array}{c}\text { Tensión adherente a } \\
200^{\circ} \mathrm{C} .\end{array}$ & \\
\hline CB & 13,2 & 6,7 & 1,1 & 91,7 \\
\hline $\mathrm{CPH}$ & 12,2 & 5,0 & 1,7 & 86,1 \\
\hline CPI & 10,9 & 6,7 & 1,6 & 85,3 \\
\hline NG & 4,1 & 0,8 & 0,8 & 80,5 \\
\hline ST & 11,2 & 8,1 & 6,9 & 38,4 \\
\hline
\end{tabular}

Tabla 2.30. Valor de la tensión adherente en barras de FRP y acero a $20^{\circ} \mathrm{C}$ y $200^{\circ} \mathrm{C}$. Katz et al., 1999, 2000.

Por el contrario, a un rango de temperaturas inferiores a $100^{\circ} \mathrm{C}$ el comportamiento adherente varía en gran medida dependiendo de las propiedades físicas y mecánicas de la matriz polimérica y de la tipología de barra de CFRP. Davalos et al., (2008), observaron una disminución del 4 al 9\% de la tensión adherente en barras de CFRP texturizadas tras ser sometidas a diferentes condiciones ambientales (a un rango de temperaturas del orden de $-20^{\circ} \mathrm{C}$ a $+60^{\circ} \mathrm{C}$ ); tales como, 90 días inmersas en un tanque de agua a $20^{\circ} \mathrm{C}$ (condición "W"), 90 días inmersas en un tanque de agua a 60 $\mathrm{C}$ (condición "T"), y 30 días sometidas a ciclos de 1 día, en el cual se varía la temperatura de $60^{\circ} \mathrm{C}$ a $-20^{\circ} \mathrm{C}$ (condición "E"). Los valores obtenidos de la tensión adherente respecto a la tensión adherente en condiciones de control a $+20^{\circ} \mathrm{C}$ (tensión adherente de 22,26 $\mathrm{MPa}$ ) son del 92,9\% (tensión adherente de 20,68 $\mathrm{MPa}$ ) para la condición ambiental "W", del 90,1\% (tensión adherente de 20,04 MPa) para la condición tipo "T" y por último del 95,6\% (tensión adherente de 21,27 $\mathrm{MPa}$ ) para la condición ambiental tipo "E". En la Fig. 2.83 se muestra el comportamiento adherente de este tipo de barras de CFRP en cada condición ambiental.

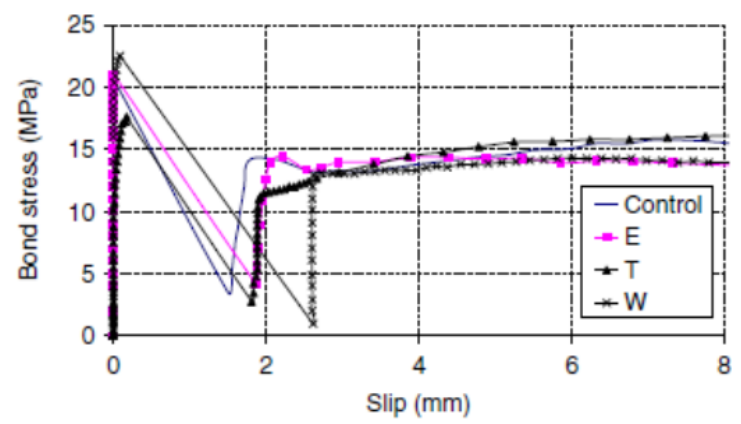

Fig. 2.83. Comportamiento adherente de las barras de CFRP texturizadas ante diferentes condiciones ambientales. Davalos et al., 2008. 
En el mismo sentido, Alvarez et al., (2005), observaron una disminución de la tensión adherente (respecto de la tensión adherente obtenida a la temperatura de control de $20^{\circ} \mathrm{C}$ ) a 40,60 y $80{ }^{\circ} \mathrm{C}$ del 2,19 y $32 \%$ (Tabla 2.31). Estos resultados difieren de los obtenidos por Davalos et al., presentando una reducción menor de la tensión adherente a temperaturas iguales o inferiores a $40^{\circ} \mathrm{C}$ y por el contrario una mayor reducción a temperaturas superiores a $40^{\circ} \mathrm{C}$. Esta discordancia puede deberse a las diferentes propiedades de la matriz polimérica. Cabe destacar que la tensión adherente a una temperatura de $80^{\circ} \mathrm{C}$ es mayor a 11,3 $\mathrm{MPa}$, lo que supone que es eficiente estructuralmente a dicha temperatura.

\begin{tabular}{ccc}
\hline Tipo de barra & $\begin{array}{c}\text { Temperatura, } \\
\text { en }{ }^{\circ} \mathrm{C} .\end{array}$ & $\begin{array}{c}\text { Tensión adherente, en } \\
\text { MPa. }\end{array}$ \\
\hline & -20 & 16,6 \\
CFRP arenada & +20 & 16,5 \\
& +40 & 16,2 \\
& +60 & 13,3 \\
& +80 & 11,3 \\
\hline
\end{tabular}

Tabla 2.31. Influencia de la temperatura en la tensión adherente de las barras de CFRP arenadas. Alvarez, et al., 2005.

En contraposición de la reducción de la tensión adherente a temperaturas superiores $40^{\circ} \mathrm{C}$, a temperaturas inferiores a $0^{\circ} \mathrm{C}$ la tensión adherente de las barras de CFRP se incrementa levemente. Alvarez et al., (2005), observaron que a una temperatura de $-20^{\circ} \mathrm{C}$ se incrementa la tensión adherente de las barras de CFRP arenadas $\left(9,5 \mathrm{~mm}\right.$ de diámetro y $\mathrm{T}_{\mathrm{g}}$ del orden de $\left.120^{\circ} \mathrm{C}\right)$ alrededor del $1 \%$ respecto a la tensión adherente obtenida a una temperatura de $+20^{\circ} \mathrm{C}$ (Tabla 2.31).

Respecto al modo de rotura por adherencia, las barras de acero corrugadas durante todo el rango de temperaturas de $0-400^{\circ} \mathrm{C}$ muestran una rotura de adherencia por pullout (aplastamiento del hormigón, situado enfrente de las corrugas), mientras que las barras de FRP muestran un comportamiento similar hasta alcanzar la temperatura de transición vítrea (alrededor de $130^{\circ} \mathrm{C}$ ) y, 
una vez superada esta temperatura, la rotura de adherencia se produce en la superficie de la barra de FRP y, por este motivo el hormigón circundante a la barra tras el ensayo de pullout presentará restos de la matriz polimérica. Lo cual, indica que el efecto producido por la disminución de la resistencia del hormigón, a temperaturas alrededor de $30-330^{\circ} \mathrm{C}$, no influye en la disminución de la tensión adherente de las barras de FRP, en cambio, esta sí que afecta las barras de acero (Katz et al., 1999). En cambio, a un rango de temperaturas de 20 a $80^{\circ} \mathrm{C}$ el comportamiento adherente tras la rotura no varía. Este está formado por una disminución gradual de la tensión adherente al mismo tiempo que se producen grandes deslizamientos (Fig. 2.84) (Alvarez et al., (2005).

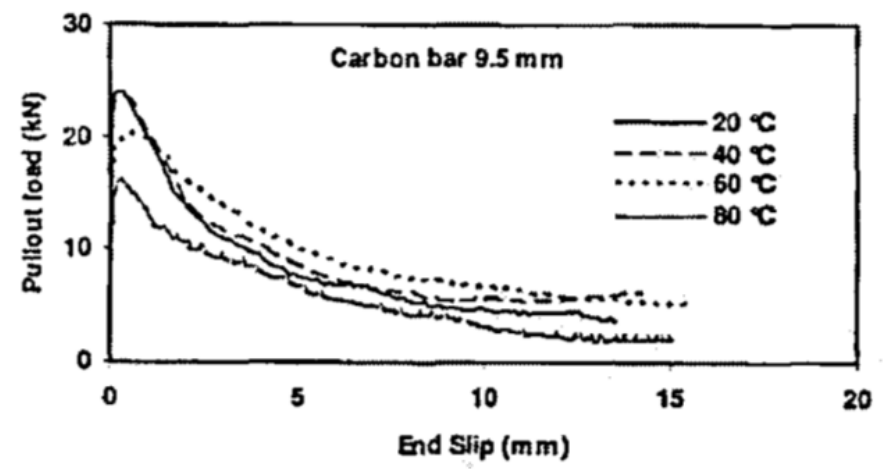

Fig. 2.84. Comportamiento adherente de las barras de CFRP arenadas a diferentes temperaturas. Alvarez, et al., 2005.

Las barras de FRP con algún tipo de recubrimiento superficial muestran una mayor tensión adherente residual. Katz et al., (1999, 2000), observó que las barras de FRP arenadas o con hélice adherida (CPH, CPI), muestran a $200^{\circ} \mathrm{C}$ una mayor tensión adherente residual, debido a las propiedades térmicamente no conductoras de esos compuestos inorgánicos (Tabla 2.30). Por lo tanto, la tensión adherente frente a altas temperaturas depende de la resina polimérica de la capa superficial de la barra, tanto de su espesor como de su temperatura de transición vítrea, y del recubrimiento superficial de esta. 

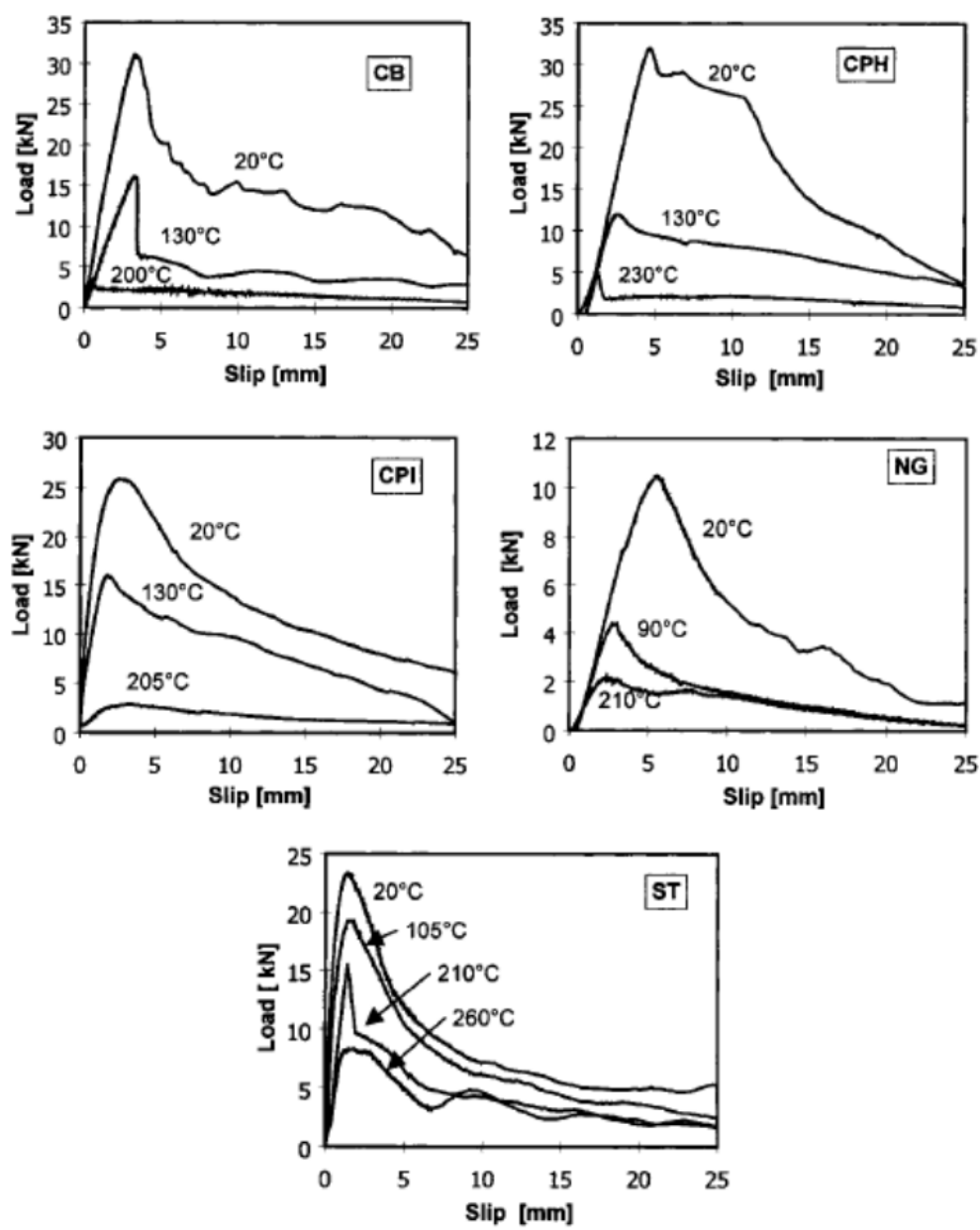

Fig. 2.85. Comportamiento de adherencia de las barras de FRP y acero en función de la temperatura. Katz et al., 1999.

La rigidez de la tensión adherente (pendiente ascendente inicial de la gráfica de tensión adherente/deslizamiento) de las barras de FRP disminuye al a temperaturas superiores a $130{ }^{\circ} \mathrm{C}$ de un modo más acusado que en las barras de acero (Fig. 2.85). Esto es debido a la degradación de la matriz polimérica superficial, lo cual, produce un cambio del mecanismo de adherencia, que pasa de acuñamiento mecánico a un mecanismo más friccional (Katz et al., 1999). Sin embargo, Alvarez et al., (2005) observó que a un rango de temperaturas inferiores, del orden de $20-80^{\circ} \mathrm{C}$ la rigidez adherente no varía (Fig. 2.84). 


\subsubsection{Posición de la Barra}

Del mismo modo que en las barras de acero, la posición de la barra en el elemento de hormigón afecta a su tensión adherente, puesto que durante el vertido del hormigón, el aire, el agua y los finos se sitúan entre las corrugas de la barra produciendo un hormigón más pobre en dicha zona, por lo tanto, al tensionar el elemento se producen mayores deslizamientos y una menor tensión adherente. En el caso de las barras de CFRP situadas a $280 \mathrm{~mm}$ de la base del elemento de hormigón la tensión adherente es del orden de $66 \%$ de la desarrollada por las barras de CFRP situadas a $19 \mathrm{~mm}$ de la base (Eshani et al., 1993). En cuanto a la otro estudio la relación entre la tensión adherente de las barras situadas en posición adherente deficiente y las situadas en posición de adherencia buena, obteniendo un valor de la relación entre la tensión adherente de las barras situadas en posición de adherencia buena ${ }^{24}$ respecto a las situadas en posición de adherencia deficiente de 1,23, en el caso de hormigón de resistencia convencional. Este valor se reduce a 1,18 en el caso de hormigón de alta resistencia el valor se reduce a 1,18 (Benmokrane et al., 1993).

\footnotetext{
${ }^{24}$ La posición de adherencia buena, es aquella posición de la barra en el interior de la pieza de hormigón, donde cualquier zona de la armadura cuyo eje forma durante el hormigonado un ángulo con la horizontal igual o mayor que $45^{\circ}$, ó que si el ángulo es inferior a $45^{\circ}$, la zona de la barra considerada está en la mitad inferior de la sección o a una distancia igual o mayor a $300 \mathrm{~mm}$ de la cara libre de una capa de hormigonado.
} 
2.5.5. Métodos de Cálculo del Comportamiento Adherente entre el Hormigón y las Barras de CFRP

En la actualidad, debido al corto periodo de tiempo desde que se introdujeron las barras de CFRP en el ámbito estructural, la falta de estandarización y la gran cantidad de tipologías de barras de CFRP, todavía se está procediendo a la recogida de datos (valores de la tensión adherente) mediante ensayos directos de laboratorio, que posteriormente serán empleados para calibrar los diferentes métodos de cálculo analíticos del comportamiento adherente de las barras de CFRP.

En el presente apartado, se describen y analizan los diferentes métodos de cálculo analíticos y directos del comportamiento adherente entre las barras de CFRP y el hormigón.

\subsubsection{Métodos Analíticos}

Los métodos de cálculo analíticos del comportamiento adherente entre las barras de CFRP y el hormigón calculan la relación constitutiva de tensión de adherencia/deslizamiento. Estos métodos de cálculo son calibrados mediante los resultados del comportamiento adherente obtenidos a través de los ensayos directos, normalmente por pullout.

Inicialmente estos métodos analíticos se basaron en los métodos de cálculo de estructuras de hormigón armado con acero (Método Bertero, Eligehausen y Popov “B.E.P”, 1983). Para ello, se introdujeron modificaciones a los métodos de cálculo analíticos en barras de acero, puesto que los datos recogidos en los ensayos de adherencia (pullout) con barras de acero, se asume la distribución constante de la tensión de adherencia a lo largo de la longitud de anclaje, mientras que, el deslizamiento relativo se calcula en el extremo de la barra no tensionado. Este procedimiento es adecuado para este tipo de barras, 
puesto que los valores de los deslizamientos en los extremos tensionado y no tensionado, son muy similares, por lo tanto, se asume una distribución constante de la tensión adherente. Por el contrario, esta hipótesis no es correcta en las barras de CFRP, puesto que los valores de los deslizamientos obtenidos en los dos extremos de la barra son dispares.

En el año 1997, Karlsson y Tepfers, pretendieron solucionar este problema reduciendo la longitud de anclaje durante el ensayo de pullout, a 2-3 veces el diámetro de la barra, pero observaron, debido a las irregularidades de la barra, que esta reducción producía grandes dispersiones de los resultados. Por este motivo, los métodos de cálculo analíticos desarrollados predicen la relación constitutiva de tensión de adherencia/deslizamiento.

El primer método de cálculo analítico fue el desarrollado por Malvar en el año 1994, conocido como el Método Malvar. Seguidamente, durante los años 1995 y 1996, E. Cosenza, G. Manfredi y R. Realfonzo desarrollaron un nuevo método de cálculo, basado en el Método B.E.P de 1983, denominado Método B.E.P Modificado o también conocido por el nombre de Método de la Doble Pendiente (en anglosajón, denominado "Double Branch Model"). Finalmente, en el año 1995, E. Cosenza, G. Manfredi y R. Realfonzo desarrollan un nuevo método analítico de cálculo de la relación constitutiva entre la tensión adherente y el deslizamiento, denominado Método C.M.R.

\subsection{Método Malvar}

Malvar, (1994), con base en su investigación desarrolla un nuevo método de cálculo analítico del comportamiento adherente entre las barras de FRP y el hormigón. Este método calcula y modeliza todo el comportamiento de la curva de tensión de adherencia/deslizamiento. A su vez, depende de dos constantes empíricas, las cuales son calculadas mediante el ajuste de las curvas constitutivas y experimentales de tensión de adherencia/deslizamiento. El 
Método Malvar emplea la Ec. 2.20 para el cálculo de la gráfica de tensión de adherencia/deslizamiento.

$$
\frac{\tau}{\tau_{\max }}=\frac{F \cdot\left(\frac{s}{s_{m}}\right)+(G-1) \cdot\left(\frac{s}{s_{m}}\right)^{2}}{1+(F-2) \cdot\left(\frac{s}{s_{m}}\right)+G \cdot\left(\frac{s}{s_{m}}\right)^{2}}
$$

Donde: $\tau_{\max }$, es la tensión adherente máxima. $\tau$, es la tensión adherente. $\mathrm{s}_{\mathrm{m}}$, es el deslizamiento producido a tensión adherente máxima. $\mathrm{s}$, es el deslizamiento de la barra. F y $\mathrm{G}$, son constantes empíricas no dimensionales calculadas para cada tipo de barra.

Con base en su estudio anterior Malvar, (1995), desarrolló otras dos nuevas ecuaciones de cálculo del comportamiento adherente en función del confinamiento (Ec. 2.21 y 2.22).

$$
\begin{aligned}
& \frac{\tau_{\max }}{f_{t}}=A+B \cdot\left(1-e^{\frac{-C \sigma}{f_{t}}}\right) \\
& \frac{s_{m}}{d_{b}}=D+E \cdot \frac{\sigma}{f_{t}}
\end{aligned}
$$

Donde: $\tau_{\max }$, es la tensión adherente máxima. $\mathrm{s}_{\mathrm{m}}$, es el deslizamiento producido a tensión adherente máxima. $\mathrm{f}_{\mathrm{t}}$, es la resistencia a tracción del hormigón. $\sigma$, es la presión radial de confinamiento. $d_{b}$, es el diámetro nominal de la barra. A, B, C, D y E son constantes empíricas no dimensionales calculadas para cada tipo de barra.

\subsection{Método B.E.P Modificado}

El Método B.E.P fue desarrollado por V. V. Bertero, R. Eligehausen y E.P. Popov en el año 1983, para el cálculo analítico de la gráfica constitutiva de tensión adherente/deslizamiento entre barras de acero corrugadas y el hormigón. 
Este método, también fue empleado inicialmente en barras de FRP (Faoro, 1992; Alunno Rossetti et al., 1995; Cosenza et al., 1995).

La ley analítica del Método B.E.P se muestra en la Fig. 2.86. Esta se compone, inicialmente, de una pendiente ascendente que finaliza cuando se alcanza la tensión adherente máxima $\left(\tau_{1}=\tau_{\max }\right)$ a un deslizamiento $\mathrm{s}_{1}\left(\mathrm{~s}_{1}=\mathrm{s}_{\max }\right)$, seguidamente, se produce una tensión adherente constante, durante la cual se desarrolla la tensión adherente máxima $\left(\tau_{1}=\tau_{\max }\right)$ hasta un deslizamiento $\mathrm{s}_{2}$, posteriormente, se produce una pendiente lineal descendente que transcurre desde, $s_{2}, \tau_{1}$, hasta $s_{3}, \tau_{3}$, y finalmente se desarrolla una tensión adherente friccional $\tau_{3}$ de un modo constante.

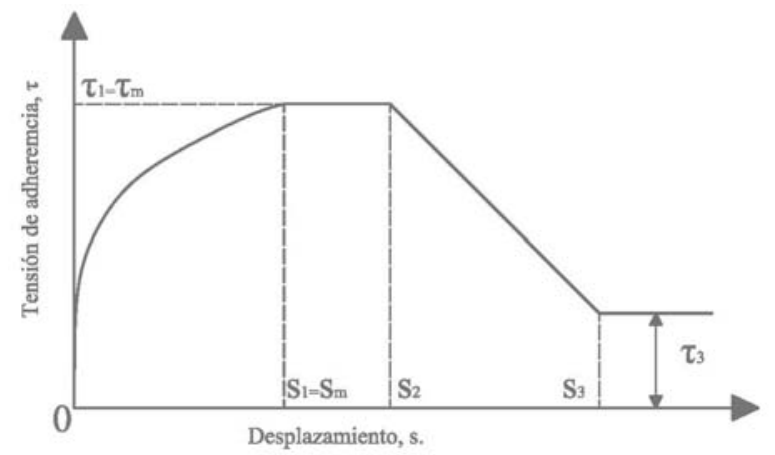

Fig. 2.86. Gráfica constitutiva de tensión adherente/deslizamiento del modelo analítico B.E.P. Eligehausen et al., 1983.

Para el cálculo analítico de la pendiente ascendente $\left(\mathrm{s} \leq \mathrm{s}_{1}\right)$ de la gráfica constitutiva de tensión adherente/deslizamiento mediante el Método B.E.P, se emplea la Ec. 2.23.

$$
\frac{\tau}{\tau_{m}}=\left(\frac{s}{s_{m}}\right)^{\alpha} \quad s \leq s_{m}
$$

Donde: $\tau_{1}$, es la tensión adherente máxima $\left(\tau_{\mathrm{m}}\right) . \mathrm{s}_{1}$, es el deslizamiento durante la tensión adherente máxima $\left(\mathrm{s}_{\mathrm{m}}\right)$. $\alpha$, es el parámetro de ajuste de la gráfica, el cual no debe ser mayor que 1. En el caso de las barras de acero corrugadas el valor de $\alpha$ propuesto por Eligehausen et al., (1983), es 0,40, también adoptado por el Model Code de 1990. 
Los valores de los parámetros $\mathrm{s}_{2}, \mathrm{~s}_{3}$ y $\tau_{3}$ deben ser calibrados (calibrados por el método de mínimos cuadrados) para cada tipo de barra en función a los resultados experimentales obtenidos.

Durante los años 1995 y 1996, E. Cosenza, G. Manfredi y R. Realfonzo desarrollan una nueva versión modificada del Método B.E.P de Eligehausen et al., (1983), denominada Método B.E.P. Modificado, o también denominado Método de la Doble Pendiente (en anglosajón "Double Branch Model"). Este método fue desarrollado con base al estudio experimental realizado por Cosenza et al., (1995), los cuales observaron que las gráficas constitutivas experimentales no mostraban la segunda pendiente constante de adherencia. Por lo tanto, la gráfica constitutiva de tensión adherente/deslizamiento de este método modificado se compone de dos pendientes principales; inicialmente, de una pendiente ascendente (igual a la pendiente ascendente del Método B.E.P) que finaliza cuando se alcanza la tensión adherente máxima $\left(\tau_{1}=\tau_{\max }\right)$ a un deslizamiento $\mathrm{s}_{1}\left(\mathrm{~s}_{1}=\mathrm{s}_{\max }\right)$, posteriormente, de una pendiente lineal descendente desde $s_{1}\left(s_{1}=s_{\text {max }}\right)$ hasta $s_{3}\left(s_{3}=s_{u}\right)$, y finalmente se desarrolla una tensión adherente friccional $\tau_{3}$ de un modo constante.

La ley analítica del Método B.E.P Modificado se muestra en la Fig. 2.87.

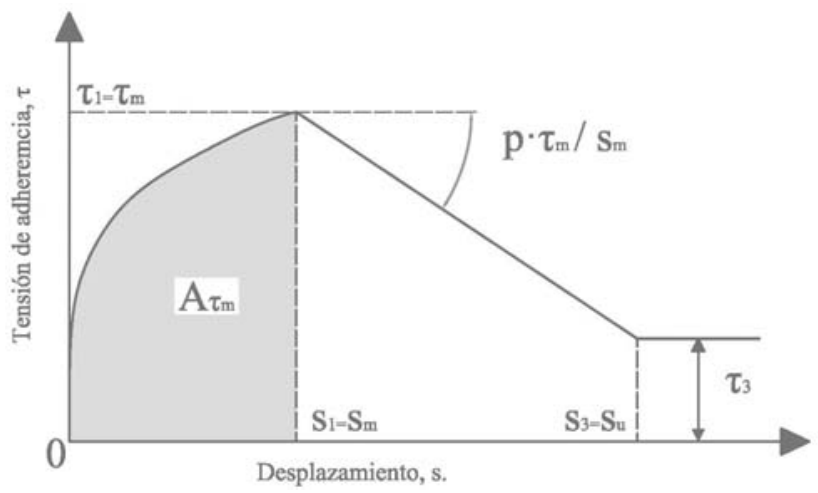

Fig. 2.87. Gráfica constitutiva de tensión adherente/deslizamiento del modelo analítico B.E.P Modificado. Cosenza et al., 1995. 
El cálculo de la pendiente ascendente de la gráfica se realiza del mismo modo que en el Método B.E.P, mediante la Ec. 2.23. Mientras que para el cálculo de la pendiente descendente $\left(\mathrm{s}>\mathrm{s}_{\mathrm{m}}\right.$ ) se emplea la Ec. 2.24. La tensión adherente residual para un deslizamiento $\mathrm{s}>\mathrm{s}_{3}$ será $\tau=\tau_{3}$.

$$
\frac{\tau}{\tau_{m}}=1-p\left(\frac{s}{s_{m}}-1\right) \quad s_{m} \leq s \leq s_{3}
$$

Donde: $\alpha, \mathrm{p} \mathrm{y} \tau_{3}$, son parámetros que deben ser calibrados para cada tipo de barra en función a los resultados experimentales obtenidos.

El valor del parámetro $\alpha$, que determina la pendiente ascendente, se calcula mediante el ajuste del área " $A_{t}$ " por debajo de la pendiente ascendente entre las curvas analíticas y experimentales, mediante la Ec. 2.25.

$A_{t}=\int_{0}^{s_{m}} \tau(s) \cdot d s=\int_{0}^{s_{m}} \tau_{m} \cdot\left(\frac{s}{s_{m}}\right)^{\alpha} \cdot d s=\frac{\tau_{m} \cdot s_{m}}{1+\alpha}$

Despejando

$$
\alpha=\frac{\tau_{m} \cdot s_{m}}{A_{t}}-1
$$

El valor del parámetro $\mathrm{p}$, que determina la pendiente descendente, se calcula mediante el ajuste del área situada por debajo de la pendiente descendente entre las curvas analíticas y experimentales, del mismo modo que el parámetro $\alpha$. En este caso se establece un valor constante de $\tau$ igual a $\tau_{\text {residual, }}$ si el deslizamiento " $\mathrm{s}$ " es mayor que $\mathrm{s}_{\mathrm{u}}$, correspondiente a la adherencia friccional.

Cosenza et al., (1997), con base en su investigación obtuvieron los siguientes valores de los parámetros de ajuste $\alpha$, p y $\tau_{3}$, mostrados en la Tabla 2.41, para diferentes tipos de barras de FRP. 


\begin{tabular}{lccc}
\hline \multirow{2}{*}{ Tipo de barra de FRP } & \multicolumn{3}{c}{ Modelo B.E.P Modificado } \\
\cline { 3 - 4 } & $\alpha$ & $\mathrm{p}$ & $\tau_{3}(\mathrm{MPa})$ \\
\hline Lisas & $0,145(0,44)$ & $1,87(0,53)$ & $0,99(0,47)$ \\
\cline { 1 - 1 } Recubrimiento de gránulos & $0,067(0,81)$ & $3,11(0,96)$ & $3,17(0,22)$ \\
\cline { 1 - 1 } Recubrimiento de arena & $0,251(0,97)$ & $2,63(0,47)$ & $1,38(0,53)$ \\
\cline { 1 - 1 } Hélice adherida & $0,175(0,44)$ & $4,15(0,11)$ & $3,68(0,15)$ \\
\cline { 1 - 1 } Corrugadas & $0,283(0,56)$ & $14,88(1,20)$ & $7,79(0,60)$ \\
\cline { 1 - 1 } Endentadas & $0,177(0,05)$ & $12,80(0,61)$ & $6,26(0,36)$ \\
\cline { 1 - 1 } Endentadas y arenadas & $0,069(0,07)$ & $0,95(0,16)$ & $7,13(0,33)$ \\
\hline \multicolumn{2}{c}{ Los valores entre paréntesis representan el coeficiente de variación. }
\end{tabular}

Tabla 2.41. Valores medios y coeficiente de variación de los parámetros de ajuste del Método B.E.P Modificado. Cosenza et al., 1997.

El valor del parámetro $\alpha$, que caracteriza la pendiente ascendente, obtenido para las barras corrugadas es de 0,283. Este valor comparado con el propuesto por Eligehausen et al., (1983), para barras de acero corrugadas de 0,40 , demuestra que las barras de FRP presentan una pendiente inicial menos rígida que las barras de acero.

\subsection{Método C.M.R.}

En el año 1995, E. Cosenza, G. Manfredi y R. Realfonzo, con base en su investigación desarrollaron un nuevo método analítico basado en el Método B.E.P Modificado ${ }^{25}$. Este nuevo modelo denominado Método C.M.R., modeliza la pendiente ascendente inicial de la gráfica constitutiva de tensión adherente/deslizamiento. Con la modelización de la pendiente inicial se obtiene el comportamiento del elemento de hormigón armado con FRP en condiciones de servicio (para un deslizamiento $\mathrm{s}<\mathrm{s}_{\mathrm{m}}$ ).

El Método C.M.R. emplea la Ec. 2.26 para el cálculo del comportamiento de la pendiente ascendente de la gráfica constitutiva de tensión adherente/deslizamiento.

\footnotetext{
${ }^{25}$ El Método C.M.R se basa en el Método B.E.P Modificado debido a que este método realiza una mejor modelización del comportamiento adherente inicial (la pendiente ascendente inicial para un desplazamiento " $\mathrm{s}=0$ " tiende a infinito, lo que representa el mecanismo adherente por adhesión química) que el Método Malvar (la pendiente inicial en "s $=0$ " es $\mathrm{F} \tau_{\mathrm{m}} / \mathrm{s}_{\mathrm{m}}$, es decir igual a $\mathrm{F}$ veces la pendiente secante en la tensión de adherencia máxima).
} 
$\frac{\tau}{\tau_{m}}=\left(1-e^{\frac{-s}{s_{r}}}\right)^{\beta}$

Donde: $\mathrm{s}_{\mathrm{r}}, \mathrm{y} \beta$, son parámetros de ajuste entre las curvas analíticas y experimentales. Estos parámetros son calibrados a través del método de mínimos cuadrados.

Con base en la investigación llevada a cabo por E. Cosenza, G. Manfredi y R. Realfonzo durante los años 1995 y1996 sobre los diferentes métodos de cálculo analíticos (M. Malvar, M. B.E.P Modificado y M .C.M.R.) obtuvieron la siguiente observación:

"El Método Malvar calcula de un modo sencillo toda la gráfica constitutiva de tensión adherente/deslizamiento, pero este método presenta una menor exactitud que el Método B.E.P Modificado. Mientras que, el Método C.M.R. es el más preciso para la modelización de la pendiente ascendente de la gráfica de tensión adherente/deslizamiento. Al mismo tiempo, el Método Malvar no es muy apropiado debido a que infravalora la rigidez de la pendiente inicial de la gráfica" T-S”.

En la Fig. 2.88 se muestra una comparativa entre el Método C.M.R y el B.E.P. Modificado. En esta figura se puede apreciar que el Método C.M.R calcula con una mayor precisión la pendiente ascendente de la gráfica de tensión adherente/deslizamiento.

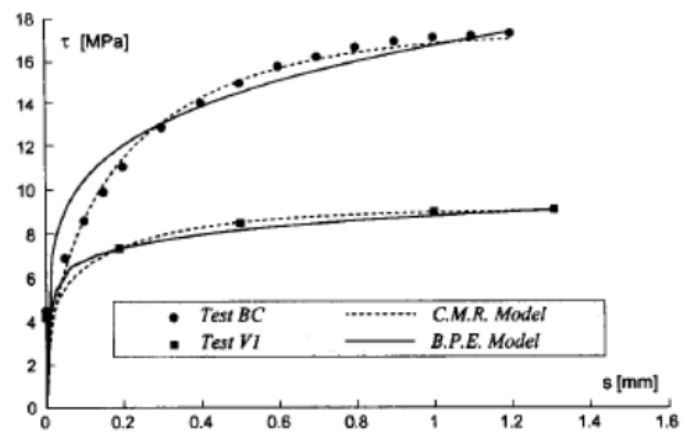

Fig. 2.88. Comparativa entre el Método C.M.R y el B.E.P. Modificado. Cosenza et al., 1997. 
En la Fig. 2.89.a, se muestra una comparativa del cálculo de toda la gráfica “ $T-S$ ” entre los métodos Malvar y B.E.P Modificado. Mientras que, en la Fig. 2.89.b, se muestra la comparativa de cálculo de la pendiente inicial mediante estos dos métodos. En estas dos figuras se puede comprobar que el Método B.E.P Modificado calcula con una mayor precisión el comportamiento adherente entre las barras de FRP y el hormigón.
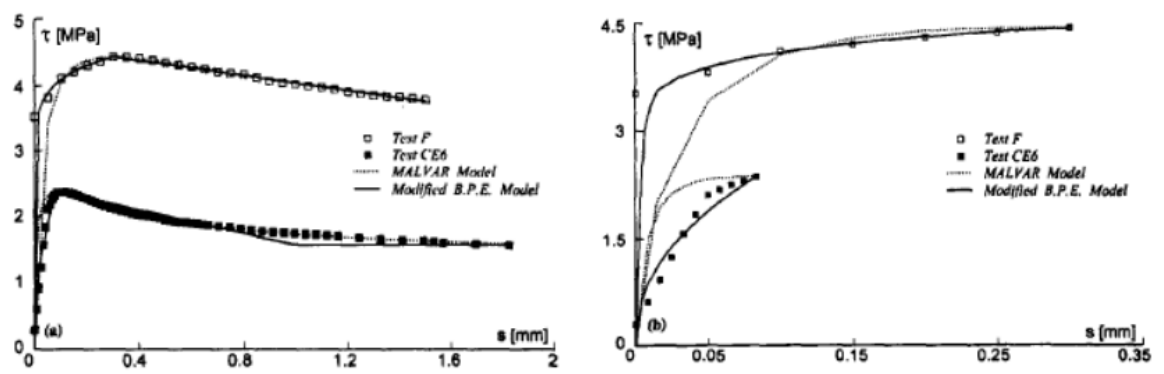

Fig. 2.89. Comparativa entre el Método Malvar y el B.E.P. Modificado. a) Toda la gráfica " $T-S$ ", b) Pendiente ascendente inicial. Cosenza et al., 1997.

Cosenza et al., (1997), con base en su investigación obtuvieron los siguientes valores de los parámetros de ajuste $\beta$ y s $\mathrm{s}_{\mathrm{r}}$, mostrados en la Tabla 2.42, para diferentes tipos de barras de FRP.

\begin{tabular}{lcc}
\hline \multirow{2}{*}{ Tipo de barra de FRP } & \multicolumn{2}{c}{ Modelo C.M.R. } \\
Lisas & $0,314(0,90)$ & $\mathrm{S}_{\mathrm{r}}$ \\
\cline { 1 - 1 } Recubrimiento de gránulos & $0,138(1,50)$ & $0,11(0,81)$ \\
\cline { 1 - 1 } Recubrimiento de arena & $0,559(0,52)$ & $0,41(1,81)$ \\
\cline { 1 - 1 } Hélice adherida & $0,593(0,57)$ & $0,12(0,24)$ \\
\cline { 1 - 1 } Corrugadas & $0,575(0,52)$ & $0,45(1,60)$ \\
\cline { 1 - 1 } Endentadas & $0,473(0,66)$ & $0,78(0,76)$ \\
\cline { 1 - 1 } Endentadas y arenadas & $0,025(0,60)$ & $0,08(0,07)$ \\
\hline \multicolumn{1}{c}{ Los valores entre paréntesis representan el coeficiente de variación. } \\
\hline
\end{tabular}

Tabla 2.42. Valores medios y coeficiente de variación de los parámetros de ajuste del Método C.M.R. Cosenza et al., 1997.

Malvar et al., (2003), con base en su investigación desarrolló un nuevo método de cálculo analítico denominado Método C.M.R. Modificado, basado en el Método C.M.R de E. Cosenza, (1995). Esté nuevo método añade al método 
inicial la presión de confinamiento a través de la sustitución en la Ec. 2.26 del parámetro $\mathrm{s}_{\mathrm{r}}$, por $\mathrm{s}_{\mathrm{r}}=\mathrm{s}_{\mathrm{m}} / \gamma$. Donde: $\gamma$, es el un parámetro adimensional, calculado mediante el ajuste, por el método de mínimos cuadrados, entre el desplazamiento obtenido experimental y analíticamente.

Para el cálculo de la gráfica "T-S", inicialmente se define la tensión adherente máxima y el deslizamiento a dicho nivel de tensión adherente en función del confinamiento. Este cálculo se realiza mediante las Ecs. 2.27 y 2.28.

$$
\begin{aligned}
& \frac{\tau_{m}}{f_{t}}=A+B \frac{\sigma}{f_{t}} \\
& \frac{s_{m}}{d_{b}}=C+D \frac{\sigma}{f_{t}}
\end{aligned}
$$

Donde: $\sigma$, es la presión radial de confinamiento. $\mathrm{f}_{\mathrm{t}}$, es la resistencia a tracción del hormigón. $s_{\mathrm{m}}$, es el alargamiento durante la tensión adherente máxima. $\mathrm{d}_{\mathrm{b}}$, es el diámetro nominal de la barra. $\mathrm{A}, \mathrm{B}, \mathrm{C}$ y $\mathrm{D}$ son constantes empíricas no dimensionales calculadas para cada tipo de barra. Estas constantes se calculan mediante el ajuste, por el método de mínimos cuadrados, entre la tensión obtenida experimental y analíticamente.

Seguidamente, mediante la Ec. 2.29 se calcula la pendiente ascendente de la gráfica " $T-S$ ".

$$
\frac{\tau}{\tau_{m}}=\left(1-e^{\frac{-s \cdot y}{s_{m}}}\right)^{\beta}
$$

\subsubsection{Métodos Directos}

En la actualidad, se encuentran numerosos métodos de cálculo directos del comportamiento adherente entre las barras de FRP y el hormigón (pullout con o sin confinamiento, beam-end, ensayo de viga "simple beam test", ensayo de empalme en viga "overlap splice test", ensayo de viga con muesca "notched 
beam test", ensayo de viga articulada "hinged beam test", ensayo de viga en voladizo "cantiléver beam test", ensayo de desarrollo de tensión de rigidez “tensión stiffening test", ensayo de adherencia en la zona de apoyo en vigas "bond in región supporrt-transverse compression test", ensayo de tensión directa axial "direct axial tensión”). Sin embargo, las diferentes normativas, tales como ACI 440.1R-06, JSCE 1997(b), CAN CSA S806-02, CNR-DT 203/2006, recomiendan el empleo del método de ensayo de adherencia denominado pullout. ACI 440.1R-06 también recomienda el método de ensayo de adherencia denominado beam-end, recogido en la norma ASTM A944.

Las principales diferencias entre el método de pullout y beam-end, se deben a que los resultados del ensayo beam-end dan menores valores de la tensión adherente, debido a un menor confinamiento, ya que el hormigón circundante presenta un menor recubrimiento. Además, en este tipo de ensayo, el hormigón circundante a la barra de FRP se encuentra traccionado, lo que también produce una disminución de la tensión adherente. Sin embargo, el ensayo beam-end reproduce con mayor realidad, que el ensayo de pullout, las condiciones de trabajo a flexión del elemento de hormigón armado con FRP.

Generalmente se emplea el método de pullout, puesto que es un método con una mayor facilidad de aplicación y menor coste económico que el método beam-end.

Mediante los métodos de pullout y beam-end se consigue modelizar el comportamiento adherente (gráfica de tensión adherente/deslizamiento), y definir los diferentes modos de rotura por adherencia de las barras de FRP (no se emplean para establecer los valores de la tensión adherente de diseño ni la longitud de anclaje). Al mismo tiempo, los resultados obtenidos son comparados con los resultados de las barras de acero, para posteriormente proceder a la modificación de las ecuaciones de diseño de elementos de hormigón armado con acero mediante los respectivos coeficientes obtenidos. Los valores de los 
resultados obtenidos también son empleados para calibrar los diferentes métodos de cálculo analíticos del comportamiento adherente entre las barras de FRP y el hormigón.

\subsection{Ensayo Pullout}

Las diferentes normativas de diseño de estructuras de hormigón armado con barras de FRP (ACI 440.1R-06, JSCE 1997(b), CAN/CSA-S806-02, CNRDT 203/2006) recomiendan en sus artículos el ensayo de pullout centrado, para la determinación del comportamiento adherente. Sin embargo, debido a que estas Instrucciones comenzaron a recoger los métodos de ensayo de adherencia a partir de finales de la década de los 90 y a su vez estos métodos son recomendables y no obligatorios, algunos investigadores han optado por realizar ensayos de adherencia mediante pullout descentrado o pullout con confinamiento.

El ensayo de pullout centrado se emplea para el cálculo comportamiento adherente entre la barra de FRP y el hormigón, mediante la determinación de la gráfica que relaciona la tensión adherente y el deslizamiento relativo de la barra (gráfica 'T-S'). La acción de confinamiento del hormigón circundante a la barra debe ser tal, que evite la rotura de la probeta por splitting del hormigón. ACI.440.3R-04 establece una dimensión de probetas de forma cúbica de 200 mm de lado (Fig. 2.90) y, JSCE 1997(b) establece dependiendo el diámetro de la barra unas dimensiones de $100 \mathrm{~mm}$ y $150 \mathrm{~mm}$ de lado (Fig. 2.91), para barras de 8-10 mm y $12-15 \mathrm{~mm}$, respectivamente. La longitud adherente debe ser tal, que permita que la tensión adherente sea distribuida en todos los estados de carga. Para ello, ACI.440.3R-04 recomienda una longitud adherente de 5 diámetros de la barra, y JSCE 1997(b) 4 veces el diámetro de la barra. La tensión adherente máxima obtenida mediante este ensayo es la mayor posible de todos los ensayos de pullout sin confinamiento. La dirección de vertido del hormigón en la probeta varía dependiendo de la normativa escogida, así ACI.440.3R-04 establece el 
vertido del hormigón en la dirección del eje longitudinal de la barra, mientras que JSCE 1997(b) lo realiza perpendicularmente al eje longitudinal de la barra. Del mismo modo, ACI.440.3R-04 también recoge el vertido del hormigón perpendicular al eje longitudinal de la barra para el tipo de ensayo de pullout centrado que calcula la influencia de la posición de la barra (Fig. 2.92). Otra diferencia sustancial entre los métodos propuestos por las normativas, se debe a que JSCE 1997(b) introduce un armado de confinamiento helicoidal en la probeta de pullout.

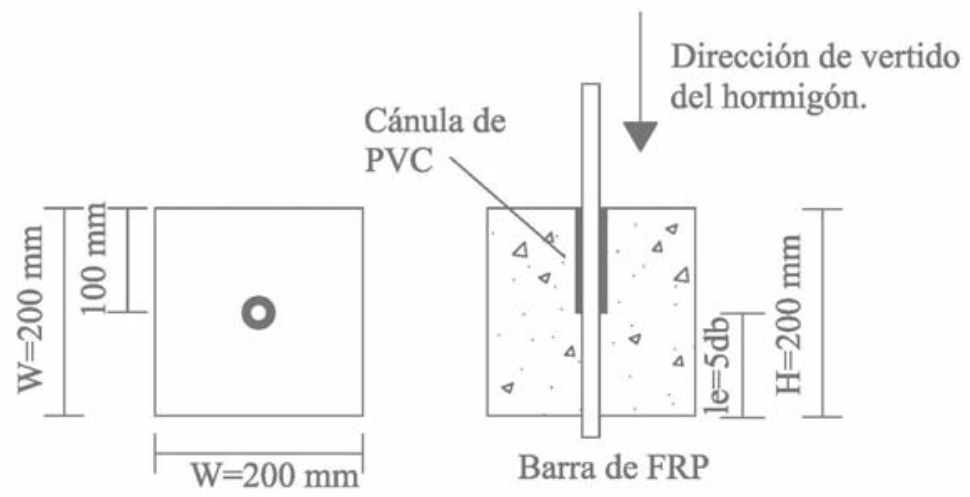

Fig. 2.90. Dimensiones y características de las probetas para el ensayo de adherencia por pullout centrado. ACI.440.3R-04.

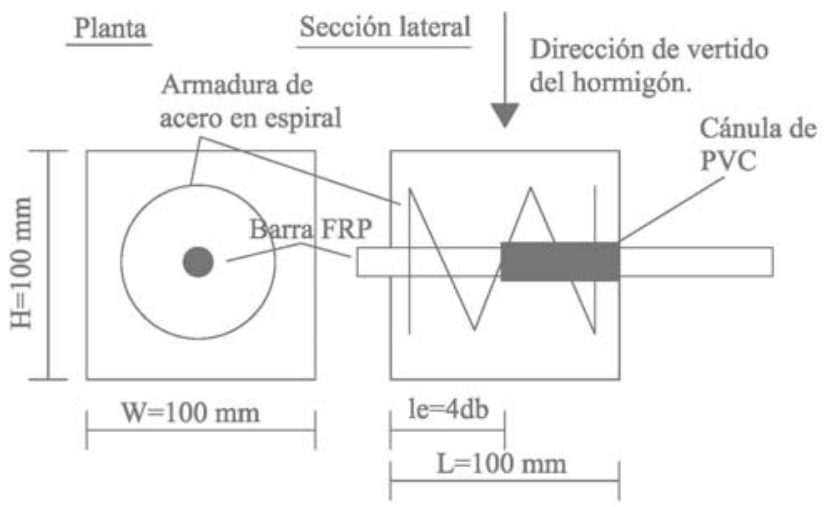

Fig. 2.91. Dimensiones y características de las probetas para el ensayo de adherencia por pullout centrado. JSCE 1997(b). 


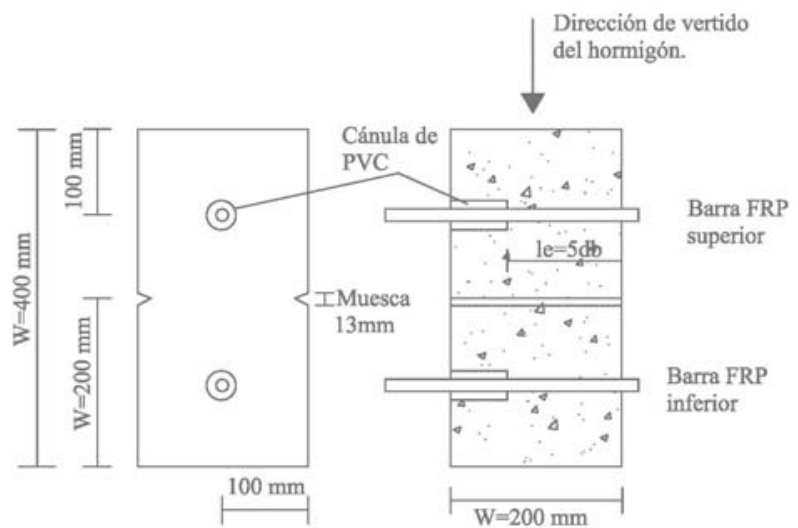

Fig. 2.92. Dimensiones y características de las probetas para el ensayo de adherencia por pullout centrado, con la influencia de la posición de la barra. ACI.440.3R-04.

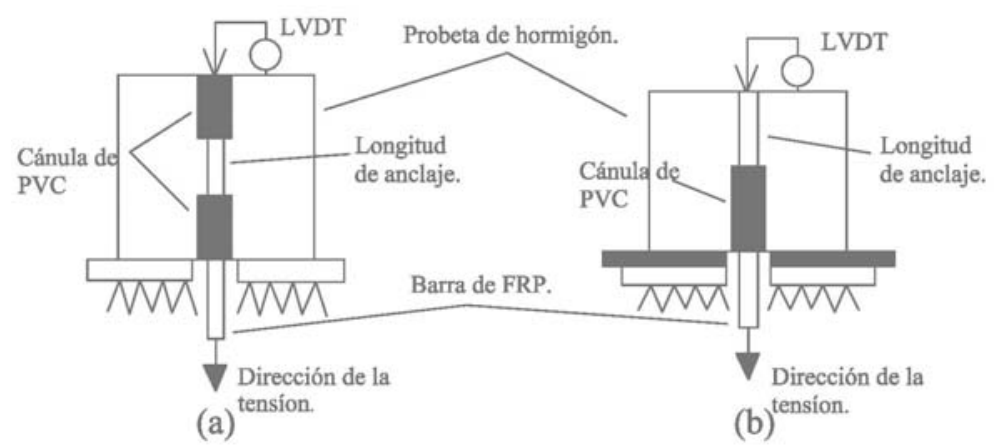

Fig. 2.93. Ensayos de pullout centrado. a) Ensayo de Rehm (1961) y Losberg (1962),b) Ensayo RILEM, 1970. FIB Task Group 2.5.

Otra variación del ensayo de pullout centrado empleada por algunos investigadores se debe a la diferente disposición de la cánula que evita la adherencia de la barra con el hormigón. El ensayo de pullout centrado definido por Rehm (1961) y Losberg (1962), mostrado en la Fig. 2.93a, sobrevalora la tensión adherente máxima, debido a que se produce un incremento de esta tensión adherente por la introducción de nuevas corrugas de la barra no dañadas en la longitud de anclaje (véase apart. 2.5.3.2). Por ello, las normativas basan su ensayo de pullout centrado en el ensayo de RILEM, (1970), mostrado en la Fig. 2.93b. 
El ensayo de adherencia por pullout descentrado (Fig. 2.94) calcula la resistencia a splitting del recubrimiento de hormigón, debido a la tensión adherente. Este tipo de ensayo no es apropiado para el cálculo de la tensión adherente máxima. El recubrimiento de hormigón normalmente es 1,5 veces el diámetro de la barra. La longitud de anclaje es similar al ensayo de pullout centrado, entre 3-5 veces el diámetro de la barra. Los resultados de este ensayo con barras de FRP deben ser comparados con los resultados en obtenidos en barras de acero.

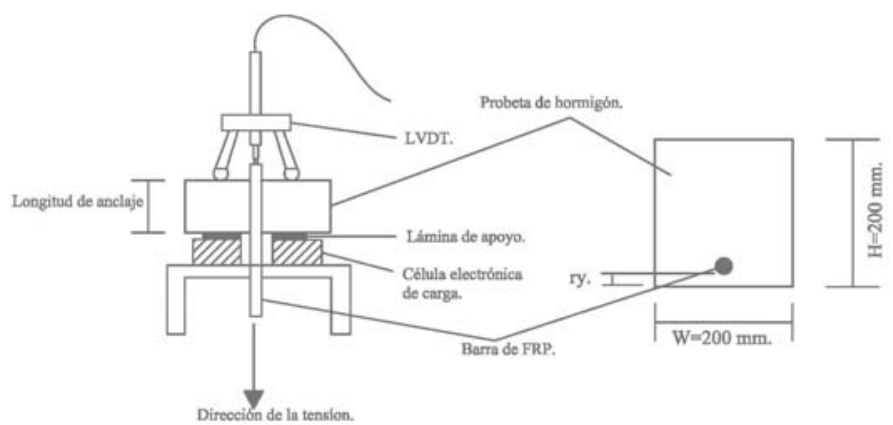

Fig. 2.94. Dimensiones y características de las probetas para el ensayo de adherencia por pullout descentrado. R. Tepfers, 1997.

El ensayo de pullout con confinamiento se emplea para establecer el comportamiento adherente de las barras de FRP en condiciones de confinamiento mediante el cálculo del ángulo del brazo mecánico ' $\alpha$ ' producido por el equilibrio de tensiones entre el hormigón y la tensión adherente originada por la barra, durante diferentes estados de carga (Tepfers et al., 1992). Este tipo de ensayo se compone de una camisa de acero cilíndrica que confina la probeta de hormigón (Fig. 2.95). La altura de la probeta de pullout es igual a la longitud de anclaje de la barra de FRP. 

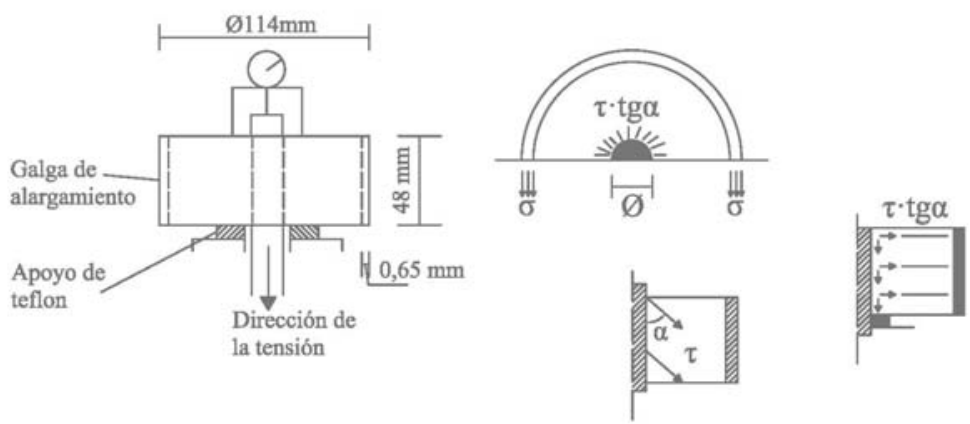

Fig. 2.95. Dimensiones y características de las probetas para el ensayo de adherencia por pullout con confinamiento. Tepfers et al.,1992.

El ángulo del brazo mecánico originado por el equilibrio de tensiones entre la barra y el hormigón ' $\alpha$ ' se calcula mediante el procedimiento siguiente:

I. La tensión adherente ' $\tau$ ', en la dirección longitudinal de la barra se calcula mediante la Ec. 2.30 .

$\tau=F / \pi \cdot \emptyset \cdot h$

II. El componente lateral de la tensión adherente ortogonal al eje longitudinal de la barra, se calcula mediante la Ec. 2.31.

$\tau \cdot \tan \alpha \cdot \emptyset \cdot h=2 \cdot \varepsilon_{r s} \cdot E \cdot h \cdot t$

Despejando ' $\alpha$ ':

$$
\alpha=\arctan \left(2 \cdot \varepsilon_{r s} \cdot E \cdot t / \tau \cdot \emptyset\right)=\arctan (2 \cdot E \cdot t \cdot h \cdot \pi / F)
$$

Donde: E, es el módulo de elasticidad del acero. $\varepsilon_{\mathrm{rs}}$, es el alargamiento tangencial de la camisa de acero. $t$, es el espesor de la camisa de acero. $h$, es la altura de la camisa de acero. Ø, es el diámetro de la barra. F, es la tensión en la dirección longitudinal de la barra durante el ensayo de pullout. 


\subsection{Ensayo Beam-End}

Los ensayos de adherencia por pullout se emplean en un gran número de investigaciones, sin embargo, estos no representan las condiciones a las cuales se encuentra sometida una viga de hormigón armado con FRP. Este tipo de ensayo reproduce de un modo más real las condiciones de adherencia del armado de FRP en elementos de hormigón armado a flexión. Los resultados obtenidos mediante este método son, la gráfica que relaciona la tensión adherente y el deslizamiento relativo de la barra 'T-S', y el modo de rotura por adherencia.

El ensayo de adherencia beam-end para barras de FRP está definido por la normativa ASTM A-944. El procedimiento y características de este ensayo son las mismas que para barras de acero. En la Fig. 2.96 se muestra el procedimiento del ensayo, el cual consiste en la aplicación de una tensión de tracción en el extremo de la barra de FRP anclada en la probeta de hormigón armado.

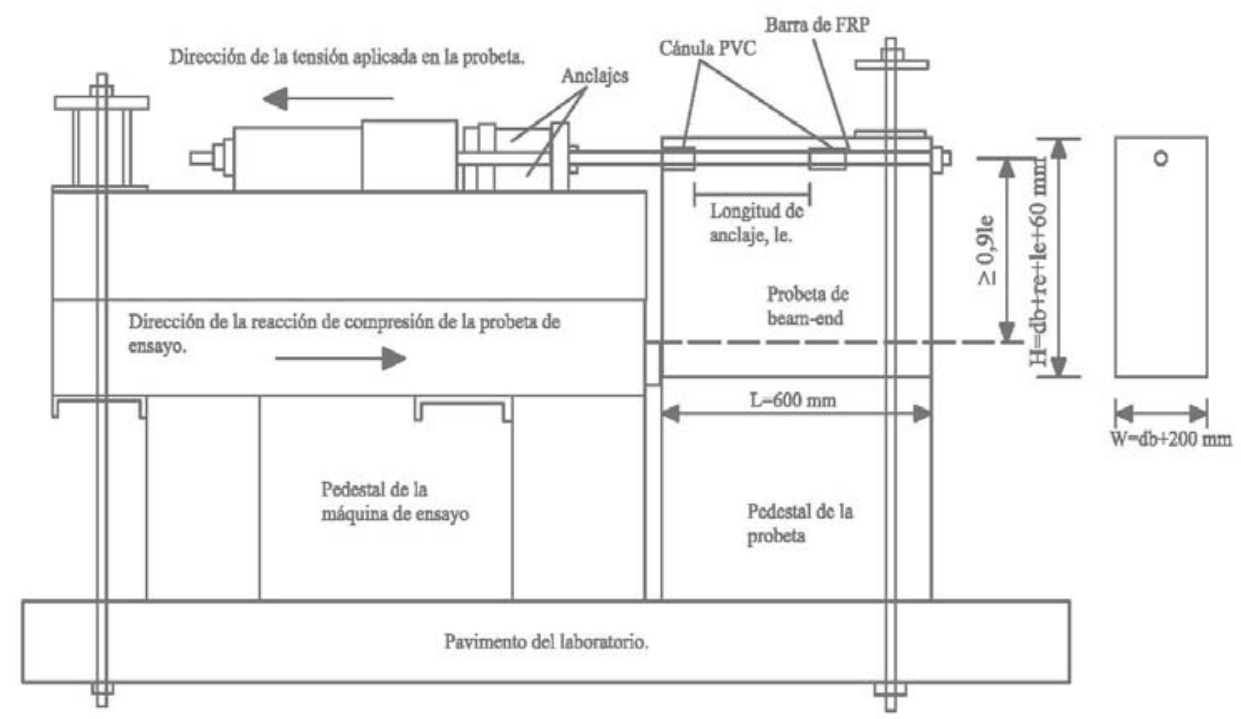

Fig. 2.96. Dimensiones y características de las probetas para el ensayo de adherencia por beamend. Adaptado de ASTM A-944. 


\subsection{Normativa de Cálculo de Estructuras de Hormigón Armado con Barras de CFRP. Parámetros de Adherencia que Influyen en el Cálculo}

Las diferentes normativas de diseño de elementos de hormigón armado con FRP están basadas en las normativas de diseño de elementos de hormigón armado con acero. Por ello, estas instrucciones introducen una serie de coeficientes que tienen en cuenta el diferente comportamiento de las barras de FRP. En cuanto a los coeficientes de adherencia introducidos en las normativas de diseño, estos están basados en una base de datos experimentales, y todavía no tienen carácter definitivo, puesto que los diferentes comités se encuentran recopilando una base de datos para posteriormente establecer los valores definitivos de todos estos coeficientes.

En este apartado se procede al análisis de los parámetros de adherencia que influyen en el cálculo, introducidos en las disposiciones de las diferentes normativas de diseño de elementos de hormigón armado con FRP.

\subsubsection{ACI.440.1R-06}

La normativa ACI.440.1R-06 (American Concrete Institute) para el diseño de elementos de hormigón armado con barras de FRP basada en la Instrucción de Hormigón Estructural ACI.318-05 (diseño de elementos de hormigón armado con acero) contempla en su articulado una serie de coeficientes correctores que dependen de la relación del comportamiento adherente entre las barras de FRP y acero. Estos coeficientes correctores de adherencia se introducen principalmente en las ecuaciones de cálculo del estado límite de servicio.

En cuanto a la comprobación del ancho de fisura máximo de un elemento a flexión, la normativa ACI.440.1R-06 emplea la Ec. 2.32. Esta 
ecuación, basada en la ecuación empleada por ACI.318-05, ha sido modificada por el coeficiente corrector de adherencia $\mathrm{K}_{\mathrm{b}}$. Este coeficiente varía para cada tipo de armado de FRP (y a su vez, para cada tipología de barras de CFRP), estableciéndose los siguientes valores:

- Si el comportamiento adherente de las barras de FRP es similar al de las barras de acero corrugadas, el valor del coeficiente $\mathrm{K}_{\mathrm{b}}$ será igual a 1.

- Si el comportamiento adherente de las barras de FRP es inferior al de las barras de acero corrugadas, el valor del coeficiente $\mathrm{K}_{\mathrm{b}}$ será mayor a 1.

- Si el comportamiento adherente de las barras de FRP es superior al de las barras de acero corrugadas, el valor del coeficiente $\mathrm{K}_{\mathrm{b}}$ será menor a 1.

- Si no se dispone de valores del comportamiento adherente de las barras de FRP, el valor del coeficiente $\mathrm{K}_{\mathrm{b}}$ será igual a 1,4.

$$
w=2 \frac{f_{f}}{E_{f}} \beta \cdot K_{b} \sqrt{d_{c}^{2}+\left(\frac{s}{2}\right)^{2}}
$$

Donde: $w$, es el ancho de fisura, en $\mathrm{mm}$. $\mathrm{f}_{\mathrm{f}}$, es la tensión a la cual está sometido el armado, en $\mathrm{MPa}$. $\mathrm{E}_{\mathrm{f}}$, es el módulo de elasticidad del armado, en MPa. $\beta$, es la relación entre la distancia del eje neutro al punto más traccionado y la distancia entre el eje neutro y el centroide de armado. $d_{c}$, es el espesor del recubrimiento, en $\mathrm{mm}$. $\mathrm{s}$, es el espaciado entre armado, en $\mathrm{mm}$.

La longitud de anclaje de las barras de FRP, tal y como se ha comentado en el apart. 2.5.1 de la presente tesis doctoral, dependerá principalmente de la tensión adherente desarrollada entre el armado de FRP y el hormigón circundante. ACI.44.1R-06 define la Ec. 2.33 para el cálculo de la longitud de anclaje básica. Dicha ecuación está basada en el equilibrio entre la tensión a la 
cual se encuentra sometida el armado y la tensión adherente desarrollada entre este y el hormigón.

$$
l_{e} \cdot \pi \cdot d_{b} \cdot u=A_{f, b a r} \cdot f_{f}
$$

Donde: $1_{\mathrm{e}}$, es la longitud de anclaje básica, en mm. $\mathrm{d}_{\mathrm{b}}$, es el diámetro de la barra en mm. u, es la tensión adherente media de la barra. $\mathrm{f}_{\mathrm{f}}$, es la tensión máxima que desarrolla la barra. $\mathrm{A}_{\mathrm{f}, \mathrm{bar}}$, es el área transversal de la barra.

Por lo tanto, la longitud de anclaje que depende de la longitud de anclaje básica (Ec. 2.34), a su vez, está condicionada por el comportamiento adherente de las barras de FRP.

$$
l_{d}=\frac{\alpha \cdot \frac{f_{f r}}{\sqrt{f^{\prime} c}}-340}{13,6+\frac{C}{d_{b}}} d_{b}
$$

Donde $: \alpha$, es un coeficiente que depende de la posición de la barra, cuyo valor en caso de posición buena de adherencia es 1, y 1,5 en caso de posición de adherencia deficiente (estos valores basados en pocos ensayos experimentales y no son definitivos). $\mathrm{f}_{\mathrm{fr}}$, es la tensión limitante de la barra (flexión o adherencia), en $\mathrm{MPa} . \mathrm{f}^{\prime}{ }^{\prime}$, es la resistencia a compresión del hormigón, en MPa. C, es el menor recubrimiento hasta el centro de la barra, en $\mathrm{mm}$. $\mathrm{d}_{\mathrm{b}}$, es el diámetro de la barra, en $\mathrm{mm}$.

\subsubsection{JSCE 1997(b)}

La normativa de diseño de estructuras de hormigón armado con barras de FRP denominada JSCE 1997(b) (Japan Society of Civil Engineers) está basada en la normativa Japonesa de diseño de estructuras de hormigón armado con acero "Standard Specification for Design and Construction of Concrete Structures (Design)". JSCE 1997(b), del mismo modo que ACI.440.1R-06, 
contempla en su contenido una serie de coeficientes correctores que dependen de la relación del comportamiento adherente entre las barras de FRP y acero.

Para el cálculo del ancho de fisura máximo, JSCE 1997(b) define la Ec. 2.35, basada en la norma de diseño con armado de acero, e introduce un coeficiente corrector de adherencia denominado "k", cuyo valor será igual a 1 si el armado de FRP presenta un comportamiento adherente similar a las barras de acero corrugadas. Para diferente comportamiento adherente de las barras de FRP, el valor del coeficiente " $k$ " deberá ser definido mediante ensayos experimentales, adoptando valores mayores y menores a 1, en el caso de un peor y mejor comportamiento adherente en comparación con las barras de acero corrugadas, respectivamente.

$$
w=k\left[4 c+0,7\left(c_{f}-\emptyset\right)\right] \cdot\left(\frac{\sigma_{f k}}{E_{f}}+\varepsilon^{\prime}{ }_{c s d}\right)
$$

Donde: w, es el ancho de fisura, en mm. c, es el menor recubrimiento del hormigón, en mm. $c_{\mathrm{f}}$, es el espaciado entre barras de armado, en mm. $\varnothing$, es el diámetro de la barra, en mm. $\varepsilon^{\prime}$ csd, es el alargamiento de compresión debido a la retracción y fluencia del hormigón. $\sigma_{\mathrm{fk}}$, es la tensión a la cual se encuentra sometido el armado, en $\mathrm{MPa}$. $\mathrm{E}_{\mathrm{f}}$, es el módulo de elasticidad del armado, en MPa.

El dimensionado de la longitud de anclaje se realiza mediante la Ec. 2.36. Al mismo tiempo, esta dependerá del comportamiento adherente de la barra de FRP empleada como armado.

$$
l_{d}=\alpha_{1} \frac{f_{d}}{4 \cdot f_{\text {bod }}} \cdot \emptyset
$$

Donde: $1_{\mathrm{d}}$, es la longitud básica de anclaje, en $\mathrm{mm}$. Ø, es el diámetro del armado, en mm. $f_{d}$, es la resistencia a tracción del armado, en MPa. $\alpha_{1}$, presenta los siguientes valores $1,0,0,9,0,8,0,7$ y 0,6 , para $\mathrm{k}_{\mathrm{c}} \leq 1,0,1,0<\mathrm{k}_{\mathrm{c}} \leq 1,5$, 
$1,5<\mathrm{k}_{\mathrm{c}} \leq 2,0,2,0<\mathrm{k}_{\mathrm{c}} \leq 2,5$ y $2,5<\mathrm{k}_{\mathrm{c}}$, respectivamente. Donde $\mathrm{k}_{\mathrm{c}}=(\mathrm{c} / Ø)+$ $\left[\left(15 \mathrm{~A}_{\mathrm{t}} / \mathrm{s} \emptyset\right) \cdot\left(\mathrm{E}_{\mathrm{t}} / \mathrm{E}_{0}\right)\right]$; c, es el menor recubrimiento de hormigón, en mm. $\mathrm{A}_{\mathrm{t}}$, es el área transversal del armado, en $\mathrm{mm}$. s, es el espaciamiento entre barras, en $\mathrm{mm}$. $\mathrm{E}_{\mathrm{t}}$, es el módulo de elasticidad del armado, en $\mathrm{MPa}$. $\mathrm{E}_{0}$, es el módulo de elasticidad del acero, en MPa.

$\mathrm{f}_{\text {bod, }}$, es la tensión adherente de la barra de FRP, en $\mathrm{N} / \mathrm{mm}^{2}$, calculada mediante la Ec. 2.37.

$$
f_{\text {bod }}=\frac{0,28 \cdot \alpha_{2} \cdot \sqrt[3]{f^{\prime} c k}{ }^{2}}{\gamma_{c}}
$$

Donde: $\mathrm{f}_{\text {bod }}$, debe ser menor o igual a $3,2 \mathrm{~N} / \mathrm{mm}^{2}$. $\alpha_{2}$, es un coeficiente modificador que depende de la adherencia del armado, cuyo valor será igual a 1 si el comportamiento adherente es similar o mejor que el de las barras de acero corrugadas. Para diferente comportamiento adherente, este coeficiente modificador debe ser calculado de acuerdo con los ensayos normalizados (JSCE E-539).

Esta normativa en los comentarios del apart. 10.5.3 establece que debido a la caracterización del comportamiento adherente mediante los ensayos de pullout (este tipo de ensayos no reflejan el comportamiento adherente real), se puede realizar el cálculo de la tensión adherente de las barras de FRP cuyo modo de rotura por adherencia sea por splitting del hormigón (igual que las barras de acero corrugadas) mediante la Ec. $2.38^{26}$. Esta ecuación sustituirá a la Ec. 2.37, para el cálculo de la longitud de anclaje básica de barras de FRP cuya rotura de adherencia sea por splitting del hormigón, en la Ec. 2.36.

\footnotetext{
${ }^{26}$ Esta ecuación es el resultado de la sustitución de la ecuación de la tensión adherente, obtenida por igualación de tensiones, en la ecuación de cálculo de la longitud de anclaje de elementos de hormigón armado con acero, establecida en la norma "Standard Specification for Design and Construction of Concrete Structures (Design)".
} 


$$
f_{\text {bod }}=\alpha_{2} \cdot \frac{0,318+0,795\left(\frac{c}{\emptyset}+\frac{15 A_{t}}{s \emptyset} \cdot \frac{E_{t}}{E_{0}}\right)}{\frac{3,2}{\sqrt{f^{\prime} c}}-\frac{53,2}{f_{y}}}
$$

Donde: $\alpha_{2}$, es el coeficiente de adherencia obtenido mediante ensayos de adherencia experimentales, cuyo valor será igual o menor a 1, dependiendo de si su comportamiento adherente es igual o inferior al de las barras de acero corrugadas.

En caso de rotura de adherencia por pullout, la longitud de anclaje deber ser calculada mediante ensayos de adherencia experimentales.

\subsubsection{CNR-DT 203/2006}

La normativa de diseño de estructuras de hormigón armado con FRP denominada CNR-DT 203-2006 "Guide for the Design and Construction of Concrete Structures Reinforced with Fiber-Reinforced Polymer Bars", desarrollada por el Comité Nacional de Investigación Italiano (C.N.R), basada en la normativa de diseño de estructuras de hormigón armado con acero denominada EuroCódigo 2 (EuroCode 2), introduce una serie de coeficientes de adherencia que tienen en cuenta el diferente comportamiento adherente entre las barras de FRP y de acero corrugado.

En su apart. 4.7.3.3., emplea la Ec. 2.39 para el cálculo de la deformación máxima del elemento. En esta ecuación introduce el coeficiente de adherencia " $\beta_{1}$ ", el cual depende del comportamiento adherente de las barras de FRP empleadas.

$$
f=f_{1} \cdot \beta_{1} \cdot \beta_{2} \cdot\left(\frac{M_{c r}}{M_{\max }}\right)^{2}+f_{2}\left[1-\beta_{1} \cdot \beta_{2} \cdot\left(\frac{M_{c r}}{M_{\max }}\right)^{2}\right]
$$

Donde: $\mathrm{f}_{1}$, es la deformación de la sección $\sin$ fisurar. $\mathrm{f}_{2}$, es la deformación de la sección fisurada. $\beta_{2}$, es un coeficiente que depende de la duración de la carga, cuyo valor es 1,0 y 0,5 , para cargas de corta duración y 
cargas permanentes o cíclicas, respectivamente. $\mathrm{M}_{\max }$, es el momento máximo que actúa en el elemento. $\mathrm{M}_{\mathrm{cr}}$, es el momento de fisuración.

En su apart. 4.7.3.4., emplea la Ec. 2.40 para el cálculo del ancho de fisura.

$$
w_{k}=\beta \cdot s_{r m} \cdot \varepsilon_{f m}
$$

Donde: $\mathrm{w}_{\mathrm{k}}$, es el ancho de fisura característico, en $\mathrm{mm}$. $\beta$, es el coeficiente que relaciona el valor medio con el característico. $\mathrm{s}_{\mathrm{rm}}$, es la distancia media entre fisuras, en $\mathrm{mm}$. $\varepsilon_{\mathrm{fm}}$, es el alargamiento medio entre fisuras.

Para el cálculo de la distancia media entre fisuras " $\mathrm{s}_{\mathrm{rm}}$ ", se emplea la Ec. 2.41. En esta ecuación se introduce el coeficiente de adherencia $\mathrm{k}_{1}$, el cual depende del comportamiento adherente de la barra de FRP, este coeficiente tiene un valor de 1,6 y 0,8 , para barras con adherencia deficiente y buena adherencia, respectivamente.

$$
s_{r m}=50+0,25 \cdot k_{1} \cdot k_{2} \cdot \frac{d_{b}}{\rho_{r}}
$$

Donde: $\mathrm{k}_{2}$, es un coeficiente que depende del tipo de esfuerzo al que está sometido, cuyo valor es 0,5 y 1,0 , para flexión y tracción, respectivamente. $\mathrm{d}_{\mathrm{b}}$, es el diámetro equivalente del armado, en $\mathrm{mm}$. $\rho_{\mathrm{r}}$, es la cuantía de la sección de la armadura de FRP referida al área de la sección de la zona efectiva de tracción $\mathrm{A}_{\text {ceff. }}$

El cálculo del alargamiento medio entre fisuras " $\varepsilon_{\mathrm{fm}}$ " se realiza mediante la Ec. 2.42. En esta ecuación se introduce el coeficiente de adherencia $\beta_{1}$, empleado en la Ec. 2.39.

$$
\varepsilon_{f m}=\frac{\sigma_{r}}{E_{f}} \cdot\left[1-\beta_{1} \cdot \beta_{2} \cdot\left(\frac{\sigma_{f s}}{\sigma_{f}}\right)^{2}\right]
$$


Donde: $\sigma_{\mathrm{f}}$, es la tensión del armado a tracción de la sección fisurada. $\beta_{2}$, presenta los mismos valores que en la Ec. 2.39. $\sigma_{\mathrm{fr}}$, es la tensión del armado a tracción en el momento de fisuración de la sección. 


\section{CAPÍTULO 3}

\section{Programa Experimental y Resultados}

\subsection{Introducción}

El programa experimental de esta investigación se desarrolla con la finalidad de estudiar el comportamiento adherente de las barras de CFRP, comparándolo con el de las barras de acero ${ }^{27}$, para posteriormente analizar los parámetros que influyen en él, como son el tipo de acabado o geometría superficial, la temperatura, la resistencia del hormigón, el diámetro y temperatura de transición vítrea de las barras de CFRP. Para ello, debido a la ausencia de normativa española específica para el análisis de la adherencia de barras de CFRP, siendo la UNE -EN $10080^{28}$ la única norma española que desarrolla ensayos de adherencia (beam-end y pullout) para barras de acero, se ha optado por realizar todos los ensayos del programa experimental mediante la norma ACI 440-3R-04, puesto que es, de todas las normativas de ensayo de adherencia de FRP (JSCE 1997(b), CNR-DT 203/2006, CAN-CSA S806/02) la más empleada. Al mismo tiempo, esta norma ACI es complementada con normas ASTM, debido a que la propia norma en algunos casos recoge diferentes normas ASTM (cálculo del C.T.E, $\mathrm{T}_{\mathrm{g}}$, \% Fibra, etc..) para la realización de ensayos (Tabla 3.1).

Para llevar a cabo el objetivo principal de la presente investigación se realizan ensayos de pullout en varios tipos de barras de CFRP (arenadas,

\footnotetext{
${ }^{27}$ Puesto que las normativas de diseño de estructuras de hormigón armado están basadas en el comportamiento del acero, se realiza la comparación con éste, para poder establecer posteriormente los coeficientes de ponderación correspondiente a cada estado de cálculo.

${ }^{28}$ El ensayo de adherencia de pullout de UNE-EN10080 se basa, del mismo modo que ACI 440.3R-04, en la recomendación RILEM RC-06. Este ensayo es similar al de ACI, sin embargo, se diferencian en la velocidad de aplicación de carga (UNE más baja que ACI), la dirección de vertido del hormigón en el molde y en la inclusión de una banda elastomérica en el apoyo de la probeta de hormigón con la placa de ensayo.
} 
corrugadas y texturizadas) y acero, sometidas a diferentes condiciones ambientales (Hielo/Deshielo, $5^{\circ} \mathrm{C}, 20^{\circ} \mathrm{C}, 40^{\circ} \mathrm{C}$ y $80^{\circ} \mathrm{C}$ ). Para poder realizar los ensayos de pullout es necesario determinar con anterioridad las propiedades geométricas y mecánicas de este tipo de barras. Es por ello que se realizan los ensayos experimentales preliminares de diámetro equivalente, estudio de la geometría superficial y tracción longitudinal. Del mismo modo, para llevar a cabo los ensayos de pullout y preliminares, es necesario realizar ensayos previos para definir parámetros, como son la longitud de anclaje de las barras de CFRP, el tipo de material de agarre de los anclajes y el periodo de los ciclos térmicos y de hielo/deshielo, así como la duración del tiempo de trabajo a cada temperatura que afectan a los ensayos. Una vez finalizados los ensayos de pullout se realizan ensayos complementarios (TGA, DSC, Microscopia óptica, Microdureza, SEM y AFM) sobre las muestras ensayadas a pullout, comprobando de este modo, a nivel microestructural, la adherencia de las barras de CFRP.

\begin{tabular}{|c|c|c|c|}
\hline Propiedades & $\begin{array}{l}\text { Método } \\
\text { ASTM }\end{array}$ & $\begin{array}{l}\text { Método } \\
\text { ACI } 440\end{array}$ & Resumen de diferencias \\
\hline Área transversal & - & B.1 & No hay métodos ASTM disponibles \\
\hline $\begin{array}{l}\text { Resistencia a tracción y } \\
\text { módulo }\end{array}$ & D 3916 & B.2 & $\begin{array}{l}\text { El método ACI detalla el tipo de anclaje y } \\
\text { el procedimiento de la colocación de los } \\
\text { dispositivos de medida. }\end{array}$ \\
\hline Adherencia & A 944 & B.3 & $\begin{array}{l}\text { El ensayo de pullout ASTM C234 no } \\
\text { previene el splitting del hormigón en barras } \\
\text { de FRP. El ensayo de beam-end A } 944 \text { de } \\
\text { barras de acero puede ser empleado, sin } \\
\text { modificaciones, en barras de FRP. }\end{array}$ \\
\hline \multirow{4}{*}{ Resistencia a cortante } & D 5379 & \multirow{4}{*}{ B.4 } & \multirow{4}{*}{$\begin{array}{l}\text { El método ACI se centra en la acción } \\
\text { dovela de las barras y no se solapa con los } \\
\text { métodos ASTM. }\end{array}$} \\
\hline & D 3846 & & \\
\hline & D 2344 & & \\
\hline & D 4475 & & \\
\hline Resistencia de la parte curva & - & B.5 & No hay métodos ASTM disponibles \\
\hline Durabilidad & - & B.6 & No hay métodos ASTM disponibles \\
\hline Fatiga & D 3479 & B.7 & \multirow{4}{*}{$\begin{array}{l}\text { Los métodos ACI proporcionan una } \\
\text { información específica del anclaje y de la } \\
\text { conexión de los dispositivos de medida. }\end{array}$} \\
\hline Fluencia & D 2990 & B. 8 & \\
\hline \multirow{2}{*}{ Relajación } & D 2990 & \multirow{2}{*}{ B.9 } & \\
\hline & E 328 & & \\
\hline Propiedades del Anclaje & - & B.10 & No hay métodos ASTM disponibles \\
\hline $\begin{array}{l}\text { Resistencia a tracción de } \\
\text { barras dobladas }\end{array}$ & - & B.11 & No hay métodos ASTM disponibles \\
\hline
\end{tabular}




\begin{tabular}{|c|c|c|c|}
\hline $\begin{array}{l}\text { Efecto de la parte curva en la } \\
\text { resistencia a tracción }\end{array}$ & - & B. 12 & No hay métodos ASTM disponibles \\
\hline \multirow{2}{*}{ Flexión } & D 790 & \multirow{2}{*}{-} & \multirow{2}{*}{ No hay métodos ACI disponibles } \\
\hline & D 4476 & & \\
\hline \multirow{2}{*}{ C.T.E. } & E 831 & \multirow{2}{*}{-} & \multirow{2}{*}{ No hay métodos ACI disponibles } \\
\hline & D 696 & & \\
\hline \multirow{4}{*}{$\mathrm{Tg}$} & E 1356 & \multirow{4}{*}{-} & \multirow{4}{*}{ No hay métodos ACI disponibles } \\
\hline & E 1640 & & \\
\hline & D648 & & \\
\hline & E 2092 & & \\
\hline \multirow{2}{*}{ Fracción de Volumen } & D3171 & \multirow{2}{*}{-} & \multirow{2}{*}{ No hay métodos ACI disponibles } \\
\hline & D 2584 & & \\
\hline
\end{tabular}

Tabla 3.1. Métodos de ensayo de barras de FRP. ACI 440.3R-04 Tabla 1.1.

\subsection{Materiales Empleados}

Los materiales seleccionados en esta investigación son barras de CFRP con diferentes tipos de geometrías superficiales y diámetros. Al mismo tiempo, con el objetivo de establecer una comparación del comportamiento adherente, se emplean barras de acero corrugadas con diámetros similares a las barras de CFRP.

\subsubsection{Barras de CFRP}

Las barras de CFRP empleadas en este programa experimental presentan las siguientes geometrías superficiales: texturizadas, corrugadas y arenadas, éstas han sido facilitadas por las empresas Sika S.A.U, Marshall Composites Technologies LLC. y Pulltrall INC, respectivamente. Se han seleccionado estos tres tipos de geometrías debido a que son las más empleadas y representativas de los armados de CFRP.

Puesto que el estudio de la adherencia es el objetivo principal de esta investigación, se han seleccionado los diámetros con base en la superficie adherente de cada barra (diámetro equivalente), dentro de los propios fabricados por cada fabricante. Estos son una serie pequeña $(\varnothing \leq 10 \mathrm{~mm})$ que consta de 
barras arenadas de 8,27 $\mathrm{mm}(2 \#)$; y una serie media $(10 \mathrm{~mm}<\varnothing \leq 20 \mathrm{~mm})$ formada por barras arenadas de 13,69 $\mathrm{mm}(4 \#)$, corrugadas de 10,61 $\mathrm{mm}(3 \#)$ y texturizadas de $11,55 \mathrm{~mm} \mathrm{(3 \# )} \mathrm{(todos} \mathrm{estos} \mathrm{diámetros} \mathrm{son} \mathrm{diámetros}$ equivalentes, no son nominales, véase apart. 3.4.1.2).

- Barras de CFRP arenadas: Este tipo de barras se compone de un núcleo resistente de fibra de carbono y matriz polimérica de viniléster, con una geometría superficial a base de arena de sílice (Fig. 3.1a y b). Las propiedades de las barras arenadas definidas por el fabricante se muestran en la Tabla 3.2.
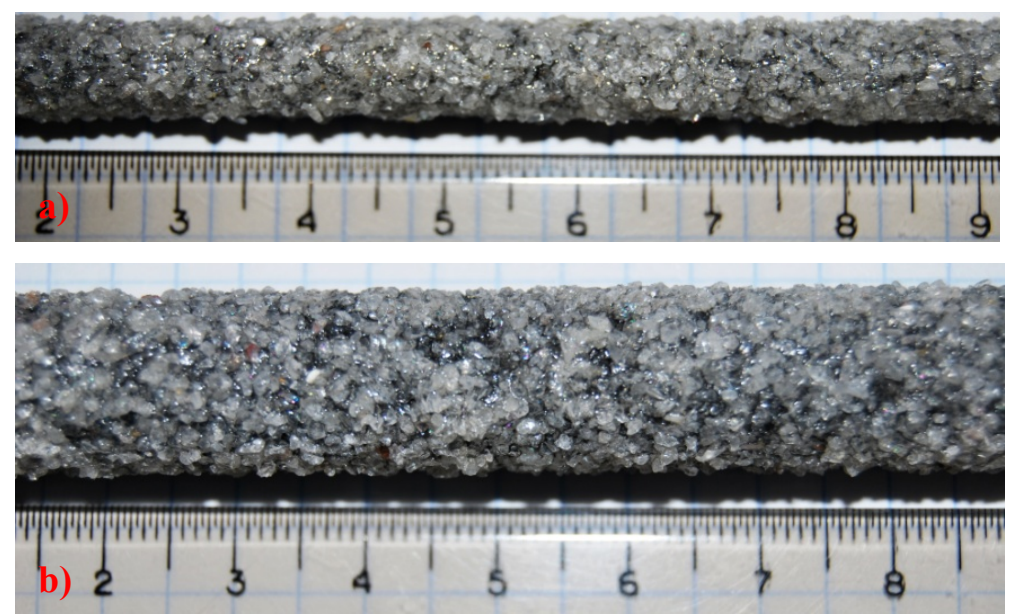

Fig. 3.1. Barras de CFRP arenadas: a) $\emptyset_{\mathrm{e}} 8,27 \mathrm{~mm}$; b) $\emptyset_{\mathrm{e}} 13,69 \mathrm{~mm}$.

- Barras de CFRP corrugadas: Están compuestas por un refuerzo de fibra de carbono y una matriz polimérica de viniléster, con una geometría superficial a base de corrugas, similar a las barras de acero corrugadas (Fig. 3.2). Las propiedades de este tipo de barras definidas por el fabricante se muestran en la Tabla 3.2.

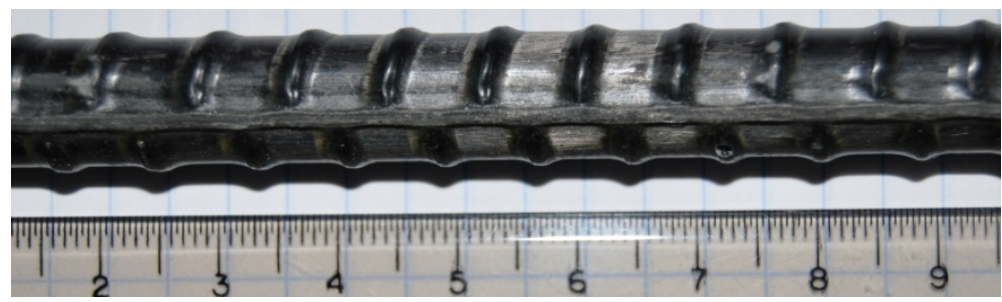

Fig. 3.2. Barra de CFRP Corrugada. 
- Barras de CFRP texturizadas: Este tipo de barra ha sido denominada en esta investigación de este modo debido a la capa de texturización, a base de una malla de zunchado superficial que dispone en su superficie, aunque principalmente se trate de una geometría con corrugas invertidas (Fig. 3.3). Están compuestas por un refuerzo de fibra de carbono y una matriz polimérica de epoxi. Las propiedades definidas por el fabricante se recogen en la Tabla 3.2.

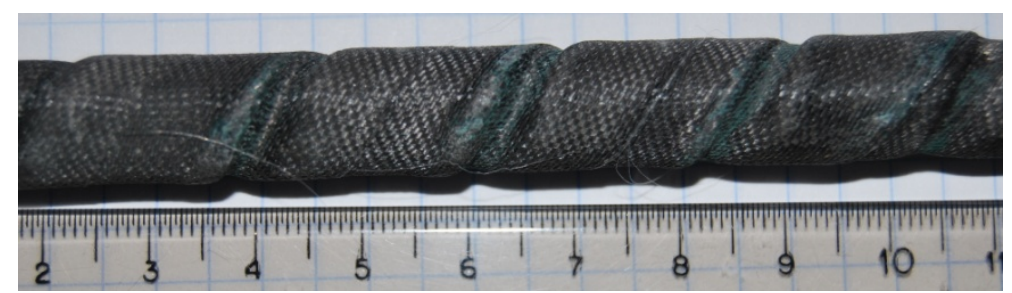

Fig. 3.3. Barra de CFRP Texturizada.

La denominación establecida para cada tipo de barras en el programa experimental se ha basado en el tipo de material, la geometría superficial y en el diámetro exterior (la primera sigla corresponde al tipo de material: $\mathrm{C}$ de carbono o A de acero; la segunda sigla al tipo de geometría superficial: A de arenada, C de corrugada y $\mathrm{T}$ de texturizada; y los números al diámetro exterior en $\mathrm{mm}$ ), siendo en el caso de barras arenadas los tipos CA8 y CA14, en barras corrugadas CC12 y en texturizadas CT13.

\begin{tabular}{|c|c|c|c|c|}
\hline Propiedades/Armado & CA8 & CA14 & CC12 & CT13 \\
\hline Diámetro nominal, $\mathrm{mm}$. & 6,35 & 12,70 & 9,50 & 9,52 \\
\hline Área nominal, $\mathrm{mm}^{2}$. & 31,67 & 126,70 & 71 & 71,25 \\
\hline Resistencia a tracción media, $\mathrm{MPa}(\sigma)$ & $1.518(54)$ & $1.899(44,66)$ & - & $2.800 *$ \\
\hline Módulo elástico, $\mathrm{GPa}$ & 127 & 144 & - & 155 \\
\hline Alargamiento de rotura, $\%$. & 1,20 & 1,32 & - & 1,80 \\
\hline
\end{tabular}

Tabla. 3.2. Propiedades definidas por el fabricante de las barras de CFRP. Los valores son medios. 


\subsubsection{Barras de Acero}

En esta investigación se han empleado barras de acero corrugadas de tipo B 500 SD (Fig. 3.4 a,b y c), puesto que este tipo de acero es el más empleado en la construcción como armado estructural. Los diámetros de las barras son: de la serie fina $8 \mathrm{~mm}$ (Arcelor Mittal), y de la serie media $12 \mathrm{~mm}$ (Corrugados Getafe) y $16 \mathrm{~mm}$ (Corrugados Azpeitia). Lo óptimo hubiera sido emplear barras de $14 \mathrm{~mm}$, con el fin de compararlas con las barras CA14, sin embargo, ha sido imposible encontrar barras de este diámetro debido a que los fabricantes no las producen. En la Tabla 3.3 se muestran las propiedades de las barras de acero corrugadas.

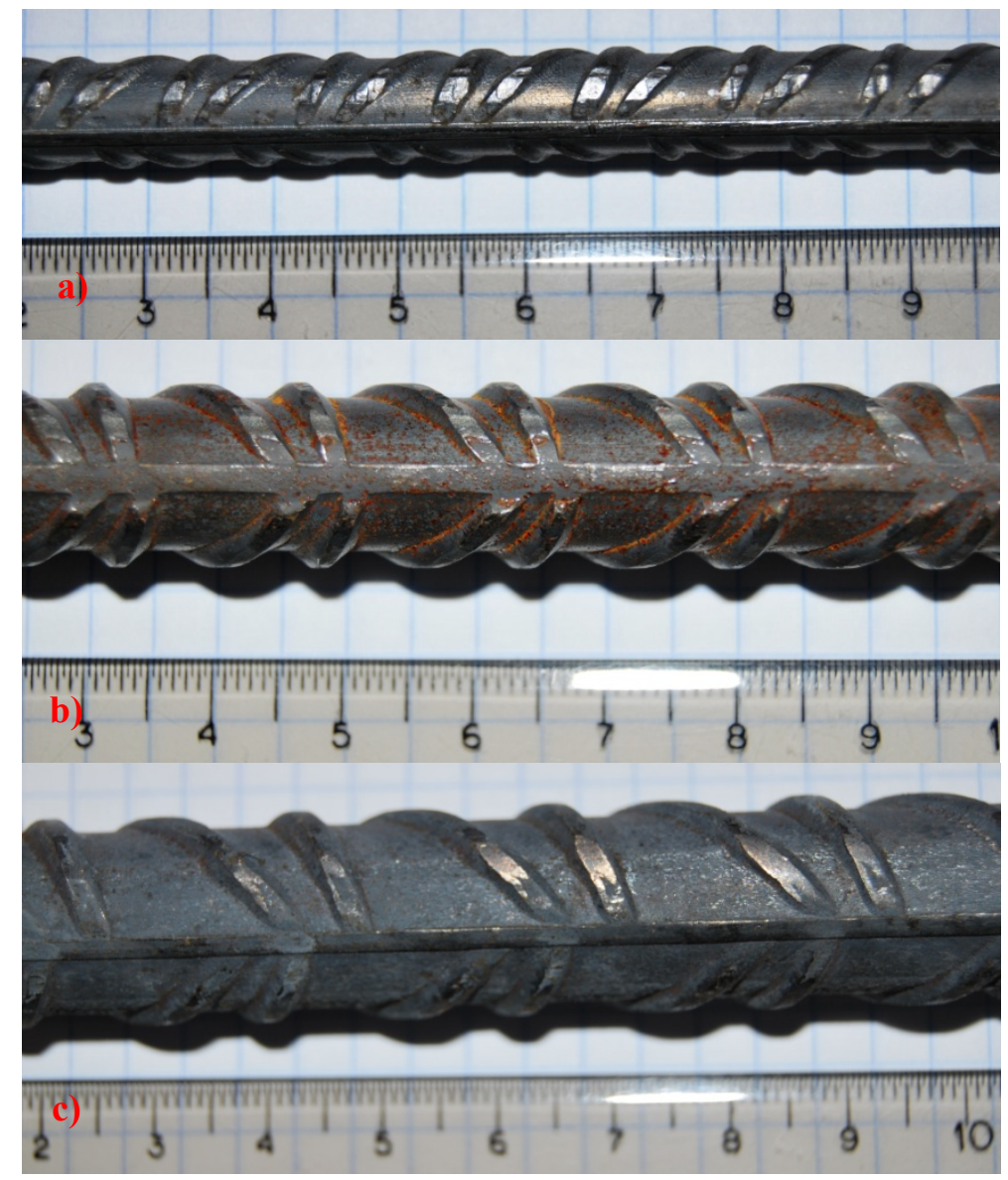

Fig. 3.4. Barra de Acero Corrugada: a) $\varnothing 8 \mathrm{~mm}$.; b) $\varnothing 12 \mathrm{~mm}$. ; c) $\varnothing 16 \mathrm{~mm}$. 
La denominación establecida para cada tipo de barras de acero corrugadas se ha basado (del mismo modo que en las barras de CFRP) en el tipo de material y diámetro exterior, siendo A8, A12 y A16, barras de acero corrugadas (acero B $500 \mathrm{SD}$ ) de diámetros 8, 12 y 16 mm, respectivamente.

\begin{tabular}{|c|c|c|c|}
\hline Propiedades/Armado & A8 & A12 & A16 \\
\hline Diámetro nominal, mm. & 8 & 12 & 16 \\
\hline Área nominal, mm². & 50,3 & 113,0 & 201,0 \\
\hline Tensión máxima, MPa. & $\geq 575$ & $575-843$ & $575-844$ \\
\hline Tensión a límite elástico, MPa. & $\geq 500$ & $500-625$ & $500-625$ \\
\hline Módulo elástico, GPa. & 200 & 200 & 200 \\
\hline Alargamiento de rotura, $\%$. & $\geq 16$ & $\geq 16$ & $\geq 16$ \\
\hline Alargamiento carga máxima, \%. & $\geq 9,5$ & $\geq 7,5$ & $\geq 8$ \\
\hline
\end{tabular}

Tabla. 3.3. Propiedades definidas por el fabricante de las barras de Acero. Los valores son medios.

\subsection{Ensayos Previos}

En este apartado se muestran los ensayos previos necesarios para realizar los ensayos experimentales de tracción y pullout.

Debido a que la normativa de ensayo de barras de FRP's empleada en este programa experimental, ACI 440.3R-04, se ha implantado hace pocos años y tan solo establece en el Apéndice A el tipo de anclajes que se deben de disponer en las barras de FRP, en el caso de barras de fibra de vidrio de $6,4 \mathrm{~mm}$ $\leq \varnothing \leq 22 \mathrm{~mm}$ y de CFRP solo en $\varnothing=9,5 \mathrm{~mm}$, tanto para el ensayo de tracción como de pullout. Por ello, se ha decidido comprobar que los parámetros principales de los ensayos de tracción y pullout contemplados en el programa experimental, como son el tipo y características de los anclajes de las barras de CFRP $^{29}$, son válidos en el caso de los tres tipos de barras de CFRP empleadas.

\footnotetext{
${ }^{29}$ Las barras de FRP requieren de un anclaje en cada extremo para la transmisión de las tensiones de la máquina de ensayo a la barra en los ensayos de tracción y pullout. Esto es debido a la reducida resistencia a cortante de este tipo de barras que conllevaría la rotura prematura por
} 
Al mismo tiempo, debido a que se van a realizar ensayos de pullout en condiciones ambientales de Hielo/Deshielo, $5{ }^{\circ} \mathrm{C}, 20{ }^{\circ} \mathrm{C}, 40{ }^{\circ} \mathrm{C}$ y $80{ }^{\circ} \mathrm{C}$, diferentes a las especificadas por la norma de ensayo ACI.440.3R-03.B.3 de 23 $\pm 3^{\circ} \mathrm{C}$ y $50 \pm 10 \%$ de humedad relativa, se realizan ensayos para el cálculo del periodo de exposición de las probetas en cada condición térmica o ambiental y del tiempo máximo de ensayo tras el periodo de exposición.

\subsubsection{Cálculo del Periodo de Exposición de las Probetas de Pullout en cada Condición Térmica}

En este apartado se calcula el periodo de exposición de las probetas a cada condición térmica o ambiental para el ensayo de pullout, debido a que los seis tratamientos térmicos principales definidos en ASTM D 618 no son óptimos para este programa experimental. Para ello, se realizan tres ensayos: el primero establecerá el ciclo térmico de Hielo/Deshielo; el segundo el ciclo de $5{ }^{\circ} \mathrm{C}$; y el tercer ensayo los ciclos de 40 y $80^{\circ} \mathrm{C}$.

- Cálculo del ciclo Hielo/Deshielo: Con este ensayo previo se pretende calcular el tiempo que tarda la barra de CFRP, en el interior de una probeta cúbica de hormigón a $20^{\circ} \mathrm{C}$, en alcanzar la temperatura de $-20^{\circ} \mathrm{C}$, y en volver a la temperatura inicial de $20^{\circ} \mathrm{C}$. Para ello, se emplean 7 probetas de hormigón, puesto que los ensayos experimentales se van a realizar por el diseño Splitplot con 7 sublotes cada día de ensayo (véase apart. 3.4.2), obteniendo así un resultado ajustado a la realidad del ensayo experimental (puesto que no es lo mismo la inercia térmica de siete probetas dentro del arcón que una sólo). La disposición de la probeta en el interior del arcón también ha sido estudiada y se

cortadura de la sección en los extremos anclados, y por consiguiente no desarrollaría toda su capacidad tensional. 
ha colocado la probeta con el termopar en el centro de las siete probetas.

Para llevar a cabo este ensayo se emplea un arcón frigorífico de la marca Zannusi modelo ZA38 (Fig. 3.5a), una sonda insertada en la probeta de hormigón de la marca Testo y modelo $175 \mathrm{~T} 2$ (Fig. 3.5b), otra sonda en el interior del arcón de la marca AUBE y modelo TE503 (Fig. 3.5b) y 7 probetas de hormigón cúbicas de dimensiones $200 \times 200 \times 200 \mathrm{~mm}$.
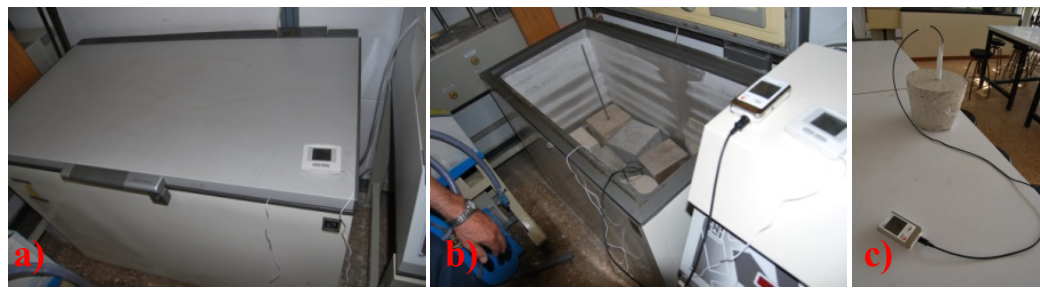

Fig. 3.5. a) arcón; b) ciclo de hielo; c) probeta de hormigón con sonda.

El procedimiento de ensayo es el siguiente: inicialmente se enfría el arcón hasta la temperatura deseada de $-20{ }^{\circ} \mathrm{C}$, seguidamente se introducen 7 probetas de hormigón cúbicas y se calcula el tiempo que transcurre hasta alcanzar la temperatura de $-20 \pm 2{ }^{\circ} \mathrm{C}$. Posteriormente, se extrae la probeta, a $-20 \pm 2{ }^{\circ} \mathrm{C}$, y se introduce en una cámara a $20 \pm 2{ }^{\circ} \mathrm{C}$ (Fig. 3.6c), y se calcula nuevamente el tiempo que tarda en alcanzar el interior de la probeta dicha temperatura.

En la Fig. 3.6 se muestran los resultados de este ensayo, obteniéndose un periodo de enfriamiento (hielo) de 21 horas y un periodo de calentamiento (deshielo) de 14 horas. Por lo tanto, se establece para cada ensayo de pullout dos ciclos de Hielo/Deshielo que duraran un total de 5 días $\left(2\right.$ días a $-20{ }^{\circ} \mathrm{C}$, más un día a $20{ }^{\circ} \mathrm{C}$ y 2 días a $-20{ }^{\circ} \mathrm{C}$ ). Esta condición ambiental 
se ha denominado 48/-20 + 24/20 + 48/-20 según ASTM D 618, o Hielo/Deshielo.

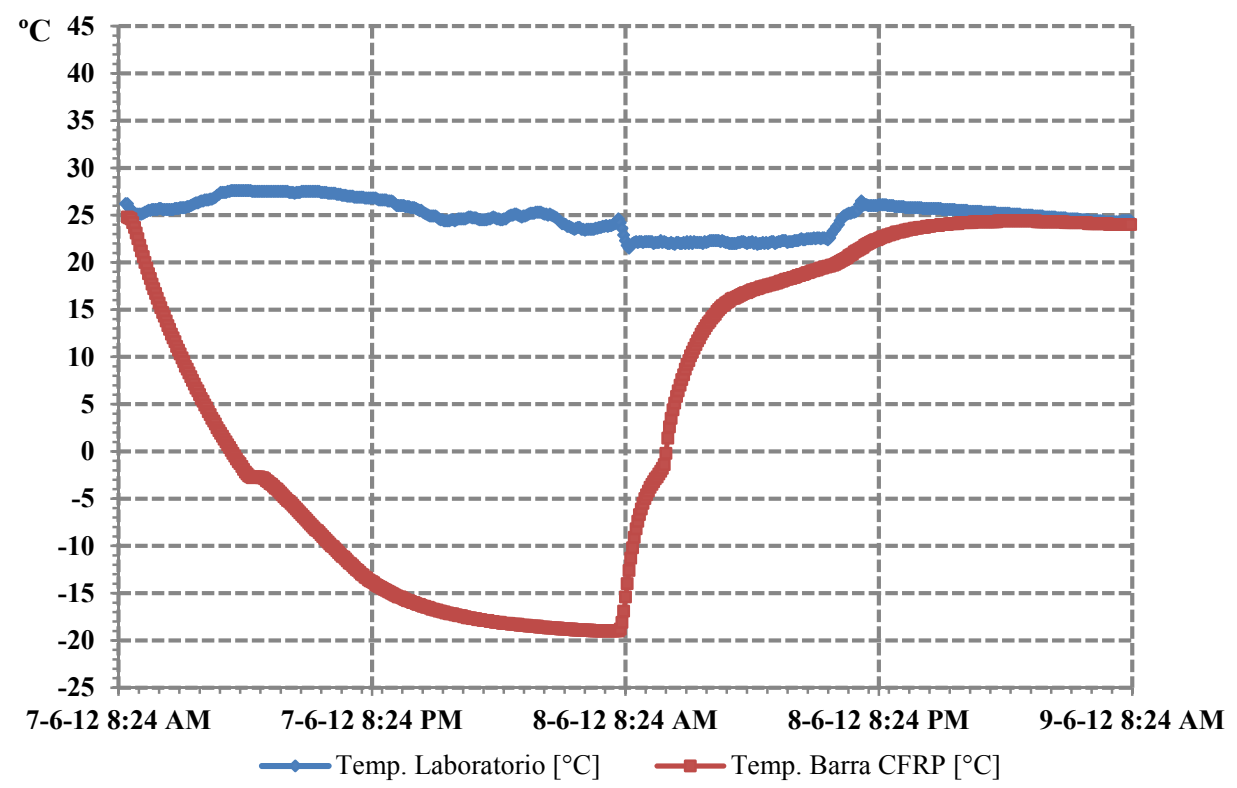

Fig. 3.6. Ciclo térmico de Hielo/Deshielo en probetas de pullout, según ASTM D 618.

El tiempo máximo de ensayo calculado tras la condición de Hielo/Deshielo es de $14 \mathrm{~min}$. (sin protección térmica de la probeta), tiempo suficiente para la realización del ensayo de pullout, debido a que el arcón se encuentra al lado de máquina de ensayo.

- Cálculo del ciclo de $5{ }^{\circ} \mathrm{C}$ : Los materiales y medios empleados en este ensayo previo son los mismos que se emplean en el ensayo de pullout. Estos son: cámara climática de la marca CTS modelo CW 10/4 (Fig. 3.7a); 7 probetas cúbicas de hormigón de dimensiones $200 \times 200 \times 200 \mathrm{~mm}$; sonda de la marca TESTO modelo 175T2; y una caja térmica (Fig. 3.7c), de poliestireno extruido XPS de $30 \mathrm{~mm}$ espesor y $\lambda=0,034 \mathrm{~W} / \mathrm{m} \mathrm{K}$, de dimensión interior 205 x 205 x $205 \mathrm{~mm}$. 

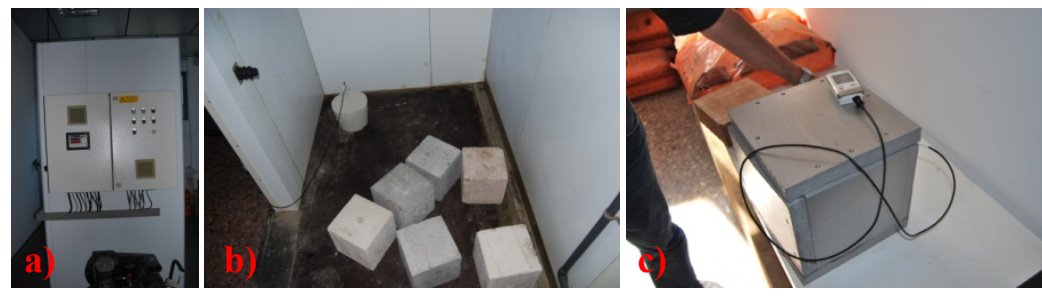

Fig. 3.7. a) Cámara; b) Ciclo de $5^{\circ} \mathrm{C}$; c) Probeta de hormigón en caja térmica con sonda.

El procedimiento consiste en introducir 7 probetas de hormigón, una de ellas con una sonda en el interior, en la cámara climática a $5{ }^{\circ} \mathrm{C}$ (Fig. 3.7b), hasta alcanzar la temperatura en el interior de la probeta de $5{ }^{\circ} \mathrm{C}$, para posteriormente extraerlas e introducirlas en una caja térmica y someterlas a temperatura de laboratorio de $23 \pm 2{ }^{\circ} \mathrm{C}$, calculando así el periodo de exposición térmica a $5{ }^{\circ} \mathrm{C}$ y el tiempo máximo de ensayo.

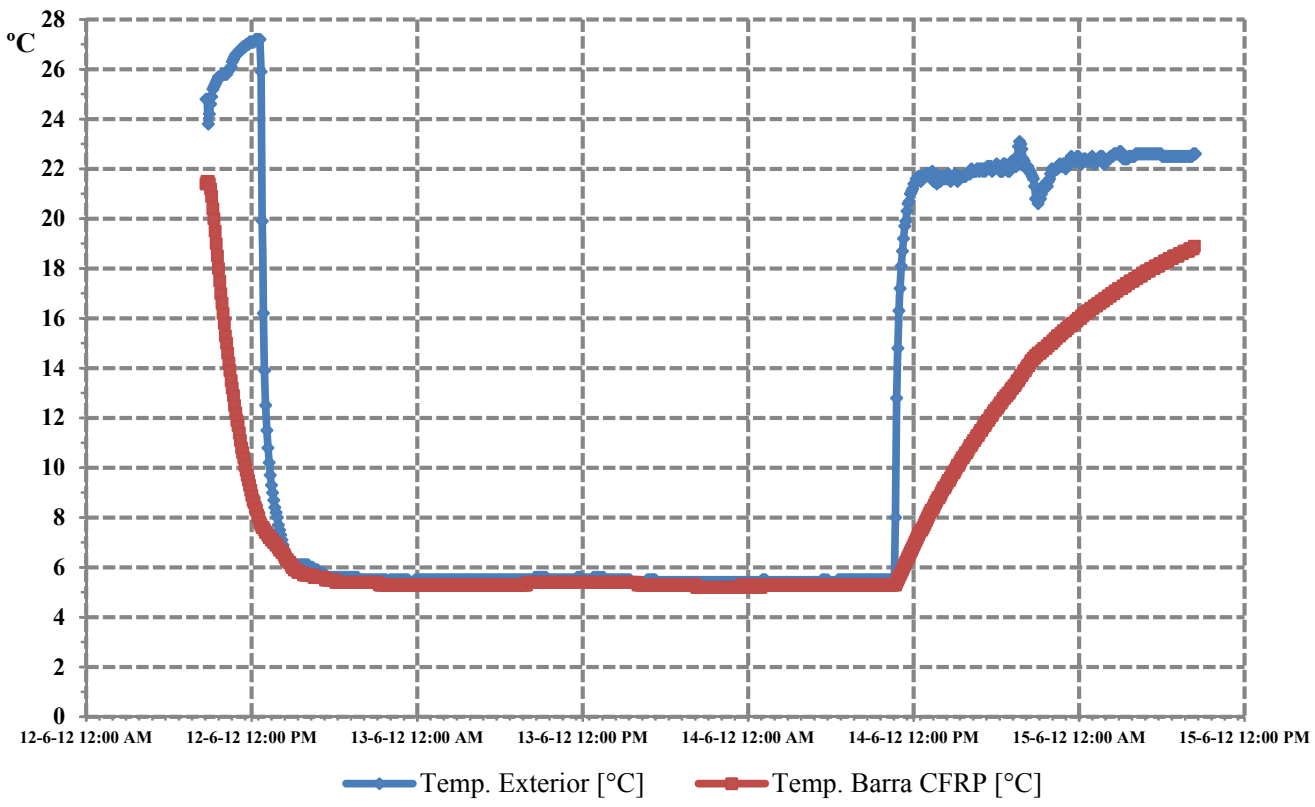

Fig.3.8. Gráfica de tiempo respecto al incremento de temperatura para el ciclo de $5{ }^{\circ} \mathrm{C}$.

El tiempo que transcurre hasta que la probeta se enfría desde las condiciones de laboratorio hasta $5{ }^{\circ} \mathrm{C}$ es de $6: 30$ horas (Fig. 8), 
por lo tanto, se establece un periodo de exposición térmica de 48 horas para la condición ambiental de $5^{\circ} \mathrm{C}$ o $48 / 5$ según ASTM D 618. En cuanto al periodo máximo de ensayo en dicha condición, se ha estimado en 1:45 horas (con protección de probetas mediante caja térmica).

- Cálculo del Ciclo de $80{ }^{\circ} \mathrm{C}$ : Para la realización de este ensayo se emplean los mismos materiales y medios utilizados en el ensayo de pullout. Estos son: estufa de la marca JP Selecta modelo Conterm; 7 probetas cúbicas de hormigón de dimensiones $200 \mathrm{x}$ 200 x 200 mm y sonda de la marca AUBE modelo TE503.

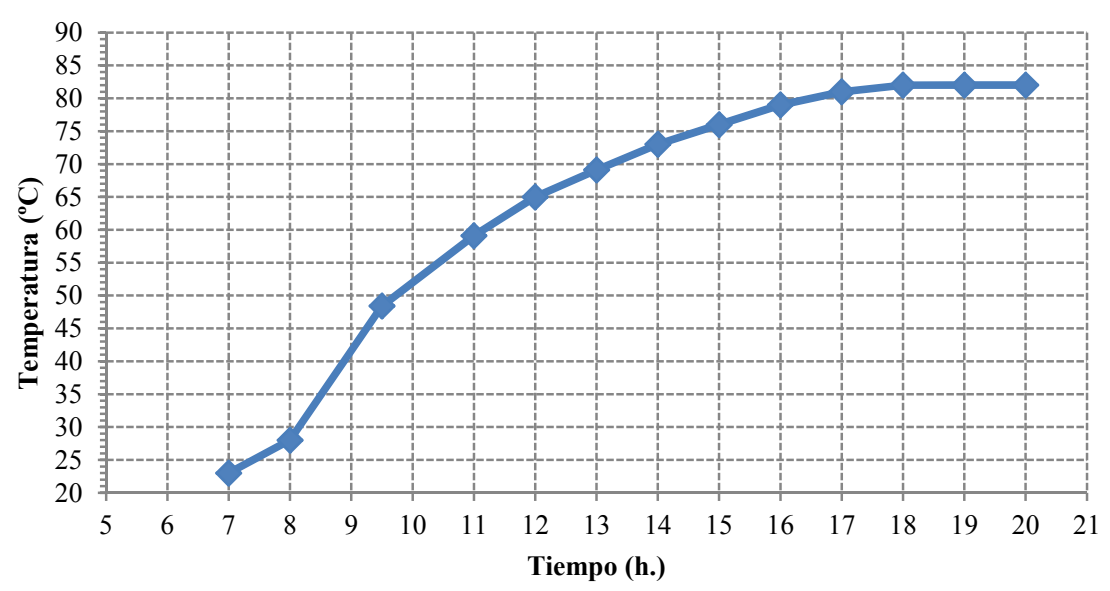

Fig. 3.9. Gráfica de tiempo respecto al incremento de temperatura para el ciclo de $80^{\circ} \mathrm{C}$.

Los resultados se muestran en la Fig. 3.9, de la cual se deduce que el tiempo transcurrido desde la temperatura de laboratorio hasta $80{ }^{\circ} \mathrm{C}$ es de 9:30 horas. Por lo tanto, se establece un periodo de exposición térmica de 48 horas, denominándose ciclo $80{ }^{\circ} \mathrm{C}$ o $48 / 80$ según ASTM D 618.

- Cálculo del Ciclo de $40{ }^{\circ} \mathrm{C}$ : Este ciclo se calcula con los datos obtenidos en el ensayo previo del ciclo de $80{ }^{\circ} \mathrm{C}$. El resultado se 
muestra en la Fig. 9, siendo el periodo de calentamiento desde temperatura de laboratorio hasta $40{ }^{\circ} \mathrm{C}$ (en el interior de la probeta) de 2 horas. Por lo tanto, se establece un periodo de exposición térmica de 48 horas a $40{ }^{\circ} \mathrm{C}$, puesto que así todas las condiciones ambientales presentan la misma duración.

3.3.2. Cálculo de la Longitud Mínima de los Anclajes de las Barras de CFRP del Ensayo de Tracción y Pullout

Debido a que las barras de CFRP poseen una resistencia a corte y al aplastamiento muy reducida (L. C. Bank, 2006), las sujeciones en ambos extremos durante los ensayo de tracción y pullout, se deben realizar con unos anclajes especiales, a base de tubo de acero, en los que la adhesión de la barra con el tubo de acero se puede realizar mediante resina de epoxi, mortero de retracción compensada y elevada resistencia o mortero expansivo (Fig. 3.10). ACI 440.3R-04 recomienda para barras de CFRP de 9,5 mm de diámetro el anclaje mediante tubos de acero de $35 \mathrm{~mm}$ de diámetro y $4,8 \mathrm{~mm}$ de espesor. Sin embargo, en estos ensayos previos se ha decidido emplear tubos de acero electrosoldado de $26,7 \mathrm{~mm}$ de diámetro exterior y $2,35 \mathrm{~mm}$ de espesor adheridos a las barras de CFRP mediante resina de epoxi tricomponente de la marca Sika modelo Sikadur 42.

\section{Probeta Ensayo de Tracción}

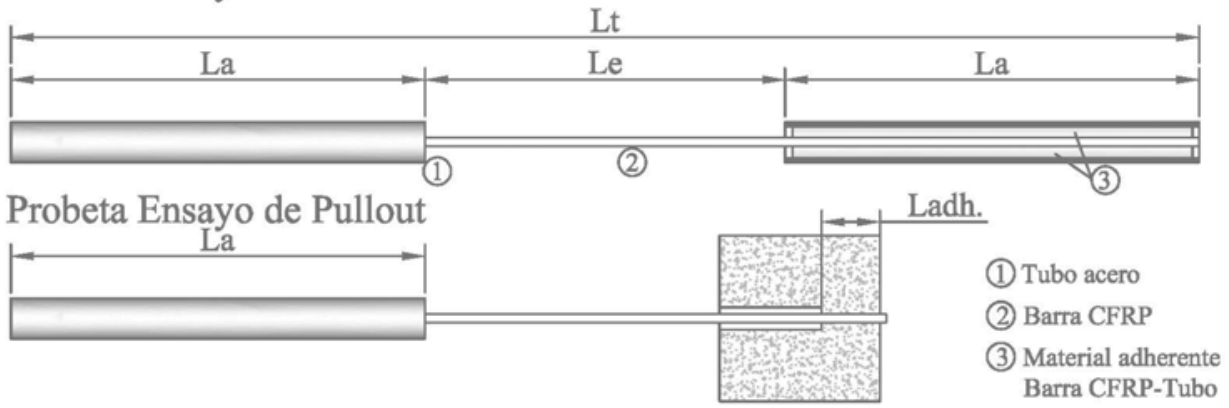

Fig. 3.10. Probetas de ensayos a tracción y pullout. 
La realización de los ensayos de la presente investigación se efectúa en su mayor parte según las disposiciones de ACI 440.3R-04. Esta norma recomienda, tanto para los ensayos de tracción como de pullout, en su Apéndice A, una longitud de anclaje " $\mathrm{L}_{\mathrm{a}}$ " mayor a $460 \mathrm{~mm}$ en el caso de barras de CFRP de diámetro $9,5 \mathrm{~mm}$ y una longitud de ensayo " $\mathrm{L}_{\mathrm{e}}$ " igual o superior a 40 diámetros de barra, mayor a $100 \mathrm{~mm}$ o 2 hélices en el caso de barras con geometría de hélice arrollada (Fig. 3.10). Otras normativas como JSCE 1997 (b) y CNR-DT 203/2006 tan solo establecen que $\mathrm{L}_{\mathrm{a}}$ sea adecuada para las cargas de rotura de cada tipo de ensayo y respecto a $\mathrm{L}_{\mathrm{e}}$ definen las mismas disposiciones que ACI 440.3R-04. Investigadores como Benmokrane et al., (2002) realizaron satisfactoriamente ensayos de tracción en barras arenadas $(\varnothing 9,5 \mathrm{~mm}) \mathrm{y}$ corrugadas $\left(\varnothing 9,0 \mathrm{~mm}\right.$ ) empleando una $\mathrm{L}_{\mathrm{a}}$ de $400 \mathrm{~mm}$ y una longitud total de la barra " $\mathrm{L}_{\mathrm{t}}$ " de 1200 mm; Del mismo modo Y. C. Wang et al., (2007) realizaron ensayos de tracción en barras arenadas $(\varnothing 9,5 \mathrm{~mm})$ con una $\mathrm{L}_{\mathrm{a}}$ de $350 \mathrm{~mm}$ y una $\mathrm{L}_{\mathrm{t}}$ de $1350 \mathrm{~mm}$, llevando hasta la rotura este tipo de barras. Por el contrario, en el caso de barras de CFRP texturizadas no se ha encontrado datos de ensayos de tracción, por lo que no se dispone de valores mínimos $L_{a}$ y $L_{t}$ para este tipo de barras.

Los fabricantes de barras arenadas Pulltrall INC (CA8 y CA14) como de barras corrugadas Marshall Composites Technologies LLC (CC12) disponen, según ensayos realizados, las siguientes $\mathrm{L}_{\mathrm{a}} \mathrm{y} \mathrm{L}_{\mathrm{t}}$ mínimas (Tabla 3.4).

\begin{tabular}{cccc} 
Tipo de Barra & $\begin{array}{c}\text { Diámetro } \\
(\mathbf{m m})\end{array}$ & $\begin{array}{c}\mathbf{L}_{\mathbf{a} \text { minina }} \\
(\mathbf{m m})\end{array}$ & $\begin{array}{c}\mathbf{L}_{\mathbf{t} \text { mínima }} \\
(\mathbf{m m})\end{array}$ \\
\hline Arenada & 6,35 & 350 & 954 \\
\cline { 1 - 1 } Arenada & 12,70 & 560 & 1628 \\
\cline { 1 - 1 } Corrugada & 10,26 & 380 & - \\
\hline
\end{tabular}

Tabla. 3.4. $\mathrm{L}_{\mathrm{a}}$ y $\mathrm{L}_{\mathrm{t}}$ mínimas en barras de CFRP arenadas y corrugadas. Marshall Composites Technologies LLC (2012) y Pultrall INC (1995).

\footnotetext{
${ }^{30}$ El diámetro de cada tipo de barra se encuentra definido en el apart. 3.4.1.2 "Estudio de la Geometría Superficial" de la presente tesis doctoral.
} 
Debido a la disparidad de datos anteriores se realiza una campaña de ensayos previos de tracción, según las disposiciones de ensayo definidas en ACI 440.3R-04 ensayo B.2, para la definición de $\mathrm{L}_{\mathrm{a}}$ en cada tipo de barra de CFRP, para posteriormente realizar los ensayos experimentales de tracción y pullout.

Para cada tipo de barra CC12, CA8 y CA14 se realizan 3 muestras con $\mathrm{L}_{\mathrm{a}} \mathrm{y} \mathrm{L}_{\mathrm{e}}=400 \mathrm{~mm}$ (Tabla 3.5), debido a que Benmokrane et al., (2002) y Wang et al., (2007) obtuvieron resultados satisfactorios con $L_{a}$ entre $350-400 \mathrm{~mm}$. Además las restricciones, como $\mathrm{L}_{\mathrm{t}}$ restringida por la máquina de ensayo a 1250 mm y $\mathrm{L}_{\mathrm{e}} \geq 40 \varnothing, 100 \mathrm{~mm}$ ó 2 hélices por las normas ACI 440.3R-04, JSCE 1997 (b) y CNR-DT 203/2006, nos limitan dichas dimensiones y variables a ensayar.

\begin{tabular}{cccccc}
\hline $\begin{array}{c}\text { Tipo de } \\
\text { Barra }\end{array}$ & CÓDIGO & $\begin{array}{c}\mathbf{L}_{\mathbf{e} \text { minina }} \\
(\mathbf{m m})\end{array}$ & $\begin{array}{c}\mathbf{L}_{\mathbf{a} \text { minina }} \\
(\mathbf{m m})\end{array}$ & $\begin{array}{c}\mathbf{L}_{\mathbf{t} \text { mínima }} \\
(\mathbf{m m})\end{array}$ & $\begin{array}{c}\mathbf{N}^{\mathbf{0}} \mathbf{d e} \\
\mathbf{m u}\end{array}$ \\
\hline CA8 & CA8-L400 & 400 & 400 & 1200 & 3 \\
\hline CA14 & CA14-L400 & 400 & 400 & 1200 & 3 \\
\hline CC12 & CC12-L400 & 400 & 400 & 1200 & 3 \\
\hline & CT13-L500 & 200 & 500 & 1200 & 3 \\
& CT13-L450 & 300 & 450 & 1200 & 3 \\
CT13 & CT13-L400 & 400 & 400 & 1200 & 3 \\
& CT13-L350 & 500 & 350 & 1200 & 3 \\
& CT13-L300-600 & 600 & 300 & 1200 & 3 \\
& CT13-L300-650 & 650 & 300 & 1250 & 3 \\
\hline
\end{tabular}

Tabla. 3.5. Dimensiones, Codificación y Plan de ensayos previos para caracterización de La.

En el caso de las barras CT13 se realizan un total de 18 ensayos (Tabla 3.5), realizando 3 muestras para cada $L_{a}(5$ posibles variables) más 3 muestras variando la longitud total de la barra (una vez establecida $L_{a}$ mínima).

\begin{tabular}{cccccccccc}
\hline Tipo barra / & \multicolumn{8}{c}{ Posición de ensayo } \\
\cline { 2 - 11 }$N^{\mathbf{0}}$ Muestra / \\
\cline { 2 - 10 } Día ensayo & 1 & \multicolumn{1}{c}{ CC12 } & 3 & 1 & 2 & 3 & 1 & 2 & 3 \\
\hline DIA 1 & 8 & 3 & 5 & 7 & 9 & 4 & 1 & 6 & 2 \\
\hline
\end{tabular}

Tabla. 3.6. Planificación de ensayos previos para cálculo de $\mathrm{L}_{\mathrm{a}}$ en CC12, CA14 y CA8.

La planificación estadística de estos primeros ensayos previos se ha dividido en dos partes. La primera es un diseño completamente aleatorizado. De 
este modo se reparte homogéneamente el ruido sobre las respuestas de los tratamientos, en los tipos de barras CC12, CA14 y CA8 (Tabla 3.6). La segunda planificación es un diseño de bloques incompletos, similar al diseño balanceado de cuadrado de Youden. Mediante este diseño se analiza la significación de las diferentes " $\mathrm{L}_{\mathrm{e}}$ " (tratamientos) en las barras CT13 y de este modo se elimina la fuente de variabilidad debida a los diferentes días de ensayo y se distribuye homogéneamente el ruido en cada $\mathrm{L}_{\mathrm{e}}$ (Tabla 3.7).

\begin{tabular}{|c|c|c|c|c|c|c|c|c|c|c|c|c|c|c|c|c|c|c|}
\hline \multirow{2}{*}{$\begin{array}{c}\text { Tipo } \\
\text { barra/ } \\
\text { Nomuestra }^{\circ}\end{array}$} & \multicolumn{3}{|c|}{ CT13-L500 } & \multicolumn{3}{|c|}{ CT13-L450 } & \multicolumn{3}{|c|}{ CT13-L400 } & \multicolumn{3}{|c|}{ CT13-L350 } & \multicolumn{3}{|c|}{$\begin{array}{c}\text { CT13-L300 } \\
-600 \\
\end{array}$} & \multicolumn{3}{|c|}{$\begin{array}{c}\text { CT13-L300 } \\
-650 \\
\end{array}$} \\
\hline & 1 & 2 & 3 & 1 & 2 & 3 & 1 & 2 & 3 & 1 & 2 & 3 & 1 & 2 & 3 & 1 & 2 & 3 \\
\hline DIA 1 & & 6 & & 3 & & & & 1 & & 2 & & & & & 5 & & 4 & \\
\hline DIA 2 & 2 & & & & & 5 & 1 & & & & 4 & & 6 & & & & & 3 \\
\hline DIA 3 & & & 4 & & 1 & & & & 6 & & & 2 & & 3 & & 5 & & \\
\hline
\end{tabular}

Tabla. 3.7. Planificación de ensayos previos para cálculo de $\mathrm{L}_{\mathrm{a}}$ en CT13.

El diámetro empleado para el cálculo de la tensión de cada tipo de barra está definido en el apart. 3.4.1.2. "Estudio de la Geometría Superficial" y es $6,35,12,70,10,26$ y $9,58 \mathrm{~mm}$ para las barras CA8, CA14, CC12 у CT13, respectivamente. El procedimiento de fabricación y ensayo de tracción se define en el apart. 3.4.1.3 "Ensayos de Tracción" de la presente investigación.

Los resultados obtenidos en los ensayos de tracción se resumen en la Tabla 3.8, donde se muestra que $\mathrm{L}_{\mathrm{e}}$ y $\mathrm{L}_{\mathrm{a}}=400 \mathrm{~mm} \mathrm{y} \mathrm{L}_{\mathrm{t}}=1200 \mathrm{~mm}$ son adecuados para los ensayos de tracción y pullout en los tipos de barras CA8 y $\mathrm{CC} 12$, puesto que en ambos tipos el modo de rotura es por splitting de la barra y, por lo tanto, similar al obtenido por el fabricante en el caso de las barras CA8 y por Benmokrane et al.,( 2002) en barras CC12. En las barras CC12 el anclaje no desliza; sin embargo, en las barras CA8 si se produce un pequeño deslizamiento del anclaje, pero éste no afecta a la lectura del LVDT, por lo que, las dimensiones especificadas anteriormente pueden considerarse válidas. 


\begin{tabular}{|c|c|c|c|c|c|c|}
\hline Tipo de barra & & $\begin{array}{c}\text { Fuerza } \\
(\mathbf{k N})\end{array}$ & $\begin{array}{l}\text { Tensión } \\
\text { (MPa) }\end{array}$ & $\begin{array}{c}\text { Módulo } \\
\text { (GPa) }\end{array}$ & $\begin{array}{c}\mathcal{\varepsilon}_{\text {carga }} \\
\text { máxima } \\
(\%)\end{array}$ & Modo de rotura \\
\hline \multirow{3}{*}{$\mathrm{CC} 12$} & 1 & 154,31 & 1866,57 & 115,02 & 1,71 & Splitting \\
\hline & 2 & 153,71 & 1859,34 & 114,89 & 1,70 & Splitting \\
\hline & 3 & 151,52 & 1832,86 & 113,55 & 1,69 & Splitting \\
\hline \multirow{3}{*}{ CA14 } & 1 & 102,96 & 812,63 & 119,59 & 0,78 & Desliza en anclaje. No rotura \\
\hline & 2 & 154,81 & 1221,93 & 137,04 & 0,95 & Desliza en anclaje. No rotura \\
\hline & 3 & 87,84 & 693,31 & 133,11 & 0,55 & Desliza en anclaje. No rotura \\
\hline \multirow{3}{*}{ CA8 } & 1 & 59,99 & 1894,51 & 133,06 & 1,16 & Splitting \\
\hline & 2 & 64,06 & 2022,97 & 146,18 & 1,00 & Splitting \\
\hline & 3 & 59,13 & 1867,25 & 134,51 & 1,20 & Splitting \\
\hline \multirow{3}{*}{ CT13-L500 } & 1 & 54,53 & 756,10 & 166,31 & 0,51 & Cortante \\
\hline & 2 & 60,21 & 834,86 & 155,35 & 0,85 & Cortante \\
\hline & 3 & 55,30 & 766,78 & 161,20 & 0,77 & Cortante \\
\hline \multirow{3}{*}{ CT13-L450 } & 1 & 65,50 & 908,21 & 125,36 & 0,99 & Cortante \\
\hline & 2 & 61,23 & 849,00 & 136,80 & 1,05 & Cortante \\
\hline & 3 & 68,50 & 949,81 & 145,50 & 0,89 & Cortante \\
\hline \multirow{3}{*}{ CT13-L400 } & 1 & 93,65 & 1298,53 & 119,71 & 1,11 & Splitting \\
\hline & 2 & 92,05 & 1276,34 & 101,29 & 1,19 & Splitting \\
\hline & 3 & 104,25 & 1445,51 & 200,93 & 0,05 & Splitting \\
\hline \multirow{3}{*}{ CT13-L350 } & 1 & 82,21 & 1139,91 & 168,83 & 0,66 & Splitting \\
\hline & 2 & 95,80 & 1328,34 & 152,52 & 0,91 & Splitting \\
\hline & 3 & 103,25 & 1431,64 & 157,01 & 0,86 & Splitting \\
\hline \multirow{3}{*}{ CT13-L300-600 } & 1 & 103,57 & 1436,08 & 159,61 & 0,92 & Splitting \\
\hline & 2 & 91,33 & 1266,36 & 109,28 & 1,15 & Splitting \\
\hline & 3 & 116,01 & 1608,57 & 150,56 & 1,10 & Splitting \\
\hline \multirow{3}{*}{ CT13-L300-650 } & 1 & 96,50 & 1338,05 & 119,86 & 1,56 & Splitting \\
\hline & 2 & 115,26 & 1598,17 & 118,46 & 1,73 & Splitting \\
\hline & 3 & 99,25 & 1376,18 & 120,36 & 1,45 & Splitting \\
\hline
\end{tabular}

Tabla. 3.8. Resultados ensayos previos de cálculo de $L_{a}$.

En cuanto a las barras CT13 ( $\varnothing 9,583 \mathrm{~mm})$, los datos de ensayo muestran que $\mathrm{L}_{\mathrm{e}}<400 \mathrm{~mm}\left(\mathrm{~L}_{\mathrm{e}}<40-42 \varnothing\right)$ producen un cambio en el modo de rotura, pasando éste de rotura por splitting a rotura por cortadura. Este cambio se produce debido a que una menor longitud de ensayo (mayor longitud de anclaje) con una misma $\mathrm{L}_{\mathrm{t}}$ incrementa el efecto de una posible desalineación de la barra respecto a las mordazas durante el ensayo, originándose de este modo fuerzas perpendiculares a la barra o de corte que provocan una rotura prematura. Es por ello que la barra no alcanza toda su capacidad resistente durante el ensayo de tracción. Esta afirmación queda demostrada significativamente con un nivel de 
confianza del 95\% mediante el Análisis de Varianza "ANOVA" y el test de contraste Múltiple de Rango (Tablas 3.9., 3.10 y Fig. 3.11), puesto que el valor de probabilidad de la distribución $\mathrm{F}$ del ANOVA menor a 0,05 prueba la hipótesis de la diferencia estadísticamente significativa de las medias de la variable independiente $L_{e}$ respecto de la variable dependiente tensión, con un nivel de confianza del 95\%. Al mismo tiempo, para determinar si las medias de los niveles de la variable independiente $\mathrm{L}_{\mathrm{e}}$ son significativamente diferentes unas de otras se ha realizado el test de Contraste Múltiple de Rango, en el que se prueba una diferencia estadísticamente significativa a un nivel de confianza del $95 \%$ entre los niveles de la variable independiente $\mathrm{L}_{\mathrm{e}} \leq 300 \mathrm{~mm}$ y $\mathrm{L}_{\mathrm{e}} \geq 400 \mathrm{~mm}$. Por lo tanto, $\mathrm{L}_{\mathrm{e}} \geq 400 \mathrm{~mm}(40-42 \varnothing)$ desarrolla estadísticamente mayores tensiones en las barras CT13.

\begin{tabular}{|c|c|c|c|c|c|}
\hline Fuente & $\begin{array}{l}\text { Suma de } \\
\text { cuadrados }\end{array}$ & $\begin{array}{c}\text { Grados de } \\
\text { libertad }\end{array}$ & $\begin{array}{l}\text { Cuadrado } \\
\text { medio }\end{array}$ & Cociente $\mathrm{F}$ & P-Valor \\
\hline Entre tratamientos & $1,20677 \cdot 10^{6}$ & 5 & 241354,0 & 17,29 & 0,0000 \\
\hline Dentro de tratamientos & 167470,0 & 12 & 13955,8 & & \\
\hline $\begin{array}{l}\text { Total sobre la media } \\
\text { global }\end{array}$ & $1,37424 \cdot 10^{6}$ & 17 & & & \\
\hline
\end{tabular}

Tabla. 3.9. Tabla ANOVA de la variable Tensión de la muestra CT13 según $\mathrm{L}_{\mathrm{e}}$.

\begin{tabular}{|c|c|c|c|}
\hline $\mathrm{L}_{\mathrm{e}}$ & Frecuencia & Media & $\begin{array}{c}\text { Grupos } \\
\text { homogéneos }^{31}\end{array}$ \\
\hline 200 & 3 & 785,91 & $\mathrm{X}$ \\
\hline 300 & 3 & 902,34 & $\mathrm{X}$ \\
\hline 400 & 3 & 1299,96 & $\mathrm{X}$ \\
\hline 500 & 3 & 1340,13 & $\mathrm{X}$ \\
\hline 600 & 3 & 1437,00 & $X$ \\
\hline 650 & 3 & 1437,47 & $X$ \\
\hline
\end{tabular}

Tabla. 3.10. Test de contraste Múltiple de Rango de la variable Tensión de la muestra CT13 según $\mathrm{L}_{\mathrm{e}}$.

31 Las $\mathrm{X}$ que no se encuentran alineadas en la misma columna muestran una diferencia estadíticamente significativa con un nivel de confianza del $95 \%$. 


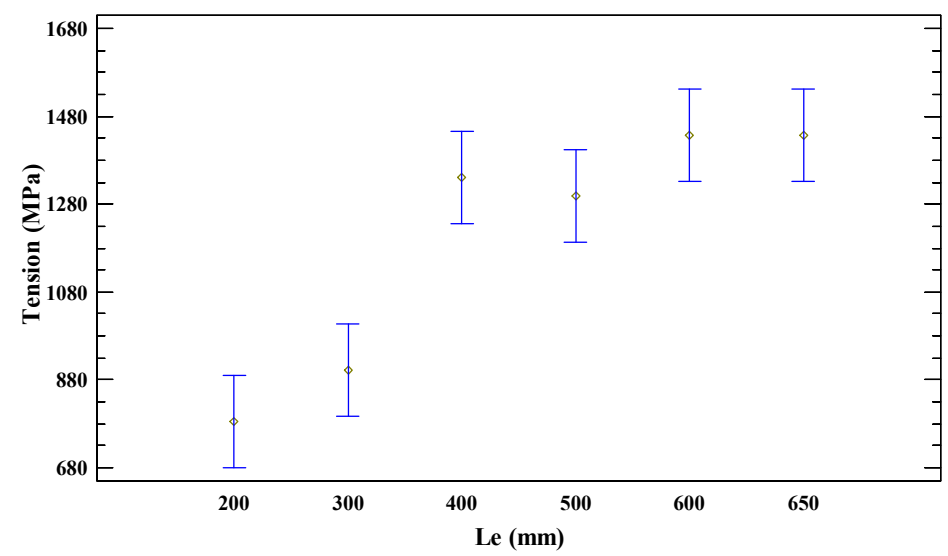

Fig. 3.11. Gráfico de Medias de la variable Tensión de la muestra CT13 según $\mathrm{L}_{\mathrm{e}}$.

En las barras CA14 se produce el deslizamiento en el anclaje antes de la rotura de la barra (Fig. 3.12), afectando a la lectura de los captadores de deformación LVDTs ${ }^{32}$, debido a la rotura de la adhesión entre la geometría superficial (recubrimiento de arena) y el núcleo de la propia barra. Esta rotura puede estar originada por una falta de $\mathrm{L}_{\mathrm{a}}$ o por una elevada temperatura de polimerización de la resina adherente entre el tubo de acero y la barra, que puede producir una descomposición de la matriz polimérica de la propia barra al alcanzar temperaturas superiores a su $\mathrm{T}_{\mathrm{g}}$ (véase apart. 3.4.3.1 y 3.4.3.2 de la presente investigación). Debido a que existe una restricción de $\mathrm{L}_{\mathrm{t}}$ por la máquina de ensayo, se decide que los ensayos de tracción se realicen con una $L_{t}$ de 1250 $\mathrm{mm}$ (longitud máxima de la máquina de ensayo) y $\mathrm{L}_{\mathrm{a}}=425 \mathrm{~mm}$, puesto que si se disminuye $\mathrm{L}_{\mathrm{e}}$ se puede originar, del mismo modo que en las barras CT13, una rotura prematura de la barra por cortante. Al mismo tiempo, se reduce la velocidad de ensayo de 0,61 a $0,30 \mathrm{kN} / \mathrm{s}$ con el objetivo de evitar que las descargas originadas en cada deslizamiento afecten a la lectura de los captadores. También se solicita al fabricante nuevas barras CA14 para los

\footnotetext{
32 Al producirse el deslizamiento y debido a la elevada tensión a la que se origina con este diámetro de barra, se produce un golpe repentino que paraliza la máquina de ensayo afectando a la lectura del captador de deformación. Este deslizamiento también se produce en las barras CA8 (con menor diámetro), pero al estar sometidas a menor tensión no afecta al captador de deformación puesto que no se produce una sacudida tan abrupta.
} 
ensayos de tracción y pullout, con la finalidad de descartar un posible fallo de la matriz polimérica. Del mismo modo, se realizan ensayos complementarios para el diseño del tipo de material adherente entre el tubo de acero y la barra CFRP, como son la resina de epoxi, cemento expansivo y mortero de altas prestaciones y retracción compensada, para eliminar la posibilidad de degradación de la matriz polimérica.
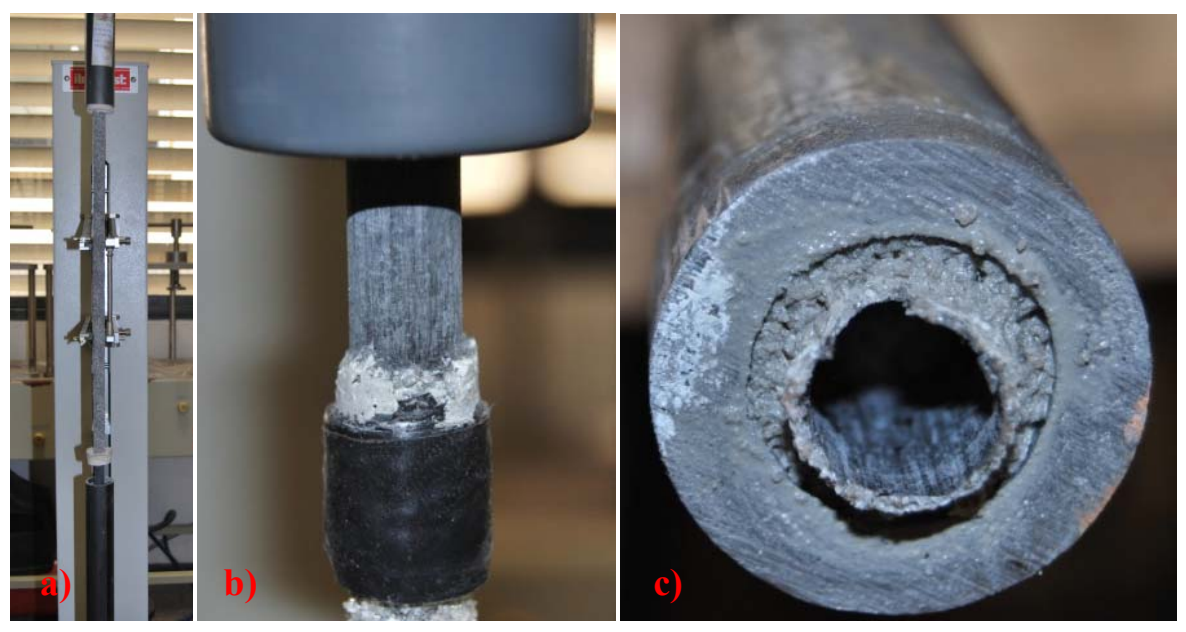

Fig. 3.12. Deslizamiento barra CA14: a) Deslizamiento en extremo inferior; b) Deslizamiento en extremo superior; c) Rotura de adhesión entre geometría superficial y núcleo de la barra.

En el caso de los ensayos de pullout con el tipo de barra CA14, debido a la limitación de $\mathrm{L}_{\mathrm{t}}$ de la máquina de ensayo que origina una $\mathrm{L}_{\mathrm{a} \text {.maxima }}=300 \mathrm{~mm}$, se decide realizar estos ensayos con $\mathrm{L}_{\mathrm{a}}=300 \mathrm{~mm}$, puesto que:

Los deslizamientos en los anclajes de CA14 comienzan a una fuerza aproximada de 90-100 kN. La tensión adherente máxima $\tau_{\text {adh.máxima }}$ en el anclaje es:

$$
\tau_{\text {adh.máxima }}=\frac{F}{L_{a} \cdot C_{b}}
$$

donde $\mathrm{F}$ es la fuerza $(\mathrm{N}), \mathrm{L}_{\mathrm{a}}$ es la longitud de anclaje $(\mathrm{mm})$ y $\mathrm{C}_{\mathrm{b}}$ es el perímetro de la barra (mm). 
Sustituyendo en la Ec. 3.1., la $\tau_{\text {adh.máxima }}$ en el anclaje del ensayo de tracción es:

$\tau_{\text {adh.máxima,anclaje tracción } C A 14}=\frac{95000}{390 \cdot 43,01}=5,66 \mathrm{MPa}$

entonces, se debe cumplir que la $\tau_{\text {adh.máxima,anclaje tracción en el anclaje durante el }}$ ensayo previo de tracción debe ser mayor a la $\tau_{\text {adh.máxima,anclaje pullout }}$ en el anclaje durante el ensayo experimental de pullout ${ }^{33}$, garantizando así la correcta ejecución del ensayo.

$\tau_{\text {adh.máxima,anclaje pullout } C A 14}=\frac{35000}{295 \cdot 43,01}=2,75 \mathrm{MPa}$

Se cumple $\tau_{\text {adh.máxima, anclaje tracción CA14 }}>\tau_{\text {adh.máxima, anclaje pullout CA14 }}$

$$
5,66 \mathrm{MPa}>2,75 \mathrm{MPa}
$$

Del mismo modo, en los tipos de barra CA8, CT13 y CC12, se comprueba que una $\mathrm{L}_{\mathrm{a}}=300 \mathrm{~mm}$ es suficiente para el ensayo experimental de pullout:

$$
\begin{aligned}
& \tau_{\text {adh.máxima,anclaje tracción } C A 8}=\frac{64060}{390 \cdot 25,99}=6,32 \mathrm{MPa} \\
& \tau_{\text {adh.máxima,anclaje tracción } C T 13}=\frac{116010}{390 \cdot 36,29}=8,19 \mathrm{MPa} \\
& \tau_{\text {adh.máxima,anclaje tracción } C \mathrm{C} 12}=\frac{154310}{390 \cdot 33,35}=11,86 \mathrm{MPa} \\
& \tau_{\text {adh.máxima,anclaje pullout } C A 8}=\frac{10324}{295 \cdot 25,99}=1,34 \mathrm{MPa} \\
& \tau_{\text {adh.máxima,anclaje pullout } C T 13}=\frac{19000}{295 \cdot 36,29}=1,77 \mathrm{MPa} \\
& \tau_{\text {adh.máxima,anclaje pullout } C \mathrm{C} 12}=\frac{34900}{295 \cdot 33,35}=3,54 \mathrm{MPa}
\end{aligned}
$$

\footnotetext{
${ }^{33}$ Para ello, se estima una fuerza máxima durante el ensayo de pullout según Baena et al., (2009) en barras CA14 y CT13 de 35 y $19 \mathrm{kN}$, respectivamente (en condiciones de ensayo similares). En el caso de las barras CC12, Benmokrane et al., (2002) obtuvieron una fuerza máxima en el ensayo de pullout de 29,9 kN. Las barras CA8, según el fabricante Pulltrall INC, romperán por pullout a una fuerza de $10,32 \mathrm{kN}$.
} 
Se cumple $\tau_{\text {adh.máxima, anclaje tracción }}>\tau_{\text {adh.máxima, anclaje pullout }}$

$\mathrm{CA} \quad 6,32 \mathrm{MPa}>1,34 \mathrm{MPa}$

CT13 8,19 MPa $>1,77 \mathrm{MPa}$

CC12 $11,86 \mathrm{MPa}>3,54 \mathrm{MPa}$

Por lo tanto, los ensayos experimentales de pullout se realizarán en todos los tipos de barras, CA8, CA14, CC12 y CT13, con una longitud de anclaje de $300 \mathrm{~mm}$.

3.3.3. Ensayo de Tracción para Definir el Material Adherente en los Anclajes de las Barras de CFRP

Una vez calculadas las dimensiones de los anclajes en los tipos de barras CC12, CA8 y CT13, se procede a definir el tipo de material adherente (del anclaje); del mismo modo, también se pretende establecer las dimensiones de ensayo $L_{a}, L_{e} y L_{t}$, así como el material adherente anclaje-barra en el caso de las barras arenadas CA14.

Este ensayo previo de tracción se realiza, de igual forma que el anterior, siguiendo las disposiciones de ACI 440.3R-04. En cuanto al proceso de fabricación y ensayo, éste se encuentra definido en el apart. 3.4.1.3.

Las dimensiones de las barras y anclajes para este ensayo previo se han definido en el ensayo previo anterior. Las dimensiones de CC12 y CA8 son $\mathrm{L}_{\mathrm{e}} \mathrm{y}$ $\mathrm{L}_{\mathrm{a}}=400 \mathrm{~mm} \mathrm{y} \mathrm{L}_{\mathrm{t}}=1200 \mathrm{~mm}$; en CT13 $\mathrm{L}_{\mathrm{e}}=300 \mathrm{~mm} \mathrm{y} \mathrm{L}_{\mathrm{a}}=650 \mathrm{~mm}$; y en CA14 las dimensiones $\mathrm{L}_{\mathrm{e}}, \mathrm{L}_{\mathrm{a}}$ y $\mathrm{L}_{\mathrm{t}}$ son iguales a 400, 425 y $1250 \mathrm{~mm}$.

En cuanto al material de relleno en los anclajes o adherente entre la barra y el tubo de acero, ACI 440.3R-04 en su Apéndice A recomienda el empleo de resina polimérica pura, resina polimérica mezclada con arena y cemento expansivo. Benmokrane et al. (2000) realizaron ensayos de tracción satisfactorios en barras de CFRP, con geometría de cable $(\varnothing 7,5 \mathrm{~mm})$ y corrugas embebidas en la barra $(\varnothing 7,9 \mathrm{~mm})$, cuyas dimensiones eran $L_{a}=600 \mathrm{~mm} \mathrm{y}$ $\mathrm{L}_{\mathrm{e}}=400 \mathrm{~mm}$, en los cuales emplearon resina de epoxi como material adherente. 
Estos resultados son similares a los obtenidos por Malvar et al. (2003) en barras de CFRP corrugadas $(\varnothing 10,2 \mathrm{~mm})$ y arenadas $(\varnothing 8,2 \mathrm{~mm})$ con $\mathrm{L}_{\mathrm{a}}=610 \mathrm{~mm}$ y $\mathrm{L}_{\mathrm{t}}$ $=1803 \mathrm{~mm}$, con material adherente a base de resina de epoxi. Sin embargo, Benmokrane et al. (2002) realizaron ensayos de tracción en barras de CFRP arenadas $(\varnothing 9,5 \mathrm{~mm})$ y corrugadas $(\varnothing 9,0 \mathrm{~mm})$, también con resultados satisfactorios, en las que disminuyeron las dimensiones de ensayo pasando a $L_{a}=400 \mathrm{~mm}$ y $L_{t}=1200 \mathrm{~mm}$. En estos ensayos también emplearon resina de epoxi como material adherente. En cambio, Protasio et al. (1998) emplearon cemento de alta resistencia en los anclajes de diferentes tipos de barras de GFRP: hélice arrollada y arenada $(\varnothing 9 \mathrm{~mm})$, hélice arrollada $(\varnothing 12,7 \mathrm{~mm})$, corrugada $(\varnothing 15 \mathrm{~mm})$, lisa $(\varnothing 12,7 \mathrm{~mm})$ y lisa cuadrada $(\varnothing 12,7 \mathrm{~mm})$; con $\mathrm{L}_{\mathrm{a}}$ del orden de 150, 200 y $220 \mathrm{~mm}$, en el caso de $\varnothing 10,3,12,7$ y 14,4 mm, respectivamente. Los resultados también fueron satisfactorios. Por el contrario, el fabricante de barras de CFRP arenadas Pulltrall INC recomienda como material adherente cemento expansivo de las marcas Da-Mite o Rockfrac y unas dimensiones de ensayo mayores a las estudiadas por Benmokrane et al. (2002) y Protasio et al., (1998) e inferiores a las analizadas por Benmokrane et al. (2000)

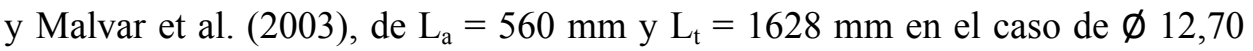
$\mathrm{mm}$.

Por lo tanto, debido a los diferentes tipos de materiales adherentes empleados en las diversas investigaciones y a los resultados obtenidos en el ensayo previo anterior, en el cual no se logra alcanzar la rotura de las barras CA14, se lleva a cabo el estudio de varios materiales adherentes mediante ensayos de tracción. Estos son:

- "RE" Resina de epoxi tricomponente de la marca Sika modelo Sikadur 42.

- “CE" Cemento expansivo de la marca CBA S.L.

- "MA" Mortero de altas prestaciones y retracción compensada de la marca Sika modelo SikaGrout 295. 
También se analiza otra variable denominada "SG", en la cual se elimina la geometría superficial de la barra en la zona de anclaje y se emplea como material adherente resina de epoxi tricomponente de la marca Sika modelo Sikadur 42.

La resina de epoxi tricomponente de la marca Sika modelo Sikadur 42 (Fig. 3.13) está compuesta por un precursor epoxídico (A), un catalizador a base de aminas (B) y un relleno de arena (C). La dosificación de los tipos de barra CT13 y CA8 se realiza según la recomendación del fabricante (Tabla 3.11). Sin embargo, en el caso de las barras CA14 se realiza una dosificación diferente, con una carga inferior de arena (Tabla 3.11), puesto que el espesor medio entre la barra y el tubo de acero es menor que en los otros tipos de barra, lo que produce una mejor trabajabilidad del producto. Las propiedades mecánicas de este material se encuentran definidas en la Tabla 3.12.
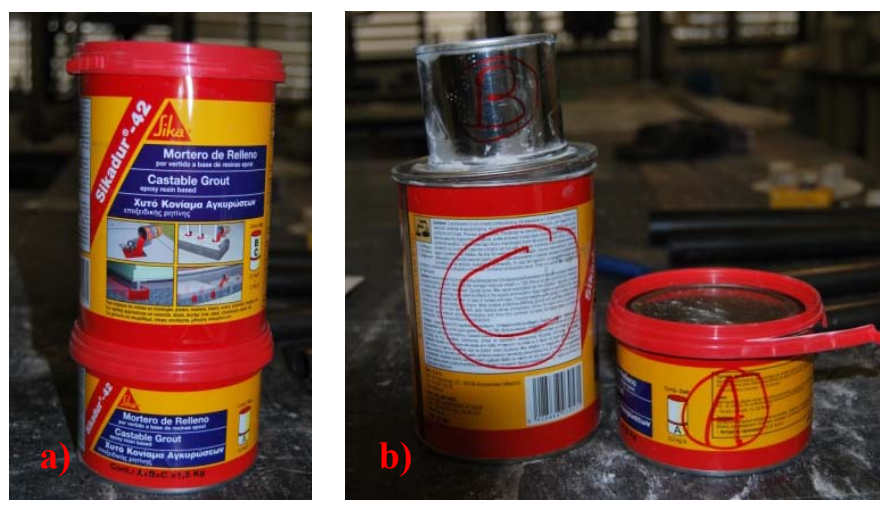

Fig. 3.13. Resina de epoxi Sikadur 42: a) formato 1,5 kg; b) Componentes Sikadur 42

\begin{tabular}{ccc}
\multirow{2}{*}{ Componente } & \multicolumn{2}{c}{ Dosificación (\%) } \\
\cline { 2 - 3 } & CC12, CA8 y CT13 & CA14 \\
\hline A & 14 & 23,44 \\
B & 6 & 9,99 \\
C & 80 & 66,67 \\
\hline
\end{tabular}

Tabla 3.11. Dosificación Sikadur 42 
El mortero de la marca Sika modelo SikaGrout295 es un mortero monocomponente, a base de cemento, fluido, de retracción compensada, ligeramente expansivo y de elevadas resistencias mecánicas. Éste presenta una mayor fluidez que el Sikadur42, lo cual mejora la trabajabilidad de las muestras de ensayo. Este mortero se ha dosificado, según fabricante, con una relación agua/cemento igual a 0,11 . Las propiedades mecánicas de este material se encuentran definidas en la Tabla 3.12. Las muestras de ensayo han sido curadas durante un periodo de 7 días (curado normalizado $23 \pm 2{ }^{\circ} \mathrm{C}$ y $50 \pm 10 \%$ de H.R), tras el cual, han sido ensayadas a temperatura de laboratorio $23 \pm 2{ }^{\circ} \mathrm{C}$.

\begin{tabular}{ccccc}
\hline \multirow{2}{*}{ Material Adherente } & \multicolumn{4}{c}{ Resistencia (MPa) } \\
\cline { 2 - 5 } & Adherencia & Compresión & Flexotracción & Módulo \\
\hline "RE" Sikadur42 & $>17,5$ & $80-90$ & $30-40$ & 19000 \\
\cline { 1 - 4 } "MA"SikaGrout295 & - & $70,5(24 \mathrm{~h})-95,4$ & $6,3(24 \mathrm{~h})-10,1$ & - \\
& & $(28$ días $)$ & (28días) &
\end{tabular}

Tabla 3.12. Propiedades mecánicas de los materiales adherentes barra/tubo de anclaje

El cemento expansivo de la marca CBA S.L posee una presión del orden de 80-90 MPa, dependiendo del agua de amasado y de la temperatura de curado (Fig. 3.14). En la presente investigación se ha dosificado con 2,7 litros de agua por cada $10 \mathrm{~kg}$ de cemento expansivo a una temperatura media de curado de 22 ${ }^{\circ} \mathrm{C}$ (durante 48 horas); por lo tanto, según el fabricante, la presión del cemento expansivo durante el ensayo de tracción es de $80 \mathrm{MPa}$.
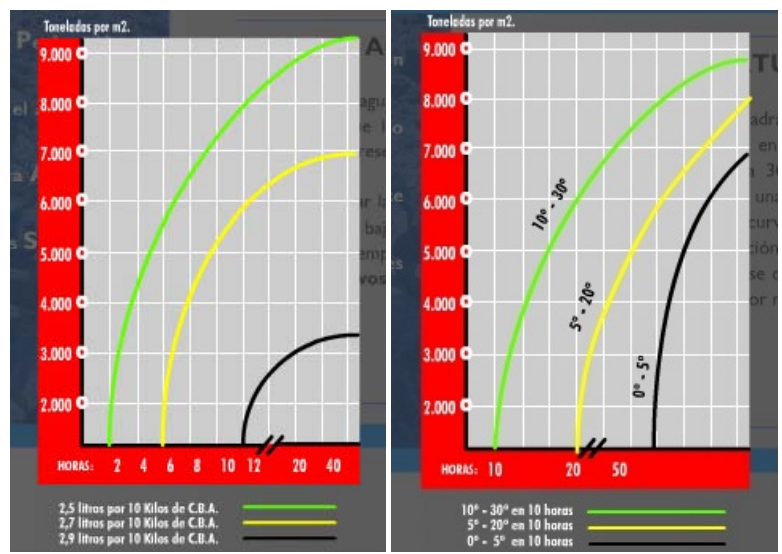

Fig. 3.14. Propiedades mecánicas cemento expansivo CBA S.L; a) Presión según cantidad de agua de amasado; b) Presión según temperatura de curado. 
La última variable de ensayo consta de la eliminación, mediante medios mecánicos (amoladora eléctrica), de la geometría superficial de las barras de CFRP (Fig. 3.15) y la adhesión mediante resina de epoxi tricomponente de la marca Sika modelo Sikadur 42. Los objetivos de esta variable son:

- El trabajo conjunto de todas las fibras de la sección de la barra, puesto que según Z. Achillides et al., (2004) se produce una diferente respuesta entre las fibras de carbono situadas en el alma y en la superficie de la barra, debido a que la sección de la barra no plastifica por su comportamiento elástico y lineal, lo que produce una distribución no uniforme de tensiones.

- Evitar el deslizamiento en los anclajes de la barras CFRP arenadas.
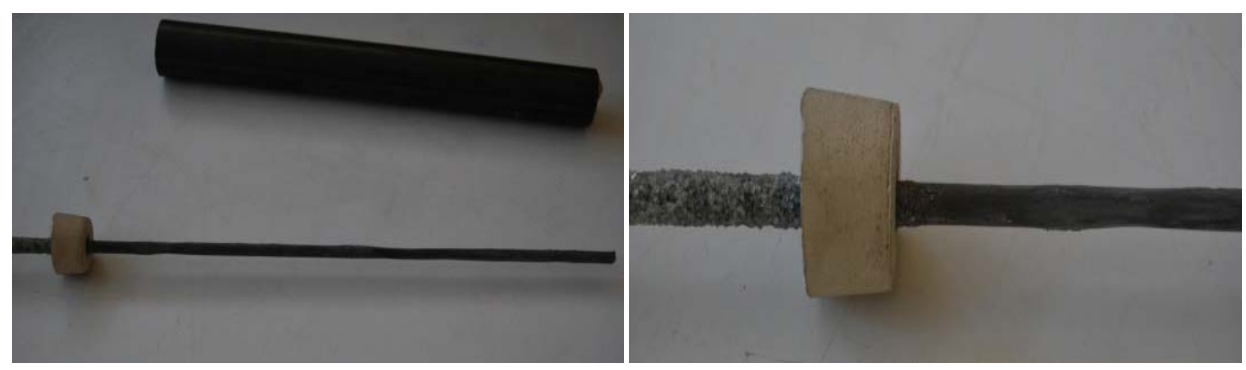

Fig. 3.15. Longitud de anclaje sin geometría superficial en barras de CFRP arenadas.

La dosificación y preparación de las muestras de ensayo es similar a la desarrollada en el caso de resina de epoxi con geometría superficial, para ambos tipos de barras.

\begin{tabular}{ccccc}
$\begin{array}{c}\text { Tratamiento/ } \\
\text { Bloque }\end{array}$ & RE & MA & CE & SG \\
\hline \multirow{3}{*}{ DIA 1 } & CA8 & CA8 & CT13 & CT13 \\
\cline { 2 - 5 } & CT13 & CA8 & CT13 & CA8 \\
\cline { 2 - 5 } & CA8 & CT13 & CA8 & CT13 \\
\hline \multirow{2}{*}{ DIA2 } & CT13 & CT13 & CT13 & CA8 \\
\cline { 2 - 5 } & CA8 & CA8 & CA8 & CA8 \\
\cline { 2 - 5 } & CT13 & CT13 & CA8 & CT13
\end{tabular}

Tabla 3.13. Diseño de bloques aleatorizados del primer ensayo previo de material adherente 


\begin{tabular}{lcc}
\hline $\begin{array}{c}\text { Tratamiento/ } \\
\text { Bloque }\end{array}$ & RE & MA \\
\hline \multirow{3}{*}{ DIA 1 } & CA14 & CT13 \\
\cline { 2 - 3 } & CA8 & CA8 \\
\cline { 2 - 3 } & CT13 & CT13 \\
\cline { 2 - 3 } & CA14 & CA14 \\
\cline { 2 - 3 } & CT13 & CT13 \\
\cline { 2 - 3 } & CA8 & CA8 \\
\hline \multirow{5}{*}{ DIA2 } & CA14 & CA14 \\
\cline { 2 - 3 } & CT13 & CT13 \\
\cline { 2 - 3 } & CA8 & CA8 \\
\cline { 2 - 3 } & CA14 & CA14 \\
\cline { 2 - 3 } & CT13 & CA14 \\
\cline { 2 - 3 } & CA8 & CA8
\end{tabular}

Tabla 3.14. Diseño de bloques aleatorizados del segundo ensayo previo de material adherente

Este ensayo se ha planificado mediante un doble diseño de bloques aleatorizados, debido a que la finalidad del mismo es la comparación de los distintos tipos de material adherente "RE, MA, CE y SG" (tratamientos). Mediante este método, con la formación de bloques se controla la variabilidad conocida de los diferentes días de ensayo y tipos de barras, y con la aleatorización se fuerza a que los riesgos y sesgos conocidos y los no considerados actúen aleatoriamente y de esta forma no perjudiquen a las conclusiones. De este modo, se ha diseñado dos bloques aleatorizados a través de los cuales se logra realizar dos análisis de los tratamientos diferentes: en el primer análisis se analizan 4 tipos de material adherente, RE, MA, CE y SG, con dos bloques que son los días de ensayo y se aleatorizan los tipos de barra CA8 y CT13 dentro de cada bloque (Tabla 3.13), de modo que en el segundo análisis de bloques aleatorizados se comparten los ensayos de los tipos de barras CA8 y CT13 en los tratamientos RE y MA (de los bloques 1 y 2 del primer análisis) y se ensaya el tipo de barra CA14 (Tabla 3.14). En ambos diseños se realizan 3 repeticiones por cada tipo de barra y un total de 30 ensayos. 


\begin{tabular}{|c|c|c|c|c|}
\hline Variable & $\begin{array}{c}\text { Tipo de } \\
\text { barra }\end{array}$ & $\begin{array}{c}\text { Fuerza } \\
(\mathrm{kN})\end{array}$ & $\begin{array}{c}\text { Tensión } \\
(\mathrm{MPa})\end{array}$ & Modo de rotura \\
\hline \multirow{9}{*}{$\mathrm{RE}$} & \multirow{3}{*}{ CA8 } & 59,99 & 1894,51 & Splitting \\
\hline & & 64,06 & 2022,97 & Splitting \\
\hline & & 59,13 & 1867,25 & Splitting \\
\hline & \multirow{3}{*}{ CA14 } & 102,96 & 812,63 & Desliza en anclaje. No rotura \\
\hline & & 154,81 & 1221,93 & Desliza en anclaje. No rotura \\
\hline & & 87,84 & 693,31 & Desliza en anclaje. No rotura \\
\hline & \multirow{3}{*}{ CT13 } & 103,57 & 1436,08 & Splitting \\
\hline & & 91,33 & 1266,36 & Splitting \\
\hline & & 116,01 & 1608,57 & Splitting \\
\hline \multirow{9}{*}{ MA } & \multirow{3}{*}{ CA8 } & 46,14 & 1456,92 & Desliza en anclaje. No rotura \\
\hline & & 48,20 & 1521,94 & Desliza en anclaje. No rotura \\
\hline & & 44,58 & 1407,64 & Desliza en anclaje. No rotura \\
\hline & \multirow{3}{*}{ CA14 } & 112,34 & 886,68 & Desliza en anclaje. No rotura \\
\hline & & 180,05 & 1421,14 & Desliza en anclaje. No rotura \\
\hline & & 135,50 & 1069,45 & Desliza en anclaje. No rotura \\
\hline & \multirow{3}{*}{ CT13 } & 54,73 & 758,87 & Splitting \\
\hline & & 55,86 & 774,54 & Splitting \\
\hline & & 57,20 & 793,12 & Splitting \\
\hline \multirow{6}{*}{$\mathrm{CE}$} & \multirow{3}{*}{ CA8 } & 44,91 & 1418,23 & Splitting \\
\hline & & 46,81 & 1478,16 & Splitting \\
\hline & & 44,35 & 1400,47 & Splitting \\
\hline & \multirow{3}{*}{ CT13 } & 95,38 & 1322,52 & Splitting \\
\hline & & 92,82 & 1287,02 & Splitting \\
\hline & & 96,32 & 1335,55 & Splitting \\
\hline \multirow{6}{*}{ SG } & \multirow{3}{*}{ CA8 } & 47,34 & 1494,97 & Splitting \\
\hline & & 48,25 & 1523,63 & Splitting \\
\hline & & 47,80 & 1509,47 & Splitting \\
\hline & \multirow{3}{*}{ CT13 } & 86,21 & 1195,37 & Splitting \\
\hline & & 89,52 & 1241,26 & Splitting \\
\hline & & 85,43 & 1184,55 & Splitting \\
\hline
\end{tabular}

Tabla. 3.15. Resultados de los ensayos previos de tracción para el diseño del material adherente.

En la Tabla 3.15 se muestran los resultados de los ensayos junto con el modo de rotura. En el caso de las barras CA14 se observa que con ninguno de los dos tipos de materiales adherentes ensayados, RE y MA, se logra alcanzar la rotura a tracción por agotamiento de la barra. Esto es debido a que se produce un deslizamiento en ambos anclajes originado por la rotura de la adhesión entre la geometría superficial y el núcleo de la propia barra (Fig. 3.16). Además, se producen sacudidas en la máquina de ensayo, al inicio de los deslizamientos en 
los anclajes, que detienen la lectura de los LVDT. Por lo tanto, dado que estos datos no son válidos, no se realiza el análisis del segundo bloque aleatorizado.
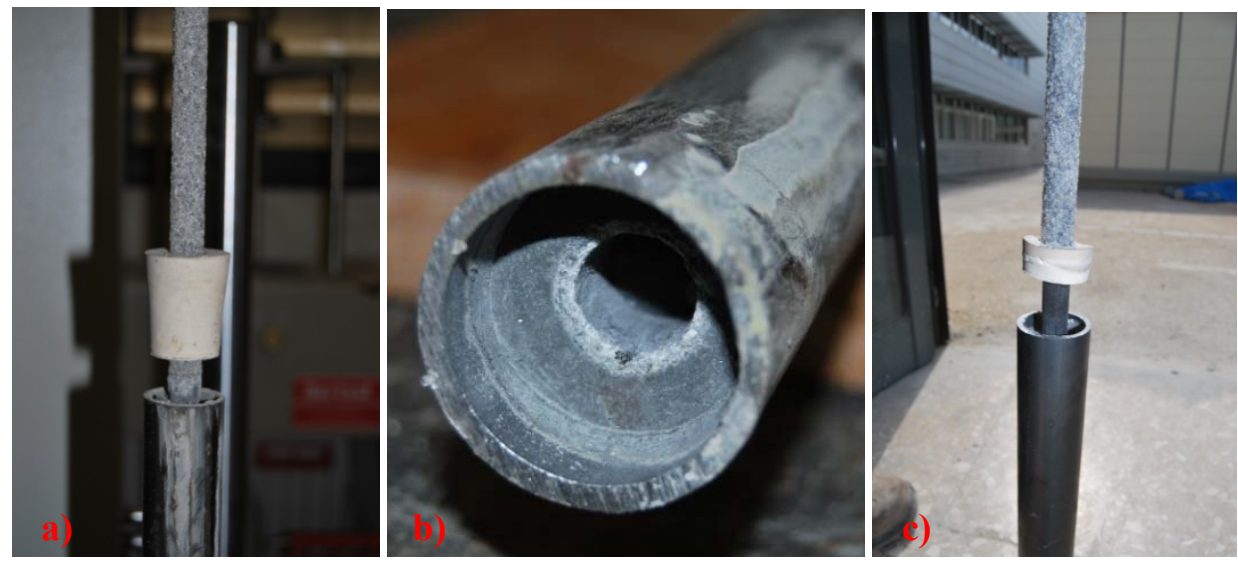

Fig. 3.16. Deslizamiento en anclajes en ensayo de tracción de barras CA14: a) Deslizamiento extremo inferior con MA; b) Rotura adhesión geometría/núcleo con MA; c) Deslizamiento extremo inferior con RE.

Respecto a los dos tipos de materiales empleados en el análisis de las barras CA14 (arenadas de 12,70 mm de diámetro), se puede demostrar (véase apart. 3.4.3.1 y 3.4.3.2) que la matriz polimérica de la barra de CFRP no se ve afectada por la temperatura de polimerización o curado en el caso de los materiales adherentes RE y MA, respectivamente. En este estudio previo no ha sido posible definir el material adherente adecuado para este tipo y diámetro de barras. Una posible solución es adoptar las $L_{a}$ y $L_{t}$ que especifica el fabricante, 560 y $1628 \mathrm{~mm}$ respectivamente, pero en nuestro caso no es posible debido a la limitación de $\mathrm{L}_{\mathrm{t}}$ de la máquina de ensayo que lleva asociada una respectiva limitación de $\mathrm{L}_{\mathrm{a}}$. También cabe mencionar que los ensayos realizados por Benmokrane et al. (2002) y Pultrall INC con unas dimensiones similares a las de estos ensayos previos se han realizado mediante una máquina de ensayo (Fig. 3.17.b) que ancla el tubo de anclaje en el comienzo de $\mathrm{L}_{\mathrm{a}}$ de la barra lo que puede ocasionar un mayor confinamiento en dicha sección que incrementa la adherencia entre la capa de arenado y el núcleo de la barra, evitando la rotura prematura. Por el contrario, la máquina de ensayo de esta investigación 
(Fig.3.17.a) ancla el tubo de anclaje en su parte superior (más alejada del inicio de la $L_{a}$ ), lo cual puede producir un menor confinamiento en la longitud adherente de la barra, ocasionando una menor adherencia de la resina polimérica que adhiere la capa de arenado de la barra.

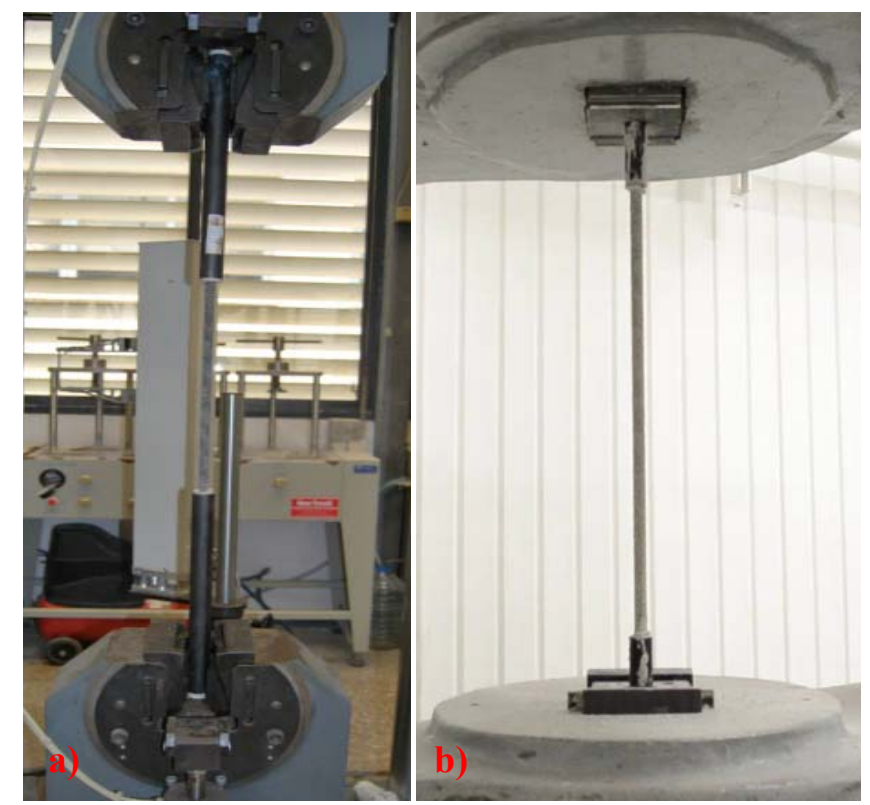

Fig. 3.17. Anclajes máquinas de ensayo a tracción: a) Presente investigación; b) Pultrall INC

El ANOVA del primer bloque aleatorizado (Tabla 3.16) demuestra que hay diferencia estadísticamente significativa, con un nivel de confianza del 95\%, entre los diferentes materiales adherentes RE, MA, CE y SG. Además, en el test de Contraste Múltiple de Rangos (Tabla 3.17) se observa que hay tres grupos diferentes de materiales adherentes: 1) RE, 2) CE y SG, 3) MA, y que el material $\mathrm{RE}$ es el que permite desarrollar una mayor fuerza durante el ensayo de tracción respecto de los otros tres (Fig. 3.18). Además, es el único material que logra un modo de rotura adecuado "splitting", tanto en CA8 y CT13 (Fig. 3.19), y en el caso de CA8 es el único cuyos deslizamientos producidos en los anclajes no afectan a la lectura de los LVDT, al contrario de los materiales CE y SG (Fig. 3.20). Por lo tanto, los ensayos experimentales de tracción y pullout, en los tipos 
de barras CA8 y CT13, se ha decidido realizarlos con resina de epoxi tricomponente de la marca Sika modelo Sikadur 42. En el caso de las barras CC12 también se emplea como material adherente la resina de epoxi Sikadur42, tanto en los ensayos de tracción como de pullout, puesto que en los ensayos previos de cálculo de la longitud mínima de los anclajes se han alcanzado tensiones y un modo de rotura satisfactorio. Respecto de las barras CA14, debido a la limitación de $\mathrm{L}_{\mathrm{t}}$, se decide realizar los ensayos de tracción y pullout con la resina de epoxi Sikadur42 "RE", con la finalidad de homogeneizar materiales y periodos de ensayo ${ }^{34}$.

\begin{tabular}{|c|c|c|c|c|c|}
\hline Fuente & $\begin{array}{l}\text { Suma de } \\
\text { cuadrados }\end{array}$ & $\begin{array}{c}\text { Grados de } \\
\text { libertad }\end{array}$ & $\begin{array}{l}\text { Cuadrado } \\
\text { medio }\end{array}$ & Cociente F & P-Valor \\
\hline \multicolumn{6}{|c|}{ EFECTOS PRINCIPALES } \\
\hline A: TIPO DE BARRA & 7449,03 & 1 & 7449,03 & 81,28 & 0,0000 \\
\hline $\begin{array}{l}\text { B: MATERIAL } \\
\text { ADHERENTE }\end{array}$ & 2972,06 & 3 & 990,688 & 10,81 & 0,0002 \\
\hline RESIDUOS & 1741,38 & 19 & 90,6516 & & \\
\hline Total (CORREGIDO) & 12162,5 & 23 & & & \\
\hline
\end{tabular}

Tabla. 3.16. Tabla ANOVA de la variable Fuerza respecto de los factores Material Adherente y Tipo de Barra.

\begin{tabular}{|c|c|c|c|}
\hline $\begin{array}{c}\text { Tipo } \\
\text { Material } \\
\text { Adherente }\end{array}$ & Frecuencia & Media & $\begin{array}{c}\text { Grupos } \\
\text { homogéneos }\end{array}$ \\
\hline MA & 6 & 51,11 & $X$ \\
\hline SG & 6 & 67,42 & $\mathrm{X}$ \\
\hline $\mathrm{CE}$ & 6 & 70,09 & $\mathrm{X}$ \\
\hline $\mathrm{RE}$ & 6 & 82,34 & $\mathrm{X}$ \\
\hline Contraste & \multicolumn{2}{|c|}{ Diferencias } & +/- Límites \\
\hline CE-MA & \multicolumn{2}{|c|}{$* 18,98$} & 11,5687 \\
\hline CE-RE & \multicolumn{2}{|c|}{$*-12,25$} & 11,5687 \\
\hline CE-SG & \multicolumn{2}{|c|}{2,67} & 11,5687 \\
\hline MA-RE & \multicolumn{2}{|c|}{$*-31,23$} & 11,5687 \\
\hline MA-SG & \multicolumn{2}{|c|}{$*_{-}-16,30$} & 11,5687 \\
\hline RE-SG & \multicolumn{2}{|c|}{$* 14,92$} & 11,5687 \\
\hline
\end{tabular}

Tabla. 3.17. Test de contraste Múltiple de Rango de la variable Fuerza respecto del factor material adherente.

\footnotetext{
${ }^{34}$ En el caso de emplear un material diferente a RE en CA14 los periodos de curado y por consiguiente de ensayo cambiarían entre los diferentes tipos de barra, lo que afectaría en gran medida al diseño experimental y a la distribución de errores entre dichos factores.
} 


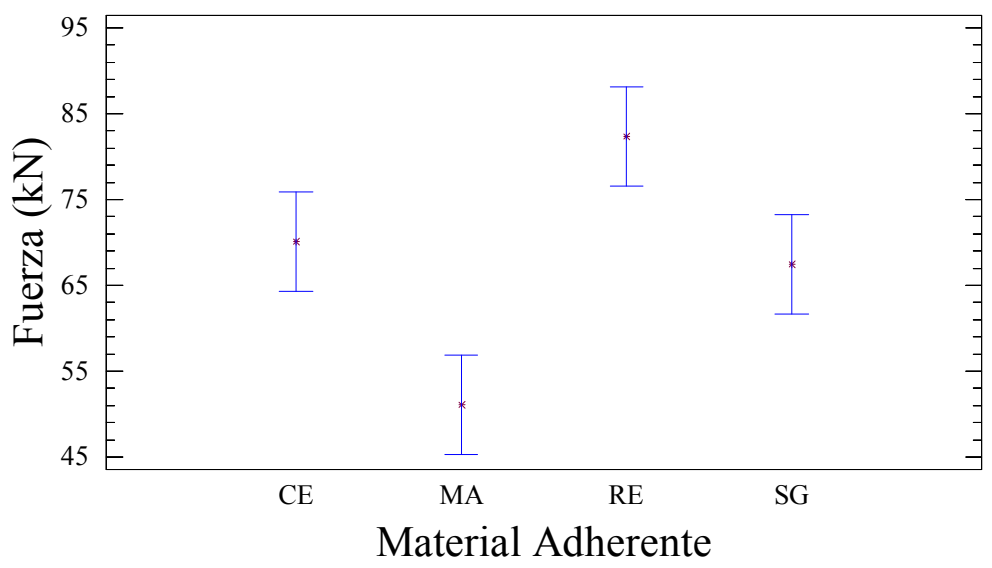

Fig. 3.18. Gráfico de Medias de la variable Fuerza respecto del factor Material Adherente.

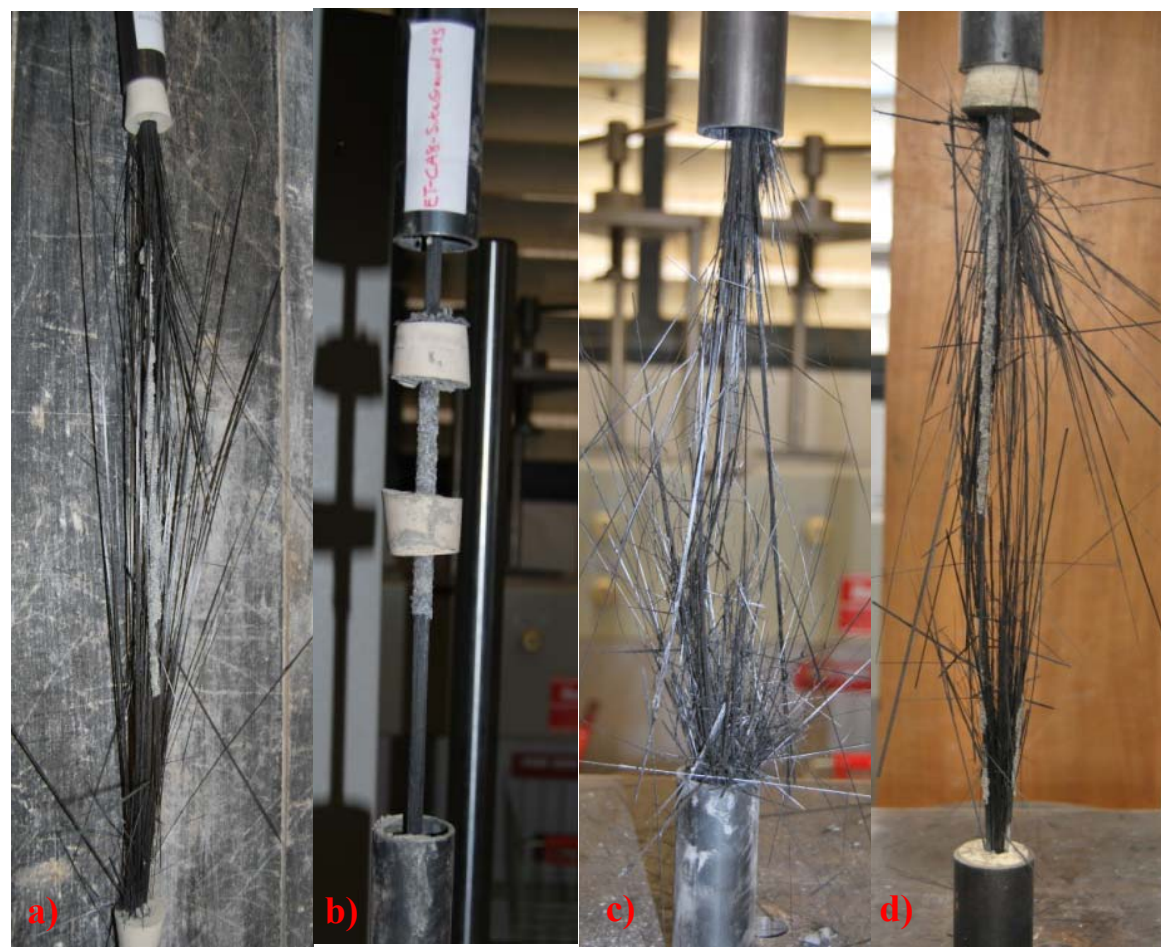

Fig. 3.19. Modo de rotura a tracción en CA8 con diferentes materiales de anclaje: a) RE; b) MA; c) $\mathrm{CE}$; d) SG. 

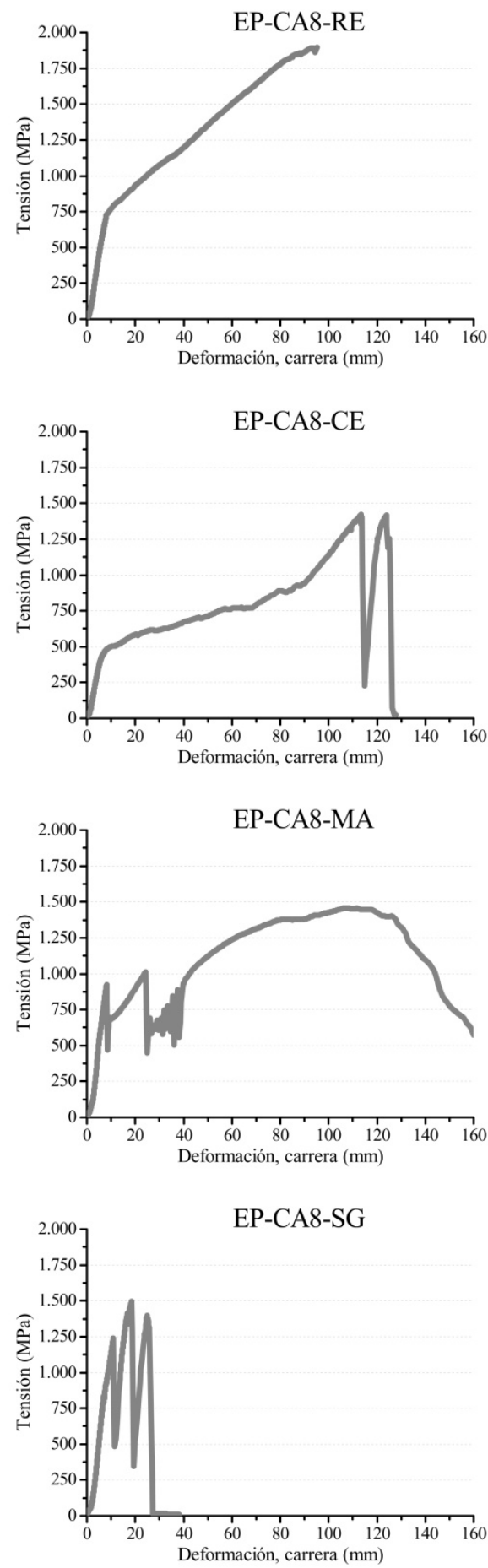

Fig. 3.20. Gráficos de Tensión / Deformación en barras CA8 con diferentes materiales adherentes. 


\subsection{Ensayos Experimentales}

En este apartado se indican en primer lugar los ensayos experimentales preliminares (cálculo del diámetro equivalente de las barras, estudio de la geometría superficial y ensayo de tracción), mediante los cuales se obtienen los parámetros necesarios para la realización de los ensayos de pullout. El cálculo del diámetro equivalente se emplea para la definición de la longitud adherente de cada tipo de barra de CFRP con el hormigón. En el estudio de la geometría superficial se obtiene la sección resistente de la barra, para el posterior cálculo de la resistencia a tracción, y además se caracteriza dicha geometría para establecerla como factor de análisis en el ensayo de pullout. En el ensayo de tracción se obtiene el módulo elástico de cada tipo de barra, dato necesario para el posterior cálculo de la deformación en el extremo tensionado de cada barra en el ensayo de pullout, así como la tensión resistente y deformación de los diferentes tipos de barras de CFRP y acero. Además se realizan los ensayos de pullout en diferentes condiciones ambientales, mediante los cuales se caracteriza la adherencia de cada tipo de barra. Por último, se realizan los ensayos complementarios (TGA, DSC, Microscopia óptica, Microdureza, SEM y AFM), necesarios para el análisis de los ensayos de pullout.

\subsubsection{Ensayos Experimentales Preliminares}

Los ensayos experimentales preliminares realizados en este apartado son el cálculo del diámetro equivalente, el estudio de la geometría superficial y el ensayo a tracción de todos los tipos de barras de CFRP y acero contempladas en el estudio.

\subsubsection{Ensayo de Diámetro Equivalente}

El ensayo del diámetro equivalente se realiza siguiendo las disposiciones de ACI 440.3R-04 B.1 "Test methods for cross-sectional properties of FRP 
bars". Con este método se calcula el diámetro equivalente " $\mathrm{d}_{\mathrm{b}}$ ", el área equivalente " $\mathrm{A}_{\mathrm{b}}$ " y el perímetro equivalente " $\mathrm{C}_{\mathrm{b}}$ " de cada tipo y diámetro de barra.

Los materiales empleados para la realización de este ensayo son:

- Volunómetro con gradiente de $10 \mathrm{~mL}$. (Fig. 3.21)

- $\quad$ Agua destilada (Fig. 3.21).

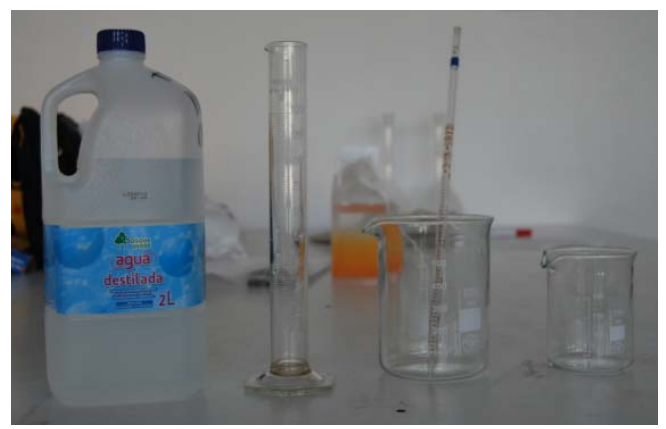

Fig. 3.21. Agua destilada, Volunómetro, pajita y vasos graduados.

- Calibre digital de la marca Powerfix modelo Z22855F versión $7 / 2008$ con una precisión de $0,01 \mathrm{~mm}$ (Fig. 3.22).

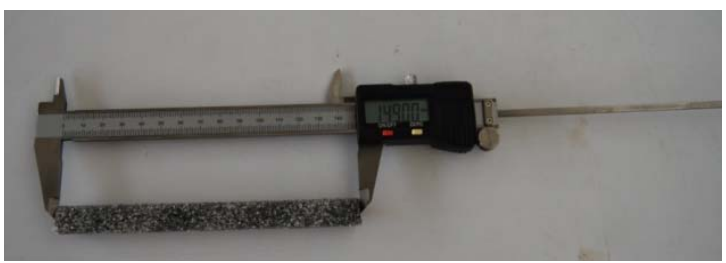

Fig. 3.22. Calibre digital.

- Barras de CFRP arenadas CA8 y CA14, corrugadas CC12, texturizadas CT13, y barras de acero corrugadas A8, A12 y A16.

El procedimiento y la metodología realizados en este ensayo son los siguientes:

I. Selección aleatoria de 3 muestras de cada tipo de barra y diámetro. 
II. Corte mediante sierra eléctrica, con disco para acero, de cada muestra de barra a una longitud de $150 \mathrm{~mm}$ (Fig. 3.23)

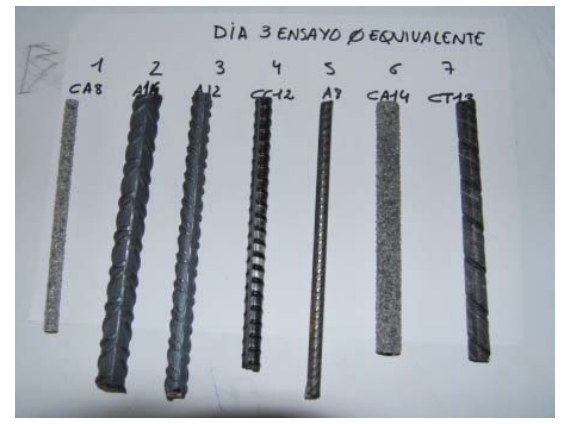

Fig. 3.23. Muestras para ensayo de Diámetro Equivalente.

III. Denominación de cada muestra de ensayo, según el siguiente criterio, DE-X-N ${ }^{o}$, por ejem. DE-CA8-3: las siglas iniciales "DE" se refieren al tipo de ensayo, en este caso diámetro equivalente, "CA8" corresponde al tipo de barra definido en apart. 3.2., y el segundo número "3" está referido al número de muestra.

IV. Almacenamiento de las muestras de ensayo durante un periodo de 48 horas en condiciones de laboratorio $\left(23 \pm 2{ }^{\circ} \mathrm{C}\right.$ y $50 \pm 10 \%$ de H.R.).

V. Medición 3 veces de la longitud de cada muestra de ensayo rotando la barra $120^{\circ}$ (en condiciones de laboratorio).

VI. Medición del volumen inicial " $\mathrm{V}_{0}$ " de agua destilada, mediante el volunómetro, en condiciones de laboratorio (Fig. 3.24.a).

VII. Introducción de la barra en el volunómetro con agua y medición del volumen final " $\mathrm{V}_{1}$ ", en condiciones de laboratorio (Fig. 3.24.b).

VIII. Repetición 3 veces de los pasos 6 y 7 por cada muestra de barra. 


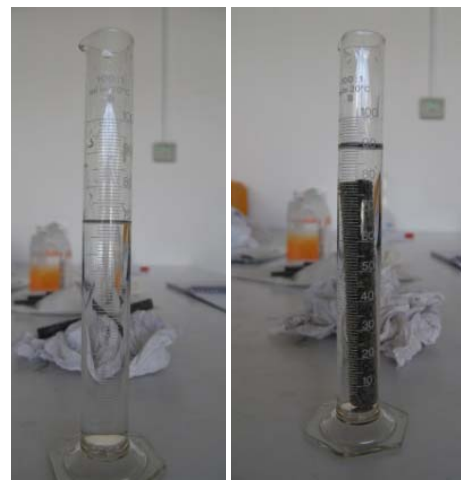

Fig. 3.24. Medición del volumen: a) $\mathrm{V}_{0}$; b) $\mathrm{V}_{1}$.

IX. Cálculo de $A_{b}, d_{b}$ y $C_{b}$ de cada tipo de barra (Ecs. 3.2., 3.3 y 3.4.):

$$
\begin{array}{ll}
A_{b}=\frac{\Delta V}{L} \cdot 1000=\frac{V_{1}-V_{0}}{L} \cdot 1000 & \left(\mathrm{~mm}^{2}\right) \\
d_{b}=2 \cdot \sqrt{\frac{A_{b}}{\pi}} & (\mathrm{mm}) \\
C_{b}=2 \cdot \sqrt{\pi \cdot A_{b}} & (\mathrm{~mm})
\end{array}
$$

Debido a que se dispone de la restricción del número de muestras ensayadas durante un día (inferior a 9), la planificación de este ensayo se ha realizado mediante un bloque aleatorizado (Tabla 3.18), en el que los tipos de barra son los tratamientos y los días de ensayo los bloques. Mediante este método se elimina la posible correlación seriada de las mediciones del volumen en cada tipo de barra, puesto que se ensayan un total de 7 muestras por día, siendo cada una de un tipo de barra y diámetro diferente. En total se realizan 24 ensayos, 3 por cada tipo de barra y diámetro (Tabla 3.19).

\begin{tabular}{cccccccc}
\hline $\begin{array}{c}\text { Tipo de barra / } \\
\text { Día ensayo }\end{array}$ & CA8 & CA14 & CC12 & CT13 & A8 & A12 & A16 \\
\hline DİA 1 & 2 & 5 & 1 & 3 & 7 & 4 & 6 \\
\hline DÏA 2 & 7 & 2 & 5 & 4 & 3 & 6 & 1 \\
\hline DÏA 3 & 1 & 6 & 4 & 7 & 5 & 3 & 2 \\
\hline
\end{tabular}

Tabla 3.18. Planificación del ensayo de diámetro equivalente (el número corresponde a la posición de ensayo). 

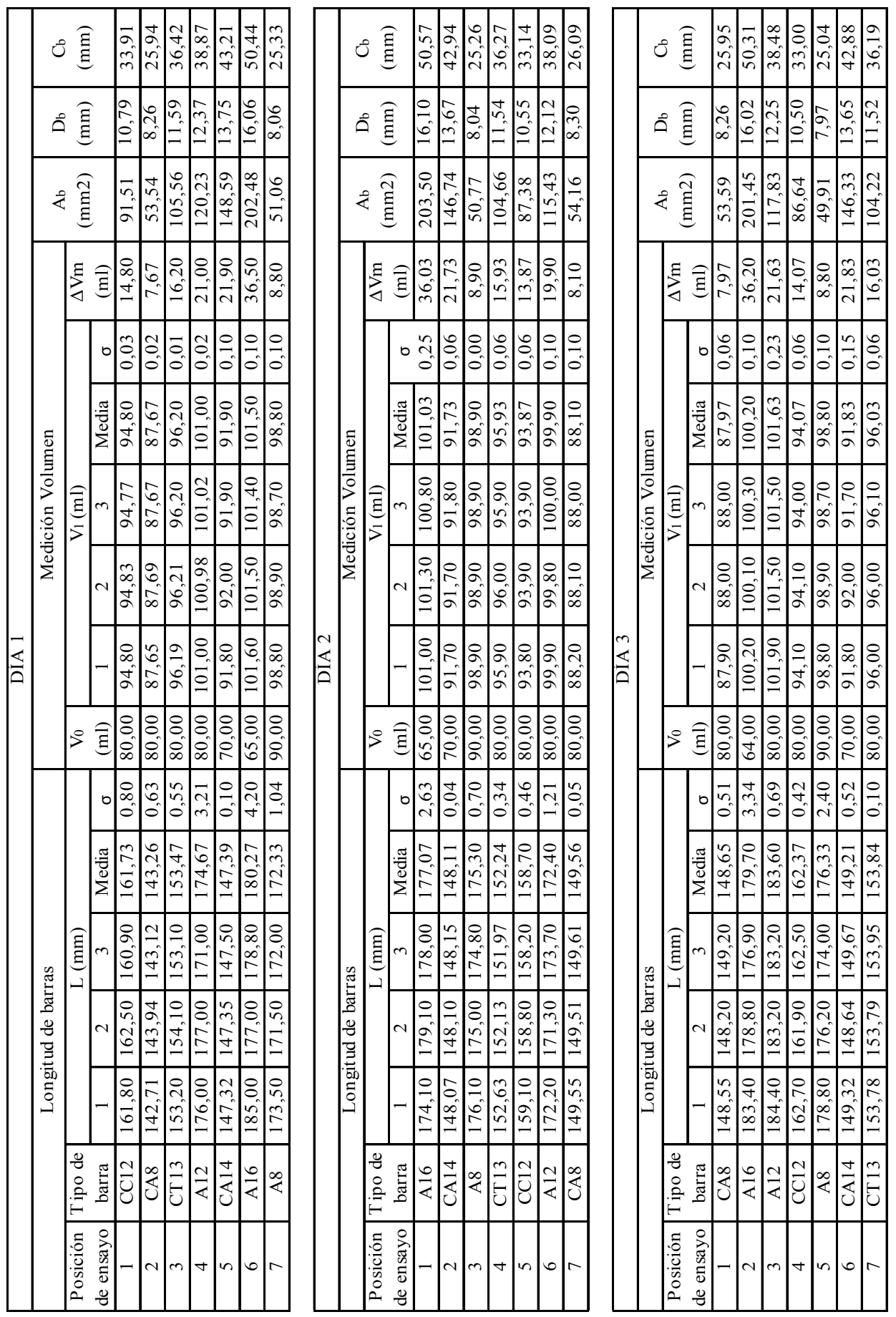

Tabla 3.19. $d_{b}, A_{b}, C_{b}$ y $\sigma$ de cada muestra ensayada. 
El tratamiento de los datos se ha realizado mediante un análisis unidimensional en cada tipo de barra y diámetro, obteniendo de este modo el $\mathrm{d}_{\mathrm{b}}$,

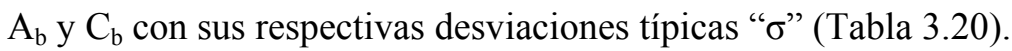

\begin{tabular}{|c|c|c|c|c|c|c|}
\hline $\begin{array}{l}\text { Tipo de } \\
\text { barra }\end{array}$ & $\begin{array}{c}\mathbf{d}_{\mathbf{b}} \\
(\mathbf{m m})\end{array}$ & $\sigma$ & $\begin{array}{c}C_{b} \\
(\mathbf{m m})\end{array}$ & $\sigma$ & $\underset{\left(\mathbf{m m}^{2}\right)}{A_{b}}$ & $\sigma$ \\
\hline CA8 & 8,27 & 0,02 & 25,99 & 0,08 & 53,76 & 0,34 \\
\hline CA14 & 13,69 & 0,05 & 43,01 & 0,18 & 147,22 & 1,20 \\
\hline CC12 & 10,61 & 0,16 & 33,35 & 0,49 & 88,51 & 2,62 \\
\hline CT13 & 11,55 & 0,04 & 36,29 & 0,12 & 104,81 & 0,68 \\
\hline A8 & 8,02 & 0,05 & 25,21 & 0,15 & 50,58 & 0,60 \\
\hline A12 & 12,25 & 0,13 & 38,48 & 0,39 & 117,83 & 2,40 \\
\hline A16 & 16,06 & 0,04 & 50,34 & 0,09 & 202,48 & 1,03 \\
\hline
\end{tabular}

Tabla 3.20. $d_{b}, A_{b}, C_{b}$ y $\sigma$ de cada tipo de barra.

\subsubsection{Estudio de la Geometría Superficial}

En la actualidad no se ha desarrollado una normativa específica para el estudio de la geometría superficial de las barras de FRP, debido a que no se han estandarizado los tipos de barras de FRP aptas para el empleo como armado del hormigón. Por lo tanto, el estudio de la geometría superficial de los diferentes tipos de barras de CFRP y acero se ha realizado conforme a las normativas específicas de armado de acero para hormigón EHE-08, UNE-EN 10080 y UNE-EN ISO 15630-1 (2011).

Los aceros corrugados, aptos para su empleo como armado del hormigón, se caracterizan por las dimensiones, número y configuración de las corrugas transversales y longitudinales. Los parámetros del corrugado pueden especificarse a través del área proyectada o relativa de las corrugas $f_{R}$, mediante la combinación de la separación, altura e inclinación de las corrugas transversales, o bien mediante ambos criterios. En el caso de barras de CFRP corrugadas (similares a las barras corrugadas de acero) y texturizadas, el estudio 
de la geometría superficial se realiza a través del parámetro $f_{R}$, del mismo modo que en las barras de acero corrugadas.

El parámetro $f_{R}$ se puede calcular mediante la ecuación simplificada del trapecio (Ec. 3.5) o mediante la ecuación simplificada de la parábola (Ec. 3.6), ambas definidas en UNE-EN ISO 15630-1 (2011).

$$
\begin{aligned}
& f_{R, \text { Trapecio }}=\frac{\left(a_{1 / 4}+a_{m}+a_{3 / 4}\right) \cdot\left(\pi \cdot \emptyset-\sum e_{i}\right)}{4} \cdot \frac{1}{c} \cdot \frac{1}{\pi \emptyset} \\
& f_{R, \text { Parábola }}=\frac{2 a_{m} \cdot\left(\pi \cdot \emptyset-\sum e_{i}\right)}{3} \cdot \frac{1}{c} \cdot \frac{1}{\pi \emptyset}
\end{aligned}
$$

Donde: $a_{1 / 4}, a_{m}, a_{3 / 4}$ es la altura de las corrugas transversales a $1 / 4$, la mitad y $3 / 4$ de su longitud, en mm. $\varnothing$, es el diámetro nominal de la barra, en $\mathrm{mm}$. $\Sigma \mathrm{e}_{\mathrm{i}}$, es la parte de la circunferencia sin corrugas, en mm. c, es la separación entre corrugas transversales, en mm.

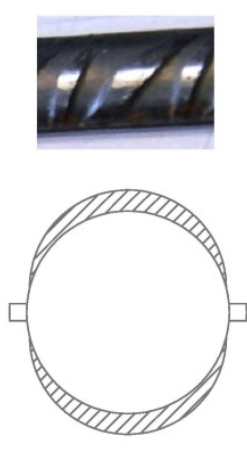

Acero Corrugado

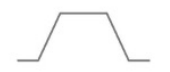

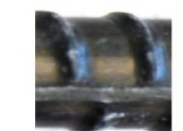

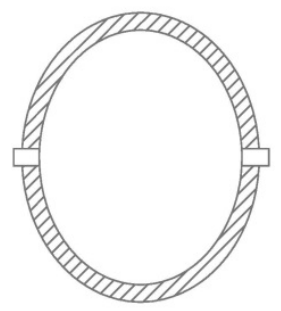

CFRP Corrugada

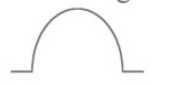

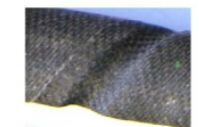

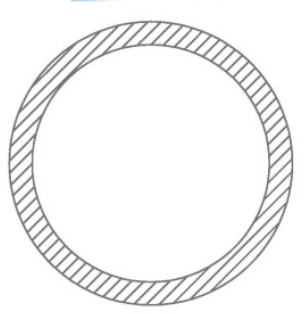

CFRP Texturizada

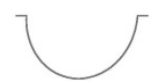

Fig. 3.25. Tipos de corrugas en barras de acero, CFRP corrugadas y CFRP texturizadas.

Sin embargo, debido a que tanto las barras de CFRP corrugadas "CC12" como texturizadas "CT13" no poseen corrugas asimilables a la forma de un trapecio o una parábola (Fig. 3.25), se han obtenido, a partir de la ecuación general definida en UNE-EN ISO 15630-1 (2011) apart. 11.3.1, las ecuaciones 
de cálculo del parámetro $f_{\mathrm{R}}$ para ambos tipos de barras (Ecs. 3.7 y 3.8, respectivamente).

$$
\begin{aligned}
& f_{R, C C 12}=\left(\left(\pi \cdot\left(\left(r+a_{m}\right)^{2}\right)\right)-\left(\pi \cdot r^{2}\right)-\left(\left(e_{1} \cdot a_{m}\right)+\left(e_{2} \cdot a_{m}\right)\right)\right) \cdot \frac{1}{c} \cdot \frac{1}{\pi \emptyset} \\
& f_{R, C T 13}=\left(\pi \cdot\left(\left(2 \cdot r \cdot a_{m}\right)-{a_{m}}^{2}\right)\right) \cdot \frac{1}{c} \cdot \frac{1}{\pi \varnothing}
\end{aligned}
$$

También se definen otras dimensiones que caracterizan la geometría superficial de las barras especificadas por UNE-EN ISO 15630-1 (2011) (Fig. 3.26):

- Ángulo de inclinación de la corruga transversal “ $\beta$ ”. En el caso de dos tipos de corrugas transversales, se designarán como " $\beta_{1}$ " y " $\beta_{2}$ ".

- Inclinación de flanco de la corruga transversal " $\alpha$ ”.

- Anchura de la corruga transversal, de la zona superior "b" y de la zona inferior "d", en mm.
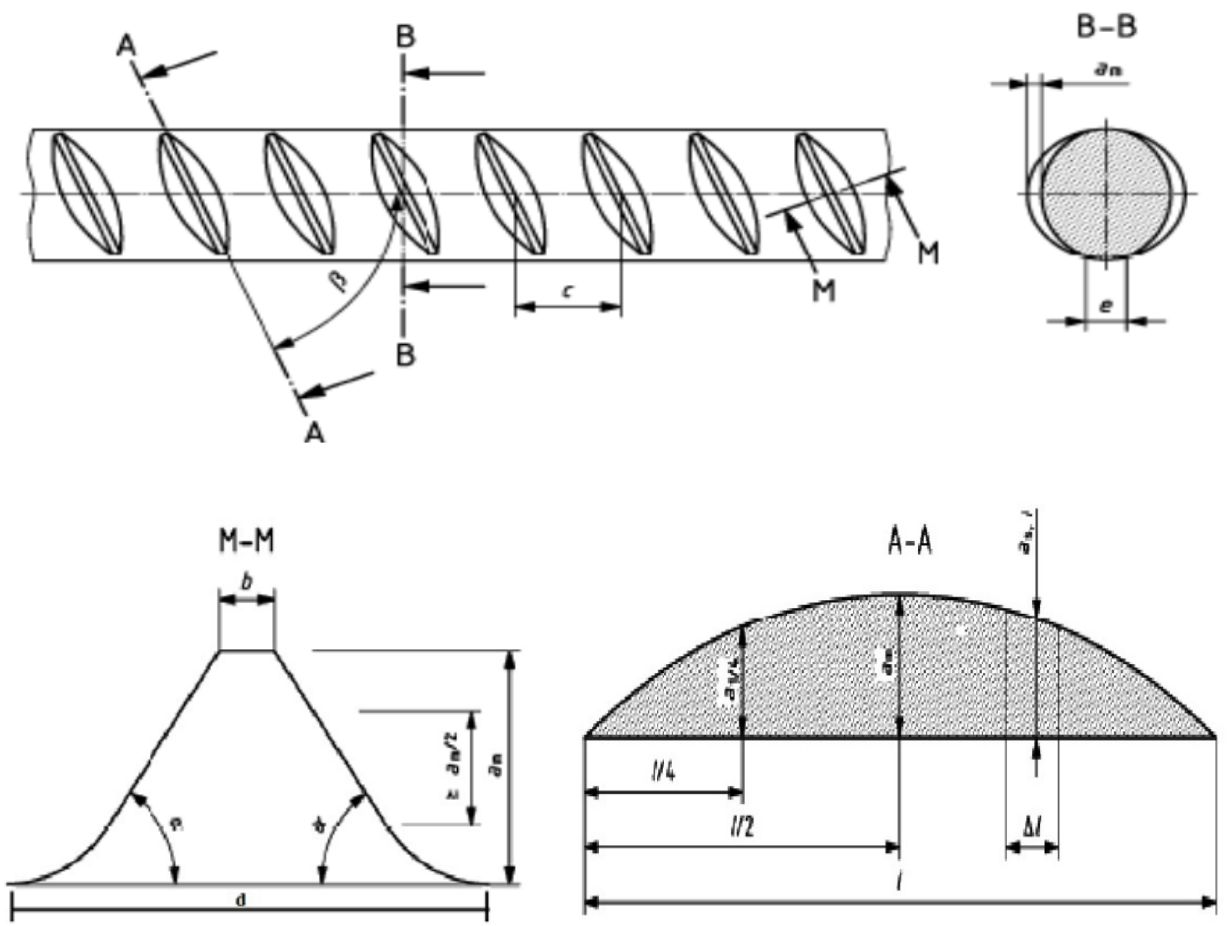

Fig. 3.26. Parámetros de la geometría superficial 
Otros parámetros, mediante los cuales también se puede estudiar la influencia de la geometría superficial de la barras de armado respecto de la adherencia, son los denominados Concrete Lug Ratio "C.L.R" y "a”, definidos por Al-mahmoud et al., (2007) y Baena et al. (2009), respectivamente. El parámetro C.L.R relaciona la longitud de la corruga de acuñamiento de hormigón respecto de la distancia entre dos corrugas de la barra consecutivas (Ec. 3.9):

$$
\text { C.L.R }=\frac{w_{c}}{w_{c}+w_{f}}
$$

donde $\mathrm{w}_{\mathrm{c}}$ es la longitud de la corruga de hormigón que produce el acuñamiento (distancia entre corrugas consecutivas menos el ancho de corruga) y $\mathrm{w}_{\mathrm{f}}$ es el ancho máximo de la corruga de la barra de acero o CFRP.

$\mathrm{a}_{\mathrm{s}}$ es un parámetro que relaciona el área proyectada de la corruga y la distancia entre corrugas (Ec. 3.10).

$$
a_{s}=\frac{A_{p . c}}{c}
$$

donde $A_{\text {p.c. }}$ es el área proyectada de la corruga $\left(\mathrm{mm}^{2}\right)$ y c es la distancia entre corrugas consecutivas $(\mathrm{mm})$.

Para el cálculo de los parámetros anteriormente desarrollados $f_{\mathrm{R}}$, C.L.R y $\mathrm{a}_{\mathrm{s}}$, inicialmente se definen las diferentes dimensiones especificadas en cada uno de ellos, para los tipos de barras de CFRP corrugadas, texturizadas y acero corrugadas. En el caso de las barras de CFRP arenadas se definen los factores que intervienen en la adherencia, como son el espesor o altura de la geometría superficial " $\mathrm{a}_{\mathrm{m}}$ ", el diámetro del grano " $\emptyset_{\text {grano" }}$ y el diámetro equivalente; así como también el diámetro sin geometría superficial del que depende la resistencia a tracción.

El estudio de la geometría superficial de las barras se ha realizado en todas las muestras de los distintos tipos de barras que posteriormente se ensayan 
a pullout, con un total de 175 muestras (véase apart.3.4.2.). De este modo se caracteriza totalmente el material de ensayo. La planificación del ensayo se ha realizado mediante un bloque aleatorizado (Tabla 3.21.), en el que los bloques son los tipos de barras y los factores cada temperatura de ensayo a pullout (cada temperatura son 5 factores, debido a que se repite el ensayo 5 veces por temperatura). Además, se aleatoriza la posición de ensayo dentro de cada bloque, eliminando una posible correlación en la medición de barras iguales.

\begin{tabular}{cccccccccccccccc}
\hline $\begin{array}{c}\text { Factor/Blo } \\
\text { que }\end{array}$ & HD-1 & HD-2 & HD-3 & HD-4 & HD-5 & $5-1$ & $5-2$ & $5-3$ & $5-4$ & $5-5$ & $20-1$ & $20-2$ & $20-3$ & $20-4$ & $20-5$ \\
\hline CA8 & 25 & 11 & 3 & 8 & 22 & 6 & 7 & 4 & 9 & 15 & 2 & 12 & 19 & 14 & 10 \\
\hline CA14 & 22 & 15 & 6 & 14 & 3 & 25 & 18 & 12 & 16 & 2 & 11 & 4 & 23 & 8 & 24 \\
\hline CC12 & 7 & 12 & 23 & 1 & 16 & 13 & 10 & 15 & 3 & 2 & 17 & 19 & 6 & 21 & 24 \\
\hline CT13 & 18 & 4 & 9 & 5 & 19 & 17 & 14 & 21 & 8 & 24 & 16 & 22 & 3 & 15 & 2 \\
\hline A8 & 22 & 25 & 11 & 6 & 3 & 16 & 2 & 1 & 23 & 13 & 17 & 18 & 19 & 10 & 14 \\
\hline A12 & 11 & 23 & 6 & 22 & 20 & 10 & 2 & 1 & 25 & 17 & 13 & 24 & 5 & 16 & 7 \\
\hline A16 & 2 & 23 & 20 & 16 & 22 & 7 & 25 & 13 & 11 & 14 & 24 & 13 & 19 & 18 & 21 \\
\hline
\end{tabular}

\begin{tabular}{|c|c|c|c|c|c|c|c|c|c|c|}
\hline $\begin{array}{c}\text { Factor/Blo } \\
\text { que }\end{array}$ & $40-1$ & $40-2$ & $40-3$ & $40-4$ & $40-5$ & $80-1$ & $80-2$ & $80-3$ & $80-4$ & $80-5$ \\
\hline CA8 & 16 & 21 & 18 & 13 & 20 & 17 & 5 & 23 & 24 & 1 \\
\hline CA14 & 9 & 20 & 7 & 1 & 17 & 21 & 19 & 5 & 10 & 13 \\
\hline $\mathrm{CCl} 2$ & 14 & 5 & 22 & 9 & 11 & 8 & 4 & 20 & 18 & 25 \\
\hline CT13 & 20 & 1 & 13 & 23 & 25 & 6 & 12 & 10 & 7 & 11 \\
\hline A8 & 20 & 21 & 24 & 8 & 4 & 5 & 7 & 15 & 12 & 9 \\
\hline A12 & 21 & 3 & 18 & 15 & 12 & 19 & 14 & 8 & 9 & 4 \\
\hline A16 & 10 & 8 & 6 & 4 & 12 & 5 & 17 & 9 & 3 & 15 \\
\hline
\end{tabular}

Tabla 3.21. Planificación del estudio de la geometría superficial.

Los materiales y equipos utilizadas en este ensayo son los siguientes:

- $\quad$ Máquina de sombras marca Starrett modelo HB-350 (Fig. 3.27). 


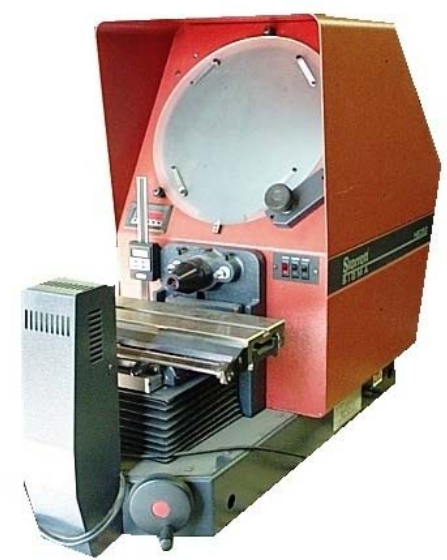

Fig. 3.27. Máquina de sombras Starrett modelo HB-350

- Calibre digital de la marca Powerfix modelo Z22855F versión 7/2008 con una precisión de $0,01 \mathrm{~mm}$.

- Transportador de ángulos marca Staedtler modelo 569-69-9.

- Barras de CFRP arenadas CA8 y CA14, corrugadas CC12, texturizadas CT13, y barras de acero corrugadas A8, A12 y A16.

Este ensayo se ha realizado siguiendo la metodología y el procedimiento que se describe a continuación:

I. Selección aleatoria de 5 muestras por cada tipo de barra, diámetro y temperatura de ensayo a pullout. Esta selección se repite 5 veces debido a las 5 distintas temperaturas de ensayo a pullout.

II. Corte mediante sierra eléctrica, con disco para acero, de cada muestra de barra a una longitud de $750 \mathrm{~mm}$ (véase apart. 3.4.2.)

III. Denominación de cada muestra de ensayo, según el siguiente criterio, EGS-X-N-N. Por ejemplo, EGS-CA8-20-3: las siglas iniciales "EGS" se refieren al tipo de ensayo, en este caso estudio de la geometría superficial, "CA8" corresponde al tipo de barra definido en apart. 3.2., el primer número "20" está 
referido a la temperatura de ensayo y el segundo número "3" define una de las 5 repeticiones de ensayo, en este caso la tercera.

IV. Almacenamiento de las muestras de ensayo durante un periodo de 48 horas en condiciones de laboratorio $\left(23 \pm 2{ }^{\circ} \mathrm{C}\right.$ y $50 \pm 10 \%$ de H.R.).

V. Medición 3 veces de cada una de las dimensiones que caracterizan a cada tipo de barra (en condiciones de laboratorio).

Con los datos obtenidos en las mediciones, siguiendo la planificación de ensayo, se realiza un análisis unidimensional en cada uno de los factores o dimensiones de cada barra, caracterizando de este modo las diferentes geometrías superficiales de las barras de CFRP y acero corrugadas:

I. Las dimensiones de las barras de CFRP arenadas "CA8" (Fig. 3.28) se muestran en la Tabla 3.22.

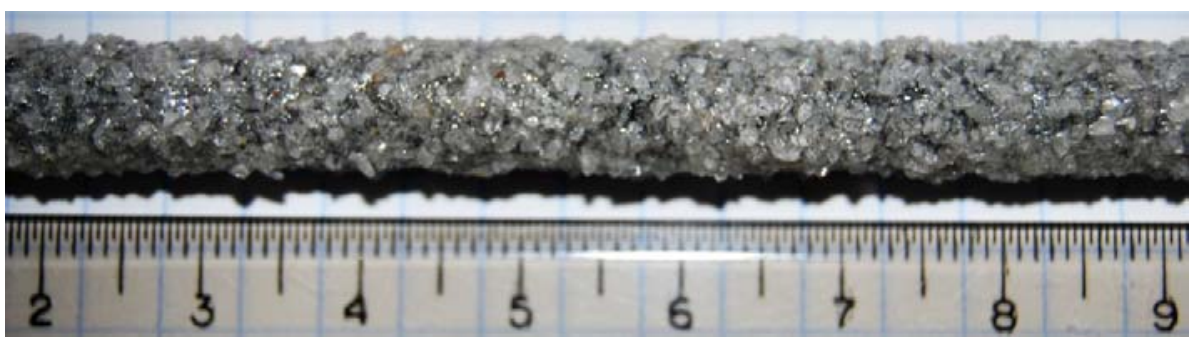

Fig. 3.28. Geometría superficial de las barras de CFRP arenadas CA8.

\begin{tabular}{cc}
\hline \multicolumn{2}{c}{ DATOS CALCULADOS } \\
\hline Parámetro & Media $(\overline{\mathrm{y}})$ \\
\hline Diámetro con geometría superficial $(\mathrm{mm})$ & 8,68 \\
\hline Diámetro sin geometría superficial $(\mathrm{mm})$ & 6,35 \\
\hline Diámetro equivalente $(\mathrm{mm})$ & 8,2735 \\
\hline Área equivalente $\left(\mathrm{mm}^{2}\right)$ & 53,76 \\
\hline $\mathrm{a}_{\mathrm{m}}(\mathrm{mm})$ & 1,165 \\
\hline$\emptyset_{\text {grano }}(\mathrm{mm})$ & $0,2-2,0$ \\
\hline
\end{tabular}




\begin{tabular}{cc}
\hline \multicolumn{2}{c}{ DATOS FABRICANTE (PULLTRALL INC.) } \\
\hline Parámetro & Media $(\eta)$ \\
\hline Área nominal $\left(\mathrm{mm}^{2}\right)$ & 31,67 \\
\hline Diámetro nominal $(\mathrm{mm})$ & 6,35
\end{tabular}

Tabla 3.22. Dimensiones de las barras de CFRP arenadas CA8.

II. Las dimensiones de las barras de CFRP arenadas "CA14" (Fig. 3.29.) se muestran en la Tabla 3.23.

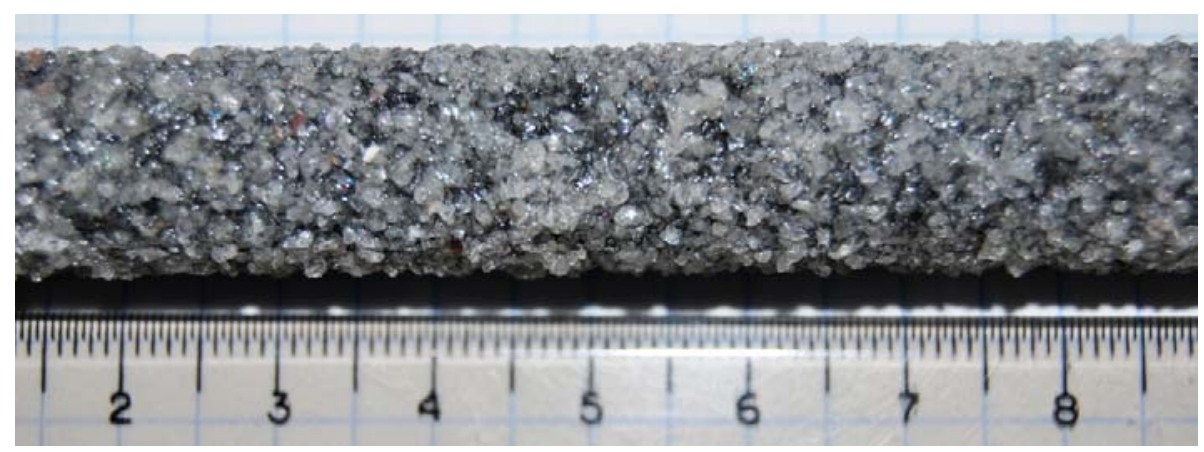

Fig. 3.29. Geometría superficial de las barras de CFRP arenadas CA14.

\begin{tabular}{cc}
\hline \multicolumn{2}{c}{ DATOS CALCULADOS } \\
\hline Parámetro & Media $(\overline{\mathrm{y}})$ \\
\hline Diámetro con geometría superficial $(\mathrm{mm})$ & 14,51 \\
\hline Diámetro sin geometría superficial $(\mathrm{mm})$ & 12,70 \\
\hline Diámetro equivalente $(\mathrm{mm})$ & 13,6911 \\
\hline Área equivalente $\left(\mathrm{mm}^{2}\right)$ & 147,22 \\
\hline $\mathrm{a}_{\mathrm{m}}(\mathrm{mm})$ & 0,905 \\
\hline$\emptyset_{\text {grano }}(\mathrm{mm})$ & $0,2-2,0$ \\
\hline PATOS FABRICANTE $($ PULLTRALL INC.) \\
\hline Parámetro & Media $(\eta)$ \\
\hline Área nominal $\left(\mathrm{mm}^{2}\right)$ & 126,70 \\
\hline Diámetro nominal $(\mathrm{mm})$ & 12,70 \\
\hline
\end{tabular}

Tabla 3.23. Dimensiones de las barras de CFRP arenadas CA14. 
III. Las dimensiones de las barras de CFRP corrugadas "CC12" (Fig. 3.30) se muestran en la Tabla 3.24.

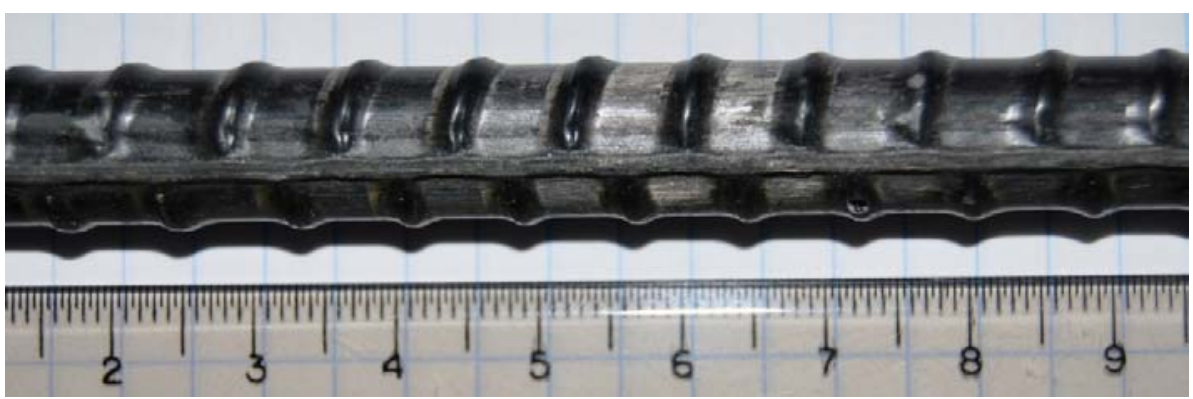

Fig. 3.30. Geometría superficial de las barras de CFRP corrugadas CC12.

\begin{tabular}{|c|c|}
\hline \multicolumn{2}{|c|}{ DATOS CALCULADOS } \\
\hline Parámetro & Media $(\bar{y})$ \\
\hline $\mathrm{a}_{\mathrm{m}}(\mathrm{mm})$ & 0,5352 \\
\hline $\mathrm{c}(\mathrm{mm})$ & 7,9397 \\
\hline$\beta\left(^{(}\right)$ & $71,00^{\circ}$ \\
\hline$\alpha\left({ }^{\circ}\right)$ & $23,89^{\circ}$ \\
\hline $\mathrm{e}_{1}(\mathrm{~mm})$ & 1,378 \\
\hline $\mathrm{e}_{2}(\mathrm{~mm})$ & 1,401 \\
\hline $\mathrm{b}(\mathrm{mm})$ & 1,092 \\
\hline $\mathrm{d}(\mathrm{mm})$ & 3,509 \\
\hline Diámetro mayor sin corruga (mm) & 10,72 \\
\hline Diámetro menor sin corruga $(\mathrm{mm})$ & 9,80 \\
\hline Diámetro medio sin corruga $(\mathrm{mm})$ & 10,26 \\
\hline Área equivalente $\left(\mathrm{mm}^{2}\right)$ & 88,51 \\
\hline Diámetro equivalente (mm) & 10,6157 \\
\hline \multicolumn{2}{|c|}{ DATOS FABRICANTE (MARSHALL COMPOSITES) } \\
\hline Parámetro & Media $(\eta)$ \\
\hline $\mathrm{a}_{\mathrm{m}}(\mathrm{mm})$ & 0,76 \\
\hline $\mathrm{c}(\mathrm{mm})$ & 5,72 \\
\hline Área nominal $\left(\mathrm{mm}^{2}\right)$ & 71,00 \\
\hline Diámetro nominal (mm) & 9,50 \\
\hline
\end{tabular}

Tabla 3.24. Dimensiones de las barras de CFRP corrugadas CC12. 
IV. Las dimensiones de las barras de CFRP texturizadas "CT13" (Fig. 3.31) se muestran en la Tabla 3.25.

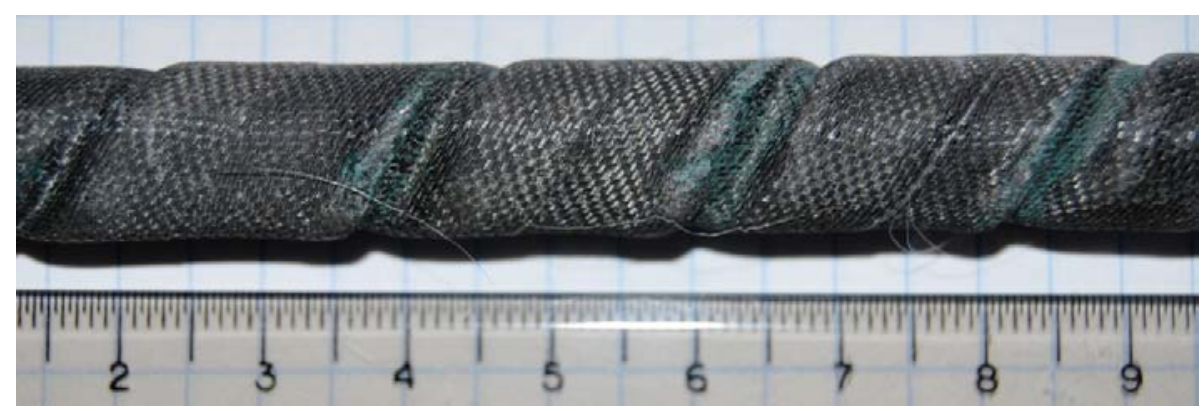

Fig. 3.31. Geometría superficial de las barras de CFRP texturizadas CT13.

\begin{tabular}{cc}
\hline \multicolumn{2}{c}{ DATOS CALCULADOS } \\
\hline Parámetro & Media $(\overline{\mathrm{y}})$ \\
\hline $\mathrm{a}_{\mathrm{m}}(\mathrm{mm})$ & 1,074 \\
\hline $\mathrm{c}(\mathrm{mm})$ & 23,267 \\
\hline$\beta\left(^{\circ}\right)$ & $27,50^{\circ}$ \\
\hline$\alpha\left(^{\circ}\right)$ & $54,84^{\circ}$ \\
\hline $\mathrm{b}(\mathrm{mm})$ & 1,077 \\
\hline $\mathrm{d}(\mathrm{mm})$ & 3,478 \\
\hline Diámetro exterior $(\mathrm{mm})$ & 11,731 \\
\hline Diámetro sin corrugas $(\mathrm{mm})$ & 9,583 \\
\hline Área equivalente $\left(\mathrm{mm}^{2}\right)$ & 104,81 \\
\hline Diámetro equivalente $(\mathrm{mm})$ & 11,5519 \\
\hline DATOS FABRICANTE (SIKA S.A.) \\
\hline Parámetro & Media $(\eta)$ \\
\hline Área nominal $\left(\mathrm{mm}^{2}\right)$ & 71,25 \\
\hline Diámetro nominal $(\mathrm{mm})$ & 9,5246 \\
\hline
\end{tabular}

Tabla 3.25. Dimensiones de las barras de CFRP texturizadas CT13. 
V. Las dimensiones de las barras de acero corrugadas "A8" (Fig. 3.32) se muestran en la Tabla 3.26.

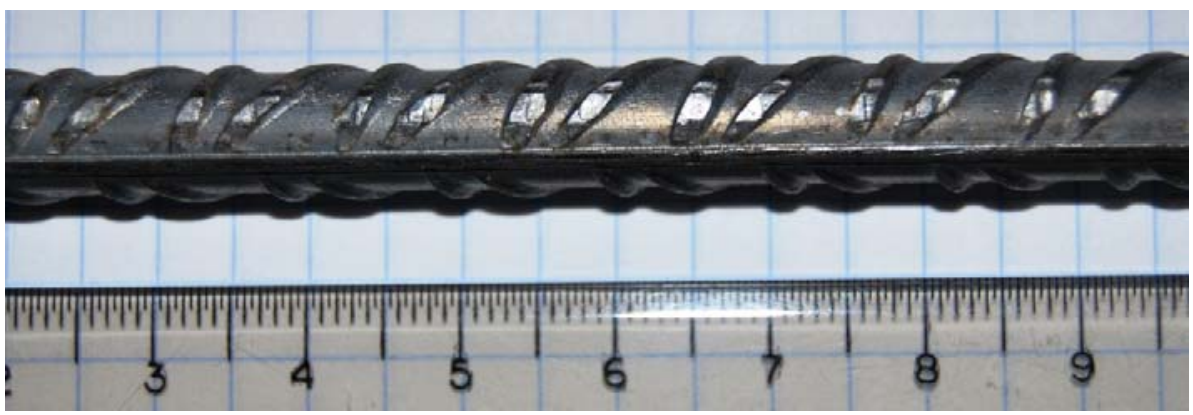

Fig. 3.32. Geometría superficial de las barras de acero corrugadas A8.

\begin{tabular}{cc}
\hline \multicolumn{2}{c}{ DATOS CALCULADOS } \\
\hline Parámetro & Media $(\overline{\mathrm{y}})$ \\
\hline $\mathrm{a}_{1 / 4}(\mathrm{~mm})$ & 0,5312 \\
\hline $\mathrm{a}_{1 / 2}(\mathrm{~mm})$ & 0,7799 \\
\hline $\mathrm{a}_{3 / 4}(\mathrm{~mm})$ & 0,5312 \\
\hline $\mathrm{c}(\mathrm{mm})$ & 6,078 \\
\hline$\beta_{1}\left({ }^{\circ}\right)$ & $34,5^{\circ}$ \\
\hline$\beta_{2}\left({ }^{\circ}\right)$ & $53,0^{\circ}$ \\
\hline$\alpha\left(^{\circ}\right)$ & $60,30^{\circ}$ \\
\hline $\mathrm{e}_{1}(\mathrm{~mm})$ & 1,1616 \\
\hline $\mathrm{e}_{2}(\mathrm{~mm})$ & 1,1817 \\
\hline $\mathrm{b}(\mathrm{mm})$ & 1,180 \\
\hline $\mathrm{d}(\mathrm{mm})$ & 1,860 \\
\hline Diámetro Sin corrugas $(\mathrm{mm})$ & 7,221 \\
\hline Diámetro equivalente $(\mathrm{mm})$ & 8,0249 \\
\hline Área equivalente $\left(\mathrm{mm}^{2}\right)$ & 50,58 \\
\hline DATOS FABRICANTE $($ ARCELOR MITTAL) & Media $(\eta)$ \\
\hline Parámetro & 8,00 \\
\hline Diámetro nominal $(\mathrm{mm})$ &
\end{tabular}

Tabla 3.26. Dimensiones de las barras de acero corrugadas A8. 
VI. Las dimensiones de las barras de acero corrugadas "A12" (Fig. 3.33) se muestran en la Tabla. 3.27.

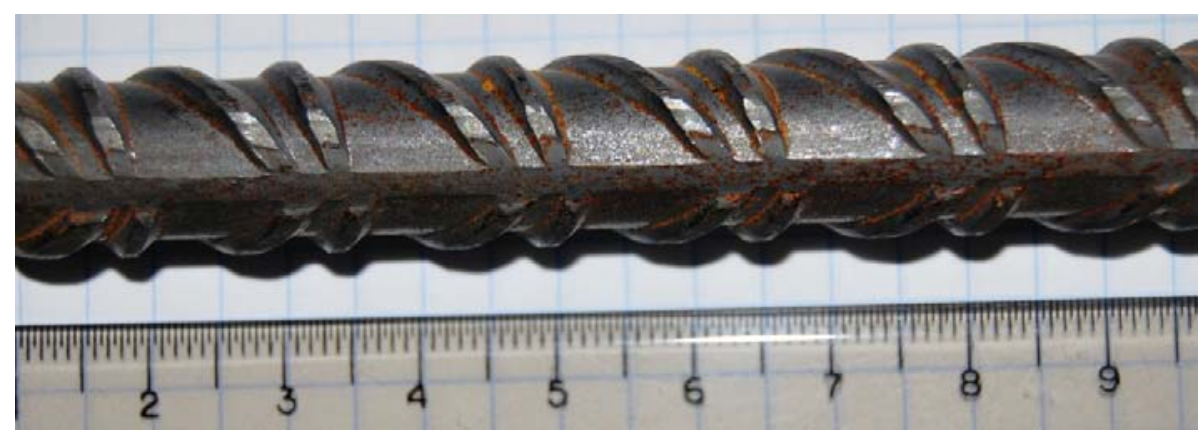

Fig. 3.33. Geometría superficial de las barras de acero corrugadas A12.

\begin{tabular}{cc}
\hline \multicolumn{2}{c}{ DATOS CALCULADOS } \\
\hline Parámetro & Media $(\overline{\mathrm{y}})$ \\
\hline $\mathrm{a}_{1 / 4}(\mathrm{~mm})$ & 0,7383 \\
\hline $\mathrm{a}_{1 / 2}(\mathrm{~mm})$ & 1,1956 \\
\hline $\mathrm{a}_{3 / 4}(\mathrm{~mm})$ & 0,7383 \\
\hline $\mathrm{c}(\mathrm{mm})$ & 8,131 \\
\hline$\beta_{1}\left(^{\circ}\right)$ & $34,5^{\circ}$ \\
\hline$\beta_{2}\left(^{\circ}\right)$ & $55,0^{\circ}$ \\
\hline$\alpha\left(^{\circ}\right)$ & $55,9^{\circ}$ \\
\hline $\mathrm{e}_{1}(\mathrm{~mm})$ & 1,8349 \\
\hline $\mathrm{e}_{2}(\mathrm{~mm})$ & 1,8056 \\
\hline $\mathrm{b}(\mathrm{mm})$ & 1,37 \\
\hline $\mathrm{d}(\mathrm{mm})$ & 2,53 \\
\hline Diámetro Sin corrugas $(\mathrm{mm})$ & 11,1754 \\
\hline Diámetro equivalente $(\mathrm{mm})$ & 12,2485 \\
\hline Área equivalente $\left(\mathrm{mm}^{2}\right)$ & 117,83 \\
\hline DATOS FABRICANTE $(\mathrm{CORRUGADOS}$ GETAFE) & Media $(\eta)$ \\
\hline Parámetro & 12,00 \\
\hline Diámetro nominal $(\mathrm{mm})$ & \\
\hline &
\end{tabular}

Tabla 3.27. Dimensiones de las barras de acero corrugadas A12. 
VII. Las dimensiones de las barras de acero corrugadas "A16" (Fig. 3.34) se muestran en la Tabla 3.28.

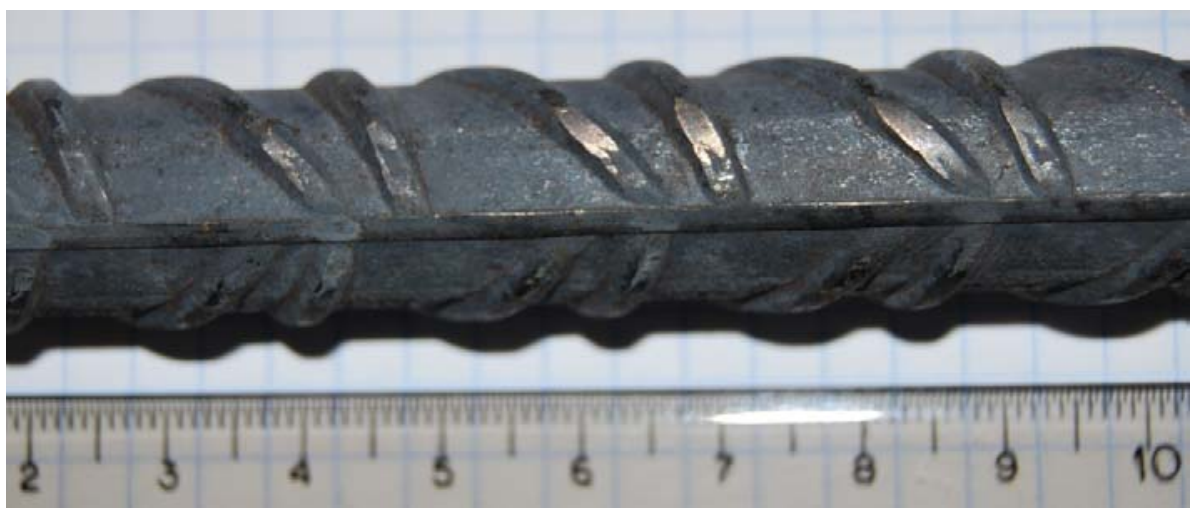

Fig. 3.34. Geometría superficial de las barras de acero corrugadas A16.

\begin{tabular}{cc}
\hline \multicolumn{2}{c}{ DATOS CALCULADOS } \\
\hline Parámetro & Media $(\overline{\mathrm{y}})$ \\
\hline $\mathrm{a}_{1 / 4}(\mathrm{~mm})$ & 0,8416 \\
\hline $\mathrm{a}_{1 / 2}(\mathrm{~mm})$ & 1,2391 \\
\hline $\mathrm{a}_{3 / 4}(\mathrm{~mm})$ & 0,8416 \\
\hline $\mathrm{c}(\mathrm{mm})$ & 10,499 \\
\hline$\beta_{1}\left(^{\circ}\right)$ & $32,5^{\circ}$ \\
\hline$\beta_{2}\left({ }^{\circ}\right)$ & $48,0^{\circ}$ \\
\hline$\alpha\left(^{\circ}\right)$ & $53,27^{\circ}$ \\
\hline $\mathrm{e}_{1}(\mathrm{~mm})$ & 1,7618 \\
\hline $\mathrm{e}_{2}(\mathrm{~mm})$ & 1,7852 \\
\hline $\mathrm{b}(\mathrm{mm})$ & 2,07 \\
\hline $\mathrm{d}(\mathrm{mm})$ & 3,48 \\
\hline Diámetro Sin corrugas $(\mathrm{mm})$ & 15,2048 \\
\hline Diámetro equivalente $(\mathrm{mm})$ & 16,0563 \\
\hline Área equivalente $\left(\mathrm{mm}^{2}\right)$ & 202,48 \\
\hline DATOS FABRICANTE $($ AZPEITIA $)$ \\
\hline Parámetro & Media $(\eta)$ \\
\hline Diámetro nominal $(\mathrm{mm})$ & 16,00 \\
\hline
\end{tabular}

Tabla 3.28. Dimensiones de las barras de acero corrugadas A16.

Una vez realizada la caracterización de las dimensiones de cada tipo de barra, se calcula, para los tipos de barras de CFRP corrugadas, texturizadas y 
acero corrugado, los parámetros $f_{\mathrm{R}}$, C.L.R y a ${ }_{\mathrm{s}}^{35}$ (Tabla 3.29). En el caso de las barras de CFRP arenadas no es posible el cálculo de estos parámetros, debido a que la geometría superficial es arenada.

\begin{tabular}{cccccc}
\hline & \multicolumn{5}{c}{ Tipo de barra } \\
\cline { 3 - 6 } Parámetro & $\mathrm{CC12}$ & $\mathrm{CT} 13$ & $\mathrm{~A} 8$ & $\mathrm{~A} 12$ & $\mathrm{~A} 16$ \\
\hline$f_{R}$ trapecio & 0,065 & 0,041 & 0,068 & 0,074 & 0,064 \\
\cline { 1 - 1 }$f_{R}$ parábola & 0,065 & 0,041 & 0,077 & 0,088 & 0,073 \\
\cline { 1 - 3 } C.L.R. & 0,71 & 0,10 & 0,75 & 0,76 & 0,74 \\
\cline { 1 - 3 } & 2,09 & 1,54 & 1,55 & 2,59 & 3,06 \\
\hline
\end{tabular}

Tabla 3.29. Parámetros de la geometría superficial de las barras de CFRP y acero.

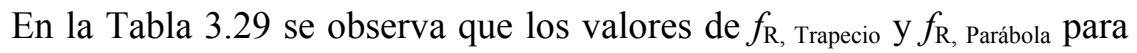
los tipos de barras CC12 y CT13 es el mismo debido a que la ecuación de cálculo de $f_{\mathrm{R}}$ es la misma ya que se ha obtenido a partir de la ecuación general. Respecto a los valores de $f_{\mathrm{R}}$ en las barras $\mathrm{A} 8, \mathrm{~A} 12$ y A16, se observa que con la ecuación de la parábola dan unos valores mayores a los obtenidos con la ecuación del trapecio. Esto es debido a que la ecuación de la parábola sobrevalora la altura de las corrugas.

\subsubsection{Ensayo de Tracción}

El ensayo de tracción se realiza siguiendo las disposiciones de la normativa ACI 440.3R-04 B.2 "Test method for longitudinal tensile properties of FRP bars". Con este método se calcula la fuerza " $F_{u}$ ", tensión resistente " $f$ ", el módulo elástico " $\mathrm{E}_{\mathrm{L}}$ " y el alargamiento " $\varepsilon$ " para cada nivel tensional y " $\varepsilon_{\mathrm{u}}$ " bajo carga máxima de las barras de CFRP y acero. En el caso de las barras de acero corrugadas también se emplea la norma UNE-EN ISO 15630-1 para el

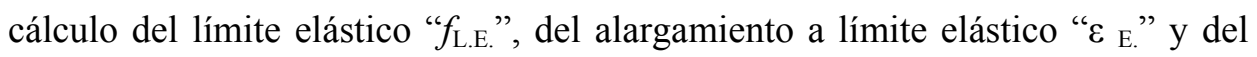
alargamiento de rotura " $\varepsilon_{\text {r.". }}$.

\footnotetext{
${ }^{35}$ Los valores de los parámetros $f_{\mathrm{R}}$, C.L.R y a , son valores medios, obtenidos a partir de los 25 valores individuales, de cada tipo de barra (CC12, CT13, A8, A12 y A16) ensayada posteriormente a pulllout.
} 
Los materiales ensayados en este apartado son barras de CFRP arenadas "CA8 y CA14", corrugadas "CC12", texturizadas "CT13" y barras de acero corrugadas “A8, A12 y A16”. Las propiedades geométricas de todos los tipos de barras se han definido previamente en el apart. 3.4.1.2 "Estudio de la Geometría Superficial" de la presente investigación.

Las máquinas y equipos empleados para la realización de este ensayo son las siguientes:

- Maquina de ensayo de la marca IBERTEST modelo UIB 600 DAU (Fig. 3.35.a).

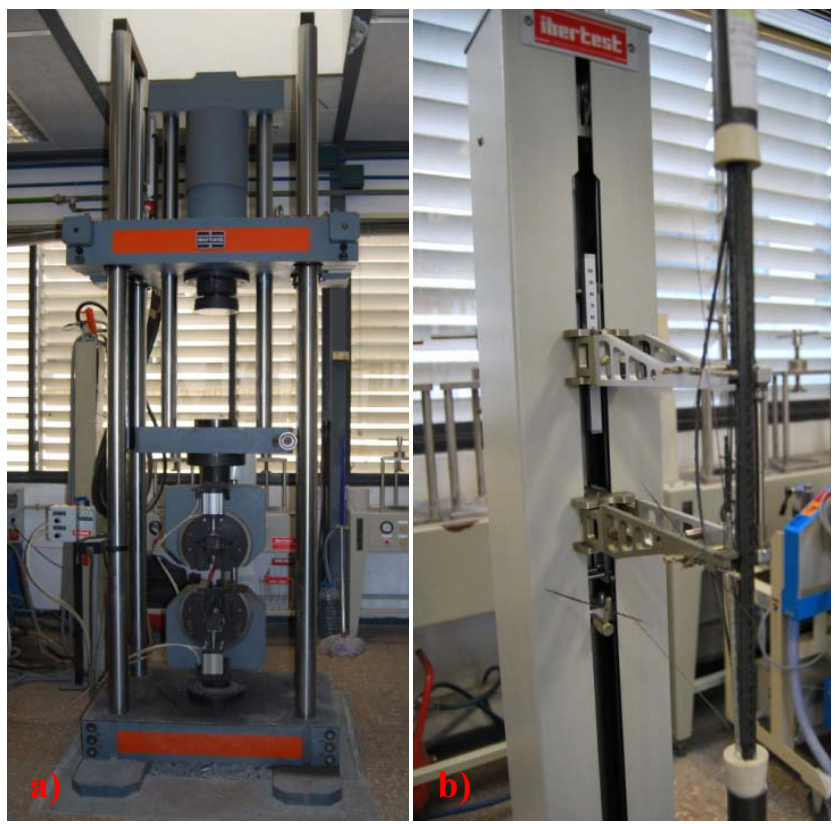

Fig. 3.35. a) Máquina de ensayo a tracción; b) Captador de deformaciones.

- Captador de deformaciones hasta la rotura de la muestra, de la marca IBERTEST modelo IB-CRA-2-500 (distancia entre mordazas $100 \mathrm{~mm}$ ) (Fig. 3.35.b).

- Bascula de pesada con precisión de 0,01 g., de la marca METTLER TOLEDO modelo PM 4000 (FIg. 3.36). 


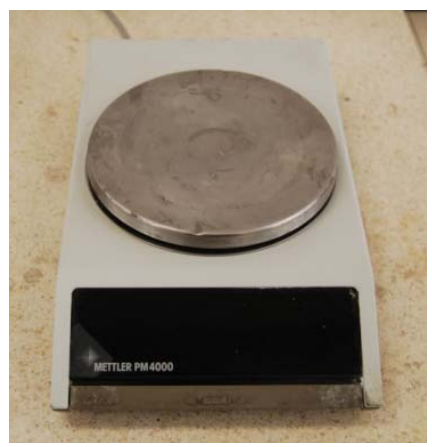

Fig. 3.36. Báscula de precisión.

- Resina de epoxi tricomponente de la marca Sika tipo Sikadur 42.

- Anclajes a base de tubo de acero electrosoldado (norma ISO R-65). En el caso de barras de CA14 se emplea tubo de $32 \mathrm{~mm}$ de diámetro exterior y $6 \mathrm{~mm}$ de espesor. Por el contrario, en barras CA8, CC12 y CT13 el tubo empleado es de $26,65 \mathrm{~mm}$ diámetro exterior y $2,35 \mathrm{~mm}$ espesor (Fig. 3.37).

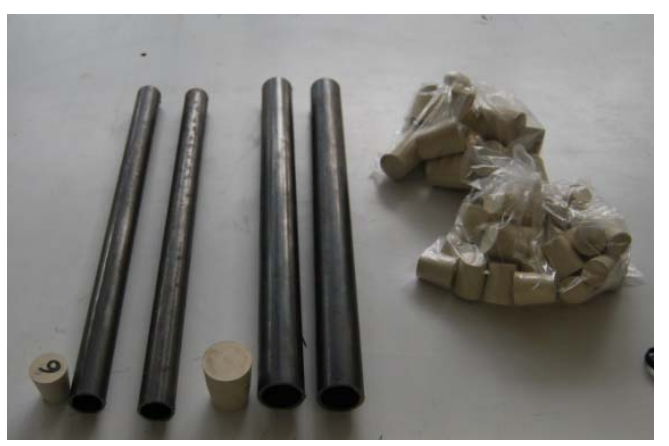

Fig. 3.37. Tubos de acero y tapones de goma.

- Tapones de goma troncocónicos. En el caso de barras CA14 las dimensiones son $29 \mathrm{~mm}$ de diámetro inferior, $36 \mathrm{~mm}$ de diámetro superior y $43 \mathrm{~mm}$ de altura. En barras CA8, CC12 y CT13 los tapones son de $21 \mathrm{~mm}$ de diámetro inferior, $28 \mathrm{~mm}$ de diámetro superior y $30 \mathrm{~mm}$ de altura (Fig. 3.37). 
El procedimiento y la metodología empleada para la realización del ensayo de tracción, es la siguiente:

I. Selección aleatoria de 3 muestras por cada tipo de barra (Fig. 3.38).
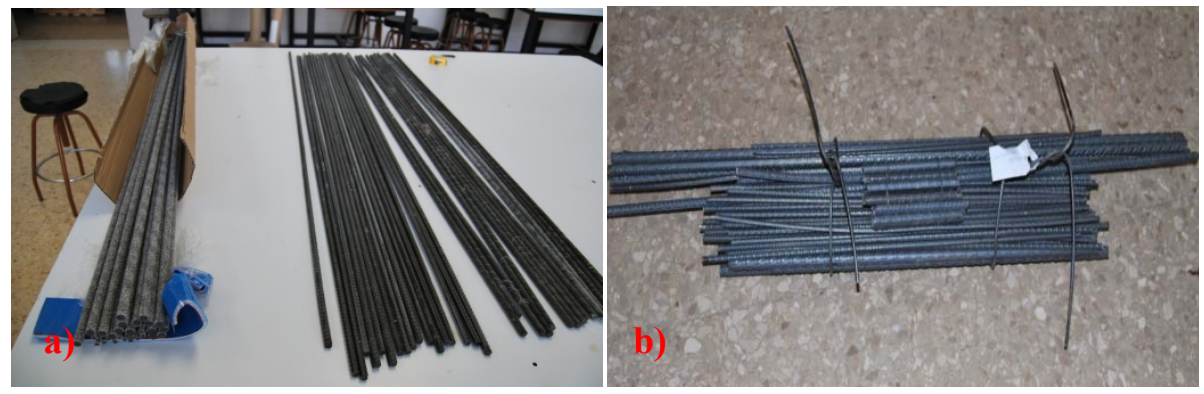

Fig. 3.38. Barras a ensayar: a) CFRP; b) Acero

II. Corte mediante sierra eléctrica con disco para acero de cada tipo de barra de CFRP, fijando una longitud de $1200 \mathrm{~mm}$ para las barras CA8, CC12 y $1250 \mathrm{~mm}$ en barras CT13 y CA14 (estas dimensiones han sido calculadas en el apart. 3.3.2. de la presente investigación). En el caso de las barras de acero, se ha decidido fijar la longitud en $1200 \mathrm{~mm}$ con el fin de uniformizar criterios de ensayo (esta longitud también es válida según UNE-EN ISO 15630-1).
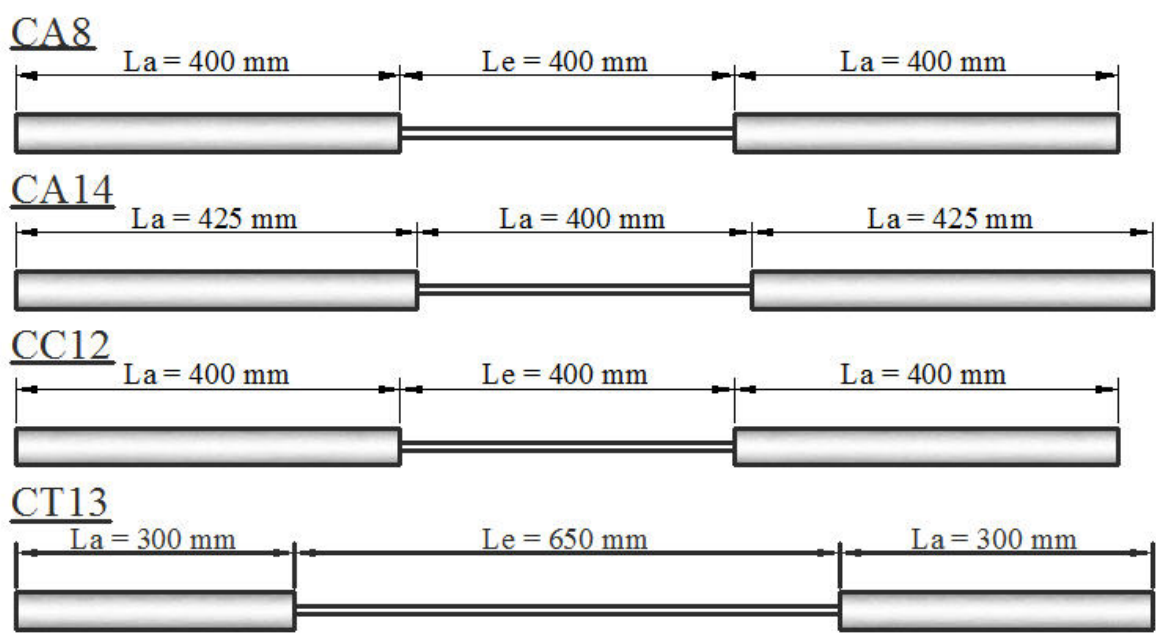

Fig. 3.39. Dimensiones de barras de CFRP para ensayo a tracción. 
III. Fabricación de los anclajes de las barras de CFRP ${ }^{36}$ en condiciones de laboratorio $\left(23 \pm 2{ }^{\circ} \mathrm{C}\right.$ y $50 \pm 10 \%$ de H.R.): Inicialmente se fabrica la resina de epoxi con la dosificación establecida en el apart. 3.3.3. Tabla 3.11. (Fig. 3.40.a). Seguidamente, se vierte la resina en el interior del tubo que posee la barra de CFRP con un tapón en la parte inferior (Fig. 3.40.b). Mediante un vibrador eléctrico se vibra el anclaje para distribuir homogéneamente la resina por todo el tubo y evitar posibles oclusiones de aire (Fig. 3.40.c). Finalmente, se coloca el tapón en la parte superior del tubo, evitando el derrame de resina de epoxi y alineando de este modo la barra en los tubos de anclaje (Fig. 3.40.d). Se repite la operación con el anclaje inferior.
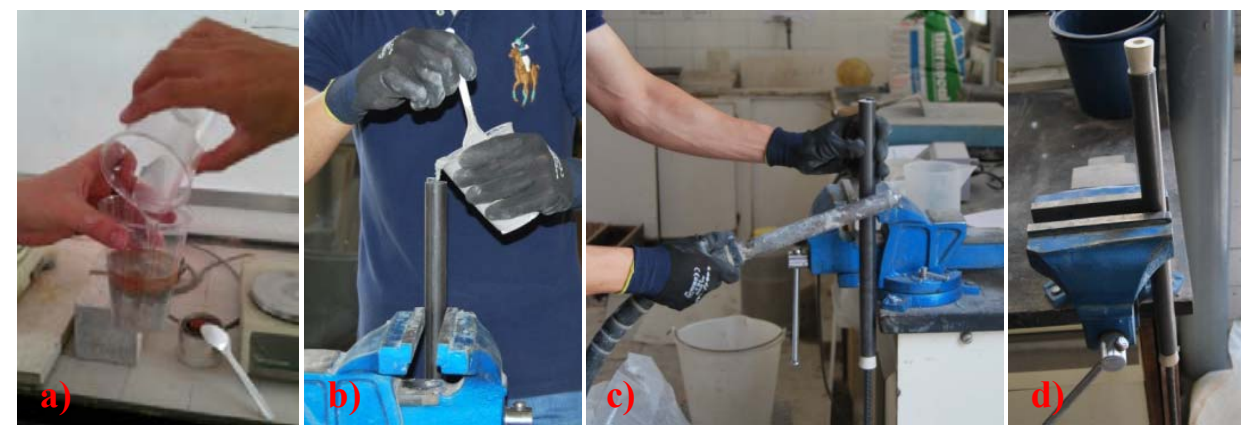

Fig. 3.40. Proceso de fabricación de los anclajes de las barras de CFRP.

IV. Curado de la resina de epoxi durante 48 horas en condiciones de laboratorio de $23 \pm 2{ }^{\circ} \mathrm{C}$ y $50 \pm 10 \%$ de H.R.

V. Ensayo de cada muestra a temperatura de laboratorio.

Debido a que ACI 440.3R-04 no establece una velocidad específica de ensayo (tan solo establece que la muestra debe de romper de 1 a $10 \mathrm{~min}$ ). La

\footnotetext{
${ }^{36}$ Los tubos de acero para los anclajes del ensayo de tracción, se cortan previamente en el almacén de distribución a las dimensiones calculadas en el apart. 3.3.2 de la presente investigación para cada tipo de barra de CFRP. En el caso de las barras CT13 se ha seleccionado una $L_{a}=300 \mathrm{~mm}$, $\mathrm{L}_{\mathrm{e}}=650 \mathrm{~mm} \mathrm{y} \mathrm{L}_{\mathrm{t}}=1250 \mathrm{~mm}$ para prevenir la rotura por cortadura de la barra, ya que para el rango de $L_{e}$ entre 400 y $650 \mathrm{~mm}$ no hay diferencia estadísticamente significativa en la tensión desarrollada.
} 
velocidad de ensayo de cada tipo de barra ha sido calculada a partir de la norma JSCE 1997(b), que en su disposición JSCE-E 531-1995 "Test method for tensile properties of continuous fiber reinforcing materials" establece una velocidad entre 100-500 MPa/min, y a partir de la norma Canadian Highway Design Code section 16 "CHBDC" que define una velocidad de ensayo de $250 \mathrm{MPa} / \mathrm{min}$. Por lo tanto, se establece para los ensayos de tracción de esta investigación una velocidad de ensayo de $250 \mathrm{MPa} / \mathrm{min}$.

El estudio de la resistencia a tracción de las barras se realiza sobre 3 muestras de cada tipo de barra y diámetro, con un total de 21 ensayos. El plan de ensayos a tracción se ha efectuado mediante un diseño de Cuadrado de Youden, en el cual los tratamientos son los tipos de barras y los días de ensayo son los bloques (Tabla 3.30). Los números dentro de cada bloque indican la posición de ensayo de cada barra. De este modo se elimina parte de la variación conocida debida a los días y posición de ensayo.

\begin{tabular}{|c|c|c|c|c|c|c|c|}
\hline $\begin{array}{c}\text { Tratamientos / } \\
\text { Bloques }\end{array}$ & CA8 & CA14 & $\mathrm{CC} 12$ & CT13 & A8 & A12 & A16 \\
\hline DIA 1 & & 2 & & 1 & 3 & & \\
\hline DIA 2 & 1 & & 2 & & & 3 & \\
\hline DIA 3 & & & & 2 & 1 & & 3 \\
\hline DIA 4 & 3 & 1 & & & & & 2 \\
\hline DIA 5 & & & 1 & 3 & 2 & & \\
\hline DIA 6 & 2 & 3 & & & & 1 & \\
\hline DIA 7 & & & 3 & & & 2 & 1 \\
\hline
\end{tabular}

Tabla 3.30. Diseño del plan de ensayos a tracción.

La codificación de cada muestra de ensayo se ha realizado según la siguiente nomenclatura, por ejemplo ET-5-1-CC12: las siglas "ET" definen el tipo de ensayo, en este caso ensayo de tracción, el primer número "5" corresponde al día de ensayo, el segundo número "1" a la posición de ensayo y por último las siglas "CC12" definen el tipo de barra. 
El cálculo de la tensión y módulo elástico de cada barra se realiza mediante las Ecs. 3.11 y 3.12 , respectivamente.

$$
\begin{aligned}
& f_{u}=\frac{F_{u}}{A} \\
& E_{L}=\frac{F_{1}-F_{2}}{\left(\varepsilon_{1}-\epsilon_{2}\right) \cdot A}
\end{aligned}
$$

donde $f_{\mathrm{u}}$ es la tensión máxima $(\mathrm{MPa}), \mathrm{F}_{\mathrm{u}}$ es la fuerza máxima $(\mathrm{N}), \mathrm{A}$ es el área de la sección resistente de la barra ${ }^{37}\left(\mathrm{~mm}^{2}\right), \mathrm{F}_{1}$ y $\mathrm{F}_{2}$ es la fuerza aplicada al $20 \mathrm{y}$ $50 \%$ de la fuerza máxima $\mathrm{F}_{\mathrm{u}}(\mathrm{N})$ y $\varepsilon_{1}$ y $\varepsilon_{2}$ son los alargamientos correspondientes al 20 y $50 \%$ del alargamiento a carga máxima, adimensional.

Los resultados del ensayo de tracción realizados en cada tipo de barra,

\begin{tabular}{|c|c|c|c|c|c|c|c|c|}
\hline Muestra & $\begin{array}{c}\mathrm{F}_{\mathrm{u}} \\
(\mathrm{kN})\end{array}$ & $\begin{array}{c}f_{\mathrm{u}} \\
(\mathrm{MPa})\end{array}$ & $\begin{array}{c}f_{\mathrm{L} . \mathrm{E}} \\
(\mathrm{MPa})\end{array}$ & $\begin{array}{c}\mathrm{E}_{\mathrm{L}} \\
(\mathrm{GPa})\end{array}$ & $\begin{array}{c}\varepsilon_{\mathrm{u}} \\
(\%)\end{array}$ & $\begin{array}{c}\varepsilon_{\mathrm{r}} \\
(\%)\end{array}$ & $\begin{array}{c}\varepsilon_{\mathrm{E}} \\
(\%)\end{array}$ & $\begin{array}{l}\text { Modo de } \\
\text { rotura* }\end{array}$ \\
\hline ET-2-1-CA8 & 66,6441 & 2104,33 & - & 148,965 & 1,35 & - & - & SP \\
\hline ET-4-3-CA8 & 66,3085 & 2093,73 & - & 158,651 & 1,31 & - & - & SP \\
\hline ET-6-2-CA8 & 68,3660 & 2158,69 & - & 148,103 & 1,41 & - & - & SP \\
\hline ET-1-2-CA14 & 112,6396 & 889,02 & - & 144,862 & 0,62 & - & - & DSR \\
\hline ET-4-1-CA14 & 102,4272 & 808,42 & - & 119,355 & 0,68 & - & - & DSR \\
\hline ET-6-3-CA14 & 87,8427 & 693,31 & - & 133,116 & 0,55 & - & - & DSR \\
\hline ET-2-2-CC12 & 152,6763 & 1846,81 & - & 135,554 & 1,53 & - & - & SP \\
\hline ET-5-1-CC12 & 154,9064 & 1873,79 & - & 115,195 & 1,70 & - & - & SP \\
\hline ET-7-3-CC12 & 153,6796 & 1858,95 & - & 111,854 & 1,76 & - & - & SP \\
\hline ET-1-1-CT13 & 103,5799 & 1436,21 & - & 157,693 & 0,93 & - & - & SP \\
\hline ET-3-2-CT13 & 115,2647 & 1598,23 & - & 127,933 & 1,28 & - & - & SP \\
\hline ET-5-3-CT13 & 115,5453 & 1602,12 & - & 148,749 & 1,03 & - & - & SP \\
\hline ET-1-3-A8 & 32,0831 & 638,34 & 542,34 & 198,630 & 14,31 & 25,00 & 0,29 & AS \\
\hline ET-3-1-A8 & 32,3146 & 642,94 & 515,25 & 197,336 & 12,32 & 24,15 & 0,64 & AS \\
\hline ET-5-2-A8 & 32,7428 & 651,46 & 544,21 & 204,099 & 11,85 & 26,10 & 0,47 & AS \\
\hline ET-2-3-A12 & 74,2974 & 656,97 & 556,50 & 197,647 & 8,76 & 22,68 & 0,48 & AS \\
\hline ET-6-1-A12 & 73,0563 & 646,00 & 541,78 & 201,320 & 8,21 & 18,16 & 0,66 & AS \\
\hline ET-7-2-A12 & 73,8414 & 652,94 & 538,64 & 202,876 & 12,77 & 22,95 & 0,78 & AS \\
\hline ET-3-3-A16 & 133,5320 & 664,14 & 580,32 & 197,560 & 9,82 & 13,91 & 0,38 & AS \\
\hline ET-4-2-A16 & 134,8619 & 670,75 & 569,95 & 206,180 & 8,79 & 20,00 & 0,37 & AS \\
\hline ET-7-1-A16 & 141,8663 & 705,59 & 631,11 & 196,726 & 9,33 & 13,33 & 0,39 & AS \\
\hline
\end{tabular}
$\mathrm{F}_{\mathrm{u}}, f_{\mathrm{u}}, f_{\mathrm{L} . \mathrm{E}}, \mathrm{E}_{\mathrm{L}}, \varepsilon_{\mathrm{u}}, \varepsilon_{\mathrm{r}} \mathrm{y} \varepsilon_{\mathrm{E}}$, se muestran en la Tabla 3.31.

*SP: rotura por splitting de la barra; DSR: deslizamiento de la barra en los anclajes sin rotura; AS: rotura por agotamiento de la sección.

Tabla 3.31. Resultados ensayo de tracción en cada tipo de barra.

${ }^{37}$ El área resistente de cada tipo de barra se ha calculado a partir del diámetro sin geometría superficial en las barras arenadas CA8 y CA14, y a partir del diámetro medio sin corrugas en las barras corrugadas CC12 y texturizadas CT13. En las barras de acero corrugadas A8, A12 y A16 se ha calculado a partir del diámetro nominal de cada barra. 
Los resultados del ensayo de tracción muestran que las barras de CFRP CA8, CC12 y CT13 poseen un modo de rotura frágil, en el cual la barra rompe repentinamente por splitting de la sección resistente (Fig. 3.41.a,b y c). En cambio, las barras de acero corrugadas A8, A12 y A16 poseen un modo de rotura dúctil ocasionado por el agotamiento de la sección resistente (Fig. 3.41.d y e.). En el caso de las barras de CFRP arenadas CA14, no ha sido posible la rotura de las mismas por agotamiento de la sección, debido a que se produce un deslizamiento de la barra en los anclajes, ocasionado por la rotura de la adhesión entre la geometría superficial de la barra y el propio núcleo de la barra (Fig. 3.42). Por lo tanto, los ensayos de tracción realizados en las barras CA14 con una $\mathrm{L}_{\mathrm{a}}=425 \mathrm{~mm}$, mayor a $\mathrm{L}_{\mathrm{a}}=400 \mathrm{~mm}$ de ensayos previos apart. 3.3.2 y 3.3.3, no ha podido solucionar el problema de deslizamiento en los anclajes.
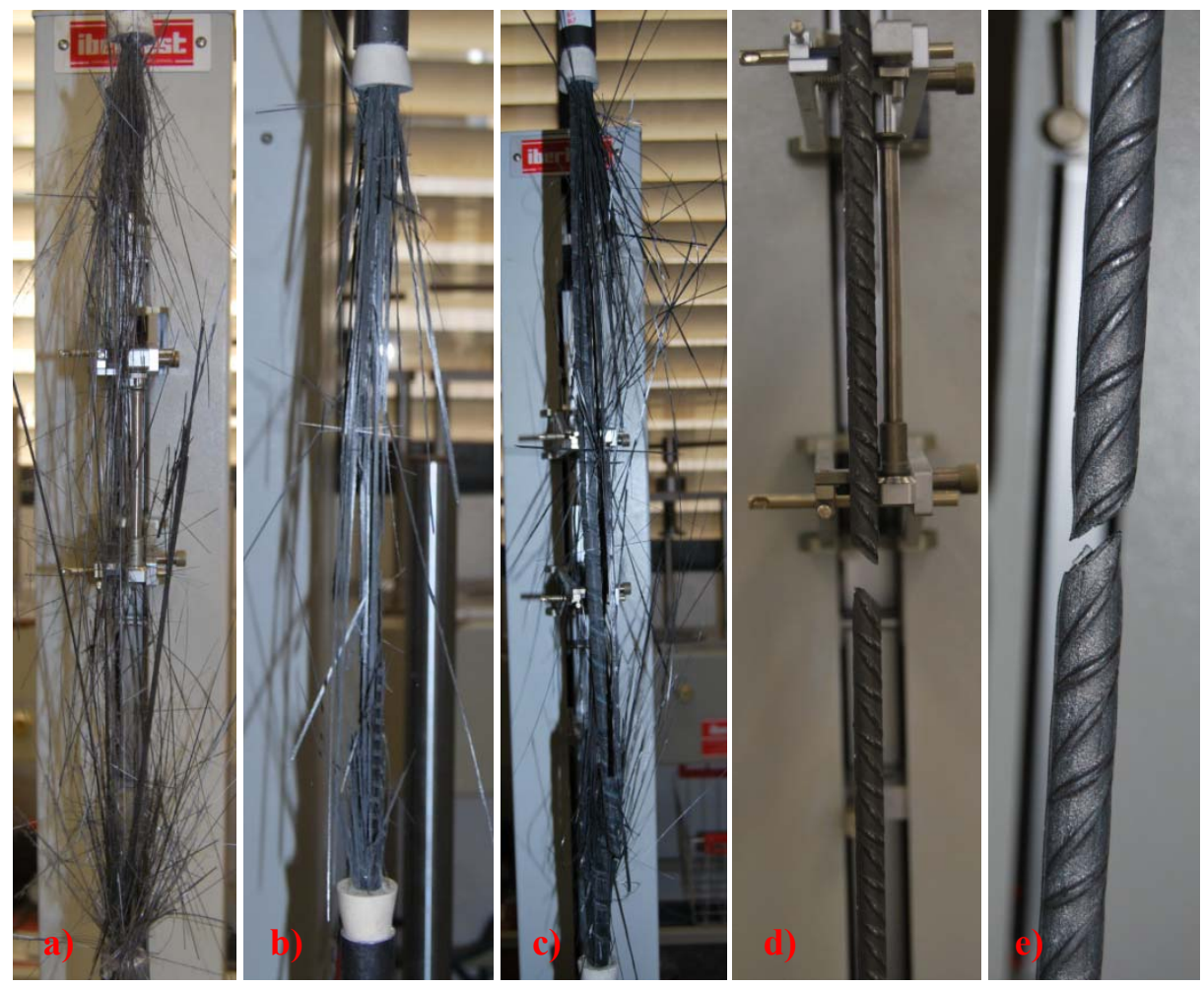

Fig. 3.41. Modo de rotura: a) Splitting CA8; b) Splitting CC12; c) Splitting CT13; d) Agotamiento, A8; e) Agotamiento A12 

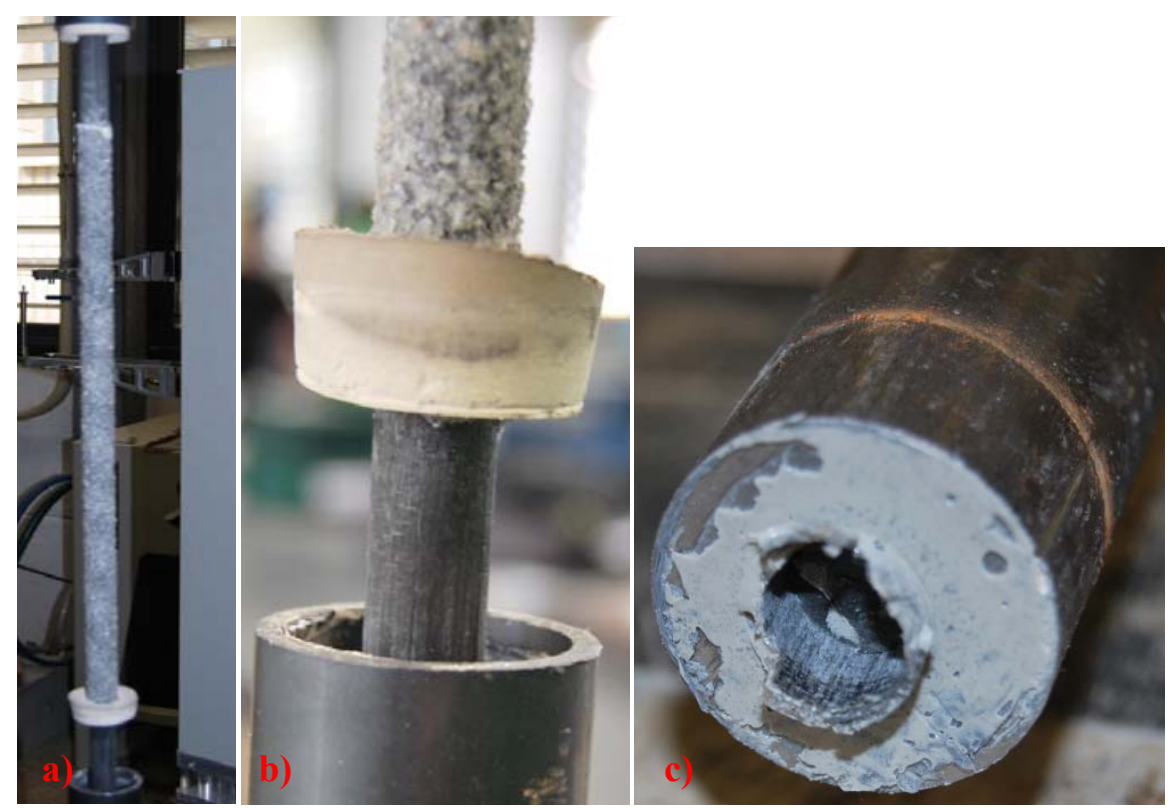

Fig. 3.42. Deslizamiento sin rotura de las barras CA14: a) Deslizamiento en ambos anclajes; b) Rotura adhesión geometría superficial/núcleo; c) Geometría superficial adherida a resina anclaje.

El comportamiento ante los esfuerzos de tracción de todas las barras de CFRP ensayadas en esta investigación es elástico-lineal hasta la rotura (Fig. 3.43). Por el contrario, las barras de acero corrugadas ensayadas a tracción poseen un comportamiento elasto-plástico (Fig. 3.43).

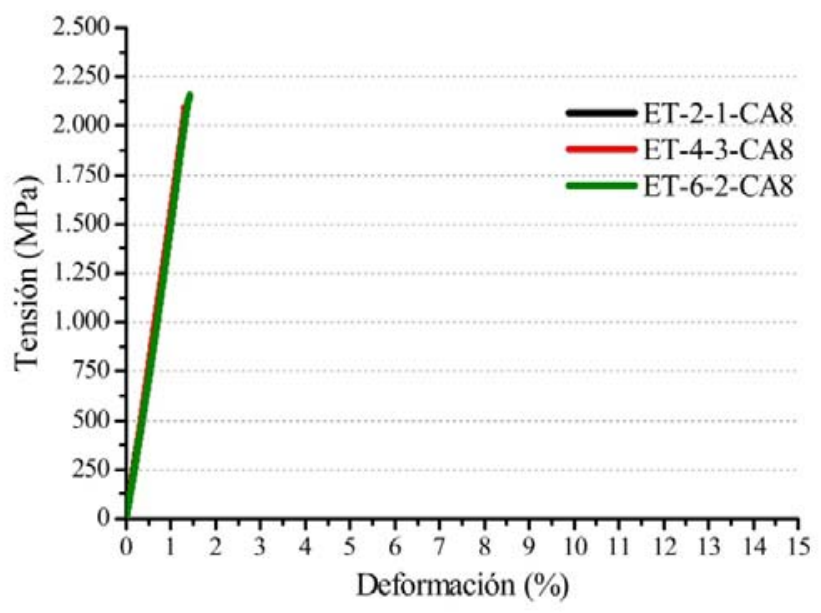



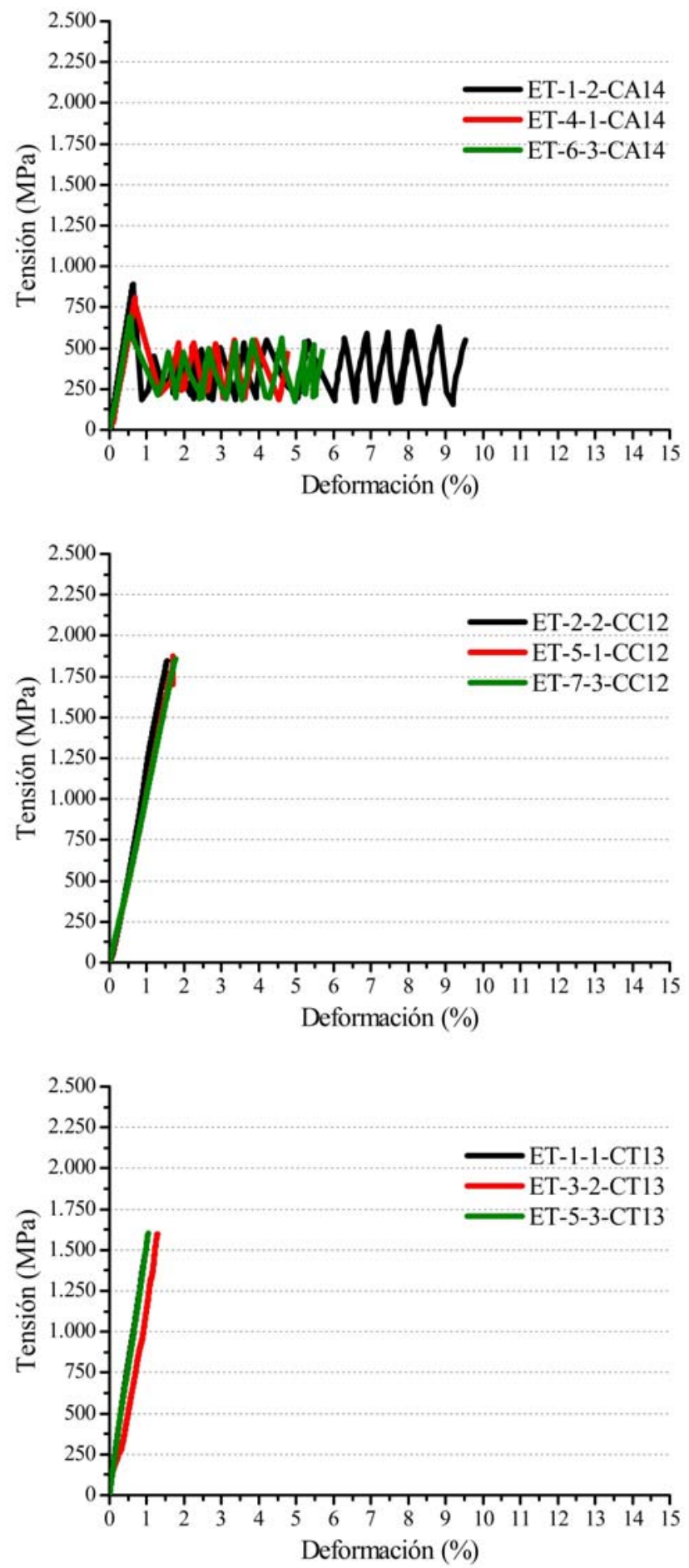

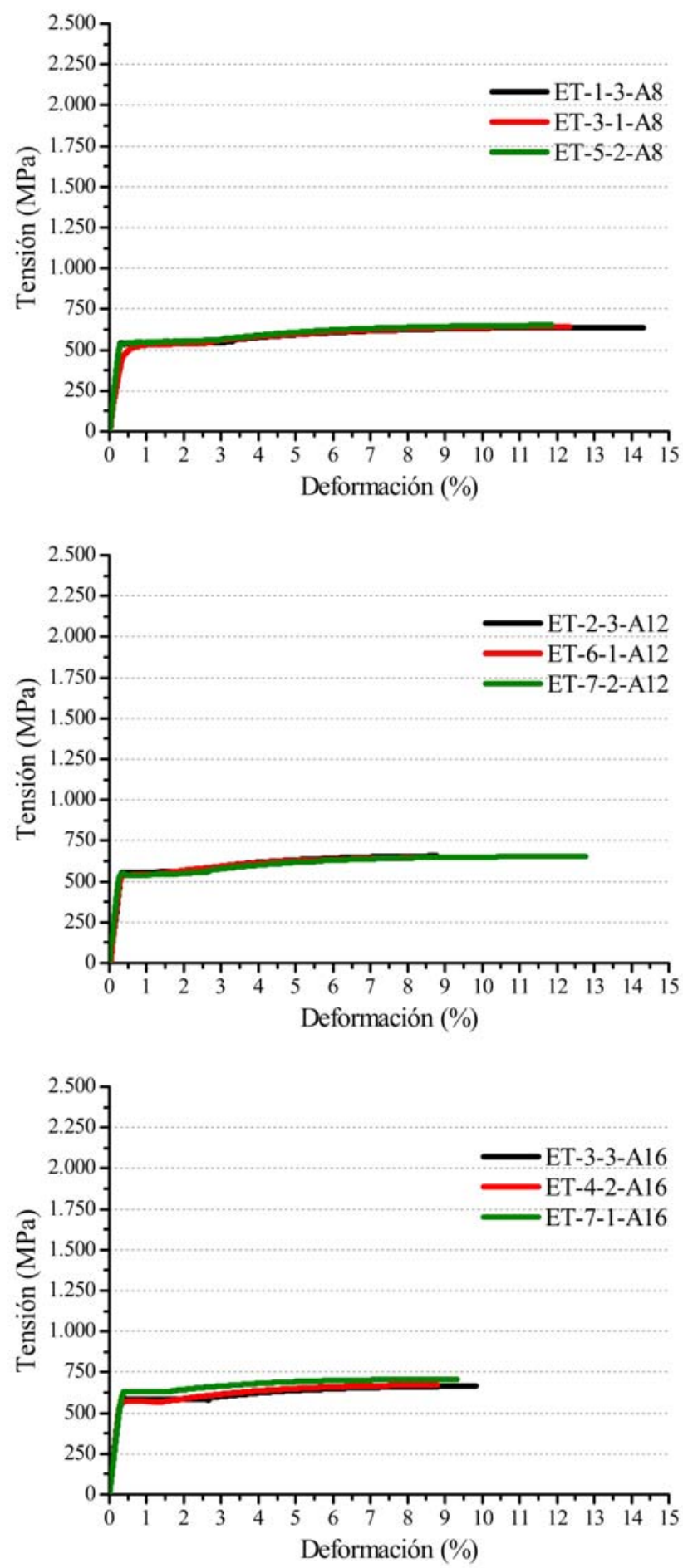

Fig. 3.43. Comportamiento a tracción de las barras de CFRP CA8, CA14, CC12, CT13 y de acero corrugadas A8, A12 y A16. Gráfica de tensión/Deformación. 
En la Tabla 3.32 se muestran los valores medios " $\bar{y}$ " y las desviaciones típicas “ $\sigma$ " de $\mathrm{F}_{\mathrm{u}}, f_{\mathrm{u}}, f_{\mathrm{L} . \mathrm{E}}, \mathrm{E}_{\mathrm{L}}, \varepsilon_{\mathrm{u}}, \varepsilon_{\mathrm{r}}$ y $\varepsilon_{\mathrm{E}}$, en cada tipo de barra, calculados mediante un análisis unidimensional, en los diferentes tipos de barras, a partir de los resultados obtenidos en cada muestra.

\begin{tabular}{ccccc}
$\begin{array}{c}\text { Tipo de } \\
\text { Barra }\end{array}$ & $\begin{array}{c}\mathrm{F}_{\mathrm{u}} \\
(\mathrm{kN})\end{array}$ & $\sigma$ & $\begin{array}{c}f_{\mathrm{u}} \\
(\mathrm{MPa})\end{array}$ & $\sigma$ \\
\hline CA8 & 67,106 & 1,1038 & 2118,92 & 34,8501 \\
\hline CA14 & 100,970 & 12,4624 & 796,91 & 98,3608 \\
\hline CC12 & 153,754 & 1,1169 & 1859,85 & 13,5125 \\
\hline CT13 & 111,463 & 6,8286 & 1545,52 & 94,6852 \\
\hline A8 & 32,380 & 0,3347 & 644,247 & 6,6568 \\
\hline A12 & 73,731 & 0,6277 & 651,97 & 5,5489 \\
\hline A16 & 136,753 & 4,47755 & 680,16 & 22,2696 \\
\hline & & & & \\
\hline Tipo de & $\varepsilon_{\mathrm{u}}$ & $\sigma$ & $\varepsilon_{\mathrm{E}}$ & $\sigma$ \\
Barra & $(\%)$ & & $(\%)$ & - \\
\hline CA8 & 1,35667 & 0,05033 & - & - \\
\hline CA14 & 0,61667 & 0,06506 & - & - \\
\hline CC12 & 1,66333 & 0,11930 & - & - \\
\hline CT13 & 1,08000 & 0,18028 & - & - \\
\hline A8 & 12,8267 & 1,30592 & 0,46667 & 0,17502 \\
\hline A12 & 9,9133 & 2,48918 & 0,64 & 0,151 \\
\hline A16 & 9,3133 & 0,51520 & 0,38 & 0,01 \\
\hline
\end{tabular}

Tabla 3.32 Propiedades mecánicas $\mathrm{F}_{\mathrm{u}}, f_{\mathrm{u}}, f_{\mathrm{L} . \mathrm{E}}, \mathrm{E}_{\mathrm{L}}, \varepsilon_{\mathrm{u}}, \varepsilon_{\mathrm{r}}, \varepsilon_{\mathrm{E}} \mathrm{y} \sigma$ de las barras de CFRP y acero ensayadas

Los valores medios de la Tabla 3.32 muestran que las barras CA8 desarrollan una mayor tensión $(2118,92 \mathrm{MPa})$ y poseen un módulo elástico más rígido $(151,906 \mathrm{GPa})$ respecto a los otros tipos de barras de CFRP. Además, este tipo de barras presenta una menor variabilidad en sus propiedades mecánicas que el resto de barras de CFRP. Los valores obtenidos en la Tabla 3.32 para las barras CA14 no son válidos debido a que no se ha alcanzado la rotura de la barra en ningún ensayo; por lo tanto, las propiedades mecánicas de este tipo de barras no son comparables con el resto de barras ensayadas. Respecto a las propiedades mecánicas de las barras CC12, se puede observar que presentan una elevada 
tensión resistente, del orden de 1859,85 MPa, con un módulo elástico menor que el resto de barras de CFRP. Sin embargo, las barras CT13 poseen menor resistencia a tracción que el resto de barras de CFRP (1545,52 MPa), en cambio desarrollan un módulo más elevado y una menor deformación a rotura que las barras $\mathrm{CC} 12$.

Las barras de CFRP poseen una tensión del orden de 2,9-3,9 veces mayor que las barras de acero corrugadas de tipo B-500-SD (Fig. 3.44). Sin embargo, el módulo elástico de las barras de acero es del orden de 1,3-1,6 veces mayor que en las barras de CFRP. En cuanto a la deformación, las barras de CFRP poseen una deformación similar $(0,40-0,64 \%)$ a las barras de acero cuando la tensión es igual al límite elástico. Por lo tanto, el comportamiento a tracción de las barras de CFRP es más resistente pero menos dúctil que el de las barras de acero. En cambio, la rigidez a tensión de límite elástico en las barras de CFRP y acero es similar, pero el comportamiento global a tracción de las barras de CFRP es menos rígido respecto a las barras de acero.

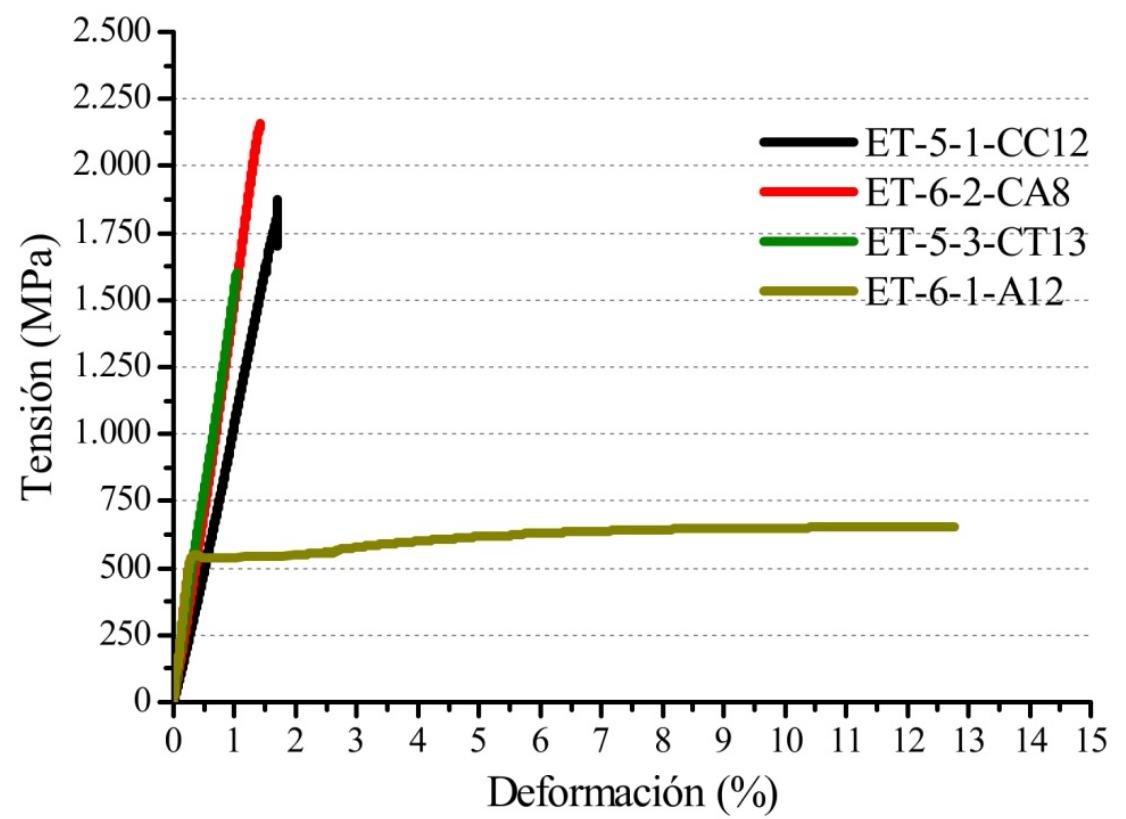

Fig. 3.44. Comportamiento a tracción de las barras de CFRP y acero corrugadas. Gráfica de tensión/Deformación. 
En cuanto a los valores característicos de las barras de CFRP las normas ACI 440.1R-06 y ACI 440.6M-08 establecen las Ecs. 3.13 y 3.14 para el cálculo de la tensión " $f_{u, c k}$ " y alargamiento bajo carga máxima " $\varepsilon_{\mathrm{u}, \mathrm{ck}}$ " característicos (nivel de confianza del 99,87\%), mientras que para el cálculo del módulo elástico característico " $\mathrm{E}_{\mathrm{L}, \mathrm{ck}}$ " define que este es igual al módulo elástico medio $\mathrm{E}_{\mathrm{L}}$ (Tabla 3.33). Respecto a los valores característicos de las barras de acero, estos se calculan mediante las disposiciones definidas por UNE-EN 10080 (con un nivel de confianza del 95\%).

$f_{u, c k}=f_{u}-(3 \cdot \sigma)$
$\varepsilon_{u, c k}=\varepsilon_{u}-(3 \cdot \sigma)$

\begin{tabular}{|c|c|c|c|c|c|c|c|}
\hline \multirow{2}{*}{$\begin{array}{l}\text { Parámetro / } \\
\text { Tipo de } \\
\text { barra }\end{array}$} & \multicolumn{3}{|c|}{ Calculado Ec. 3.13 y 3.14} & \multicolumn{3}{|c|}{ Definido por fabricante } & \multirow{2}{*}{ 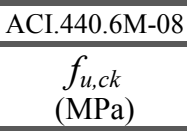 } \\
\hline & $\begin{array}{c}f_{u, c k} \\
(\mathrm{MPa})\end{array}$ & $\begin{array}{c}\varepsilon_{\mathrm{u}, \mathrm{ck}} \\
(\%)\end{array}$ & $\begin{array}{c}\mathrm{E}_{\mathrm{L}} \\
(\mathrm{GPa})\end{array}$ & $\begin{array}{c}f_{u, c k} \\
(\mathrm{MPa})\end{array}$ & $\begin{array}{c}\varepsilon_{\mathrm{u}, \mathrm{ck}} \\
(\%)\end{array}$ & $\begin{array}{c}\mathrm{E}_{\mathrm{L}} \\
(\mathrm{GPa})\end{array}$ & \\
\hline CA8 & 2014,3 & 1,2 & 151,9 & 1356 & 1,20 & 127 & 1450 \\
\hline CA14 & - & - & 132,4 & 1765 & 1,32 & 144 & 1170 \\
\hline $\mathrm{CC} 12$ & 1819,3 & 1,3 & 120,8 & - & - & - & 1310 \\
\hline CT13 & 1261,4 & 0,5 & 144,7 & 2800 & 1,8 & 155 & 1310 \\
\hline A8 & 633,2 & 10,6 & 200,0 & $\geq 575$ & $\geq 9,5$ & 200 & - \\
\hline A12 & 642,8 & 5,8 & 200,6 & $575-843$ & $\geq 7,5$ & 200 & - \\
\hline A16 & 643,5 & 8,4 & 200,1 & $575-844$ & $\geq 8,0$ & 200 & - \\
\hline
\end{tabular}

Tabla 3.33 Propiedades mecánicas $f_{\mathrm{u}, \mathrm{ck}}, f_{\mathrm{LE}, \mathrm{ck}}, \mathrm{E}_{\mathrm{L}}, \varepsilon_{\mathrm{u}, \mathrm{ck}}$ de las barras de CFRP y acero.

El valor de $f_{u, c k}$ en los tipos de barras CA8, A8, A12 y A16 cumple con el mínimo determinado por el fabricante. Sin embargo, en las barras CT13 este valor es inferior al definido por Sika y al mínimo exigido por la norma ACI.440.6M-08. En cuanto a las barras CC12 debido a que no se dispone de datos del fabricante, se puede afirmar que su $f_{u, c k}$, del mismo modo que en las barras CA8, es superior al mínimo determinado por la norma ACI 440.6M-08 para dicho diámetro de barra. Respecto al alargamiento bajo carga máxima, en las barras CA8, A8 y A16 se cumplen los valores definidos por el fabricante. En cambio, la elevada variabilidad entre los valores de los ensayos de las barras CT13 y A12 produce una disminución del $\varepsilon_{\mathrm{u}, \mathrm{ck}}$ que no alcanza el valor mínimo 
definido por el fabricante ${ }^{38}$. El módulo elástico de los tipos de barras CA8, A8, A12 y A16 cumple con las disposiciones del fabricante, sin embargo el calculado para las barras CT13 es ligeramente inferior. En las barras CA14 el módulo es inferior al definido por el fabricante debido a que la barra no alcanza la rotura en el ensayo de tracción por deslizamiento del anclaje lo cual invalida los resultados de este tipo de barras.

Una vez analizados los valores del ensayo de tracción, se va a considerar que para el cálculo de la deformación en el extremo tensionado de cada probeta de ensayo a pullout se empleen los valores del $\mathrm{E}_{\mathrm{L}}$ de cada tipo de barra obtenidos en el ensayo de tracción (Tabla 3.32 y 3.33), menos para el tipo de barra CA14, que debido a que no ha sido posible obtener unos resultados adecuados se emplea el módulo elástico definido por el fabricante de este tipo de barras (Pultrall INC), igual a 144,00 GPa.

\subsubsection{Ensayo de Pullout}

En este apartado se realizan los ensayos de pullout en barras de CFRP arenadas, corrugadas, texturizadas y de acero corrugadas (definidas en apart. 3.2 y 3.4.1 del presente estudio), sometidas a diferentes condiciones ambientales de Hielo/Deshielo, $5{ }^{\circ} \mathrm{C}, 20{ }^{\circ} \mathrm{C}, 40{ }^{\circ} \mathrm{C}$ y $80{ }^{\circ} \mathrm{C}$, para el cálculo del comportamiento adherente y el posterior análisis de la influencia de diferentes parámetros en la tensión adherente, cálculo de los coeficientes adherentes, longitud de anclaje de diferentes normativas de diseño de elementos de hormigón armado y ajuste de métodos de cálculo analíticos del comportamiento adherente.

\footnotetext{
${ }^{38}$ Un número de ensayos reducido (inferior a 5) puede producir una variabilidad defecto en la muestra de la población, que afecta a la distribución de dicha muestra realizándola no reconocible de la población. Por lo tanto, dos posibles soluciones son: 1) el aumento del número de muestras ensayadas; o, 2) la simulación de una muestra de 500 datos de la misma población; de este modo se crea un subconjunto reconocible de datos con una variabilidad similar a la población, en la que los valores característicos calculados son similares a los de la población.
} 


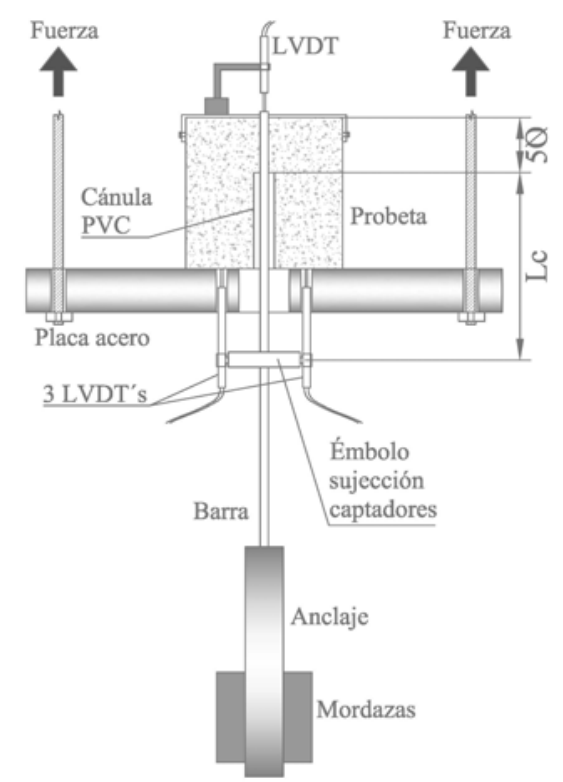

Fig. 3.45 Metodología de ensayo a pullout.

Los ensayos de pullout realizados en este apartado se ejecutan siguiendo las disposiciones de la norma ACI.440.3R-04. B.3 "Test method for bond strength of FRP bars by pullout testing" ( $\operatorname{similar}^{39}$ al ensayo de pullout para barras de acero de la norma UNE-EN 10080). Este ensayo consiste en aplicar una fuerza de tracción en el extremo de una barra que se encuentra embebida en el extremo contrario en una probeta de hormigón cúbica de dimensiones $200 \mathrm{x}$ 200 x 200 mm (Fig. 3.45). La longitud adherente entre la barra y el hormigón es de 5 diámetros de barra, por lo que en la longitud restante se coloca una cánula de PVC para evitar el contacto entre el hormigón y la barra. Este método define que la cánula de PVC debe colocarse anteriormente a la longitud adherente de la barra, con el fin de evitar el confinamiento del hormigón sobre la barra, que incrementaría la tensión adherente (véase apart. 2.5.5.1.). A pesar de las

\footnotetext{
${ }^{39}$ El ensayo de arrancamiento o pullout definido en UNE-EN 10080 es similar a ACI.440.3R-04, sin embargo, hay varias modificaciones como: la velocidad de aplicación de carga, la cual en ACI es no mayor a $20 \mathrm{kN} / \mathrm{min}$, superior a la establecida por UNE de $0,56 \cdot \emptyset^{2}$; la captación de deformaciones donde ACI establece la captación en ambos extremos y UNE tan solo en el extremo no tensionado; el vertido de hormigón, el cual en ACI es en la misma dirección de la barra y UNE establece un vertido perpendicular a la barra.
} 
disposiciones de la norma, debido a las características de las máquinas y materiales de ensayo disponibles, se han realizado varias modificaciones respecto al método de ACI.440.3R-04, que no influyen en los resultados obtenidos:

- Se ha eliminado la lámina elastomérica situada entre la probeta y la placa de apoyo, con el fin de eliminar el ruido que produce ésta en la medición del extremo tensionado, debido a la deformación elástica de la lámina.

- Se ha modificado la dirección de vertido del hormigón en la probeta. En esta investigación el vertido es perpendicular a la dirección de la barra debido a la tipología de los moldes.

- Se ha modificado la longitud de las probetas, debido a que la longitud máxima de ensayo de la máquina es aproximadamente $750 \mathrm{~mm}$. Por lo tanto, la longitud de cada probeta de ensayo a pullout es de $750 \mathrm{~mm}$.

Mediante este ensayo se calcula la tensión adherente " $\tau$ " (Ec. 3.15) y los deslizamientos en el extremo tensionado " $\delta_{\mathrm{ET}}$ " y no tensionado " $\delta_{\mathrm{ENT}}$ " de la barra, obteniendo de este modo la relación tensión adherente/deformación. El cálculo de $\delta_{\text {ENT }}$ se obtiene directamente del LVDT instalado en el extremo no tensionado de la barra, sin embargo, para el cálculo de $\delta_{\mathrm{ET}}$ hay que restar a la deformación media de los tres captadores instalados en el extremo no tensionado la deformación elástica de la barra " $\mathrm{S}_{\mathrm{c}}$ " (Ec. 3.16 y Fig. 3.45).

$$
\begin{gathered}
\tau=\frac{F}{C_{b} \cdot l_{a}} \\
S_{c}=\frac{F \cdot L_{c}}{E_{L} \cdot A}
\end{gathered}
$$

donde $\mathrm{F}$ es la fuerza aplicada (en N), $\mathrm{C}_{\mathrm{b}}$ es el perímetro de la barra (en mm), $1_{\mathrm{a}}$ es la longitud adherente (en $\mathrm{mm}$ ), $\mathrm{L}_{\mathrm{c}}$ es la longitud entre el punto medio de sujeción de los captadores del extremo tensionado hasta el inicio de la longitud adherente 
de la barra (en mm), $E_{L}$ es el módulo elástico de la barra (en MPa) y A es el área resistente de la barra $\left(\mathrm{en} \mathrm{mm}^{2}\right)$.

Para llevar a cabo los cálculos de $\tau$ y $\delta_{\mathrm{ET}}$, previamente se ha calculado según las disposiciones de ACI.440.3R-04. B.3. los siguientes parámetros (Tabla 3.34):

- El diámetro, área y perímetro equivalente siguiendo la norma ACI. 440.3R-04. B.1 (véase apart. 3.4.1.1. del presente estudio),

- Área resistente (véase apart. 3.4.1.2.), y

- Módulo elástico, según la norma ACI.440.3R-04. B.2 (véase apart. 3.4.1.3).

En cuanto a las diferentes condiciones ambientales de ensayo de pullout, la norma ACI.440.3R-04- B.3 solo recoge una condición ambiental de ensayo a $23 \pm 3{ }^{\circ} \mathrm{C}$ y $50 \pm 10 \%$ de humedad relativa (condición de laboratorio), y recomienda la norma ASTM D618 para el diseño de otras condiciones ambientales de ensayo. Debido a que una de las finalidades de esta investigación es el estudio del comportamiento adherente bajo las diferentes condiciones ambientales a las cuales se someten las estructuras de hormigón armado con CFRP a lo largo de un año, se establecen 5 diferentes condiciones ambientales: Hielo/Deshielo y $5{ }^{\circ} \mathrm{C}$ en el caso de climas fríos, $20^{\circ} \mathrm{C}$ como temperatura media y $40{ }^{\circ} \mathrm{C}$ y $80^{\circ} \mathrm{C}$ en el caso de climas cálidos y zonas de radiación solar directa. En el apart. 3.3.1 de la presente investigación, previamente, se han calculado los parámetros de cada condición ambiental, siendo:

- En el caso de la condición de Hielo/Deshielo, un ciclo de hielo a $-20{ }^{\circ} \mathrm{C}$ durante $48 \mathrm{~h}$., seguido de un ciclo de deshielo a $20{ }^{\circ} \mathrm{C}$ durante $24 \mathrm{~h}$. y posteriormente otro ciclo de hielo durante $48 \mathrm{~h}$ a $-20^{\circ} \mathrm{C}$. Por lo tanto, esta condición ambiental dura 5 días. 
- En el caso de las condiciones de $5{ }^{\circ} \mathrm{C}, 20{ }^{\circ} \mathrm{C}, 40{ }^{\circ} \mathrm{C}$ y $80{ }^{\circ} \mathrm{C}$ se establece un único ciclo ambiental durante 48 horas a la temperatura ambiental de cada condición.

Al mismo tiempo, en el apart. 3.3.1 de la presente investigación, también se define el periodo de trabajo, con o sin protección térmica de las probetas (dependiendo de cada caso), que transcurre entre la extracción de las probetas de la cámara climática hasta su posterior ensayo.

En cuanto al hormigón empleado en los ensayos de pullout, se ha dosificado un hormigón, de resistencia a compresión media " $f_{c}$ " igual $30 \pm 3 \mathrm{Mpa}$ y un tamaño máximo de árido de $12,5 \mathrm{~mm}$, siguiendo las disposiciones de ACI.440.3R-04. La toma de muestras de cada lote se ha realizado conforme a UNE-EN 12350-1, la forma y medidas de las probetas y los moldes según UNEEN 12390-1, la fabricación y curado de probetas de acuerdo a UNE-EN 123902, la determinación de la resistencia a compresión conforme a UNE-EN 12390-3 y la determinación de la consistencia de cada amasada según UNE-EN 12350-2. Debido al volumen máximo de la hormigonera empleada ${ }^{40}$, alrededor de 65-70 $\mathrm{dm}^{3}$, se ha decidido controlar la resistencia del hormigón mediante probetas cúbicas de dimensiones $100 \times 100 \times 100 \mathrm{~mm}$. Por lo tanto, la resistencia media y característica de cada lote se calcula mediante las disposiciones del art. 86.3.2 de la EHE-08 (Ec. 3.17).

$$
f_{c}=\lambda_{\text {cil }, c u b} \cdot f_{c, \text { cúbica }}
$$

donde $f_{c}$ es la resistencia a compresión del hormigón referida a probeta cilíndrica de 150 x $300 \mathrm{~mm}$ (en MPa), $\lambda_{\text {cil,cúb }}$ es el coeficiente de conversión obtenido de la Tabla 86.3.3.a de la EHE-08, en este caso 0,90 y $f_{c \text {,cúbica }}$ es la resistencia de la probeta cúbica (en MPa).

\footnotetext{
${ }^{40}$ En cada amasada se fabrican 7 probetas de pullout de dimensiones $200 \times 200$ x $200 \mathrm{~mm}$, con un volumen total de $56 \mathrm{dm}^{3}$.
} 
Para llevar a cabo este ensayo ha sido necesario diseñar varios mecanismos para adaptar las máquinas de ensayo a las barras de CFRP. Los materiales y equipos empleados para la realización del ensayo de pullout conforme a ACI.440.3R-04 son los siguientes:

- Barras de CFRP arenadas, corrugadas, texturizadas y acero corrugadas de $750 \mathrm{~mm}$ de longitud (Fig. 3.46), cuyas características geométricas y mecánicas se encuentran definidas en los aparts. 3.2 y 3.4 .1 .
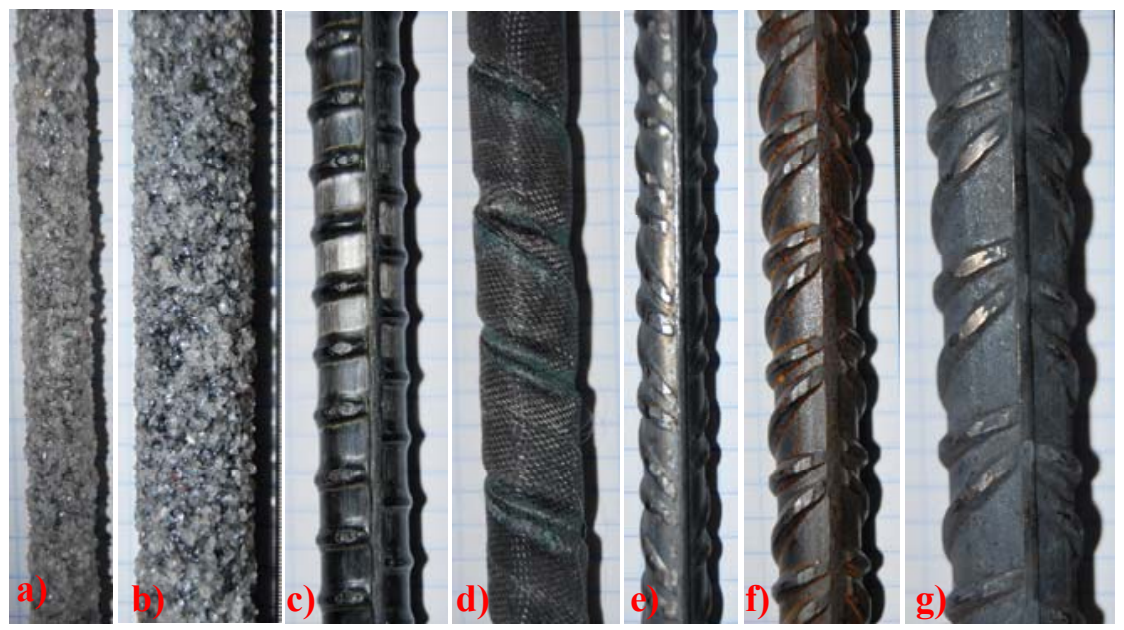

Fig. 3.46 Barras de CFRP: a) arenada "CA8"; b) arenada "CA14"; c) Corrugada "CC12"; d) Texturizada "CT13"; y de acero: e) Corrugada "A8"; f) Corrugada "A12"; g) Corrugada "A16".

- Anclajes de barras de tubo de acero electrosoldado de $300 \mathrm{~mm}$ de longitud (propiedades mecánicas y geométricas definidas en apart. 3.3.2) y material adherente entre barra y tubo a base de resina de epoxi de la marca Sika modelo Sikadur 42 (propiedades mecánicas y dosificación definidas en apart. 3.3.3).

- Cánula a base de tubo de P.V.C corrugado de la marca LEXMAN de 20 y $25 \mathrm{~mm}$ de diámetro, resistente a temperaturas entre $-5^{\circ} \mathrm{C}$ a $90{ }^{\circ} \mathrm{C}$. 
- Moldes de probetas de pullout conforme a ACI.440.3R-04 y UNE-EN 12390-1. Con este tipo de moldes no es necesario el pulido o refrentado de la cara de la probeta en contacto con la placa de ensayo debido a que la cara donde se encuentra la barra corresponde a una de las caras del molde (Fig. 3.47).

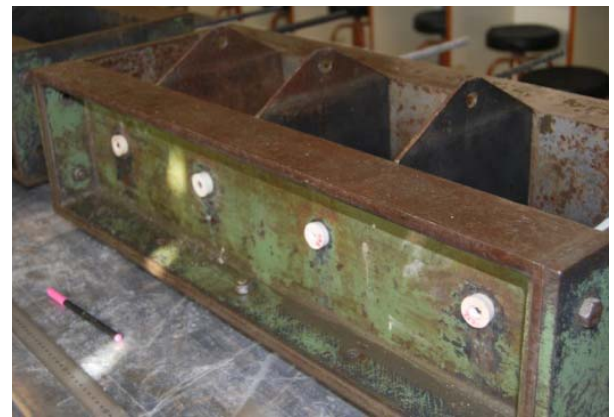

Fig. 3.47 Molde de fabricación de probetas de pullout.

Para el empleo de este tipo de moldes se ha diseñado unos tapones de goma para cada tipo y diámetro de barra (Fig. 3.47).

- Émbolo metálico para sujeción de 3 LVDT en el extremo tensionado dispuestos a $120^{\circ}$ (Fig. 3.48).
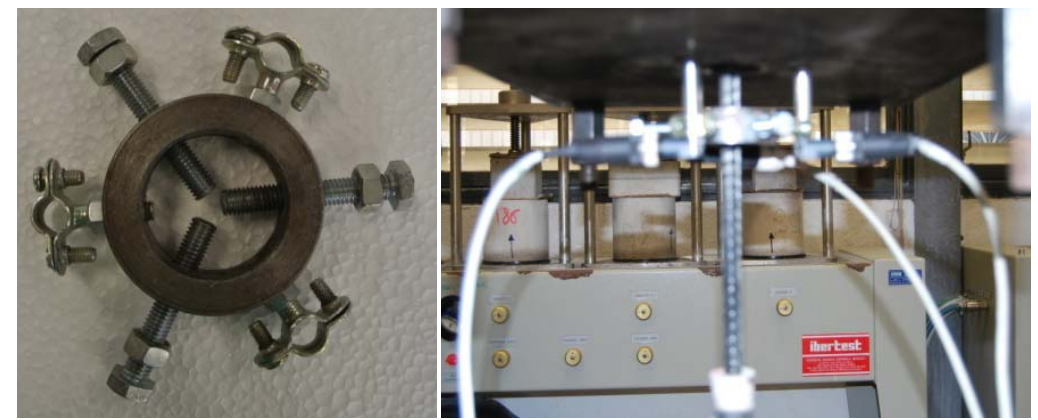

Fig. 3.48 Émbolo de sujeción de LVDT's en el extremo tensionado.

- 3 LVDT de la marca Schreiber modelo SM222.20.2.S Sc.Nr:23887 situados en el émbolo, más 1 LVDT de la marca HBM Tipo:WA/50mm $\mathrm{N}^{\circ} 060710247$ situado en el extremo tensionado. 
- Placa metálica de sujeción del LVDT en el extremo no tensionado (Fig. 3.49.a).
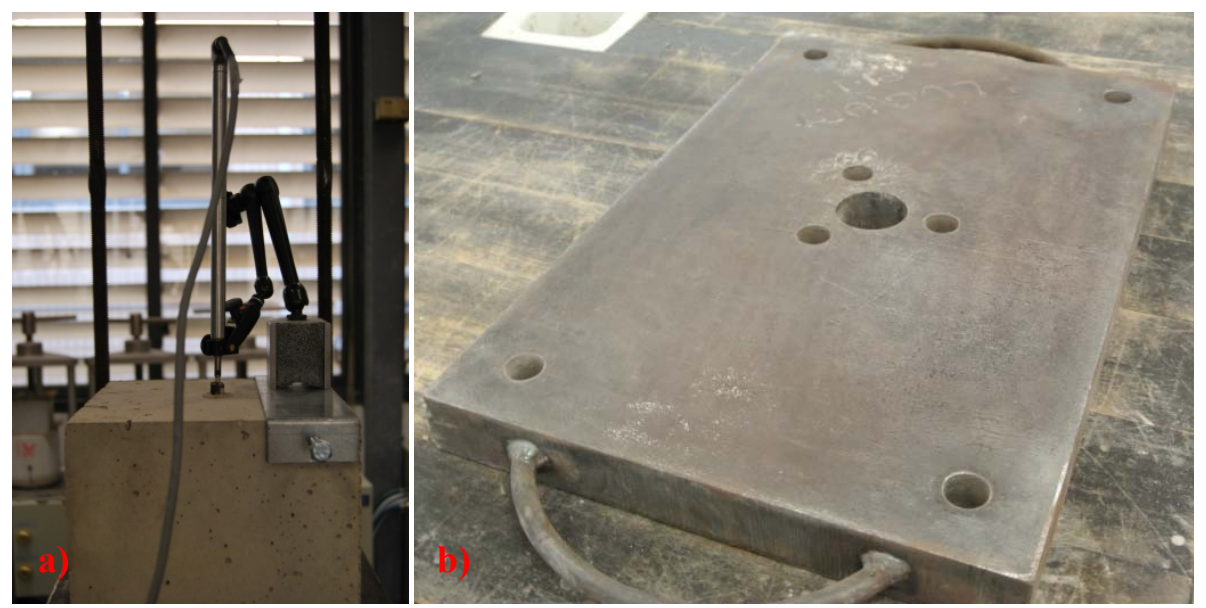

Fig. 3.49. a) Placa de sujeción captador extremo no tensionado; b) Placa de sujeción de probetas de pullout.

- Placa de acero de $50 \mathrm{~mm}$ de espesor para sujeción de probetas durante el ensayo de pullout (Fig. 3.49.b).

- Cámara climática para curado de probetas a $20 \pm 2{ }^{\circ} \mathrm{C}$ y H.R. $>95 \%$ (Fig. 3.50.a).
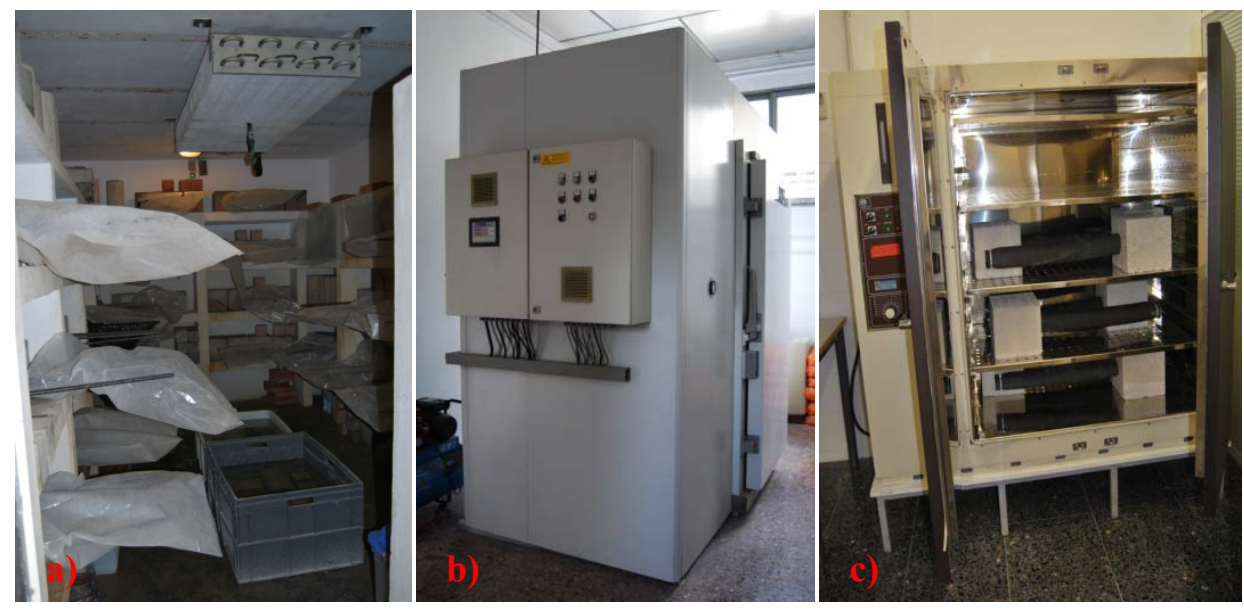

Fig. 3.50. a) Cámara de curado; b) Cámara climática de condición 5,20 y $40{ }^{\circ} \mathrm{C}$; c) Cámara climática de condición $80^{\circ} \mathrm{C}$. 
- Cámaras climáticas: a) Para la condición climática de $5{ }^{\circ} \mathrm{C}$, $20{ }^{\circ} \mathrm{C}$ y $40{ }^{\circ} \mathrm{C}$ cámara de la marca CTS modelo CW10/4 (Fig. 3.50.b); b) Para la condición climática de $80{ }^{\circ} \mathrm{C}$ cámara climática de la marca P.Selecta modelo Conterm (Fig. 3.50.c); c) Para la condición de Hielo/Deshielo a $-20{ }^{\circ} \mathrm{C}$ se emplea el arcón frigorífico de la marca Zanussi modelo ZA38 (Fig. 3.51).
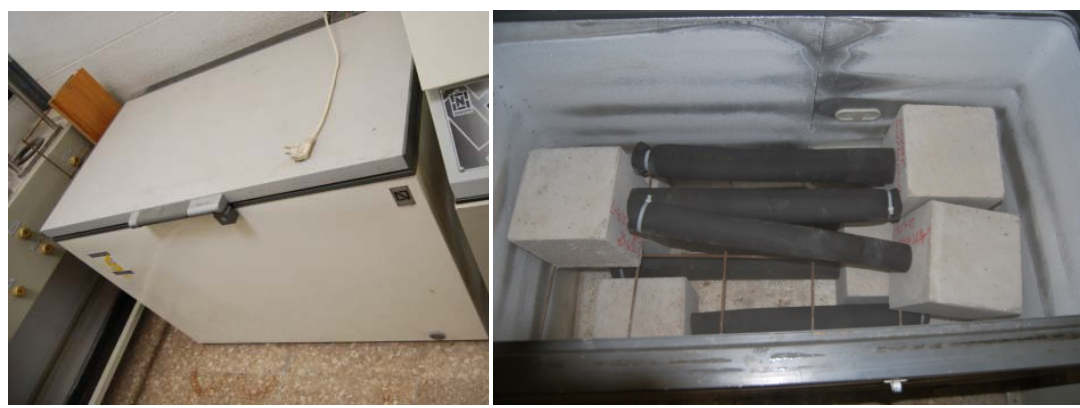

Fig. 3.51. Arcón frigorífico para condición climática de Hielo/Deshielo a $-20^{\circ} \mathrm{C}$.

- Prensa de ensayo de pullout de la marca Ibertest modelo UIB 600 DAU (fuerza aplicada máxima de $600 \mathrm{kN}$ ) con adaptación de la placa de sujeción diseñada (Fig. 3.52.a). La lectura de los LVDT se realiza mediante un módulo de la marca MBM modelo Spider 8 .
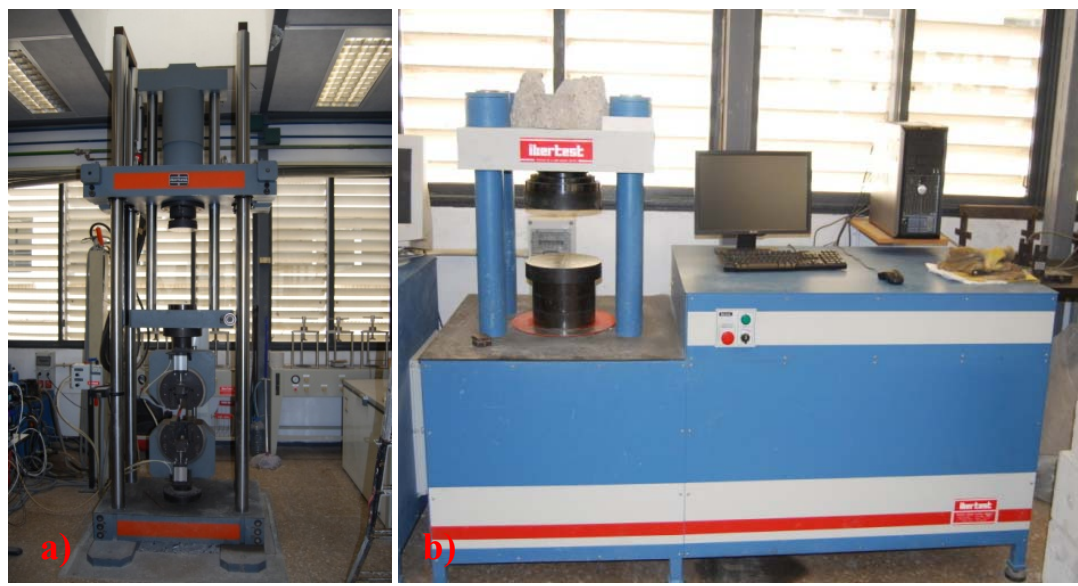

Fig. 3.52. Máquinas de ensayo: a) Prensa pullout; b) Prensa compresión. 
- Prensa de ensayo a compresión del hormigón de la marca Ibertest modelo MEI-1500-SW, con una fuerza aplicada máxima de $1500 \mathrm{kN}$ (Fig. 3.52.b).

La metodología y el procedimiento seguido para la realización de cada ensayo de pullout es el siguiente:

I. Selección aleatoria y corte de cada tipo de barra a la longitud de $750 \mathrm{~mm}$. Preparación de las barras mediante la colocación de una cánula de PVC que define la longitud adherente (Tabla 3.34). Disposición de cada tipo de barra en los moldes de pullout en el orden establecido por el plan de ensayo y colocación de tapones y aceite desencofrante en cada molde (Fig. 3.53).

\begin{tabular}{|c|c|c|c|}
\hline Tipo de barra & $\mathrm{d}_{\mathrm{b}}(\mathrm{mm})$ & $\mathrm{L}_{\mathrm{adh}}(\mathrm{mm})$ & $\mathrm{L}_{\text {cánula }}(\mathrm{mm})$ \\
\hline CA8 & 8,27 & 42 & 158 \\
\hline CA14 & 13,69 & 69 & 131 \\
\hline CC12 & 10,61 & 54 & 146 \\
\hline CT13 & 11,55 & 58 & 142 \\
\hline A8 & 8,02 & 40 & 160 \\
\hline A12 & 12,25 & 61 & 139 \\
\hline A16 & 16,06 & 80 & 120 \\
\hline
\end{tabular}

Tabla 3.34. Dimensiones de $d_{b}, L_{a d h}$ y $L_{\text {cánula }}$.
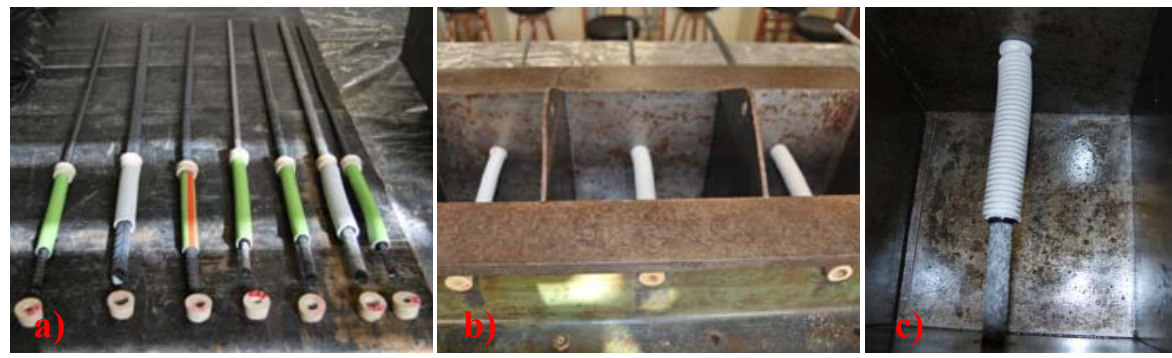

Fig. 3.53. Preparación de moldes y barras para vertido de hormigón: a) Orden de fabricación de probetas, cánulas y tapones; b) Moldes preparados; c) Interior molde pullout preparado.

II. Fabricación del hormigón de $f_{c}$ igual a $30 \mathrm{MPa}$, ensayo de consistencia y posterior vertido en los moldes de pullout y 
probetas de control del hormigón a compresión según las disposiciones de cada normativa (Fig.3.54). La compactación de las probetas de pullout y compresión se realiza mediante vibrador eléctrico.
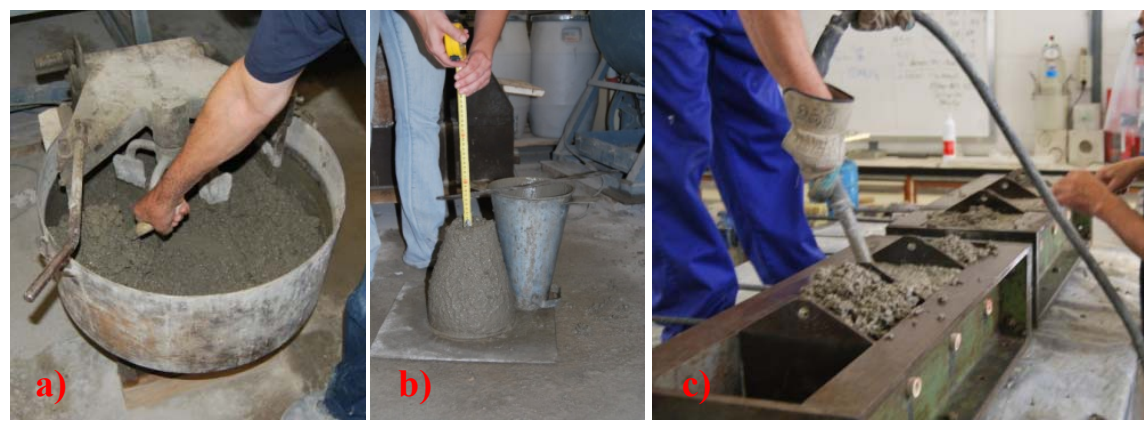

Fig. 3.54. a) Fabricación de hormigón; b) Ensayo de consistencia; c) Vertido y compactado de hormigón.

III. 24 horas después de la fabricación se desmoldan y marcan las probetas de pullout y control del hormigón (Fig. 3.55). Posteriormente se introducen en la cámara de curado a temperatura de $20 \pm 2{ }^{\circ} \mathrm{C}$ y H.R. $>95 \%$ de H.R.
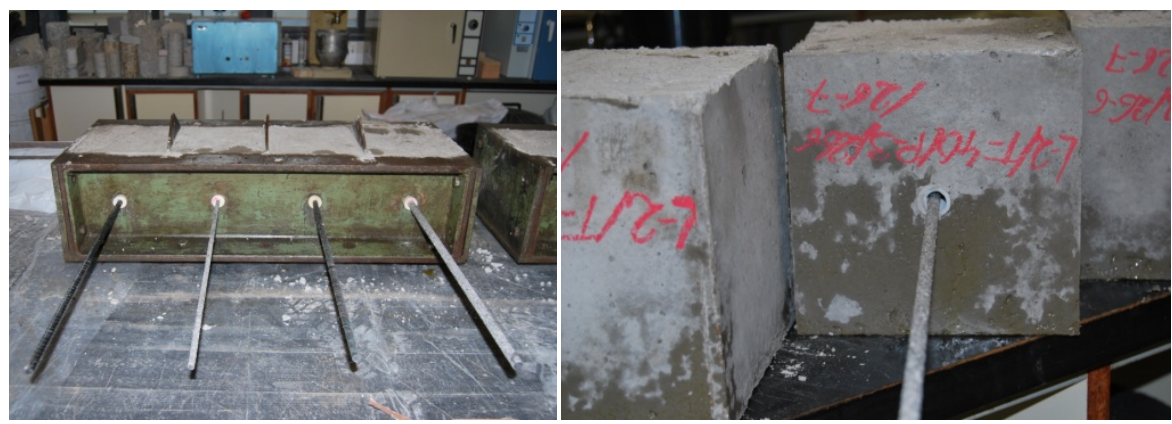

Fig. 3.55. Desmoldado y marcado de las probetas de pullout y control de hormigón.

IV. A los 26 días de edad se extraen las probetas de pullout de la cámara de curado, se fabrican los anclajes de las barras de CFRP (la longitud de cada anclaje, material adherente y dosificación se han definido en los aparts. 3.3.2 y 3.3.3, respectivamente) y se 
mantienen durante 48 horas (curado de la resina polimérica de los anclajes) a temperatura controlada de $20 \pm 2{ }^{\circ} \mathrm{C}$ (Fig. 3.56.a).
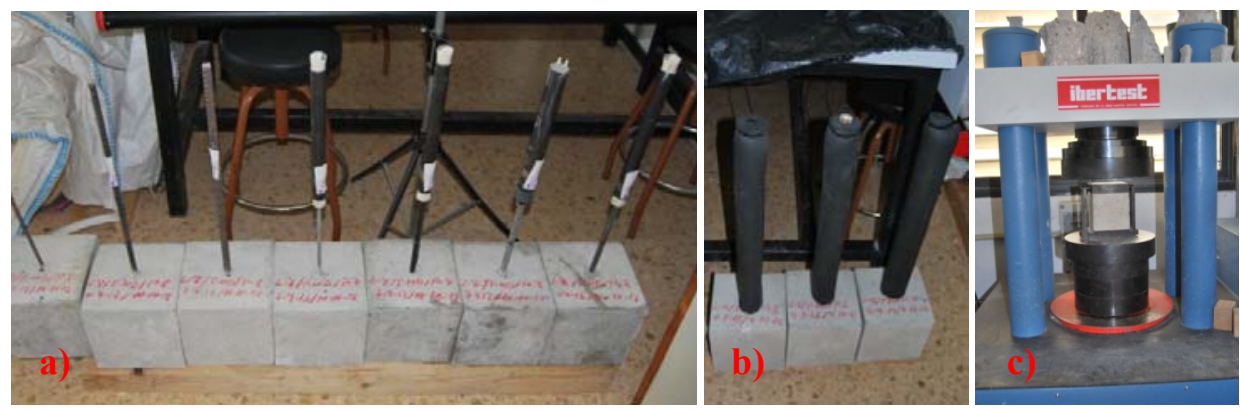

Fig. 3.56. a) Fabricación de anclajes; b) Colocación de aislante térmico en probetas de pullout; C) Ensayo de compresión en probetas de control del hormigón.

V. A los 28 días de edad se ensayan las probetas de control del hormigón a compresión (Fig. 3.56.c) y se preparan las probetas de pullout mediante la colocación de un tubo aislante ${ }^{41}$ de 25 $\mathrm{mm}$ de espesor en toda la longitud de las barras de pullout, con la finalidad de proteger los anclajes durante el tratamiento térmico (Fig. 3.56.b). Posteriormente se insertan las probetas de pullout en la cámara climática que corresponda según el tratamiento térmico (véase apart. 3.4.2 "materiales y máquinas empleados") y se mantienen durante un periodo de 48 horas en el caso de los tratamientos de $5{ }^{\circ} \mathrm{C}, 20^{\circ} \mathrm{C}, 40^{\circ} \mathrm{C}$ y $80{ }^{\circ} \mathrm{C}$, o 5 días en el caso de la condición de Hielo/Deshielo (48 h. a $-20^{\circ} \mathrm{C}$ +24 h. a $20^{\circ} \mathrm{C}+48$ h. a $\left.-20^{\circ} \mathrm{C}\right)$.

VI. Tras el ciclo térmico de cada lote de ensayo a pullout se extraen las probetas de la cámara climática, se insertan en cajas térmicas (en el caso de las probetas sometidas a condición de Hielo/Deshielo no es necesaria, véase apart. 3.3.1) (Fig. 3.57.a) y se procede al ensayo de pullout de las mismas (Fig. 3.57.b). La

\footnotetext{
${ }^{41}$ El aislante es de la marca Armaflex modelo IT con una conductividad térmica de 0,039 W/mK y temperatura de trabajo del orden de -50 a $105^{\circ} \mathrm{C}$
} 
velocidad de ensayo empleada es de $100 \mathrm{MPa} / \mathrm{min}$ y el número de registros por segundo es de 5 .
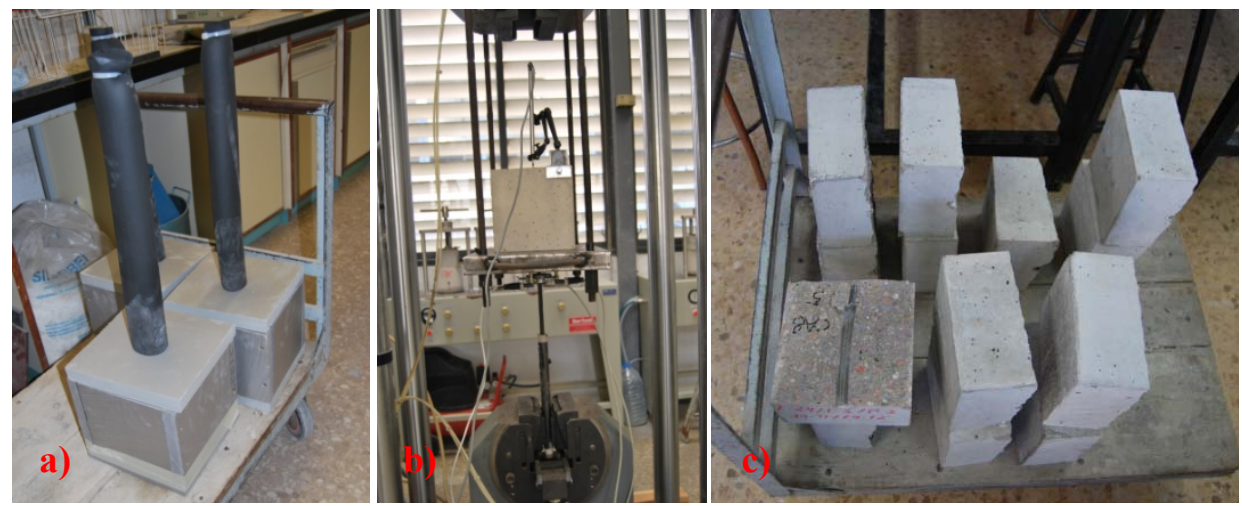

Fig. 3.57. a) Caja térmica; b) Ensayo de pullout; C) Rotura de las probetas de pullout por la mitad.

VII. Una vez realizado el ensayo de pullout se rompen las probetas por la mitad (Fig. 3.57.c), se mide el diámetro resultante de cada probeta mediante un calibre $e^{42}$ y se obtienen imágenes de la longitud adherente de las barras y zona adherente de la probeta de hormigón mediante cámara digital.

VIII. Posteriormente se obtienen imágenes de la superficie adherente de las probetas de hormigón mediante un microscopio digital de la marca PCE modelo MM200.

IX. Finalmente se obtienen imágenes de la longitud adherente de las barras mediante un microscopio de la marca Nikon modelo SMZ-10A.

La codificación empleada para la denominación de las probetas de pullout es la siguiente:

\section{Tipo de Ensayo / Número de Lote / Tratamiento Térmico / Posición de Ensayo y Fabricación / Tipo de Barra}

\footnotetext{
42 El calibre digital es de la marca marca Powerfix modelo Z22855F versión 7/2008 con una precisión de $0,01 \mathrm{~mm}$.
} 
Por ejemplo:

\section{EPU / L-3 / T-5 / P-1 / CC12}

Corresponde al ensayo de pullout de la probeta del lote 3 cuyo tratamiento térmico es de $5{ }^{\circ} \mathrm{C}$ durante 48 horas, su posición de fabricación y ensayo es la número $1^{\mathrm{a}} \mathrm{y}$ el tipo de barra es $\mathrm{CC} 12$.

En el caso de las probetas de control del hormigón la denominación es distinta a las probetas de pullout:

\section{Lote-Sublote / Fecha de Fabricación / Fecha de Ensayo}

Por ejemplo:

\section{L-1.2 / 25-6-12 / 23-7-12}

Corresponde a la probeta del lote 1 cuya posición de fabricación y ensayo es la segunda, el día de fabricación es el 25/06/2012 y el día de ensayo a compresión el 23/07/2012.

En cuanto a la planificación de los ensayos de pullout se ha decidido emplear un diseño Split-Plot ${ }^{43}$, debido a que con este diseño se obtiene la comparación entre varios factores y la interacción entre ellos con un menor número de ensayos (se divide en lotes y sublotes) y al mismo tiempo los efectos de interés pueden estimarse con un menor error (presenta dos varianzas distintas: una en lotes y otra en sublotes, además todas las interacciones presentan el mismo error del sublote) que con un diseño factorial (una sola varianza y fuente de error influyendo sobre las diferencias entre factores).

\footnotetext{
${ }^{43}$ La denominación anglosajona Split-Plot, en castellano "lotes subdivididos", se mantiene en esta investigación, puesto que es el término generalizado y conocido.
} 


\begin{tabular}{|c|c|c|c|c|c|c|c|c|}
\hline \multirow{2}{*}{$\begin{array}{l}\mathrm{N}^{\mathrm{o}} \\
\text { Lote }\end{array}$} & \multirow{2}{*}{$\begin{array}{c}\text { Lotes } \\
\text { (Temperaturas) }\end{array}$} & \multicolumn{7}{|c|}{$\begin{array}{c}\text { Sublotes (Tipos de barras y diámetros) / } \\
\text { Posición fabricación y ensayo }\end{array}$} \\
\hline & & CA8 & CA14 & $\mathrm{CC12}$ & CT13 & A8 & A12 & A16 \\
\hline 1 & 20 & 2 & 4 & 1 & 3 & 7 & 6 & 5 \\
\hline 2 & 40 & 3 & 5 & 2 & 6 & 4 & 1 & 7 \\
\hline 3 & 5 & 6 & 3 & 1 & 4 & 7 & 5 & 2 \\
\hline 4 & H/D & 4 & 2 & 7 & 3 & 1 & 5 & 6 \\
\hline 5 & 20 & 6 & 3 & 7 & 4 & 5 & 2 & 1 \\
\hline 6 & 80 & 1 & 4 & 2 & 3 & 7 & 6 & 5 \\
\hline 7 & 40 & 2 & 5 & 6 & 1 & 4 & 3 & 7 \\
\hline 8 & H/D & 7 & 3 & 4 & 2 & 5 & 6 & 1 \\
\hline 9 & 5 & 4 & 2 & 7 & 6 & 1 & 5 & 3 \\
\hline 10 & 80 & 6 & 2 & 1 & 5 & 4 & 3 & 7 \\
\hline 11 & 20 & 3 & 7 & 5 & 6 & 2 & 1 & 4 \\
\hline 12 & H/D & 1 & 5 & 2 & 3 & 6 & 7 & 4 \\
\hline 13 & 40 & 3 & 6 & 5 & 1 & 2 & 4 & 7 \\
\hline 14 & 20 & 7 & 5 & 4 & 2 & 3 & 1 & 6 \\
\hline 15 & 40 & 5 & 6 & 2 & 3 & 1 & 7 & 4 \\
\hline 16 & H/D & 2 & 7 & 4 & 3 & 6 & 5 & 1 \\
\hline 17 & 80 & 6 & 5 & 3 & 4 & 1 & 2 & 7 \\
\hline 18 & H/D & 7 & 4 & 2 & 5 & 6 & 3 & 1 \\
\hline 19 & 40 & 2 & 6 & 7 & 4 & 3 & 1 & 5 \\
\hline 20 & 5 & 1 & 3 & 4 & 7 & 2 & 5 & 6 \\
\hline 21 & 80 & 4 & 5 & 2 & 3 & 6 & 7 & 1 \\
\hline 22 & 20 & 6 & 2 & 3 & 7 & 5 & 1 & 4 \\
\hline 23 & 5 & 7 & 1 & 4 & 5 & 6 & 2 & 3 \\
\hline 24 & 5 & 3 & 6 & 2 & 1 & 4 & 5 & 7 \\
\hline 25 & 80 & 4 & 7 & 6 & 3 & 5 & 1 & 2 \\
\hline
\end{tabular}

Tabla 3.34. Diseño Split-Plot del plan de ensayos a pullout.

El diseño Split-Plot empleado en esta investigación consta de 175 ensayos a pullout (Tabla 3.34), en el cual los lotes son las 5 condiciones climáticas de ensayo, repetidos genuinamente en 5 ocasiones (ACI.440.3R-04 y ACI.440.6M-08 establecen un mínimo de 5 ensayos en cada condición para el control de propiedades mecánicas y de durabilidad), y los sublotes son los 7 tipos de barras CA8, CA14, CC12, CT13, A8, A12 y A16. La designación de lotes y sublotes, se debe a que la mayor restricción de ensayo es el número de probetas fabricadas por amasada, $\mathrm{n}^{\mathrm{o}} \leq 7$ (otras restricciones son: el número 
máximo de ensayos durante un día $\mathrm{n}^{\mathrm{0}} \leq 12$ ensayos, y la cuantía de probetas introducidas en cada cámara climática $\mathrm{n}^{\circ} \leq 12$ en cámara de $80^{\circ} \mathrm{C}$ y $\mathrm{n}^{\circ} \leq 8$ en arcón frigorífico). Al mismo tiempo, en este diseño se ha aleatorizado la posición de ensayo de cada lote (temperatura) y la posición de fabricación y ensayo de cada sublote (tipo de barra) dentro de cada lote, consiguiendo de este modo:

- una homogenización del error residual y del efecto de ruido sobre la respuesta de cada lote y sublote.

- la eliminación de una posible correlación seriada de los resultados debida a los lotes y sublotes (factor que invalidaría los resultados).

\begin{tabular}{|c|c|c|c|}
\hline \multirow{2}{*}{$\begin{array}{c}\text { Lote } \\
\mathbf{1}\end{array}$} & \multicolumn{3}{|c|}{ Posición Fabricación/Ensayo } \\
\hline & 2 & 1 & 3 \\
\hline 2 & 3 & 2 & 1 \\
\hline 3 & 2 & 3 & 1 \\
\hline 4 & 3 & 1 & 2 \\
\hline 5 & 2 & 1 & 3 \\
\hline 6 & 3 & 1 & 2 \\
\hline 7 & 2 & 3 & 1 \\
\hline 8 & 1 & 3 & 2 \\
\hline 9 & 1 & 2 & 3 \\
\hline 10 & 1 & 3 & 2 \\
\hline 11 & 2 & 1 & 3 \\
\hline 12 & 1 & 2 & 3 \\
\hline 13 & 2 & 3 & 1 \\
\hline 14 & 1 & 3 & 2 \\
\hline 15 & 3 & 2 & 1 \\
\hline 16 & 3 & 1 & 2 \\
\hline 17 & 2 & 3 & 1 \\
\hline 18 & 3 & 1 & 2 \\
\hline 19 & 2 & 3 & 1 \\
\hline 20 & 1 & 2 & 3 \\
\hline 21 & 1 & 3 & 2 \\
\hline 22 & 3 & 1 & 2 \\
\hline 23 & 1 & 3 & 2 \\
\hline 24 & 1 & 2 & 3 \\
\hline 25 & 3 & 2 & 1 \\
\hline
\end{tabular}

Tabla 3.35. Diseño del plan de ensayos de control del hormigón a compresión. 
Debido a que la resistencia del hormigón es un parámetro influyente en el comportamiento adherente, se realizan ensayos de control de resistencia a compresión del hormigón en cada amasada o lote de pullout. En cuanto al número de probetas de control del hormigón, la limitación fijada por el volumen de la hormigonera a $65-70 \mathrm{dm}^{3}$ y el número de probetas de ensayo a pullout, definido en 7 (volumen $=56 \mathrm{dm}^{3}$ ), originan que el número de probetas cúbicas de control de la resistencia a compresión sea de 3 probetas de 100 × 100 × 100 $\mathrm{mm}$. Por lo tanto, el plan de ensayos de control del hormigón, que consta de 75 probetas, se realiza mediante un diseño similar al de bloques aleatorizados; sin embargo, debido a que cada lote o amasada corresponde a un lote de ensayo a pullout, únicamente se ha aleatorizado la posición de fabricación y ensayo en cada lote (Tabla 3.35).

En la Tabla 3.36 se muestran los valores de la tensión adherente máxima " $\tau_{\max }$ ", las deformaciones en el extremo tensionado " $\delta_{\mathrm{ET}}$ " y no tensionado " $\delta_{\mathrm{ENT}}$ " y el modo de rotura, obtenidos mediante el ensayo de pullout en los diferentes tipos de barras de CFRP arenadas (CA8 y CA14), corrugadas (CC12) y texturizadas (CT13) y acero corrugadas (A8, A12 y A16), sometidas a los tratamientos térmicos de $\mathrm{H} / \mathrm{D}, 5{ }^{\circ} \mathrm{C}, 20^{\circ} \mathrm{C}, 40{ }^{\circ} \mathrm{C}$ y $80{ }^{\circ} \mathrm{C}$. Al mismo tiempo, también se define, para cada muestra de ensayo, la resistencia media a compresión " $f_{c}$ " (referida a probeta cilíndrica de 150 x $300 \mathrm{~mm}$ ) de cada lote o amasada.

\begin{tabular}{|c|c|c|c|c|c|c|}
\hline Muestra & $\begin{array}{c}f c \\
(\mathrm{MPa})\end{array}$ & $\begin{array}{c}\tau_{\max } \\
(\mathrm{MPa})\end{array}$ & $\begin{array}{c}\delta_{\mathrm{ENT}} \\
(\mathrm{mm})\end{array}$ & $\begin{array}{c}\delta_{\mathrm{ET}} \\
(\mathrm{mm})\end{array}$ & $\begin{array}{l}\text { Modo } \\
\text { rotura }\end{array}$ & Observaciones \\
\hline EPU/L4/THD/P4/CA8 & 37,58 & 9,2778175 & 0,0861 & 0,2869 & RA & \multirow{8}{*}{$\begin{array}{l}1^{\mathrm{er}} \mathrm{cm} . \text { de geometría } \\
\text { intacto. El resto cortado. } \\
1^{\mathrm{er}} \mathrm{cm} \text {. de geometría } \\
\text { intacto. El resto cortado }\end{array}$} \\
\hline EPU/L8/THD/P7/CA8 & 39,59 & 13,1768812 & 0,0531 & 0,1906 & RA & \\
\hline EPU/L12/THD/P1/CA8 & 35,66 & 11,5062845 & 0,0547 & 0,2341 & RA & \\
\hline EPU/L16/THD/P2/CA 8 & 37,34 & 10,5854816 & 0,0902 & 0,1931 & RA & \\
\hline EPU/L18/THD/P7/CA8 & 37,06 & 13,2418971 & 0,0625 & 0,2437 & RA & \\
\hline EPU/L3/T5/P6/CA8 & 40,91 & 8,4081735 & 0,0436 & 0,1600 & RA & \\
\hline EPU/L9/T5/P4/CA8 & 37,69 & 11,9426428 & 0,0764 & 0,3859 & RA & \\
\hline EPU/L20/T5/P1/CA8 & 42,55 & 10,7766998 & 0,0774 & 0,3098 & RA & \\
\hline
\end{tabular}




\begin{tabular}{|c|c|c|c|c|}
\hline EPU/L23/T5/P7/CA8 & 42,25 & 11,4326847 & 0,0874 & 0,2185 \\
\hline EPU/L24/T5/P3/CA8 & 40,73 & 11,7221642 & 0,0425 & 0,8321 \\
\hline EPU/L1/T20/P2/CA8 & 34,93 & 9,1338290 & 0,0009 & 0,1553 \\
\hline EPU/L5/T20/P6/CA8 & 44,60 & 8,4814773 & 0,0471 & 0,3395 \\
\hline EPU/L11/T20/P3/CA8 & 36,84 & 8,9667051 & 0,0748 & 0,1730 \\
\hline EPU/L14/T20/P7/CA8 & 37,13 & 7,9798860 & 0,0008 & 0,2151 \\
\hline EPU/L22/T20/P6/CA 8 & 42,31 & 11,1897525 & 0,0664 & 0,1877 \\
\hline EPU/L2/T40/P3/CA8 & 38,06 & 8,2003747 & 0,0514 & 0,2199 \\
\hline EPU/L7/T40/P2/CA8 & 36,69 & 7,5237775 & 0,0444 & 0,2657 \\
\hline EPU/L13/T40/P3/CA8 & 39,04 & 7,9032540 & 0,0241 & 0,1372 \\
\hline EPU/L15/T40/P5/CA8 & 38,43 & 7,3792118 & 0,0352 & 0,1785 \\
\hline EPU/L19/T40/P2/CA 8 & 39,31 & 6,3593708 & 0,0347 & 0,1286 \\
\hline EPU/L6/T80/P1/CA8 & 39,57 & 7,2053052 & 0,0179 & 0,1235 \\
\hline EPU/L10/T80/P6/CA8 & 38,73 & 8,8074717 & 0,0441 & 0,3337 \\
\hline EPU/L17/T80/P6/CA8 & 40,96 & 6,1856144 & 0,0558 & 0,3015 \\
\hline EPU/L21/T80/P4/CA8 & 39,75 & 8,2773200 & 0,0506 & 0,3481 \\
\hline EPU/L25/T80/P4/CA8 & 43,31 & 5,7305401 & 0,0638 & 0,2409 \\
\hline EPU/L4/THD/P2/CA14 & 37,58 & 16,1851204 & 0,2441 & 0,5058 \\
\hline EPU/L8/THD/P3/CA14 & 39,59 & 16,9511607 & 152 & 0,4721 \\
\hline EPU/L12/THD/P5/CA14 & 35,66 & 17,1620284 & 0,5723 & 0,7503 \\
\hline EPU/L16/THD/P7/CA14 & 37,34 & 16,1953775 & 0,1397 & 0,4311 \\
\hline EPU/L18/THD/P4/CA14 & 37,06 & 18,2100826 & 0,1151 & 0,4954 \\
\hline EPU/L3/T5/P3/CA14 & 40,91 & 14,9320549 & 0,1662 & 0,3010 \\
\hline EPU/L9/T5/P2/CA14 & 37,69 & 15,6998474 & 0,3746 & 0,7878 \\
\hline EPU/L20/T5/P3/CA14 & 42,55 & 15,5617366 & 0,1030 & 0,5101 \\
\hline EPU/L23/T5/P1/CA14 & 42,25 & 14,6594152 & 0,1674 & 0,5428 \\
\hline EPU/L24/T5/P6/CA14 & 40,73 & 16,2776402 & 0,1598 & 0,6426 \\
\hline EPU/L1/T20/P4/CA14 & 34,93 & 10,7990053 & 0,2899 & 0,6910 \\
\hline EPU/L5/T20/P3/CA14 & 44,60 & 14,6063437 & 0,0852 & 0,2771 \\
\hline EPU/L11/T20/P7/CA14 & 36,84 & 12,3240062 & 0,1863 & 0,4667 \\
\hline EPU/L14/T20/P5/CA14 & 37,13 & 13,7239907 & 0,2630 & 0,4957 \\
\hline EPU/L22/T20/P2/CA14 & 42,31 & 14,8538897 & 0,1294 & 0,3441 \\
\hline EPU/L2/T40/P5/CA14 & 38,06 & 12,0058598 & 0,1183 & 0,5320 \\
\hline EPU/L7/T40/P5/CA14 & 36,69 & 11,2282583 & 0,1146 & 0,2153 \\
\hline EPU/L13/T40/P6/CA14 & 39,04 & 13,8289410 & 0,0654 & 0,4543 \\
\hline EPU/L15/T40/P6/CA14 & 38,43 & 10,1196891 & 0,0282 & 0,3082 \\
\hline EPU/L19/T40/P6/CA14 & 39,31 & 10,7287891 & 0,1106 & 0,4035 \\
\hline EPU/L6/T80/P4/CA14 & 39,57 & 11,8031466 & 0,0973 & 0,4176 \\
\hline EPU/L10/T80/P2/CA14 & 38,73 & 11,3899936 & 0,1447 & 0,5160 \\
\hline
\end{tabular}

$1^{\text {er }} \mathrm{cm}$. de geometría intacto. El resto cortado

$5 \mathrm{~cm}$ iniciales de geometría intactos. El resto cortados.

$3 \mathrm{~cm}$ iniciales de geometría intactos. El resto cortados.

$1^{\text {er }} \mathrm{cm}$. de geometría intacto. El resto cortado

$1^{\text {er }} \mathrm{cm}$. de geometría intacto. El resto cortado $2 \mathrm{~cm}$ iniciales de geometría intactos. El resto cortados.

$1^{\text {er }} \mathrm{cm}$. de geometría intacto. El resto cortado $1,5 \mathrm{~cm}$. iniciales de geometría intactos. El resto cortado.

$1^{\text {er }} \quad \mathrm{cm}$. inicial de geometría intacto. El resto cortado.

$2,5 \mathrm{~cm}$ iniciales de geometría intactos. El resto cortados. 


\begin{tabular}{|c|c|c|c|c|c|c|}
\hline EPU/L17/T80/P5/CA14 & 40,96 & 13,9654816 & 0,1369 & 0,4847 & RA & $\begin{array}{lll}1^{\text {er }} \mathrm{cm} . \quad \text { inicial } & \text { de } \\
\text { geometría intacto. } & \text { El } \\
\text { resto cortado. } & \end{array}$ \\
\hline EPU/L25/T80/P7/CA14 & 43,31 & 13,9703743 & 0,1313 & 0,3550 & RA & \\
\hline EPU/L4/THD/P7/CC12 & 37,58 & 19,2610584 & 1,3545 & 1,9218 & $\mathrm{RC}$ & $\begin{array}{l}\text { Las } 5 \text { primeras corrugas } \\
\text { intactas. Rotura parcial } 3 \\
\text { últimas. Total } 8 \text { corrugas. }\end{array}$ \\
\hline EPU/L8/THD/P4/CC12 & 39,59 & 20,7202787 & 1,9593 & 2,4644 & $\mathrm{RC}$ & $\begin{array}{l}\text { Las } 4 \text { primeras corrugas } \\
\text { intactas. Rotura parcial } 4 \\
\text { últimas. Total } 8 \text { corrugas }\end{array}$ \\
\hline EPU/L12/THD/P2/CC12 & 35,66 & 19,0971237 & 1,4668 & 2,0665 & $\mathrm{RC}$ & $\begin{array}{l}\text { Las } 5 \text { primeras corrugas } \\
\text { intactas. Rotura parcial } 3 \\
\text { últimas. Total } 8 \text { corrugas. }\end{array}$ \\
\hline EPU/L16/THD/P4/CC12 & 37,34 & 22,3801655 & 1,6622 & 1,9794 & $\mathrm{RC}$ & $\begin{array}{l}\text { Las } 4 \text { primeras corrugas } \\
\text { intactas. Rotura parcial } 4 \\
\text { últimas. Total } 8 \text { corrugas }\end{array}$ \\
\hline EPU/L18/THD/P2/CC12 & 37,06 & 21,1864346 & 1,5612 & 2,2983 & $\mathrm{RC}$ & $\begin{array}{l}\text { Las } 4 \text { primeras corrugas } \\
\text { intactas. Rotura parcial } 4 \\
\text { últimas. Total } 8 \text { corrugas }\end{array}$ \\
\hline EPU/L3/T5/P1/CC12 & 40,91 & 24,5557277 & 1,1242 & 1,4451 & RA & Toda corruga cortada \\
\hline EPU/L9/T5/P7/CC12 & 37,69 & 17,0744517 & 1,0322 & 1,3108 & $\mathrm{RC}$ & $\begin{array}{l}\text { Las } 3 \text { primeras corrugas } \\
\text { intactas. Rotura } 5 \text { últimas }\end{array}$ \\
\hline EPU/L20/T5/P4/CC12 & 42,55 & 20,2968738 & 1,1262 & 1,4685 & RA & $\begin{array}{l}1^{\text {a }} \text { corruga intacta. El } \\
\text { resto cortadas. }\end{array}$ \\
\hline EPU/L23/T5/P4/CC12 & 42,25 & 21,6004831 & 1,0453 & 1,5298 & RA & $\begin{array}{l}1^{\text {a }} \text { corruga intacta. El } \\
\text { resto cortadas. }\end{array}$ \\
\hline EPU/L24/T5/P2/CC12 & 40,73 & 19,3044589 & 1,4733 & 1,8131 & $\mathrm{RC}$ & $\begin{array}{l}3 \text { primeras corrugas al } \\
60 \% \text {. El resto cortadas. }\end{array}$ \\
\hline EPU/L1/T20/P1/CC12 & 34,93 & 17,1974568 & 1,3239 & 1,4059 & $\mathrm{RC}$ & $\begin{array}{l}4 \text { primeras corrugas al } \\
60 \% \text {. El resto cortadas. }\end{array}$ \\
\hline EPU/L5/T20/P7/CC12 & 44,60 & 20,9389000 & 0,8825 & 1,1443 & RA & $\begin{array}{l}1^{\text {a }} \text { corruga intacta. El } \\
\text { resto cortadas. }\end{array}$ \\
\hline EPU/L11/T20/P5/CC12 & 36,84 & 18,1848020 & 1,3325 & 2,1304 & $\mathrm{RC}$ & $\begin{array}{l}2 \text { primeras corrugas } \\
\text { intactas.El resto cortadas. }\end{array}$ \\
\hline EPU/L14/T20/P4/CC12 & 37,13 & 17,0391582 & 1,4355 & 1,9478 & RA & $\begin{array}{l}1^{\text {a }} \text { corruga intacta. El } \\
\text { resto cortadas. }\end{array}$ \\
\hline EPU/L22/T20/P3/CC12 & 42,31 & 19,4935477 & 0,9581 & 1,5989 & RA & $\begin{array}{l}1^{\mathrm{a}} \text { corruga intacta. El } \\
\text { resto cortadas. }\end{array}$ \\
\hline EPU/L2/T40/P2/CC12 & 38,06 & 19,9966905 & 1,0696 & 1,3183 & RA & Todas corrugas cortadas \\
\hline EPU/L7/T40/P6/CC12 & 36,69 & 17,5489533 & 0,9703 & 1,2306 & RA & $\begin{array}{l}1^{\text {a }} \text { corruga intacta. El } \\
\text { resto cortadas. }\end{array}$ \\
\hline EPU/L13/T40/P5/CC12 & 39,04 & 17,5795935 & & 1,3508 & RA & Todas corrugas cortadas \\
\hline EPU/L15/T40/P2/CC12 & 38,43 & 17,0453384 & 0,7047 & 0,9835 & RA & Todas corrugas cortadas \\
\hline EPU/L19/T40/P7/CC12 & 39,31 & 18,9887001 & 0,8862 & 1,4786 & RA & Todas corrugas cortadas \\
\hline EPU/L6/T80/P2/CC12 & 39,57 & 12,3829363 & 0,6313 & 0,8466 & RA & Todas corrugas cortadas \\
\hline EPU/L10/T80/P1/CC12 & 38,73 & 11,7739963 & 0,4650 & 0,8700 & RA & Todas corrugas cortadas \\
\hline EPU/L17/T80/P3/CC12 & 40,96 & 13,0954079 & 0,5529 & 1,1891 & RA & Todas corrugas cortadas \\
\hline EPU/L21/T80/P2/CC12 & 39,75 & 11,4876229 & 0,5644 & 0,7669 & RA & Todas corrugas cortadas \\
\hline EPU/L25/T80/P6/CC12 & 43,31 & 13,5547599 & 0,5528 & 0,9997 & RA & Todas corrugas cortadas \\
\hline EPU/L4/THD/P3/CT13 & 37,58 & 10,5060908 & 2,6542 & 2,8462 & $\mathrm{PO}$ & \\
\hline EPU/L8/THD/P2/CT13 & 39,59 & 10,1342253 & 2,5377 & 2,6489 & $\mathrm{PO}$ & \\
\hline EPU/L12/THD/P3/CT13 & 35,66 & 10,2742895 & 4,3033 & 4,5157 & PO & \\
\hline EPU/L16/THD/P3/CT13 & 37,34 & 11,2369751 & 3,2294 & 3,4165 & PO & \\
\hline EPU/L18/THD/P5/CT13 & 37,06 & 9,9759885 & 5,8735 & 7,0480 & PO & \\
\hline EPU/L3/T5/P4/CT13 & 40,91 & 12,1804715 & 2,4389 & 2,8985 & $\mathrm{PO}$ & \\
\hline EPU/L9/T5/P6/CT13 & 37,69 & 8,3313205 & 2,7461 & 3,0037 & PO & \\
\hline
\end{tabular}




\begin{tabular}{|c|c|c|c|c|c|c|}
\hline EPU/L20/T5/P7/CT13 & 42,55 & 5,8644397 & 2,0266 & 2,2186 & $\mathrm{PO}$ & \\
\hline EPU/L23/T5/P5/CT13 & 42,25 & 9,5547695 & 3,4128 & 3,8219 & $\mathrm{PO}$ & \\
\hline EPU/L24/T5/P1/CT13 & 40,73 & 6,8002221 & 3,2591 & 3,6069 & $\mathrm{PO}$ & \\
\hline EPU/L1/T20/P3/CT13 & 34,93 & 5,2382294 & 1,4098 & 1,6169 & $\mathrm{PO}$ & \\
\hline EPU/L5/T20/P4/CT13 & 44,60 & 6,8204000 & 4,2996 & 4,5683 & $\mathrm{PO}$ & \\
\hline EPU/L11/T20/P6/CT13 & 36,84 & 5,4468600 & 2,0082 & 2,1071 & $\mathrm{PO}$ & \\
\hline EPU/L14/T20/P2/CT13 & 37,13 & 11,3871210 & 3,5573 & 3,9658 & $\mathrm{PO}$ & \\
\hline EPU/L22/T20/P7/CT13 & 42,31 & 10,6376270 & 3,7823 & 3,8746 & $\mathrm{PO}$ & \\
\hline EPU/L2/T40/P6/CT13 & 38,06 & 8,7214809 & 1,2298 & 3,4775 & $\mathrm{PO}$ & Daño en texturizado \\
\hline EPU/L7/T40/P1/CT13 & 36,69 & 6,6187322 & 4,5009 & 4,6818 & $\mathrm{PO}$ & Daño en texturizado \\
\hline EPU/L13/T40/P1/CT13 & 39,04 & 8,0281212 & 2,2111 & 2,6918 & $\mathrm{PO}$ & Daño en texturizado \\
\hline EPU/L15/T40/P3/CT13 & 38,43 & 6,0183579 & 4,5413 & 4,7358 & $\mathrm{PO}$ & Daño en texturizado \\
\hline EPU/L19/T40/P4/CT13 & 39,31 & 7,7428046 & 3,0706 & 3,2063 & $\mathrm{PO}$ & Daño en texturizado \\
\hline EPU/L6/T80/P3/CT13 & 39,57 & 7,1465826 & 5,3840 & 5,5279 & $\mathrm{PO}$ & Daño en texturizado \\
\hline EPU/L10/T80/P5/CT13 & 38,73 & 5,7785084 & 3,0230 & 3,2335 & $\mathrm{PO}$ & Daño en texturizado \\
\hline EPU/L17/T80/P4/CT13 & 40,96 & 7,3440674 & 3,9774 & 4,0632 & $\mathrm{PO}$ & Daño en texturizado \\
\hline EPU/L21/T80/P3/CT13 & 39,75 & 7,8360287 & 2,8355 & 3,2026 & $\mathrm{PO}$ & Daño en texturizado \\
\hline EPU/L25/T80/P3/CT13 & 43,31 & 7,4083437 & 3,1369 & 3,2033 & $\mathrm{PO}$ & Daño en texturizado \\
\hline EPU/L4/THD/P1/A8 & 37,58 & 16,1224217 & 1,6265 & 1,6803 & $\mathrm{PO}$ & \\
\hline EPU/L8/THD/P5/A8 & 39,59 & 23,4654701 & 1,5156 & 1,6564 & $\mathrm{PO}$ & \\
\hline EPU/L12/THD/P6/A8 & 35,66 & 19,3036989 & 1,5105 & 1,5948 & $\mathrm{PO}$ & \\
\hline EPU/L16/THD/P6/A8 & 37,34 & 24,1077350 & 1,6444 & 2,1014 & $\mathrm{PO}$ & \\
\hline EPU/L18/THD/P6/A8 & 37,06 & 20,7184451 & 1,2121 & 1,4725 & $\mathrm{PO}$ & \\
\hline EPU/L3/T5/P7/A8 & 40,91 & 16,7559000 & 1,1367 & 1,9016 & $\mathrm{PO}$ & \\
\hline EPU/L9/T5/P1/A8 & 37,69 & 12,3215986 & 0,9476 & 1,0129 & $\mathrm{PO}$ & \\
\hline EPU/L20/T5/P2/A8 & 42,55 & 20,2746232 & 0,8234 & 1,2085 & $\mathrm{PO}$ & \\
\hline EPU/L23/T5/P6/A8 & 42,25 & 22,0447541 & 1,0828 & 1,5952 & $\mathrm{PO}$ & \\
\hline EPU/L24/T5/P4/A8 & 40,73 & 18,0738001 & 0,7080 & 1,0777 & $\mathrm{PO}$ & \\
\hline EPU/L1/T20/P7/A8 & 34,93 & 14,8817268 & 0,7411 & 1,3566 & $\mathrm{PO}$ & \\
\hline EPU/L5/T20/P5/A8 & 44,60 & 21,9702000 & 1,2044 & 1,4184 & $\mathrm{PO}$ & \\
\hline EPU/L11/T20/P2/A8 & 36,84 & 13,9631396 & 0,9762 & 1,2713 & $\mathrm{PO}$ & \\
\hline EPU/L14/T20/P3/A8 & 37,13 & 18,9250397 & 1,0801 & 1,3344 & $\mathrm{PO}$ & \\
\hline EPU/L22/T20/P5/A8 & 42,31 & 17,8373364 & 0,8725 & 1,8716 & $\mathrm{PO}$ & \\
\hline EPU/L2/T40/P4/A8 & 38,06 & 15,1025783 & 1,3300 & 1,4459 & $\mathrm{PO}$ & \\
\hline EPU/L7/T40/P4/A8 & 36,69 & 15,7165212 & 0,7019 & 1,3341 & $\mathrm{PO}$ & \\
\hline EPU/L13/T40/P2/A8 & 39,04 & 14,2897164 & 0,8783 & 0,9106 & $\mathrm{PO}$ & \\
\hline EPU/L15/T40/P1/A8 & 38,43 & 13,8748711 & 1,0148 & 1,4552 & $\mathrm{PO}$ & \\
\hline EPU/L19/T40/P3/A8 & 39,31 & 14,1414221 & 1,4909 & 1,9673 & $\mathrm{PO}$ & \\
\hline EPU/L6/T80/P7/A8 & 39,57 & 9,9951805 & 0,5208 & 0,6360 & $\mathrm{PO}$ & \\
\hline EPU/L10/T80/P4/A8 & 38,73 & 10,1562773 & 1,3170 & 1,5462 & $\mathrm{PO}$ & \\
\hline EPU/L17/T80/P1/A8 & 40,96 & 15,0575764 & 0,8352 & 0,9722 & $\mathrm{PO}$ & \\
\hline EPU/L21/T80/P6/A8 & 39,75 & 12,2889429 & 0,9889 & 1,4190 & $\mathrm{PO}$ & \\
\hline EPU/L25/T80/P5/A8 & 43,31 & 11,3620190 & 0,8725 & 1,1428 & $\mathrm{PO}$ & \\
\hline EPU/L4/THD/P5/A12 & 37,58 & 23,0333492 & 1,4883 & 1,8791 & $\mathrm{PO}$ & \\
\hline EPU/L8/THD/P6/A12 & 39,59 & 19,6130756 & 1,6498 & 1,8710 & $\mathrm{PO}$ & \\
\hline EPU/L12/THD/P7/A12 & 35,66 & 22,0798626 & 1,5185 & 1,8059 & $\mathrm{PO}$ & \\
\hline EPU/L16/THD/P5/A12 & 37,34 & 18,8417743 & 1,8693 & 1,9408 & $\mathrm{PO}$ & \\
\hline EPU/L18/THD/P3/A12 & 37,06 & 25,0716020 & 1,7279 & 2,0816 & $\mathrm{PO}$ & \\
\hline EPU/L3/T5/P5/A12 & 40,91 & 19,4178027 & 1,7032 & 1,7642 & $\mathrm{PO}$ & \\
\hline EPU/L9/T5/P5/A12 & 37,69 & 19,7041086 & 1,6679 & 1,9660 & $\mathrm{PO}$ & \\
\hline EPU/L20/T5/P5/A12 & 42,55 & 17,2763880 & 1,3649 & 1,6211 & $\mathrm{PO}$ & \\
\hline EPU/L23/T5/P2/A12 & 42,25 & 17,0327400 & 1,7590 & 1,8603 & $\mathrm{PO}$ & \\
\hline
\end{tabular}




\begin{tabular}{|c|c|c|c|c|c|}
\hline EPU/L24/T5/P5/A12 & 40,73 & 23,1920436 & 1,6009 & 2,4159 & $\mathrm{PO}$ \\
\hline EPU/L1/T20/P6/A12 & 34,93 & 15,3973912 & 1,4242 & 1,6882 & $\mathrm{PO}$ \\
\hline EPU/L5/T20/P2/A12 & 44,60 & 20,3618699 & 1,6745 & 1,7277 & $\mathrm{PO}$ \\
\hline EPU/L11/T20/P1/A12 & 36,84 & 17,6248978 & 1,3752 & 1,7586 & $\mathrm{PO}$ \\
\hline EPU/L14/T20/P1/A12 & 37,13 & 14,2665127 & 1,4006 & 1,6299 & $\mathrm{PO}$ \\
\hline EPU/L22/T20/P1/A12 & 42,31 & 15,8678513 & 1,5088 & 1,5837 & PO \\
\hline EPU/L2/T40/P1/A12 & 38,06 & 19,8603087 & 1,5590 & 2,1080 & $\mathrm{PO}$ \\
\hline EPU/L7/T40/P3/A12 & 36,69 & 18,0513999 & 1,2578 & 1,7326 & $\mathrm{PO}$ \\
\hline EPU/L13/T40/P4/A12 & 39,04 & 17,2829232 & 1,5476 & 1,7335 & $\mathrm{PO}$ \\
\hline EPU/L15/T40/P7/A12 & 38,43 & 19,1302699 & 1,8302 & 2,3698 & $\mathrm{PO}$ \\
\hline EPU/L19/T40/P1/A12 & 39,31 & 18,2340250 & 1,0029 & 1,8386 & PO \\
\hline EPU/L6/T80/P6/A12 & 39,57 & 16,3170989 & 1,2051 & 1,6622 & $\mathrm{PO}$ \\
\hline EPU/L10/T80/P3/A12 & 38,73 & 13,5353942 & 1,5056 & 1,7265 & $\mathrm{PO}$ \\
\hline EPU/L17/T80/P2/A12 & 40,96 & 14,9205123 & 0,9419 & 0,9687 & $\mathrm{PO}$ \\
\hline EPU/L21/T80/P7/A12 & 39,75 & 15,0018149 & 1,2900 & 2,0055 & $\mathrm{PO}$ \\
\hline EPU/L25/T80/P1/A12 & 43,31 & 16,6944421 & 1,0792 & 1,7803 & PO \\
\hline EPU/L4/THD/P6/A16 & 37,58 & 27,5916766 & 1,3782 & - & $\mathrm{PO}$ \\
\hline EPU/L8/THD/P1/A16 & 39,59 & 24,0434942 & 2,2381 & 2,5866 & $\mathrm{PO}$ \\
\hline EPU/L12/THD/P4/A16 & 35,66 & 20,9112882 & 1,9462 & 2,2333 & $\mathrm{PO}$ \\
\hline EPU/L16/THD/P1/A16 & 37,34 & 25,2864025 & 1,0760 & - & $\mathrm{PO}$ \\
\hline EPU/L18/THD/P1/A16 & 37,06 & 24,1544125 & 2,3150 & 2,4536 & PO \\
\hline EPU/L3/T5/P2/A16 & 40,91 & 26,9847040 & 2,1128 & 3,0563 & $\mathrm{PO}$ \\
\hline EPU/L9/T5/P3/A16 & 37,69 & 18,3838250 & 1,3819 & 1,6514 & $\mathrm{PO}$ \\
\hline EPU/L20/T5/P6/A16 & 42,55 & 23,5874106 & - & - & $\mathrm{PO}$ \\
\hline EPU/L23/T5/P3/A16 & 42,25 & 25,5536849 & 3,2986 & - & $\mathrm{PO}$ \\
\hline EPU/L24/T5/P7/A16 & 40,73 & 23,8902513 & 1,9982 & - & PO \\
\hline EPU/L1/T20/P5/A16 & 34,93 & 17,0263136 & 1,9395 & 2,8776 & $\mathrm{PO}$ \\
\hline EPU/L5/T20/P1/A16 & 44,60 & 25,2323947 & 2,5795 & - & $\mathrm{PO}$ \\
\hline EPU/L11/T20/P4/A16 & 36,84 & 17,8586586 & 1,8487 & 2,6982 & $\mathrm{PO}$ \\
\hline EPU/L14/T20/P6/A16 & 37,13 & 23,3891190 & 1,6706 & 1,8216 & $\mathrm{PO}$ \\
\hline EPU/L22/T20/P4/A16 & 42,31 & 20,1476137 & 1,7242 & 2,0846 & $\mathrm{PO}$ \\
\hline EPU/L2/T40/P7/A16 & 38,06 & 20,9659515 & 2,4490 & 2,7536 & $\mathrm{PO}$ \\
\hline EPU/L7/T40/P7/A16 & 36,69 & 17,8791269 & 1,4201 & 1,5652 & $\mathrm{PO}$ \\
\hline EPU/L13/T40/P7/A16 & 39,04 & 19,4524856 & 1,5148 & 1,9716 & $\mathrm{PO}$ \\
\hline EPU/L15/T40/P4/A16 & 38,43 & 15,9452647 & 0,9010 & 1,3459 & $\mathrm{PO}$ \\
\hline EPU/L19/T40/P5/A16 & 39,31 & 20,0440952 & 1,6602 & 2,4838 & PO \\
\hline EPU/L6/T80/P5/A16 & 39,57 & 15,9276619 & 1,6017 & 2,2217 & $\mathrm{PO}$ \\
\hline EPU/L10/T80/P7/A16 & 38,73 & 16,8846767 & 1,2849 & 1,5977 & $\mathrm{PO}$ \\
\hline EPU/L17/T80/P7/A16 & 40,96 & 16,0469284 & 1,6605 & 1,7777 & $\mathrm{PO}$ \\
\hline EPU/L21/T80/P1/A16 & 39,75 & 16,9975119 & 1,8262 & 2,1783 & $\mathrm{PO}$ \\
\hline EPU/L25/T80/P2/A16 & 43,31 & 17,6269294 & 1,4860 & 2,4190 & $\mathrm{PO}$ \\
\hline
\end{tabular}

PO: Pullout; RA: Rotura adhesión entre la geometría superficial y el núcleo de la barra; RC: Rotura combinada por rotura del hormigón y rotura parcial entre la geometría superficial y el núcleo de la barra.

Tabla 3.36. Resultados del ensayo de pullout en barras de CFRP arenadas (CA8 y CA14), corrugadas (CC12), texturizadas (CT13), y acero corrugadas (A8, A12 y A16), sometidas a los tratamientos térmicos de $\mathrm{H} / \mathrm{D}, 5^{\circ} \mathrm{C}, 20^{\circ} \mathrm{C}, 40{ }^{\circ} \mathrm{C}$ y $80^{\circ} \mathrm{C}$.

Los valores de $\delta_{\mathrm{ET}}$ y $\delta_{\mathrm{ENT}}$ identificados con guión (“_“") en la Tabla 3.36, se deben al bloqueo de los tres LVDT's situados en el extremo tensionado 
durante el ensayo (generalmente cuando se alcanza una fuerza del orden de 60 $\mathrm{kN}$ ) o del LVDT ubicado en el extremo no tensionado. Por lo tanto, se ha decidido que los valores de la deformación obtenidos en dichas muestras de ensayo no son válidos (no se determinó parar el ensayo durante su ejecución y volverlo a realizar, debido a que se supone que la adherencia desarrollada en la repetición del ensayo puede encontrarse afectada por el primer ensayo).

En la Fig. 3.58 se representa el comportamiento adherente de cada tipo de barra de CFRP (CA8, CA14, CC12 y CT13) y acero corrugado (A8, A12 y A16), sometida a las diferentes condiciones ambientales del estudio $\left(\mathrm{H} / \mathrm{D}, 5{ }^{\circ} \mathrm{C}\right.$, $20{ }^{\circ} \mathrm{C}, 40^{\circ} \mathrm{C}$ y $80^{\circ} \mathrm{C}$ ), mediante la gráfica que relaciona la tensión adherente " $\tau$ " y el deslizamiento " $\delta$ " (en ambos extremos). En esta Fig. 3.58 únicamente se muestra para cada tipo de barra un ensayo de cada condición ambiental, el resto de gráficas $\tau / \delta$ obtenidas en el estudio se encuentran definidas en el Anejo I.

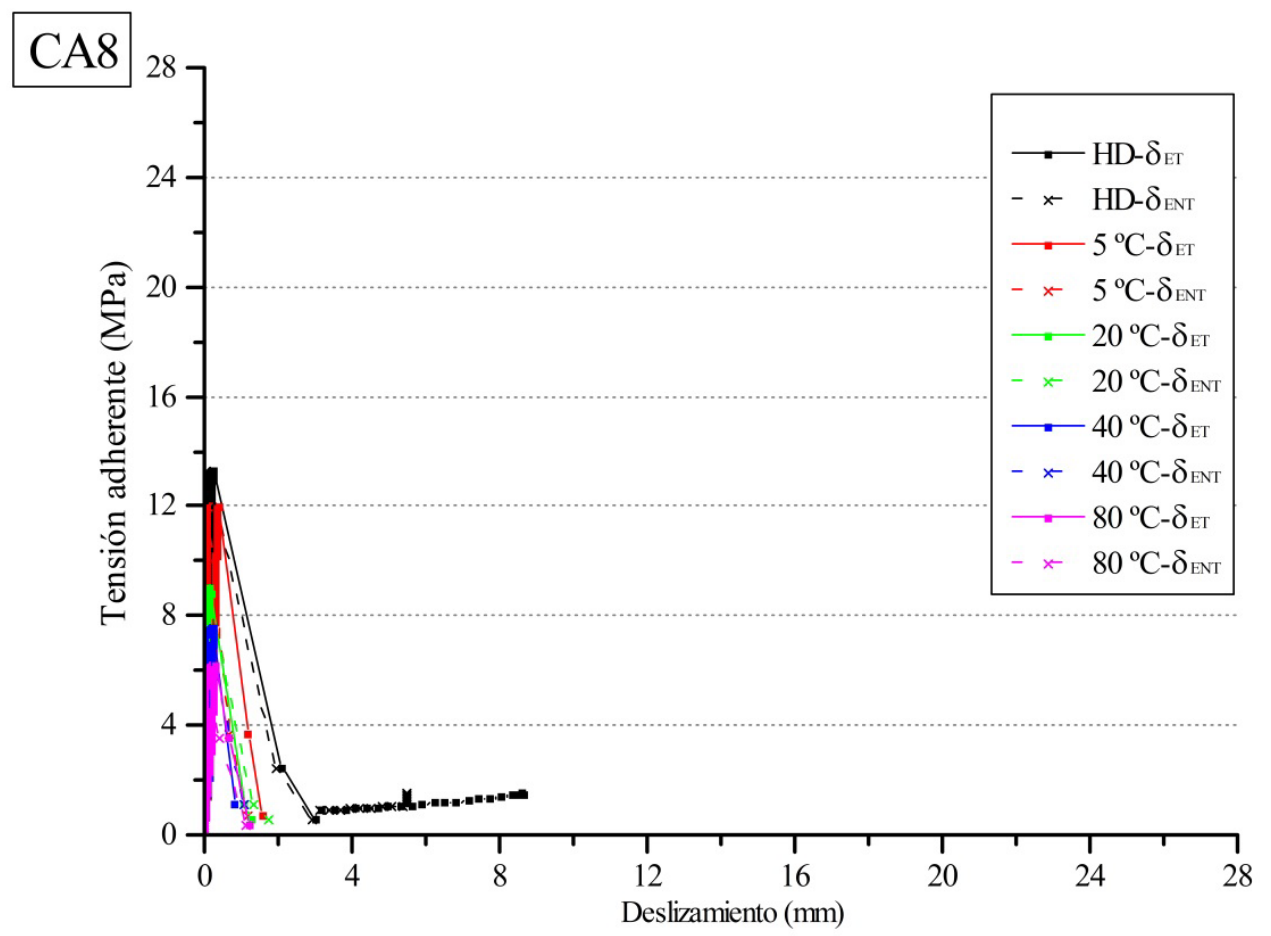




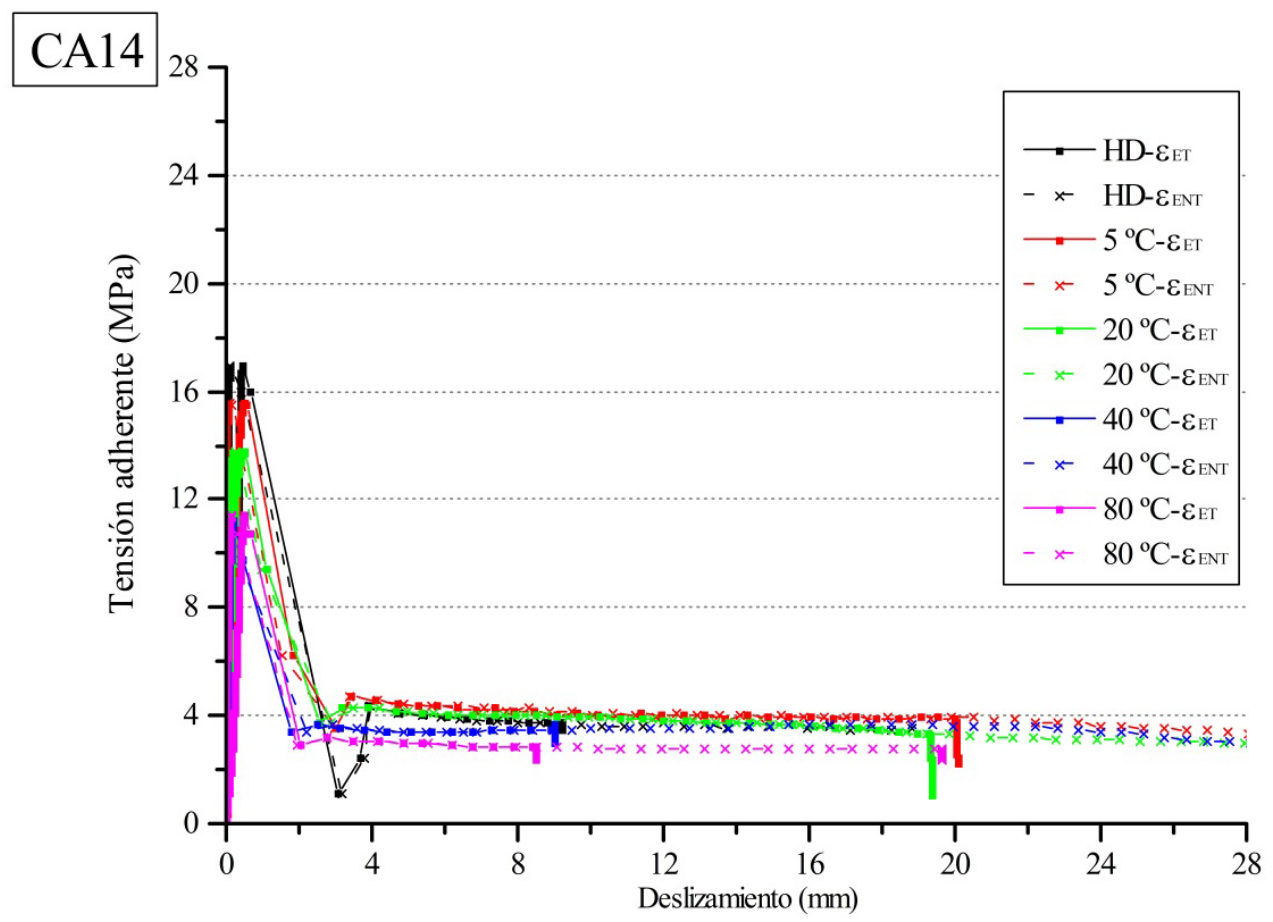

\section{$\mathrm{CC} 12$}

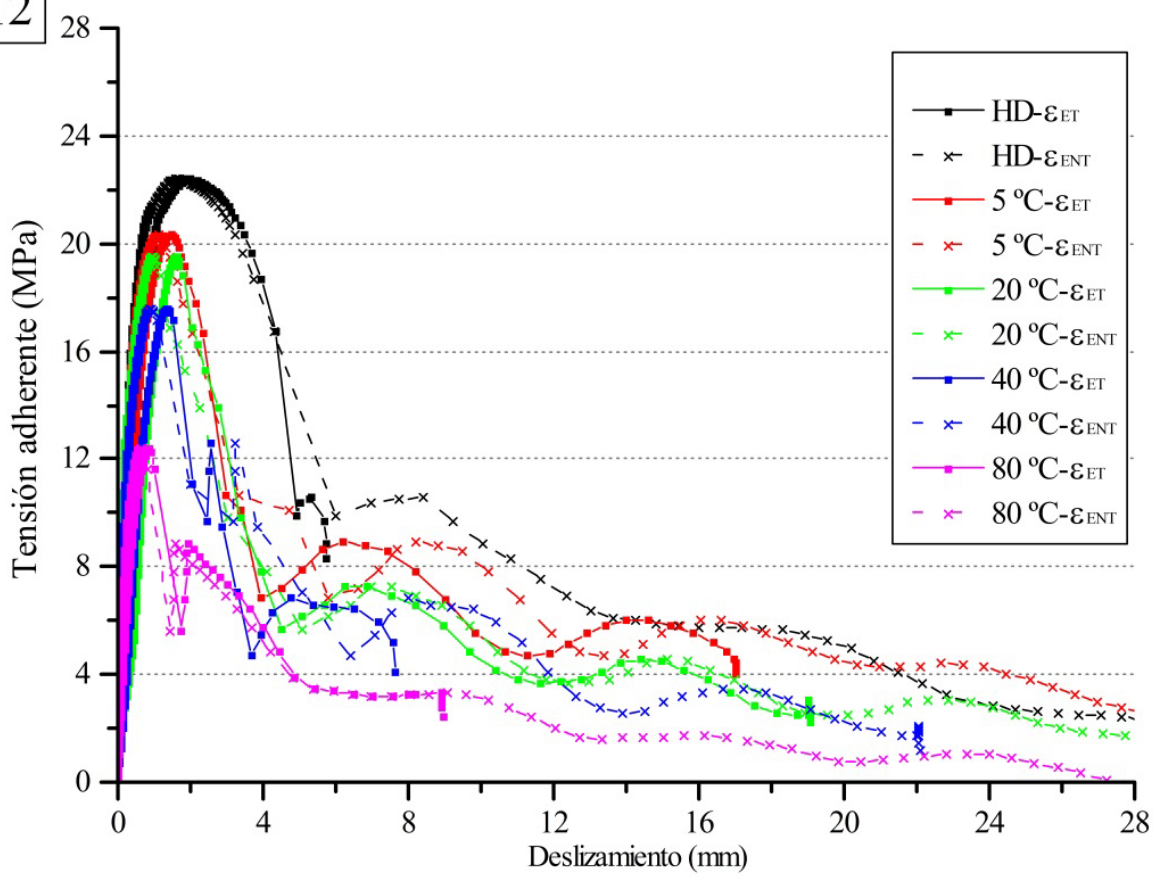



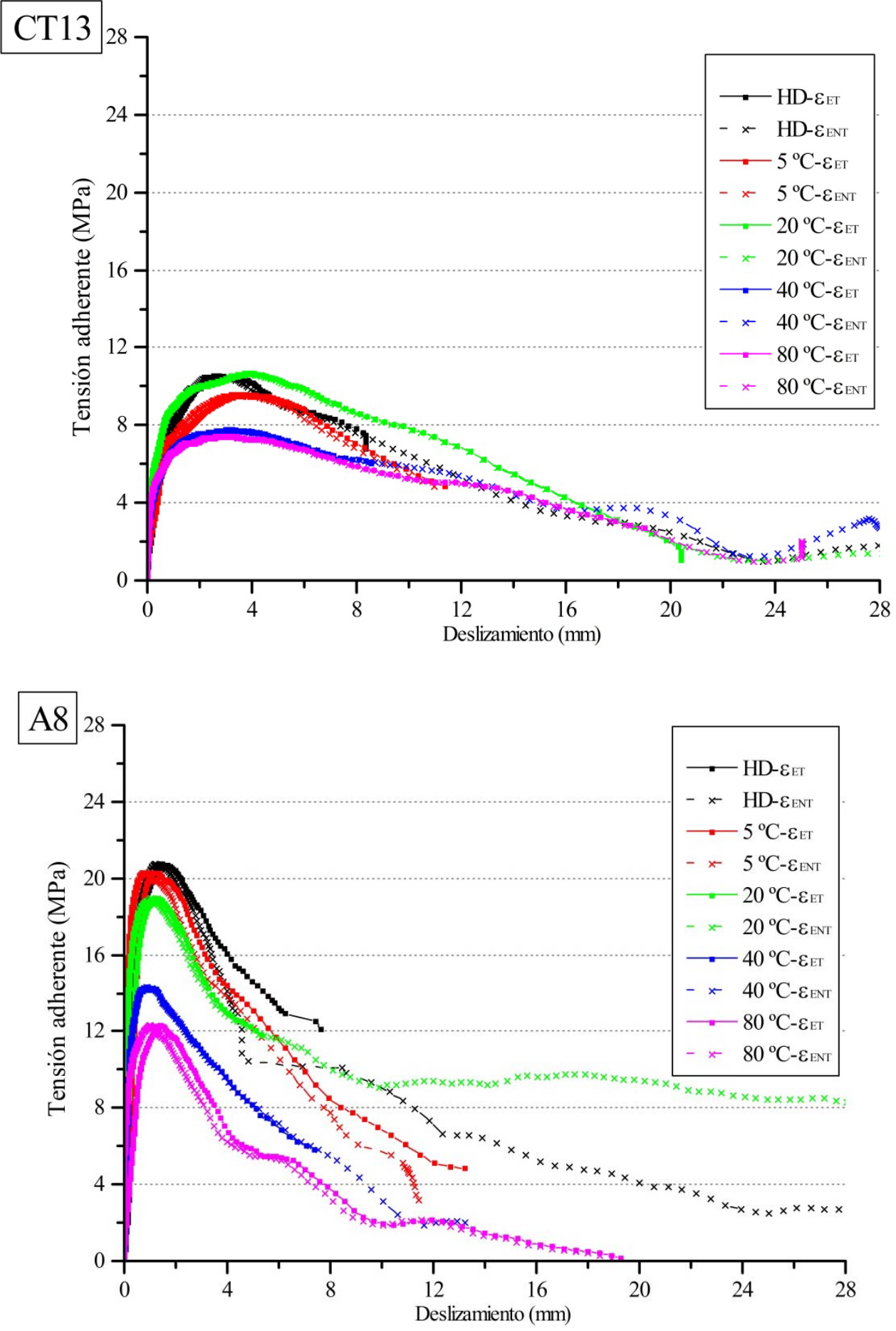

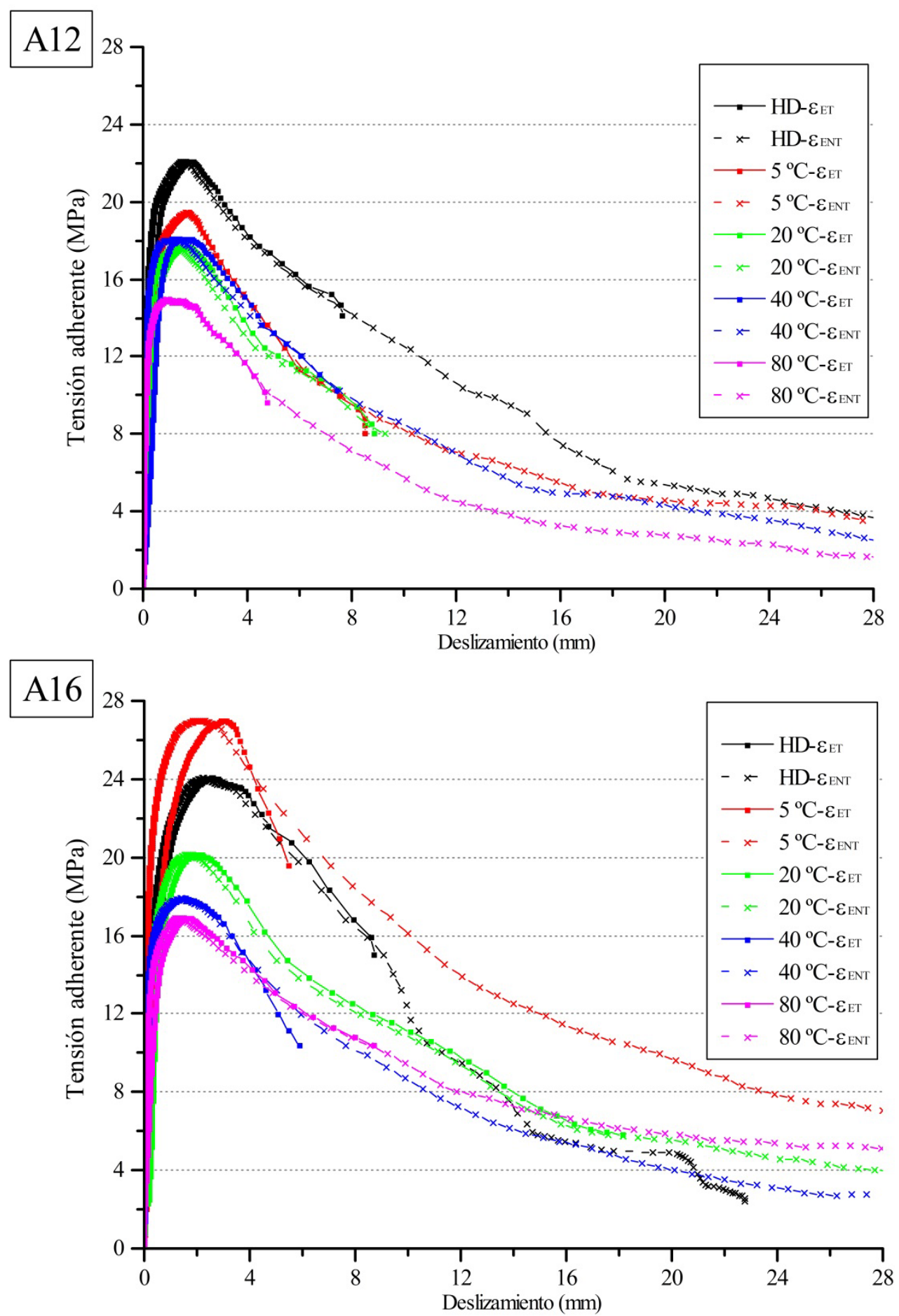

Fig. 3.58. Comportamiento adherente de las barras de CFRP arenadas "CA8 y CA14", corrugadas "CC12" y texturizadas "CT13" y acero corrugadas "A8, A12 y A16", sometidas a las condiciones ambientales de $\mathrm{HD}, 5^{\circ} \mathrm{C}, 20^{\circ} \mathrm{C}, 40^{\circ} \mathrm{C}$ y $80^{\circ} \mathrm{C}$. Gráficas de tensión adherente / deslizamiento. 
Siguiendo la metodología de ensayo definida en este apartado, tras la realización de cada lote de ensayo a pullout, se ha obtenido el diámetro de barra resultante, medido en la longitud adherente de cada barra a $1 / 4,1 / 2$ y $3 / 4$ del inicio de la misma. Para ello, se ha diseñado un plan de ensayo mediante un diseño Split-Plot (Tabla 3.34), idéntico al realizado en los ensayos de pullout, puesto que la medición de cada lote y barra se realiza a continuación de cada ensayo a pullout. Por lo tanto, este ensayo constará de 3 mediciones en cada uno de los 175 ensayos de pullout. En la Tabla 3.37 se muestran los resultados del diámetro de barra resultante tras el ensayo de pullout.

\begin{tabular}{|c|c|c|c|c|c|c|c|c|c|c|c|c|c|}
\hline \multirow[b]{2}{*}{ C.C. } & \multirow[b]{2}{*}{ Lote } & \multicolumn{3}{|c|}{ CA8 } & \multicolumn{3}{|c|}{ CA14 } & \multicolumn{3}{|c|}{ CC12 } & \multicolumn{3}{|c|}{ CT13 } \\
\hline & & $1 / 4$ & $1 / 2$ & $3 / 4$ & $1 / 4$ & $1 / 2$ & $3 / 4$ & $1 / 4$ & $1 / 2$ & $3 / 4$ & $1 / 4$ & $1 / 2$ & $3 / 4$ \\
\hline \multirow{5}{*}{ HD } & 4 & 6,06 & 6,09 & 6,06 & 11,89 & 11,88 & 11,82 & 10,90 & 10,77 & 10,73 & 11,45 & 11,39 & 11,18 \\
\hline & 8 & 6,10 & 6,09 & 6,06 & 11,92 & & 11,82 & 10,94 & 10,83 & 10,71 & 11,71 & 11,63 & 11,60 \\
\hline & 12 & 6,05 & 6,04 & 5,93 & 11,93 & & 11,85 & 10,76 & 10,71 & 10,70 & 11,65 & 11,53 & 11,33 \\
\hline & 16 & 6,17 & 6,16 & 6,16 & 11,88 & & 11,83 & 10,82 & 10,72 & 10,69 & 12,10 & 11,98 & 11,84 \\
\hline & 18 & 6,09 & 6,07 & 6,04 & 11,92 & 11,88 & 11,85 & 10,86 & 10,83 & 10,78 & 11,86 & 11,84 & 11,68 \\
\hline \multirow{5}{*}{$5^{\circ} \mathrm{C}$} & 3 & 18 & 6,14 & 6,08 & 12,02 & 11,97 & 11,87 & 10,94 & 10,86 & 10,72 & 11,51 & 11,70 & 11,43 \\
\hline & 9 & 6,20 & 6,18 & 6,16 & 13,93 & & 11,99 & 10,80 & 10,73 & 10,67 & 11,80 & 1,68 & 11,46 \\
\hline & 20 & 6,17 & 6,12 & 6,10 & 12,00 & 11,87 & 11,82 & 10,89 & 10,76 & 10,78 & 11,88 & 11,80 & 11,71 \\
\hline & 23 & 6,20 & 6,14 & 6,12 & 14,00 & 11,86 & 11,83 & 10,85 & 10,78 & 10,70 & 11,77 & 11,66 & 11,49 \\
\hline & 24 & 6,24 & 6,18 & 6,09 & 12,00 & 11,94 & 11,91 & 11,10 & 11,02 & 10,97 & 11,92 & 11,86 & 11,77 \\
\hline \multirow{5}{*}{$20^{\circ} \mathrm{C}$} & 1 & 6,11 & 6,11 & 6,05 & 11,99 & 11,87 & 11,80 & 11,06 & 11,01 & 10,84 & 11,36 & 11,27 & 11,36 \\
\hline & 5 & 6,07 & 6,03 & 6,03 & 11,87 & 11,82 & 11,77 & 10,70 & 10,66 & 10,58 & 11,80 & 11,79 & 11,59 \\
\hline & 11 & 6,17 & 6,15 & 6,13 & 13,35 & 11,90 & 11,89 & 10,57 & 10,64 & 10,84 & 11,87 & 11,76 & 11,62 \\
\hline & 14 & 6,18 & 6,17 & 6,13 & 11,89 & 11,84 & 11,78 & 11,15 & 11,11 & 11,09 & 11,90 & 11,69 & 11,65 \\
\hline & 22 & 6,21 & 6,17 & 6,13 & 12,33 & 11,90 & 11,83 & 10,96 & 10,85 & 10,73 & 11,87 & 11,67 & 11,26 \\
\hline \multirow{5}{*}{$40^{\circ} \mathrm{C}$} & 2 & 6,03 & 5,96 & 5,89 & 12,01 & 11,90 & 11,72 & 10,83 & 10,79 & 10,66 & 11,50 & 11,70 & 11,72 \\
\hline & 7 & 6,17 & 6,13 & 6,06 & 11,93 & 11,89 & 11,77 & 10,54 & 10,59 & 10,70 & 11,45 & 11,18 & 10,90 \\
\hline & 13 & 6,06 & 6,05 & 6,00 & 11,92 & 11,87 & 11,71 & 10,74 & 10,63 & 10,54 & 11,78 & 11,71 & 11,56 \\
\hline & 15 & 6,15 & 6,14 & 6,13 & 11,95 & 11,87 & 11,76 & 10,89 & 10,85 & 10,83 & 11,84 & 11,66 & 11,62 \\
\hline & 19 & 6,20 & 6,17 & 6,16 & 11,93 & 11,83 & 11,71 & 10,73 & 10,70 & 10,57 & 12,02 & 11,85 & 11,83 \\
\hline \multirow{5}{*}{$80^{\circ} \mathrm{C}$} & 6 & 6,13 & 6,11 & 6,07 & 13,75 & 11,92 & 11,85 & 10,92 & 10,85 & 10,78 & 11,06 & 11,28 & 11,60 \\
\hline & 10 & 6,18 & 6,14 & 6,07 & 11,93 & 11,87 & 11,80 & 10,69 & 10,63 & 10,57 & 11,58 & 11,46 & 11,35 \\
\hline & 17 & 6,19 & 6,11 & 6,09 & 11,90 & 11,85 & 11,78 & 10,73 & 10,70 & 10,68 & 11,78 & 11,77 & 11,55 \\
\hline & 21 & 6,18 & 6,14 & 6,12 & 11,97 & 11,85 & 11,75 & 10,74 & 10,69 & 10,64 & 11,74 & 11,70 & 11,66 \\
\hline & 25 & 6,24 & 6,19 & 6,17 & 11,90 & 11,86 & 11,69 & 10,78 & 10,75 & 10,62 & 11,85 & 11,69 & 11,59 \\
\hline
\end{tabular}




\begin{tabular}{|c|c|c|c|c|c|c|c|c|c|c|}
\hline \multirow[b]{2}{*}{ C.C. } & \multirow[b]{2}{*}{ Lote } & \multicolumn{3}{|c|}{ A8 } & \multicolumn{3}{|c|}{ A12 } & \multicolumn{3}{|c|}{ A16 } \\
\hline & & $1 / 4$ & $1 / 2$ & $3 / 4$ & $1 / 4$ & $1 / 2$ & $3 / 4$ & $1 / 4$ & $1 / 2$ & $3 / 4$ \\
\hline \multirow{5}{*}{ HD } & 4 & & 8,38 & & & 13,32 & & & 17,78 & \\
\hline & 8 & & 8,58 & & & 13,25 & & & 17,87 & \\
\hline & 12 & & 8,71 & & & 13,43 & & & 18,15 & \\
\hline & 16 & & 8,64 & & & 13,41 & & & 17,73 & \\
\hline & 18 & & 8,69 & & & 13,40 & & & 17,83 & \\
\hline \multirow{5}{*}{$5^{\circ} \mathrm{C}$} & 3 & & 8,58 & & & 13,43 & & & 18,35 & \\
\hline & 9 & & 8,73 & & & 13,35 & & & 18,20 & \\
\hline & 20 & & 8,38 & & & 13,12 & & & 17,14 & \\
\hline & 23 & & 8,53 & & & 13,81 & & & 17,67 & \\
\hline & 24 & & 8,54 & & & 13,20 & & & 17,47 & \\
\hline \multirow{5}{*}{$20^{\circ} \mathrm{C}$} & 1 & & 8,89 & & & 13,63 & & & 18,28 & \\
\hline & 5 & & 8,75 & & & 13,43 & & & 17,43 & \\
\hline & 11 & & 8,83 & & & 13,24 & & & 18,15 & \\
\hline & 14 & & 8,92 & & & 13,36 & & & 18,27 & \\
\hline & 22 & & 8,49 & & & 13,31 & & & 17,45 & \\
\hline \multirow{5}{*}{$40^{\circ} \mathrm{C}$} & 2 & & 8,53 & & & 13,39 & & & 18,31 & \\
\hline & 7 & & 8,54 & & & 13,17 & & & 17,84 & \\
\hline & 13 & & 8,66 & & & 13,35 & & & 17,73 & \\
\hline & 15 & & 8,65 & & & 13,74 & & & 17,79 & \\
\hline & 19 & & 8,63 & & & 13,22 & & & 17,44 & \\
\hline \multirow{5}{*}{$80^{\circ} \mathrm{C}$} & 6 & & 8,72 & & & 13,20 & & & 17,51 & \\
\hline & 10 & & 8,69 & & & 13,24 & & & 17,87 & \\
\hline & 17 & & 8,62 & & & 13,33 & & & 18,02 & \\
\hline & 21 & & 8,72 & & & 13,23 & & & 18,68 & \\
\hline & 25 & & 8,71 & & & 13,20 & & & 17,90 & \\
\hline
\end{tabular}

Tabla 3.37. Resultados del diámetro resultante de cada barra de CFRP y acero tras el ensayo de pullout.

Finalmente, con el objetivo de caracterizar el comportamiento adherente de cada tipo de barra sometida a las diferentes condiciones ambientales del estudio, se ha procedido a la captación de imágenes de la superficie de la barra y hormigón en su longitud adherente. Con la finalidad de obtener una muestra representativa de imágenes para su posterior comparación se ha decidido la obtención de las mismas a la distancia de la segunda corruga en barras de CFRP y acero corrugadas, o distancia equivalente en barras de CFRP arenadas y texturizadas (Fig. 3.59). 


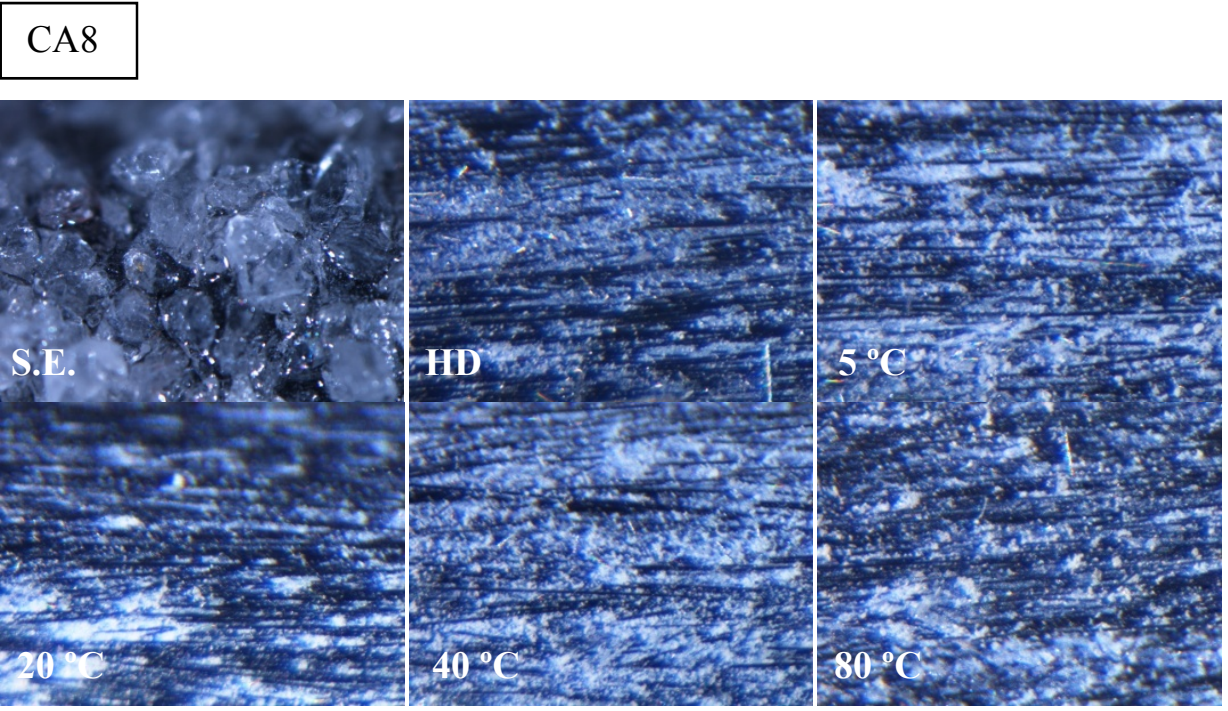

\section{CA14}
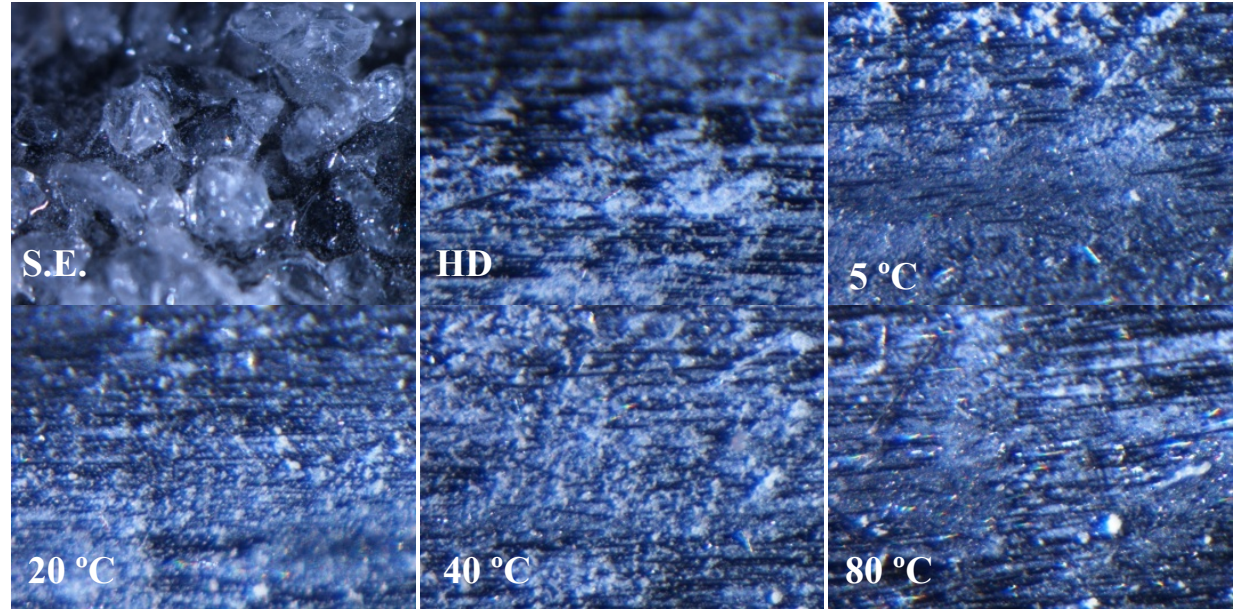

\section{$\mathrm{CC} 12$}
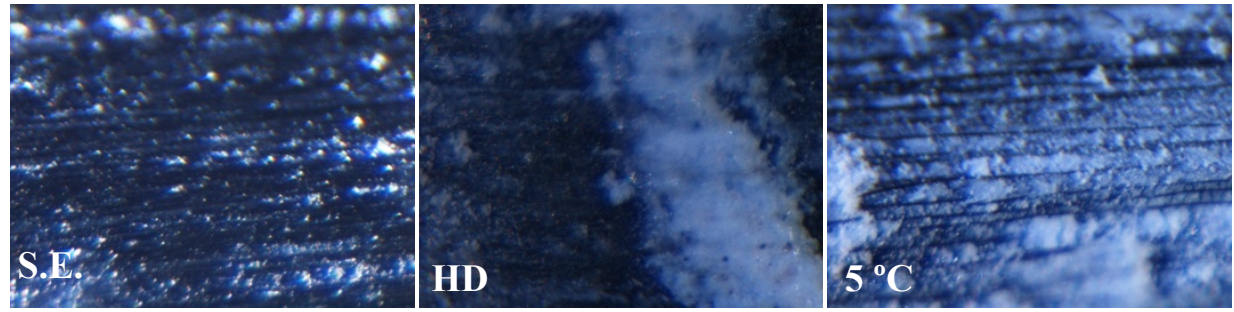


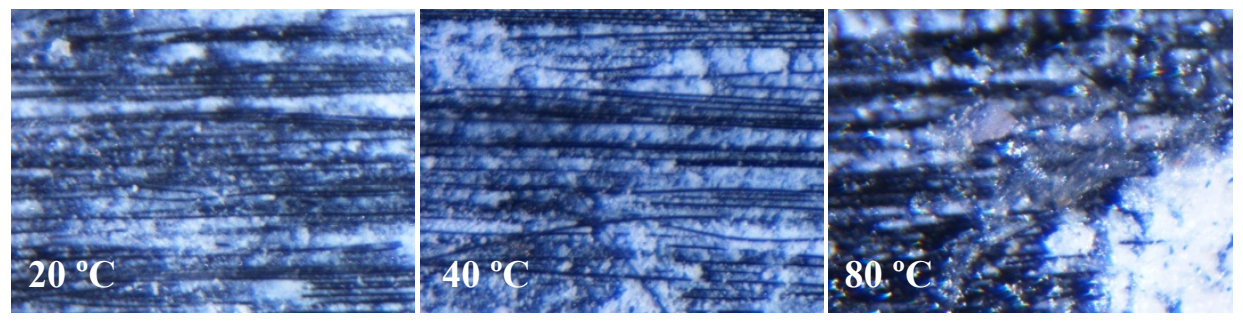

\section{CT13}
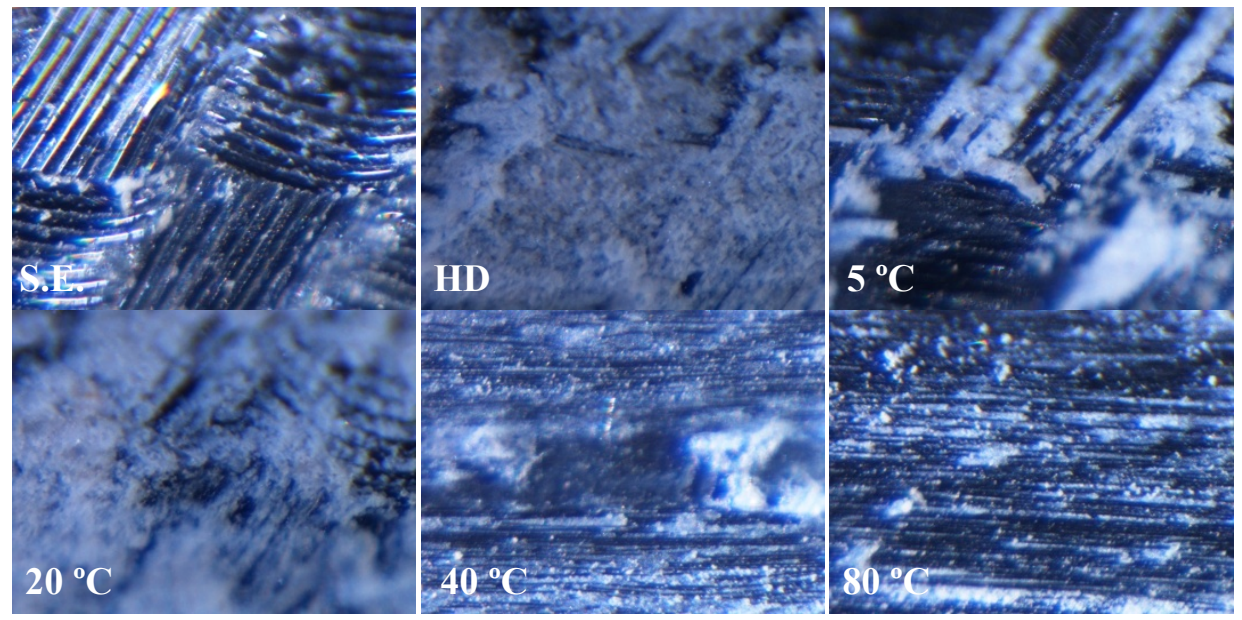

\section{A8}
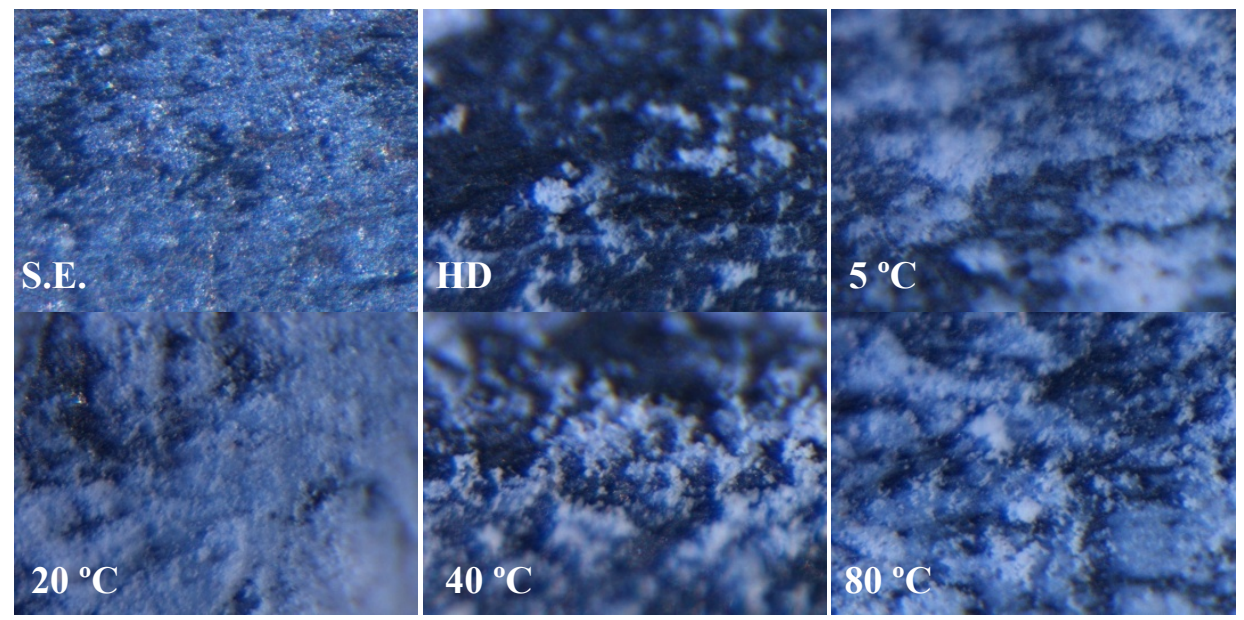


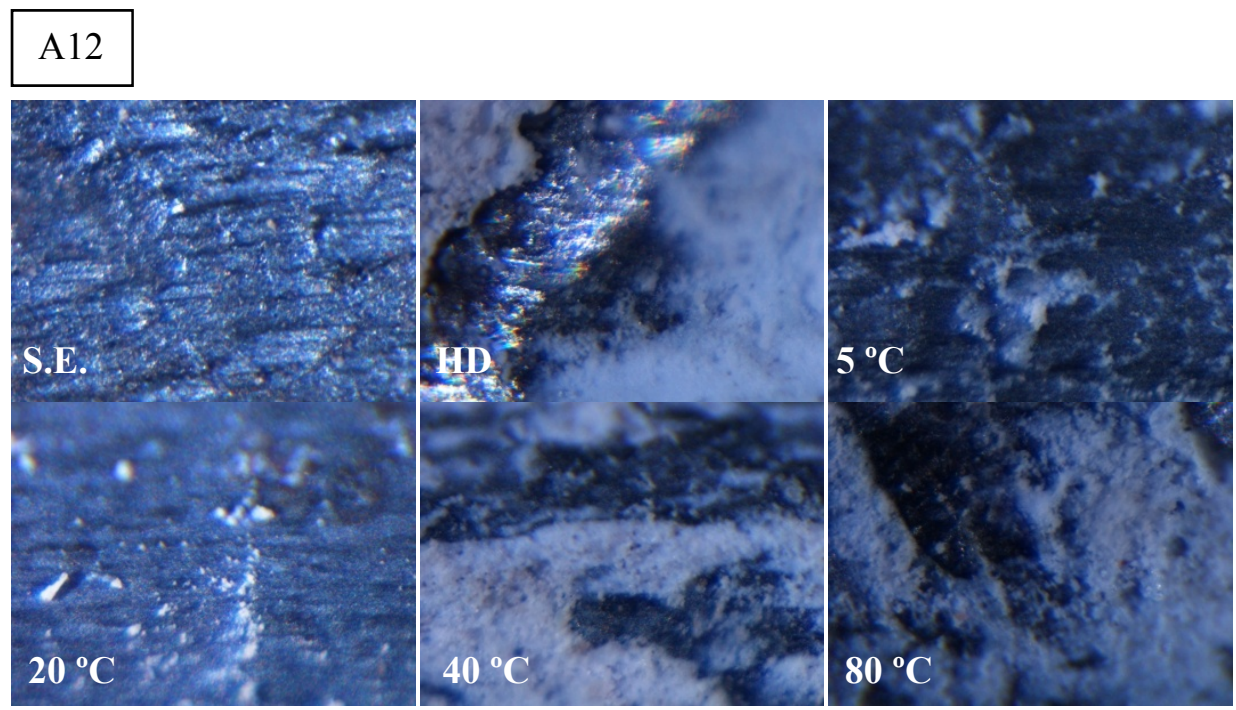

\section{A16}
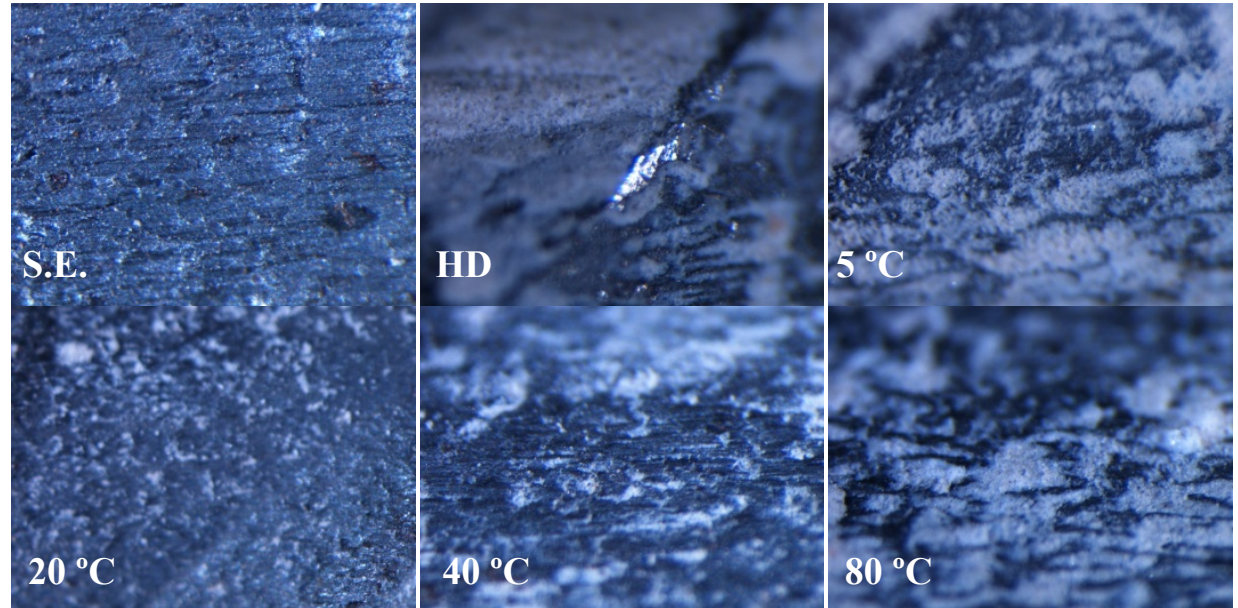

Fig. 3.59. Imágenes de la superficie de las barras CA8, CA14, CC12, CT13, A8, A12 y A16 en la zona de la segunda corruga. Imágenes ampliadas: x 9,8 aumentos en barras CA8, CA14, CC12, CT13, A8 y A12; x 4 aumentos en barras A16. (S.E. corresponde a la barra sin ensayar).

En las imágenes de la Fig. 3.59 se aprecia el modo de rotura correspondiente a cada tipo de barra, siendo en las barras: CA8 y CA14 por rotura de la adhesión entre la geometría superficial y el núcleo de la barra; $\mathrm{CC} 12$ en HD por modo combinado entre el hormigón y la geometría (en la Fig. 3.59CC12-HD se aprecia la segunda corruga intacta con restos de hormigón) y en el 
resto de temperaturas por cortadura de las corrugas; CT13, A8, A12 y A16 la rotura se produce por pullout.

Al mismo tiempo, también se han obtenido imágenes de la longitud adherente tras la rotura en las probetas de hormigón a la distancia de 1/4, 1/2 y 3/4 del inicio de la longitud adherente. En la Fig. 3.60 se muestra el modo de rotura por rotura de la adhesión entre la geometría superficial y el núcleo de la barra y el modo combinado producido por las barras arenadas CA8 y CA14. Del mismo modo, en la Fig. 3.61 se muestra el modo de rotura combinado y por cortadura de la corrugas de las barras CC12. Por último, en la Fig. 3.62 se muestra el modo de rotura por pullout de las barras CT13 y A8, A12 y A16.
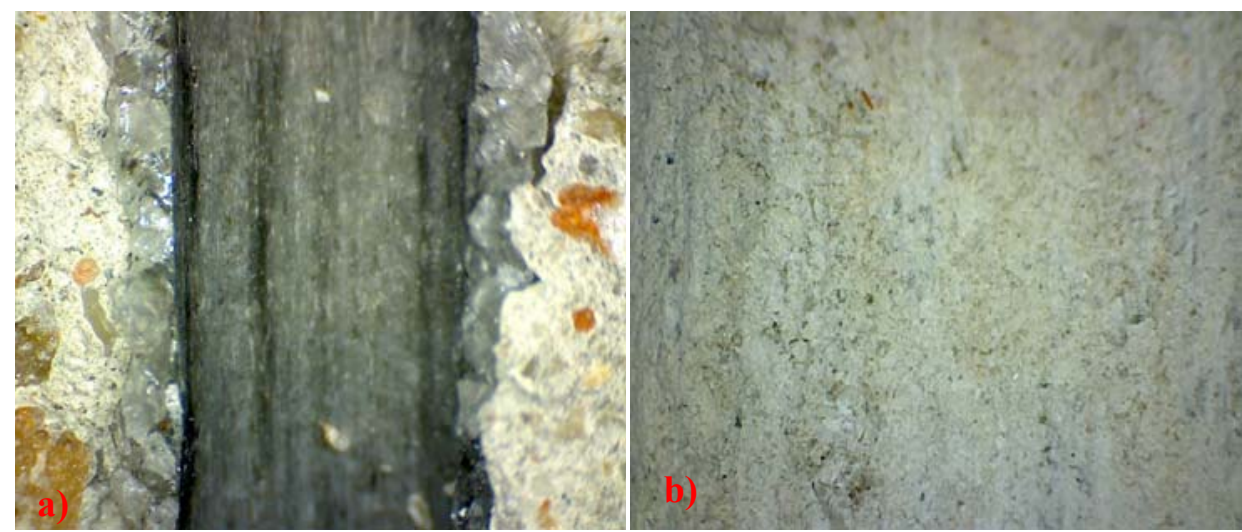

Fig. 3.60. Modo de rotura de las barras CA 8 y CA14: a) Rotura por rotura de la adhesión entre la geometría superficial y el núcleo. $1 / 2$ en EPU-L4-THD-P4-CA8; b) Rotura del hormigón en $1 / 4$ en EPU-L9-T5-P2-CA14 (modo combinado).
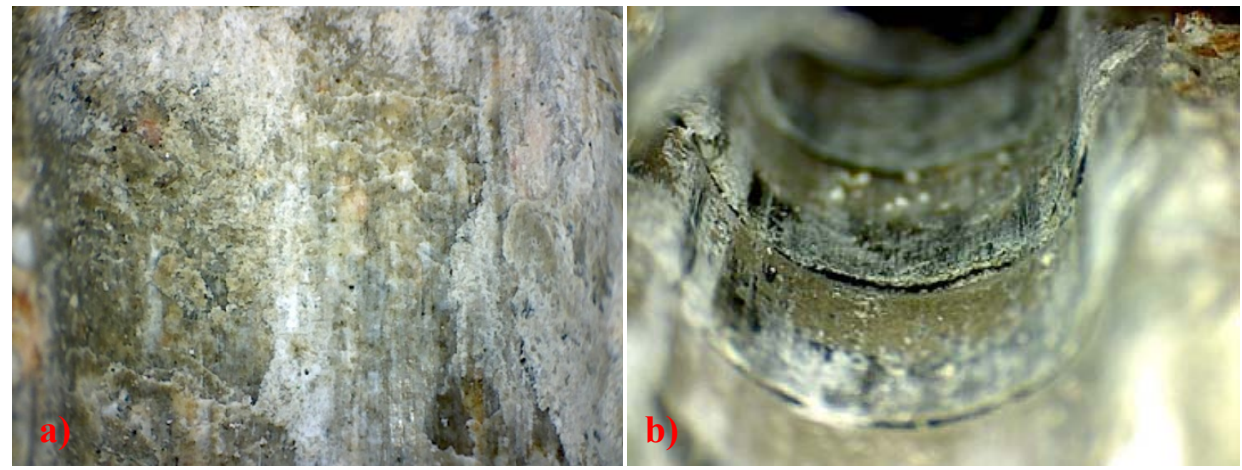

Fig. 3.61. Modo de rotura de las barras CC12: a) Rotura por pullout en inicio $\mathrm{L}_{\text {adh. }}$, Modo de rotura combinado. $1 / 4$ en EPU-L16-THD-P4-CC12; b) Rotura por cortadura de las corrugas.EPUL10-T80-P1-CC12. 


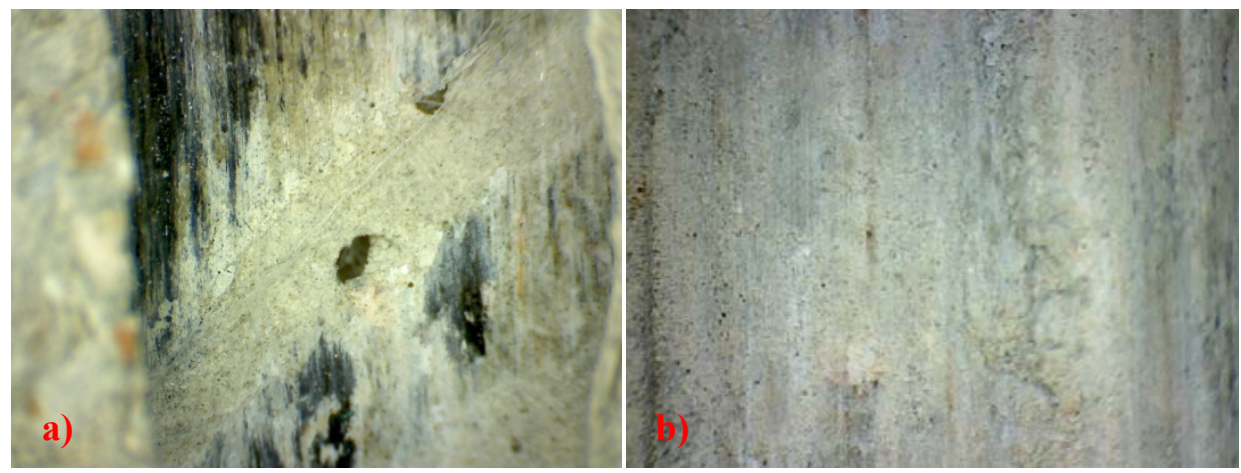

Fig. 3.62. Modo de rotura por pullout: a) Rotura por pullout en CT13. 1/4 en EPU-L4-THD-P3CT13; b) Rotura por pullout en A16. 1/2 en EPU-L5-T20-P1-A16.

\subsubsection{Ensayos Complementarios}

En este apartado se muestran los resultados de los ensayos complementarios del plan experimental, necesarios para el análisis de los ensayos de pullout y la influencia de diferentes factores en el comportamiento adherente. Inicialmente se realiza el ensayo de Análisis Termogravimétrico "TGA" para el cálculo del volumen de refuerzo de fibra de carbono y matriz polimércia, así como para el establecimiento de la temperatura máxima del ensayo posterior de Calorimetría Diferencial de Barrido "DSC", mediante el cual se calcula la temperatura de transición vítrea de cada barra de CFRP. También se realizan ensayos de Microdureza en muestras de barras de CFRP sometidas a idénticas condiciones ambientales que los ensayos de pullout, tras el cual se obtienen imágenes de Microscopia Óptica en dichas muestras de ensayo. Por último, se realizan imágenes en una muestra representativa de barras ensayadas a pullout mediante Microscopia Electrónica de Barrido "SEM" y Microscopia de Fuerza Atómica "AFM".

\subsubsection{Análisis Termogravimétrico "TGA"}

El Análisis termogravimétrico o TGA se realiza según la norma ASTM D 2584, puesto que el Comité ACI.440 no ha desarrollado ninguna norma al 
respecto. Con este ensayo se calcula el porcentaje de refuerzo de fibra de carbono y matriz polimérica que contiene cada tipo de barra de CFRP, al mismo tiempo que se fija la temperatura máxima del ensayo de DSC, a la cual comienzan a emitirse compuestos volátiles, que pueden dañar la máquina de ensayo.

Los materiales y equipos empleados en la realización de este ensayo son los siguientes:

- Barras de CFRP arenadas "CA14", corrugadas "CC12" y texturizadas "CT13". No se emplean barras CA8 debido a que la composición de este tipo de barras es idénticas a las barras CA14. Del mismo modo, no se emplean barras de acero debido a que este tipo barras no dispone de temperatura de transición vítrea.

- Báscula de la marca KERN modelo 770 con una precisión de 0,001 g (Fig. 3.63.a).

- Cortadora de precisión de la marca Struers modelo Accutom 5 (Fig. 3.63.b).
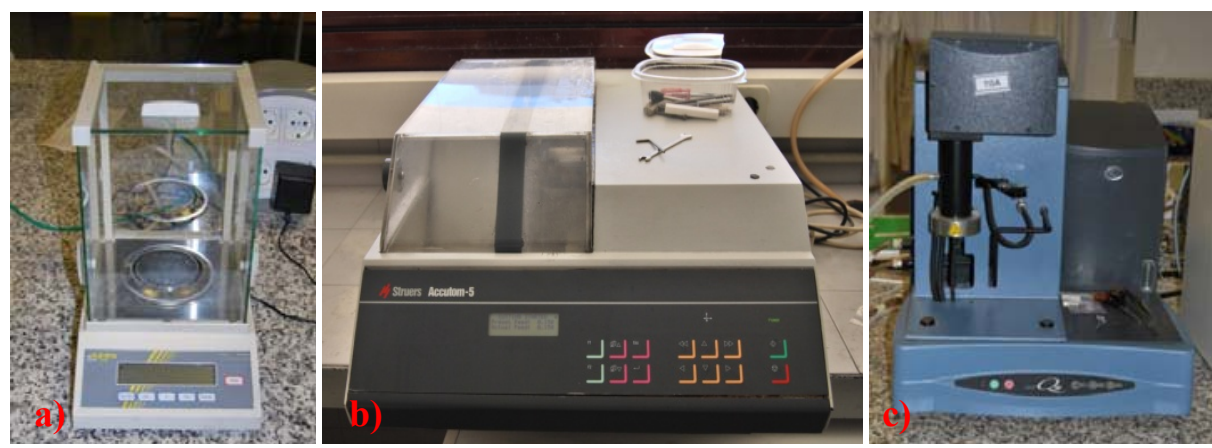

Fig. 3.63. Máquinas ensayo TGA: a) Báscula de precisión; b) Cortadora; c) Máquina de TGA.

- Máquina de TGA de la marca TA Instruments modelo Q50, con un rango de temperaturas desde temperatura ambiente hasta $1000^{\circ} \mathrm{C}$, una precisión de $0,1 \mu \mathrm{g} \mathrm{y} \pm 1^{\circ} \mathrm{C}$ (Fig. 3.63.c). 
El procedimiento y metodología empleada para la realización de este ensayo es el definido por ASTM D 2584:

I. Selección aleatoria de 3 muestras de ensayo en diferentes barras de CA14, CC12 y CT13.

II. Cortado de las muestras a un espesor de $\approx 1,5 \mathrm{~mm}$ (Fig. 3.64.a).

III. Modelado de muestras mediante pulidora a la dimensión aproximada de 5 x $5 \mathrm{~mm}$ (Fig. 3.64.b).
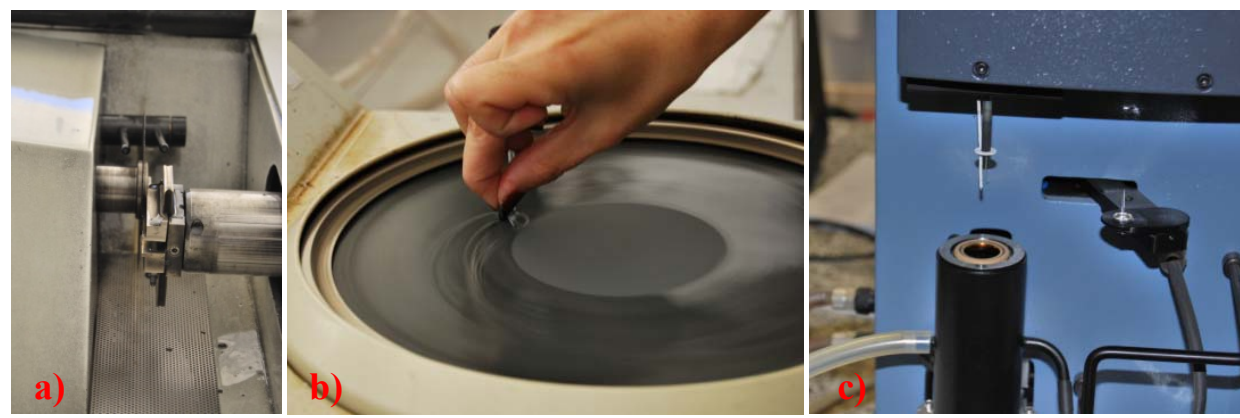

Fig. 3.64. Proceso de ensayo de TGA: a) Cortado de muestras; b) Modelado de muestras; c) Ensayo en máquina de TGA.

IV. Almacenamiento de muestras a temperatura de laboratorio durante un periodo de 48 horas.

V. Pesado de muestras mediante báscula de precisión.

$\mathrm{VI}$. Ensayo mediante máquina de análisis termogravimétrico en atmósfera de nitrógeno (Fig. 3.64.c).

En cuanto al diseño experimental, se ensayan tres muestras de cada tipo de barra de CFRP (mínimo número de muestras definido por ATM D 2584), con un total de 12 , seleccionadas aleatoriamente entre todas las barras disponibles. Debido a que se dispone de la restricción de 3 muestras ensayadas por día, se decide plantear un diseño de bloques aleatorizados, en el cual el tipo de barra son los tratamientos y los días de ensayo los bloques. Al mismo tiempo, se aleatoriza la posición de ensayo cada día (Tabla 3.38). 


\begin{tabular}{cccc}
\hline $\begin{array}{c}\text { Tipo de barra (Tratamiento) } \\
\text { Día de ensayo (Bloque) }\end{array}$ & CA14 & CC12 & CT13 \\
\hline DİA 1 & 2 & 3 & 1 \\
\hline DÏA 2 & 3 & 1 & 2 \\
\hline DÏA 3 & 1 & 2 & 3 \\
\hline
\end{tabular}

Tabla 3.38. Diseño del plan de ensayos de TGA.

En cuanto a la denominación de cada muestra de ensayo se ha empleado la siguiente codificación:

\section{Tipo de Ensayo / Tipo de Barra / Día de Ensayo.}

Por ejemplo:

\section{$\mathrm{TGA} / \mathrm{CC} 12 / 2$}

corresponde al ensayo de TGA de la barra CC12 ensayada el día 2.

En la Tabla 3.39 se muestra los resultados del porcentaje de refuerzo de fibra de carbono y matriz polimérica, así como la temperatura que produce una pérdida de peso del $1 \%$. Dicha temperatura será la máxima alcanzada durante el ensayo de DSC.

\begin{tabular}{cccc}
\hline Muestra & $\begin{array}{c}\text { \% Fibra de } \\
\text { Carbono }\end{array}$ & $\begin{array}{c}\text { \% Resina } \\
\text { Polimérica }\end{array}$ & $\begin{array}{c}\text { Temperatura a pérdida } \\
\text { de peso de } 1 \% \text {, en }{ }^{\circ} \mathrm{C} .\end{array}$ \\
\hline TGA/CA14/1 & 77,67 & 22,33 & 280,6 \\
\hline TGA/CA14/2 & 78,20 & 21,80 & 278,2 \\
\hline TGA/CA14/3 & 76,85 & 23,15 & 279,5 \\
\hline TGA/CC12/1 & 62,15 & 37,85 & 300,0 \\
\hline TGA/CC12/2 & 63,15 & 36,85 & 301,1 \\
\hline TGA/CC12/3 & 62,52 & 37,48 & 299,7 \\
\hline TGA/CT13/1 & 79,07 & 20,93 & 354,8 \\
\hline TGA/CT13/2 & 78,25 & 21,75 & 355,2 \\
\hline TGA/CT13/3 & 78,90 & 21,10 & 354,9
\end{tabular}

Tabla 3.39. Resultados del ensayo de TGA.

En la Fig. 3.65 se muestra para cada tipo de barra la gráfica que relaciona el porcentaje de pérdida de masa (ordenadas) y la temperatura 
(abscisas). Al mismo tiempo, se muestra la temperatura a partir de la cual pierde más del $1 \%$ de masa y él porcentaje de pérdida total de masa.
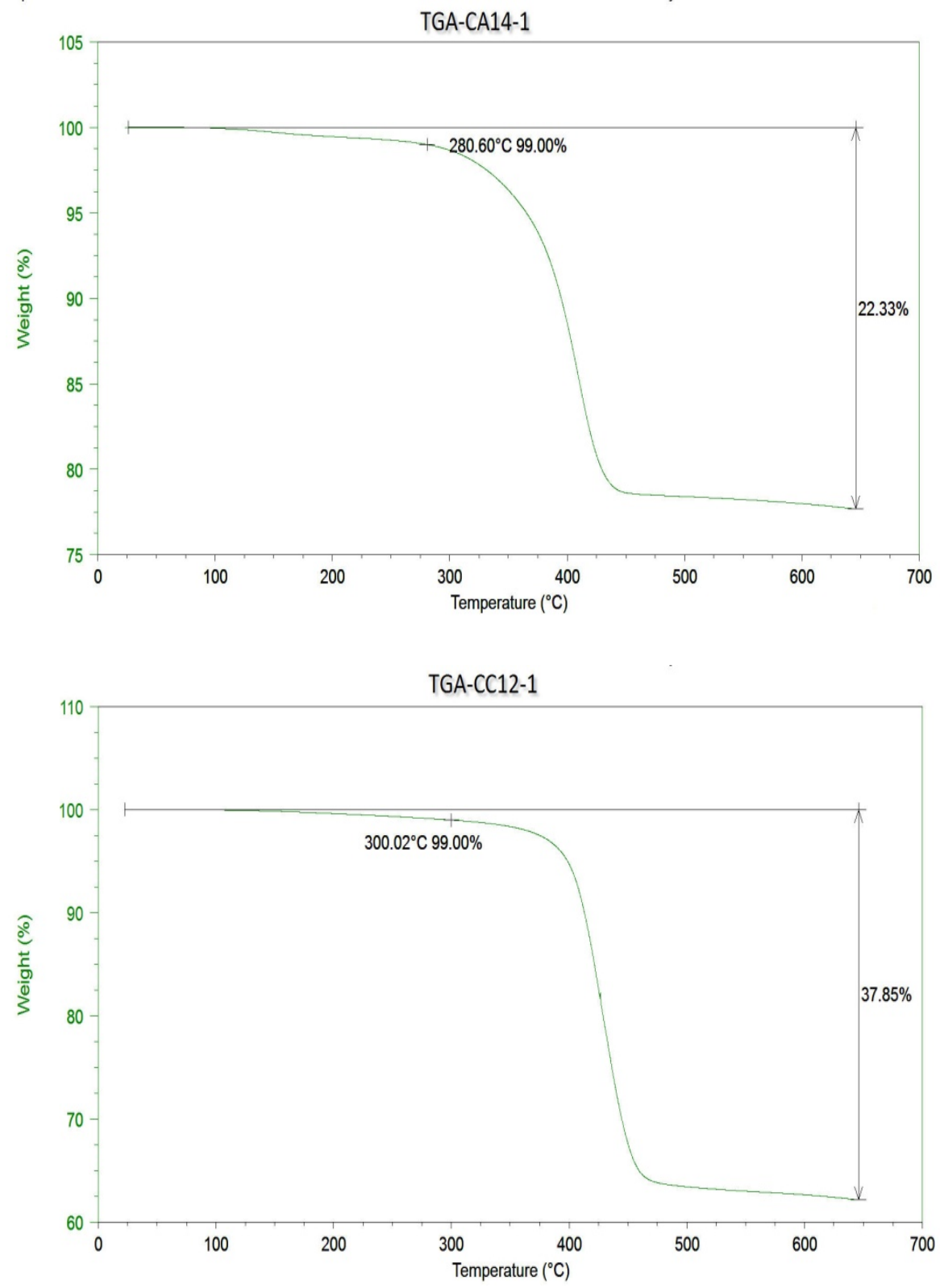


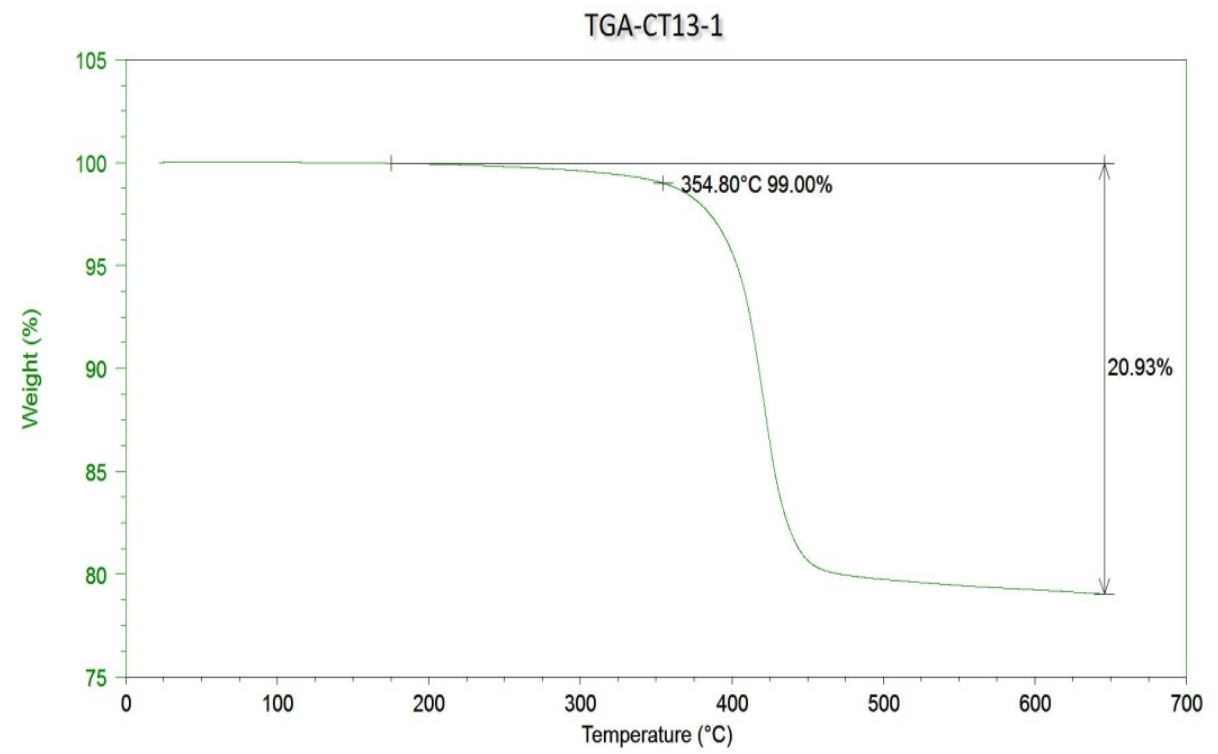

Fig. 3.65. Pérdida de masa en función de la temperatura en barras CA14, CC12 y CT13.

En la Fig. 3.66 se muestra una imagen de la sección transversal de las barras CC12 y CT13 tras el ensayo, donde se observa únicamente los filamentos de fibra de carbono (no se encuentran restos de matriz polimérica).
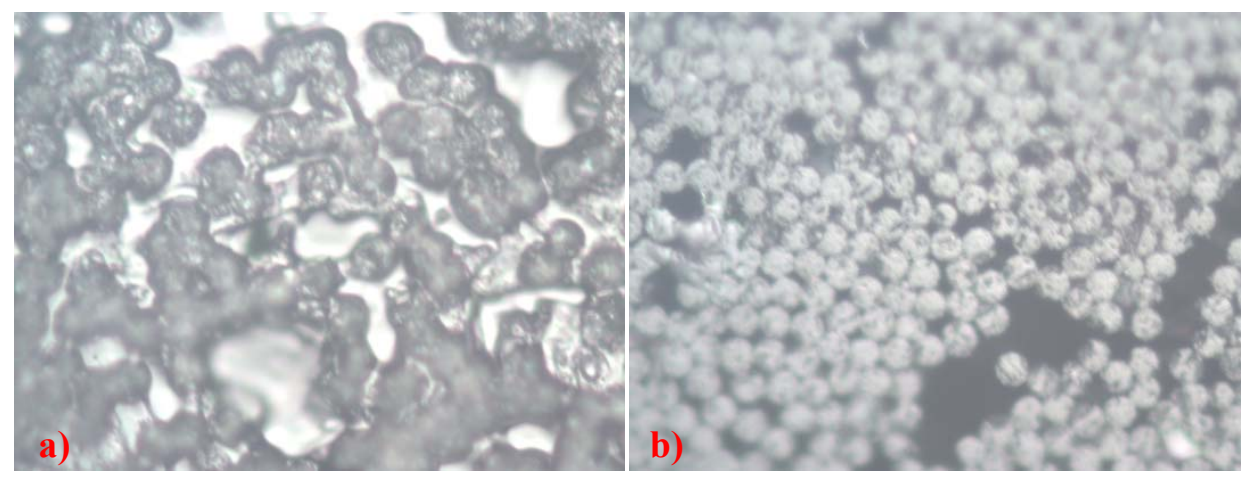

Fig. 3.66. Sección transversal de la barra de CFRP tras el ensayo de TGA (x 200): a) CC12; b) CT13.

\subsubsection{Calorimetría Diferencial de Barrido "DSC"}

El cálculo de la temperatura de transición vítrea “ $\mathrm{T}$ " se realiza mediante el ensayo de Calorimetría Diferencial de Barrido o DSC. Para ello y debido a 
que ACI.440 no dispone de normativa de ensayo, del mismo modo que en el ensayo de TGA anterior, se realiza el cálculo de la $T_{\mathrm{g}}$ mediante la norma ASTM E 1356. Este ensayo consiste en calentar una muestra de cada tipo de barra hasta una temperatura de unos $20^{\circ} \mathrm{C}$ mayor a la $\mathrm{T}_{\mathrm{g}}$. Para ello se realizan dos ciclos de calentamiento con un ciclo de enfriamiento intermedio (se enfría hasta unos $50{ }^{\circ} \mathrm{C}$ por debajo de la $\mathrm{T}_{\mathrm{g}}$ ). El primer ciclo térmico se realiza con el objetivo de eliminar la historia térmica de la muestra, de este modo la muestra se encuentra totalmente polimerizada en el segundo ciclo y el cálculo de la $T_{g}$ es representativo y comparable con otras muestras.

Los materiales y equipos empleados en este ensayo son los que se detallan a continuación:

- Barras de CFRP arenadas "CA14", corrugadas "CC12" y texturizadas "CT13". No se emplean barras CA8 debido a que la composición de este tipo de barras es idénticas a las barras CA14. Del mismo modo, no se emplean barras de acero debido a que este tipo barras no dispone de temperatura de transición vítrea.

- Báscula de la marca KERN modelo 770 con una precisión de 0,001 g (Fig. 3.63.a).

- Cortadora de precisión de la marca Struers modelo Accutom 5 (Fig. 3.63.b).

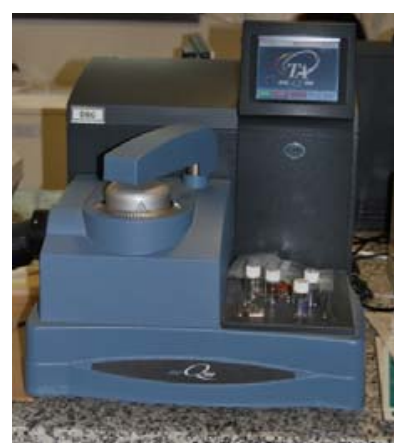

Fig. 3.67. Máquina de DSC 
- Máquina de DSC de la marca TA Instruments modelo Q100 con un rango de temperaturas de $-180^{\circ} \mathrm{C}$ a $725^{\circ} \mathrm{C}$, una sensibilidad de $\pm 0,2 \mu \mathrm{W}$ y precisión de $\pm 0,01{ }^{\circ} \mathrm{C}$ (Fig. 3.67).

El procedimiento y metodología utilizada para la realización de este ensayo es la siguiente:

I. Selección aleatoria de 3 muestras de ensayo en diferentes barras de CA14, CC12 y CT13.

II. Cortado de las muestras a un espesor de $\approx 1,5 \mathrm{~mm}$.

III. Modelado de muestras mediante pulidora a la dimensión aproximada de 5 x $5 \mathrm{~mm}$ (5 a $20 \mathrm{mg})$.

IV. Almacenamiento de muestras a temperatura de laboratorio durante un periodo de 48 horas.

V. Pesado de muestras mediante báscula de precisión.

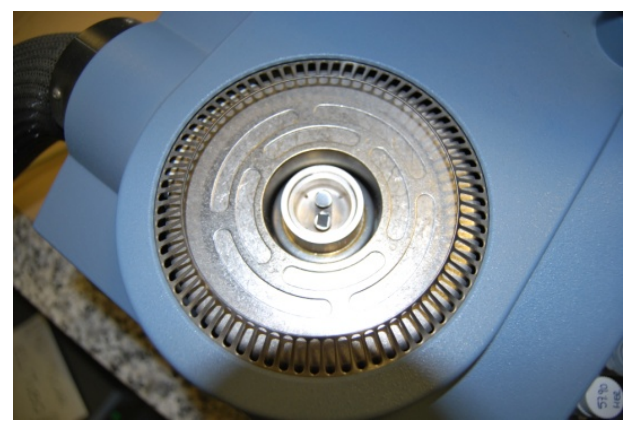

Fig. 3.68. Ensayo de DSC

VI. Ensayo mediante máquina de calorimetría diferencial de barrido en atmósfera de nitrógeno a una velocidad de $10{ }^{\circ} \mathrm{C} / \mathrm{min}$ durante los dos ciclos de calentamiento y de $20{ }^{\circ} \mathrm{C} / \mathrm{min}$ en el ciclo de enfriamiento (Fig. 3.68). El rango de temperatura empleado en el ensayo es de $30^{\circ} \mathrm{C}$ a $180^{\circ} \mathrm{C}$.

En cuanto al diseño experimental, se realizan tres ensayos en cada tipo de barra CA14, CC12 y CT13, con un total de 9 ensayos. Por lo tanto, se ha 
decidido un diseño completamente aleatorizado de todos los ensayos en un mismo día (Tabla 3.40).

\begin{tabular}{cccccccccc}
\hline Tipo de barra & CA14 & CA14 & CA14 & CC12 & CC12 & CC12 & CT13 & CT13 & CT13 \\
\hline $\begin{array}{c}\text { Posición } \\
\text { Ensayo }\end{array}$ & 2 & 9 & 5 & 1 & 4 & 3 & 8 & 6 & 7 \\
\hline
\end{tabular}

Tabla 3.40. Diseño del plan de ensayos de DSC.

La denominación de las probetas utilizada en el ensayo de DSC para el cálculo de la $\mathrm{T}_{\mathrm{g}}$, es la siguiente:

\section{Tipo de Ensayo / Tipo de Barra / Posición de Ensayo.}

Por ejemplo:

\section{$\mathrm{DSC} / \mathrm{CT} 13 / 8$}

corresponde al ensayo de DSC de la barra CT13 ensayada en la posición 8.

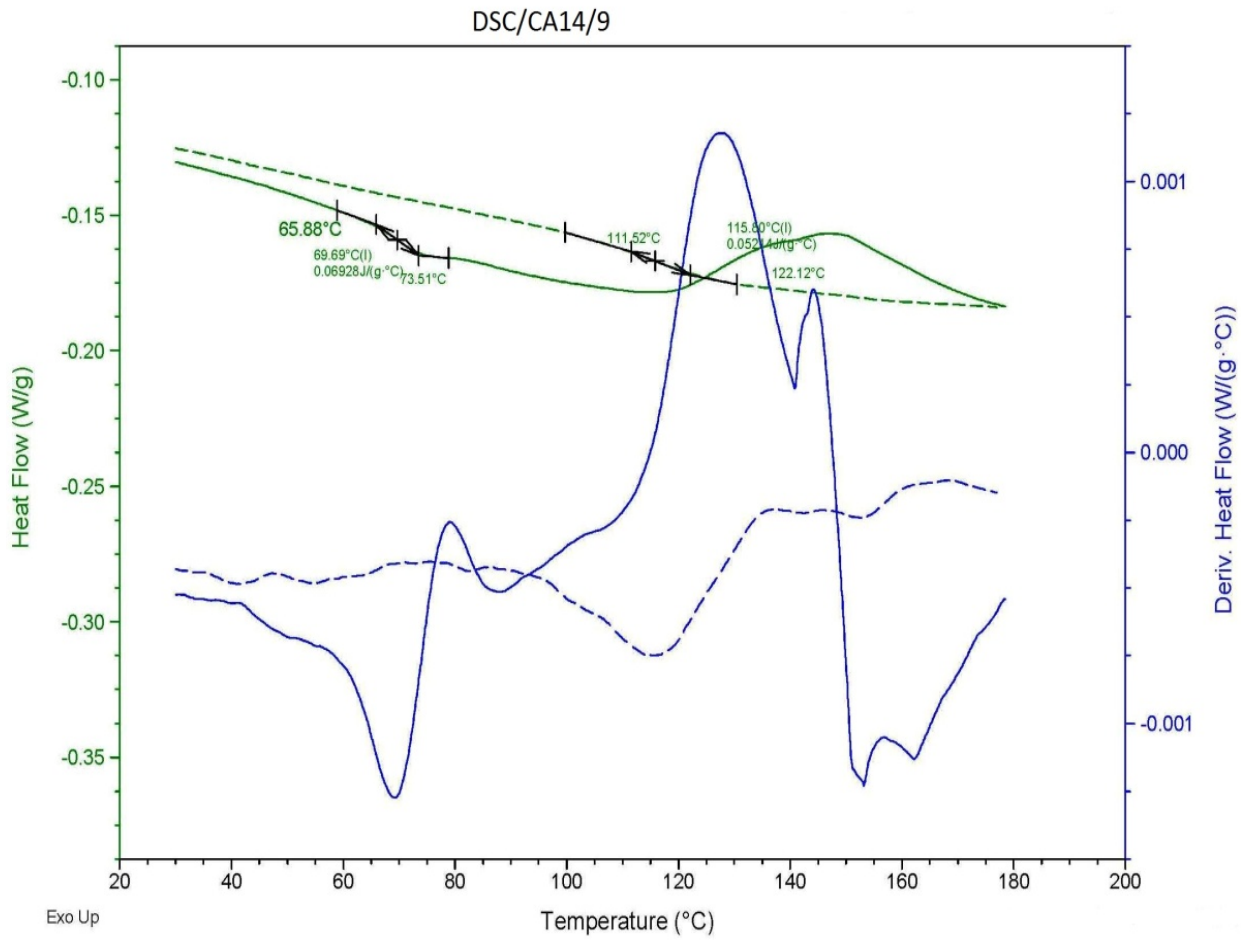

Fig. 3.69. Gráfica de relación entre la tasa de calor y la temperatura en CA14. 
En la Tabla 3.41 se exponen los resultados de los ensayos de DSC en cada tipo de barra. Los tres valores de temperatura de $\mathrm{T}_{\mathrm{g}}$ para cada uno de los dos ciclos de calentamiento realizados $T_{i}, T_{m}$ y $T_{f}$ corresponden a la temperatura inicial extrapolada, temperatura media y temperatura de inflexión o final, respectivamente, de la función que define el cambio del flujo de calor respecto de la temperatura, donde la derivada de dicha función refleja una mayor reacción endotérmica de la muestra en la cual se produce la $T_{g}$. Puesto que ASTM E 1356 dispone que las tres temperaturas son adecuadas para el cálculo de la $T_{g}$, en este caso se selecciona la $\mathrm{T}_{\mathrm{m}}$, recomendada por dicha norma, para el cálculo de la $\mathrm{T}_{\mathrm{g}}$. Del mismo modo, la $\mathrm{T}_{\mathrm{m}}$ seleccionada corresponde al segundo ciclo de calentamiento (definido por ASTM E 1356), puesto que en el primer ciclo, tal y como se muestra en la Fig. 3.69 y Tabla 3.41, la matriz polimérica no ha polimerizado completamente (a causa de su historia térmica), debido a que la relación del flujo de calor en función de la temperatura se incrementa en abscisas y ordenadas (su derivada es exotérmica), por lo que su $T_{g}$ se incrementa notablemente.

\begin{tabular}{ccccc}
\hline \multirow{2}{*}{ Muestra } & $\begin{array}{c}\text { Tipo de } \\
\text { temperatura }\end{array}$ & $\begin{array}{c}1^{\text {er }} \text { Ciclo } \\
\left({ }^{\circ} \mathrm{C}\right)\end{array}$ & $\begin{array}{c}2^{\text {do }} \text { Ciclo } \\
\left({ }^{\circ} \mathrm{C}\right)\end{array}$ & $\begin{array}{c}\mathrm{Tg} \\
\left({ }^{\circ} \mathrm{C}\right)\end{array}$ \\
\hline \multirow{3}{*}{$\mathrm{DSC} / \mathrm{CA} 14 / 2$} & $\mathrm{Ti}$ & 64,68 & 109,61 & \\
& $\mathrm{Tm}$ & 69,11 & 110,76 & 110,76 \\
& $\mathrm{Tf}$ & 72,77 & 121,39 & \\
\hline \multirow{2}{*}{$\mathrm{DSC} / \mathrm{CA} 14 / 5$} & $\mathrm{Ti}$ & 68,21 & 111,63 & \\
& $\mathrm{Tm}$ & 70,86 & 119,43 & 119,43 \\
& $\mathrm{Tf}$ & 75,48 & 125,98 & \\
\hline \multirow{2}{*}{$\mathrm{DSC} / \mathrm{CA} 14 / 9$} & $\mathrm{Ti}$ & 65,88 & 111,52 & \\
& $\mathrm{Tm}$ & 69,69 & 115,80 & 115,80 \\
& $\mathrm{Tf}$ & 73,51 & 122,12 & \\
$\mathrm{DSC} / \mathrm{CC} 12 / 1$ & $\mathrm{Ti}$ & 98,61 & 100,20 & \\
& $\mathrm{Tm}$ & 101,37 & 105,70 & 105,70 \\
& $\mathrm{Tf}$ & 107,49 & 113,22 & \\
$\mathrm{DSC} / \mathrm{CC} 12 / 4$ & $\mathrm{Ti}$ & 93,51 & 98,66 & \\
& $\mathrm{Tm}$ & 94,62 & 101,27 & 101,27 \\
& $\mathrm{Tf}$ & 104,92 & 111,34 & \\
\hline \multirow{2}{*}{$\mathrm{DSC} / \mathrm{CC} 12 / 3$} & $\mathrm{Ti}$ & 92,71 & 98,72 & \\
& $\mathrm{Tm}$ & 100,16 & 106,85 & 106,85 \\
& $\mathrm{Tf}$ & 106,16 & 110,64 & \\
\hline \multirow{2}{*}{$\mathrm{DSC} / \mathrm{CT} 13 / 8$} & $\mathrm{Ti}$ & 104,99 & 114,61 & \multirow{2}{*}{124,15} \\
& $\mathrm{Tm}$ & 117,14 & 124,15 & \\
& & & &
\end{tabular}




\begin{tabular}{lcccc} 
& $\mathrm{Tf}$ & 125,05 & 128,41 & \\
\hline & $\mathrm{Ti}$ & 111,22 & 115,20 & \\
$\mathrm{DSC} / \mathrm{CT} 13 / 6$ & $\mathrm{Tm}$ & 119,41 & 123,58 & 123,58 \\
& $\mathrm{Tf}$ & 119,3 & 125,63 & \\
\hline & $\mathrm{Ti}$ & 112,11 & 115,81 & \\
$\mathrm{DSC} / \mathrm{CT} 13 / 7$ & $\mathrm{Tm}$ & 116,64 & 122,48 & 122,48 \\
& $\mathrm{Tf}$ & 125,04 & 126,99 & \\
\hline
\end{tabular}

Tabla 3.41. Resultados del ensayo de DSC en barras CA14, CC12 y CT13.

\subsubsection{Microscopia Óptica}

Las imágenes de microscopia óptica se realizan en muestras de barras de CFRP arenadas CA8, CA14, corrugadas CC12 y texturizadas CT13, que no se han sometido a ensayo de pullout, pero si a las diferentes condiciones ambientales de hielo/deshielo, $20^{\circ} \mathrm{C}$ y $80{ }^{\circ} \mathrm{C}$. De este modo se obtiene el comportamiento de las barras de CFRP ante cada condición ambiental (condiciones extremas de $\mathrm{HD}$ y $80^{\circ} \mathrm{C}$, y condición de control de $20^{\circ} \mathrm{C}$ ), sin estar sometidas a ningún tipo de tensión. En todos los casos las imágenes corresponden a la sección transversal de la barra.

Los materiales y equipos empleadas en este ensayo son los siguientes:

- Barras de CFRP arenadas CA8 y CA14, corrugadas CC12 y texturizadas CT13.

- Cortadora de la marca Remet modelo TR100 Evolution (Fig. 3.70.a) y cortadora de precisión de la marca Struers modelo Accutom 5 (Fig. 3.63.b).

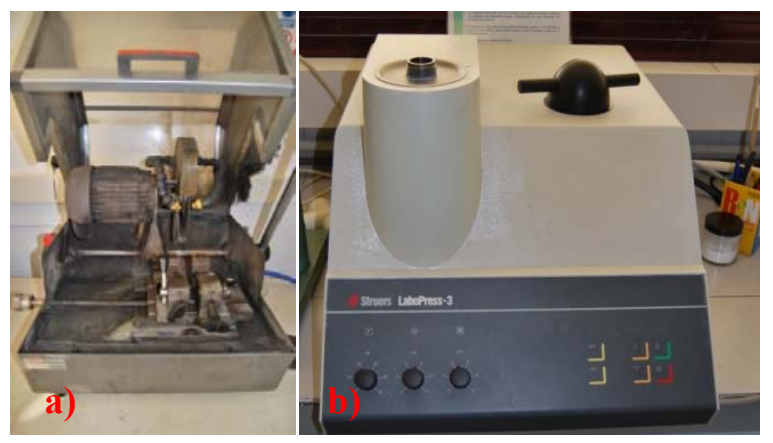

Fig. 3.70. Equipos de ensayo: a) Cortadora; b) Embutidora; c) Microscopio Óptico 
- Máquina de preparación metalográfica en caliente mediante Polimetilmetacrilato de la marca Struers modelo LaboPress-3 (Fig. 3.70.b).

- Máquina pulidora de muestras de la marca Struers modelo LaboPol-5 y LaboPol-21.

- Lijas de finura 250, 500, 1000 y 4000. Paños de 3 y $1 \mu$.

- Cámaras climáticas: a) Para condición climática $20^{\circ} \mathrm{C}$ se emplea la cámara de la marca CTS modelo CW10/4 (Fig. 3.50.b); b) Para la condición climática de $80{ }^{\circ} \mathrm{C}$ se emplea la cámara climática de la marca P.Selecta modelo Conterm (Fig. 3.50.c); c) Para condición de Hielo/Deshielo a $-20{ }^{\circ} \mathrm{C}$ se emplea el arcón frigorífico de la marca Zanussi modelo ZA38 (Fig. 3.51).

- Caja térmica (Fig. 3.7c), de poliestireno extruido XPS de $30 \mathrm{~mm}$ espesor y $\lambda=0,034 \mathrm{~W} / \mathrm{m} \mathrm{K}$, de dimensión interior 205 x $205 \mathrm{x}$ $205 \mathrm{~mm}$. Para el transporte de muestras hasta captación de imágenes.

- Microscopio óptico de la marca Nikon modelo Eclipse LV 100 (Fig. 3.71.a.).
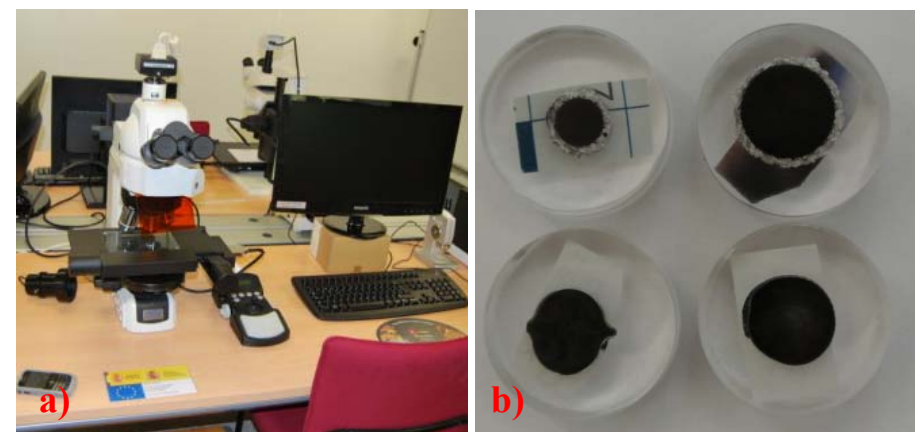

Fig. 3.71. a) Microscopio Óptico; b) Muestras de ensayo

En cuanto al procedimiento y metodología de este ensayo, inicialmente se han preparado las muestras metalográficamente (Fig. 3.71.b). Seguidamente se han sometido a las condiciones de temperatura consideradas (HD, $20^{\circ} \mathrm{C}$ y 80 
${ }^{\circ} \mathrm{C}$ ), se han trasladado las muestras al microscopio dentro de una caja térmica (en el caso de $80{ }^{\circ} \mathrm{C}$ y $\mathrm{HD}$, en el interior de la caja térmica se han introducido piedras a $110{ }^{\circ} \mathrm{C}$ y enfriadores de hielo a $-20{ }^{\circ} \mathrm{C}$, respectivamente) y se han obtenido las imágenes de dichas muestras a la temperatura considerada.

El diseño de este ensayo es idéntico el ensayo posterior de microdureza, debido a que este último ensayo se realiza seguidamente al de microscopia óptica sobre las mismas probetas y condiciones de termperatura. Por lo tanto, debido a la restricción de una temperatura de trabajo por cada día de ensayo, se selecciona un diseño de bloques aleatorizados, en el cual los tratamientos son el tipo de barra y los bloques cada condición ambiental (Tabla 3.42). La posición de ensayo de cada tipo de barra es aleatoria cada día de ensayo. Se captan imágenes de una muestra por cada tipo de barra y temperatura, con un total de 12 muestras.

\begin{tabular}{ccccc}
\hline $\begin{array}{c}\text { Tipo de barra (Tratamiento) } / \\
\text { Condición ambiental (Bloque) }\end{array}$ & CA14 & CA8 & CC12 & CT13 \\
\hline HD & 2 & 4 & 1 & 3 \\
\hline $20^{\circ} \mathrm{C}$ & 3 & 1 & 2 & 4 \\
\hline $80^{\circ} \mathrm{C}$ & 1 & 3 & 4 & 2 \\
\hline
\end{tabular}

Tabla 3.42. Diseño del plan de ensayos de Microscopia Óptica.

La denominación de las probetas es idéntica a la empleada en el ensayo posterior de microdureza. Ésta es la siguiente:

\section{Tipo de Ensayo / Tipo de Barra / Condición Climática}

Por ejemplo:

$$
\text { MICRO / CA8 / } 20
$$

corresponde al ensayo de Microscopia óptica y Microdureza de la barra CA8 sometida a la temperatura de $20^{\circ} \mathrm{C}$ durante 48 horas. 
Los resultados de este ensayo son imágenes de la sección transversal de las barras (tanto en la zona de la superficie de la corruga como en el núcleo de la barra) a diferentes temeperaturas (Figs. 3.72-3.75). Estas imágenes se emplean para el análisis y contraste del comportamiento adherente (obtenido mediante los ensayos de pullout) de las diferentes barras de CFRP.

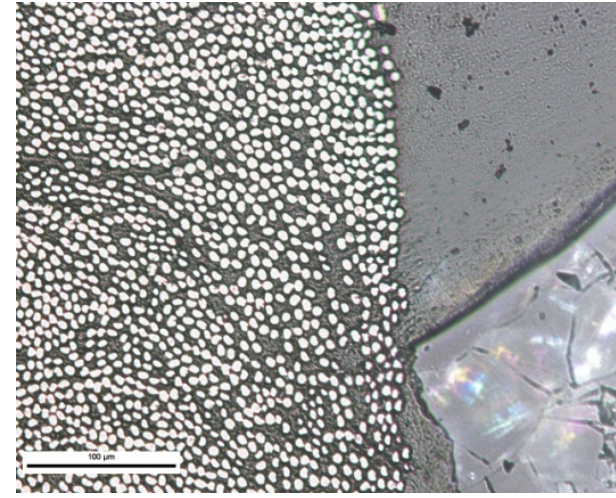

a.1)

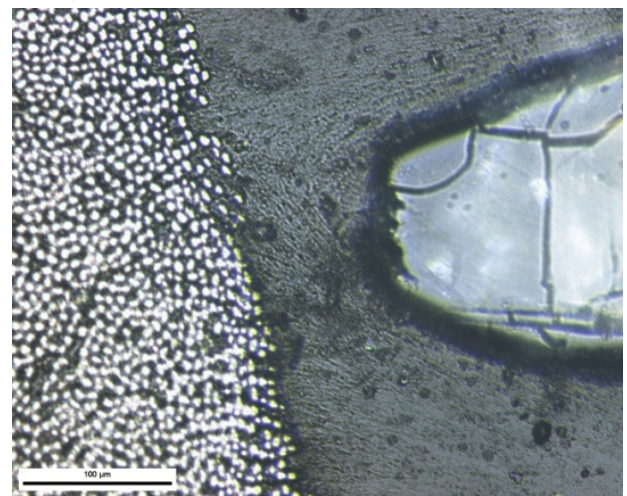

b.1)

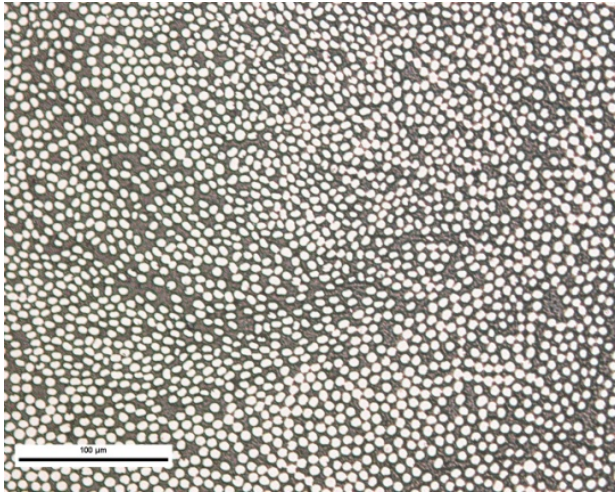

a.2)

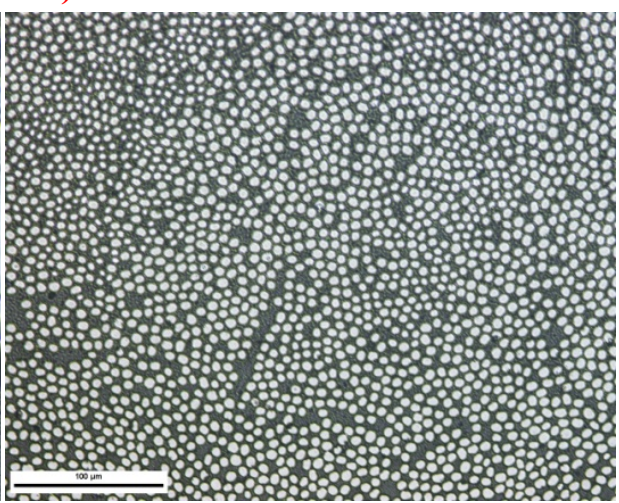

b.2) 


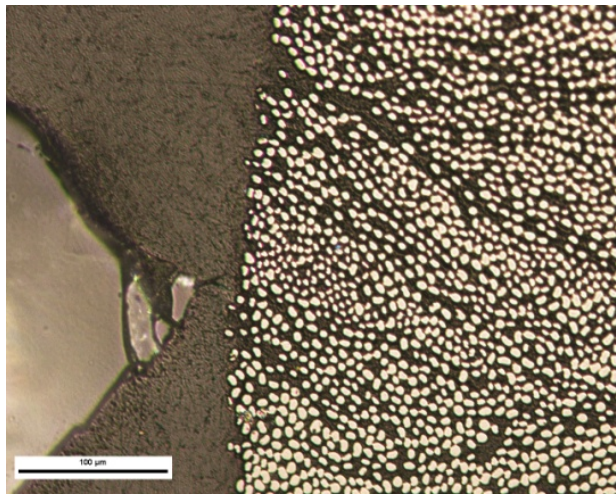

c.1)

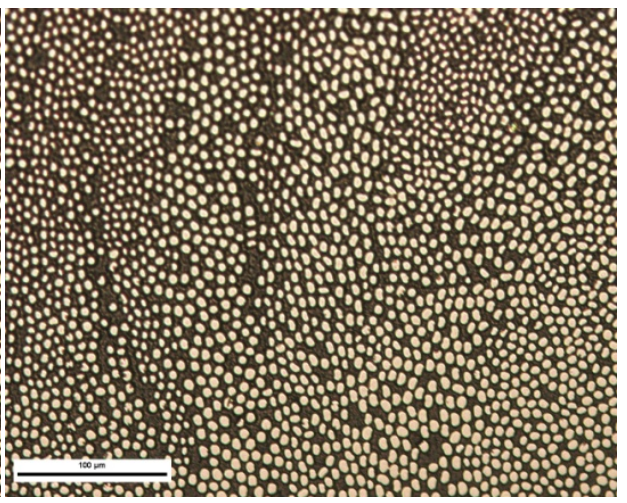

c.2)

Fig. 3.72. Imágenes de las barras CA 8 (x 200): a.1 y a.2) Intefaz núcleo-capa de arenado y núcleo, MICRO/CA8/HD; b.1 y b2) Intefaz núcleo-capa de arenado y núcleo, MICRO/CA8/20; c.1 y c.2) Intefaz núcleo-capa de arenado y núcleo, MICRO/CA8/80;

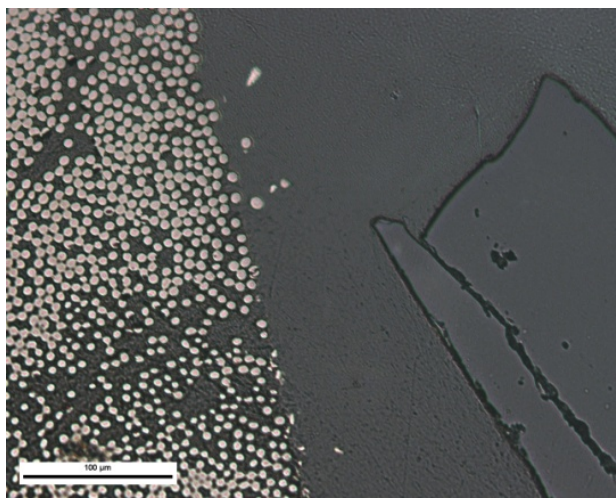
a.1)

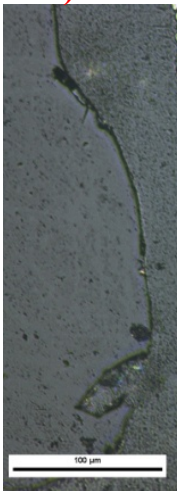

b.1)

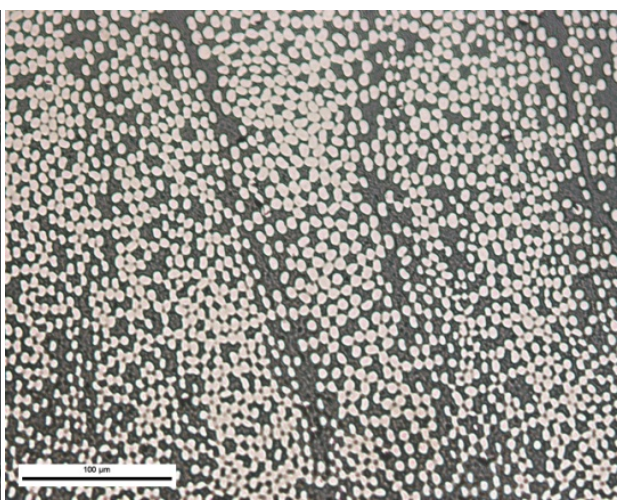

a.2)

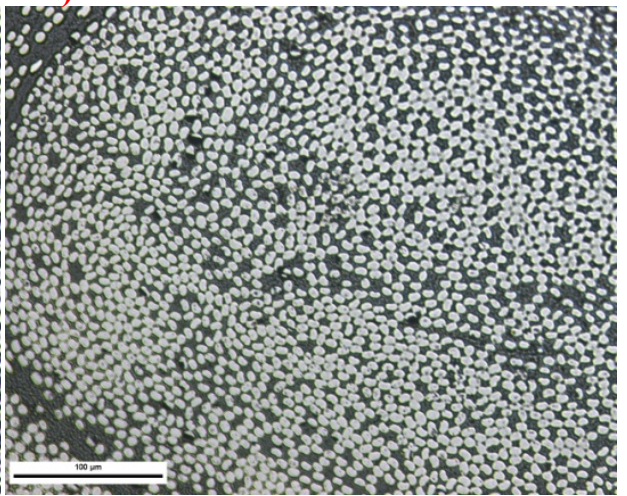

b.2) 


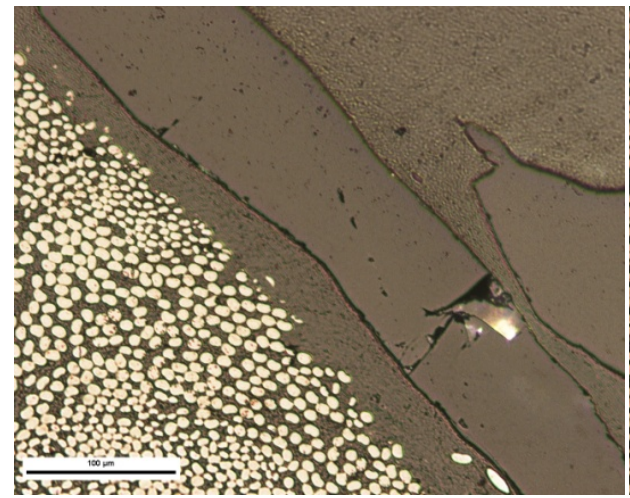

c.1)

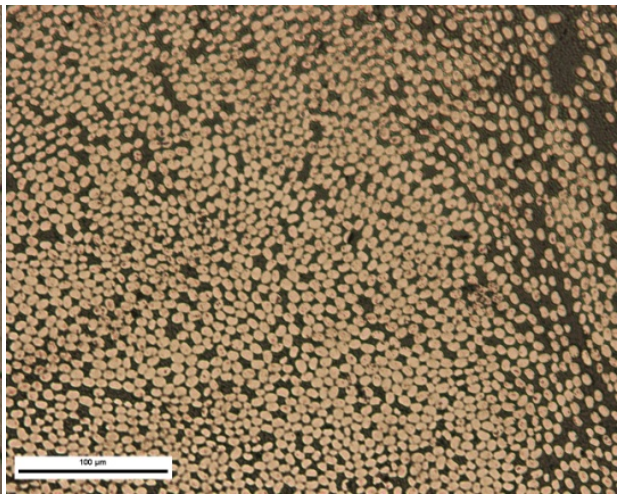

c.2)

Fig. 3.73. Imágenes de las barras CA14 (x 200): a.1 y a.2) Intefaz núcleo-capa de arenado y núcleo, MICRO/CA14/HD; b.1 y b2) Intefaz núcleo-capa de arenado y núcleo, MICRO/CA14/20; c.1 y c.2) Intefaz núcleo-capa de arenado y núcleo, MICRO/CA14/80;

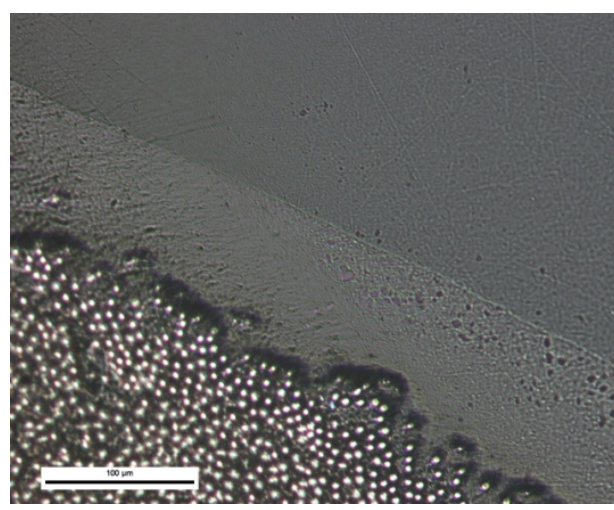

a.1)

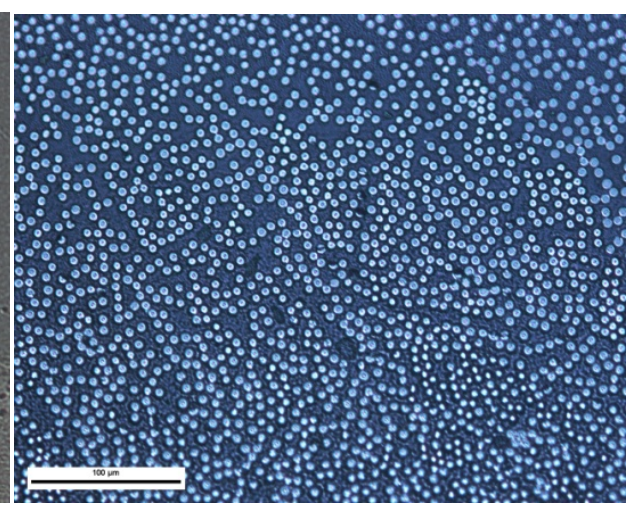

a.2)

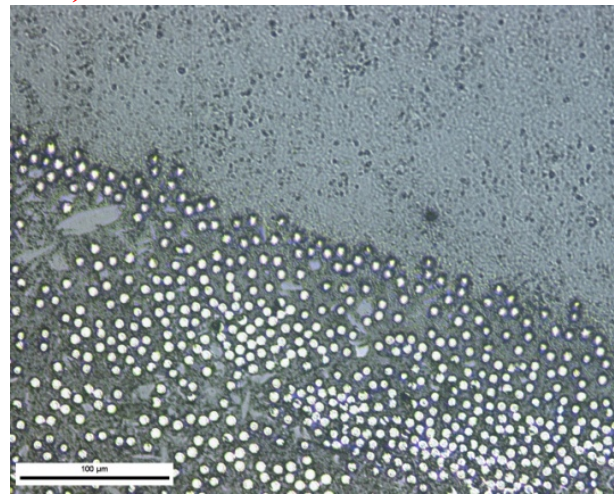

b.1)

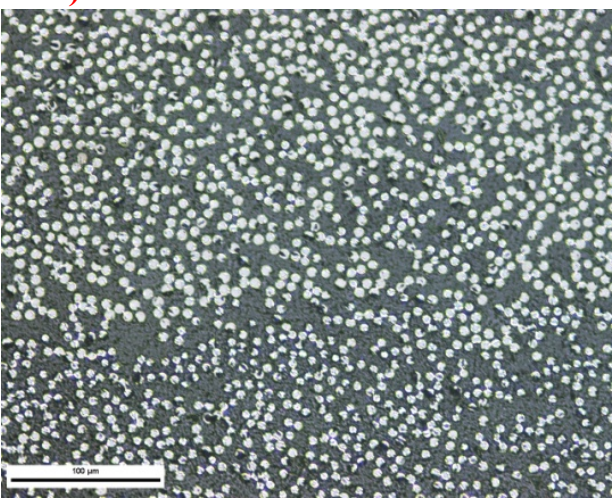

b.2) 


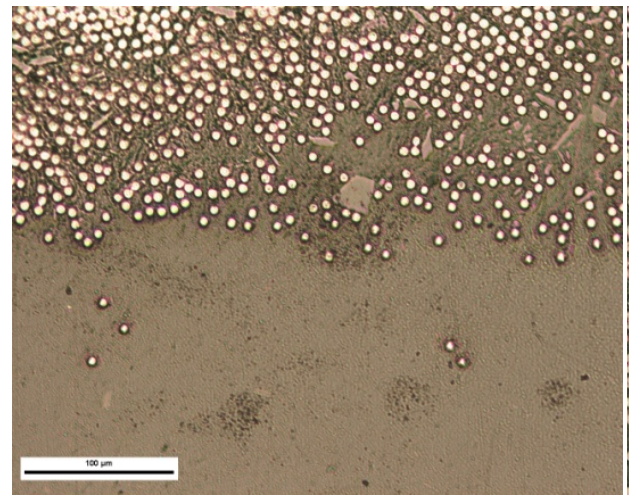

c.1)

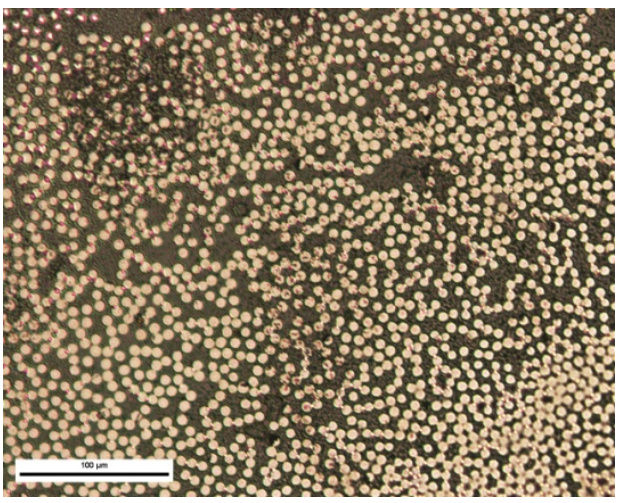

c.2)

Fig. 3.74. Imágenes de las barras $\mathrm{CC} 12$ (x 200): a.1 y a.2) Intefaz núcleo-geometría superficial y núcleo, MICRO/CC12/HD; b.1 y b2) Intefaz núcleo-geometría superficial y núcleo, MICRO/CC12/20; c.1 y c.2) Intefaz núcleo-geometría superficial y núcleo, MICRO/CC12/80;

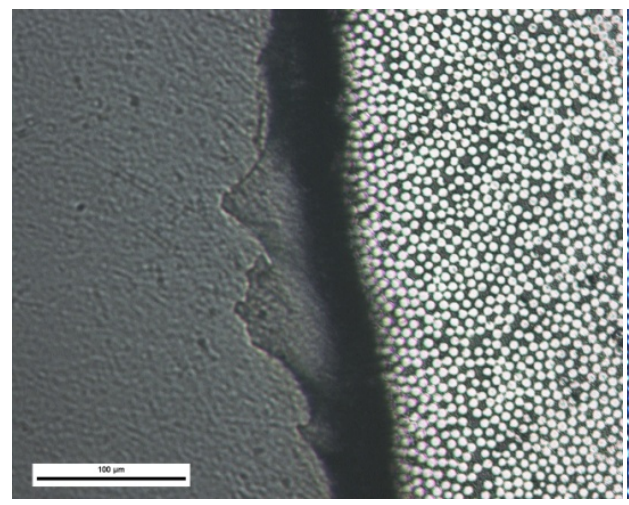
a.1)

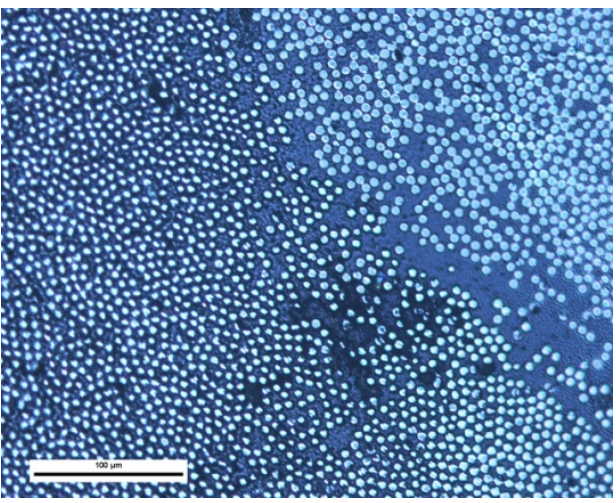

a.1)

a.2)

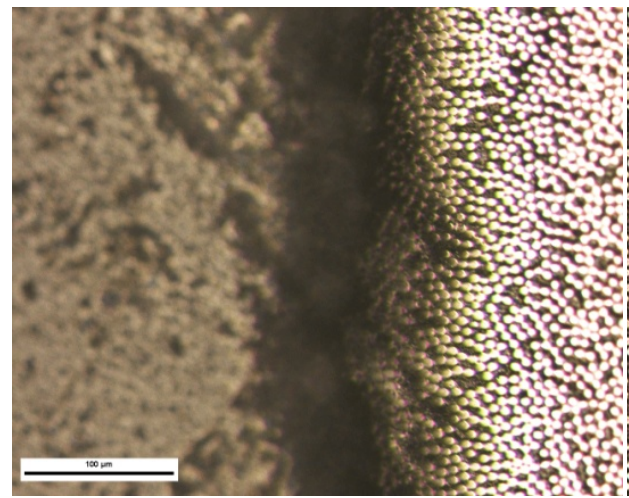

b.1)

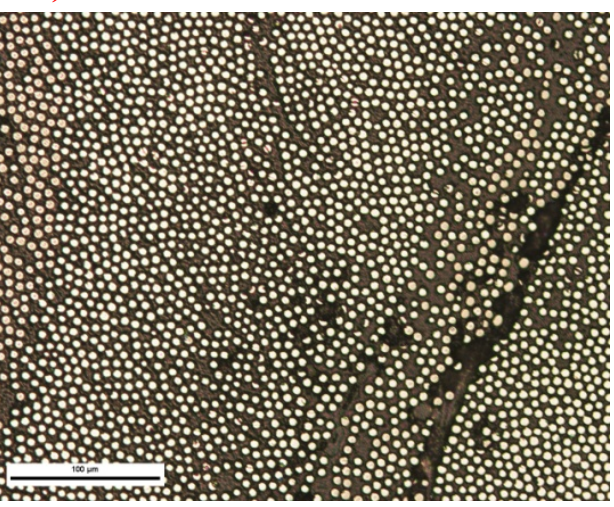

b.2) 


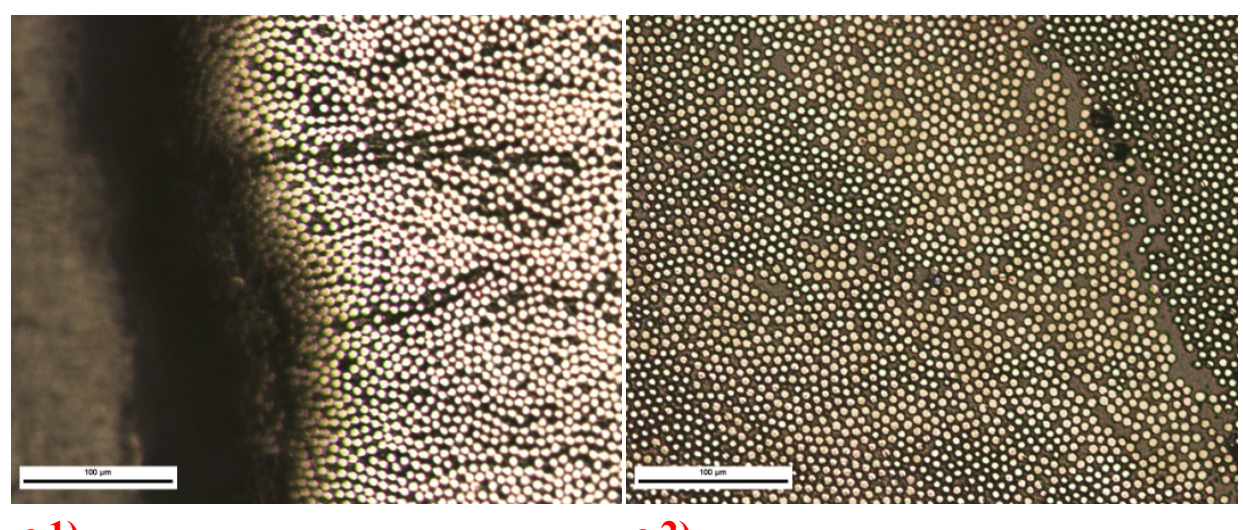
c.1)

c.2)

Fig. 3.75. Imágenes de las barras CT13 (x 200): a.1 y a.2) Intefaz núcleo-geometría superficial y núcleo, MICRO/CT13/HD; b.1 y b2) Intefaz núcleo-geometría superficial y núcleo, MICRO/CT13/20; c.1 y c.2) Intefaz núcleo-geometría superficial y núcleo, MICRO/CT13/80;

\subsubsection{Microdureza}

El ensayo de Microdureza se realiza siguiendo las disposiciones de ASTM E 384 y ASTM C 1327. Este ensayo consiste en la introducción de una micro punta con forma piramidal, de dimensiones estandarizadas, con fuerza, velocidad y duración conocidas, en la muestra de ensayo, para posteriormente medir la huella realizada. Puesto que el objetivo de este ensayo es la obtención de la dureza de la matriz polimérica de cada tipo de barra de CFRP en las condiciones de temperatura de $\mathrm{HD}, 20^{\circ} \mathrm{C}$ y $80^{\circ} \mathrm{C}$ sin someterse a ningún ensayo mecánico, previamente al ensayo de microdureza se expone a cada muestra a unas condiciones de temperatura genuinamente iguales a las realizadas en el ensayo de pullout.

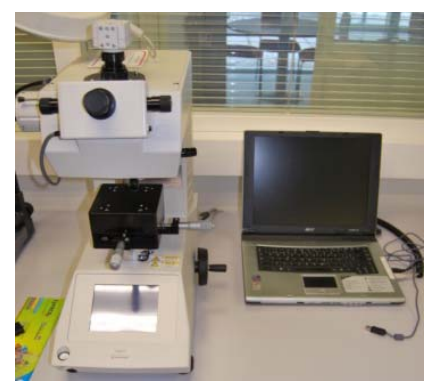

Fig. 3.76. Máquina de ensayo de microdureza. Microdurómetro Shimadzu modelo HMV-2. 
Los materiales y máquinas de ensayo son los mismos que los empleados en el ensayo de Microscopia Óptica a excepción de la máquina de ensayo, que en este caso se trata de una máquina de microdureza de la marca Shimadzu modelo HMV-2, con una precisión de medición de $0,01 \mu$ (Fig. 3.76).

El proceso de fabricación, temperatura de trabajo y transporte de las muestras de ensayo es análogo al realizado en el ensayo de Microscopia Óptica. Sin embargo, el procedimiento y metodología de ensayo de Microdureza se realiza mediante los siguientes pasos:

I. Ajuste de los parámetros de ensayo: Carga igual a 0,01 kp y duración total ensayo de10 $\mathrm{s}$.

II. Hincado de la punta piramidal.

III. Medición de la huella realizada.

IV. Determinación de la dureza en Vickers "HV” $\left(\mathrm{kp} / \mathrm{mm}^{2}\right)$.

El diseño del plan de ensayos y la denominación de las muestras es idéntico al descrito en el apartado 3.4.3.3. "Microscopia Óptica". Sin embargo, en este ensayo, se realizan por cada muestra 3 mediciones de la dureza en la matriz polimérica del núcleo de cada tipo de barra (CA8, CA14, CC12 y CT13) y 3 mediciones en la resina polimérica de la geometría superficial de los tipos de barra CA8, CA14 y CC12. Los resultados obtenidos en el ensayo de Microdureza se muestran en la Tabla 3.43.

\begin{tabular}{|c|c|c|c|c|}
\hline \multirow{2}{*}{ Muestra } & \multirow{2}{*}{$\begin{array}{c}\text { Zona } \\
\text { ensayo }\end{array}$} & \multirow{2}{*}{$\begin{array}{c}\mathrm{N}^{\mathrm{o}} \\
\text { Repetición }\end{array}$} & \multicolumn{2}{|c|}{ Dureza Vickers “HV” } \\
\hline & & & $\mathrm{Kp} / \mathrm{mm}^{2}$ & $\mathrm{MPa}$ \\
\hline \multirow{6}{*}{$\mathrm{MICRO} / \mathrm{CA} 8 / \mathrm{HD}$} & \multirow{3}{*}{$\begin{array}{l}\text { Geometría } \\
\text { Superficial }\end{array}$} & 1 & 22,00 & 215,60 \\
\hline & & 2 & 21,90 & 214,62 \\
\hline & & 3 & 21,90 & 214,62 \\
\hline & \multirow{3}{*}{ Núcleo } & 1 & 43,90 & 430,22 \\
\hline & & 2 & 26,10 & 255,78 \\
\hline & & 3 & 29,30 & 287,14 \\
\hline \multirow{4}{*}{ MICRO/CA8/20 } & \multirow{3}{*}{$\begin{array}{l}\text { Geometría } \\
\text { Superficial }\end{array}$} & 1 & 22,30 & 218,54 \\
\hline & & 2 & 22,00 & 215,60 \\
\hline & & 3 & 21,60 & 211,68 \\
\hline & Núcleo & 1 & 27,40 & 268,52 \\
\hline
\end{tabular}




\begin{tabular}{|c|c|c|c|c|}
\hline & & 2 & 27,40 & 268,52 \\
\hline & & 3 & 25,40 & 248,92 \\
\hline \multirow{6}{*}{$\mathrm{MICRO} / \mathrm{CA} 8 / 80$} & \multirow{3}{*}{$\begin{array}{l}\text { Geometría } \\
\text { Superficial }\end{array}$} & 1 & 23,50 & 230,30 \\
\hline & & 2 & 21,30 & 208,74 \\
\hline & & 3 & 24,20 & 237,16 \\
\hline & \multirow{3}{*}{ Núcleo } & 1 & 29,30 & 287,14 \\
\hline & & 2 & 32,90 & 322,42 \\
\hline & & 3 & - & - \\
\hline \multirow{6}{*}{ MICRO/CA14/HD } & \multirow{3}{*}{$\begin{array}{l}\text { Geometría } \\
\text { Superficial }\end{array}$} & 1 & 20,80 & 203,84 \\
\hline & & 2 & 20,70 & 202,86 \\
\hline & & 3 & 20,80 & 203,84 \\
\hline & \multirow{3}{*}{ Núcleo } & 1 & 22,00 & 215,60 \\
\hline & & 2 & 23,70 & 232,26 \\
\hline & & 3 & 23,10 & 226,38 \\
\hline \multirow{6}{*}{ MICRO/CA14/20 } & \multirow{3}{*}{$\begin{array}{l}\text { Geometría } \\
\text { Superficial }\end{array}$} & 1 & 21,70 & 212,66 \\
\hline & & 2 & 20,30 & 198,94 \\
\hline & & 3 & 19,40 & 190,12 \\
\hline & \multirow{3}{*}{ Núcleo } & 1 & 21,10 & 206,78 \\
\hline & & 2 & 22,60 & 221,48 \\
\hline & & 3 & 21,60 & 211,68 \\
\hline \multirow{6}{*}{ MICRO/CA14/80 } & \multirow{3}{*}{$\begin{array}{l}\text { Geometría } \\
\text { Superficial }\end{array}$} & 1 & 21,20 & 207,76 \\
\hline & & 2 & 22,00 & 215,60 \\
\hline & & 3 & 22,30 & 218,54 \\
\hline & \multirow{3}{*}{ Núcleo } & 1 & 32,10 & 314,58 \\
\hline & & 2 & 33,60 & 329,28 \\
\hline & & 3 & - & - \\
\hline \multirow{6}{*}{$\mathrm{MICRO} / \mathrm{CC} 12 / \mathrm{HD}$} & \multirow{3}{*}{$\begin{array}{l}\text { Geometría } \\
\text { Superficial }\end{array}$} & 1 & - & - \\
\hline & & 2 & - & - \\
\hline & & 3 & - & - \\
\hline & \multirow{3}{*}{ Núcleo } & 1 & 44,70 & 438,06 \\
\hline & & 2 & 42,30 & 414,54 \\
\hline & & 3 & 42,30 & 414,54 \\
\hline \multirow{6}{*}{ MICRO/CC12/20 } & \multirow{3}{*}{$\begin{array}{l}\text { Geometría } \\
\text { Superficial }\end{array}$} & 1 & 24,50 & 240,10 \\
\hline & & 2 & 24,30 & 238,14 \\
\hline & & 3 & 26,30 & 257,74 \\
\hline & \multirow{3}{*}{ Núcleo } & 1 & 19,50 & 191,10 \\
\hline & & 2 & 23,20 & 227,36 \\
\hline & & 3 & 21,20 & 207,76 \\
\hline \multirow{6}{*}{ MICRO/CC12/80 } & \multirow{3}{*}{$\begin{array}{l}\text { Geometría } \\
\text { Superficial }\end{array}$} & 1 & 24,50 & 240,10 \\
\hline & & 2 & 25,00 & 245,00 \\
\hline & & 3 & 25,90 & 253,82 \\
\hline & \multirow{3}{*}{ Núcleo } & 1 & 28,90 & 283,22 \\
\hline & & 2 & 33,90 & 332,22 \\
\hline & & 3 & 35,00 & 343,00 \\
\hline \multirow{3}{*}{ MICRO/CT13/HD } & & 1 & 21,60 & 211,68 \\
\hline & Núcleo & 2 & 19,40 & 190,12 \\
\hline & & 3 & 25,50 & 249,90 \\
\hline & & 1 & 17,90 & 175,42 \\
\hline MICRO/CT13/20 & Núcleo & 2 & 23,40 & 229,32 \\
\hline & & 3 & 24,20 & 237,16 \\
\hline
\end{tabular}




\begin{tabular}{lllll}
\hline \multirow{2}{*}{ MICRO/CT13/80 Núcleo } & 1 & 35,30 & 345,94 \\
& & 2 & 35,00 & 343,00 \\
& 3 & 28,20 & 276,36 \\
\hline
\end{tabular}

Las casillas marcadas con un guión (“-“) son valores de ensayo erróneos.

Tabla 3.43. Resultados ensayo Microdureza.

\subsubsection{Microscopia Electrónica de Barrido "SEM"}

El ensayo de microscopia electrónica de barrido o SEM, se realiza con la finalidad de obtener una base para la comprensión del comportamiento adherente de las barras de CFRP durante el ensayo de pullout. Para ello, se realizan imágenes en la sección transversal y longitudinal de los tipos de barras de CFRP arenadas "CA8 y CA14", corrugadas "CC12" y texturizadas "CT13", sometidas previamente al ensayo de pullout en las condiciones de temperatura de $\mathrm{HD}, 20{ }^{\circ} \mathrm{C}$ y $80{ }^{\circ} \mathrm{C}$, en la zona de adherencia situada en la segunda corruga ${ }^{44}$ (en el caso de barras sin corrugas la zona escogida es la equivalente a la segunda corruga de barras corrugadas).

Los materiales y equipos de ensayo empleados en este ensayo son los siguientes:

- Barras de CFRP arenadas "CA8 y CA14", corrugadas "CC12" y texturizadas "CT13"sometidas al ensayo de pullout (Fig. 3.77.a).

- Cortadora de la marca Remet modelo TR100 Evolution (Fig. 3.70.a) y cortadora de precisión de la marca Struers modelo Accutom 5 (Fig. 3.63.b).

- Moldes de PVC de $15 \mathrm{~mm}$ de diámetro (Fig. 3.77.b)

- Resina de epoxi para preparación metalográfica de las muestras en frio de la marca Struers modelo EpoxiFix kit (Fig. 3.77.c).

\footnotetext{
${ }^{44}$ Para unificar criterios se toman las imágenes en la zona de la segunda corruga debido a que se supone que es la zona inicial de mayor tensión adherente.
} 

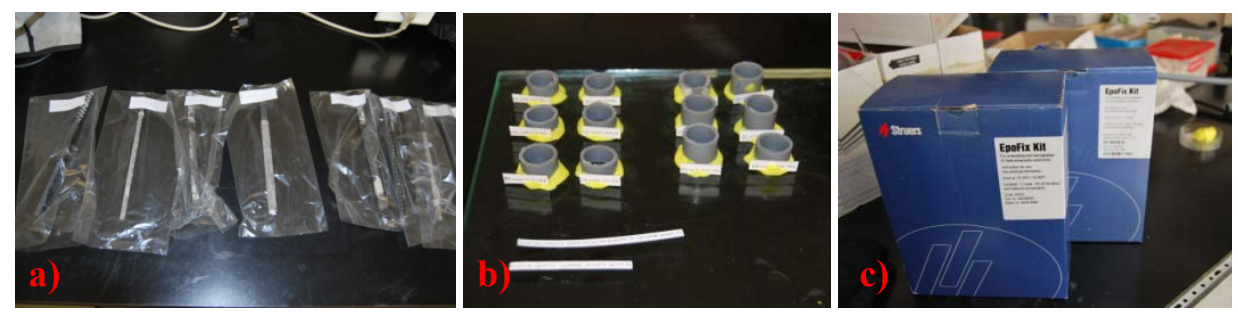

Fig. 3.77. Materiales para ensayo SEM: a) Barras de CFRP a pullout; b) Moldes preparación metalográfíca en frio; c) Resina de epoxi para preparación metalográfica en frio.

- Máquina pulidora de muestras de la marca Struers modelo LaboPol-5 y LaboPol-21 (Fig. 3.78.a y b).

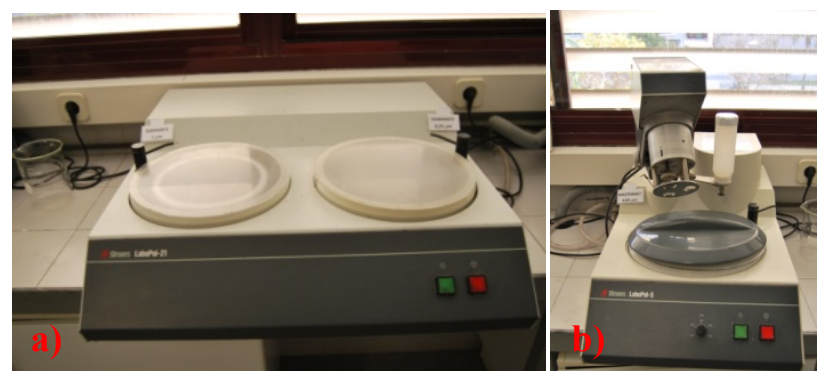

Fig. 3.78. Maquinas pulidoras de muestras a) Labopol-5; b) Labopol-21

- Lijas de finura 250, 500, 1000 y 4000. Paños de 3 y $1 \mu$.

- Recubridor de bajo vacio de la marca BAL-TEC modelo SCD005 (Fig. 3.79.a)
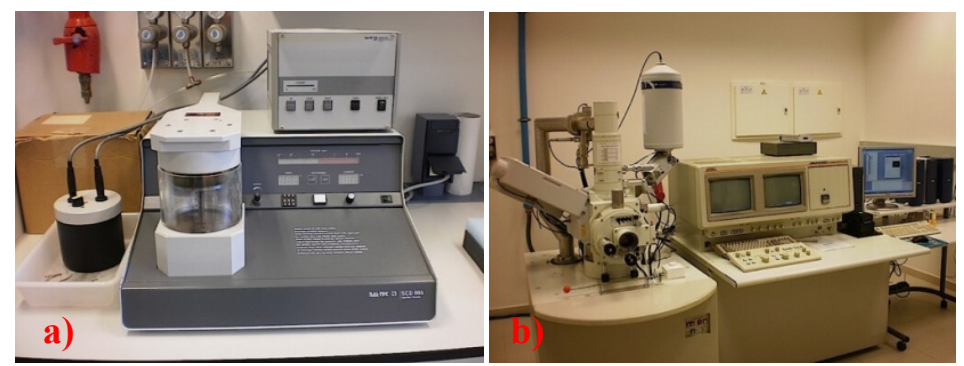

Fig. 3.79. a) Recubridor de muestras; b) Microscopio electrónico de barrido.

- Microscopio electrónico de barrido de la marca JEOL modelo JSM6300 (Fig. 3.79.b). 
En cuanto al procedimiento y metodología de ensayo se ha seguido el siguiente:

I. La selección de las barras para fabricación de muestras de ensayo se ha realizado bajo el supuesto de máxima representatividad, atendiendo a los criterios siguientes: comportamiento adherente, diámetro resultante y modo de rotura. Con base en estos criterios se han seleccionado los lotes 18,1 y 21 , para las condiciones ambientales de $\mathrm{HD}, 20{ }^{\circ} \mathrm{C}$ y $80^{\circ} \mathrm{C}$, respectivamente.

II. Corte grueso $(20 \mathrm{~mm})$ de cada barra del lote considerado, a la altura de la segunda corruga, mediante la cortadora Remet.

III. Corte fino de la muestra de $3 \mathrm{~mm}$ de espesor mediante la cortadora de precisión de la marca Struers modelo Accutom 5.

IV. Preparación metalográfica en frio de las muestras ${ }^{45}$, mediante resina de epoxi y tubos de PVC de $15 \mathrm{~mm}$ de diámetro. Posteriormente, las muestras han sido curadas durante $48 \mathrm{~h}$ a temperatura de laboratorio.

V. Preparación de la cara a observar mediante diferentes tipos de lijas: inicialmente con 500, 1000 y 4000 (con agua), y finalmente con paños de 3 y $1 \mu$ (los paños se realizan con pasta de diamante de 3 y $0,25 \mu$ ). La eliminación de la pasta de diamante de la superficie de la muestra se realiza mediante inmersión de las muestras en un tanque con agua y jabón y la aplicación de ultrasonidos durante $20 \mathrm{~min}^{46}$.

\footnotetext{
${ }^{45}$ Se ha decidido preparar las muestras metalograficamente en frío, con el objetivo no variar las condiciones físicas y químicas de las barras, puesto que la preparación en caliente exige una presión de unos $20 \mathrm{kN}$ y una temperatura de $180^{\circ} \mathrm{C}$ durante al menos $7 \mathrm{~min}$.

${ }^{46}$ No se limpian las muestras con etanol y secado con aire caliente, debido a que este proceso puede dañar los componentes de las barras de CFRP.
} 
VI. Una vez preparadas las muestras se recubren con oro $^{47}$, en su cara a visualizar, mediante el recubridor de bajo vacio (Fig. 3.80).

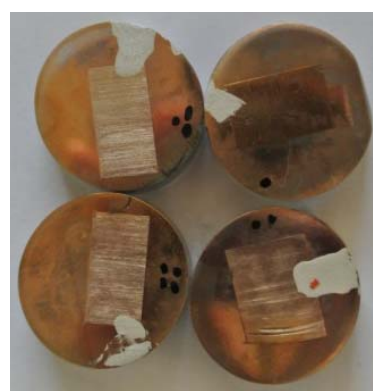

Fig. 3.80. Muestras de CFRP para ensayo de SEM

VII. Captación de imágenes de la sección transversal y longitudinal en cada tipo de muestra, mediante el microscopio electrónico de barrido (a temperatura de laboratorio).

Respecto a la denominación de las muestras se ha seguido el siguiente criterio:

\section{Tipo de Ensayo / Tipo de Barra / Condición Climática}

Por ejemplo:

$\mathrm{SEM} / \mathrm{CC} 12 / 80$

corresponde al ensayo de microscopia electrónica de barrido de la barra de CFRP corrugada "CC12" sometida al ensayo de pullout tras haber permanecido durante 48 horas a una temperatura de $80{ }^{\circ} \mathrm{C}$.

Las imágenes obtenidas mediante el SEM se realizan en tres zonas de la barra (superficie, interfaz superficie/núcleo y núcleo de la barra) a tres niveles de aumentos (x 250, x 1000 y x 5000), tanto en las muestras de sección transversal

${ }^{47}$ Se recubren las muestras con oro puesto que únicamente se van a obtener imágenes, no se va a realizar análisis químico. 
como longitudinal. Mediante las imágenes de menor aumento se observa el resultado del comportamiento mecánico en toda la barra (Fig. 3.81) y a través de las imágenes de mayor aumento se observa el resultado del comportamiento de adherencia fibra/matriz polimérica (Fig. 3.82). Al mismo tiempo ambos tipos de imágenes se observan en las diferentes condiciones térmicas (Fig. 3.83).

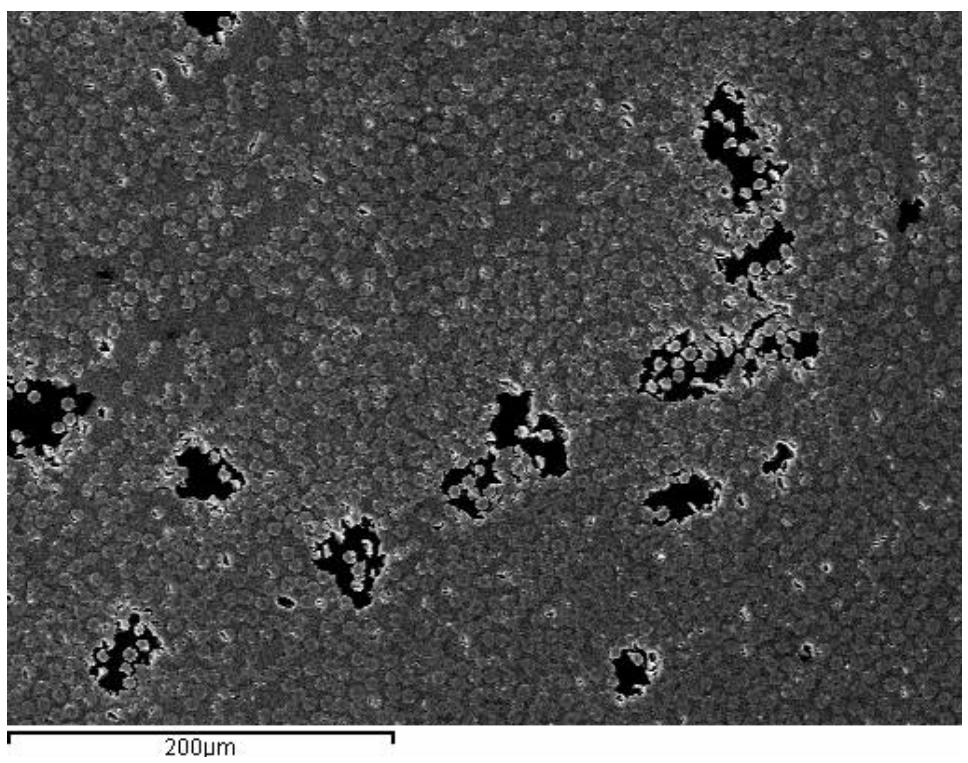

Fig. 3.81. SEM/CC12/HD en núcleo de sección transversal, x 250.

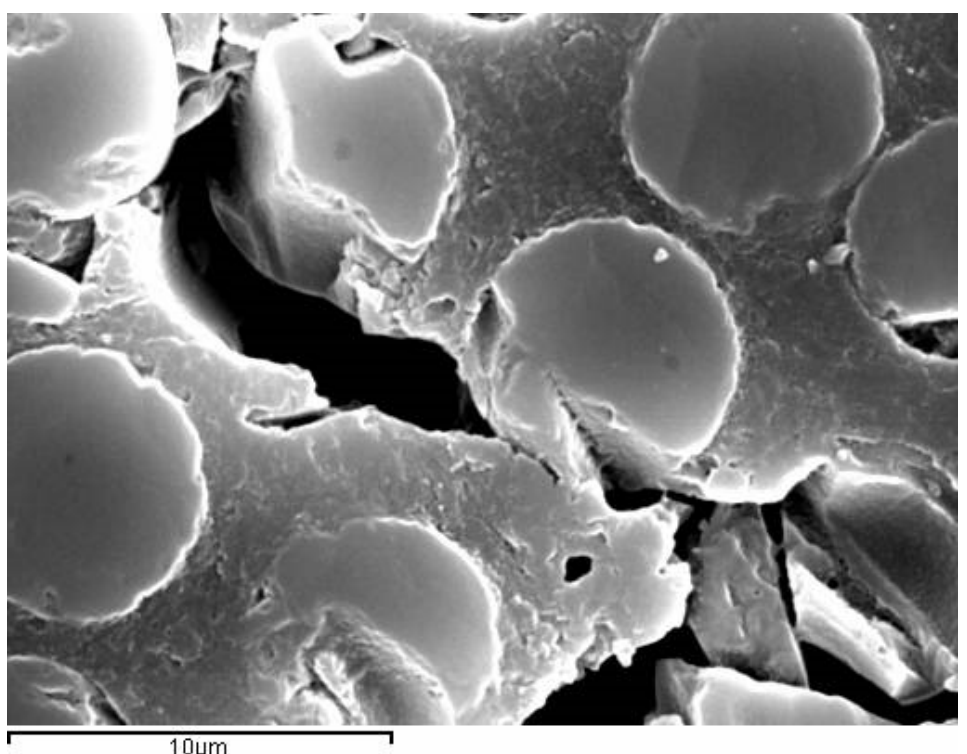

Fig. 3.82. SEM/CC12/HD en núcleo de sección transversal, x 5000. 


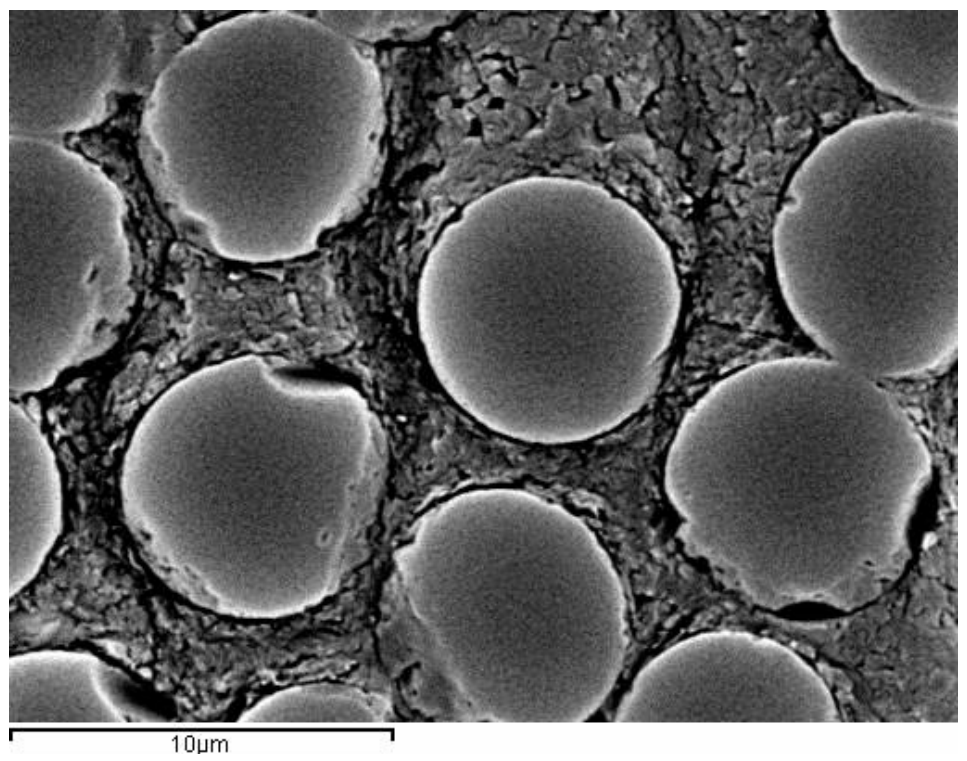

Fig. 3.83. SEM/CC12/80 en interfaz superficie/núcleo de sección transversal, x 5000.

\subsubsection{Microscopia de Fuerza Atómica "AFM"}

Mediante el ensayo de microscopia de fuerza atómica o AFM se obtienen imágenes en tres dimensiones de la interfaz fibra de carbono/matriz polimérica. El método seleccionado para la captación de imágenes es el Tapping, que consiste en una punta afilada oscilante (microscópica) situada en el extremo de una palanca flexible que recorre la superficie de la muestra manteniendo constante una pequeña fuerza de interacción (en este método se eliminan las fuerzas laterales y de presión que pueden dañar las partes blandas). Este movimiento de barrido se realiza mediante un escáner piezo-eléctrico y la interacción punta/muestra se monitoriza reflejando un láser en la parte trasera de la palanca, que se recoge en un detector fotodiodo. El fotodiodo está dividido en 4 segmentos y las diferencias de voltaje entre los distintos segmentos (generalmente los 2 superiores respecto de los 2 inferiores) determinan con precisión los cambios en la inclinación o amplitud de oscilación de la punta. 
Los materiales y equipos empleados en este ensayo de AFM son idénticos a los empleados en SEM, a excepción de la máquina de ensayo, que en este caso se trata de un microscopio de fuerza atómica de la marca Veeco modelo Multimode (Fig. 3.84).

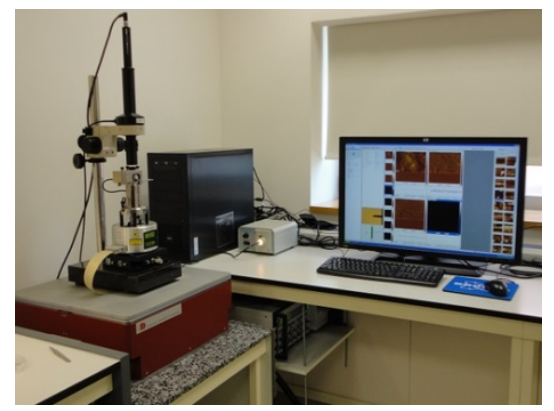

Fig. 3.84. Máquina de ensayo de AFM

El ensayo de AFM se realiza sobre las mismas muestras empleadas en el ensayo de SEM. Sin embargo, en este caso sólo se captan imágenes en las muestras con sección transversal. Dos pequeñas diferencias en el método de ensayo producen que este ensayo se realice posteriormente al ensayo de SEM:

- Debido a que AFM no requiere el paso de corriente a través de la muestras para la obtención de las imágenes, no es necesario recubrir las muestras con un conductor (como es el oro en SEM).

- Las muestras para AFM poseen una dimensión menor a la establecida para SEM, debido a la limitación de la máquina de ensayo a una dimensión máxima de $14 \mathrm{~mm}$ de diámetro y $4 \mathrm{~mm}$ de espesor.

Por lo tanto, una vez concluido el ensayo de SEM el procedimiento y metodología del ensayo de AFM es el siguiente:

I. Eliminación del recubrimiento de oro de las muestras con un paño de $1 \mu$ y pasta de diamante de $0,25 \mu$. La eliminación de la 
pasta de diamante de la superficie de la muestra se realiza mediante inmersión de las muestras en un tanque con agua y jabón y la aplicación de ultrasonidos durante $20 \mathrm{~min}$.

II. Reducción de las dimensiones de las caras laterales y posteriores de cada muestra, a las dimensiones máximas para AFM (14 mm de diámetro y $3 \mathrm{~mm}$ de espesor), mediante diferentes tipos de lijas de 500 y 1000 en medio acuoso (Fig. 3.85).

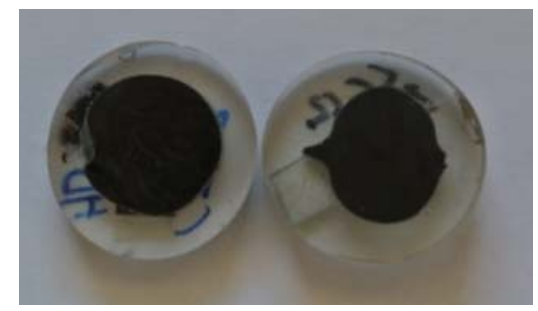

Fig. 3.85. Muestras de ensayo de AFM.

III. Captación de imágenes en cada muestra mediante el microscopio de AFM.

En cuanto a la denominación de las muestras de ensayo, se ha seguido el siguiente criterio:

Tipo de Ensayo / Tipo de Barra / Condición Climática

Por ejemplo:

$\mathrm{AFM} / \mathrm{CA} 8$ / HD

corresponde al ensayo de microscopia de fuerza atómica de la barra de CFRP arenada "CA8" sometida al ensayo de pullout tras haber estado sometida a un ciclo de Hielo/Deshielo.

Las imágenes de AFM se realizan en la zona del núcleo de la sección transversal de cada muestra en una zona de dimensiones 15 x $15 \mu$ (Fig. 3.86). En este ensayo no es posible la obtención de imágenes en diferentes zonas de 
cada muestra debido: a la disminuida dimensión máxima establecida por la máquina de ensayo y a la inmovilidad de la punta oscilante. Por lo tanto, la obtención de imágenes en otra zona de la sección requiere la rotura de la muestra en varias partes, acción que modifica el estado de la barra y muestra un estado no representativo de la misma.

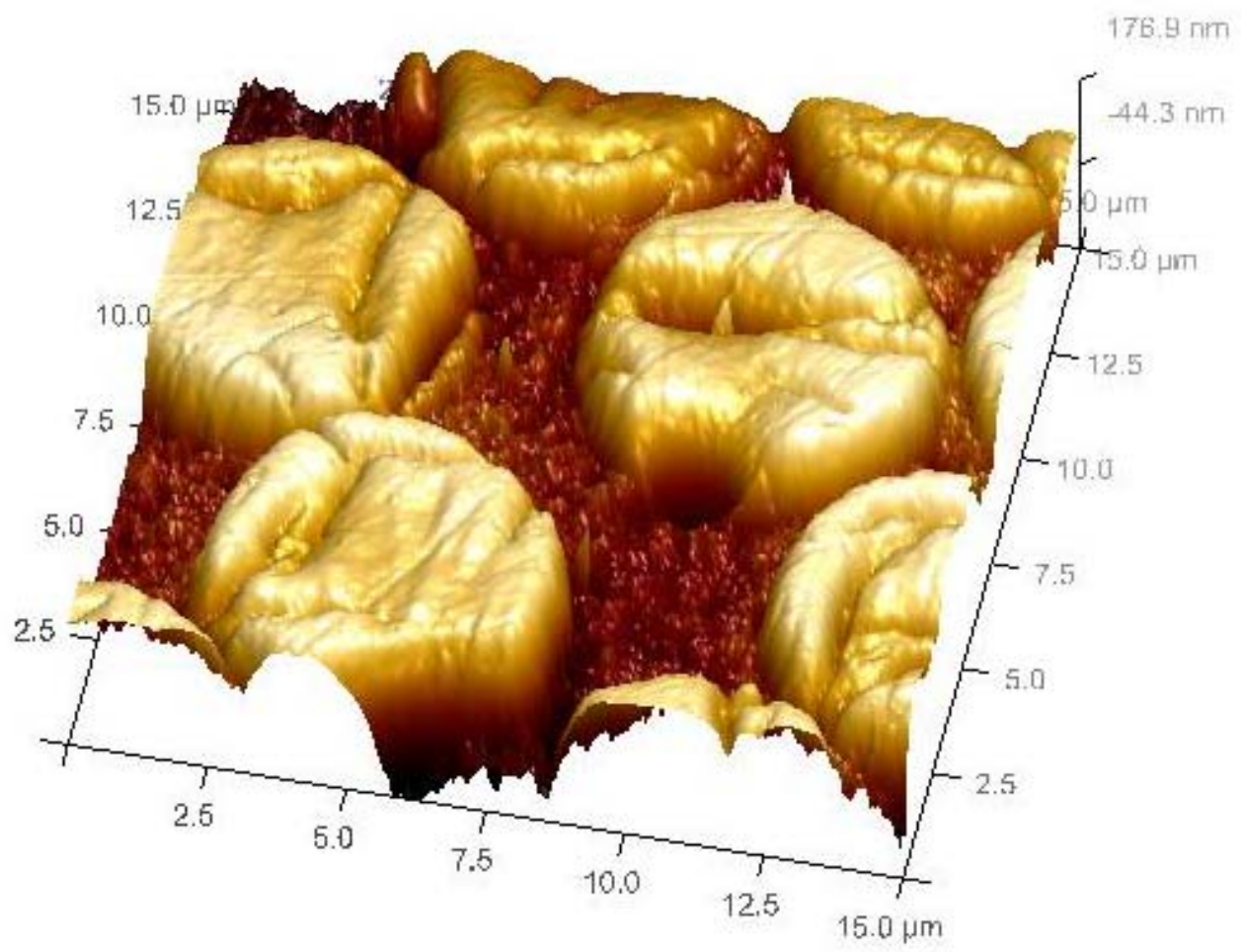

Fig. 3.86. Imagen de la sección transversal AFM/CT13/HD 


\section{CAPÍTULO 4}

\section{Análisis de los Resultados y Discusión}

\subsection{Influencia de Diferentes Parámetros en el Comportamiento Adherente}

En este apartado se analiza la influencia que sobre la adherencia de las barras de CFRP tienen determinados parámetros como: la geometría o acabado superficial, temperatura, resistencia del hormigón, diámetro y temperatura de transición vitrea de la matriz polimérica. Al mismo tiempo, se compara la adherencia de las barras de CFRP con las de acero corrugado en diferentes condiciones ambientales.

\subsubsection{Geometría o Acabado Superficial}

El comportamiento adherente de los diferentes tipos de barras analizadas en esta investigación difiere en gran medida entre los distintos tipos de barras de CFRP y entre estos y las barras de acero corrugadas. Las diferencias afectan al tipo de mecanismo adherente (inicial y bajo tensión máxima), a la tensión adherente máxima, al modo de rotura y a la tensión adherente residual de cada tipo de barra.

En este apartado se analiza y compara el comportamiento adherente de los distintos tipos de geometrías o acabados superficiales de las barras de CFRP (arenadas, corrugadas y texturizadas) y acero (corrugadas) sometidas al ensayo de pullout bajo una misma variable de ensayo como es la condición ambiental de $20^{\circ} \mathrm{C}$ (véase apart. 3.4.2 de la presente investigación).

a) Estudio del Comportamiento Adherente de las Barras de CFRP en Condiciones Térmicas de $20^{\circ} \mathrm{C}$ 


\section{- Barras de CFRP Arenadas}

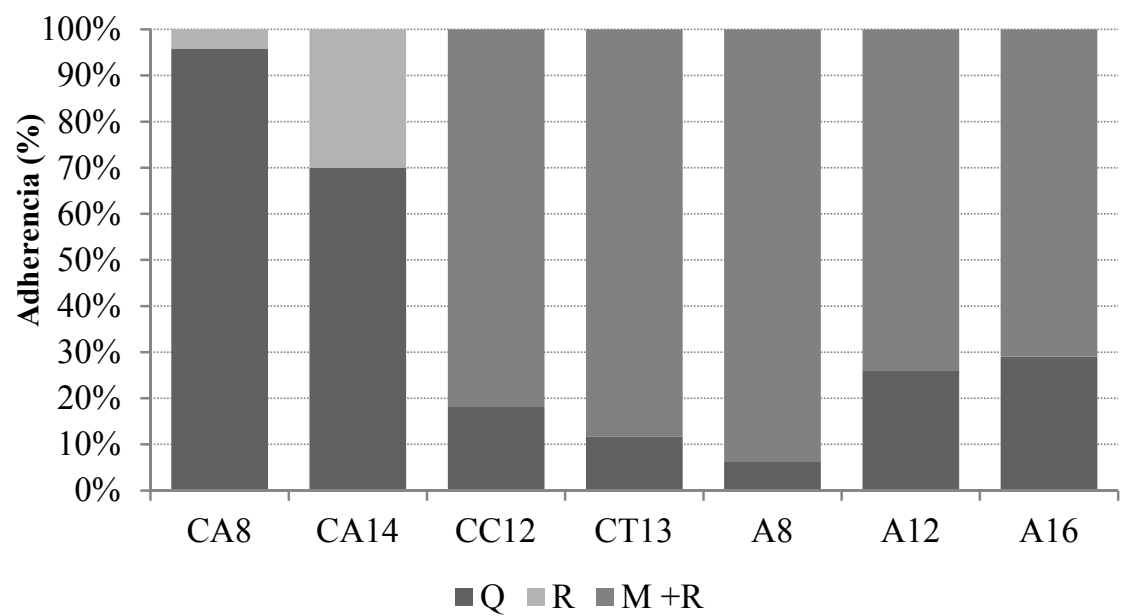

Fig. 4.1. Tipo de mecanismo adherente de las barras de CFRP y acero corrugadas (condición térmica de $20^{\circ} \mathrm{C}$ ). Las siglas $\mathrm{Q}, \mathrm{F}$ y $\mathrm{M}+\mathrm{R}$, corresponden a adhesión química, rozamiento y mecánica más rozamiento, respectivamente.

Las barras de CFRP arenadas, CA8 y CA14, desarrollan casi la totalidad de su adherencia, en torno al 96 y $70 \%$ de la $\tau_{\max }$, respectivamente, mediante adhesión química $^{48}$. Seguidamente al incrementar la tensión, el mecanismo de de adherencia pasa a ser por rozamiento entre el acabado superficial de arena y el hormigón (Fig. 4.1). Este mecanismo adherente difiere del desarrollado por las barras de acero corrugadas, que por el contrario, ejercen inicialmente una adhesión química muy reducida, del 6,37 y 29,05\% de la $\tau_{\max }$, en las barras A8 y A16, respectivamente, mientras que desarrollan casi toda su adherencia, del orden de 93,63 y $70,95 \%$ de la $\tau_{\max }$, a través del mecanismo de acuñamiento de las corrugas contra el hormigón más rozamiento. Por lo tanto, este comportamiento adherente de las barras de CFRP arenadas produce una rigidez de la pendiente inicial de la gráfica de tensión adherente-deslizamiento mayor que el de resto de barras ensayadas (Figs. 4.2 y 4.3), puesto que el deslizamiento a misma tensión adherente es menor. Por ejemplo: a $5 \mathrm{MPa}$ las barras arenadas

\footnotetext{
${ }^{48} \mathrm{La}$ adhesión química ha sido calculada para un deslizamiento medio entre ambos extremos (tensionado y no tensionado) de la barra de $0,1 \mathrm{~mm}$.
} 
CA8 y CA14 deslizan 0,04 mm, mientras que las barras CC12, CT13, A8, A12 y A16 deslizan $0,11,0,60,0,17,0,14$ y $0,13 \mathrm{~mm}$, respectivamente.

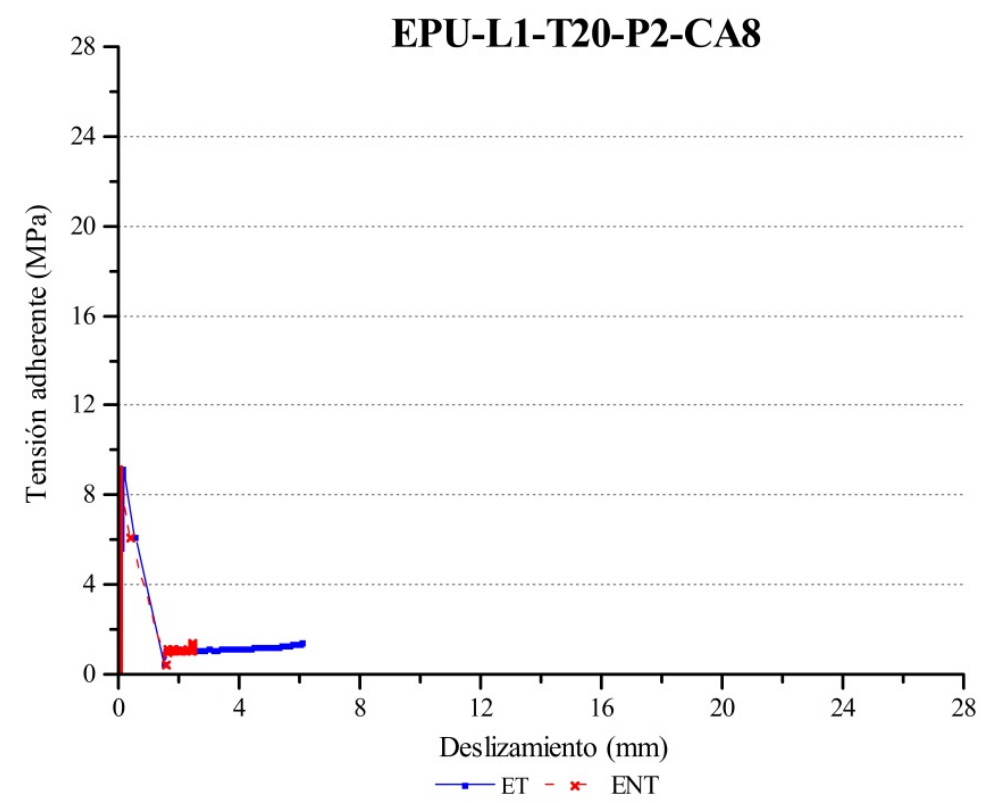

Fig. 4.2. Comportamiento adherente de las barras CA8. Gráfica tensión adherente / deslizamiento en extremo tensionado "ET" y no tensionado "ENT".

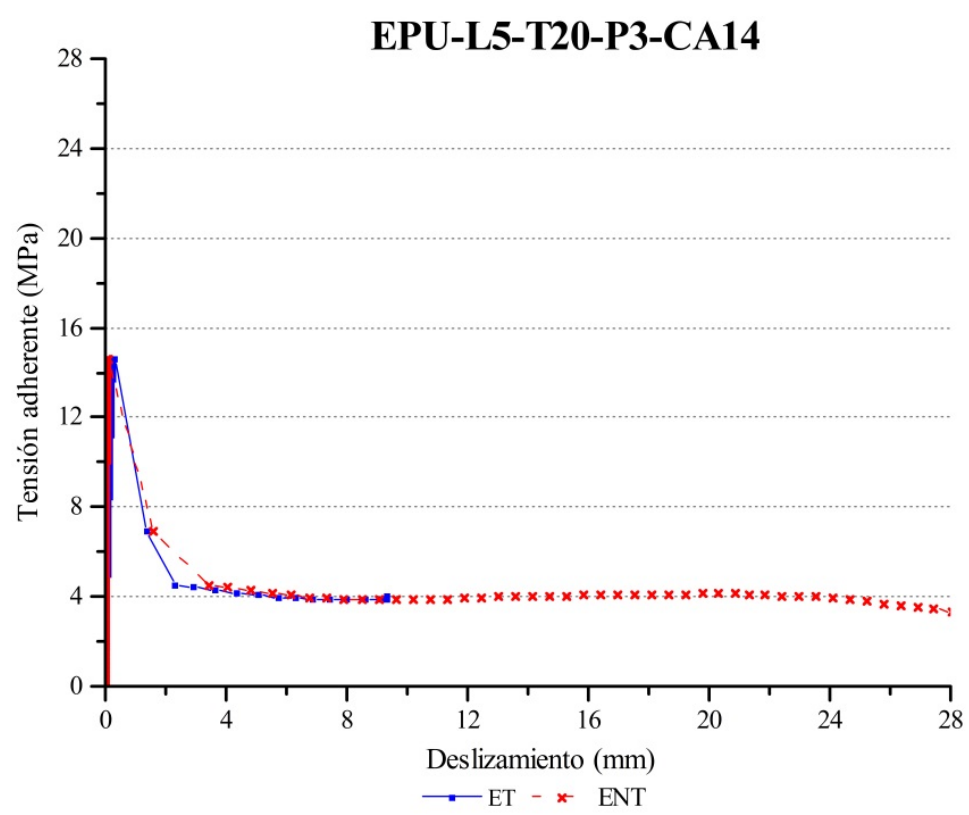

Fig. 4.3. Comportamiento adherente de las barras CA14. Gráfica tensión adherente/deslizamiemto en extremo tensionado "ET" y no tensionado "ENT". 


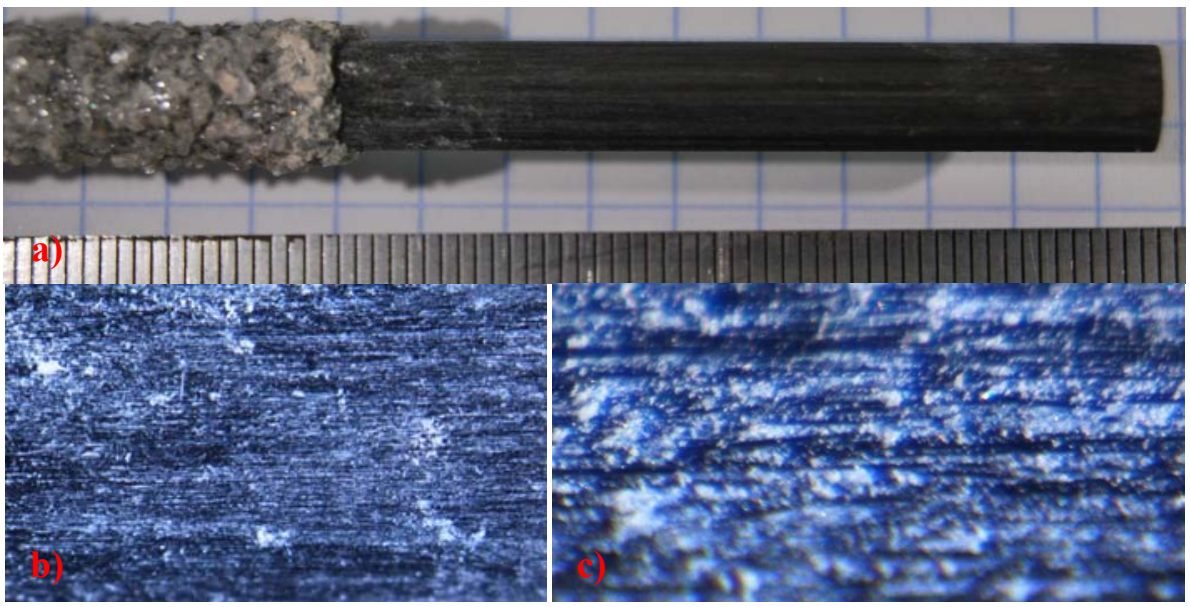

Fig. 4.4. Barra EPU/L5/T20/P6/CA8 tras el ensayo de pullout. a) Longitud adherente sin acabado superficial; b) Imagen microscopio de la superficie de la barra, x 1,5; c) Imagen microscopio de la superficie de la barra, x 9,8.

La máxima tensión adherente media de las barras de CFRP arenadas, CA8 y CA14, presenta unos valores de 9,15 y 13,26 MPa, respectivamente (Figs. 4.2 y 4.3). Una vez alcanzada ésta, se produce la rotura adherente de un modo frágil (durante el ensayo se escucha un ruido muy fuerte cuando tiene lugar la rotura), por rotura de la adhesión entre la capa de arena superficial (resina polimérica y arenado) y el núcleo de la barra (Fig. 4.4), permaneciendo la zona adherente entre el hormigón y la capa de arena intacta (Fig. 4.5). Una vez concluido el ensayo de pullout se comprueba, al dividir la probeta de pullout por la mitad, que el acabado superficial de arena ha permanecido en el interior de la probeta de hormigón extrayéndose la barra de CFRP arenada sin ningún tipo de acabado superficial (Fig. 4.6).

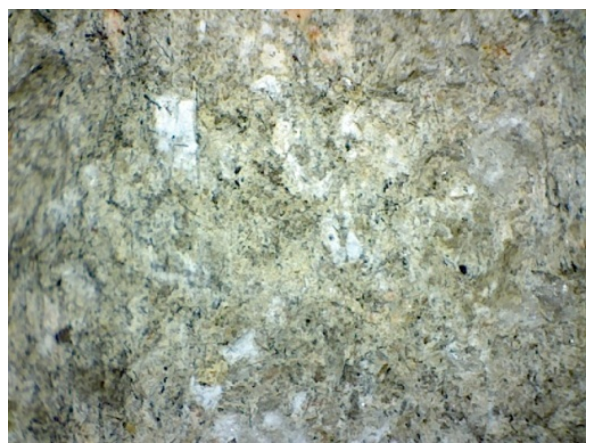

Fig. 4.5. Superficie de la longitud adherente de hormigón tras el ensayo de EPU/L11/T20/P7/CA14 


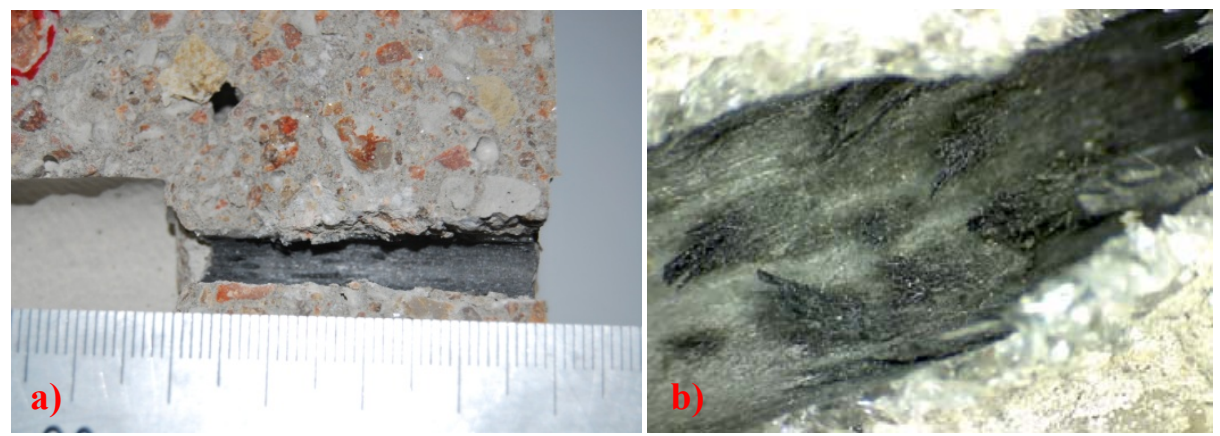

Fig. 4.6. Longitud adherente de hormigón, EPU/L1/T20/P2/CA8, tras el ensayo de pullout. a) Geometría superficial de la barra atrapada en el hormigón; b) Mechones de fibra de carbono en la geometría superficial atrapada por el hormigón.

Por lo tanto, la adherencia de este tipo de barras depende fundamentalmente de la resistencia de la resina polimérica que adhiere el acabado o tratamiento superficial de arena al núcleo de la barra (Figs. 3.72 .b1 y 3.73.b1). Este hecho se confirma mediante las imágenes obtenidas por SEM, en las que se observa, en las barras CA8 y CA14, menores daños en la zona del núcleo de la barra, debido a un nivel tensional muy reducido (Figs. 4.7, 4.8.b, 3.72.b2 y 3.73.b2). Mientras que en la zona próxima a la interfaz entre la capa de arenado y el núcleo se observan mayores daños (Figs. 4.6.b y 4.8,a) producidos por un elevado nivel tensional.
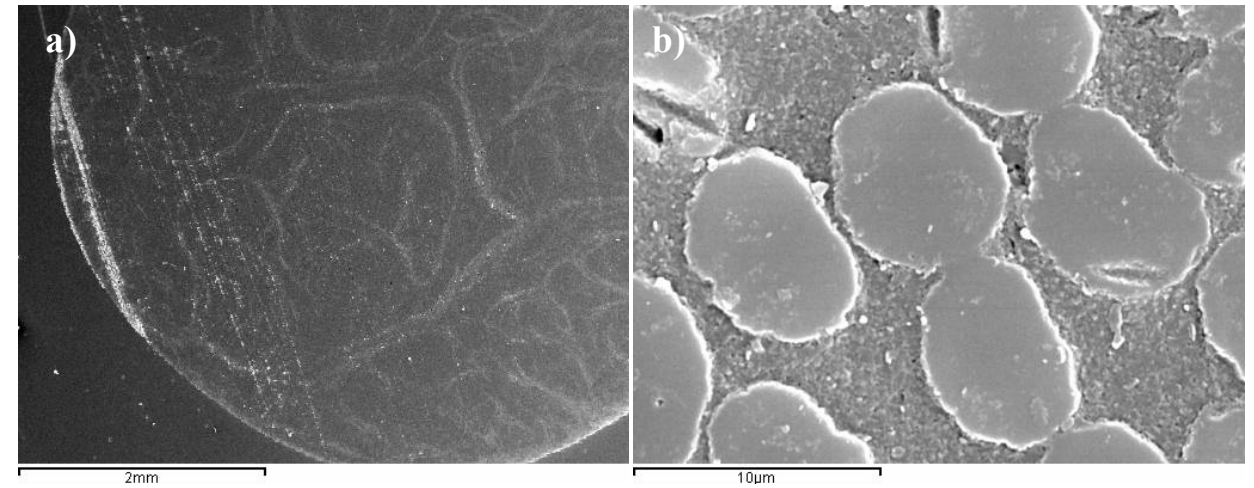

Fig. 4.7. Fibras y resina sin daños tras el ensayo de pullout: a) SEM/CA8/20, sección transversal barra x25; b) SEM/CA14/20, núcleo barra x5000. 

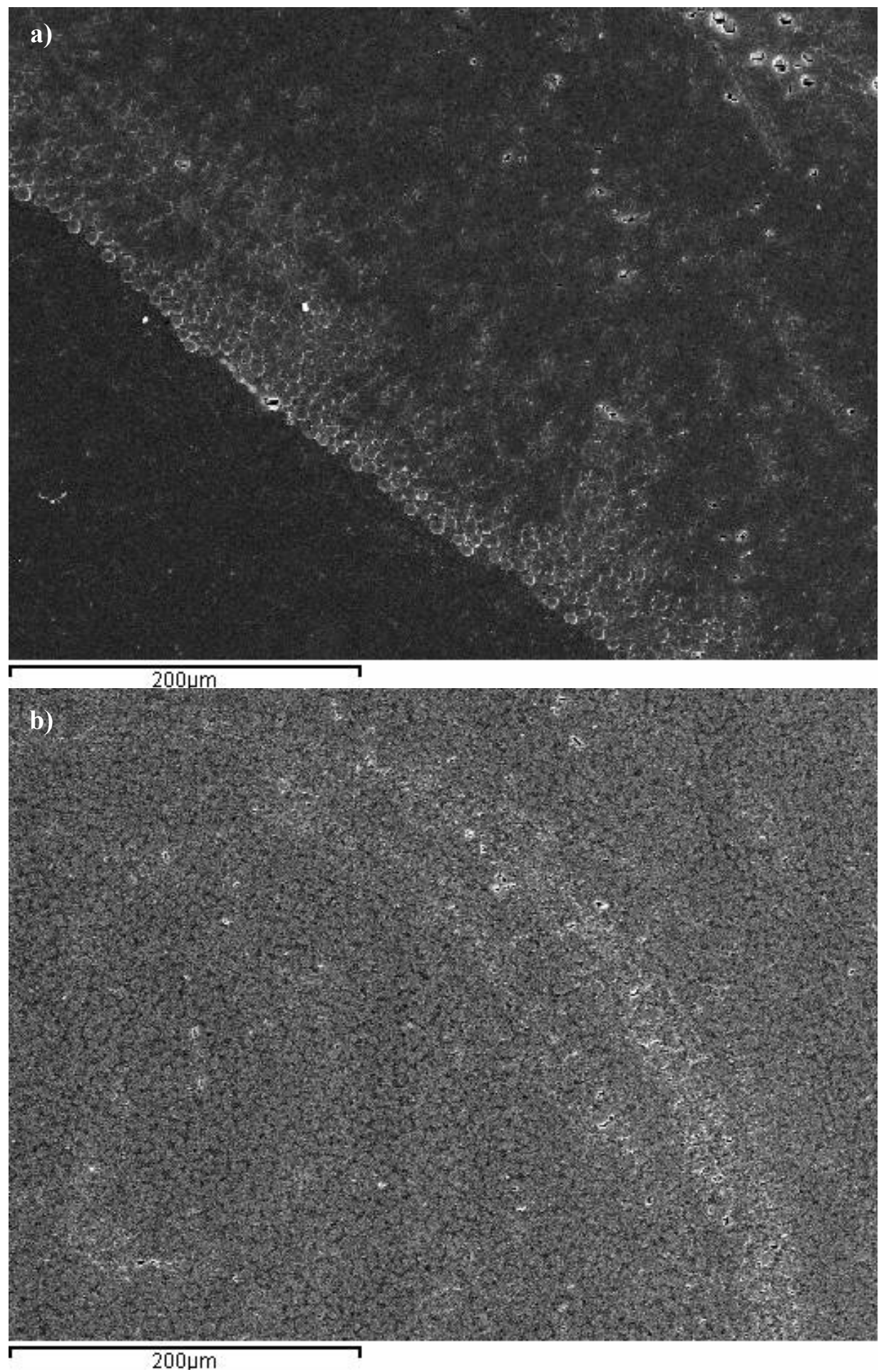

Fig. 4.8. SEM/CA8/20 tras ensayo pullout: a) Daños, producidos en fibras y resina polimérica próxima al acabado superficial; b) Núcleo sin daños. 
Una vez alcanzada la tensión adherente máxima se produce la rotura de un modo fragil (Figs. 4.2 y 4.3), quedando una tensión adherente residual ${ }^{49}$ como consecuencia del rozamiento entre el núcleo de la barra y la capa de resina polimérica y arena retenida por el hormigón. La tensión adherente media residual de las barras de CFRP arenadas es la más reducida de todas las barras ensayadas en esta investigación (Fig. 4.9), presentando unos valores de 0,711 y 3,458 MPa en barras CA8 y CA14, respectivamente.

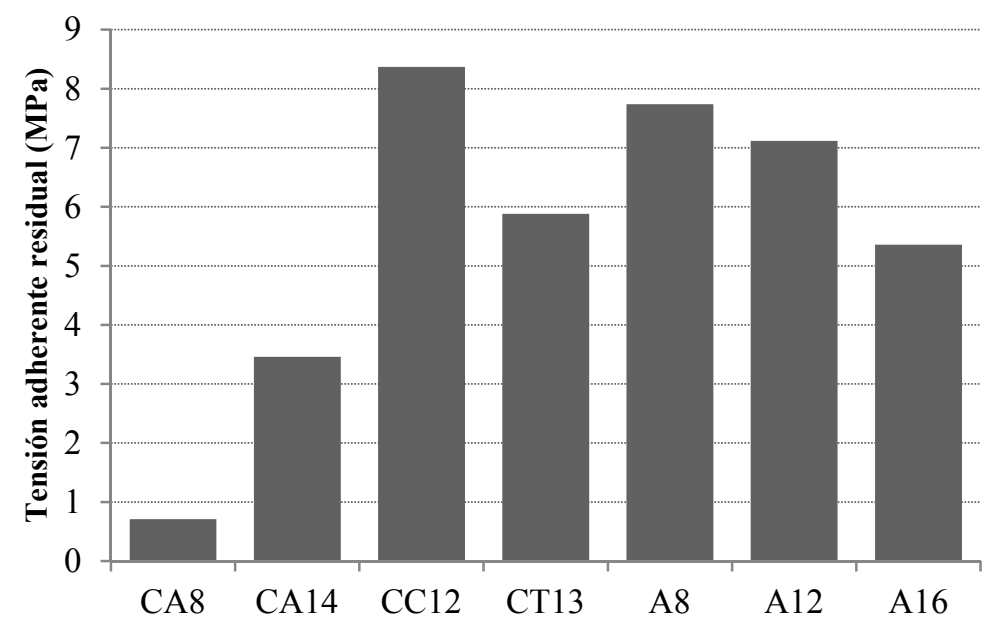

Fig. 4.9. Gráfico comparativo de la tensión adherente residual ejercida por las barras una vez producida la rotura adherente.

El comportamiento de las barras de CFRP arenadas, CA8 y CA14, obtenido en esta investigación, es similar al obtenido por Al-Mahmoud et al. (2007), Baena et al. (2009) y Okelo y Yuan (2005) (véase apart. 2.5.3.2 y Figs. 2.56 y 2.62$)$.

\section{- Barras de CFRP Corrugadas}

Las barras de CFRP corrugadas CC12 desarrollan inicialmente su adherencia por adhesión química, con un valor medio de 3,43 MPa, similar al

\footnotetext{
${ }^{49}$ La tensión adherente residual es el promedio de la tensión adherente tras la rotura hasta un deslizamiento de $28 \mathrm{~mm}$.
} 
obtenido por Oketo et al. (2005). Al mismo tiempo, se observa que la adhesión química desarrollada por las este tipo de barras es es similar a la desarrollada por las barras de acero corrugado A12, puesto que no presenta diferencia estadísticamente significativa, con un nivel de confianza del 95\%, según el estudio estadístico realizado mediante ANOVA (Tabla 4.1 y Fig. 4.10). Por lo tanto, se puede considerar que las barras de CFRP corrugadas poseen una adhesión química similar a las barras de acero corrugadas. Seguidamente y a diferencia de las barras de CFRP arenadas, al incrementarse la tensión, el mecanismo adherente cambia de adhesión química a un mecanismo de acuñamiento mecánico más rozamiento de las corrugas de la barra contra el hormigón, comenzado de este modo el deslizamiento relativo de la barra respecto al hormigón, al mismo tiempo que se reduce la rigidez de la pendiente ascendente de la gráfica tensión adherente-deslizamiento (Fig. 4.11a). Este comportamiento, tal y como se observa en la Fig. 4.11, es similar al desarrollado por las barras de acero corrugadas.

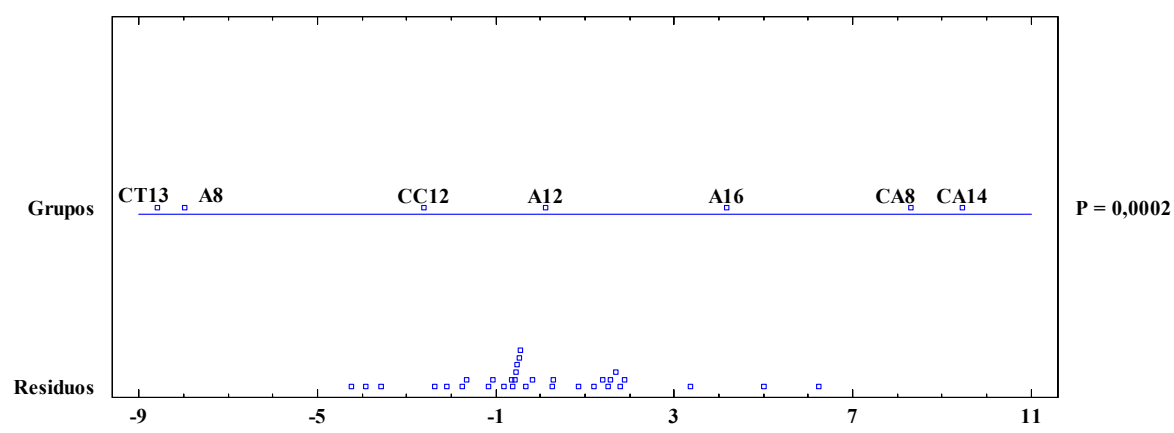

Fig. 4.10. ANOVA Gráfico de adhesión química de las barras de CFRP y acero corrugadas.

\begin{tabular}{|c|c|c|c|}
\hline & Casos & Media (MPa) & Grupos Homogéneos \\
\hline CT13 & 5 & 0,96 & $\mathrm{X}$ \\
\hline A8 & 5 & 1,21 & $x$ \\
\hline $\mathrm{CC} 12$ & 5 & 3,43 & $x X$ \\
\hline A12 & 5 & 4,56 & $X$ \\
\hline A16 & 5 & 6,24 & $x X$ \\
\hline CA14 & 4 & 8,89 & $x$ \\
\hline CA8 & 3 & 8,95 & $x$ \\
\hline
\end{tabular}

Tabla. 4.1. Tabla de Contraste Múltiple de Rango de adhesión química en barras de CFRP y acero, a temperatura de $20^{\circ} \mathrm{C}$. 


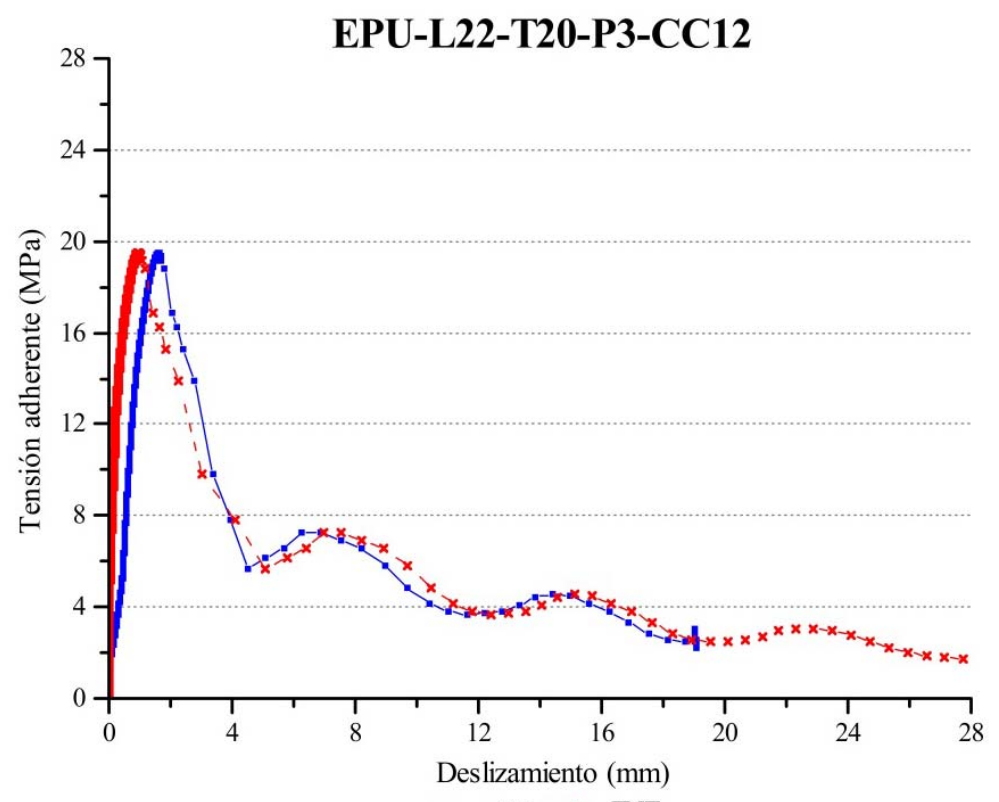

a)

$\longrightarrow$ ET $-*$ ENT

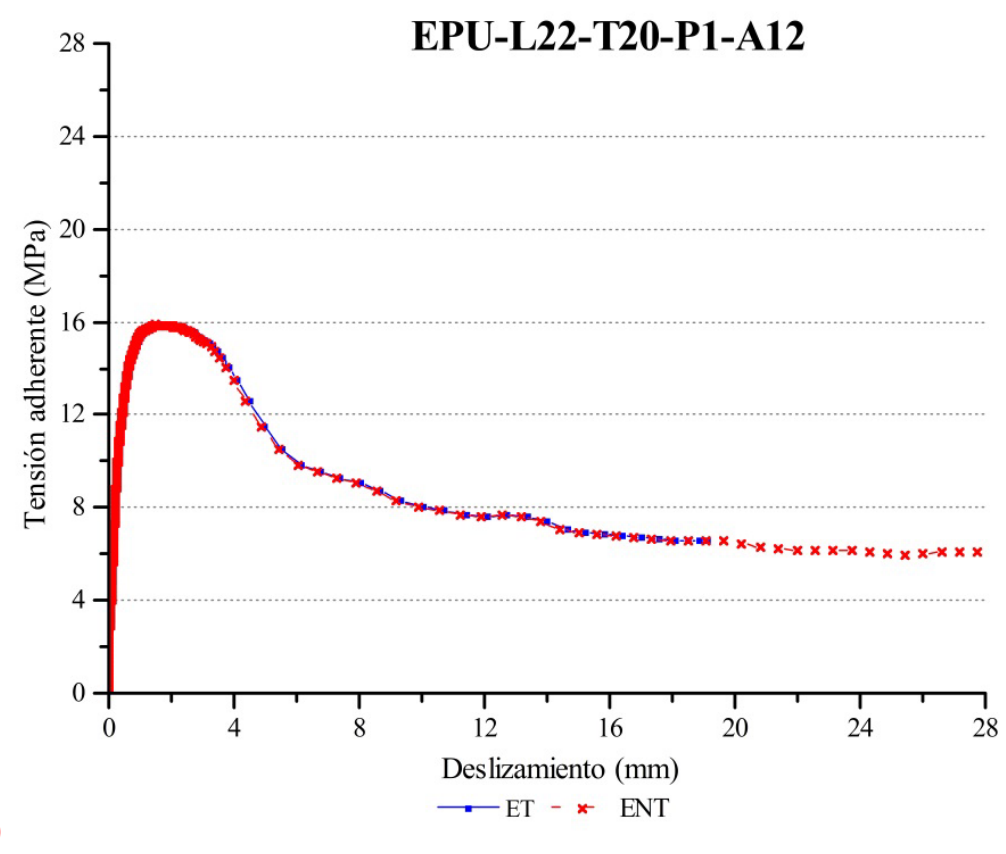

Fig. 4.11. Comportamiento adherente de las barrasde CFRP y acero corrugadas: a) Barras de CFRP corrugadas $\mathrm{CC} 12$; b) Barras de acero corrugadas A12. Gráfica tensión adherente / deslizamiento en extremo tensionado "ET" y no tensionado "ENT". 
La tensión adherente máxima de las barras de CFRP corrugadas presenta un valor medio de 18,57 MPa. Esta se alcanza con un deslizamiento medio en el extremo tensionado de $\delta_{\mathrm{ET}}=1,64 \mathrm{~mm}$, y en el extremo no tensionado de $\delta_{\mathrm{ENT}}=1,18 \mathrm{~mm}$ (Fig. 4.11.a). Estos valores de tensión adherente y deslizamiento desarrollados por las barras de CFRP corrugadas son similares a los desarrollados por las barras de acero corrugadas A12, puesto que, estas desarrollan una $\tau_{\max }=16,70 \mathrm{MPa}$ con $\delta_{\mathrm{ET}}=1,67 \mathrm{~mm}$ y $\delta_{\mathrm{ENT}}=1,47 \mathrm{~mm}$ (Fig. 4.11.b).

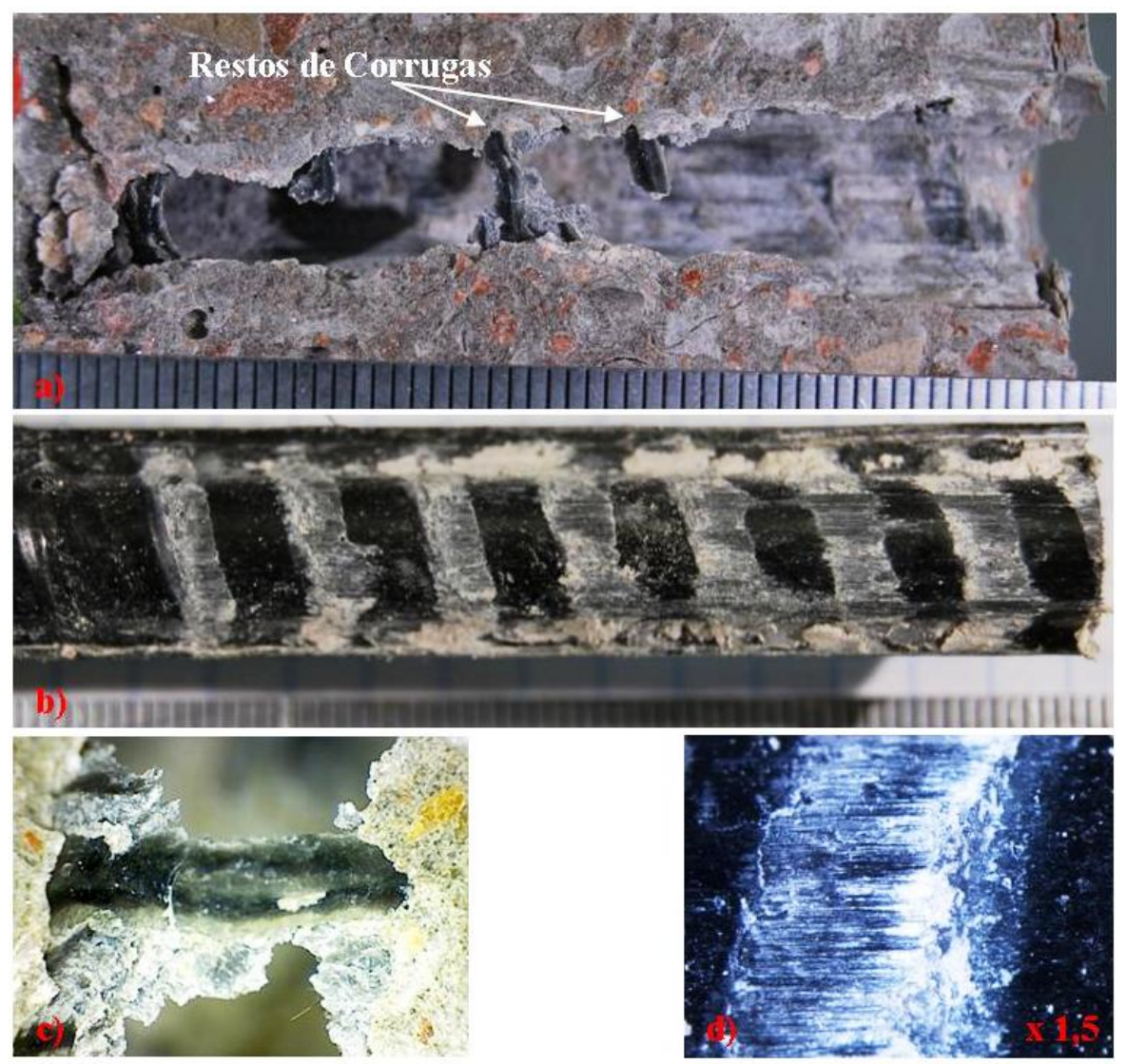

Fig. 4.12. Rotura adherente por cortadura de las corrugas en la muestra EPU-L5-T20-P7-CC12. a) $L_{\text {adh }}$ probeta hormigón con restos corrugas; b) Barra CFRP sin corrugas; c) Detalle de corruga en hormigón; d) Detalle de corruga cortada en barra.

Una vez alcanzada la tensión adherente máxima se produce la rotura por adherencia. A diferencia de las barras de CFRP arenadas y de acero corrugadas 
ésta se puede producir de dos modos diferentes: por corte de las corrugas de la geometría superficial de la barra "RA" (Fig. 4.12), o de un modo combinado "RC", por corte del hormigón entre corrugas y corte de las corrugas (Fig.4.13).
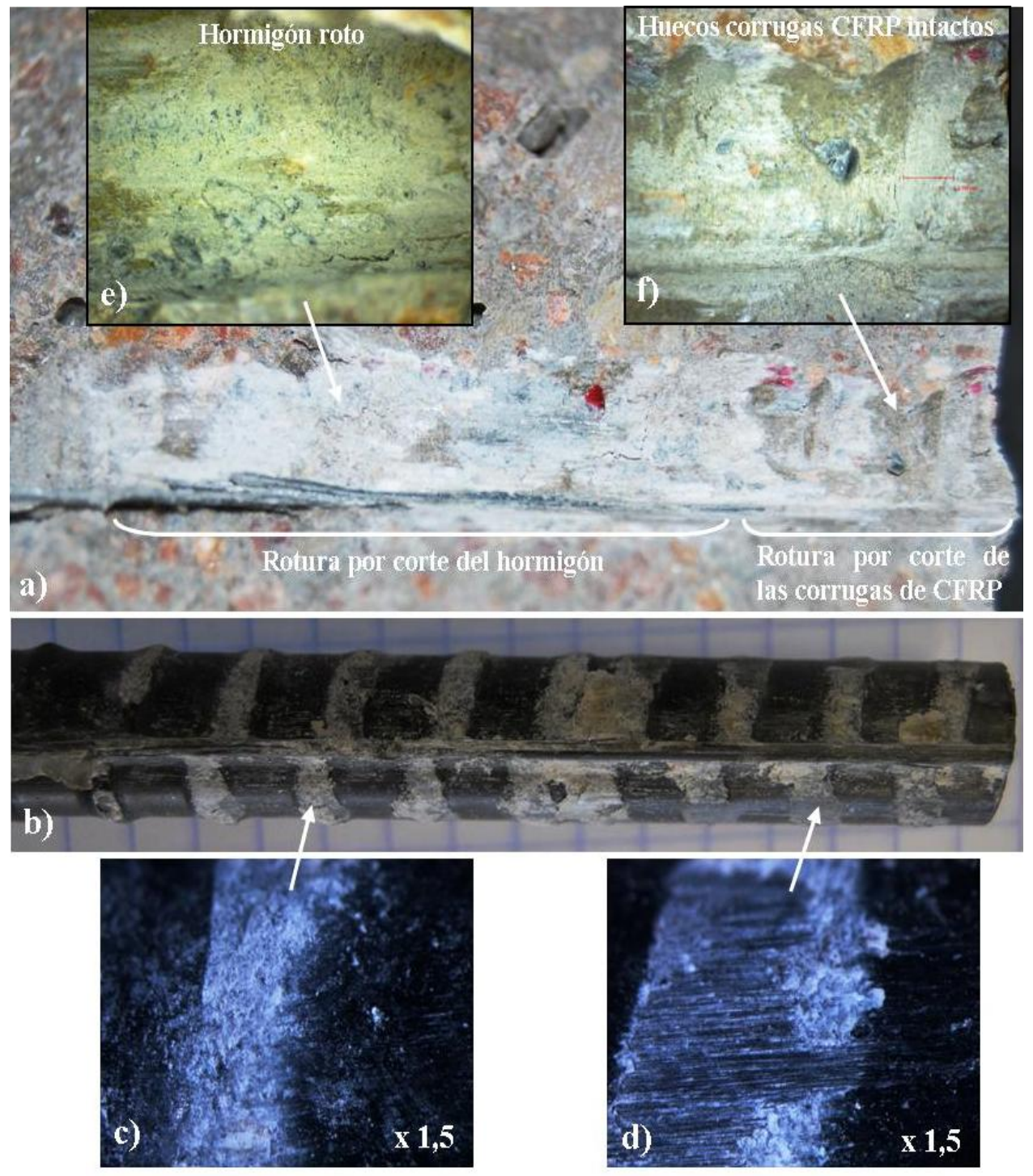

Fig. 4.13. Rotura adherente por modo combinado EPU-L1-T20-P1-CC12. a) $\mathrm{L}_{\text {adh }}$ probeta hormigón, rotura modo combinado; b) Barra CFRP con restos de hormigón en corrugas; c) Detalle de corruga de CFRP intacta con restos de hormigón; d) Detalle de corruga cortada por el hormigón; e) Detalle de primera zona de $\mathrm{L}_{\text {adh }}$ donde se produce rotura por corte del hormigón; f) Detalle de zona de rotura por corte de las corrugas, huecos de corrugas intactos en el hormigón. 
El modo de rotura por corte de las corrugas de la barra es debida a la menor resistencia a corte de la resina polimérica, que forma las corrugas de la geometría superficial, respecto de la resistencia a cortante del hormigón entre corrugas. Está resina polimérica de las corrugas de la barra, a diferencia de la resina del núcleo, está compuesta, según los análisis realizados mediante Microscopía Electrónica de Barrido "SEM", por: resina de viniléster y un $15 \%$ de adición a base de compuestos cerámicos "SiCa" y "SiAl", que incrementa el módulo elástico (Fig. 4.14).
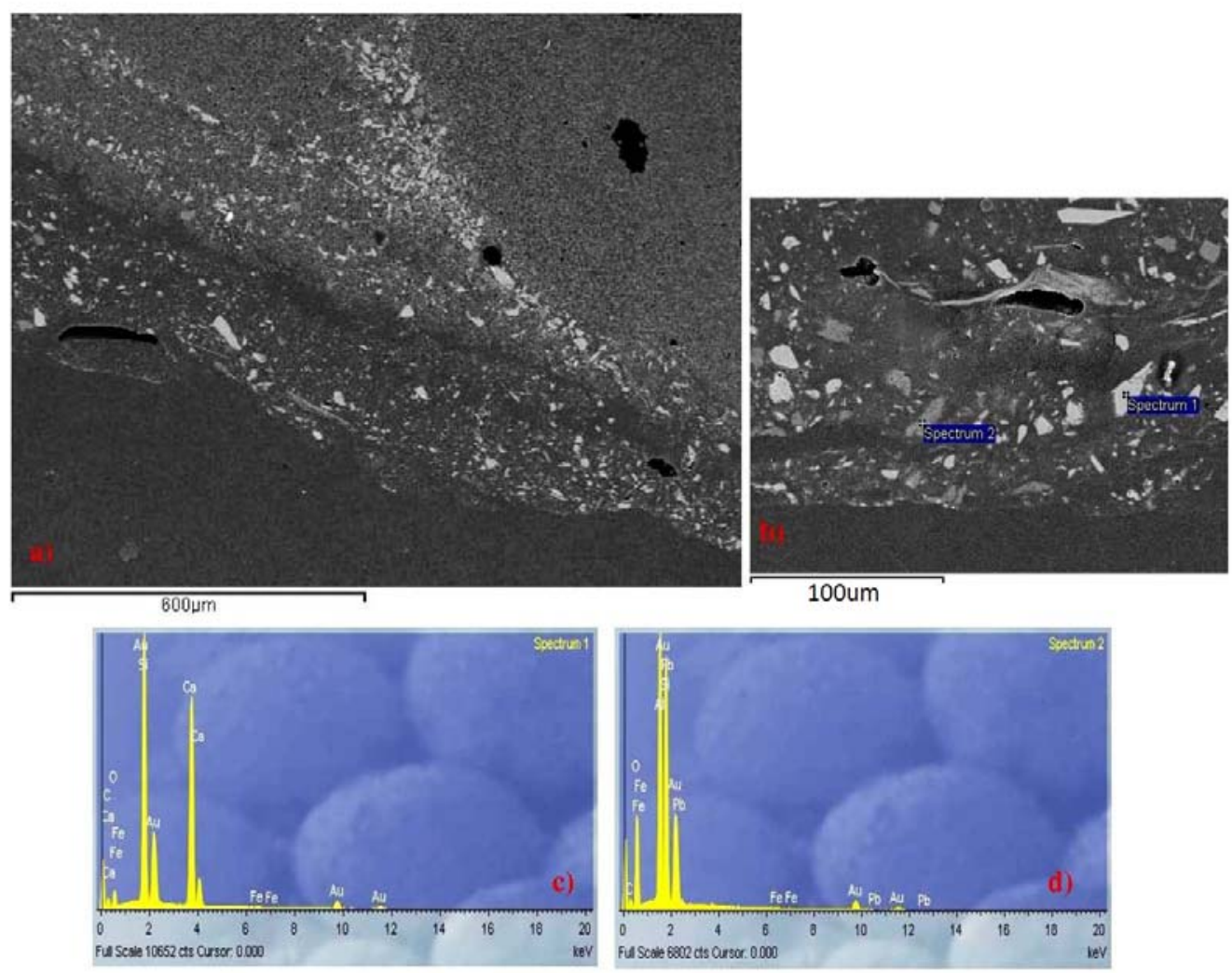

Fig. 4.14. Corruga, de muestra SEM/CC12/20, tras ensayo de pullout: a) Corruga y difusión de adición corruga al núcleo de la barra, x 100; b) Detalle de composición corruga, x 500; c) Análisis espectrómetro de adición corruga 1, SiCa; d) Análisis espectrómetro de adición corruga 2, SiAl.

En el modo combinado de rotura se distinguen en la barra dos zonas bien diferenciadas: en el primer tramo de la longitud adherente, en el cual la 
resistencia a corte del hormigón es menor debido a la falta de confinamiento del hormigón en el extremo tensionado (Fig. 4.15), la rotura se produce por corte del hormigón que acuña a las corrugas; es decir, de un modo similar a lo que sucede con las barras de acero corrugadas (Fig. 3.13.d y e). Más allá de ese primer tramo inicial de la longitud adherente, el hormigón pasa a estar confinado en todas las direcciones y su resistencia a esfuerzo cortante aumenta, produciéndose entonces la rotura por corte parcial o total de las corrugas de la barra (Fig. 4.13.f).

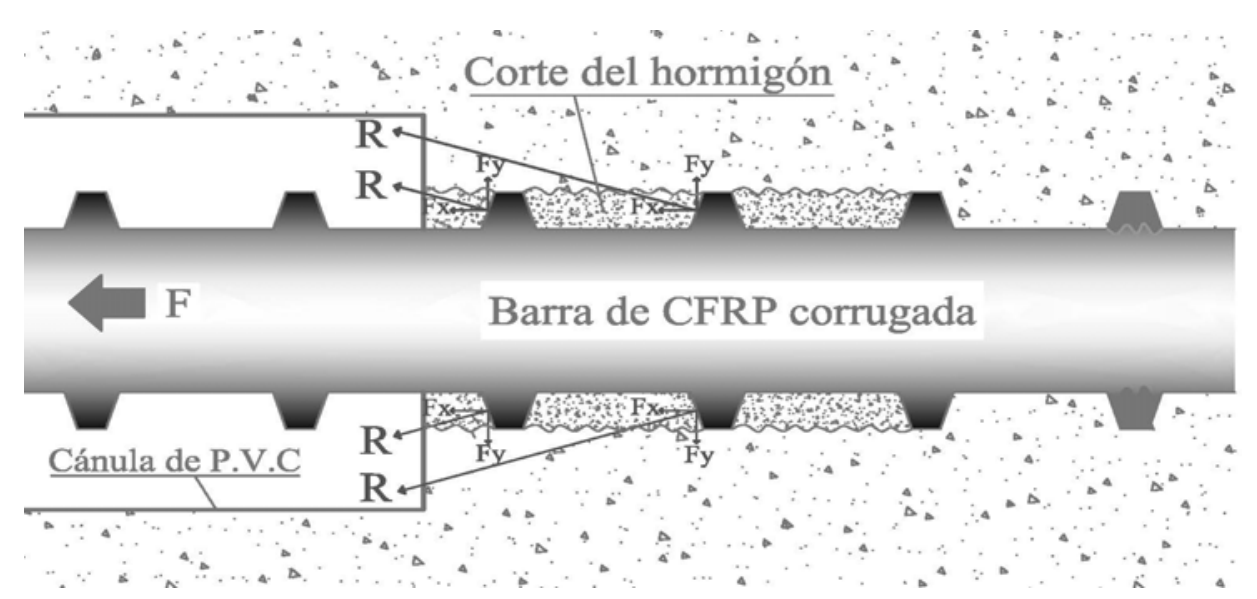

Fig. 4.15. Rotura del hormigón entre las corrugas y la cánula de PVC.

Así pues, dependiendo de la magnitud de la resistencia a corte de la resina respecto de la resistencia a corte del hormigón, el número de corrugas rotas variará. Si la resistencia a cortante del hormigón entre corrugas es superior a la de las corrugas de la barra de resina polimérica, el número de corrugas dañadas es mayor, al mismo tiempo que se reduce la zona inicial de la longitud adherente donde tiene lugar la rotura por cortante del hormigón, produciéndose en este caso la rotura por por corte de las corrugas "RA". En cambio, si la resistencia a cortante del hormigón es menor, el número de corrugas cortadas por el hormigón circundante es menor, produciéndose la rotura por el modo combinado "RC" o, en el caso de hormigones de baja calidad, por rotura a cortante únicamente del hormigón. 
Por lo tanto, tal y como se confirma en el apart. 4.1.3, el modo de rotura de las barras de CFRP corrugadas depende de la resistencia a corte de la resina polimérica de las corrugas y de la resistencia del hormigón.

Tras la rotura, el comportamiento adherente de todas las barras de CFRP corrugadas es similar (véase gráficas Anejo I). Este comportamiento se puede esquematizar de la siguiente forma (Fig. 4.16): Tal y como se ha comentado anteriormente para niveles de carga importantes, próximos a la tensión adherente máxima, se puede producir un agotamiento por cortante del hormigón entre corrugas situado en la zona de anclaje más próxima al extremo tensionado de la barra. Cuanto peor sea la calidad del hormigón más larga será esa zona, pudiendo darse el agotamiento por cortante del hormigón en toda la zona de anclaje sin que se produzcan daños en las corrugas de resina polimérica (comportamiento similar al de una barra corrugada de acero, con agotamiento por deslizamiento de la armadura). Si el comportamiento se produce por rotura de las primeras corrugas de resina polimérica de la barra, una vez alcanzada la tensión adherente máxima (curva 1) se produce una pérdida de adherencia brusca y los máximos esfuerzos adherentes se trasladan a la siguiente corruga (curva 2). La tensión adherente máxima que se puede absorver ahora es menor posiblemente debido a: a) menor longitud de anclaje disponible, b) entrada en carga dinámica y e) deterioro de la interfaz barra hormigón. Una vez rotas por cortante estas segundas corrugas el proceso se va repitiendo de corruga en corruga (curvas $2,4, \ldots, \mathrm{n}$ ), hasta producirse el total deslizamiento de la armadura. 

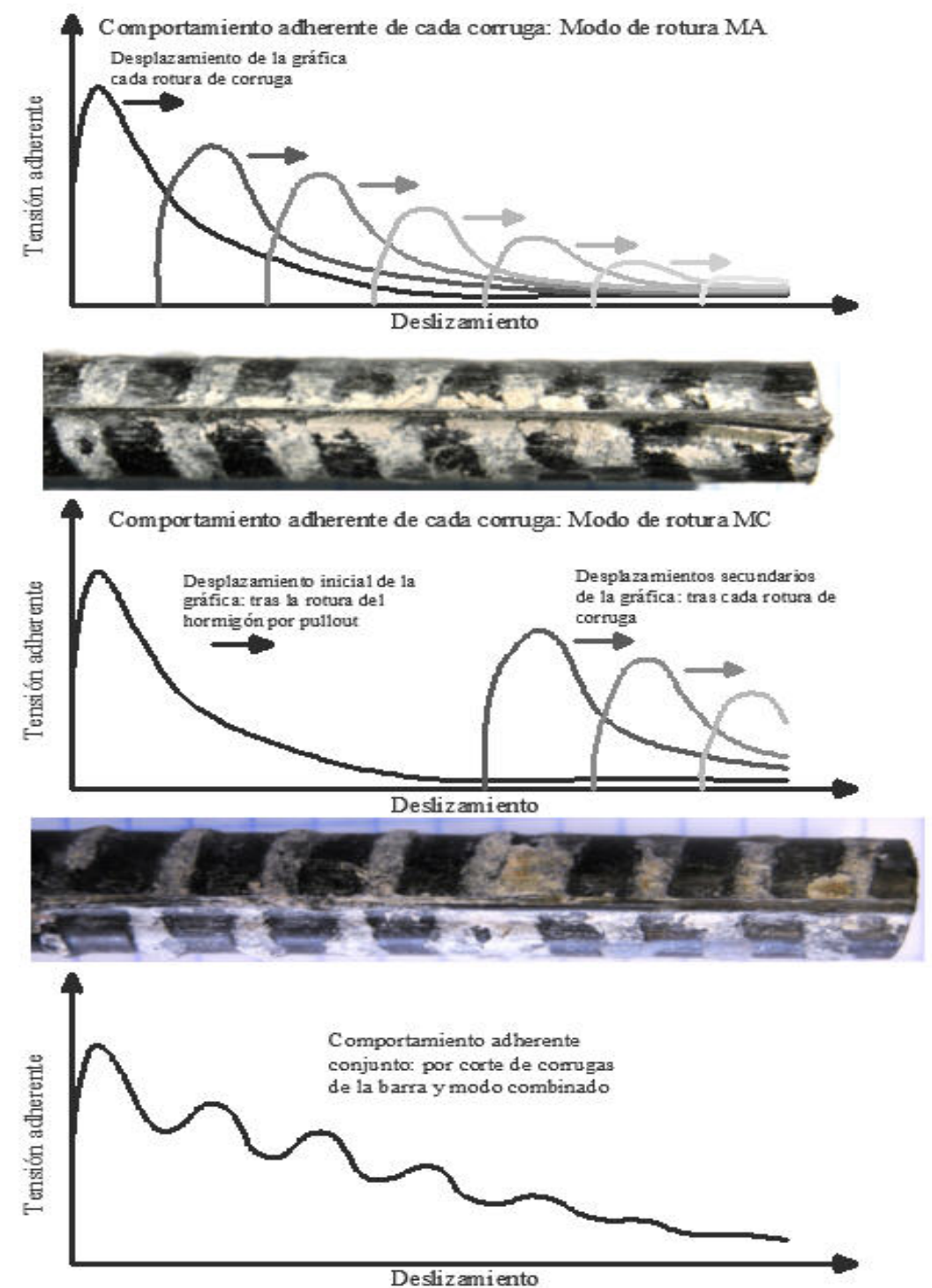

Fig. 4.16. Comportamiento adherente tras la rotura, debida a: corte de las corrugas de la barra "RA" y modo combinado "RC".

A diferencia de las barras de CFRP arenadas, las barras corrugadas alcanzan una tensión adherente muy elevada, debido a que este tipo de geometría superficial mejora la adherencia y permite que las fibras de la sección de la barra alcancen tensiones de tracción más altas. Este efecto puede observarse en las imágenes obtenidas por SEM, tras la rotura por pullout, en las cuales se 
identifican: daños tanto en el núcleo (Fig.4.17.a) como en la zona próxima a la superficie de la barra (Fig. 4.17.b) y unas fisuras transversales, que se inician en el círculo definido por el daño de la zona próxima a la superficie y se unen en el centro de la barra, dividiéndola en tres o cuatro partes (Fig. 4.18). Por el contratio, las barras arenadas no muestran daños en el núcleo ni en la zona próxima al acabado superficial (Fig. 4.8.b).
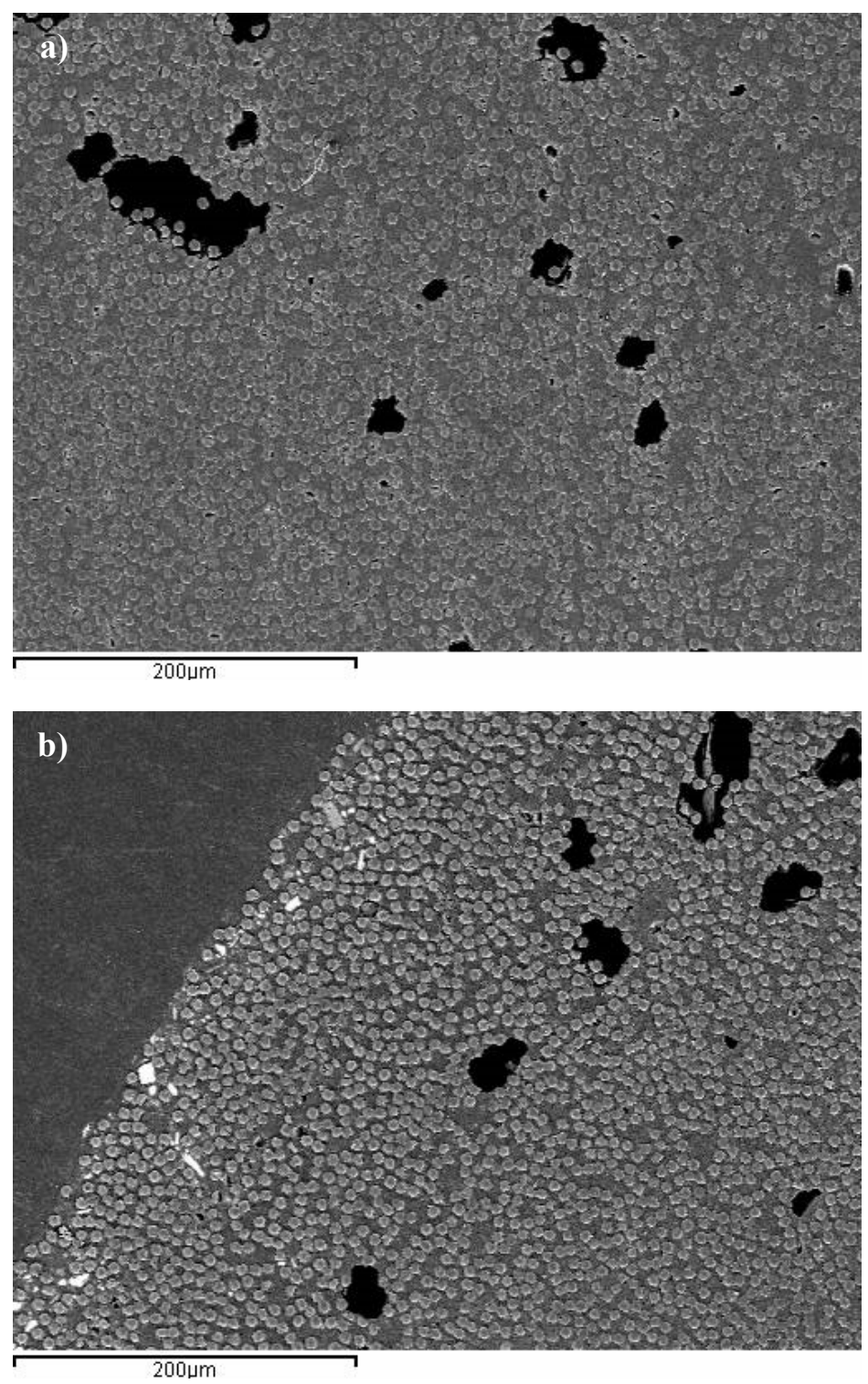

Fig. 4.17. Daños en las fibras y matriz polimérica tras el ensayo de pullout. a) SEM/CC12/20, núcleo con daños, x 250; b) SEM/CC12/20, daños en zona próxima a superficie, x 250. 


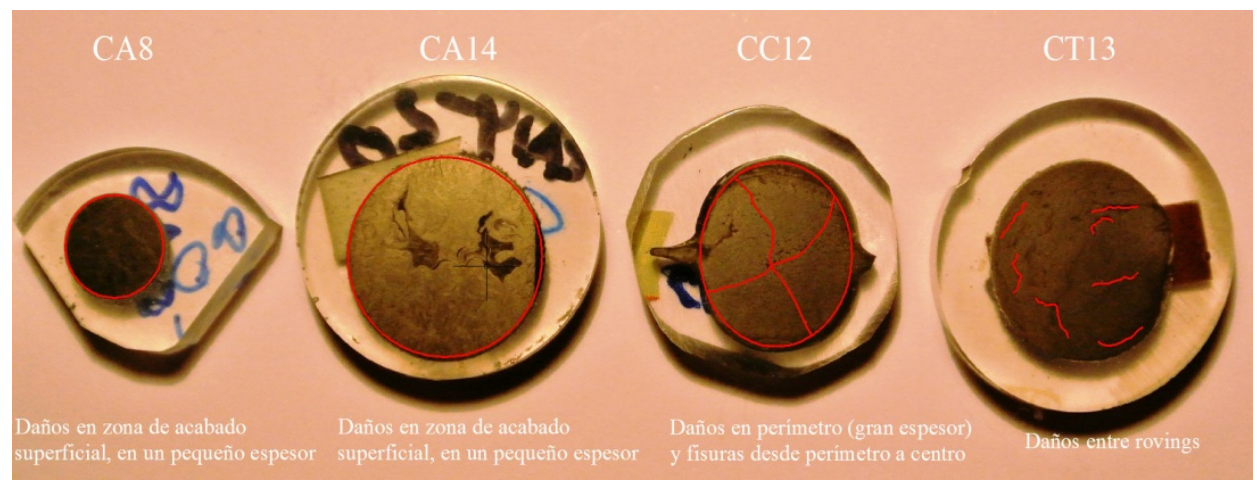

Fig. 4.18. Daños y fisuras en las barras de CFRP tras el ensayo de pullout.

El comportamiento tras la rotura adherente de las barras de CFRP corrugadas, producido por los dos modos de rotura, corte de las corrugas de la barra y modo combinado, es menos dúctil que el desarrollado por las barras de acero corrugadas, puesto que la pendiente descendente de la gráfica de tensión adherente-deslizamiento es más acusada (Fig. 4.11). Sin embargo, según el ANOVA realizado, la tensión adherente residual de ambos tipos de barras, CFRP y acero corrugadas, es similar (Fig. 4.19). El efecto de estos dos modos de rotura de las barras de CFRP corrugadas es similar al obtenido por Achillides et al. (2004) y Okelo et al. (2005).

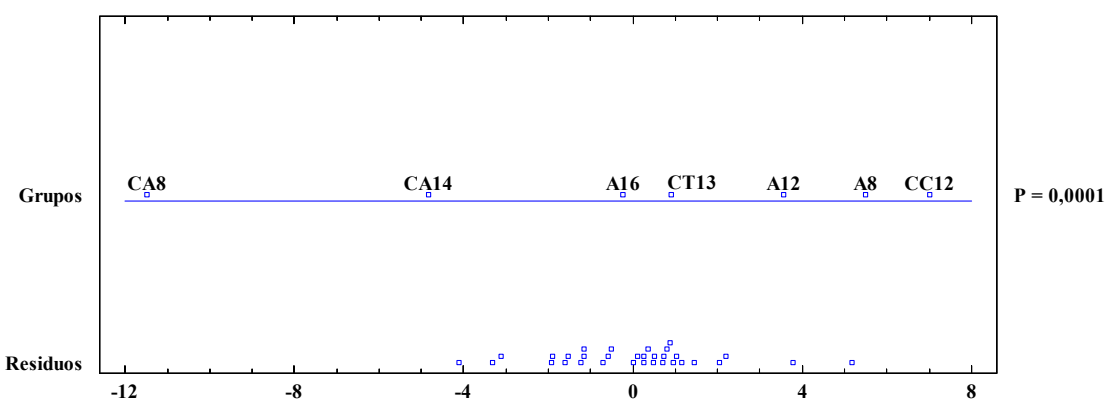

Fig. 4.19. ANOVA gráfico de tensión adherente residual en barras de CFRP y acero corrugadas.

\section{- Barras de CFRP texturizadas}

Del mismo modo que el resto de barras, las barras de CFRP texturizadas CT13 desarrollan inicialmente su adherencia por adhesión química, con un valor 
medio de 0,96 MPa (Tabla 4.1). Sin embargo, la adhesión química desarrollada por este tipo de barras texturizadas (Fig. 4.20.a) es inferior a la desarrollada por las barras A12 (Fig. 4.20.b), con menor rugosidad superficial (Tabla 4.1). Este hecho puede ser debido a la menor resistencia de la resina polimérica que adhiere el texturizado al núcleo de las barras de CFRP texturizadas, que puede producir un deslizamiento precipitado de la barra al deformarse la resina polimérica de dicha interfaz.
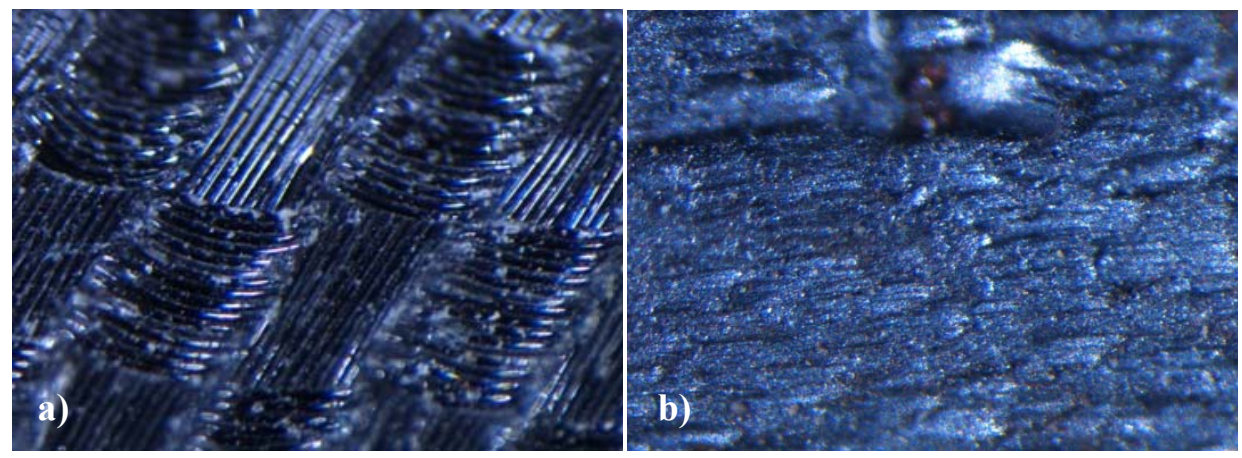

Fig. 4.20. Detalle de superficie: a) Texturización barra CT13, x 9,8; b) Barra de acero corrugada A12, x 9,8.

Seguidamente, pasan a actuar los mecanismos adherentes de acuñamiento y rozamiento. Sin embargo, en las barras de CFRP texturizadas CT13, a diferencia de las barras de CFRP y acero corrugadas, debido al diseño de su geometría superficial, las corrugas de la barra se encuentran invertidas (embebidas en el interior de la barra), diseño que produce que en este tipo de barras sea el hormigón depositado en el interior de las mismas el que acuñe mecánicamente contra la sección de la barra, y no las corrugas contra el hormigón (Fig. 4.21). Por lo tanto, la tensión adherente máxima de las barras de CFRP texturizadas, se encuentra condicionada por la resistencia a cortante de la corruga de hormigón en mayor medida que las barras de acero corrugadas y que las barras de CFRP corrugadas. 


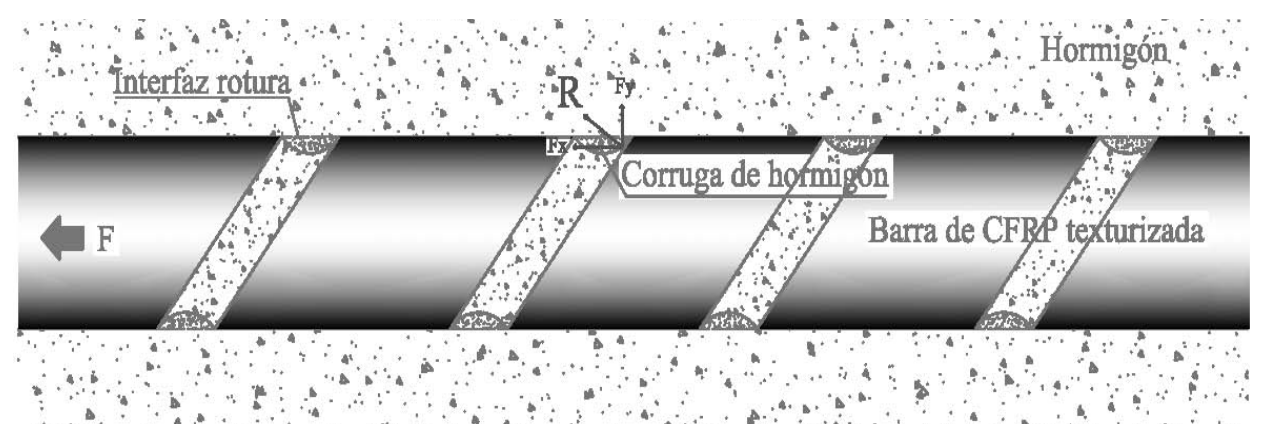

Fig. 4.21. Mecanismo adherente por acuñamiento mecánico de las corrugas de hormigón contra la barra de CFRP texturizada.

El diseño de la geometría superficial de las barras texturizadas, genera unas corrugas de hormigón con una superficie y volumen muy reducido. Estas al incrementarse la tensión rompen prematuramente por corte del hormigón, desarrollando una tensión adherente máxima muy reducida, $\tau_{\max }=7,90 \mathrm{MPa}, \mathrm{y}$ uno deslizamiento a $\tau_{\max }$, tanto el extremo tensionado, $\delta_{\mathrm{ET}}=3,22 \mathrm{~mm}$, como no tensionado, $\delta_{\mathrm{ENT}}=3,01 \mathrm{~mm}$, muy elevados (valores similares a los obtenidos por Hao et al., 2009). Este comportamiento de las barras de CFRP texturizadas CT13, difiere del desarrollado por las barras de acero y CFRP corrugadas, presentando una menor tensión adherente y mayores deslizamientos (Fig. 4.22).

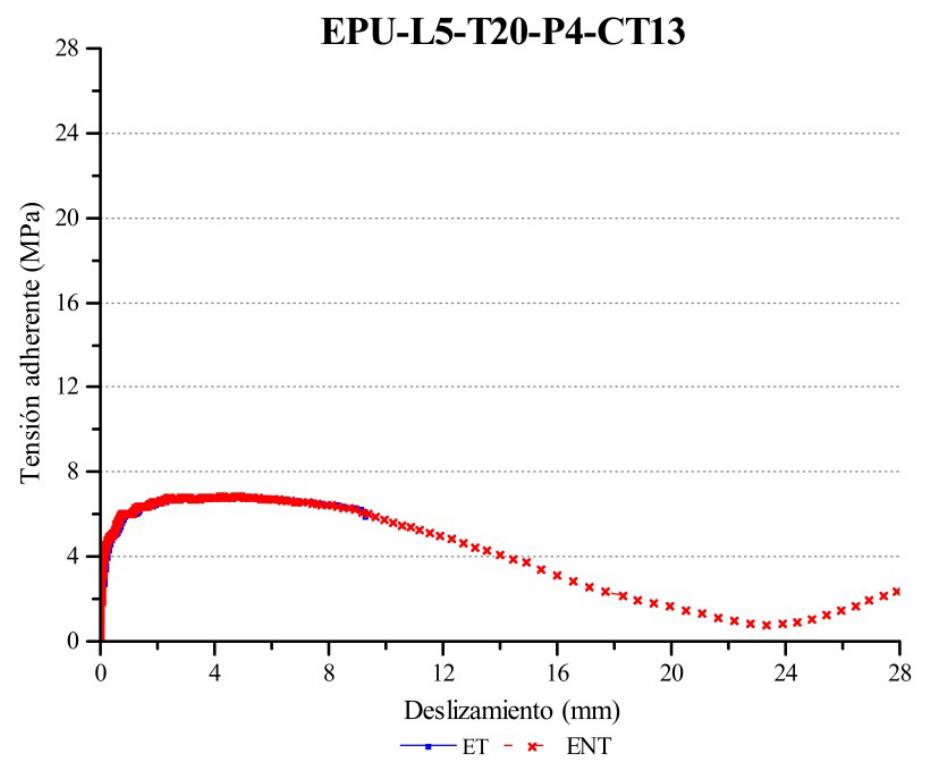

Fig. 4.22. Comportamiento adherente de las barras CT13. Gráfica tensión adherente / deslizamiento en extremo tensionado "ET" y no tensionado "ENT". 
El modo de rotura de las barras de CFRP texturizadas se produce, a diferencia de las barra de CFRP arenadas, por corte de las corrugas de hormigón embebidas en la barra (Fig. 4.23), presentando muy pocos daños la barra de CFRP (véase interior de corruga en Fig. 4.23.c).
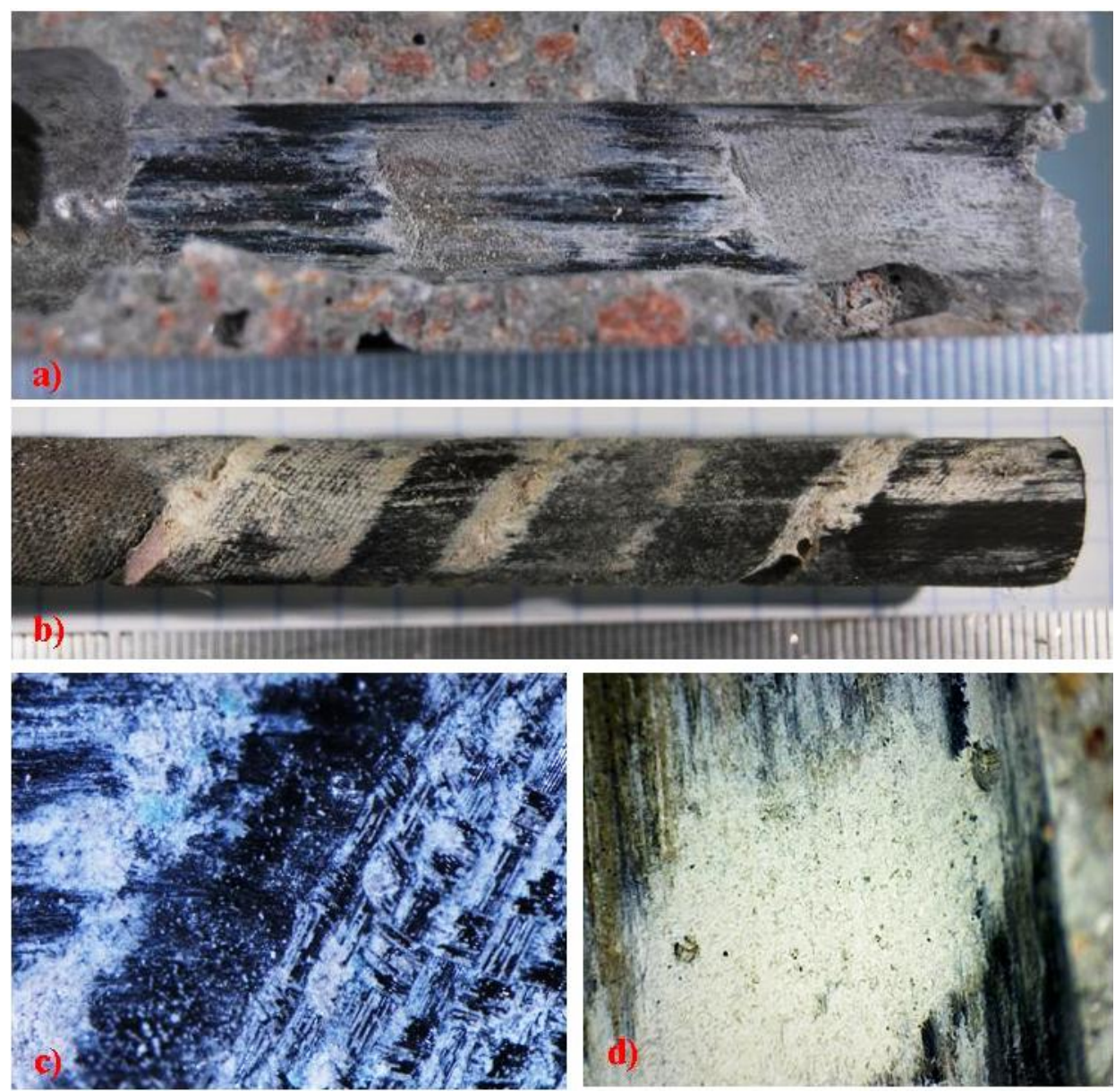

Fig. 4.23. Rotura adherente por modo pullout, debida a corte de las corrugas de hormigón EPU/L5/T20/P4/CT13. a) $\mathrm{L}_{\text {adh }}$ de la probeta de hormigón tras la rotura. b) $\mathrm{L}_{\text {adh }}$ barra CT13 tras la rotura; c) Detalle de interior corruga de barra CT13, x 4; d) Detalle de corte de la corruga de hormigón en la $\mathrm{L}_{\mathrm{adh}}$ de la probeta hormigón tras la rotura,

El diseño de la geometría superficial de este tipo de barras texturizadas, genera una rotura adherente prematura, ocasionando únicamente daños en la matriz polimérica de la zona del núcleo de la barra próxima a la corruga (Fig. 4.24). Este efecto puede ser debido a la reducida tensión generada, por lo que el 
núcleo de la sección de la barra no se encuentra sometido a elevadas tensiones (Fig. 4.17).

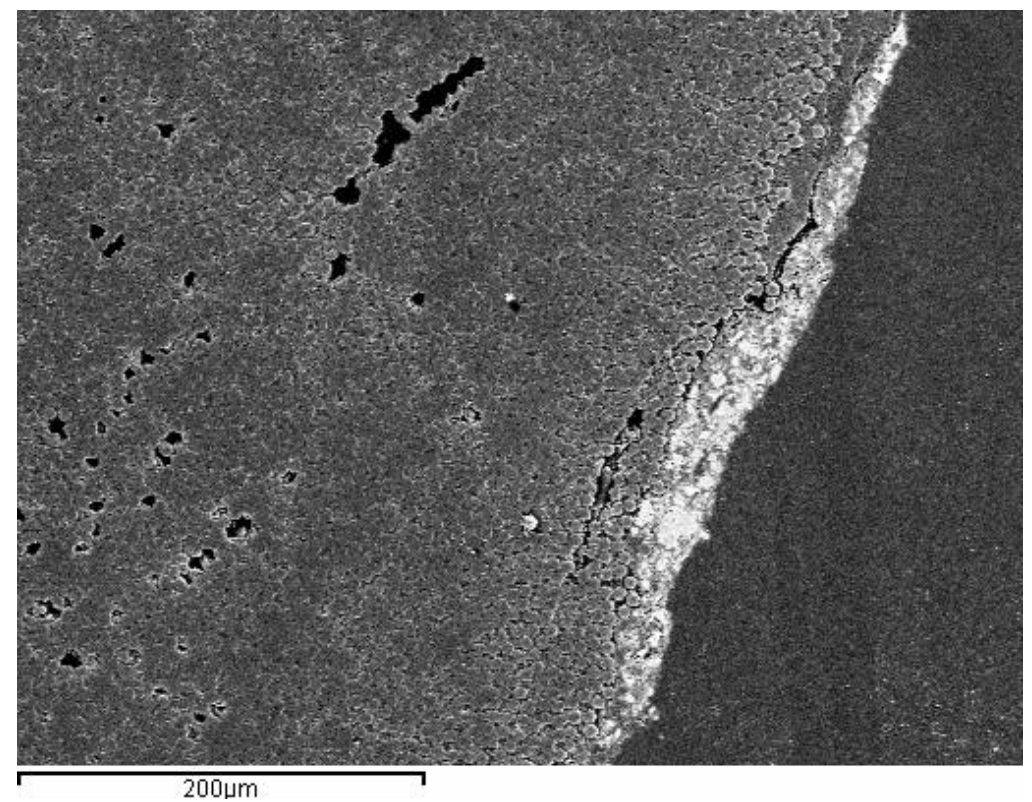

Fig. 4.24. Imagen de zona próxima a la corruga. Daños en resina polimérica y restos de hormigón en la corruga.SEM/CT13/20. x 250.

Este modo de rotura posee un comportamiento más dúctil que el desarrollado por las barras de CFRP arenadas, corrugadas y acero corrugadas. Puesto que, una vez alcanzada la tensión adherente máxima, se produce en la gráfica de tensión adherente-deslizamiento una menor pendiente descendiente desde la rotura adherente, generándose una tensión de rozamiento cuya magnitud es inicialmente similar a la tensión adherente de rotura (Fig. 4.22). En este caso la fricción no se produce entre la capa de hormigón cortado por pullout y el hormigón que se mantiene en la probeta (Fig. 2.37), como es el caso de las barras de acero corrugadas, sino que esta se produce entre la capa de texturizado de la barra y el hormigón que la rodea (Fig.4.25). 

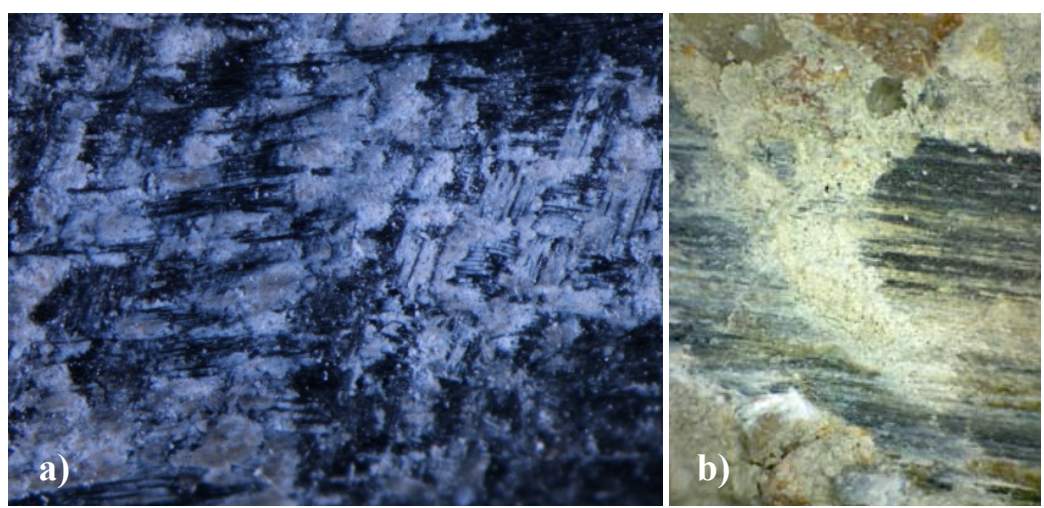

Fig. 4.25. EPU/L1/T20/P3/CT13: a) Acabado superficial de la barra con restos de hormigón, tras ensayo de pullout; b) Hormigón roto y restos de acabado superficial de barra en $\mathrm{L}_{\mathrm{adh}}$ de probeta.

\section{b) Análisis Estadístico del Comportamiento Adherente en Condiciones Térmicas de $20^{\circ} \mathrm{C}$}

Los datos obtenidos, mediante el ensayo de pullout en la condición térmica de $20{ }^{\circ} \mathrm{C}$ (Tabla 3.36), han sido analizados, mediante el programa de análisis estadístico Statgraphics Centurión XVI.I.

Inicialmente, se han calculado los estadísticos de las distribuciones de tensión adherente máxima y deslizamiento en los extremo tensionado y no tensionado, para cada muestra de tipo de barra (Tabla 4.2, 4.3 y 4.4). Posteriormente, se ha analizado si hay diferencia estadísticamente significativa, con un nivel de confianza del $95 \%$, entre los distintos tipos de barras de cada parámetro o factor (tensión adherente y deslizamiento en extremo tensionado y no tensionado), a través del procedimiento de análisis de varianza "ANOVA" (Tablas 4.5, 4.6 y 4.7).

Tensión adherente máxima

\begin{tabular}{|c|c|c|c|c|c|c|c|}
\hline & Frecuencia & $\begin{array}{l}\text { Media } \\
(\mathrm{MPa})\end{array}$ & Varianza & $\begin{array}{c}\text { Desviación } \\
\text { Estándar }(M P a)\end{array}$ & $\begin{array}{c}\text { Coeficiente de } \\
\text { Variación }\end{array}$ & $\begin{array}{c}\text { Mínimo } \\
(\mathrm{MPa})\end{array}$ & $\begin{array}{c}\text { Máximo } \\
(M P a)\end{array}$ \\
\hline CA8 & 5 & 9,1503 & 1,5026 & 1,22582 & $13,3965 \%$ & 7,979 & 11,189 \\
\hline CA14 & 5 & 13,2614 & 2,8752 & 1,69565 & $12,7863 \%$ & 10,799 & 14,853 \\
\hline $\mathrm{CC} 12$ & 5 & 18,5708 & 2,7100 & 1,64623 & $8,8646 \%$ & 17,039 & 20,938 \\
\hline
\end{tabular}




\begin{tabular}{|c|c|c|c|c|c|c|c|}
\hline CT13 & 5 & 7,9060 & 8,4807 & 2,91217 & $36,8347 \%$ & 5,238 & 11,387 \\
\hline A8 & 5 & 17,5155 & 10,3727 & 3,22067 & $18,3875 \%$ & 13,963 & 21,970 \\
\hline A12 & 5 & 16,7037 & 5,6439 & 2,37570 & $14,2226 \%$ & 14,266 & 20,361 \\
\hline A16 & 5 & 20,7308 & 12,4109 & 3,52291 & $16,9936 \%$ & 17,026 & 25,232 \\
\hline
\end{tabular}

Tabla. 4.2. Estadísticos de cada tipo de barra, en la condición térmica de $20^{\circ} \mathrm{C}$, para el parámetro de tensión adherente máxima.

\begin{tabular}{|c|c|c|c|c|c|c|c|}
\hline \multicolumn{8}{|c|}{ Deslizamiento en extremo tensionado } \\
\hline & Frecuencia & $\begin{array}{l}\text { Media } \\
(\mathrm{mm})\end{array}$ & Varianza & $\begin{array}{c}\text { Desviación } \\
\text { Estándar }(\mathrm{mm})\end{array}$ & $\begin{array}{c}\text { Coeficiente de } \\
\text { Variación }\end{array}$ & $\begin{array}{l}\text { Mínimo } \\
(\mathrm{mm})\end{array}$ & $\begin{array}{c}\text { Máximo } \\
(\mathrm{mm})\end{array}$ \\
\hline CA8 & 5 & 0,2141 & 0,0053 & 0,07343 & $34,2954 \%$ & 0,155 & 0,339 \\
\hline CA14 & 5 & 0,4549 & 0,0253 & 0,15924 & $35,0052 \%$ & 0,277 & 0,691 \\
\hline $\mathrm{CC} 12$ & 5 & 1,6454 & 0,1593 & 0,39915 & $24,2579 \%$ & 1,144 & 2,130 \\
\hline CT13 & 5 & 3,2265 & 1,6527 & 1,28558 & $39,8440 \%$ & 1,616 & 4,568 \\
\hline A8 & 5 & 1,4504 & 0,0581 & 0,24122 & $16,6312 \%$ & 1,271 & 1,871 \\
\hline A12 & 5 & 1,6776 & 0,0050 & 0,07119 & $4,2439 \%$ & 1,583 & 1,758 \\
\hline A16 & 5 & 1,9252 & 1,1783 & 1,08552 & $56,3848 \%$ & 0,144 & 2,877 \\
\hline
\end{tabular}

Tabla. 4.3. Estadísticos de cada tipo de barra, en la condición térmica de $20^{\circ} \mathrm{C}$, para el parámetro de deslizamiento en extremo tensionado.

\begin{tabular}{|c|c|c|c|c|c|c|c|}
\hline \multicolumn{8}{|c|}{ Deslizamiento en extremo no tensionado } \\
\hline & Frecuencia & $\begin{array}{l}\text { Media } \\
(\mathrm{mm})\end{array}$ & Varianza & $\begin{array}{c}\text { Desviación } \\
\text { Estándar }(\mathrm{mm})\end{array}$ & $\begin{array}{c}\text { Coeficiente de } \\
\text { Variación }\end{array}$ & $\begin{array}{c}\text { Mínimo } \\
(\mathrm{mm})\end{array}$ & $\begin{array}{c}\text { Máximo } \\
(\mathrm{mm})\end{array}$ \\
\hline CA8 & 5 & 0,0380 & 0,0012 & 0,0353 & $93,0763 \%$ & 0,000 & 0,074 \\
\hline CA14 & 5 & 0,1907 & 0,0074 & 0,0865 & $45,3799 \%$ & 0,085 & 0,289 \\
\hline $\mathrm{CC} 12$ & 5 & 1,1865 & 0,0616 & 0,2483 & $20,9342 \%$ & 0,882 & 1,435 \\
\hline CT13 & 5 & 3,0114 & 1,5308 & 1,2372 & $41,0855 \%$ & 1,409 & 4,299 \\
\hline $\mathrm{A} 8$ & 5 & 0,9748 & 0,0322 & 0,1795 & $18,4133 \%$ & 0,741 & 1,204 \\
\hline A12 & 5 & 1,4766 & 0,0147 & 0,1214 & $8,2249 \%$ & 1,375 & 1,674 \\
\hline A16 & 5 & 1,9525 & 0,1339 & 0,3659 & $18,7423 \%$ & 1,670 & 2,579 \\
\hline
\end{tabular}

Tabla. 4.4. Estadísticos de cada tipo de barra, en la condición térmica de $20^{\circ} \mathrm{C}$, para el parámetro de deslizamiento en extremo no tensionado.

En el ANOVA y test de Contraste Múltiple de Rango se comprueba (Tabla 4.5) que las barras de CFRP corrugadas "CC12" son las únicas que desarrollan una tensión adherente máxima similar a las barras de acero corrugadas A12, A16 y A8. Además, las barras CC12 desarrollan un deslizamiento, tanto en el extremo tensionado como en el extremo no tensionado (Tablas 4.6 y 4.7), similar al de las barras de acero corrugado A12 (también a las 
barras A8, y únicamente en el extremo tensionado a las barras A16, puesto que en el no tensionado desarrolla un menor nivel de deslizamientos). Por lo tanto, se puede considerar que, estadísticamente con un nivel de confianza del $95 \%$, las barras de CFRP corrugadas CC12 desarrollan un comportamiento adherente similar a las barras de acero corrugadas (Fig. 4.26).

\begin{tabular}{llllll}
\hline \multicolumn{5}{c}{ Análisis de Varianza } \\
Fuente & Suma de Cuadrados & $G l$ & Cuadrado Medio & Razón- $F$ & Valor- $P$ \\
\hline Entre grupos & 710,978 & 6 & 118,496 & 18,85 & 0,0000 \\
\cline { 1 - 1 } Intra grupos & 175,985 & 28 & 6,28517 & & \\
\cline { 1 - 4 } Total (Corr.) & 886,963 & 34 & & & \\
\hline
\end{tabular}

\begin{tabular}{|c|c|c|c|}
\hline \multicolumn{4}{|c|}{ Test de Contraste Múltiple de Rango } \\
\hline & Frecuencia & Media $(\mathrm{MPa})$ & Grupos Homogéneos \\
\hline CT13 & 5 & 7,9060 & $\mathrm{X}$ \\
\hline CA8 & 5 & 9,1503 & $\mathrm{x}$ \\
\hline CA14 & 5 & 13,2614 & $\mathrm{X}$ \\
\hline A12 & 5 & 16,7037 & $x$ \\
\hline A8 & 5 & 17,5155 & $x x$ \\
\hline $\mathrm{CC} 12$ & 5 & 18,5708 & $X X$ \\
\hline A16 & 5 & 20,7308 & $x$ \\
\hline
\end{tabular}

Tabla. 4.5. Estudio estadístico de los resultados de tensión adherente máxima en la condición térmica de $20^{\circ} \mathrm{C}$ : ANOVA y test de Contraste Múltiple de Rango.

\begin{tabular}{llllll}
\hline \multicolumn{5}{c}{ Análisis de Varianza } \\
Fuente & Suma de Cuadrados & $G l$ & Cuadrado Medio & Razón-F & Valor-P \\
\hline Entre grupos & 29,8065 & 6 & 4,96775 & 11,27 & 0,0000 \\
\cline { 1 - 3 } Intra grupos & 12,3376 & 28 & 0,44063 & & \\
\cline { 1 - 3 } Total (Corr.) & 42,1442 & 34 & & & \\
\hline
\end{tabular}

\begin{tabular}{|c|c|c|c|}
\hline \multicolumn{4}{|c|}{ Test de Contraste Múltiple de Rango } \\
\hline & Frecuencia & $\operatorname{Media}(\mathrm{mm})$ & Grupos Homogéneos \\
\hline CT13 & 5 & 0,2141 & $\mathrm{X}$ \\
\hline CA8 & 5 & 0,4549 & $x$ \\
\hline CA14 & 5 & 1,4504 & $x$ \\
\hline $\mathrm{A} 12$ & 5 & 1,6454 & $x$ \\
\hline A8 & 5 & 1,6776 & $\mathrm{x}$ \\
\hline $\mathrm{CC} 12$ & 5 & 1,9252 & $x$ \\
\hline A16 & 5 & 3,2265 & $\mathrm{x}$ \\
\hline
\end{tabular}

Tabla. 4.6. Estudio estadístico de los resultados de deslizamiento en extremo tensionado en la condición térmica de $20^{\circ} \mathrm{C}$ : ANOVA y test de Contraste Múltiple de Rango. 
Análisis de Varianza

\begin{tabular}{cccccc}
\hline Fuente & Suma de Cuadrados & Gl & Cuadrado Medio & Razón-F & Valor-P \\
\hline Entre grupos & 31,5864 & 6 & 5,26441 & 20,68 & 0,0000 \\
\cline { 1 - 3 } Intra grupos & 7,1286 & 28 & 0,254593 & & \\
\cline { 1 - 4 } Total (Corr.) & 38,715 & 34 & & & \\
\hline
\end{tabular}

\begin{tabular}{|c|c|c|c|}
\hline \multicolumn{4}{|c|}{ Test de Contraste Múltiple de Rango } \\
\hline & Frecuencia & $\operatorname{Media}(\mathrm{mm})$ & Grupos Homogéneos \\
\hline CT13 & 5 & 0,0380 & $\mathrm{X}$ \\
\hline CA8 & 5 & 0,1907 & $x$ \\
\hline CA14 & 5 & 0,9748 & $x$ \\
\hline A12 & 5 & 1,1865 & $x$ \\
\hline A8 & 5 & 1,4766 & $x x$ \\
\hline $\mathrm{CC} 12$ & 5 & 1,9525 & $x$ \\
\hline A16 & 5 & 3,0114 & $x$ \\
\hline
\end{tabular}

Tabla. 4.7. Estudio estadístico de los resultados de deslizamiento en extremo no tensionado en la condición térmica de $20^{\circ} \mathrm{C}$ : ANOVA y test de Contraste Múltiple de Rango.
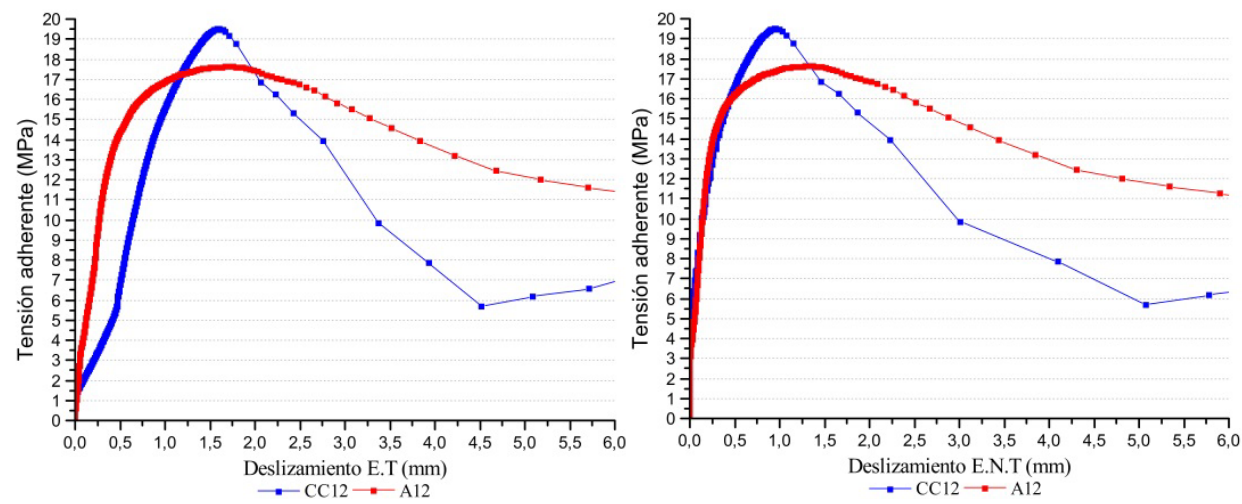

Fig. 4.26. Comportamiento adherente de las barras de CFRP y acero corrugadas, CC12 y A12. Gráfica tensión adherente-deslizamiento.

En cuanto a las barras de CFRP arenadas CA8, se comprueba estadísticamente (Tabla 4.5) que desarrollan una tensión adherente menor que las barras de acero corrugadas A8. Sin embargo, las barras CA8 producen un menor nivel de deslizamientos que las barras de acero corrugado A8, tanto a tensión adherente máxima (Tablas 4.6 y 4.7) como al mismo nivel de tensión (Tabla 4.8). Por consiguiente, las barras de CFRP arenada CA8 presentan un comportamiento adherente diferente a las barras de acero corrugadas, con un menor deslizamiento y una menor tensión adherente máxima (Fig. 4.27). 
Análisis de Varianza

\begin{tabular}{cccccc}
\hline Fuente & Suma de Cuadrados & Gl & Cuadrado Medio & Razón-F & Valor-P \\
\hline Entre grupos & 0,0265363 & 1 & 0,0265363 & 15,41 & 0,0111 \\
\cline { 1 - 2 } Intra grupos & 0,00860742 & 5 & 0,00172148 & & \\
\cline { 1 - 4 } Total (Corr.) & 0,0351437 & 6 & & & \\
\hline
\end{tabular}

\begin{tabular}{cccc}
\hline \multicolumn{4}{c}{ Test de Contraste Múltiple de Rango } \\
\hline & Frecuencia & Media $(\mathrm{mm})$ & Grupos Homogéneos \\
\hline CA8 & 4 & 0,042 & $\mathrm{X}$ \\
\hline A8 & 3 & 0,166 & $\mathrm{X}$ \\
\hline
\end{tabular}

Tabla. 4.8. Estudio estadístico del deslizamiento medio a tensión de $5 \mathrm{MPa}$ en la condición térmica de $20^{\circ} \mathrm{C}$, entre las barras CA8 y A8: ANOVA y test de Contraste Múltiple de Rango.
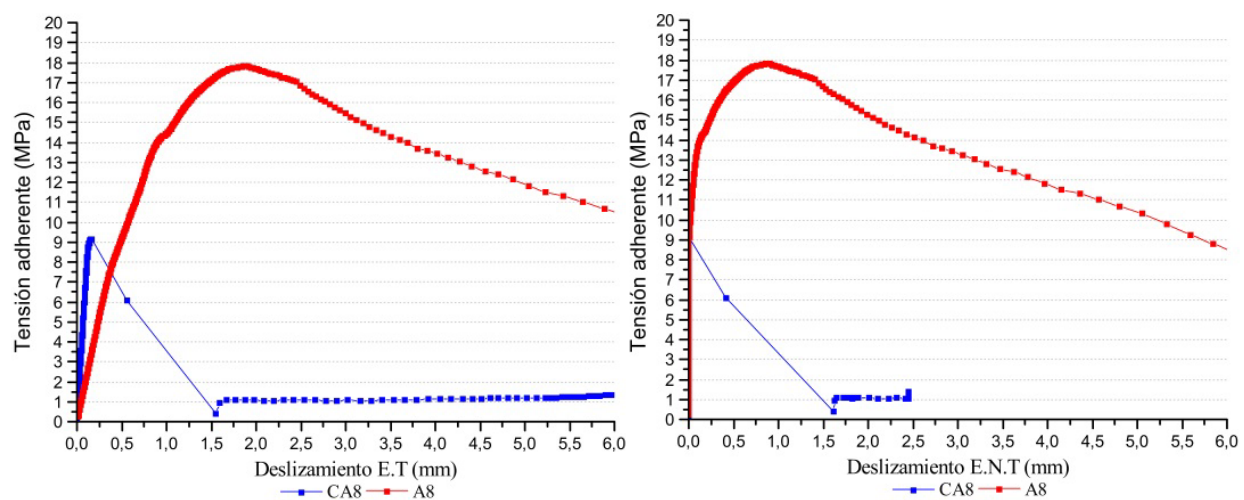

Fig. 4.27. Comportamiento adherente de las barras de CFRP arenadas CA8 y acero corrugadas A8. Gráfica de tensión adherente-deslizamiento.

Las barras de CFRP arenadas CA14, desarrollan una tensión adherente máxima (Tabla 4.5) menor que las barras de acero corrugadas A16. Por el contrario, producen un menor deslizamiento que las barras de acero corrugado A16, tanto a tensión adherente máxima (Tablas 4.6 y 4.7) como a la misma tensión (Tabla 4.9). Por lo tanto, las barra de CFRP arenadas CA14 desarrollan un comportamiento adherente con una menor tensión adherente máxima y menores deslizamientos que las barras de acero y CFRP corrugadas (Fig. 4.28).

\begin{tabular}{cccccc}
\hline \multicolumn{5}{c}{ Análisis de Varianza } \\
\cline { 1 - 5 } Fuente & Suma de Cuadrados & Gl & Cuadrado Medio & Razón-F & Valor- $P$ \\
\hline Entre grupos & 0,012144 & 1 & 0,012144 & 39,39 & 0,0015 \\
\cline { 1 - 2 } Intra grupos & 0,00154167 & 5 & 0,000308333 & & \\
\cline { 1 - 2 } Total (Corr.) & 0,0136857 & 6 & & & \\
\hline
\end{tabular}




\begin{tabular}{cccc}
\hline \multicolumn{4}{c}{ Test de Contraste Múltiple de Rango } \\
\hline & Frecuencia & Media $(\mathrm{mm})$ & Grupos Homogéneos \\
\hline CA14 & 3 & 0,043 & $\mathrm{X}$ \\
\cline { 1 - 1 } A16 & 4 & 0,127 & $\mathrm{X}$
\end{tabular}

Tabla. 4.9. Estudio estadístico del deslizamiento medio a tensión de $5 \mathrm{MPa}$ en la condición térmica de $20^{\circ} \mathrm{C}$, entre las barras CA14 y A16: ANOVA y test de Contraste Múltiple de Rango.
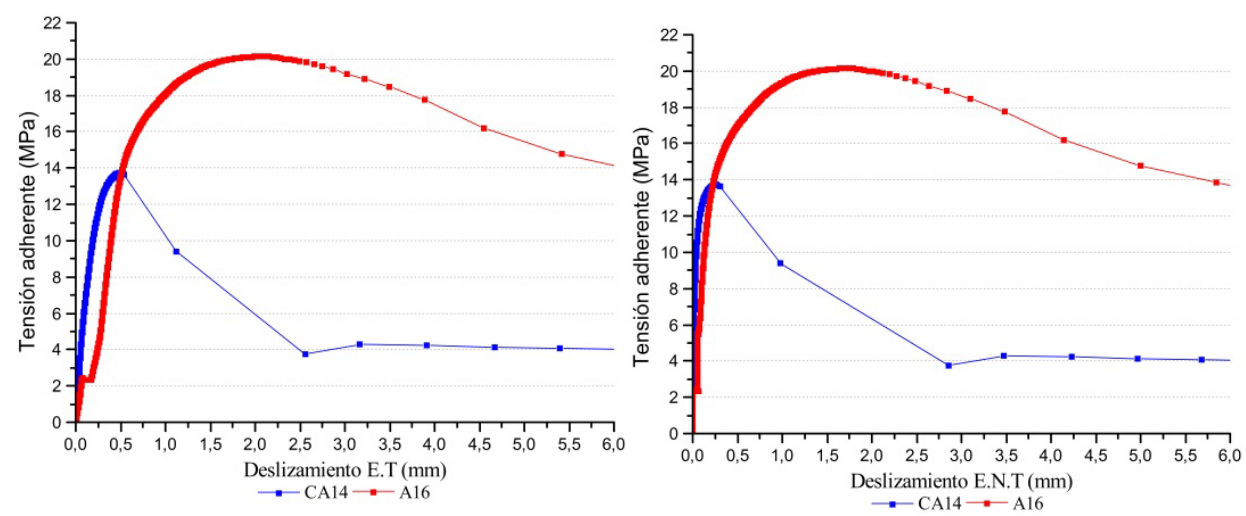

Fig. 4.28. Comportamiento adherente de las barras de CFRP arenadas CA14 y acero corrugadas A16. Gráfica de tensión adherente-deslizamiento.

Respecto a las barras de CFRP texturizadas se comprueba, según el ANOVA y el test de Contraste Múltiple de Rango realizados (Tabla 4.5), que estadísticamente con un nivel de confianza del $95 \%$, generan una menor tensión adherente máxima que las barras de acero corrugadas A12. Además, este tipo de barras CT13 produce un nivel de deslizamientos más elevado que las barras de CFRP y acero corrugadas, tanto a tensión adherente máxima (Tablas 4.6 y 4.7) como al mismo nivel de tensión (Tabla 4.10). Entonces, se puede considerar que las barras de CFRP texturizadas presentan un comportamiento adherente con una menor tensión adherente máxima y mayor deslizamiento que las barras de CFRP acero corrugadas (Fig. 4.29).

\begin{tabular}{cccccc}
\hline \multicolumn{5}{c}{ Análisis de Varianza } \\
\cline { 1 - 5 } Fuente & Suma de Cuadrados & Gl & Cuadrado Medio & Razón-F & Valor-P \\
\hline Entre grupos & 0,704776 & 2 & 0,352388 & 3,83 & 0,05 \\
\cline { 1 - 3 } Intra grupos & 0,920655 & 10 & 0,0920655 & & \\
\cline { 1 - 4 } Total (Corr.) & 1,62543 & 12 & & & \\
\hline
\end{tabular}




\begin{tabular}{cccc}
\hline \multicolumn{4}{c}{ Test de Contraste Múltiple de Rango } \\
\cline { 1 - 1 } & Frecuencia & Media $(\mathrm{mm})$ & Grupos Homogéneos \\
\hline $\mathrm{y}$ CC12 & 4 & 0,112 & $\mathrm{X}$ \\
\cline { 1 - 1 } $\mathrm{A} 12$ & 4 & 0,135 & $\mathrm{X}$ \\
\cline { 1 - 1 } $\mathrm{CT13}$ & 5 & 0,602 & $\mathrm{X}$ \\
\hline
\end{tabular}

Tabla. 4.10. Estudio estadístico del deslizamiento medio a tensión de $5 \mathrm{MPa}$ en la condición térmica de $20^{\circ} \mathrm{C}$, entre las barras CT13 y A12: ANOVA y test de Contraste Múltiple de Rango.
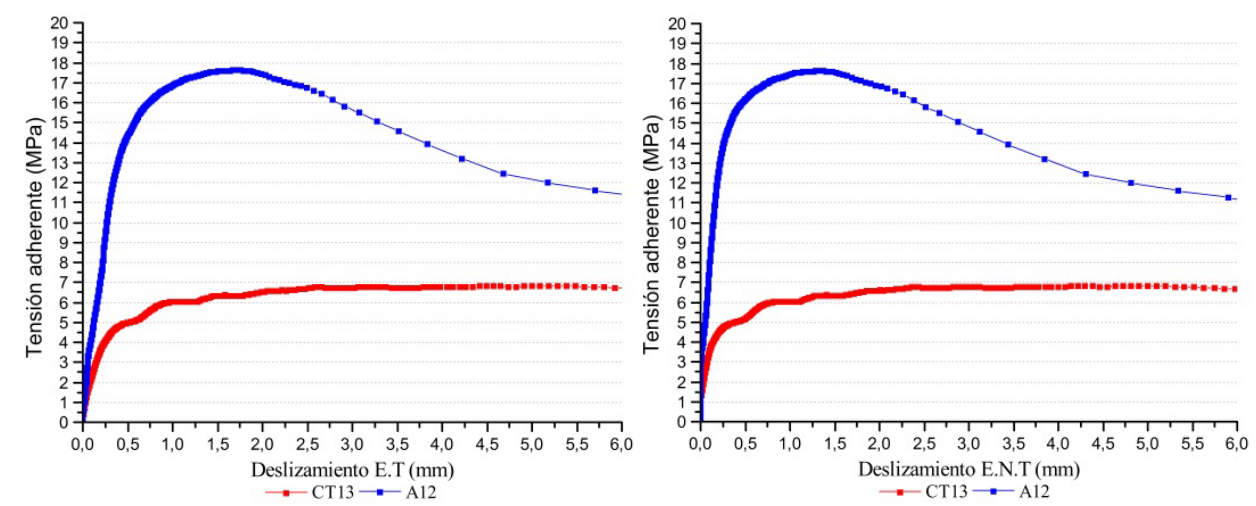

Fig. 4.29. Comportamiento adherente de las barras de CFRP texturizadas CT13 y acero corrugadas A12. Gráfica de tensión adherente-deslizamiento.

\section{c) Análisis de la Influencia de los Parámetros $f_{r}$, $a_{s}$ y C.L.R, en el Comportamiento Adherente, en Condiciones Térmicas de $20^{\circ} \mathrm{C}$}

Las características de adherencia de las barras de acero y CFRP corrugadas o deformadas, pueden comprobarse, mediante el método general, a base de ensayos de adherencia (Pullout o Beam-End), o alternativamente mediante las características de la geometría de las corrugas, a través del parámetro $f_{R}$ (véase apart. 3.4.1.2 de la presente investigación). En esta investigación, el parámetro $f_{R}$ únicamente es posible calcularlo en los tipos de barras de CFRP, corrugadas CC12, texturizadas CT13 y acero corrugadas A8, A12 y A16. En los otros tipos de barras, como son las de CFRP arenadas, no es posible su cálculo debido al acabado superficial a base de arena de sílice. 
En la Tabla 4.11 se muestran los valores medios del parámetro $f_{R}$. calculados en cada tipo de barra para cada tratamiento térmico, y la media global del parámetro por tipo de barra.

\begin{tabular}{|c|c|c|c|c|c|c|}
\hline & HD & $5^{\circ} \mathrm{C}$ & $20^{\circ} \mathrm{C}$ & $40^{\circ} \mathrm{C}$ & $80^{\circ} \mathrm{C}$ & $\begin{array}{c}\text { Media } \\
\text { población }\end{array}$ \\
\hline $\mathrm{CC} 12$ & 0,0655 & 0,0632 & 0,0614 & 0,0705 & 0,0629 & 0,065 \\
\hline CT13 & 0,0419 & 0,0397 & 0,0406 & 0,0378 & 0,0418 & 0,041 \\
\hline A8 & 0,0682 & 0,0682 & 0,0682 & 0,0682 & 0,0682 & 0,068 \\
\hline A12 & 0,0711 & 0,0796 & 0,0768 & 0,0711 & 0,0711 & 0,074 \\
\hline A16 & 0,0596 & 0,0717 & 0,0656 & 0,0596 & 0,0656 & 0,064 \\
\hline
\end{tabular}

Tabla. 4.11. Valores obtenidos del parámetro $f_{R}$ en cada tipo de barra.

El estudio estadístico realizado sobre el parámetro $f_{R}$ en los tipos de barras $\mathrm{CC} 12$, CT13, A8, A12 y A16, en la condición térmica de $20^{\circ} \mathrm{C}$, confirma que hay tres grupos homogéneos de tipos de barras con un parámetro $f_{R}$ estadísticamente diferente: $1^{\text {er. }}$ CT13; $2^{\text {do }}$ : CC12 A16 y A8; $3^{\text {ro }}$ : A8 y A12 (Tabla 4.12). Estos grupos homogéneos, de tipos de barras, son similares a los resultados obtenidos en el estudio estadístico de la tensión adherente (Tabla 4.5, Test de Contraste Múltiple de Rango). Por lo tanto, se puede afirmar, con un nivel de confianza del $95 \%$, que el parámetro $f_{R}$ es un buen indicador de la tensión adherente desarrollada por las barras de CFRP corrugadas CC12, texturizadas CT13 y de acero corrugadas A8, A12 y A16, en condición térmica de $20^{\circ} \mathrm{C}$.

\begin{tabular}{lccc}
\hline \multicolumn{4}{c}{ Test de Contraste Múltiple de Rango } \\
\hline & Frecuencia & Media $\left(f_{R}\right)$ & Grupos Homogéneos \\
\cline { 1 - 1 } $\mathrm{CT} 13$ & 5 & 0,0406 & $\mathrm{X}$ \\
$\mathrm{y} \mathrm{C} 12$ & 5 & 0,0614 & $\mathrm{X}$ \\
$\mathrm{y} 16$ & 5 & 0,0656 & $\mathrm{X}$ \\
$\mathrm{y} \mathrm{A} 8$ & 5 & 0,0682 & $\mathrm{XX}$ \\
$\mathrm{y} 12$ & 5 & 0,0768 & $\mathrm{X}$ \\
\hline
\end{tabular}

Tabla. 4.12. Test de Contraste Múltiple de Rango del parámetro $f_{R}$ en condición térmica de $20^{\circ} \mathrm{C}$.

En cuanto a la relación entre el parámetro $f_{R}$ y la tensión adherente, se puede establecer inicialmente, para cada tipo y diámetro de barra estudiados en 
esta investigación (CC12, CT13, A8, A12 y A16), una relación doblemente inversa ${ }^{50}$ (Fig. 4.30). Esta relación confirma, con un nivel de confianza del $95 \%$, un ajuste $\mathrm{R}^{2}$ de 87,20 y $92,20 \%$ y un coeficiente de correlación de 0,93 y 0,96 , para la condición térmica de $20^{\circ} \mathrm{C}$ o en el caso de los valores medios de toda la población, respectivamente, que a medida que se incrementa el parámetro $f_{R}$ aumenta la tensión adherente (Figs. 4.30.a y b).

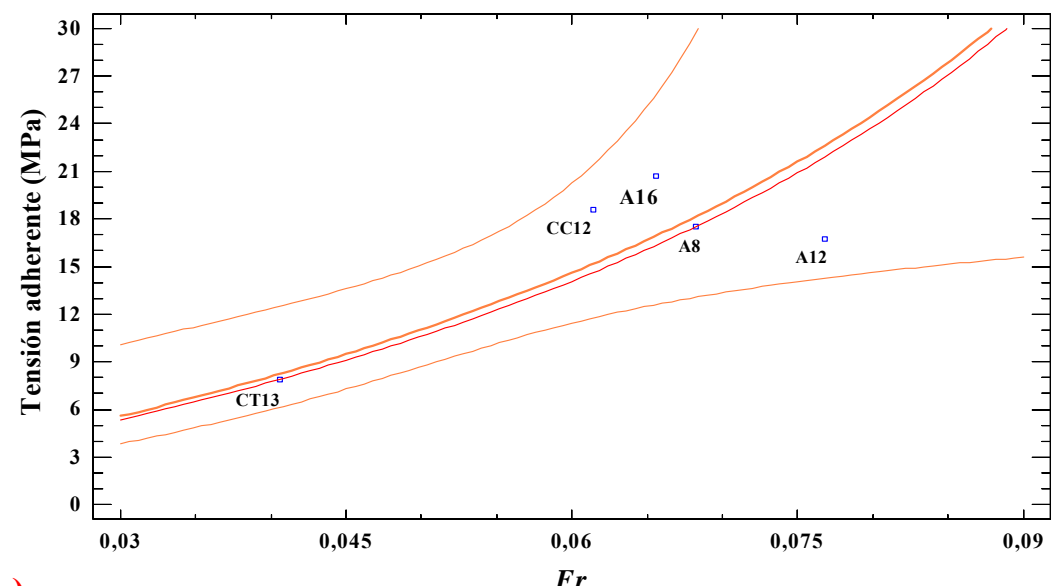

a)

Mínimos Cuadrados:Tensión adherente_20 $=1 /\left(-0,0422617+0,00664132 / F r \_20\right)$ M.A.D.:Tensión adherente_20 $=1 /\left(-0,0449872+0,00696182 / F r \_20\right)$

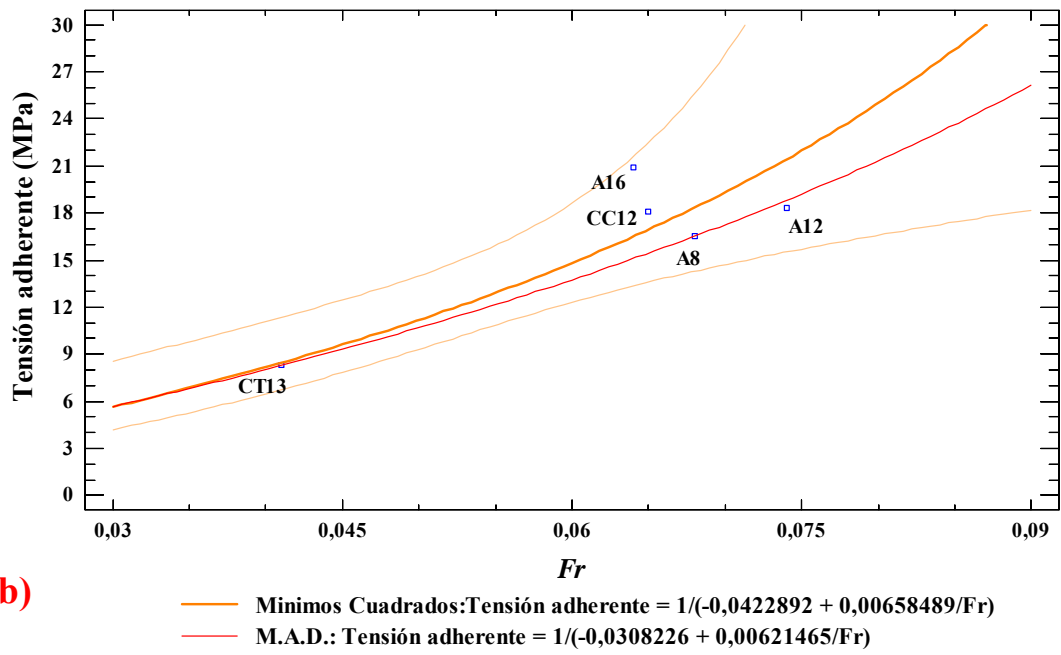

Fig. 4.30. Relación doblemente inversa entre la tensión adherente y el parámetro $f_{R}$. en los tipos de barras CC12, AT13, A8, A12 y A16: a) Tratamiento térmico de $20^{\circ} \mathrm{C}$; b) Toda la población.

\footnotetext{
${ }^{50}$ La regresión ha sido ajustada mediante dos métodos: mínimos cuadrados y error absoluto medio (M.A.D).
} 
En el caso de las barras de CFRP corrugadas CC12, la tensión adherente, en condiciones térmicas normales $\left(20\right.$ y $\left.40{ }^{\circ} \mathrm{C}\right)$ y bajas $\left(\mathrm{H} / \mathrm{D}\right.$ y $\left.5{ }^{\circ} \mathrm{C}\right)$, se incrementa a medida que aumenta el parámetro $f_{R}$ (Fig. 4.31). En la condición térmica de $80{ }^{\circ} \mathrm{C}$ la influencia de otros factores, como la temperatura, no demuestra este incremento de tensión adherente en función del parámetro $f_{R}$ (véase apart. 4.1.2 de la presente investigación).

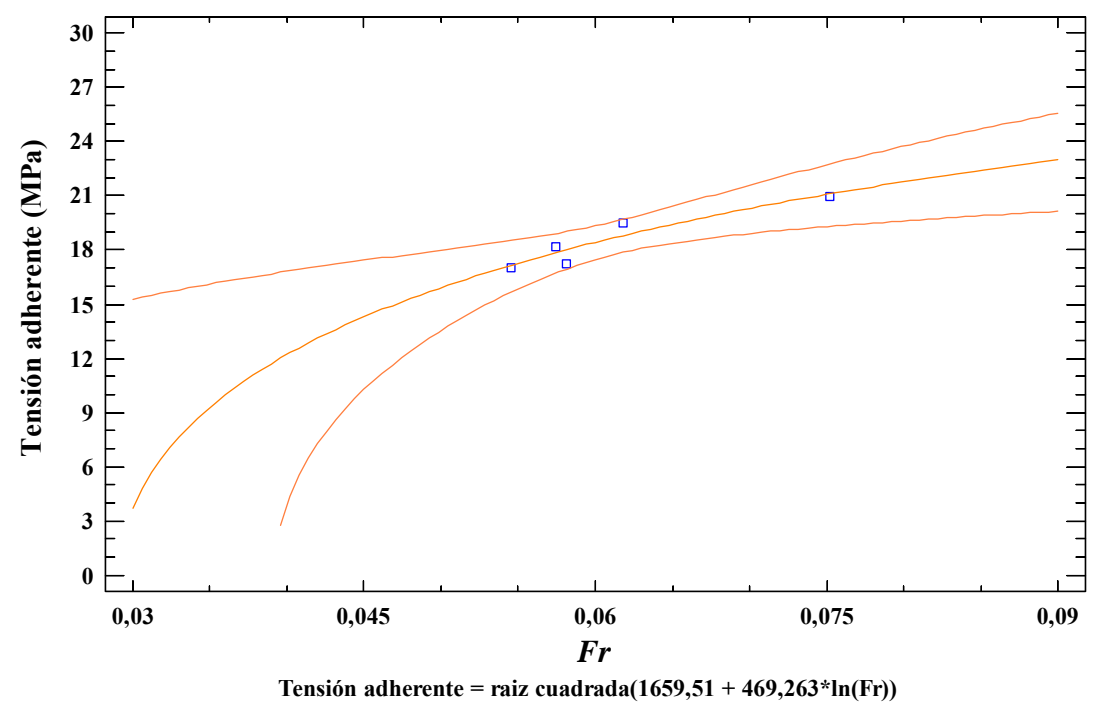

Fig. 4.31. Relación entre la tensión adherente y el parámetro $f_{R}$. en las barras de CFRP corrugadas CC12, en la condición térmica de $20^{\circ} \mathrm{C}\left(\mathrm{r}^{2}=88,82 \%\right.$ y Coeficiente de correlación $\left.=0,9425\right)$.

Además, se comprueba que el incremento del parámetro $f_{R}$ produce un comportamiento adherente, desde el inicio hasta la tensión adherente máxima, mucho más rígido. Es decir, a una misma tensión adherente le corresponde un deslizamiento menor. Este efecto, por ejemplo, se puede observar en las gráficas de tensión adherente-deslizamiento de las barras CC12, L5-T20-P7-CC12 y L14-T20-P7-CC12 (condición térmica de $20^{\circ} \mathrm{C}$ ), en las que el parámetro $f_{R}$ varia de 0,0545 a 0,0752, obteniendo una mayor rigidez adherente a mayor parámetro $f_{R}$ (Fig. 4.32 y Anejo I). También se observa entre las barras CT13, con $f_{R}$ igual a 0,041, y el resto de barras de CFRP y acero corrugadas, con $f_{R}$ igual o mayor a 0,065 (véase Anejo I). 


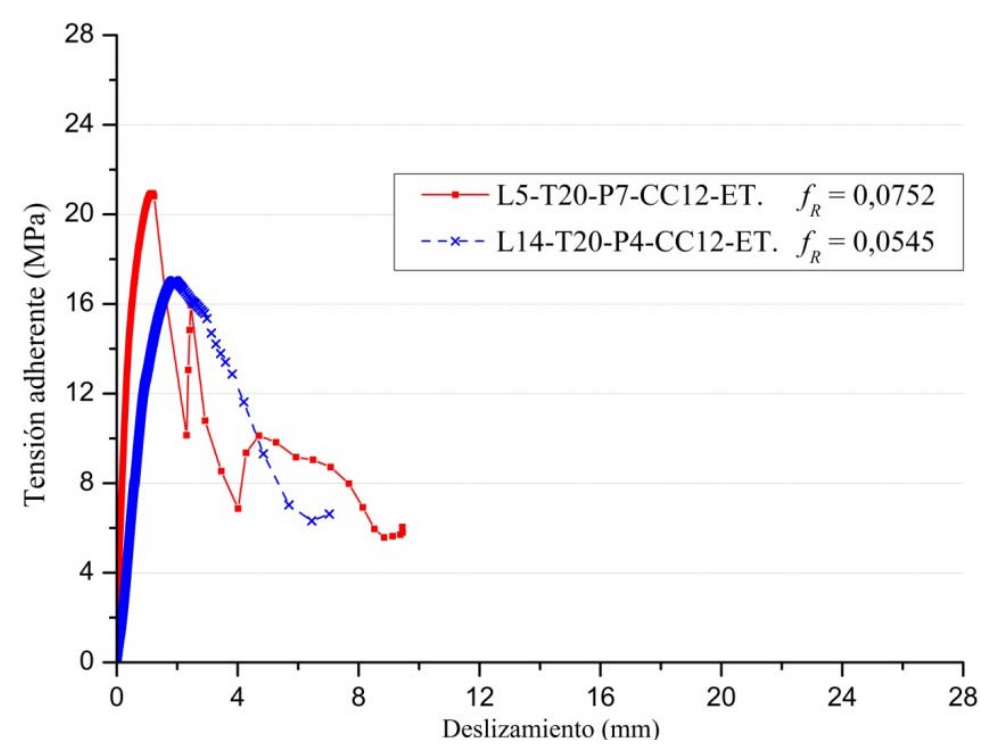

Fig. 4.32. Comportamiento adherente en función del parámetro $f_{R}$. Gráfica de tensión adherentedeslizamiento.

En esta investigación se puede calcular, para el tipo de barras de CFRP corrugadas $\mathrm{CC} 12$, el valor del parámetro $f_{R}$ para el cual se produce la mayor tensión adherente. Para ello únicamente se han seleccionado los valores correspondientes a la condición térmica de $20{ }^{\circ} \mathrm{C}$, evitando de este modo la influencia de otros factores como la temperatura. El valor del parámetro $f_{R}$ que produce una mayor tensión adherente es igual a 0,0752. Este valor, del mismo modo que el valor medio de toda la muestra igual a 0,065 , es superior al valor del $f_{R}$ óptimo igual a 0,06 , recomendado por Hao et al. (2009), para barras de GFRP corrugadas. Por el contrario, Hammad (1995) recomienda, en el caso de barras de acero corrugadas, un valor de $f_{R}$ igual 0,20 , para el desarrollo de la máxima tensión adherente. Del mismo modo, el fabricante de las barras de CFRP corrugadas CC12, utilizadas en esta investigación, Marshall Compsosites C.O., establece para el diámetro y tipo de barras suministrado un valor del parámetro $f_{R}$ igual a 0,13 . Estos dos valores distan mucho del obtenido en cada muestra de barra $\mathrm{CC} 12$ y de la media a cada temperatura y total de todas las barras. Además, ningún tipo de barra ensayada en esta investigación alcanza un 
valor superior a 0,0854 (tan solo en cuatro muestras A12). En estos casos de $f_{R}$ elevado, el modo de rotura y la tensión adherente máxima dependen en mayor medida, que en el caso de $f_{R}$ reducidos, de la resistencia de la resina polimérica de las corrugas de la barra y de la resistencia del hormigón.

Por otro lado, a través de la regresión entre la tensión adherente y el parámetro $f_{R}$ obtenida para barras CC12 (Fig. 4.27), se puede obtener la tensión adherente para los valores del parámetro $f_{R}$ definidos por el fabricante $\mathrm{y}$ recomendados (Tabla 4.13). Estos valores, de tensión adherente obtenidos, son similares a los definidos en las diferentes investigaciones que los recomiendan. Por lo tanto, la regresión calculada presenta un buen ajuste con los datos de otras investigaciones, aunque la geometría superficial no es idéntica.

\begin{tabular}{|c|c|c|c|c|}
\hline Definido por: & $f_{R}$ & $\begin{array}{l}\text { Tensión adherente } \\
\text { regresión, (MPa). } \\
\text { (1) }\end{array}$ & $\begin{array}{l}\text { Tensión adherente, } \\
\text { cada investigación, } \\
(\mathrm{MPa}) .(2)\end{array}$ & $\begin{array}{c}\text { Diferencia } \\
(1) /(2)\end{array}$ \\
\hline Hao et al., (2009) & 0,060 & 18,42 & 13,96 & 1,31 \\
\hline Esta investigación & 0,075 & 21,10 & 20,93 & 1,01 \\
\hline Marshall Composites & 0,130 & 26,49 & - & - \\
\hline Hammad, (1995) & 0,200 & 30,07 & 30,50 & 0,99 \\
\hline
\end{tabular}

Tabla 4.13. Valores de la tensión adherente obtenidos mediante la regresión: Tensión adherente $=\sqrt{\left(1659,51+469,263 * \ln \left(f_{R}\right)\right.}$ y en cada investigación.

En cuanto a los parámetros dimensionales que definen el parámetro $f_{R}$, como son la altura de corruga " $\mathrm{a}_{\mathrm{m}}$ " y la distancia entre corrugas "c". Los valores obtenidos para toda la muestra de barras $\mathrm{CC} 12, \mathrm{a}_{\mathrm{m}}$ igual a $0,62 \mathrm{~mm}(0,06$ diámetros de barra) y c igual a $8,02 \mathrm{~mm}$ ( 0,78 diámetros de barra), cumplen las recomendaciones definidas por Hao et al. (2009). Sin embargo, estos valores no alcanzan los mínimos definidos por Marshall Composites C.O. Dispersión que puede ser debida a un escaso control de calidad de la producción. Del mismo modo, estos valores son inferiores a los óptimos, definidos por Hammad (1995), para el desarrollo de la tensión adherente máxima (Tabla 4.14). Por lo tanto, la tensión adherente de las barras CC12 podría incrementarse si se modifican estos 
parámetros, alcanzado un parámetro $f_{R}$ igual o superior a 0,13 o 0,20 . Para ello es necesaria una investigación en este ámbito.

\begin{tabular}{ccc}
\hline Definido por: & $\mathrm{a}_{\mathrm{m}}(\%$ de $\varnothing)$ & $\mathrm{c}(\%$ de $\varnothing)$ \\
\hline Hao et al., (2009) & 6 & 100 \\
\hline Esta investigación & 6 & 78 \\
\hline Marshall Composites & 8 & 60 \\
\hline Hammad, (1995) & 10 & 50 \\
\hline
\end{tabular}

Tabla 4.14. Valores de los parámetros dimensionales que definen la geometría superficial de las barras CC12.

Respecto al resto de parámetros que definen la geometría superficial de las barras corrugadas o deformadas (véase apart. 3.4.1.2 de la presente investigación), las barras CC12 (Tabla 3.24) cumplen con las limitaciones, establecidas por EHE-08 a través de UNE EN 10080, de altura de corruga " $\mathrm{a}_{\mathrm{m}}$ " ( $a_{m}$ entre 0,03 y 016 diámetros de barra), separación de corrugas "c" (c entre 0,4 y 1,2 diámetros de barra), inclinación de corrugas " $\beta$ " ( $\beta$ entre 35 y $75^{\circ}$ ) y altura de aletas longitudinales "e $\mathrm{e}_{1} \mathrm{e}_{2}$ " ( $\mathrm{e}_{1-2}$ menor o igual a 0,15 diámetros de barra). Sin embargo, no cumplen con la inclinación de los flancos de corruga " $\alpha$ ", puesto que la norma define que $\alpha$ debe ser mayor o igual a $45^{\circ}$, y en este tipo de barras $\alpha$ es igual a $23,89^{\circ}$.

\begin{tabular}{ccccc}
\hline \multirow{2}{*}{ Parámetro } & \multicolumn{5}{c}{ Diámetro de barra $(\mathrm{mm})$} \\
\cline { 2 - 5 } & 8 & 10 & 12 & 16 \\
\hline$f_{R}$ & $\geq 0,045$ & $\geq 0,052$ & $\geq 0,056$ & $\geq 0,056$ \\
\hline
\end{tabular}

Tabla. 4.15. Valores mínimos, establecidos por EHE-08, del parámetro $f_{R}$.

Para la comprobación de las características de adherencia, la EHE-08 en su artículo 32.2, establece unos valores mínimos del parámetro $f_{R}$ (Tabla 4.15). Esta limitación se cumple en los tipos de barras CC12, A8, A12 y A16. En cambio, en las barras CT13, este parámetro no alcanza el valor mínimo definido de 0,056 . Por lo tanto, tal y como se ha demostrado en el estudio estadístico anterior del parámetro $f_{R}$, se comprueba que: este parámetro es un buen indicador 
de la tensión adherente, y que las prescripciones establecidas por EHE-08 en su art. 32.2 son válidas.

Además, en el caso de las barras de CFRP texturizadas CT13, con un valor medio del parámetro $f_{R}$ igual a 0,041 y una geometría superficial que produce corrugas invertidas, se comprueba que, para el valor medio de toda la muestra y todos los valores de $f_{R}$ de cada barra ensayada de CT13 (rango de $f_{R}$ entre 0,030 y 0,050 ), se produce una rotura adherente prematura por pullout, debida a corte de las corrugas de hormigón que acuñan contra la barra. Estos valores pequeños de $f_{R}$ se originan por una geometría superficial con una distancia entre corrugas elevada, c igual a 23,267 mm (1,98 diámetros de barra), y una pequeña altura de corruga en relación con la distancia entre corrugas, $a_{m}$ igual a $1,074 \mathrm{~mm}$.

En cuanto al parámetro Concrete Lug Ratio o C.L.R. (véase apart. 3.4.1.2 de la presente investigación), en la Tabla 4.16 se muestran los valores, calculados mediante la Ec. 3.9, tanto para toda la muestra como para cada condición térmica de barras ensayadas a pullout.

\begin{tabular}{|c|c|c|c|c|c|c|}
\hline & HD & $5^{\circ} \mathrm{C}$ & $20^{\circ} \mathrm{C}$ & $40^{\circ} \mathrm{C}$ & $80^{\circ} \mathrm{C}$ & $\begin{array}{c}\text { Media } \\
\text { población }\end{array}$ \\
\hline $\mathrm{CC} 12$ & 0,71 & 0,70 & 0,72 & 0,71 & 0,72 & 0,71 \\
\hline CT13 & 0,10 & 0,11 & 0,10 & 0,10 & 0,10 & 0,10 \\
\hline A8 & 0,75 & 0,75 & 0,75 & 0,75 & 0,75 & 0,75 \\
\hline A12 & 0,76 & 0,75 & 0,76 & 0,76 & 0,76 & 0,76 \\
\hline A16 & 0,74 & 0,74 & 0,74 & 0,74 & 0,74 & 0,74 \\
\hline
\end{tabular}

Tabla. 4.16. Valores obtenidos del parámetro C.L.R en cada tipo de barra.

El análisis estadístico de este parámetro demuestra que hay diferencia estadísticamente significativa, con un nivel de confianza del 95\%, entre el tipo de barra CT13 y el resto de barras (CC12, A8, A12 y A16). Además, los siguientes pares de barras forman grupos homogéneos similares a los obtenidos en el análisis de la tensión adherente: $2^{\text {do }}$ grupo: CC12 y A16; $3^{\text {er }}$ grupo: A16 y 
A8; $4^{\text {to }}$ grupo: A8 y A12. Por lo tanto, el parámetro C.L.R puede ser un indicador de la tensión adherente.

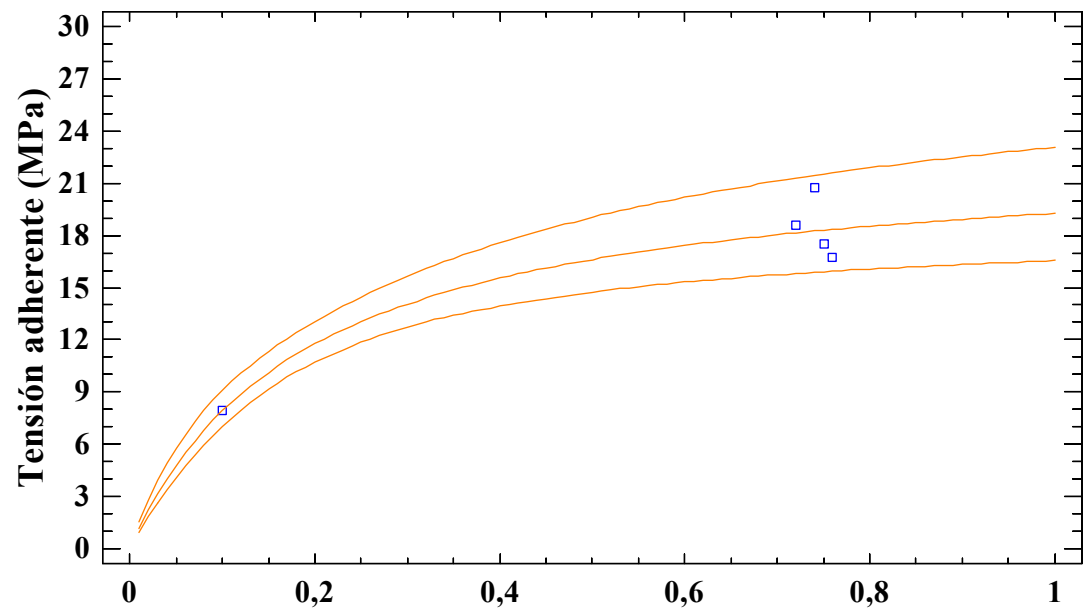

a)

C.L.R

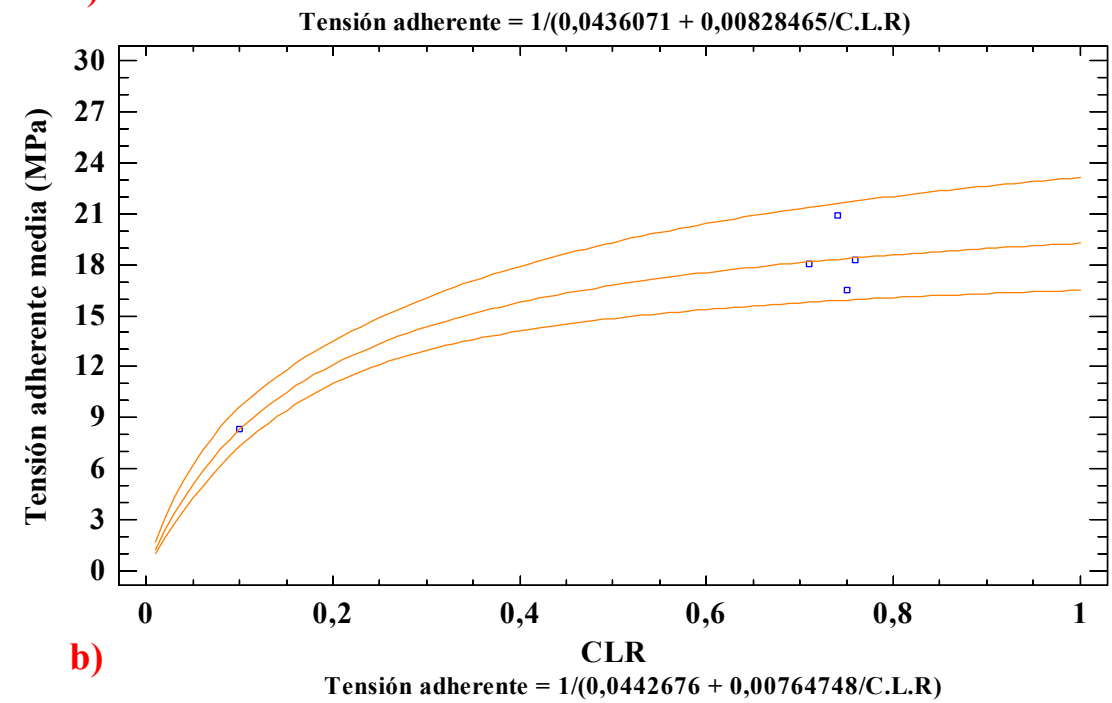

Fig. 4.33. Relación entre la tensión adherente y el parámetro C.L.R: a) En la condición térmica de $20{ }^{\circ} \mathrm{C}\left(\mathrm{r}^{2}=98,10 \%\right.$ y Coeficiente de correlación $\left.=0,99\right)$; $\left.\mathrm{b}\right)$ En toda la población $\left(\mathrm{r}^{2}=97,70 \% \mathrm{y}\right.$ Coeficiente de correlación $=0,9885$ );

En cuanto a la relación entre el parámetro C.L.R y la tensión adherente, en la Fig. 4.33 se muestra una regresión doble inversa, entre los valores medios de toda la población y en la condición térmica de $20^{\circ} \mathrm{C}$. Esto demuestra que a medida que se incrementa el parámetro C.L.R aumenta la tensión adherente. 
Además, se comprueba que valores bajos de C.L.R, del orden de 0,07 a 0,12, producen una tensión adherente dos o tres veces menor, y unos deslizamientos, tanto en el extremo tensionado y no tensionado, de 2 a 3 veces mayores, respecto a unos valores de C.L.R del orden de 0,71 a 0,76. Al mismo tiempo, los valores bajos del parámetro C.L.R originan un modo de rotura prematuro por corte de la corruga de hormigón (Fig. 4.23), al contrario de lo que ocurre con valores altos de C.L.R, con una anchura de la corruga de hormigón elevada. Estos resultados confirman los obtenidos por la investigación de Al-Mahmoud et al. (2007) en barras de CFRP corrugadas, en la cual, los valores de C.L.R inferiores a 0,40 producen un modo de rotura adherente por corte de la corruga de hormigón, mientras que, valores de C.L.R iguales a 0,75 originan una rotura por corte de las corrugas de la barra de CFRP. Estos resultados también confirman los obtenidos por Nanni et al. (1995) y Al-Zahrani et al. (1995), en barras de CFRP corrugadas con un parámetro C.L.R igual a 0,70 , donde la rotura se produce por corte de las corrugas. En la Fig. 4.34 se muestra la relación entre el parámetro C.L.R y la tensión adherente obtenida en las anteriores investigaciones y en ésta.

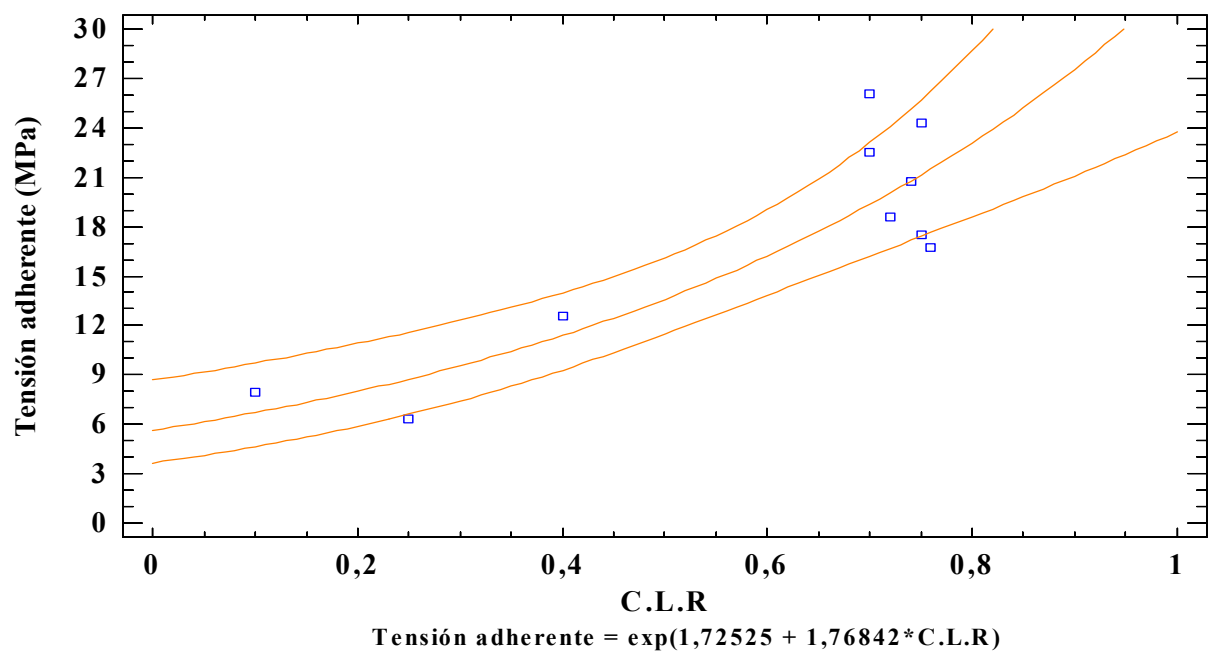

Fig. 4.34. Relación entre la tensión adherente y el parámetro C.L.R, en la condición térmica de $20{ }^{\circ} \mathrm{C}\left(\mathrm{r}^{2}=81,41 \%\right.$ y Coeficiente de correlación $\left.=0,90\right)$. Valores obtenidos en esta investigación y por Al-mahmoud et al. (2007), Al-Zahrani et al. (1999) y Nanni et al. (1995). 
Por el contrario, este parámetro no predice la rigidez del comportamiento adherente con la misma fiabilidad que el parámetro $f_{R}$, ya que entre el mismo tipo de barra la variación del parámetro C.L.R no es significativa respecto a la tensión adherente. Esto es debido a que en el cálculo tan solo tiene en cuenta el ancho de la corruga de hormigón y de la barra, desestimando la altura de corruga que produce el acuñamiento.

En cuanto al parámetro $\mathrm{a}_{\mathrm{s}}$, los valores calculados mediante la Ec. 3.10 (definida en el apart. 3.4.1.2 de la presente investigación), en el caso de toda la población de barras y cada condición térmica, se muestran en la Tabla 4.17.

\begin{tabular}{|c|c|c|c|c|c|c|}
\hline & HD & $5^{\circ} \mathrm{C}$ & $20^{\circ} \mathrm{C}$ & $40^{\circ} \mathrm{C}$ & $80^{\circ} \mathrm{C}$ & $\begin{array}{c}\text { Media } \\
\text { población }\end{array}$ \\
\hline $\mathrm{CC} 12$ & 2,12 & 2,04 & 1,98 & 2,26 & 2,03 & 2,09 \\
\hline CT13 & 1,57 & 1,50 & 1,54 & 1,43 & 1,58 & 1,54 \\
\hline A8 & 1,55 & 1,55 & 1,55 & 1,55 & 1,55 & 1,55 \\
\hline A12 & 2,49 & 2,82 & 2,71 & 2,49 & 2,49 & 2,59 \\
\hline A16 & 2,90 & 3,32 & 3,11 & 2,90 & 3,11 & 3,06 \\
\hline
\end{tabular}

Tabla. 4.17. Valores obtenidos del parámetro $\mathrm{a}_{\mathrm{s}}$ en cada tipo de barra.

El análisis estadístico de este parámetro demuestra que no es un buen estimador de la tensión adherente, puesto que los grupos homogéneos de barras con el mismo parámetro ( $1^{\mathrm{er}}$ grupo: CT13 y CA8; $2^{\text {do }}$ grupo: CC $12 ; 3^{\text {er }}$ grupo: A12 y $4^{\text {to }}$ grupo: A16), no son similares a los obtenidos en el análisis de la tensión adherente, tanto para toda la población como en la condición térmica de $20{ }^{\circ} \mathrm{C}$.

Además, según el estudio estadístico realizado, en los tipos de barras estudiados, no existe una relación estadísticamente significativa entre el parámetro $\mathrm{a}_{\mathrm{s}} \mathrm{y}$ la tensión adherente (Tabla 4.18).

\begin{tabular}{|c|c|c|c|c|c|}
\hline \multicolumn{6}{|c|}{ Análisis de Varianza } \\
\hline Fuente & Suma de Cuadrados & $G l$ & Cuadrado Medio & Razón-F & Valor-P \\
\hline Modelo & 32671,9 & 1 & 32671,9 & 2,34 & 0,2236 \\
\hline Residuos & 41884,3 & 3 & 13961,4 & & \\
\hline Total (Corr.) & 74556,2 & 4 & & & \\
\hline
\end{tabular}

Tabla. 4.18. Análisis estadístico de la relación entre el parámetro $\mathrm{a}_{\mathrm{s}} \mathrm{y}$ la tensión adherente, en la condición térmica de $20^{\circ} \mathrm{C}$. En el caso de toda la población el Valor-P es igual a 0,0817 . 
Por lo tanto, este parámetro de la geometría del corrugado, definido por Baena et al. (2009) no es un indicador de la tensión adherente de las barras de CFRP corrugadas, texturizadas $\mathrm{y}$ acero corrugadas, empleadas en esta investigación. Esto es debido a que en el cálculo de dicho parámetro no se tiene en cuenta el diseño de la corruga ni el diámetro de la barra (Ec. 3.10); únicamente se valora el área de corruga proyectada y la distancia entre corrugas. Este efecto se observa entre las barras CT13 y A8, en el que las barras CT13 presentan un valor de $a_{\mathrm{s}}$ similar a las barras A8, sin embargo, la tensión adherente de las barras CT13 es la mitad que la de las barras A8 (Fig. 4.35).

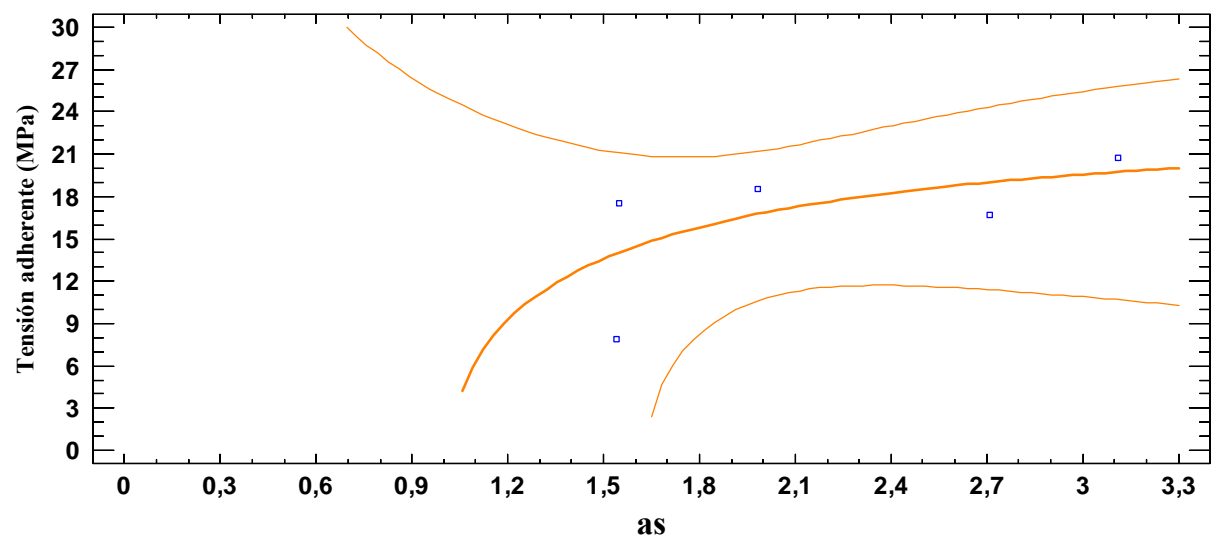

Fig. 4.35. Relación entre la tensión adherente y el parámetro $a_{s}$, en la condición térmica de $20^{\circ} \mathrm{C}$ $\left(r^{2}=42,16 \%\right.$ y Coeficiente de correlación $\left.=0,64\right)$.

\subsubsection{Temperatura}

En este apartado se analiza la influencia de los diferentes tratamientos térmicos $\left(-20^{\circ} \mathrm{C}\right.$ o Hielo/Deshielo, $5{ }^{\circ} \mathrm{C}, 40{ }^{\circ} \mathrm{C}$ y $\left.80{ }^{\circ} \mathrm{C}\right)$ en el comportamiento adherente, de las barras de CFRP corrugadas, texturizadas y arenadas, respecto del tratamiento térmico de control de $20^{\circ} \mathrm{C}$. Al mismo tiempo, se compara el comportamiento adherente, en cada temperatura, con el desarrollado por las barras de acero corrugadas. De este modo, se establecen las diferencias del comportamiento adherente entre cada tipo de barra de CFRP y acero corrugadas. 
a) Análisis de la influencia de la temperatura en el comportamiento adherente de las barras de CFRP:

- Barras de CFRP arenadas CA8:
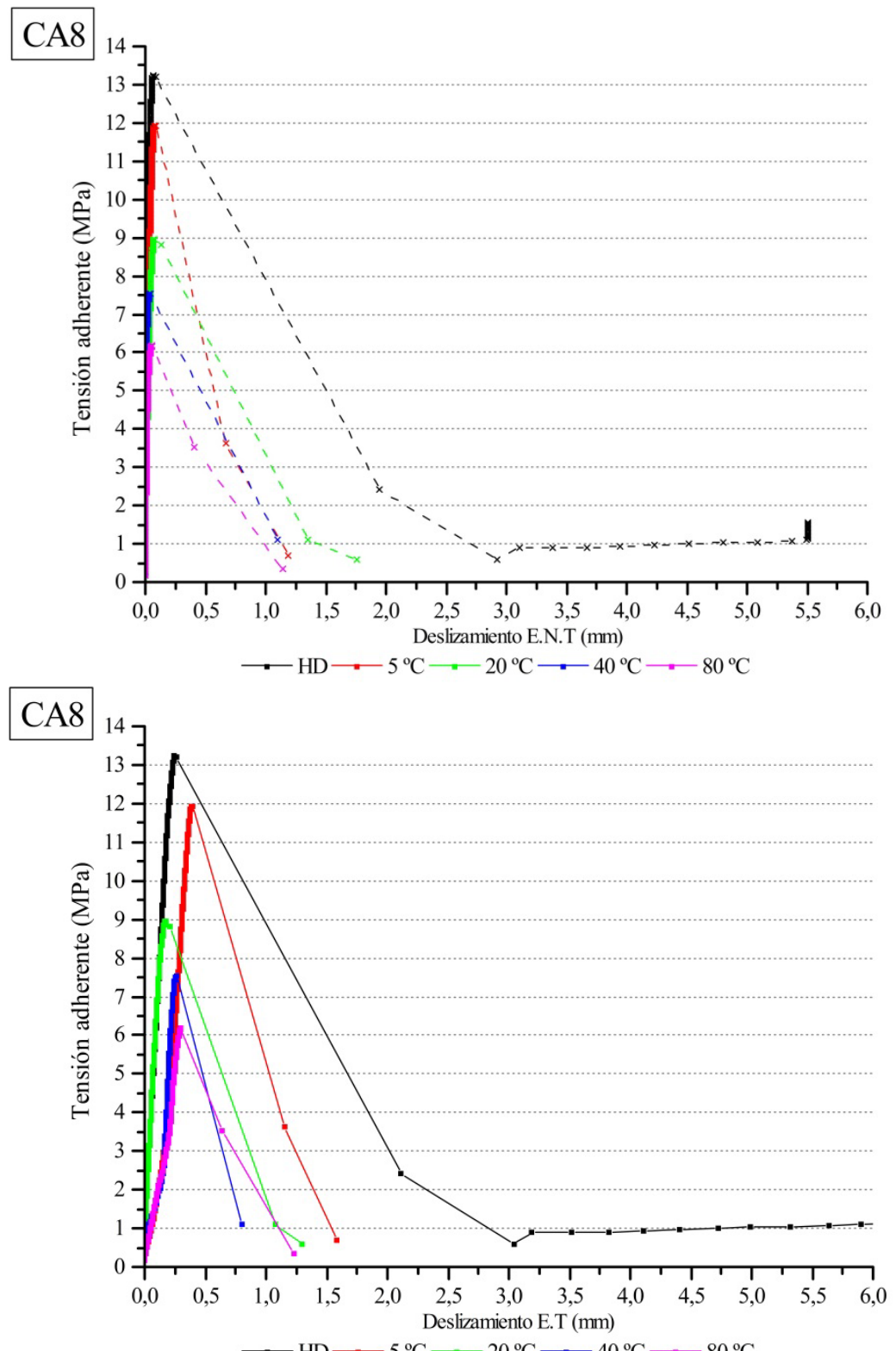

Fig. 4.36. Comportamiento adherente de las barras de CFRP arenadas CA 8 en condiciones térmicas de Hielo/Deshielo, $5{ }^{\circ} \mathrm{C}, 20{ }^{\circ} \mathrm{C}, 40{ }^{\circ} \mathrm{C}$ y $80{ }^{\circ} \mathrm{C}$. Gráfica de tensión adherentedeslizamiento. 
Las barras de CFRP arenadas CA8, desarrollan inicialmente casi toda su adherencia, en todas las condiciones térmicas estudiadas, mediante adhesión química (Fig. 4.36 y 4.37). Además, se comprueba estadísticamente, con un nivel de confianza del $95 \%$, que la adhesión química aumenta a medida que se disminuye la temperatura (Fig. 4.38). Seguidamente, el mecanismo de adhesión química se sustituye por el de rozamiento, hasta alcanzar la tensión adherente máxima. Este se desarrolla con unos valores similares, desde 0,42 hasta 2,32 $\mathrm{MPa}$, en todas las condiciones térmicas estudiadas (Fig. 4.38).

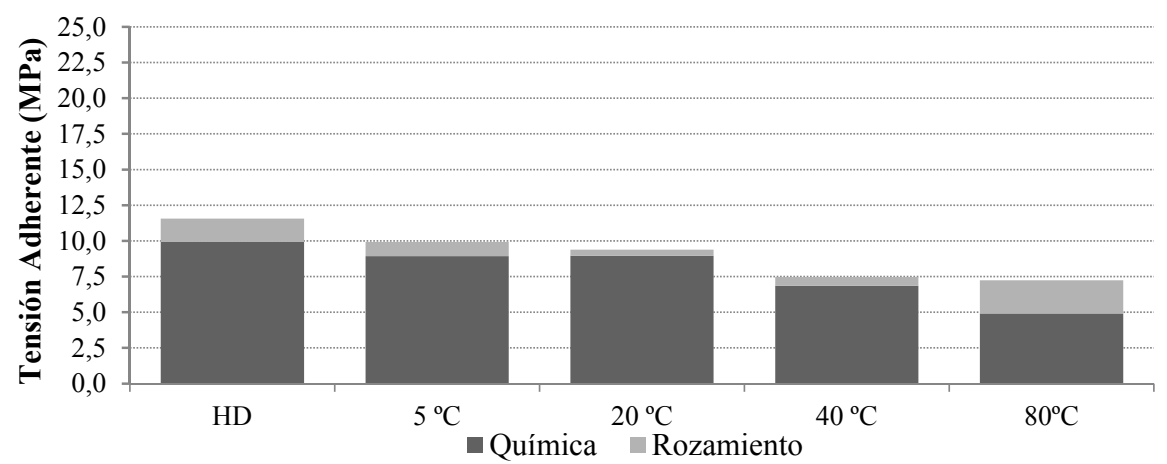

Fig. 4.37. Tipo de mecanismo adherente en barras de CFRP arenadas CA8.

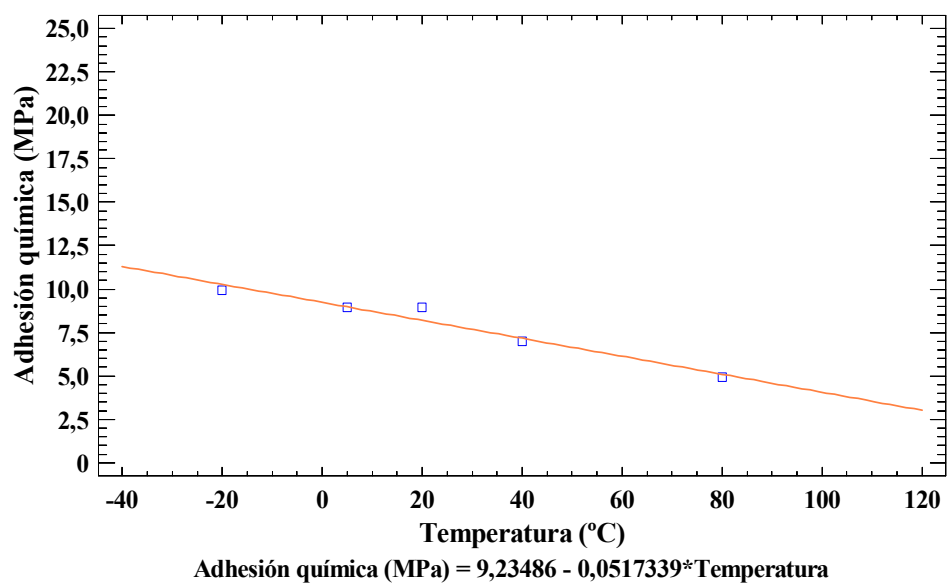

Fig. 4.38. Relación entre la adhesión química y la temperatura en barras de CFRP arenadas CA8.

Debido a que la adherencia, en las barras CA8, se desarrolla por los mecanismos de adhesión química y rozamiento, en todas las condiciones 
térmicas, la tensión adherente máxima se alcanza con unos deslizamientos muy reducidos. En todas las condiciones térmicas estudiadas, su comportamiento es más rígido que el de las barras de CFRP y acero corrugadas, y de CFRP texturizadas (Tabla 4.19 y Fig. 4.36).

\begin{tabular}{cccccc}
\hline $\begin{array}{c}\text { Condición Térmica / } \\
\text { Deslizamiento }(\mathrm{mm})\end{array}$ & $\mathrm{HD}$ & $5{ }^{\circ} \mathrm{C}$ & $20{ }^{\circ} \mathrm{C}$ & $40{ }^{\circ} \mathrm{C}$ & $80{ }^{\circ} \mathrm{C}$ \\
\hline Extremo Tensionado " $\delta_{\mathrm{ET}}$ ” & 0,229 & 0,381 & 0,214 & 0,185 & 0,269 \\
\cline { 1 - 2 } Extremo No Tensionado " $\delta_{\mathrm{ENT}}$ " & 0,069 & 0,065 & 0,038 & 0,037 & 0,046 \\
\hline
\end{tabular}

Tabla. 4.19. Valores medios del deslizamiento, en extremo tensionado y no tensionado, de las barras de CFRP arenadas CA8 en las diferentes condiciones térmicas.

En cuanto a la tensión adherente máxima de las barras CA8, según el estudio estadístico realizado (Tabla 4.20), mediante ANOVA, se comprueba con un nivel de confianza del $95 \%$, que hay diferencia estadíticamente significativa en el efecto que producen las distintas condiciones térmicas en la tensión adherente (Valor-P < 0,05). Además, se demuestra en el Test de Contraste Múltiple de Rango, con un nivel de confianza del $95 \%$, que con la condición HD es cuando se produce una mayor tensión adherente, seguida de la condición $5{ }^{\circ} \mathrm{C}$ y $20{ }^{\circ} \mathrm{C}$. Al mismo tiempo, se comprueba que con las condiciones de $40{ }^{\circ} \mathrm{C}$ y $80{ }^{\circ} \mathrm{C}$ se produce una menor tensión adherente en este tipo de barras, no habiendo diferencia estadísticamente significativa entre estas dos últimas (Fig. 4.36).

\begin{tabular}{|c|c|c|c|c|c|}
\hline \multicolumn{6}{|c|}{ Análisis de Varianza } \\
\hline Fuente & Suma de Cuadrados & $G l$ & Cuadrado Medio & Razón-F & Valor- $P$ \\
\hline Entre grupos & 75,5399 & 4 & 18,885 & 10,36 & 0,0001 \\
\hline Intra grupos & 34,7664 & 20 & 1,73832 & & \\
\hline Total (Corr.) & 110,306 & 24 & & & \\
\hline
\end{tabular}

\begin{tabular}{|c|c|c|c|}
\hline \multicolumn{4}{|c|}{ Test de Contraste Múltiple de Rango } \\
\hline & Frecuencia & Media $(M P a)$ & Grupos Homogéneos \\
\hline $80^{\circ} \mathrm{C}$ & 5 & 7,2412 & $\mathrm{X}$ \\
\hline $40^{\circ} \mathrm{C}$ & 5 & 7,4732 & $X X$ \\
\hline $20^{\circ} \mathrm{C}$ & 5 & 9,1503 & $x X$ \\
\hline $5^{\circ} \mathrm{C}$ & 5 & 10,8565 & $x X$ \\
\hline $\mathrm{HD}$ & 5 & 11,5577 & $x$ \\
\hline
\end{tabular}

Tabla. 4.20. Estudio estadístico del efecto de las condiciones térmicas en la tensión adherente de las barras de CFRP arenadas CA8: ANOVA y test de Contraste Múltiple de Rango. 
Por lo tanto, la disminución de la temperatura produce un incremento de la tensión adherente en las barras CA8; por ejemplo, a $-20{ }^{\circ} \mathrm{C}$ se incrementa el $26,31 \%$ respecto a $20{ }^{\circ} \mathrm{C}$. Del mismo modo, el incremento de la temperatura produce una reducción de la tensión adherente; por ejemplo, a $80{ }^{\circ} \mathrm{C}$ se reduce un $20,86 \%$ respecto a $20{ }^{\circ} \mathrm{C}$ (Figs. 4.39.a y b). Este efecto es originado por cambios en la estructura molecular de la resina polimérica, a base de viniléster, de la cual depende la adherencia de este tipo de barras (véase apart. 4.1.1), debido a que la resina polimérica se debilita al incrementar la temperatura o se vuelve más estable al disminuir esta (Fig. 4.39.b). Sin embargo, puesto que este tipo de barras poseen una capa de arenado en su superficie (cuya transmisión térmica es menor a la de la resina), la degradación de la resina polimérica de la barra debido a la temperatura no es muy acusada (Fig. 4.40).

a)

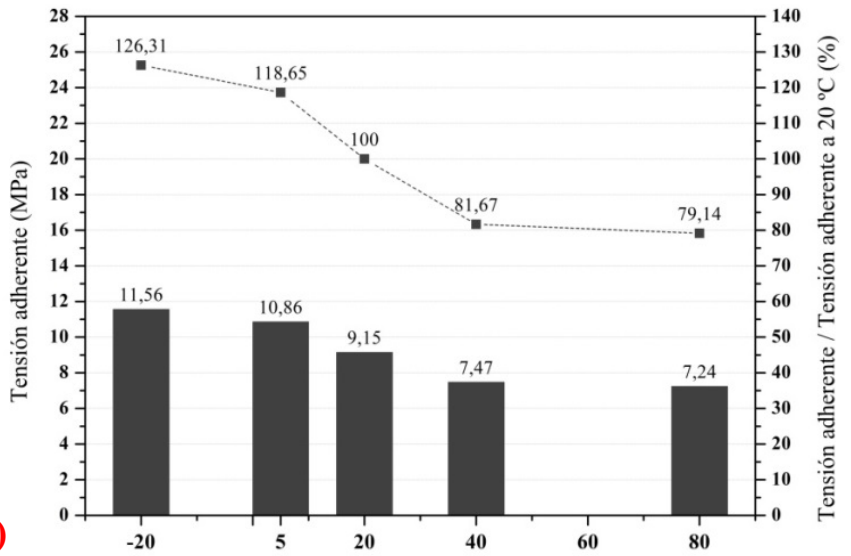

Temperatura $\left({ }^{\circ} \mathrm{C}\right)$

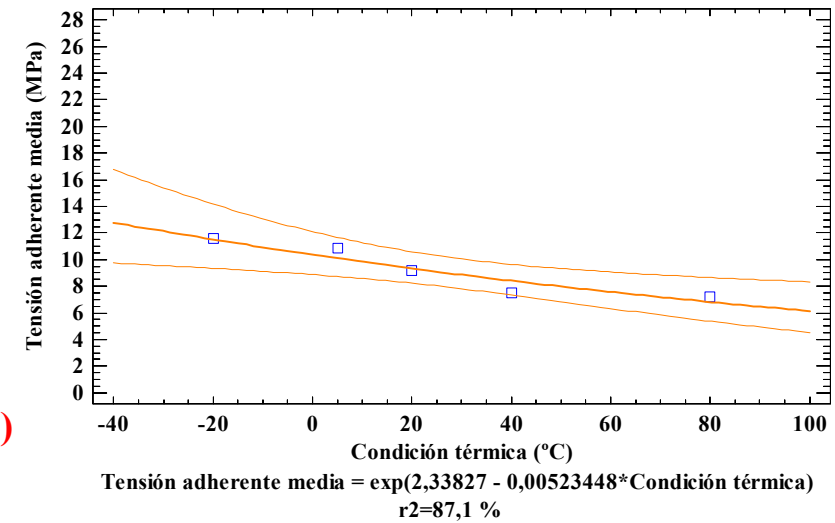

Fig. 4.39. Relación entre la tensión adherente y la temperatura en barras de CFRP arenadas CA8: a) Gráfico de barras de la tensión adherente) b) Relación exponencial con un nivel de confianza del $95 \%$. 


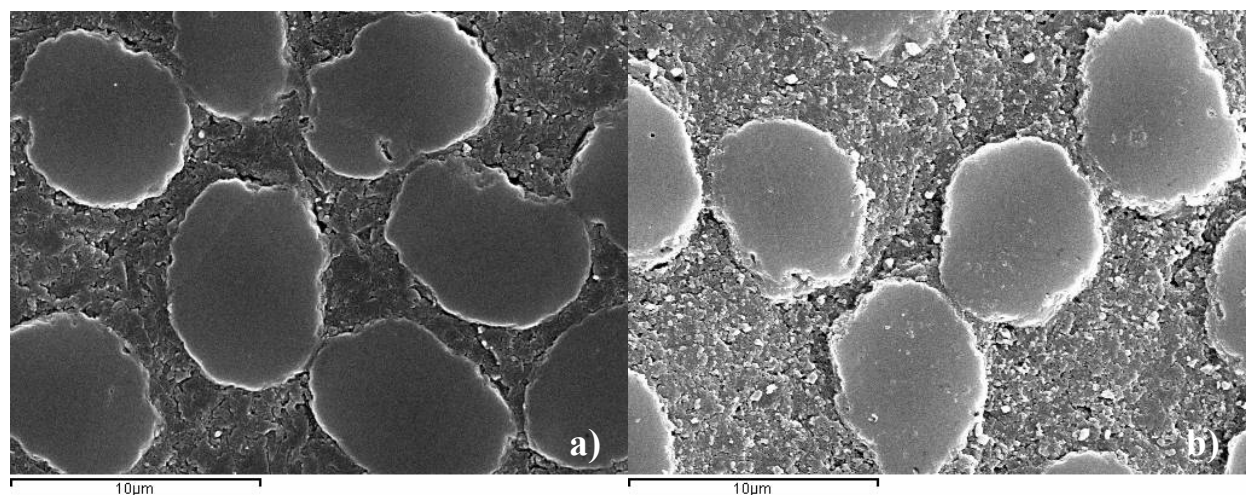

Fig. 4.40. Imágenes de la zona cercana a la interfaz entre la capa de arenado y el núcleo de la barra (x5000): a) Tratamiento térmico de $20^{\circ} \mathrm{C}$; b) Tratamiento térmico de $80^{\circ} \mathrm{C}$.

La tensión adherente máxima se alcanza cuando se produce la rotura de la adhesión entre la capa superficial de arenado y el núcleo de la barra. Este modo de rotura se observa en todas la temperaturas estudiadas (Fig. 4.41).

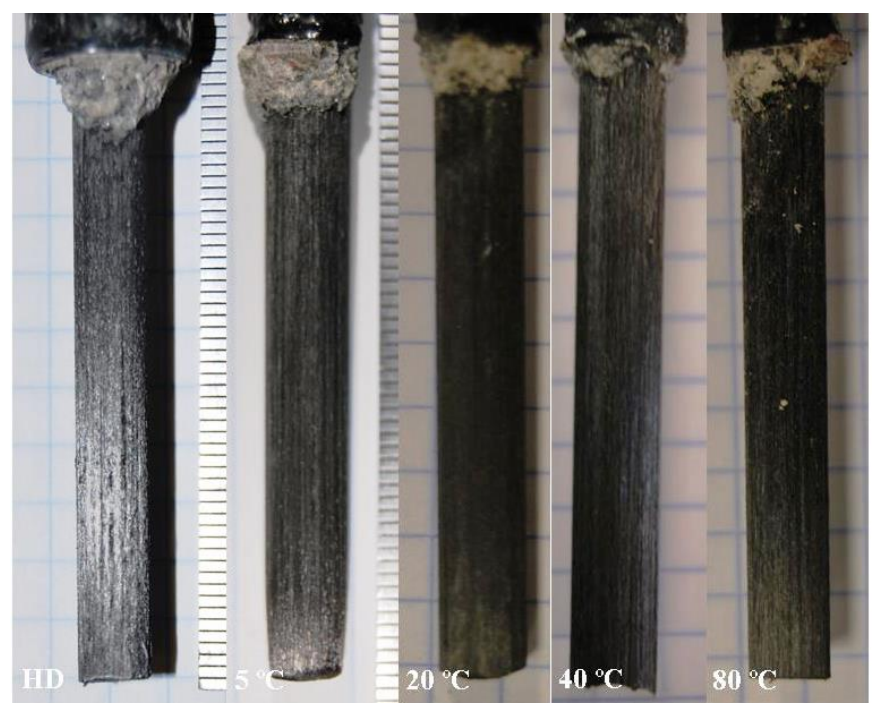

Fig. 4.41. Estado de las barras de CFRP arenadas CA8 tras el ensayo de pullout.

A temperaturas elevadas de $80{ }^{\circ} \mathrm{C}$ el deterioro de la resina polimérica en la interfaz de la capa de arenado y el núcleo es más acusado, efecto que produce una menor tensión adherente (Fig. 4.42.a). Por contra, a medida que desciende la temperatura se observa un menor deterioro de la resina polimérica y se muestran progresivamente un mayor número de surcos en la superficie de la barra, 
producidos por un mayor nivel tensional (Fig. 4.42.b). Esto demuestra que la influencia de la temperatura sobre la adherencia de este tipo de barras arenadas depende de la resina polimérica de la interfaz entre el núcleo y la capa de arenado. Al mismo tiempo, se observa a cualquier temperatura, que la matriz polimérica del núcleo (tanto en la zona cercana a la capa de arenado como en el centro) no se encuentra casi deteriorada (Fig. 4.40), efecto que también prueba que la adherencia de las barras arenadas CA8 depende de la matriz polimérica de la interfaz entre el núcleo y la capa de arenado.
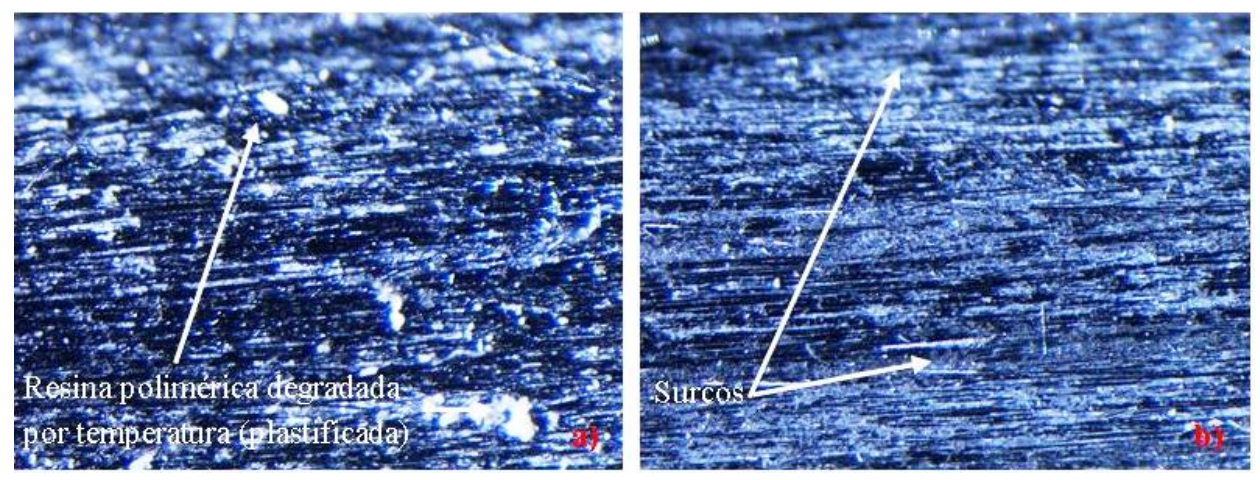

Fig. 4.42. Imágenes de superficie de la barra tras el ensayo de pullout (interfaz capa arenado y núcleo) (x2): a) Tratamiento térmico de $80^{\circ} \mathrm{C}$; b) Tratamiento térmico de $20^{\circ} \mathrm{C}$.

Respecto al comportamiento adherente tras la rotura, las barras de CFRP arenadas CA8 presentan en todas las temperaturas estudiadas un descenso brusco de la tensión adherente, existiendo una tensión adherente residual debido al rozamiento entre el núcleo de la barra y la capa de arenado. Esta tensión adherente residual media oscila entre 0,71 y 1,27 MPa (Tabla 4.21). Además, según el estudio estadístico realizado, se demuestra con un nivel de confianza del $95 \%$, que no hay diferencia estaditicamente significativa en la tensión adherente residual desarrollada tras la rotura para las diferentes temperaturas estudiadas $\left(-20,5,20,40\right.$ y $\left.80^{\circ} \mathrm{C}\right)$. Por lo tanto, el comportamiento adherente residual de las barras CA8 en las diferentes temperaturas estudiadas es similar. 


\begin{tabular}{|c|c|c|c|}
\hline \multicolumn{4}{|c|}{ Test de Contraste Múltiple de Rango } \\
\hline & Frecuencia & Media $(M P a)$ & Grupos Homogéneos \\
\hline $20^{\circ} \mathrm{C}$ & 5 & 0,7110 & $\mathrm{X}$ \\
\hline HD & 5 & 0,9216 & $x$ \\
\hline $80^{\circ} \mathrm{C}$ & 5 & 0,9952 & $x$ \\
\hline $40^{\circ} \mathrm{C}$ & 5 & 1,1162 & $X$ \\
\hline $5^{\circ} \mathrm{C}$ & 5 & 1,2701 & $x$ \\
\hline
\end{tabular}

Tabla. 4.21. Estudio estadístico del efecto de las condiciones térmicas en la tensión adherente residual de las barras de CFRP arenadas CA8: Test de Contraste Múltiple de Rango.

\section{- Barras de CFRP arenadas CA14:}

En cuanto a las barras de CFRP arenadas CA14, estas desarrollan inicialmente, a cualquier temperatura, su adherencia por adhesión química, con unos valores similares según el estudio estadístico realizado. A diferencia de las barras CA8, la adhesión química inicial es del orden 47-69 \% de la tensión adherente máxima (Fig. 4.43).

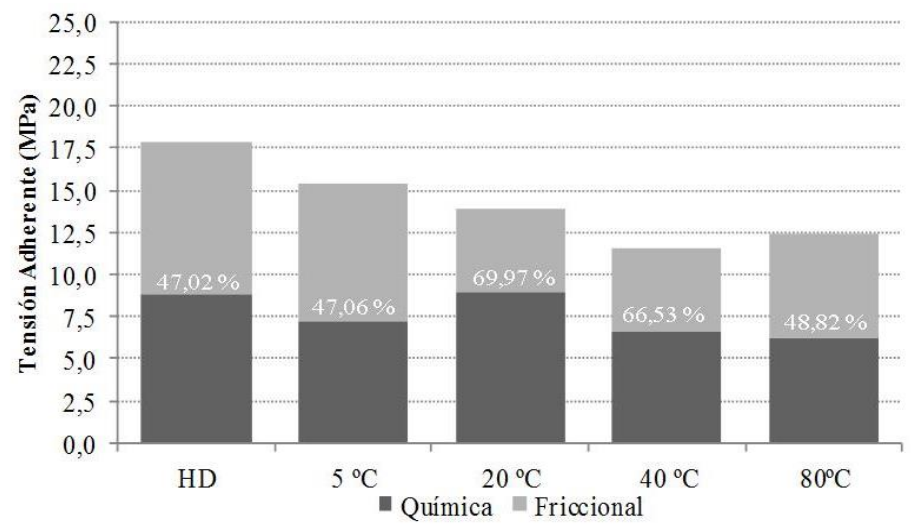

Fig. 4.43. Tipo de mecanismo adherente en barras de CFRP arenadas CA14.

Seguidamente, en todas las temperaturas estudiadas, al incrementarse en mayor medida los deslizamientos, finaliza el mecanismo de adhesión química y se sustituye por el mecanismo mecánico de rozamiento (Fig. 4.44). Este alcanza unos valores más elevados que en las barras CA8, debido a la mayor superficie específica adherente de la capa de arena superficial (Figs. 4.43 y 4.37). Al mismo tiempo, se comprueba, mediante un estudio estadístico, que el incremento 
o disminución de la temperatura no influye en la tensión adherente desarrollada por el mecanismo de rozamiento.

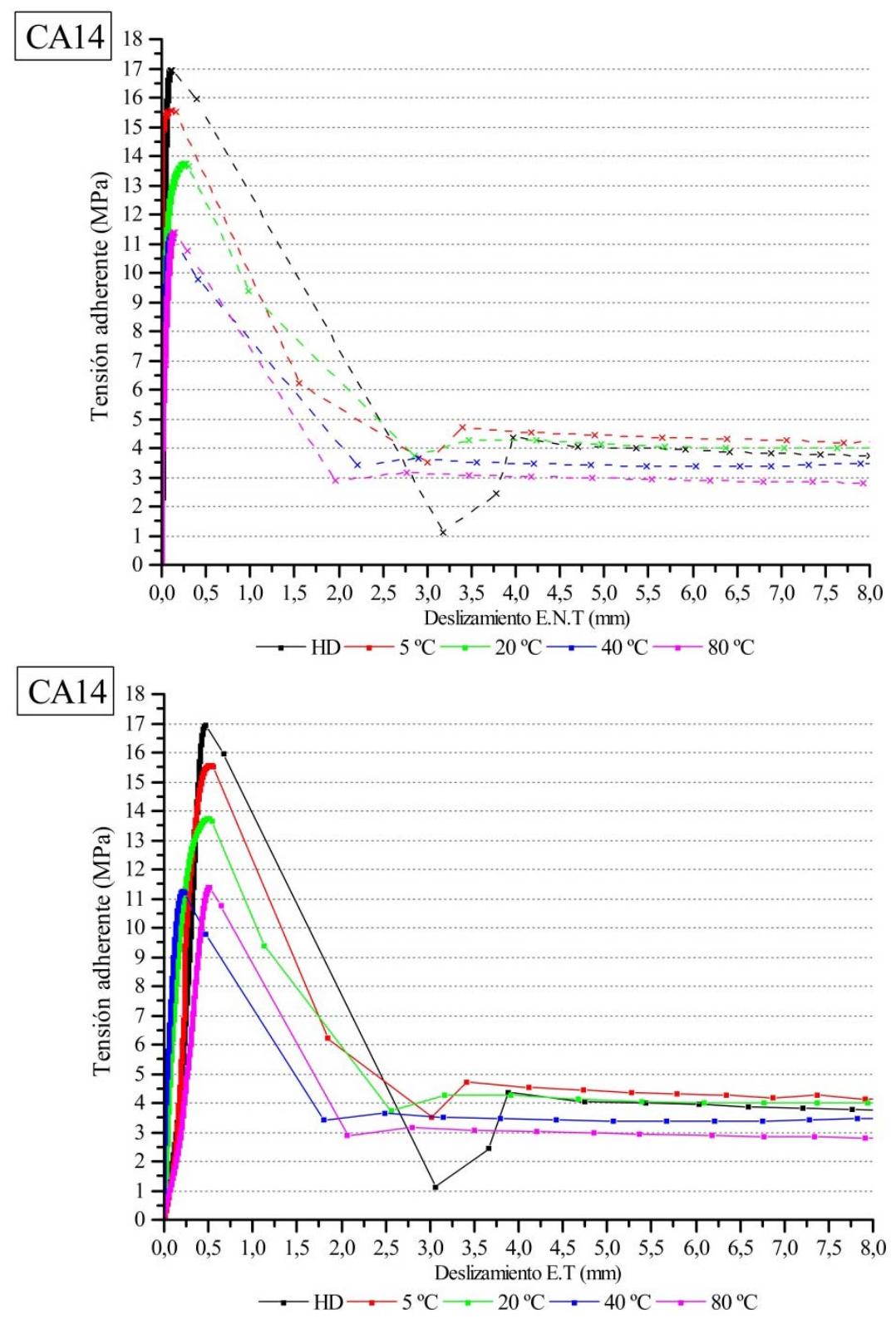

Fig. 4.44. Comportamiento adherente de las barras de CFRP arenadas CA14 en condiciones térmicas de Hielo/Deshielo, $5{ }^{\circ} \mathrm{C}, 20{ }^{\circ} \mathrm{C}, 40{ }^{\circ} \mathrm{C}$ y $80{ }^{\circ} \mathrm{C}$. Gráfica de tensión adherentedeslizamiento. 
Debido a que los mecanismos adherentes son por adhesión química y rozamiento, este tipo de barras desarrolla una tensión adherente máxima a unos deslizamientos muy reducidos (véase apart. 4.1.1.a). Estos deslizamientos, según el estudio estadístico realizado, son similares en todas las temperaturas estudiadas (Tabla 4.22).

\begin{tabular}{cccccc}
\hline $\begin{array}{c}\text { Condición Térmica / } \\
\text { Deslizamiento }(\mathrm{mm})\end{array}$ & $\mathrm{HD}$ & $5{ }^{\circ} \mathrm{C}$ & $20{ }^{\circ} \mathrm{C}$ & $40{ }^{\circ} \mathrm{C}$ & $80{ }^{\circ} \mathrm{C}$ \\
\hline Extremo Tensionado " $\delta_{\mathrm{ET}}$ " & 0,53 & 0,55 & 0,45 & 0,38 & 0,42 \\
\cline { 1 - 2 } Extremo No Tensionado " $\delta_{\mathrm{ENT}}$ " & 0,24 & 0,19 & 0,19 & 0,09 & 0,14 \\
\hline
\end{tabular}

Tabla. 4.22. Valores medios del deslizamiento, en extremo tensionado y no tensionado, de las barras de CFRP arenadas CA14 en las diferentes condiciones térmicas.

La tensión adherente máxima alcanzada por las barras CA14, según el estudio estadístico realizado, es similar a temperatura de control, de $20{ }^{\circ} \mathrm{C}$, y a temperaturas elevadas, de $40{ }^{\circ} \mathrm{C}$ y $80{ }^{\circ} \mathrm{C}$ (forman grupos homogéneos, Tabla 4.23). Sin embargo, a temperaturas bajas, de $5{ }^{\circ} \mathrm{C}$ y $-20^{\circ} \mathrm{C}$, la tensión adherente es significativamente ${ }^{51}$ mayor que a temperaturas elevadas. Además, a $5^{\circ} \mathrm{C}$ y -20 ${ }^{\circ} \mathrm{C}$ la tensión adherente desarrollada por las barras CA14 es similar (Tabla 4.23).

\begin{tabular}{cccccc}
\hline \multicolumn{6}{c}{ Análisis de Varianza } \\
\cline { 1 - 5 } Fuente & Suma de Cuadrados & Gl & Cuadrado Medio & Razón-F & Valor- $P$ \\
\hline Entre grupos & 98,6645 & 4 & 24,6661 & 14,74 & 0,0000 \\
\cline { 1 - 3 } Intra grupos & 33,4737 & 20 & 1,67369 & & \\
\cline { 1 - 5 } Total (Corr.) & 132,138 & 24 & & & \\
\hline
\end{tabular}

\begin{tabular}{|c|c|c|c|}
\hline \multicolumn{4}{|c|}{ Test de Contraste Múltiple de Rango } \\
\hline & Frecuencia & Media $(\mathrm{MPa})$ & Grupos Homogéneos \\
\hline $40^{\circ} \mathrm{C}$ & 5 & 11,5823 & $\mathrm{X}$ \\
\hline $80^{\circ} \mathrm{C}$ & 5 & 12,3576 & $x$ \\
\hline $20^{\circ} \mathrm{C}$ & 5 & 13,2614 & $x$ \\
\hline $5{ }^{\circ} \mathrm{C}$ & 5 & 15,4261 & $x$ \\
\hline$-20^{\circ} \mathrm{C}$ & 5 & 16,9408 & $x$ \\
\hline
\end{tabular}

Tabla. 4.23. Estudio estadístico del efecto de las condiciones térmicas en la tensión adherente residual de las barras de CFRP arenadas CA14: Test de Contraste Múltiple de Rango.

${ }^{51}$ Con un nivel de confianza del $95 \%$, según el ANOVA realizado. 


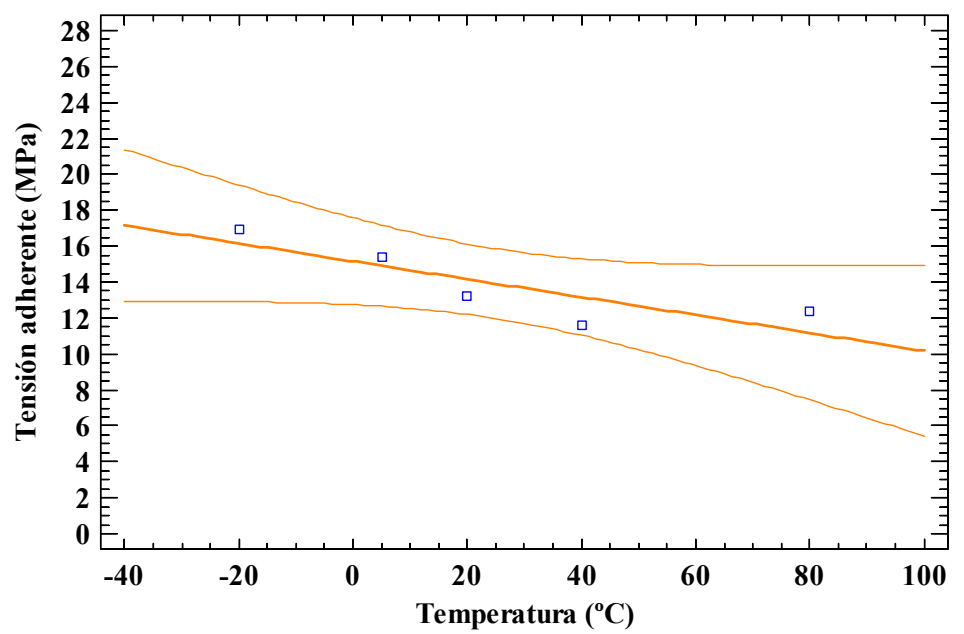

a)

Tensión adherente media $=15,1582-(0,0497829 *$ Temperatura $)$

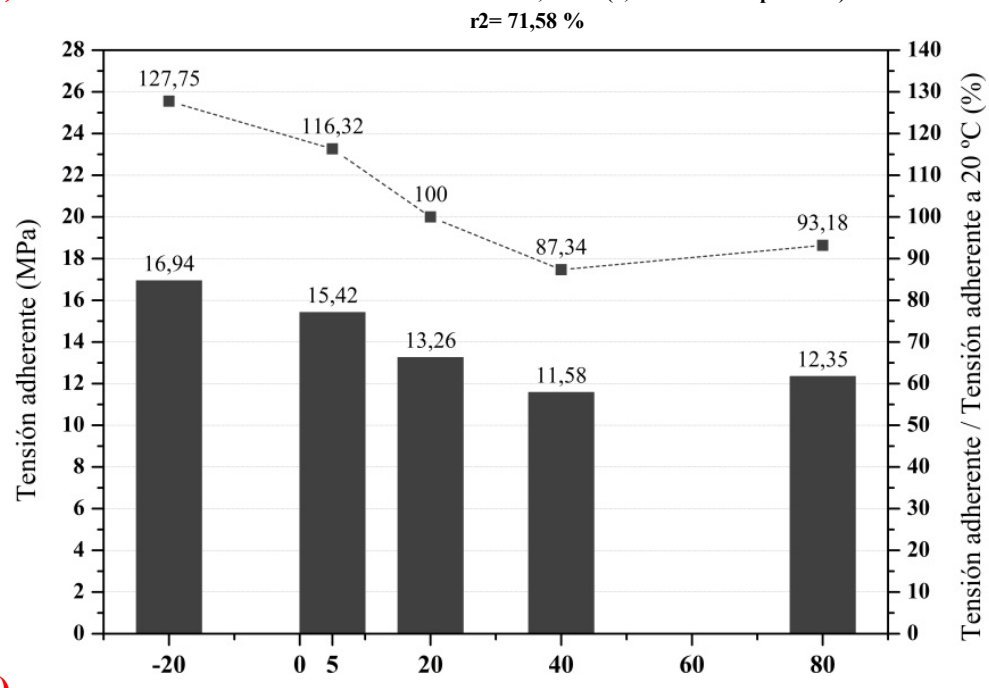

b)

Temperatura $\left({ }^{\circ} \mathrm{C}\right)$

Fig. 4.45. Relación entre la tensión adherente y la temperatura en barras de CFRP arenadas CA14: a) Relación lineal con un nivel de confianza del $95 \%$.

Al mismo tiempo, se comprueba significativamente con un nivel de confianza del 95\%, según análisis de regresión, que al disminuir la temperatura, respecto a la de control, la tensión adherente se incrementa (Fig. 4.45.a); por ejemplo, a $-20{ }^{\circ} \mathrm{C}$ y $5{ }^{\circ} \mathrm{C}$ se incrementa un $27,75 \%$ y $16,32 \%$ respecto a la temperatura de control, estos valores son similares a los obtenidos en las barras CA8 (Fig. 4.45.b). Por el contrario, al incrementar la temperatura disminuye la 
tensión adherente (Fig. 4.45.a); por ejemplo, a $40{ }^{\circ} \mathrm{C}$ y $80{ }^{\circ} \mathrm{C}$ disminuye un 12,66 $\%$ y $6,82 \%$ respecto a la temperatura de control (Fig. 4.45.b). Sin embargo, esta última diferencia no es significativa, por lo que el comportortamiento a dichas temperaturas se puede considerar similar. Este comportamiento de las barras CA14 a temperaturas de $20{ }^{\circ} \mathrm{C}, 40{ }^{\circ} \mathrm{C}$ y $80{ }^{\circ} \mathrm{C}$, diferente al desarrollado por las barras $\mathrm{CA} 8$, puede ser debido al mayor espesor de la capa de resina polimérica en la interfaz, entre la capa de arenado y el núcleo de la barra, de las barras CA14 respecto a las CA8.

Las variaciones de la tensión adherente máxima en función de la temperatura, desarrollada por las barras CA14, son debidas, del mismo modo que en las barras CA8, a cambios en la estructura molecular de la resina polimérica de la interfaz entre la capa de arenado y el núcleo de la barra. Estos cambios se observan en la Fig. 4.46, en la cual se muestra que a temperatura de $80{ }^{\circ} \mathrm{C}$ la resina polimérica se encuentra más degradada que a temperatura de $-20{ }^{\circ} \mathrm{C}$.

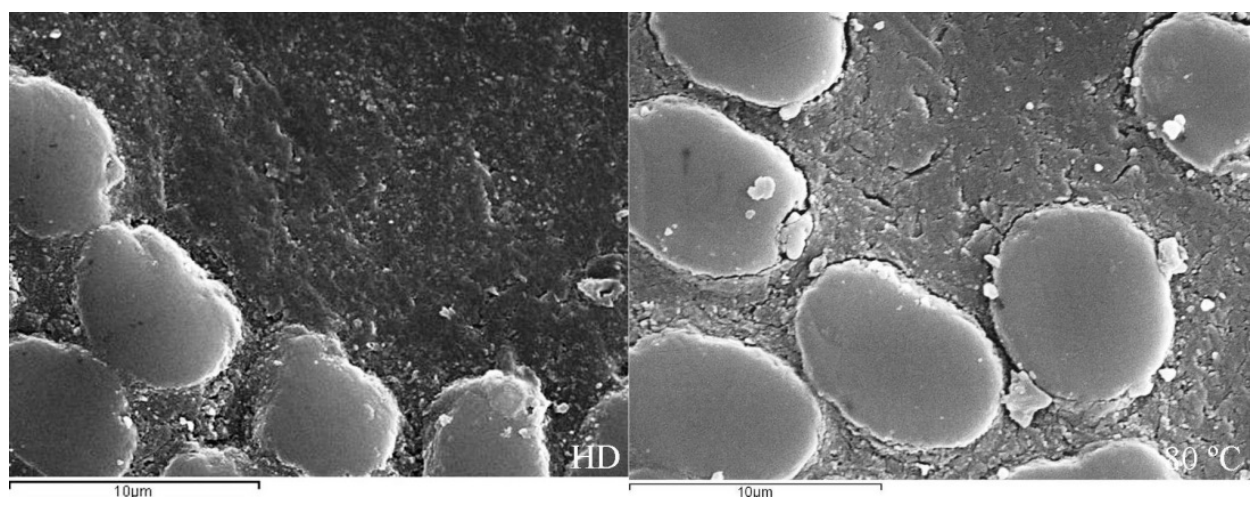

Fig. 4.46. Imágenes de la zona cercana a la interfaz entre la capa de arenado y el núcleo de la barra (x5000): a) Tratamiento térmico de hielo/deshielo; b) Tratamiento térmico de $80{ }^{\circ} \mathrm{C}$.

Tras alcanzar la tensión adherente máxima, se produce una rotura frágil y repentina, por rotura de la adhesión entre la capa de arenado y el núcleo de la barra (Fig. 4.44). Este modo de rotura se desarrolla en todas las temperaturas estudiadas y depende principalmente de la resistencia y comportamiento frente a 
temperatura de la resina polimérica de la interfaz núcleo/capa de arenado (Fig. 4.47).

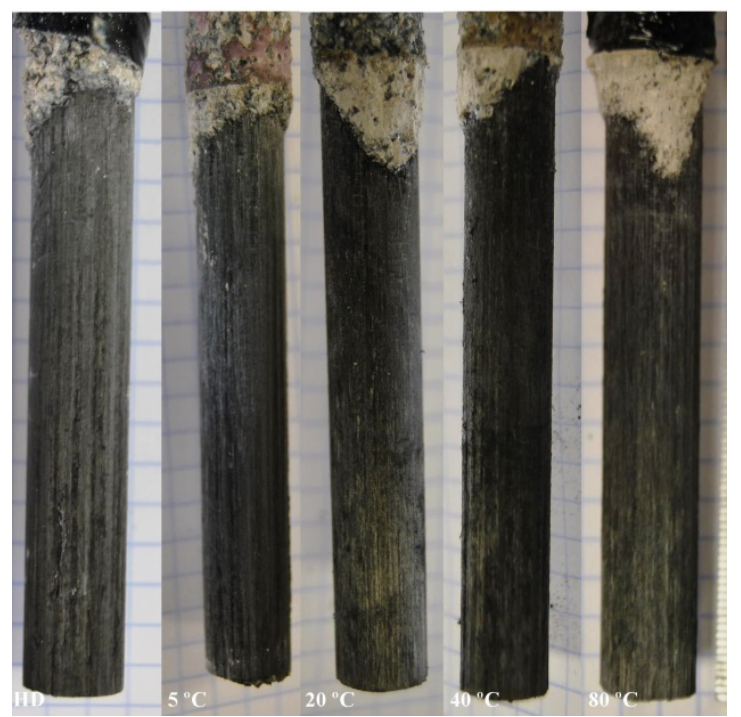

Fig. 4.47. Modo de rotura de las barras de CFRP arenadas CA14 en el ensayo de pullout.

Al mismo tiempo, se observa que aleatoriamente a $5{ }^{\circ} \mathrm{C}, 20^{\circ} \mathrm{C}$ y $80{ }^{\circ} \mathrm{C}$, se produce en algunas barras ensayadas (cuatro casos) la rotura por un modo combinado (Tabla 3.36). En este modo, se produce inicialmente la rotura adherente por rotura de la adherencia entre la capa de arenado y el hormigón en la primera mitad adherente de la barra, y seguidamente, en la segunda mitad adherente, rompe por rotura de la adhesión entre la capa de arenado y el núcleo de la barra (Fig. 4.48). Este cambio en el modo de rotura de las barras CA14 puede deberse según Al-Mahmoud et al. (2007), al tamaño del grano del arenado de la capa superficial. Con tamaños de grano grandes, del orden de 0,3 a 0,4 $\mathrm{mm}$, la adherencia con el hormigón mejora y entonces el agotamiento se produce por rotura de la adhesión entre la capa de arenado y el núcleo. No obstante, con tamaños de grano ligeramente inferiores, del orden de 0,2 a $0,3 \mathrm{~mm}$, la adherencia con el hormigón empeora y da lugar a una rotura de modo combinado, que afecta tanto a la interfaz hormigón-árido, como a la interfaz 
árido-núcleo. Al mismo tiempo, si el tamaño de grano es muy pequeño, del orden de 0,1 a $0,2 \mathrm{~mm}$, la rotura se produce completamente por rotura del hormigón. Por lo tanto, debido a que el tamaño del grano de arena de la capa superficial de las barras CA14 es del orden de 0,2 a 2,0 mm, el modo predominante de rotura es por rotura de la adhesión entre la capa de arenado y el núcleo de la barra, mientras que aleatoriamente en algunas barras, debido al exceso de resina polimérica de la capa de arenado o al desprendimiento de los árido más gruesos, el tamaño medio del árido disminuye, por lo que el modo de rotura se produce por el modo combinado.

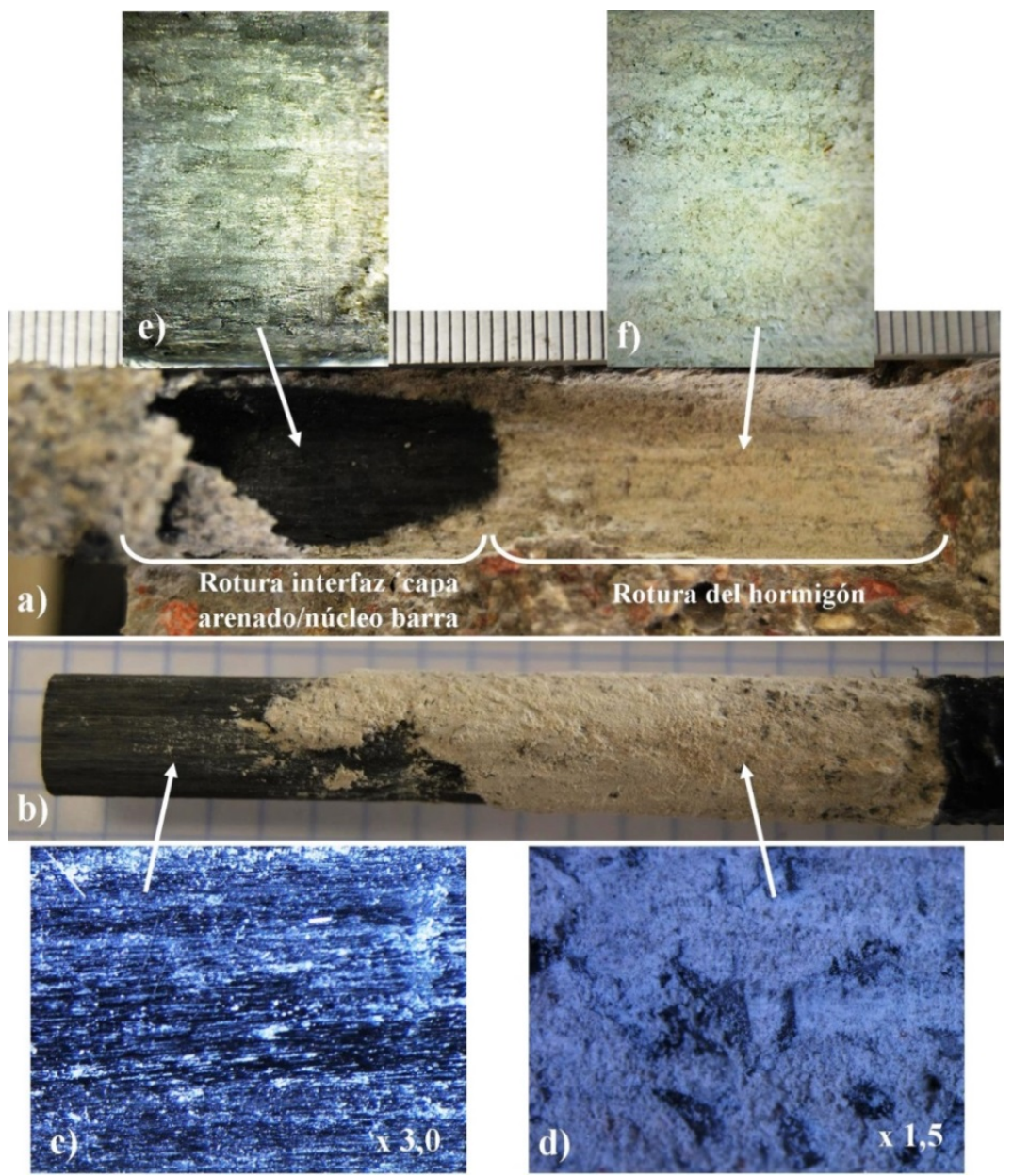

Fig. 4.48. Rotura adherente de las barrras CA14 por modo combinado EPU/L9/T5/P2/CA14: a) $\mathrm{L}_{\text {adh }}$ de la probeta de hormigón tras la rotura. b) $\mathrm{L}_{\text {adh }}$ barra CA14 tras la rotura; c) Detalle de superficie barra en interfaz; d) Detalle superficie barra con restos de hormigón en capa arenado; e) Restos capa de arenado: interfaz rotura; f) Hormigón roto. 
El comportamiento de las barras CA14 tras la rotura depende del modo de rotura: si la rotura se produce por rotura de la adherencia entre la capa de arenado y el núcleo, se origina un descenso brusco de la tensión adherente hasta un nivel de tensión uniforme, desarrollándose esta por rozamiento entre el núcleo de la barra y la capa de arenado (Fig. 4.44). En cambio, si la rotura es por el modo combinado, se produce un descenso menos brusco de la tensión adherente, similar al desarrollado por las barras de acero, desarrollándose esta por rozamiento entre la capa de arenado y el hormigón (Fig. 4.49).

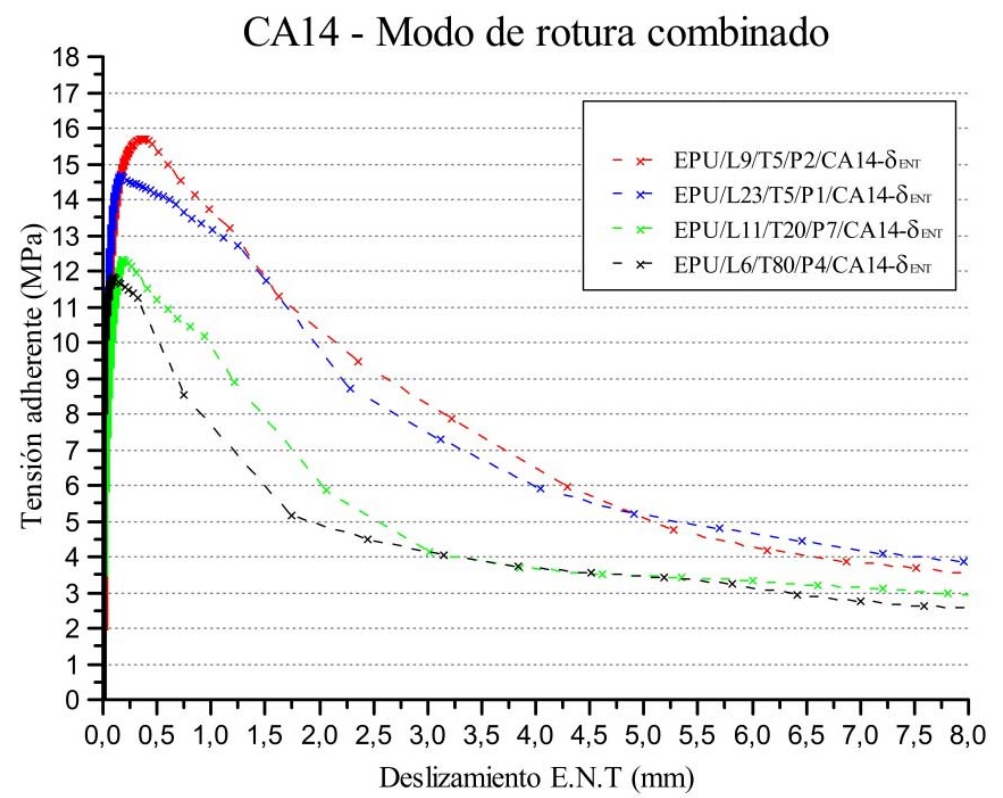

Fig. 4.49. Comportamiendo adherente, a diferentes temperaturas, de las barras de CFRP arenadas CA14 cuyo modo de rotura es combinado.

La tensión adherente residual de las barras CA14 es ligeramente superior cuando el modo de rotura se produce por el modo combinado, $\tau_{\text {residual }}=4,38$ Mpa, que cuando se produce por rotura de la adherencia entre la capa de arenado y el núcleo de la barra, $\tau_{\text {residual }}=3,83 \mathrm{Mpa}$ (Fig. 4.50). Este efecto puede ser debido a la mayor capacidad de rozamiento generada por la interfaz capa de arenado-hormigón. Sin embargo, según el estudio estadístico realizado con los datos obtenidos, se concluye que no hay diferencia estadísticamente significativa 
entre la tensión adherente residual desarrollada por los dos modos de rotura (Fig. 4.50). Del mismo modo, se prueba estadísticamente, en todos los tratamientos térmicos realizados, que la tensión adherente residual es similar, puesto que no hay diferencia estadísticamente significativa entre las tensiones adherentes residuales a cada temperatura (Fig. 4.50). Este efecto puede ser debido a que, en general, en todas las temperaturas se produce el rozamiento entre la capa de arenado y el núcleo de la barra.

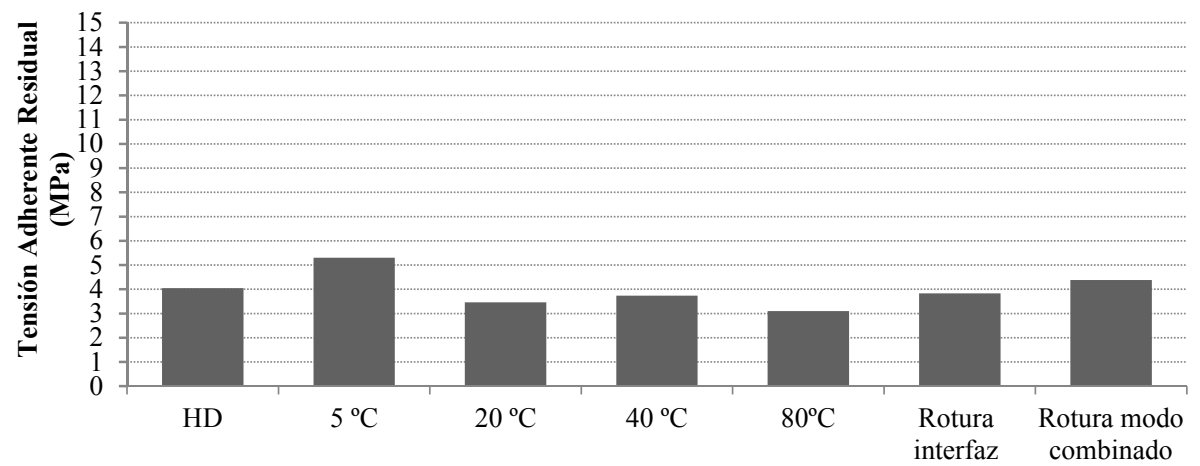

Fig. 4.50. Valores medios de la tensión adherente residual de las barras de CFRP arenadas CA14, a diferentes temperaturas y según el modo de rotura.

\section{- Barras de CFRP corrugadas:}

Las barras de CFRP corrugadas desarrollan inicialmente su adherencia por adhesión química, con unos valores medios entre 3,2 y 4,1 MPa (Figs. 4.51 y 4.52). Esta adhesión química se produce con unos valores similares en todas las temperaturas, puesto que no hay diferencia estadísticamente significativa.

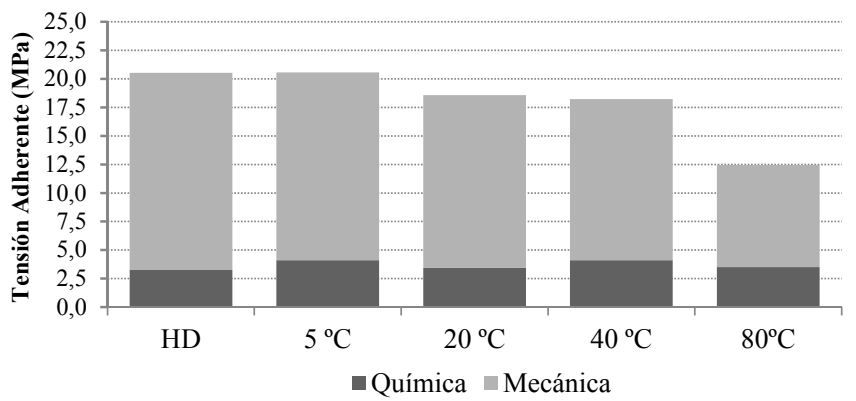

Fig. 4.51. Tipo de mecanismo adherente en barras de CFRP corrugadas CC12. 

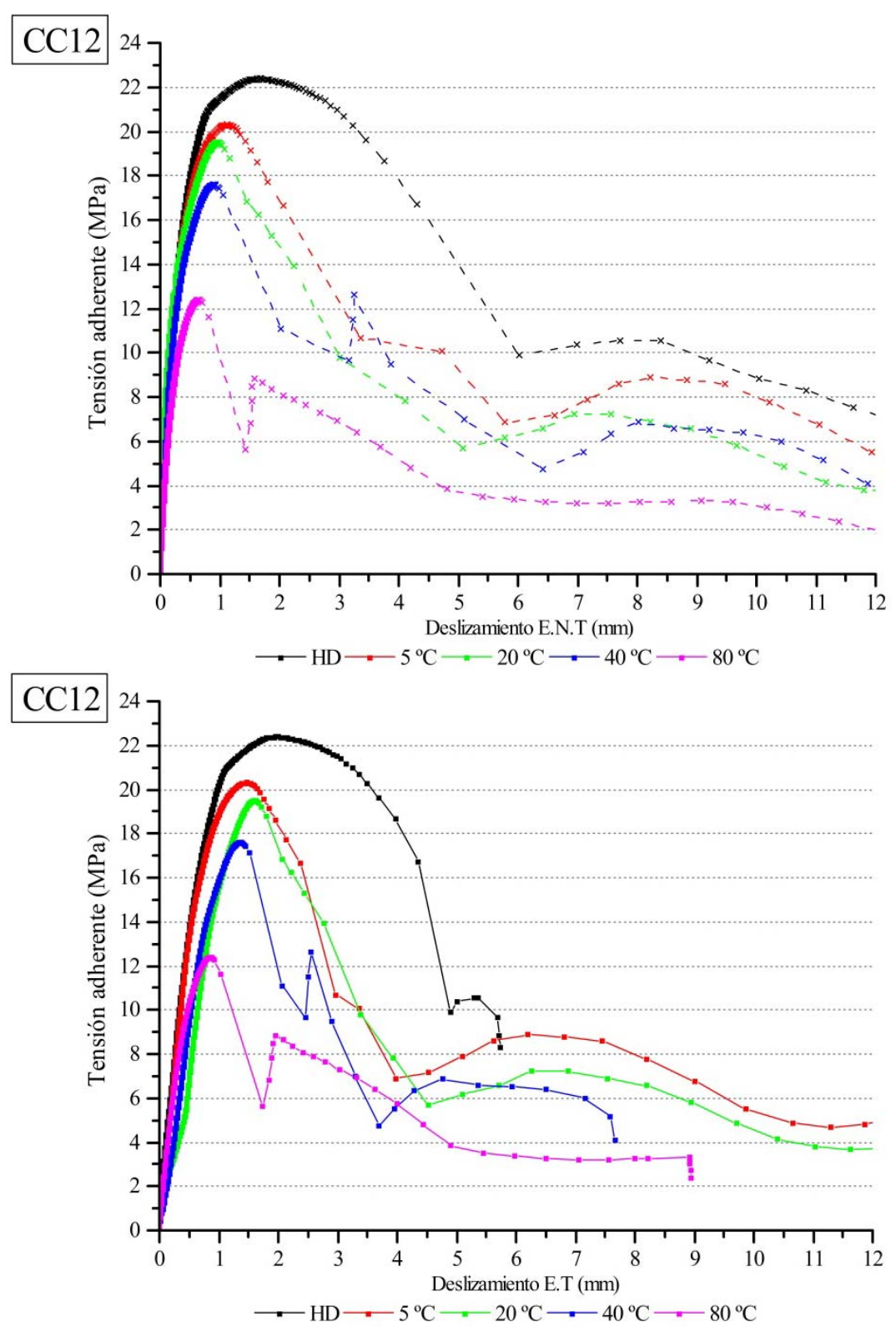

Fig. 4.52. Comportamiento adherente de las barras de CFRP corrugadas $\mathrm{CC} 12$ en condiciones térmicas de Hielo/Deshielo, $5{ }^{\circ} \mathrm{C}, 20{ }^{\circ} \mathrm{C}, 40{ }^{\circ} \mathrm{C}$ y $80{ }^{\circ} \mathrm{C}$. Gráfica de tensión adherentedeslizamiento.

Al aumentar la fuerza aplicada en la barra, se incrementa la tensión adherente y comienzan los deslizamientos relativos de la barra respecto al 
hormigón, sustituyéndose el mecanismo adherente de adhesión química por un mecanismo mecánico de acuñamiento más rozamiento (Fig. 4.52).

En las barras $\mathrm{CC12}$, según el estudio estadístico realizado mediante ANOVA (Tabla 4.24), se demuestra con un nivel de confianza del $95 \%$, que hay diferencia estadíticamente significativa en el efecto que producen las distintas condiciones térmicas en la tensión adherente. Además, en el Test de Contraste Múltiple de Rango, se prueba que hay tres grupos homogéneos de temperatura que producen el mismo efecto en la tensión adherente: $1^{\text {er }}$ grupo: abarca las condiciónes de temperaturas frías y de control, $\mathrm{HD}, 5^{\circ} \mathrm{C}$ y $20^{\circ} \mathrm{C}$, que producen una mayor tensión adherente; $2^{\text {do }}$ grupo: son las temperaturas de control y medias de $20{ }^{\circ} \mathrm{C}$ y $40{ }^{\circ} \mathrm{C} ; 3^{\text {er }}$ grupo: de temperaturas elevadas de $80{ }^{\circ} \mathrm{C}$, que producen la menor tensión adherente en este tipo de barras.

\begin{tabular}{|c|c|c|c|c|c|}
\hline \multicolumn{6}{|c|}{ Análisis de Varianza } \\
\hline Fuente & Suma de Cuadrados & $G l$ & Cuadrado Medio & Razón-F & Valor-P \\
\hline Entre grupos & 220,198 & 4 & 55,0496 & 18,90 & 0,0000 \\
\hline Intra grupos & 58,2482 & 20 & 2,91241 & & \\
\hline Total (Corr.) & 278,446 & 24 & & & \\
\hline
\end{tabular}

\begin{tabular}{|c|c|c|c|}
\hline \multicolumn{4}{|c|}{ Test de Contraste Múltiple de Rango } \\
\hline & Frecuencia & Media $(\mathrm{MPa})$ & Grupos Homogéneos \\
\hline $80^{\circ} \mathrm{C}$ & 5 & 12,4589 & $\mathrm{X}$ \\
\hline $40^{\circ} \mathrm{C}$ & 5 & 18,2319 & $x$ \\
\hline $20^{\circ} \mathrm{C}$ & 5 & 18,5708 & $X X$ \\
\hline$-20^{\circ} \mathrm{C}$ & 5 & 20,5290 & $\mathrm{X}$ \\
\hline $5^{\circ} \mathrm{C}$ & 5 & 20,5664 & $x$ \\
\hline
\end{tabular}

Tabla. 4.24. Estudio estadístico del efecto de las condiciones térmicas en la tensión adherente de las barras de CFRP corrugadas CC12: ANOVA y Test de Contraste Múltiple de Rango.

Al mismo tiempo, se observa que las temperaturas frías de $-20{ }^{\circ} \mathrm{C}$ y $5{ }^{\circ} \mathrm{C}$ tienden a producir un incremento de la tensión adherente máxima, del orden del $10 \%$, respecto a la temperatura de referencia de $20^{\circ} \mathrm{C}$. Del mismo modo, que las temperaturas elevadas de $80{ }^{\circ} \mathrm{C}$ tienden a producir una disminución de la tensión adherente entorno al $33 \%$. Sin embargo, únicamente se prueba, según el estudio 
estadístico realizado, que las temperaturas elevadas a partir de $40{ }^{\circ} \mathrm{C}$ producen una reducción significativa de la tensión adherente máxima (Fig. 4.53). En cambio, a diferencia de las barras de CFRP arenadas, la reducción de las temperaturas respecto a la de control, no produce ningún cambio significativo en la tensión adherente.

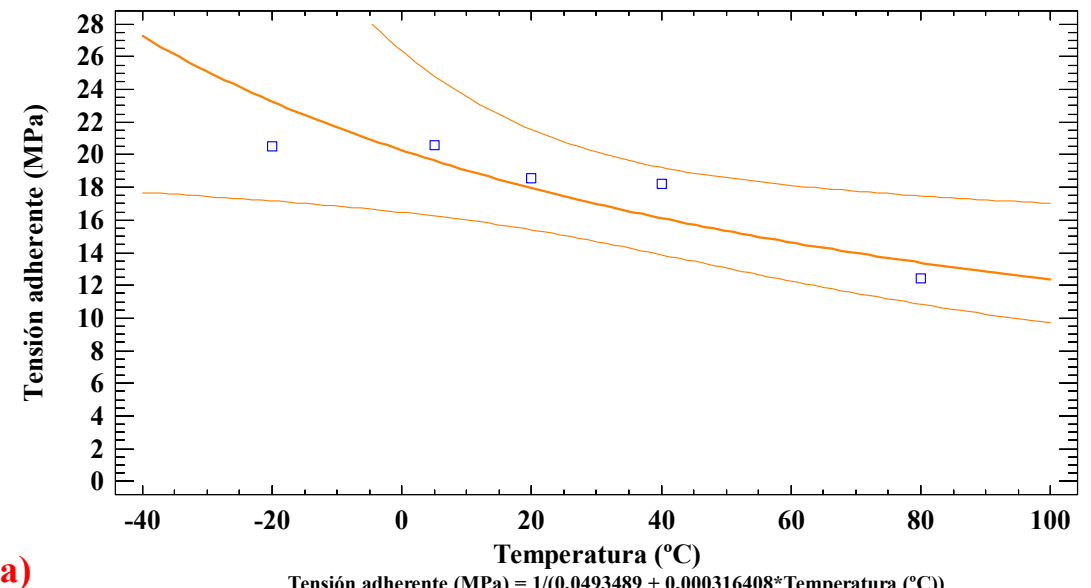

a)

Tensión adherente $(\mathrm{MPa})=\mathbf{1} /\left(\mathbf{0 , 0 4 9 3 4 8 9}+\mathbf{0 , 0 0 0 3 1 6 4 0 8}{ }^{*}\right.$ Temperatura $\left.\left({ }^{\circ} \mathrm{C}\right)\right)$

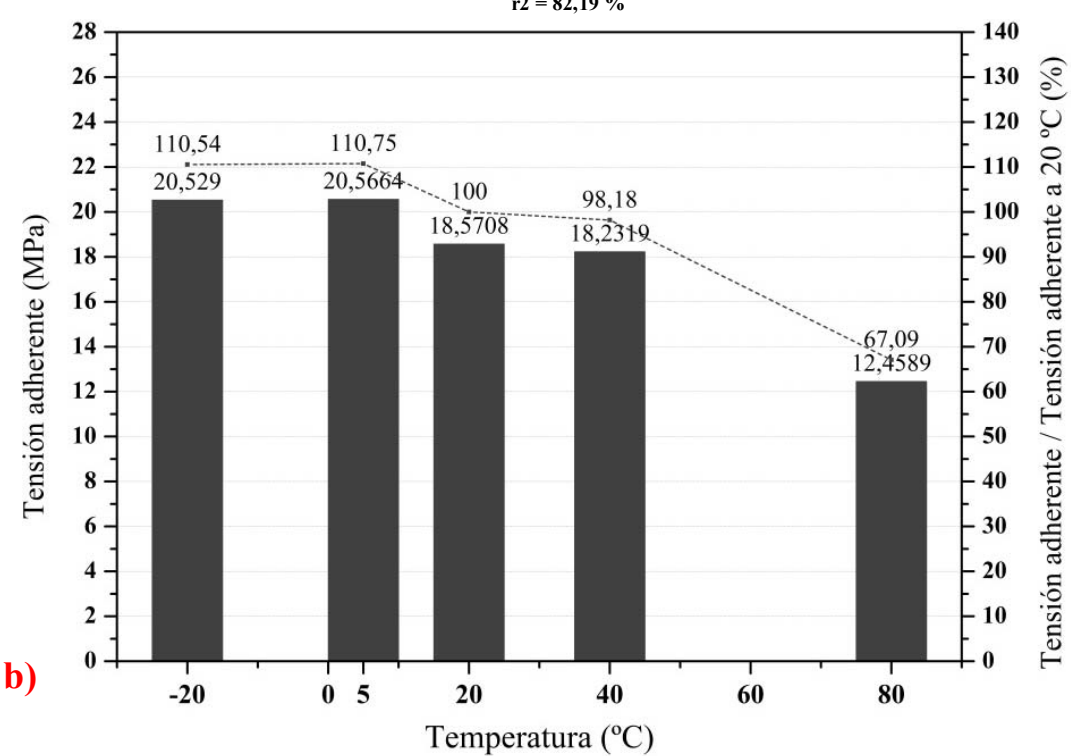

Fig. 4.53. Relación entre la tensión adherente máxima y la temperatura en barras de CFRP corrugadas CC12: a) Relación lineal con un nivel de confianza del $95 \%$; b) Comparación de la tensión adherente máxima a diferentes temperaturas. 
Del mismo modo, se comprueba, mediante un estudio estadístico, que la temperatura también influye en los deslizamientos relativos de la barra respecto del hormigón, habiendo registrado diferencias significativas en los deslizamientos, tanto en el extremo tensionado como en el no tensionado, en cada temperatura estudiada (Tabla 4.25). En este tipo de barras el deslizamiento, se incrementa a bajas temperaturas de $-20{ }^{\circ} \mathrm{C}$ o disminuye a altas temperaturas de $80{ }^{\circ} \mathrm{C}$, respecto a la temperatura de control (Fig. 4.52).

\begin{tabular}{|c|c|c|c|c|c|c|c|}
\hline \multicolumn{4}{|c|}{ Deslizamiento en EXTREMO TENSIONADO } & \multicolumn{4}{|c|}{ Deslizamiento en EXTREMO NO TENSIONADO } \\
\hline \multicolumn{4}{|c|}{ Test de Contraste Múltiple de Rango } & \multicolumn{4}{|c|}{ Test de Contraste Múltiple de Rango } \\
\hline & Frecuencia & Media (mm) & $\begin{array}{c}\text { Grupos } \\
\text { Homogéneos }\end{array}$ & & Frecuencia & Media (mm) & $\begin{array}{c}\text { Grupos } \\
\text { Homogéneos }\end{array}$ \\
\hline $80^{\circ} \mathrm{C}$ & 5 & 0,93446 & $\mathrm{X}$ & $80^{\circ} \mathrm{C}$ & 5 & 0,55328 & $\mathrm{X}$ \\
\hline $40^{\circ} \mathrm{C}$ & 5 & 1,27236 & $\mathrm{X}$ & $40^{\circ} \mathrm{C}$ & 5 & 0,90326 & $\mathrm{x}$ \\
\hline $5^{\circ} \mathrm{C}$ & 5 & 1,51346 & $X X$ & $5^{\circ} \mathrm{C}$ & 5 & 1,16024 & $x$ \\
\hline $20^{\circ} \mathrm{C}$ & 5 & 1,64546 & $x$ & $20^{\circ} \mathrm{C}$ & 5 & 1,1865 & $\mathrm{x}$ \\
\hline$-20^{\circ} \mathrm{C}$ & 5 & 2,14608 & $x$ & $-20^{\circ} \mathrm{C}$ & 5 & 1,6008 & $x$ \\
\hline
\end{tabular}

Tabla. 4.25. Estudio estadístico del efecto de las condiciones térmicas en los deslizamientos de las barras de CFRP corrugadas CC12: Test de Contraste Múltiple de Rango.

Estos cambios en la tensión adherente máxima de las barras $\mathrm{CC} 12$ producidos por la temperatura, se deben a la variación de resistencia de la resina polimérica de las corrugas de la barra. Puesto que a $20{ }^{\circ} \mathrm{C}$ (tal y como se expone en apart. 4.1.1) la resistencia a corte de la corruga de la barra es similar a la resistencia a corte del hormigón, por consiguiente el agotamiento se puede producir tanto por rotura de la corruga de la barra como por corte del hormigón entre corrugas. Por ello, se observa que al aumentar la temperatura a $40{ }^{\circ} \mathrm{C} \mathrm{u}$ $80{ }^{\circ} \mathrm{C}$ (Tabla 3.36), el modo de rotura se produce únicamente por corte de las corrugas del acabado superfical de la barra (Fig. 4.54).Por el contrario, al disminuir la temperatura a $-20{ }^{\circ} \mathrm{C}$ (condición HD), el modo de rotura se produce únicamente por modo combinado (Fig. 4.54). Al mismo tiempo, se observa que a $5{ }^{\circ} \mathrm{C}$, la rotura se produce de ambas formas que a $20^{\circ} \mathrm{C}$ (Tabla 3.36 ). 
-Rotura por corte de las corrugas de la geometría superficial de la barra:

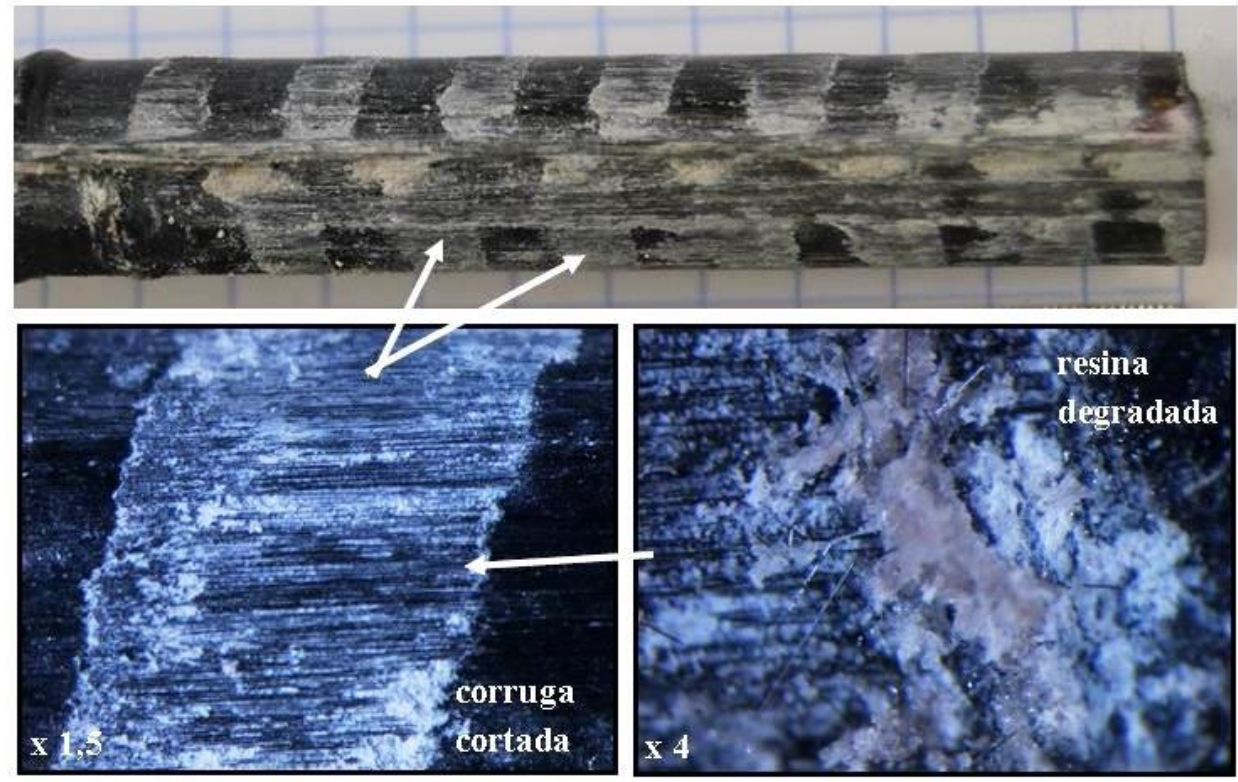

-Rotura por modo combinado:
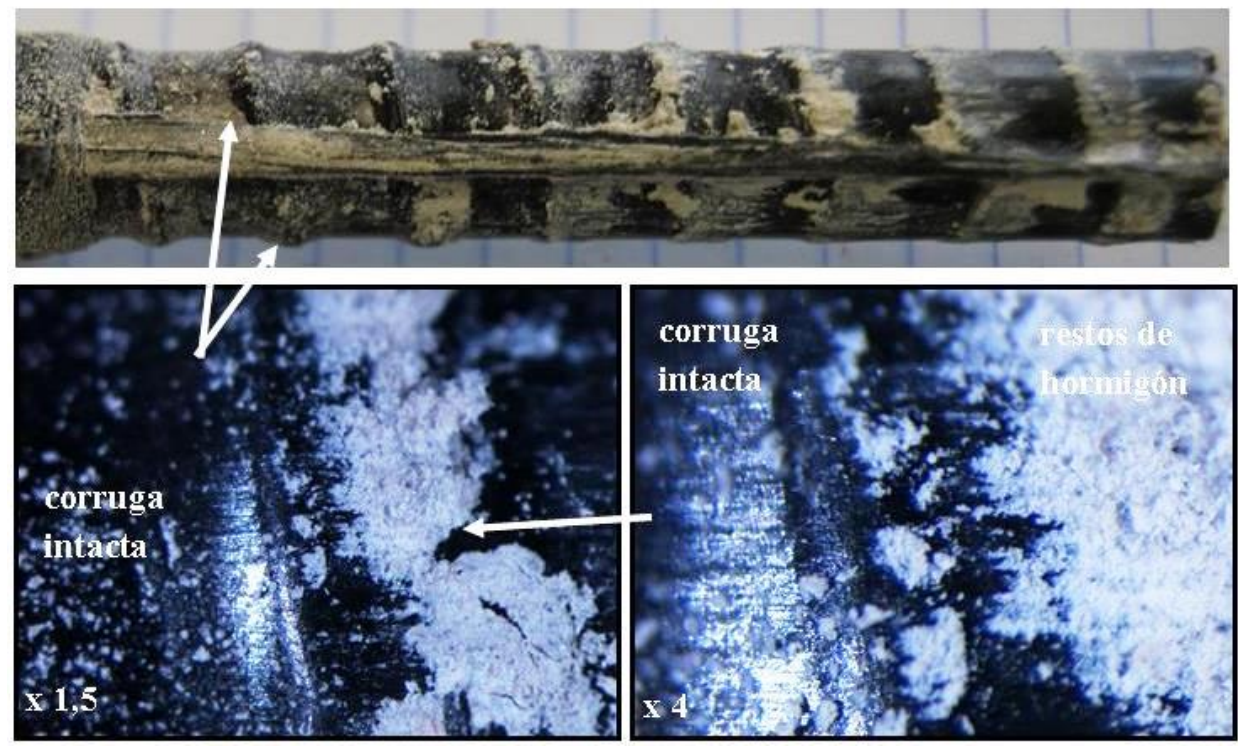

Fig. 4.54. Modos de rotura de las barras de CFRP corrugadas CC12: Imágenes y detalle de rotura por corte de las corrugas de la geometría superficial de la barra; Imágenes y detalle de rotura por modo combinado, donde se muestra la corruga intacta con restos de hormigón.

Esta influencia de la temperatura en la tensión adherente máxima también se comprueba en las imágenes obtenidas con el Microscopio 
Electrónico de Barrido "SEM" y con el Microscopio de Fuerza Atómica “AFM", en las cuales se muestra que a temperatura de $-20{ }^{\circ} \mathrm{C}$ (HD) la resina de las corrugas de la barra no se encuentra degradada (Fig. 4.55.a), lo que produce una mayor transmisión de tensiones a las fibras del núcleo de la barra (Fig. 4.55.b y 4.57.a). En cambio, a temperatura de $80^{\circ} \mathrm{C}$, cercana a la temperatura de transición vítrea inicial, del orden de $94{ }^{\circ} \mathrm{C}$ (Tabla 3.41), la resina polimérica de las corrugas de la barra presenta una mayor degradación (Fig. 4.56.b), produciendo una rotura por corte de la misma a una menor tensión de la barra (Fig. 4.56.a y 4.57.b).
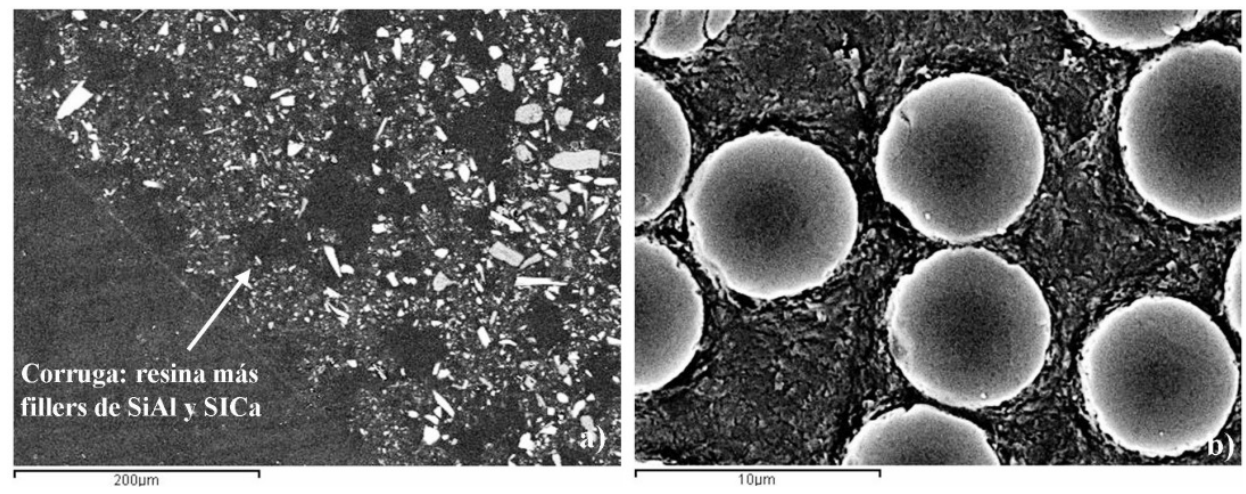

Fig. 4.55. Imágenes SEM/CC12/HD: a) Detalle de corruga sin daños tras ensayo de pullout, modo de rotura combinado, x250; b) Detalle del núcleo de la barra tras ensayo de pullout, resina sin deterioros, x 5000 .
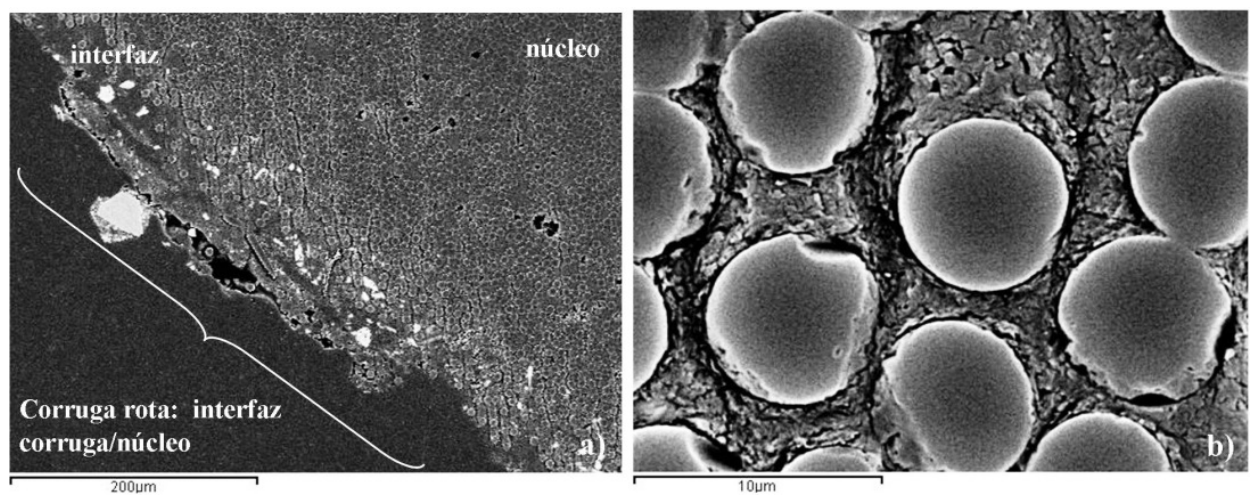

Fig. 4.56. Imágenes SEM/CC12/80: a) Detalle de zona de corruga rota tras ensayo de pullout, modo de rotura por corte de las corrugas de la barra, x250; b) Detalle de la matriz polimérica, situada en el núcleo en la zona cercana a la interfaz, tras el ensayo de pullout, resina deteriorada, x 5000 . 


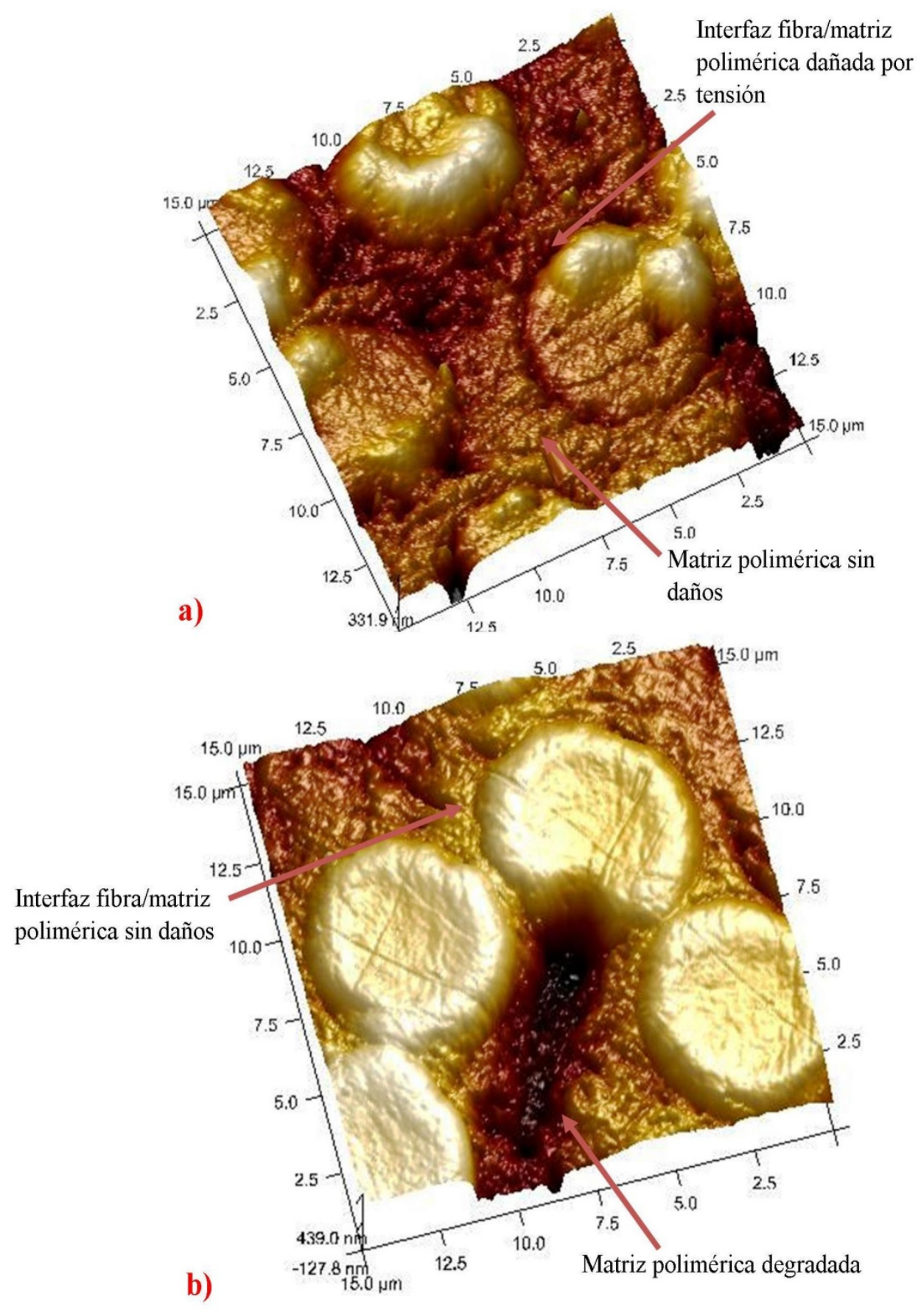

Fig. 4.57. Imágenes de Microscopia de Fuerza Atómica "AFM" en barras de CFRP corrugadas CC12: a) Detalle del núcleo de la barra en condición térmica de Hielo/Deshielo, donde se observa un mayor nivel tensional en la adherencia fibra-matriz; b) Detalle del núcleo de la barra en condición térmica de $80{ }^{\circ} \mathrm{C}$, donde se observa un menor nivel tensional en adherencia fibra-matriz y mayores daños en la matriz polimérica. 
Al mismo tiempo, se observa que a temperatura de $-20{ }^{\circ} \mathrm{C}$ se producen mayores daños en el núcleo de la barra que a tempertura de $20{ }^{\circ} \mathrm{C}$ (Fig. 4.58). Además, estas roturas se producen tanto en las fibras como en la matriz polimérica (Fig. 4.59). En cambio, a temperatura elevada de $80^{\circ} \mathrm{C}$, los daños son más importantes y están más localizados (Fig. 4.60.a). Pero al contrario que a temperatura de $-20{ }^{\circ} \mathrm{C}$, las roturas en el núcleo se producen solo en la matriz polimérica y no en las fibras (Fig. 4.60.b). Estas observaciónes, confirman:

- el mayor deterioro de la matriz polimérica de la barra, producido por las temperaturas elevadas, y el menor nivel tensional resistido por esta.

- El mayor nivel tensional alcanzado por el núcleo a temperatura de $-20^{\circ} \mathrm{C}$, que ocasiona roturas tanto en la matriz como en las fibras.
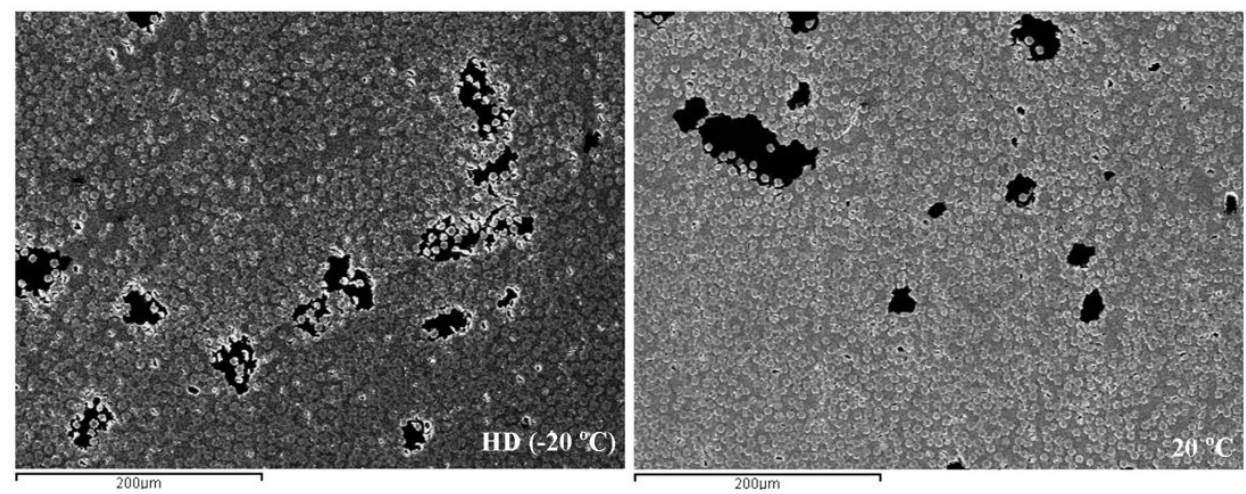

Fig. 4.58. Imágenes SEM/CC12/HD y SEM/CC12/20, x250: Detalle del estado del núcleo tras el ensayo de pullout en las barras $\mathrm{CC} 12$. Roturas más extendidas a $-20{ }^{\circ} \mathrm{C}$.
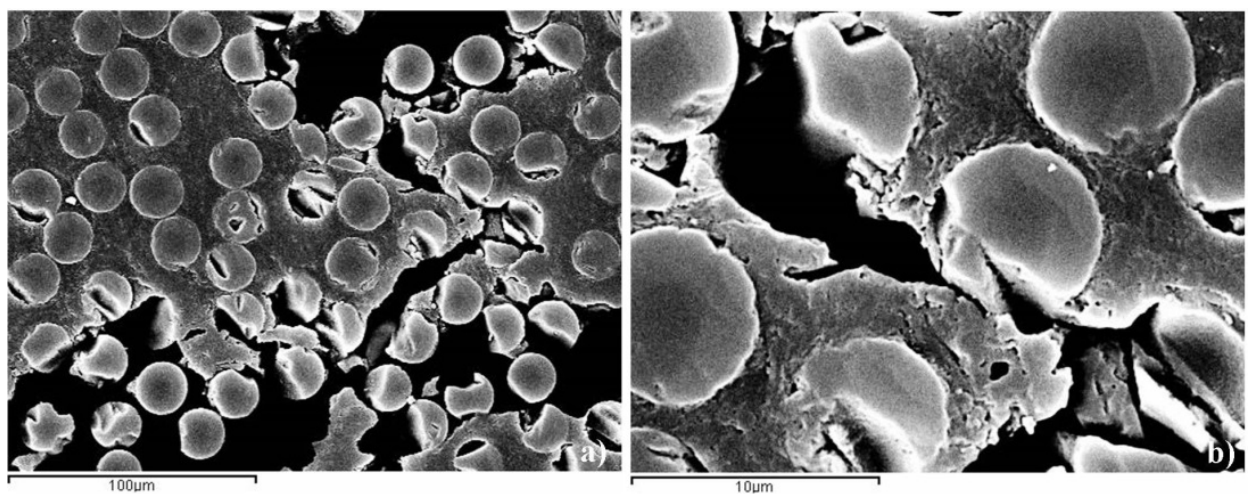

Fig. 4.59. Imágenes núcleo de SEM/CC12/HD: a) Modo de rotura en núcleo por rotura matriz polimérica y fibras, $\mathrm{x} 500$; b) Rotura en núcleo por rotura de fibras y matriz polimérica, $\mathrm{x} 5000$. 


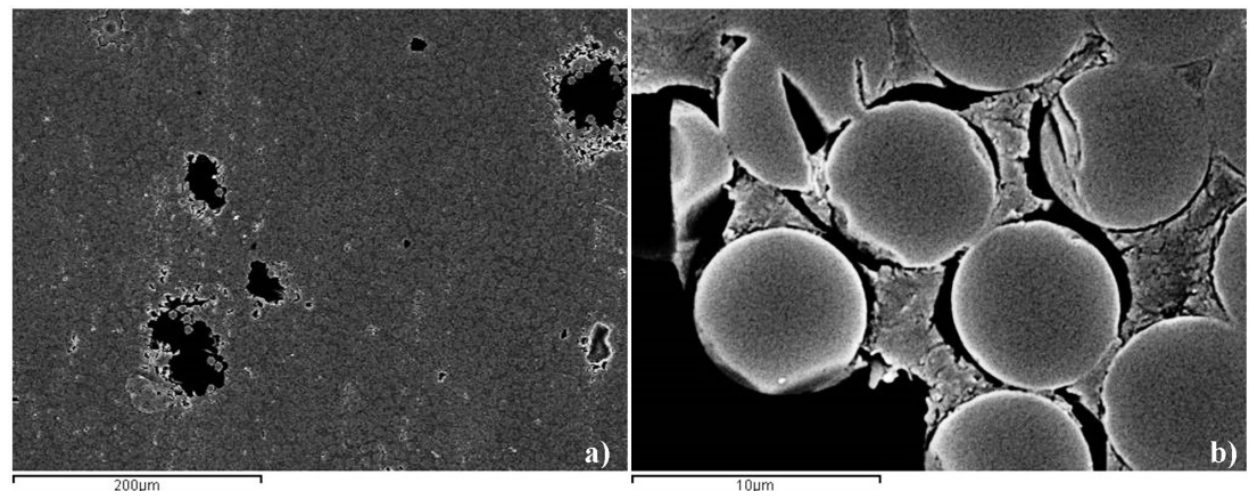

Fig. 4.60. Imágenes núcleo de $\mathrm{SEM} / \mathrm{CC} 12 / 80$ : a) Modo de rotura en núcleo por rotura matriz polimérica, x250; b) Rotura en núcleo por rotura de la matriz polimérica, x5000.

En cuanto al comportamiento adherente de las barras CC12 tras la rotura (Fig. 4.52), se observa que a cualquier temperatura estudiada es similar al desarrollado a la temperatura de control de $20{ }^{\circ} \mathrm{C}$ (véase apart. 4.1.1). Sin embargo, la tensión adherente residual es significativamente diferente dependiendo de la temperatura de ensayo (Tabla 4.26). Se observa que la tensión adherente residual aumenta a medida que disminuye la temperatura y viceversa: por ejemplo, a $-20^{\circ} \mathrm{C}$ aumenta un $36 \%$ respecto a $20{ }^{\circ} \mathrm{C}$ y a $80{ }^{\circ} \mathrm{C}$ disminuye un $41 \%$ (Tabla 4.26 y Fig. 4.61). Este efecto se debe a la pérdida o ganancia de resistencia de la resina polimérica de las corrugas de la barra, puesto que los dos modos de rotura producidos en este tipo de barras, dependen de la relación entre la resistencia a corte de la resina polimérica de las corrugas de la barra y la resistencia a cortante del hormigón entre corrugas.

\begin{tabular}{|c|c|c|c|}
\hline \multicolumn{4}{|c|}{ Test de Contraste Múltiple de Rango } \\
\hline & Frecuencia & Media $(M P a)$ & Grupos Homogéneos \\
\hline $80^{\circ} \mathrm{C}$ & 5 & 4,8855 & $X$ \\
\hline $40^{\circ} \mathrm{C}$ & 5 & 6,2258 & $\mathrm{X}$ \\
\hline $20^{\circ} \mathrm{C}$ & 5 & 8,3680 & $\mathrm{X}$ \\
\hline $5^{\circ} \mathrm{C}$ & 5 & 10,141 & $X X$ \\
\hline HD & 5 & 11,350 & $\mathrm{X}$ \\
\hline
\end{tabular}

Tabla. 4.26. Estudio estadístico del efecto de la temperatura en la tensión adherente residual de las barras de CFRP corrugadas CC12: Test de Contraste Múltiple de Rango. 


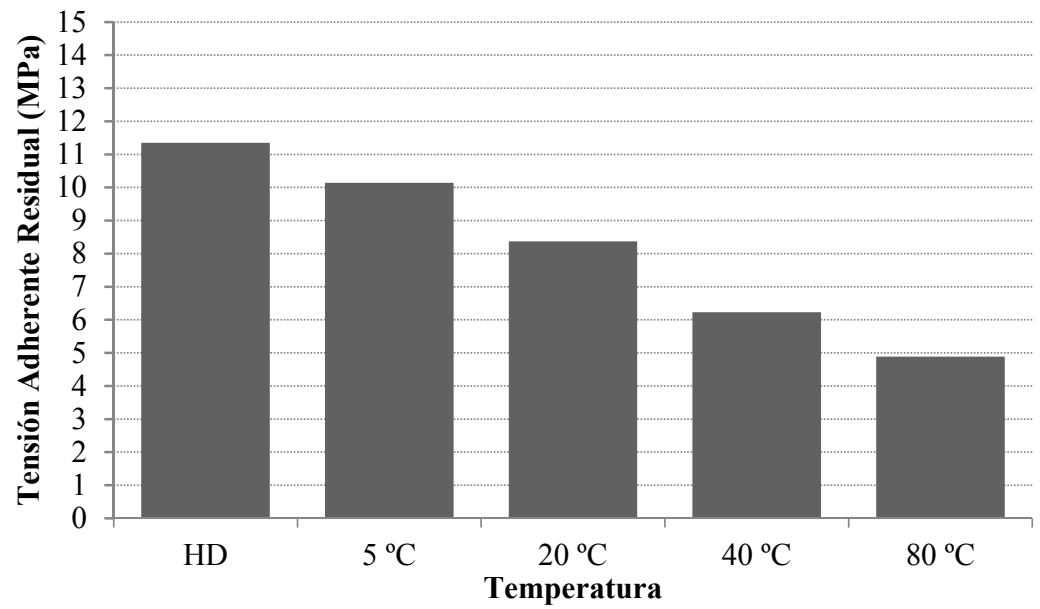

Fig. 4.61. Relación entre la tensión adherente residual y la temperatura en las barras de CFRP corrugadas CC12.

\section{- Barras de CFRP texturizadas:}

Las barras de CFRP texturizadas CT13 desarrollan inicialmente su adherencia, en todas las temperaturas estudiadas, por adhesión química. Esta tiende a incrementarse a bajas temperaturas y a disminuir a altas temperaturas (Fig. 4.62). Sin embargo, a diferencia de las barras CC12, y según el estudio realizado, la adhesión química de las barras CT13 no depende estadísticamente de la temperatura.

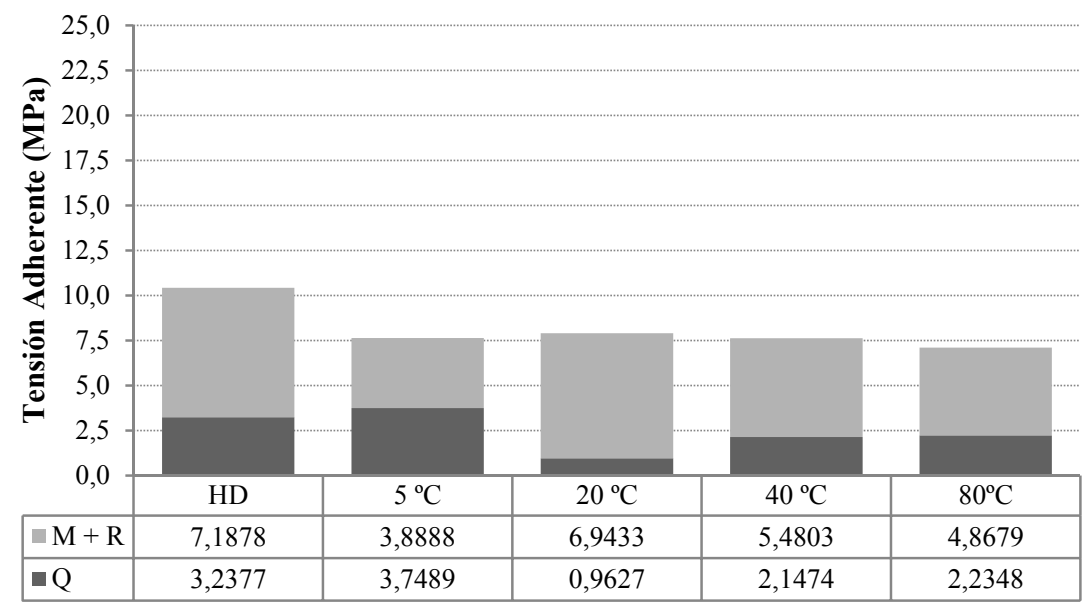

Fig. 4.62. Tipo de mecanismo adherente de las barras de CFRP texturizadas CT13. Las siglas M correspnden a adherencia mecánica, $\mathrm{R}$ a rozamiento $\mathrm{y} \mathrm{Q}$ a adhesión química. 


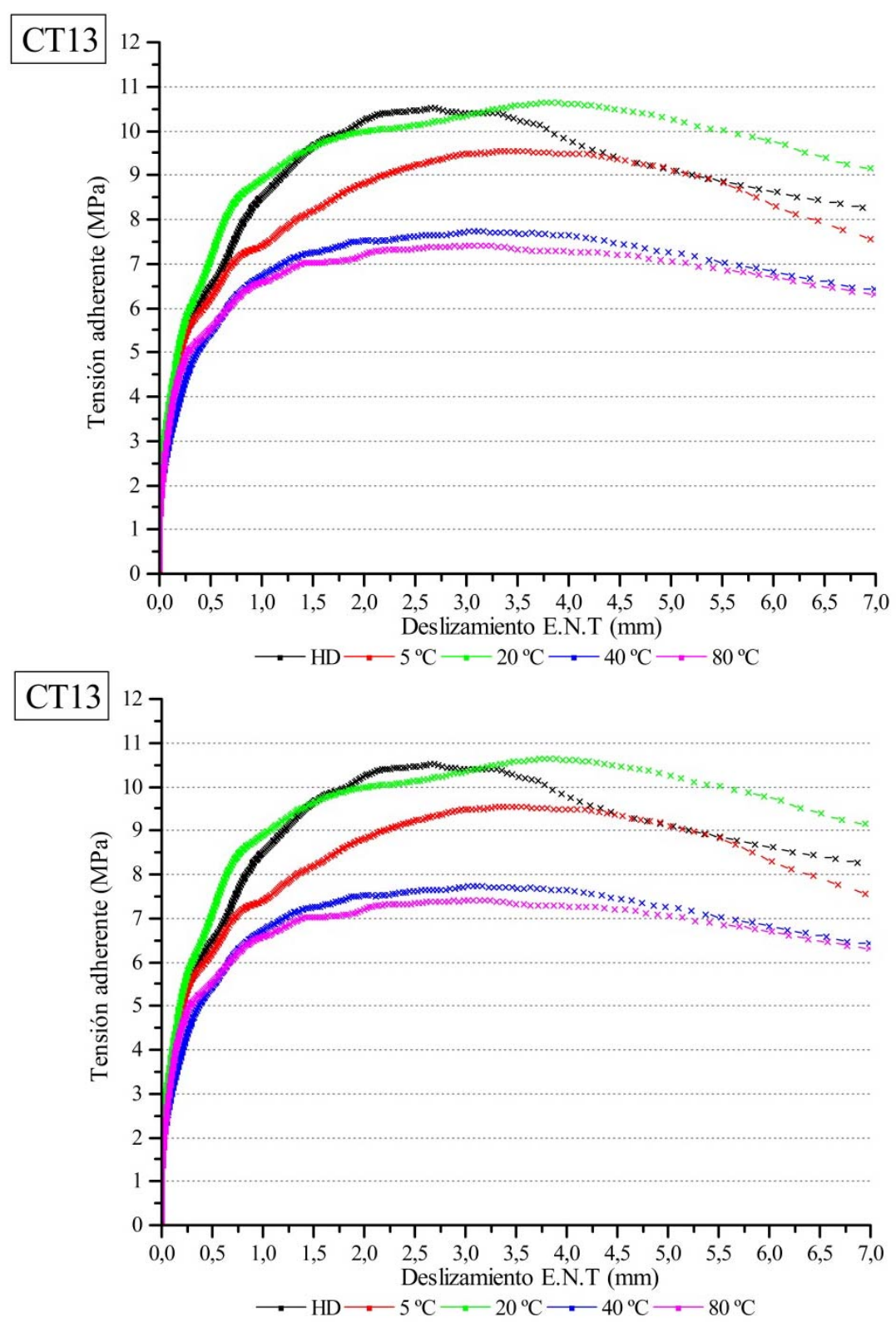

Fig. 4.63. Comportamiento adherente de las barras de CFRP corrugadas $\mathrm{CC} 12$ en condiciones térmicas de Hielo/Deshielo, $5{ }^{\circ} \mathrm{C}, 20{ }^{\circ} \mathrm{C}, 40{ }^{\circ} \mathrm{C}$ y $80{ }^{\circ} \mathrm{C}$. Gráfica de tensión adherentedeslizamiento.

Al incrementar la tensión, el mecanismo adherente cambia y pasa a actuar, en todas las temperaturas estudiadas, el mecanismo de acuñamiento mecánico y el rozamiento. Sin embargo, debido al diseño de la geometría 
superficial, a base de corruga invertida, la tensión adherente máxima alcanzada por este tipo de barras texturizadas es más reducida que en las barras de CFRP y acero corrugadas (véase apart. 4.1.1). Al mismo tiempo, se observa que la tensión adherente máxima de las barras CT13 tiende a aumentar a temperaturas bajas y a disminuir a temperaturas elevadas; por ejemplo, a $-20{ }^{\circ} \mathrm{C}$ aumenta un $31 \%$ respecto a la temperatura de referencia de $20{ }^{\circ} \mathrm{C}$ y a $80{ }^{\circ} \mathrm{C}$ disminuye un 10 \% (Figs. 4.63 y 4.64). Por el contrario, según el estudio estadístico realizado, se observa que las barras de CFRP texturizadas producen una tensión adherente máxima estadisticamente similar en todas las temperaturas estudiadas, excepto a $-20{ }^{\circ} \mathrm{C}$ que se incrementa del orden de 2,5 MPa (Tabla 4.27). Este incremento puede estar originado por:

- aumento del confinamiento del hormigón, debido a la diferencia de los coeficientes de expansión térmica entre el hormigón y las barras de CFRP texturizadas, $\mathrm{y}$

- por el aumento de la resistencia a corte de las corrugas de hormigón al disminuir la temperatura (Samir et al., 2011).

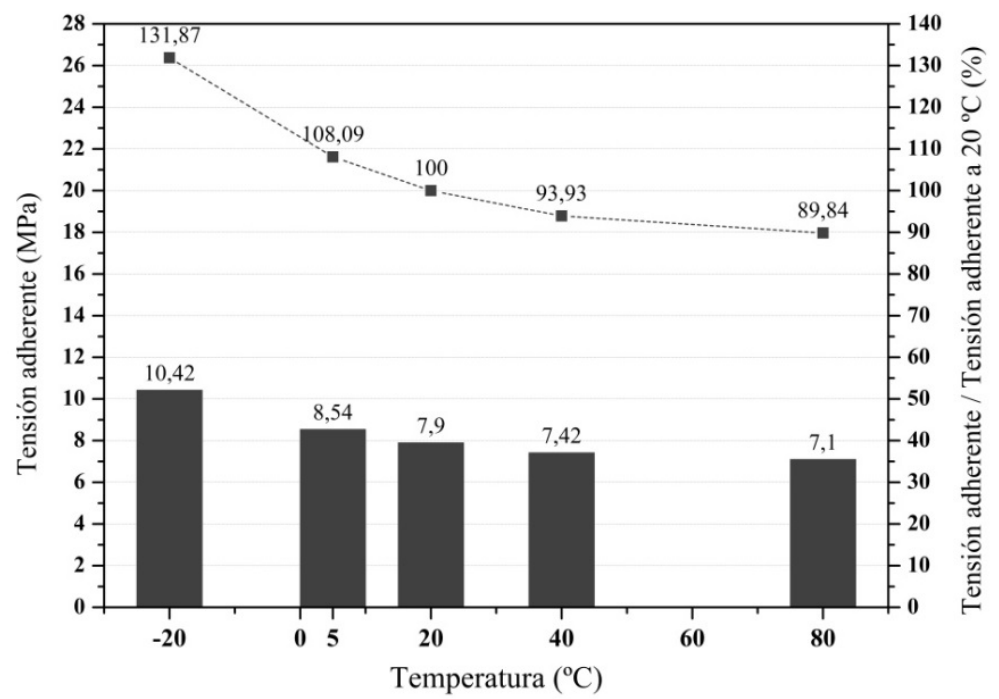

Fig. 4.64. Relación entre la tensión adherente y la temperatura en barras de CFRP texturizadas CT13. 


\begin{tabular}{|c|c|c|c|}
\hline \multicolumn{4}{|c|}{ Test de Contraste Múltiple de Rango } \\
\hline & Frecuencia & Media $(M P a)$ & Grupos Homogéneos \\
\hline $80^{\circ} \mathrm{C}$ & 5 & 7,10271 & $\mathrm{X}$ \\
\hline $40^{\circ} \mathrm{C}$ & 5 & 7,42590 & $x$ \\
\hline $20^{\circ} \mathrm{C}$ & 5 & 7,90605 & $x$ \\
\hline $5^{\circ} \mathrm{C}$ & 5 & 8,54624 & $X X$ \\
\hline$-20^{\circ} \mathrm{C}$ & 5 & 10,42550 & $\mathrm{X}$ \\
\hline
\end{tabular}

Tabla. 4.27. Estudio estadístico del efecto de la temperatura en la tensión adherente máxima de las barras de CFRP texturizadas CT13: Test de Contraste Múltiple de Rango.

Al mismo tiempo, se observa, según el estudio estadístico realizado, que los deslizamientos, tanto en el extremo tensionado como en el no tensionado, son estadísticamente similares a cualquier temperatura (Tabla 4.28).

\begin{tabular}{cccccc}
\hline $\begin{array}{c}\text { Condición Térmica / } \\
\text { Deslizamiento (mm) }\end{array}$ & $\mathrm{HD}$ & $5{ }^{\circ} \mathrm{C}$ & $20{ }^{\circ} \mathrm{C}$ & $40{ }^{\circ} \mathrm{C}$ & $80{ }^{\circ} \mathrm{C}$ \\
\hline Extremo Tensionado " $\delta_{\mathrm{ET}}$ " & 4,10 & 3,11 & 3,23 & 3,76 & 3,85 \\
\cline { 1 - 2 } Extremo No Tensionado " $\delta_{\mathrm{ENT}}$ " & 3,72 & 2,78 & 3,01 & 3,11 & 3,67 \\
\hline
\end{tabular}

Tabla. 4.28. Valores medios del deslizamiento, en extremo tensionado y no tensionado, de las barras de CFRP texturizadas CT13 en las diferentes condiciones térmicas.

Consecuentemente, se puede considerar que la temperatura no produce una modificación, estadísticamente significativa con un nivel de confianza del $95 \%$, en el comportamiento adherente, debido a que dicho comportamiento está dominado por el diseño de la geometría superficial de la barra. Sin embargo, si que se produce una tendencia a incrementar la tensión adherente al reducir la temperatura y a disminuir al aumentar la temperatura (Figs. 4.63 y 4.64). Estos incrementos pueden estar producidos por:

- el incremento de resistencia de la matriz polimérica de la barra de CFRP debida a cambios en la estructura molecular que se vuvelve más estable a temperaturas más bajas (Fig. 4. 65.a,b), y

- por el aumento de resistencia de la corruga de hormigón, debida al mayor confinamiento y efecto de las bajas temperaturas. 

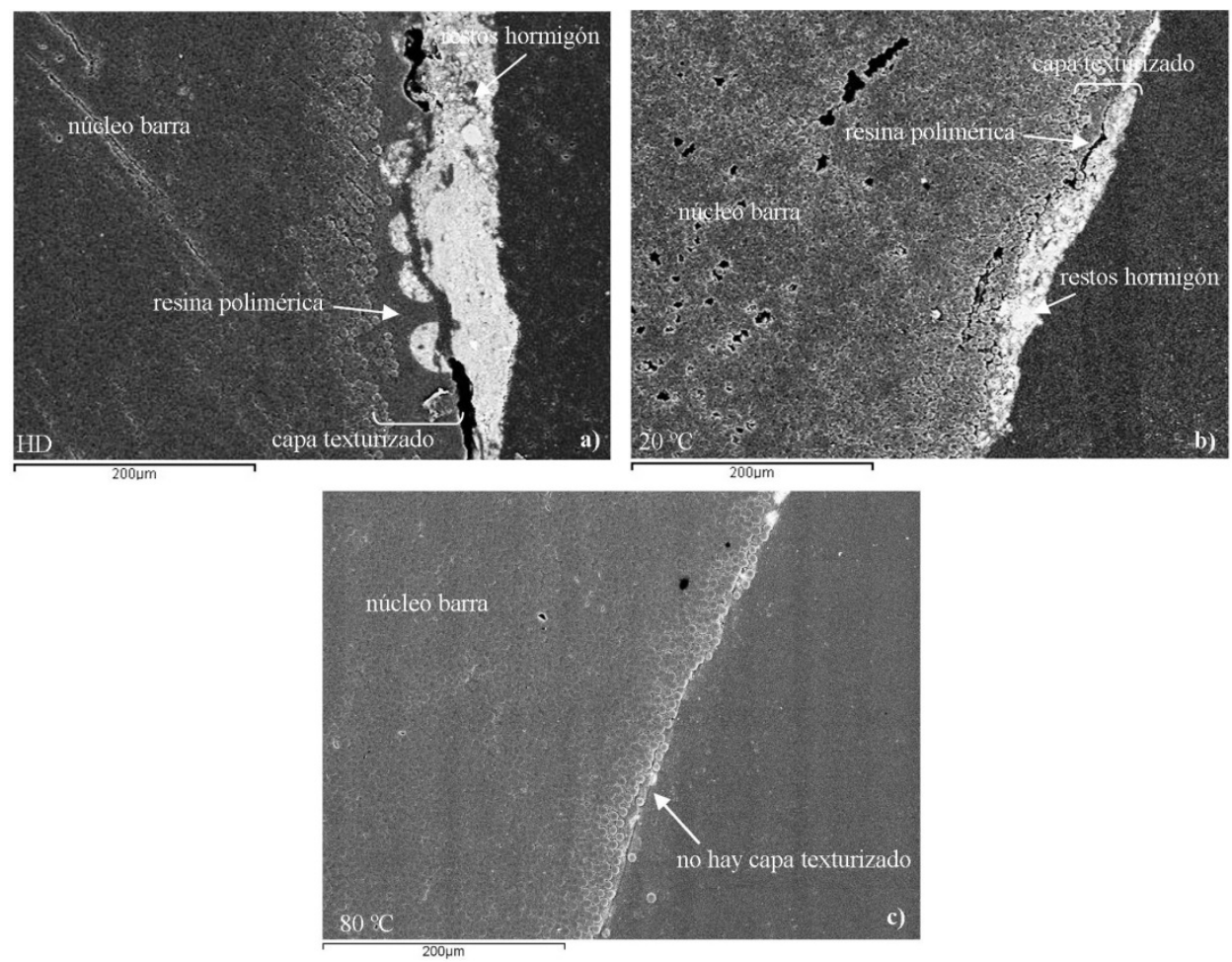

Fig. 4.65. Estado de las barras de CFRP texturizadas CT13 tras el ensayo de pullout: a) Detalle de zona superficial, resina polimérica y capa de texturizado en buen estado, SEM/CT13/HD, x250; b) Detalle de zona superficial, resina polimérica y capa de texturizado un poco degradadas, $\mathrm{SEM} / \mathrm{CT} 13 / 20, \mathrm{x} 250 ; \mathrm{c})$ Detalle de zona superficial, capa de texturizado rota, SEM/CT13/80, x250.

Del mismo modo, al incrementarse la temperatura, de $20{ }^{\circ} \mathrm{C}$ a $40{ }^{\circ} \mathrm{C}$ y $80{ }^{\circ} \mathrm{C}$, se observa una ligera disminución de la tensión adherente de 0,48 y 0,8 MPa (Fig. 4.63 y 4.64), que puede ser debida a la degradación de la matriz polimérica de la barra de CFRP, que conlleva una destrucción del texturizado superficial de la barra, tanto en zona de corruga como en el superficie (Fig. 4.65.c,b).

En cuanto al modo de rotura de las barras de CFRP texturizadas, este es idéntico en todas las temperaturas estudiadas (véase apart. 4.1.1), produciendose por corte de las corrugas de hormigón embebidas en la barra, ocasionado una rotura prematura (Fig. 4.66). Por tanto, se obseva que el modo de rotura en este tipo de barras depende del diseño de la geometría superficial. 

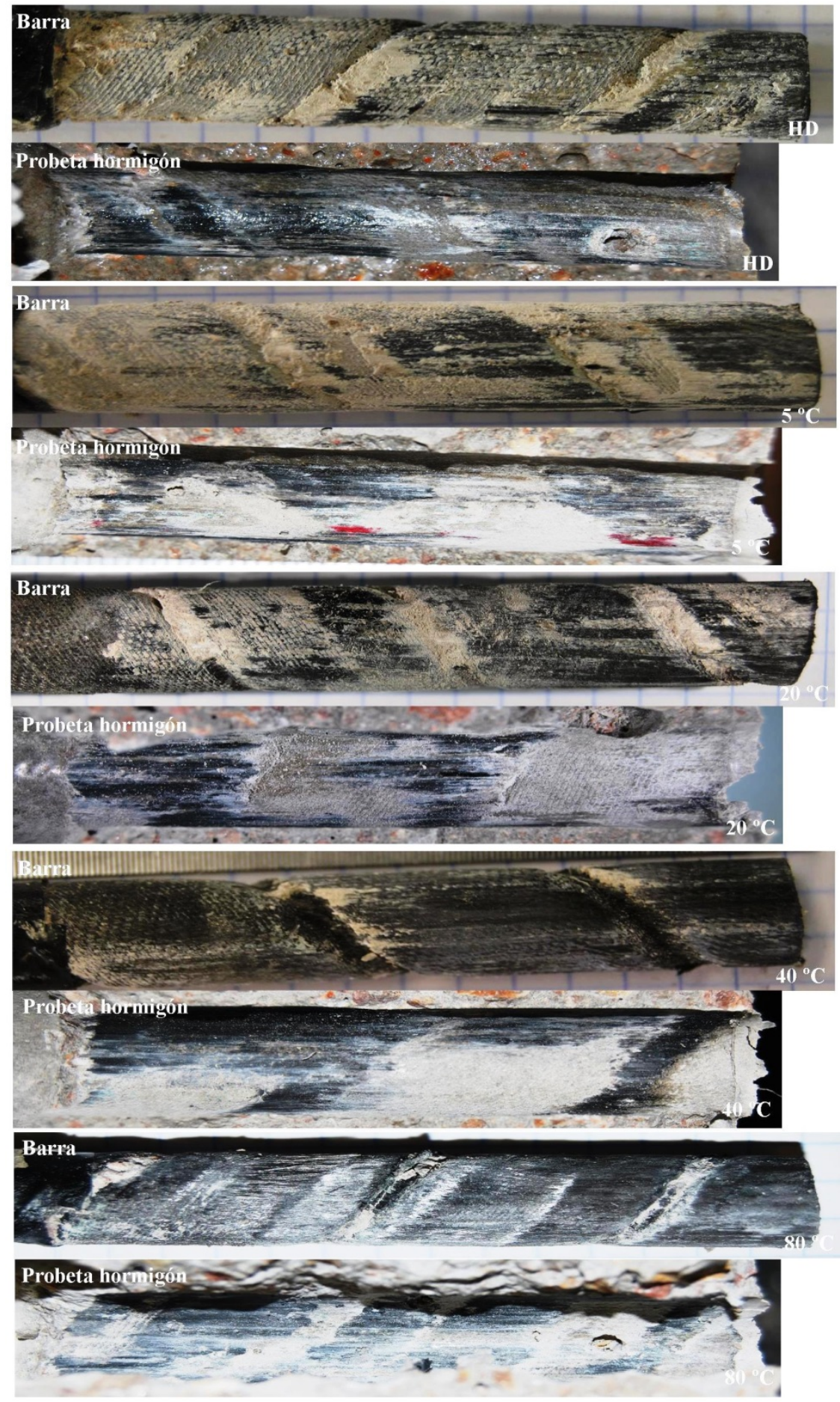

Fig. 4.66. Rotura por corte de las corrugas de hormigón, estado de las probetas de hormigón y barras de CFRP texturizadas CT13, tras el ensayo de pullout a diferentes temperaturas: Mayor degradación de la barra y más restos de la barra en probeta de hormigón a mayor temperatura. 
Al mismo tiempo, se detecta que las temperaturas elevadas producen una rotura del texturizado superficial y mayores daños en la zona de corrugas de la barra (Fig. 4.66 y 4.67$)$.
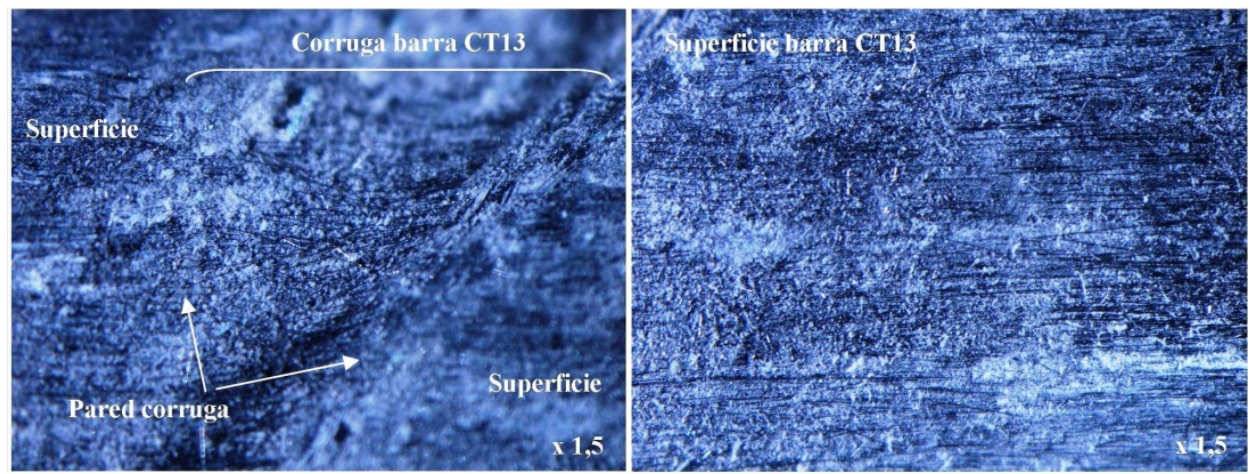

Fig. 4.67. Estado de la superficie de la barra de CFRP texturizada CT13 tras el ensayo de pullout a temperatura de $80{ }^{\circ} \mathrm{C}$ : Texturizado completamente roto y matriz polimérica de la superficie degradada.

Por el contratio a bajas temperaturas, se observa el texturizado de la barra en perfecto estado y menores daños en la zona de corruga de la barra, en la cual se muestran restos de hormigón (Fig. 4.68).
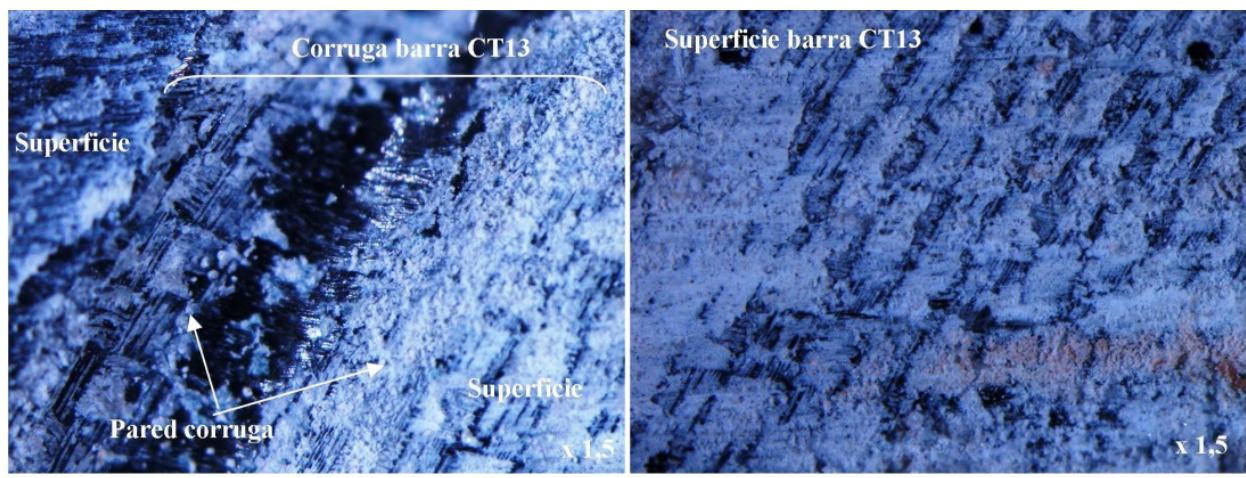

Fig. 4.68. Estado de la superficie de la barra de CFRP texturizada CT13 tras el ensayo de pullout a temperatura de $-20^{\circ} \mathrm{C}$ : Corruga y superficie de la barra con texturizado en buen estado y restos de hormigón.

El comportamiento tras la rotura adherente en este tipo de barras es similar en todas las temperaturas estudiadas, puesto que la pendiente descendente tras la tensión adherente máxima presenta una inclinación similar 
(Fig. 4.63). Sin embargo, se observa una tendencia a incrementar la tensión adherente residual a medida que la temperatura disminuye (Fig. 4.69). Este efecto puede ser debido a la mayor degradación de la capa de texturizado de la superficie de la barra producida por las altas temperaturas, que degradan la resina polimérica de la misma, ocasionando su desprendimiento y un menor rozamiento (Fig. 4.67 y 4.68 ).

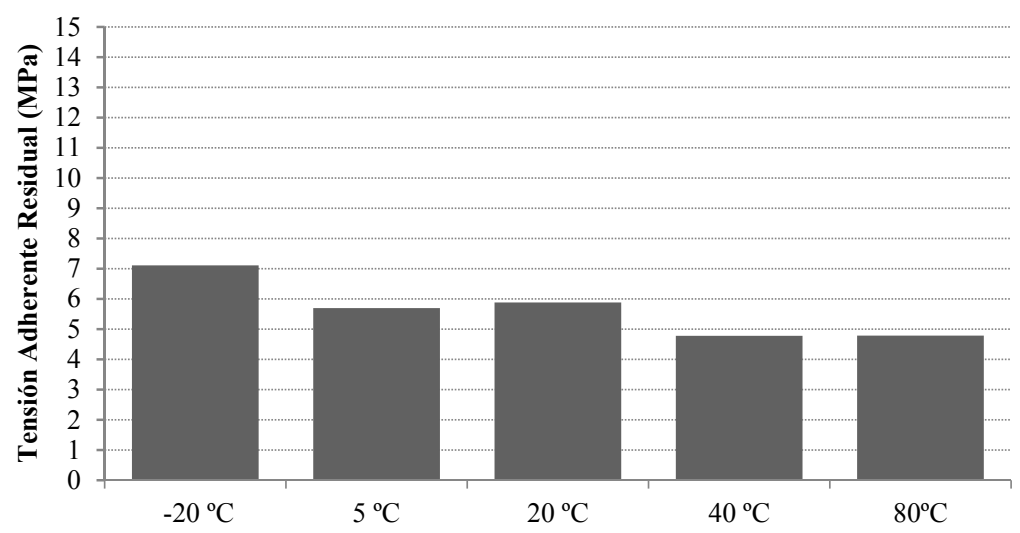

Fig. 4.69. Tensión adherente residual de las barras de CFRP texturizadas CT13.

b) Comparación del comportamiento adherente, entre las barras de CFRP y acero corrugadas, en función de la temperatura:

\section{- Comparación entre barras de CFRP arenadas CA8 y acero corrugado A8:}

Las barras de CFRP arenadas CA8, según el estudio estadístico realizado $^{52}$, desarollan una tensión adherente menor a la desarrollada por las barras de acero corrugadas A8 (Tablas 4.29). Al mismo tiempo, se observa que las barras CA8 desarrollan un menor deslizamiento a misma tensión adherente que las barras A8 (Fig. 4.70). Este comportamiento es debido principalmente a la distinta geometría de los dos tipos de barras (véase apart. 4.1.1), y en segundo

\footnotetext{
${ }^{52}$ El estudio estadístico se realiza mediante un ANOVA Multifactorial, cuya variable dependiente es la tensión adherente o deslizamiento medio y los factores son el tipo de barra y la temperatura.
} 
lugar al efecto de la temperatura, tanto en la resina polimérica de las barras CA8 (véase apart. 4.1.2) como en la resistencia del hormigón en el caso de las barras A8. Estos resultados se comprueban ante la significación de ambos factores (Pvalor $<0,05)$ y en el mayor valor obtenido de la F de Snedecor del tipo de barra respecto al de la temperatura (Tabla 4.30).

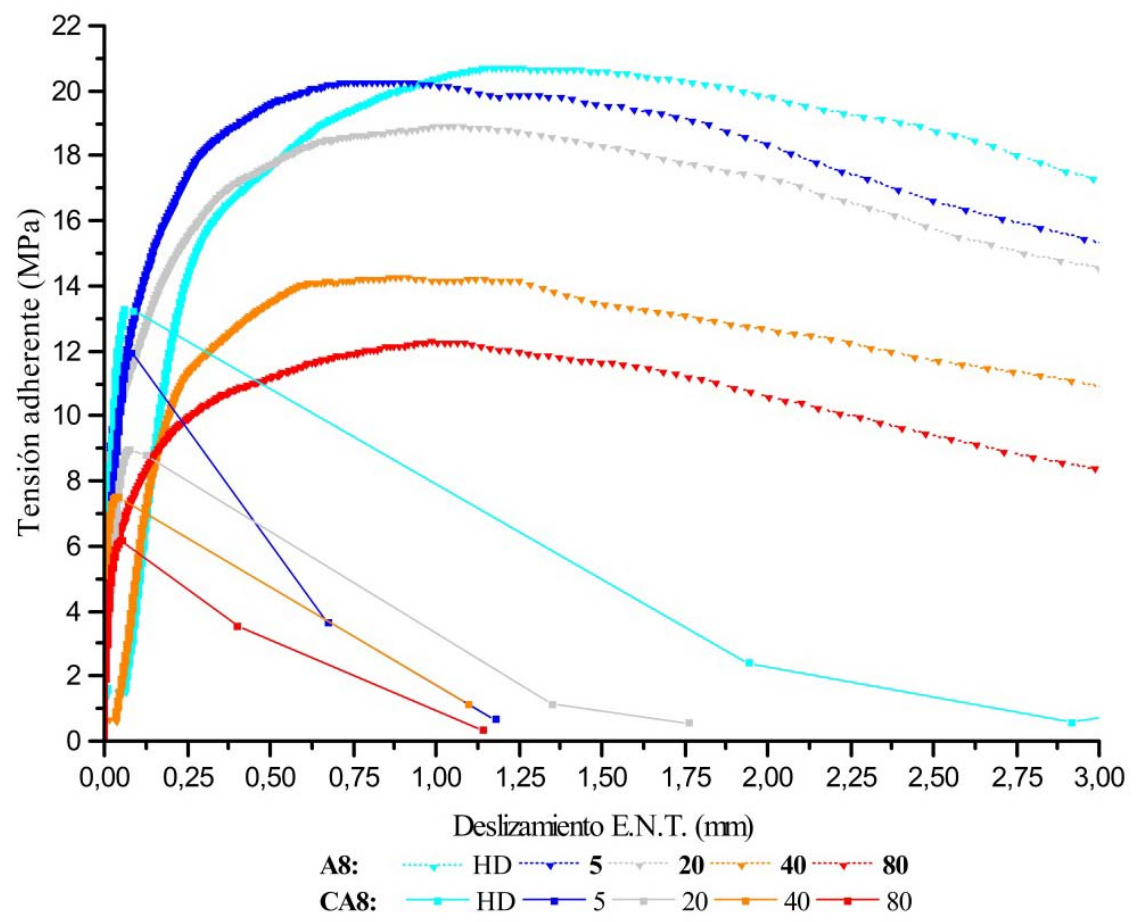

Fig. 4.70. Comparativa del comportamiento adherente entre las barras de CFRP arenadas CA8 y acero corrugadas A8.

\begin{tabular}{cccc}
\hline & \multicolumn{2}{c}{ Tensión adherente $(\mathrm{MPa})$} & \\
\cline { 2 - 3 } Temperatura & $\begin{array}{c}\mathrm{CA} 8 \\
(1)\end{array}$ & $\begin{array}{c}\mathrm{A} 8 \\
(2)\end{array}$ & $(2) /(1)$ \\
\cline { 1 - 2 } $\begin{array}{c}\text { Media todas } \\
\text { temperaturas }\end{array}$ & 9,26 & 16,51 & 1,78 \\
\cline { 1 - 1 }$-20^{\circ} \mathrm{C}$ & 11,56 & 20,74 & 1,79 \\
\cline { 1 - 1 } $55^{\circ} \mathrm{C}$ & 10,86 & 17,89 & 1,65 \\
\hline $20^{\circ} \mathrm{C}$ & 9,15 & 17,51 & 1,91 \\
\hline $40^{\circ} \mathrm{C}$ & 7,47 & 14,62 & 1,96 \\
\hline $80^{\circ} \mathrm{C}$ & 7,24 & 11,77 & 1,63 \\
\hline
\end{tabular}

Tabla. 4.29. Tensión adherente máxima (valores medios de los 5 ensayos de cada temperatura) de las barras de CFRP arenadas CA8 y acero corrugadas A8. 


\begin{tabular}{|c|c|c|c|c|c|}
\hline Fuente & $\begin{array}{c}\text { Suma de } \\
\text { Cuadrados }\end{array}$ & $G l$ & $\begin{array}{c}\text { Cuadrado } \\
\text { Medio }\end{array}$ & Razón-F & Valor-P \\
\hline \multicolumn{6}{|l|}{ EFECTOS PRINCIPALES } \\
\hline A:Temperatura $\left({ }^{\circ} \mathrm{C}\right)$ & 278,697 & 4 & 69,6744 & 14,44 & 0,0000 \\
\hline B:Tipo de barra & 657,803 & 1 & 657,803 & 136,32 & 0,0000 \\
\hline \multicolumn{6}{|l|}{ INTERACCIONES } \\
\hline $\mathrm{AB}$ & 31,1004 & 4 & 7,77511 & 1,61 & 0,1903 \\
\hline RESIDUOS & 193,014 & 40 & 4,82535 & & \\
\hline TOTAL (CORREGIDO) & 1160,61 & 49 & & & \\
\hline
\end{tabular}

Tabla. 4.30. Análisis de Varianza Multifactorial de la variable dependiente tesnión adherente y las variables independientes tipo de barra (CA8 y A8) y temperatura $\left(-20,5,20,40\right.$ y $\left.80^{\circ} \mathrm{C}\right)$.

Consecuentemente, según el cálculo de la rigidez adherente ${ }^{53}$ en ambos tipos de barras (Tabla 4.31), se puede considerar que las barras CA8 poseen un comportamiento adherente, en el global de las temperaturas y a cada temperatura estudiada, más rígido que las barras A8, del orden de 5 veces mayor. Este comportamiento se debe principalmente a la diferente geometría superficial de las barras.

\begin{tabular}{|c|c|c|c|}
\hline \multirow[b]{2}{*}{ Temperatura } & \multicolumn{2}{|c|}{ Rigidez adherente } & \multirow[b]{2}{*}{$(1) /(2)$} \\
\hline & $\begin{array}{l}\text { CA8 } \\
\text { (1) }\end{array}$ & $\begin{array}{l}\text { A8 } \\
(2)\end{array}$ & \\
\hline $\begin{array}{l}\text { Media todas } \\
\text { temperaturas }\end{array}$ & 68,07 & 13,67 & 4,98 \\
\hline$-20^{\circ} \mathrm{C}$ & 79,76 & 13,06 & 6,11 \\
\hline $5^{\circ} \mathrm{C}$ & 58,30 & 16,05 & 3,63 \\
\hline $20^{\circ} \mathrm{C}$ & 79,04 & 14,41 & 5,49 \\
\hline $40^{\circ} \mathrm{C}$ & 70,78 & 12,34 & 5,74 \\
\hline $80^{\circ} \mathrm{C}$ & 52,46 & 12,50 & 4,20 \\
\hline
\end{tabular}

Tabla. 4.31. Rigidez adherente de las barras de CFRP arenadas CA8 y acero corrugadas A8.

En cuanto al efecto de la temperatura estudiada el comportamiento adherente, se obtienen los siguientes resultados:

- Al disminuir la temperatura se produce, en ambos tipos de barras, un incremento significativo de la tensión adherente. Por

\footnotetext{
${ }^{53}$ La rigidez adherente se define como el cociente entre la tensión adherente máxima y el respectivo deslizamiento medio de ambos extremos $\left(\mathrm{E}_{\mathrm{adh}}=\tau /\left(\left(\delta_{\mathrm{ET}}+\delta_{\mathrm{ENT}}\right) / 2\right)\right)$.
} 
el contrario, al incrementar la temperatura se produce una reducción significativa de la adherencia (Tabla 4.29). Esta variación de la tensión adherente, respecto a la desarrollada a temperatura de $20{ }^{\circ} \mathrm{C}$, es mayor en las barras de acero corrugadas A8, puesto que la influencia de la temperatura sobre la resistencia del hormigón es mayor que sobre la resistencia de la resina polimérica, al estar esta última protegida por una capa de arena.

- En todas las temperaturas estudiadas, la tensión adherente desarrollada por las barras de acero corrugadas A8 es significativamente mayor que la alcanzada por las barras de CFRP arenadas CA8, del orden de 1,6-1,9 veces mayor (Tabla 4.29).

- La rigidez adherene de las barras CA8 es del orden de 3,6 a 6 veces mayor que la de las barras A8 (Tabla 4.31). Por lo tanto, las barras CA8 desarrollan un menor deslizamiento a misma tensión adherente.

Respecto al comportamiento tras la rotura adherente, las barras de CFRP arenadas presentan un comportamiento frágil, a diferencia de las barras de acero corrugas cuyo comportamiento es más ductil. Esta observación se puede comprobar mediante la mayor inclinación de la pendiente descendente tras la tensión adherente máxima de las barras de CFRP arenadas CA8 respecto de las barras de acero corrugado (Fig. 4.70). En cuanto a la tensión adherente residual tras la rotura adherente, las barras de acero corrugado desarrollan una tensión adherente residual mayor a las barras de CFRP arenadas, alrededor de 6 a 11 veces más (Tabla 4.32). Esta diferencia de comportamiento es debida al diferente modo de rotura, puesto que en las barras de CFRP arenadas la rotura adherente se produce de un modo frágil por rotura de la adherencia entre la capa de arenado y el núcleo de la barra, manteniendo una cierta adherencia por 
rozamiento entre el núcleo y la capa de arenado, mientras que en las barras de acero la rotura se produce por corte de las corrugas de hormigón, generando una tensión adherente residual por rozamiento entre el hormigón entre corrugas y el resto de hormigón de la probeta.

\begin{tabular}{|c|c|c|c|}
\hline \multirow[b]{2}{*}{ Temperatura } & \multicolumn{2}{|c|}{$\begin{array}{l}\text { Tensión adherente residual } \\
\qquad(\mathrm{MPa})\end{array}$} & \multirow[b]{2}{*}{$(2) /(1)$} \\
\hline & $\begin{array}{c}\text { CA8 } \\
\text { (1) }\end{array}$ & $\begin{array}{l}\text { A8 } \\
(2)\end{array}$ & \\
\hline $\begin{array}{l}\text { Media todas } \\
\text { temperaturas }\end{array}$ & 1,00 & 7,96 & 7,94 \\
\hline$-20^{\circ} \mathrm{C}$ & 0,92 & 10,36 & 11,24 \\
\hline $5^{\circ} \mathrm{C}$ & 1,27 & 7,56 & 5,95 \\
\hline $20^{\circ} \mathrm{C}$ & 0,71 & 7,74 & 10,88 \\
\hline $40^{\circ} \mathrm{C}$ & 1,12 & 7,39 & 6,62 \\
\hline $80^{\circ} \mathrm{C}$ & 0,99 & 6,79 & 6,82 \\
\hline
\end{tabular}

Tabla. 4.32. Tensión adherente residual de las barras de CFRP arenadas CA8 y acero corrugadas A8.

Por lo tanto, las barras de CFRP arenadas CA8 desarrollan un comportamiento adherente significativamente diferente al de las barras de acero corrugado A8: con una menor tensión adherente máxima, mayor rigidez adherente y un comportamiento menos ductil trás la rotura adherente (Fig. 4.70).

\section{- Comparación entre barras de CFRP arenadas CA14 y acero corrugado A16:}

Del mismo modo que en el caso anterior, según el estudio estadístico realizado, las barras de CFRP arenadas CA14 desarollan una tensión adherente significativamente menor a la producida por las barras de acero corrugadas A16 (Tabla 4.33). Esta diferente tensión adherente se debe principalmente a la distinta geometría de los dos tipos de barras (véase apart. 4.1.1), y seguidamente al efecto de la temperatura, tanto en la resina polimérica de las barras CA14 (véase apart. 4.1.2) como en la resistencia del hormigón en el caso de las barras 
A16 (Tabla 4.34). Al mismo tiempo, se observa que las barras CA14 desarrollan un menor deslizamiento a misma tensión adherente que las barras A16 (Fig. 4.71).

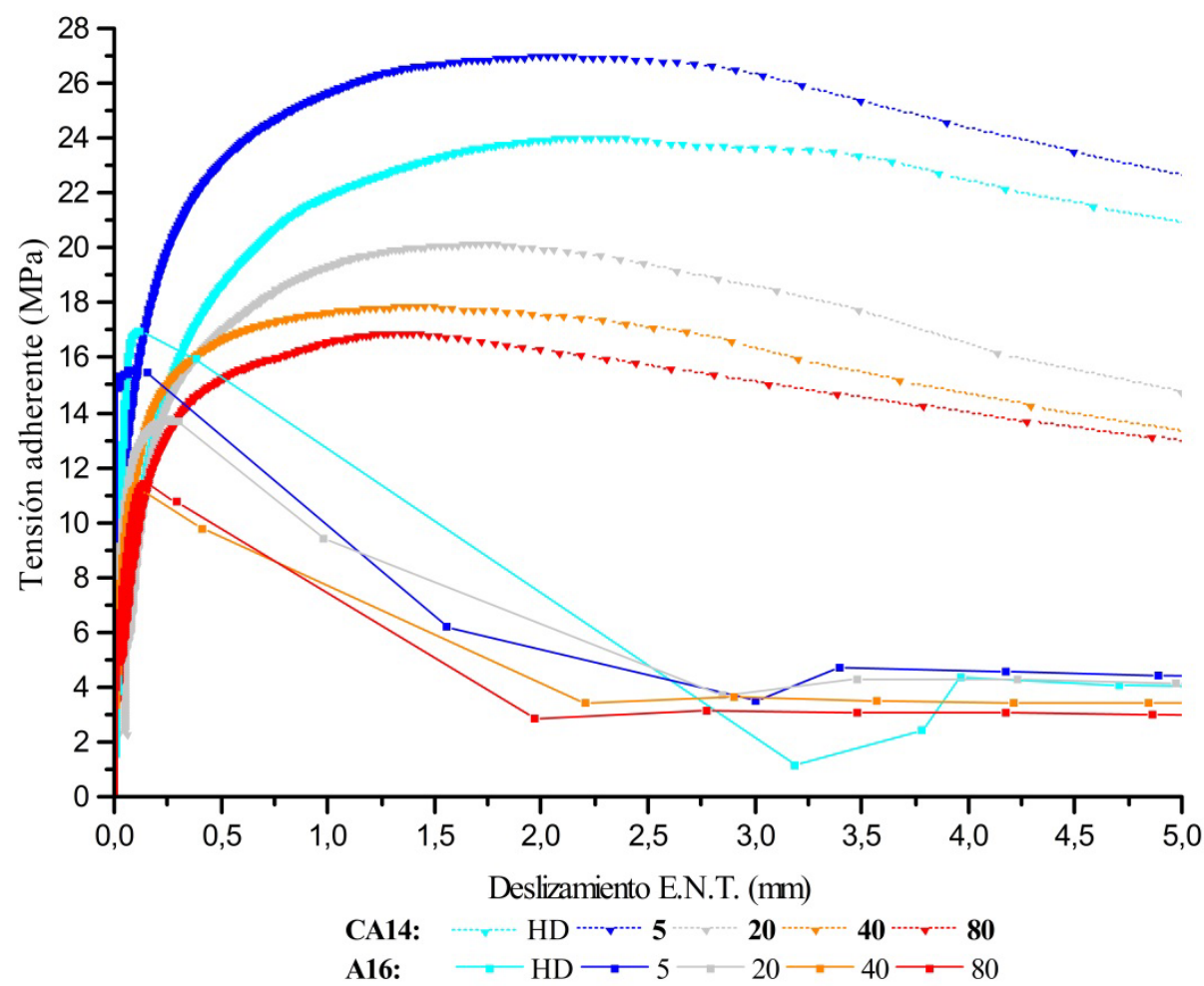

Fig. 4.71. Comparativa del comportamiento adherente entre las barras de CFRP arenadas CA14 y acero corrugadas A16.

\begin{tabular}{|c|c|c|c|}
\hline \multirow[b]{2}{*}{ Temperatura } & \multicolumn{2}{|c|}{ Tensión adherente (MPa) } & \multirow[b]{2}{*}{$(2) /(1)$} \\
\hline & $\begin{array}{c}\text { CA14 } \\
\text { (1) }\end{array}$ & $\begin{array}{l}\text { A16 } \\
(2)\end{array}$ & \\
\hline $\begin{array}{l}\text { Media todas } \\
\text { temperaturas }\end{array}$ & 13,91 & 20,87 & 1,50 \\
\hline$-20^{\circ} \mathrm{C}$ & 16,94 & 24,39 & 1,44 \\
\hline $5^{\circ} \mathrm{C}$ & 15,43 & 23,68 & 1,54 \\
\hline $20^{\circ} \mathrm{C}$ & 13,26 & 20,73 & 1,56 \\
\hline $40^{\circ} \mathrm{C}$ & 11,58 & 18,86 & 1,63 \\
\hline $80^{\circ} \mathrm{C}$ & 12,36 & 16,69 & 1,35 \\
\hline
\end{tabular}

Tabla. 4.33. Tensión adherente máxima (valores medios de los 5 ensayos de cada temperatura) de las barras de CFRP arenadas CA14 y acero corrugadas A16. 


\begin{tabular}{|c|c|c|c|c|c|}
\hline Fuente & $\begin{array}{c}\text { Suma de } \\
\text { Cuadrados }\end{array}$ & $G l$ & $\begin{array}{c}\text { Cuadrado } \\
\text { Medio }\end{array}$ & Razón-F & Valor- $P$ \\
\hline \multicolumn{6}{|l|}{ EFECTOS PRINCIPALES } \\
\hline A:Temperatura $\left({ }^{\circ} \mathrm{C}\right)$ & 284,919 & 4 & 71,2297 & 17,10 & 0,0000 \\
\hline B:Tipo de barra & 605,317 & 1 & 605,317 & 145,31 & 0,0000 \\
\hline \multicolumn{6}{|l|}{ INTERACCIONES } \\
\hline $\mathrm{AB}$ & 22,8705 & 4 & 5,71762 & 1,37 & 0,2607 \\
\hline RESIDUOS & 166,633 & 40 & 4,16582 & & \\
\hline TOTAL (CORREGIDO) & 1079,74 & 49 & & & \\
\hline
\end{tabular}

Tabla. 4.34. Análisis de Varianza Multifactorial de la variable dependiente tesnión adherente y las variables independientes tipo de barra (CA14 y A16) y temperatura $\left(-20,5,20,40\right.$ y $\left.80^{\circ} \mathrm{C}\right)$.

Por consiguiente, las barras de CFRP arenadas CA14 presentan un comportamiento adherente, en global de la temperatura, más rígido que las barras de acero corrugadas A16 (Tabla 4.35). Según los valores calculados las barras CA14 poseen una rigidez adherente 4,7 veces mayor a las barras A16, valor similar al obtenido entre las barras CA8 y A8.

\begin{tabular}{|c|c|c|c|}
\hline \multirow[b]{2}{*}{ Temperatura } & \multicolumn{2}{|c|}{ Rigidez adherente } & \multirow[b]{2}{*}{$(1) /(2)$} \\
\hline & $\begin{array}{l}\text { CA14 } \\
\text { (1) }\end{array}$ & $\begin{array}{l}\text { A16 } \\
(2)\end{array}$ & \\
\hline $\begin{array}{l}\text { Media todas } \\
\text { temperaturas }\end{array}$ & 47,76 & 10,19 & 4,69 \\
\hline$-20^{\circ} \mathrm{C}$ & 48,65 & 10,03 & 4,85 \\
\hline $5^{\circ} \mathrm{C}$ & 44,71 & 11,28 & 3,96 \\
\hline $20^{\circ} \mathrm{C}$ & 47,86 & 9,72 & 4,92 \\
\hline $40^{\circ} \mathrm{C}$ & 52,02 & 11,01 & 4,72 \\
\hline $80^{\circ} \mathrm{C}$ & 45,56 & 9,38 & 4,86 \\
\hline
\end{tabular}

Tabla. 4.35. Rigidez adherente de las barras de CFRP arenadas CA14 y acero corrugadas A16.

Respecto al efecto de cada temperatura estudiada en el comportamiento adherente, se pueden establecer las siguientes observaciones:

- En ambos tipos de barras, al disminuir la temperatura se produce un incremento significativo de la tensión adherente. En cambio, al aumentar la temperatura se produce una reducción significativa de la tensión adherente (Tabla 4.33 y Fig. 4.72). Esta variación de la tensión adherente, respecto a la desarrollada 
a temperatura de $20{ }^{\circ} \mathrm{C}$, es mayor en las barras de acero corrugadas A16, puesto que la influencia de la temperatura sobre la resistencia del hormigón es mayor que sobre la resistencia de la resina polimérica, al estar esta última protegida por una capa de arena.

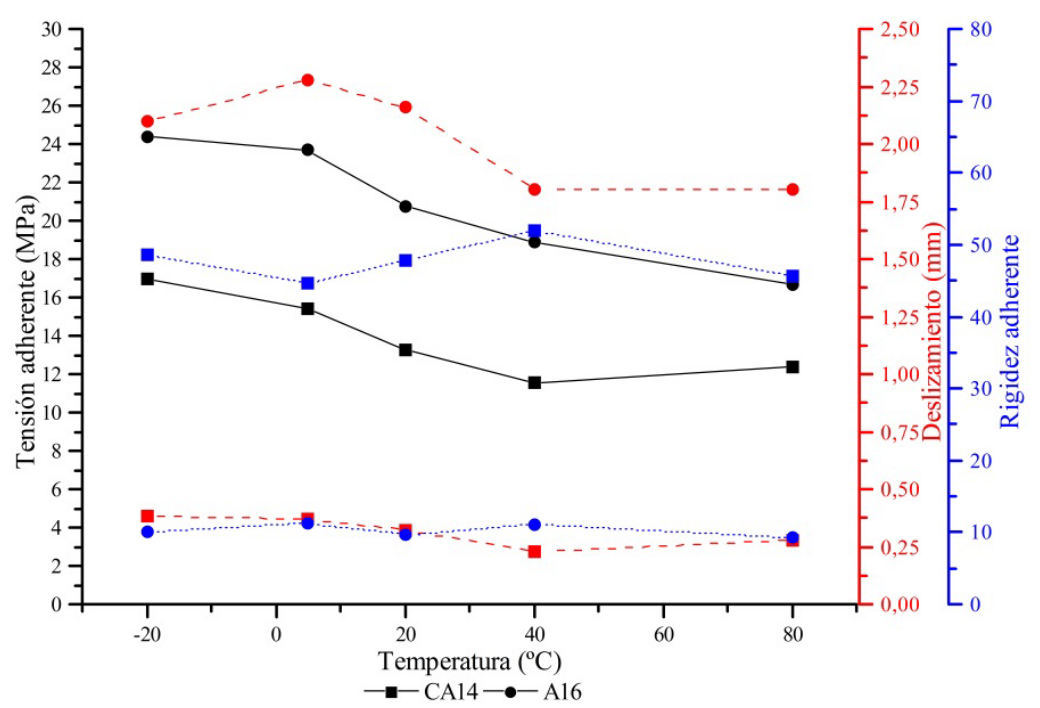

Fig. 4.72. Comparativa de la tensión adherente, deslizamiento medio de ambos extremos y rigidez adherente, de las barras de CFRP arenadas CA14 y de acero corrugadas A16.

- En todas las temperaturas estudiadas, la tensión adherente desarrollada por las barras de acero corrugadas A16 es significativamente mayor que la alcanzada por las barras de CFRP arenadas CA14, del orden de 1,3-1,6 veces mayor (Tabla 4.33 y Fig. 4.72).

- La rigidez adherene de las barras CA14 es, a cualquier temperatura, significativamente mayor a la desarrollada por las barras A16, del orden de 3,9 a 4,9 veces mayor (Tabla 4.35 y Fig. 4.72). Por lo tanto, las barras CA14 desarrollan un menor deslizamiento a misma tensión adherente que las barras A16. 
En cuanto al comportamiento tras la rotura adherente, las barras de CFRP arenadas presentan un comportamiento mucho más frágil, a diferencia de las barras de acero corrugas cuyo comportamiento es más ductil (Fig. 4.71). La tensión adherente residual de las barras CA14 es menor a la desarrollada por las barras de acero corrugado A16, unas 2,5 veces menor (Fig. 4.73). Del mismo modo, a cada temperatura la tensión adherente residual de las barras CA14 es estadísticamente menor a la de las barras A16 (Fig. 4.73). Este comportamiento es debido, del mismo modo que en el caso de las barras CA8, al distinto modo de rotura, entre las barras de CFRP arenadas y acero corrugadas, que origina diferente modo de rozamiento entre la barra y el hormigón.

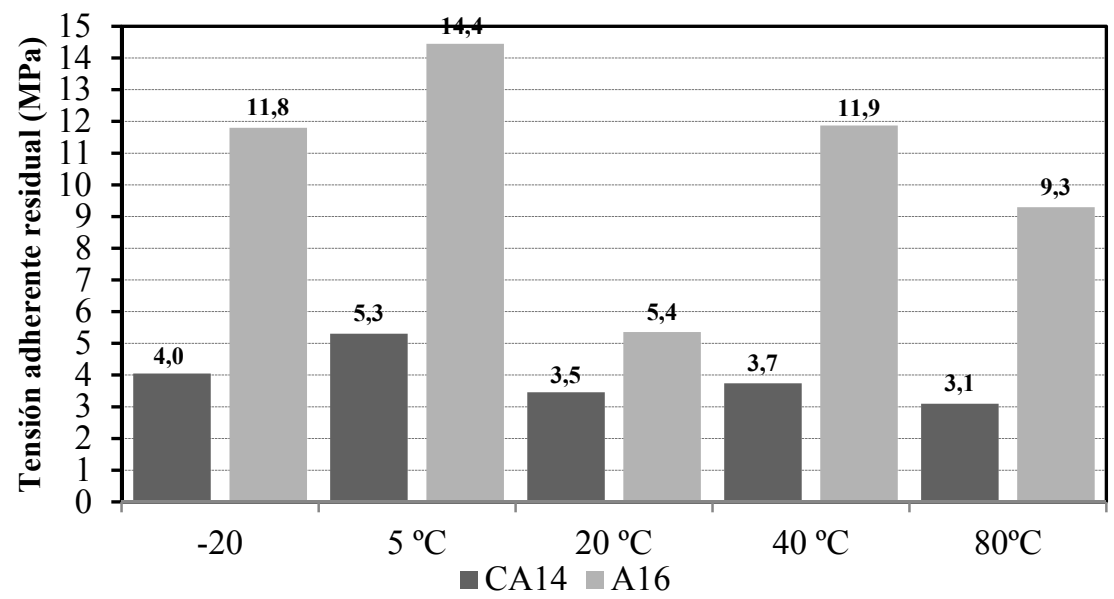

Fig. 4.73. Comparativa de la tensión adherente residual entre las barras de CFRP arenadas CA14 y las barras de acero corrugado A16.

\section{- Comparación entre barras de CFRP corrugadas CC12 y acero corrugado A12:}

Las barras de CFRP corrugadas CC12 desarrollan estadísticamente, en el conjunto de todas las temperaturas estudiadas, una tensión adherente similar a las barras de acero corrugadas A12, del orden de $18 \mathrm{MPa}$ (Fig. 4.74 y Tabla 4.36). 


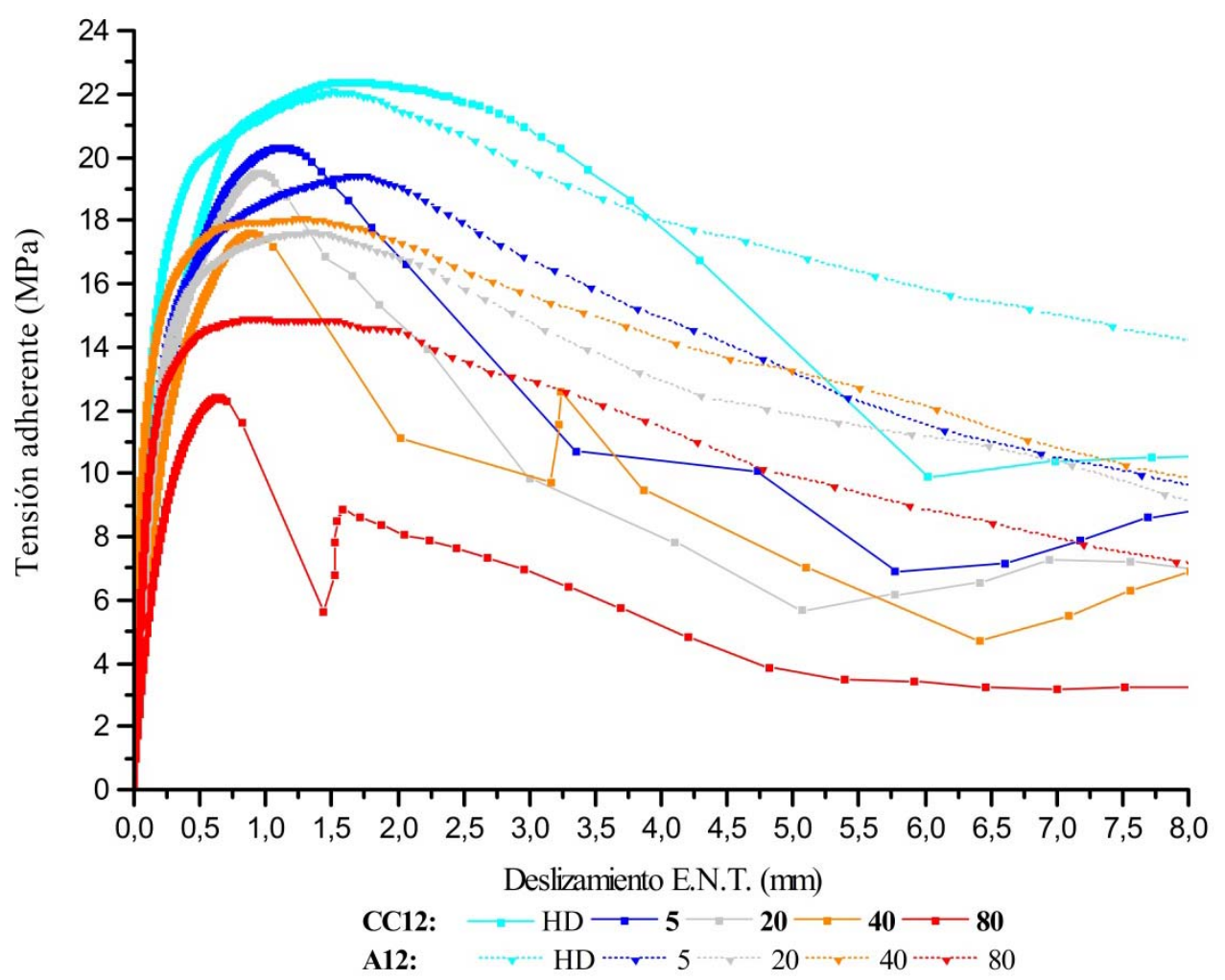

Fig. 4.74. Comparativa del comportamiento adherente entre las barras de CFRP corrugadas $\mathrm{CC} 12$ y acero corrugadas A12.

\begin{tabular}{cccc} 
& \multicolumn{2}{c}{ Tensión adherente $(\mathrm{MPa})$} & \\
\cline { 2 - 3 } Temperatura & $\begin{array}{c}\mathrm{CC} 12 \\
(1)\end{array}$ & $\begin{array}{c}\mathrm{A} 12 \\
(2)\end{array}$ & $(2) /(1)$ \\
\cline { 1 - 2 } $\begin{array}{c}\text { Media todas } \\
\text { temperaturas }\end{array}$ & 18,07 & 18,31 & 1,01 \\
\cline { 1 - 1 }$-20^{\circ} \mathrm{C}$ & 20,53 & 21,73 & 1,06 \\
\cline { 1 - 1 } $55^{\circ} \mathrm{C}$ & 20,57 & 19,32 & 0,94 \\
\hline $20^{\circ} \mathrm{C}$ & 18,57 & 16,70 & 0,90 \\
\hline $40^{\circ} \mathrm{C}$ & 18,23 & 18,51 & 1,02 \\
\hline $80^{\circ} \mathrm{C}$ & 12,46 & 15,29 & 1,23 \\
\hline
\end{tabular}

Tabla. 4.36. Tensión adherente máxima (valores medios de los 5 ensayos de cada temperatura) de las barras de CFRP corrugadas CC12 y acero corrugadas A12.

Al mismo tiempo, se observa a temperaturas del orden de $-20{ }^{\circ} \mathrm{C}$ a $20{ }^{\circ} \mathrm{C}$ que las barras de CFRP corrugadas poseen un deslizamiento a misma tensión adherente similar al de las barras de acero corrugado (Fig. 4.74). Del mismo 
modo, se puede considerar que el deslizamiento a tensión adherente máxima, en los tratamientos térmicos desde $-20{ }^{\circ} \mathrm{C}$ a $40{ }^{\circ} \mathrm{C}$ es similar al producido por las barras A12 (Tabla 4.37).

\begin{tabular}{|c|c|c|c|c|c|c|}
\hline \multirow[b]{2}{*}{ Temperatura } & \multicolumn{2}{|c|}{$\begin{array}{l}\text { Deslizamiento Extremo } \\
\text { Tensionado (mm) }\end{array}$} & \multirow[b]{2}{*}{$(1) /(2)$} & \multicolumn{2}{|c|}{$\begin{array}{l}\text { Deslizamiento Extremo } \\
\text { No tensionado (mm) }\end{array}$} & \multirow[b]{2}{*}{$(1) /(2)$} \\
\hline & $\begin{array}{c}\mathrm{CC} 12 \\
(1)\end{array}$ & $\begin{array}{c}\text { A12 } \\
(2)\end{array}$ & & $\begin{array}{c}\mathrm{CC} 12 \\
(1)\end{array}$ & $\begin{array}{c}\text { A12 } \\
(2)\end{array}$ & \\
\hline $\begin{array}{l}\text { Media todas } \\
\text { temperaturas }\end{array}$ & 1,50 & 1,82 & $82,51 \%$ & 1,08 & 1,48 & $73,12 \%$ \\
\hline$-20^{\circ} \mathrm{C}$ & 2,15 & 1,92 & $112,0 \%$ & 1,60 & 1,65 & $96,97 \%$ \\
\hline $5^{\circ} \mathrm{C}$ & 1,51 & 1,93 & $78,60 \%$ & 1,16 & 1,62 & $71,66 \%$ \\
\hline $20^{\circ} \mathrm{C}$ & 1,65 & 1,68 & $98,08 \%$ & 1,19 & 1,48 & $80,35 \%$ \\
\hline $40^{\circ} \mathrm{C}$ & 1,27 & 1,96 & $65,03 \%$ & 0,90 & 1,44 & $62,75 \%$ \\
\hline $80^{\circ} \mathrm{C}$ & 0,93 & 1,63 & $57,38 \%$ & 0,55 & 1,20 & $45,94 \%$ \\
\hline
\end{tabular}

Tabla. 4.37. Deslizamiento a tensión adherente máxima en extremo tensionado y no tensionado (valores medios de los 5 ensayos de cada temperatura) de las barras de CFRP corrugadas CC12 y acero corrugadas A12.

Por lo tanto, el comportamiento adherente de las barras de CFRP corrugadas $\mathrm{CC} 12$, en el rango de temperaturas desde $-20{ }^{\circ} \mathrm{C}$ a $40{ }^{\circ} \mathrm{C}$, es similar al desarrollado por las barras de acero corrugadas A12 (Fig. 4.74 y Tabla 4.38).

\begin{tabular}{cccc}
\hline & \multicolumn{2}{c}{ Rigidez adherente } & \\
\cline { 2 - 3 } Temperatura & $\begin{array}{c}\mathrm{CC} 12 \\
(1)\end{array}$ & $\begin{array}{c}\mathrm{A} 12 \\
(2)\end{array}$ & $(1) /(2)$ \\
\hline $\begin{array}{c}\text { Media todas } \\
\text { temperaturas }\end{array}$ & 14,84 & 11,20 & 1,32 \\
\cline { 1 - 1 }$-20^{\circ} \mathrm{C}$ & 11,04 & 12,23 & 0,90 \\
\cline { 1 - 1 } $5^{\circ} \mathrm{C}$ & 15,57 & 10,92 & 1,43 \\
\hline $20^{\circ} \mathrm{C}$ & 13,82 & 10,56 & 1,31 \\
\hline $40^{\circ} \mathrm{C}$ & 16,93 & 11,08 & 1,53 \\
\hline
\end{tabular}

Tabla. 4.38. Rigidez adherente de las barras de CFRP corrugadas CC12 y acero corrugadas A12.

En cuanto a la influencia de la temperatura en el comportamiento adherente de ambos tipos de barras, se obtienen las siguientes observaciones:

- La tensión adherente es similar a bajas $\left(-20^{\circ} \mathrm{C}\right.$ y $\left.5{ }^{\circ} \mathrm{C}\right)$ y medias temperaturas $\left(20^{\circ} \mathrm{C}\right.$ y $\left.40{ }^{\circ} \mathrm{C}\right)$ tanto en cada tipo de barra como 
entre los dos tipos distintos de barras. Por lo tanto, las temperaturas bajas y medias producen el mismo efecto en la tensión adherente en ambos tipos de barras (Tabla 4.36 y Fig. 4.75).

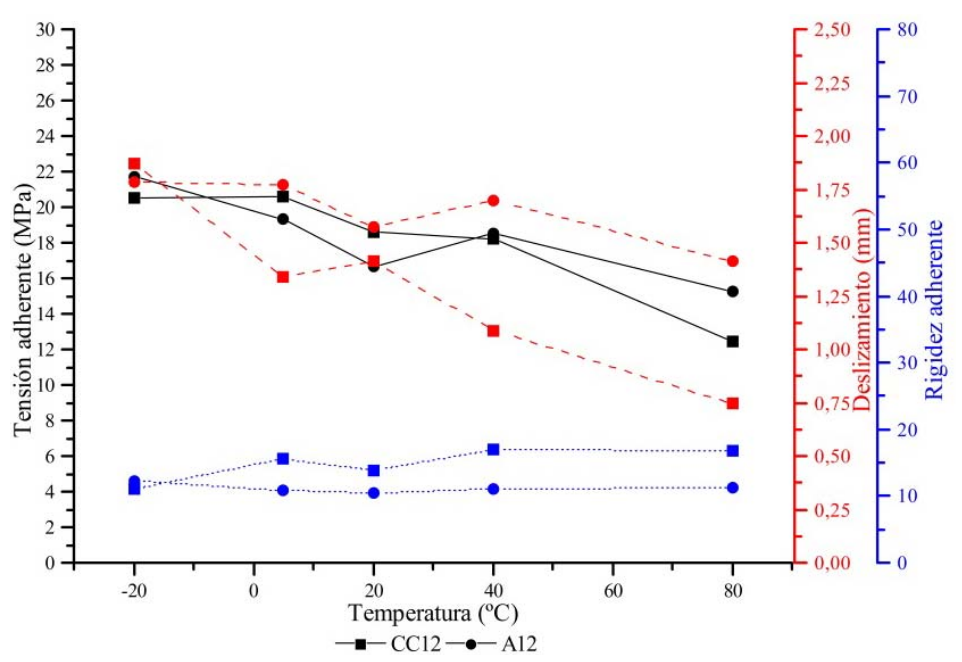

Fig. 4.75. Comparativa de la tensión adherente, deslizamiento medio de ambos extremos y rigidez adherente, de las barras de CFRP corrugadas CC12 y de acero corrugadas A12.

- Las altas temperaturas de $80{ }^{\circ} \mathrm{C}$ producen una disminución significativa de la tensión adherente en ambos tipos de barras, siendo la tensión adherente de las barras $\mathrm{CC} 12$ significativamente menor (alrededor de 2,8 MPa) respecto a las barras A12 (Tabla 4.36 y Fig. 4.75). Por lo tanto, las temperaturas elevadas producen una mayor disminución de la tensión adherente máxima en las barras de CFRP corrugadas que en las barras de acero corrugadas. Este efecto es debido a la mayor influencia de la temperatura en la pérdida de resistencia de la resina polimérica de la corruga en las barras de CFRP corrugadas respecto de la resistencia a corte del hormigón entre corrugas. 
- El comportamiento adherente de las barras de CFRP corrugadas a temperaturas bajas $\left(-20^{\circ} \mathrm{C}\right.$ y $\left.5{ }^{\circ} \mathrm{C}\right)$ y medias $\left(20^{\circ} \mathrm{C}\right.$ y $\left.40{ }^{\circ} \mathrm{C}\right)$ es similar, debido a que producen un deslizamiento similar a misma tensión adherente. Por el contrario, a temperturas elevadas de $80^{\circ} \mathrm{C}$, las barras de CFRP corrugadas desarrollan un comportamiento adherente menos rígido, es decir, con un mayor deslizamiento a misma tensión adherente (Figs. $4.74 \mathrm{y}$ 4.75).

Respecto, al comportamiento adherente tras la rotura, se puede considerar que las barras de CFRP corrugadas presentan un comportamiento menos dúctil que las barras de acero corrugado. Este efecto se observa en todas las temperaturas estudiadas, en la mayor inclinación de la pendiente descendente tras la rotura adherente de la gráfica de tensión adherente deslizamiento (Fig. 4.74). Del mismo modo, se puede considerar estadísticamente que las barras CC12 presentan una tensión adherente residual similar a las barras A12 a temperaturas de $-20^{\circ} \mathrm{C}, 5^{\circ} \mathrm{C}$ y $20^{\circ} \mathrm{C}$. Sin embargo, a temperaturas altas de $40{ }^{\circ} \mathrm{C}$ y $80^{\circ} \mathrm{C}$ las barras $\mathrm{A} 12$ desarrollan una tensión adherente residual mayor que las barras CC12 (Fig. 4.76). Este efecto, puede ser debido a la mayor influencia de la temperatura en la pérdida de resistencia de la resina polimérica de las barras de CFRP respecto a la pérdida de resistencia de las barras de acero corrugado (véase apart. 4.1.2.a "Barras de CFRP corrugadas CC12").

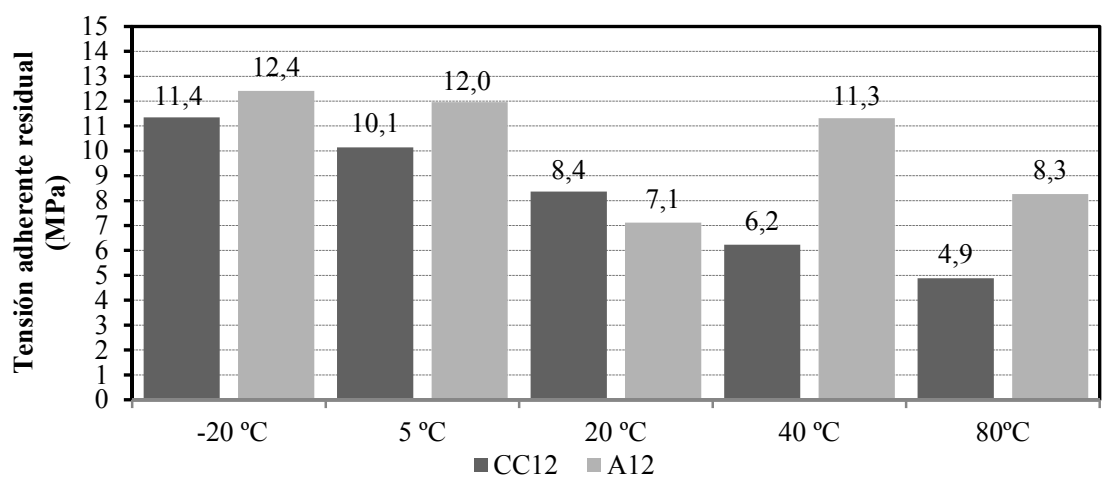

Fig. 4.76. Comparativa de la tensión adherente residual entre las barras de CFRP corrugadas CC12 y las barras de acero corrugado A12. 


\section{- Comparación entre barras de CFRP texturizadas y acero corrugado:}

Según el estudio estadístico realizado, las barras de CFRP texturizadas CT13 desarrollan, en el conjunto de todas las temperaturas estudiadas, una tensión adherente menor que las barras de acero corrugado A12 (Fig. $4.77 \mathrm{y}$ Tabla 4.39). Por el contrario, las barras de CFRP texturizadas desarrollan un mayor deslizamiento a misma tensión adherente que las barras de acero corrugadas (Fig. 4.77). Este diferente comportamiento adherente se debe en primer lugar a la diferente geometría superficial (véase apart. 4.1.1) y en segundo lugar al efecto de la temperatura en la resistencia del hormigón (Tabla $4.40)$.

\begin{tabular}{|c|c|c|c|}
\hline \multirow[b]{2}{*}{ Temperatura } & \multicolumn{2}{|c|}{ Tensión adherente (MPa) } & \multirow[b]{2}{*}{$(1) /(2)$} \\
\hline & $\begin{array}{c}\text { CT13 } \\
\text { (1) }\end{array}$ & $\begin{array}{l}\text { A12 } \\
\text { (2) }\end{array}$ & \\
\hline $\begin{array}{l}\text { Media todas } \\
\text { temperaturas }\end{array}$ & 8,28 & 18,31 & 2,21 \\
\hline$-20^{\circ} \mathrm{C}$ & 10,43 & 21,73 & 2,08 \\
\hline $5^{\circ} \mathrm{C}$ & 8,55 & 19,32 & 2,26 \\
\hline $20^{\circ} \mathrm{C}$ & 7,91 & 16,70 & 2,11 \\
\hline $40^{\circ} \mathrm{C}$ & 7,43 & 18,51 & 2,49 \\
\hline $80{ }^{\circ} \mathrm{C}$ & 7,10 & 15,29 & 2,15 \\
\hline
\end{tabular}

Tabla. 4.39. Tensión adherente máxima (valores medios de los 5 ensayos de cada temperatura) de las barras de CFRP texturizadas CT13 y acero corrugadas A12.

\begin{tabular}{|c|c|c|c|c|c|}
\hline Fuente & $\begin{array}{c}\text { Suma de } \\
\text { Cuadrados }\end{array}$ & $G l$ & $\begin{array}{c}\text { Cuadrado } \\
\text { Medio }\end{array}$ & Razón-F & Valor- $P$ \\
\hline \multicolumn{6}{|l|}{ EFECTOS PRINCIPALES } \\
\hline A:Temperatura $\left({ }^{\circ} \mathrm{C}\right)$ & 136,311 & 4 & 34,0777 & 9,09 & 0,0000 \\
\hline B:Tipo de barra & 1257,79 & 1 & 1257,79 & 335,64 & 0,0000 \\
\hline \multicolumn{6}{|l|}{ INTERACCIONES } \\
\hline $\mathrm{AB}$ & 20,4851 & 4 & 5,12128 & 1,37 & 0,2627 \\
\hline RESIDUOS & 149,898 & 40 & 3,74746 & & \\
\hline TOTAL (CORREGIDO) & 1564,48 & 49 & & & \\
\hline
\end{tabular}

Tabla. 4.40. Análisis de Varianza Multifactorial de la variable dependiente tensión adherente y las variables independientes tipo de barra (CT13 y A12) y temperatura $\left(-20,5,20,40\right.$ y $\left.80{ }^{\circ} \mathrm{C}\right)$. 


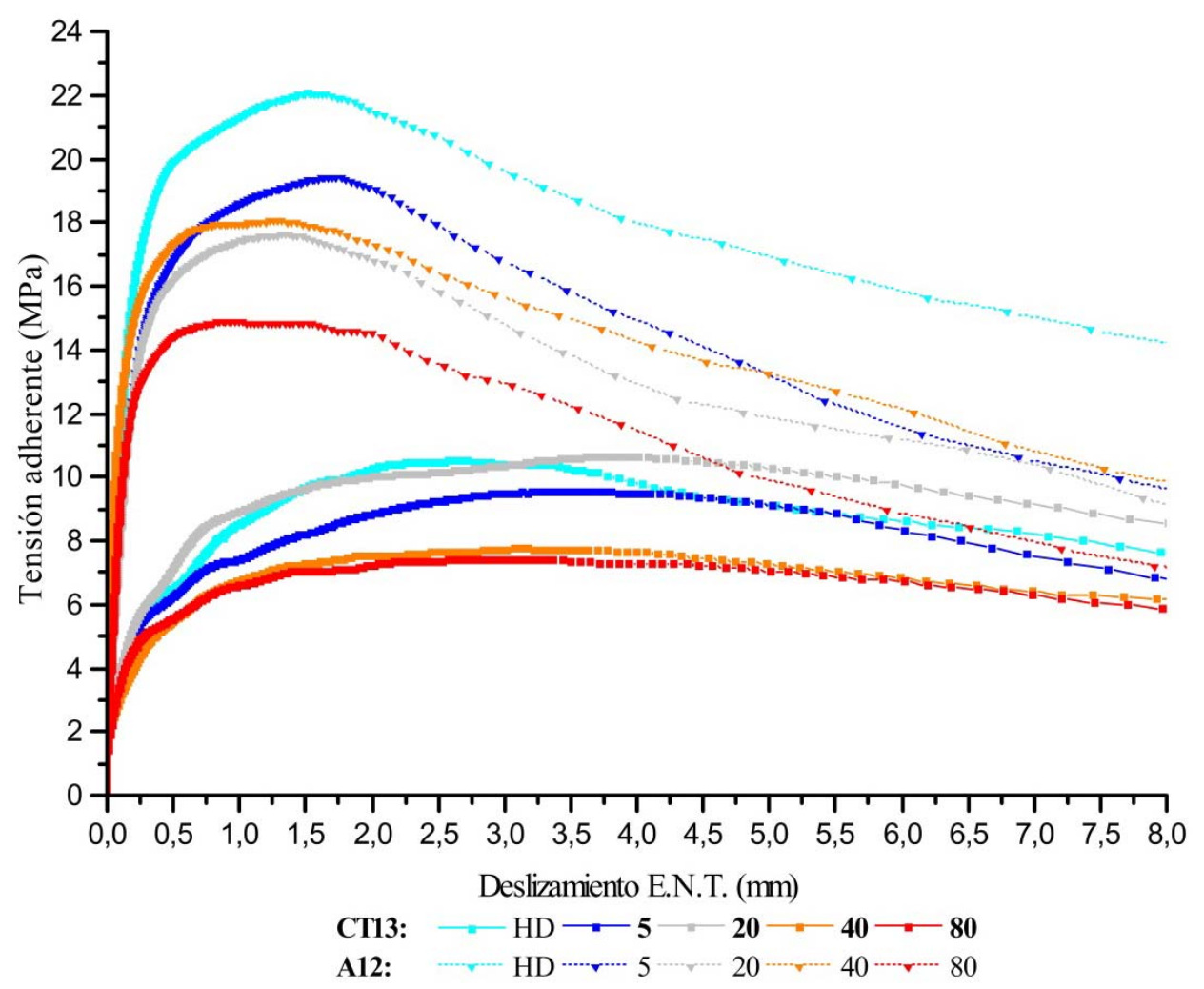

Fig. 4.77. Comparativa del comportamiento adherente entre las barras de CFRP corrugadas CT13y acero corrugadas A12.

Respecto a la influencia de cada temperatura en el comportamiento adherente de ambos timpos de barras, se puede considerar que:

- Las temperaturas frias de $-20^{\circ} \mathrm{C}$ y $5{ }^{\circ} \mathrm{C}$ producen un incremento de la tensión adherente en ambos tipos de barras. Sin embargo, este incremento es mucho mayor en las barras A12, del orden de $5 \mathrm{MPa}$ respecto a los 2,5 Mpa de las barras CT13 (Tabla 4.39). Este efecto puede ser debido a la mayor influencia de la resistencia del hormigón en la tensión adherente de las barras A12 respecto a las barras CT13, puesto que en este último tipo 
de barras la tensión adherente depende en gran medida del diseño de la geometría superficial (véase apart. 4.1.3).

- Las temperaturas medias, de $20^{\circ} \mathrm{C}$ y $40{ }^{\circ} \mathrm{C}$, y elevadas de $80{ }^{\circ} \mathrm{C}$ producen, en los dos tipos de barras, efectos diferentes en la tensión adherente. Puesto que en las barras CT13 la tensión adherente es similar en todas estas temperaturas, en cambio, en las barras A12 las altas temperaturas producen una disminución de la tensión adherente (Tabla 4.39 y Fig. 4.77). Esta diferencia de comportamiento entre ambos tipos de barras se debe a que la tensión adherente de las barras CT13 depende en mayor medida diseño de su geometría superficial.

- Las barras de CFRP texturizadas CT13 desarrollan a cualquier temperatura una menor tensión adherente que las barras de acero corrugadas, alrededor del 50-60\% de A12 (Tabla 4.39 y Fig. 4.77).

- El comportamiento adherente de las barras de CFRP texturizadas es menos rígido que el de las barras de acero corrugado. Puesto que en todas las temperaturas estudiadas las barras CT13 desarrollan un mayor deslizamiento a misma tensión adherente (Fig. 4.77). Además, la rigidez adherente de las barras CT13 es menor a la desarrollada por las barras A12, del orden del 20-40\% menor (Tabla. 4.41).

\begin{tabular}{|c|c|c|c|}
\hline \multirow[b]{2}{*}{ Temperatura } & \multicolumn{2}{|c|}{ Rigidez adherente } & \multirow[b]{2}{*}{$(1) /(2)$} \\
\hline & $\begin{array}{l}\text { CT13 } \\
\text { (1) }\end{array}$ & $\begin{array}{c}\text { A12 } \\
(2)\end{array}$ & \\
\hline $\begin{array}{l}\text { Media todas } \\
\text { temperaturas }\end{array}$ & 5,64 & 10,25 & $55 \%$ \\
\hline$-20^{\circ} \mathrm{C}$ & 7,11 & 12,41 & $57 \%$ \\
\hline $5^{\circ} \mathrm{C}$ & 5,70 & 11,96 & $47 \%$ \\
\hline $20^{\circ} \mathrm{C}$ & 5,88 & 7,12 & $82 \%$ \\
\hline $40^{\circ} \mathrm{C}$ & 4,78 & 11,31 & $42 \%$ \\
\hline $80^{\circ} \mathrm{C}$ & 4,79 & 8,27 & $57 \%$ \\
\hline
\end{tabular}

Tabla. 4.41. Rigidez adherente de las barras de CFRP corrugadas CC12 y acero corrugadas A12. 
Respecto al comportamiento adherente tras la rotura, se observa que las barras de CFRP texturizadas poseen un comportamiento más ductil que las barras de acero corrugado. Este efecto se observa en la gráfica de tensión adherente-deslizamiento donde tras la rotura adherente la tensión adherente residual de las barras CT13 permanece a un nivel de tensión similar a la tensión adherente máxima (Fig. 4.77). Al mismo tiempo, se observa que las barras de CFRP texturizadas desarrollan una menor tensión residual que las barras A12 (Fig. 4.78). Por el contrario, también se observa que a deslizamiento elevado la tensión residual de ambos tipos de barras es similar (Fig. 4.77).

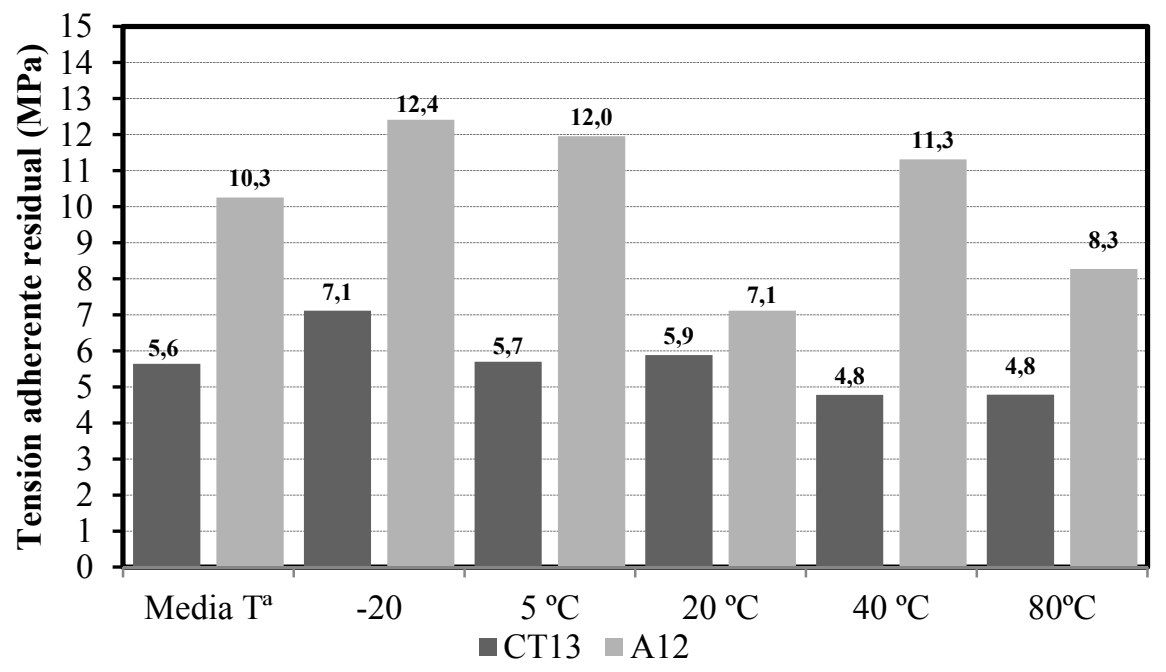

Fig. 4.78. Tensión adherente residual a diferentes temperaturas de las barras de CFRP texturizadas CT13 y acero corrugadas A12.

\subsubsection{Resistencia del Hormigón.}

En este apartado se analiza la influencia de la resistencia a compresión del hormigón " $f_{c}$ " en el comportamiento adherente. La resistencia del hormigón empleado en esta investigación oscila entre 35 y $45 \mathrm{MPa}$ (Tabla 4.42). 


\begin{tabular}{|c|c|c|c|c|c|c|c|c|c|}
\hline \multirow{2}{*}{ Lote } & \multirow{2}{*}{$\begin{array}{c}\text { Temperatura } \\
\left({ }^{\circ} \mathrm{C}\right)\end{array}$} & \multirow{2}{*}{$\begin{array}{c}f_{c} \\
(\mathbf{M P a})\end{array}$} & \multicolumn{7}{|c|}{ Tensión adherente máxima (MPa) } \\
\hline & & & CA8 & CA14 & CC12 & CT13 & $\mathbf{A 8}$ & A12 & A16 \\
\hline 4 & -20 & 37,6 & 9,28 & 16,19 & 19,26 & 10,51 & 16,12 & 23,03 & 27,59 \\
\hline 8 & -20 & 39,6 & 13,18 & 16,95 & 20,72 & 10,13 & 23,47 & 19,61 & 24,04 \\
\hline 12 & -20 & 35,7 & 11,51 & 17,16 & 19,10 & 10,27 & 19,30 & 22,08 & 20,91 \\
\hline 16 & -20 & 37,3 & 10,59 & 16,20 & 22,38 & 11,24 & 24,11 & 18,84 & 25,29 \\
\hline 18 & -20 & 37,1 & 13,24 & 18,21 & 21,19 & 9,98 & 20,72 & 25,07 & 24,15 \\
\hline 3 & 5 & 40,9 & 8,41 & 14,93 & 24,56 & 12,18 & 16,76 & 19,42 & 26,98 \\
\hline 9 & 5 & 37,7 & 11,94 & 15,70 & 17,07 & 8,33 & 12,32 & 19,70 & 18,38 \\
\hline 20 & 5 & 42,6 & 10,78 & 15,56 & 20,30 & 5,86 & 20,27 & 17,28 & 23,59 \\
\hline 23 & 5 & 42,3 & 11,43 & 14,66 & 21,60 & 9,55 & 22,04 & 17,03 & 25,55 \\
\hline 24 & 5 & 40,7 & 11,72 & 16,28 & 19,30 & 6,80 & 18,07 & 23,19 & 23,89 \\
\hline 1 & 20 & 34,9 & 9,13 & 10,80 & 17,20 & 5,24 & 14,88 & 15,40 & 17,03 \\
\hline 5 & 20 & 44,6 & 8,48 & 14,61 & 20,94 & 6,82 & 21,97 & 20,36 & 25,23 \\
\hline 11 & 20 & 36,8 & 8,97 & 12,32 & 18,18 & 5,45 & 13,96 & 17,62 & 17,86 \\
\hline 14 & 20 & 37,1 & 7,98 & 13,72 & 17,04 & 11,39 & 18,93 & 14,27 & 23,39 \\
\hline 22 & 20 & 42,3 & 11,19 & 14,85 & 19,49 & 10,64 & 17,84 & 15,87 & 20,15 \\
\hline 2 & 40 & 38,1 & 8,20 & 12,01 & 20,00 & 8,72 & 15,10 & 19,86 & 20,97 \\
\hline 7 & 40 & 36,7 & 7,52 & 11,23 & 17,55 & 6,62 & 15,72 & 18,05 & 17,88 \\
\hline 13 & 40 & 39,0 & 7,90 & 13,83 & 17,58 & 8,03 & 14,29 & 17,28 & 19,45 \\
\hline 15 & 40 & 38,4 & 7,38 & 10,12 & 17,05 & 6,02 & 13,87 & 19,13 & 15,95 \\
\hline 19 & 40 & 39,3 & 6,36 & 10,73 & 18,99 & 7,74 & 14,14 & 18,23 & 20,04 \\
\hline 6 & 80 & 39,6 & 7,21 & 11,80 & 12,38 & 7,15 & 10,00 & 16,32 & 15,93 \\
\hline 10 & 80 & 38,7 & 8,81 & 11,39 & 11,77 & 5,78 & 10,16 & 13,54 & 16,88 \\
\hline 17 & 80 & 41,0 & 6,19 & 10,66 & 13,10 & 7,34 & 15,06 & 14,92 & 16,05 \\
\hline 21 & 80 & 39,8 & 8,28 & 13,97 & 11,49 & 7,84 & 12,29 & 15,00 & 17,00 \\
\hline 25 & 80 & 43,3 & 5,73 & 13,97 & 13,55 & 7,41 & 11,36 & 16,69 & 17,63 \\
\hline
\end{tabular}

Tabla. 4.42. Resultados de ensayos de resistencia a compresión del hormigón.

\section{- Barras de CFRP arenadas:}

En las barras de CFRP arenadas (CA8 y CA14) se puede considerar, para el rango de resistencias a compresión estudiadas, que la resistencia del hormigón no produce estadísticamente ningún efecto en la tensión adherente máxima, valor de probabilidad mayor a 0,05 (Tablas 4.43-4.44 y Figs. 4.794.80). Este resultado confirma las conclusiones realizadas en los apartados 4.1.1 y 4.1.2, en las cuales se deduce que la tensión adherente máxima de este tipo de barras de CFRP arenadas depende de la resistencia de la resina polimérica de la 
barra, puesto que en todas las temperaturas y resistencias de hormigón estudiadas la rotura adherente se produce por rotura de la adherencia entre la capa de arenado y el núcleo de la barra (Figs. 4.41 y 4.47).

\begin{tabular}{|c|c|c|c|c|c|}
\hline Fuente & $\begin{array}{c}\text { Suma de } \\
\text { Cuadrados }\end{array}$ & $G l$ & $\begin{array}{c}\text { Cuadrado } \\
\text { Medio }\end{array}$ & Razón-F & Valor-P \\
\hline \multicolumn{6}{|l|}{ EFECTOS PRINCIPALES } \\
\hline A:Temperatura $\left({ }^{\circ} \mathrm{C}\right)$ & 61,2763 & 4 & 15,3191 & 7,10 & 0,0045 \\
\hline B:Resistencia a compresión (MPa) & 11,0237 & 9 & 1,22485 & 0,57 & 0,7980 \\
\hline RESIDUOS & 23,7427 & 11 & 2,15843 & & \\
\hline TOTAL (CORREGIDO) & 110,306 & 24 & & & \\
\hline
\end{tabular}

Tabla. 4.43. Análisis de Varianza Multifactorial en el tipo de barra CA8 de la variable dependiente tensión adherente y las variables independientes Temperatura $\left(-20,5,20,40\right.$ y $\left.80{ }^{\circ} \mathrm{C}\right)$ y resistencia a compresión del hormigón (35-45 MPa).

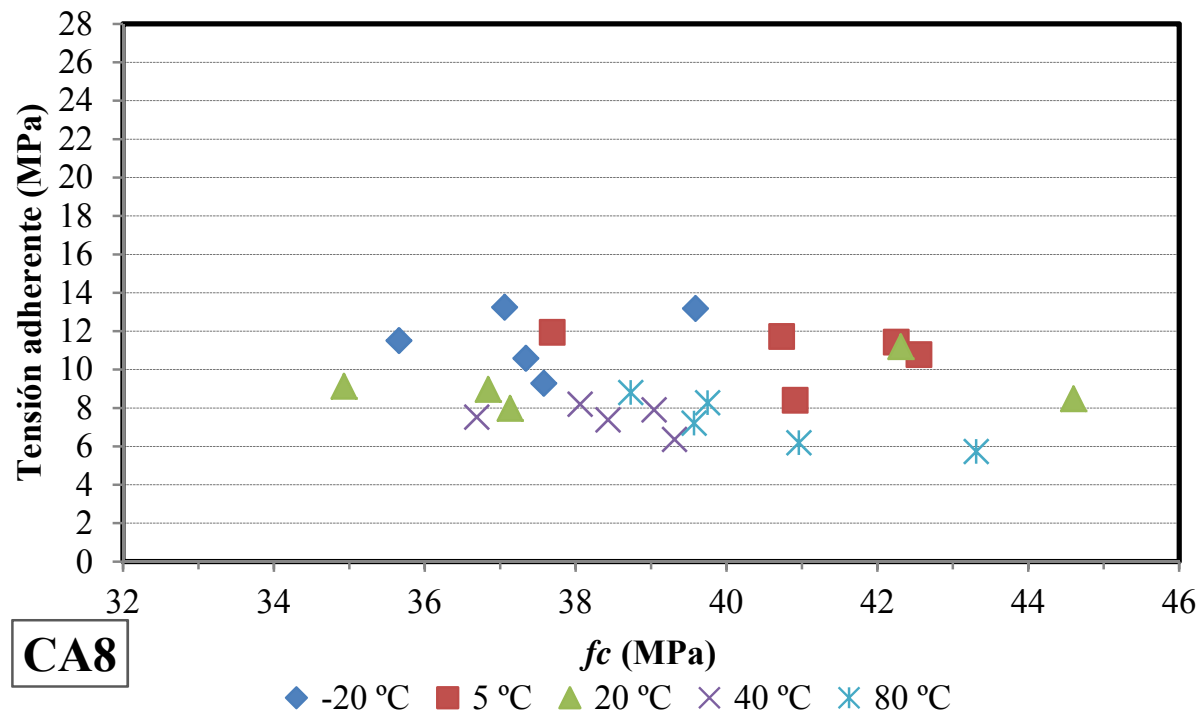

Fig. 4.79. Relación entre la resistencia a compresión del hormigón y la tensión adherente máxima de las barras CA8.

\begin{tabular}{|c|c|c|c|c|c|}
\hline Fuente & $\begin{array}{c}\text { Suma de } \\
\text { Cuadrados }\end{array}$ & $G l$ & $\begin{array}{c}\text { Cuadrado } \\
\text { Medio }\end{array}$ & Razón-F & Valor-P \\
\hline \multicolumn{6}{|l|}{ EFECTOS PRINCIPALES } \\
\hline A:Temperatura $\left({ }^{\circ} \mathrm{C}\right)$ & 74,5566 & 4 & 18,6391 & 9,81 & 0,0012 \\
\hline B:Resistencia a compresión (MPa) & 12,5805 & 9 & 1,39783 & 0,74 & 0,6721 \\
\hline RESIDUOS & 20,8933 & 11 & 1,89939 & & \\
\hline TOTAL (CORREGIDO) & 132,138 & 24 & & & \\
\hline
\end{tabular}

Tabla. 4.44. Análisis de Varianza Multifactorial en el tipo de barra CA14 de la variable dependiente tensión adherente y las variables independientes Temperatura $\left(-20,5,20,40\right.$ y $\left.80{ }^{\circ} \mathrm{C}\right)$ y resistencia a compresión del hormigón (35-45 MPa). 


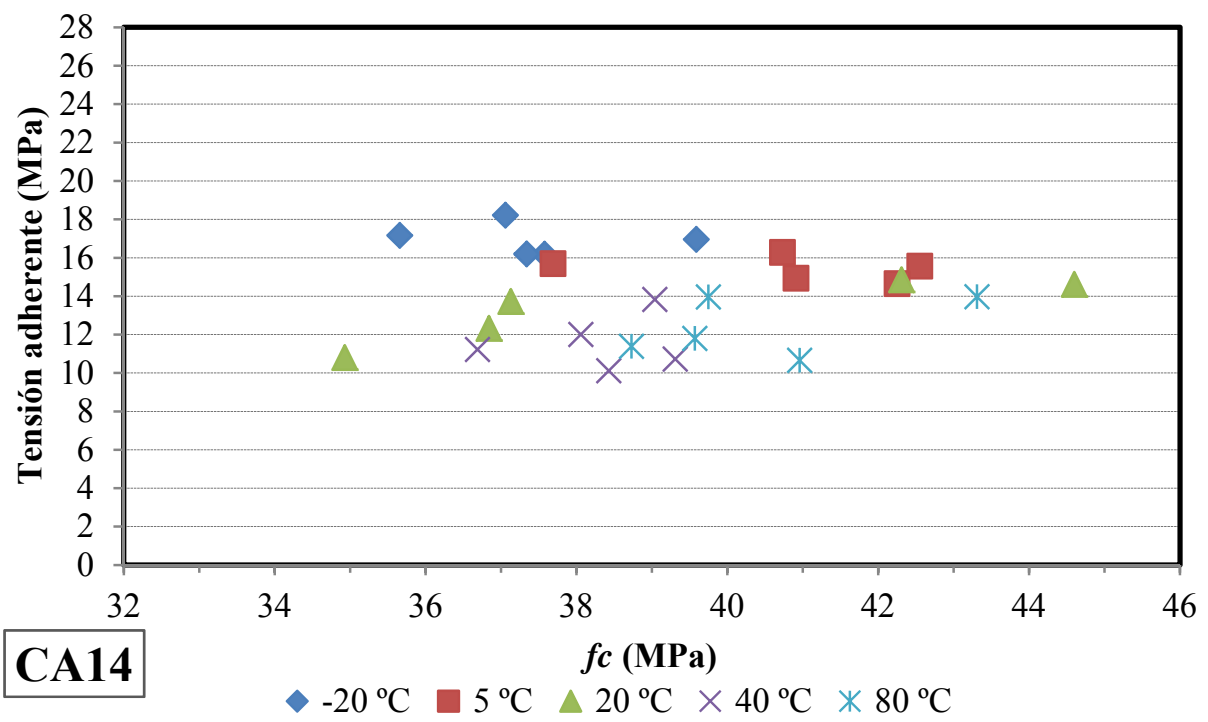

Fig. 4.80. Relación entre la resistencia a compresión del hormigón y la tensión adherente máxima de las barras CA14.

Este resultado es similar al obtenido en las investigaciones realizadas por Achillides et al. (2004) y Tepfers (2006), en las cuales se afirma que a partir de una $f_{c}$ de 30 o $40 \mathrm{MPa}$ la tensión adherente máxima de las barras de CFRP arenadas no depende de la resistencia a compresión del hormigón.

\section{- Barras de CFRP corrugadas:}

En el caso de las barras de CFRP corrugadas (CC12) se observa en el rango de temperaturas desde $-20^{\circ} \mathrm{C}$ a $20^{\circ} \mathrm{C}$ que hay una cierta tendencia a incrementar la tensión adherente a medida que se incrementa la resistencia del hormigón (Fig. 4.81). Por contra, a temperaturas elevadas entre $40{ }^{\circ} \mathrm{C}$ y $80{ }^{\circ} \mathrm{C}$ esta tendencia no se produce, debido a la mayor influencia de la temperatura en la resistencia de la resina polimérica de las corrugas de la barra respecto a la resistencia a corte del hormigón entre corrugas. Sin embargo, se puede considerar, estadísticamente con un nivel de confianza del $95 \%$, que para el rango de resistencias a compresión estudiadas (35 a $45 \mathrm{MPa}$ ) la tensión adherente máxima no depende de la resistencia del hormigón (Tabla 4.45). 


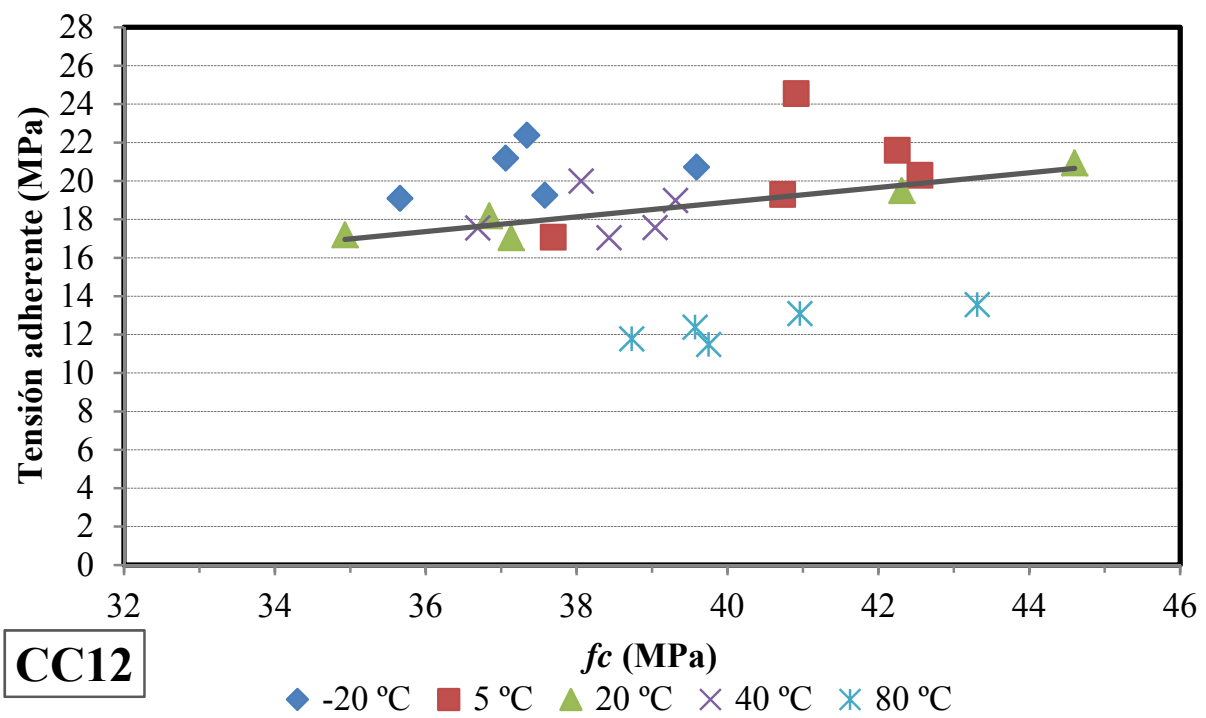

Fig. 4.81. Relación entre la resistencia a compresión del hormigón y la tensión adherente máxima de las barras $\mathrm{CC} 12$.

\begin{tabular}{llllll}
\multicolumn{1}{c}{ Fuente } & $\begin{array}{c}\text { Sumade } \\
\text { Cuadrados }\end{array}$ & Gl & $\begin{array}{c}\text { Cuadrado } \\
\text { Medio }\end{array}$ & Razón-F & Valor-P \\
\cline { 1 - 1 } EFECTOS PRINCIPALES & & & & & \\
\hline A:Temperatura $\left({ }^{\circ} \mathrm{C}\right)$ & 172,874 & 4 & 43,2184 & 16,78 & 0,0001 \\
\cline { 1 - 2 } B:Resistencia a compresión (MPa) & 29,9201 & 9 & 3,32445 & 1,29 & 0,3393 \\
\hline RESIDUOS & 28,3282 & 11 & 2,57529 & & \\
\hline TOTAL (CORREGIDO) & 278,446 & 24 & & & \\
\hline
\end{tabular}

Tabla. 4.45. Análisis de Varianza Multifactorial en el tipo de barra $\mathrm{CC} 12$ de la variable dependiente tensión adherente y las variables independientes Temperatura $\left(-20,5,20,40\right.$ y $\left.80^{\circ} \mathrm{C}\right)$ y resistencia a compresión del hormigón (35-45 MPa).

En cuanto al modo de rotura de las barras de CFRP corrugadas (CC12) se ha comprobado, estadísticamente con un nivel de confianza del $95 \%$, que este depende de la resistencia del hormigón (Tabla 4.46). Puesto que al reducirse dicha resistencia la rotura se produce por el modo combinado "RC", mientras que al incrementarse la resistencia a compresión del hormigón la rotura adherente se produce por corte de las corrugas de la barra de CFRP "RA" (Fig. 4.82). Este resultado confirma las conclusiones obtenidas en el apart. 4.1.2.a "Barras de CFRP corrugadas CC12", en el cual se expone que el modo de rotura 
adherente de las barras CC12 depende de la relación entre la resistencia del hormigón y la resistencia a corte de las corrugas de la barra de CFRP.

\begin{tabular}{|c|c|c|c|c|c|}
\hline \multicolumn{6}{|c|}{ Análisis de Varianza } \\
\hline Fuente & Suma de Cuadrados & $G l$ & Cuadrado Medio & Razón-F & Valor-P \\
\hline Entre grupos & 61,5205 & 1 & 61,5205 & 14,09 & 0,0024 \\
\hline Intra grupos & 56,7704 & 13 & 4,36696 & & \\
\hline Total (Corr.) & 118,291 & 14 & & & \\
\hline
\end{tabular}

\begin{tabular}{|c|c|c|c|}
\hline \multicolumn{4}{|c|}{ Test de Contraste Múltiple de Rango } \\
\hline & recuencia & Media $(M P a)$ & Grupos Homogéneos \\
\hline $\mathrm{RC}$ & 9 & 37,49 & $\mathrm{X}$ \\
\hline RA & 6 & 41,62 & $\mathrm{x}$ \\
\hline Contraste & Sig & Diferencia & +/- Limites \\
\hline $\mathrm{RA}-\mathrm{RC}$ & $\mathrm{C}$ & 4,13389 & 2,3794 \\
\hline
\end{tabular}

Tabla. 4.46. Análisis del modo de rotura en función de la resistencia a compresión del hormigón en las barras de CFRP corrugadas CC12: ANOVA y test de Contraste Múltiple de Rango.

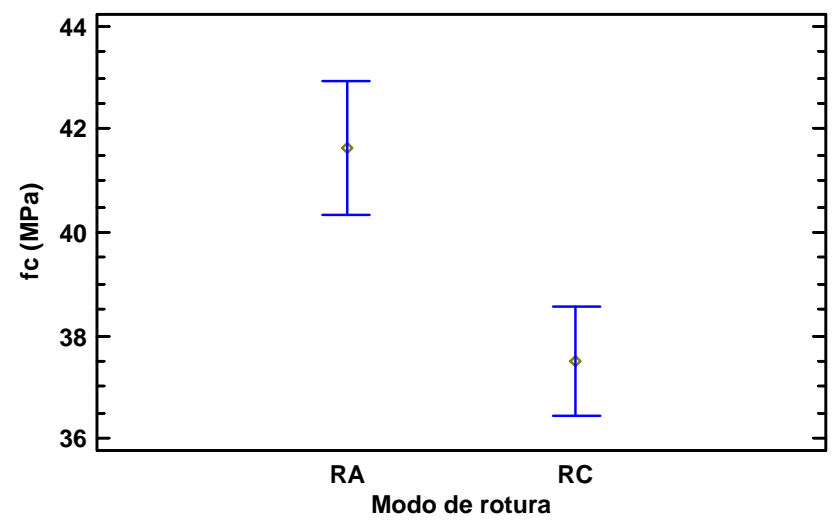

Fig. 4.82. Gráfico de medias del ANOVA de la variable dependiente resistencia del hormigón respecto de la variable independiente modo de rotura, en las barras $\mathrm{CC} 12$.

Al mismo tiempo, se comprueba que la tensión adherente de las barras de CFRP corrugadas depende del modo de rotura (Tabla 4.47), produciéndose una mayor tensión adherente cuando la rotura se produce por corte de las corrugas de la barra de CFRP "RA" que cuando la rotura es por el modo combinado "RC" (Fig. 4.83). Este efecto puede explicarse al considerar una resistencia similar de la resina polimérica de las corrugas de la barra de CFRP, 
que al incrementar la resistencia del hormigón por encima de la dicha resistencia produce el agotamiento completo de la misma por corte de las corrugas de la barra. En cambio, cuando la resistencia del hormigón es menor, la resina polimérica no llega a agotarse debido a que el agotamiento se produce por rotura del hormigón.

\begin{tabular}{|c|c|c|c|c|c|}
\hline Fuente & $\begin{array}{c}\text { Suma de } \\
\text { Cuadrados }\end{array}$ & $G l$ & $\begin{array}{c}\text { Cuadrado } \\
\text { Medio }\end{array}$ & Razón-F & Valor-P \\
\hline \multicolumn{6}{|l|}{ EFECTOS PRINCIPALES } \\
\hline A:Temperatura $\left({ }^{\circ} \mathrm{C}\right)$ & 24,8485 & 2 & 12,4242 & 4,33 & 0,0410 \\
\hline B:Resistencia a compresión (MPa) & 17,6756 & 1 & 17,6756 & 6,16 & 0,0305 \\
\hline RESIDUOS & 31,5612 & 11 & 2,8692 & & \\
\hline TOTAL (CORREGIDO) & 62,2679 & 14 & & & \\
\hline
\end{tabular}

Tabla. 4.47. Análisis de Varianza Multifactorial en el tipo de barra $\mathrm{CC} 12$ de la variable dependiente tensión adherente y las variables independientes temperatura $\left(-20,5,20,40\right.$ y $\left.80^{\circ} \mathrm{C}\right)$ y modo de rotura (MA y MC).

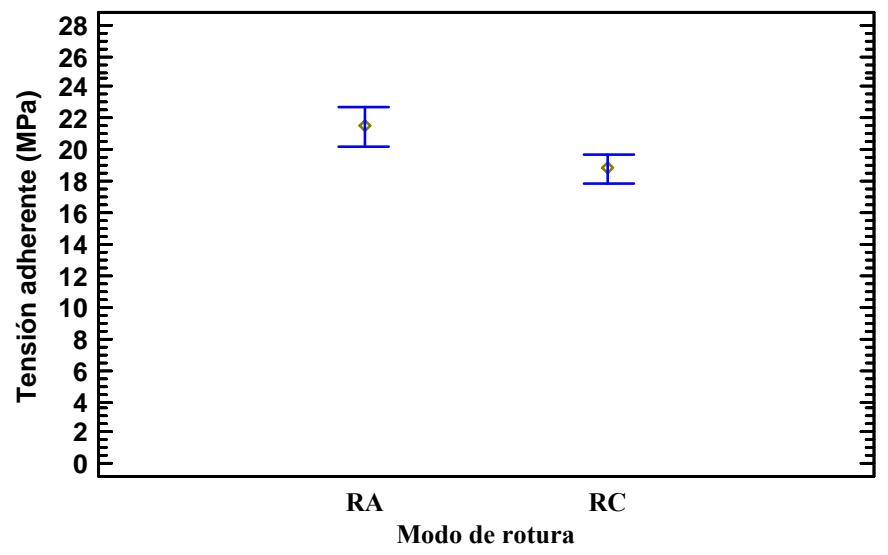

Fig. 4.83. Gráfico de medias del ANOVA de la variable dependiente tensión adherente respecto de la variable independiente modo de rotura, en las barras de CFRP corrugadas. RA es el modo de rotura por corte de las corrugas y RC por el modo combinado.

\section{- Barras de CFRP texturizadas:}

En cuanto a las barras de CFRP texturizadas (CT13) se puede considerar, para el rango de resistencias a compresión del hormigón de 35 a 45 MPa, que la tensión adherente no depende de la resistencia del hormigón (Tabla 4.48 y Fig. 4.84). Este resultado puede ser debido, a que para que para el rango 
de resistencias analizado, la tensión adherente de este tipo de barras depende en mayor medida del diseño de la geometría superficial que de la resistencia del hormigón (véase aparts. 4.1.1 y 4.1.2), puesto que las corrugas de hormigón originadas por el diseño de la geometria de la barra son de escasa dimensión, requiriendo un hormigón con elevada resistencia para absorber las tensiónes transmitidas por la barra. En futuras líneas de investigación se podría evaluar la dependencia de la tensión adherente respecto a hormigones de elevada resistencia, que podrían producir una mayor resistencia a las tensiones de acuñamiento de la barra.

\begin{tabular}{|c|c|c|c|c|c|}
\hline Fuente & $\begin{array}{c}\text { Suma de } \\
\text { Cuadrados }\end{array}$ & $G l$ & $\begin{array}{c}\text { Cuadrado } \\
\text { Medio }\end{array}$ & Razón-F & Valor- $P$ \\
\hline \multicolumn{6}{|l|}{ EFECTOS PRINCIPALES } \\
\hline A:Temperatura $\left({ }^{\circ} \mathrm{C}\right)$ & 23,4029 & 4 & 5,85072 & 1,46 & 0,2783 \\
\hline B:Resistencia a compresión (MPa) & 22,6705 & 9 & 2,51894 & 0,63 & 0,7512 \\
\hline RESIDUOS & 43,9579 & 11 & 3,99618 & & \\
\hline TOTAL (CORREGIDO) & 101,276 & 24 & & & \\
\hline
\end{tabular}

Tabla. 4.48. Análisis de Varianza Multifactorial en el tipo de barra CT13 de la variable dependiente tensión adherente y las variables independientes temperatura $\left(-20,5,20,40\right.$ y $\left.80^{\circ} \mathrm{C}\right)$ y resistencia a compresión (35-45 $\mathrm{MPa})$.

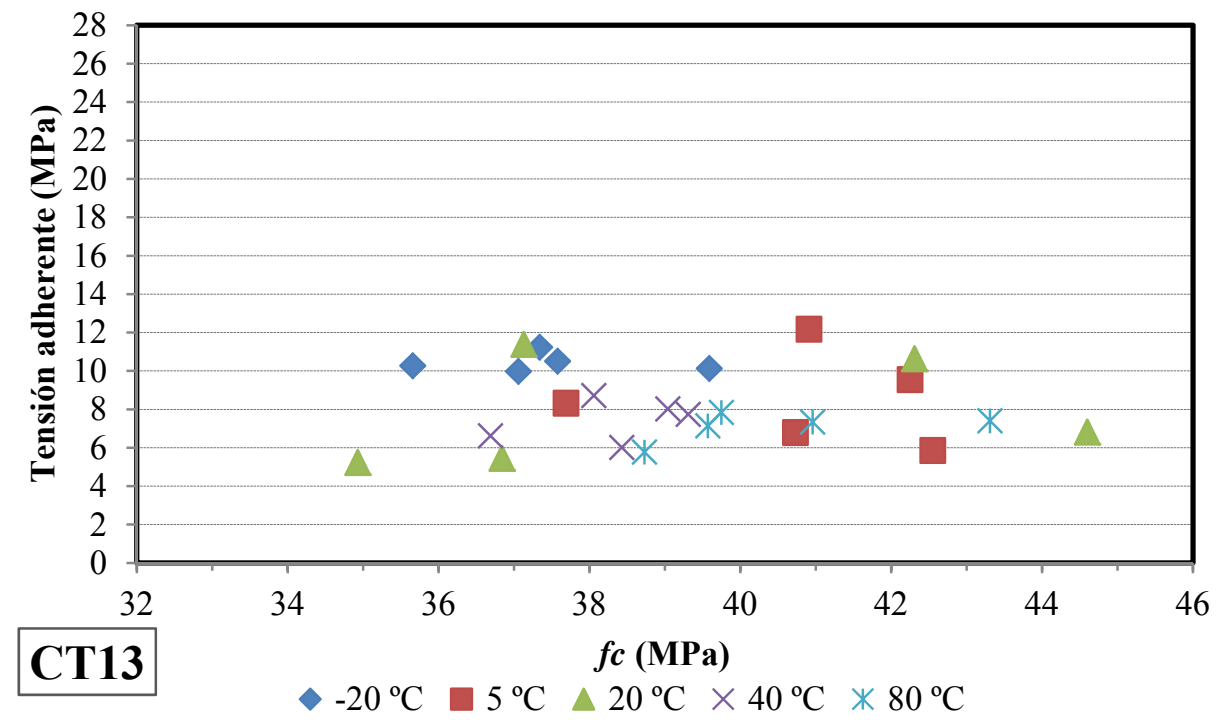

Fig. 4.84. Relación entre la resistencia a compresión del hormigón y la tensión adherente máxima de las barras CT13. 


\subsubsection{Diámetro de las Barras}

En este apartado se analiza la influencia del diámetro equivalente de las barras de CFRP y acero corrugado en el comportamiento adherente. Sin embargo, debido a que en las barras de CFRP corrugadas y texturizadas tan solo se dispone de un diámetro por tipo de barra, únicamente es posible el cálculo de la influencia del diámetro en las barras de CFRP arenadas y en las barras de acero corrugadas. El diámetro equivalente de ambos tipos de barras se define en la Tabla 4.49 .

\begin{tabular}{cc}
\hline Tipo de barras & Diámetro equivalente $(\mathrm{mm})$ \\
\hline CFRP arenadas CA8 & 8,27 \\
\cline { 1 - 1 } CFRP arenadas CA14 & 13,69 \\
\cline { 1 - 1 } Acero corrugado A8 & 8 \\
\cline { 1 - 2 } Acero corrugado A12 & 12 \\
\cline { 1 - 2 } Acero corrugado A16 & 16
\end{tabular}

Tabla. 4.49. Diámetro equivalente de las barras de CFRP arenadas y acero corrugado.

En cuanto a las barras de CFRP arenadas, se observa que el diámetro no influye en el comportamiento adherente hasta tensión adherente máxima (Fig. 4.85), puesto que en ambos tipos de barras: la pendiente asecendente de la gráfica tensión adherente-deslizamiento posee la misma inclinación (Fig. 4.84) y la adhesión química generada por los dos diámetros presenta valores estadísticamente similares (Fig. 4.86).
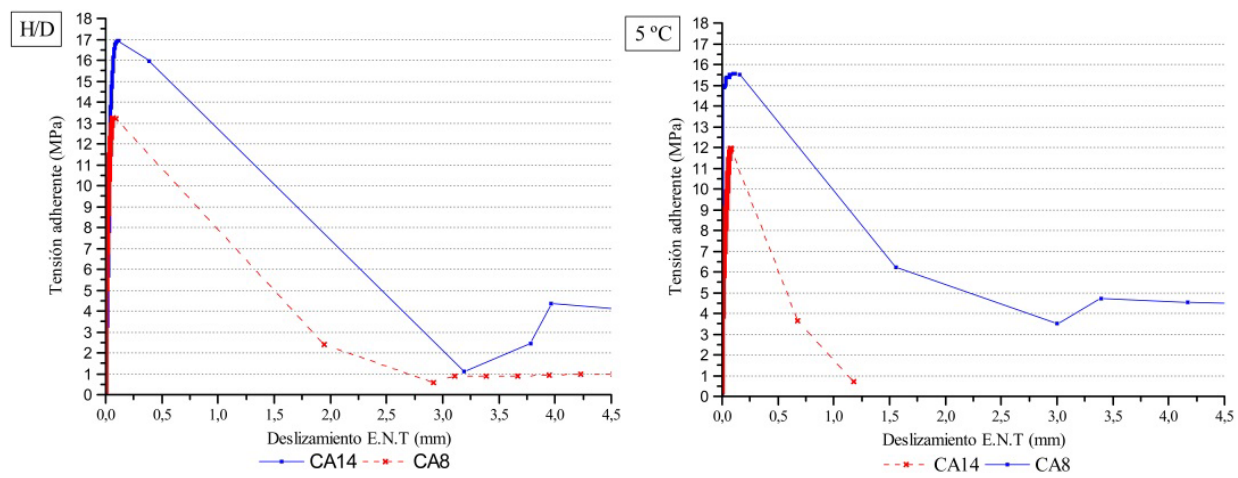

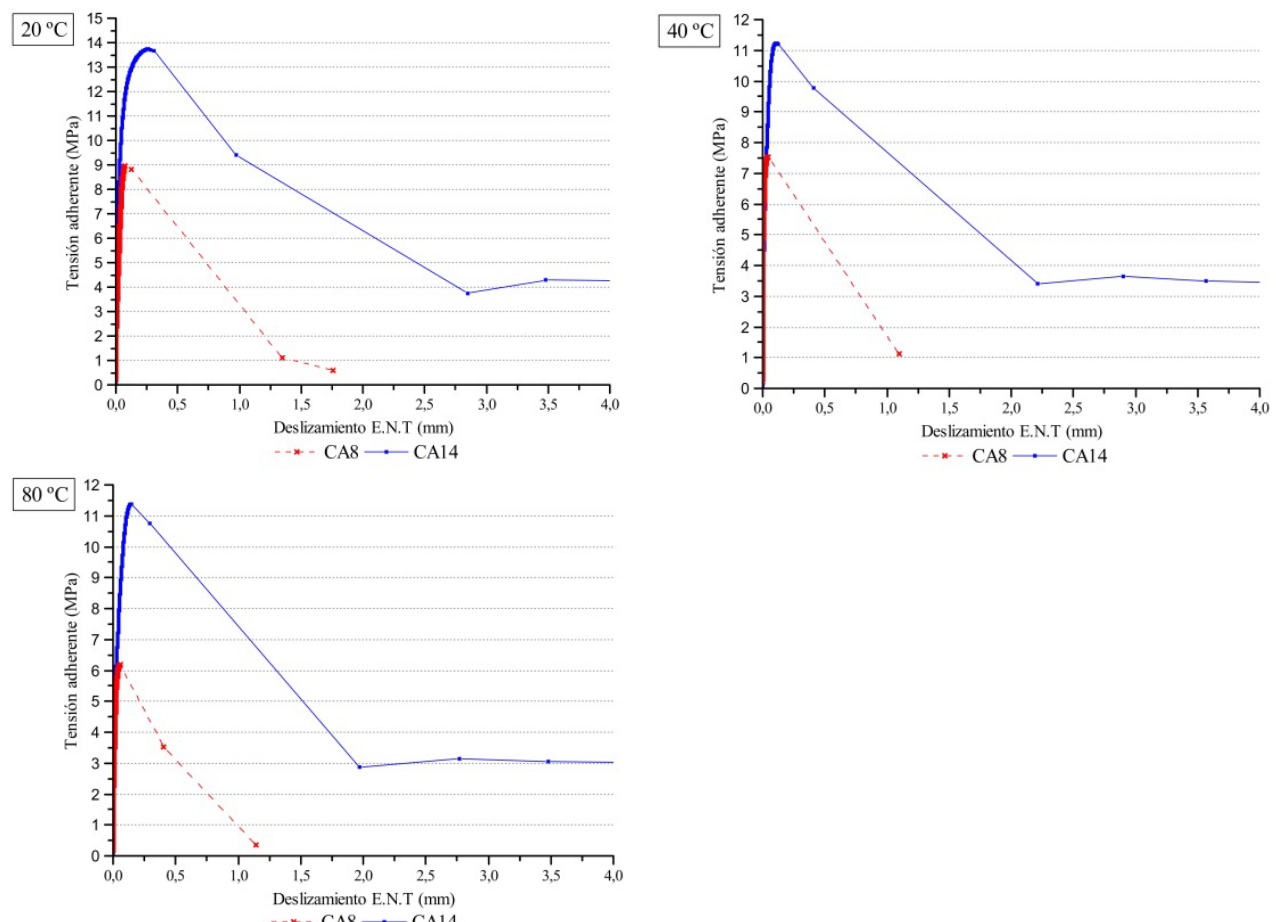

Fig. 4.85. Comporamiento adherente de las barras de CFRP arenadas según su diámetro.

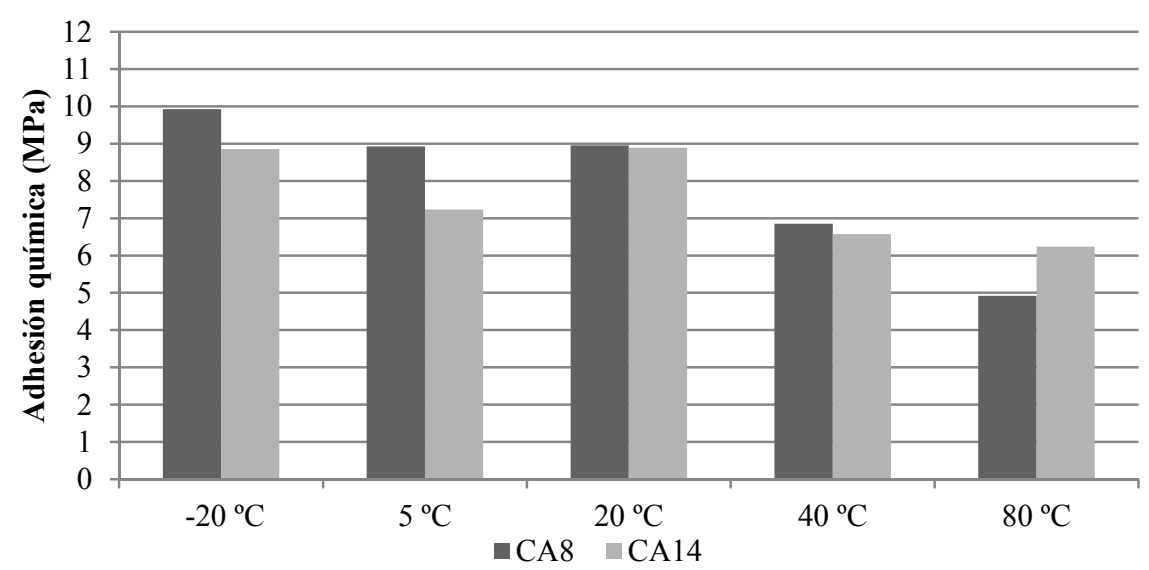

Fig. 4.86. Adhesión química de las barras de CFRP arenadas según su diámetro.

Sin embargo, la tensión adherente máxima de este tipo de barras de CFRP varía dependiendo del diámetro. Puesto que se comprueba estadísticamente, con un nivel de confianza del $95 \%$, que las barras de mayor 
diámetro "CA14" producen una tensión adherente mayor que las barras de menor diámetro "CA8" (Tabla 4.50 y 4.51). Este efecto puede ser debido, tal y como se observa en las imágenes de microscopia digital (Fig. 4.87), al mayor espesor de la capa de resina polimérica que adhiere el núcleo a la capa de arenado superficial, que produce una mayor resistencia; puesto en este tipo de barras de CFRP la tensión adherente máxima depende de la resistencia de dicha resina polimérica (véase aparts. 4.1.1.a y 4.1.2.a).

\begin{tabular}{|c|c|c|c|}
\hline \multirow[b]{2}{*}{ Temperatura } & \multicolumn{2}{|c|}{$\begin{array}{l}\text { Tensión adherente máxima } \\
(\mathrm{MPa})\end{array}$} & \multirow[b]{2}{*}{$\begin{array}{l}(2)-(1) \\
(\mathrm{MPa})\end{array}$} \\
\hline & $\begin{array}{c}\text { CA8 } \\
(1)\end{array}$ & $\begin{array}{l}\text { CA14 } \\
(2)\end{array}$ & \\
\hline $\begin{array}{l}\text { Media todas } \\
\text { temperaturas }\end{array}$ & 9,26 & 13,91 & 4,66 \\
\hline$-20^{\circ} \mathrm{C}$ & 11,56 & 16,94 & 5,38 \\
\hline $5^{\circ} \mathrm{C}$ & 10,86 & 15,43 & 4,57 \\
\hline $20{ }^{\circ} \mathrm{C}$ & 9,15 & 13,26 & 4,11 \\
\hline $40^{\circ} \mathrm{C}$ & 7,47 & 11,58 & 4,11 \\
\hline $80^{\circ} \mathrm{C}$ & 7,24 & 12,36 & 5,12 \\
\hline
\end{tabular}

Tabla. 4.50. Tensión adherente máxima (valores medios de los 5 ensayos de cada temperatura) de las barras de CFRP arenadas CA8 y CA14.

\begin{tabular}{|c|c|c|c|c|c|}
\hline Fuente & $\begin{array}{c}\text { Suma de } \\
\text { Cuadrados }\end{array}$ & $G l$ & $\begin{array}{c}\text { Cuadrado } \\
\text { Medio }\end{array}$ & Razón-F & Valor-P \\
\hline \multicolumn{6}{|l|}{ EFECTOS PRINCIPALES } \\
\hline A:Diámetro equivalente $(\mathrm{mm})$ & 271,196 & 1 & 271,196 & 158,97 & 0,0000 \\
\hline B:Temperatura $\left({ }^{\circ} \mathrm{C}\right)$ & 170,844 & 4 & 42,7111 & 25,04 & 0,0000 \\
\hline \multicolumn{6}{|l|}{ INTERACCIONES } \\
\hline $\mathrm{AB}$ & 3,35991 & 4 & 0,839978 & 0,49 & 0,7413 \\
\hline
\end{tabular}

\begin{tabular}{|c|c|c|c|}
\hline \multicolumn{4}{|c|}{ Test de Contraste Múltiple de Rango } \\
\hline & Frecuencia & Media $(\mathrm{MPa})$ & Grupos Homogéneos \\
\hline 8,27 & 25 & 9,25578 & $\mathrm{X}$ \\
\hline 13,69 & 25 & 13,9136 & $\mathrm{x}$ \\
\hline \multicolumn{2}{|c|}{ Contraste } & Diferencia & +/- Limites \\
\hline \multicolumn{2}{|c|}{$8,27-13,69$} & $-4,65786$ & 0,746652 \\
\hline
\end{tabular}

Tabla. 4.51. Análisis de la tensión adherente de las barras de CFRP arenadas en función del diámetro equivalente y la temperatura: ANOVA y test de Contraste Múltiple de Rango. 

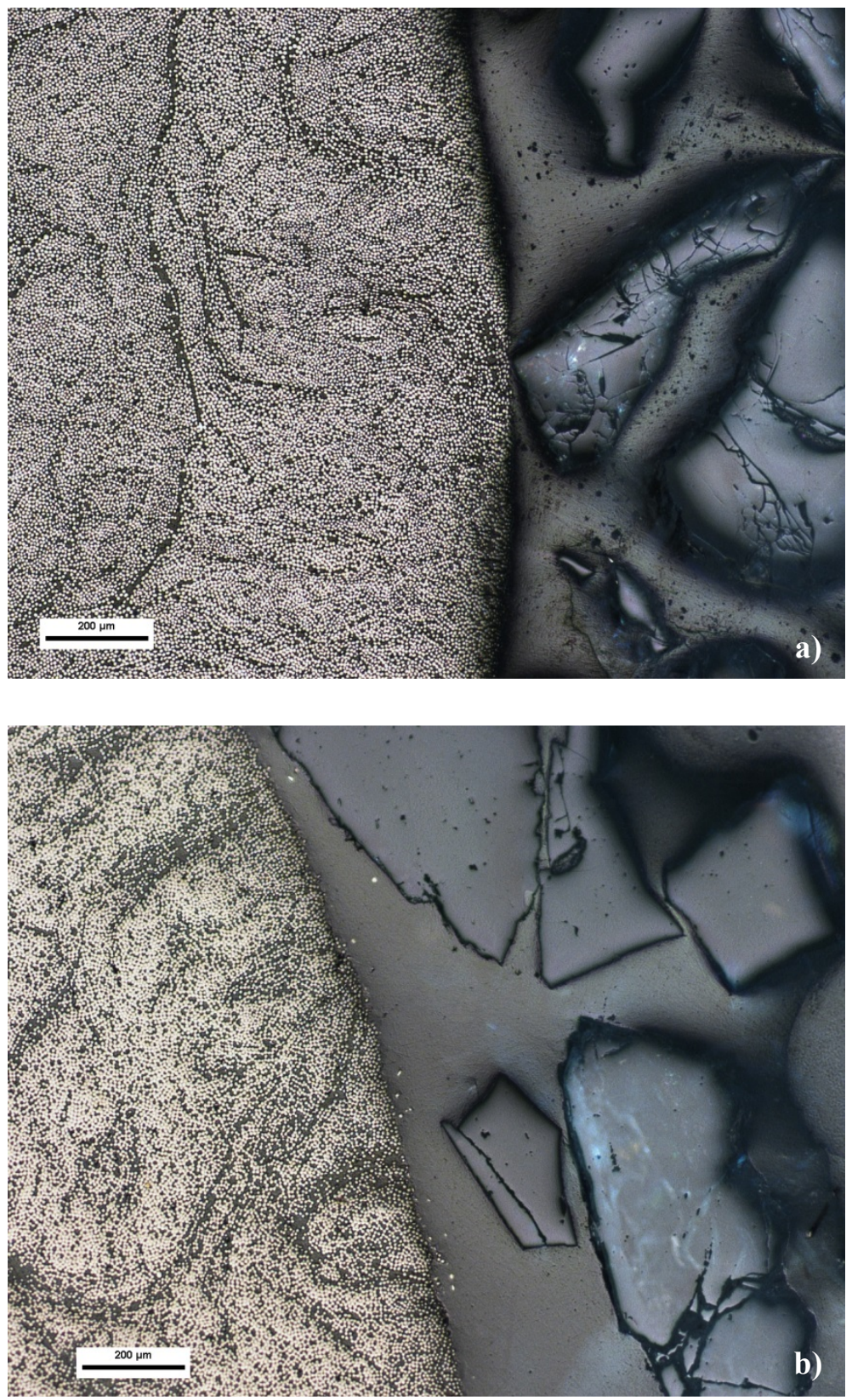

Fig. 4.87. Imágnes de microscopia digital de la interfaz capa de arenado y núcleo de barras de CFRP arenadas (x50): a) Barra CA8 con menor espesor de interfaz; b) Barra CA14 con mayor espesor de interfaz.

Al mismo tiempo, se comprueba que la pérdida de tensión adherente en función de la temperatura en ambos diámetros es similar (Tabla 4.50 y Fig. 
4.88). Este efecto puede ser debido al espesor similar de la capa de arenado, que produce una trasmisión térmica desde la superficie de la barra hasta la interfaz capa de arenado-núcleo del mismo orden, originando una misma influencia (aumento o disminución) en la resistencia de la resina polimérica de la interfaz núcleo-capa de arenado.

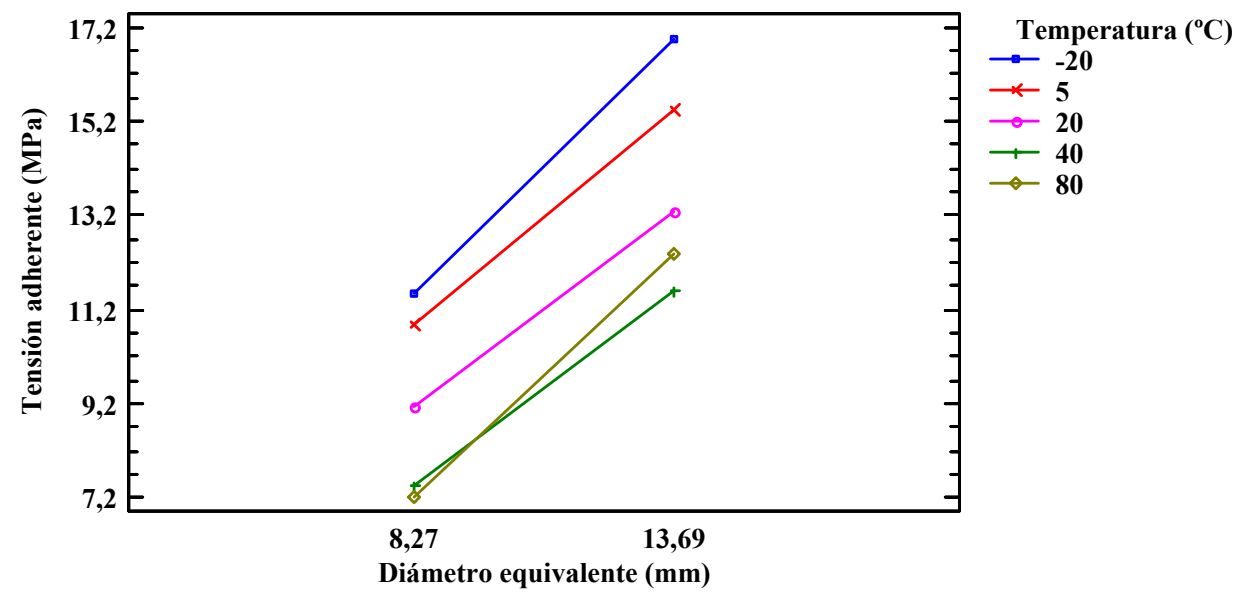

Fig. 4.88. Gráfico de interacciónes entre la temperatura y el diámetro equivalente en la tensión adherente máxima de las barras de CFRP arenadas.

Tras alcanzar la tensión adherente máxima, en ambos diámetros se produce la rotura adherente de un modo frágil, por rotura de la adherencia entre la capa de arenado y el núcleo de la barra. Del mismo modo, se observa que el comportamiento tras la rotura es similar, puesto que la pendiente descendente de la gráfica tensión adherente-deslizamiento en ambos diámetros presenta la misma pendiente (Fig. 4.85). Sin embargo, la tensión adherente residual de las barras CA14 es estadíticamente mayor que la desarrollada por las barra CA8 (Fig. 4.89). 


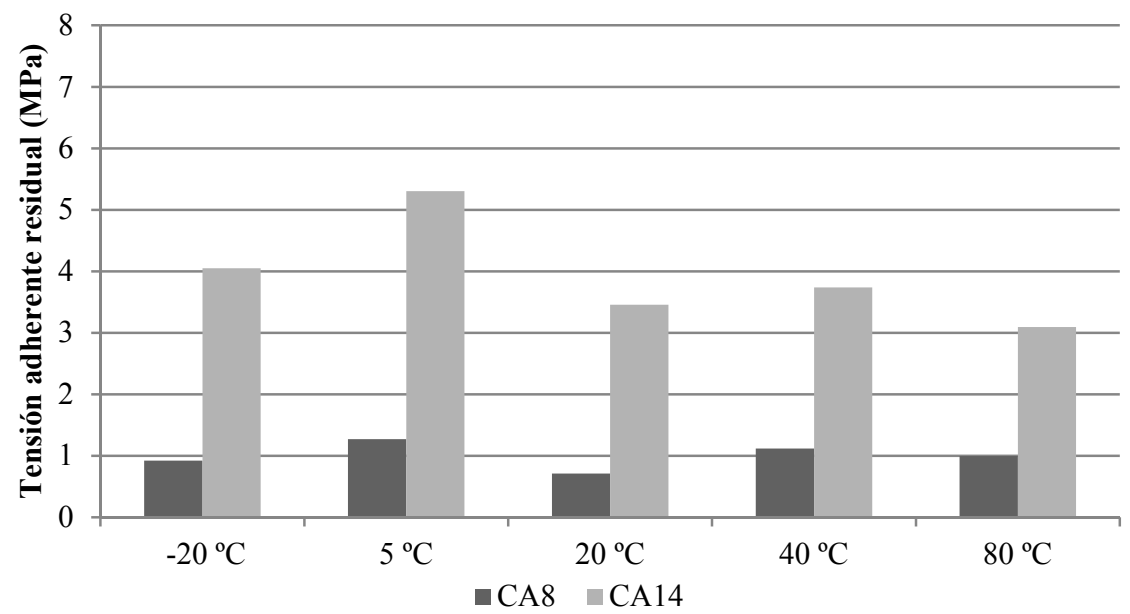

Fig. 4.89. Gráfico de la tensión adherente residual de las barras de CFRP arenadas según su diámetro.

Respecto a las barras de acero corrugadas, se observa, del mismo modo que las barras de CFRP arenadas, que el diámetro no influye en el comportamiento adherente hasta tensión adherente máxima (Fig. 4.90), debido que en los tres tipos de barras la pendiente asecendente de la gráfica tensión adherente-deslizamiento posee la misma inclinación (Fig. 4.90) y la adhesión química generada por los dos diámetros presenta valores estadíticamente similares (Fig. 4.91).
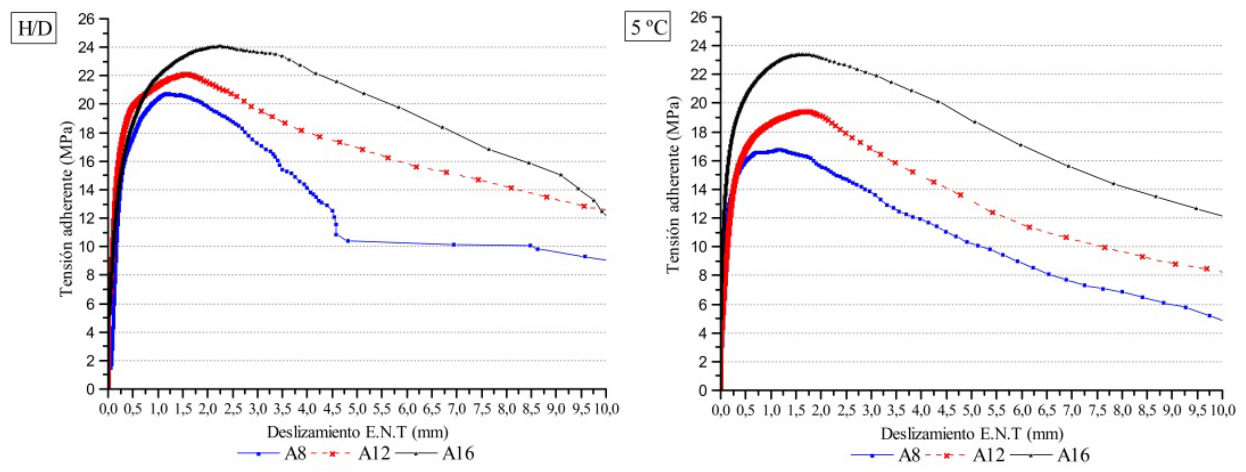

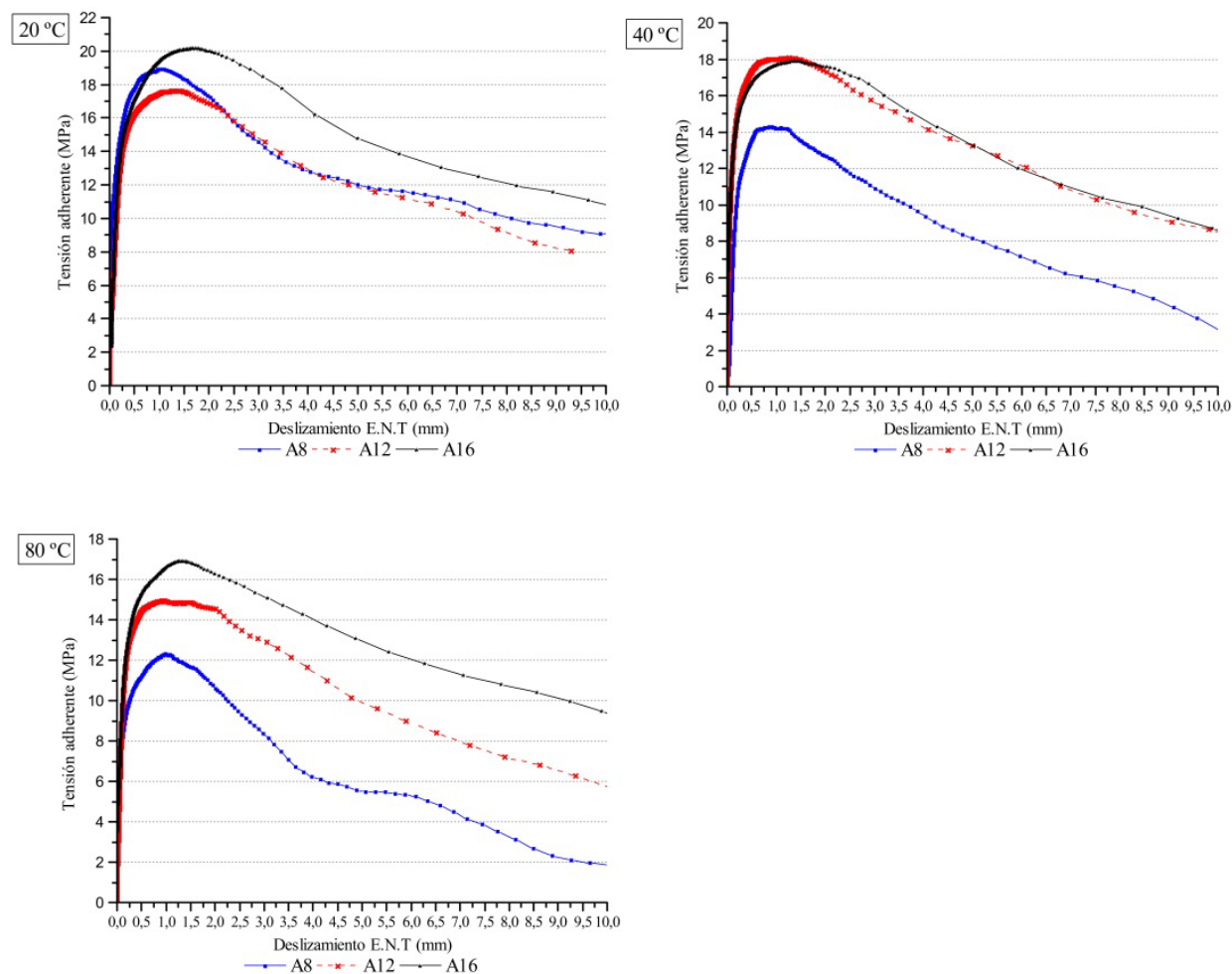

Fig.. 4.90. Comporamiento adherente de las barras de CFRP arenadas según su diámetro.

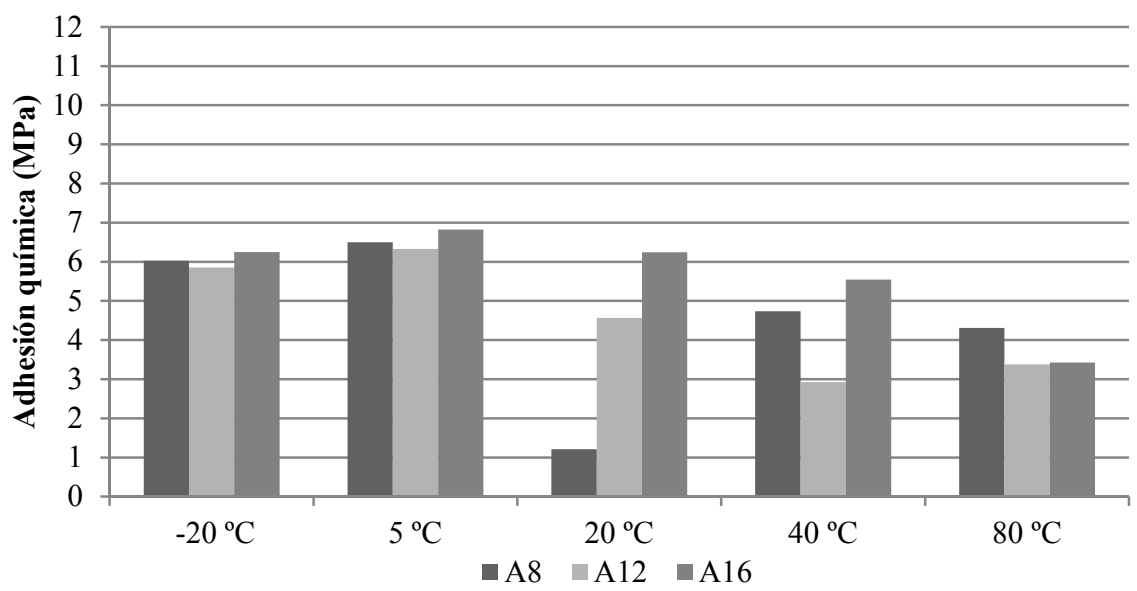

Fig. 4.91. Adhesión química de las barras de acero corrugado según su diámetro.

En cuanto a la tensión adherente máxima de las barras de acero corrugado, se comprueba mediante estudio estadístico que el incremento del diámetro de la barra produce un incremento de la tensión adherente (Fig. 4.90 y 
Tablas 4.52 y 4.53). Este efecto es similar al producido en las barras de CFRP arenadas.

\begin{tabular}{|c|c|c|c|}
\hline \multirow[b]{2}{*}{ Temperatura } & \multicolumn{3}{|c|}{ Tensión adherente máxima (MPa) } \\
\hline & A8 & A12 & A16 \\
\hline $\begin{array}{l}\text { Media todas } \\
\text { temperaturas }\end{array}$ & 16,51 & 18,31 & 20,87 \\
\hline$-20^{\circ} \mathrm{C}$ & 20,74 & 21,73 & 24,40 \\
\hline $5^{\circ} \mathrm{C}$ & 17,89 & 19,32 & 23,68 \\
\hline $20^{\circ} \mathrm{C}$ & 17,52 & 16,70 & 20,73 \\
\hline $40^{\circ} \mathrm{C}$ & 14,63 & 18,51 & 18,86 \\
\hline $80^{\circ} \mathrm{C}$ & 11,77 & 15,29 & 16,70 \\
\hline
\end{tabular}

Tabla. 4.52. Tensión adherente máxima (valores medios de los 5 ensayos de cada temperatura) de las barras de CFRP arenadas CA8 y CA14.

\begin{tabular}{|c|c|c|c|c|c|}
\hline Fuente & $\begin{array}{c}\text { Suma de } \\
\text { Cuadrados }\end{array}$ & $G l$ & $\begin{array}{c}\text { Cuadrado } \\
\text { Medio }\end{array}$ & Razón-F & Valor-P \\
\hline \multicolumn{6}{|l|}{ EFECTOS PRINCIPALES } \\
\hline A:Diámetro equivalente (mm) & 240,278 & 2 & 120,139 & 19,24 & 0,0000 \\
\hline B:Temperatura $\left({ }^{\circ} \mathrm{C}\right)$ & 514,282 & 4 & 128,57 & 20,59 & 0,0000 \\
\hline \multicolumn{6}{|l|}{ INTERACCIONES } \\
\hline $\mathrm{AB}$ & 51,2497 & 8 & 6,40621 & 1,03 & 0,4269 \\
\hline
\end{tabular}

\begin{tabular}{|c|c|c|c|}
\hline \multicolumn{4}{|c|}{ Test de Contraste Múltiple de Rango } \\
\hline & recuencia & Media $(\mathrm{MPa})$ & Grupos Homogéneos \\
\hline 8 & 25 & 16,51 & $\mathrm{X}$ \\
\hline 12 & 25 & 18,3124 & $x$ \\
\hline 16 & 25 & 20,8725 & $x$ \\
\hline \multicolumn{2}{|c|}{ Contraste } & Diferencia & +/- Limites \\
\hline \multicolumn{2}{|l|}{$8-12$} & $-1,80234$ & 1,41382 \\
\hline \multicolumn{2}{|l|}{$8-16$} & $-4,36244$ & 1,41382 \\
\hline \multicolumn{2}{|l|}{$12-16$} & $-2,5601$ & 1,41382 \\
\hline
\end{tabular}

Tabla. 4.53. Análisis de la tensión adherente de las barras de acero corrugado en función del diámetro equivalente y la temperatura: ANOVA y test de Contraste Múltiple de Rango.

Respecto al modo de rotura adherente, se observa que en todos los diámetros se produce una rotura dúctil por corte de las corrugas de hormigón. Del mismo modo, se comprueba que el comportamiento tras la rotura adherente es similar en todos los diámetros, puesto que la pendiente descendente de la 
gráfica es similar (Fig. 4.90). Por el contrario, se observa que las barras de mayor diámetro producen una tensión adherente residual mayor que las barras de menor diámetro (Fig. 4.92).

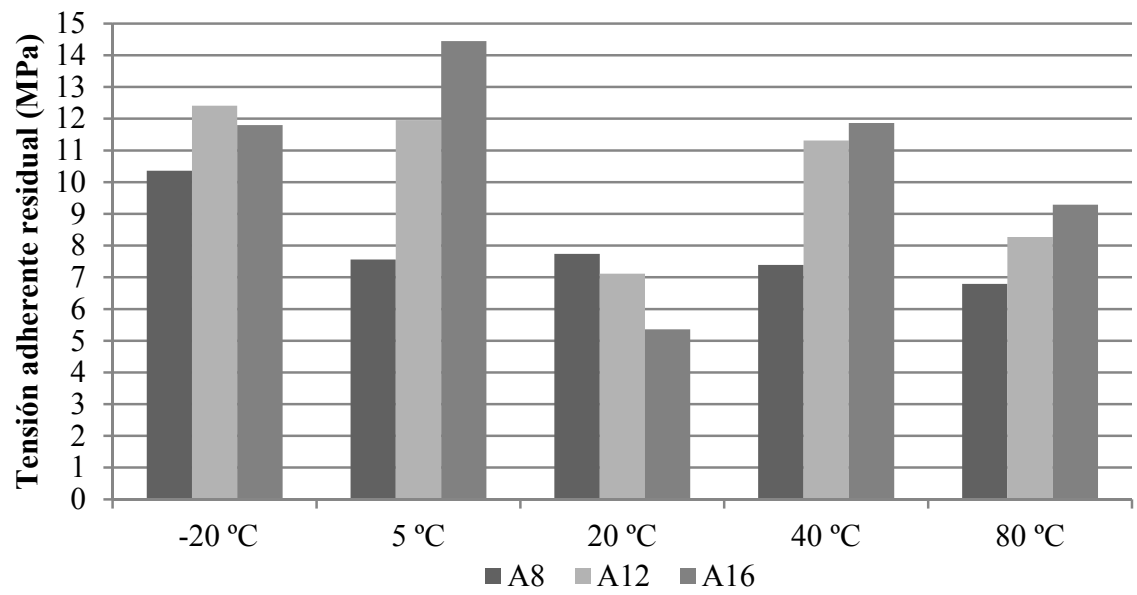

Fig. 4.92. Gráfico de la tensión adherente residual de las barras de acero corrugado según su diámetro.

\subsubsection{Temperatura de Transición Vítrea " $\mathrm{T}_{\mathrm{g}}$ ” de la Matriz Polimérica}

En este apartado se analiza la influencia de la temperatura de transición vítrea " $\mathrm{T}_{\mathrm{g}}$ " de la matriz polimérica de las barras de CFRP en el comportamiento adherente. Este factor es un indicador, a temperaturas elevadas, de la resistencia de la matriz polimérica, de la que depende entre otros factores el comportamiento adherente de las barras de CFRP corrugadas, texturizadas y arenadas (véase aparts. 4.1.1, 4.1.2, 4.1.3. y 4.1.4)

El valor de la temperatura de transisición vítrea media “ $\mathrm{T}_{\mathrm{g}, \mathrm{m}}$ ” de cada tipo de barra, ha sido calculado a partir de los resultados de $\mathrm{T}_{\mathrm{g}}$ obtenidos por calorimetría diferencial de barrido en el apart. 3.4.3.2 (Tabla 4.54). 


\begin{tabular}{ccccccc}
\hline Tipo de barra & $\begin{array}{c}\text { Tipo de matriz } \\
\text { polimérica }\end{array}$ & $\begin{array}{c}\mathrm{N}^{\mathrm{o}} \mathrm{de} \\
\text { muestra }\end{array}$ & $\begin{array}{c}\mathrm{T}_{\mathrm{g}} \\
\left({ }^{\circ} \mathrm{C}\right)\end{array}$ & $\begin{array}{c}\mathrm{T}_{\mathrm{g}, \mathrm{m}} \\
\left({ }^{\circ} \mathrm{C}\right)\end{array}$ & $\begin{array}{c}\sigma \\
\left({ }^{\circ} \mathrm{C}\right)\end{array}$ & $\begin{array}{c}\text { C.O.V } \\
(\%)\end{array}$ \\
\hline \multirow{3}{*}{ Arenada } & Viniléster & 1 & 110,76 & & & \\
& & 2 & 119,43 & 115,33 & 4,35 & 3,77 \\
\hline \multirow{3}{*}{ Corrugada } & 3 & 115,70 & & & \\
\hline \multirow{3}{*}{ Texturizada } & Viniléster & 1 & 105,70 & & & \\
& modificado & 2 & 101,27 & 104,61 & 2,95 & 2,82 \\
& con Uretano & 3 & 106,85 & & & \\
\hline & \multirow{2}{*}{ Epoxi } & 1 & 124,15 & & & \\
& & 2 & 123,58 & 123,40 & 0,85 & 0,69 \\
\hline
\end{tabular}

Tabla 4.54. Temperatura de transición vítrea de las barras de CFRP.

En cuanto a los resultados de la temperatura de transición vítrea media de cada tipo de barra (Tabla 4.54), se obtiene según el estudio estadístico realizado, que las barras texturizadas con matriz polimérica de epoxi presentan una mayor $\mathrm{T}_{\mathrm{g}, \mathrm{m}}$ que las barras arenadas y corrugadas con matiz polimérica a base de viniléster. Además, se comprueba que las barras arenadas con matriz polimérica de viniléster poseen una $T_{g, m}$ mayor que las barras corrugadas con matriz plomérica de viniléster modificada con uretano (Tabla 4.55 y Fig. 4.93). Estos valores son acordes con lo definido en el apart. 2.2.1.

\begin{tabular}{cccccc}
\hline \multicolumn{5}{c}{ Análisis de Varianza } \\
\cline { 1 - 5 } Fuente & Suma de Cuadrados & Gl & Cuadrado Medio & Razón- $F$ & Valor- $P$ \\
\hline Entre grupos & 533,483 & 2 & 266,742 & 28,22 & 0,0009 \\
\cline { 1 - 2 } Intra grupos & 56,7183 & 6 & 9,45306 & & \\
\cline { 1 - 4 } Total (Corr.) & 590,202 & 8 & & & \\
\hline
\end{tabular}

\begin{tabular}{|c|c|c|c|}
\hline \multicolumn{4}{|c|}{ Test de Contraste Múltiple de Rango } \\
\hline & Frecuencia & Media $(\mathrm{MPa})$ & Grupos Homogéneos \\
\hline Corrugada & 3 & 104,61 & $\mathrm{X}$ \\
\hline Arenada & 3 & 115,33 & $x$ \\
\hline Texturizada & 3 & 123,40 & $x$ \\
\hline
\end{tabular}

Tabla. 4.55. Estudio estadístico del efecto del tipo matriz polimérica en la temperatura de transición vítrea de las barras de CFRP: ANOVA y test de Contraste Múltiple de Rango. 


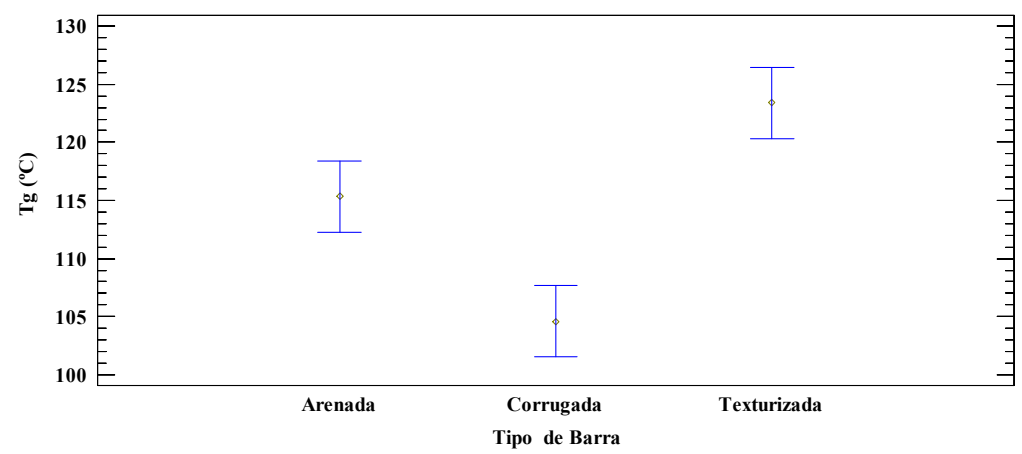

Fig. 4.93. Gráfico de comparación de la temperatura de transición vítrea media de las barras de CFRP arenadas, corrugadas y texturizadas.

Respecto al comportamiento adherente incial de las barras de CFRP (desde tensión adherente nula hasta tensión adherente máxima), se comprueba que para el rango de temperaturas de transición vítrea de la matriz polimérica, de $104{ }^{\circ} \mathrm{C}$ a $123{ }^{\circ} \mathrm{C}$, no presenta influencia, estadísticamente significativa con un nivel de confianza del $95 \%$, en la adherencia por adhesión química (Tabla 4.56 y Fig. 4.94) y en la rigidez adherente (Tabla 4.57 y Fig. 4.95). Por lo tanto, se puede considerar que el comportamiento adherente inicial no depende de la temperatura de transición vítrea de la matriz polimérica. Este efecto se debe a que para las temperaturas de transición vítrea de las barras de CFRP analizadas y niveles bajos de tensión adherente, las temperaturas de estudio no afectan al comportamiento de la matriz polimérica. Esta observación confirma los resultados y conclusiones obtenidas en el apart. 4.1.2.

\begin{tabular}{|c|c|c|c|c|}
\hline \multirow{2}{*}{$\begin{array}{c}\left(A d h . q u i_{, n\left({ }^{\circ} C\right)}\right)-\left(A d h . q u i_{n+x\left({ }^{\circ} C\right)}\right) \\
(\mathrm{MPa})\end{array}$} & \multicolumn{2}{|c|}{$\begin{array}{l}\text { Barras arenadas } \\
\left(\mathrm{T}_{\mathrm{g}}=115,33^{\circ} \mathrm{C}\right)\end{array}$} & \multirow{2}{*}{$\begin{array}{c}\text { Corrugadas } \\
\left(\mathrm{T}_{\mathrm{g}}=104,61^{\circ} \mathrm{C}\right)\end{array}$} & \multirow{2}{*}{$\begin{array}{c}\text { Texturizadas } \\
\left(\mathrm{T}_{\mathrm{g}}=123,40^{\circ} \mathrm{C}\right)\end{array}$} \\
\hline & CA8 & CA14 & & \\
\hline$\left(\right.$ Adh. $\left.q u i_{20^{\circ} C}\right)-\left(\right.$ Adh. $\left.q u i_{40^{\circ} C}\right)$ & 2,32 & 2,10 & $-0,68$ & $-1,18$ \\
\hline$\left(\right.$ Adh. $\left.q u i_{40} \mathrm{o} C\right)-\left(\right.$ Adh. $\left.q u i_{80^{\circ} C}\right)$ & 0,34 & 1,93 & 0,62 & $-0,09$ \\
\hline$\left(\right.$ Adh. $\left.q u i_{20^{\circ} C}\right)-\left(\right.$ Adh. $\left.q u i_{80^{\circ} C}\right)$ & 2,66 & 4,04 & $-0,07$ & $-1,27$ \\
\hline
\end{tabular}

Tabla. 4.56. Pérdida de adhesión química a temperaturas elevadas de las barras de CFRP, en MPa. 


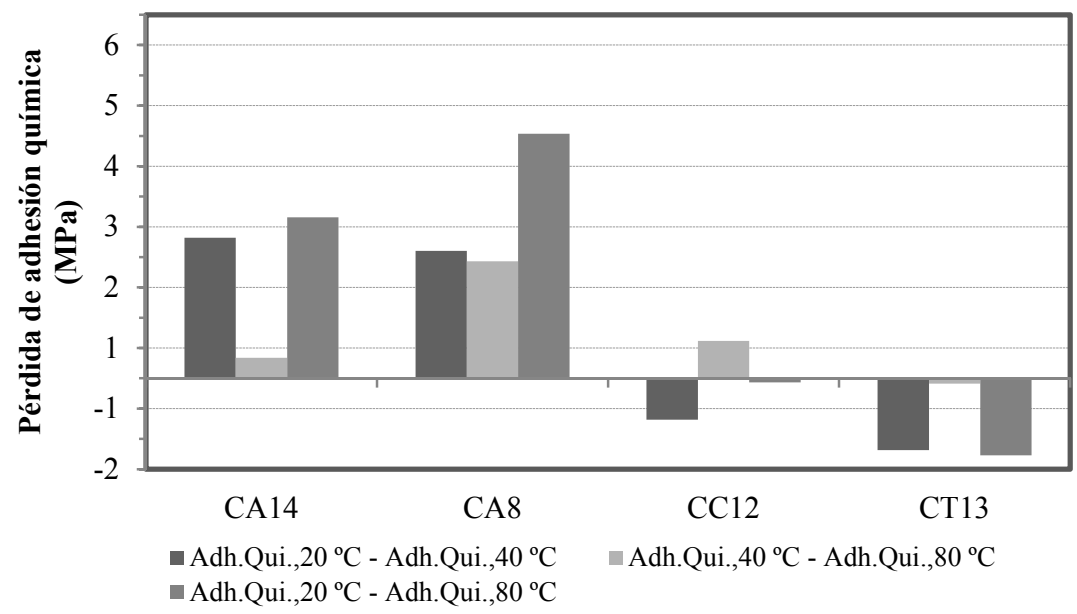

Fig. 4.94. Gráfico de comparación de pérdida de adherencia química, de las barras de CFRP con diferentes $T_{g}$, a elevadas temperaturas.

\begin{tabular}{|c|c|c|c|c|}
\hline \multirow{2}{*}{$\begin{array}{c}\left.\left(\text { Rig.adh }_{\cdot, n\left({ }^{\circ} \mathrm{C}\right)}\right)-(\text { Rig. }) \mathrm{adh}_{\cdot n+x\left({ }^{\circ} \mathrm{C}\right)}\right) \\
(\mathrm{MPa})\end{array}$} & \multicolumn{2}{|c|}{$\begin{array}{l}\text { Barras arenadas } \\
\left(\mathrm{T}_{\mathrm{g}}=115,33^{\circ} \mathrm{C}\right)\end{array}$} & \multirow{2}{*}{$\begin{array}{c}\text { Corrugadas } \\
\left(\mathrm{T}_{\mathrm{g}}=104,61^{\circ} \mathrm{C}\right)\end{array}$} & \multirow{2}{*}{$\begin{array}{c}\text { Texturizadas } \\
\left(\mathrm{T}_{\mathrm{g}}=123,40^{\circ} \mathrm{C}\right)\end{array}$} \\
\hline & CA8 & CA14 & & \\
\hline$\left(\right.$ Rig.adh. $\left.{ }_{20} \mathrm{o} C\right)-\left(\right.$ Rig.adh. $\left.{ }_{40} \mathrm{o} C\right)$ & $-4,16$ & 8,26 & $-3,12$ & 0,25 \\
\hline$\left(\right.$ Rig.adh. $\left.{ }_{40^{\circ} \mathrm{C}}\right)-\left(\right.$ Rig.adh. $\left.{ } 0^{\circ} \mathrm{C}\right)$ & 6,47 & 18,32 & 0,10 & 0,45 \\
\hline$\left(\right.$ Rig.adh. $\left.{ }_{20} \mathrm{o} C\right)-\left(\right.$ Rig.adh. $\left.{ }_{80}{ }^{\circ} \mathrm{C}\right)$ & 2,31 & 26,58 & $-3,01$ & 0,71 \\
\hline
\end{tabular}

Tabla. 4.57. Pérdida de rigidez adherente a temperaturas elevadas de las barras de CFRP, en MPa.

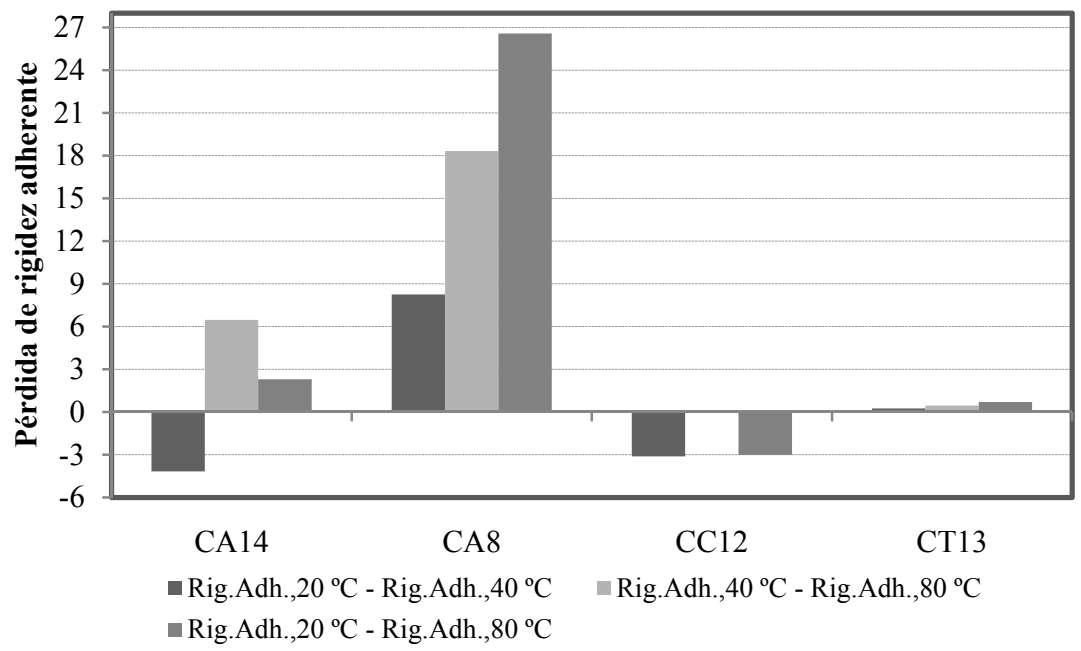

Fig. 4.95. Gráfico de comparación de pérdida de rigidez adherente, de las barras de CFRP con diferentes $\mathrm{T}_{\mathrm{g}}$, a elevadas temperaturas. 
En cuanto a la influencia de la temperatura de transición vítrea en la tensión adherente máxima de las barras de CFRP, se observa lo siguiente (Tabla 4.58):

\begin{tabular}{|c|c|c|c|c|}
\hline \multirow{2}{*}{$\begin{array}{c}\left(\tau_{\max , n\left({ }^{\circ} C\right)}\right)-\left(\tau_{\max , n+x\left({ }^{\circ} C\right)}\right) \\
(\mathrm{MPa})\end{array}$} & \multicolumn{2}{|c|}{$\begin{array}{c}\text { Barras arenadas } \\
\left(\mathrm{T}_{\mathrm{g}}=115,33^{\circ} \mathrm{C}\right)\end{array}$} & \multirow{2}{*}{$\begin{array}{c}\text { Corrugadas } \\
\left(\mathrm{T}_{\mathrm{g}}=104,61^{\circ} \mathrm{C}\right)\end{array}$} & \multirow{2}{*}{$\begin{array}{c}\text { Texturizadas } \\
\left(\mathrm{T}_{\mathrm{g}}=123,40^{\circ} \mathrm{C}\right)\end{array}$} \\
\hline & CA8 & CA14 & & \\
\hline$\left(\tau_{\max , 20^{\circ} C} C\right)-\left(\tau_{\max , 40^{\circ} C} C\right)$ & 1,68 & 1,68 & 0,34 & 0,48 \\
\hline$\left(\tau_{\max , 40^{\circ} C}\right)-\left(\tau_{\max , 80^{\circ} C}\right)$ & $-0,78$ & 0,23 & 5,77 & 0,32 \\
\hline$\left(\tau_{\max , 20^{\circ} C}\right)-\left(\tau_{\max , 80^{\circ} C}\right)$ & 0,90 & 1,91 & 6,11 & 0,80 \\
\hline
\end{tabular}

Tabla. 4.58. Pérdida de tensión adherente máxima a temperaturas elevadas de las barras de CFRP, en MPa.

- En las barras de CFRP corrugadas, con la $\mathrm{T}_{\mathrm{g}, \mathrm{m}}$ menor de todos los tipos de barras estudiados (Tabla 4.54), se produce la mayor reducción de tensión adherente máxima a temperatura elevada de todos los tipos de barras (Tabla 4.58 y Fig. 4.96).

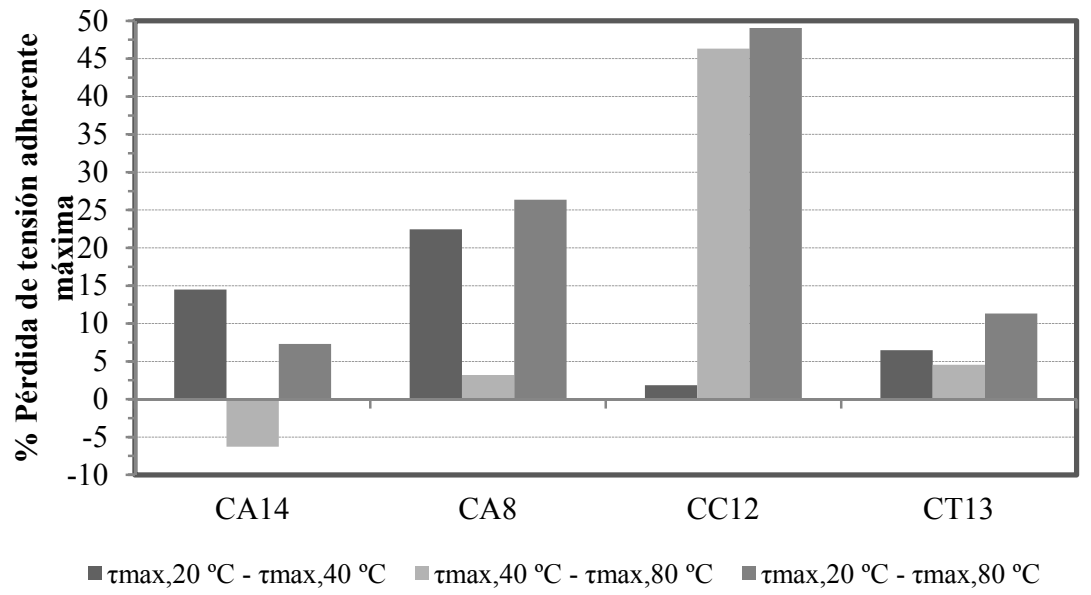

Fig. 4.96. Gráfico de comparación de pérdida de tensión adherente máxima de las barras de CFRP con diferentes $\mathrm{T}_{\mathrm{g}}$, a elevadas temperaturas.

- En las barras de CFRP arenadas se produce una disminución de la tensión adherente máxima a elevadas temperaturas ligeramente superior a las barras de texturizadas (Tabla $4.58 \mathrm{y}$ 
Fig. 4.96). En este caso particular hay que tener en cuenta que la capa de arenado superficial origina una menor transmitancia térmica desde el acabado superficial hasta la interfaz entre núcleo-capa de arenado, lo que puede favorecer algo el comportamiento a temperaturas altas $\left(80^{\circ} \mathrm{C}\right)$.

- En las barras de CFRP texturizadas, que poseen la temperatura de transición vítrea mayor de todos los tipos de barras estudiados (Tabla 4.54), se produce la menor disminución de la tensión adherente (Tabla 4.58 y Fig. 4.96).

Por lo tanto, se puede considerar que la temperatura de transición vítrea de la matriz polimérica de las barras de CFRP influye en el comportamiento adherente de las barras de CFRP cuando la temperatura es alta, debido a que una mayor $\mathrm{T}_{\mathrm{g}}$ produce una menor pérdida de tensión adherente al aumentar la temperatura.

Por último, debido a que el comportamiento adherente tras la rotura depende en mayor medida del tipo de geometría superficial de las barras de CFRP, se observa que la temperatura de transición vítrea no produce cambios en dicho comportamiento. Este hecho se observa en las gráficas recogidas en la Fig. 4.97, donde se aprecia que la pendiente descendente presenta una inclinación similar en todas las temperaturas estudiadas. 


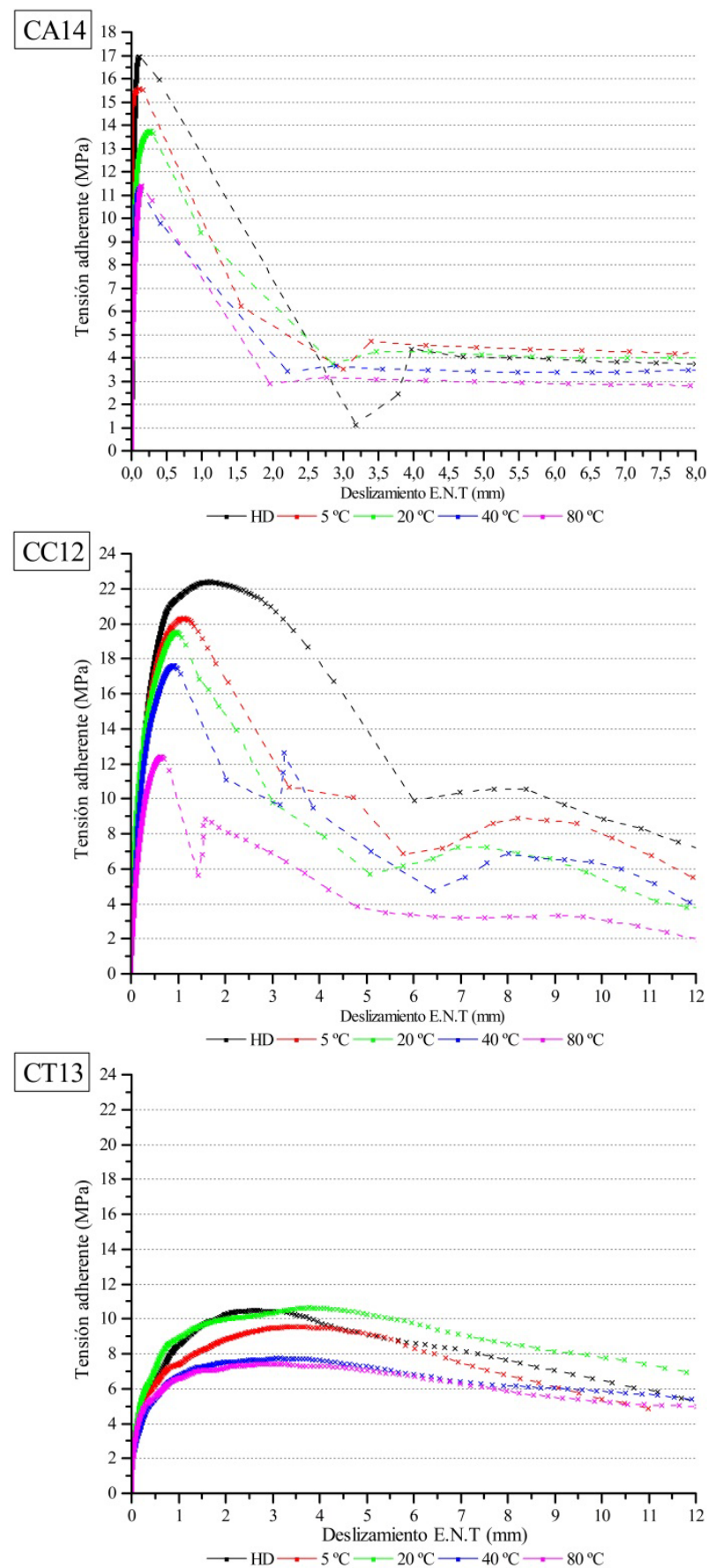

Fig. 4.97. Comportamiento adherente de las barras de CFRP arenadas "CA14", corrugadas "CC12" y texturizadas "CT13". 
Sin embargo, si que se observa una influencia de la $T_{g}$ en la tensión adherente residual, puesto que a mayor $\mathrm{T}_{\mathrm{g}}$ la pérdida de tensión adherente residual a temperaturas elevadas es menor (Tabla 4.59 y Fig. 4.98).

\begin{tabular}{ccccc}
\hline$\left(\frac{\tau_{\text {res }, n\left({ }^{\circ} \mathrm{C}\right)}}{\tau_{\text {res. }, n+x\left({ }^{\circ} \mathrm{C}\right)}}\right) \times 100$ & \multicolumn{2}{c}{$\begin{array}{c}\text { Barras arenadas } \\
\left(\mathrm{T}_{\mathrm{g}}=115,33^{\circ} \mathrm{C}\right)\end{array}$} & $\begin{array}{c}\text { Corrugadas } \\
\left(\mathrm{T}_{\mathrm{g}}=104,61^{\circ} \mathrm{C}\right)\end{array}$ & $\begin{array}{c}\text { Texturizadas } \\
\left(\mathrm{T}_{\mathrm{g}}=123,40^{\circ} \mathrm{C}\right)\end{array}$ \\
\cline { 2 - 4 }$\left(\frac{\tau_{\text {res }, 20^{\circ} \mathrm{C}}}{\tau_{\text {res }, 40^{\circ} \mathrm{C}}}\right) \times 100$ & $-7,52 \%$ & $-36,31 \%$ & $34,41 \%$ & $23,01 \%$ \\
\hline$\left(\frac{\tau_{\text {res }, 40^{\circ} \mathrm{C}}}{\tau_{\text {res }, 80^{\circ} \mathrm{C}}}\right) \times 100$ & $20,80 \%$ & $12,17 \%$ & $27,43 \%$ & $-0,12 \%$ \\
\hline$\left(\frac{\tau_{r e s, 20^{\circ} \mathrm{C}}}{\tau_{\text {res }, 80^{\circ} \mathrm{C}}}\right) \times 100$ & $11,71 \%$ & $-28,56 \%$ & $71,28 \%$ & $22,86 \%$ \\
\hline
\end{tabular}

Tabla. 4.59. Pérdida de tensión adherente residual a temperaturas elevadas de las barras de CFRP, en MPa.

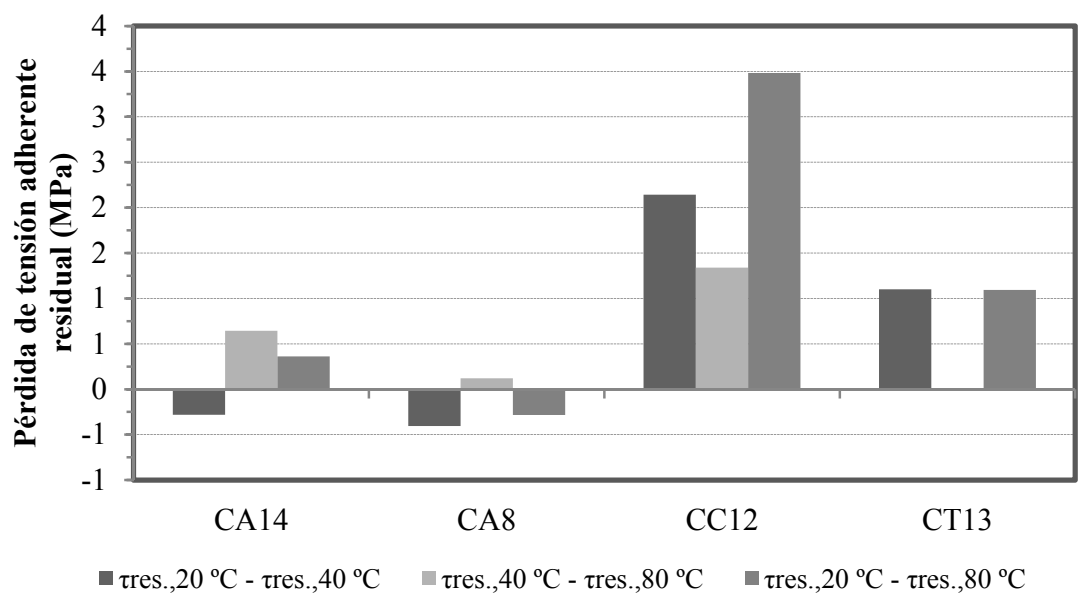

Fig. 4.98. Gráfico de comparación de pérdida de tensión adherente residual de las barras de CFRP con diferentes $\mathrm{T}_{\mathrm{g}}$, a elevadas temperaturas. 


\section{CAPÍTULO 5}

\section{Conclusiones y Futuras Líneas de}

\section{INVESTIGACIÓN}

En este último capítulo, se establecen las conclusiones más relevantes del estudio experimental sobre el comportamiento adherente entre los diferentes tipos de barras de CFRP y el hormigón en diferentes condiciones térmicas. Al mismo tiempo, se definen las futuras líneas de investigación que pueden llevarse a cabo a partir de este estudio experimental.

\subsection{Conclusiones}

Las conclusiones más sobresalientes de la presente investigación, son las siguientes:

I. Las barras de CFRP resisten una tensión de tracción del orden de 2,9 a 3,9 veces mayor que las barras de acero corrugado de tipo B-500-SD. Sin embargo, el módulo elástico de las barras de acero es del orden de 1,3 a 1,6 veces mayor que en las barras de CFRP.

II. El comportamiento adherente inicial, es decir, hasta tensión adherente máxima, depende en mayor medida del tipo de tratamiento o geometría superficial de la barra de CFRP. Las barras de CFRP arenadas, poseen un comportamiento adherente inicial de tres a cuatro veces más rígido que las barras de CFRP y acero corrugado y quince veces más rígido

que las barras de CFRP texturizadas. Por contra, las barras de CFRP 
corrugadas poseen un comportamiento adherente inicial similar a las barras de acero corrugado.

III. La tensión adherente máxima de las barras de CFRP depende del tipo de tratamiento o geometría superficial y de la resistencia de la matriz polimérica. En las barras de CFRP corrugadas la tensión adherente máxima desarrollada es similar a la producida por las barras de acero corrugado, del orden de $18 \mathrm{Mpa}$. En cambio, la tensión adherente máxima producida por las barras de CFRP arenadas y texturizadas es del orden de 1,5 a 2 veces menor a la desarrollada por las barras de CFRP y acero corrugado.

IV. El modo de rotura adherente de las barras de CFRP depende del tipo de tratamiento superficial. En las barras de CFRP arenadas además depende de la resistencia de la resina polimérica de la interfaz. En las barras de CFRP corrugadas, el modo de rotura depende a su vez de la relación entre la resistencia de la corruga de la barra y la resistencia del hormigón entre corrugas. En este caso el modo de rotura es más dúctil que en las barras arenadas, pudiéndose producir la rotura por corte de las corrugas de la barra o por corte del hormigón entre corrugas. En las barras de CFRP texturizadas la rotura adherente es más dúctil que en las barras de CFRP y acero corrugado, produciéndose siempre la rotura por corte de las corrugas de hormigón.

V. Las barras de CFRP arenadas presentan una menor tensión adherente residual que el resto de barras de CFRP y acero corrugado. Al mismo tiempo, las barras de CFRP texturizadas poseen una tensión adherente residual menor que las barras de CFRP y acero corrugadas, siendo similar en estos dos tipos de barras. 
VI. Los parámetros $f_{R}$ y C.L.R son buenos indicadores de la adherencia de las barras de CFRP corrugadas y texturizadas, si bien, el parámetro $\mathrm{a}_{\mathrm{s}}$ no lo es. Al mismo tiempo, se comprueba que el parámetro $f_{R}$ es mejor indicador del comportamiento adherente que el parámetro C.L.R.

VII. Para el desarrollo de una adherencia similar a la de las barras de acero corrugado, se propone unos valores mínimos de los parámetros $f_{R} \mathrm{y}$ C.L.R de 0,06 y 0,7 , respectivamente.

VIII. La variación de la temperatura produce una variación de la tensión adherente máxima de las barras de CFRP arenadas. A $80{ }^{\circ} \mathrm{C}$ la $\tau_{\max }$ disminuye del orden del 7 a $20,86 \%$ respecto a $20{ }^{\circ} \mathrm{C}$ y a $-20{ }^{\circ} \mathrm{C}$ aumenta un $27 \%$. Sin embargo, esta influencia de la temperatura en la tensión adherente máxima es del orden de 1,3 a 1,6 veces mayor en las barras de acero corrugado.

IX. El comportamiento adherente de las barras de CFRP corrugadas y acero corrugado a un rango de temperaturas desde $-20{ }^{\circ} \mathrm{C}$ hasta $40{ }^{\circ} \mathrm{C}$ es similar. Sin embargo, a $80^{\circ} \mathrm{C}$ se produce una disminución de la tensión adherente máxima del orden del $33 \%$, siendo la $\tau_{\max }$ menor que en las barras de acero corrugado.

X. En las barras de CFRP texturizadas la temperatura no produce una influencia significativa en el comportamiento adherente.

XI. Para el rango de resistencias a compresión del hormigón de 35 a 45 $\mathrm{MPa}$, la tensión adherente máxima de las barras de CFRP arenadas, corrugadas y texturizadas no depende de la resistencia a compresión del hormigón.

XII. En las barras de CFRP corrugadas, para el rango de resistencias a compresión del hormigón de 35 a $45 \mathrm{MPa}$, el agotamiento se puede 
producir por rotura a cortante de las corrugas de la barra y/o por rotura a cortante del hormigón entre corrugas.

XIII. En las barras de CFRP arenadas la tensión adherente máxima es mayor cuanto mayor es el diámetro de las barras.

XIV. La temperatura de transición vítrea de la matriz polimérica no influye sobre la relación tensión de adherencia-deslizamiento.

XV. La temperatura de transición vítrea influye en la tensión adherente máxima y residual, puesto que cuanto menor es la $\mathrm{Tg}$ más negativamente influyen las temperaturas elevadas $\left(80^{\circ} \mathrm{C}\right)$ sobre la $\tau_{\max } \mathrm{y}$ la $\tau_{\text {res. }}$.

\subsection{Futuras Líneas de Investigación}

Todo el trabajo realizado en esta tesis deja abierta la posibilidad de futuras líneas de investigación, de las cuales destacan las siguientes:

- Cáculo de los coeficientes de adherencia, longitud de anclaje y tensión adherente mínima de las normativas de cálculo de estructuras de hormigón armado con CFRP.

- Ajuste de los diferentes métodos de cálculo analíticos del comportamiento adherente entre barras de CFRP y el hormigón.

- Analisis de la influencia de distintos tipos de matriz polimérica en la adherencia de las barras de CFRP arenadas y corrugadas.

- Influencia de distintas configuraciones de ancho, alto y distancia entre corrugas en el comportamiento adherente de las barras de CFRP corrugadas. 
- Comportamiento adherente de las barras de CFRP texturizadas con hormigones de alta resistencia.

- A partir de los resultados obtenidos, diseño de un nuevo tipo de barra de CFRP que subsane los inconvenientes de cada tipo de barra. 


\section{Referencias Bibliográficas}

Achillides, Z., Pilakoutas, K.: "Bond behaviour of fiber reinforced polymer bars under direct pullout conditions". ASCE J. Composor. Constr., vol.8, n 2 (2004), pp. 173-181.

Achillides, Z., Pilakoutas, K., and Waldron, P.: "Bond behaviour of FRP bars to concrete"' Proc., 3rd Int. Symp. on Non-Metallic (FRP) Reinforcement for Concrete Structures, Japan Concrete Society, Sapporo, Japan, (1997b), pp. 341-348.

ACI (1996): American Concrete Institute (1996), State-of-the-Art Report on Fiber Reinforced Plastic (FRP) Reinforcement for Concrete Structures. ACI Report 440R-96, Detroit, (1996).

ACI Committee 215, "Consideration for Design of Concrete Structure Subjected to Fatigue Loading," (ACI 215R-74, revised 1992), ACI manual of concrete practice, American Concrete Institute, Detroit, Michigan, USA, 1993, pp. 215R-1 to 215R-24.

ACI-318-08: Building Code Requirements for Structural Concrete (ACI 318-08) and Commentary (318R-08). American Concrete Institute, Farmington Hills, Mich., (2008).

ACI 440.1R-03: American Concrete Institute (2003), Guide for the Design and Construction of Concrete Reinforced with FRP Bars. ACI Report 440.1R-0103, Farmington Hills, (2003).

ACI 440.1R-06: Guide for the Design and Construction of Structural Concrete Reinforced with FRP Bars, ACI Committee 440, American Concrete Institute, Farmington Hills, Michigan, USA, (2007).

ACI 440.3R-04: Guide test methods for fiber-reinforced polymers (FRP's) for reinforcing or strengthening concrete structures, ACI Committee 440, American Concrete Institute, Farmington Hills, Michigan, USA, (2004). 
ACI 440.5-08: Specification for Construction with Fiber-Reinforced Polymer Reinforcing Bars, ACI Committee 440, American Concrete Institute, Farmington Hills, Michigan, USA, (2009).

ACI 440.6M-08: Specification for Carbon and Glass Fiber-Reinforced Polymer Bar Materials for Concrete Reinforcement, ACI Committee 440, American Concrete Institute, Farmington Hills, Michigan, USA, (2009).

ACI 440.XR-06: Report on Fiber-Reinforced Polymer (FRP) Reinforcement for Concrete Structures. ACI Committee 440, American Concrete Institute, Farmington Hills, Michigan, USA, (2006).

Adimi, R.; Rahman, H.; Benmokrane, B.; and Kobayashi, K..: "Effect of Temperature and Loading Frequency onthe Fatigue Life of a CFRP Bar in Concrete," Proceedings of the Second International Conference on Composites in Infrastructure (ICCI-98), Tucson, Ariz., Vol. 2 (1998), pp. 203-210.

Allred, R.E., The effects of temperature and moisture content on the flexural response of Kevlar/epoxy laminates: Part II [45/0/90] Filament orientation, Environmental Effects on Composites Materials, v. 2, Springer, G. (Ed.), Lancaster, PA: Technomic Publishing Company, (1984).

Ando, N., Matsukawa, H., Hattori, A. and Mashima, A.: "Experimental Studies on the Long-term Tensile properties of FRP Tendons". In Proceedings of the Third International Symposium on Non-Metallic (FRP) Reinforcement for Concrete Structures (FRPRCS-3), Sapporo, Japan, vol. 2 (1997), pp. 203-210.

Aiello, A.M., Leone, M., and Pecce, M.: "Bond performances of FRP rebars-reinforced concrete". ASCE J. Mater. Civil. Eng., vol.19, nº 3 (2007), pp. 205-213.

Al-Mahmoud, F., Castel, A., François, R., Tourneur, C.: "Effect of surface preconditioning on bond of carbon fibre reinforced polymer rods to concrete". Cement \& Concrete Composites, vol. 29 (2007), pp. 677-689. 
Al-Zahrani, M., Al-Dulaijan, S., Nanni, A., Bakis, C., Boothby, T.: "Evaluation of bond using FRP rods with axisymmetric deformations". Construction and Building Materials. Vol. 13 (1999), pp. 299-309.

Agarwal, B.D. and Broutman, L.J.: Analysis and Performance of Fibre Composites. Second edition. Willey-Interscience, New-York, (1990).

Arockiasamy, M., Amer, A., Shahawy, M., and Chidambaram, S.: "Long-term behaviour of concrete beams reinforced with CFRP bars under sustained loads", $A C M B S-I I$, ElBadry, M. (Ed.), Montreal, August (1996).

ASTM (2012: Book of Standards. American Society for Testing and Materials, West Conshohocken, PA, (2012).

Baena, M., Torres, L1., Turon, A., Barris, C.: "Experimental study of bond behaviour between concrete and FRP bars using a pull-out test". Composites: Part B, vol. 40 (2009), pp. 784-797.

Bakis E, Freimanis, J., Gremel, D., Nanni, A.: "Effect of resin material on bond and tensile properties of unconditioned and conditioned FRP reinforced rods". Proc. 1st Intl. Conf. on durability of fiber reinforced polymer (FRP) composites for construction, Sherbrooke, August, (1998), pp. 525-535.

Balazs, G.: "Conecting reinforcement to concrete by bond". Beton und stahlbetonbau, vol. 102 (2007), pp.46-51.

Balazs, G. L. and Borosnyoi, A.: "Long-term Behaviour of FRP. In Proceedings of the International Workshop. American Society of Civil Engineers, Reston, (2001), pp. 84-91.

Bank, C., Gentry, R.: "Accelerated Test Methods to Determine the Long-Term Behaviour of FRP Composite Structures: Environmental Effects”. Journal of Reinforced Plastic and Composites, vol. 14 (1995), pp. 558-587.

Bank, C., Gentry, R., Barkatt, A., Prian, L., Wang, F., Mangala, R.: “Accelerated ageing of pultruded glass/vinyl ester rods". Proc. 2nd. Intl. Conf. On Fibre Composites in Infrastructure, vol. 2 (1998), pp. 423-437. 
Barbero, E.J.: Introduction to Composite Materials Design, Taylor \&Francis, Philadelphia, (1999).

Benmokrane, B., Tighiouart, B., Chaallal, O.: "Bond strength and load distribution of composite GFRP reinforcing bars in concrete". ACI Mater. J., vol. 93, no 3 (1996), pp. 246-253.

Benmokrane, B., Zhang, B., Chennouf, A.: "Tensile properties and pullout behaviour of AFRP and CFRP rods for grouted anchor applications". Construction and Building Materials, vol. 14 (2000), pp. 157-170.

Benmokrane, B., Wang, P., Gentry, T.R., and Faza, S.: “Test Methods to Determine Properties of FRP Rods for Concrete Structures. In Proceedings of the International Workshop “. American Society of Civil Engineers, Reston, (2001), pp. 75-83.

Benmokrane, B., Zhang, B., Laoubi, K., Tighiouart, B., Lord, I.: "Mechanical and bond properties of new generation of carbon fibre reinforced polymer reinforcing bars for concrete structures”. Can. J. Civ. Eng., vol. 29 (2009), pp. 338-343.

Benmokrane, B., El-Salakawy, E., El-Ragaby, A., Desgagne, G., Lackey, T.: "Design, Construction and Monitoring of Four Innovative Concrete Bridge Decks Using NonCorrosive FRP Composite Bars," 2004 Annual Conference of the Transportation Association of Canada, Québec City, Québec, Canada, (2004).

Bank LC, Gentry T R.: "Accelerated Test Methods to Determine the Long-Term Behaviour of FRP Composite Structures: Environmental Effects", Journal of Reinforced Plastic and Composites, Vol. 14 (1995), pp. 558-587.

Bakis, C. E.: "FRP reinforcement: materials and manufacturing." Fiberreinforcedplastic (FRP) reinforcement for concrete structures: properties and applications. Nanni, A., Editor, Elsevier Science Publishers B.V. Amsterdam, The Netherlands, (1993), pp. $13-58$.

Bakis, C. E., Bank, L. C., Brown, V. L., Cosenza, E., Davalos, J. F., Lesko, J. J., Machida, A., Rizkalla, S. H., and Triantafilliou,: "Fiber-reinforced polymer composites 
for construction: state-of-the-art review", Journal of Composites for Construction, vol. 6, $n^{\circ} .2$ (2002), pp. 73-87.

Bank, L., Puterman, M., Katz, A.: "The Effect of Material Degradation on Bond Properties of Fiber Reinforced Plastic Reinforcing Bars in Concrete". ACI Materials Journal, vol. 95, nº. 3 (1998), pp. 232-242.

Barbero, E. J.: "Introduction to Composite Materials Design", Taylor \& Francis, Philadelphia, (1999).

Beck, D.L., Hiltz A.A., and Knox, J.R.: "Experimental data of specific volume vs. Temperatura to determine Tg of polypropylene", Soc. Plast. Eng. Trans., March, 1963, pp. 279.

Bootle, J., Burzesi, F., and Fiorini, L.: "Design Guidelines”. In ASM Handbook Volume 21 Composites, ASM International, Material Park, Ohio, (2001), pp. 388-395

Boyle, M. M., Martin, C. J. and Neuner, J. D.: "Epoxy resins". In ASM Handbook Volume 21 Composites, ASM International, Material Park, Ohio, (2001), pp. 78-89.

Budelman, H., and Rostasy, F. S.: "Creep Rupture Behaviour of FRP Elements for Prestressed Concrete-Phenomenon, Results and Forecast Models". In Proceedings, ACI International Symposium on FRP Reinforcement for Concrete Structures, Vancouver, (1993), pp. 87- 100.

Byars, A., Dejke, V., Demis, S.: Development drafts of a model European durability specification for FRP concrete. Riga, Venice and Cambridge meetings of fib Task Group 9.3, (1999-2001).

Byars, .A., Waldron, W., Dejke, V., Demis, S.: "Durability of FRP in Concrete: Current Specifications and a New Approach". Proc: FRP Composites in Civil Engineering, Elsevier, Hong Kong, December, vol. 2 (2001), pp. 1497-1507.

Byars, .A., Waldron, W., Dejke, V., Demis, S.: "Durability of FRP in Concrete: Deterioration Mechanisms". Proc: FRP Composites in Civil Engineering, Elsevier, Hong Kong, December, vol. 2(2001), pp. 1517 - 1525. 
Byars, A., Waldron, P., Dejke, V., Demis, S., Heddadin, S.: "Durability of FRP in Concrete-Current Specifications and a New Approach". International Journal of Materials and Product Technology, vol. 19, n 1-2(2003), pp. 40-52.

CAN/CSA-S806-02: Design and construction of building components with fibre reinforced polymers. Canadian Standards Association, Ontario, (2002).

CEB-FIP: Model Code 1990, Comité Euro-International de Béton. London: Thomas Telford Services Ltd., (1990).

Chaallal, O., Benmokrane, B.: "Pullout and bond of glass-fibre rods embedded in concrete and cement grout”. Mater. Struct., vol. 26, nº 3 (1993), pp-167-175.

Chang, K. K.: "Aramid Fibers". In: ASM Handbook Volume 21 Composites, ASM International, Material Park, Ohio, (2001), pp. 41-45.

Chateauminois, A., Chabert, B., Soulier, J.P., and Vincent, L.: Effects of hygrothermal aging on the durability of glass/epoxy composites. Physico-chemical analysis and damage mapping in static fatigue, Proc. ICCM '93, (1993).

CHBDC (1996): Section 16: Fibre reinforced structures, Canadian Highway Bridge Design Code, Final Draft. Canada, (1996).

Chen, Y., Davalos, J., Ray, I., Kim, H.: “Accelerated aging tests for evaluations of durability performance of FRP reinforcing bars for concrete structures". Composite Structures, vol. 78 (2007), pp. 101-111.

Chin JW, Nguyen T and Aouadi K.: "Effects of Environmental Exposure on FiberReinforced Plastic (FRP) Materials Used in Construction", Journal of Composites Technology and Research, Vol 19, No 4 (1997), pp. 205-213.

(CISPI) Composites Institute of the Society of the Plastics Industry, Introduction to Composites, Washington, DC, (1992). 
Clarke, L., Sheard, P.: "Designing Durable FRP Reinforced Concrete Structures". Durability of Fibre Reinforced Polymer (FRP) Composites for Construction. Proc. 1st Intl. Conf. (CDCC' 98), Sherbrooke, (1998), pp 3-24.

CNR-DT 203/2006: Guide for the design and construction of concrete structures reinforced with fiber-reinforced polymers bars. Advisory commitee on technical recommendations for construction, Italy, Rome, June (2007).

Cosenza, E., Manfredi, G., and Realfonzo, R.: "Bond characteristics and anchorage length of FRP rebars". Advanced Composite materials in bridges and structures., Canadian Society for Civil Engineering, Montreal. Duebec, (1996), pp. 909-916.

Cosenza, E., Manfredi, G., and Realfonzo, R.: "Behavior and modeling of bond of FRP rebars to concrete". Jour. Compo. Constr., vol. 1, n 2 (1997), pp. 40-51.

Cosenza, E., Manfredi, G., and Realfonzo, R.: "Development length of FRP straight rebars". Composites B., vol. 33, no 7 (2002), pp. 493-504.

Cossis, F.A. and Talbot, R.C.: "Polyester and vinyl ester resins", in Handbook of Composites, S.T. Peters (Ed.), New York: Chapman \& Hall, (1998).

Cox, J., Cochran, B.: "Bond between Carbon Fiber Reinforced Polymer Bars and Concrete. II: Computational Modeling”. Journal of Composites for Construction, vol. 7, No. 2 (2003), pp. 164-171.

CSA 2000: "Canadian Standards Association: Canadian Highways Bridge Design Code", Section 16, Fiber Reinforced Structures, (2000).

Curtis, P. T.: "The Fatigue Behavior of Fibrous Composite Materials". Journal of Strain Analysis, vol 24, nº 4 (1989), pp. 235-244.

Darwin, D., Graham, E.: "Effect of Deformation Height and Spacing on Bond Strength of Reinforcing Bars”. ACI Structural Journal, vol. 90, nº6 (1993), pp. 646-657. 
Devalapura, R.K., Greenwood, M.E., Gauchel, J.V., and Humphrey, T.J.: "Evaluation of GFRP performance using accelerated test methods”, Proc. CDCC '98, Benmokrane, B. and Rahman, H. (Eds.), Sherbrooke, Québec, Canada, August 5-7, (1998).

Davalos, J., Chen, Y., Ray, I.: "Effect of FRP bar degradation on interface bond with high strength concrete”. Cement \& Concrete composites, vol. 30 (2008), pp. 722-730.

Dewprashad, B., and Eisenbraun, E.J.: "Fundamentals of epoxy formulation," J. Chem. Educ., vol.71, no 4 (1994), pp. 290-294.

Edwards A.D., Yannopoulos PJ.: "Local bond stress-slip relationship under repeated loading”, Magazine of Concrete Research, vol. 30, nº 103 (1978), pp. 62-72.

EHE-08. Instrucción Hormigón Estructural. Ministerio de Fomento ed., Madrid, Spain. (2008).

Eligehausen, R., Popov, E.P., and Bertero, V.V.: "Local bond stress-slip relationships of deformed bars under generalized excitations". EERC, University of California, Berkeley, Report no 83/23(1983).

Ehsani, M. R., Saadatmanesh, H., and Nelson Thompson, C.: "Transfer and flexural bond performance of aramid and carbon FRP tendons." PCI Journal, V. 42, No.1(1997a)., pp. 76-86.

Ehsani, M. R., Saadatmanesh, H., and Tao, S.: " Bond behavior of deformed GFRP bars." Journal of Composite Materials, V. 31, No. 14 (1997b)., pp. 1413-1430.

Esfandeh, M., Sabet, A., Rezadoust, A., Alavi, M.: "Bond Performance of FRP Rebars With Various Surface Deformations in Reinforced Concrete". Polymer Composites, vol. 30 (2009), pp. 576-582.

Faza, S.S.: "Bending and bond behavior and design of concrete beams reinforced with fiber reinforced plastic rebars", Ph.D. dissertation, Morgantown, WV: West Virginia State University, (1991). 
Faza, S,. GangaRao, .S.: "Glass FRP Reinforcing Bars for Concrete. Fiber Reinforced Plastic (FRP) Reinforcement for Concrete Structures: Properties and Applications", Developments in Civil Engineering, Elsevier, Amsterdam, vol. 42 (1992), pp.167-188.

Ferry, J. D.: Viscoelastic Properties of Polymers. 3rd edition, Willey, New York (1980).

FIB. Task Group 9.3: FRP reinforcement in RC structures: Design and use of fibre reinforced polymer reinforcement (FRP) in reinforced concrete structures. Federation Internationale de Beton Task Grouo 9.3, Lausanne, Switzerland, (2007).

FIB: Bond of reinforcement in concrete, State-of-art Report, Bulletin 10, fibInternational Federation for Concrete Task Group Bond Models, Lausanne, Switzerland, (2000).

Fortec Stabilization, Inc. 184 West 64th Street Holland MI 49423. http://www.fortecstabilization.com/

Galati, N., Nanni, A., Dharani, L., Focacci, F., Aiello, M.: “Thermal effects on bond between FRP rebars and concrete". Composites: Part A, vol. 37 (2006), pp. 1223-1230.

Gangarao, S., Vijay, V.: “Aging of Structural Composites Under Varying Environmental Conditions, Non-Metallic (FRP) Reinforcement for Concrete Structures". Proc. 3rd Intl. Symp., vol. 2 (1997), pp 91-98.

GangaRao, H., Narendra, T., Vijay, P.: Reinforced concrete design with FRP composites. Taylor \& Francis Group, Boca Raton, Florida, USA, (2007). ISBN 0-82475829-3.

Gay, D., Hoa, V., Tsai, W.: Composite Materials. Design and Applications. CRC Press, Boca Raton, (2003).

Gibson, F.: Principles of Composite Material Mechanics. McGraw-Hill, New York, (1994).

Guigon, M., Oberlin, A. and Desarmot, G.: Fibre Sci. Technol. vol. 20 (:1984a), pp. 177. 
Guo, J., Cox, J.: “An interface model for the mechanical interaction between FRP bars and concrete". Jour. Reinfor. Plastics and Composites, vol. 19, nº 1 (2000), pp. 15-33.

Focacci, F., Nanni, A., and Bakis, C.E.: "Local bond-slip relationship for FRP reinforcement in concrete". ASCE J. Compos. Constr., vol. 4, nº 1 (2000), pp. 24-31.

Hamad, B.: "Comparative Bond Strength of Coated and Uncoated Bars with Different Rib Geometries”. ACI Materials Journal, vol. 92, nº 6 (1995), pp. 579-590.

Hamad, B.: "Bond Strength improvement of Reinforcing Bars with Specially Designed Rib Geometries”. ACI Structural Journal, vol 92, n. 1 (1995), pp. 3-13.

Hao, Q., Wang, Y., He, Z., Ou, Z.:'Bond strength of glass fiber reinforced polymer ribbed rebars in normal strength concrete". Construction and Building Materials, vol. 23 (2009), pp. 865-871.

Hollaway, L.: Polymer Composites for Civil and structural Engineering. Blackie Academic \& Professional, Glasgow, (1993).

Hull, D., Clyne, W.: An Introduction to Composite Materials. 2nd edition, Cambridge University Press, Cambridge. (1996).

ISIS Canada, 2006: http://www.isiscanada.com (accessed Sept. 2006)

IStructE: Interim Guidance on the Design of Reinforced Concrete Structures using Fibre 17 Composite Reinforcement, Institution of Structural Engineers, London, (1999).

JSCE 1997(b): Recommendation for design and construction of concrete structures using continuous fiber reinforcing materials. Research Committee on Continuous Fiber Reinforcing Materials, Japan Society of Civil Engineers, Tokyo, (1997).

Kanakubo, T., Yonemaru, K., Fukuyama, H., Fujisawa, M., Sonobe, Y.: "Bond performance of concrete members reinforced with FRP bars”. ACI international symposium on FRP reinforcement for concrete structures, ACI. SP-138, September 1, 1993, Vancouver; (1993), pp.767- 788. 
Kato, Y., Nishimura, T., Uomoto, T., and Yamaguchi, T.: "The effect of ultraviolet rays to FRP rods”, Proc. CDCC '98, Benmokrane, B. and Rahman, H. (Eds.), Sherbrooke, Québec, Canada, August 5-7, (1998).

Katz, A.: "Bond mechanism of FRP rebars to concrete". Materials and Structures/Matériaux et Constructions, vol. 32 (1999), pp. 761-768

Katz, A., Bernan, N., Bank, L.: "Effect of high temperature on bond strength of frp rebars". Journal of Composites for Construction, vol. 3, nº 2 (1999), pp. 73-81.

Katz, A., Berman, N., Bank, C.: "Effect of High Temperature on the Bond Strength of FRP Rebars," Journal of Composites for Construction, vol. 3, nº 2 (1999), pp. 73-81.

Katz, A., Berman, N.: "Modeling the e€ect of high temperature on the bond of FRP reinforcing bars to concrete". Cement \& Concrete Composites, vol. 22 (2000), pp. 433443.

Karbhari, M., Chin, W., Dunston, D., Benmokrane, B., Juska, T., Morgan, R., Kollar, P., Springer, S.: Mechanics of Composite Structures, Cambridge University Press, New York, (2003).

Kelen, T., Polymer Degradation, New York: Van Nostrand Reinhold Co., (1983)

Kollár, L. P., and Springer, G. S.:"Mechanics of Composite Structures", Cambridge University Press, New York, (2003), pp. 498.

Kumahara, S., Masuda, Y., Tanano, Y.: Tensile Strength of Continuous Fiber Bar under High Temperature". In International Symposium on Fiber-Reinforcement- Plastic Reinforcement for Concrete Structures, SP-138, Nanni, A. and C. W. Dolan, C. W. eds., American Concrete Institute, Farmington Hills, (1993), pp. 731-742.

Larralde, J., Silva-Rodriguez, R.: "Bond and slip of FRP rebars in concrete". ASCE J. Mater. Civil Eng., vol 5, no 1 (1993), pp. 30-40.

Lawrence, C. B.: Composites for construction: structural design with FRP materials. John wiley \& sons, INC., Hoboken, New Jersey, USA, (2006). 
Lee, J., Kim, T., Yi, C., Park, J., You, Y., Park, Y.: "Interfacial bond strength of glass fiber reinforced polymer bars in high-strength concrete". Composites: Part B, vol. 39 (2008), pp. 258-270.

Machida, A.:"State-of-the-Art Report on Continuous Fiber Reinforcing Materials". Society of Civil Engineers (JSCE), Tokyo, (1993).

Machida, A.: Recommendation for design and construction of concrete structures using continuous fiber reinforcing materials, Concrete Engineering Series 23, Japan Society of Civil Engineers, Tokyo, (1997).

Mallick, K.: Fiber Reinforced Composites, Materials, Manufacturing and Design, Marcel Dekker Inc., New York, (1988).

Mallick, P.K.: Fiber Reinforced Composite Materials: Manufacturing and Design. New York: Marcel Dekker, (1993).

Malvar, L.:'Tensile and Bond Properties of GFRP Reinforcing Bars". ACl Materials Journal, vol. 92,nº 3 (1995), pp. 276-285.

Malvar, L.J., Cox, J..V., and Cochran, K.B.: "Bond between carbon fiber reinforced polymer bars and concrete. I. Experimental study". ASCE J. Comp. Construct., vol. 7, $\mathrm{n}^{\circ}$ 2 (2003), pp. 154-163.

Malvar, L.J., Joshi N.R., Beran, J.A., Novinson, T.: "Environmental Effects on the Short-Term Bond of Carbon Fiber-Reinforced Polymer .CFRP. Composites”. Journal of Composites for Construction, vol. 7, nº 1 (2003), pp. 58-63.

Marshall Composite Systems LLC.: Cataloge C-Bar (1999), 2873 22nd St. NE Salem, OR 97302, Phone: (503)726-0526. http://www.marshallcomposite.com/

Masmoudi, R., Alvarez, A., Dubois, J.: "Thermal effect on bond properties of frp bars embedded in concrete". 33 rd Annual General Confcrence of the Canadian Society for Civil Engineering, June (2005), pp. 3115-3124. 
Masmoudi, A., Masmoudi, R., Ouezdou, M.: "Thermal effects on GFRP rebars: experimental study and analytical analysis". Materials and Structures, vol. 43 (2010), pp. $775-788$.

Masmoudi, R., Masmoudi, A., Ouezdou, M., Daoud, A.: "Long-term bond performance of GFRP bars in concrete under temperatura ranging from $20^{\circ} \mathrm{C}$ to $80{ }^{\circ} \mathrm{C} "$. Construction and Building Materials, vol. 25 (2011), pp. 486-493.

Meier, U.: "Carbon Fiber Reinforced Polymers: Modern Materials in Bridge Engineering," Structural Engineering International, Journal of the International Association for Bridge and Structural Engineering, vol. 2, nº 1 (1992), pp. 7-12.

Micelli, F., Nanni, A.: "Durability of FRP rods for concrete structures". Construction and Building Materials, vol. 18 (2004), pp. 491-503.

Miklofsky, H. A., Gonsior, M. J., and Santini, J. J.: "Further studies of epoxy bonding compounds". National Academy of Sciences, National Research Council. Washington, D.C, (1965).

Nanni, A., Bakis, E., Boothby, E.: "Test Methods for FRP-Concrete Systems Subjected to Mechanical Loads: State of the Art Review," Journal of Reinforced Plastics and Composites, vol. 14 (1995), pp. 524-588.

Nanni, A., Dolan, W.: "Fiber-Reinforced- Plastic Reinforcement for Concrete Structures-International Symposium”, SP-138, American Concrete Institute, Farmington Hills, Mich., (1993), pp. 977.

Nanni. A., Al-Zaharani, M.M., Al-Dulaijan, S.U, Bakis, C.E., Boothby, T.E.: "Bond of reinforcement to concrete - experimental results". Proceedings of second international RILEM symposium (FRPRCS-2), London: E and FN Spon, (1995b), pp. 114-117.

Nanni, A.: "Fiber-Reinforced-Plastic (FRP) Reinforcement for Concrete Structures: Properties and Applications," Developments in Civil Engineering, Elsevier, vol. 42 (1993a), pp. 450. 
Nanni, A.: "Guide and Specifications for the Use of Composites in Concrete and Masonry Construction in North America". In Proceedings of the International Workshop Composites in Construction: A Reality, Cosenza, E., Manfredi, G., and Nanni, A., eds. American Society of Civil Engineers, Reston, (2001), pp. 9-18.

Narendra, T., GangaRao, H.: "Bond behavior of FRP reinforcing bars-The state of the art”. 46 th. International SAMPE Symposium. May 6-10, (2001), pp. 1784-1796.

Neville, M.: Properties of Concrete, Fourth edition. Addison Wesley Longman Limited, Harlow, England, (1996).

Nielsen, E.: Mechanical Properties of Polymers and Composites, Volume 2, Marcel Dekker, New York, (1974).

Odagiri, T., Matsumoto, K., Nakai, H.: "Fatigue and Relaxation Characteristics of Continuous Aramid Fibre Reinforced Plastic Rods". Proceedings of the Third International Symposium on Non-Metallic (FRP) Reinforcement for Concrete Structures (FRPRCS-3), Sapporo, Japan, vol..2 (1997), pp. 227-234.

Okamoto, T., Matsubara, S., Tanigaki, M., Jasuao, K.: "Practical Application and Performance of PPC Beams Reinforced with Braided FRP Bars". In International Symposium on Fiber-Reinforcement-Plastic Reinforcement for Concrete Structures, SP138, Nanni, A., and C. W. Dolan, C. W., eds. American Concrete Institute, Farmington Hills, (1993), pp. 875-894.

Okelo, R., Yuan, L.: "Bond strength of fiber reinforced polymer rebars in normal stregth concrete". Journ. Compo. Construc. Vol. 9, nº 3 (2005), pp. 203-213.

Paciornik, S., Martinho, F.M., de Mauricio, M.H.P., and d'Almeida, J.R.M.: “Analysis of the mechanical behavior and characterization of pultruded glass fiber-resin matrix composites”, Composites Sci. Tech., vol. 63 (2003), pp.295-304.

Park, R., and Paulay, T.: Estructuras de concreto reforzado. Editorial Limusa, Mejico, (1983). ISBN 968-18-0100-8. 
Parkyn, B.: Glass reinforced plastics, In: Encyclopedia of Polymer Science and Engineering, 2nd Ed., London: CRC Press, 1970; New York: John Wiley \& Sons, (1985).

Pecce, M., Manfredi, G., Realfonzo, R. Cosenza, E.: "Experimental and analytical evaluation of bond properties of GFRP bars”. ASCE J. Mater. Civil Eng., vol. 13, n 4 (2001), pp. 282-290.

Pepper, T.: Polyester Resins. In: ASM Handbook Volume 21 Composites, ASM International, Material Park, Ohio, (2001), pp. 90-96.

Peters, S. T.: Handbook of composites. Chapman \& Hall, Process research, Mountain Viiew, California, USA, (1998). ISBN 0-412-54020-7.

Pritchard, G. and Speake, S.D.: "Effects of temperature on stress-rapture times in glass/polyester laminates”, Composites, vol. 19,nº 1 (1998), pp. 29-35.

Pulltrall INC.: Cataloge V-ROD-Specifications Carbon (2012). 700, 9th Street North, Thetford Mines (Quebec) Canada G6G 6Z5. http://www.pultrall.com/en/index.asp

Plecnik, J., and Ahmad, H.: "Transfer of Composite Technology to Design and Construction of Bridges," Final Report to USDOT, Contract No. DTRS 5683-C000043, (1998).

Porter, L., Mehus, J., Young, K., Barnes, B., O’Neil, F.: “Aging Degradation of fibre composite reinforcement for concrete structures". Advanced Comp. Mats.in Bridges and Structures, 2nd Int. Conference, Canada, (1997), pp. 641-648.

Protasio, F., Carino, N.: "Tensile and nondestructive testing of frp bars". Journal of Composites for Construction, vol. 2, $\mathrm{n}^{\mathrm{o}} .1$ (1998), pp. 17-27.

Rahman AH, Kingsley C, Richard J and Crimi J.: "Experimental Investigation of the Mechanism of Deterioration of FRP Reinforcement for Concrete". Proc. 2nd Intl. Conf. On Fibre Comp.in Infrastructure ICCI'98, Vol. 2 (1998), pp. 501-511. 
Rao, R.M.G.K., Balasubramanian, N., and Chanda, M.: "Factors affecting moisture absorption in polymer composites", Part-II, Influence of External Factors, Environment Effects on Composite Materials, vol. III, Springer, G. (Ed.), Lancaster, PA: Technomic Publishing Company, (1981).

RILEM. Bond test for reinforcing steel 2: pullout test. Recommendation RC6, E. and F.N. Spon., (1983), pp. 218-219.

Rizkalla, S. H.: "A New Generation of Civil Engineering Structures and Bridges," Proceedings of the Third International Symposium on Non-Metallic (FRP) Reinforcement for Concrete Structures (FRPRCS-3), V. 1, Japan Concrete Institute, Tokyo, Japan, (1997), pp. 113-128.

Rizkalla, S., Mufti, A.: Reinforcing Concrete with Fibre Reinforced Polymers, ISIS Design Manual No 3, ISIS Canada, Manitoba, (2001).

Robert, M., Benmokrane, B.: "Behavior of GFRP Reinforcing Bars Subjected to Extreme Temperatures”. Journal of Composites forConstruction, Vol. 14 (2010), No. 4

Rossetti, V.A., Galeota, D., Giammatteo, M.M.: "Local bond stress-slip relationships of glass fibre reinforced plastic bars embedded in concrete". Mater. Struct., vol. 28, $\mathrm{n}^{\circ} 6$ (1995), pp. 340-344.

Saadatmanesh, H., Tannous, E.: "Relaxation, Creep and Fatigue Behavior of Carbon Fiber Reinforced Plastic Tendons”. ACI Materials Journal, vol. 96, no 2 (1999a), pp. 143-153.

Saadatmanesh, H., Tannous, F.: "Durability of FRP rebars and tendons, Non-Metallic (FRP) Reinf. For Conc. Structures". Proc. 3rd Intl. Symp., vol. 2 (1997), pp 147-154.

Saadatmanesh, H., Tannous, E.: "Long-term Behavior of Aramid Fiber Reinforced Plastic (AFRP) Tendons”, ACI Materials Journal, vol. 96, nº 3 (1999b), pp. 297-305.

Saafi, M.:"Effect of Fire on FRP Reinforced Concrete Members," Composite Structures, vol. 6. n 58 (2002), pp. 11-20. 
Sakashita, M., Masuda, Y., Nakamura, K., Tanano, H., Nishida, I., Hashimoto, T.: "Deflection of Continuous Fiber Reinforced Concrete Beams Subjected to Loaded Heating". In Proceedings of the Third International Symposium on Non-Metallic (FRP) Reinforcement for Concrete Structures (FRPRCS-3) Sapporo, Japan, vol. 2 (1997), pp. 51-58.

Sasaki I, Nishizaki I, Sakamoto H, Katawaki K and Kawamoto Y.: "Durability Evaluation of FRP Cables by Exposure Tests", Non-Metallic (FRP) Reinforcement for Concrete Structures, Proc. 3rd Intl. Symp., Vol. 2 (1997), pp 131-137.

Schaff, R.: Fatigue and Life Prediction. ASM Handbook Volume 21 Composites, ASM International, Material Park, Ohio, (2001), pp. 252-258.

Schapery, A.: "Thermal Expansion Coefficients of Composite Materials Based on Energy Principles”. Journal of Composite Materials, vol. 2, nº 3 (1968), pp. 380-404.

Scheibe, M., Rostasy, S.: "Stress-rupture of AFRP subjected to alkaline and elevated temperaturas". Non-Metallic (FRP) Reinforcement for Concrete Structures, Proc 2nd Intl. Symp. on fiber composites in infrastructure, ICCI'98, vol. 2 (1997)-

Schwartz, M.: Composite Materials Handbook. 2nd Edition, McGraw-Hill, New York, (1992).

Seki, H., Sekijima, K., Konno, T.: "Test Method on Creep of Continuous Fiber Reinforcing Materials". Proceedings of the Third International Symposium on NonMetallic (FRP) Reinforcement for Concrete Structures (FRPRCS-3) Sapporo, Japan, vol. 2(1997), pp. 195-202.

Sen R, Shahawy M, Rosas J. and Sukumar S.:"Durability of AFRP \& CFRP pretensioned piles in a marine environment", Non-Metallic (FRP) Reinforcement for Concrete Structures, Proc. 3rd Intl. Symp. Vol 2 (1997), pp 123-130.

Sen, R., Shahawy, M., Rosas, J., and Sukumar, S.: "Durability of AFRP pretensioned elements in a marine environment", ACI Struct. J., vol. 95,nº 5 (1998),pp. 578-587. 
Sheard P, Clarke JL, Dill M, Hammersley G and Richardson D.:"EUROCRETE Taking Account of Durability for Design of FRP Reinforced Concrete Structures”. NonMetallic (FRP) Reinforcement for Concrete Structures, Proc. 3rd Intl. Symp., Vol 2 (1997), pp 75-82.

Shield, C., French, C., and Retika, A.,: “Thermal and Mechanical Fatigue Effects on GFRP Rebar-Concrete Bond," Proceedings of the Third International Symposium on Non-Metallic (FRP) Reinforcement for Concrete Structures (FRPRCS-3), Japan Concrete Institute, Tokyo, Japan, vol. 2 (199), pp. 381-388

Sika S.A.U: Cataloge CarboDur Rods. (2011). 201 Polito Avenue, Lyndhurst, NJ 07071. http://esp.sika.com/

Steckel GL, Hawkins GF and Bauer JL.: "Environmental Durability of Composites for Seismic Retrofit of Bridge Columns". Proc. 2nd Intl. Conf. on Fibre Composites in Infrastructure ICCI'98, Vol. 2, (1998), pp. 460-475.

Sturgeon, J. B.: "Creep of fibre reinforced thermosetting resins." Creep of Engineering Materials, Chapter 10, Pomeroy, C. D., Editor, Heffers Printers Ltd., Cambridge, England, (1978).

Suratno, B.R., Ye, L., and Mai, Y.M.: "Simulation of temperature and curing profiles in pultruded composite rods", Composites Sci. Tech., vol. 58 (1998),pp. 191-197

Tadros, G., Tromposch, E., Mufti, A.: "University Drive/Crowchild Trail Bridge Superstructure Replacement," Proceedings of the Second International Conference on Composites in Infrastructure (ICCI-98), V. 1, Tucson, Ariz., (1998), pp. 693-704.

Taerwe, L.: "FRP Activities in Europe: Survey of Research and Applications," Proceedings of the Third International Symposium on Non-Metallic (FRP) Reinforcement for Concrete Structures (FRPRCS-3), Japan Concrete Institute, Tokyo, Japan, vol 1 (1997), pp. 59-74.

Takewaka, K., and Khin, M.: "Deterioration of Stress-Rupture of FRP Rods in Alkaline Solution Simulating as Concrete Environment," Advanced Composite Materials in 
Bridges and Structures, M. M. El-Badry, ed., Canadian Society for Civil Engineering, Montreal, Québec, Canada, (1996), pp. 649-664.

Tamusz, V., Apinis, R., Modniks, J., Tepfers, R.: “The performance of bond of FRP reinforcement in concrete". 46 th International SAMPE Symposium. May (2001), pp. 1738-1748.

Tannous, E., Saadatmanesh, H.: "Durability and long-term behavior of carbon and aramid FRP tendons". Proc. 2nd Intl. Conf. on fiber composites in infrastructure, ICCI'98, vol. 2 (1998), pp. 524-538.

Tepfers, R.: "Bond clause proposal for FRP-bars/rods in concrete based on CEB/FIP Model Code 90. Part 1: design bond stress for FRP reinforcing bars”. Struct. Concrete, vol. $7, \mathrm{n}^{\circ} 2$ (2006), pp. 47-55.

Tepfers, R., De Lorenzis, L.; "Bond of FRP reinforcement in concrete”. Mechanics of Composite Materials, vol. 39, nº 4 (2003), pp. 315-328.

Tepfers, R., and Karlsson, M.: "Pull-out and tensile reinforcement splice tests using FRP C-bars" Proc., 3rd Int. Symp. on Non-Metallic (FRP) Reinforcement for Concrete Structures, Japanese Concrete Institute, Sapporo, Japan, vol. 2 (1997), pp. 357-364.

Tighiouart, B., Benmokrane, B., Gao, D.: "Investigation of bond in concrete member with fibre reinforced polymer (FRP) bars". Construction and Building Materials, vol. 12 (1998), pp. 453-462.

Tokyo Rope, 2000, “CFCC, Carbon Fiber Composite Cable,” Product Circular No. 9912T-SA, Tokyo Rope Manufacturing Co., Tokyo. (http://www.tokyorope.co.jp/).

Tomosawa F and Nakatsuji T.: "Evaluation of ACM Reinforcement Durability By Exposure Test. Non-Metallic (FRP) Reinforcement for Concrete Structures": Proc. 3rd Intl. Symp., Vol 2 (1997), pp. 139-146.

Toutanji H and El-Korchi T.:"Tensile Durability Performance of Cementitious Composites Externally Wrapped with FRP Sheets", Proc. 2nd Intl. Conf. on Fibre Composites in Infrastructure ICCI'98, Vol. 2 (1998), pp. 410-421. 
Vijay, P.V., GangaRao, H.V.S., and Bargo, J.M.: Mechanical Characterization of Recycled Thermoplastic Polymers for Infrastructure Applications, ACMBS-3, Ottawa, Canada, (2000), pp. 55-60.

Wai How, S., Raghavan, J., Rizkalla, S.: "Fundamental mechanisms of bonding of glass fiber reinforced polymer reinforcement to concrete". Construction and Building Materials., vol. 25 (2011), pp. 2813-2821.

Wang, N., and Evans, J. T.: "Collapse of Continuous Fiber Composite Beam at Elevated Temperatures," Composites, V. 26, No. 1 (1995), pp. 56-61.

Wang, Y., Womg, P., Kodur, V.: “An experimental study of the mechanical properties of fibre reinforced polymer (FRP) and steel reinforcing bars at elevated temperatures". Composite Structures, vol. 80 (2007), pp. 131-140.

Yamaguchi, T., Kato, Y., Nishimura, T., Uomoto, I.: “Creep Rupture of FRP Rods Made of Aramid, Carbon and Glass Fibers". In Proceedings of the Third International Symposium on Non-Metallic (FRP) reinforcement for Concrete Structures (FRPRCS-3), Japan Concrete Institute, Sapporo, Japan, vol. 2 (1997), pp. 179-186.

Ye, P., Feng, P., Zhang, K., Lin, L., Hong, H., Yue, R., Zhang, N., and Yang, T.: "FRP in Civil Engineering in China: Research and Applications," Proceedings of the Sixth International Symposium on FRP Reinforcement for Concrete Structures (FRPRCS-6), K. H. Tan, ed., Singapore, (2003), pp. 1401.

Yuan, W., and Mirmiran, A.: "Buckling Analysis of Concrete-Filled FRP Tubes," 41 International Journal of Structural Stability and Dynamics, World Scientific. (in press), (2001).

Xu, X.: "Experimental Study and Numerical Simulation of Bond Behaviors Between FRP Bar and Concrete”. Advanced Materials Research, vol. 168-170 (2011), pp. 21342138. 


\section{Anejo I: "Gráficas Experimentales de Tensión Adherente-Deslizamiento"}

I. Barras de CFRP arenadas CA8:

a. Condición Térmica de Hielo/Deshielo o -20 ${ }^{\circ} \mathrm{C}$.

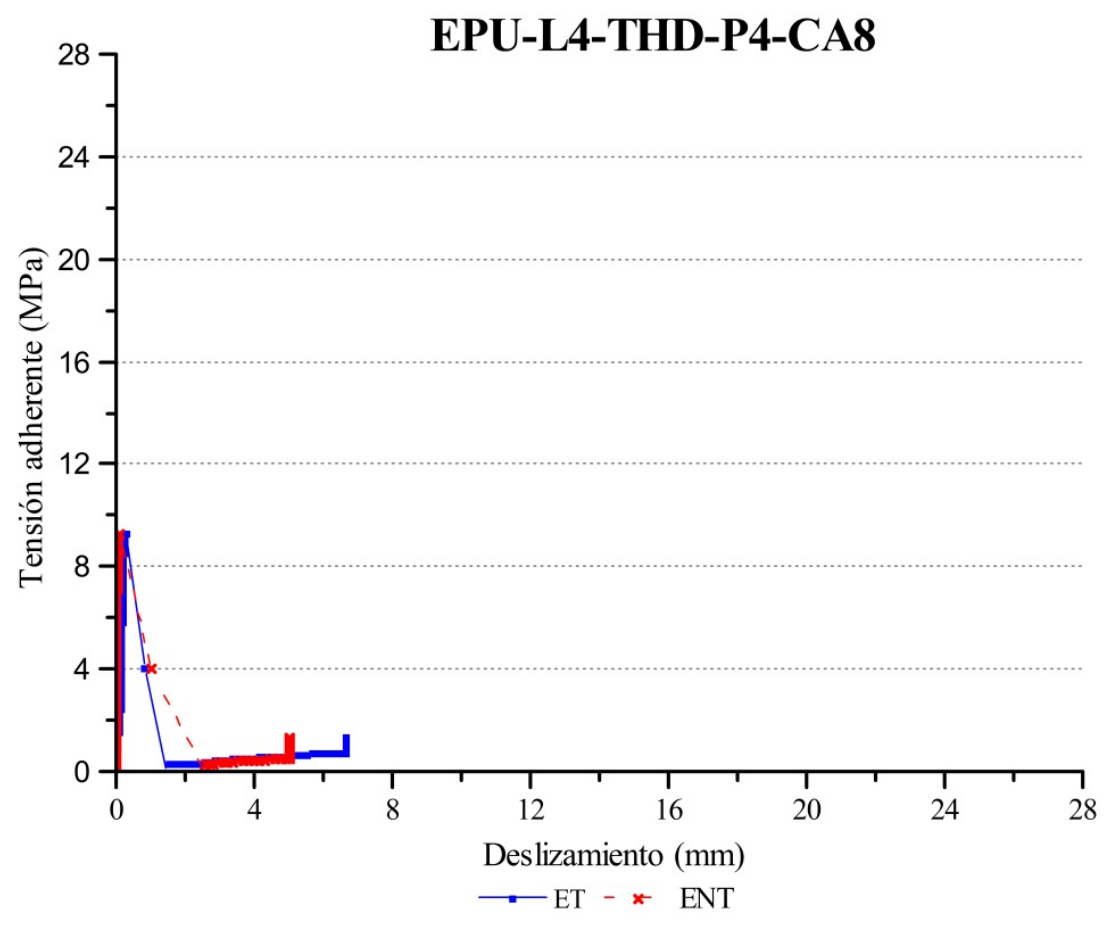



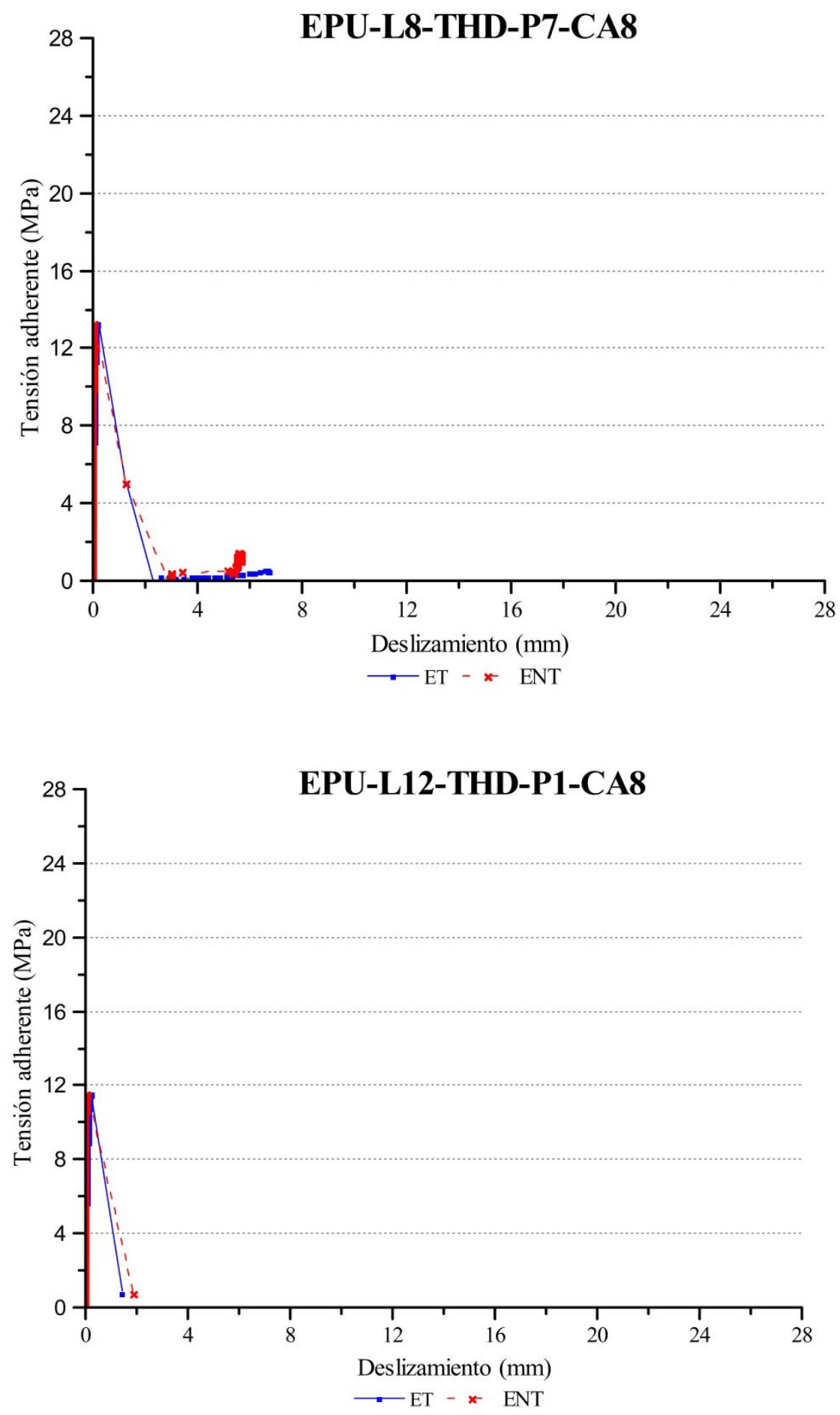

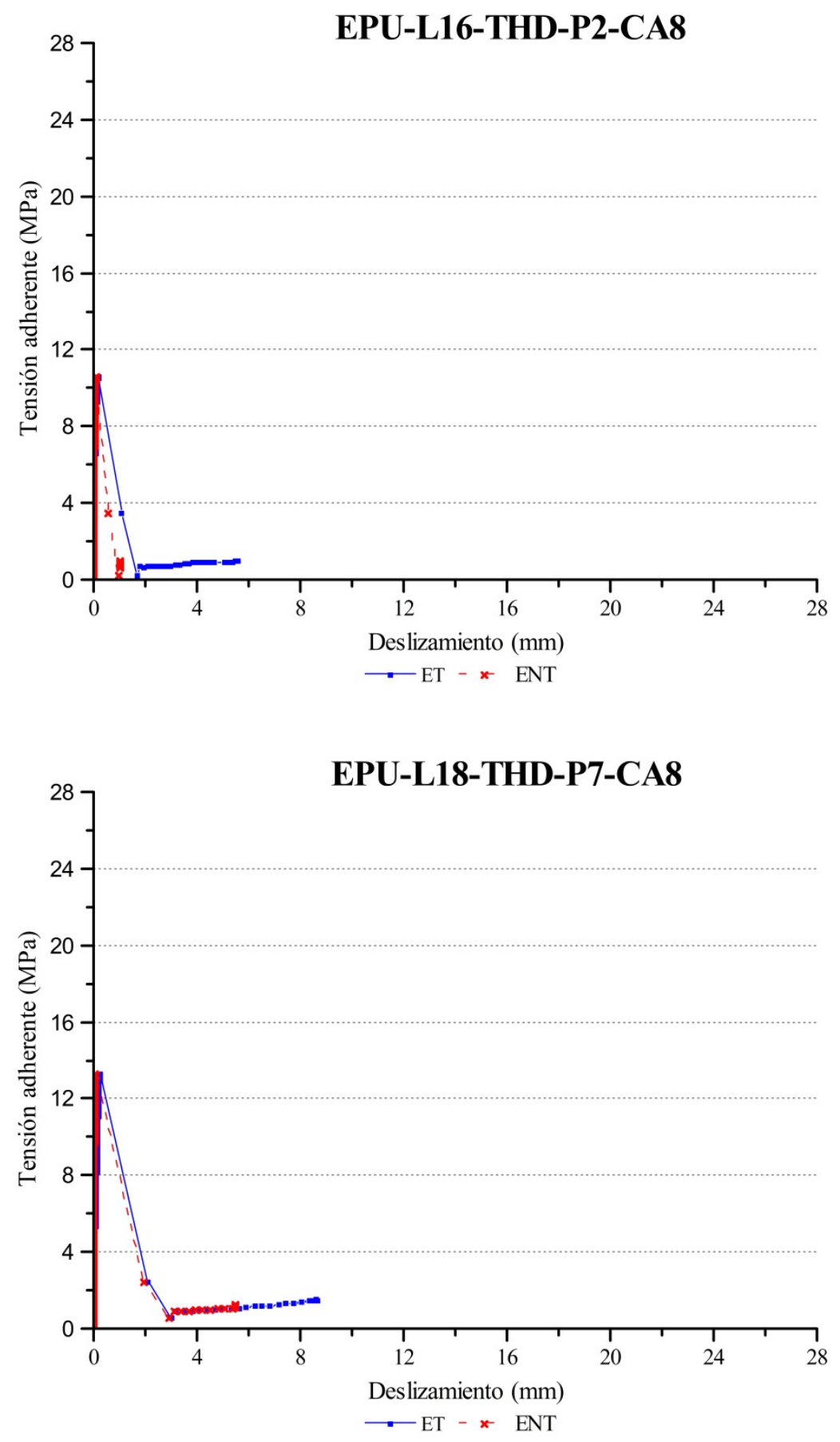
b. Condición Térmica de $5^{\circ} \mathrm{C}$.
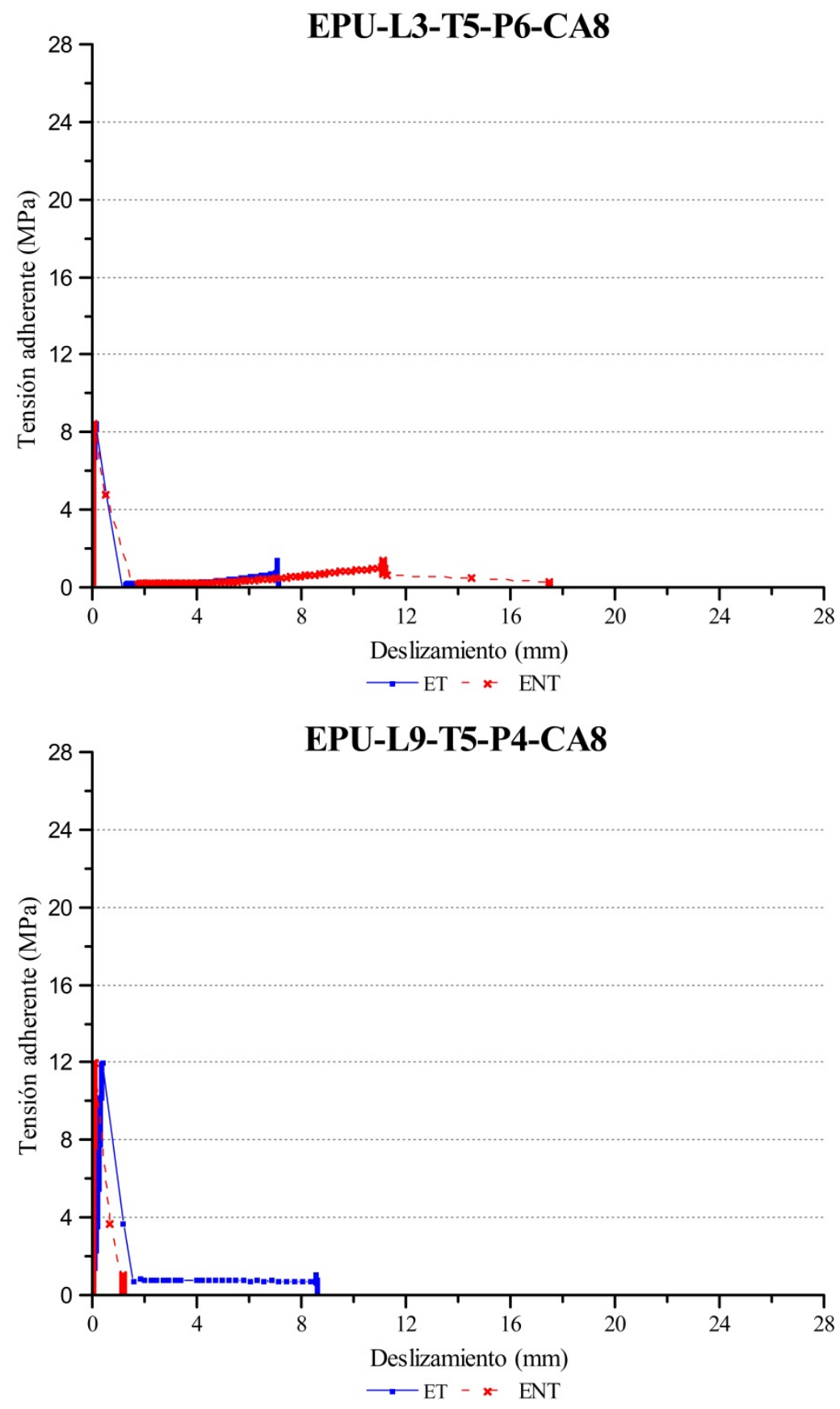

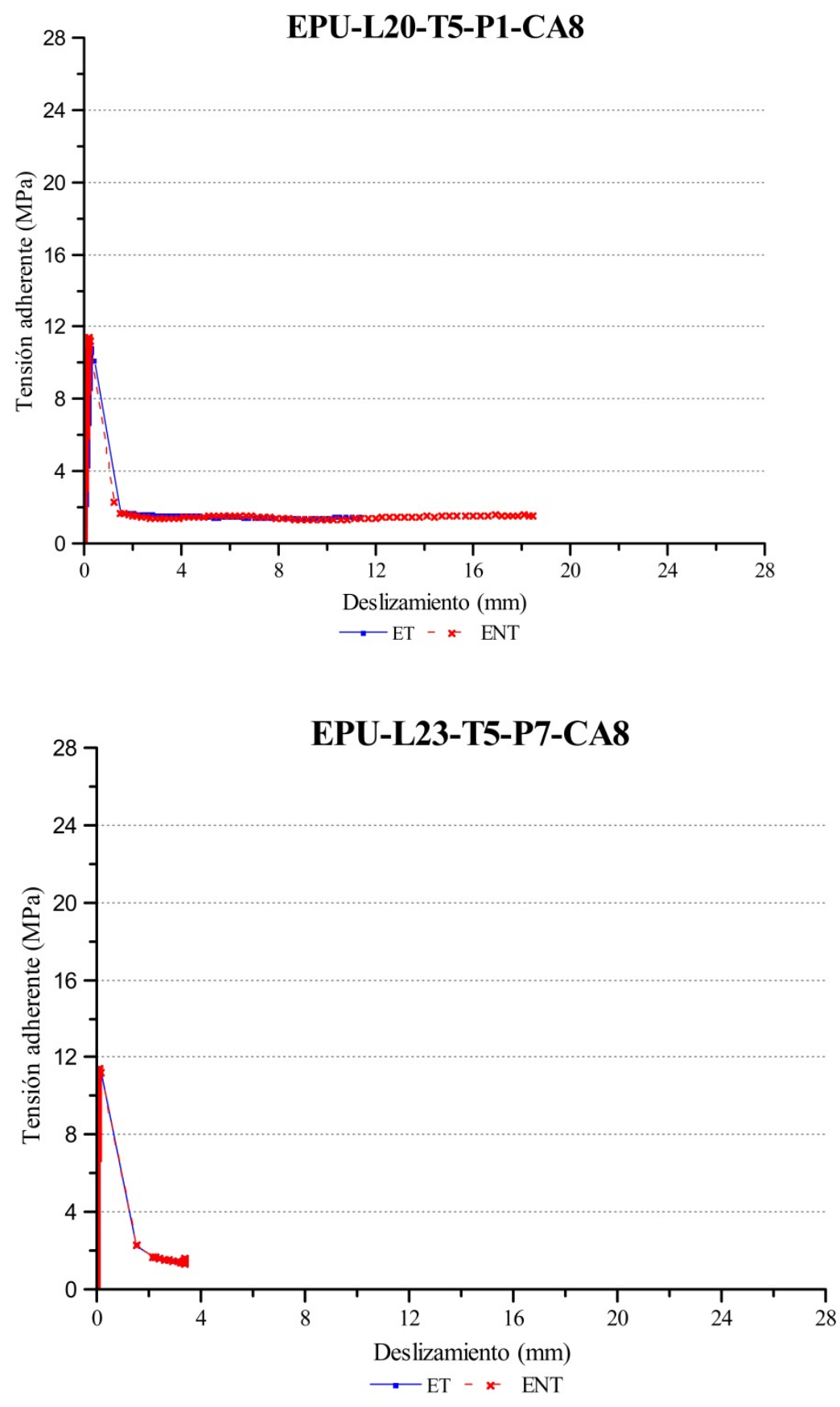


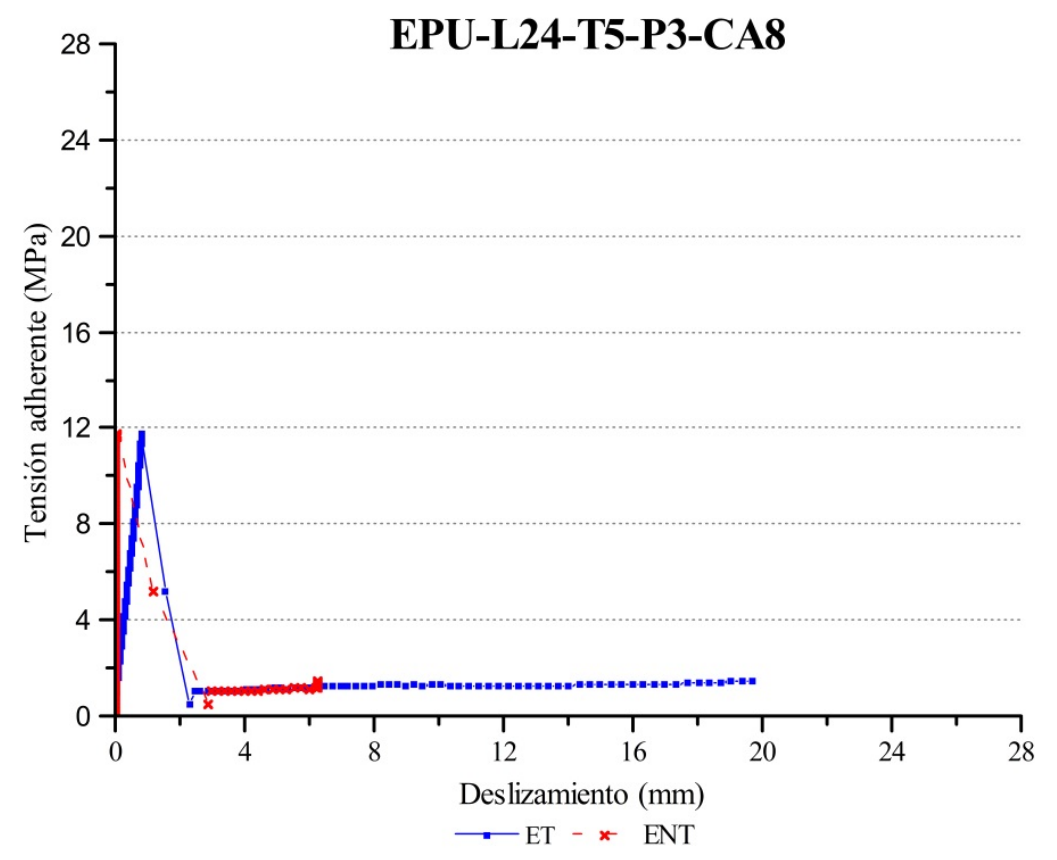

c. Condición Térmica de $20^{\circ} \mathrm{C}$.

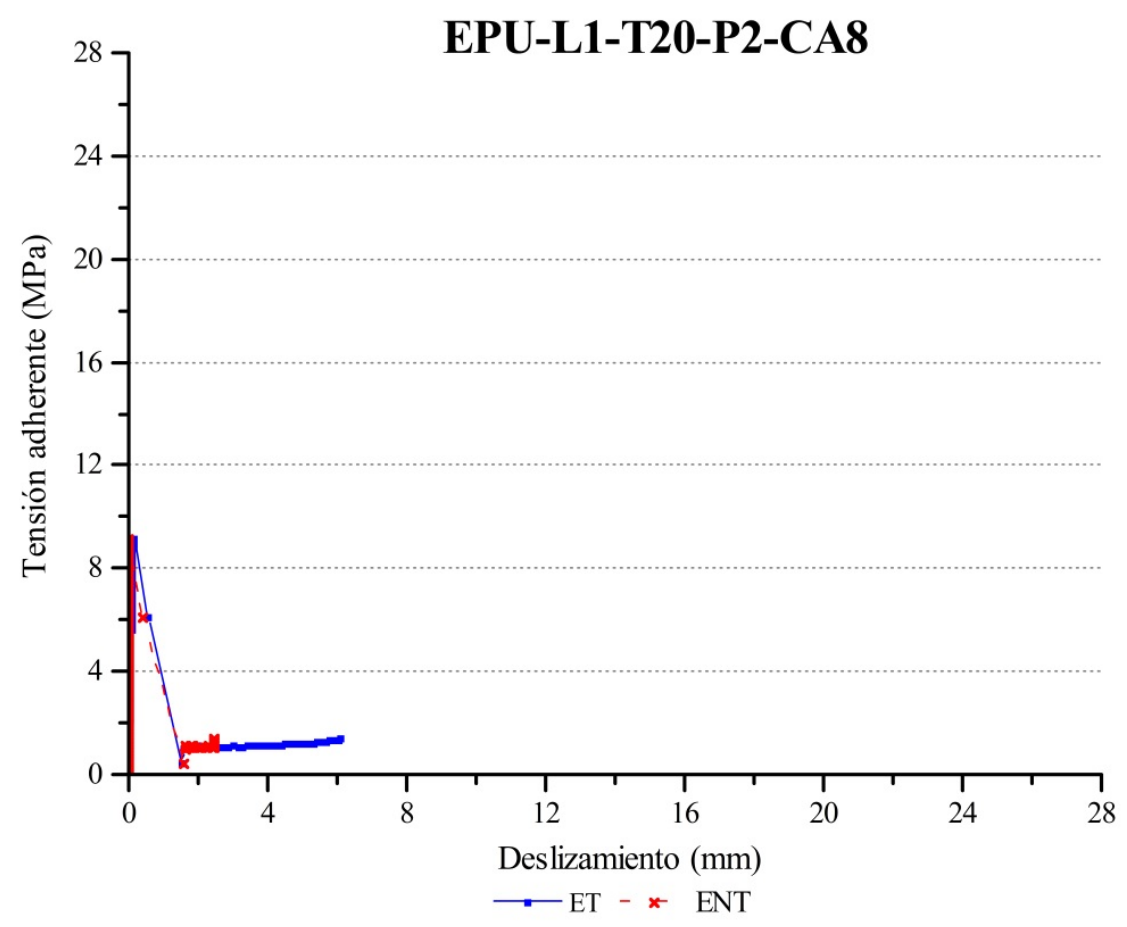



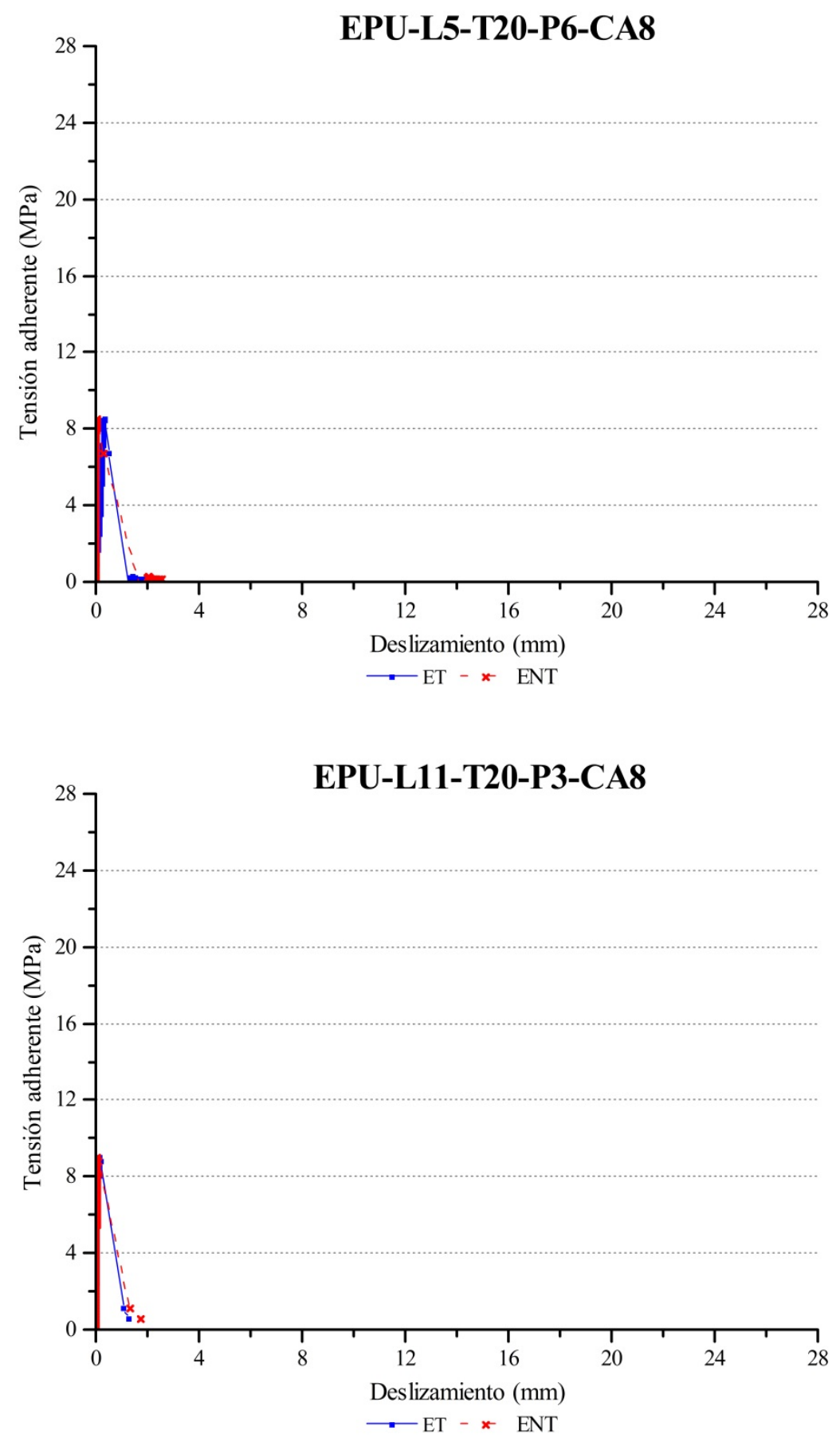

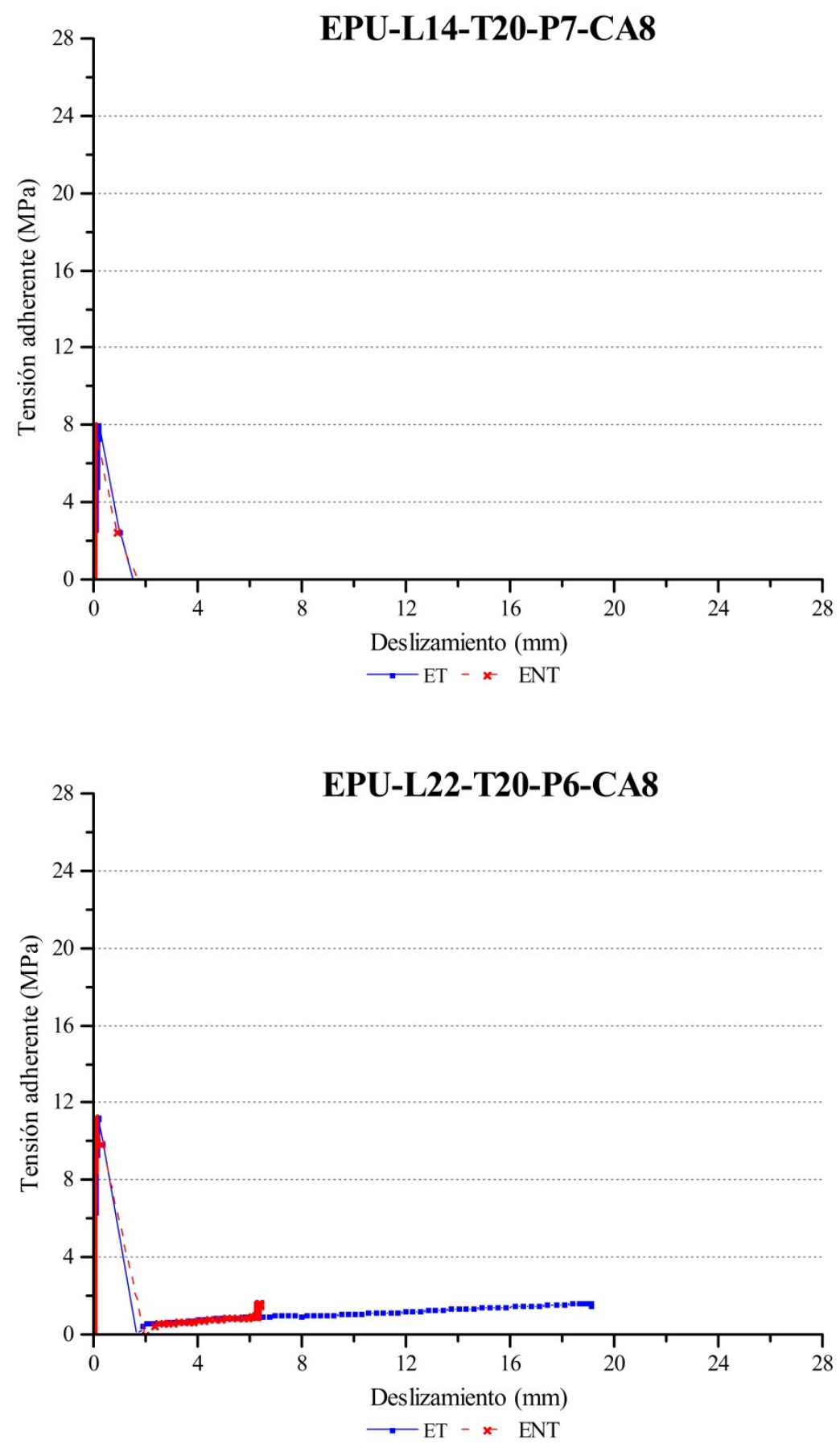


\section{d. Condición Térmica de $40^{\circ} \mathrm{C}$.}
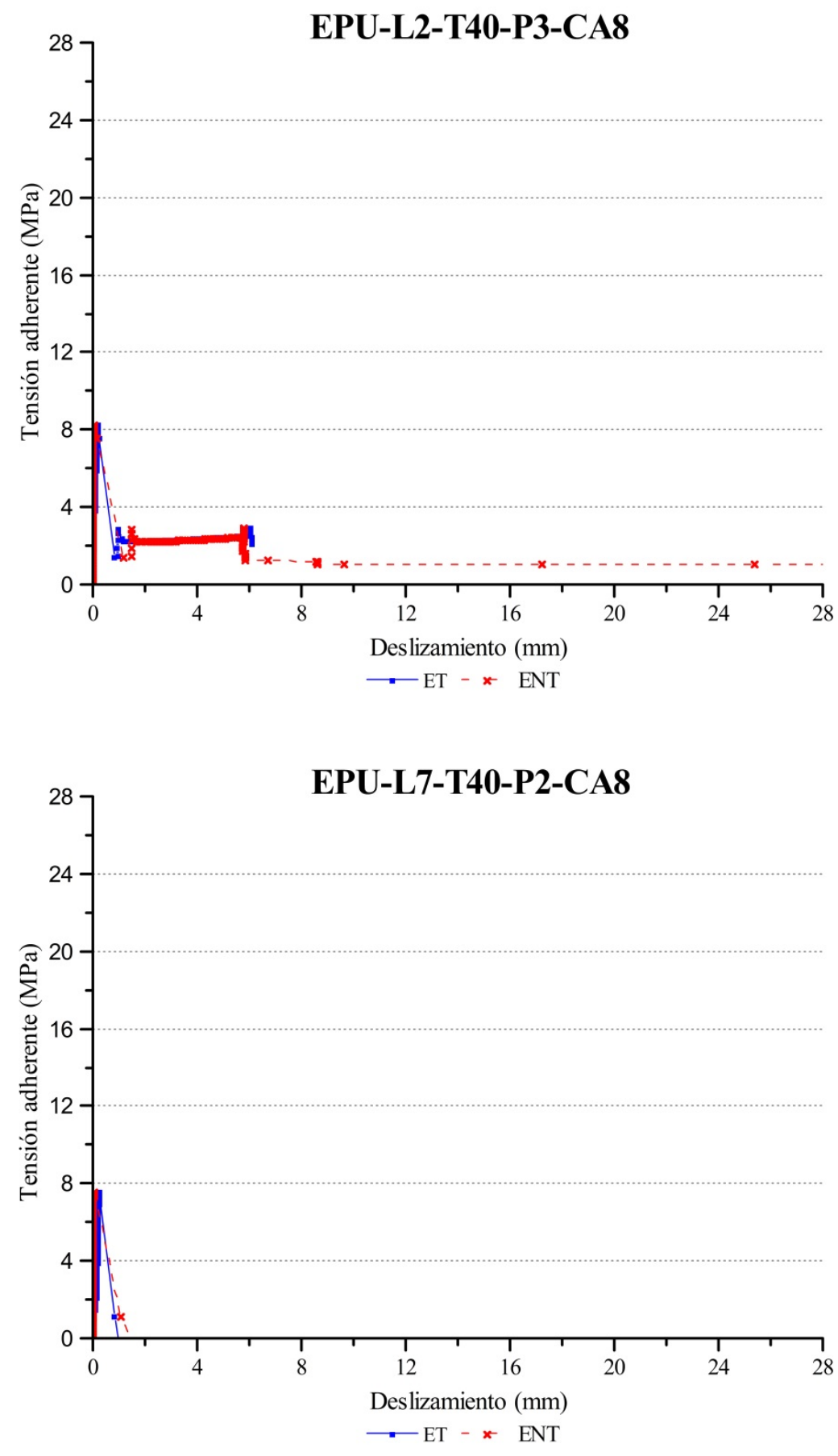

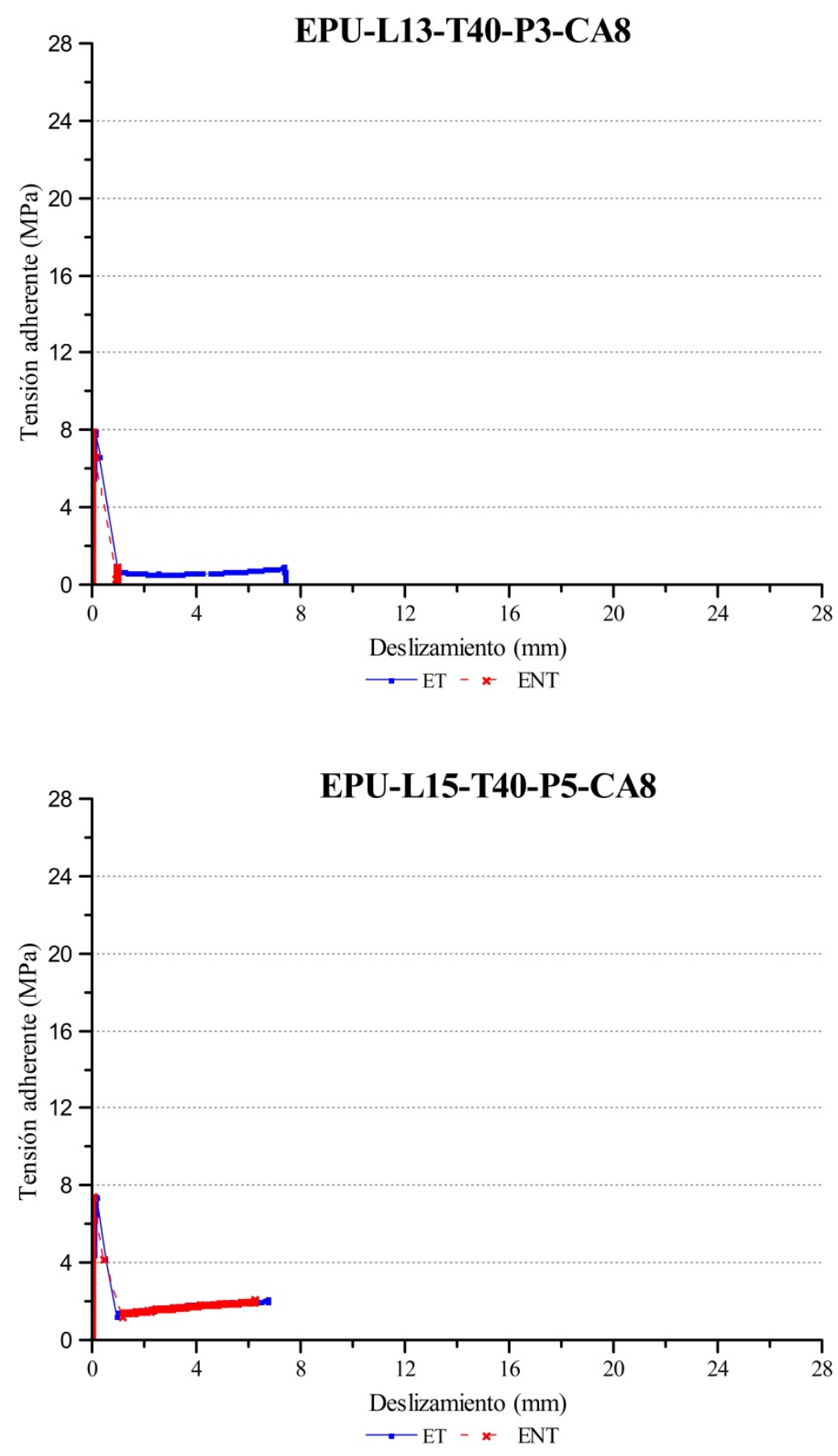


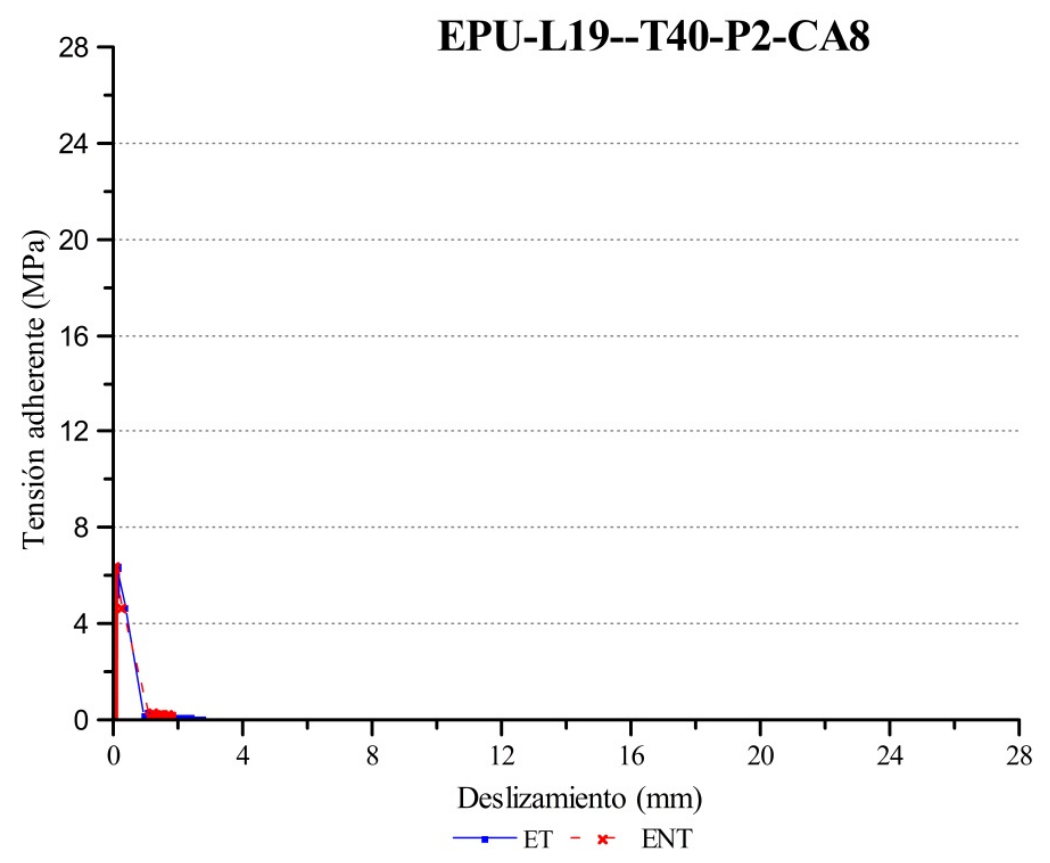

e. Condición Térmica de $80^{\circ} \mathrm{C}$.

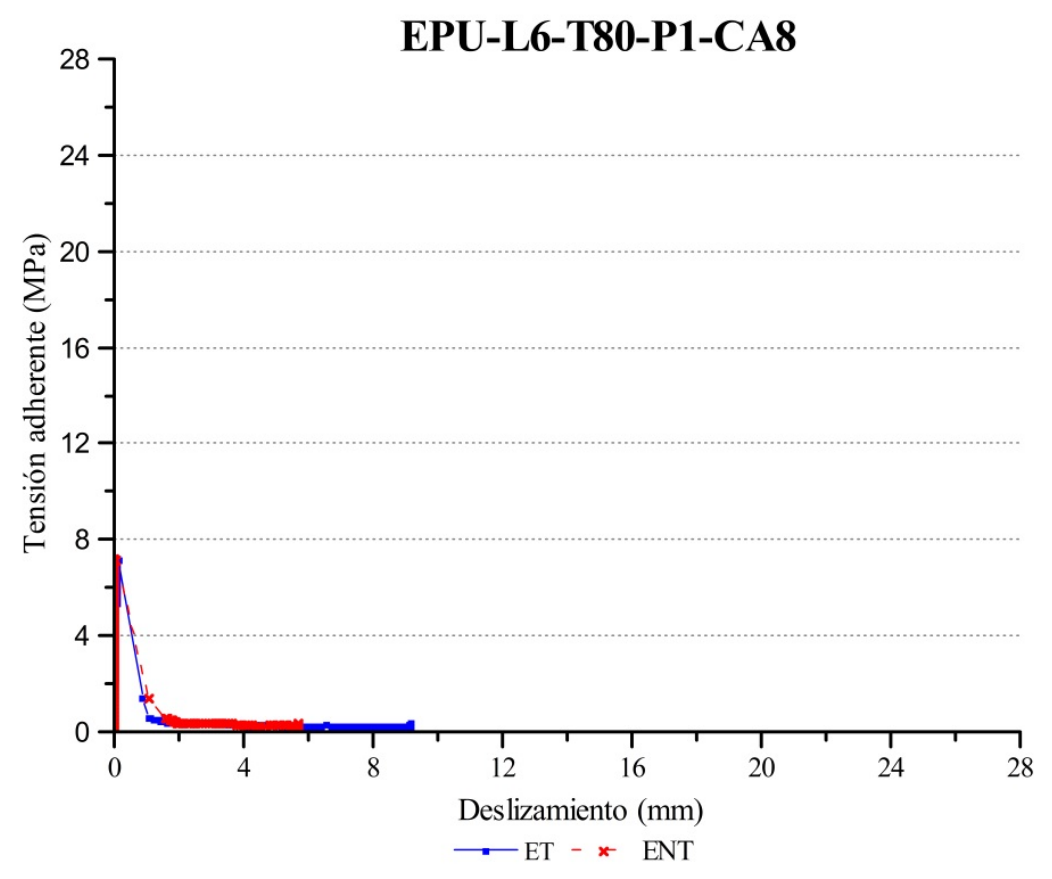



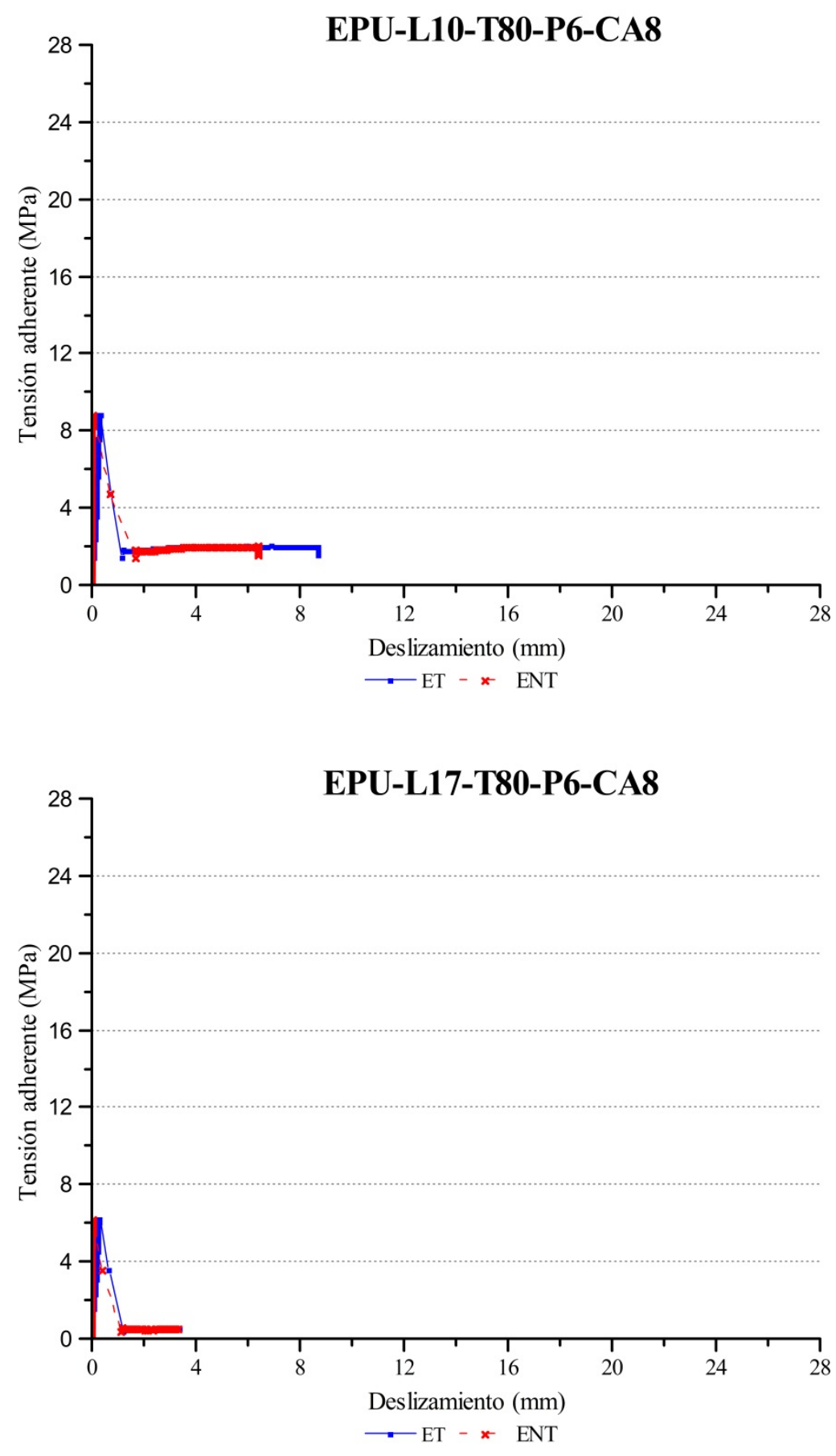

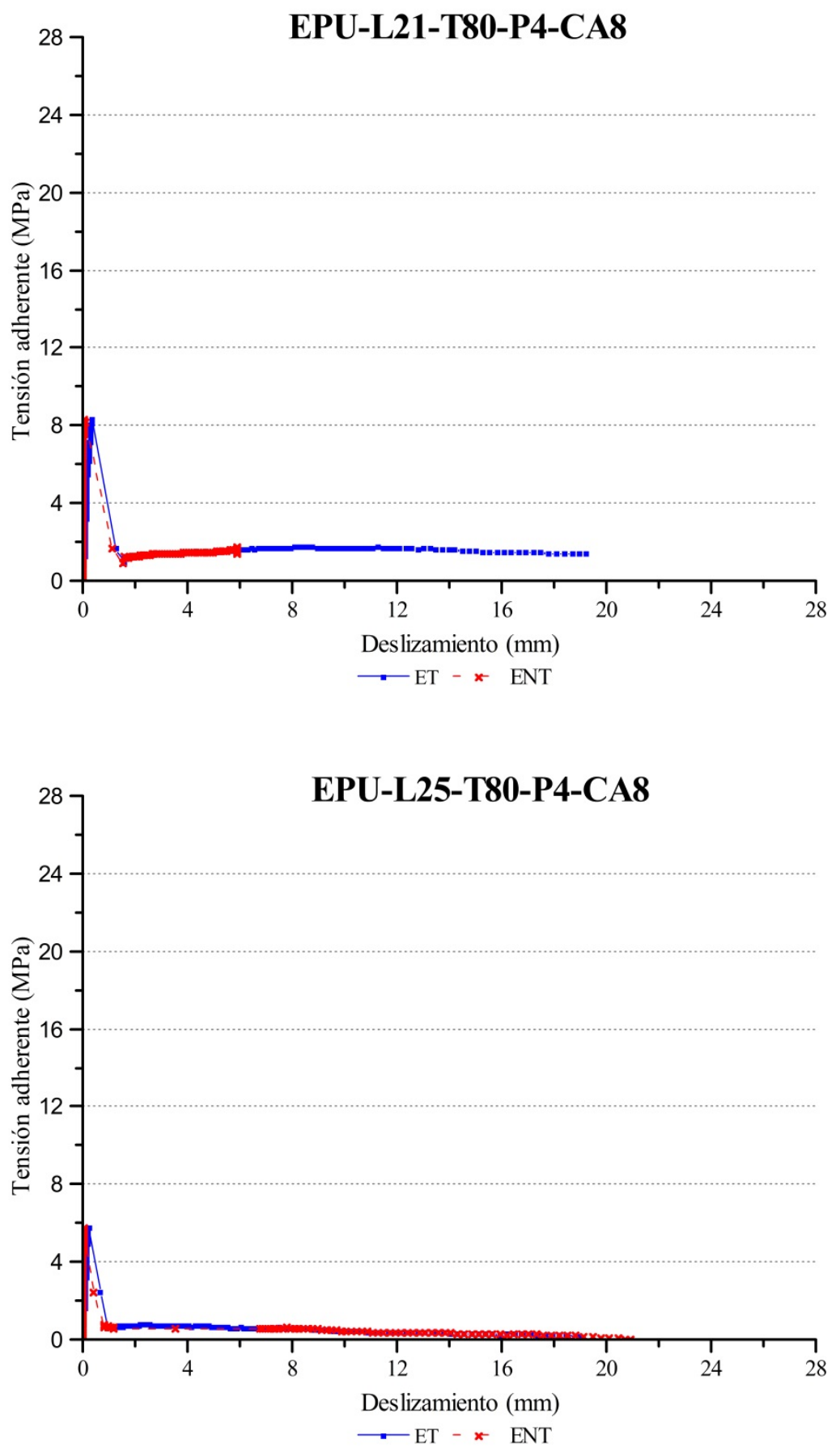


\section{Barras de CFRP arenadas CA14:}

a. Condición Térmica de Hielo/Deshielo o -20 ${ }^{\circ} \mathrm{C}$.
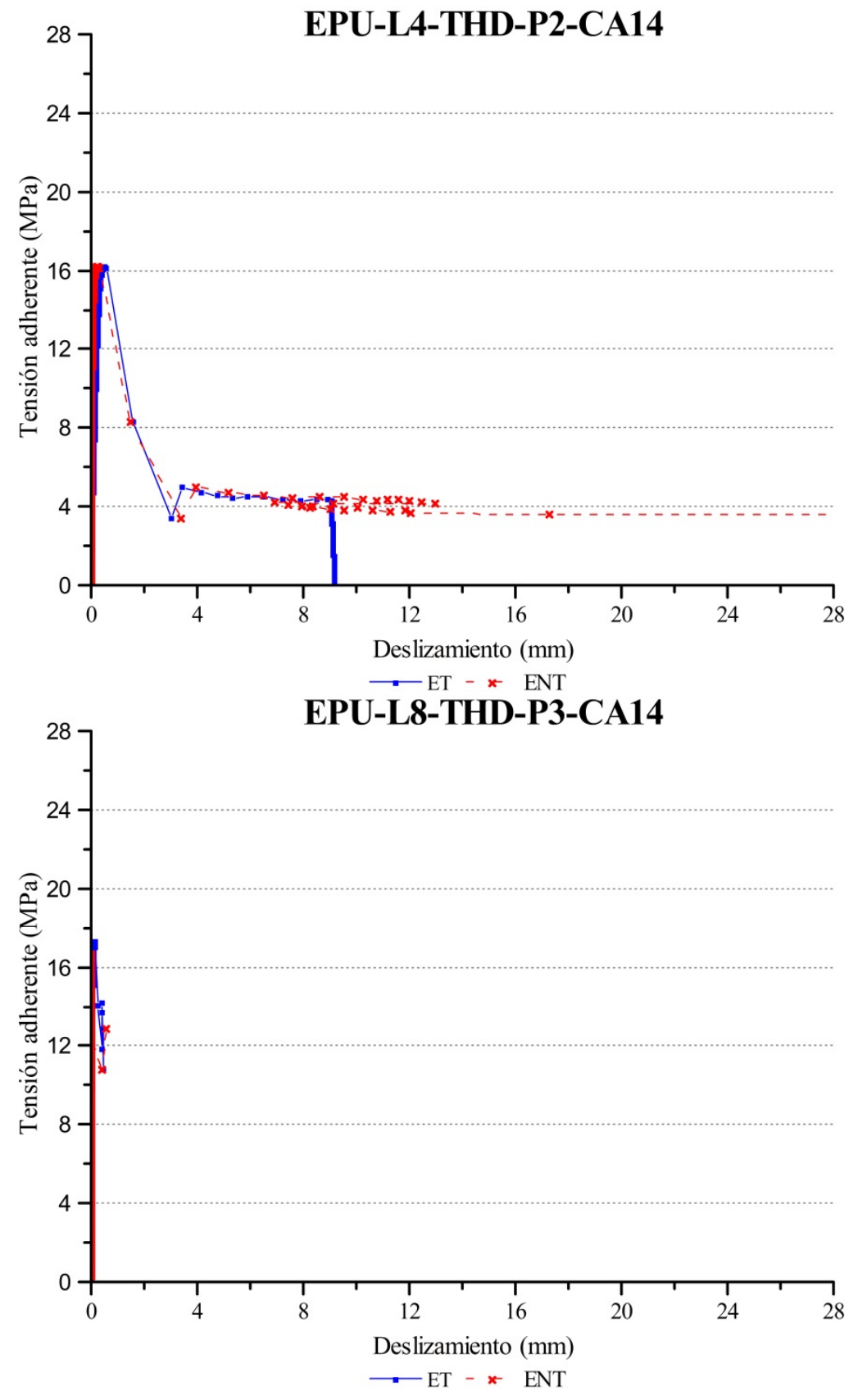

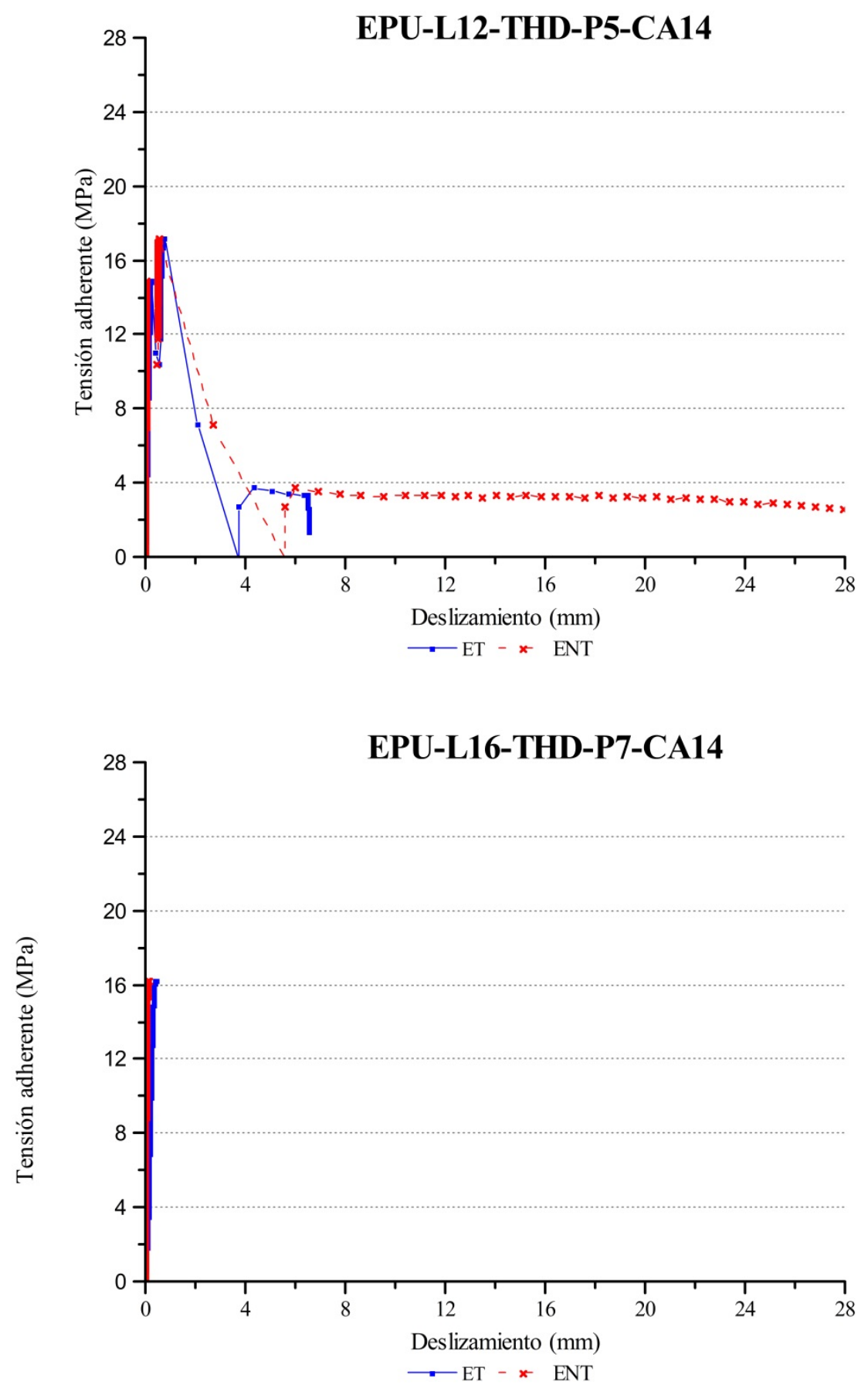


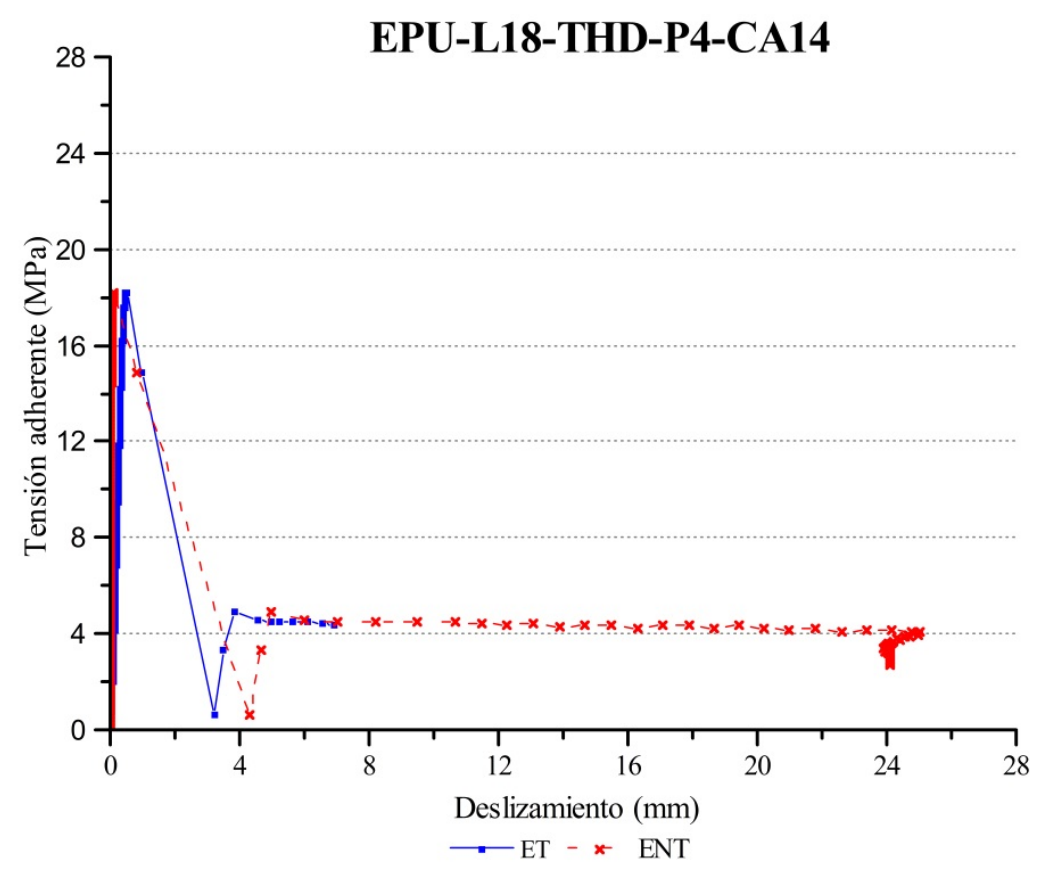

b. Condición Térmica de $5^{\circ} \mathrm{C}$.

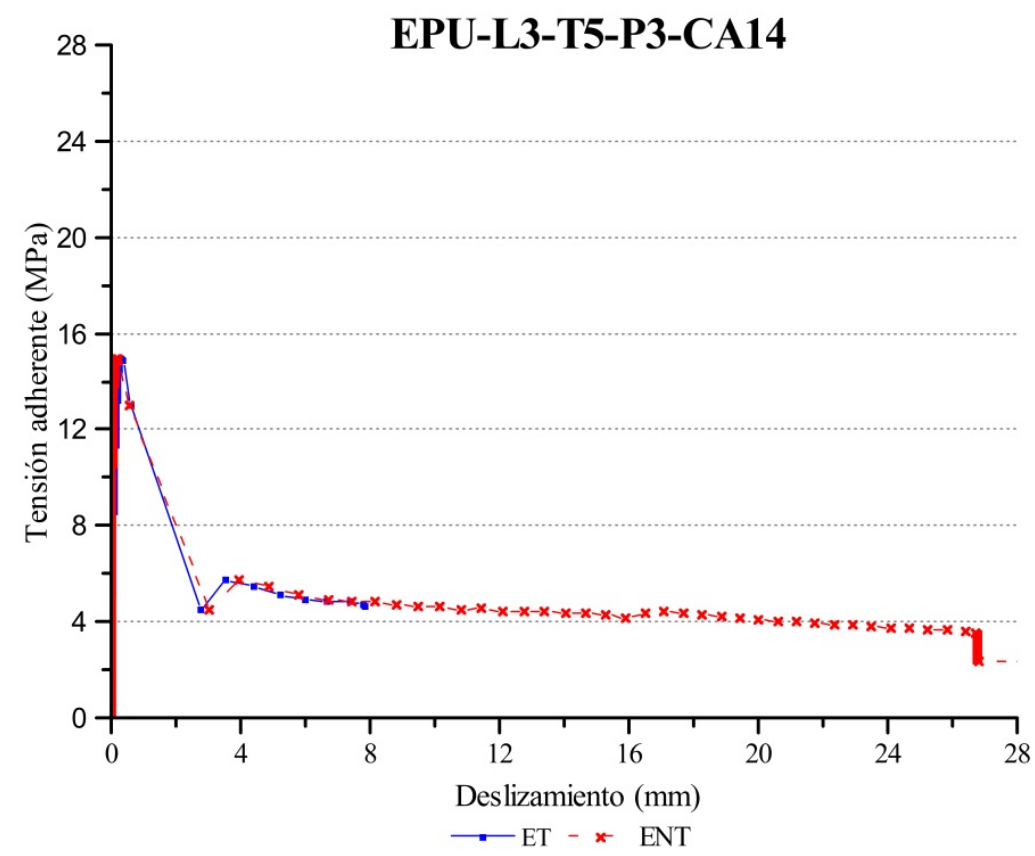



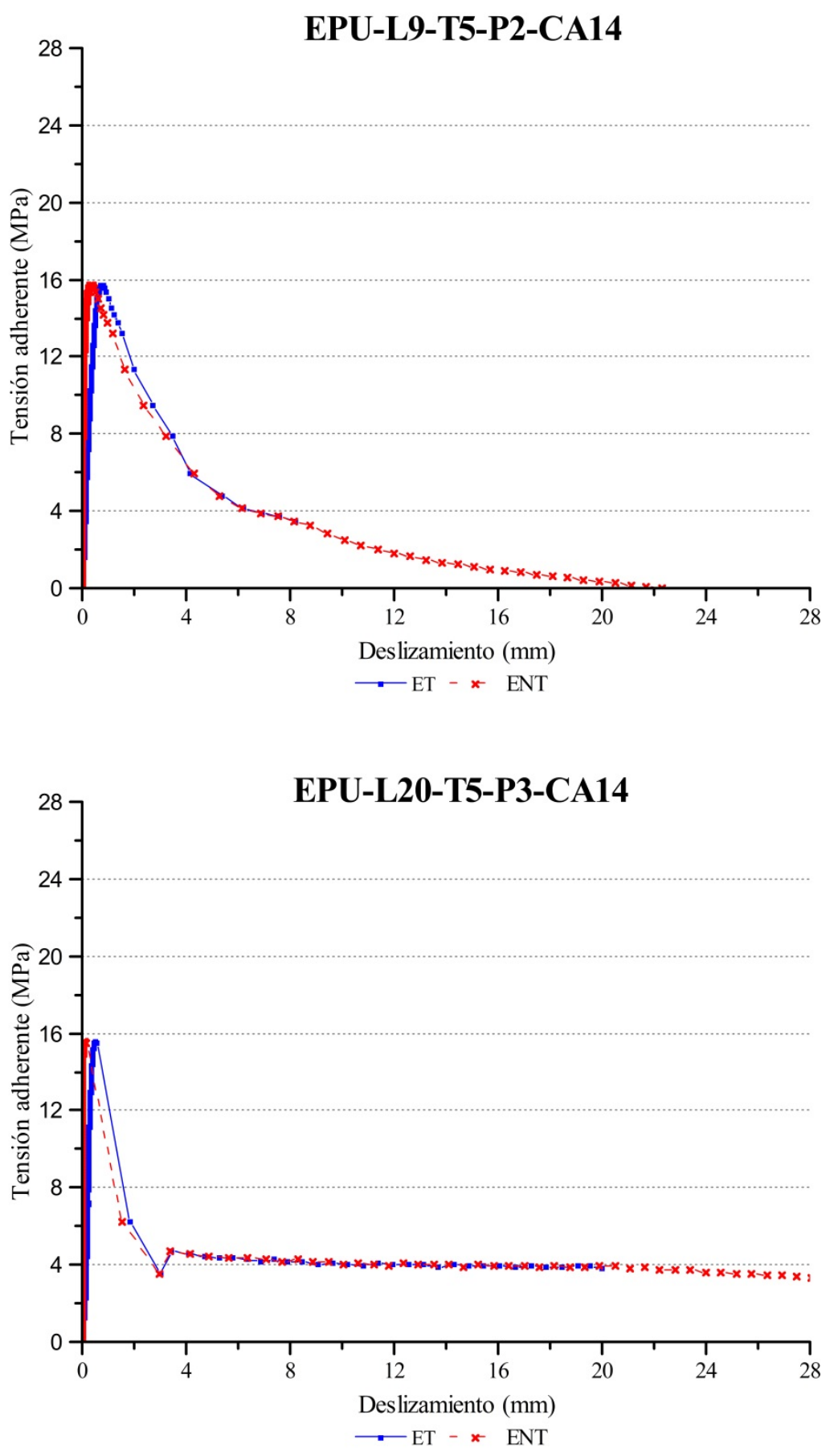

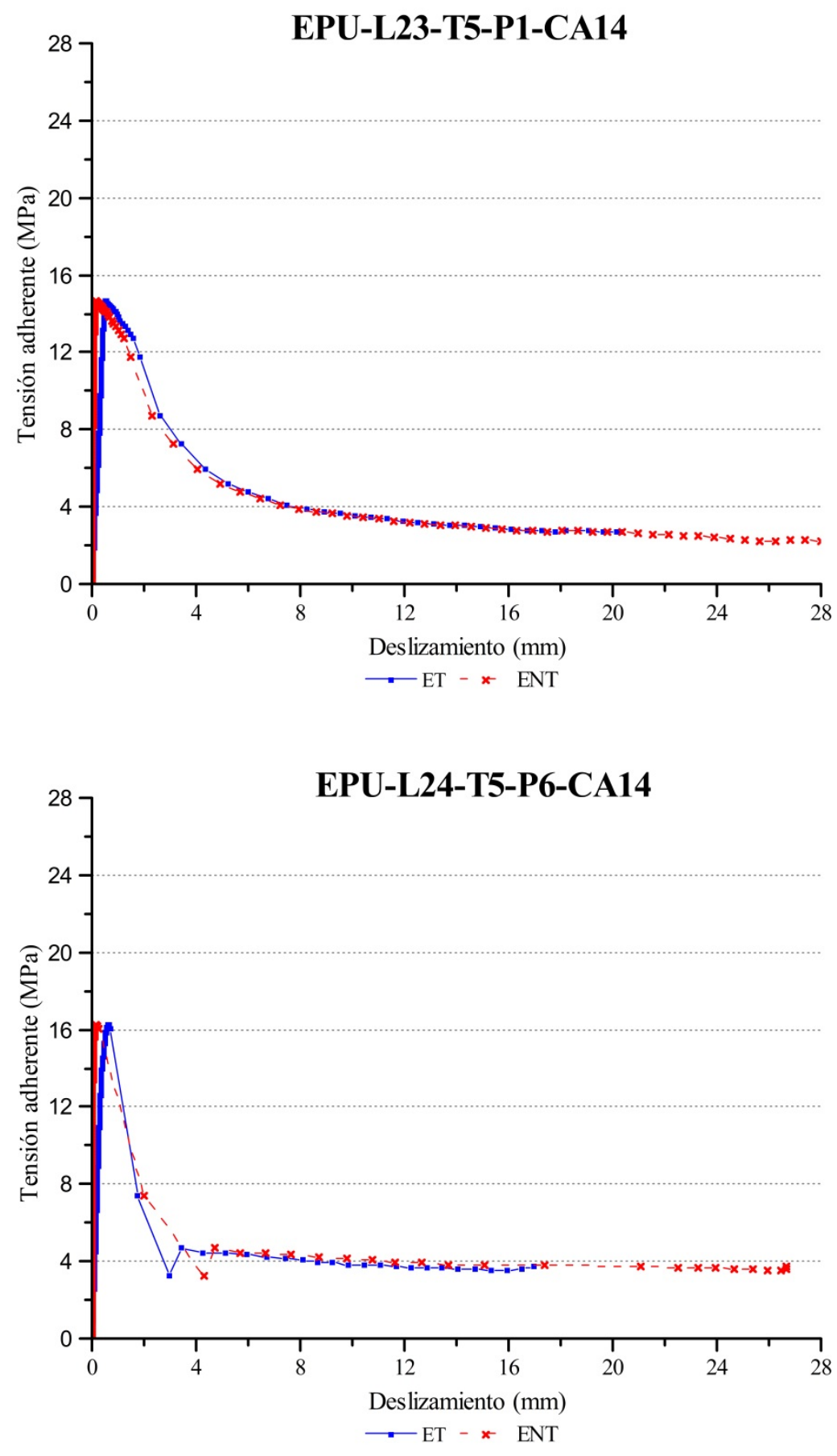
c. Condición Térmica de $20^{\circ} \mathrm{C}$.
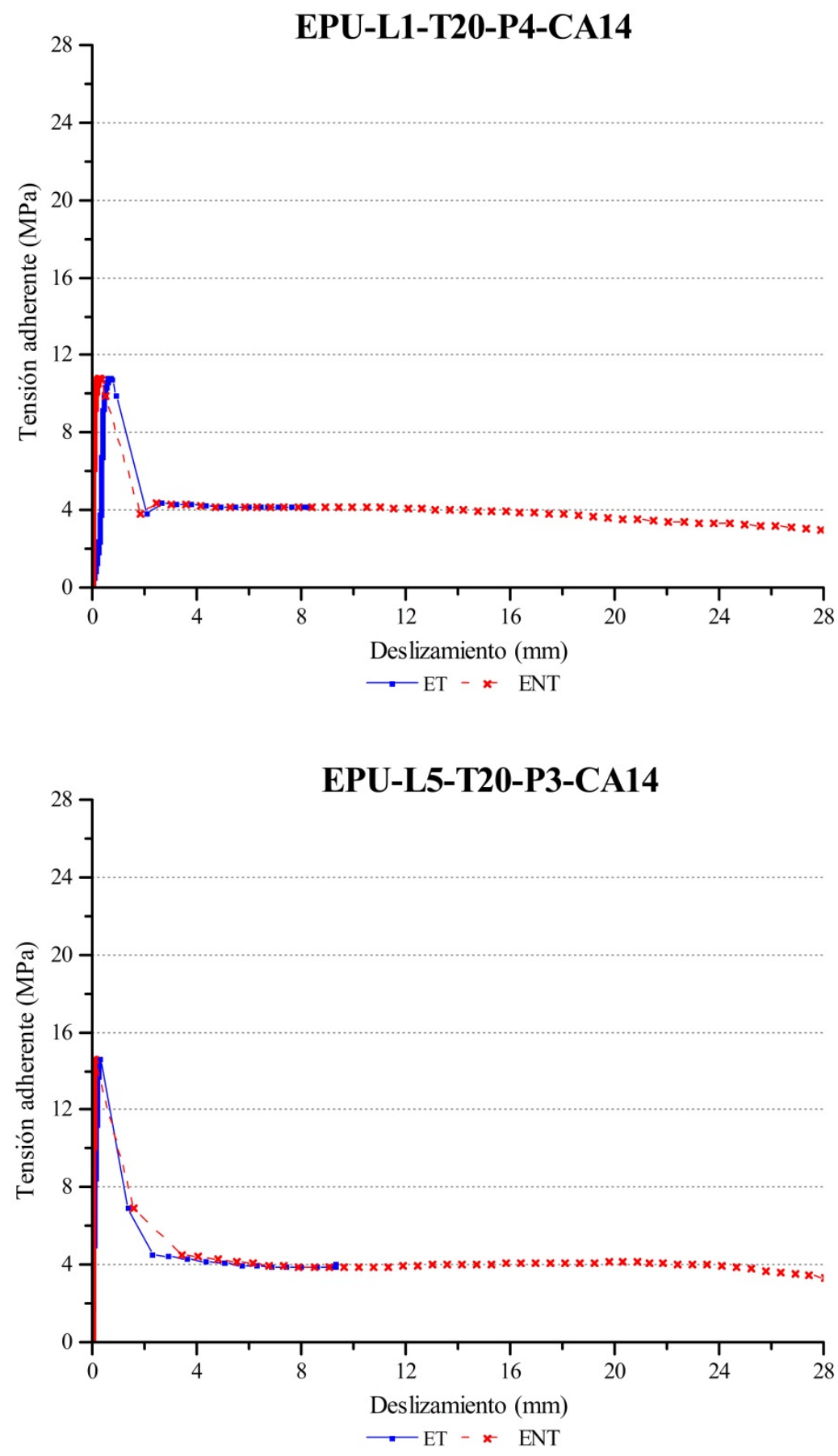

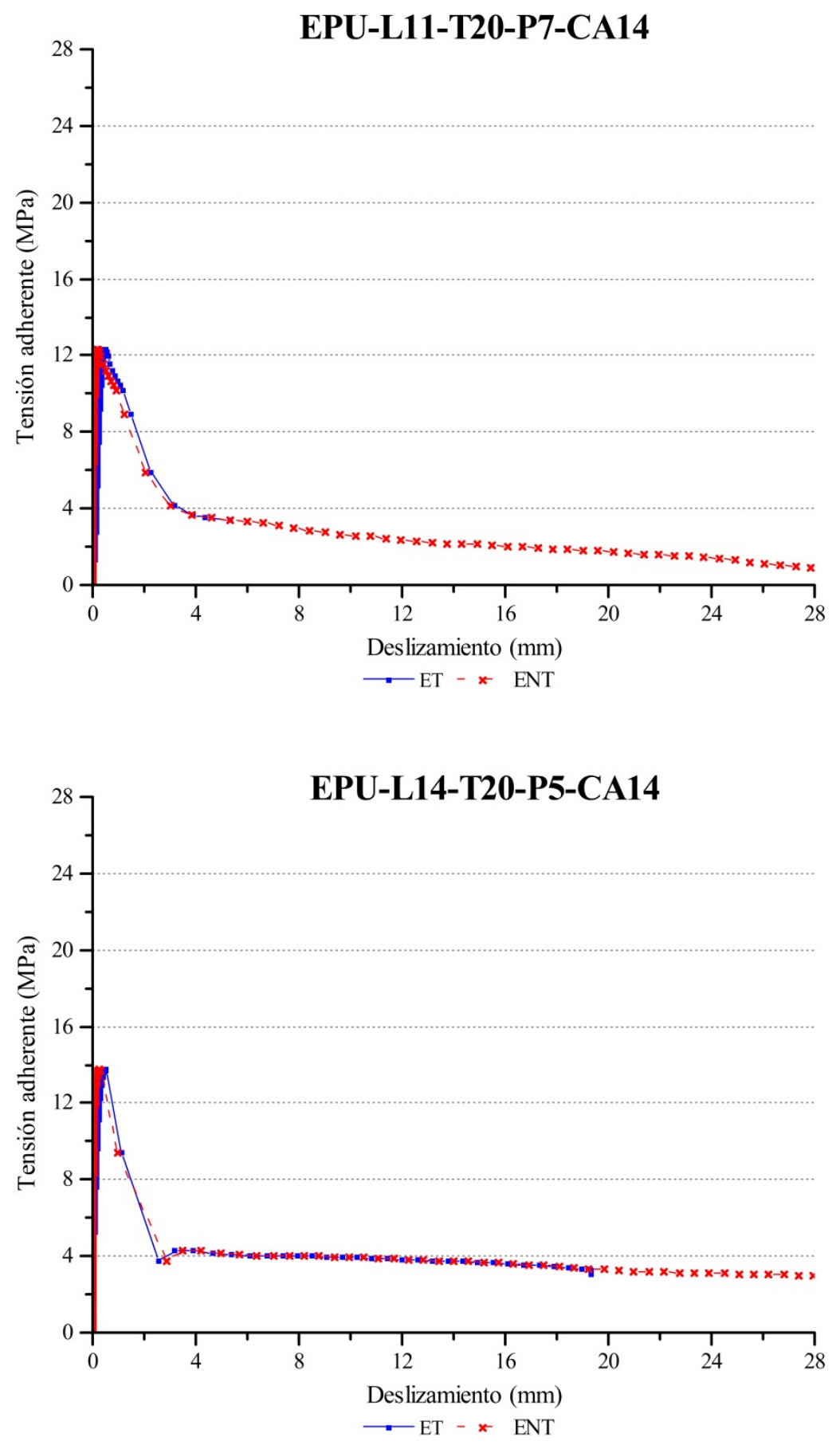


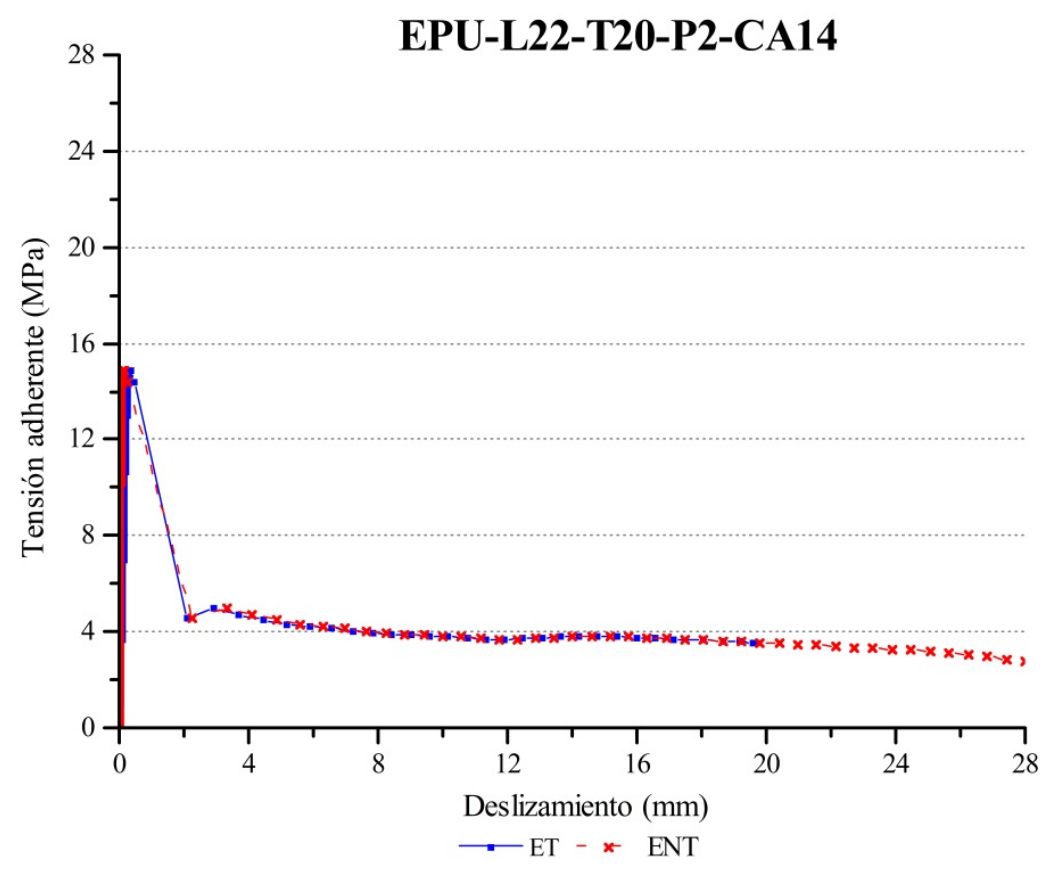

\section{d. Condición Térmica de $40^{\circ} \mathrm{C}$.}

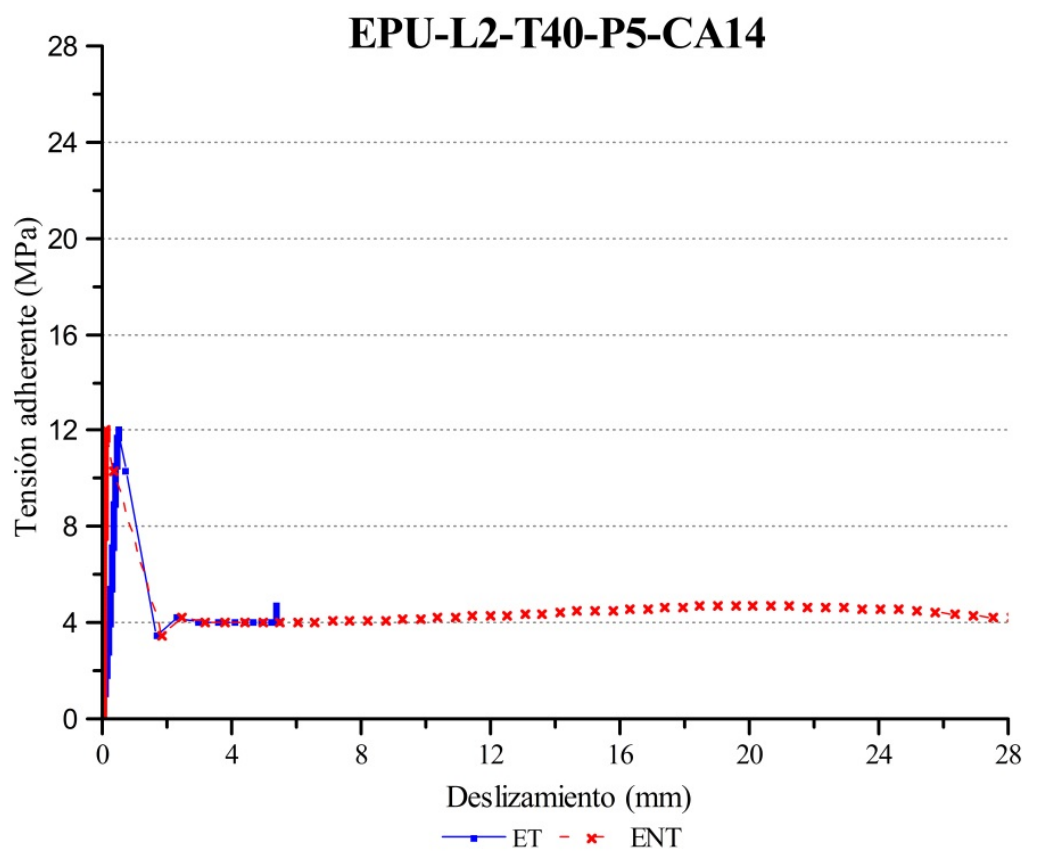



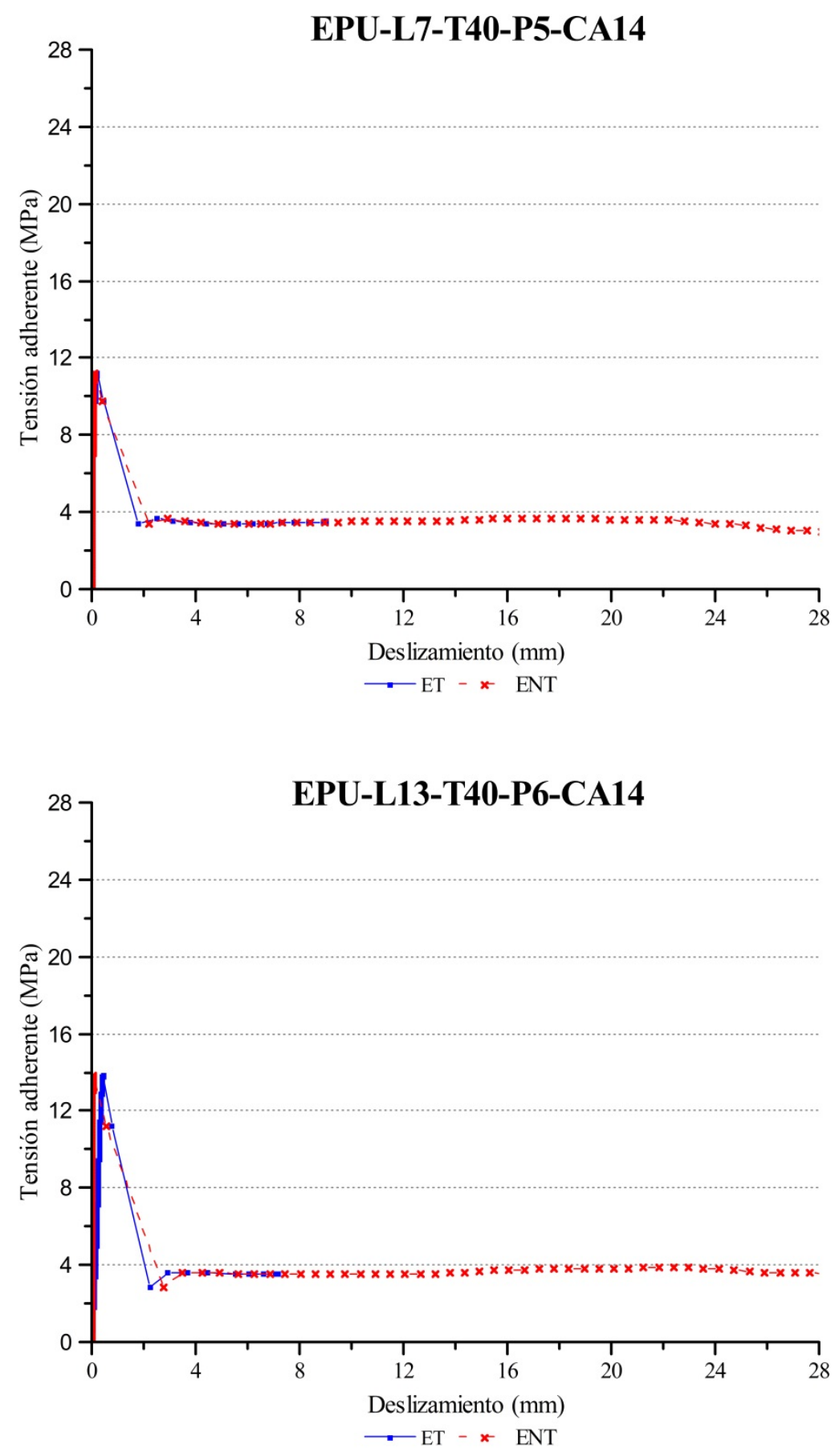

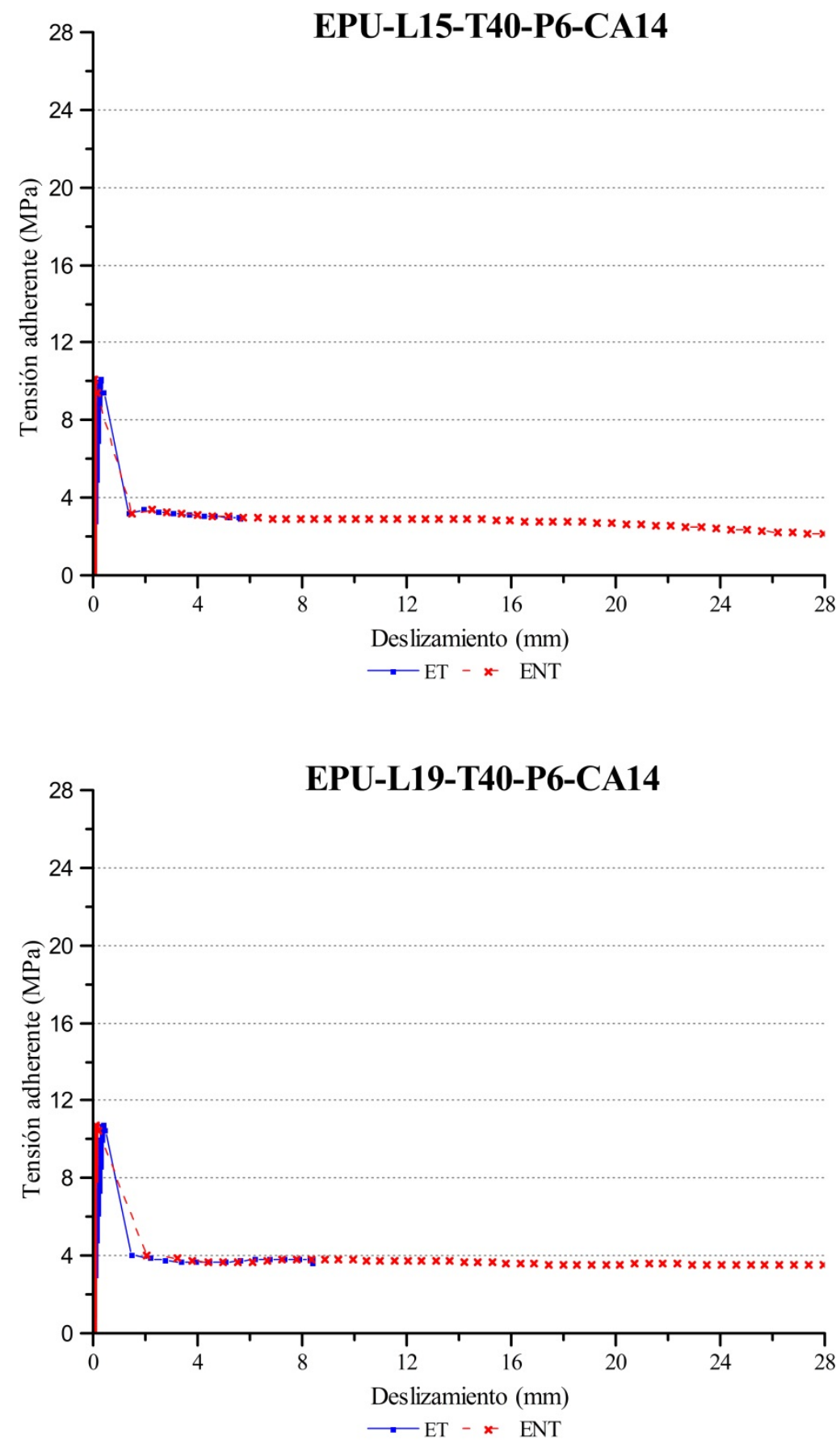
e. Condición Térmica de $80^{\circ} \mathrm{C}$.
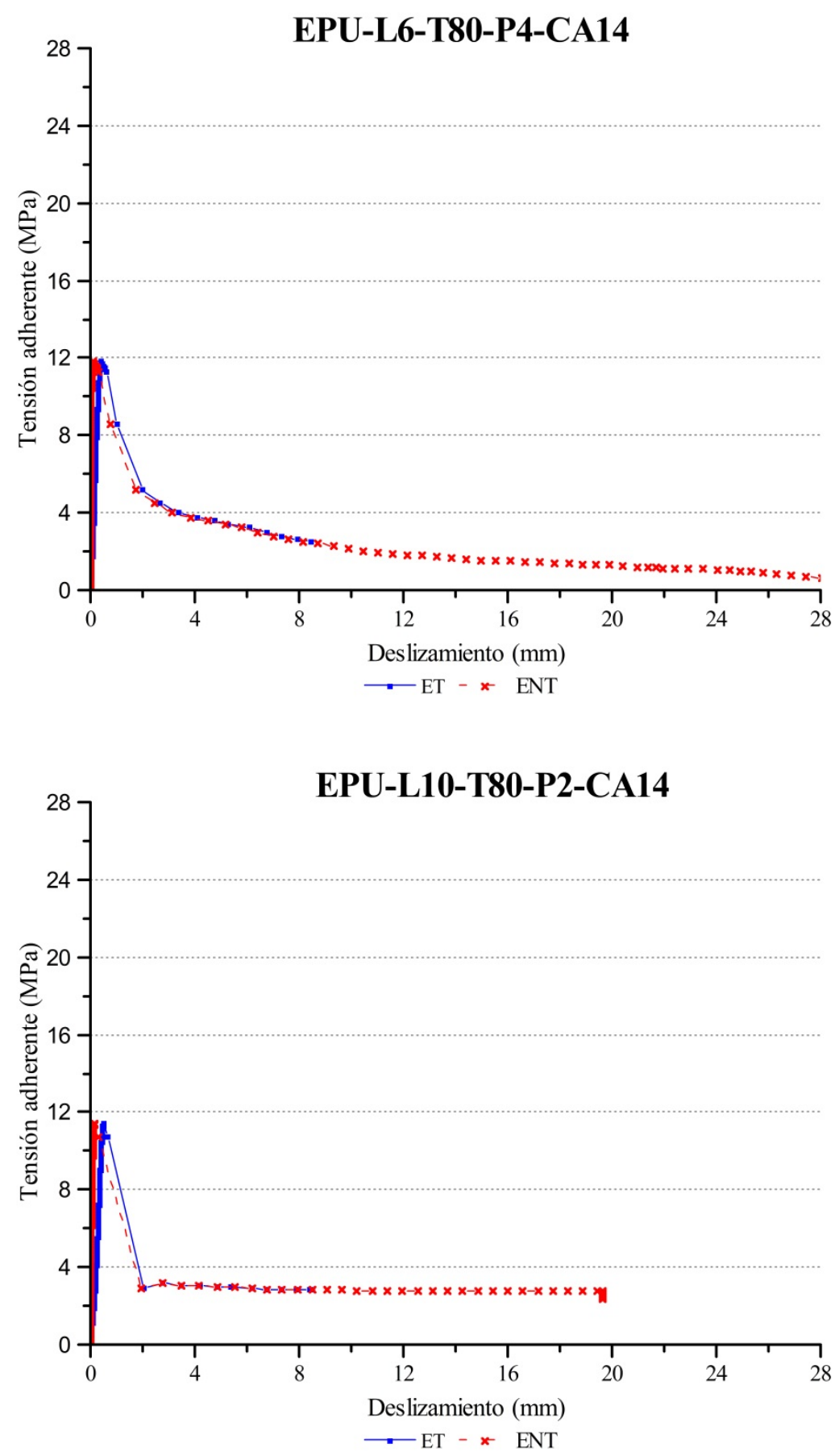

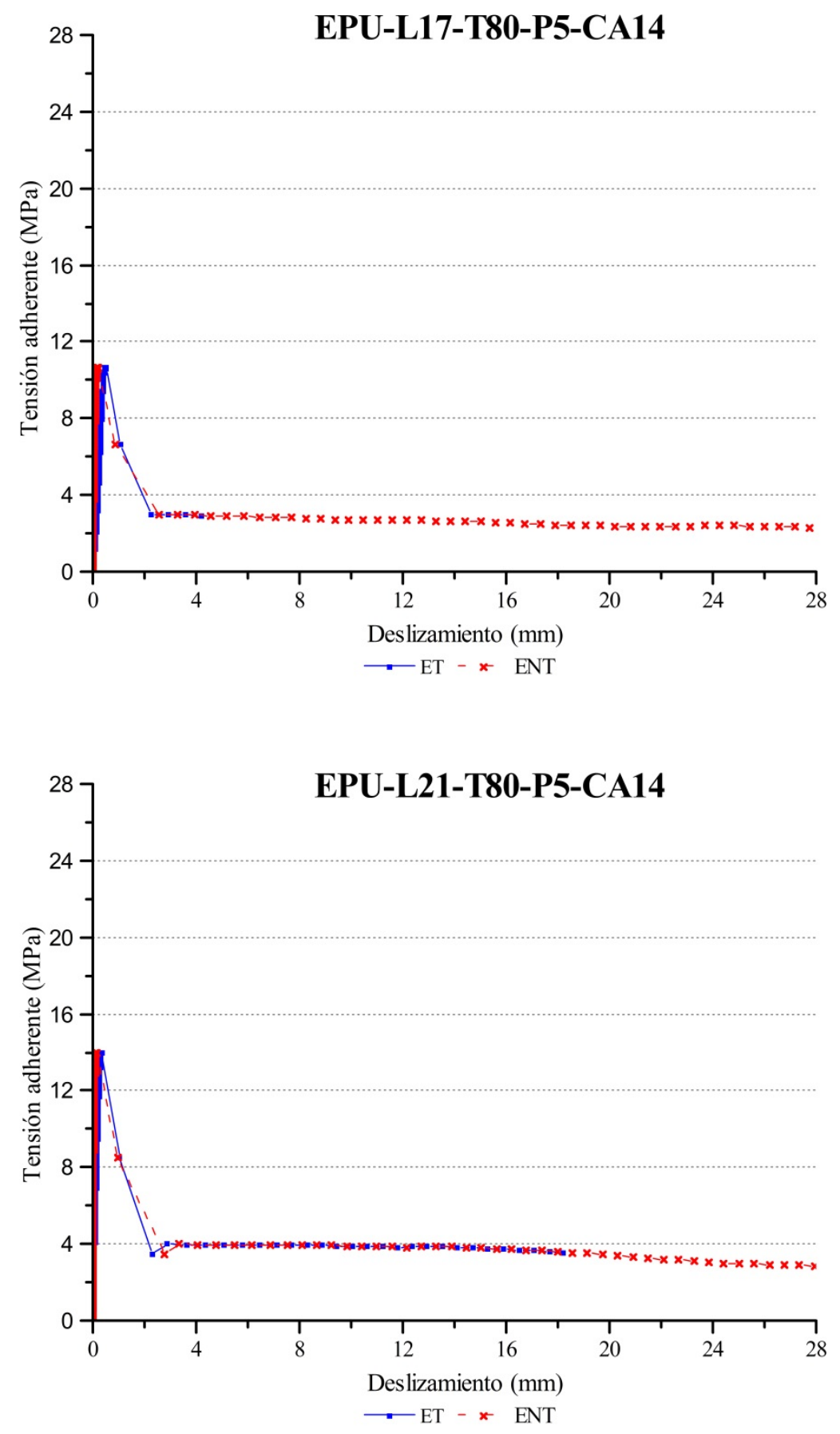


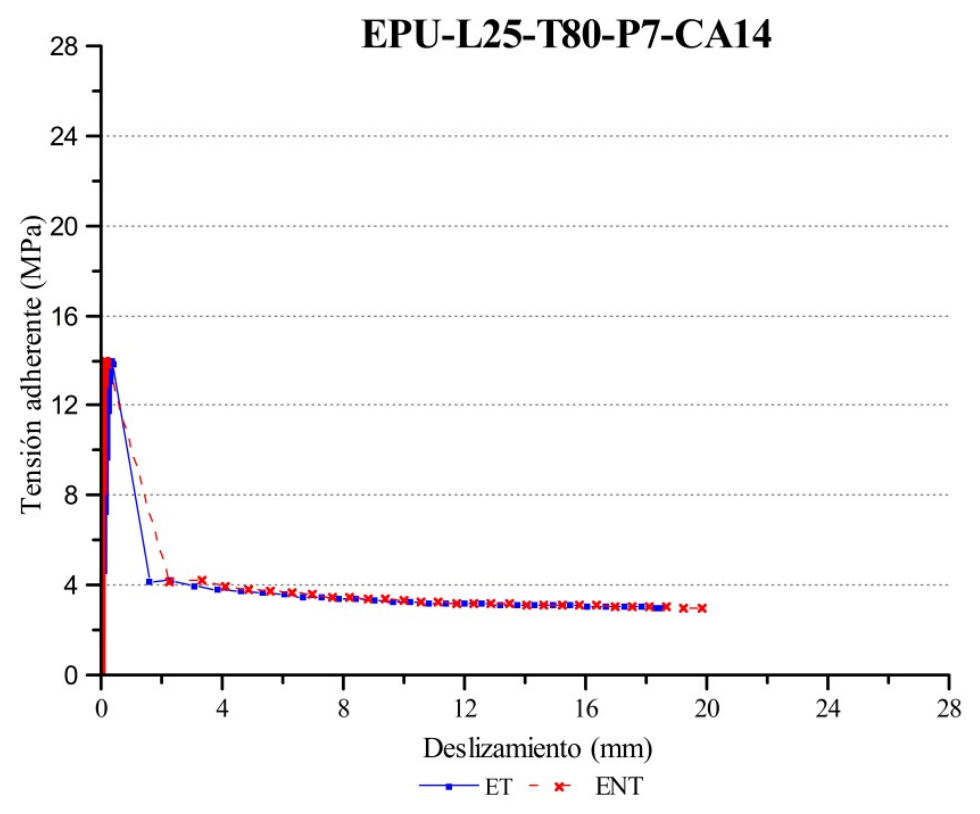

III. Barras de CFRP corrugadas CC12:

a. Condición Térmica de Hielo/Deshielo o $-20{ }^{\circ} \mathrm{C}$.

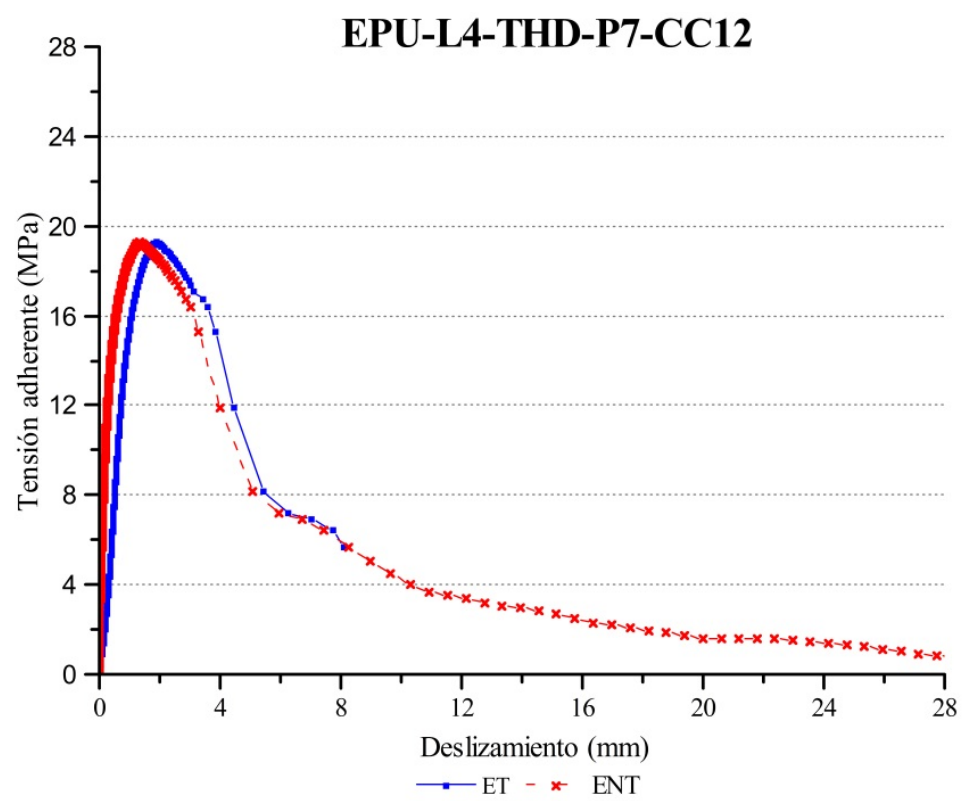



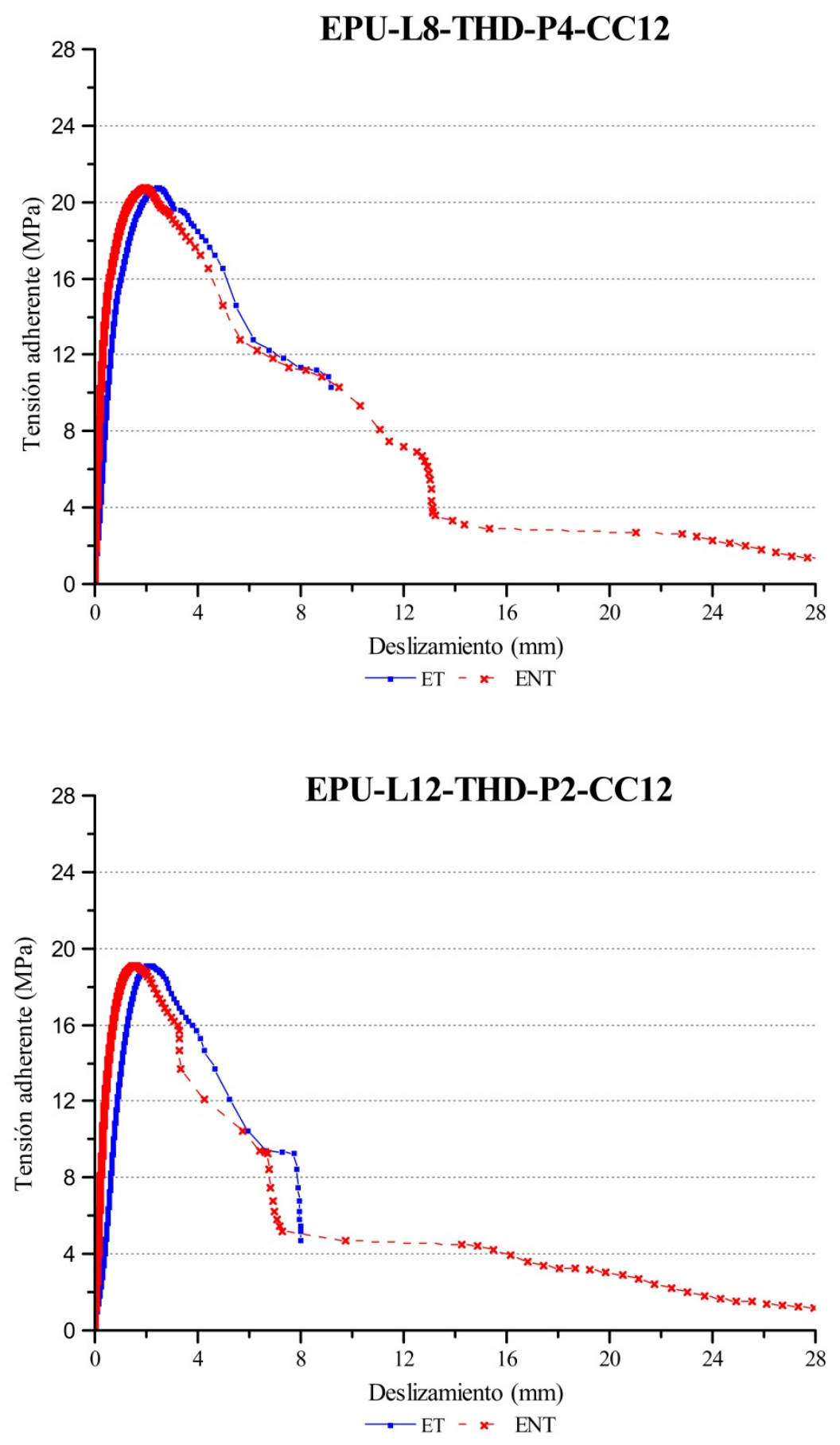

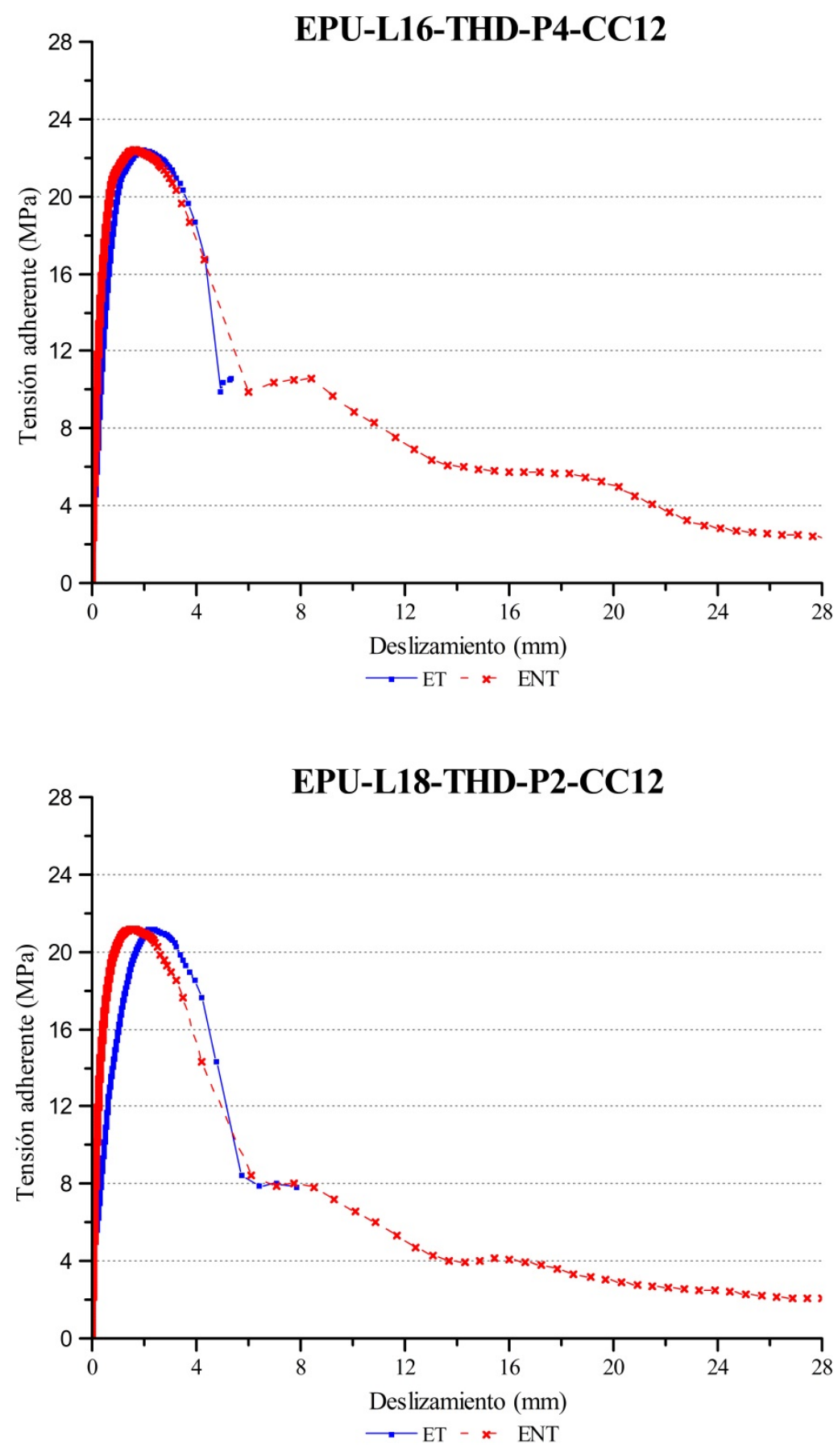


\section{b. Condición Térmica de $5^{\circ} \mathrm{C}$.}
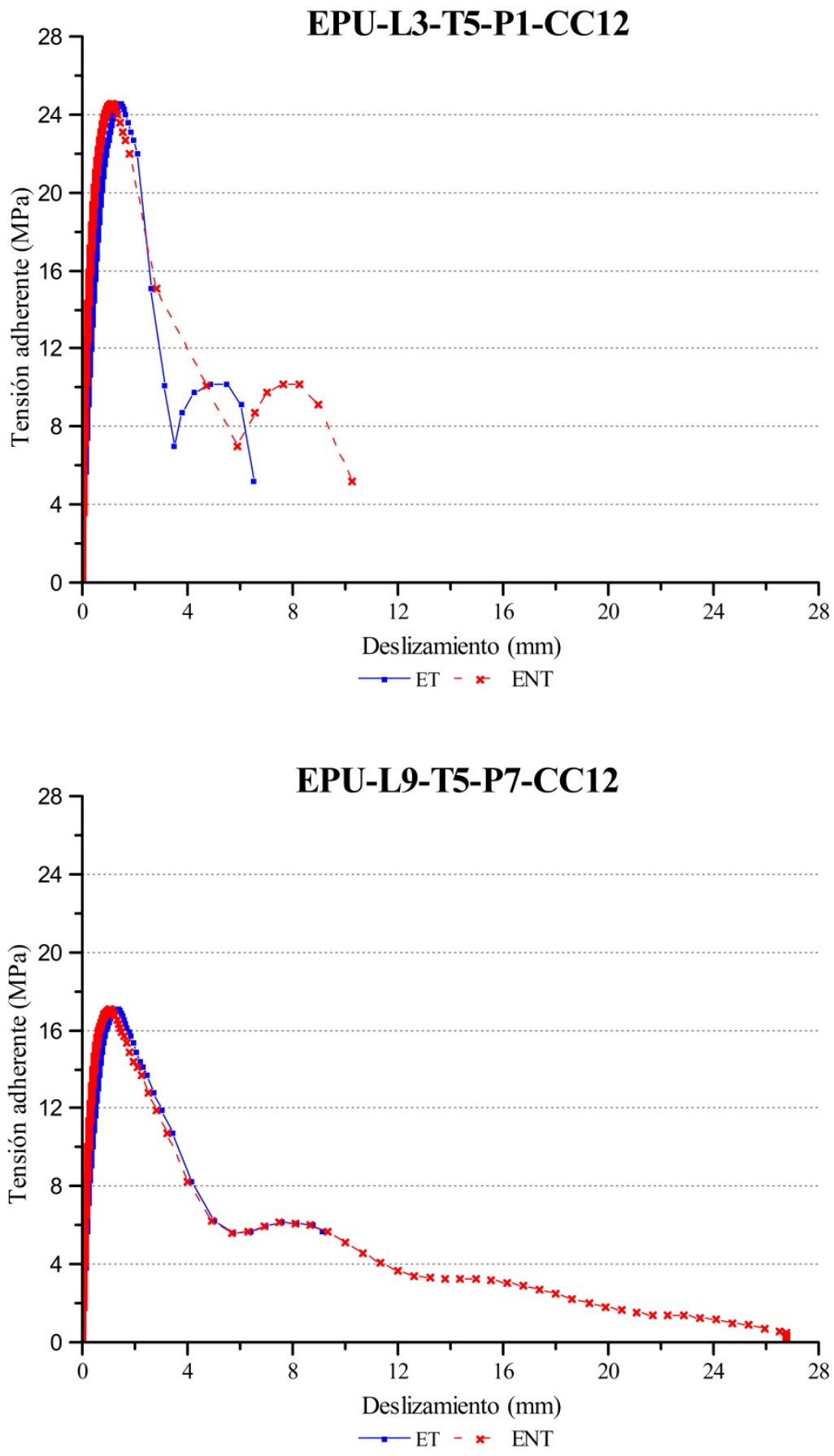

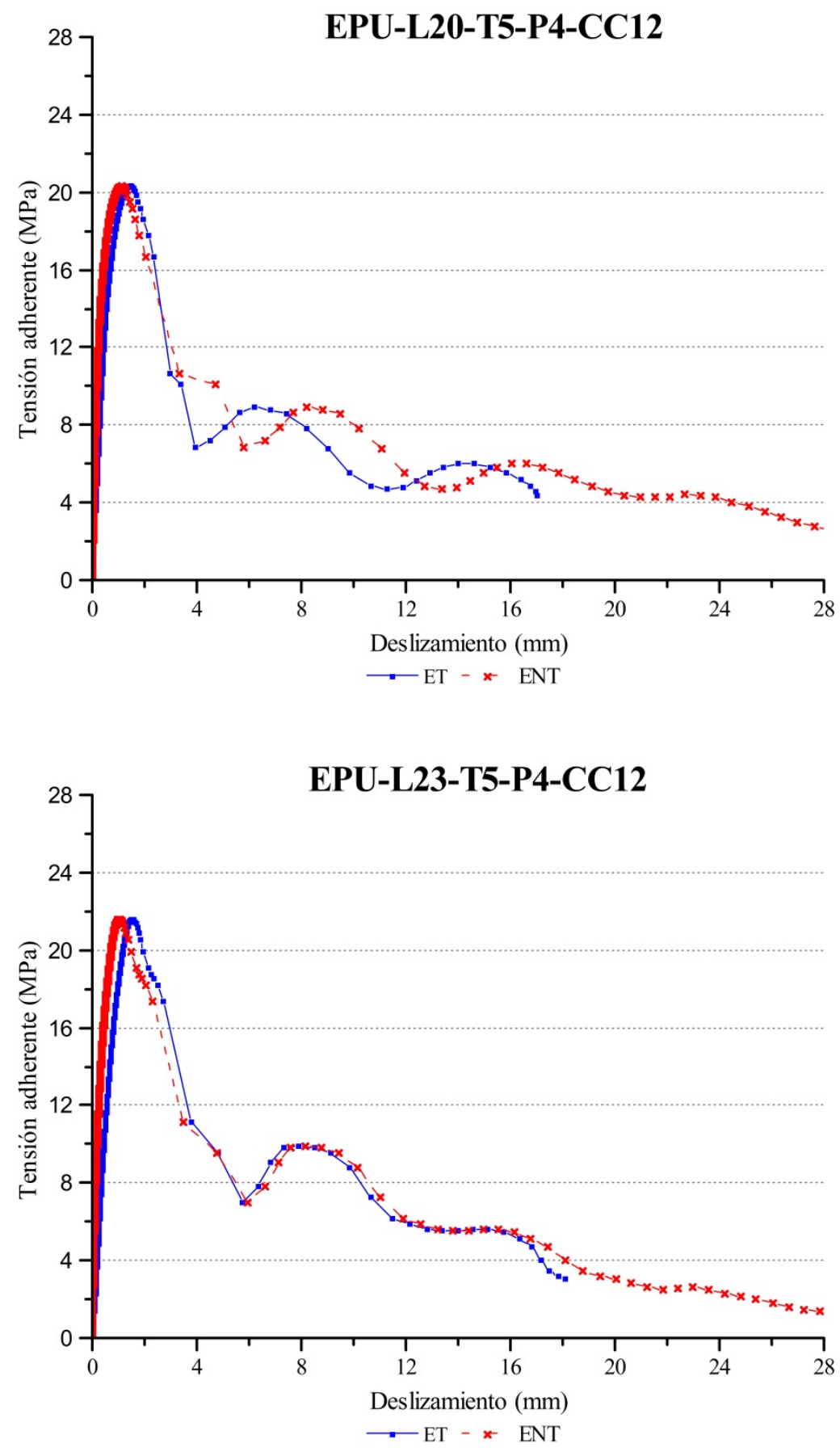


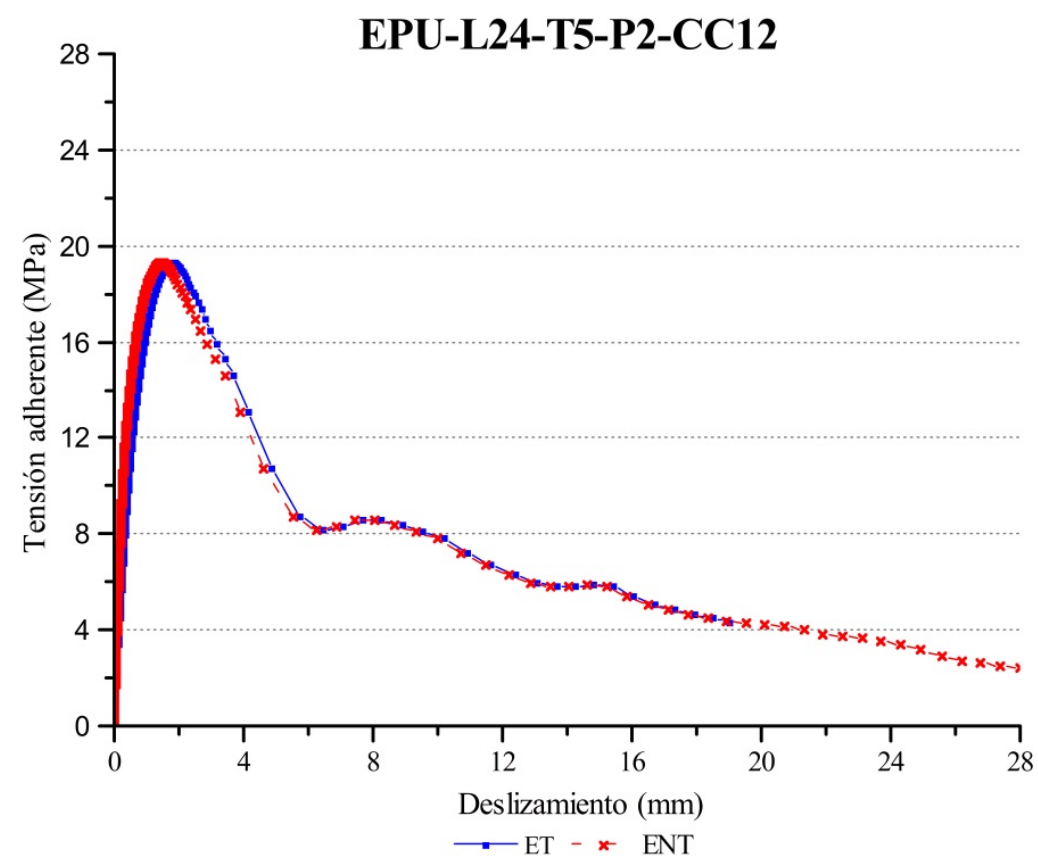

c. Condición Térmica de $20^{\circ} \mathrm{C}$.

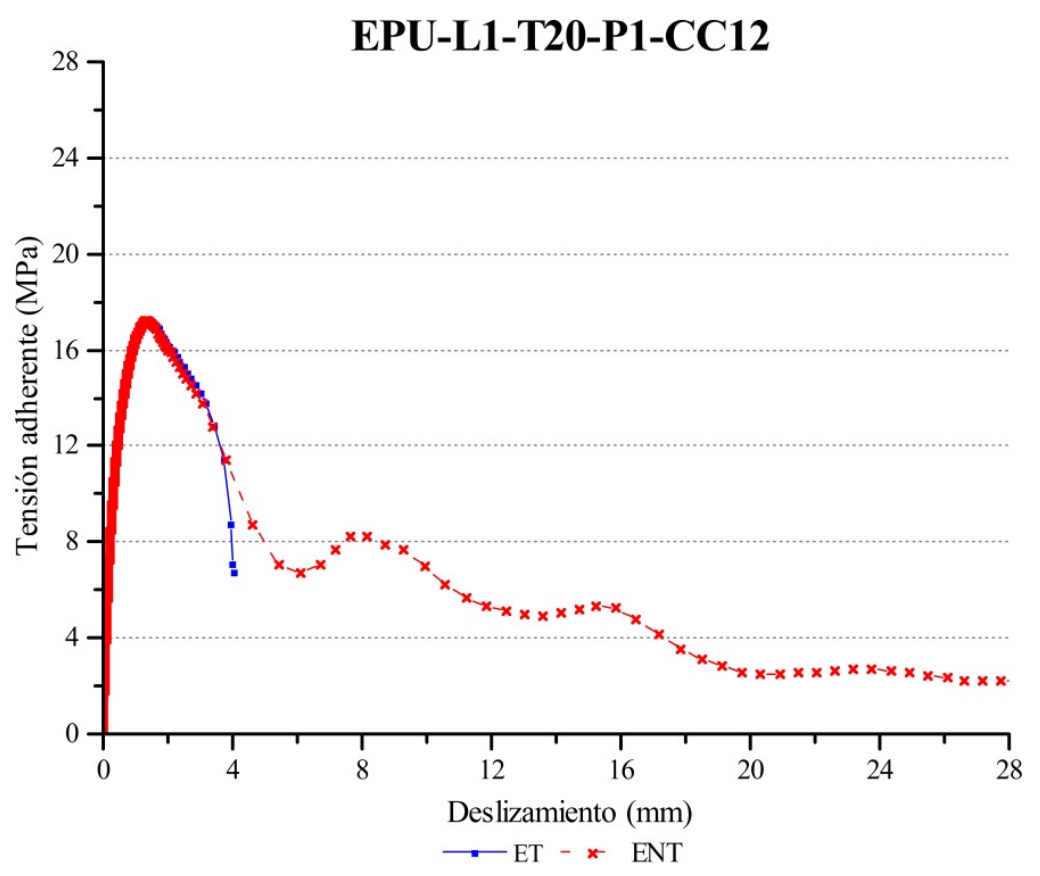



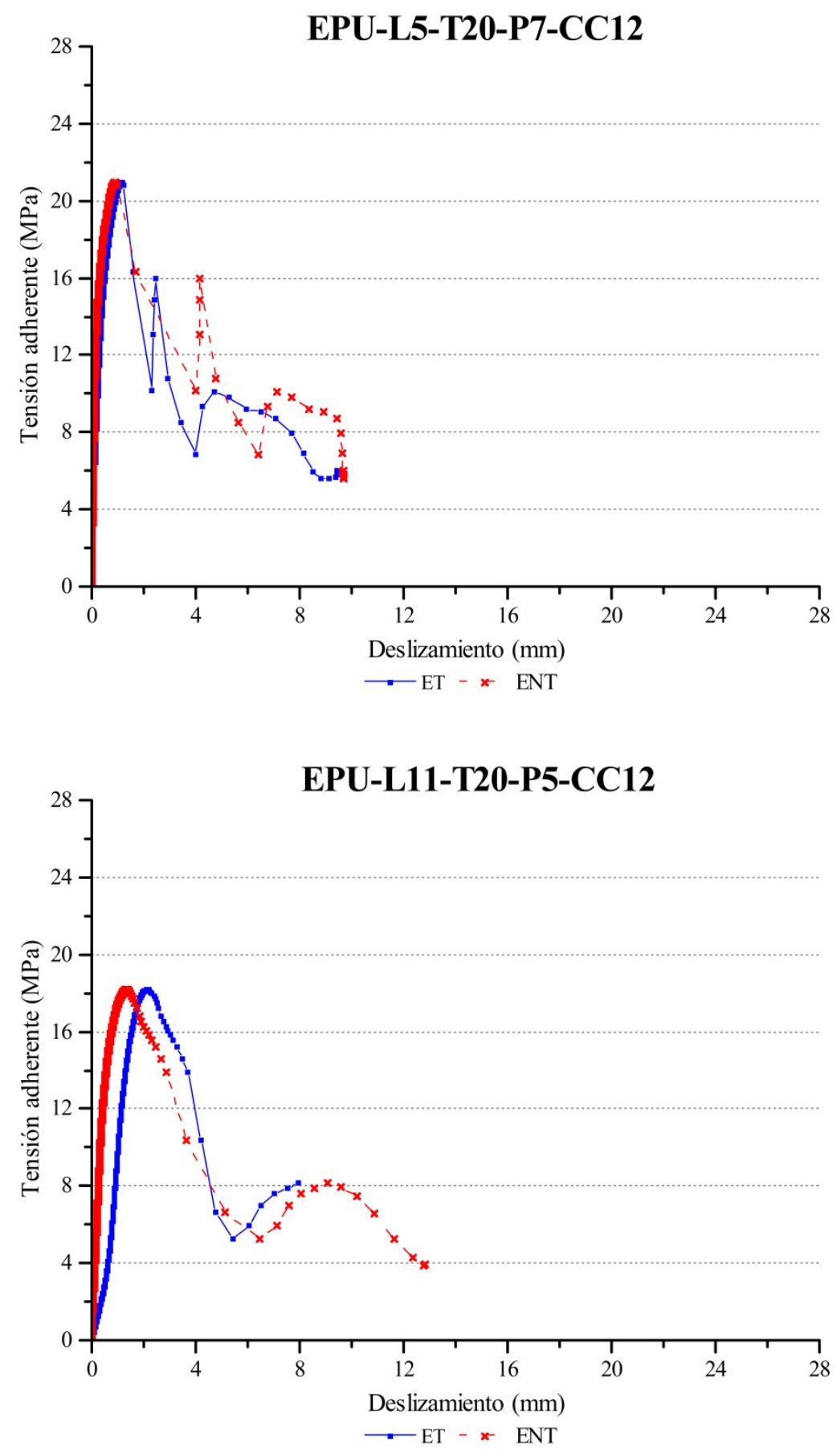

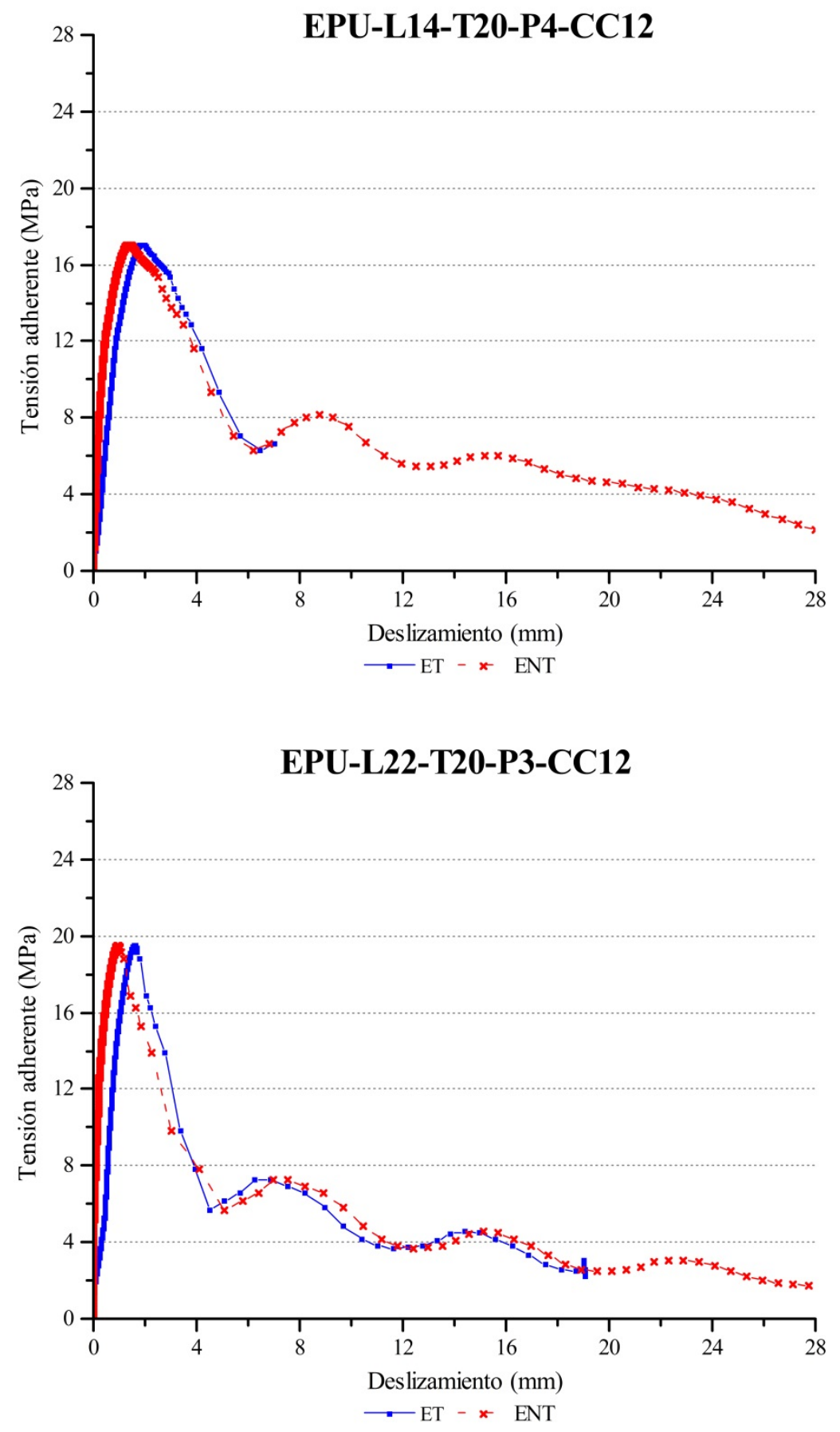
d. Condición Térmica de $40^{\circ} \mathrm{C}$.
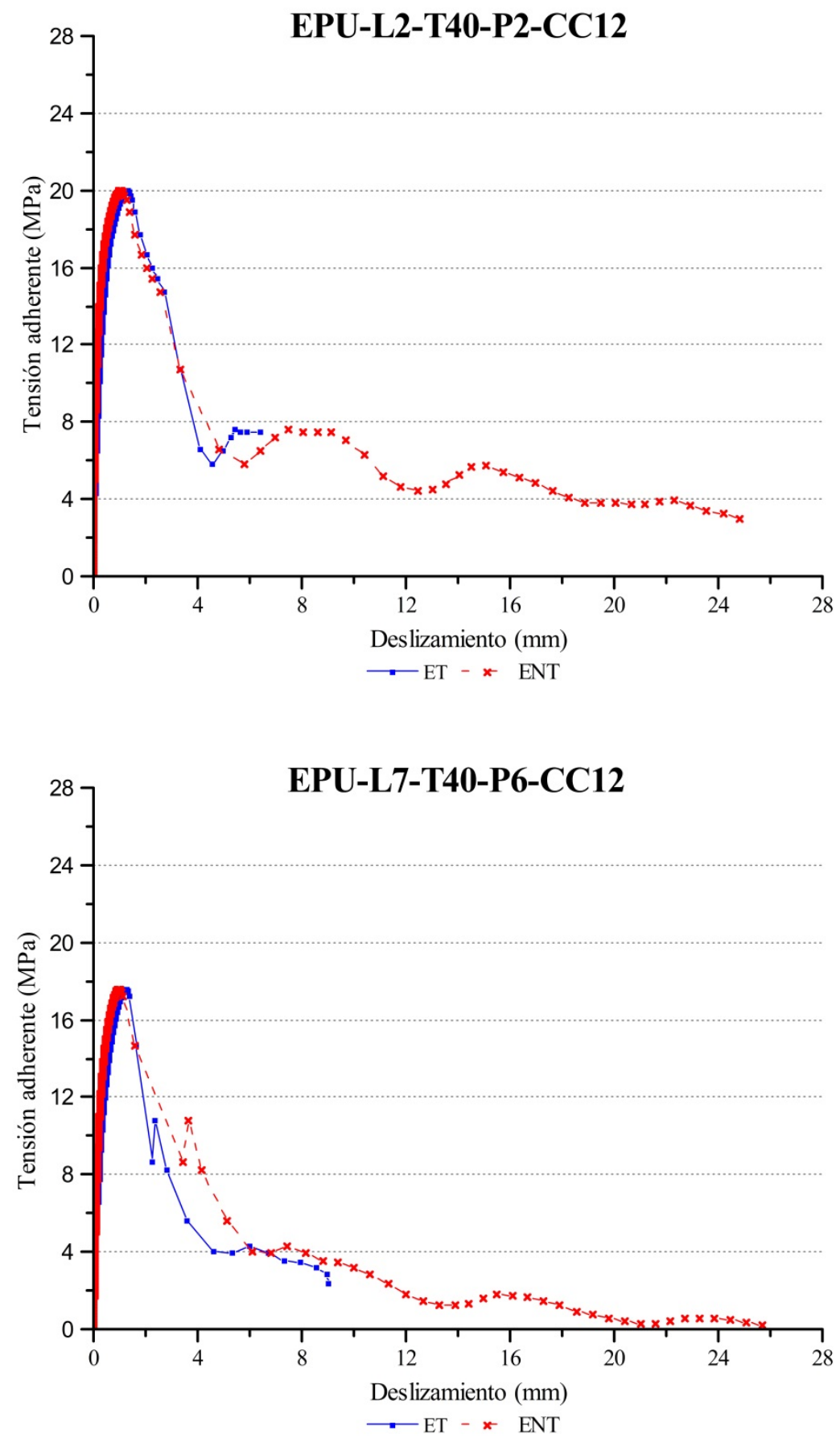

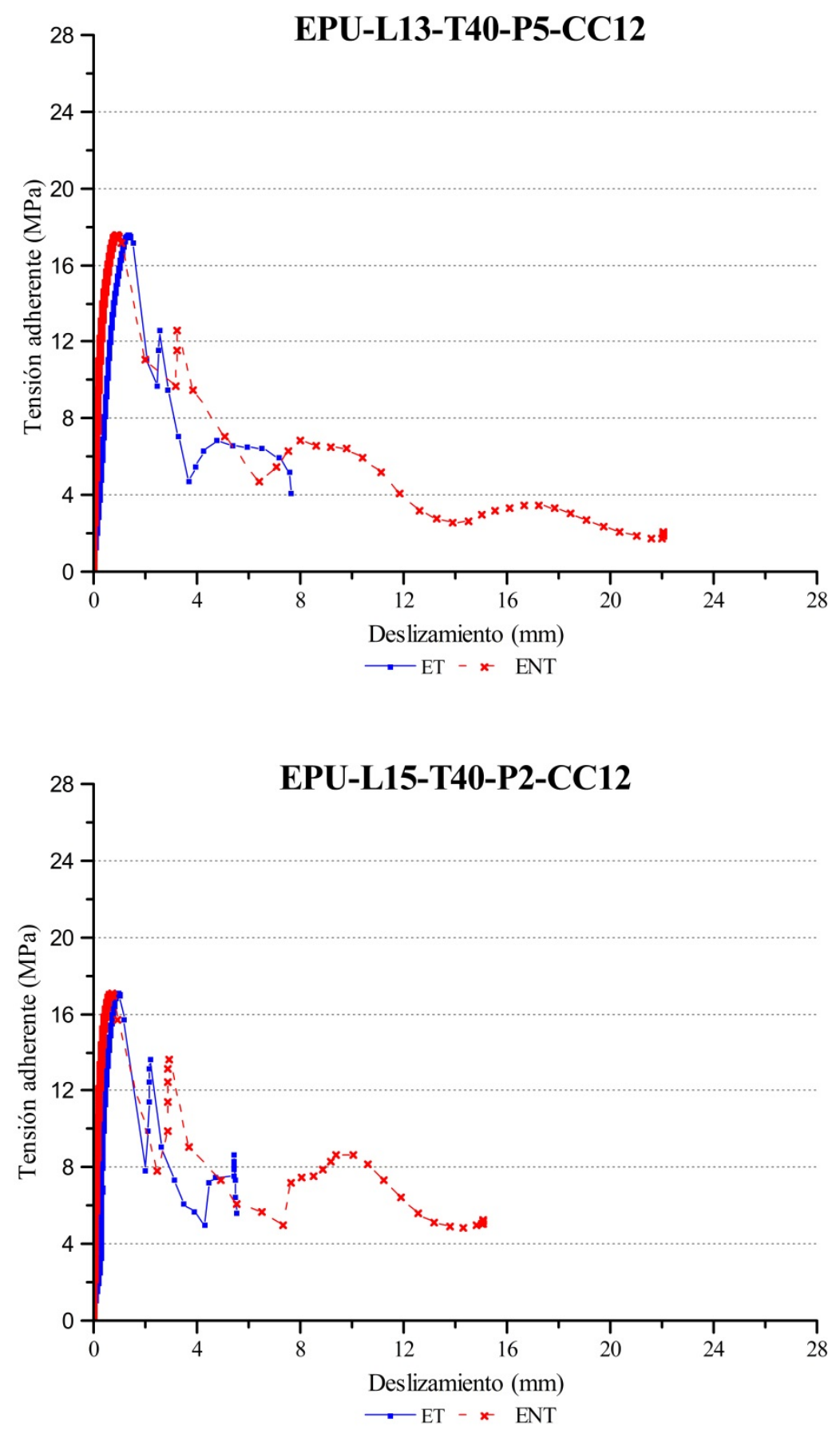


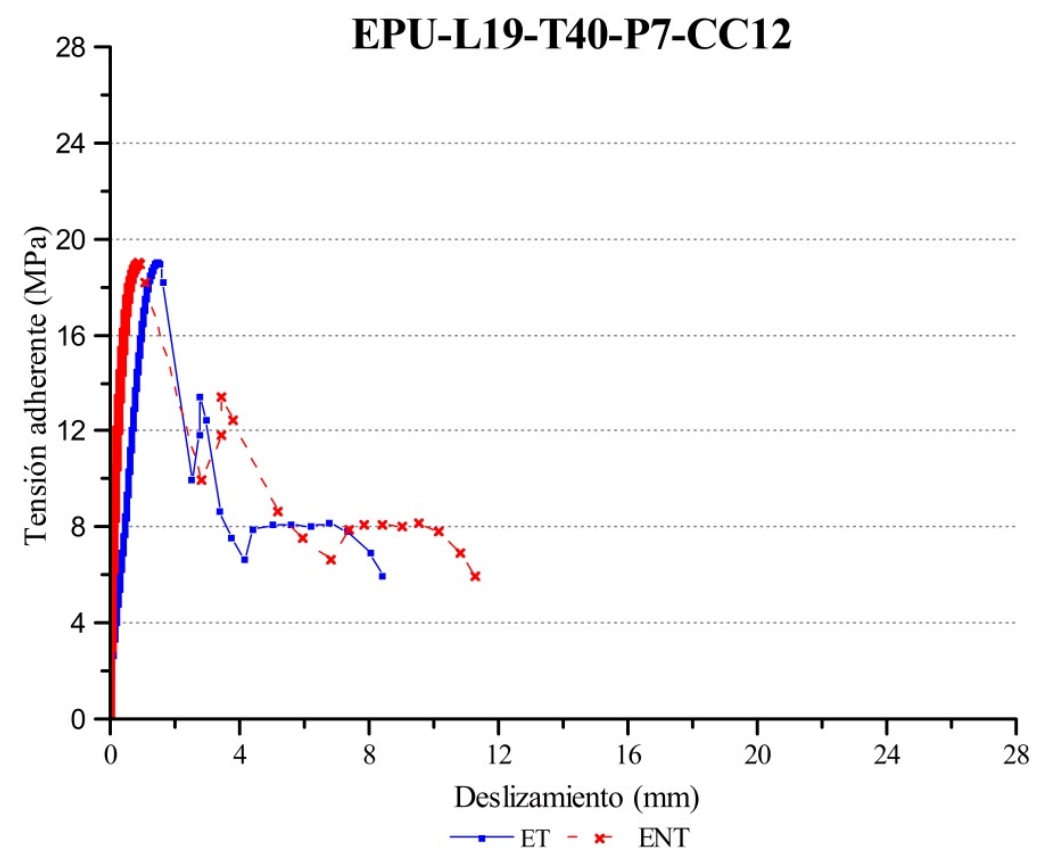

e. Condición Térmica de $80^{\circ} \mathrm{C}$.

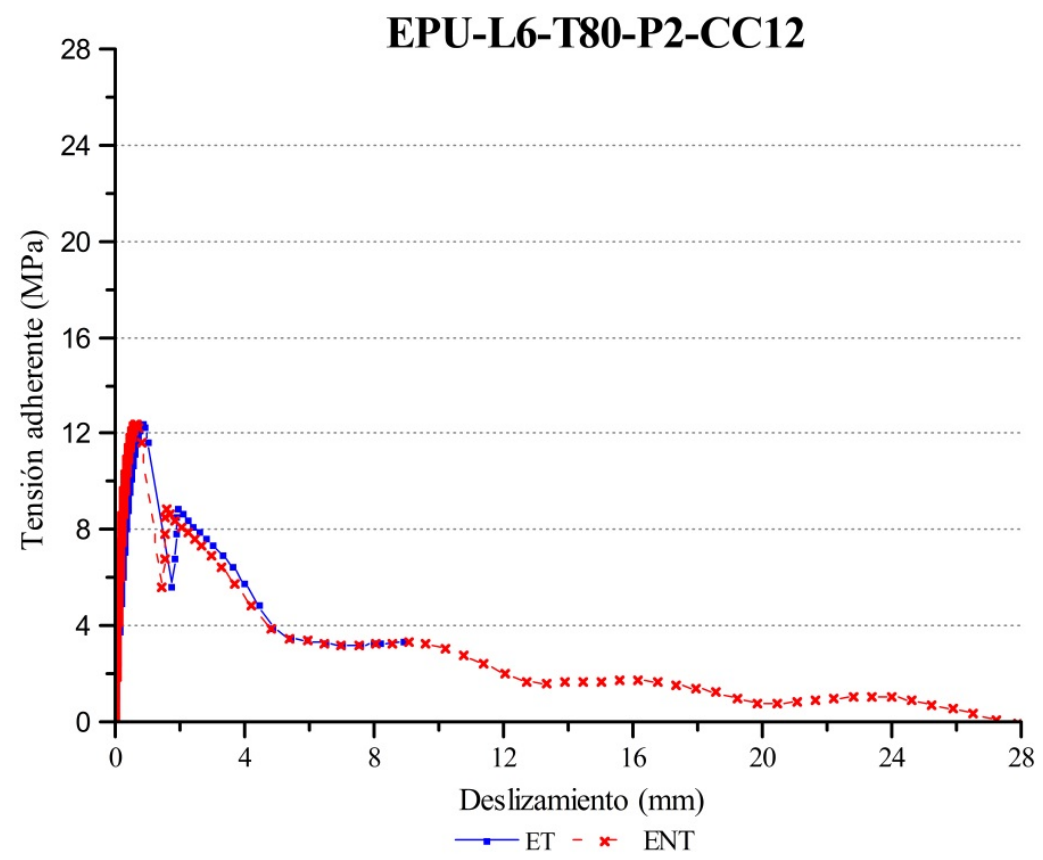



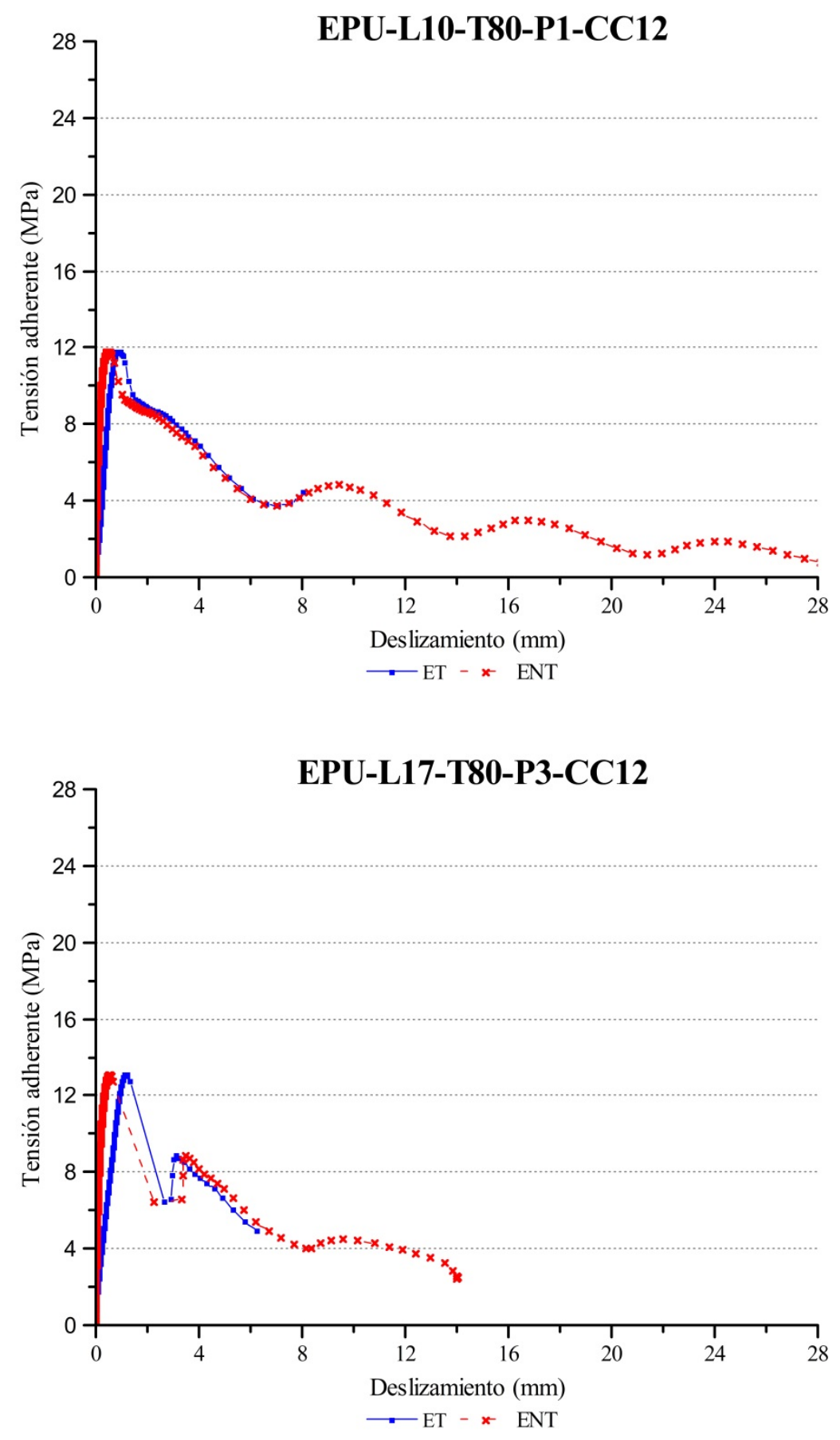

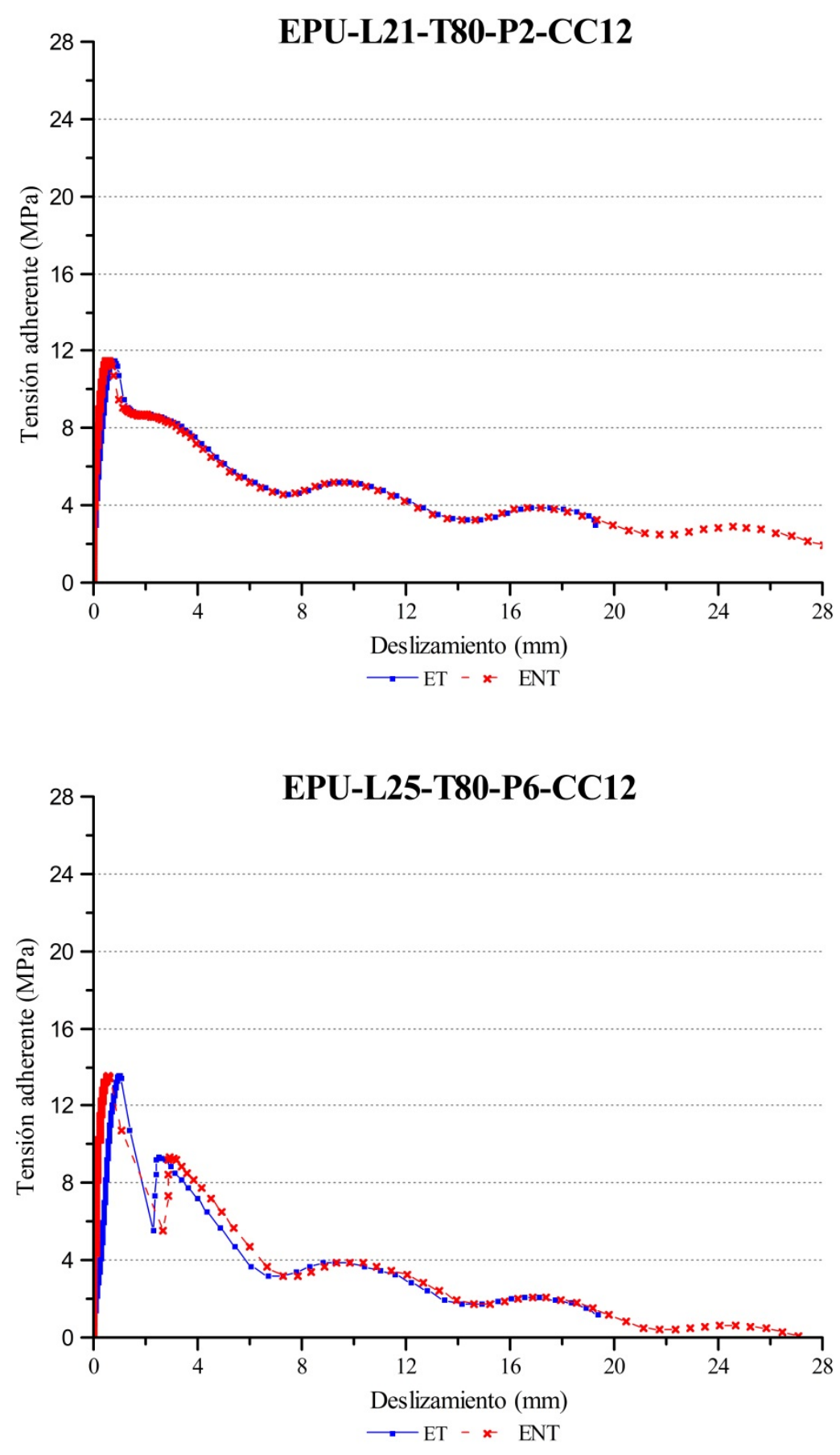


\section{Barras de CFRP Texturizadas CT13:}

a. Condición Térmica de Hielo/Deshielo o -20 ${ }^{\circ} \mathrm{C}$.
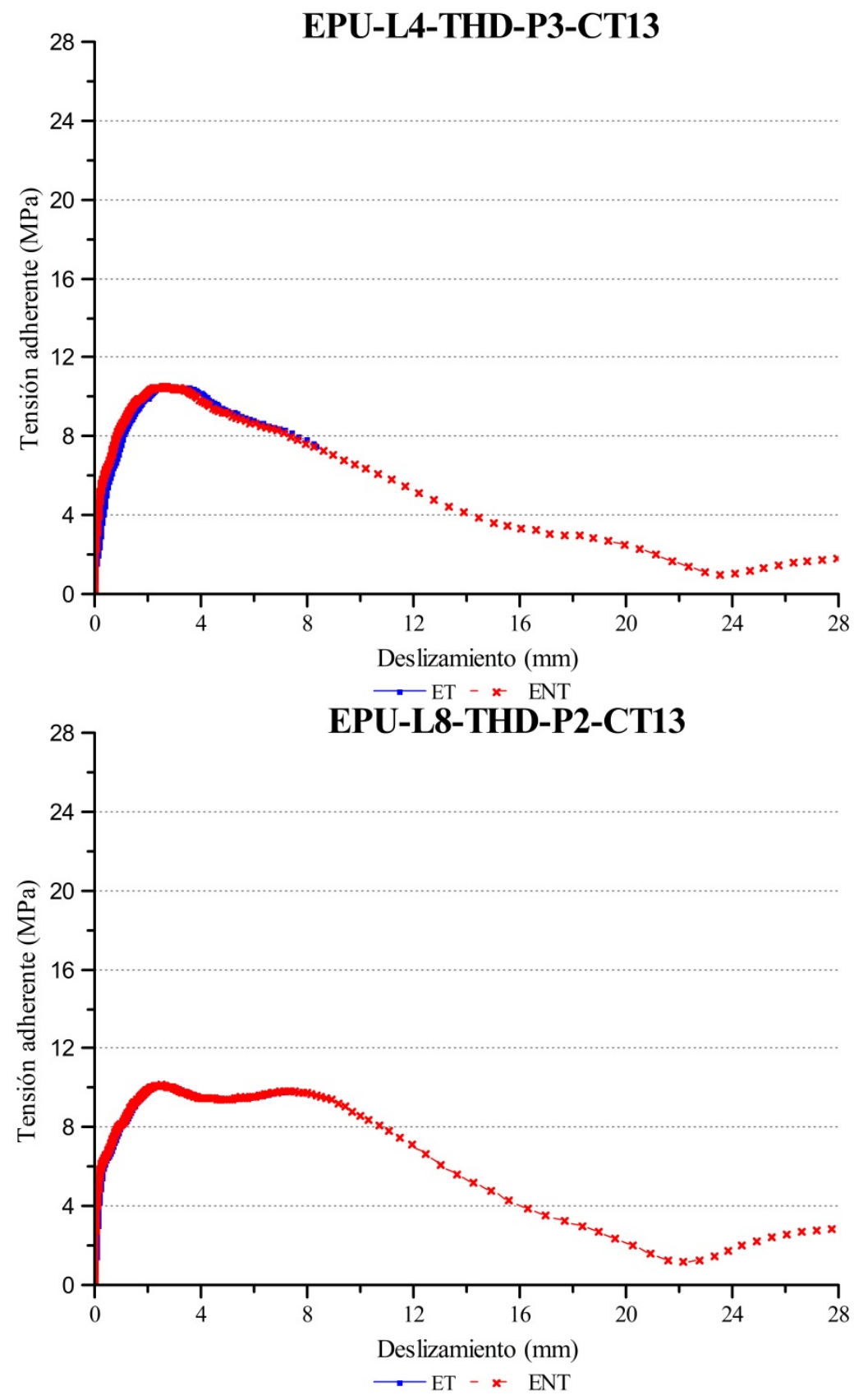

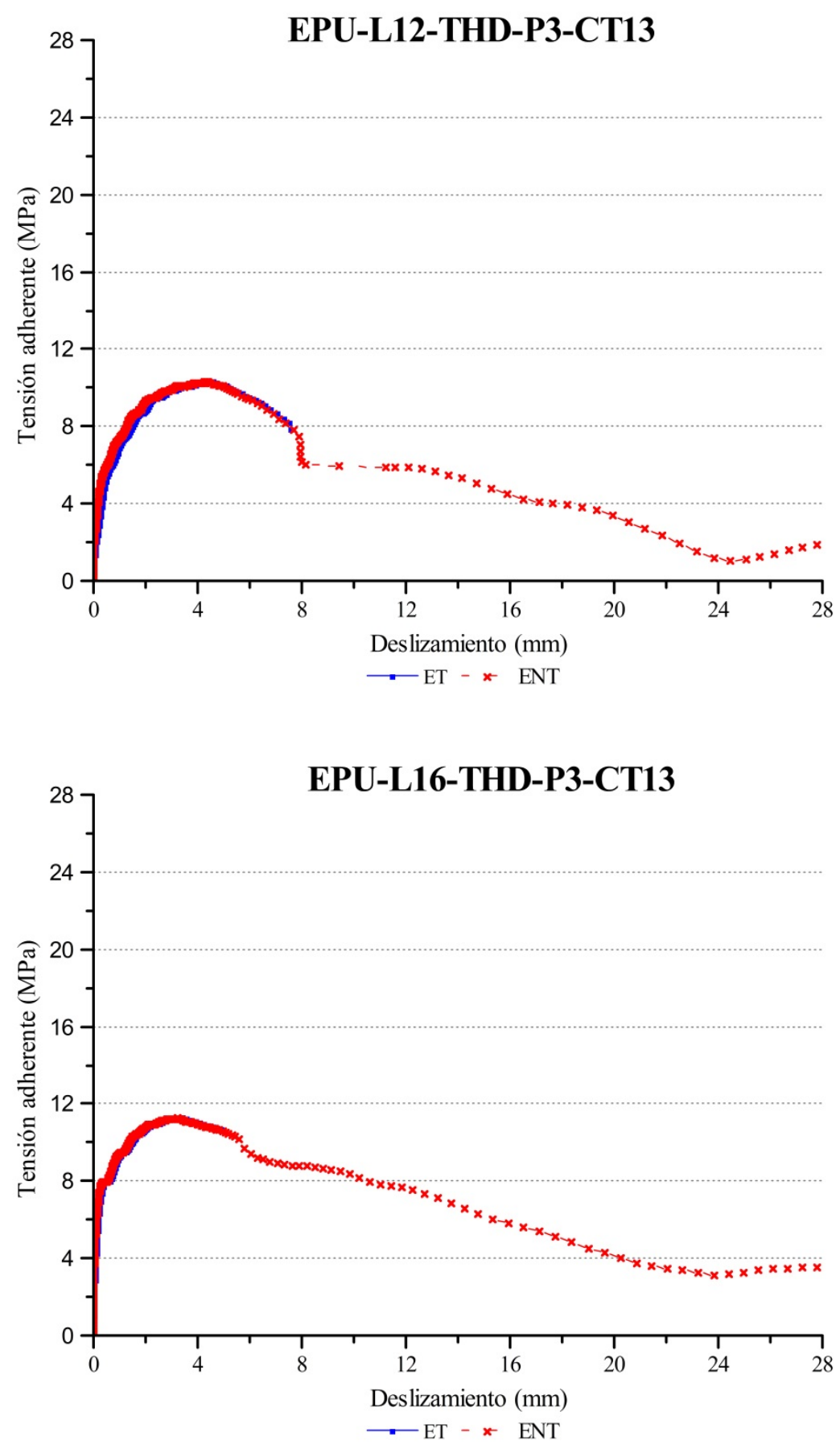


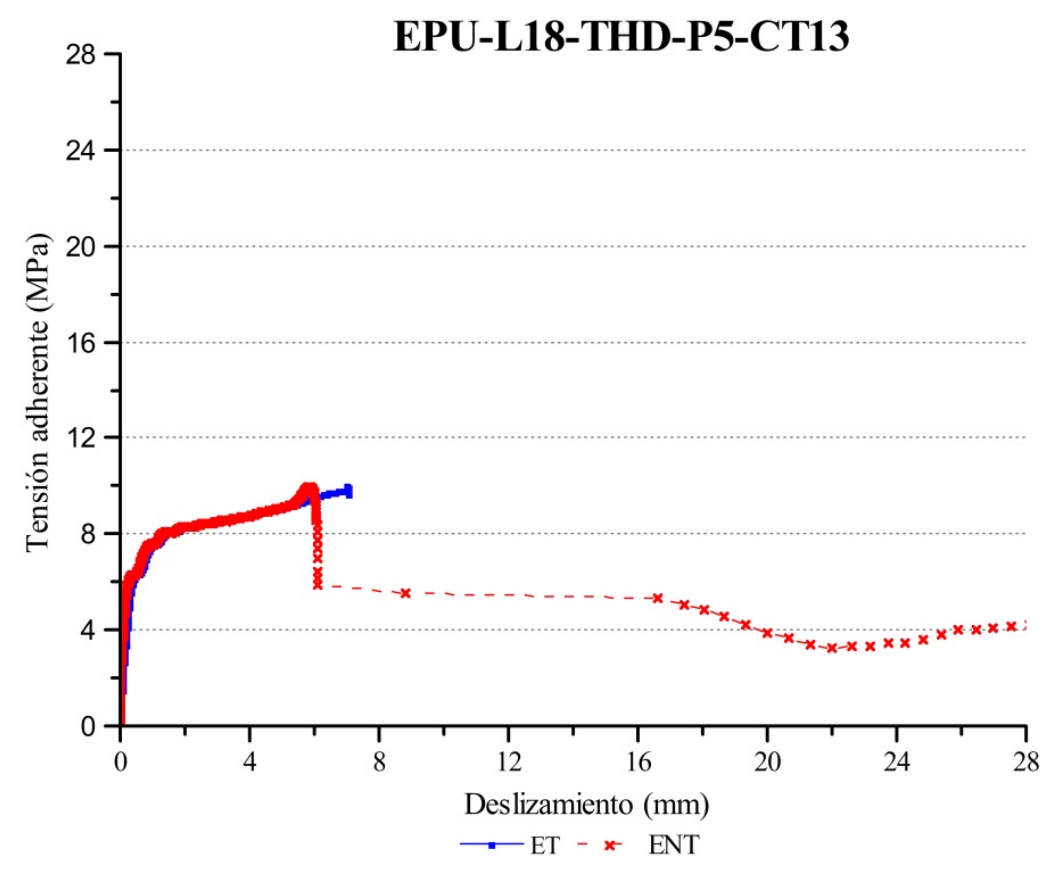

b. Condición Térmica de $5^{\circ} \mathrm{C}$.

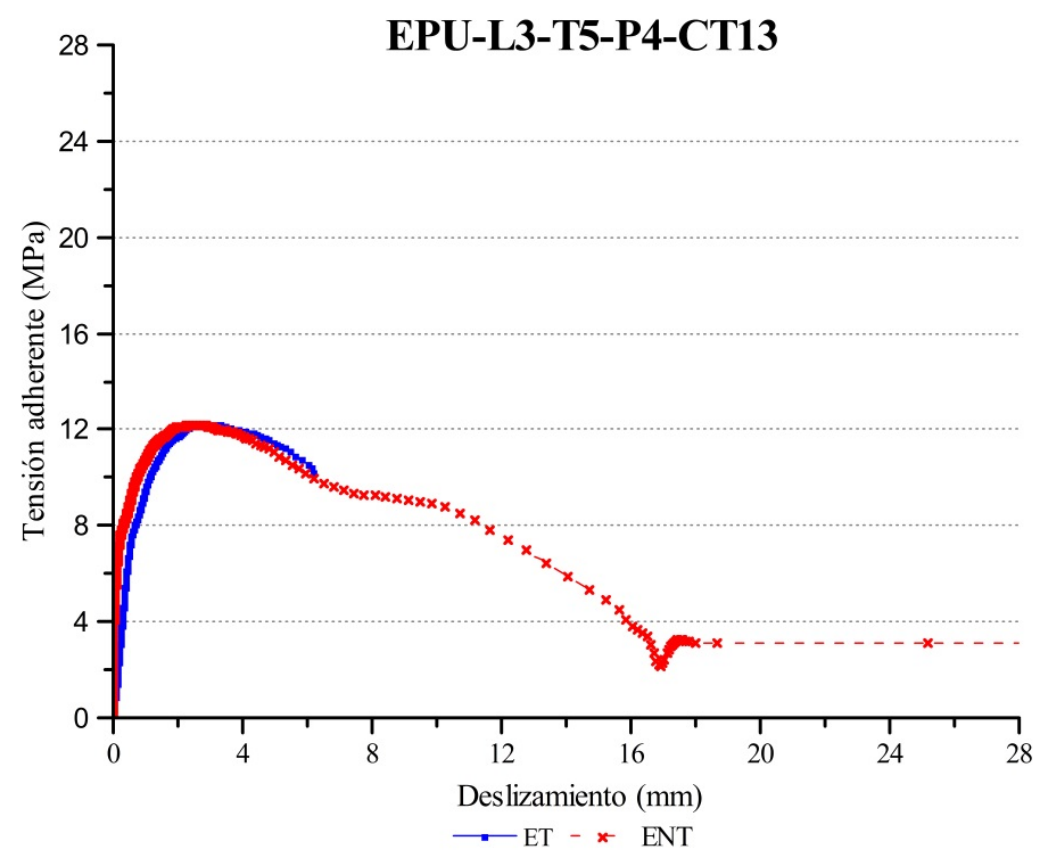



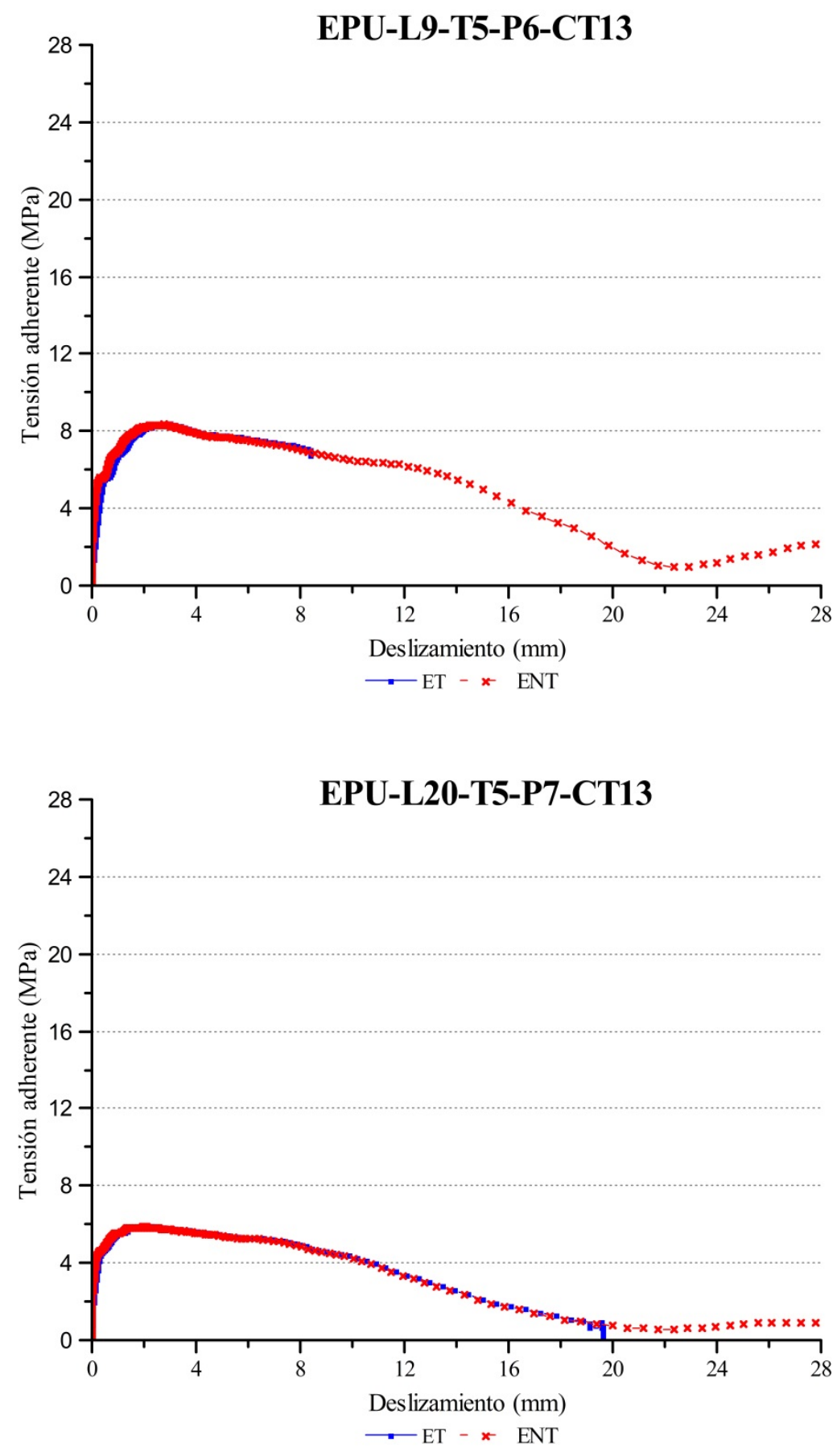

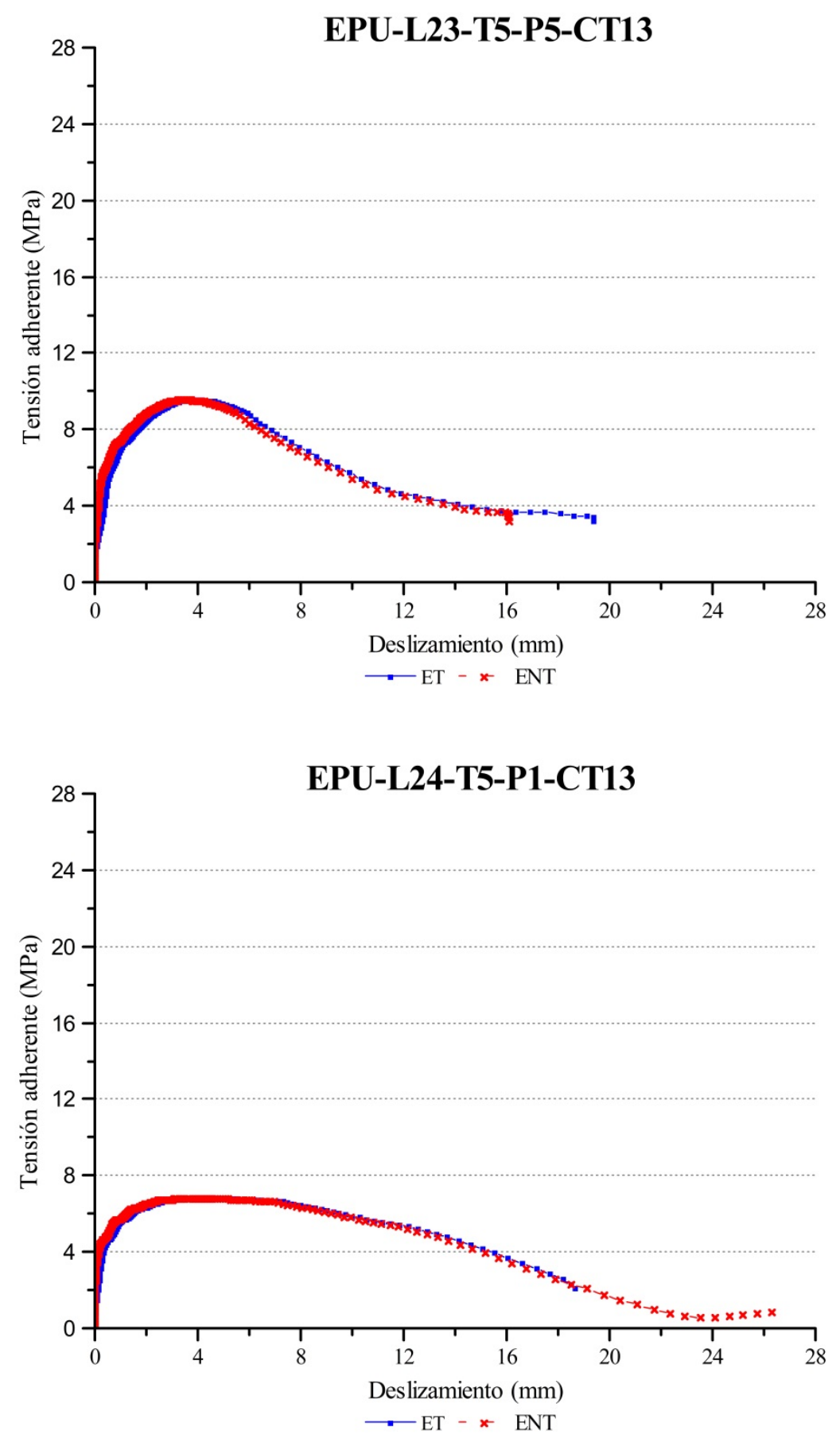
c. Condición Térmica de $20^{\circ} \mathrm{C}$.
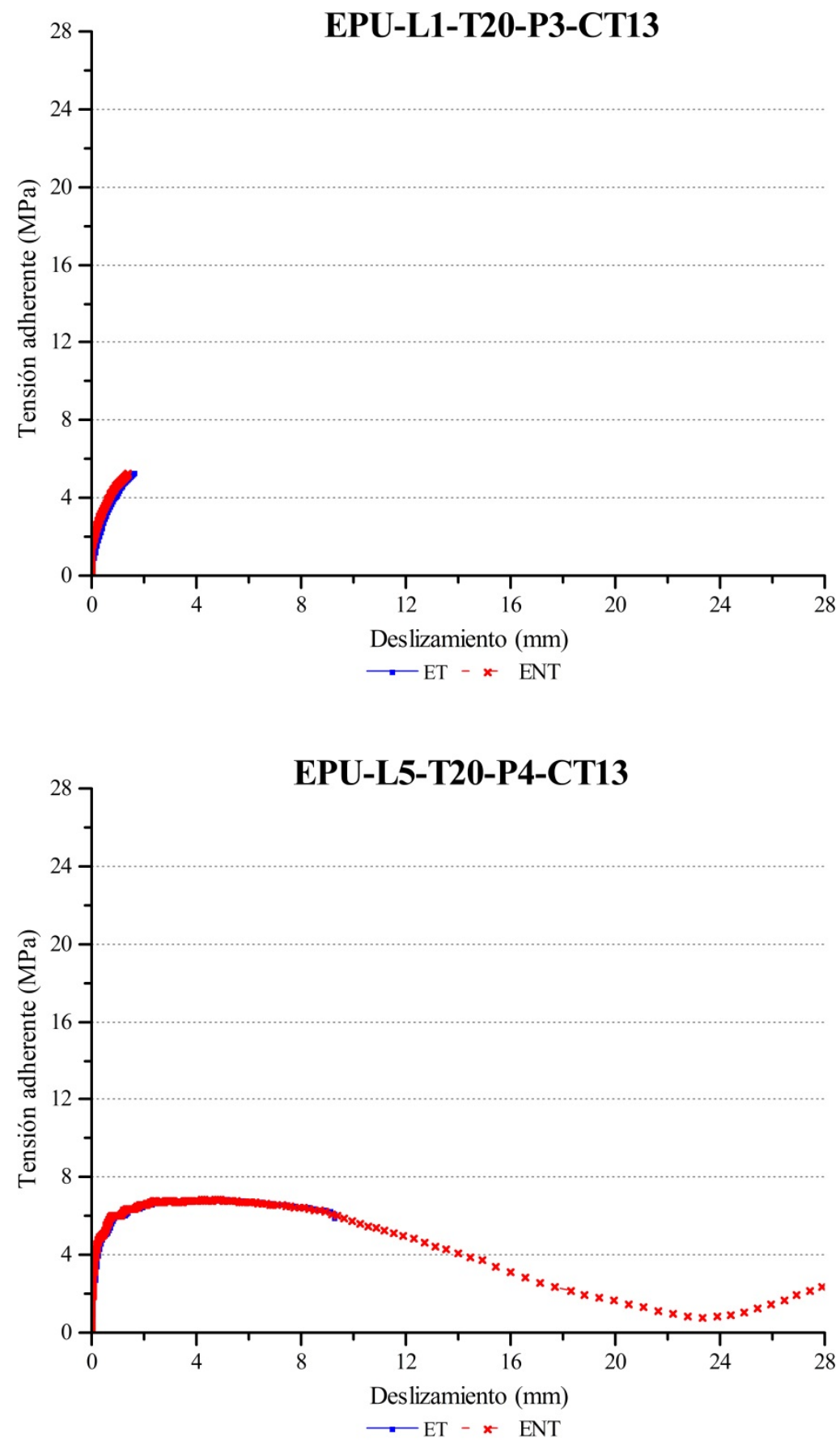
ANEJO I: "GRÁFICAS EXPERIMENTALES DE TENSIÓN ADHERENTE-DESLIZAMIENTO”

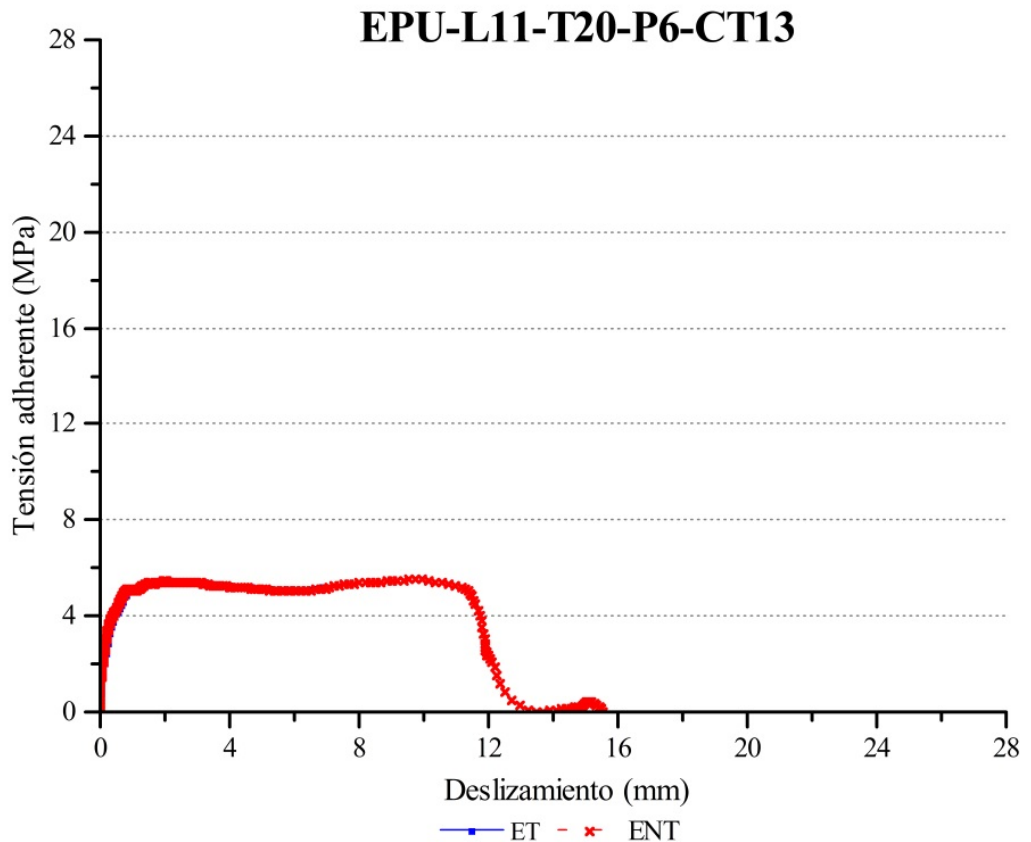

EPU-L14-T20-P2-CT13

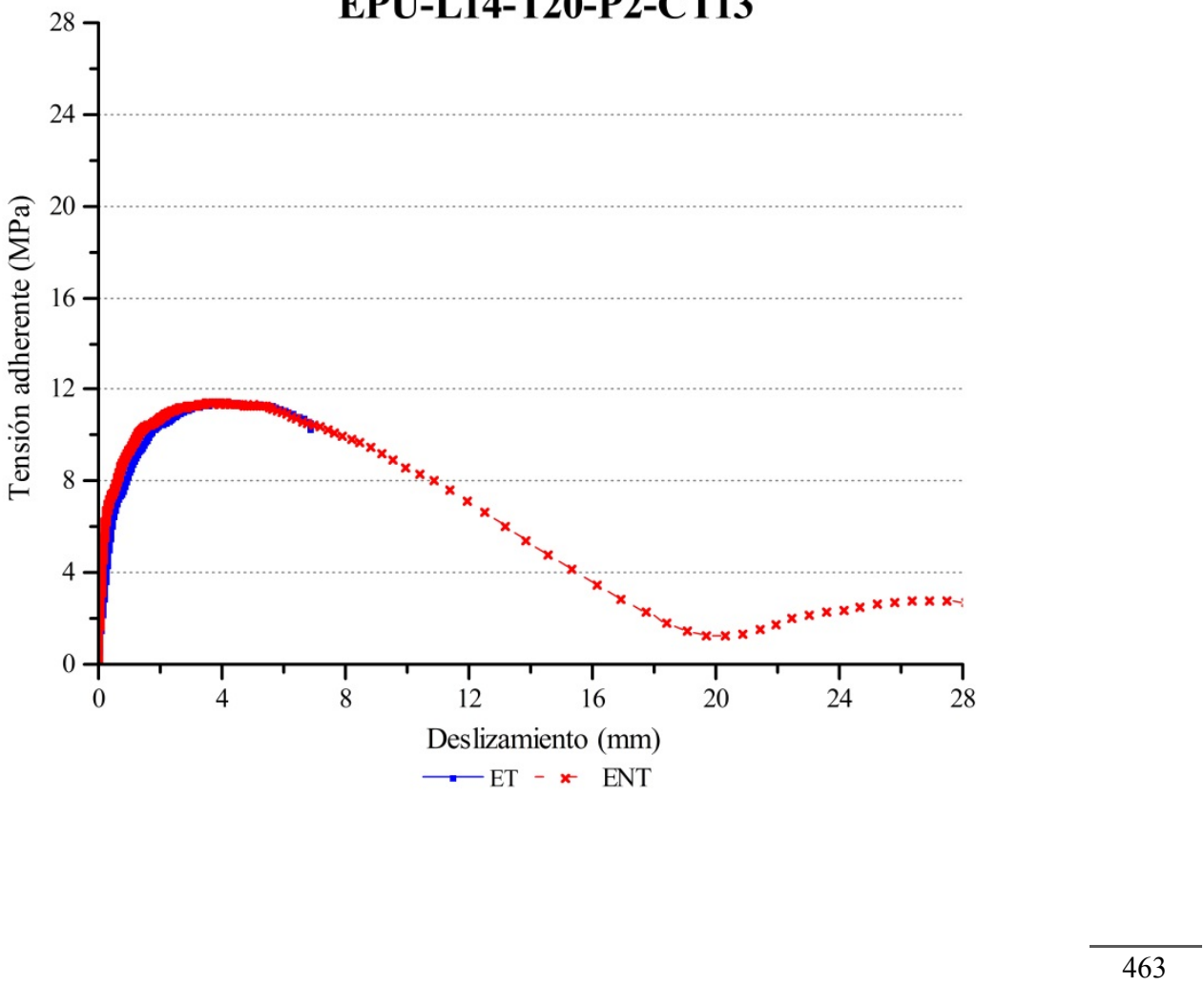


ANEJO I: "GRÁFICAS EXPERIMENTALES DE TENSIÓN ADHERENTE DESLIZAMIENTO”

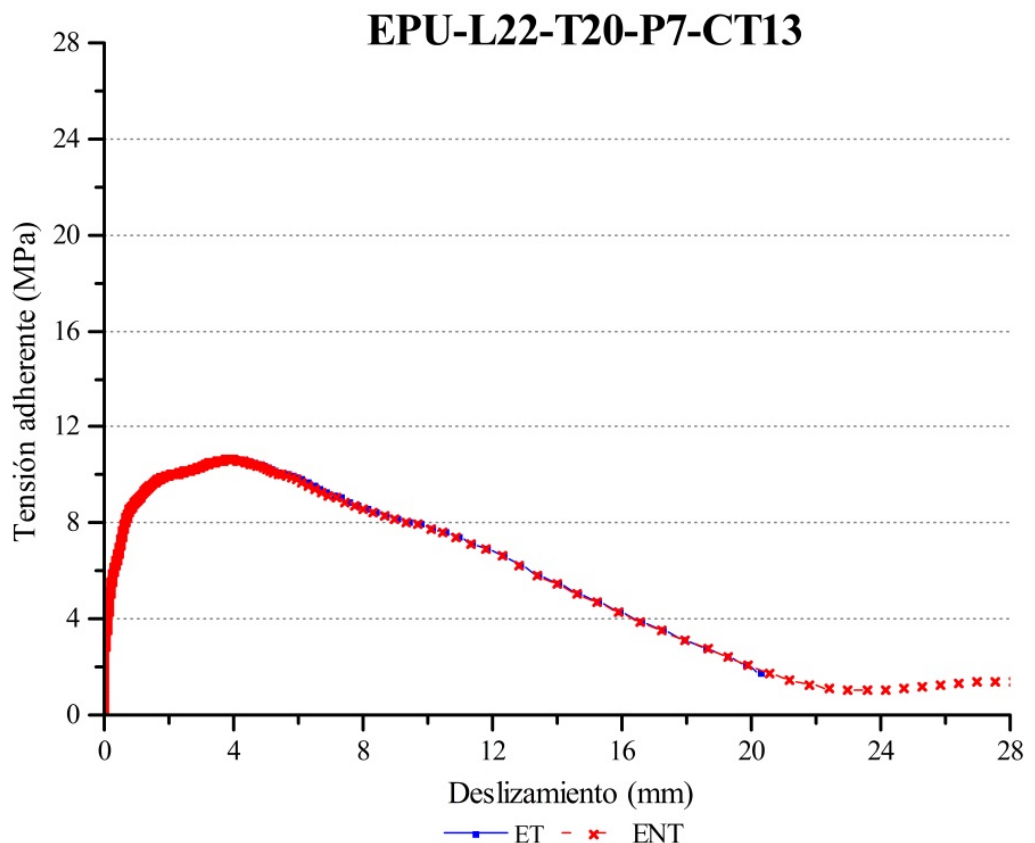

d. Condición Térmica de $40{ }^{\circ} \mathrm{C}$.

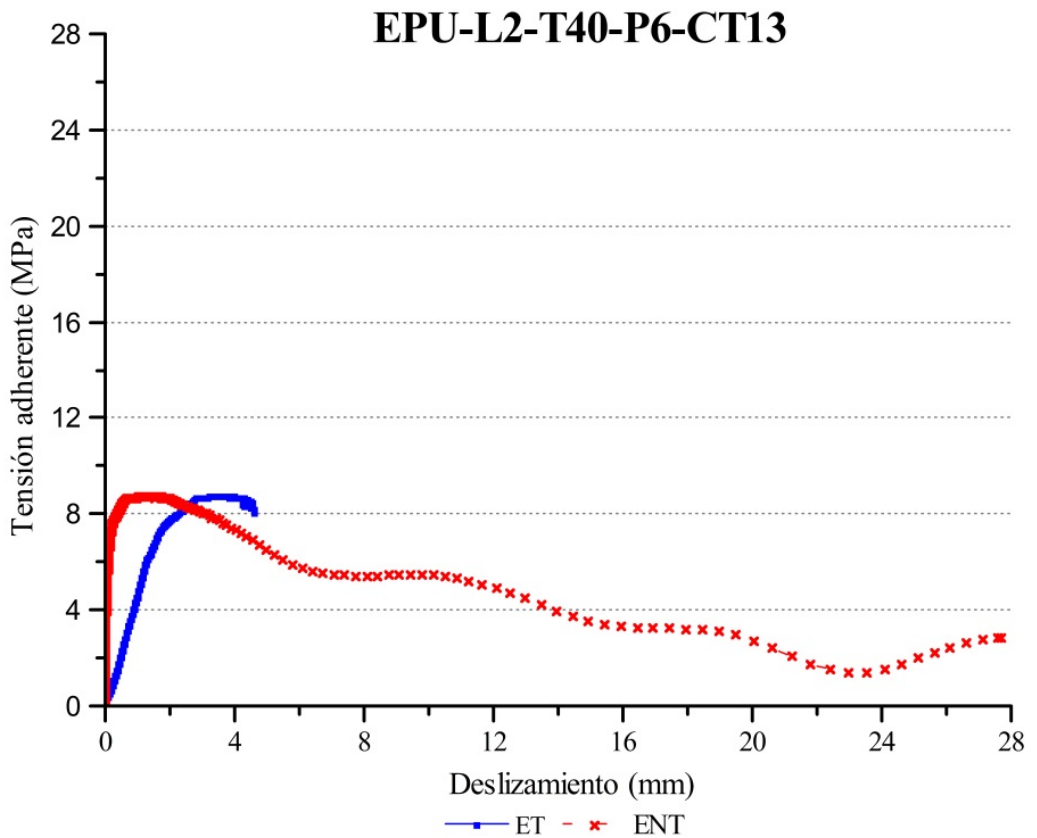

464 

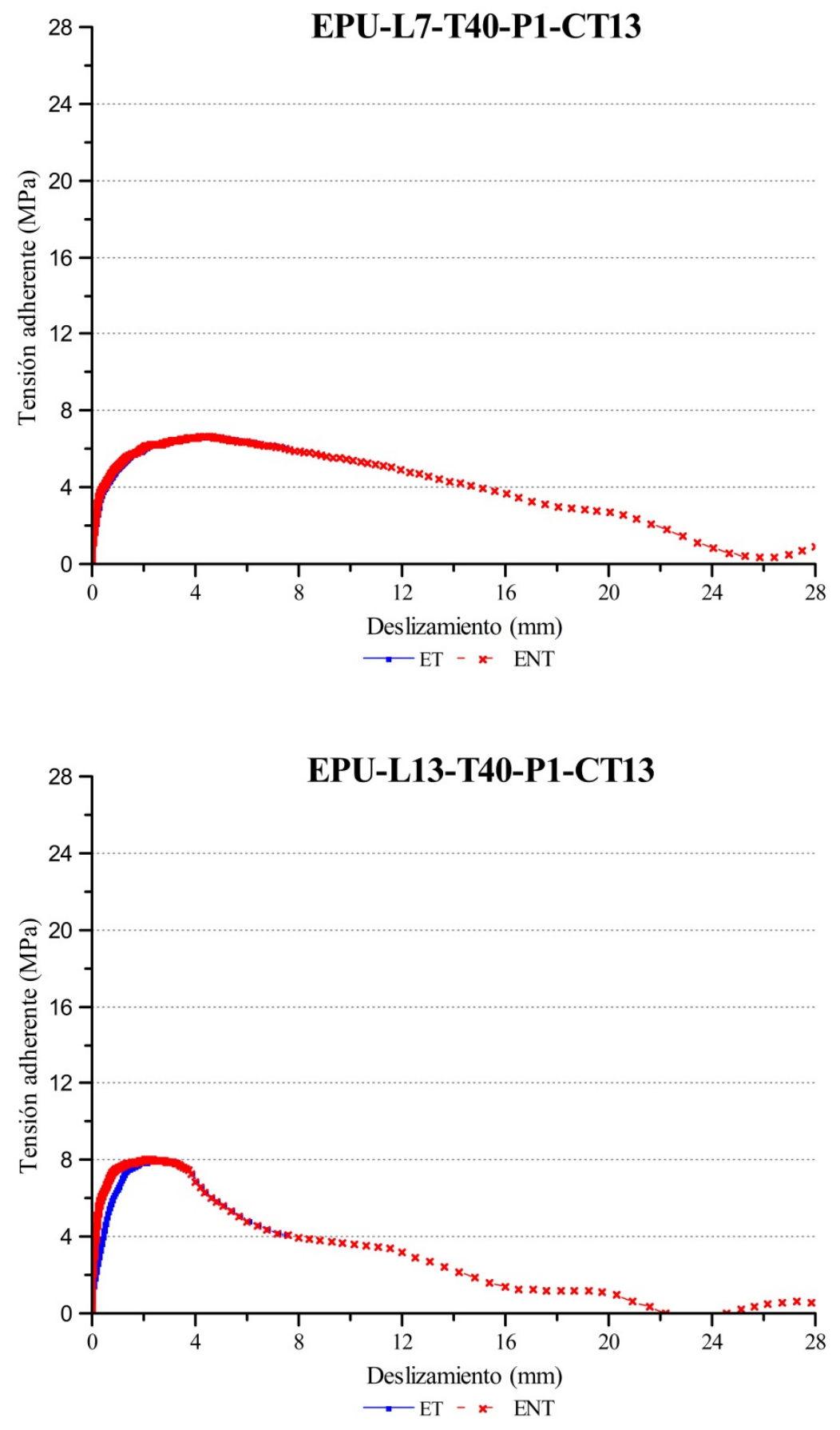

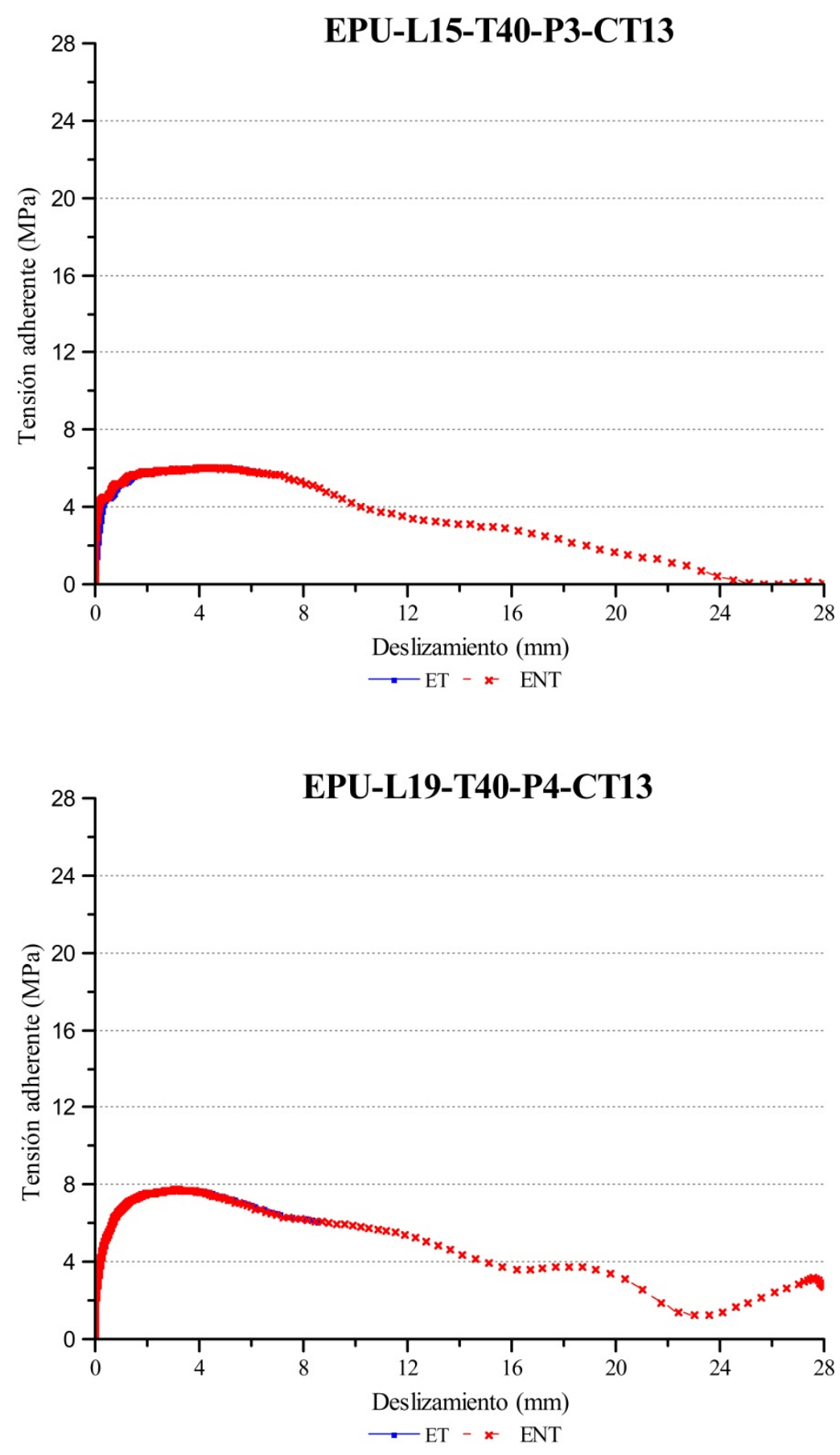
e. Condición Térmica de $80^{\circ} \mathrm{C}$.
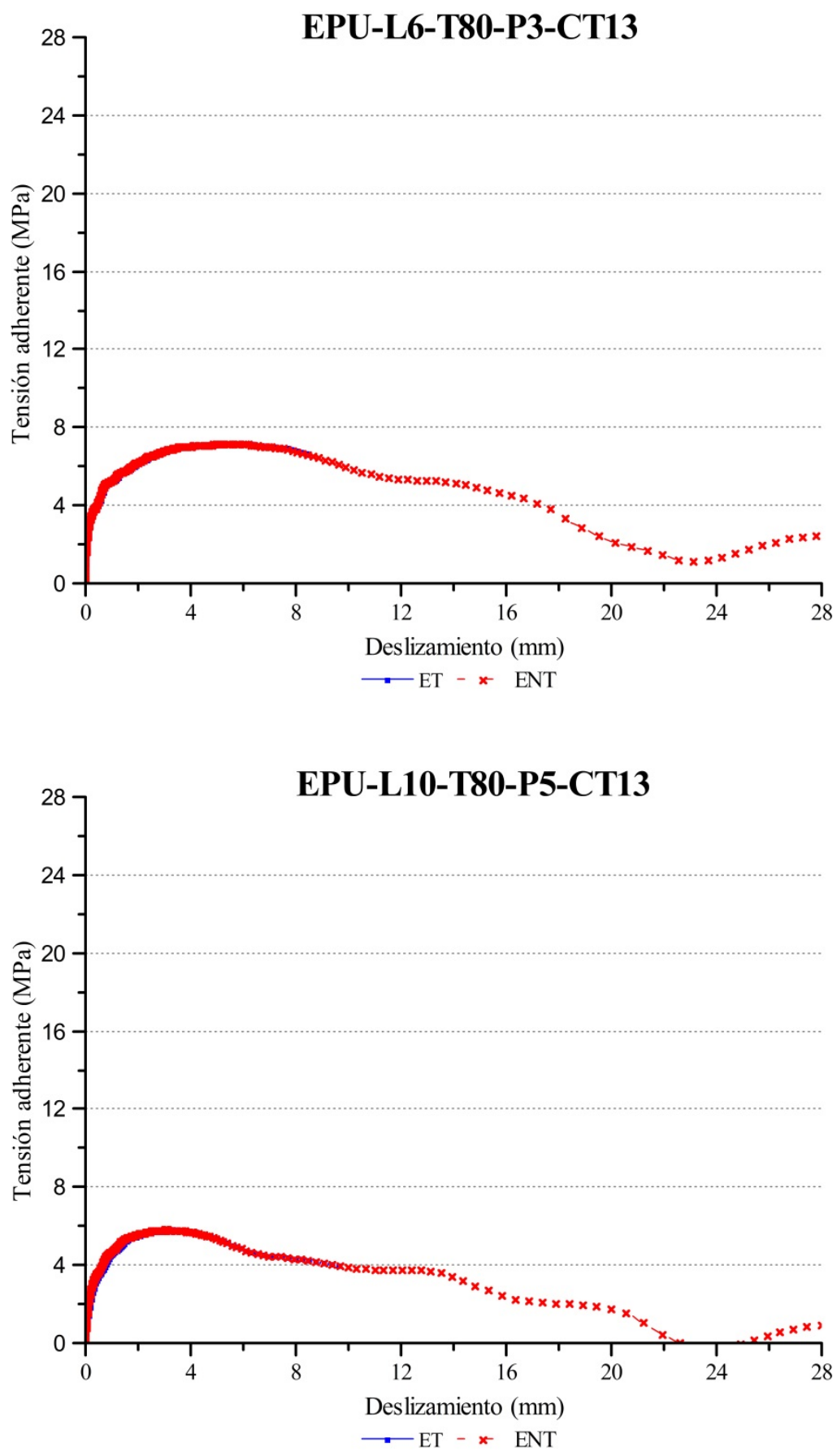

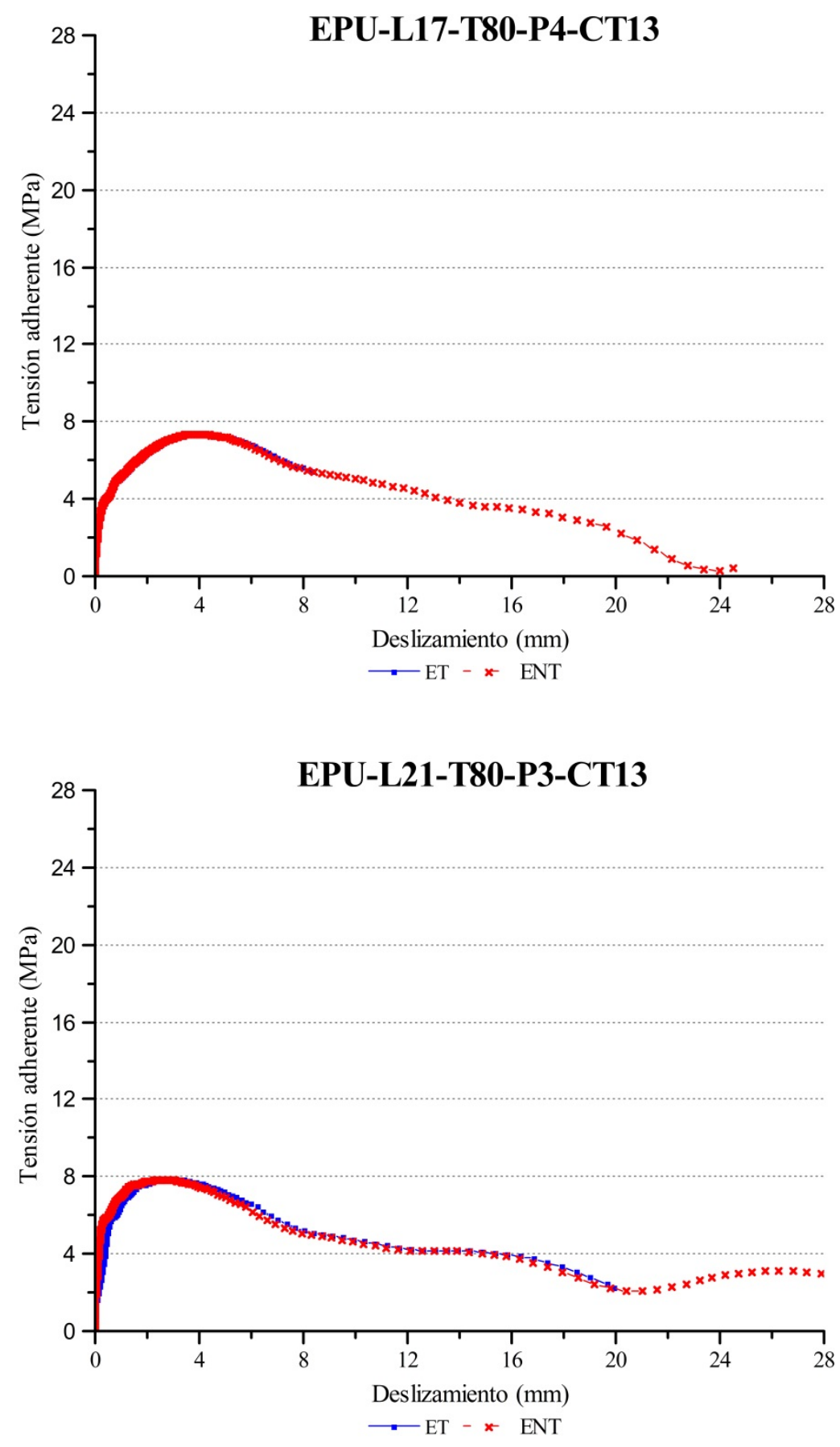


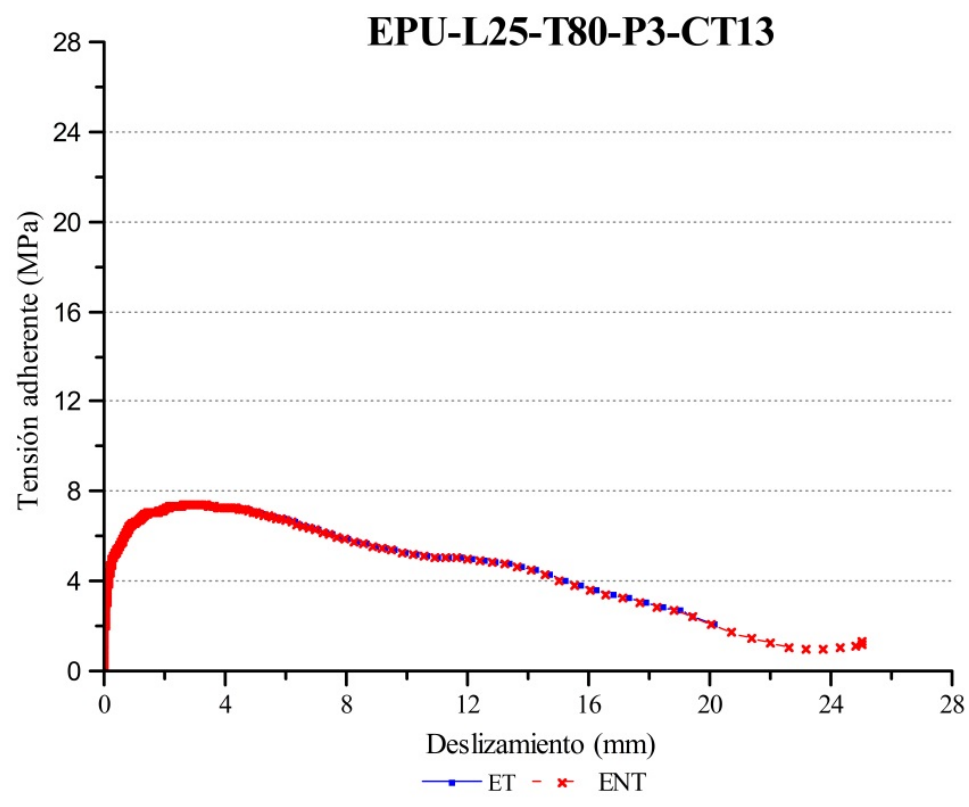

V. Barras de Acero Corrugadas A8:

a. Condición Térmica de Hielo/Deshielo o -20 ${ }^{\circ} \mathrm{C}$.

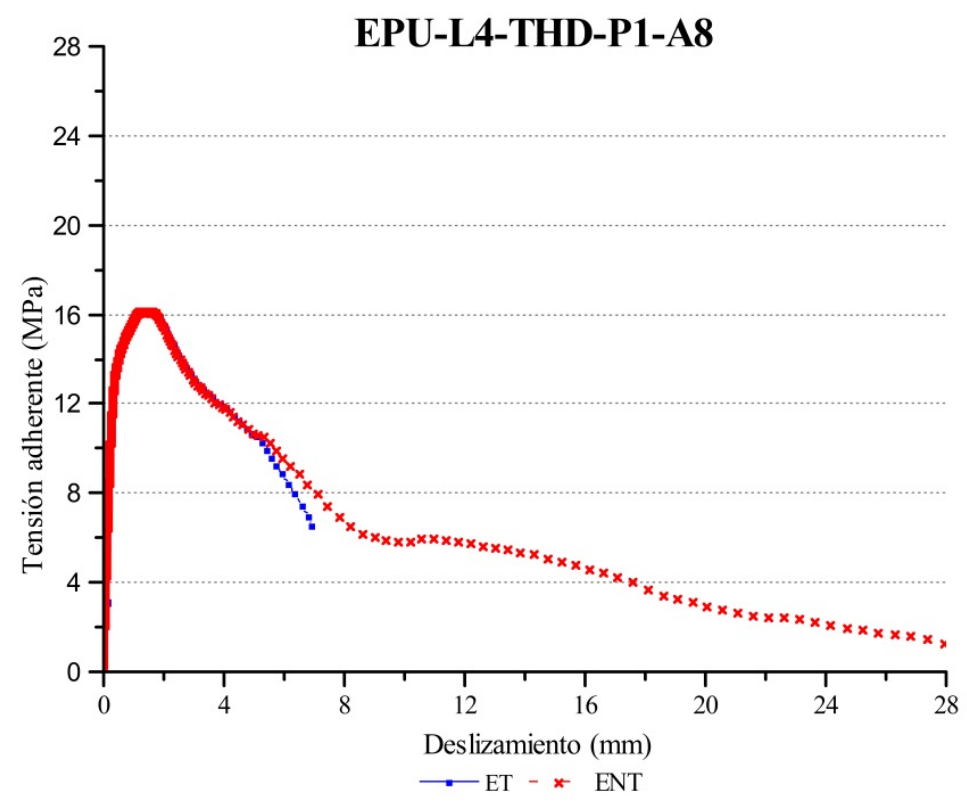



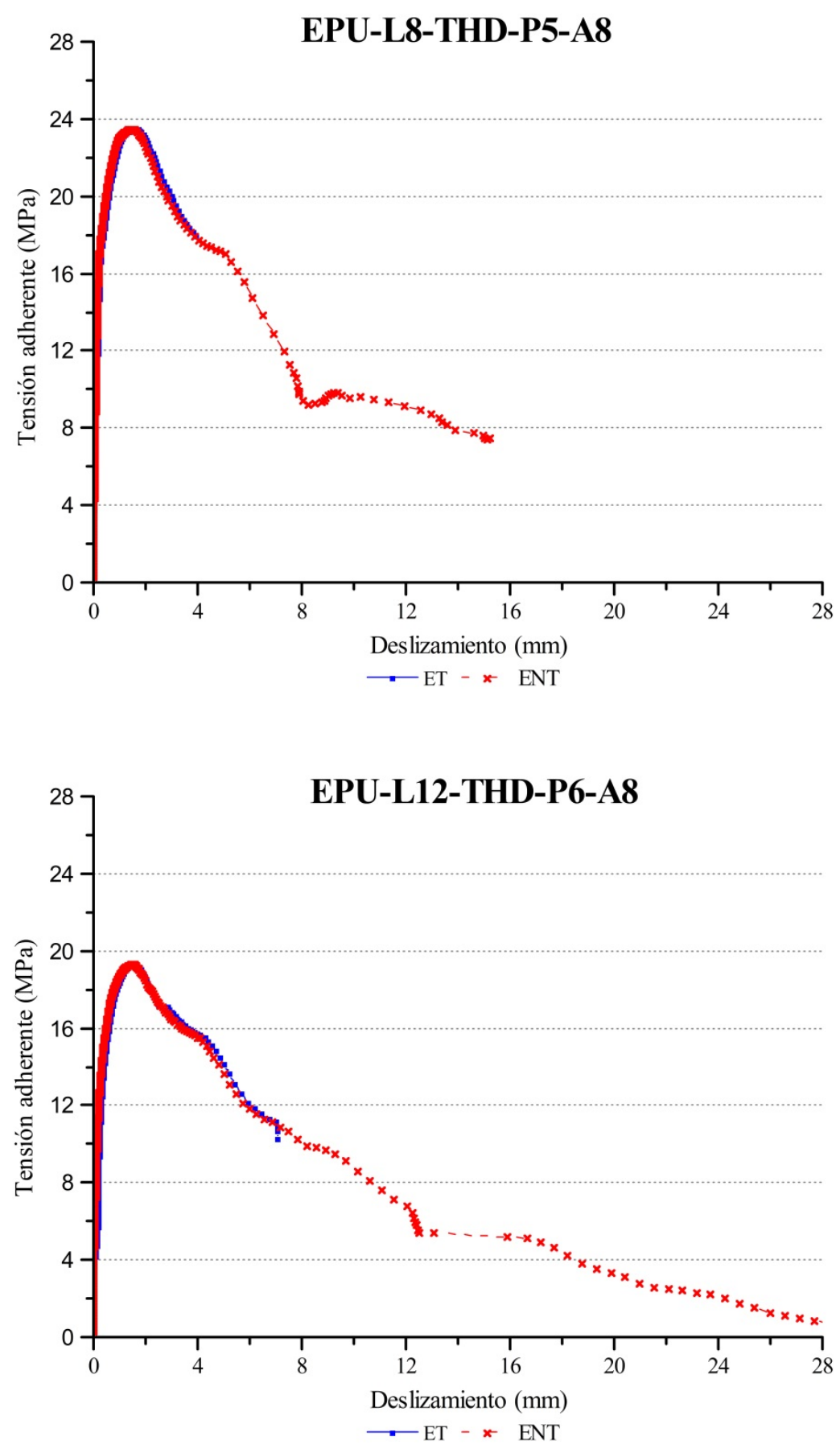

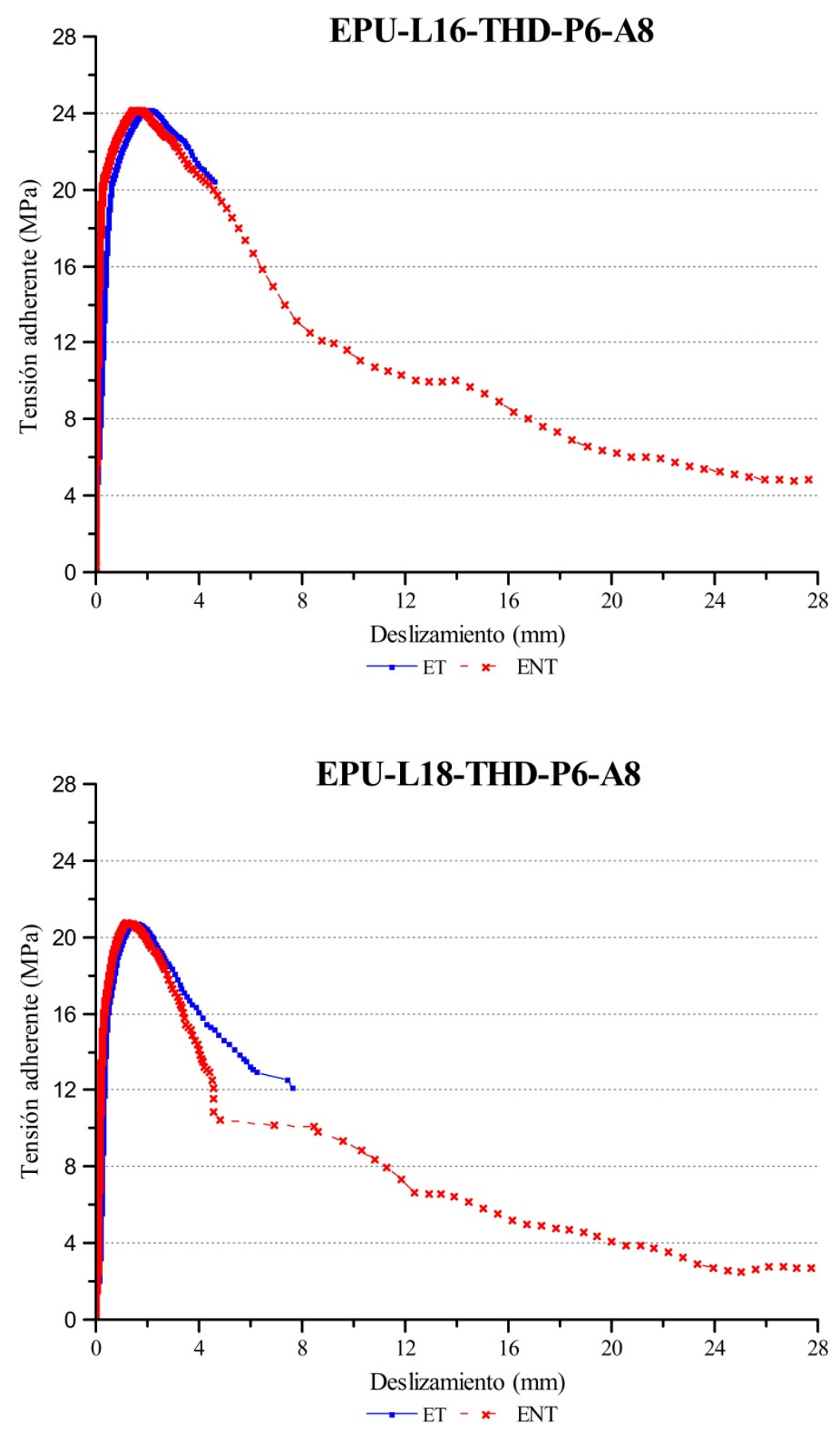
b. Condición Térmica de $5^{\circ} \mathrm{C}$.
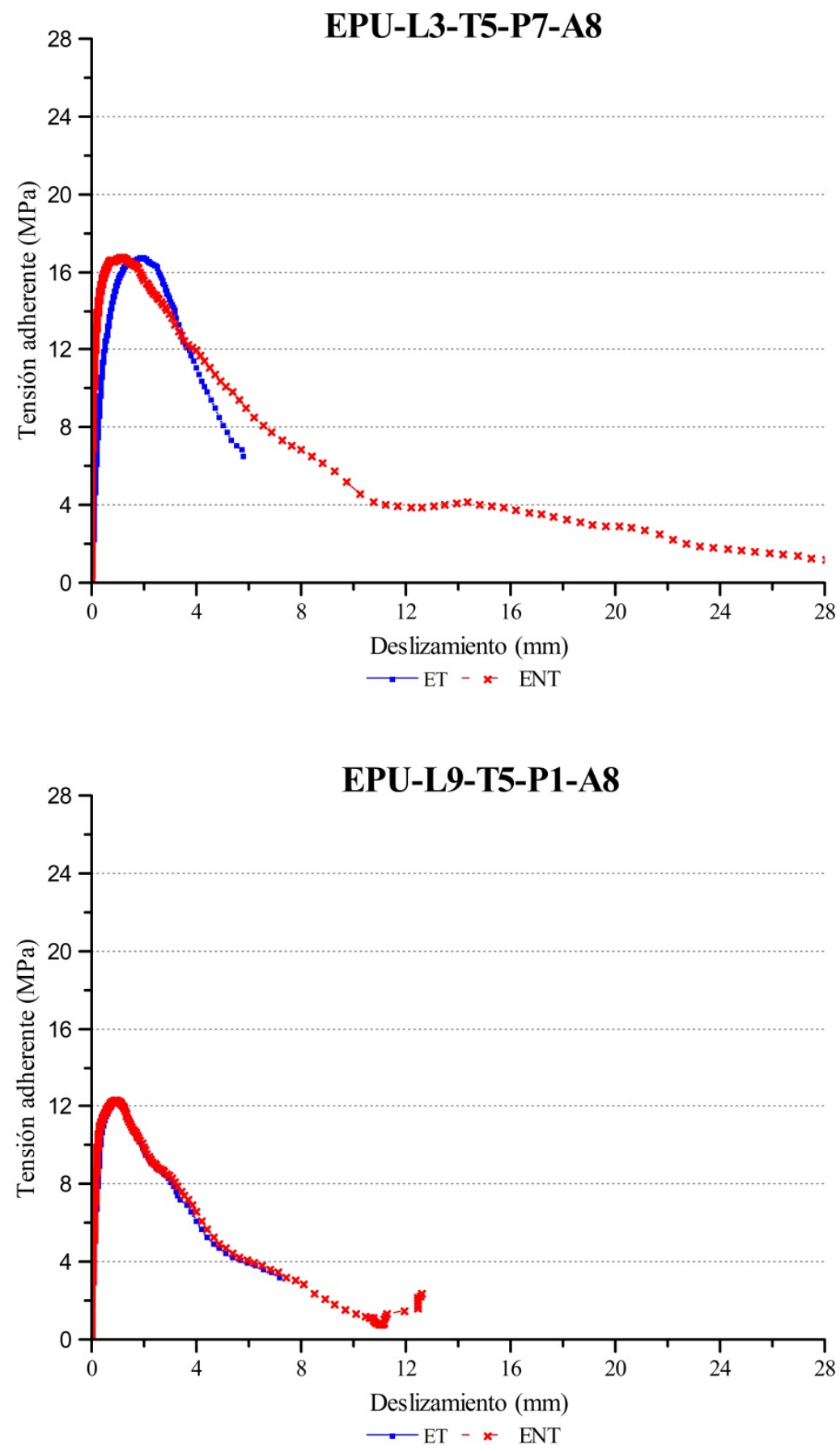

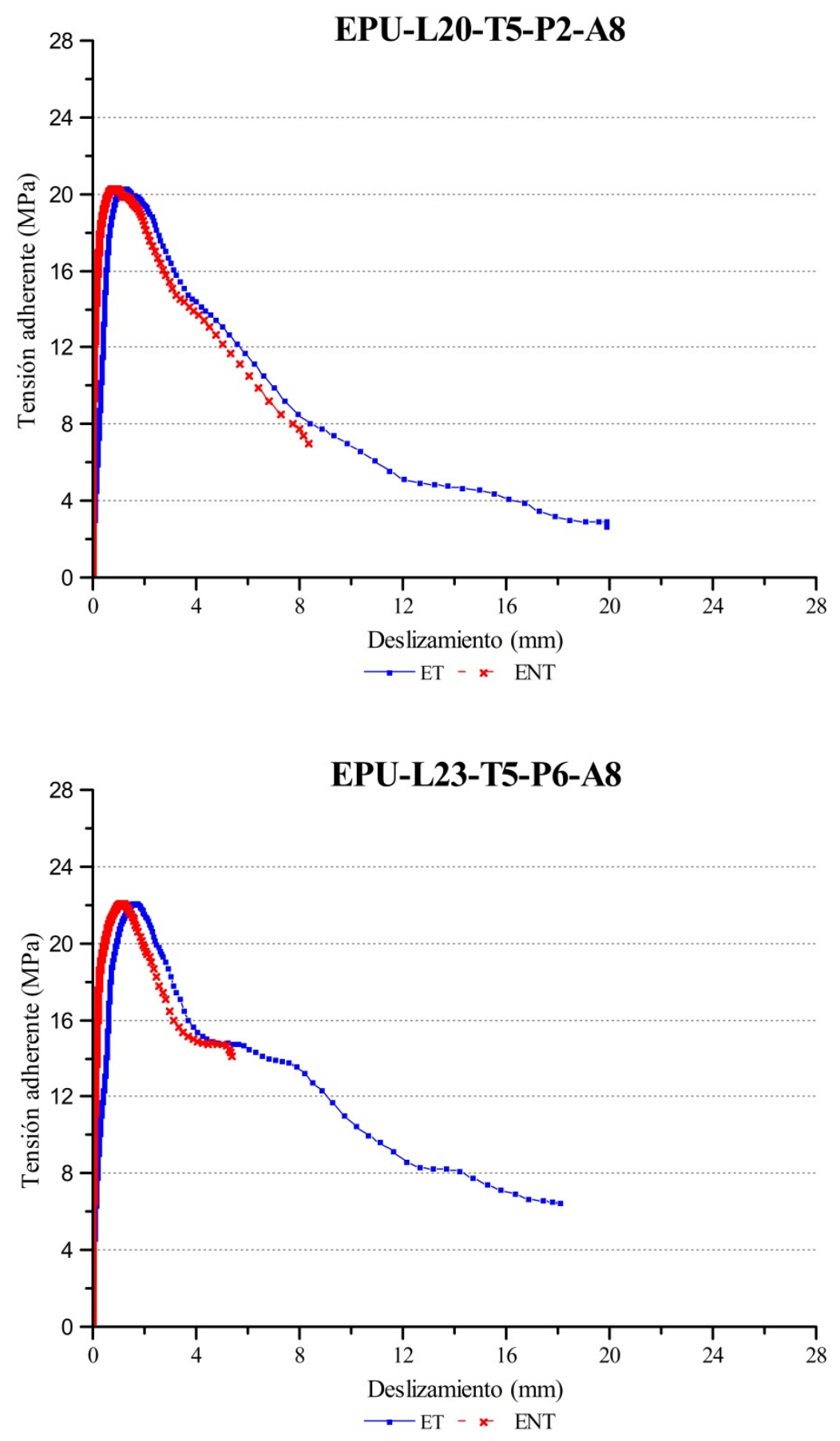


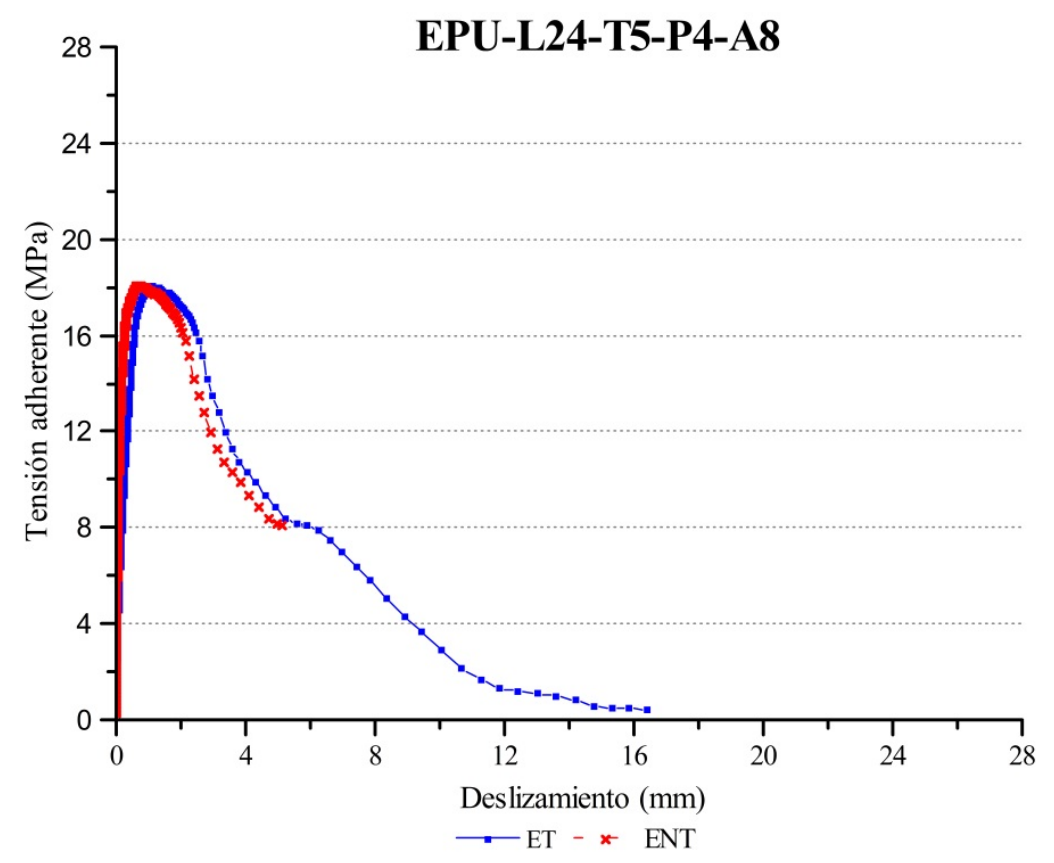

\section{c. Condición Térmica de $20^{\circ} \mathrm{C}$.}

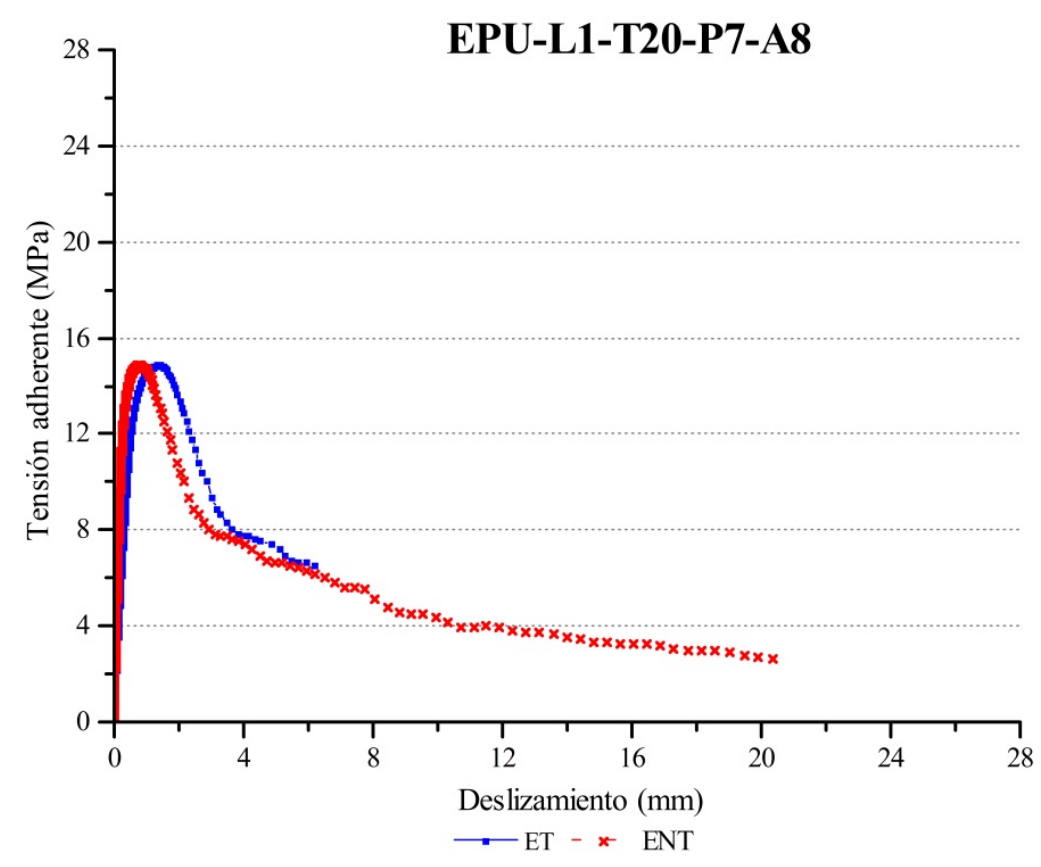



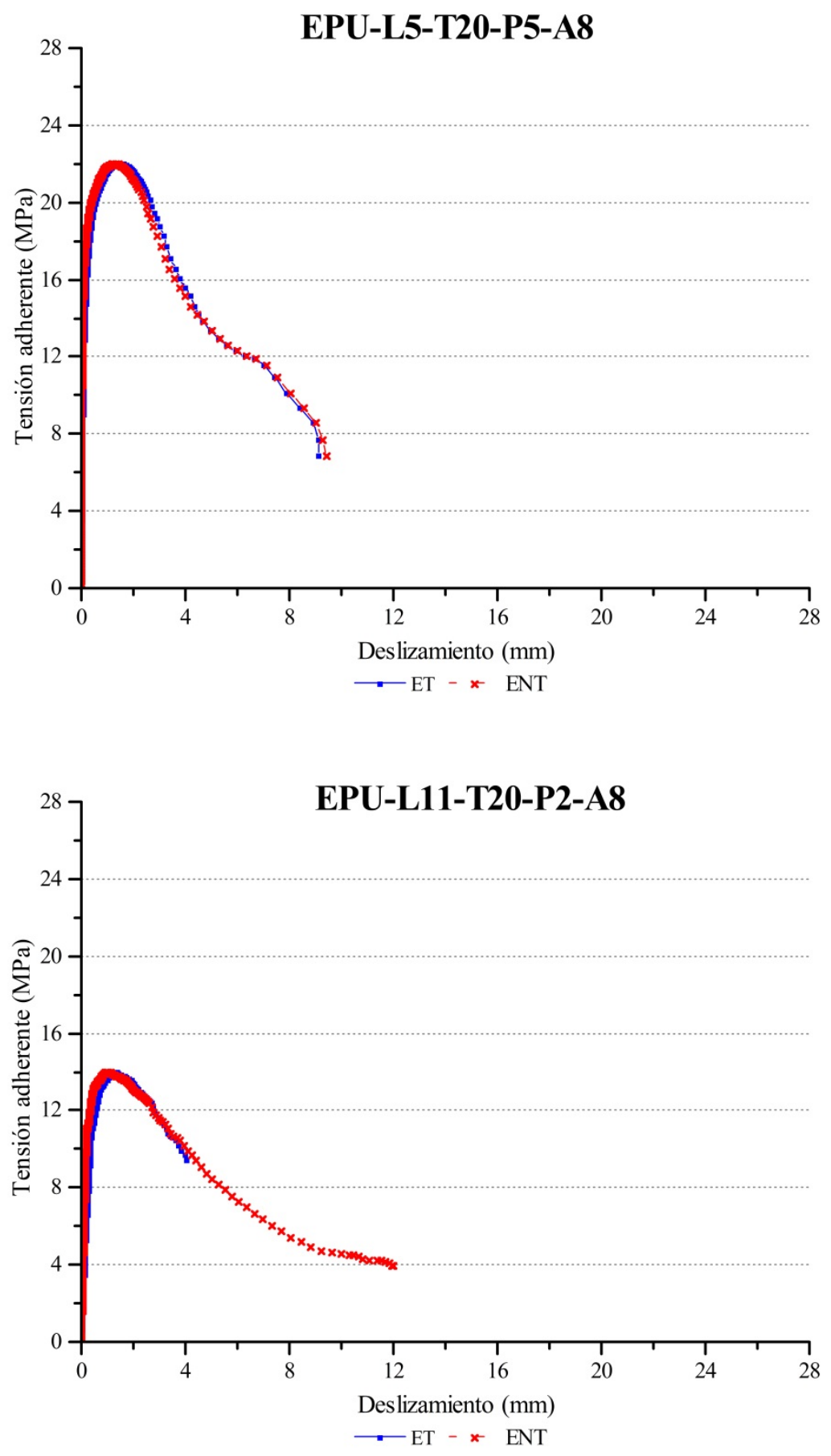

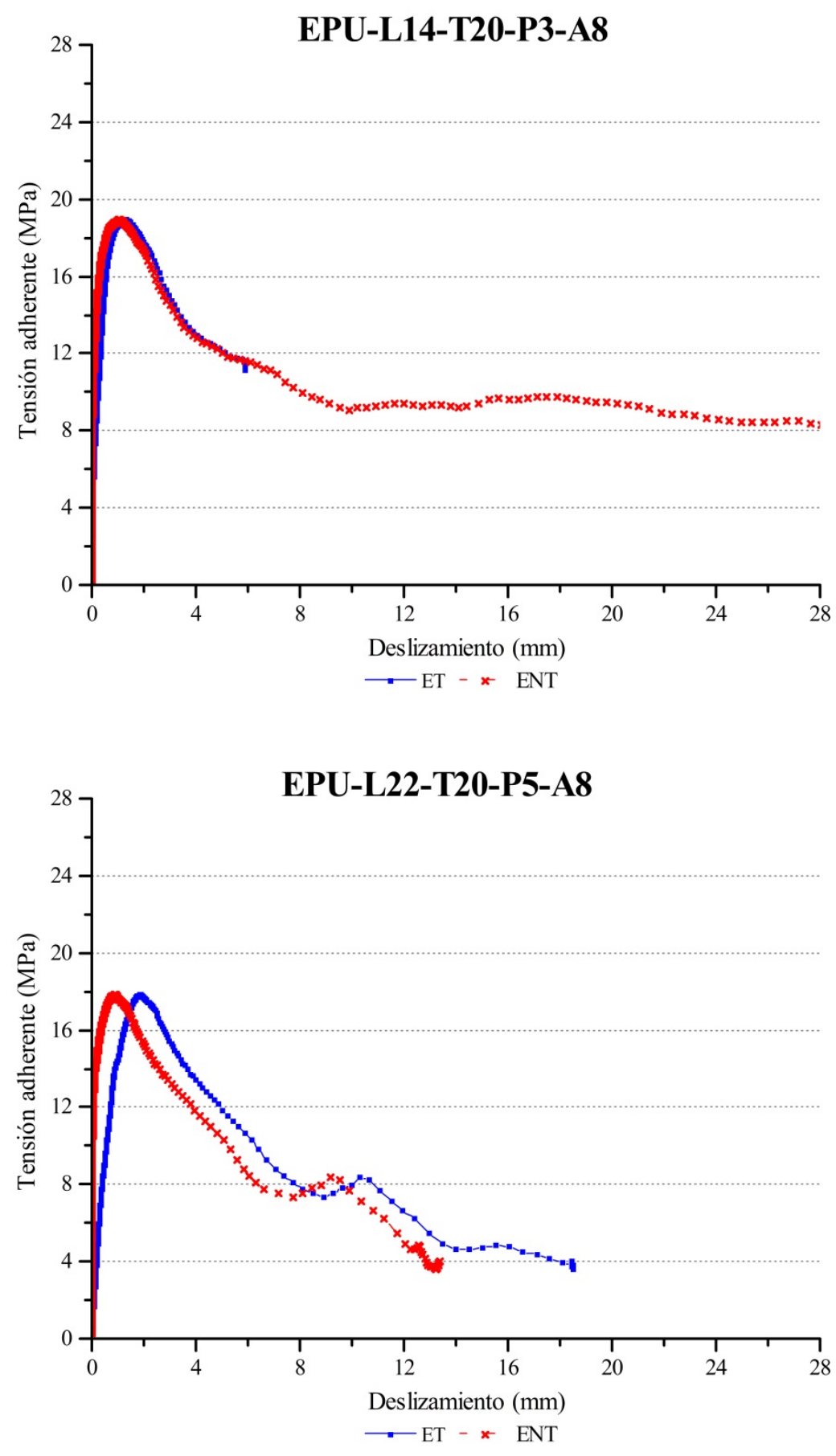


\section{d. Condición Térmica de $40{ }^{\circ} \mathrm{C}$.}
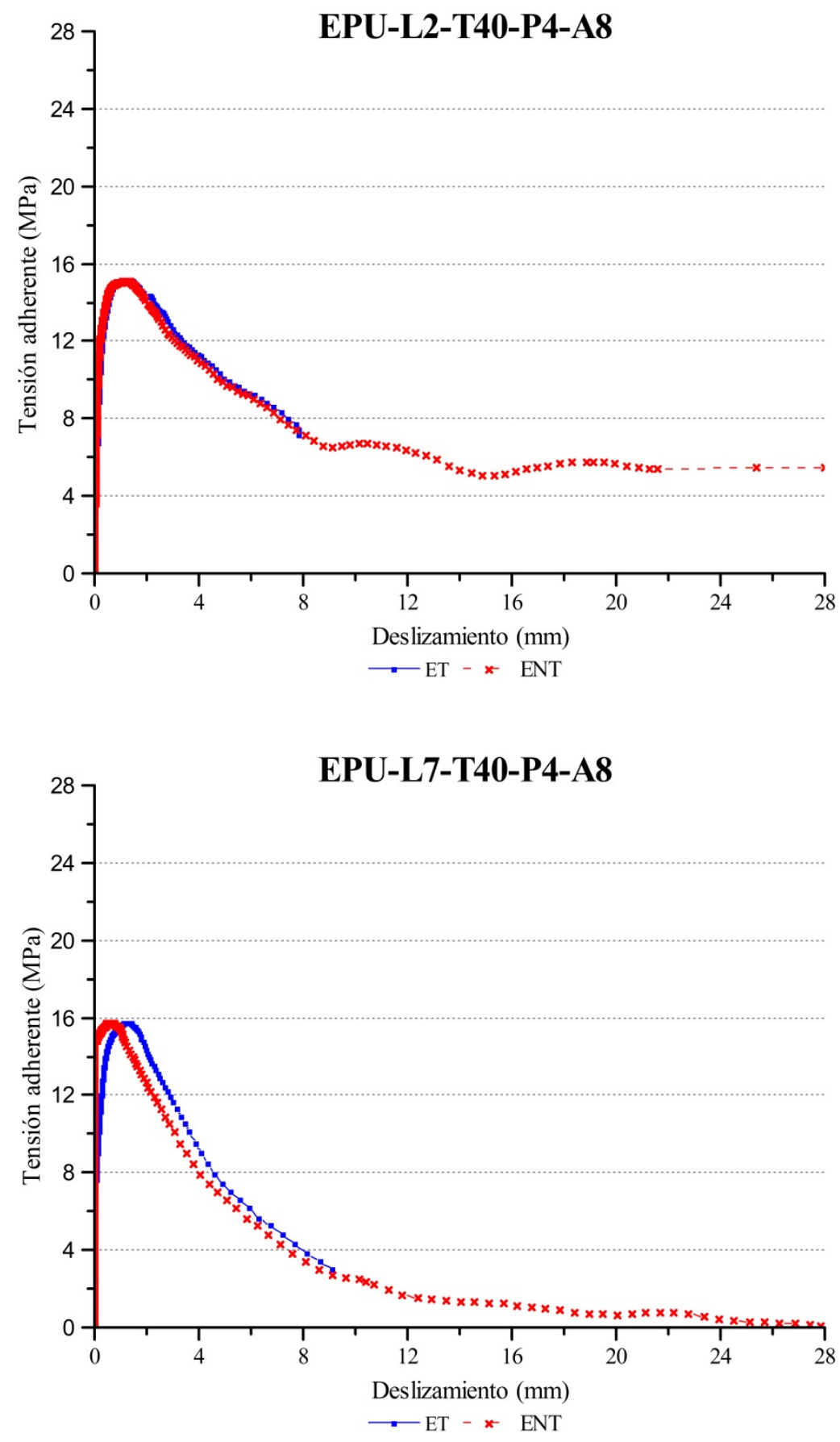

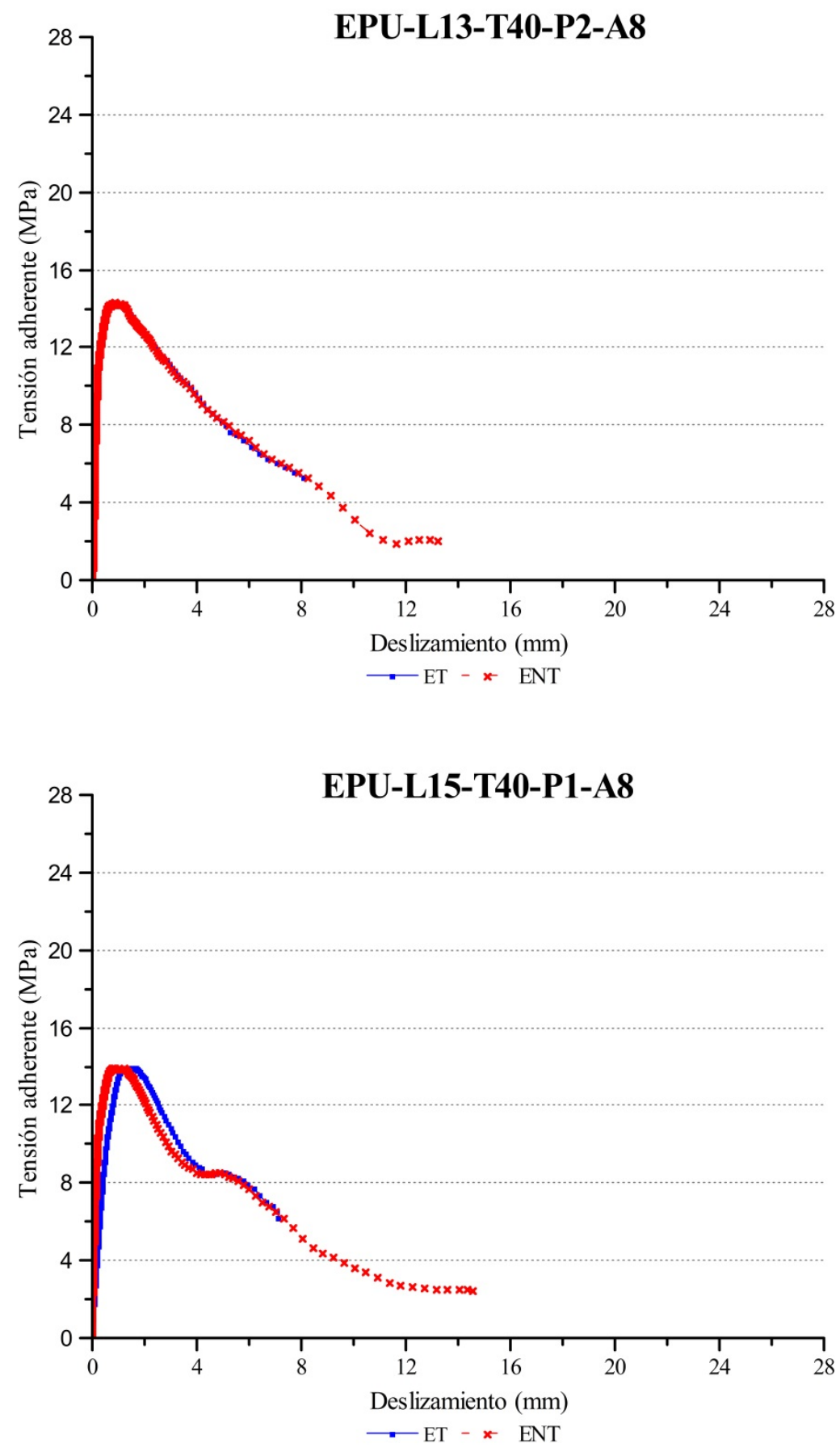


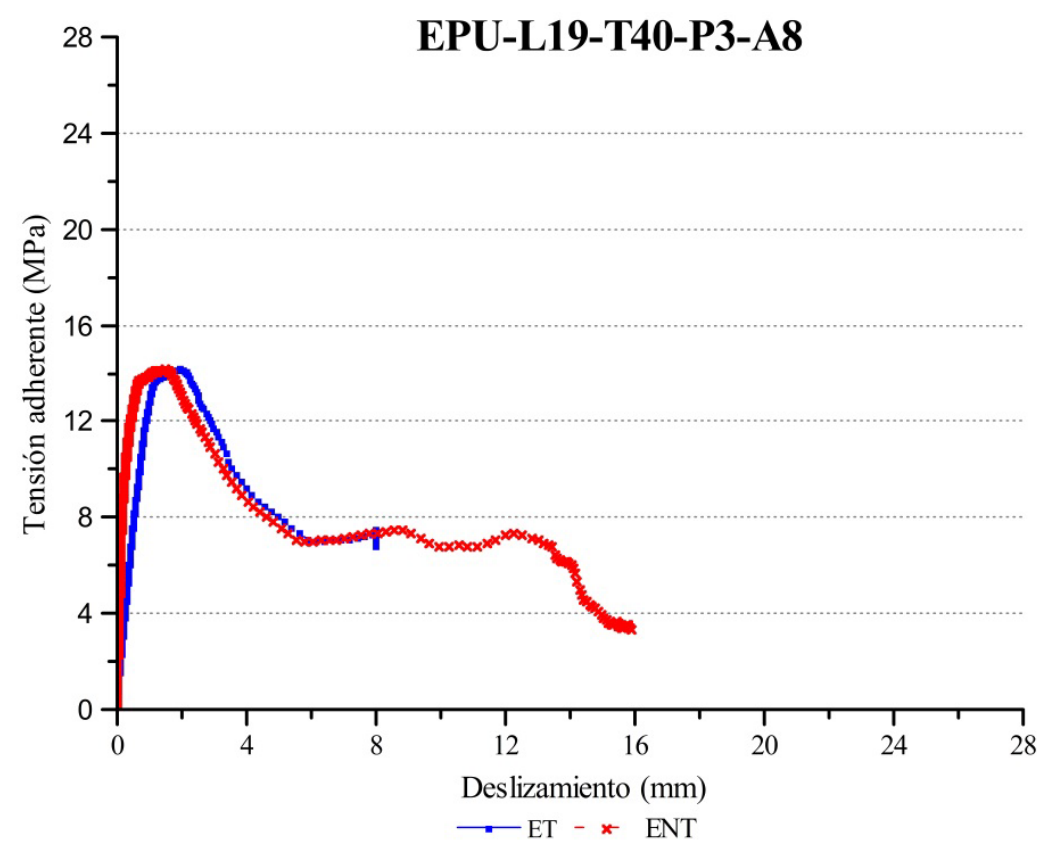

e. Condición Térmica de $80^{\circ} \mathrm{C}$.

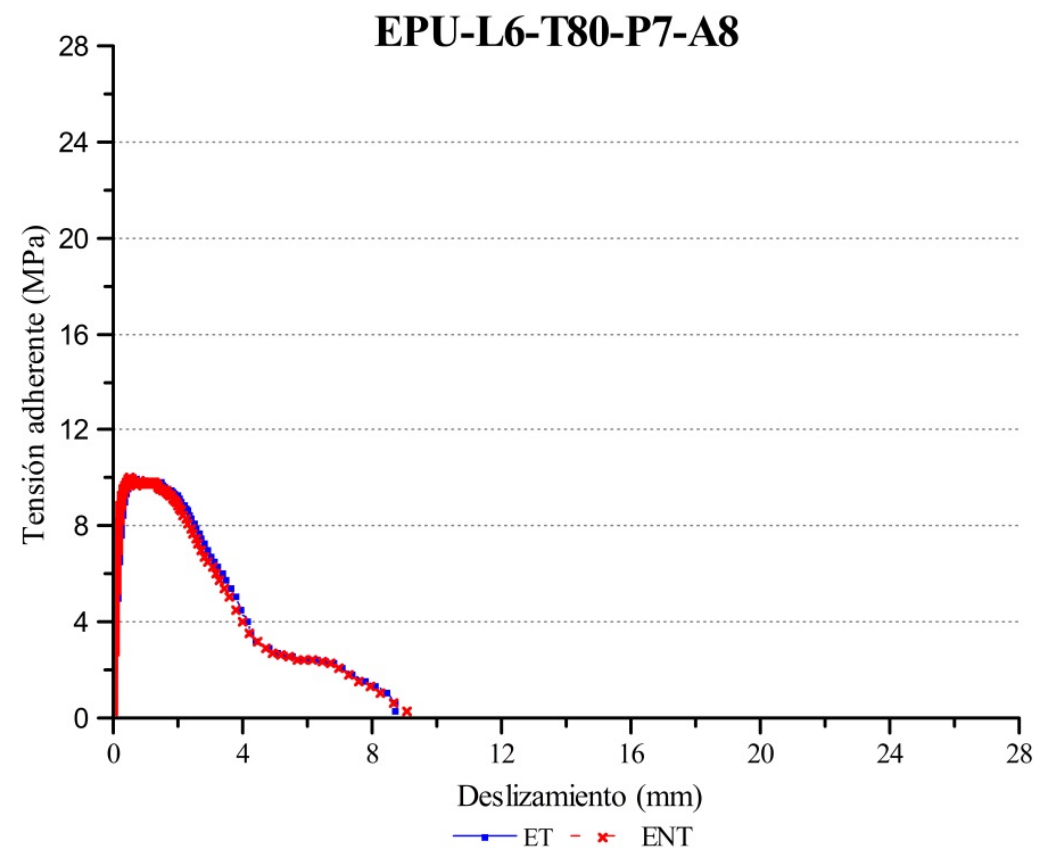



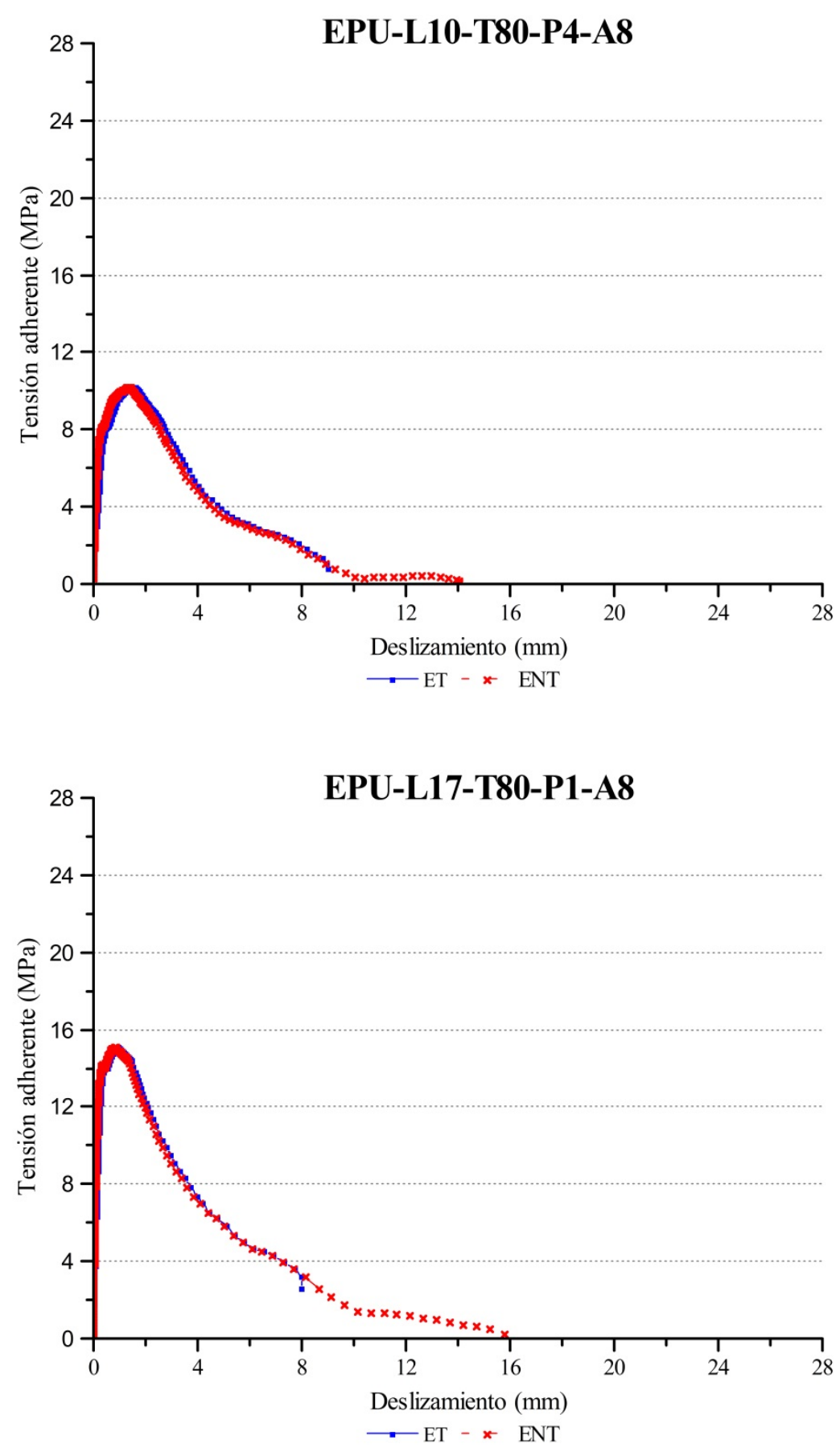

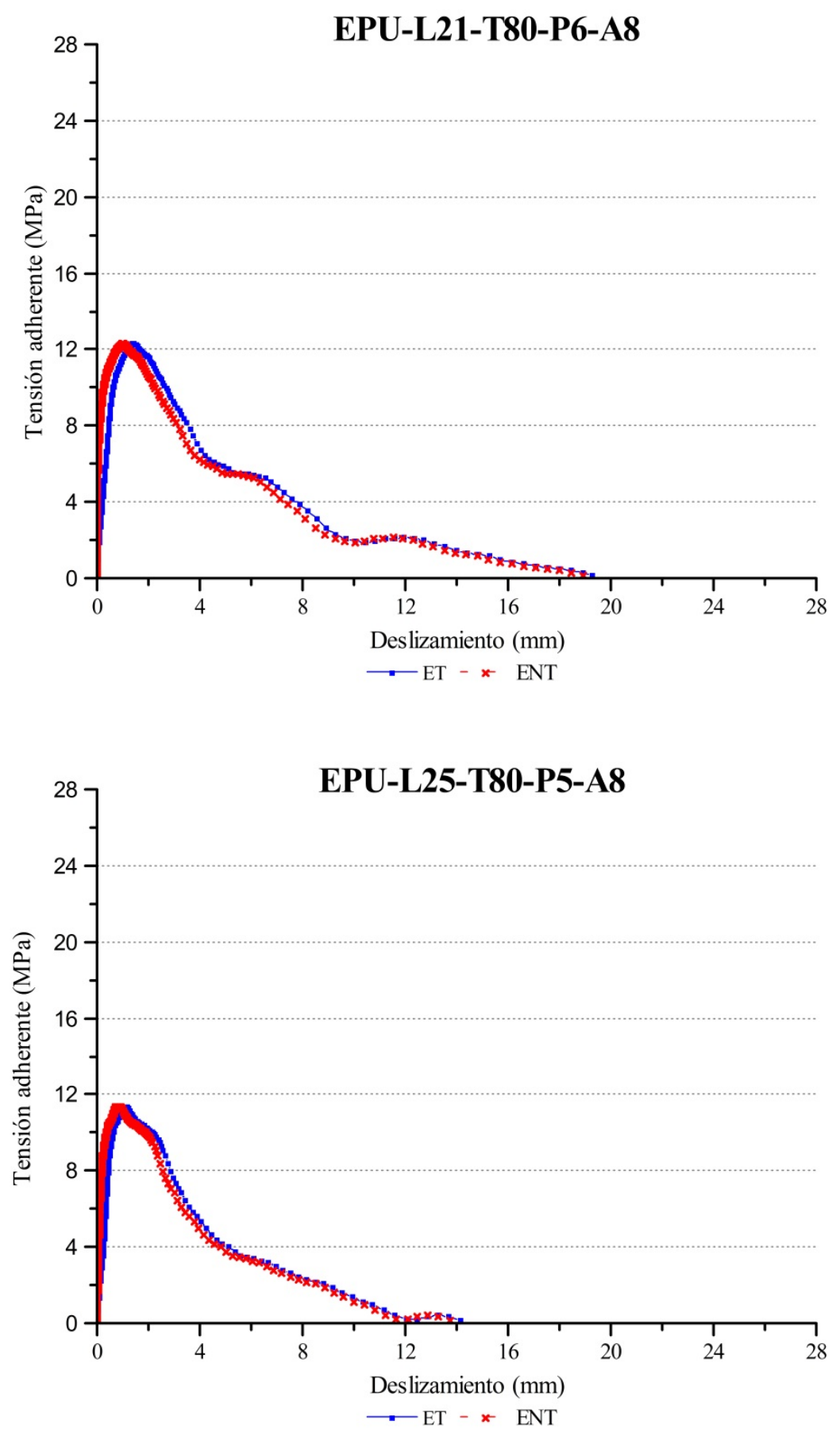


\section{Barras de Acero Corrugadas A12:}

a. Condición Térmica de Hielo/Deshielo o $-20{ }^{\circ} \mathrm{C}$.
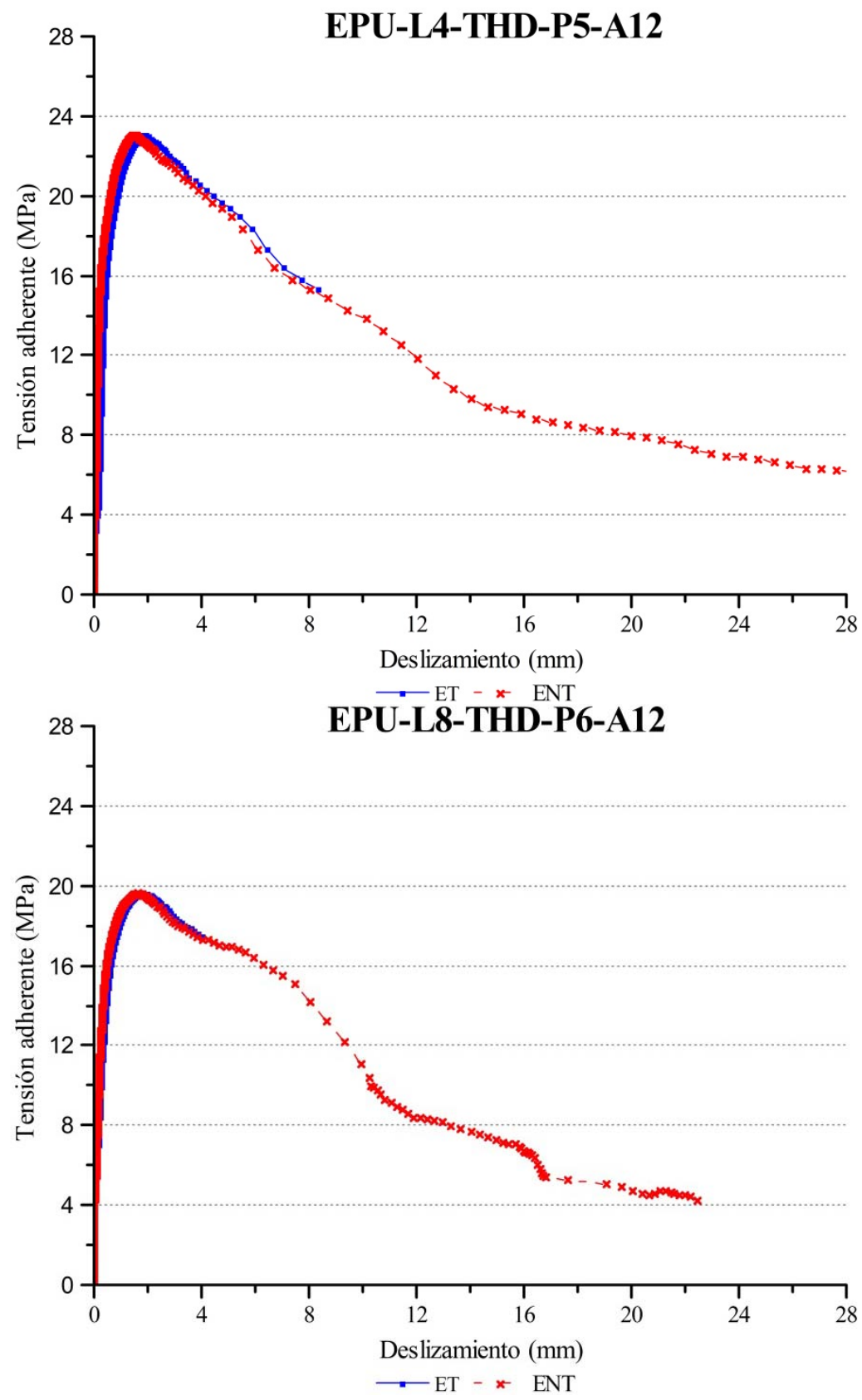

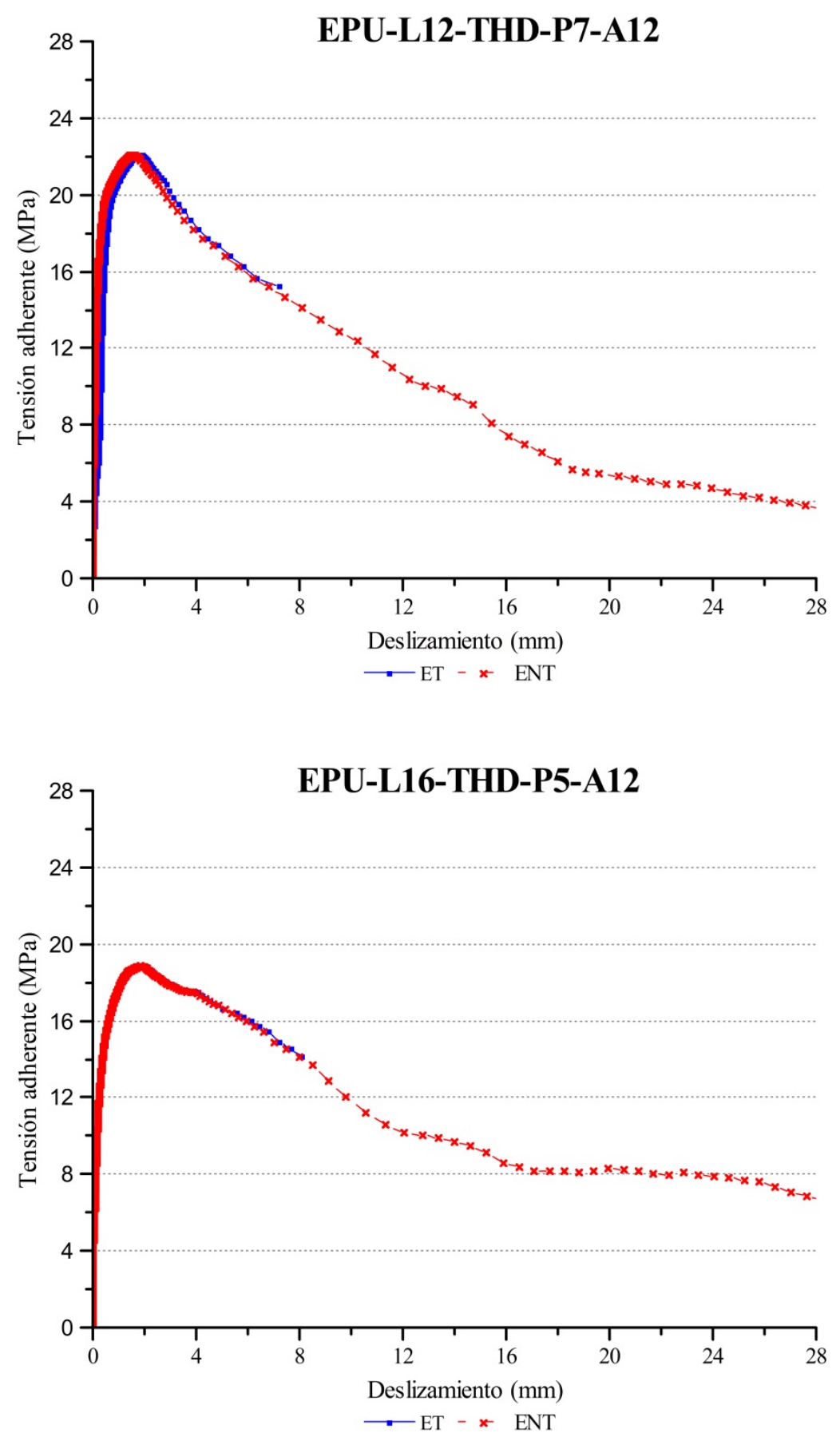


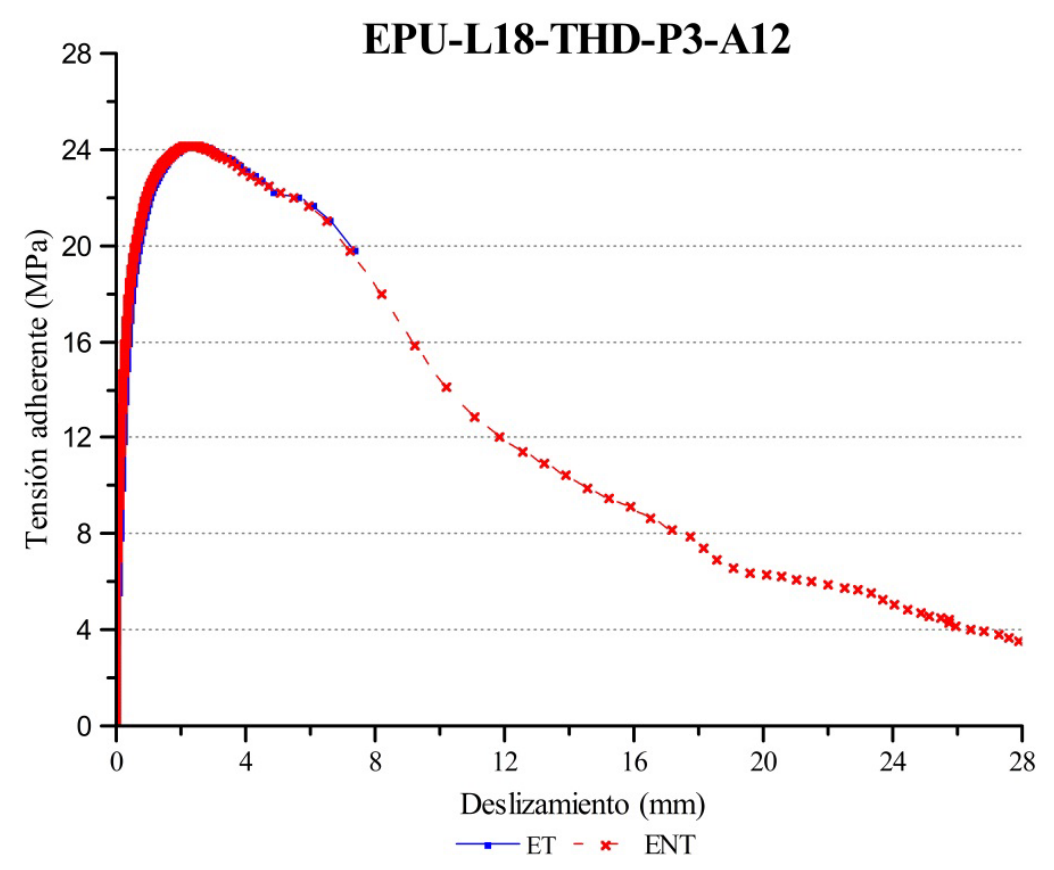

b. Condición Térmica de $5^{\circ} \mathrm{C}$.

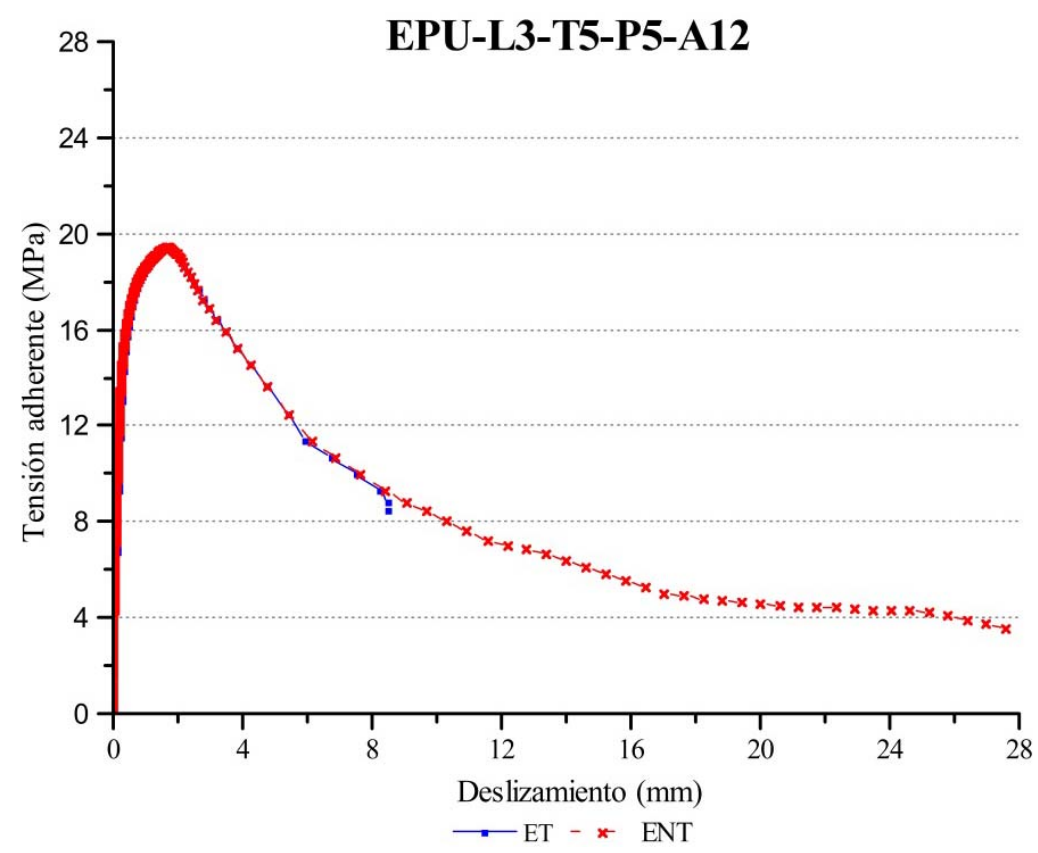



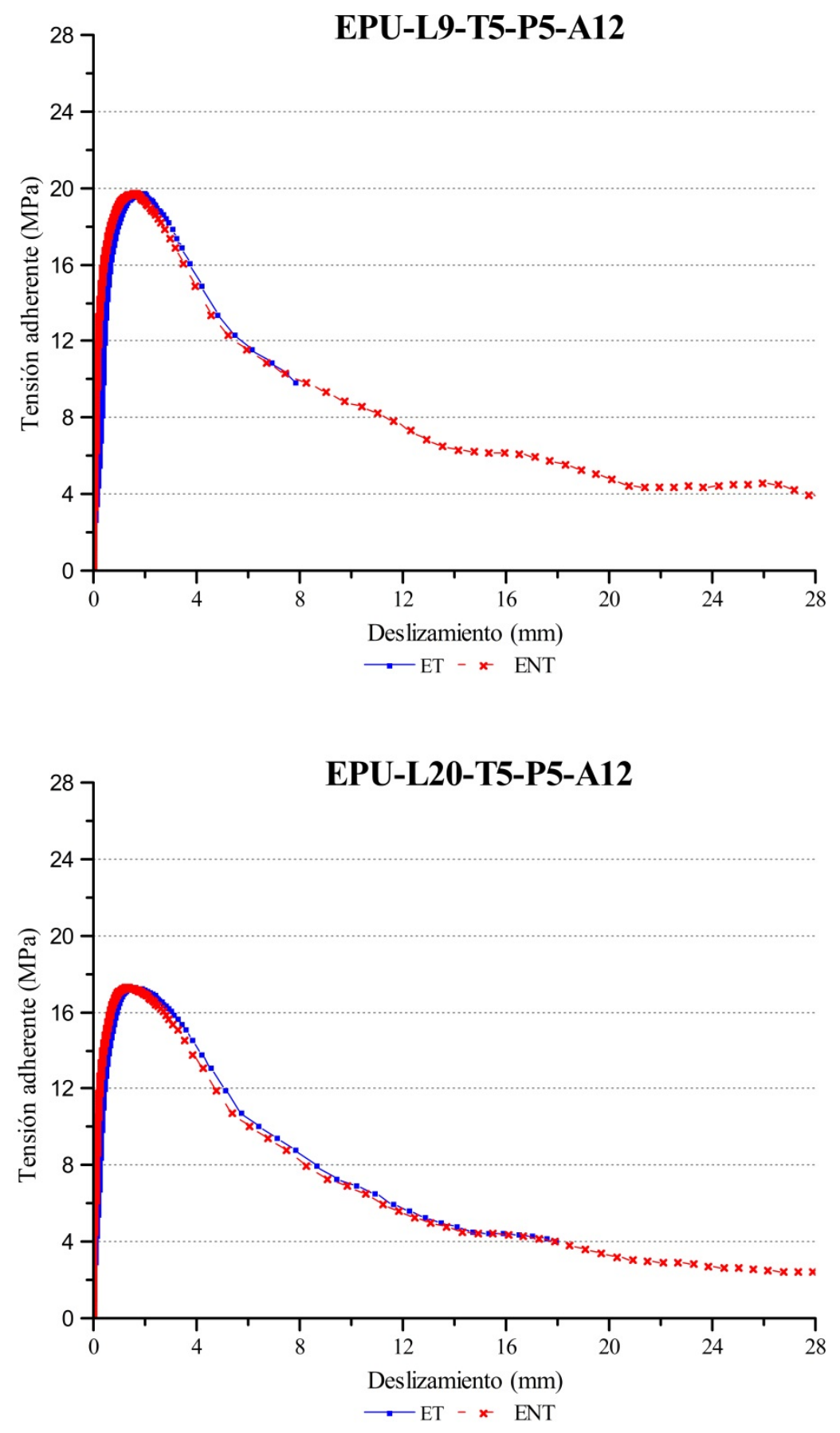

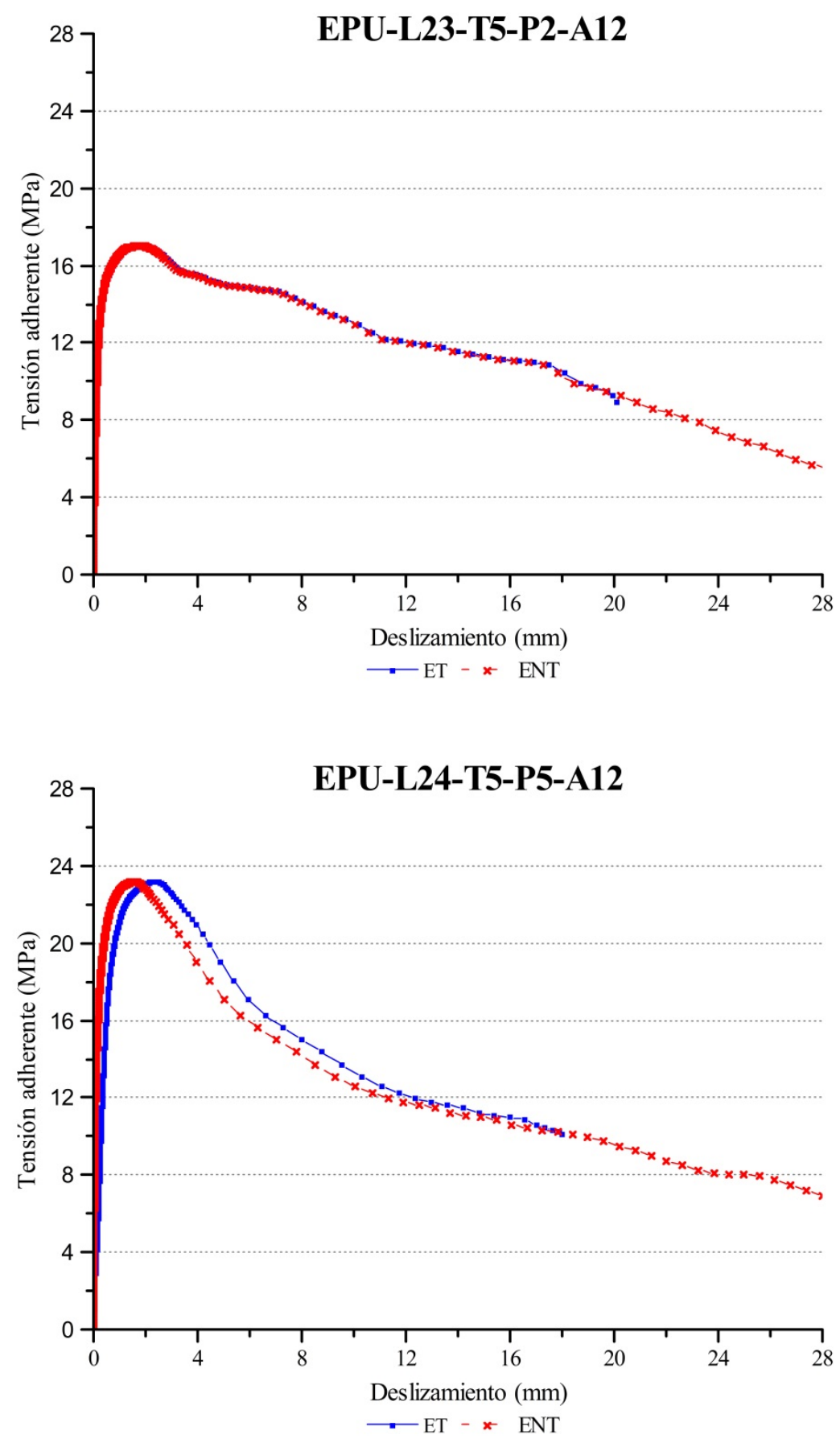
c. Condición Térmica de $20^{\circ} \mathrm{C}$.
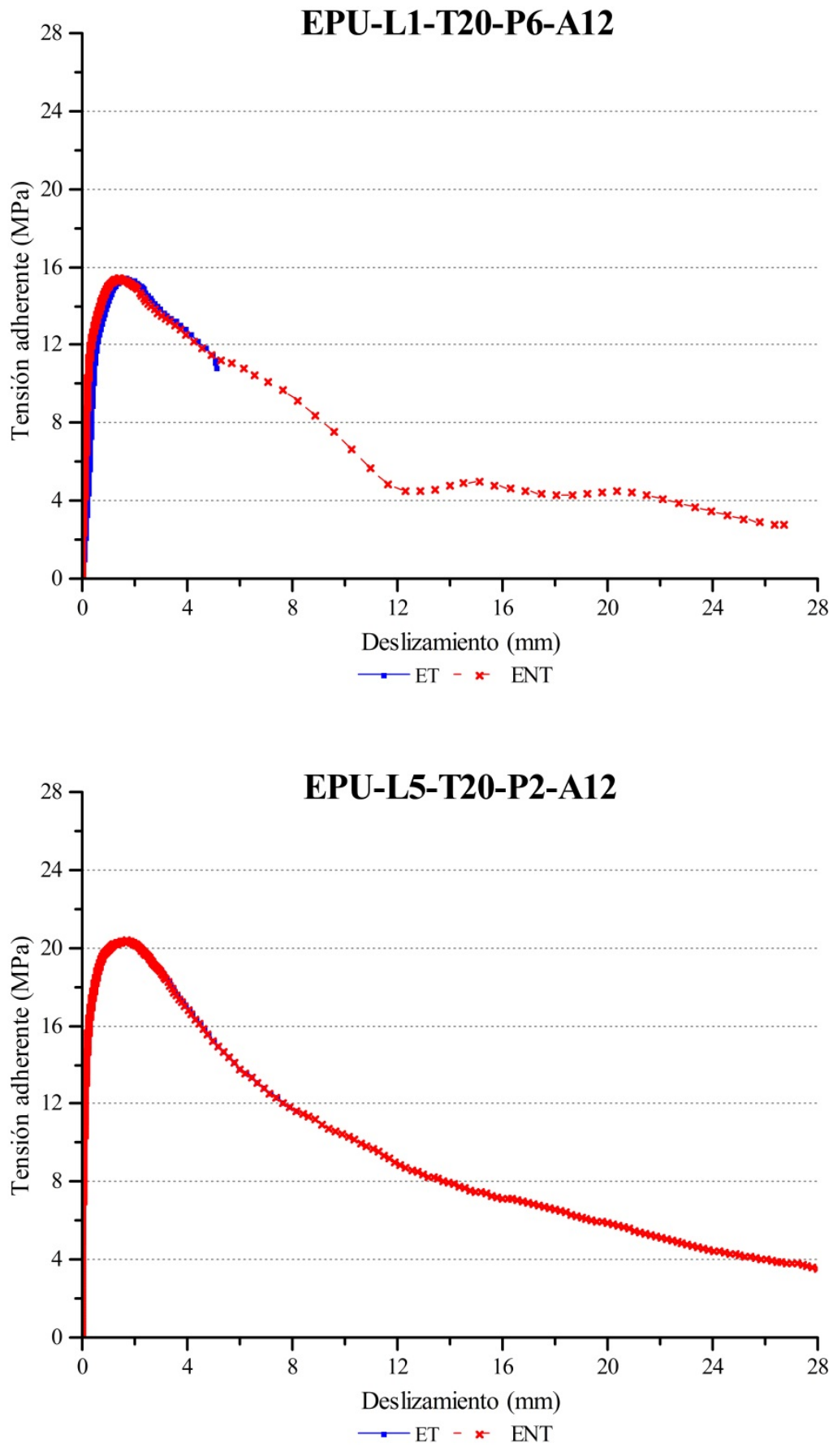

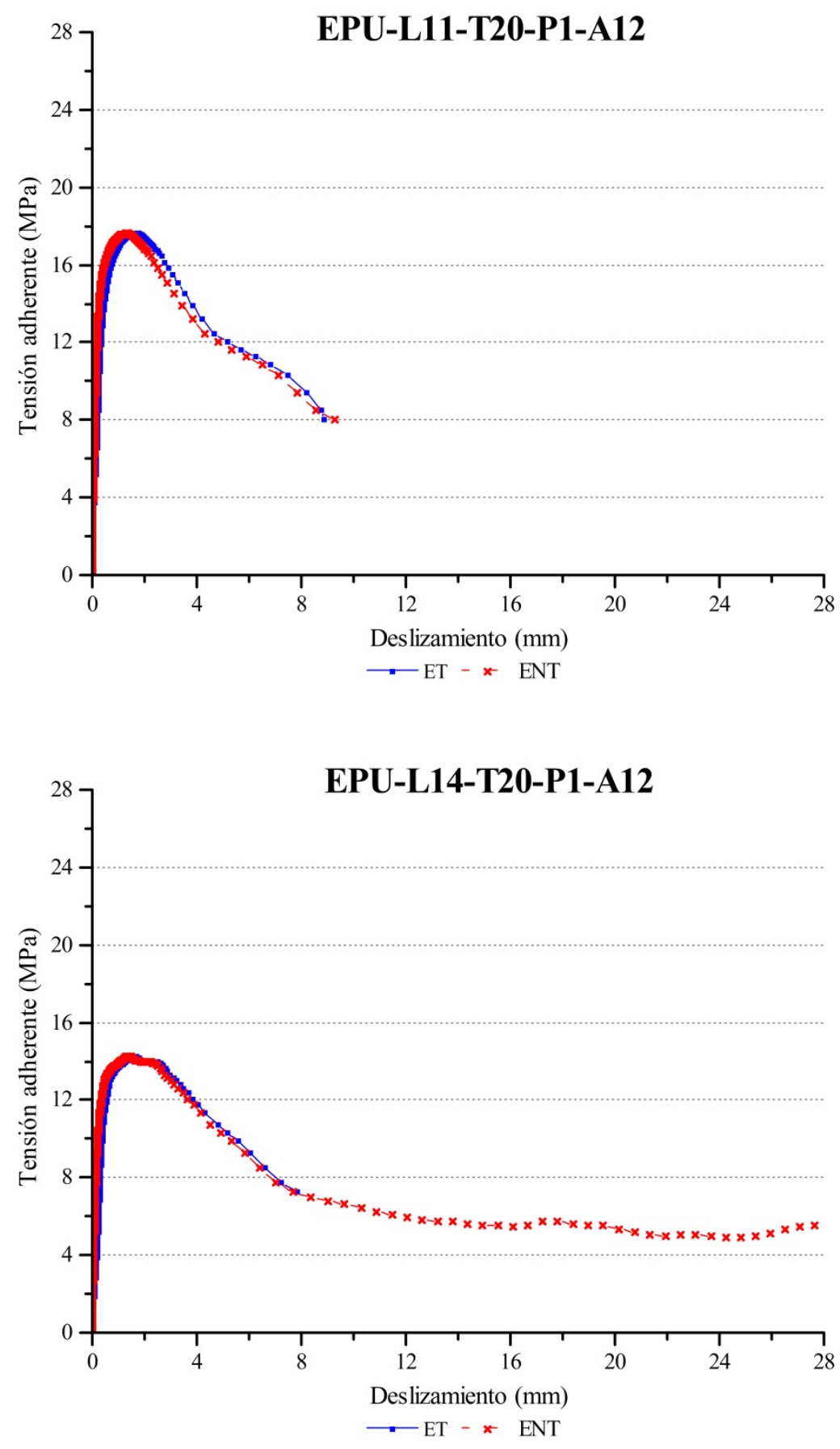


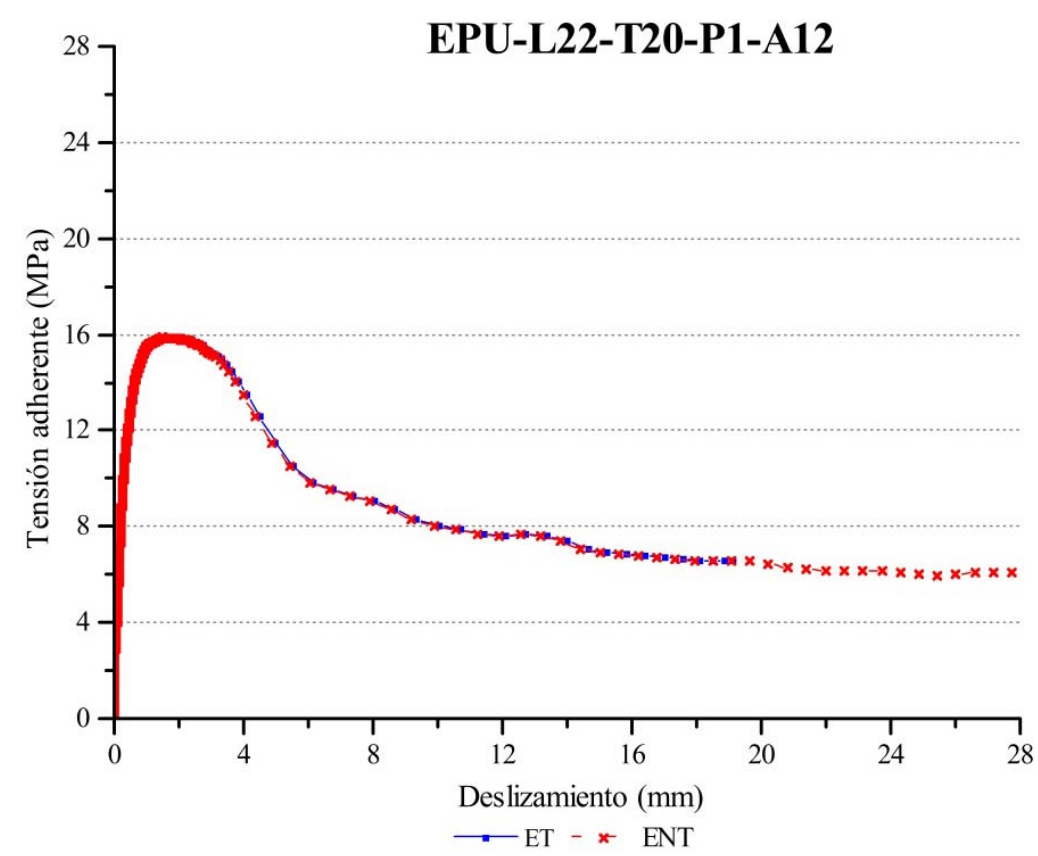

\section{d. Condición Térmica de $40^{\circ} \mathrm{C}$.}

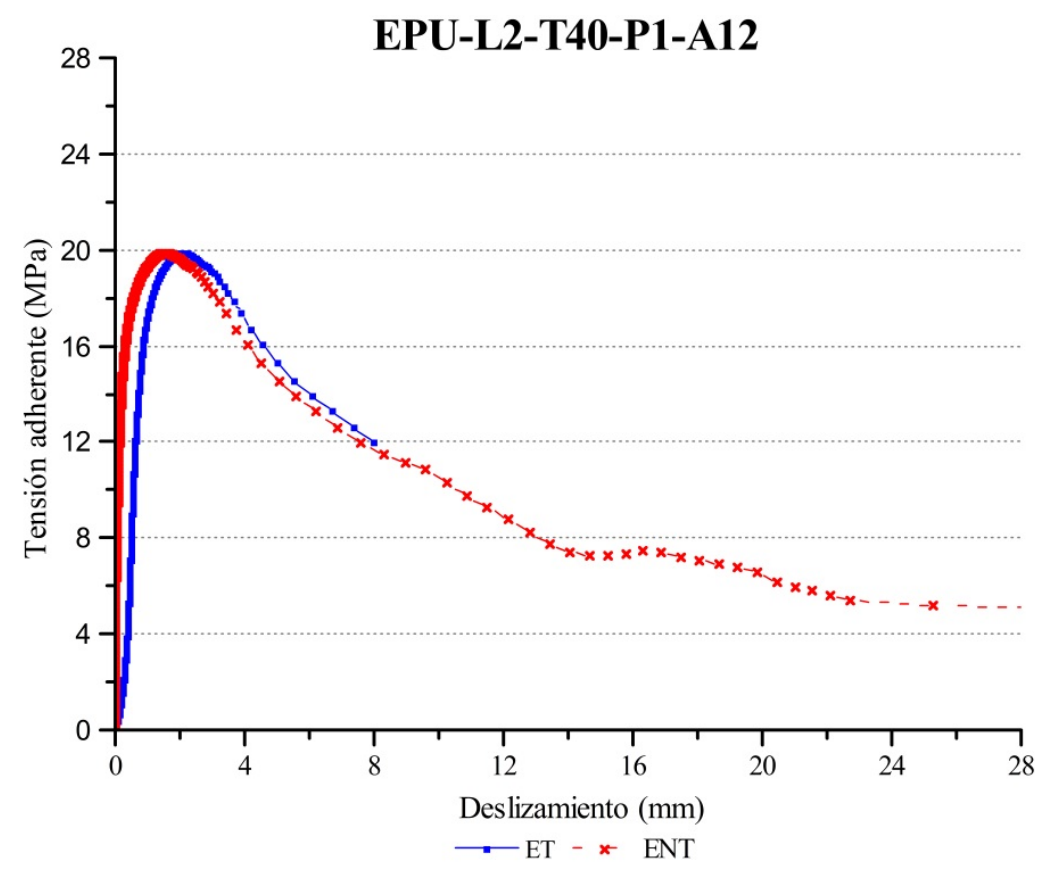



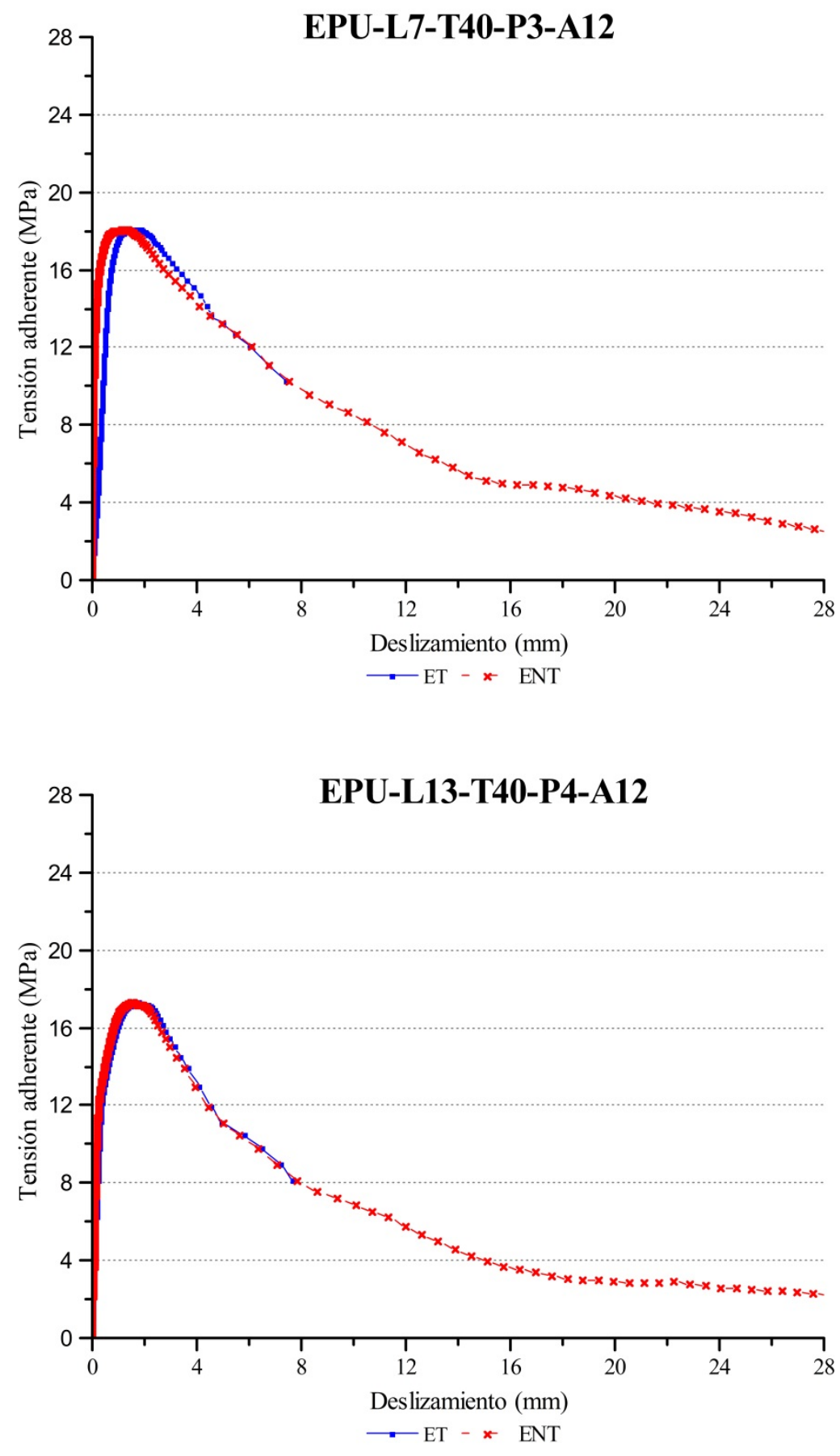

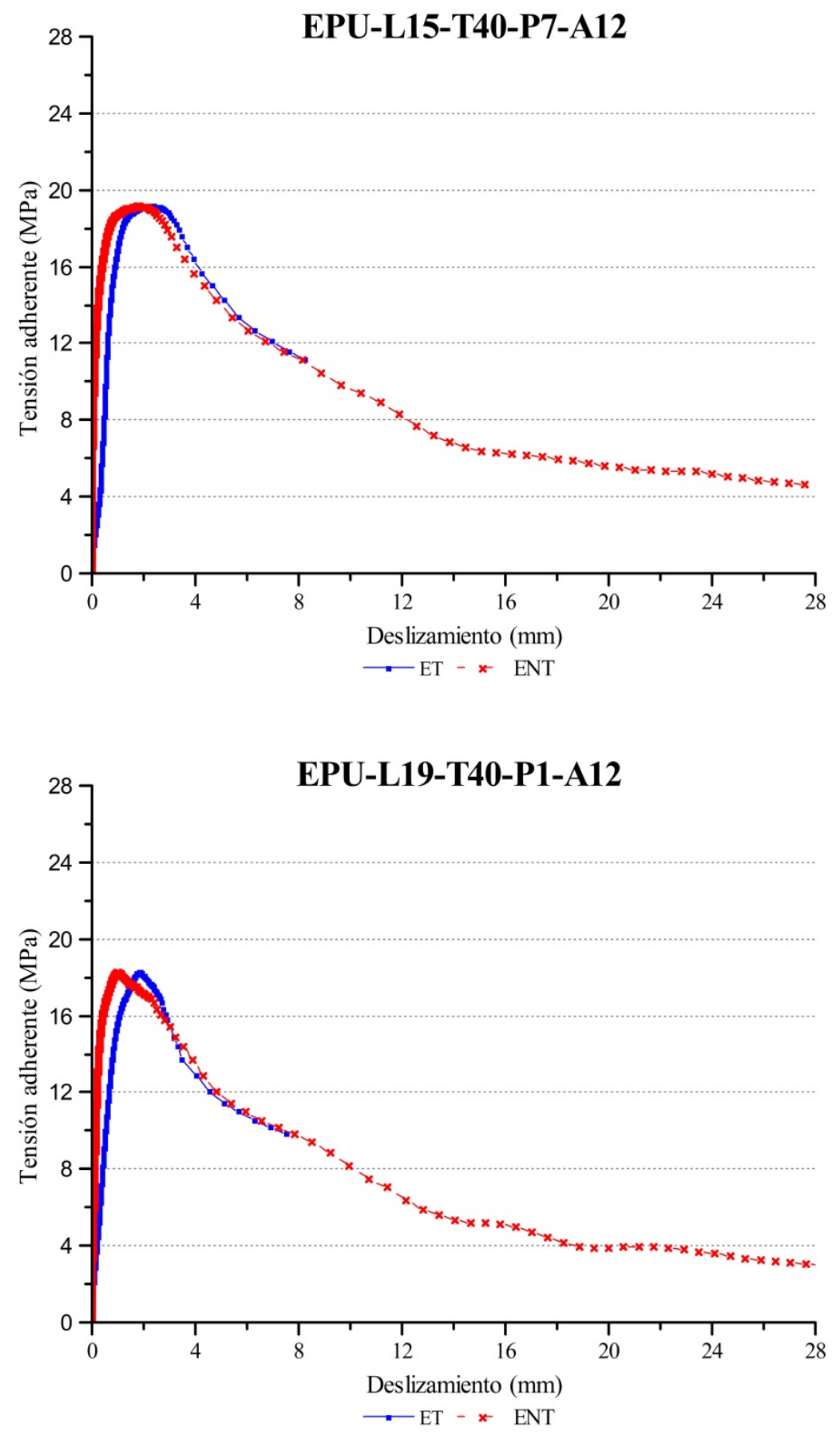
e. Condición Térmica de $80^{\circ} \mathrm{C}$.
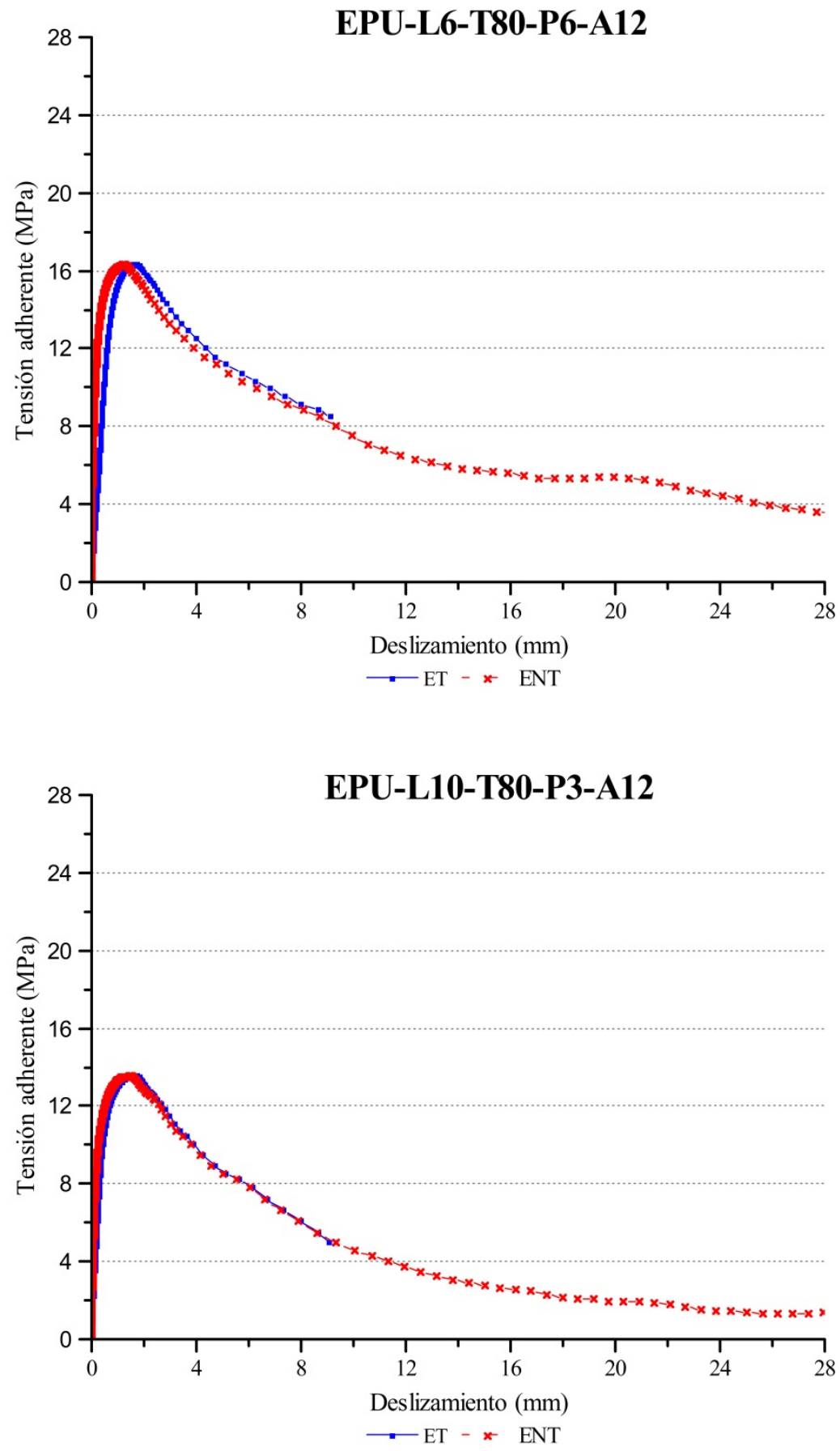

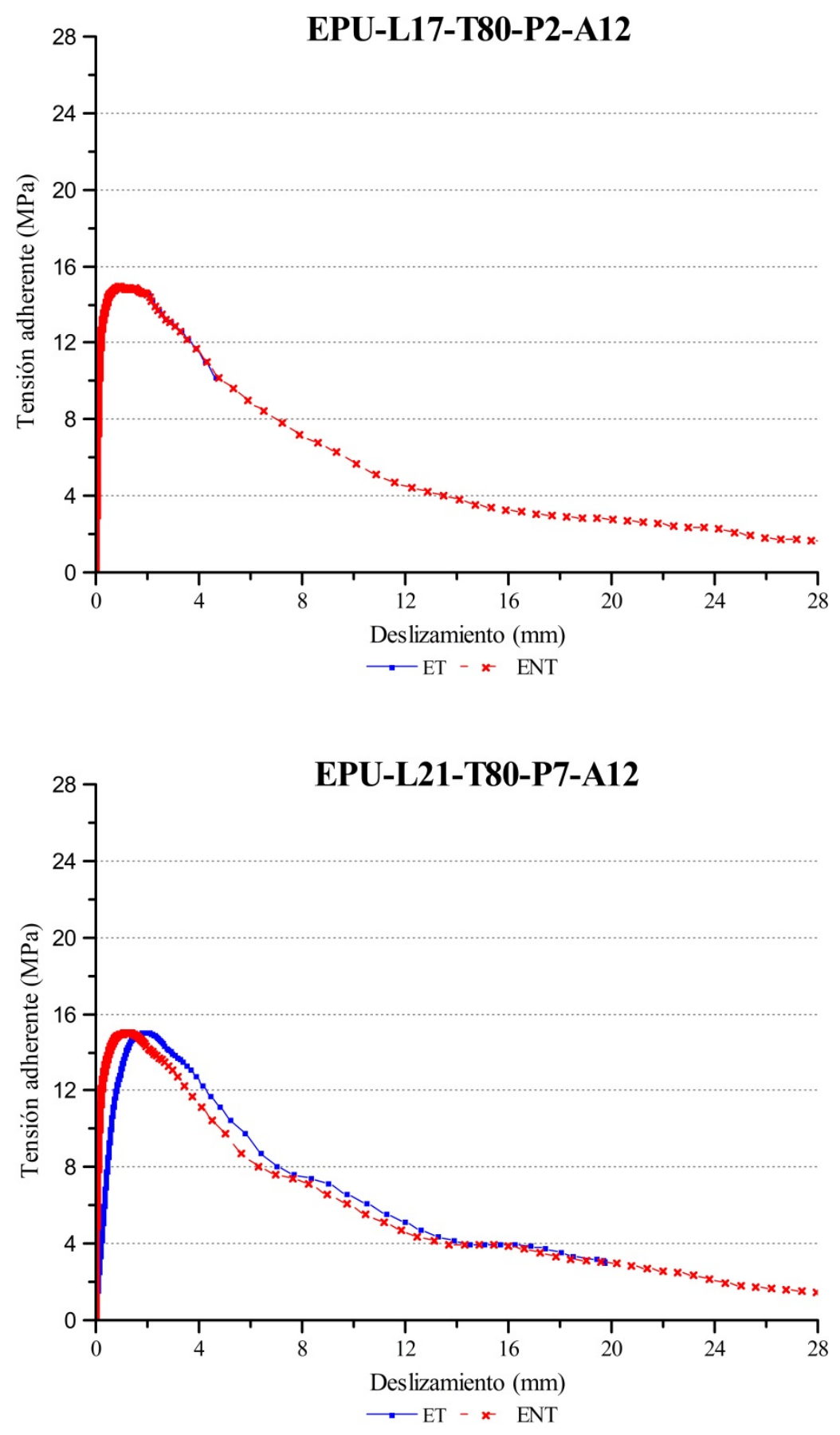


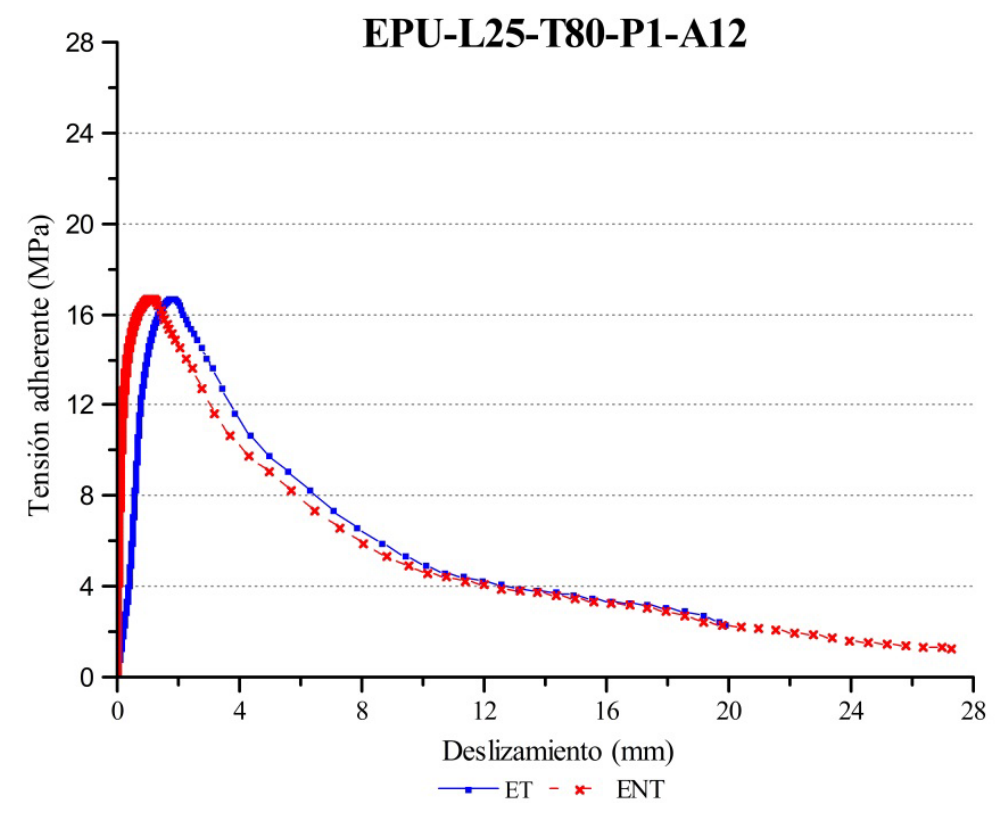

VII. Barras de Acero Corrugadas A16:

a. Condición Térmica de Hielo/Deshielo o $-20{ }^{\circ} \mathrm{C}$.

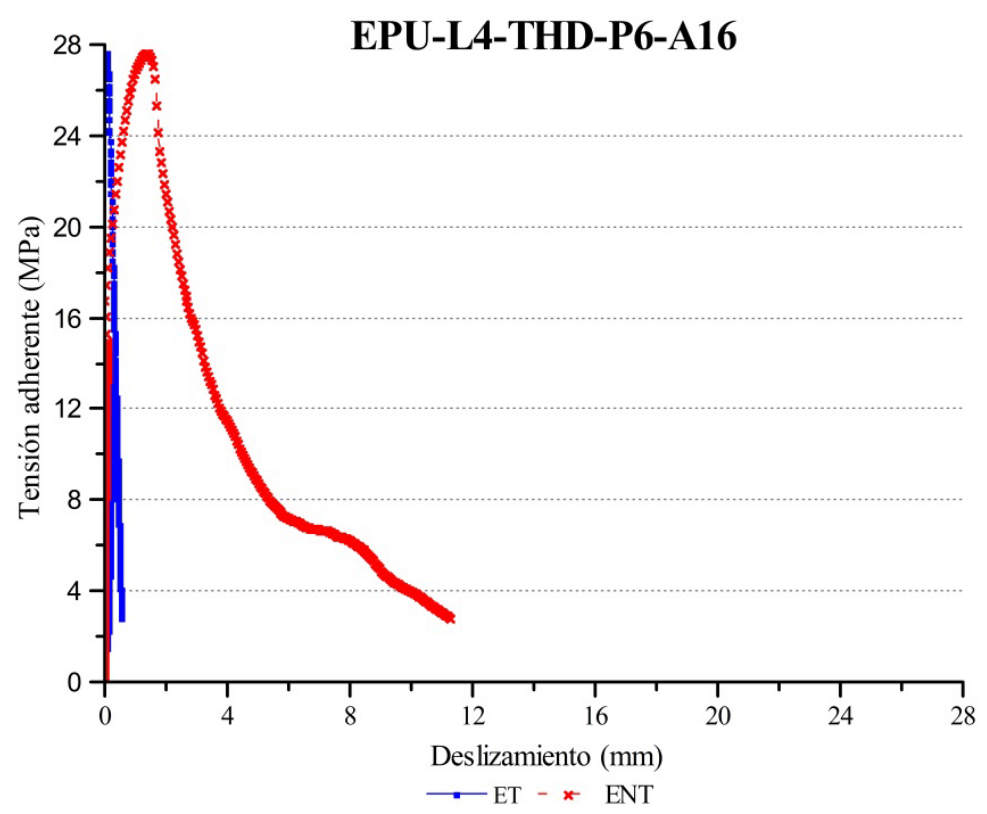



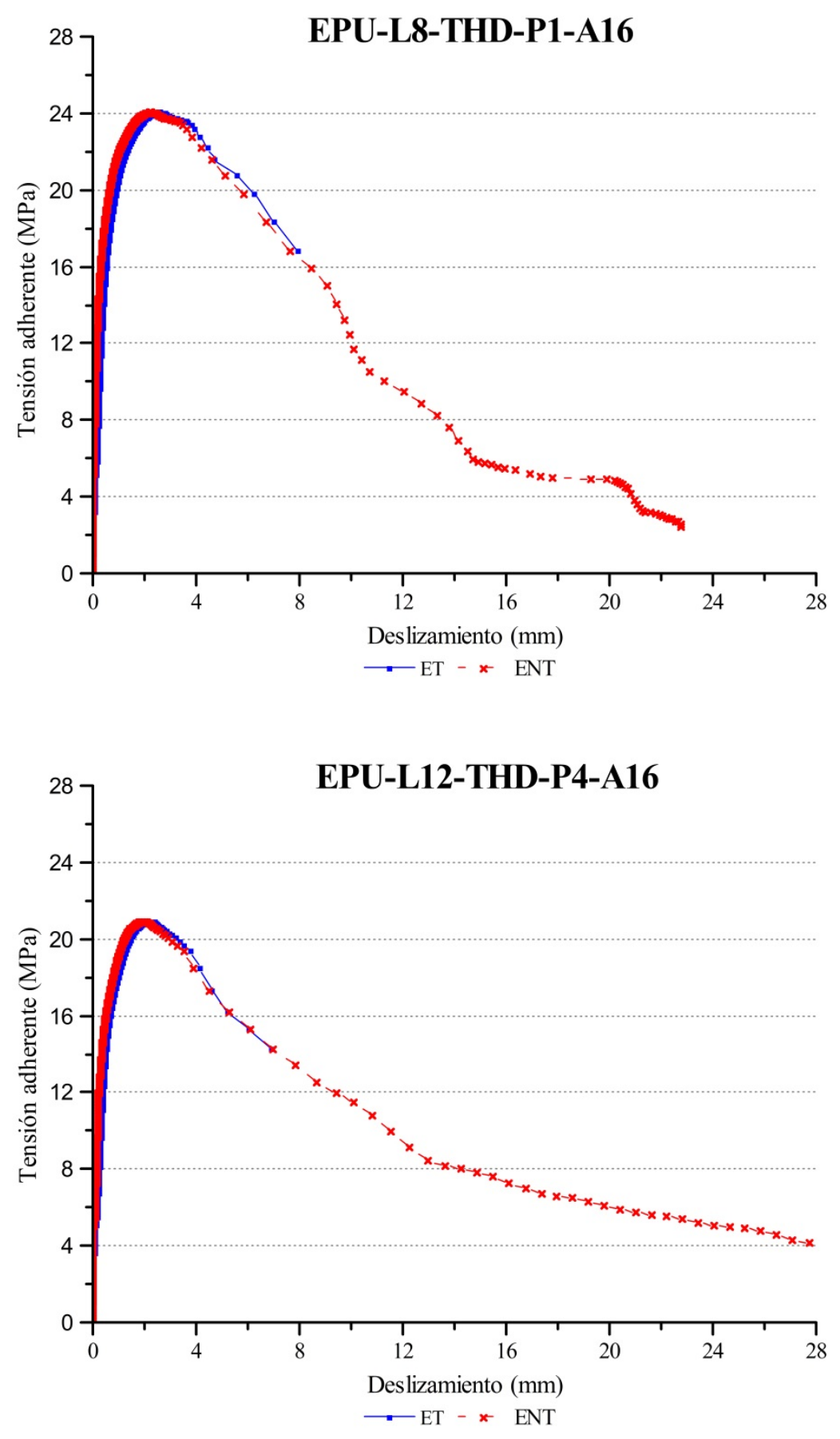

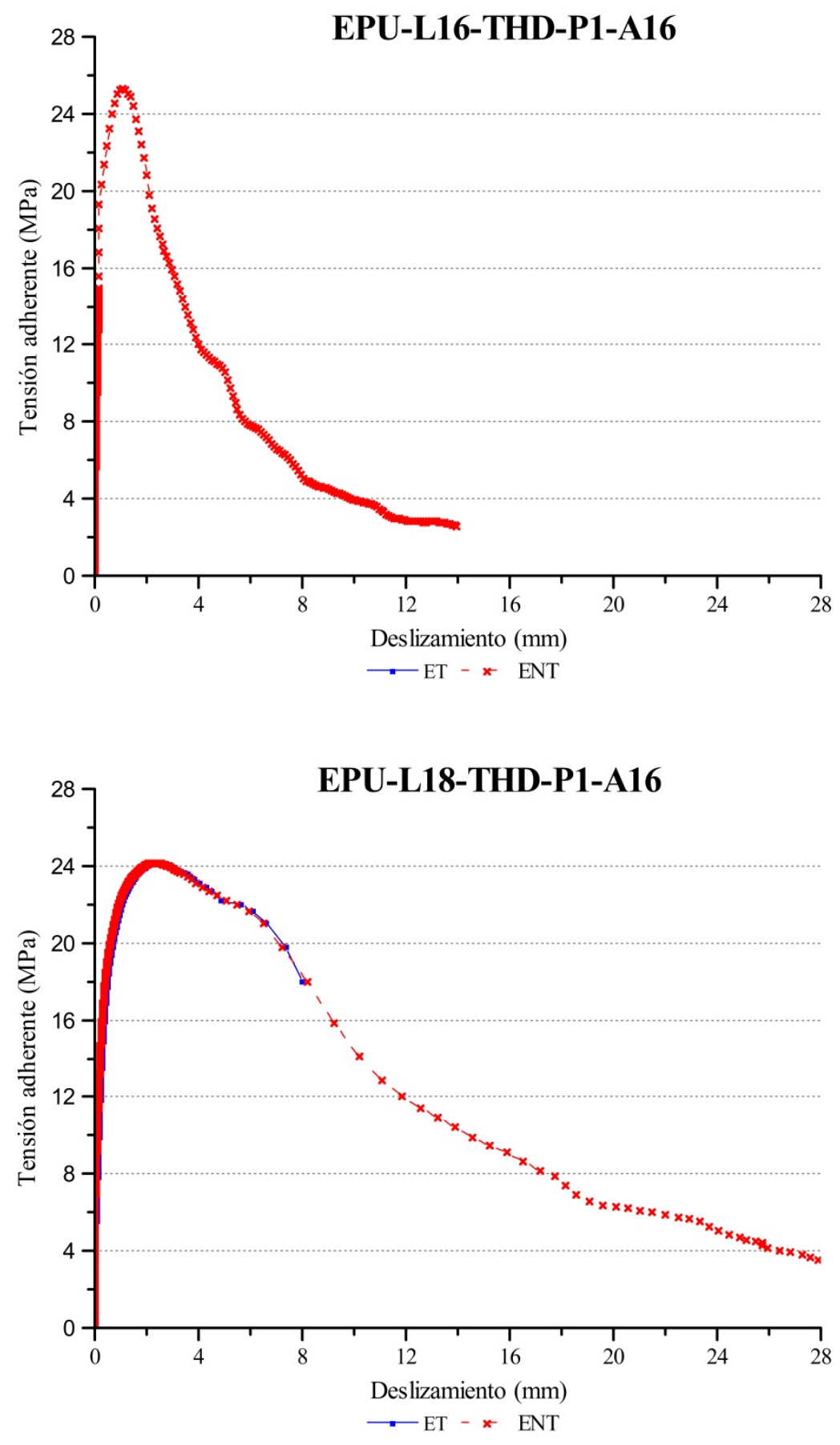


\section{b. Condición Térmica de $5^{\circ} \mathrm{C}$.}
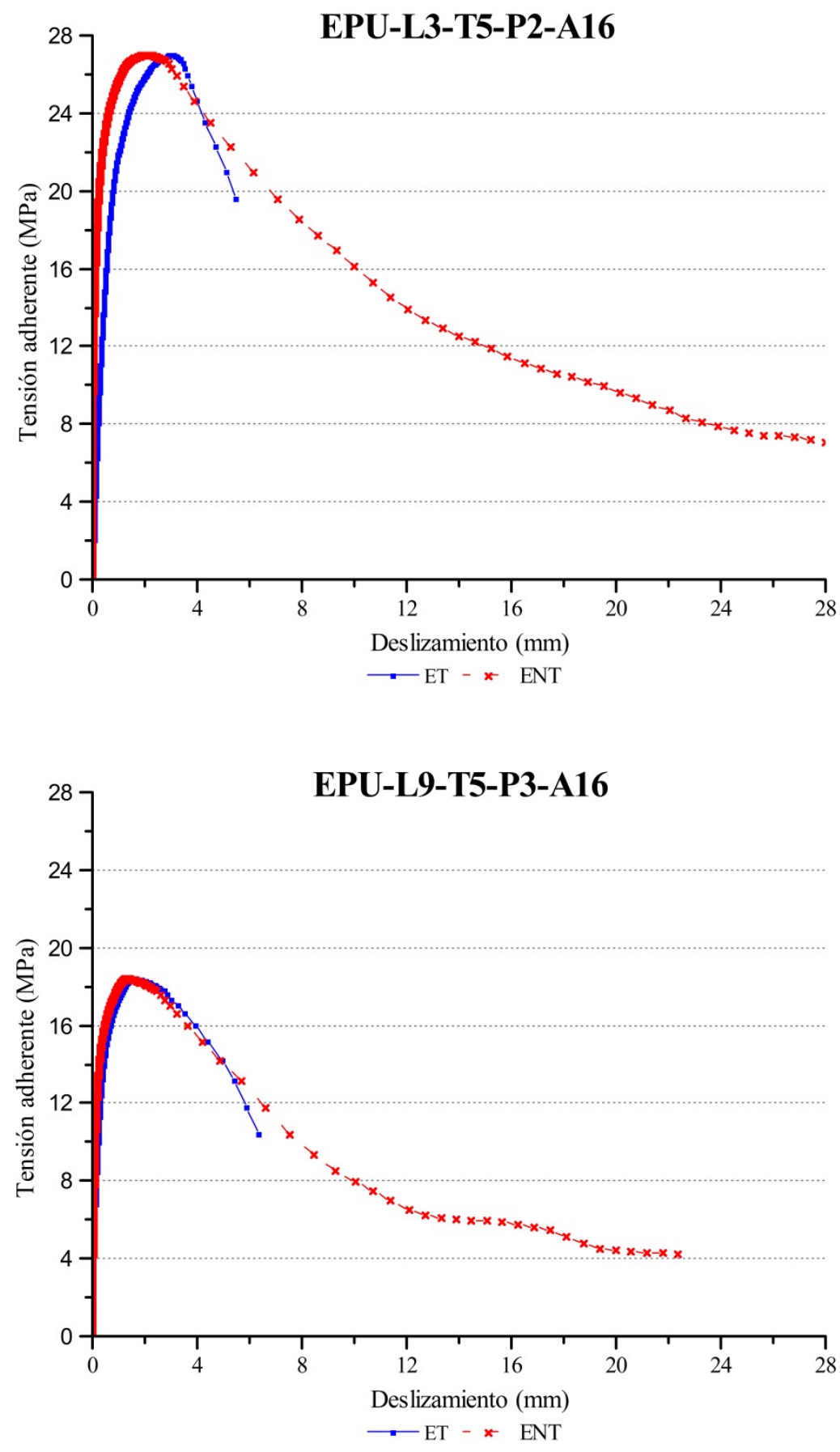

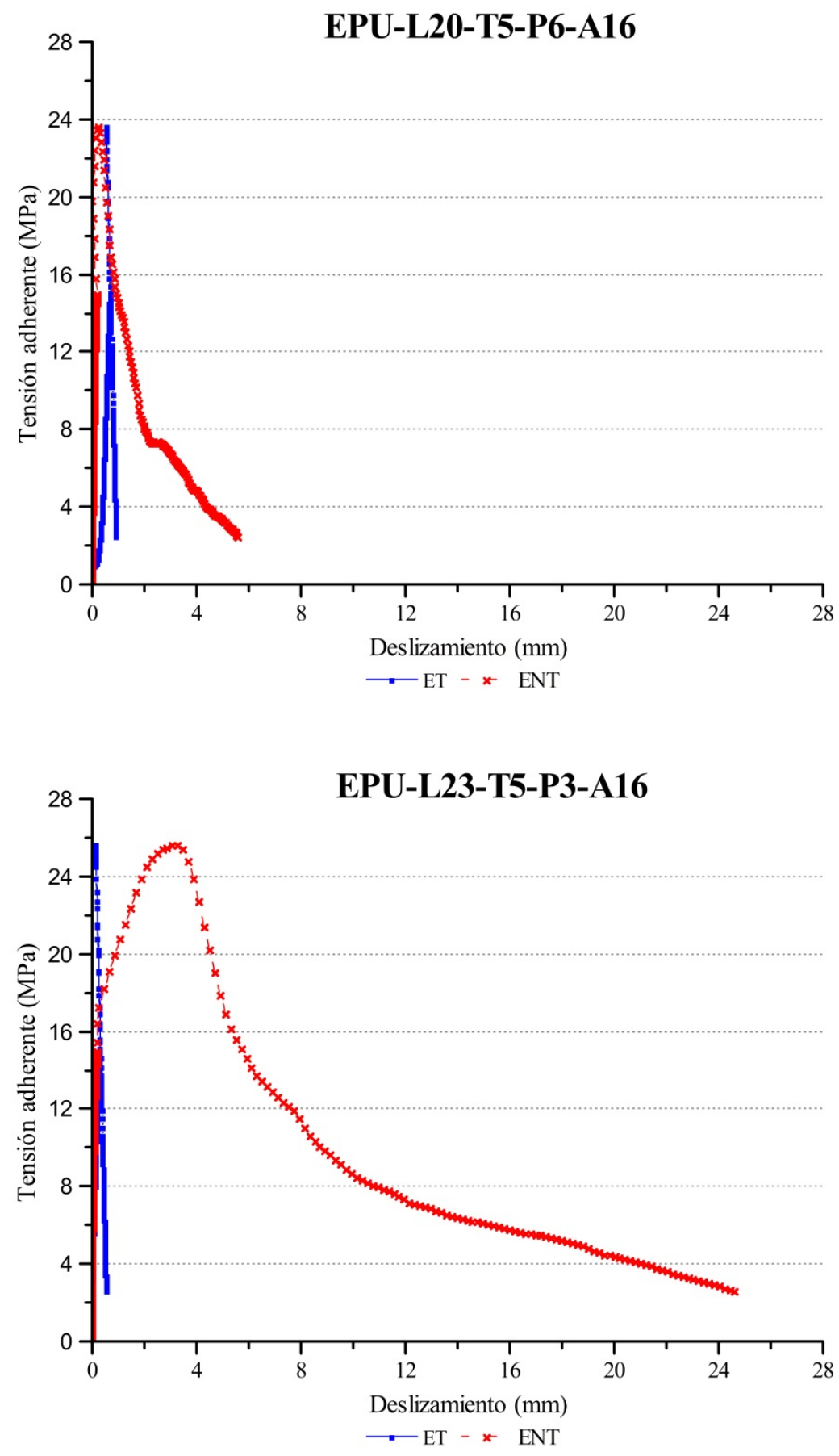


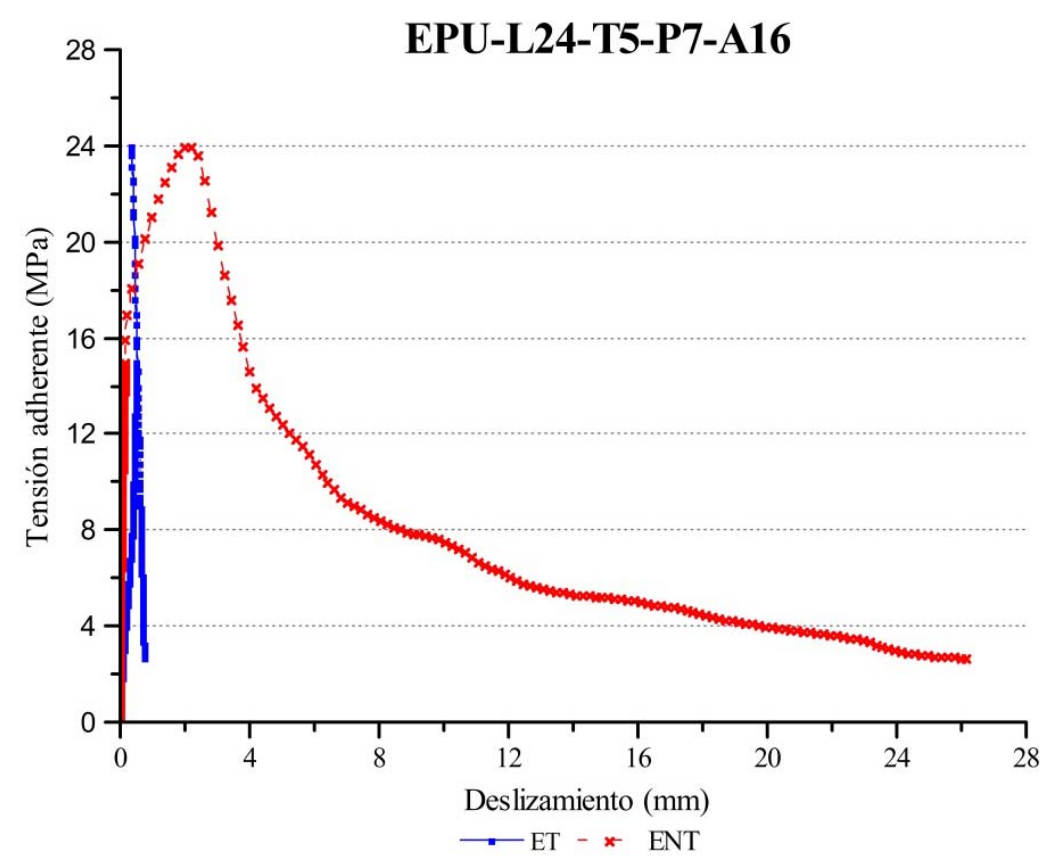

c. Condición Térmica de $20^{\circ} \mathrm{C}$.

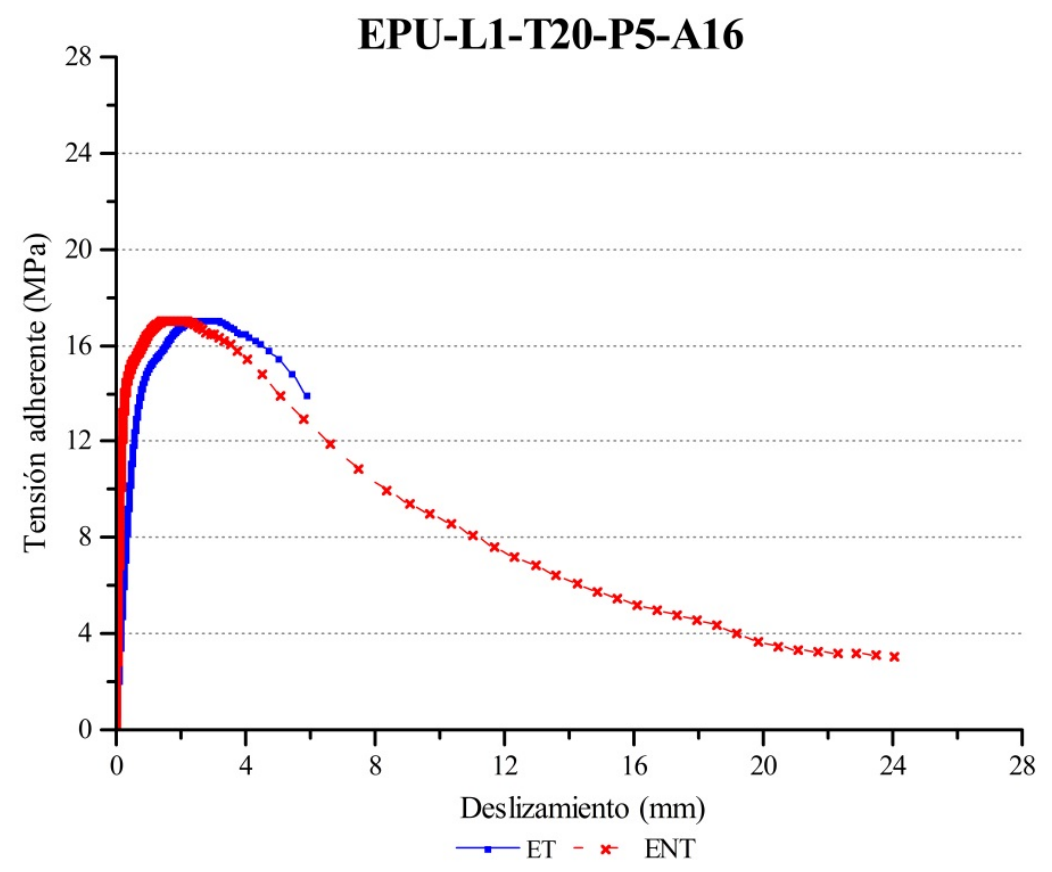



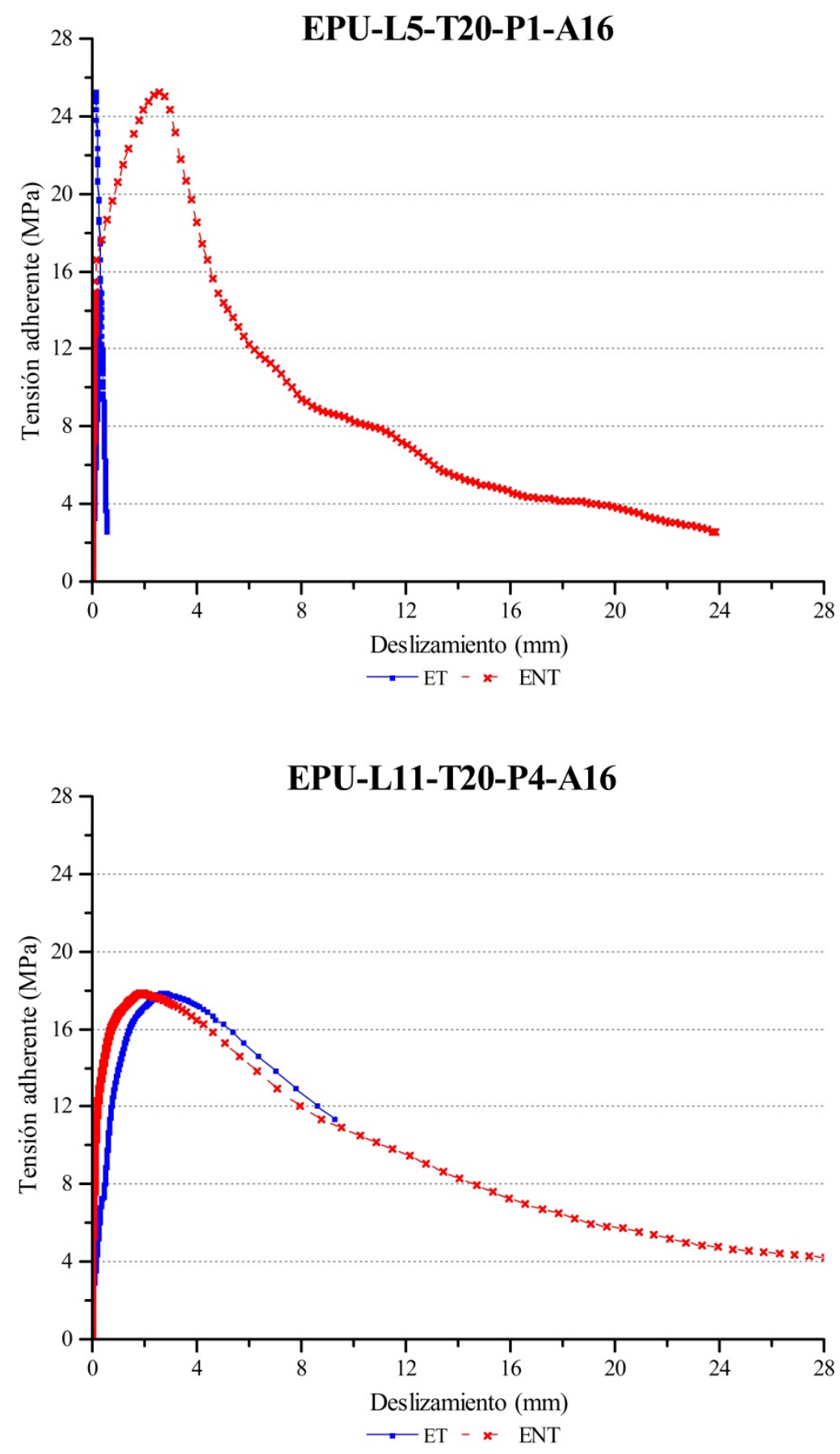

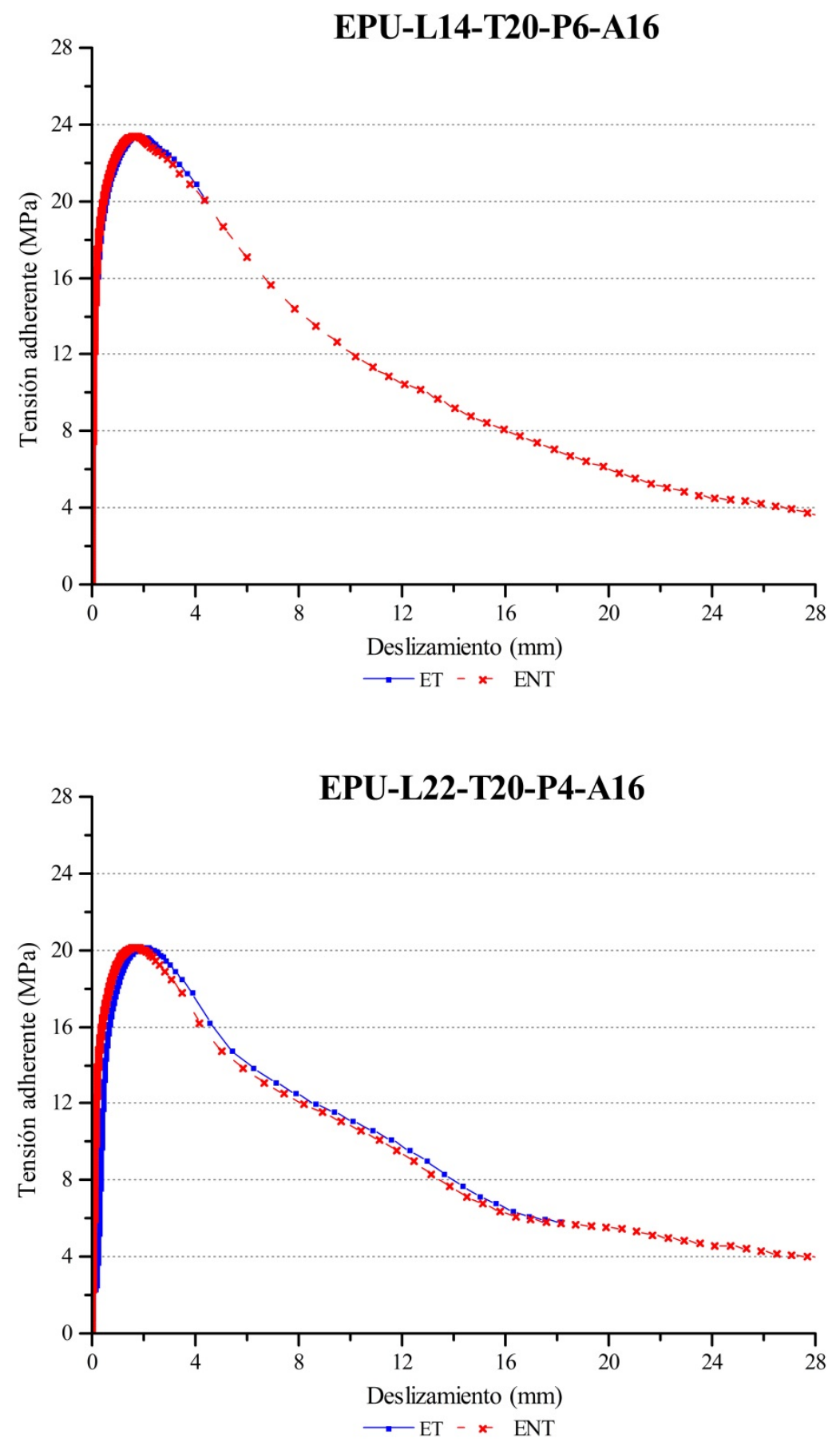
d. Condición Térmica de $40^{\circ} \mathrm{C}$.
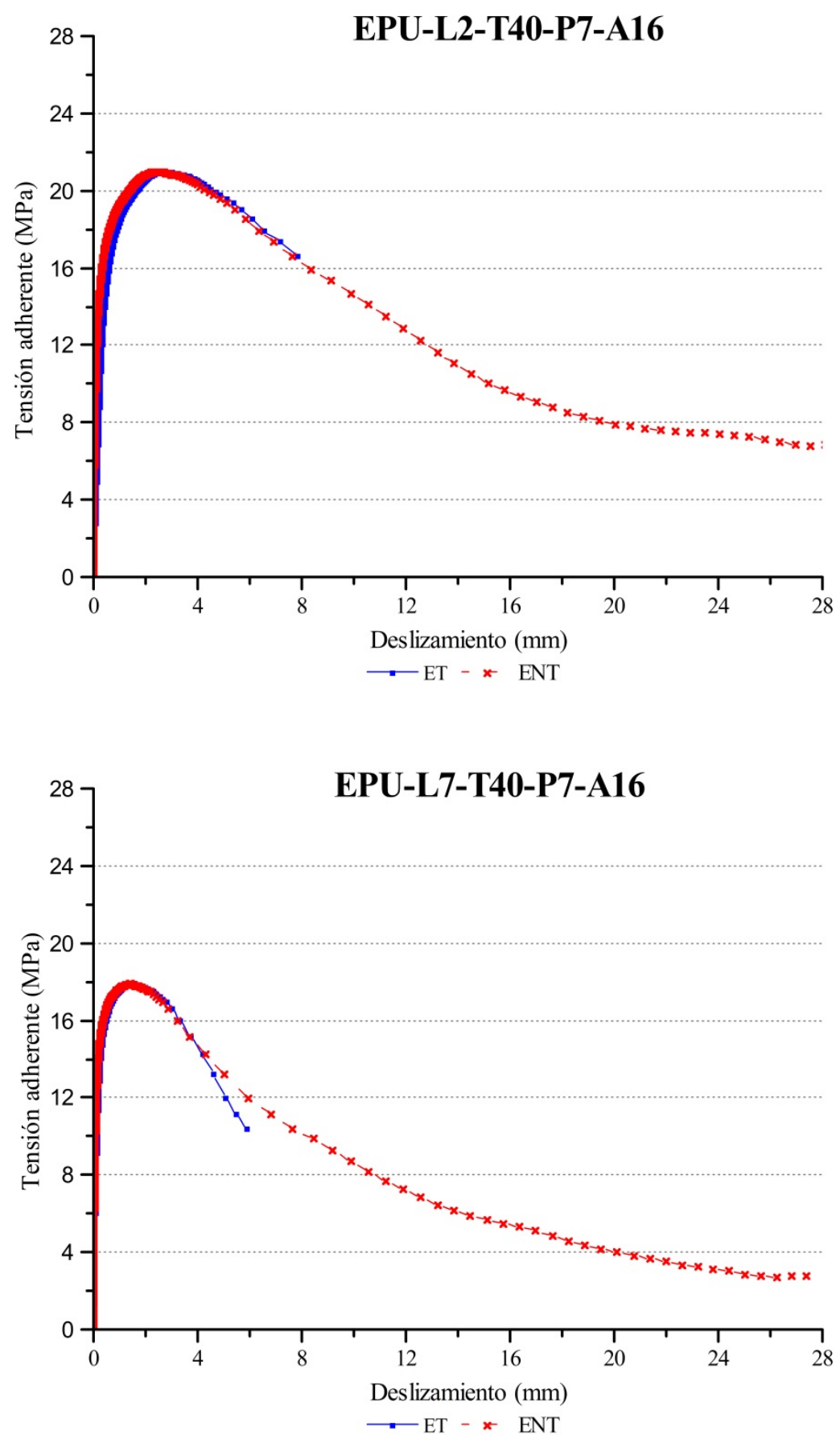

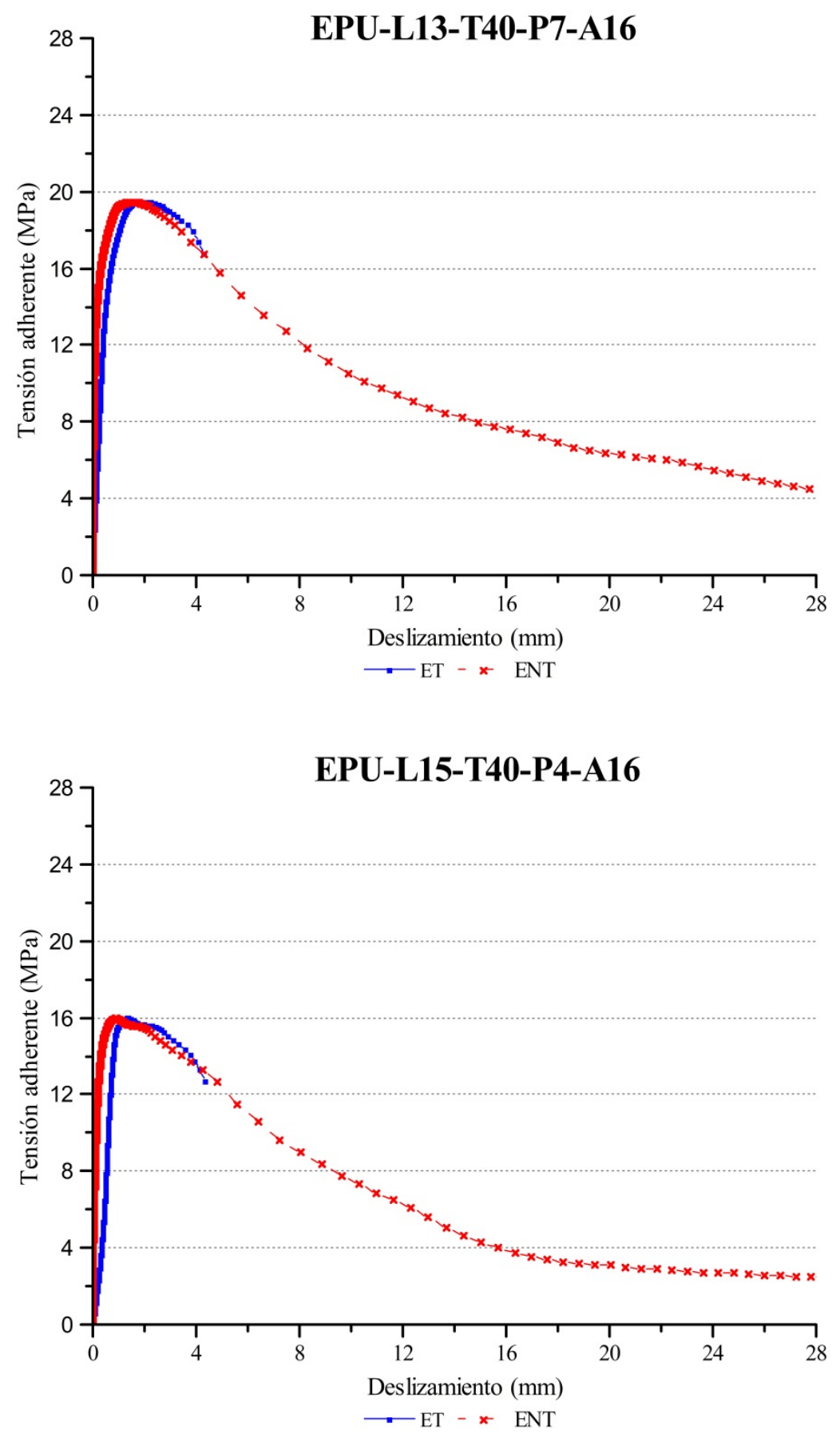


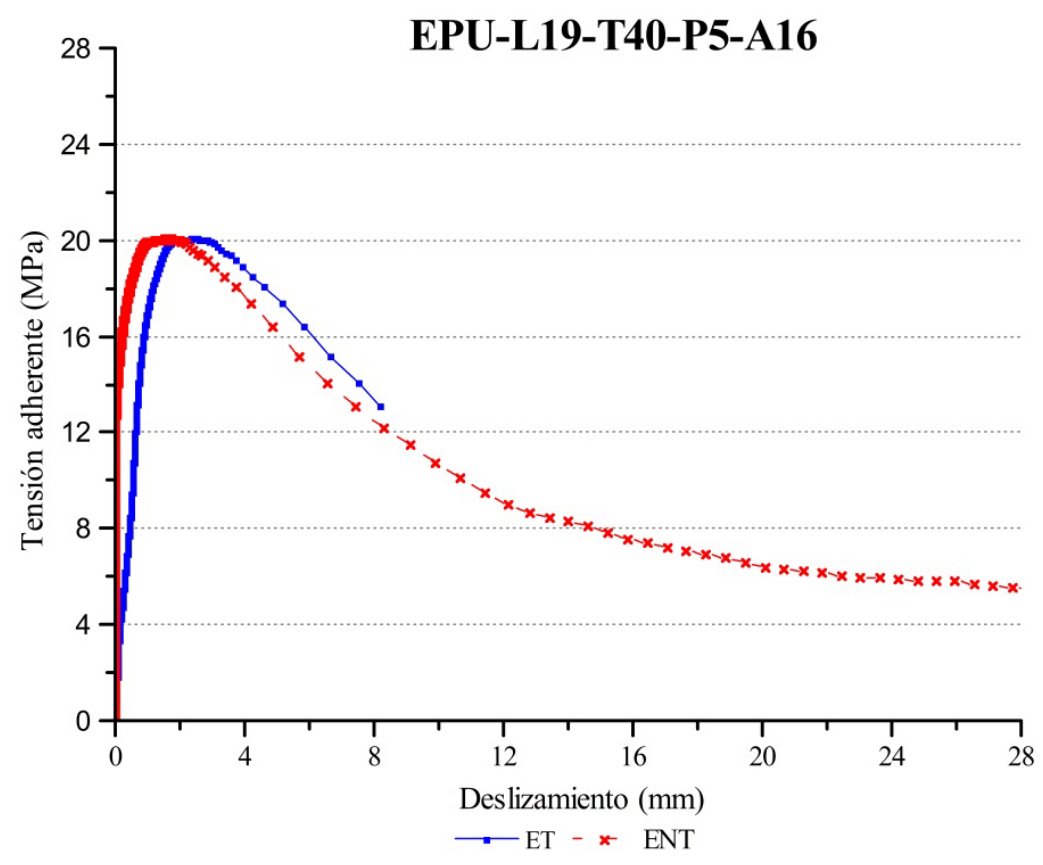

e. Condición Térmica de $80^{\circ} \mathrm{C}$.

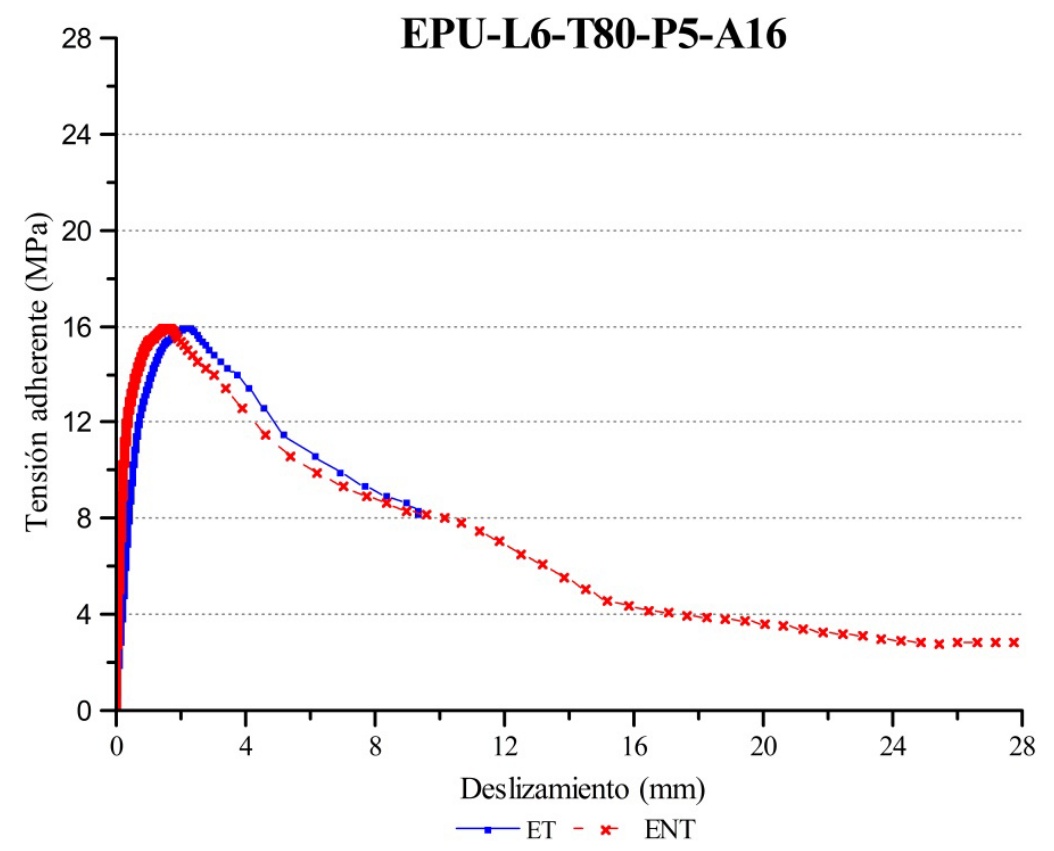



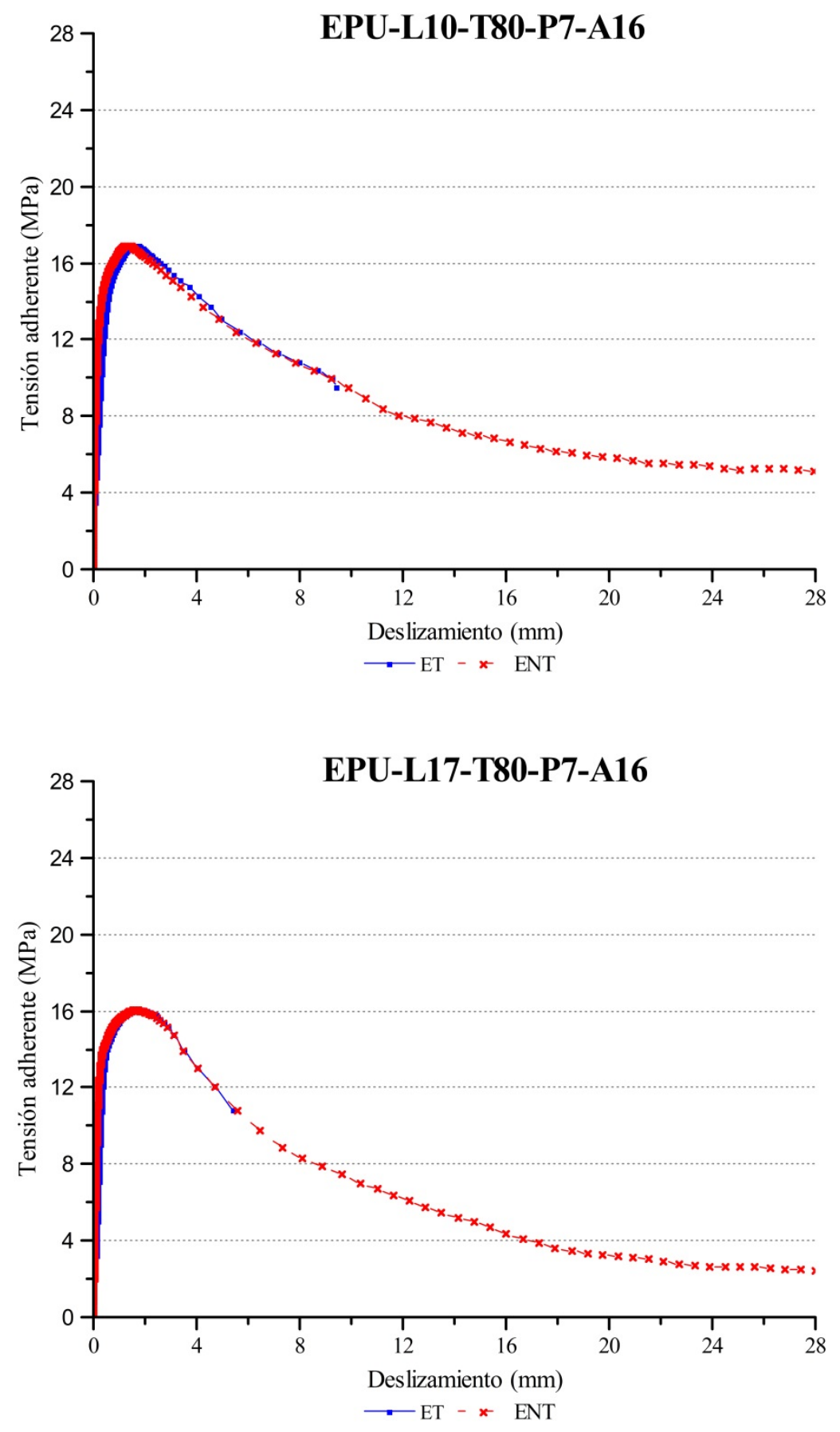

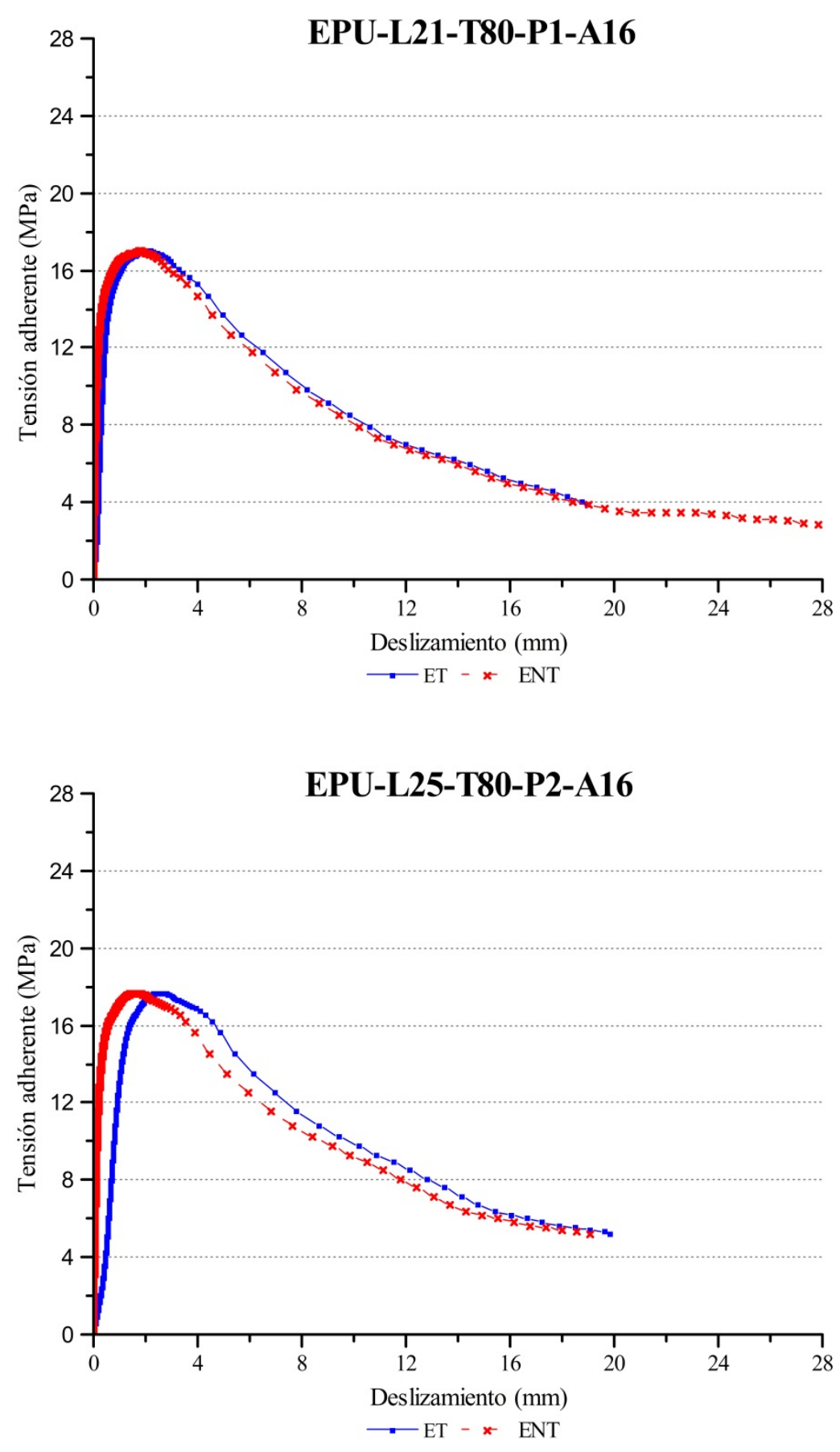